\title{
WestVirginiaUniversity
}

THE RESEARCH REPOSITORY @ WVU

Graduate Theses, Dissertations, and Problem Reports

2008

\section{CFRP repair of concrete beams aged by accelerated corrosion}

George C. Parish

West Virginia University

Follow this and additional works at: https://researchrepository.wvu.edu/etd

\section{Recommended Citation}

Parish, George C., "CFRP repair of concrete beams aged by accelerated corrosion" (2008). Graduate Theses, Dissertations, and Problem Reports. 1985.

https://researchrepository.wvu.edu/etd/1985

This Thesis is protected by copyright and/or related rights. It has been brought to you by the The Research Repository @ WVU with permission from the rights-holder(s). You are free to use this Thesis in any way that is permitted by the copyright and related rights legislation that applies to your use. For other uses you must obtain permission from the rights-holder(s) directly, unless additional rights are indicated by a Creative Commons license in the record and/ or on the work itself. This Thesis has been accepted for inclusion in WVU Graduate Theses, Dissertations, and Problem Reports collection by an authorized administrator of The Research Repository @ WVU. For more information, please contact researchrepository@mail.wvu.edu. 


\title{
CFRP Repair of Concrete Beams Aged By Accelerated Corrosion
}

\author{
George C. Parish
}

\author{
Thesis submitted to the \\ College of Engineering and Mineral Resources \\ at \\ West Virginia University \\ in partial fulfillment of the requirements \\ for the degree of \\ Master of Science \\ in \\ Civil and Environmental Engineering
}

\author{
Julio F. Davalos, Ph.D., Chair \\ Indrajit Ray, Ph.D., Co-Chair \\ Osama Mukdadi, Ph.D. \\ Department of Civil and Environmental Engineering
}

Morgantown, West Virginia

2008

KEYWORDS: Bridge Repair, Girder Repair, CFRP, Externally-bonded, Chloridecontaminated reinforced concrete, Induced Current, Accelerated aging, Rehabilitation, Fatigue, Durability.

Copyright 2008 George C. Parish 


\title{
Abstract
}

\section{CFRP Repair of Concrete Beams Aged By Accelerated Corrosion}

\author{
George C. Parish
}

In 2006, the Federal Highway Administration statistics showed that approximately one out of every 13 reinforced concrete bridges in the USA is structurally deficient. As infrastructure continues to age and deteriorate, there will not be sufficient funds to replace every deficient bridge. Therefore, effective and durable repair methods must be developed and implemented. In this research, an experimental study is presented to determine both the short- and long-term efficiencies of concrete retrofit with externallybonded carbon fiber reinforced polymer (CFRP) fabrics. The primary objective is to determine effective concrete-repair and CFRP-retrofit approaches for rehabilitation of deteriorated concrete bridge girders, based on potential for long-term durability and costs. This two-part study consisted of 35 large-scale reinforced concrete beam specimens. Part I consisted of 14 beams with dimensions 6x8x108" and Part II consisted of 21 beams with dimensions $6 \times 8 \times 78$ ". The beams were cast using chloride contaminated, lowstrength and highly porous concrete; and they were aged using an induced electric current technique. Supplementary tests were also conducted on specimens and materials, including cylinder compression, rebound hammer, ultrasonic pulse velocity, FRPconcrete pull-off, FRP direct tension, and crack measurement.

In Part I two substrate repair methods were compared, epoxy crack-injection and complete replacement of concrete cover using polymer-modified concrete, and long-term durability was studied by inducing additional corrosion after repair. In Part II the performance of three unique FRP anchorage schemes were compared under both static and cyclic loading. Scheme 1 consisted of only flexural FRP without anchors, scheme 2 consisted of only two strategically placed anchors on each beam, and scheme 3 consisted of eight anchors evenly spaced along each span. In Part I, it was found that polymer concrete patch repair with corrosion inhibitors was by far the most durable substrate repair method, although all beams experienced further deterioration and loss in strength upon additional corrosion. In Part II, there were not significant differences in load capacity, deflection, or stiffness among the three anchoring schemes. The fatigue cyclic loading affected the failure mode of the beams. The accelerated corrosion process used in this research was adjusted using trial beam samples, and became successful and dependable in producing consistently artificially-aged specimens. This research provided further insight into future bridge rehabilitation and contributed to practical guidelines for concrete patch-repair and CFRP retrofit of concrete girders, to assure long-term adequate performance under environmental and mechanical loads. 


\section{Acknowledgements}

I would first like to thank my advisor, Dr. Julio F. Davalos, for providing me the opportunity to attend West Virginia University. I thank Dr. Davalos for his support of my work, especially during times when revisions had to be made and when testing equipment was undergoing maintenance, and for advising me on ways to keep the project moving forward. I also thank Dr. Davalos for his steadfast belief and confidence in me and for entrusting me with a lot of responsibility while completing a very exciting project.

I would like to thank my co-advisor, Dr. Indrajit Ray. Dr. Ray and I worked very closely on many phases of this project. He was always available when I needed help or advice and he would make time for my questions and concerns no matter what he was doing at the time. I would also like to thank Dr. Ray for having confidence in my abilities and opinions. Dr. Ray often came to the lab and provided hands-on assistance with certain tasks for the project which provided motivation in my work. It was obvious that he truly cared about me and the work I was doing, and that is truly appreciated.

I would also like to thank the third member on my committee, Dr. Osama Mukdadi. I did not have the opportunity to work with Dr. Mukdadi, but I know that his expertise in composites is a great addition to my committee. Dr. Mukdadi showed interest and enthusiasm when asked to be on my committee and his presence is greatly appreciated.

Many others greatly helped me and they must be thanked. First, I must thank my student helpers: Vincent C. Giovanelli, Krishna C. Ravi, Varun K. Sadam, Justin D. Hayes, Arezoo S. Imani, Adam L. Justice, and Stephen F. Wallington. Without their dedicated work, successfully completing this demanding project would literally not have been possible. Next, I must acknowledge the technicians: Jarrod Grimm, Jerry L. Nestor, David H. Turner, William J. Comstock, Will Ravenscroft and Charles D. Coleman. Without their urgent help and expertise with equipment problems, testing setups, and other miscellaneous tasks, this project could have never been finished within the time constraints. Next, I thank professors that helped with portions of this work: Dr. Karl E. Barth, Dr. Eung H. Cho, Dr. Darrell R. Dean, Dr. Chunfu Lin, and Dr. Roy S. Nutter. Their knowledge, advice, and help was a great asset to this work. Other notable people who greatly assisted me with portions of this project were Joe Thereit (MTS Systems Corporation), Carly Pravlik (KTA-Tator, Inc.), Ken Stewart (National Research Center for Coal and Energy), Zachery I. Smith (Fyfe Co., LLC), and Dr. Silvia B. Ochoa (visiting scholar). Their help with technical issues, equipment, and laboratory work was truly appreciated.

I would also like to thank my fellow graduate students with whom I have had a pleasure working with every day during my 26 months in the Masters program at West Virginia University: Aaron Bertoldi, Arka Bhattacharya, Yi Chen, Nohemy Galindez, Adam Justice, Sathish Konduru, Jeremy Meadway, Gabe Nagy, Silvia Ochoa, William Sasher, 
Arezoo Imani, and Santiago Velez. These people are great friends, and they made it enjoyable to come to work each day.

I must also thank the Pennsylvania Department of Transportation for providing funding for my research. This project was very practical and exciting, and I was privileged to have the opportunity to add to the knowledge of a technology that can directly help the infrastructure industry. The state of Pennsylvania, as well as the whole United States, is in dire need of ways to repair aged and deteriorated concrete bridge structures instead of replacing them due to lack of funding, time constraints, etc.

I would like to thank the Fyfe Co., LLC, for providing all the FRP material to West Virginia University for free and for generously discounting the prices of the Tyfo-brand epoxies.

I would like to thank my immediate family members for their loving support throughout my endeavors at West Virginia University, especially my parents George J. Parish and Donna J. Parish. They were understanding during my challenging times and were gracious during my accomplishments. My grandfather, Arnold Brubaker, my grandmothers, Phyllis Brubaker and Elizabeth Parish, and my aunt, Mary Anne Hritz, also provided me with much encouragement and support. I would also like to thank my girlfriend, Laura Menser, for her constant support and understanding throughout my graduate studies.

Most of all, I would like to thank God for giving me the ability, motivation, and focus to be successful throughout my studies. There are many students who may like to go to graduate school who may never get the chance, so I am grateful to Him for providing me the opportunity. He gave me the capability and talent to have much success throughout my academic career and in life. Whenever something would go wrong in this experiment, I would turn to God and ask Him for help and guidance in solving the problems. At the times in which it seemed almost impossible to complete this large project on schedule, someone would help, or something I would adjust or try would fix a problem; this would happen every time. I honestly believe this was God providing me or someone else insight to help me overcome the obstacles. I honestly believe that He sent me all the people I have thanked above to be positive influences in my studies and in my life.

Throughout this project, there have been many high and low points. I have gained confidence from the high points, and have learned a great deal of invaluable information from the low points. I have thoroughly enjoyed my time in the Masters program at West Virginia University and would not trade the experience I've had here for the world. I feel that I am now much more prepared for my career and for the world through my learning and experiences while obtaining my Masters Degree at West Virginia University. 


\section{Table of Contents}

$\begin{array}{ll}\text { Abstract } & \text { i }\end{array}$

$\begin{array}{ll}\text { Acknowledgements } & \text { iii }\end{array}$

Table of Contents $\quad$ v

List of Figures
xii

$\begin{array}{ll}\text { List of Tables } & \text { xviii }\end{array}$

Abbreviations
$\mathbf{x x}$

$\begin{array}{lll}\text { Chapter 1: } & \text { Introduction } & 1\end{array}$

1.1 Motivation 1

$\begin{array}{ll}1.2 \text { Objectives } & 7\end{array}$

1.3 Scope $\quad 8$

$\begin{array}{lr}1.4 \text { Thesis Organization } & 10\end{array}$

Chapter 2: $\quad$ Steel Reinforced Concrete and Its Deterioration Mechanisms 13

2.1 Reinforced Concrete 13

2.1.1 Concrete the Material $\quad 13$

2.1.1.1 Introduction $\quad 13$

$\begin{array}{ll}\text { 2.1.1.2 Cement } & 14\end{array}$

2.1.1.3 Aggregate $\quad 15$

2.1.1.4 Cement Hydration and the Roles of its Products 16

2.1.1.4.1 Calcium Silicates 17

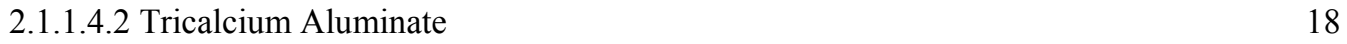

$\begin{array}{lr}2.1 .1 .4 .3 \text { Ferrites } & 18\end{array}$

$\begin{array}{ll}2.1 .1 .4 .4 \text { Porosity } & 18\end{array}$

$\begin{array}{ll}2.1 .1 .4 .5 \text { Calcium Hydroxide } & 19\end{array}$

$\begin{array}{ll}\text { 2.1.1.4.6 Calcium Sulfoaluminates } & 20\end{array}$

$\begin{array}{lr}2.1 .1 .4 .7 \text { Water } & 20\end{array}$

$\begin{array}{lr}2.1 .1 .5 \text { Admixtures } & 20\end{array}$

$\begin{array}{ll}\text { 2.1.1.6 Polymer Concrete } & 21\end{array}$

$\begin{array}{lr}2.1 .2 \text { Steel Reinforcement } & 23\end{array}$

$\begin{array}{ll}\text { 2.1.2.1 Properties } & 23\end{array}$

2.1.2.2 Sizes and Designations 24

2.1.3 Reinforced Concrete Beam Design $\quad 26$

$\begin{array}{ll}\text { 2.1.3.1 Overview } & 26\end{array}$

2.1.3.2 Flexural Design Philosophy 26

$\begin{array}{ll}\text { 2.1.3.3 Shear Design } & 29\end{array}$

2.1.3.4 Cracking and Deflection $\quad 31$

2.1.3.5 Bar Development

2.2 Deterioration of Concrete $\quad 34$

$\begin{array}{ll}\text { 2.2.1 Durability } & 34\end{array}$

2.2.2 Modes of Attack $\quad 35$

2.2.2.1 Leaching and Efflorescence $\quad 35$

2.2.2.2 Sulfate Attack 
2.2.2.3 Acid Attack

2.2.2.4 Crystallization of Salts

2.2.2.5 Alkali-Aggregate Attack

2.2.2.6 Freeze-Thaw Attack

2.2.2.7 Salt Scaling

2.3 Corrosion of Reinforcing Steel in Concrete 40

2.3.1 Initiators $\quad 40$

$\begin{array}{ll}\text { 2.3.1.1 Carbonation } & 41\end{array}$

2.3.1.2 Chloride Attack

2.3.2 Types of Corrosion and their Mechanisms 45

2.3.2.1 General Corrosion of Steel in Concrete $\quad 45$

2.3.2.2 "Black/Green Rust" $\quad 47$

2.3.2.3 Corrosion within Chloride-Contaminated Reinforced Concrete 48

2.3.2.4 Incipient Anode $\quad 51$

2.2.3 Cracking in Reinforced Concrete $\quad 51$

Chapter 3: Fiber Reinforced Polymer 53

3.1 FRP as a Composite Material 53

3.2 Constituents of Fiber Reinforced Polymer 54

$\begin{array}{ll}\text { 3.2.1 Fiber } & 54\end{array}$

3.2.1.1 Terms Associated with Composite Fiber $\quad 54$

3.2.1.2 Types of FRP Fiber $\quad 55$

$\begin{array}{ll}3.2 .1 .2 .1 \text { Carbon } & 55\end{array}$

$\begin{array}{ll}3.2 .1 .2 .2 \text { Glass } & 57\end{array}$

$\begin{array}{ll}\text { 3.2.1.2.3 Aramid } & 57\end{array}$

$\begin{array}{ll}\text { 3.2.2 Polymer Matrix } & 58\end{array}$

3.2.2.1 Terms Associated with FRP Polymer Matrix $\quad 58$

3.2.2.2 Types of FRP Polymer Matrix $\quad 60$

3.3 History of and Applications for FRP Composites 61

3.4 Properties of FRP $\quad 63$

3.4.1 Physical Properties $\quad 63$

$\begin{array}{ll}\text { 3.4.1.1 Density } & 63\end{array}$

3.4.1.2 Coefficient of Thermal Expansion $\quad 63$

3.4.1.3 High Temperature Effects

3.4.2 Mechanical Properties $\quad 64$

3.4.2.1 Tensile Properties $\quad 64$

3.4.2.2 Compressive Properties $\quad 65$

3.4.2.3 Creep-Rupture Properties $\quad 65$

3.4.2.4 Fatigue Properties $\quad 66$

3.4.2.5 Thermal Properties 66

$\begin{array}{ll}3.5 \text { Forms of FRP } & 66\end{array}$

3.5.1 Wet Lay-Up Systems $\quad 67$

$\begin{array}{ll}\text { 3.5.2 Prepreg Systems } & 67\end{array}$

$\begin{array}{ll}\text { 3.5.3 Pre-Cured Systems } & 68\end{array}$

$\begin{array}{ll}\text { 3.5.4 Other Forms of FRP } & 68\end{array}$

$\begin{array}{ll}3.6 \text { Durability of FRP } & 68\end{array}$

3.7 Other Considerations when Working with FRP 69

$\begin{array}{lr}3.7 .1 \text { Shipping } & 69\end{array}$

$\begin{array}{lr}3.7 .2 \text { Storage } & 69\end{array}$

$\begin{array}{ll}\text { 3.7.3 Handling } & 70\end{array}$

$\begin{array}{ll}\text { 3.7.4 Contractor Competency } & 71\end{array}$

3.7.5 Temperature, Humidity, and Moisture $\quad 72$ 
3.7.6 Quality Control $\quad 72$

3.7.7 Maintenance and Repair $\quad 76$

3.7.8 Temporary Protection $\quad 77$

$\begin{array}{ll}\text { Chapter 4: Bridge Repair and Rehabilitation } & 78\end{array}$

4.1 Overview of Current Methods 78

4.1.1 Concrete Repair 78

4.1.1.1 Repair with Concrete or Mortar $\quad 78$

4.1.1.2 Polymer Concrete Repair $\quad 82$

4.1.1.3 Crack Injection $\quad 82$

4.1.1.4 Coatings and Sealers 84

4.1.2 Steel Reinforcement Repair 84

4.1.2.1 Cleaning $\quad 84$

4.1.2.2 Rebar Splicing 85

4.1.2.3 Coatings $\quad 85$

4.1.3 FRP Repair 86

$\begin{array}{ll}\text { 4.1.3.1 FRP Fabric } & 87\end{array}$

$\begin{array}{ll}\text { 4.1.3.2 FRP Plates } & 87\end{array}$

$\begin{array}{ll}\text { 4.1.3.3 Near Surface Mounted (NSM) FRP Bars } & 87\end{array}$

4.1.4 Electrochemical Maintenance and Repair $\quad 88$

4.1.4.1 Cathodic Protection-Sacrificial Anode 88

4.1.4.2 Cathodic Protection - Impressed Current 89

4.1.4.3 Electrochemical Chloride Extraction 90

4.1.4.4 Re-alkalization 95

4.2 Literature Review of Experiments Conducted to Examine FRP-Repair of Flexure Members 96

4.2.1 Laboratory-Scale Research 96

4.2.1.1 Laboratory Testing: Large-Scale Repair 996

4.2.1.1.1 Maaddawy,2005 96

4.2.1.1.2 Bonacci, $2000 \quad 97$

4.2.1.1.3 Masoud, 2005 \& Masoud, $2006 \quad 99$

$\begin{array}{lr}\text { 4.2.1.1.4 Wang, K., } 2006 & 101\end{array}$

4.2.1.1.5 Kutarba, $2004 \quad 103$

4.2.1.1.6 Kachlakev, $2001 \quad 106$

$\begin{array}{ll}\text { 4.2.1.1.7 Leung, } 2006 & 107\end{array}$

$\begin{array}{ll}\text { 4.2.1.1.8 Grace, } 2004 & 109\end{array}$

$\begin{array}{lr}\text { 4.2.1.1.9 Aidoo } & 110\end{array}$

4.2.1.1.10 Quattlebaum, $2005 \quad 111$

4.2.1.2 Laboratory Testing: Small-Scale Repair $\quad 112$

$\begin{array}{ll}\text { 4.2.1.2.1 Soudki, } 2000 & 112\end{array}$

4.2.2 Studies on Bridge Repair in the Field 113

4.3 Selection of Preferred Combination of Methods for Experimental Program 115

$\begin{array}{ll}\text { Chapter 5: Experimental Program } & 119\end{array}$

5.1 Introduction and Overview of Laboratory Testing Plan 119

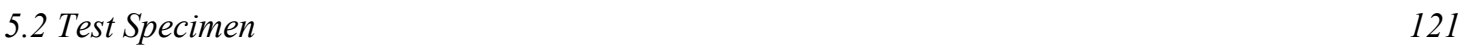

5.2.1 Design Philosophy 121

5.2.2 Part I Test Specimen $\quad 126$

5.2.2.1 Dimensions 126

$\begin{array}{lr}\text { 5.2.2.2 Materials } & 128\end{array}$

5.2.2.3 Construction 130

5.2.3 Part II Test Specimen 134

5.2.3.1 Dimensions $\quad 134$

5.2.3.2 Materials 136 
5.2.3.3 Construction 136

5.3 Accelerated Aging $\quad 138$

5.3.1 Introduction 138

5.3.2 Procedure for Experimental Testing 139

5.3.2.1 Trial Testing of Impressed Current Method 139

5.3.2.2 Impressed Current Method used in Experimental Testing Plan 141

5.4 Repair of Beam Specimens $\quad 147$

5.4.1 Part I Beam Repair 147

5.4.1.1 Two Different Substrate Repair Techniques 148

5.4.1.2 FRP Repair $\quad 165$

5.4.2 Part II Beam Repair 173

5.4.2.1 Substrate Repair 173

5.4.2.2 FRP Repair Using Three Unique Wrapping Schemes 174

$\begin{array}{ll}\text { 5.4.2.2.1 Wrapping Scheme I } & 175\end{array}$

$\begin{array}{ll}\text { 5.4.2.2.2 Wrapping Scheme 2 } & 176\end{array}$

$\begin{array}{ll}\text { 5.4.2.2.3 Wrapping Scheme } 3 & 178\end{array}$

5.5 Non-Destructive Testing 179

$\begin{array}{ll}\text { 5.5.1 Crack Measurement } & 179\end{array}$

5.5.1.1 Theory and Significance $\quad 179$

$\begin{array}{lr}\text { 5.5.1.2 Application } & 179\end{array}$

$\begin{array}{ll}\text { 5.5.2 Half-Cell Potential } & 180\end{array}$

5.5.2.1 Theory and Significance 180

5.5.2.2 Application to this Research 182

5.5.3 Rebound Hammer 183

5.5.3.1 Theory and Significance 183

5.5.3.2 Application to this Research 184

$\begin{array}{ll}\text { 5.5.4 Ultrasonic Pulse Velocity } & 187\end{array}$

$\begin{array}{ll}\text { 5.5.4.1 Theory and Significance } & 187\end{array}$

5.5.4.2 Application 189

5.6 Destructive Testing 192

5.6.1 Static Flexural Testing 192

5.6.1.1 Equipment 192

5.6.1.2 Instrumentation 193

$\begin{array}{ll}\text { 5.6.1.2.1 Part I } & 193\end{array}$

5.6.1.2.2 Part II 193

$\begin{array}{ll}\text { 5.6.1.3 Testing Setup } & 200\end{array}$

5.6.1.4 Testing Procedure $\quad 202$

5.6.2 Cyclic Flexural Testing 203

5.6.2.1 Equipment 203

5.6.2.2 Instrumentation 203

5.6.2.3 Testing Setup 203

5.6.2.4 Testing Procedure 206

5.6.3 Compression Cylinder Testing 209

$\begin{array}{ll}\text { 5.6.4 Pull-Off Testing } & 209\end{array}$

5.6.5 FRP Tension Coupon Testing 212

5.7 Beam Specimen Summary 213

Chapter 6: Test Results and Discussion $\quad 215$

6.1 Accelerated Aging Results 215

6.1.1 Results 215

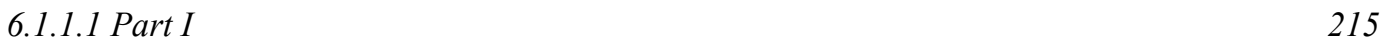

$\begin{array}{ll}\text { 6.1.1.1.1 Initial Corrosion Prior to FRP Repair } & 215\end{array}$

6.1.1.1.2 Secondary Corrosion Following FRP Repair 223 
6.1.1.2 Part II $\quad 232$

6.1.2 Literature Review of Accelerated Aging Results 238

$\begin{array}{ll}\text { 6.1.2.1 Maddaawy, } 2003 & 238\end{array}$

6.1.2.2 Maddaawy, $2005 \quad 240$

6.1.2.3 Masoud,2005 \& Masoud, 2006

6.1.2.4 Bonacci, $2000 \quad 245$

$\begin{array}{ll}\text { 6.1.2.5 Kutarba, } 2004 & 247\end{array}$

$\begin{array}{ll}\text { 6.1.2.6 Wang, K., } 2006 & 249\end{array}$

6.1.2.7 Grace, $2004 \quad 250$

6.1.2.8 Soudki, $2000 \quad 251$

6.1.2.9 Austin, 20003

6.1.3 Suggestions for Improvement 253

6.2 Non-Destructive Testing Results 255

6.2.1 Crack Measurement 255

6.2.1.1 Results 255

$\begin{array}{ll}\text { 6.2.1.1.1 Part I } & 255\end{array}$

6.2.1.1.2 Part II 257

6.2.1.2 Comparison to Literature 258

$\begin{array}{ll}\text { 6.2.1.2.1 Maddaawy, } 2005 & 258\end{array}$

6.2.1.2.2 Masoud, 2005 \& Masoud, $2006 \quad 259$

$\begin{array}{ll}6.2 .1 .2 .3 \text { Soudki, } 2000 & 260\end{array}$

6.2.1.2.4 Andrade, $1993 \quad 261$

6.2.1.3 Suggestions for Improvement 262

6.2.2 Half-Cell Potential 262

6.2.2.1 Results $\quad 262$

6.2.2.2 Suggestions for Improvement 264

6.2.3 Rebound Hammer 264

6.2.3.1 Results 264

$\begin{array}{ll}\text { 6.2.3.1.1 Part I } & 264\end{array}$

6.2.3.1.2 Part II 269

6.2.3.2 Suggestions for Improvement 274

6.2.4 Ultrasonic Pulse Velocity 274

6.2.4.1 Results 274

6.2.4.2 Suggestions for Improvement 281

6.3 Destructive Testing Results 283

6.3.1 Cyclic Flexural Testing 283

6.3.1.1 Results 283

6.3.1.2 Literature Review on Cyclic Loading 295

6.3.1.2.1 Masoud, $2005 \quad 295$

$\begin{array}{ll}6.3 .1 .2 .2 \text { Grace, } 2004 & 297\end{array}$

$\begin{array}{ll}\text { 6.3.1.2.3 Aidoo, } 2004 & 298\end{array}$

6.3.1.2.4 Quattlebaum, $2005 \quad 298$

$\begin{array}{ll}\text { 6.3.2 Static Flexural Testing } & 301\end{array}$

6.3.2.1 Results 301

$\begin{array}{ll}\text { 6.3.2.1.1 Part I } & 301\end{array}$

$\begin{array}{ll}\text { 6.3.2.1.2 Part II } & 318\end{array}$

6.3.2.2 Literature Review on Static Flexural Testing of Large-Scale FRP-Repaired Beams 352

6.3.2.2.1 Maddaawy, $2005 \quad 352$

6.3.2.2.2 Bonacci, $2000 \quad 353$

6.3.2.2.3 Wang, K. $2006 \quad 355$

6.3.2.2.4 Kutarba, $2004 \quad 356$

$\begin{array}{ll}\text { 6.3.2.2.5 Kachlakev, } 2001 & 360\end{array}$

6.3.2.2.6 Leung, $2006 \quad 363$

6.3.2.2.7 Grace, $2004 \quad 365$

$\begin{array}{ll}\text { 6.3.2.2.8 Soudki, } 2000 & 369\end{array}$ 
6.3.2.2.9 Aidoo, $2004 \quad 371$

$\begin{array}{ll}\text { 6.3.2.2.10 Quattlebaum } & 372\end{array}$

6.3.2.3 Suggestions for Improvement

6.3.3 Compression Cylinder Testing $\quad 373$

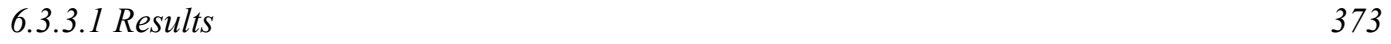

$\begin{array}{ll}\text { 6.3.3.1.1 Part I } & 373\end{array}$

$\begin{array}{ll}\text { 6.3.3.1.2 Part II } & 374\end{array}$

$\begin{array}{ll}\text { 6.3.3.2 Suggestions for Improvement } & 378\end{array}$

$\begin{array}{lr}\text { 6.3.4 Pull-Off Testing } & 378\end{array}$

$\begin{array}{ll}\text { 6.3.4.1 Results } & 378\end{array}$

6.3.4.2 Suggestions for Improvement $\quad 382$

$\begin{array}{ll}\text { 6.3.5 FRP Direct Tension Tests } & 383\end{array}$

$\begin{array}{ll}\text { 6.3.5.1 Results } & 383\end{array}$

6.3.5.2 Suggestions for Improvement 386

$\begin{array}{ll}\text { Chapter 7: Conclusions } & 387\end{array}$

$\begin{array}{lr}\text { 7.1 Laboratory Testing } & 387\end{array}$

$\begin{array}{ll}\text { 7.1.1 Accelerated Aging } & 387\end{array}$

$\begin{array}{lr}\text { 7.1.2 Crack Measurement } & 389\end{array}$

$\begin{array}{lr}\text { 7.1.3 Half-Cell Potential Testing } & 390\end{array}$

$\begin{array}{lr}\text { 7.1.4 Rebound Hammer Testing } & 390\end{array}$

$\begin{array}{ll}\text { 7.1.5 Ultrasonic Pulse Velocity Testing } & 391\end{array}$

$\begin{array}{lr}\text { 7.1.6 Cyclic Flexural Testing } & 392\end{array}$

$\begin{array}{ll}\text { 7.1.7 Static Flexural Testing } & 393\end{array}$

$\begin{array}{ll}\text { 7.1.7.1 Part I } & 393\end{array}$

$\begin{array}{ll}\text { 7.1.7.2 Part II } & 396\end{array}$

$\begin{array}{lr}\text { 7.1.8 Compression Cylinder Testing } & 401\end{array}$

$\begin{array}{lr}\text { 7.1.9 FRP-Concrete Pull-Off Testing } & 401\end{array}$

$\begin{array}{ll}\text { 7.1.10 FRP Direct Tension Testing } & 402\end{array}$

7.1.11 Summary 403

7.2 Recommendations for future work 405

$\begin{array}{lr}\text { References } & 409\end{array}$

Appendix A: $\quad$ Reinforced Concrete Beam Design Calculations 418

$\begin{array}{ll}\text { A.1 Definition of Variables } & 418\end{array}$

A.2 Part I Specimen Design and Commentary 419

A.3 Part II Specimen Design and Commentary 429

Appendix B: $\quad$ FRP Design Calculations 440

B.1 Definition of Variables 440

B.2 Part I FRP Design and Commentary 442

B.3 Part II FRP Design and Commentary 456

Appendix C: $\quad$ Final Beam Cracking Widths and Patterns $\quad 471$

$\begin{array}{ll}\text { C.1 Part I } & 472\end{array}$

$\begin{array}{lr}\text { C.2 Part II } & 478\end{array}$

$\begin{array}{ll}\text { Appendix D: Raw Data } & 487\end{array}$

D.1 Half-Cell Potential Raw Data 4487 
D.2 Rebound Hammer Raw Data 4489

D.2.1 Part I $\quad 489$

D.2.2 Part II $\quad 495$

D.3 Ultrasonic Pulse Velocity Raw Data 507

D.4 Compression Cylinder Raw Data 513

$\begin{array}{lr}\text { D.4.1 Part I } & 513\end{array}$

$\begin{array}{ll}\text { D.4.2 Part II } & 515\end{array}$

D.5 Static Flexural Testing Observations $\quad 520$

$\begin{array}{ll}\text { D.5.1 Part I Beams } & 520\end{array}$

$\begin{array}{ll}\text { D.5.2 Part II Beams } & 523\end{array}$

D.6 Mass Loss Data $\quad 532$

\begin{tabular}{lr} 
D.6.1 Part I Beams & 532 \\
\hline D.6.2 Part II Beams
\end{tabular}

$\begin{array}{ll}\text { D.6.2 Part II Beams } & 534\end{array}$

$\begin{array}{lll}\text { Appendix E: } & \text { FRP Failure Diagrams } & 537\end{array}$

Appendix F: $\quad$ Load Test Results for Individual Beams $\quad 549$

$\begin{array}{lr}\text { F.1 Static Load Tests } & 549\end{array}$

$\begin{array}{lr}\text { F.1.1 Part I Beams } & 549\end{array}$

$\begin{array}{ll}\text { F.1.2 Part II } & 557\end{array}$

$\begin{array}{ll}\text { F.1.2.1 Load-Deflection Curves } & 557\end{array}$

$\begin{array}{ll}\text { F.1.2.2 Load vs. Steel Strain Diagrams } & 568\end{array}$

F.1.2.3 Load vs. FRP Strain Diagrams

F.1.2.4 Load vs. Externally Bonded Strain Gages $\quad 575$

F.1.2.5 Load vs. Embedded Concrete Gages 577

$\begin{array}{llr}\text { F.2 Cyclic Load Effects } & 579\end{array}$

$\begin{array}{lr}\text { F.2.1 Deflection } & 579\end{array}$

$\begin{array}{ll}\text { F.2.2 Steel Strain } & 583\end{array}$

$\begin{array}{lr}\text { F.2.3 FRP Strain } & 588\end{array}$

$\begin{array}{ll}\text { F.2.4 Externally Bonded Concrete Strain } & 593\end{array}$

$\begin{array}{ll}\text { F.2.5 Embedded Concrete Strain } & 596\end{array}$

$\begin{array}{lr}\text { F.2.6 Actual Stiffness } & 598\end{array}$

Appendix G: $\quad$ Materials and Technical Data Sheets $\quad 599$

$\begin{array}{lr}\text { G.1 List of Materials } & 599\end{array}$

$\begin{array}{lr}\text { G.2 Technical Specifications } & 600\end{array}$

$\begin{array}{lr}\text { G.2.1 Sikadur 52 } & 600\end{array}$

G.2.2 SikaTop 111 Plus $\quad 606$

G.2.3 Tyfo SCH-7-UP Composite $\quad 612$

$\begin{array}{lr}\text { G.2.4 Tyfo S Epoxy } & 613\end{array}$

$\begin{array}{lr}\text { G.2.5 Tyfo WS Epoxy } & 614\end{array}$

$\begin{array}{lr}\text { G.2.6 Tyfo CB Epoxy } & 615\end{array}$

$\begin{array}{lll}\text { Appendix H: } & \text { Testing Equipment and Tools } & 616\end{array}$

H.1 List of Testing Equipment $\quad 616$

$\begin{array}{ll}\text { H.2 List of Tools } & 616\end{array}$

$\begin{array}{ll}\text { H.3 List of Safety Equipment } & 618\end{array}$ 


\section{List of Figures}

Figure 1.1: Current U.S. Bridges Categorized by Material (FHWA, 2006)

Figure 1.2: U.S. Bridge Inventory by Year of Construction (FHWA, 2006)

Figure 1.3: U.S. Bridges Older than 26 Years (FHWA, 2006)

Figure 1.4: U.S. Bridges Older than 51 Years (FHWA, 2006)

Figure 1.5: Partial collapse of the exterior girder of an overpass over I-70 near Pittsburgh, PA 6

Figure 2.1: Standard deformed rebar $\quad 24$

Figure 2.2: Actual stress block vs. assumed stress block (Nawy) 27

Figure 2.3: a.) idealized stress strain diagram of reinforcement, b.) stress distribution over the cross section for various modes of flexural failure (Nawy, 2003). 28

Figure 2.4: Types of Cracking in Reinforced Concrete (Nawy, 2003) 30

Figure 2.5: Beam failure patterns 31

Figure 2.6: Regions of a typical load deflection curve for a reinforced concrete beam (Nawy, 2003) 32

Figure 2.7 Efflorescence on the underside of a concrete member (www.answers.com) 35

Figure 2.8 Sulfate attack (www.cementaid.ie) 36

Figure 2.9 Alkali-aggregate attack (www.hydro.mb.ca) 37

Figure 2.10 Result of freeze-thaw attack (www.hydro.mb.ca) 38

Figure 2.11 Salt scaling (www.unb.ca)

Figure 2.12 Results of a carbonation test using a phenolphthalein indicator 4

Figure 2.13: The combined effect of chloride- and carbonation- induced corrosion $\quad 44$

Figure 2.14: Initiation of the Corrosion Process in Reinforced Concrete 46

Figure 2.15: Chloride-induced pitting corrosion in steel reinforcing bars 5

Figure 2.16: Cracks resulting from reinforcement corrosion (left) and cracks resulting from the application of load (right)

Figure 3.1: Cracks resulting from reinforcement corrosion (left) and cracks resulting from the application of load (right)

Figure 3.2: Epoxy resin used in this research

Figure 4.1: Examples of neat concrete removal on PennDOT Bridge \#49-4012-0250-1032 girders

Figure 4.2: Examples of formwork required for both minor and major concrete patch repairs

Figure 4.3: Epoxy crack injection (www.simpsonanchors.com)

Figure 4.4: Galvanic Series (aZo)

Figure 4.5: ECE setup in progress on a pier capbeam in Charlottesville, VA (Clemena, 2000)

Figure 4.6: Completed ECE setup on pier columns and their capbeam in Charlottesville, VA (Clemena, 2000)

Figure 4.7: Maddaawy, 2005 FRP Repair Schemes

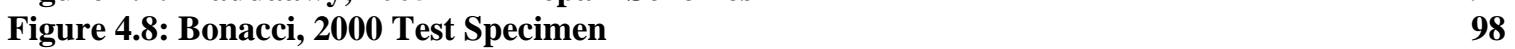

Figure 4.9: Bonacci, 2000 B5 wrapping scheme $\quad 99$

Figure 4.10: Masoud, 2006 and Masoud, 2005 Test Specimen 99

Figure 4.11: Schematic of Masoud, 2005 and Masoud, 2006 Wrapping Schemes I and II 101

Figure 4.12: Wang, K., 2006 Test Specimen 101

Figure 4.13: Various FRP Wrapping Schemes in Wang, K., $2006 \quad 102$

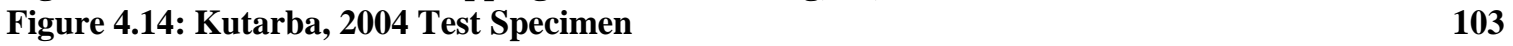

Figure 4.15: Schematic of Kutarba, 2006 Concrete Repair 103

Figure 4.16: Kutarba, 2006 Repair Schemes $\quad 105$

Figure 4.17: Kachlakev, 2001 Test Specimen $\quad 106$

Figure 4.18: Variation of Interfacial Shear Stress Obtained from Numerical Differentiation of Experimental Data (Leung, 2006)

Figure 4.19: Illustration of Crack-Induced Debonding (Leung, 2006)

Figure 4.20: Leung, 2006 test Specimen $\quad 108$

Figure 4.21: Grace, 2004 test Specimen $\quad 109$

Figure 4.22: Aidoo, 2004 test specimen 


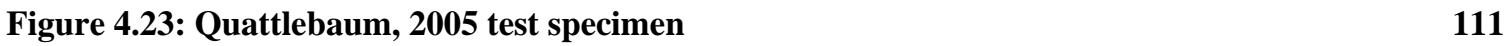

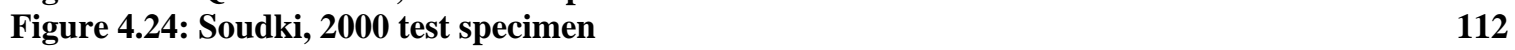

Figure 4.25: Soudki (2000) repair scheme $\quad 113$

Figure 5.1: Schematic of experimental testing plan Part I $\quad 120$

Figure 5.2: Schematic of experimental testing plan Part II 121

Figure 5.3: SEM photo of concrete extracted from an exterior girder of the PennDOT test bridge showing degradation due to deicing salts

Figure 5.4: SEM photo of concrete extracted from an exterior girder of the PennDOT test bridge showing degradation due to deicing salts

Figure 5.5: EDX spectrum of concrete extracted from an exterior girder of the PennDOT test bridge showing degradation due to deicing salts

Figure 5.7 Part I Beam Specimen (Cross-Sectional Dimensions) 127

Figure 5.8: Part I Beam Specimen (Reinforcement Diagram) 128

Figure 5.9: Wooden jigs used in assembly of rebar cages.

Figure 5.10: Completed rebar cages $\quad 131$

Figure 5.11: Wooden concrete forms built in the WVU laboratory 132

Figure 5.12: Part II Beam Specimen (Profile Dimensions) 134

Figure 5.13: Part II Beam Specimen (Cross-Sectional Dimensions) 135

Figure 5.14: Part II Beam Specimen (Reinforcement Diagram) 135

Figure 5.15: Improved Part II rebar cages with epoxy-coated shear stirrups 137

Figure 5.16: Sawhorses holding beams spaced to minimize dead load moments and creep strain 138

Figure 5.17: Rebar ground clamps attached to steel rebar that was grinded to white metal $\quad 142$

Figure 5.18: Insulation over connections and exposed reinforcing steel 143

Figure 5.19: Wiring scheme for accelerated aging via induced electric current 143

$\begin{array}{ll}\text { Figure 5.20: Beams wired to power supply } & 144\end{array}$

Figure 5.21: Beams covered with wet burlap and plastic during accelerated aging 144

Figure 5.22: Pin punch used to remove loose material from around the crack edges prior to epoxy injection

Figure 5.23: Needle attachment through which compressed air was used to clean cracks $\quad 149$

Figure 5.24: Plastic syringe next to gravity-fed epoxy-filled cracks 152

Figure 5.25: Cracks filled with epoxy 153

Figure 5.26: Inverted beam (tension steel facing upward) after air-chiseling 155

Figure 5.27: 2x4's used as a guide for saw-cutting 156

Figure 5.28: Saw cutting $\quad 157$

$\begin{array}{ll}\text { Figure 5.29: Completed saw cut } & 157\end{array}$

$\begin{array}{ll}\text { Figure 5.30: Steel cleaning with wire wheel brush } & 158\end{array}$

Figure 5.31: Small amounts of corrosion product remaining on steel after mechanical cleaning 159

Figure 5.32: Clutch-style bar clamps used to secure molds and to adjust the cross-sectional width 160

Figure 5.33: Freshly finished SikaTop 111 patch repair $\quad 163$

$\begin{array}{ll}\text { Figure 5.34: Beam cross-section at anchor locations } & 164\end{array}$

Figure 5.35: Completed polymer-modified concrete substrate repair $\quad 164$

Figure 5.36: Illustration of Dr. Leung's suggested stirrup location $\quad 166$

$\begin{array}{ll}\text { Figure 5.37: Part I FRP Wrapping Scheme } & 167\end{array}$

Figure 5.38: Primer coat and FRP layout lines on Part I beams 168

Figure 5.39: Tyfo WS epoxy used to fill voids on the sides of the beam specimens over which FRP $\begin{array}{ll}\text { would be placed } & 168\end{array}$

$\begin{array}{ll}\text { Figure 5.40: Trough built and used as FRP saturating bath } & 171\end{array}$

Figure 5.41: Part II beams with finished substrate repair and primed with Tyfo WS epoxy $\quad 174$

Figure 5.42: Schematic of Wrapping Scheme I $\quad 175$

Figure 5.43: Stirrup Location for Wrapping Scheme II 177

$\begin{array}{ll}\text { Figure 5.44: Schematic of Wrapping Scheme } 2 & 177\end{array}$

Figure 5.45: Schematic of Wrapping Scheme $3 \quad 178$

Figure 5.46: Cross-section of patch repaired beams with FRP at both shear and constant moment $\begin{array}{ll}\text { regions } & 178\end{array}$

Figure 5.47: Mastrad crack width gage (http://rissmonitor.com) 180 
Figure 5.48: Location of half-cell potential readings on Part I beams 182 Figure 5.49: Rebound hammer test locations for Part I beams 184 Figure 5.50: Rebound hammer test locations for Part II beams without externally bonded concrete strain gages

Figure 5.51: Rebound hammer test locations for Part II beams with externally bonded concrete strain gages

Figure 5.52: Three configurations for an ultrasonic pulse velocity test

Figure 5.53: Pulse velocity configurations

Figure 5.55: Pulse velocity testing locations on beams with externally bonded concrete strain gages

Figure 5.56: Part I LVDT Locations

Figure 5.57: Part II LVDT locations

Figure 5.58: Scotch tape placed over freshly-placed strain gage primer epoxy

Figure 5.59: Externally-bonded concrete strain gage locations

Figure 5.67: Final beam specimen support system for cyclic flexural testing

Figure 5.68: Loose cables used to secure beam specimens to both the supports and the 4-point bending beam in case of movement due to cyclic loading

Figure 5.69: Tabs welded to the 4-point bending beam and to the steel plate to prevent movement of the steel sphere apparatus

Figure 5.70: Load deflection curves for static tests of Beams 5, 8, and 9 showing 10-60\% Ultimate Load

Figure 5.71: Delaminated FRP on Beam 6 after just 110,000 cycles due to the high load range 207

Figure 5.72: Load deflection curves for static tests of Beams 5, 8, and 9 showing 20-40\% Ultimate Load

Figure 5.73: FRP-to-patch concrete pull-off test locations $\quad 210$

Figure 5.74: First dolly used for FRP pull-off tests $\quad 211$

Figure 5.75: Second dolly used for FRP pull-off tests $\quad 212$

$\begin{array}{lr}\text { Figure 5.76: FRP Tension Coupon } & 213\end{array}$

Figure 6.1: Extraction of steel rebar for mass loss analysis $\quad 217$

Figure 6.2: Typical corroded steel stirrup extracted from Part I beam 218

Figure 6.3: Typical extent of deterioration observed on Part I beams after initial corrosion 219

Figure 6.4: The only significant crack observed within polymer patch-repair concrete material 221

Figure 6.5: Comparison of extent corrosion damage on reinforcing steel extracted from Beams I-1 and I-5.

Figure 6.6: Steel coupon samples cut from Beam I-5 rebar at 1,200amp $\cdot$ hours

Figure 6.7: Cracking in constant moment region of corroded unrepaired Beam I-6 after two corrosion cycles

Figure 6.8: End cracking in Part I control beam subjected to two corrosion cycles

Figure 6.9: Cracks in Beam I-8 within the old concrete running parallel to the old-to-patch concrete interface

Figure 6.10: Damage of old-new concrete interface at the mark end of Beam I-8 227

Figure 6.11: The only significant crack observed within polymer patch-repair concrete material 228

Figure 6.12: New crack running parallel to injection-repaired crack on Beam I-9 229

Figure 6.13: Re-opening of epoxy-injected crack on Beam I-9 229

Figure 6.14: Steel coupon samples cut from Beams I-7 and I-8 at 1,200 and 2,400amp-hours, respectively

Figure 6.15: Profile view of steel coupon samples extracted from pristine control Beam I-14 and Beams I-6, I-9 and I-8 at 2,400amp-hours 
Figure 6.16: Cross-section view of steel coupon samples extracted from pristine control Beam I-14 and Beams I-6, I-9 and I-8 at 2,400amp-hours 232

Figure 6.17: Typical deterioration of Part II beams prior to repair 233

Figure 6.18: Corrosion observed in Beam II-3 after cover delamination 235

Figure 6.19: Part II pitting corrosion on extracted rebar 236

Figure 6.20: Unknown substance precipitating from Part II Beams 2237

Figure 6.21: Efflorescence leaching from Part II Beams $\quad 237$

Figure 6.22: Maddaawy (2003) Test Specimen 239

Figure 6.23: Maddaawy (2003) Wiring Scheme $\quad 239$

Figure 6.24: Concrete Side Strain vs. Time Relationship (Maddaawy 2003) 240

Figure 6.25: Maddaawy (2005) Test Specimen $\quad 241$

Figure 6.26: Masoud (2005) and Masoud (2006) Test Specimen 243

Figure 6.27: Location of sample coupons to determine mass loss for Masoud (2006) 245

Figure 6.28: Timeline of Average Mass Loss observed in Masoud (2006) 245

Figure 6.29: Bonacci (2000) Test Specimen $\quad 246$

Figure 6.30: Wang, K. (2006) Test Specimen 249

Figure 6.31: Schematic of Soudki (2000) accelerated corrosion setup 252

Figure 6.32: Typical crack patterns caused by corrosion (Maddaawy, 2005) 259

Figure 6.33: Total expansion in the transverse laminate due to corrosion for Soudki test specimens CF-5, CF-10, CF-S-10 and CF-15 261

Figure 6.34: Rebound hammer calibration data provided by Proceq 271

Figure 6.35: Variables used for correction of ultrasonic pulse velocity in steel-reinforced concrete (Malhotra, 2004) 276

Figure 6.36: Scheme for measuring surface crack depth using ultrasonic pulse velocity testing (Malhotra, 2004) 282

Figure 6.37: Use of surface method to determine depth of concrete deterioration and to determine approximate location of cracks or irregularities 283

Figure 6.38: Decay of Part II fatigue-loaded beams as illustrated by normalized deflections at 250,000 cycle increments during static load tests within the serviceability region 285

Figure 6.39: Decay of Part II fatigue-loaded beams as illustrated by permanent deflections after each 250,000 cycle increment

Figure 6.40: Decay of Part II fatigue-loaded beams as illustrated by normalized stiffness at 250,000 cycle increments during static load tests within the serviceability region

Figure 6.41: Decay of Part II fatigue-loaded beams as illustrated by normalized FRP Strain at 250,000 cycle increments during static load tests within the serviceability region (with outliers)

Figure 6.42: Decay of Part II fatigue-loaded beams as illustrated by normalized FRP Strain at 250,000 cycle increments during static load tests within the serviceability region (outliers removed)

Figure 6.43: Decay of Part II fatigue-loaded beams as illustrated by normalized steel strain at 250,000 cycle increments during static load tests within the serviceability region

Figure 6.44: Decay of Part II fatigue-loaded beams as illustrated by normalized bonded concrete strain at 250,000 cycle increments during static load tests within the serviceability region 293

Figure 6.45: Part I load-deflection curves $\quad 301$

Figure 6.46: Comparison of Part I load-deflection curves for beams repaired with FRP 302

Figure 6.47: Comparison of Part I load-deflection curves for beams repaired with FRP and both pristine and aged control beams

Figure 6.48: Comparison of Part I load-deflection curves for beams repaired with FRP and both pristine and aged control beams

Figure 6.49: Comparison of Part I load-deflection curves for pristine control beams 303

Figure 6.50: Part I Load Capacities $\quad 305$

Figure 6.51: Part I Deflections $\quad 311$

Figure 6.52: FRP Rupture on Beam I-7 $\quad 315$

Figure 6.53: FRP Rupture on Beam I-10 315

Figure 6.54: FRP Rupture on Beam I-8 $\quad 316$

Figure 6.55: FRP Rupture on Beam I-9 $\quad 316$ 
Figure 6.56: Concrete cover delamination on Beams I-9 and I-10 during static testing 318 Figure 6.57: Part II load-deflection curves $\quad 319$

Figure 6.58: Comparison of Part II load-deflection curves for both pristine and corroded unrepaired control beams

Figure 6.59: Comparison of Part II load-deflection curves

Figure 6.60: Comparison of Part II load-deflection curves for repaired beams subjected to fatigue loading prior to loading statically to failure

Figure 6.61: Part II load capacities $\quad 324$

Figure 6.62: Part II deflections $\quad 326$

Figure 6.63: Individual maximum overall steel strains and corresponding loads 331

Figure 6.64: Individual maximum steel strains and corresponding loads within the linear region 331

Figure 6.65: Individual maximum FRP strains and corresponding loads within the linear region 332

Figure 6.66: Individual maximum overall FRP strains and corresponding loads 333

Figure 6.67: Individual maximum bonded concrete strains (both at reinforcement level and at concrete cover level) and corresponding loads within the linear region

Figure 6.68: Individual maximum overall bonded concrete strains (both at reinforcement level and at concrete cover level) and corresponding loads

Figure 6.69: Individual maximum embedded concrete strains and corresponding loads within the linear region

Figure 6.70: Individual maximum recorded bonded concrete strains (both at reinforcement level and at concrete cover level) and corresponding loads

Figure 6.71: Photos of non-fatigued Part II beams repaired using Wrapping Scheme 1 after failure

Figure 6.72: Photos of fatigued Part II beams repaired using Wrapping Scheme 1 after failure 340 Figure 6.73: Photos of non-fatigued Part II beams repaired using Wrapping Scheme 2 after failure

Figure 6.74: Photos of fatigued Part II beams repaired using Wrapping Scheme 2 after failure 342 Figure 6.75: Photos of non-fatigued Part II beams repaired using Wrapping Scheme 3 after failure

Figure 6.76: Photos of fatigued Part II beams repaired using Wrapping Scheme 3 after failure 343

Figure 6.77: Comparison between fracture surfaces of non-fatigued and fatigued beams repaired with Wrapping Scheme 1

Figure 6.78: Comparison between fracture surfaces of non-fatigued and fatigued beams repaired with Wrapping Scheme 2

Figure 6.79: Comparison between fracture surfaces of non-fatigued and fatigued beams repaired with Wrapping Scheme 2

Figure 6.80: Typical fracture surface of non-fatigued beam specimens with polymer concrete substrate repair

Figure 6.81: Failure of Beam II-3

Figure 6.82: Failure of Beam II-4

Figure 6.83: Corroded exterior girder of PennDOT Bridge \#49-4012-0250-1032 349

Figure 6.84: Typical shear flexure cracks observed on Part II beams

Figure 6.85: Composite action between old and new concrete on Part II beams as evidenced by cracking continuity across interface

Figure 6.86: Static flexural test results for Maddaawy (2005)

Figure 6.87: Load-deflection curves for Bonacci (2000)

Figure 6.88: Illustration of apparent strain compatibility observed by Bonacci (2000) 355

Figure 6.89: Load-displacement curve for Kutarba (2004) beam C2

Figure 6.90: Load-displacement curve for Kutarba (2004) beams C2, 2B-S

Figure 6.91: Load-displacement curve for Kutarba (2004) beams C2, 4A-D, 1A-S 359

Figure 6.92: Load-displacement curve for Kutarba (2004) beams C2, 2A-D 359

Figure 6.93: Load-Displacement curve for Kutarba (2004) beams C2, 5A-D 359

Figure 6.94: Load-displacement curve for Kutarba (2004) beams C2, 3B-S 359

Figure 6.95: Load-Displacement curve for Kutarba (2004) beams C2, 7A-S 359

Figure 6.96: Load-displacement curve for Kutarba beams C2, 5B-S, 4B-D 359

Figure 6.97: Load-Displacement curve for Kutarba (2004) beams C2, 4B-S 359 
Figure 6.98: Load-displacement curve for Kutarba (2004) beams C2, 4A-S, 5B-D 359

Figure 6.99: Load-displacement curve for Kutarba (2004) beams C2, 3B-D 359

Figure 6.100: Load vs. deflection results observed by Kachlakev (2001) for the specimen strengthened in both flexure and shear

Figure 6.101: Load vs. midspan strain results observed by Kachlakev (2001) for the specimen strengthened in both flexure and shear

Figure 6.102: Load-deflection curves observed by Grace (2004) for beams strengthened with CFRP. Specimens were subjected to $100 \%$ humidity at $38^{\circ} \mathrm{C}$.

Figure 6.103: Average ultimate failure loads observed by Grace (2004) for beams strengthened with CFRP plates.

Figure 6.104: Average ultimate failure loads observed by Grace (2004) for beams strengthened with CFRP laminates.

Figure 6.105: Load-deflection curves observed by Soudki (2000) for corroded and unstrengthened specimens.

Figure 6.106: Load-deflection curves observed by Soudki (2000) for FRP-strengthened specimens.

Figure 6.107: Soudki (2000) load-deflection comparison between FRP-strengthened and unstrengthened specimens at mass losses of 5 and $10 \%$.

Figure 6.108: Typical Compression Cylinders Failures

Figure 6.109: Pull-off failure of beams having crack-injected normal concrete substrates 379

Figure 6.110: Pull-off failure of beams having patch-repaired polymer concrete substrates 380

Figure 6.111: Typical FRP fracture surface after debonding from polymer patch repair concrete 381

Figure 6.112: Stress vs. Elongation curves for FRP Direct Tension Tests

Figure 6.113: Failed FRP tension coupon samples 335

Figure B.1: Elastic Strain and Stress Distribution (ACI 220-R, Fig. 9.3) 455 


\section{List of Tables}

Table 1.1: Concrete Bridge vs. Total Bridge Deficiencies in the U.S. (FHWA, 2006) .............................. 4

Table 1.2: Concrete Bridge Deficiencies by Type (FHWA .................................................................... 4

Table 2.1: Constituents and Properties of ASTM Portland Cement Types (Mindess, 2003)................ 15

Table 2.2: Sequence of Hydration of the Calcium Silicates (Mindess, 2003)............................................ 17

Table 2.3: Beneficial Effects of Admixtures on Concrete Properties (Mindess, 2003) ........................... 21

Table 2.4: Designations, Dimensions, and Weights of Standard U.S. and Metric Steel Reinforcing

Bars (PCI, 2004; Nilson, 1987) ..................................................................................................... 25

Table 2.5: Designations, Areas, and Weights of Standard Canadian Steel Reinforcing Bars ............... 25

Table 2.6: Types of cracks found in reinforced concrete (ACI, 2003) ...................................................... 52

Table 3.1: Density range of FRP materials compared to that of steel (ACI 440-2R-02) ....................... 63

Table 3.2: Coefficients of thermal expansion for steel, concrete, and FRP materials (ACI 440-2R-02)

Table 3.3: Summary of standard testing procedures used for quality control of an FRP system .......... 76

Table 4.1: ECE Treatment on Selected North American Structures (Sharp, 2002)................................. 94

Table 4.2: Grouping of Maddaawy, 2005 Beam Specimens...................................................................... 96

Table 4.3: Summary of Bonacci, 2000 Testing Plan. .................................................................................. 98

Table 4.4: Masoud, 2005 testing plan........................................................................................................... 100

Table 4.5: Summary of Kutarba test specimens ............................................................................................. 104

Table 4.6: Anchor Locations Tested in Leung, 2006 .................................................................................... 108

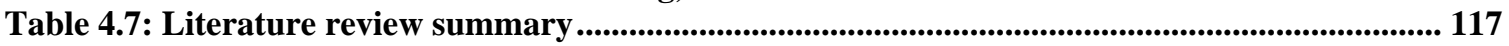

Table 4.8: Breakdown of literature review summary....................................................................... 118

Table 5.1: Concrete Mix Proportions ........................................................................................................ 129

Table 5.2: Preliminary Trial Specimens......................................................................................................... 140

Table 5.3: Maximum Outputs of Bio-Rad 1000 Power Supplies.............................................................. 141

Table 5.4: Material Properties for Gross SCH-7UP Laminate and its Components............................ 169

Table 5.5: Interpretation of Half-Cell Potential Data ....................................................................... 181

Table 5.6: Part II Instrumentation Plan................................................................................... 194

Table 5.7: Specimen Summary ............................................................................................................................. 214

Table 6.1: Part I Mass Loss Summary.......................................................................................................... 224

Table 6.2: Part II Mass Loss Summary ……………......................................................................................... 232

Table 6.3: Summary of Accelerated Corrosion Schedule and Resulting Mass Losses ......................... 240

Table 6.4: Summary of accelerated corrosion schedule and resulting mass losses................................ 242

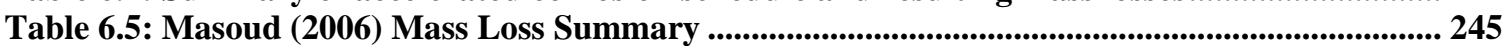

Table 6.6: Summary of corrosion procedures used in Wang, K. (2006) .................................................. 249

Table 6.7: Soudki (2000) specimen nomenclature and accelerated corrosion........................................ 251

Table 6.8: Part I Cracking Summary ....................................................................................................... 257

Table 6.9: Part II Cracking Summary............................................................................................................... 258

Table 6.10: Average Half-cell potential readings for Part I Test specimens .......................................... 263

Table 6.11: Summary of Rebound Numbers for Part I Beams .............................................................. 266

Table 6.12: Comparison of concrete strength estimated by the rebound hammer to actual concrete

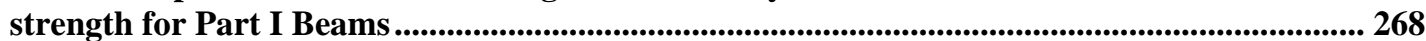

Table 6.13: Summary of Rebound Numbers for Part II Beams................................................................ 270

Table 6.14: Comparison of concrete strength estimated by the rebound hammer to actual concrete strength for Part II Beams ....................................................................................................................... 273

Table 6.15: Values for $V_{C} / V$ for ultrasonic pulse velocity readings when using the indirect configuration with the presence of longitudinal reinforcing steel (Malhotra, 2004) .................. 278

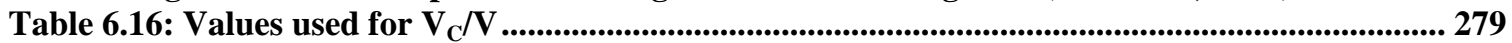

Table 6.17: Summary of Ultrasonic Pulse Velocity Results......................................................................... 280

Table 6.18: Part II permanent strains after 2,000,000 loading cycles..................................................... 295

Table 6.19: Summary of Masoud (2005) Test Results .................................................................................. 296

Table 6.20: Ultimate failure loads observed by Grace (2004) after cyclic loading was complete...... 297 


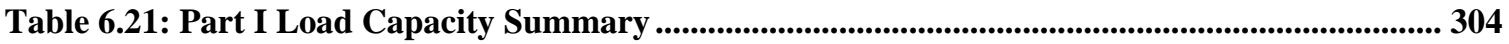

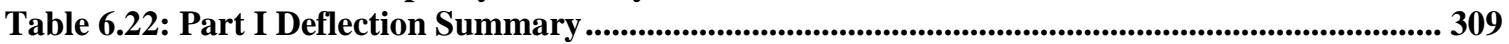

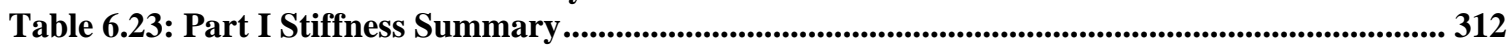

Table 6.24: Part I FRP Rupture Locations ................................................................................ 314

Table 6.25: Part II Load Capacity Summary................................................................................. 322

Table 6.26: Part II Deflection Summary .................................................................................................. 325

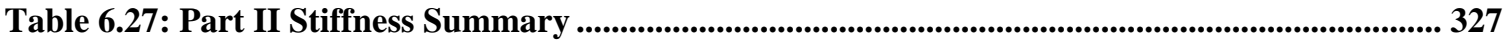

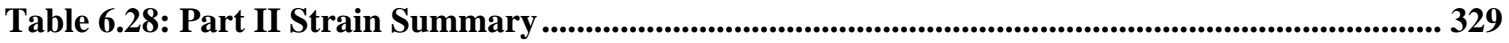

Table 6.29: Part II FRP Rupture Locations...................................................................................... 337

Table 6.30: Test results for Maddaawy (2005).............................................................................. 353

Table 6.31: Summary of Test Results for Bonacci (2000) .............................................................. 354

Table 6.32: Modes of Failure Observed in Wang, K. (2006)........................................................... 356

Table 6.33: Wang, K. (2006) Beam Specimen Coding System............................................................. 356

Table 6.34: Summary of Kutarba (2004) test specimens (PR=Post ..................................................... 357

Table 6.35: Load test results reported by Kutarba (2004) after initial corrosion............................... 357

Table 6.36: Load test results reported by Kutarba (2004) after initial corrosion................................. 358

Table 6.37: Failure modes observed by Kutarba (2004) ....................................................................... 360

Table 6.38: Summary of load-deflection results observed by Kachlakev (2001) .................................. 360

Table 6.39: Failure modes observed by Kachlakev (2001).................................................................... 361

Table 6.40: Comparison of loads and deflections observed by Kachlakev (2001) ................................ 362

Table 6.41: Summary of Soudki (2000) flexural test results ............................................................ 371

Table 6.42: Part I 28-day compression cylinder tests....................................................................... 373

Table 6.43: Part II Compression Cylinder Test Results at 28 Days................................................. 375

Table 6.44: Part II Compression Cylinder Test Results at the Time the Corresponding Beam was

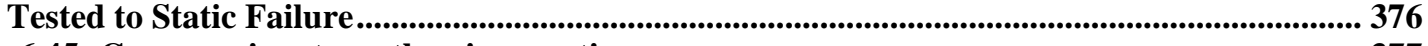

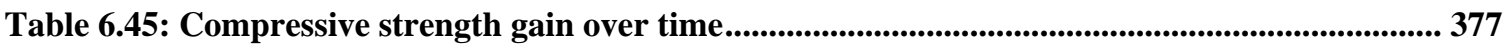

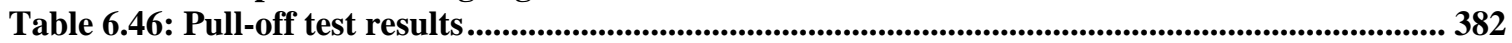

Table 6.47: Direct tension test results for FRP coupon samples ......................................................... 383

Table B.1: Environmental-Reduction Factor for Various FRP Systems and Exposure Conditions (ACI 440.2R, Table 8.1) ..............................................................................................................446

Table D.1: Part II Compressive Strengths ................................................................................. 514

Table D.2: Part II Control Beam Compressive Strengths ..................................................................... 515

Table D.3: Part II Branch 1 Beam Compressive Strengths ................................................................... 516

Table D.4: Part II Branch 2 Beam Compressive Strengths .............................................................. 517

Table D.5: Part II Branch 3 Beam Compressive Strengths ................................................................ 518

Table D.6: Part II Patch-Repair Polymer Concrete Compressive Strengths....................................... 519

Table F.1 Actual Stiffness at 250,000-Cycle Intervals ................................................................ 598 


\title{
Abbreviations
}

\author{
A - Amperes \\ ACI - American Concrete Institute \\ AFRP - Aramid Fiber Reinforced Polymer \\ C-S-H - Calcium Silica Hydrate \\ CFRP - Carbon Fiber Reinforced Polymer \\ E - Tensile Modulus \\ FRP - Fiber Reinforced Polymer \\ GFRP - Glass Fiber Reinforced Polymer \\ HM - High Modulus \\ HS - High Stiffness \\ I - Current \\ IM - Intermediate Modulus \\ mA - Milliaperes \\ $\mathrm{NaCl}$ - Sodium Chloride \\ NSM - Near Surface Mounted \\ PAN - Polyacrylonitrile \\ $\mathrm{R}$ - Resistance \\ UHM - Ultrahigh Modulus \\ V - Voltage, Volts \\ VPM - Vibrations per Minute \\ w/c - Water/Cement Ratio \\ $\mu \mathrm{A}$ - Microamperes
}




\section{Chapter 1: Introduction}

\subsection{Motivation}

In 2005, ASCE reported that 160,570 of America's 590,750 bridges (27.1\%) are rated as either structurally deficient or functionally obsolete. An even higher $31.2 \%$ of urban bridges are deficient. In West Virginia and Pennsylvania, $37 \%$ and $42 \%$ of bridges are either structurally deficient or functionally obsolete, respectively.

According to the FHWA, a bridge is classified as structurally deficient for one of two reasons. Either it is in poor structural condition due to deterioration and/or damage or its waterway opening is extremely insufficient and causes intolerable traffic interruptions. ASCE defines a structurally deficient bridge as one that is closed or restricted to light vehicles due to deteriorated structural components. Structurally deficient bridges are not necessarily unsafe, but must have speed and weight limits.

ASCE defines a bridge as functionally obsolete if it has older design features and cannot safely accommodate current traffic volumes and sustain vehicle sizes and weights. The FHWA further states that a bridge becomes functionally obsolete as traffic demand and geometry guidelines change from those to which the bridge was originally designed to meet. For example, a bridge that was built 50 years ago may have been designed to meet the demand at that time of $1,000 \mathrm{ADT}$, but the demand for the same functioning bridge is now 10,000 ADT. 
A bridge that is both structurally deficient and functionally obsolete is identified only as structurally deficient since it is potentially the more severe of the two classifications. Structurally deficient bridges and functionally obsolete bridges can be placed into one category which is simply called "deficient". A functioning deficient bridge requires a great deal of maintenance and repair to remain in service. Deficient bridges will either need to be replaced or rehabilitated. Deficient bridges are inconvenient for vehicles such as busses, trucks, and emergency vehicles, as they are required to take sometimes lengthy detours instead of using such structures.

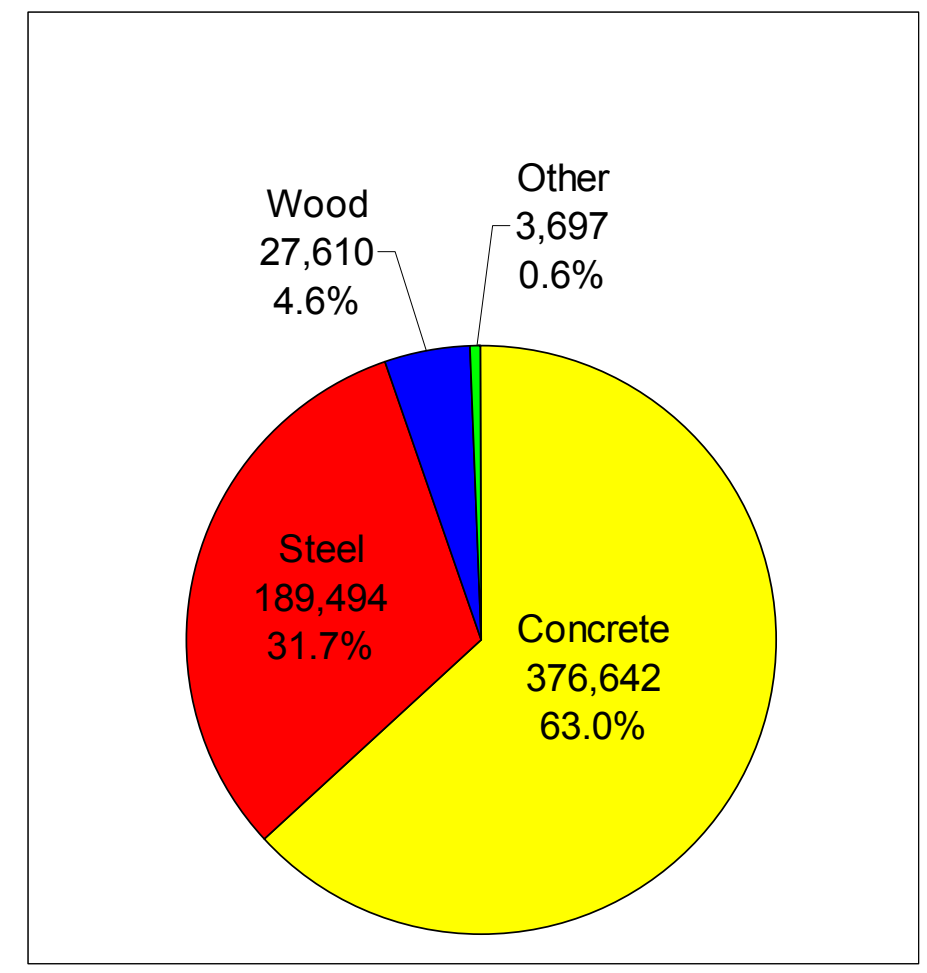

Figure 1.1: Current U.S. Bridges Categorized by Material (FHWA, 2006)

According to 2006 National Bridge Inventory data supplied by the FHWA, 376,642 $(63.0 \%)$ of the nation's current bridges include a concrete superstructure (refer to Figure 
1.1 and Table 1.1). Regular reinforced concrete accounts for $41.2 \%$ of the nation's bridge superstructures while pre-stressed concrete accounts for $21.5 \%$.

According to FHWA records $31.7 \%$ of the nation's 73,800 structurally deficient bridges and $51 \%$ of the nation's functionally obsolete bridges are made of concrete (refer to Table 1.1). Together, 64,395 concrete bridges were reported as having some type of deficiency in 2006. Approximately 1 out of 9 of America's existing bridges is a deficient concrete bridge. FHWA data shows that $25.4 \%$ of the nation's structurally deficient bridges and $35.4 \%$ of the nation's functionally obsolete bridges have regular reinforced concrete girders. Roughly 1 out of 13 regular reinforced concrete bridges in America is structurally deficient, and roughly 1 in 5 regular reinforced concrete bridges has some type of deficiency (refer to Table 1.1 and Table 1.2).

Although the percentage of bridge deficiencies has been slowly decreasing since the 1990 's, it is estimated that $25 \%$ of America's bridges will remain deficient in coming years. Furthermore, it cannot be made certain that this declining trend will continue over the next several decades. Figure 1.2 shows the age of U.S. in 20 year increments. One can reason that a large percentage of America's aging bridges will deteriorate and leave transportation officials to deal with an even larger scale problem. As can be seen in Figure 1.2, Figure 1.3, and Figure 1.4, 410,659 (73.7\%) of current U.S. bridges are more than 51 years old, 410,659 (73.7\%) are more than 26 years old, and 450,106 (75.4\%) are more than 20 years old. 
Table 1.1: Concrete Bridge vs. Total Bridge Deficiencies in the U.S. (FHWA, 2006)

\begin{tabular}{|l|l|l|l|l|l|l|l|}
\hline & $\begin{array}{l}\text { Total } \\
\text { Bridges } \\
\text { in U.S. }\end{array}$ & $\begin{array}{l}\text { Total } \\
\text { Concrete } \\
\text { Bridges }\end{array}$ & $\begin{array}{l}\% \text { of } \\
\text { Total } \\
\text { Bridges }\end{array}$ & $\begin{array}{l}\text { Regular } \\
\text { Reinforced } \\
\text { Concrete }\end{array}$ & $\begin{array}{l}\text { \% of } \\
\text { Total } \\
\text { Bridges }\end{array}$ & $\begin{array}{l}\text { Prestressed } \\
\text { Concrete }\end{array}$ & $\begin{array}{l}\text { of } \\
\text { Total } \\
\text { Bridges }\end{array}$ \\
\hline $\begin{array}{l}\text { All Existing } \\
\text { Bridges }\end{array}$ & 597,443 & 376,642 & 63.0 & 247,618 & 41.4 & 129,024 & 21.6 \\
\hline $\begin{array}{l}\text { Structurally } \\
\text { Deficient }\end{array}$ & 73,800 & 23,417 & 31.7 & 18,782 & 25.4 & 4,635 & 6.3 \\
\hline $\begin{array}{l}\text { Functionally } \\
\text { Obsolete }\end{array}$ & 80,322 & 40,978 & 51.0 & 28,434 & 35.4 & 12,544 & 15.6 \\
\hline Deficient & 154,122 & 64,395 & 41.8 & 47,216 & 30.6 & 17,179 & 11.1 \\
\hline
\end{tabular}

Table 1.2: Concrete Bridge Deficiencies by Type (FHWA 2006)

\begin{tabular}{|l|c|c|c|}
\hline & $\begin{array}{l}\text { Regular } \\
\text { Reinforced } \\
\text { Concrete }\end{array}$ & $\begin{array}{l}\text { Pre- } \\
\text { stressed } \\
\text { Concrete }\end{array}$ & $\begin{array}{l}\text { Total } \\
\text { Concrete }\end{array}$ \\
\hline Total & 247,618 & 129,024 & 376,642 \\
\hline $\begin{array}{l}\text { Structurally } \\
\text { Deficient }\end{array}$ & 18,782 & 4,635 & 23,417 \\
\hline $\begin{array}{l}\text { \% Structurally } \\
\text { Deficient }\end{array}$ & 7.6 & 3.6 & 6.2 \\
\hline $\begin{array}{l}\text { Functionally } \\
\text { Obsolete }\end{array}$ & 28,434 & 12,544 & 40,978 \\
\hline $\begin{array}{l}\text { \% Functionally } \\
\text { Obsolete }\end{array}$ & 11.5 & 9.7 & 10.9 \\
\hline Deficient & 19.1 & 13.3 & 17.1 \\
\hline \% Deficient & & 17,179 & 64,395 \\
\hline
\end{tabular}




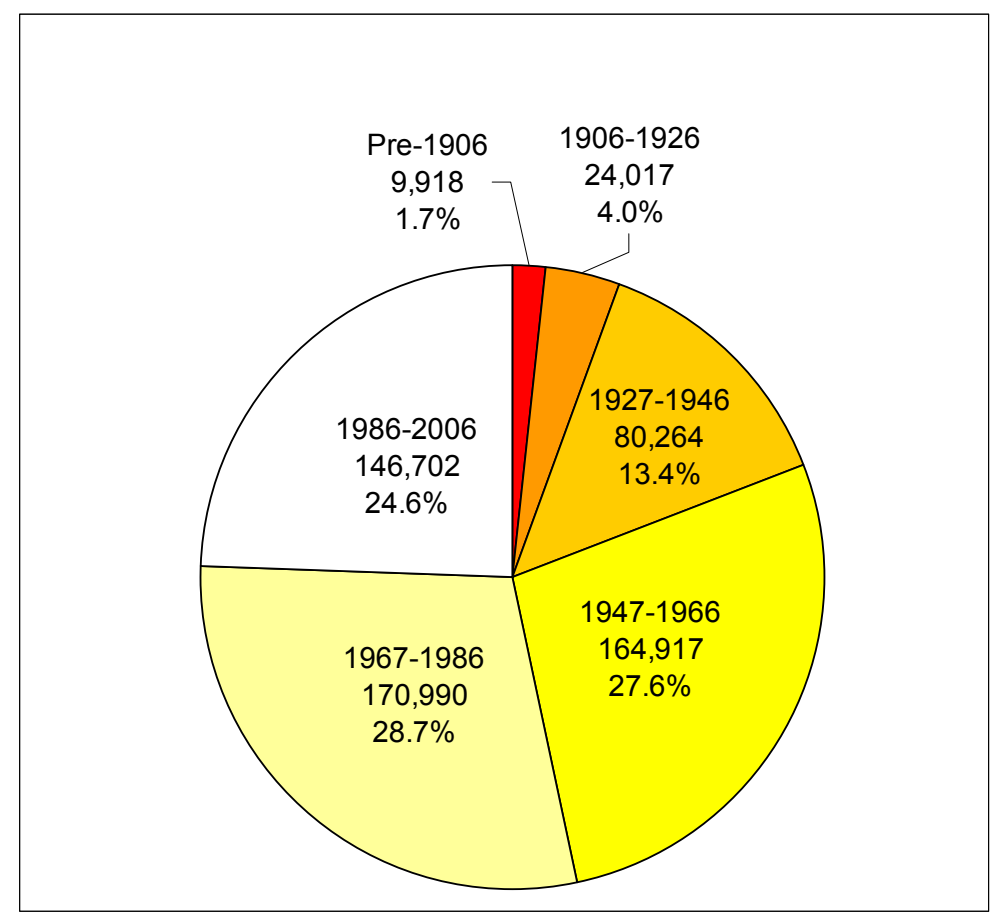

Figure 1.2: U.S. Bridge Inventory by Year of

Construction (FHWA, 2006)

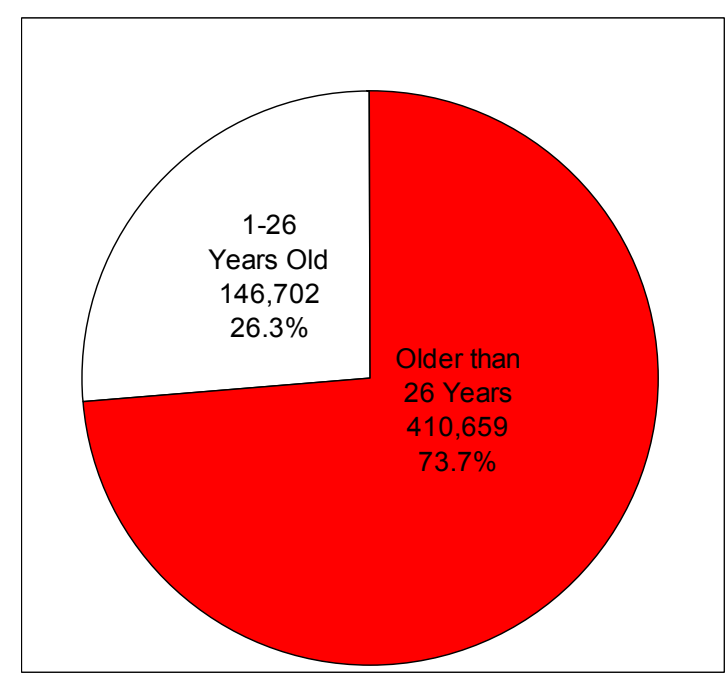

Figure 1.3: U.S. Bridges Older than 26 Years (FHWA, 2006)

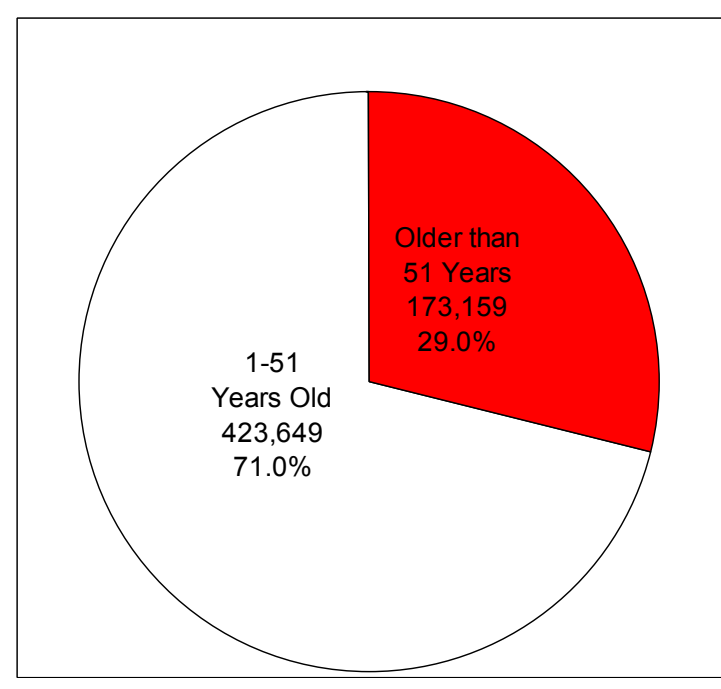

Figure 1.4: U.S. Bridges Older than 51 Years (FHWA, 2006)

It is estimated by ASCE that $\$ 9.4$ billion per year would be needed for the next 20 years to eliminate all bridge deficiencies. Due to a lack of federal transportation funds, state 
and local governments are forced to spend money on their own bridge projects. In 2003, a total $\$ 8.8$ billion dollars were spent on bridge projects by all levels of government (ASCE, 2003). If funding isn't available to conduct all necessary bridge replacements, one of two options will need to be exercised. The first option will require deteriorated bridges to be closed indefinitely until funding becomes available. This scenario will result in a replacement waiting list in order of priority which may grow faster than bridges can be replaced. Detours and traffic delays will ensue causing public dissatisfaction and a potentially dangerous situation in the case of an emergency. The second option would be to repair the bridges using a technique that is cost-effective, requires less labor and time, and is guaranteed to be durable. If reliable methods of concrete bridge repairs are standardized, the second option could be implemented resulting in the avoidance of immense government spending and long-term public disturbance.

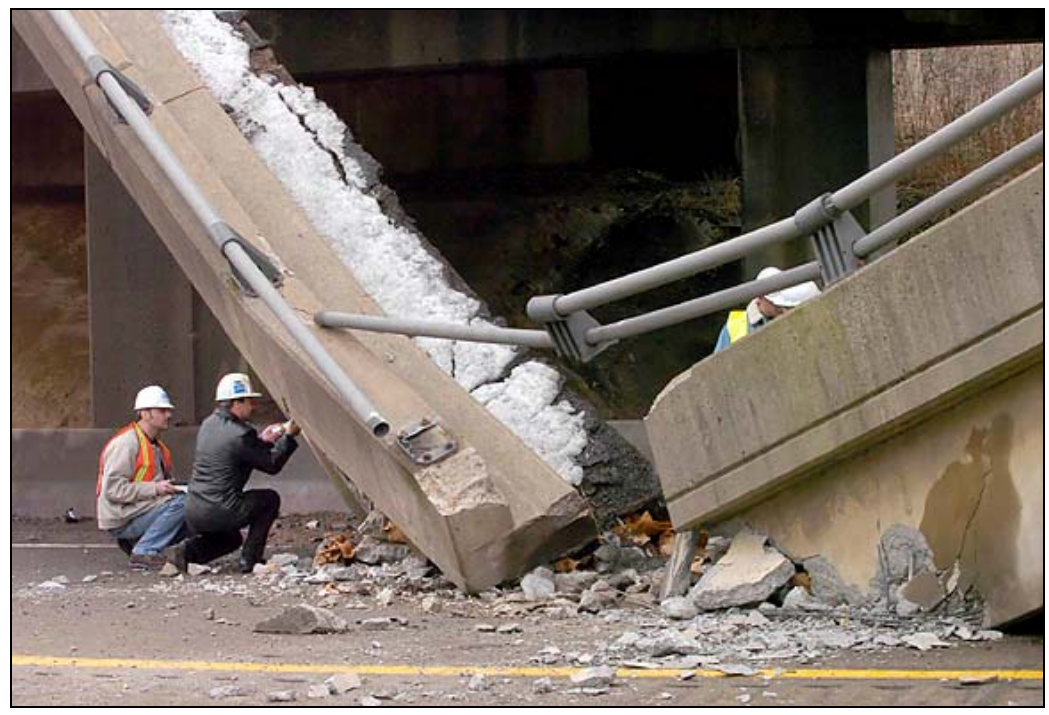

Figure 1.5: Partial collapse of the exterior girder of an overpass over I-70 near Pittsburgh, PA 
The urgent need of a reliable method of bridge repair has become even more evident in recent years with some highly publicized concrete bridge failures, such as the I-70 overpass near Pittsburgh, PA, shown in Figure 1.5, which was caused by pre-stressed reinforcement corrosion likely due to the use of deicing salts.

\subsection{Objectives}

The primary objective of this research is to determine the most durable, reliable, and economical method of deteriorated concrete bridge girder rehabilitation that is currently available in the engineering industry. All current bridge rehabilitation techniques must be studied in detail to determine the advantages and disadvantages of each. Key details to be determined will be the long-term durability of the repair, the ductility of the repair and its failure modes, and the ease of the repair. Through extensive examination of available data, a preferred rehabilitation technique will be selected to be tested and refined in the laboratory.

As will be discussed later, the rehabilitation technique chosen for further laboratory investigation was externally bonded carbon fiber reinforced polymer (CFRP) laminates. Upon reviewing the sources of reinforced concrete deterioration, chloride-initiated corrosion of the reinforcing steel, which initiates concrete cracking, spalling, and delamination, was determined to be the most common and to potentially be the most severe. Therefore, at this stage of the research, the objective became focused on determining the most durable, reliable, and economical method of rehabilitating concrete 
bridge girders deteriorated by chloride-induced corrosion using externally bonded CFRP laminates.

This research will attempt to provide insight into the long term durability of externally bonded CFRP repairs by using accelerated laboratory aging techniques to simulate decades of deterioration. Some aged specimens will also be subjected to cyclic loading to examine the effects of fatigue on a CFRP-repaired structure. The optimization of a bridge girder repair using externally-bonded CFRP sheets will be established by testing three different anchoring schemes. Flexure tests performed on beams repaired with each scheme will be analyzed. A detailed description of a complete substrate and FRP repair will be presented.

Another main objective of this research is to establish an effective, consistent, rapid and reliable way to simulate the aged conditions of deteriorated reinforced concrete members in a laboratory. A poor-quality and chloride-contaminated concrete will be designed, and an accelerated aging technique that can cause reinforcement corrosion and concrete cracking will be developed.

\subsection{Scope}

This research covers a wide variety of topics that not only will provide new insight into FRP technology, but will provide insight into proper experimental methods to be used in future FRP research. 
First, low-quality concrete was designed to simulate the old concrete found in many existing concrete bridges. An accelerated aging process via induced electric current was used to corrode reinforced concrete beam specimens. This was done to closely simulate mechanisms of corrosion and deterioration observed in aged reinforced concrete bridge members in the field. This accelerated aging process was modified several times to obtain a very dependable and successful procedure.

Corroded beams were repaired, first with concrete substrate repair, and then with FRP sheets. The effectiveness of two substrate repair techniques was studied: complete patch repair with polymer concrete and epoxy crack injection. Three different FRP wrapping schemes were incorporated to determine the effects of FRP anchorage on the global repaired concrete system.

Some test specimens were subjected to additional corrosion after repair to gain insight into the long-term durability of an FRP repair, assuming that additional corrosion of the reinforcing steel is inevitable. Other repaired specimens were subjected to cyclic fatigue loading to determine how an FRP system that is in service behaves over time.

Concrete quality was tested using several methods: compression cylinder testing, rebound hammer testing, and ultrasonic pulse velocity testing. FRP quality was tested via direct tension testing. FRP-to-concrete bond was tested via pull-off testing. 
This research experiment was designed not only to gain insight into the behavior of bridge repair techniques, but also to advance the methods used in similar future research. This was achieved in this paper by discussing the trials and errors experienced in the research and ways to correct them and by providing foresight into the future of bridge repair through extensive literature review.

\subsection{Thesis Organization}

This thesis was written to serve two purposes: 1.) to present the results of the experimental testing program and discuss the conclusions that will contribute to the knowledge base of FRP repair technology, and 2.) to serve as a guide for future researchers of bridge rehabilitation techniques.

Chapter 2 discusses all aspects of reinforced concrete. Properties of concrete and steel are presented, key aspects of reinforced concrete beam design are overviewed, and the degradation of concrete and are discussed in detail.

Chapter 3 covers many aspects FRP, including material properties, types, manufacturing, and durability.

Chapter 4 presents an overview of current bridge repair techniques. Concrete and steel repair, FRP strengthening, and electrochemical methods of maintenance and repair are discussed. Finally, a literature review of past research on FRP strengthening of beams is presented, which leads into the design of the experimental plan for this research. 
Chapter 5 provides great detail of the research plan, test specimens, and construction within the experiment, and repair of the beam specimens. The accelerated aging plan is provided along with details about the procedure. The procedures and experimental plans for the destructive and nondestructive tests performed on the beam specimens are provided.

Chapter 6 presents summaries of the results obtained from all parts of the research, including accelerated aging, crack measurement, half-cell potential, rebound hammer, ultrasonic pulse velocity, compression cylinders, FRP tensile strength, and static and cyclic loading. A literature review is also provided for accelerated aging. Suggestions for improvement are offered for each portion of the laboratory testing to assist in future similar research.

Chapter 7 presents a summary and further discussion of the conclusions obtained from the experimental testing and literature review.

A large portion of this paper consists of 8 appendices labeled A through H. Appendix A provides design calculations for the reinforced concrete beam specimens. Appendix B provides the design calculations for FRP strengthening. The final cracking patterns observed for all beams are illustrated in Appendix C. All raw data obtained in laboratory testing is presented in Appendix D. Appendix E contains drawings of the FRP after rupture. Appendix F displays the individual curves obtained from both the static and cyclic flexure tests for both deflection and strain. Appendix G lists materials and 
provides technical specifications for the repair materials. Finally, Appendix H contains lists of the testing equipment, tools, and safety equipment used in the experimental program.

The results and conclusions discussed in this paper will add to the small-but-growing knowledge base of accelerated aging techniques, FRP bridge girder repair, and FRP durability. The suggestions and detail of procedures in this paper will greatly assist future researchers in similar fields and hopefully assist them in making future developments in bridge repair technology. 


\section{Chapter 2: $\quad$ Steel Reinforced Concrete and Its Deterioration Mechanisms}

\subsection{Reinforced Concrete}

\subsubsection{Concrete the Material}

\subsubsection{Introduction}

Concrete is a composite material composed of granular material called aggregate or filler embedded in a hard matrix of material called cement or binder that fills the space between the aggregate particles and bonds them together (Mindess, 2003).

Portland cement concrete is a primary construction material used in civil engineering applications worldwide because of its versatility, availability of its constituents, adaptability, and low cost. Concrete can be molded into any shape and is adaptable in that it can be designed to possess a wide range of properties. Concrete requires less energy to produce compared to other key building materials such as steel. Concrete also has favorable aesthetic versatility as the color and texture can be manipulated through admixture addition and finishing technique.

Annual global production of concrete is about 5 billion cubic yards (EcoSmart, 2007). In 2000, 118 tons of cement was consumed in the United States (Mindess, 2003). In 2001, 
cement cost only 3 to 4 cents per pound and aggregates less than 1 cent per pound (Mindess, 2003).

Two key limitations of concrete are that it is a brittle material and is not volume-stable. Concrete has very low tensile strength of only about $10 \%$ of its compressive strength. Therefore, reinforcing steel is needed when concrete may be loaded in tension to avoid sudden brittle failure. Likewise, concrete also has a low impact resistance and toughness properties. In compression, concrete has a low strength-to-weight ratio which leads to the requirement of large masses of concrete to sufficiently support a load. As concrete cures, it undergoes irreversible shrinkage due to moisture loss. This shrinkage often leads to cracking during construction. Concrete also deforms over time due to creep.

\subsubsection{Cement}

Portland cement is the binder of choice in $95 \%$ of concrete construction projects (Mindess, 2003) and generally referred to as simply "cement." Portland cement gets its name from its similarity to a naturally occurring limestone quarried at the Isle of Portland in South West England. Portland cement consists primarily of oxides, calcium, silicon, and aluminum. ASTM classifies five unique types of Portland cement and designates them with Roman numerals as Types I through V. Specific constituents and properties of the five types are given in Table 2.1. It should be noted that the percentages in the table do not add up to 100; the remaining percentage is due to impurities. 
Table 2.1: Constituents and Properties of ASTM Portland Cement Types (Mindess, 2003)

\begin{tabular}{|c|c|c|c|c|c|c|c|}
\hline Chemical Name & \begin{tabular}{|l|} 
Chemical \\
Formula \\
\end{tabular} & $\begin{array}{l}\text { Shorthand } \\
\text { Notation }\end{array}$ & I & II & III & IV & $\mathrm{V}$ \\
\hline Tricalcium Silicate (\%) & $3 \mathrm{CaO} \cdot \mathrm{SiO}$ & $\mathrm{C}_{3} \mathrm{~S}$ & 55 & 55 & 55 & 42 & 55 \\
\hline Dicalcium Silicate (\%) & $2 \mathrm{CaO} \cdot \mathrm{SiO}$ & $\mathrm{C}_{2} \mathrm{~S}$ & 18 & 19 & 17 & 32 & 22 \\
\hline Tricalcium Aluminate (\%) & $\begin{array}{l}3 \mathrm{CaO} \cdot \mathrm{Al}_{2} \\
\mathrm{O}_{3}\end{array}$ & $\mathrm{C}_{3} \mathrm{~A}$ & 10 & 6 & 10 & 4 & 4 \\
\hline $\begin{array}{l}\text { Tetracalcium } \\
\text { Aluminoferrite (\%) }\end{array}$ & $\begin{array}{l}4 \mathrm{CaO} \cdot \mathrm{Al}_{2} \\
\mathrm{O}_{3} \cdot \mathrm{Fe}_{2} \mathrm{O}_{3}\end{array}$ & $\mathrm{C}_{4} \mathrm{AF}$ & 8 & 11 & 8 & 15 & 12 \\
\hline $\begin{array}{l}\text { Calcium Sulfate Dihydrate } \\
\text { [Gypsum] (\%) }\end{array}$ & $\begin{array}{l}\mathrm{CaSO}_{4} \cdot 2 \mathrm{H} \\
{ }_{2} \mathrm{O}\end{array}$ & $\mathrm{CSH}_{2}$ & 6 & 5 & 6 & 4 & 4 \\
\hline Fineness (Blaine, $\mathrm{m}^{2} / \mathrm{kg}$ ) & - & - & 365 & 375 & 550 & 340 & 380 \\
\hline $\begin{array}{l}\text { Compressive Strength } \\
\text { (1 day, psi) }\end{array}$ & - & - & $\begin{array}{c}220 \\
0\end{array}$ & 2000 & 3500 & 600 & 1750 \\
\hline $\begin{array}{l}\text { Heat of Hydration } \\
\text { ( } 7 \text { days, J/g) }\end{array}$ & - & - & 350 & 265 & 370 & 235 & 310 \\
\hline
\end{tabular}

Of the five types of Portland cement, only Types I and III are readily available in the United States. Type I is the most common and is used where no specialized applications are required. Type II is sometimes used in the western United States in place of Type I due to raw material availability. Type II is used when lower heat of hydration is required with a normal rate of strength gain. Type III is used for applications requiring rapid strength gain. Type IV is used where low heat of hydration cement is needed such as in dams or bridge piers where thermal cracking must be prohibited. Type $V$ has high sulfate resistance and is used in concrete exposed to aggressive environments.

\subsubsection{Aggregate}

Aggregates account for approximately 70 to $80 \%$ of the volume of concrete and therefore have a profound effect on the concrete's properties. Aggregates act as an economic filler 
material, offer dimensional stability, and provide wear resistance. Most aggregate used in concrete construction originates from natural rock and sand. Aggregate properties can directly affect the following concrete properties: resistance to freeze-thaw, endurance in wet-dry cycles, resistance to abrasion, resistance to alkali-aggregate attack, strength, shrinkage and creep, coefficient of thermal expansion, thermal conductivity, specific heat, unit weight, and modulus of elasticity.

Some aggregates can chemically react with silica in cement paste when the silica within the aggregate has differing properties. Some reactive aggregate components are opal, silica glass, chalcedony, cristobalite tridymite, and quartz. This reaction, which causes aggregate expansion and consequent cracking of the concrete, is referred to as alkaliaggregate reaction. Other expansive reactions include alkali-carbonate reactions, which occur when certain dolomitic limestones are used. Very fine crystals, large amounts of fine-grained calcite, interstitial clay, and evenly dispersed dolomite and calcite crystals are signs of a potentially alkali-carbonate reactive aggregate. Since all expansive reactions can be detrimental to the performance of a concrete structure, all aggregates should be approved by an engineer prior to construction or repair.

\subsubsection{Cement Hydration and the Roles of its Products}

The phenomenon of concrete hardening is the result of both a chemical and physical

process between cement and water called cement hydration. It is essential to have a general understanding of the products and structure of hydrated cement in concrete to 
understand the degradation mechanisms described later. The following presents the chemical reactions which take place as a result of cement hydration:

\subsection{Calcium Silicates}

Tricalcium silicate and dicalcium silicate reacts with water to form calcium silica hydrate and calcium hydroxide:

$2 \mathrm{C}_{3} \mathrm{~S}+11 \mathrm{H} \rightarrow \mathrm{C}_{3} \mathrm{~S}_{2} \mathrm{H}_{8}+3 \mathrm{CH}$

$2 \mathrm{C}_{2} \mathrm{~S}+9 \mathrm{H} \rightarrow \mathrm{C}_{3} \mathrm{~S}_{2} \mathrm{H}_{8}+\mathrm{CH}$

Calcium silica hydrate $\left(\mathrm{C}_{3} \mathrm{~S}_{2} \mathrm{H}_{8}\right)$ can be more generally referred to as $\mathrm{C}-\mathrm{S}-\mathrm{H}$ since the actual variability of the hydrate's composition can actually have a broad range. C-S-H is the primary hydration product in concrete. Table 2.2 summarizes the sequence of hydration of C-S-H.

Table 2.2: Sequence of Hydration of the Calcium Silicates (Mindess, 2003)

\begin{tabular}{|l|l|l|l|}
\hline Reaction Stage & $\begin{array}{l}\text { Kinetics of } \\
\text { Reaction }\end{array}$ & Chemical Processes & $\begin{array}{l}\text { Relevance to } \\
\text { Concrete Properties }\end{array}$ \\
\hline 1.) Initial Hydrolysis & $\begin{array}{l}\text { Chemical control; } \\
\text { rapid }\end{array}$ & $\begin{array}{l}\text { Initial hydrolysis; } \\
\text { dissolution of ions }\end{array}$ & - \\
\hline 2.) Induction Period & $\begin{array}{l}\text { Nucleation control; } \\
\text { slow }\end{array}$ & $\begin{array}{l}\text { Continued } \\
\text { dissolution of ions }\end{array}$ & $\begin{array}{l}\text { Determines initial } \\
\text { set }\end{array}$ \\
\hline 3.) Acceleration & $\begin{array}{l}\text { Chemical control; } \\
\text { rapid }\end{array}$ & $\begin{array}{l}\text { Initial formation of } \\
\text { hydration products }\end{array}$ & $\begin{array}{l}\text { Determines final set } \\
\text { and rate of initial } \\
\text { hardening }\end{array}$ \\
\hline 4.) Deceleration & $\begin{array}{l}\text { Chemical and } \\
\text { diffusion control; } \\
\text { slow }\end{array}$ & $\begin{array}{l}\text { Continued formation } \\
\text { of hydration products }\end{array}$ & $\begin{array}{l}\text { Determines rate of } \\
\text { early strength gain }\end{array}$ \\
\hline 5.) Steady state & $\begin{array}{l}\text { Diffusion control; } \\
\text { slow }\end{array}$ & $\begin{array}{l}\text { Slow formation of } \\
\text { hydration products }\end{array}$ & $\begin{array}{l}\text { Determines rate of } \\
\text { later strength gain }\end{array}$ \\
\hline
\end{tabular}




\subsection{Tricalcium Aluminate}

Tricalcium aluminate reacts with gypsum and water to form ettringite:

$\mathrm{C}_{3} \mathrm{~A}+3 \mathrm{CSH}_{2}+26 \mathrm{H} \rightarrow \mathrm{C}_{6} \mathrm{AS}_{3} \mathrm{H}_{32}$

\subsection{Ferrites}

Tricalcium aluminoferite reacts with gypsum and water to produce ettringite and amorphous hydrous oxides of iron or aluminum. Please note that formulas containing $(\mathrm{A}, \mathrm{F})$ indicates that iron oxide and alumina occur interchangeably in the compound. The reactions are written as follows:

$\mathrm{C}_{4} \mathrm{AF}+3 \mathrm{CSH}_{2}+21 \mathrm{H} \rightarrow \mathrm{C}_{6}(\mathrm{~A}, \mathrm{~F}) \mathrm{S}_{3} \mathrm{H}_{32}+(\mathrm{F}, \mathrm{A}) \mathrm{H}_{3}$

$\mathrm{C}_{4} \mathrm{AF}+\mathrm{C}_{6}(\mathrm{~A}, \mathrm{~F}) \mathrm{S}_{3} \mathrm{H}_{32}+7 \mathrm{H} \rightarrow 3 \mathrm{C}_{4}(\mathrm{~A}, \mathrm{~F}) \mathrm{SH}_{12}+(\mathrm{F}, \mathrm{A}) \mathrm{H}_{3}$

It is important that the reader understands the role of each property and product that results from cement hydration process. The most important that are discussed next are porosity, calcium hydroxide, calcium sulfoaluminates, and water.

\subsection{Porosity}

A major component of the hydrated cement microstructure is porosity. Pore sizes in concrete can range from $0.0005 \mu m$, which is the approximate size of DNA components, to $10 \mu \mathrm{m}$, which is $1 / 2$ to $1 / 8$ the size of a human hair. There are two distinct types of pores: capillary pores and gel pores. Capillary pores range from $0.01 \mu \mathrm{m}$ to $10 \mu \mathrm{m}$ in diameter and are the result from the water-filled space that exists between the partially hydrated 
cement grains. Gel pores range from $0.0005 \mu \mathrm{m}$ to $0.01 \mu \mathrm{m}$ in diameter and are inherent to the C-S-H structure (Mindess, 2003). The pores in the hydrated cement are filled with an ionic solution composed of mostly saturated calcium hydroxide which gives concrete its high $\mathrm{pH}$.

The compressive strength of concrete is directly proportional to the gel/space ratio, which is the ratio of the volume of solid hydration products to the space available for the hydration products. The total available space is defined as the volume of hydrated cement plus the volume of space occupied by the original mixing water. To illustrate this point, one unit volume of unhydrated cement occupies about 2.1 unit volumes of space when hydration is complete (Mindess, 2003). The gel/space ratio is directly proportional to $\mathrm{w} / \mathrm{c}$ ratio and denotes the capillary porosity of the cement paste. Since gel porosity is intrinsic to the hydrated structure of the cement, the term "porosity" from here on will refer to capillary porosity. Compressive strength increases and decreases and the w/c increases and decreases, respectively.

The size of the pores plays a major role in the durability of concrete, as will be illustrated later. Cracks can initiate at locations of large pores, and the permeability of the concrete depends on the size and distribution of the pores.

\subsection{Calcium Hydroxide}

Calcium hydroxide reduces the pore volume of the hydrated cement paste, thus increasing concrete strength. Calcium hydroxide acts as a double-edged sword for the 
durability of concrete. Its high alkalinity protects embedded reinforcing steel from acid attack by passivating the steel surface as will be seen later. However, since calcium hydroxide is more soluble than C-S-H, it leaches out of the concrete. As a result, the permeability and diffusivity of the concrete is increased, the cement structure becomes weakened, and contaminants ultimately are provided a route of entry.

\subsection{Calcium Sulfoaluminates}

Calcium sulfoaluminates initiate the formation of ettringite. Small amounts of ettringite contribute to the early strength of concrete, but large amounts are detrimental to the strength since the formation process of ettringite is expansive.

\subsection{Water}

Saturated concrete is about $20 \%$ weaker in compression than is dry concrete for three reasons. First, C-S-H particles can contract together producing a stronger structure due to increased van der Waals bonding. Second, water can attack Si-O-Si bonds when stressed. Third, water may actually act as a lubricant reducing the mechanical interlock of the hydrated cement structure (Mindess, 2003).

\subsubsection{Admixtures}

A concrete admixture can be defined as a material other than aggregate, cement or water, added in small quantities to the mix in order to produce desired modifications to the properties of either the mix or of the hardened product (Sebastian, 2008). Admixtures 
can be either mineral or chemical. Admixtures can be used to replace cement, to improve the workability of fresh concrete, to enhance the strength and durability of hardened concrete. For the scope of this paper, it will be sufficient to summarize the broad categories of admixtures in Table 2.3 .

Table 2.3: Beneficial Effects of Admixtures on Concrete Properties (Mindess, 2003)

\begin{tabular}{|c|c|}
\hline Property & Admixture Type \\
\hline \multirow{6}{*}{ Workability } & Water-Reducing Admixtures \\
\hline & Plasticizers \\
\hline & Air-Entraining Admixtures \\
\hline & Pumping Aids \\
\hline & Anti-Washout Admixtures \\
\hline & Mineral Admixtures \\
\hline \multirow{3}{*}{ Set Control } & Set-Accelerating Admixtures \\
\hline & Set-Retarding Admixtures \\
\hline & Extended-Set Admixtures \\
\hline \multirow{4}{*}{ Strength and Durability } & Air-Entraining Admixtures \\
\hline & Water-Reducing Admixtures \\
\hline & Corrosion Inhibitors \\
\hline & Mineral Admixtures \\
\hline Economy & Mineral Admixtures \\
\hline \multirow{8}{*}{ Miscellaneous } & Viscosity Modifiers \\
\hline & Antifreezing Admixtures \\
\hline & Expansion-Producing Admixtures \\
\hline & Gas-Forming Admixtures \\
\hline & Expansive Hydrates \\
\hline & Alkali-Aggregate Reaction Inhibiting Admixtures \\
\hline & Shrinkage-Reducing Admixtures \\
\hline & Damproofing Admixtures \\
\hline
\end{tabular}

\subsubsection{Polymer Concrete}

Polymer concrete consists of binders, compounds, and aggregate mixtures that use epoxy, polyester, vinyl ester or other polymer resin as a matrix material. These binders either 
supplement or completely replace cement. They cure through chemical reactions, thermoset bonds, and multiple component binder systems.

Polymers are long molecules consisting of repeating random patterns of smaller molecules, or monomers. When a catalyst is added, a chemical reaction occurs and causes the polymer chains to link together into three-dimensional systems, changing a liquid resin into a solid. In polymer concrete, these polymer chains bind the aggregate particles together (ACI, 2003).

Some of the advantages of polymer concrete are rapid setting times, high compressive and flexural strength properties, high early strength, ability to withstand a corrosive environment, abrasion resistance, increased freeze/thaw durability, resistance to deicing salts and other chemicals, good adhesion properties, low permeability (ACI 2003; Mindess, 2004; SIKA). Because of these superior properties, the popularity and usage of polymer concrete for both new construction and structural repair is growing.

Polymer concrete is more durable than plain concrete for three reasons: 1.) the polymer film lining capillary pore surfaces impedes water adsorption and permeability prevents the entry of aggressive agents, 2.) the improved resistance to tensile cracking reduces the formation of a network of microcracks that can assist in water transport, and 3.) the lower w/c ratio (if water is used at all) provides generally improved durability (Mindess, 2004). 
Some disadvantages of polymer concrete are that its monomers, initiators, and accelerators can be very harmful to the skin and respiratory tract. Furthermore, polymer concretes are significantly more expensive than normal concretes. However, when used as patch repair concrete, the high cost is often offset by improved performance and the relatively small quantity required.

Polymer concretes should not be immersed in water since the adsorption of water by the polymer film weakens its structural integrity. It will, however, remain stable up to about $95 \%$ relative humidity. The polymer can also be degraded chemically by the high $\mathrm{pH}$ of the concrete pore solution (Mindess, 2004).

\subsubsection{Steel Reinforcement}

\subsubsection{Properties}

As mentioned above, concrete has virtually no tensile strength. All concrete structures must therefore be reinforced with a material having a high tensile strength. Since most deteriorating concrete bridges are reinforced with steel reinforcement, standard deformed steel rebar will be the focal existing reinforcing material discussed in this paper.

Rebar is hot-rolled from steel with varying carbon content. Almost all new reinforcing bars are made from Grade 60 steel, which means they have a yield strength of 60,000 psi. Many aged concrete structures are reinforced with Grade 40 (40,000psi) steel, and some are even reinforced with A36 (36,000psi) steel bars. As is seen in Figure 2.1, steel rebar is deformed, or ribbed, so that concrete and steel can develop a solid bond. 

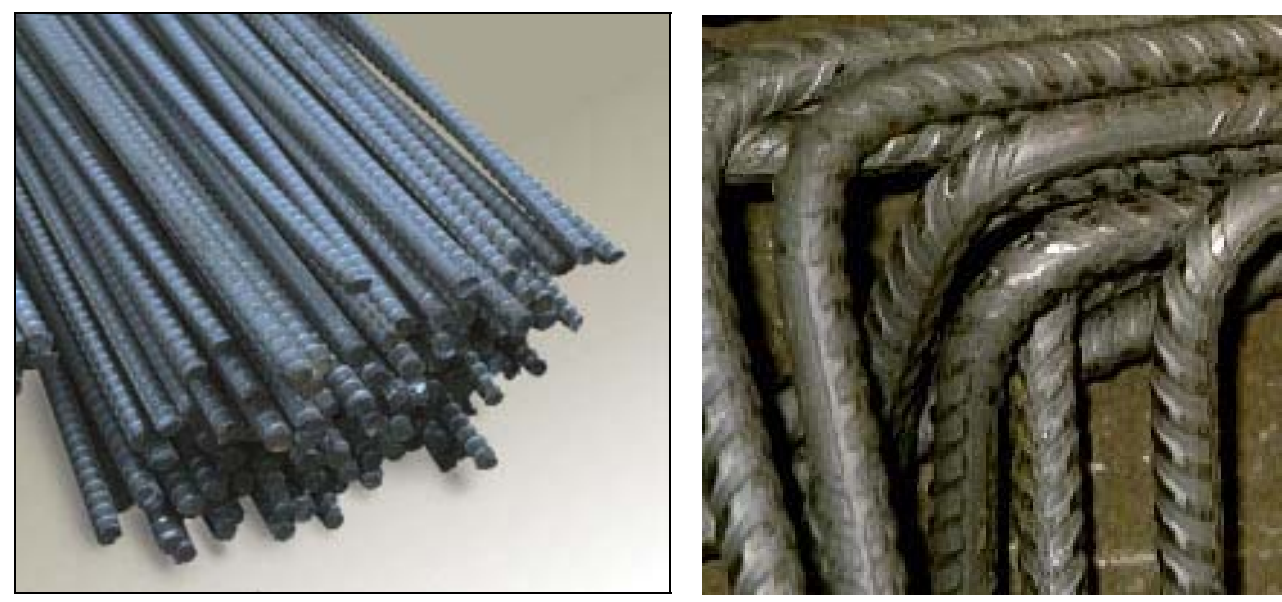

Figure 2.1: Standard deformed rebar

It is important to note that the linear and volumetric thermal expansion coefficients for steel and concrete are approximately the same, making steel an ideal concrete reinforcing material. The thermal expansion coefficient relates the change of a material's linear dimensions as it undergoes a change in temperature. Concrete and steel have linear coefficients of about 12 and 11-13 and have volumetric coefficients of 36 and 33-39, respectively. If the thermal properties of these materials were not the alike, subsequent concrete cracking or deterioration of the steel-to-concrete bond would be inevitable due to the resulting internal expansive and contractive forces.

\subsubsection{Sizes and Designations}

Steel rebar is available in a variety of sizes. Standard imperial U.S. bars are available in diameters ranging from $3 / 8$ " to $2 \frac{1}{4}$ ". The U.S. designation number represents the diameter of the bar multiplied by 8 . For instance, $\# 3$ bars are $3 / 8 "$ in diameter, $\# 7$ bars are $7 / 8$ " in diameter, and $\# 10$ bars are $1 \frac{1}{4}$ " in diameter. The metric designation number represents the diameter of the bar rounded to the nearest millimeter. For example, \#10 metric bars 
are $9.525 \mathrm{~mm}$ in diameter and \# 13 metric bars are $12.7 \mathrm{~mm}$ in diameter. Both U.S. and metric designations, dimensions, and weights are provided in Table 2.4.

Table 2.4: Designations, Dimensions, and Weights of Standard U.S. and Metric Steel Reinforcing Bars (PCI, 2004; Nilson, 1987)

\begin{tabular}{|l|l|l|l|l|l|l|l|l|}
\hline $\begin{array}{l}\text { Imperial } \\
\text { Bar } \\
\text { Size }\end{array}$ & $\begin{array}{l}\text { Soft" } \\
\text { Metric }\end{array}$ & \multicolumn{2}{|c|}{ Weight } & \multicolumn{2}{|c|}{ Nominal Diameter } & \multicolumn{2}{|c|}{ Nominal Area } & \multirow{2}{*}{$\begin{array}{l}\text { Perimeter } \\
\text { Sin })\end{array}$} \\
\cline { 3 - 9 } & $(\mathrm{lb} / \mathrm{ft})$ & $(\mathrm{kg} / \mathrm{m})$ & $(\mathrm{in})$ & $(\mathrm{mm})$ & $\left(\mathrm{in}^{2}\right)$ & $\left(\mathrm{mm}^{2}\right)$ \\
\hline$\# 3$ & $\# 10$ & 0.376 & 0.561 & 0.375 & 9.525 & 0.11 & 71 & 1.18 \\
\hline$\# 4$ & $\# 13$ & 0.668 & 0.996 & 0.500 & 12.7 & 0.20 & 129 & 1.57 \\
\hline$\# 5$ & $\# 16$ & 1.043 & 1.556 & 0.625 & 15.875 & 0.31 & 200 & 1.96 \\
\hline$\# 6$ & $\# 19$ & 1.502 & 2.24 & 0.750 & 19.05 & 0.44 & 284 & 2.36 \\
\hline$\# 7$ & $\# 22$ & 2.044 & 3.049 & 0.875 & 22.225 & 0.60 & 387 & 2.75 \\
\hline$\# 8$ & $\# 25$ & 2.670 & 3.982 & 1.000 & 25.4 & 0.79 & 509 & 3.14 \\
\hline$\# 9$ & $\# 29$ & 3.400 & 5.071 & 1.128 & 28.65 & 1.00 & 645 & 3.54 \\
\hline$\# 10$ & $\# 32$ & 4.303 & 6.418 & 1.270 & 32.26 & 1.27 & 819 & 3.99 \\
\hline$\# 11$ & $\# 36$ & 5.313 & 7.924 & 1.410 & 35.81 & 1.56 & 1006 & 4.43 \\
\hline$\# 14$ & $\# 43$ & 7.650 & 11.41 & 1.693 & 43 & 2.25 & 1452 & 5.32 \\
\hline$\# 18$ & $\# 57$ & 13.60 & 20.284 & 2.257 & 57.33 & 4.00 & 2581 & 7.09 \\
\hline
\end{tabular}

Canadian bar designations are used in some of the literature reviewed in this research.

Standard Canadian metric bars are presented in Table 2.5.

Table 2.5: Designations, Areas, and Weights of Standard Canadian Steel Reinforcing Bars

\begin{tabular}{|l|l|l|l|}
\hline $\begin{array}{l}\text { Canadian Metric } \\
\text { Bar Designations }\end{array}$ & Mass & $\begin{array}{l}\text { Nominal Diameter } \\
(\mathrm{kg} / \mathrm{m})\end{array}$ & $\begin{array}{l}\text { Cross-Sectional } \\
\text { Area } \\
\left(\mathrm{mm}^{2}\right)\end{array}$ \\
\hline$\# 10 \mathrm{M}$ & 0.785 & 11.3 & 100 \\
\hline$\# 15 \mathrm{M}$ & 1.570 & 16.0 & 200 \\
\hline$\# 20 \mathrm{M}$ & 2.355 & 19.5 & 300 \\
\hline$\# 25 \mathrm{M}$ & 3.925 & 25.2 & 500 \\
\hline$\# 30 \mathrm{M}$ & 5.495 & 29.9 & 700 \\
\hline$\# 35 \mathrm{M}$ & 7.850 & 35.7 & 1000 \\
\hline$\# 45 \mathrm{M}$ & 11.775 & 43.7 & 1500 \\
\hline$\# 55 \mathrm{M}$ & 19.625 & 56.4 & 2500 \\
\hline
\end{tabular}




\subsubsection{Reinforced Concrete Beam Design}

\subsubsection{Overview}

The magnitude of flexural stress usually governs the geometry of a reinforced concrete beam. Once a preliminary design is performed based on flexural stresses, other factors such as shear capacity, deflection, cracking, and development of the reinforcement effects are checked. These checks are known as "limit states of failure in flexure" (Nawy, 2003).

\subsubsection{Flexural Design Philosophy}

Even though reinforced concrete is not homogenous, isotropic, or elastic, the basic principles of bending theory can still be applied. The following three assumptions of basic bending theory are made by ACI when defining the behavior of a reinforced concrete section (Nawy, 2003):

1.) Strain distribution is assumed to be linear. This assumption is based on Bernoulli's theory that plane sections remain plane and perpendicular to the neutral axis during bending.

2.) Strains in the steel and the surrounding concrete are equal prior to concrete cracking or steel yielding; it is assumed that a perfect bond exists between the steel and the concrete. 
3.) Concrete in the tension zone of the beam is neglected in design and analysis; the tensile reinforcement is assumed to accept the total tensile force. This assumption is made because concrete is weak in tension, cracking at around $10 \%$ the magnitude of its compressive strength.

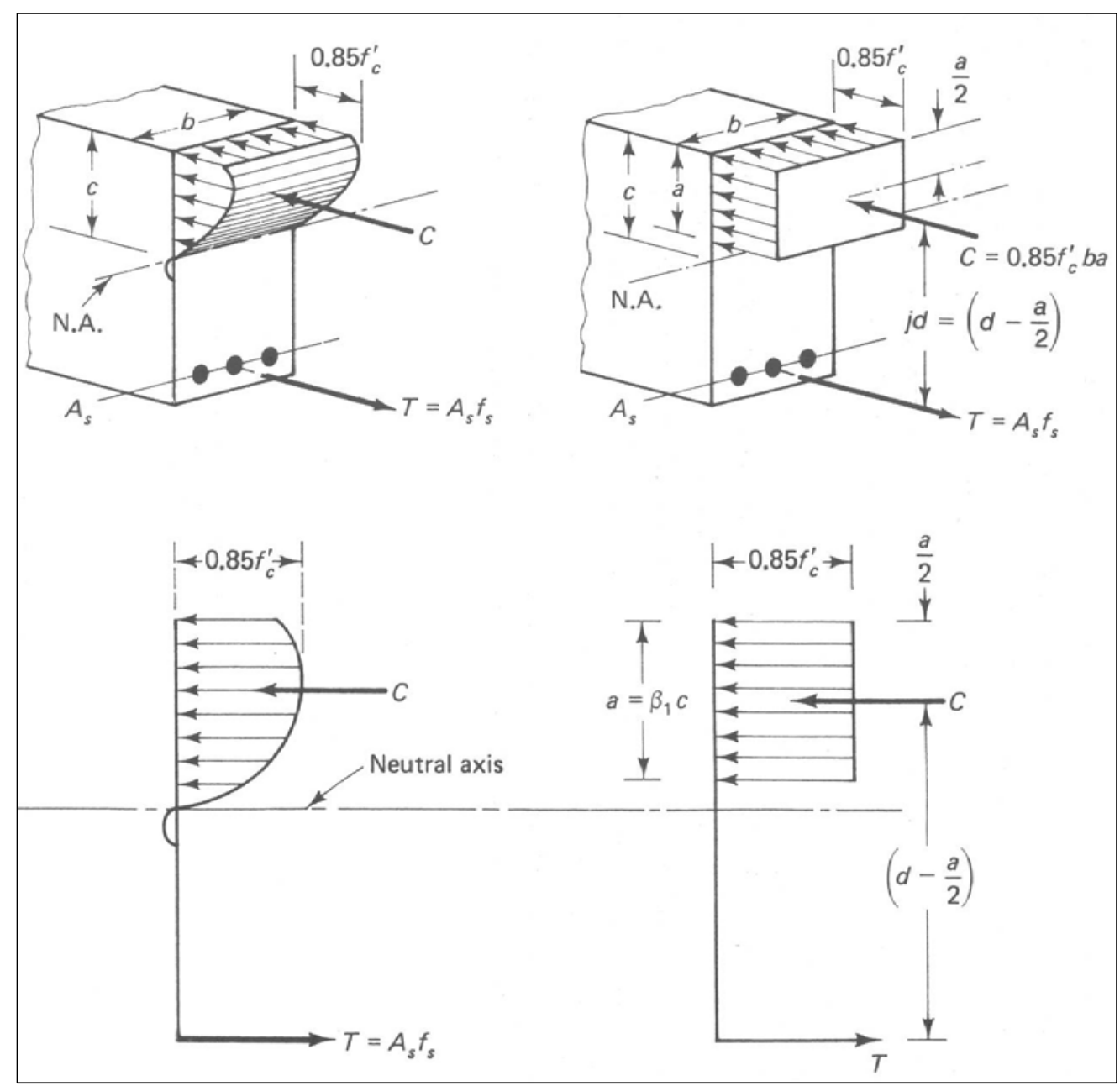

Figure 2.2: Actual stress block vs. assumed stress block (Nawy)

To satisfy equilibrium, the total tensile force must equal the resultant compression force. In reality, the distribution of the compressive strength is in the shape of a parabola (See Figure 2.2), but to save time and unnecessary calculations, an equivalent rectangular distribution known as the Whitney stress block is used. This assumed rectangular 
distribution has nearly the same area as the parabolic distribution, and the centroids of both the parabolic and rectangular shapes are located at the same approximate depths. The concrete is assumed to have a limiting strain of $0.003 \mathrm{in} / \mathrm{in}$, and the steel is assumed to behave in an elastoplastic manner (See Figure 2.3).

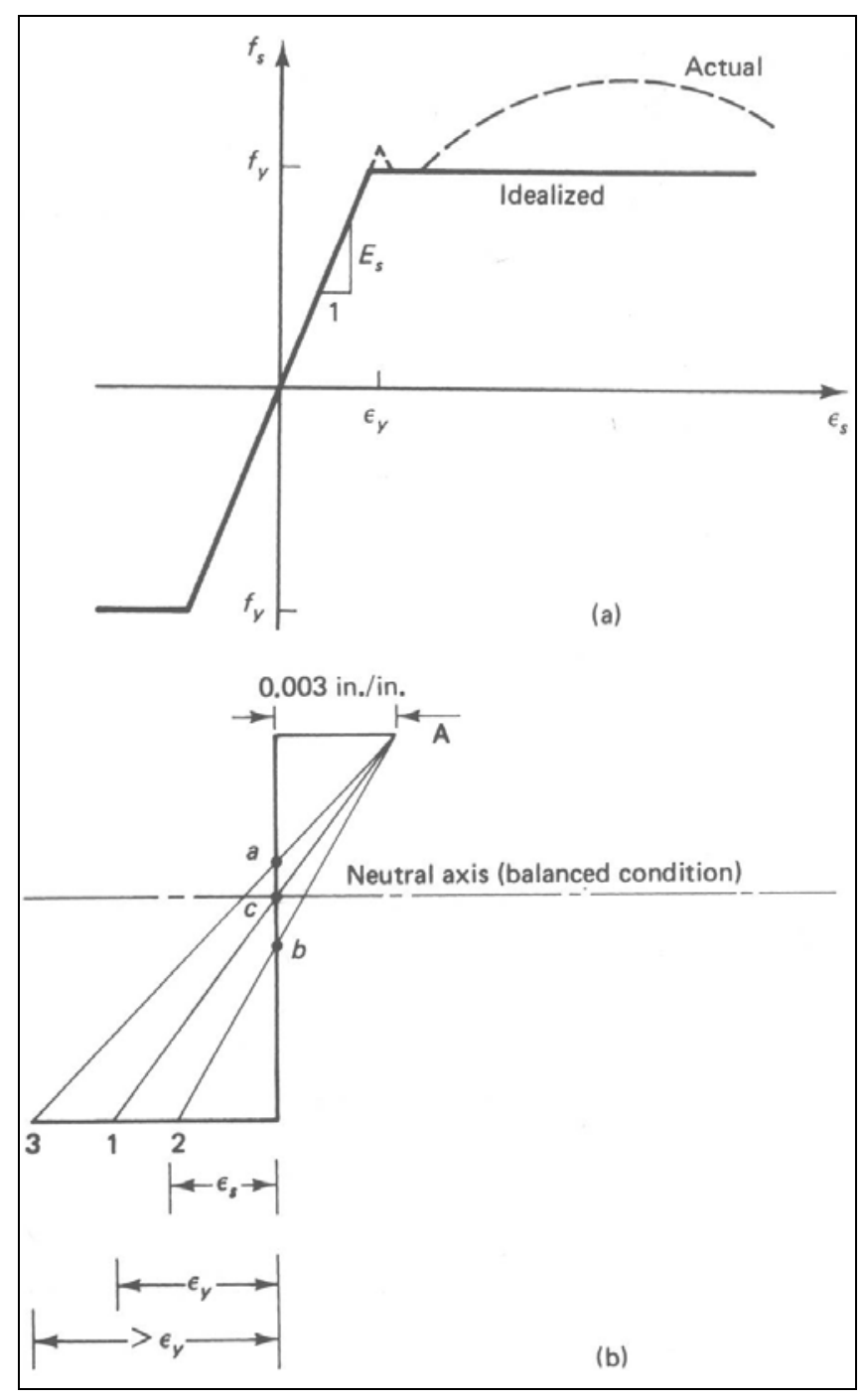

Figure 2.3: a.) idealized stress strain diagram of reinforcement, $b$.) stress distribution over the cross section for various modes of flexural failure (Nawy, 2003).

Line A-1 shows the distribution for balanced failure, Line A-2 shows the distribution for an under-reinforced section, and line A-3 shows the distribution for an over reinforced section 
Reinforced concrete can have two primary modes of flexural failure: ductile failure via steel yielding (which is the desired mode) and brittle failure via concrete crushing. If failure occurs with simultaneous steel yielding and concrete crushing, the failure mode is known as "balanced" failure. To ensure ductile failure, ACI specifies a maximum reinforcement ratio which, at its maximum value, results in $50-60 \%$ the reinforcement required to produce a balanced failure (Nawy, 2003). This limit also prevents congestion of reinforcement in the concrete member. A minimum limit also exists to prevent the section from behaving as if it were a plain concrete beam. The ACI code also specifies that a steel strain $\geq 0.005$ ensures fully ductile tension-controlled failure. Ductile failure provides warning signs of failure like excessive cracking and deflection whereas brittle failure occurs suddenly and without advanced notice.

\subsubsection{Shear Design}

Since shear failure in reinforced concrete beams is brittle and abrupt, this mode of failure must be prevented in all circumstances. Shear failure can be identified by the presence of diagonal cracks which are considerably wider than flexural cracks on the vertical face of a beam. These diagonal tension cracks form along planes perpendicular to the planes of principal tensile stress as a result of low concrete tensile strength. To prevent these cracks, shear reinforcement must be provided.

In regions of high shear and high tension, flexure shear cracks develop as an extension of the already present flexure cracks. An illustration of the types of cracks associated with both flexure and shear can be seen in Figure 2.4. 


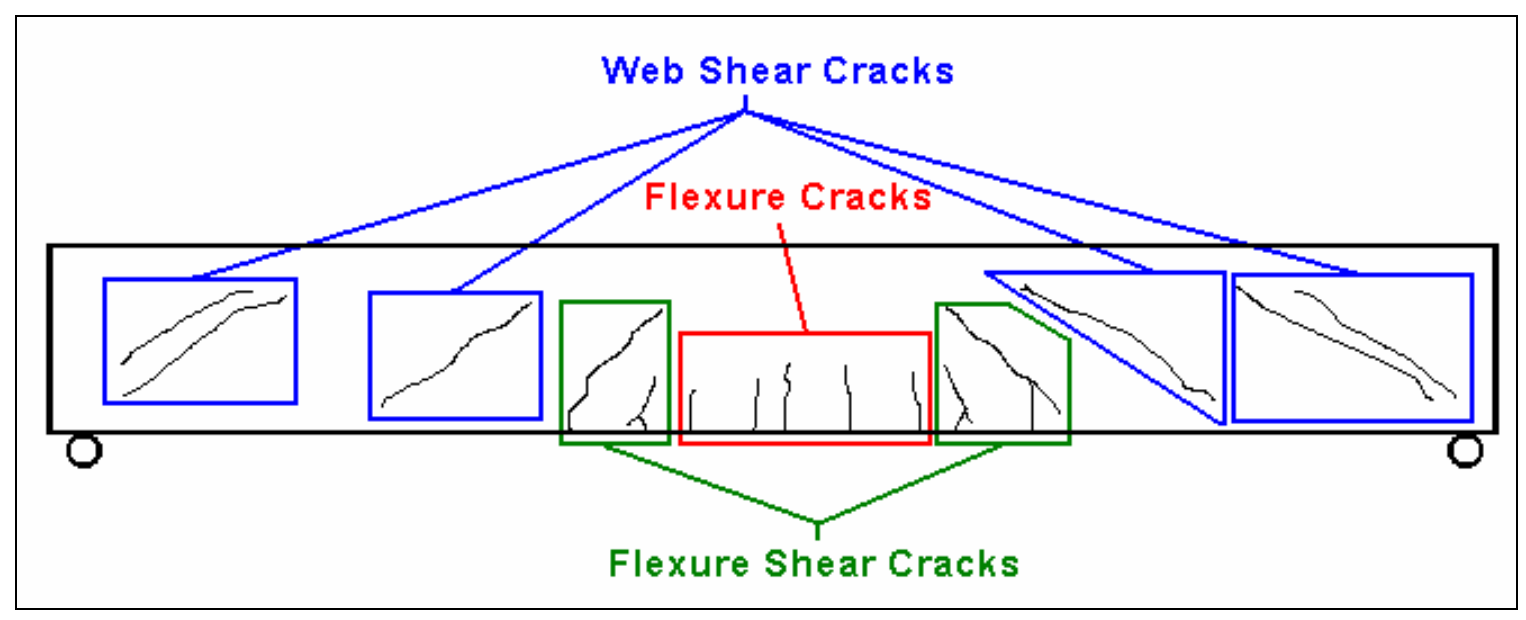

Figure 2.4: Types of Cracking in Reinforced Concrete (Nawy, 2003)

There are three fundamental failure modes for beams without shear reinforcement, and they are dependent on the shear span/depth ratio, flexural failure, diagonal tension failure, and shear compression failure. Simple flexural failure occurs at a high shear span/depth ratio. Diagonal tension failure occurs at intermediate shear span/depth ratios. Cracking begins with fine vertical flexure cracks at midspan. Next the steel-to-concrete bond is destroyed near the support. Finally, diagonal cracks form rapidly with little warning. Shear compression failure occurs at low shear span/depth ratios. Shear compression failure initiates in the same way as does diagonal tension failure. Then, however, a steeper inclined crack suddenly develops as the compression concrete begins to crush. Sudden failure occurs at the moment the inclined crack reaches the zone of crushed concrete. An illustration of these three basic failure modes can be seen in Figure 2.5. 


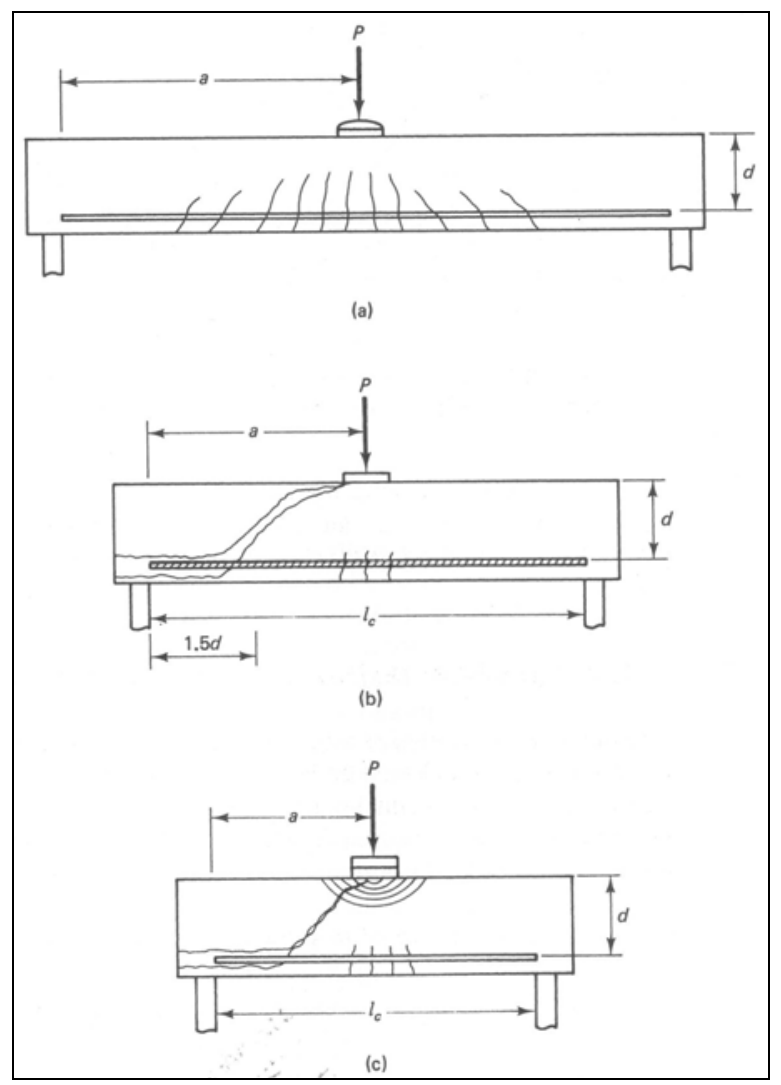

Figure 2.5: Beam failure patterns

a.) flexural failure, b.) diagonal tension failure, and c.) shear compression failure. (Nawy, 2003)

\subsubsection{Cracking and Deflection}

As a reinforced concrete beam is loaded, it will deflect while vertical cracks form across the span. However, a beam bust be designed to prevent excessive cracking or deflection at service load levels. Allowable degrees of cracking and deflection for reinforced concrete beams are governed primarily by user comfort and aesthetic appearance. There are three basic regions on a load-displacement curve for a reinforced concrete beam: the precracking stage, the postcracking stage, and the postservicability cracking stage (Nawy, 2003). These regions can be seen on a typical load-deflection curve in Figure 2.6. 


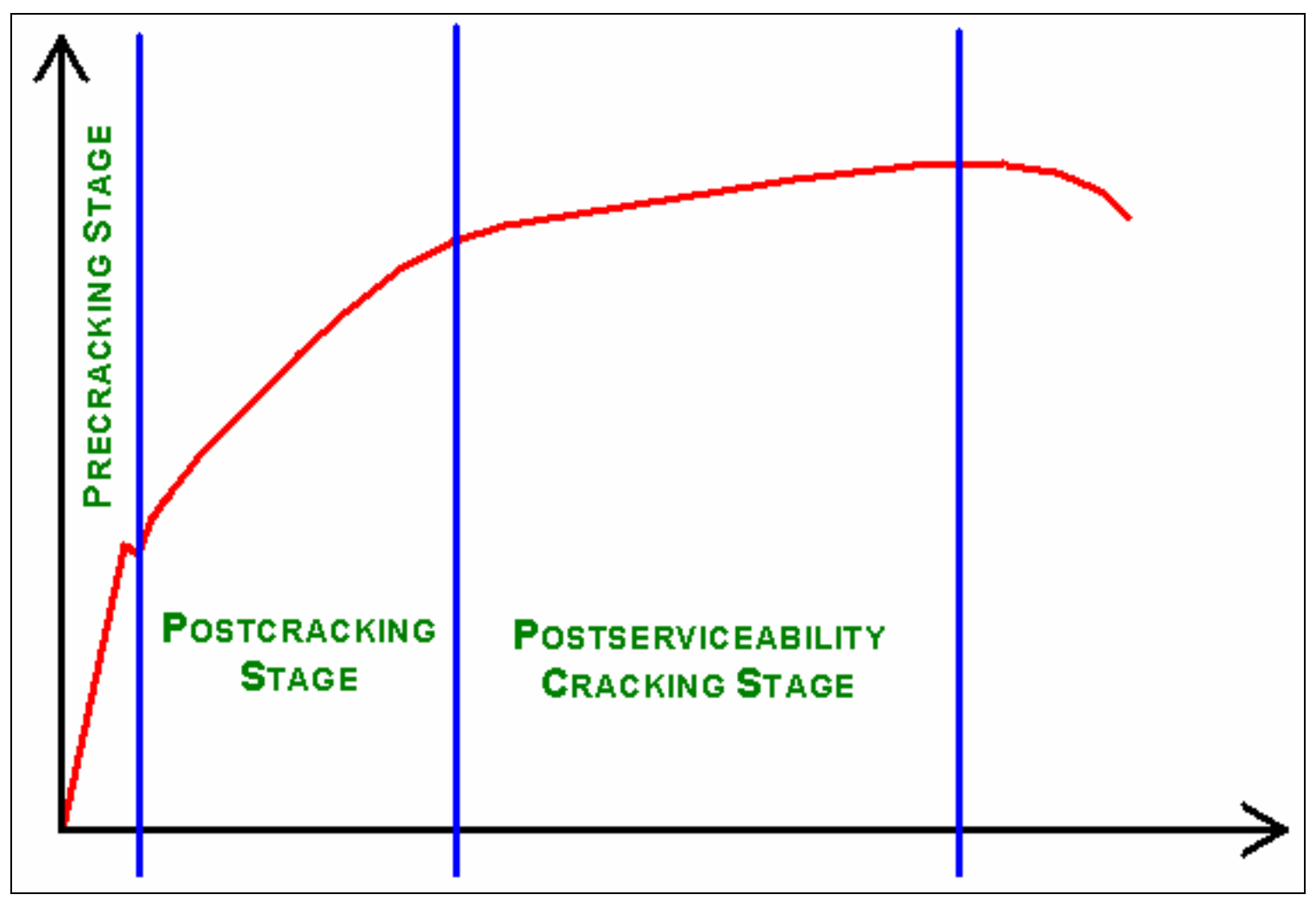

Figure 2.6: Regions of a typical load deflection curve for a reinforced concrete beam (Nawy, 2003)

As the name of the region indicates, a beam is crack-free in the precracking stage. The slope of the load-deflection curve is effectively linear and elastic.

In the postcracking stage, the "acceptable" cracking develops in which both the crack distribution and width are controlled. In this region, the slope of the load-deflection curve decreases. As the cracks grow and propagate, the stiffness of the beam continues to decline. Within this region, it can be assumed that the strain distribution across the beam depth is linear, the concrete does not resist any tension, the concrete and steel are both within their elastic limits, and the strain distribution is similar to the designed distribution but with different strains and stresses (Nawy, 2003). Cracked moment 
analysis can indicate the approximate cracking load and the resulting moment capacity. Most beams are designed to lie in this region when subjected to service loads.

In the postservicability cracking stage, the tension reinforcement yields and the cracking becomes excessive. At this stage, the beam is considered to have structurally failed. The slope of the load deflection curve is much flatter in the postservicability cracking region than in the postcracking region. This stage ends when consequent concrete crushing occurs and is followed by total rupture. From yielding of the steel reinforcement until concrete crushing, the total load level will increase between 4 and 10\%, but the deflection may increase several times as much as it was at initial yielding.

ACI provides formulas to predict maximum crack widths and supplies tolerable crack widths for comparison. ACI also limits the spacing of reinforcement in an effort to control flexural cracking.

\subsubsection{Bar Development}

Bond strength is the cumulative result from the following:

- Adhesion between the concrete and steel reinforcement

- Gripping effect due to drying shrinkage causing shear interlock between rebar deformations and surrounding concrete

- Frictional resistance to sliding and interlock when the reinforcement is subjected to tension

- Effect of concrete quality and strength in tension and compression 
- Mechanical anchorage provided at the ends of rebar such as splicing, hooks, and crossbars.

- Diameter, shape, and spacing of steel reinforcement

A reinforced concrete beam must be designed so that the maximum possible bond strength is developed. ACI provides values for minimum embedded rebar length for development based on bar size and for minimum beam width.

\subsection{Deterioration of Concrete}

\subsubsection{Durability}

$\mathrm{ACI}$ defines concrete durability as its resistance to weathering action, chemical attack, abrasion and other degradation processes (Corrosion-Club, 2008). A concrete with low durability deteriorates rapidly. Deterioration of concrete occurs when one of the three main constituents of a reinforced member (the aggregate, the cement paste, or the reinforcement) performs unfavorably due to one of the degradation processes mentioned above. The deterioration of the concrete and the corrosion of the steel reinforcement will be discussed later in this section.

One of the major variables affecting the durability of concrete is permeability. Permeability is a microstructure property which indicates the ability of the concrete to bypass a fluid with a specific viscosity under a pressure gradient (Construction, 2008). 
The more permeable the concrete, the higher the entry rate of moisture and contaminates. Permeability also controls the effect of pore solution upon freezing or heating.

The permeability of reinforced concrete is primarily influenced by the water cement ratio $(w / c)$ of the concrete. As w/c ratio increases, concrete permeability increases. The porosity increases sharply for $\mathrm{w} / \mathrm{c}$ ratios greater than 0.42 (Mindess, 2003).

\subsubsection{Modes of Attack}

\subsubsection{Leaching and Efflorescence}

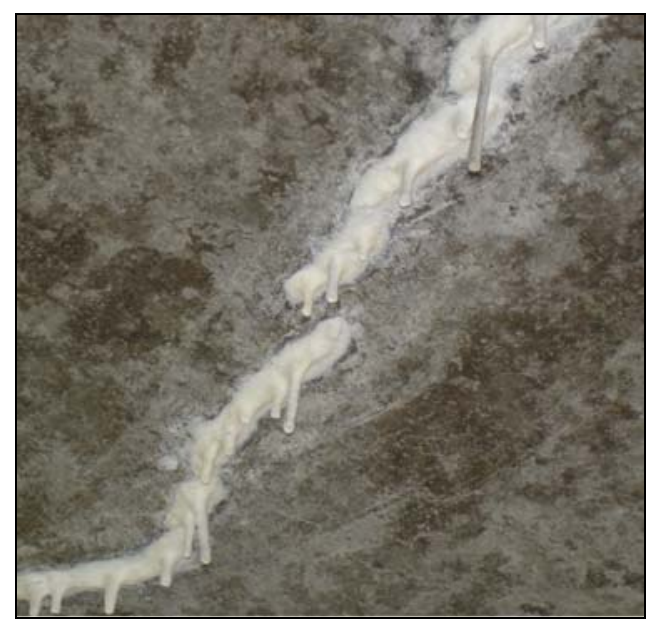

Figure 2.7 Efflorescence on the underside of a concrete member (www.answers.com)

Efflorescence consists of salt deposits, mainly calcium carbonate, that leach out of concrete and crystallize when the water evaporates or when it reacts with carbon dioxide in the air. 
Although the leaching of efflorescence is mainly an aesthetic problem, its presence can indicate an increase in porosity, a reduction of strength, and an increase in vulnerability to chemical attack. An example of efflorescence leaching from a concrete member can be seen in Figure 2.7.

\subsubsection{Sulfate Attack}

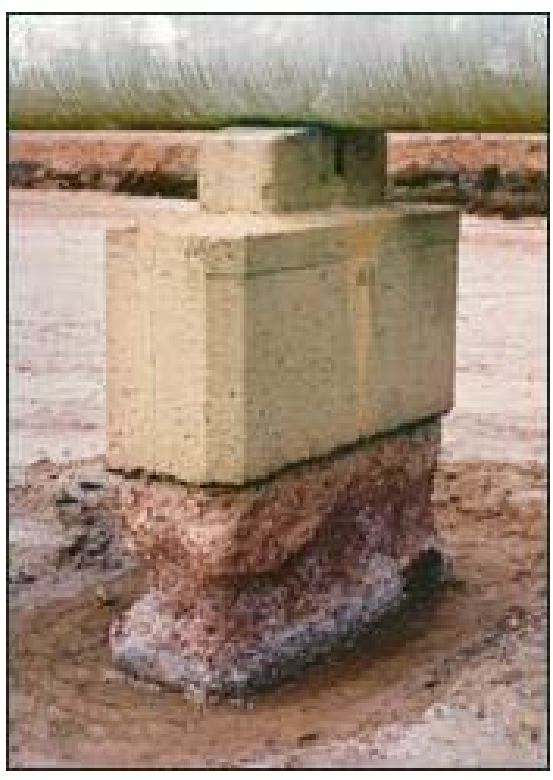

Figure 2.8 Sulfate attack (www.cementaid.ie)

Sulfate attack may be the most widespread form of chemical attack since sulfates are present in groundwater, rainwater, and biological growths. The ultimate result of sulfate attack is cracking and expansion of the concrete and softening and disintegration of the cement paste. This mode of attack occurs in three main processes: 1.) sulfate ions diffuse into the concrete pores, 2.) gypsum forms, and 3.) sulfoaluminates corrosion causes internal cracking increasing permeability and accelerating further attack. An example of concrete suffering from sulfate attack can be seen in Figure 2.8. 


\subsubsection{Acid Attack}

The hydrogen ions resulting from acid attack accelerates the leaching of calcium hydroxide from the concrete.

\subsubsection{Crystallization of Salts}

When salts, such as deicing salts, permeate into concrete, they crystallize in the pores as the water evaporates. Repeated or continuing evaporation causes the salt deposits to build until they cause cracking. A low w/c ratio and a low permeability concrete can limit the formation of expansive salt crystals.

\subsubsection{Alkali-Aggregate Attack}

Some aggregates are vulnerable to an expansive chemical reaction between the alkalis in the cement paste and various forms of reactive silica. This expansive reaction causes subsequent cracking of the concrete.

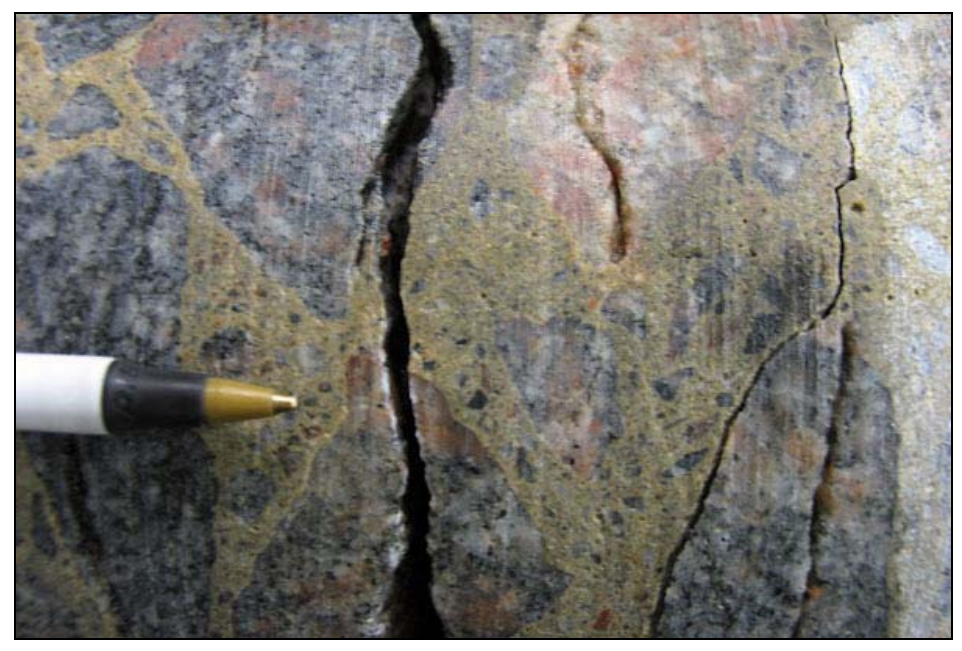

Figure 2.9 Alkali-aggregate attack (www.hydro.mb.ca) 
Alkali-aggregate attack can be avoided if aggregate materials are tested and approved by an engineer prior to use in construction. A photo of cracking due to alkali-aggregate attack can be seen in Figure 2.9.

\subsubsection{Freeze-Thaw Attack}

Several processes contribute to the deterioration of cement paste during freezing, such as hydraulic pressure that results from ice formation, osmotic pressure that is generated due to an increase in solute concentration in the pore water adjacent to freezing zones, desorption of water from C-S-H, and segregation of ice.

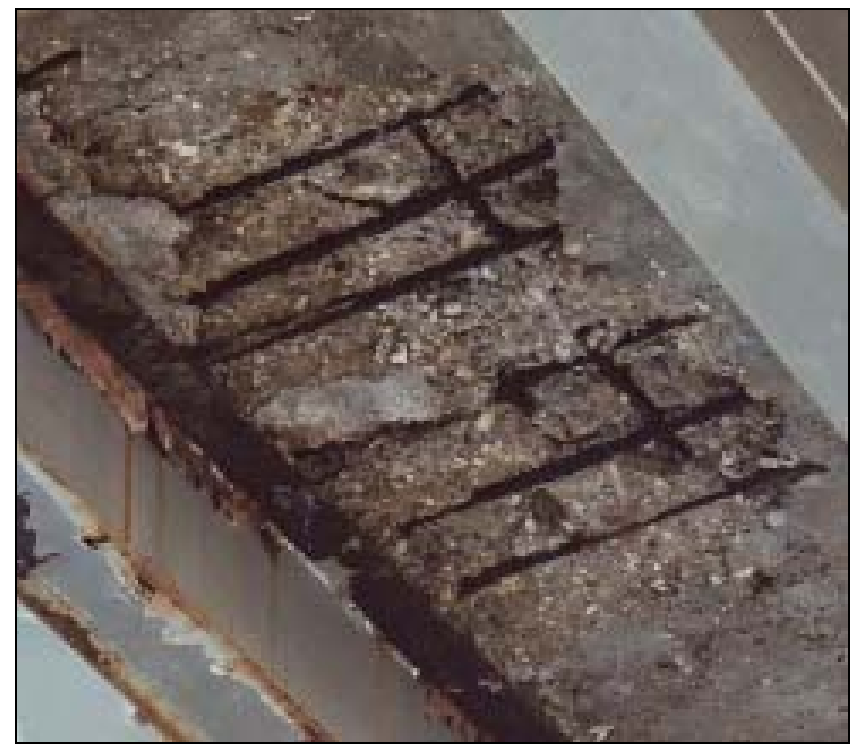

Figure 2.10 Result of freeze-thaw attack (www.hydro.mb.ca)

When water freezes, it undergoes a $9 \%$ volume increase, which accounts for some of the expansive forces that result. However, it has been proven that the other processes contribute to a majority of the deterioration resulting from freezing and thawing. The generation of osmotic pressure causes the paste to crack. Also, the drop of relative 
humidity causes the spontaneous movement of water toward the freezing zones to maintain equilibrium, causing desorption of water from the C-S-H. This causes the paste in the non-freezing zones to shrink. The use of air-entraining admixtures limits the effects of freeze-thaw attack. The result of freeze-thaw attack can be seen in Figure 2.10.

\subsubsection{Salt Scaling}

The heat required to melt ice when a deicer is used on concrete causes a rapid drop in temperature in areas just below the concrete surface, resulting in damage. Differing vapor pressures between salt solutions and pure water also cause damage during evaporation. Ice can form in these damaged areas, causing the concrete surface to become roughened and pitted due to small-scale spalling. Salt scaling can be prevented by using air-entraining admixtures with a low w/c ratio and low permeability concrete. Salt scaling on a concrete surface can be observed in Figure 2.11.

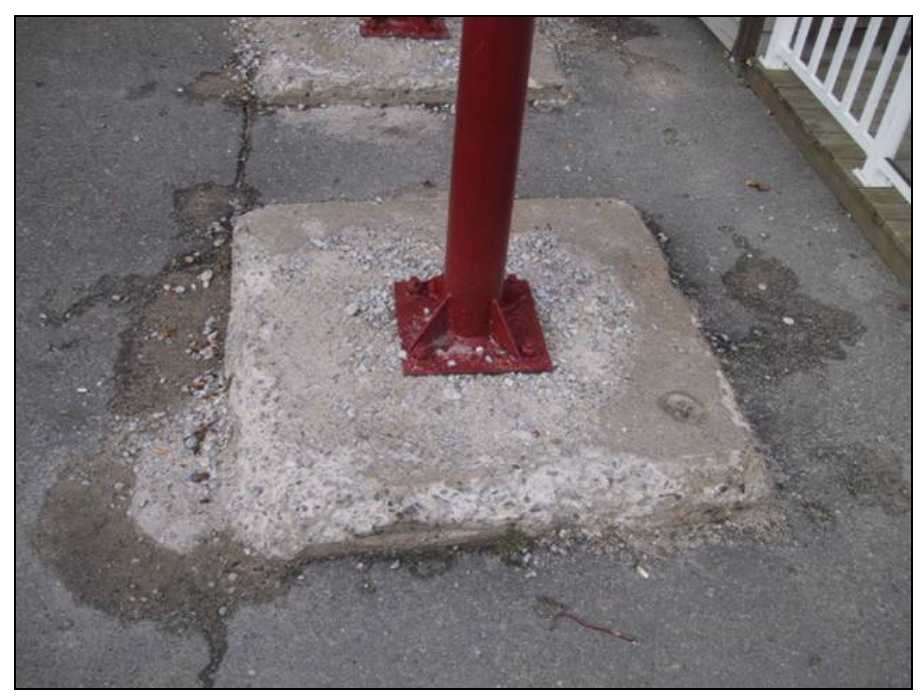

Figure 2.11 Salt scaling (www.unb.ca) 


\subsection{Corrosion of Reinforcing Steel in Concrete}

\subsubsection{Initiators}

Corrosion can be defined as the tendency of a refined metal to return to its native state. Corrosion of steel in concrete is an electrochemical process during which the production of electric current flowing between the concrete and reinforcement produces chemical changes in the reinforcement. Three essential elements must be present for the corrosion to occur in reinforced concrete: oxygen, moisture, and the flow of electrons through steel coupled by the flow of hydroxyl $\left(\mathrm{OH}^{-}\right)$ions through concrete. A detailed description of the corrosion mechanism will be given later in this section. The quality and contents of the concrete covering the reinforcing steel plays a major role in determining the rate and extent of corrosion. Contamination of this concrete layer accelerates the corrosion process. A high quality Portland cement concrete provides a protective environment for reinforcing steel due to its alkaline $\mathrm{pH}$ of 12.6 or greater (ACI, 2003). This high $\mathrm{pH}$ is due to calcium hydroxide in the hydrated cement. A thin but dense protective layer of oxide film known as a passive layer forms on the reinforcing steel when the $\mathrm{pH}$ of the surrounding concrete is at least 9 or 10 . If the concrete cover remains intact and uncontaminated, reinforcing steel will not corrode.

Corrosion of reinforcing steel in concrete is initiated by two primary forms of attack: carbonation and chloride contamination. The occurrence of either of these attacks will commence the corrosion process of the embedded steel. 


\subsubsection{Carbonation}

Carbonation occurs when hydrated cement reacts with acidic atmospheric gases. Carbon dioxide is the chief instigator of carbonation as it diffuses into the concrete and reacts with the calcium hydroxide in moist hydrated cement and forms calcium carbonate. Hydroxyl ions are removed from the pore solution and the $\mathrm{pH}$ of the concrete consequently drops sharply to less than 8 , creating an environment that becomes conducive for steel oxidation (Broomfield, 1997). Threat and rate of carbonation is dependent on the integrity, permeability, thickness, humidity, and alkali content of the concrete cover. Obviously a thick, dense, well-compacted concrete cover resists the ingress of carbon dioxide and other corrosive atmospheric gases and results in a slower rate of carbonation attack than does a porous, cracked, or thin cover. The optimum relative humidity for carbonation is in the range of $60-75 \%$. Too little moisture is available for the carbonation reaction to take place in a relative humidity below $60 \%$ and pore water slows the diffusion process of the carbon dioxide in a relative humidity above 75\% (ACI, 2003).

A $\mathrm{pH}$ indicator consisting of an aqueous alcoholic solution of phenolphthalein can be used to detect carbonation in concrete. When sprayed onto a concrete surface, the $\mathrm{pH}$ indicator will turn pink if the concrete is not carbonated or remain colorless if the concrete is carbonated. The photos in Figure 2.12 show carbonation tests conducted in the WVU laboratory. The concrete on the left is not carbonated and the concrete on the right is carbonated. 

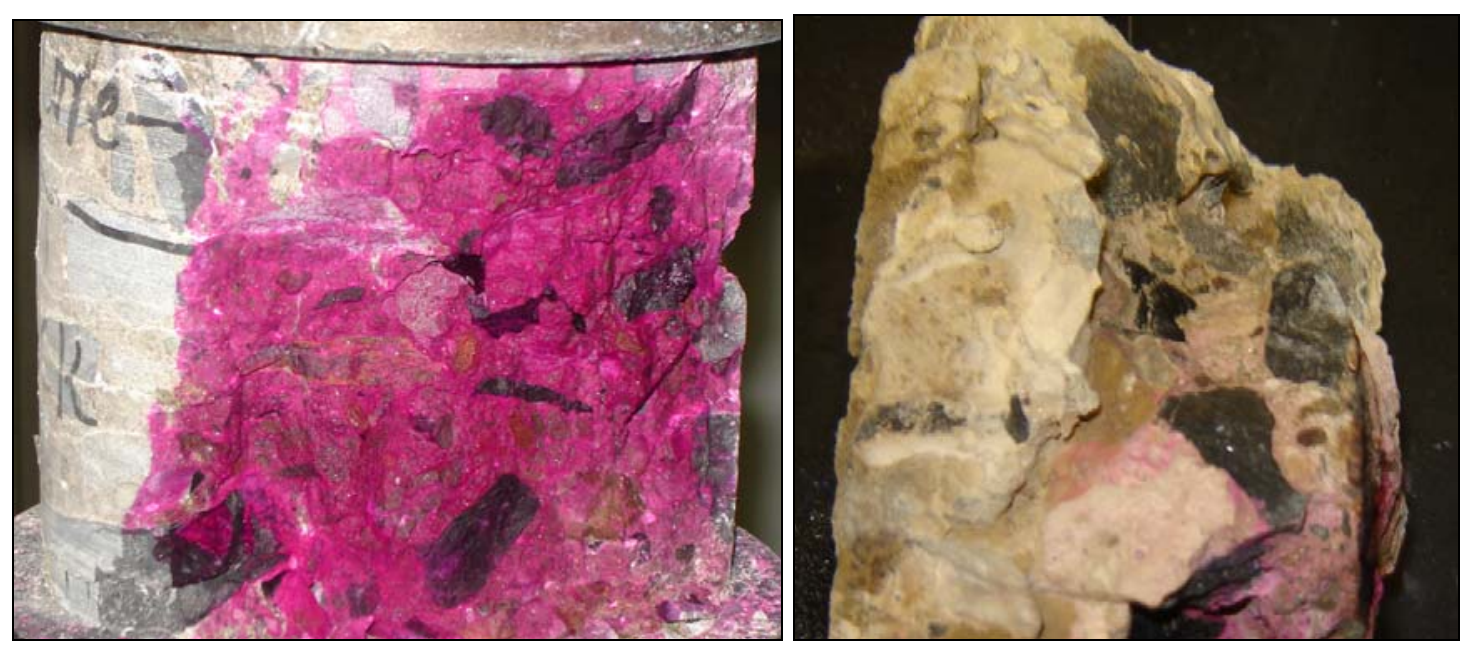

Figure 2.12 Results of a carbonation test using a phenolphthalein indicator

\subsubsection{Chloride Attack}

Chlorides can exist in concrete in two forms: they can be fixed, which means that they are chemically or physically bound in the cement minerals or hydration products, or free, which means that they are contained within the pore water of the concrete.

Chlorides can be fixed within the concrete matrix during mixing. For example, calcium chloride has been used as an accelerating admixture. Chlorides can also be present in some aggregates and cements. Most chloride that is added to a concrete mix is bound within the cement matrix. Bound chloride does not contribute to corrosion. The amount of bound chloride is dependent upon sulfate level of the cement and the extent of monosulfate, ettringite, calcium carboaluminate hydrate, and calcite formation. The remaining unbound chlorides remain present within the concrete's pore water as free chloride and instigate corrosion. A general rule of thumb used by contractors and engineers is that 1.0to $1.4 \mathrm{lbs}$ of chloride per 1 cubic yard of concrete can initiate 
corrosion of reinforcing steel (ACI 2003, Broomfield 1997). A more explicit threshold limit that is commonly accepted is $0.4 \%$ chloride by weight of cement can initiate chloride-induced corrosion can if it is cast in concrete during mixing (Broomfield, 1997). Interestingly, as free chlorides are removed from concrete components, bound chloride will be released to the pore water as free chloride to maintain equilibrium.

The vast majority of chloride-induced corrosion originates due to the diffusion of chlorides into the concrete from an external source. One of the main sources of external chloride is saltwater marine environments. If portions a reinforced concrete structure are submerged in seawater or even exposed to saltwater mists, chlorides can diffuse in. Airborne salts and groundwater salts are also culprits of corrosion initiation. Another main, and perhaps the most problematic, source of chloride ingress in North America is from the use of deicing salts. These salts diffuse through the reinforced concrete components of bridges and parking structures and aggressively attack the underlying rebar. A commonly accepted threshold limit for corrosion is $0.2 \%$ chlorides by weight of cement if chlorides are diffused in (Broomfield, 1997).

If enough free chloride, oxygen, and moisture are present, reinforcement can corrode even in a highly alkaline concrete environment. This is because chloride ions destroy the passive layer of oxide on the steel in localized regions and allow the corrosion process to proceed quickly even though there is no overall drop in concrete $\mathrm{pH}$. The hydroxyl ions in the concrete actively repair these damaged regions of passive film until a critical chloride ion / hydroxyl ion ratio $\left(\mathrm{Cl}^{-} / \mathrm{OH}^{-}\right)$is reached. 

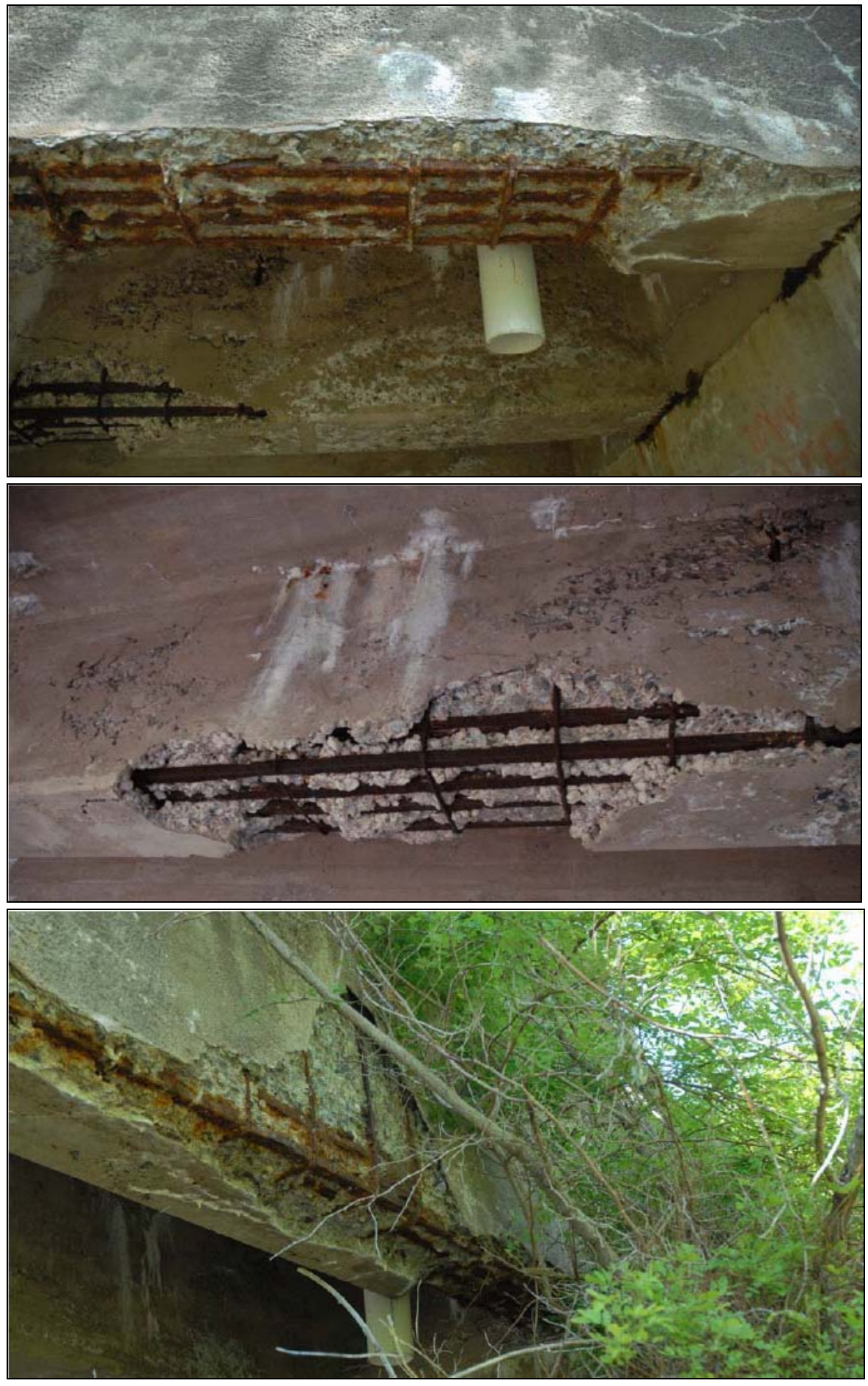

Figure 2.13: The combined effect of chloride- and carbonationinduced corrosion 
A commonly accepted value for the limit that has been observed throughout many research endeavors is a free chloride ion / hydroxyl ion ratio $\left(\mathrm{Cl}^{-} / \mathrm{OH}^{-}\right)$greater than or equal to 0.6. Once this ratio drops below the critical value, pitting corrosion will occur. As one can see, carbonation accelerates chloride corrosion since it destroys the selfhealing hydroxyl ions surrounding the steel. Also, carbonation leads to the decomposition of the bound chloride salts releasing more free chloride ions to corrode the steel. The photos in Figure 2.13 show the corrosion and concrete delamination resulting from the combined effect of chloride- and carbonation- induced corrosion on PennDOT bridge \#49-4012-0250-1032.

\subsubsection{Types of Corrosion and their Mechanisms}

\subsubsection{General Corrosion of Steel in Concrete}

As mentioned above, when steel is in the presence of moisture and oxygen, an electrochemical oxidation-reduction reaction ensues. A simple diagram of this corrosion initiating process can be observed in Figure 2.14. In this figure, it is apparent how the flow of electrons and $\mathrm{OH}^{-}$ions and the presence of oxygen and moisture is required for corrosion to take place. Andrade (1993) reports that a normal corrosion rate in steel is $\left.10-100 \mu \mathrm{A} / \mathrm{cm}^{2}\right)$. 


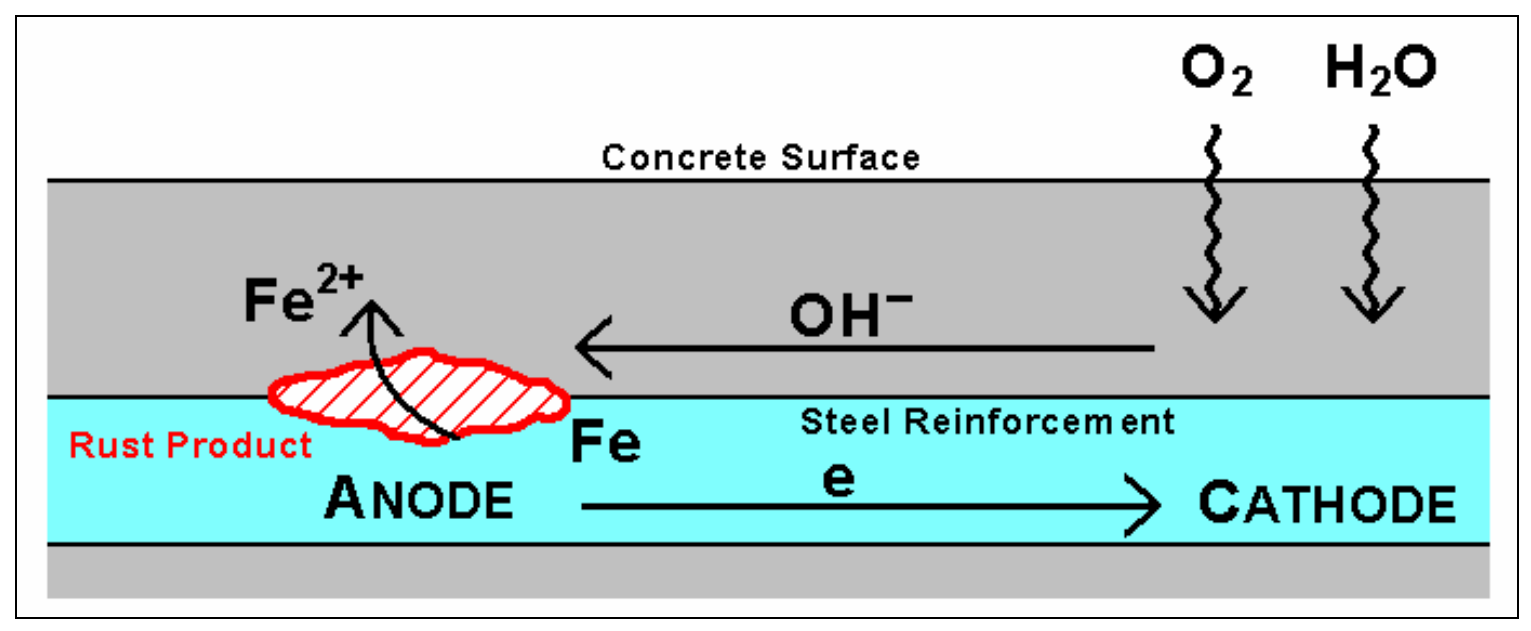

Figure 2.14: Initiation of the Corrosion Process in Reinforced Concrete

Iron becomes oxidized at some locations on the steel while the water molecules become reduced. First, oxidation occurs at the anode and reduction occurs at the cathode. The anodic reaction can be written as:

$\mathrm{Fe} \leftrightarrow 2 \mathrm{e}^{-}+\mathrm{Fe}^{2+}$

Water, consequently, is reduced by oxygen and hydroxyl ions are produced:

$1 / 2 \mathrm{O}_{2}+\mathrm{H}_{2} \mathrm{O}+2 \mathrm{e}^{-} \leftrightarrow 2 \mathrm{OH}^{-}$

This first set of reactions also represents a general corrosion mechanism of steel, whether or not it is embedded in concrete.

Second, $\mathrm{Fe}^{2+}$ and hydroxide ions from the concrete combine to form ferrous hydroxide:

$\mathrm{Fe}^{2+}+2\left(\mathrm{OH}^{-}\right) \rightarrow \mathrm{Fe}\left(\mathrm{OH}_{2}\right)$ 
Third, if the $\mathrm{pH}$ in the concrete is less than 11.5 due to carbonation, the ferrous hydroxide combines with oxygen and water to produce $\mathrm{Fe}(\mathrm{OH})_{3}$ and then spontaneously ferric oxide and water:

$2 \mathrm{Fe}(\mathrm{OH})_{2} \stackrel{\mathrm{O}_{2}, \mathrm{H}_{2} \mathrm{O}}{\rightarrow} 2 \mathrm{Fe}(\mathrm{OH})_{3} \rightarrow \mathrm{Fe}_{2} \mathrm{O}_{3} \cdot \mathrm{nH}_{2} \mathrm{O}$

Ferric oxide is what is commonly referred to as "rust"; it is also the product responsible for large volume increases that yield cracking, spalling, and delamination.

If the $\mathrm{pH}$ of the concrete is greater than 13 due to potassium hydroxide and sodium hydroxide in the concrete pore solution, however, the third reaction shown above can be replaced by a new reaction that actually prohibits or slows the corrosion process. In this reaction, the ferrous hydroxide combines with oxygen to form ferritic hydroxide and water:

$\mathrm{Fe}(\mathrm{OH})_{2}+\mathrm{O}_{2} \rightarrow \mathrm{FeOOH}+\mathrm{H}_{2} \mathrm{O}$

Ferritic hydroxide is a tightly adhering oxide film that forms on the surface of the reinforcing steel. Ferritic hydroxide limits the ingress of oxygen and moisture to the metal and, therefore, prevents corrosion (Mindess, 2003).

\subsubsection{2 "Black/Green Rust"}

If the anodic and cathodic areas along a reinforcing bar are well separated and the anodic area is starved of oxygen, iron ions tend to remain in solution. This type of corrosion is commonly referred to as "black" or "green rust", and will be referred to as "black rust" in 
this paper. Black rust is actually ferrous hydroxide. As in the formation of expansive rust, the initiation of black rust occurs with first the formation of $\mathrm{Fe}^{2+}$ ions, and second with the formation of ferrous hydroxide. However, since oxygen is not readily available, the corrosion process ends at this second step and expansive ferric hydroxide is never formed.

The formation of black rust potentially creates a dangerous scenario because it generates no external symptoms of corrosion within the member. No expansive forces develop within the concrete and, therefore, visual inspection does not reveal deterioration. Black rust is mostly found in water saturated conditions where no oxygen ingress can take place.

\subsubsection{Corrosion within Chloride-Contaminated Reinforced Concrete}

Chloride contamination creates an environment favorable to corrosion in reinforced concrete even if carbonation has not occurred and the $\mathrm{pH}$ of the concrete is high. First, the chloride ions combine with $\mathrm{Fe}^{2+}$ ions and form an iron-chloride complex:

$\mathrm{Fe}^{2+}+\mathrm{Cl}^{-} \rightarrow[\mathrm{FeCl} \text { complex }]^{+}$

The iron chloride complex then combines with hydroxyl ions in the concrete and forms ferrous hydroxide and free chloride ions:

$[\mathrm{FeCl} \text { complex }]^{+}+2(\mathrm{OH})^{-} \rightarrow \mathrm{Fe}(\mathrm{OH})_{2}+\mathrm{Cl}^{-}$ 
The ferrous hydroxide can now react with oxygen and moisture to form expansive corrosion products, as described in Section 2.3.2.1, or if oxygen is not present, the $\mathrm{Fe}(\mathrm{OH})_{2}$ can remain as black rust, as described in Section 2.3.2.2. Another obvious dilemma with this reaction is that free chloride ions are released when $\mathrm{Fe}(\mathrm{OH})_{2}$ is formed. These chloride ions are free to continue forming additional $\mathrm{FeCl}$ complex to react with more hydroxyl ions, thus producing a cyclic process in which no chlorides are actually consumed or made unavailable. Chloride-induced corrosion also yields another predicament. It can be assumed that a source of chloride ions is readily available if chloride-induced corrosion has already begun to corrode. As the corrosion products expand and crack the concrete, new chloride contaminates can then enter the structure and proceed to the reinforcing steel much more swiftly than before. As cracks widen or as spalling or delamination occurs, the chloride can access the reinforcing steel even more rapidly.

Corrosion of steel in chloride-contaminated concrete generally initiates with the formation of pits. This is often thought to occur at a void in the cement paste or at a sulfide inclusion in the steel. Corrosion is often local, with a few centimeters of corrosion and then up to a meter of clean bar, especially for chloride-induced corrosion. Pitting corrosion indicates the separation of the anodic reaction and the cathodic reaction to form a macrocell. Chloride induced corrosion gives rise to particularly well defined macrocells. Figure 2.15 shows examples of chloride-induced pitting corrosion that was observed in this research. 

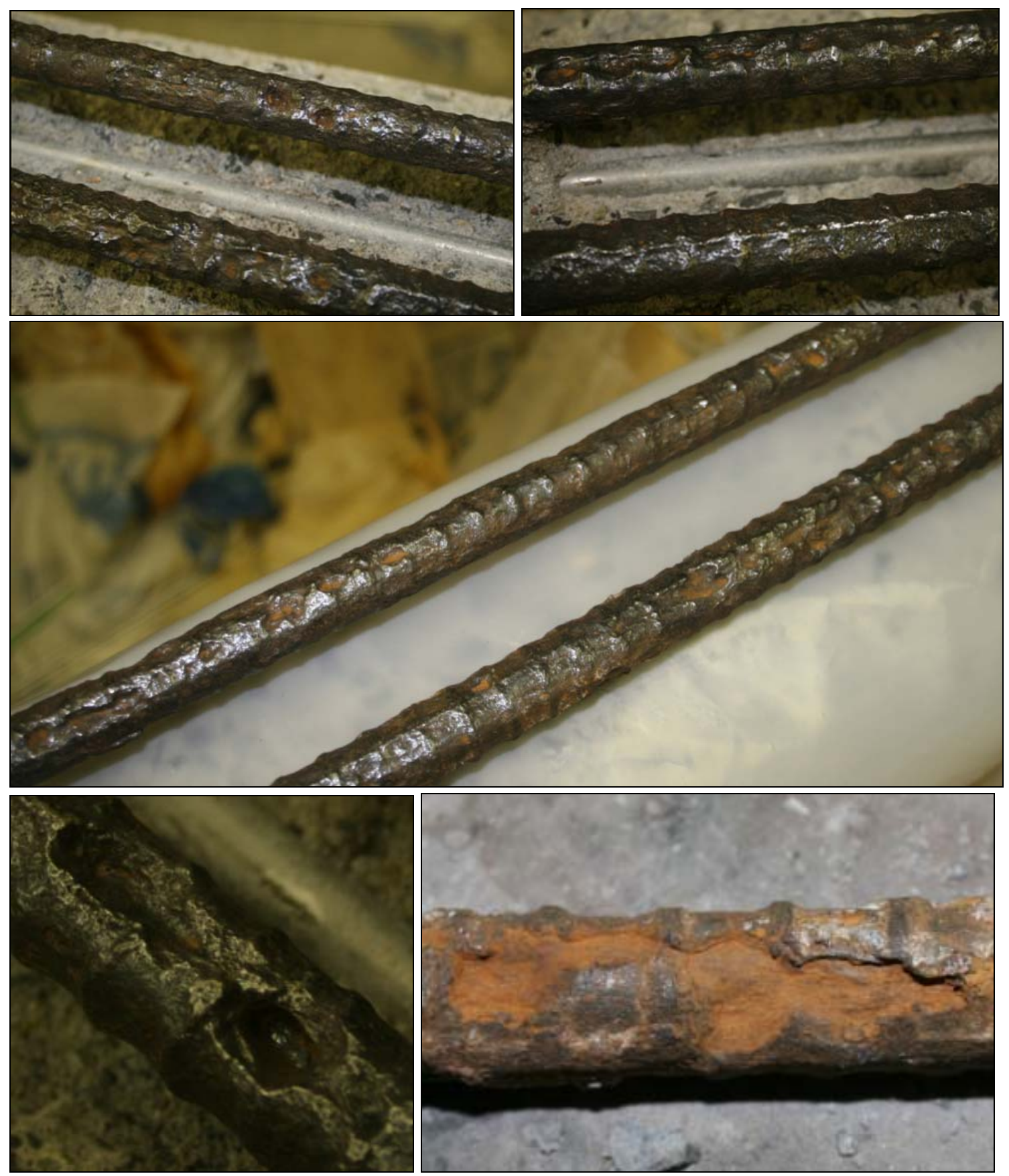

Figure 2.15: Chloride-induced pitting corrosion in steel reinforcing bars

Many times, steel must first be cleaned, as in Figure 2.15, to visually detect pitting corrosion. This is because the expansive corrosion products accumulate in the pits, resulting in the appearance that no pit exists and that corrosion is uniform over the length 
of the bar. This is why, in bridge inspection, steel rebar should always be cleaned prior to recording observations.

\subsubsection{Incipient Anode}

When only certain regions of concrete are removed from around a reinforcing bar and are replaced with new concrete, an incipient anode can form due to the potential differences instigated by the two concretes. The potential in areas adjacent to the patch is much higher than the potential within the patch, resulting in a localized corrosion cell. The surface area of the steel encased within the old contaminated concrete becomes an incipient anode (the literal meaning of incipient is "just beginning to exist"), and the steel encased within the new highly-alkaline patch concrete becomes the cathode. This cell actually produces accelerated corrosion at locations adjacent to the patch repair. This was evidenced in work done by Wang (2006), where the corrosion rate of reinforcing steel in unrepaired areas of patched beams was actually greater than in contaminated specimens without any repair.

\subsubsection{Cracking in Reinforced Concrete}

Table 2.6 provides an overview of the types of cracking commonly found in reinforced concrete. The two types of cracking that were studied in this research resulted from the corrosion (left photo in Figure 2.16) of reinforcement and the application of both static and cyclic loads (right photo in Figure 2.16). 
Table 2.6: Types of cracks found in reinforced concrete (ACI, 2003)

\begin{tabular}{|c|c|c|c|}
\hline \multirow{17}{*}{$\begin{array}{l}\text { Types of } \\
\text { Cracks }\end{array}$} & \multirow{12}{*}{$\begin{array}{l}\text { After } \\
\text { Hardening }\end{array}$} & \multirow{3}{*}{ Physical } & Shrinkable Aggregates \\
\hline & & & Drying Shrinkage \\
\hline & & & Crazing \\
\hline & & \multirow{3}{*}{ Chemical } & Corrosion of Reinforcement \\
\hline & & & Alkali-Aggregate Reactions \\
\hline & & & Cement Carbonation \\
\hline & & \multirow{3}{*}{ Thermal } & Freeze/Thaw Cycles \\
\hline & & & External Seasonal Temperature Variations \\
\hline & & & Early Thermal Contraction \\
\hline & & \multirow{3}{*}{ Structural } & Accidental Overload \\
\hline & & & Creep \\
\hline & & & Design Loads \\
\hline & \multirow{5}{*}{$\begin{array}{l}\text { Before } \\
\text { Hardening }\end{array}$} & --- & Early Frost Damage \\
\hline & & \multirow{2}{*}{ Plastic } & Plastic Shrinkage \\
\hline & & & Plastic Settlement \\
\hline & & \multirow{2}{*}{$\begin{array}{l}\text { Construction } \\
\text { Movement }\end{array}$} & Formwork Movement \\
\hline & & & Sub-Grade Movement \\
\hline
\end{tabular}
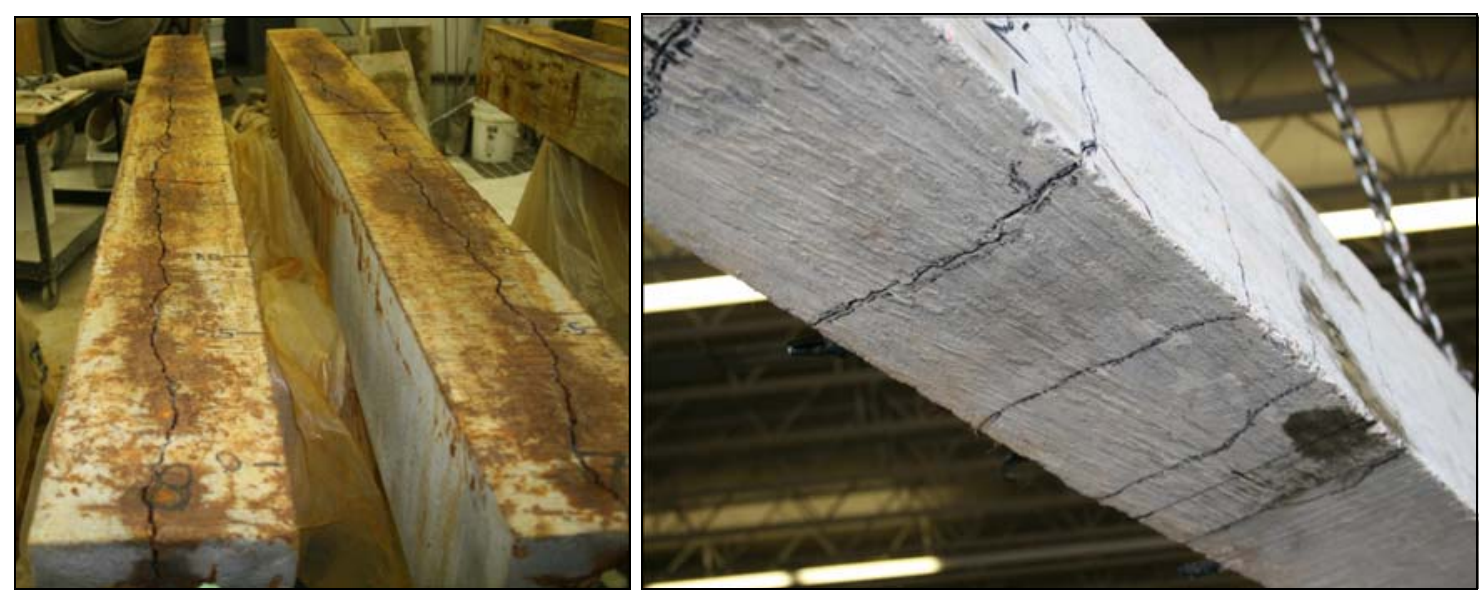

Figure 2.16: Cracks resulting from reinforcement corrosion (left) and cracks resulting from the application of load (right) 


\section{Chapter 3: Fiber Reinforced Polymer}

\subsection{FRP as a Composite Material}

A composite material can be defined as a "combination of two or more distinct materials to form a new material with enhanced properties" (Barbero, 1999). It is important to note that, in a composite material, the constituent materials retain their chemical and physical identities without dissolving or merging completely into one another. The components of a composite material act in concert with one another, and clear interfaces exist between the unique components (ACI 440-2R-02). FRP is a composite material that consists of two primary components: fiber and polymer matrix binder. Figure 3.1 shows an FRP sheet bonded a concrete beam that was used in this research.

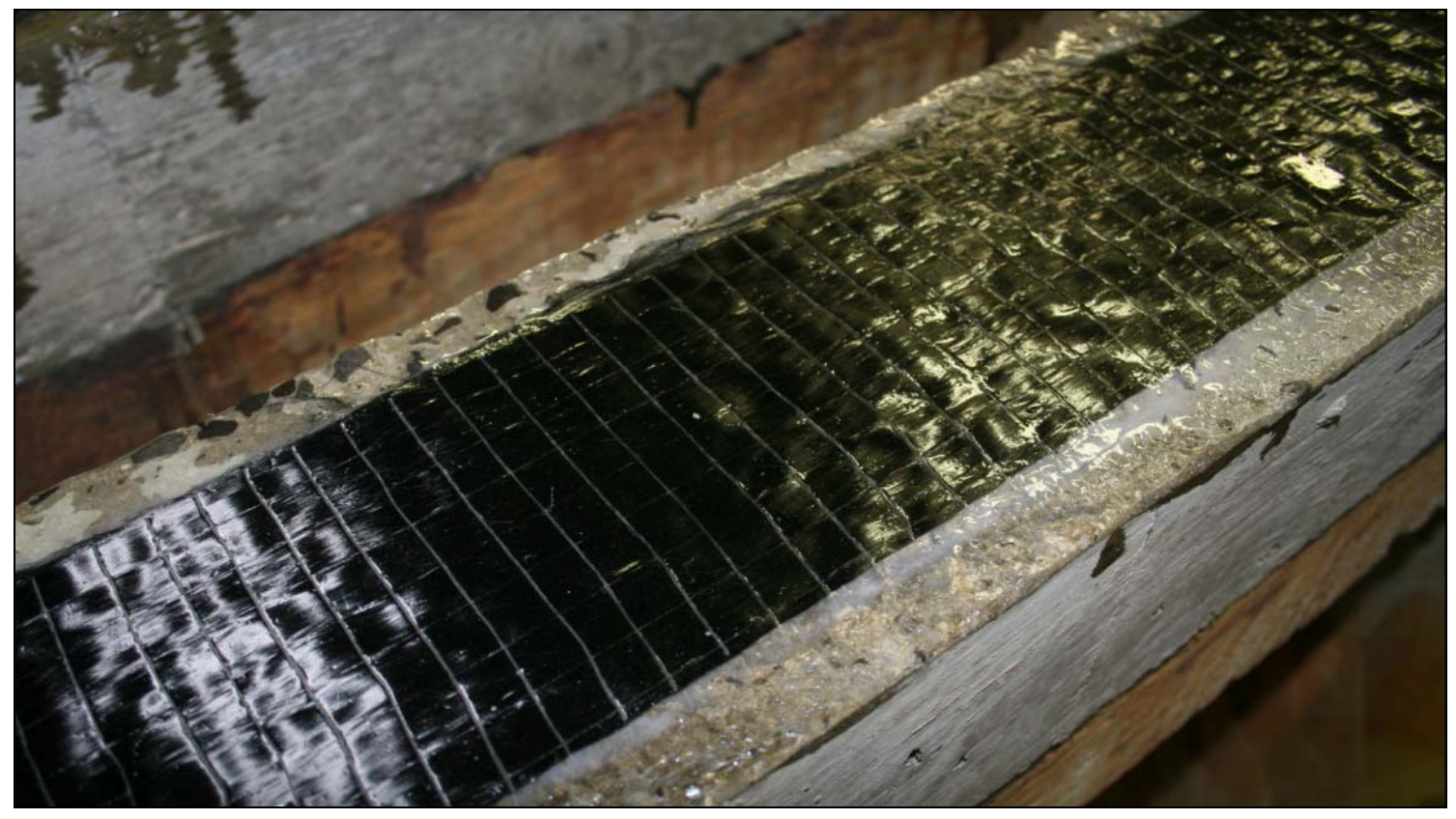

Figure 3.1: Cracks resulting from reinforcement corrosion (left) and cracks resulting from the application of load (right) 


\subsection{Constituents of Fiber Reinforced Polymer*}

\subsubsection{Fiber}

\subsubsection{Terms Associated with Composite Fiber}

It is important to know and to differentiate between the numerous descriptive terms that are commonly associated with fiber in composite material design. These terms are in bold type for the reader's convenience. Fiber, sometimes referred to filament, is defined as any fine thread-like natural or synthetic object of mineral or organic origin (ACI 4402R-02). In composite materials design, the term "fiber" generally refers to a material whose length is at least 100 times its diameter (ACI 440-2R-02).

FRP fibers exist in many forms. FRP fibers can be either continuous or chopped into discontinuous lengths and bonded together. A strand, a tow, or end is an untwisted bundle of continuous fibers handled as a unit. All fibers in a strand are produced at the same time. A yarn is a group of twisted filaments, fibers, or strands that are formed into a continuous length. A roving consists of multiple yarns, strands, tows, or ends of fibers assembled into a parallel bundle with little or no twist. Rovings and tows are unidirectional, meaning they provide reinforcement in only the direction parallel to the fibers. Yield is the length of yarn or roving per unit weight of fiber material, commonly expressed in the unit "yards per pound." Fibers can also be chopped into either long or short fibers and be bound into what is known as a mat. A chopped strand mat contains

\footnotetext{
* A majority of the definitions and information in this section were found in Barbero, 1999; ACI 440-2R02; and GangaRao 2007, even if not directly cited.
} 
randomly oriented chopped fibers. A continuous strand mat contains long, swirled fibers. A fabric is an arrangement of fibers held together in two dimensions. Fabric can be referred to as multidirectional, as it provides reinforcement in two or more directions. Fabrics can be woven by interloping (knitting) or interlacing (weaving) or non-woven by direct construction from strands. Multiple layers of fabric may also be stitched together. The fabric architecture specifically describes the fibers, orientations, and construction of a fabric. Fiber content is the percentage volume fraction percentage or weight fraction of fiber in a composite material. A ply is a single layer of fabric or mat. Often times, the fiber surfaces are treated or coated to improve bonding and improve processing and durability characteristics. This treatment is called sizing.

\subsubsection{Types of FRP Fiber}

FRP fiber is generally made from one of three materials: carbon, glass, or aramid.

\subsection{Carbon}

Carbon fibers, or graphite fibers, are advantageous because they have a high tensile strength-to-weight ratio, a high tensile modulus-to-weight ratio, a very low coefficient of linear thermal expansion, high fatigue strength, a wide variety of material properties, and excellent chemical resistance. The disadvantages of using carbon fibers are their relatively high cost, their high brittleness, and their high electrical conductivity. 
The material properties of carbon fibers greatly depend on what precursors, or raw materials, they were derived from. The two primary classes of material are polyacrylonitrile (PAN), which is stronger but more expensive (and also the most common), and pitch, which is cheaper but not as strong.

Apart from their origin, carbon fibers can be classified by their tensile modulus (E), for example: high stiffness (HS) fibers such as those designated as T300, AS2, or AS4D, intermediate modulus (IM, 29,000,000 psi $<\mathrm{E}<47,000,000 \mathrm{psi}$ ) fibers such as those designated as IM6, high modulus (HM, 47,000,000 psi $<\mathrm{E}<65,000,000 \mathrm{psi}$ ) fibers such as those designated as HSM4, ultrahigh modulus (UHM, E > 65,000,000 psi) fibers such as those designated as M50, and even higher-modulus fibers such as those designated as P100 (Barbero, 1999; GangaRao, 2007). High modulus fibers are often desired because they emulate the properties of steel. Carbon fibers can also be classified by their tensile strength, for example: Low modulus and high-tensile (HT, E $<14,500,000$ psi, tensile strength $>435,000 \mathrm{psi}$ ) fibers, or super high-tensile (SHT, tensile strength $>653,000 \mathrm{psi}$ ) fibers (GangaRao, 2007).

Finally, carbon fibers can be classified by their head treatment temperature as Type I (high-heat-treatment) which produces high-modulus fiber, Type II (intermediate-heattreatment) which produces high-strength fiber, and Type III (low-heat-treatment) which produces low-strength fibers (GangaRao, 2007). 
Carbon fibers were chosen for this research because of their versatility, chemical resistance, and lack of electrical conductivity.

\subsection{Glass}

Glass fibers are advantageous because they are very hard, corrosion and chemical resistant, inert, flexible, lightweight, strong, and inexpensive. Glass fibers are the most commonly found in FRP. The disadvantages of glass fibers are low tensile modulus, high specific gravity, sensitivity to abrasion during handling, and low fatigue resistance.

Glass Fibers can be classified as follows: E-glass, Z-glass, A-glass, C-glass, S-glass, Rglass, D-glass or K-glass. E-glass, which is the most common, has a low alkali content, a high resistance to corrosion, a low cost, a low susceptibility to moisture, and high mechanical properties. Z-glass is highly resistant to alkali attack, A-glass has a high alkali content, C-glass is chemical resistant and is beneficial in acidic environments, and S- and R-glass have extra-high strength and a high modulus. D- and K-glass is in its experimental stages and is intended to improve electrical properties (Barbero,1999; GangaRao, 2007).

\subsection{Aramid}

Aramid, or Kevlar ${ }^{\mathrm{TM}}$ (the material used to make bulletproof vests), fibers have many unique advantages. They have high energy absorption properties during failure, a high damping coefficient, and a high degree of yielding under compression, which results in 
high impact resistance. Aramid fibers have a low density, a high tensile strength-toweight ratio, a high modulus-to-weight ratio, a low thermal conductivity, and a high resistance to heat (Barbero, 1999; GangaRao, 2007). A disadvantage of aramid fibers is that they are hygroscopic, which means that they absorb moisture (up to $10 \%$ of the fiber weight). High moisture content often results in longitudinal splitting of the fibers. Some other functional disadvantages are that they are difficult to cut and machine and are sensitive to ultraviolet light.

\subsubsection{Polymer Matrix}

\subsubsection{Terms Associated with FRP Polymer Matrix}

It is important to know and to differentiate between the numerous descriptive terms that are commonly associated with polymer matrix in composite material design. These terms are in bold type for the reader's convenience. Binder can be defined as "chemical treatment applied to the random arrangement of fibers to give integrity to mats, roving, and fabric" (ACI 440-2R-02). Matrix is defined as the materials that serve to bind the fibers together, transfer load to the fibers, and protect them against environmental attack and damage due to handling. A polymer is a natural or synthetic organic compound formed by carbon and hydrogen with a high molecular weight and a repeating molecular structure. The repeating units are referred to as monomers.

Resin is a polymeric material that is rigid or semi-rigid at room temperature, usually with a melting point or glass transition temperature above room temperature. A thermoset is a resin that is formed by the irreversible chemical transformation of a resin system into an 
amorphous cross-linked polymer matrix. Thermoset resins are advantageous because they have a low viscosity, which allows for excellent impregnation (saturation of FRP fibers with resin), they are easy to process, and they are very economical. Shelf life is the time that an unmixed resin system can be stored under specified conditions and remain usable without degradation. Refrigeration of resin products is often recommended to ensure they achieve their shelf life. Resin systems are normally packaged in two parts, the resin and a curing agent, and are mixed together immediately before impregnation. In a two-component adhesive, the curing agent is the chemical component that causes the resin component to cure. The curing agent is a catalytic or reactive agent that causes polymerization when added to a resin. It provides a source of free radicals (groups of atoms that have at least one unpaired electron) and is used to initiate the curing process for unsaturated resins. Peroxides are the most common source of free radicals. The curing agent can also be referred to as the hardener, the initiator or the catalyst. Pot life, cure time, or gel time, is the time in which the resin is workable once the hardener and resin are combined and mixed. The term "flow" describes movement of uncured resin under pressure or gravity loads. During the curing cycle, polymerization occurs, and the mixture thickens, releases heat, solidifies, and shrinks. Polymerization is defined as the reaction in which two or more molecules of the same substance combine to form a compound containing the same elements and in the same proportions but of higher molecular weight. Once polymerization occurs, the cured resin system and fibers become a true composite. 
Fiber volume fraction is the ratio of the volume of fibers to the volume of the composite and fiber weight fraction is the ratio of the weight of fibers to the weight of the composite.

Fiber Reinforced Polymer, or FRP, is a composite material that consists of a polymer matrix reinforced with cloth, mat, strands, or any other fiber form. ACI defines an FRP system as "all the fibers and resins used to create the composite laminate, all applicable resins used to bond it to the concrete substrate, and all applied coatings used to protect the constituent materials" (ACI 440-2R-02).

\subsubsection{Types of FRP Polymer Matrix}

Epoxy resin (see Figure 3.2) is an organic thermosetting polymer bonding system. An epoxy is defined as the reaction product of epoxy resin and an amino hardener. Epoxies are frequently used since they are very versatile, are corrosion resistant, have favorable mechanical properties, bear low shrinkage, resist water and heat, and have a simple cure process. Epoxy resin is the polymer matrix used for the FRP in this experiment.

A phenolic is a thermosetting resin produced by the condensation of an aromatic alcohol with an aldehyde, particularly of phenol with formaldehyde. These are used for their thermal resistance (GangaRao, 2007).

A polyester, commonly referred to as "unsaturated polyester", is one of a large group of synthetic resins and is commonly used as a binder for resin mortars and concretes, fiber 
laminates (mainly glass), and adhesives. Polyesters are commonly used in outdoor applications since they have good UV and chemical resistance.

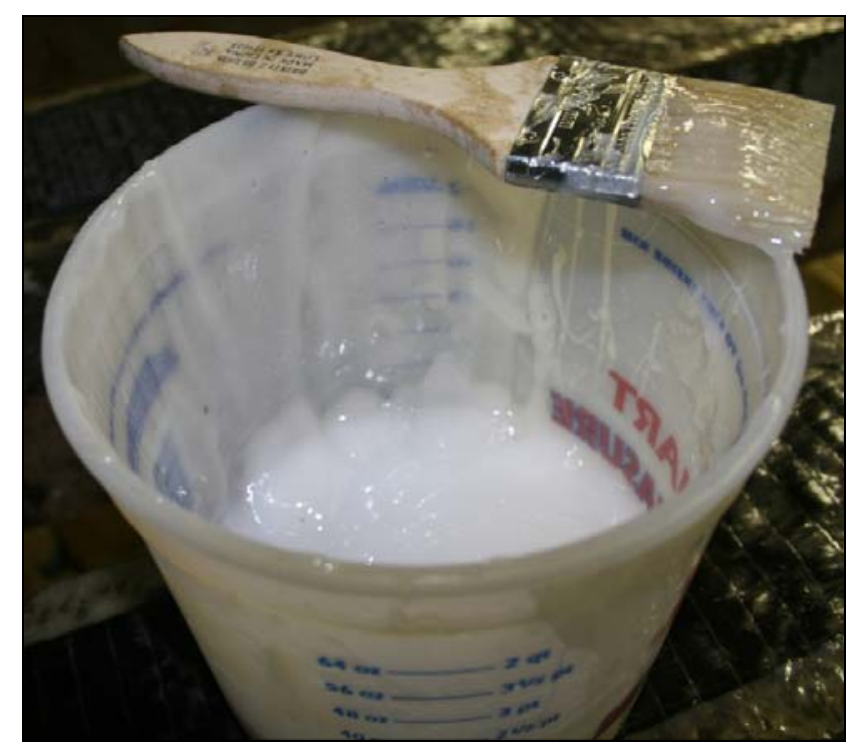

Figure 3.2: Epoxy resin used in this research

A vinyl ester is a thermosetting resin containing both vinyl and ester components, and cured by additional polymerization initiated by free-radical generation. Vinyl esters are used as binders for fiber laminates and adhesives. They have high mechanical properties and are highly resistant to many chemicals and contaminants.

\subsection{History of and Applications for FRP Composites}

Externally bonded FRP systems have been used to strengthen and retrofit existing concrete structures around the world since the mid 1980s. In 1967, bonding steel plates to the tension zones of concrete members with epoxy was shown to increase moment capacity. However, external steel plates were found to actively corrode. They were also 
difficult to install due to their weight. Therefore, researchers began searching for and experimenting with lighter and more inert materials with similar performance qualities of steel. Records indicate that FRP was first used to retrofit reinforced concrete structures in Germany in 1978, and was first used to strengthen reinforced concrete columns in Japan in 1981. In 1987, the first FRP system was applied to provide flexural strengthening to reinforced concrete bridges. The development of codes and standards has been an ongoing process in Europe, Japan, Canada, and the U.S., and codes are continually being modified and revised as more research is completed and verified (ACI 440-2R-02). ACI 440 currently provides the most widely accepted set of externallybonded FRP design standards in the U.S., but many standards have been developed and applied.

FRP has a variety of strengthening applications. It can be used to rehabilitate or restore strength to a deteriorated concrete member, to increase capacity to accommodate larger loads than the structure was designed or to compensate for construction errors. FRP systems have been used to structurally strengthen beams, slabs, columns, walls, joints/connections, chimneys, smokestacks, vaults, domes, tunnels, silos, pipes, trusses, masonry, timber, steel, and cast-iron structures. 


\subsection{Properties of FRP}

\subsubsection{Physical Properties}

\subsubsection{Density}

The density of FRP materials is four to six times lower than that of steel. As a result of using a lower-density material, transportation costs are lower, added dead load on the structure is reduced, and handling of the materials on the project site is easier (ACI 4402R-02).

Table 3.1 compares the density ranges of FRP materials to that of steel.

Table 3.1: Density range of FRP materials compared to that of steel (ACI 440-2R02)

\begin{tabular}{|l|c|c|c|c|}
\hline Material & Steel & GFRP & CFRP & AFRP \\
\hline Density $\left(\mathrm{lb} / \mathrm{ft}^{3}\right)$ & 490 & $75-130$ & $90-100$ & $75-90$ \\
\hline
\end{tabular}

\subsubsection{Coefficient of Thermal Expansion}

Table 3.2: Coefficients of thermal expansion for steel, concrete, and FRP materials (ACI 440-2R-02)

\begin{tabular}{|l|c|c|c|c|c|}
\hline \multirow{2}{*}{ Direction } & \multicolumn{5}{|c|}{ Coefficient of Thermal Expansion $\left(\mathrm{x} 10^{-6} /{ }^{\circ} \mathrm{F}\right)$} \\
\cline { 2 - 6 } & Steel & Concrete & GFRP & CFRP & AFRP \\
\hline Longitudinal, $\alpha_{\mathrm{L}}$ & \multirow{2}{*}{6.5} & \multirow{2}{*}{$4.0-6.0$} & $3.3-5.6$ & $-0.6-0.0$ & $-3.3--1.1$ \\
\cline { 1 - 4 } & & & $10.4-12.6$ & $12-27$ & $33-44$ \\
\hline
\end{tabular}

The coefficients of thermal expansion of unidirectional FRP materials differ in the longitudinal and transverse directions. Fiber type, resin, and volume fraction determine these thermal properties. The longitudinal and transverse coefficients of thermal 
expansion for typical FRP materials are presented in Table 3.2. A negative coefficient indicates contraction of the material as temperature increases (ACI 440-2R-02).

\subsubsection{High Temperature Effects}

Beyond the glass transition temperature, $T_{g}$, the elastic modulus of a polymer is significantly reduced due to changes in its molecular structure. The type of resin governs the value of $T_{g}$, which is typically $140-180^{\circ} \mathrm{F}$. The fiber can continue to support some load in the longitudinal direction until the temperature threshold of the fibers is reached. This can occur at temperatures near $1,800^{\circ} \mathrm{F}$ for glass fibers, $500^{\circ} \mathrm{F}$ for carbon, and $350^{\circ} \mathrm{F}$ for aramid fibers. It should be noted, however, that the tensile properties of the overall composite are reduced due to a reduction in force transfer between the fibers and the resin (ACI 440.2R-02). Kumahara (1993) showed that temperatures of $480^{\circ} \mathrm{F}$ reduced the tensile strength of GFRP and CFRP materials in excess of 20\%. Bending strength and other properties reliant upon the fiber-to-resin bond are reduced significantly at even lower temperatures (Wang and Evans, 1995).

\subsubsection{Mechanical Properties}

\subsubsection{Tensile Properties}

The tensile properties of FRP are linear elastic to failure without any plastic behavior before rupture. Direct tensile failure of FRP material alone is sudden and potentially catastrophic. The type, orientation, and quantity of fibers almost completely control the tensile properties of the material. FRP manufacturers report an ultimate strength defined 
as the mean tensile strength and ultimate rupture strain of at least twenty sample test specimens minus three times the standard deviation. Statistically, these ultimate tensile properties provide a $99.87 \%$ probability that the reported values are exceeded (ACI 4402R-02). The elastic modulus is calculated as the chord modulus between 0.003 and 0.006 strain (ASTM D 3039).

\subsubsection{Compressive Properties}

Externally bonded FRP should never be used for direct compressive strengthening. When subjected to longitudinal compression, transverse tensile failure, fiber microbuckling, or shear failure can occur, depending on the type of fiber, the fibervolume fraction, and the type of resin.

\subsubsection{Creep-Rupture Properties}

FRP materials can undergo brittle rupture when subjected to a load over time, a phenomenon known as creep-rupture. The amount of time required for such failure is called the endurance time, which decreases as the load increases, as temperature increases, and when the FRP is exposed to ultraviolet-radiation, high alkalinity, wet/dry cycles, or freeze/thaw cycles. 


\subsubsection{Fatigue Properties}

Carbon fiber material is the least likely FRP fiber material to be affected by direct-tension fatigue loading. Moisture and temperature effects in concrete structures rarely yield adverse effects CFRP materials.

\subsubsection{Thermal Properties}

Although the modulus of hardened epoxy resin is greatly reduced in the $140-180^{\circ} \mathrm{F}$ range, the carbon fibers themselves can withstand temperatures up to and above $500^{\circ} \mathrm{F}$. Due to the critical concrete-FRP bond that depends on the epoxy, however, externally bonded structural CFRP repairs may exhibit poor performance when exposed to extremely high temperatures.

Although the coefficients of thermal expansion for carbon fibers is near zero and the thermal expansion for polymer epoxy is about five times that of concrete, studies have shown that these differences do not disturb the bond when the temperature ranges are small $\left( \pm 50^{\circ} \mathrm{F}\right)$, as is the case with most FRP-repaired structure.

\subsection{Forms of FRP}

There are three primary types of commercially available externally bonded FRP systems: wet lay-up systems, prepreg systems, and pre-cured systems. 


\subsubsection{Wet Lay-Up Systems}

Wet lay-up systems are comprised of dry unidirectional or multidirectional fiber sheets which are impregnated with saturating resin, applied, and cured at the job site. Advantages of using wet lay-up include lack of geometrical limitations, minimal equipment investment, low tooling cost, low void content, and a simple cure process. The wet-lay-up procedure does have its disadvantages, though. The quality of the repair is highly dependent on skill of the workers, it is labor intensive, it yields a low production rate, the resins produce a high amount of volatile emissions, uniformity is difficult to maintain, and it often results in extensive curing times at room temperature (Barbero, 1999). A wet lay-up system using unidirectional fiber sheets was chosen for this research since it is the simplest process and is widely used in FRP bridge repair.

\subsubsection{Prepreg Systems}

Prepreg systems consist of uncured unidirectional or multidirectional fiber sheets which are impregnated with saturating resin by the manufacturer, delivered to the job site, and cured in place. Prepreg systems often require an external heating source for proper curing. Advantages of prepreg include high fiber volume fractions, uniform fiber distribution, and simplified manufacturing. Disadvantages are that the process is slow and labor intensive, and expensive curing equipment is required, resulting in a higher production cost (Barbero, 1999). 


\subsubsection{Pre-Cured Systems}

Pre-cured systems can come in a wide variety of shapes which are manufactured off-site. An adhesive, along with primer and putty, is used to bond these pre-cured systems to the concrete. Advantages of using a pre-cured system include lack of geometrical limitations, reduction of on-site labor, higher uniformity in FRP quality, and a higher production rate. Disadvantages include the requirement of highly-skilled workers, the necessity of safe transportation of large and thin cured FRP plates, and the high emission of volatiles during installation.

\subsubsection{Other Forms of FRP}

Other forms of FRP include cured FRP rigid rod and flexible strand or cable. These are often used internally in reinforced concrete. FRP rebar and cable can be inserted into the concrete member and then encased in concrete, or can be near-surface mounted. Nearsurface mounting is performed by saw-cutting a shallow grove into the concrete face, inserting the bars or cables into the grove and bonding to the concrete with grout, and filling in the rest of the grove with putty or concrete. This research, however, focuses on externally-bonded FRP applications.

\subsection{Durability of FRP}

Perhaps the most significant drawback of FRP strengthening is the unknown long-term performance and durability of the repair. Little complete long-term durability research exists for FRP repair, but much ongoing research on this issue is currently being 
conducted. Because of this, it is difficult, if not impossible, to accurately predict the service life of an FRP system. To account for this uncertainty, conservative reduction factors are included in ACI 440.2R. Investigation into the durability FRP as a material itself is not within the scope of this research and will be further studied by researchers at WVU in the near future.

\subsection{Other Considerations when Working with FRP}

\subsubsection{Shipping}

It should be ensured that FRP fibers are kept clean and free from damage during shipping. Epoxy must be kept in airtight containers and remain unopened. Materials for an FRP system packaged and shipped in a manner that conforms to all applicable federal and state packaging and shipping codes and regulations. Many resins are classified as corrosive, flammable, or poisonous under hazardous materials regulations.

\subsubsection{Storage}

FRP materials must be stored according to the manufacturer's recommendations. Some constituent chemicals of FRP systems must be stored separately, so care must be taken to read all instructions when materials are received.

The manufacturer specifies a recommended shelf life during which the properties of the resins and other constituent materials should continue to meet or exceed the reported performance criteria. Time, temperature, or humidity can change the properties of the 
uncured resin components, which in turn can affect the reactivity of the mixed system and the uncured and cured properties. Therefore, it is imperative that any material which has deteriorated, in which the shelf life has been exceeded, or which has been contaminated should not be used. FRP materials deemed unusable should be disposed of in a manner specified by the manufacturer and acceptable to state and federal environmental control regulations (ACI 440-2R-02).

\subsubsection{Handling}

Material safety data sheets (MSDS) for all FRP constituent materials and components must be obtained from the manufacturers and must be accessible at the job site. ACI $503 \mathrm{R}$ is specifically noted as a general guideline for the safe handling of epoxy compounds. ICRI and OSHA also produce and administer safety literature. Thermosetting resins are very complex, so clear understanding of safety information by laborers is essential.

Thermosetting resins present the following hazards when handling: skin irritation, skin sensitization (an allergic reaction similar to that caused by poison ivy, building insulation, or other allergens), respiratory irritation from breathing organic vapors from cleaning solvents, monomers, and dilutents, explosion or fire of flammable materials when exposed to heat, flames, pilot lights, sparks, static electricity, cigarettes, or other sources of ignition, exothermic reactions of mixtures of materials causing fires or personal injury; and nuisance dust caused by grinding or handling of the cured FRP materials. ANSI Z- 
129.1 provides further guidance regarding classification and precautions (ACI 440-2R02).

Disposable suits and gloves should be used when handling fiber and resin materials and should be discarded after each use. Safety glasses or goggles should be used when handling resin components and solvents. Respiratory protection, such as dust masks

should be used when fiber fly, dust, or organic vapors are present. Respirators are strongly recommended during mixing, handling, and placing of resins. The manufacturer can be contacted for specific information (ACI 440-2R-02).

A well-ventilated work area is required when using epoxy resins. Fans or other temporary methods of ventilation should be installed when necessary. Work surfaces should be covered as needed to protect against contamination and resin spills when specified by the manufacturer.

\subsubsection{Contractor Competency}

As stated in ACI 440-2R-02, “The FRP system installation contractor should demonstrate competency for surface preparation and application of the FRP system to be installed. Contractor competency can be demonstrated by providing evidence of training and documentation of related work previously completed by the contractor or by actual surface preparation and installation of the FRP system on portions of the structure. The FRP system manufacturer or their authorized agent should train the contractor's 
application personnel in the installation procedures of their system and ensure they are competent to install the system."

\subsubsection{Temperature, Humidity, and Moisture}

Temperature, relative humidity, and surface moisture at the time of installation can significantly affect the performance of the FRP system. Concrete surface temperature, air temperature, relative humidity, and dew point should be observed and reported before, during, and after FRP repair.

Primers, saturating resins, and adhesives generally should not be applied to cold or frozen surfaces. When the concrete surface temperature is below the minimum level specified by the manufacturer, improper saturation of the fibers and improper curing of the resin constituent materials can occur. If work cannot be postponed, an external heat source should be used to raise the ambient and surface temperature during installation.

Most resins and adhesives cannot be applied to damp or wet surfaces. FRP systems should not be applied to concrete surfaces that are subject to moisture vapor transmission, as this often causes surface bubbles and subsequent damage of the FRP-to-concrete bond.

\subsubsection{Quality Control}

Test data provided by the manufacturer demonstrating mechanical and physical design requirements including tensile strength, durability, resistance to creep, bond to substrate, and glass transition temperature should be used, but should not be the exclusive basis for 
qualification. In fact, FRP composite systems that have not been fully tested independently to check these reported properties should not be considered for use. Mechanical properties of FRP systems should be determined from tests on laminates manufactured using the same procedures as are used field installation. Modifications of standard testing procedures may be needed to simulate field conditions. Sufficient laboratory testing must be completed to measure the repeatability and reliability of critical properties. Testing of multiple batches of FRP materials is recommended (ACI 440-2R-440).

During the installation of the FRP system, daily inspection should be conducted and should include the following: date and time of installation, ambient temperature, relative humidity, general weather observations, surface temperature of concrete, surface dryness per ACI 503.4, surface preparation methods and resulting profile using the ICRI-surfaceprofile-chips, qualitative description of surface cleanliness, type of auxiliary heat source, if applicable, widths of cracks not injected with epoxy, fiber or pre-cured laminate batch numbers and approximate location in structure, batch numbers, mixture ratios, mixing times, and qualitative descriptions of the appearance of all mixed resins, including primers, putties, saturants, adhesives, and coatings mixed for the day, observations of progress of cure of resins, conformance with installation procedures, pull-off test results such as bond strength, failure mode, and location, FRP properties from tests of field sample panels or witness panels, if required, location and size of any delaminations or air voids, and general notes on the progress of work (ACI 440-2R-02). 
It is the duty of the inspector to provide the engineer or owner with the needed inspection records and witness panels. It is recommended that the records and witness panels be retained for a minimum of 10 years or a period specified by the engineer. The installation contractor should retain sample cups of mixed resin and maintain a record of the placement of each batch (ACI 440-2R-02).

FRP systems should be evaluated and accepted or rejected based on conformance or nonconformance with the design drawings and specifications. Witness panel and pull-off tests should be used to evaluate the installed FRP system. In-place load testing can also be used to confirm the installed behavior of the FRP strengthened member (ACI 440-2R02).

Evaluation of FRP materials are usually performed on material samples sent to a laboratory and can include tests for tensile strength, infrared spectrum analysis, glass transition temperature, gel time, pot life, and adhesive shear strength. Tests for pot life of resins and curing hardness are usually conducted on-site (ACI 440-2R-02).

Fiber or pre-cured-laminate orientation should be evaluated by visual inspection. Fiber or pre-cured laminate misalignment of more than 5 degrees from that specified on the design drawings should be reported to the engineer for evaluation and acceptance (ACI 440-2R-02).

The cured FRP system should be evaluated for delaminations or air between multiple plies or between the FRP system and the concrete voids measuring $2 \mathrm{in}^{2}$ or greater. 
Hammer sounding, ultrasonics, and thermography are typically used to detect delaminations. General acceptance guidelines for wet lay-up systems are

- Small delaminations less than $2 i n^{2}$ are permissible as long as the delaminated area is less than $5 \%$ of the total laminate area and there are no more than 10 such delaminations per $10 f t^{2}$.

- Large delaminations, greater than $25 \mathrm{in}^{2}$ can affect the performance of the installed FRP and should be repaired by selectively cutting away the affected sheet and applying an overlapping sheet patch of equivalent plies; and

- Delaminations less than $25 \mathrm{in}^{2}$ may be repaired by resin injection or ply replacement, depending on the size and number of delaminations and their locations (ACI 440-2R-02).

The cure of FRP systems can be evaluated by testing witness panels or resincup samples according to ASTM D 3418. Physical observation of resin tackiness and hardness of work surfaces or hardness of retained resin samples are also useful (ACI 440-2R-02).

Cure thickness can be obtained by extracting small core sample, usually $1 / 2$ " in diameter (ACI 440-2R-02).

Table 3.3 provides a summary of all applicable standard testing procedures used for the quality control of an FRP system. 
Tension adhesion strengths should be tested for bond-critical applications and should exceed 200 psi and exhibit failure of the concrete substrate (ACI 440-2R-02).

Table 3.3: Summary of standard testing procedures used for quality control of an FRP system

\begin{tabular}{|c|c|c|}
\hline FRP fom & Property & Test method \\
\hline \multirow{8}{*}{$\begin{array}{l}\text { Sheet and } \\
\text { prepreg }\end{array}$} & $\begin{array}{l}\text { Tensile strength, strain } \\
\text { elastic modulus }\end{array}$ & ISIS, ASTM D 3039 \\
\hline & Sheet to sheet-adhesive shear & ISIS \\
\hline & Sheet to concrete-adhesive shear & ISIS \\
\hline & Sheet to concrete-adhesive tension & ISIS \\
\hline & Coefficient of themal expansion & ASTM D 696 \\
\hline & Glass-transition temperature & ASTM D 4065 \\
\hline & Surface hardness & $\begin{array}{c}\text { ASTM D } 2583, \text { D } 2240, \\
\text { D } 3418\end{array}$ \\
\hline & Hoop-ring strength & ISIS \\
\hline \multirow{7}{*}{ Flat stock } & $\begin{array}{l}\text { Tensile strength, strain, } \\
\text { elastic modulus }\end{array}$ & ISIS, ASTM D 3039 \\
\hline & Flatstock to flatstock-adhesive shear & $\begin{array}{l}\text { ISIS, ASTM D } 3165 \text {. } \\
\text { D } 3528\end{array}$ \\
\hline & Flatstock to concrete-adhesive shear & ISIS \\
\hline & Flatstock to concrete-adhesive tension & ISIS \\
\hline & Coefficient of themal expansion & ASTM D 696 \\
\hline & Glass-transition temperature & ASTM D 4065 \\
\hline & Surface hardness & \begin{tabular}{|c|} 
ASTM D 2583, D 2240, \\
D 3418 \\
\end{tabular} \\
\hline \multirow{6}{*}{$\begin{array}{l}\text { Pre- } \\
\text { molded } \\
\text { shell }\end{array}$} & $\begin{array}{c}\text { Tensile strength, strain, elastic } \\
\text { modulus }\end{array}$ & ISIS, ASTM D 3039 \\
\hline & Shell to shell-adhesive shear & $\begin{array}{l}\text { ISIS, ASTM D } 3165 \text {, } \\
\text { D } 3528\end{array}$ \\
\hline & Shell to concrete-adhesive shear & ISIS \\
\hline & Shell to concrete-adhesive tension & ISIS \\
\hline & Coefficient of themal expansion & ASTM D 696 \\
\hline & Glass-transition temperature & ASTM D 4065 \\
\hline
\end{tabular}

\subsubsection{Maintenance and Repair}

A visual inspection looks for color changes, debonding, peeling, blistering, cracking, crazing, deflections, indications of reinforcing-bar corrosion, and other anomalies. Ultrasonic, hammer tapping, or thermographic tests may indicate signs of progressive 
delamination. Pull-off tension tests or conventional structural loading tests are often conducted during an inspection of an FRP system (ACI 440-2R-02).

The cause of damage, type of material, form of degradation, and level of damage governs the required method of repair.

Minor damage would include localized FRP cracking or abrasions that affect the structural integrity, any of which should be repaired by bonding FRP patches over the damaged area. Some minor delaminations may be epoxy injected. Major damage, including peeling and debonding of large areas, may require removal of the affected area, reconditioning of the cover concrete, and replacement the FRP.

\subsubsection{Temporary Protection}

Adverse temperatures, rain, dust, dirt, excessive sunlight, high humidity, or vandalism can damage an FRP system during installation and cause improper cure of the resins. Therefore, temporary protection, such as tents and plastic screens, may be required during installation and until the FRP system has cured. 


\section{Chapter 4: Bridge Repair and Rehabilitation}

\subsection{Overview of Current Methods}

\subsubsection{Concrete Repair}

When evaluating a reinforced concrete structure, it is essential to identify the locations and extent of concrete cracking, spalling, and delamination, the mechanical properties of the concrete, and the condition of the reinforcing steel. Next, it is important to investigate and understand the sources of the degradation observed within the structure and develop methods to reduce or eliminate those sources. Finally, the objectives of the repair must be decided. ACI (2003) defines seven primary objectives of concrete repair from which an engineer can select one or more for a given application: 1.) restore and increase strength, 2.) restore and increase stiffness, 3.) improve functional performance, 4.) provide watertightness, 5.) improve appearance of the concrete surface, 6.) improve durability, and 7.) prevent development of corrosive environment at reinforcement level.

\subsubsection{Repair with Concrete or Mortar}

Repair of deteriorated concrete with new concrete or mortar, or concrete patch repair, is the most common repair technique for bridge components. It can be used to repair damage caused by impact, cracking, spalling, delamination, reinforcement corrosion, and chemical contamination. The first step in performing a patch repair is the removal of 
damaged or contaminated concrete. This can be accomplished by jack hammering, chiseling, or high-pressure water-jetting. Care must be taken, however, to not damage the existing concrete that is intended to remain. If more than half the perimeter of reinforcing steel is exposed, or if the steel is corroded, the concrete should be removed from behind the reinforcement to a depth larger than the largest aggregate in the repair material. Next, the perimeter of the area to be repaired is cut using a masonry saw to a depth of about $1 / 2$ " to prevent feather edges in the repair material. If the perimeter was not saw-cut, these edges could rapidly dry and result in an inadequate bond. The concrete surface within the repair area must be carefully cleaned to remove all loose material, dust, and other contaminants. Figure 4.1 shows one minor and one major zone of removed concrete with a neatly cut perimeter. These photos were taken during field repair of PennDOT Bridge \#49-4012-0250-1032.

Bonding agents are sometimes applied to the existing concrete prior to repair to improve the adhesion between the existing and the repair materials. The most common type of bonding agents are polymer slurries mixed with mortar that are often applied by hand. The repair material should be placed while the bonding agent is still tacky to prevent bond failure.

When a bonding agent is not used, it is good practice to saturate the concrete within the repair area. No free water should be left on the surface. By saturating the concrete, the suction of water from the repair to the existing concrete is reduced. If the existing 
concrete was left dry, it would likely suction away water from the repair material and result in a weak layer of repair concrete at the interface of the two materials.
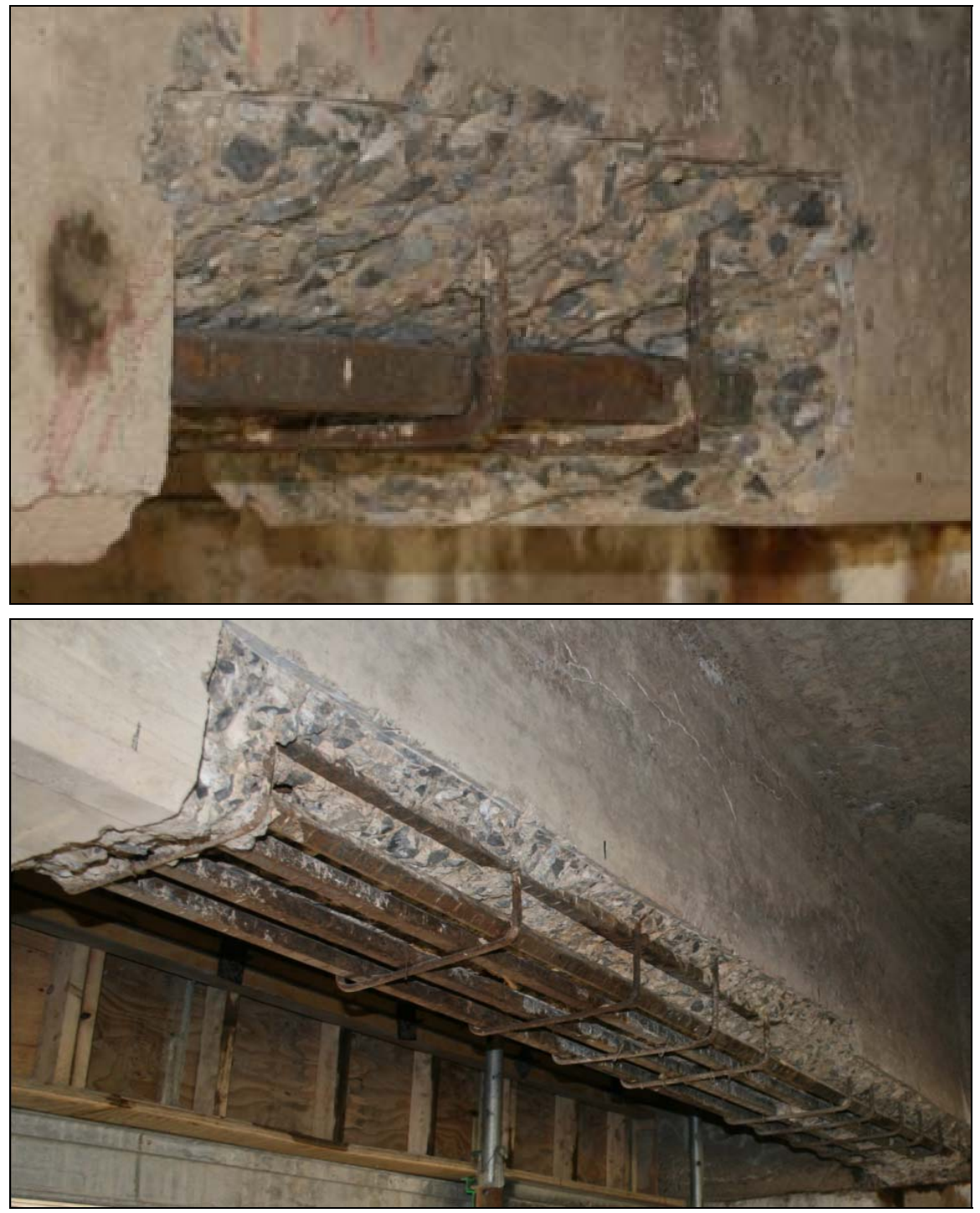

Figure 4.1: Examples of neat concrete removal on PennDOT Bridge \#49-4012-0250-1032 girders

New concrete or mortar is added in place of the old by hand-application, pouring and forming, pumping, or spraying. Hand-application with mortar is generally used for small repairs, conventional concrete or sprayed concrete is normally used for larger repairs, and 
free-flowing concrete can be used on vertical surfaces. Examples of the types of formwork constructed for both minor and major concrete repair can be seen in Figure 4.2, in which the photos were also taken from PennDOT Bridge \#49-4012-0250-1032 field repair.
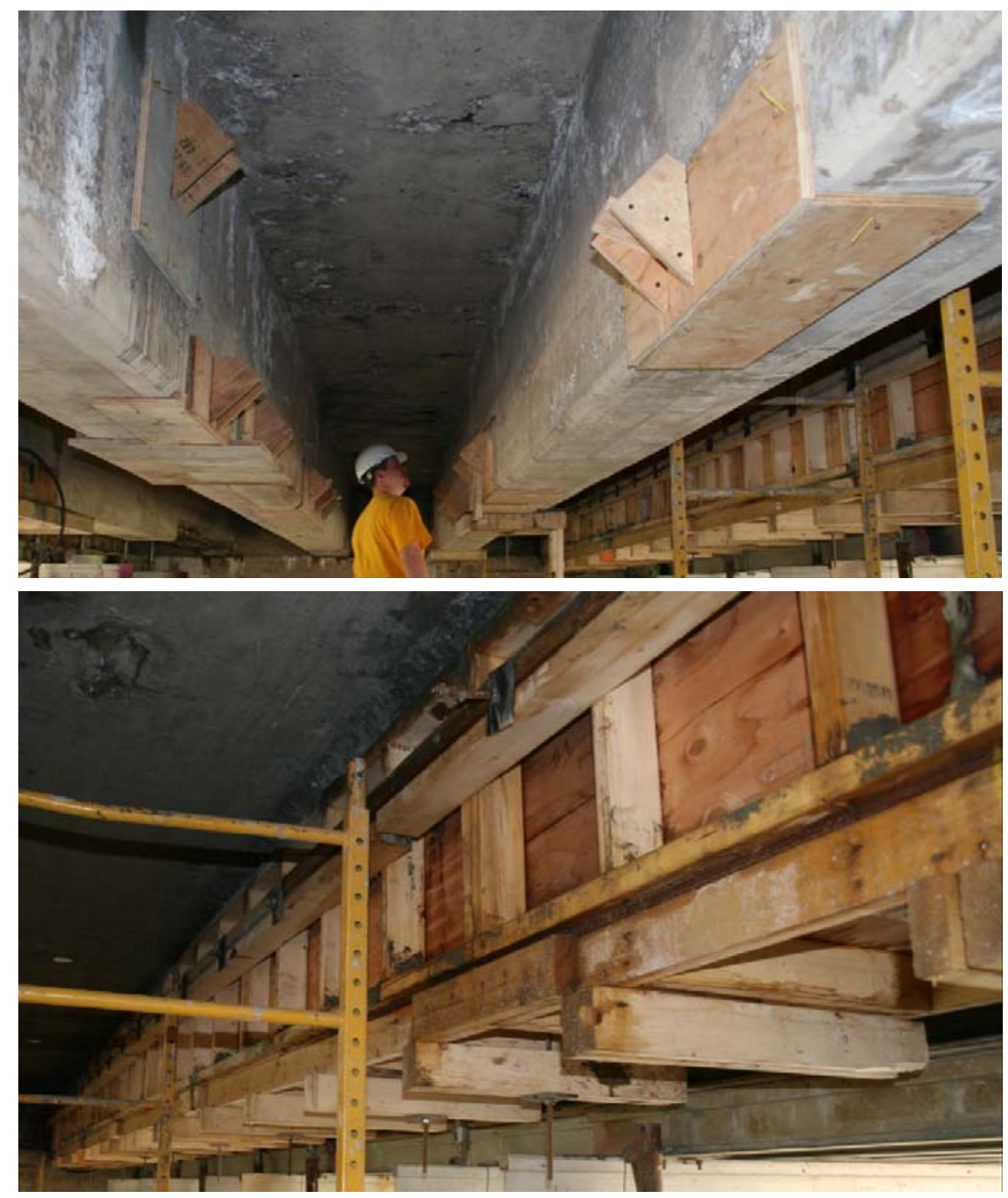

Figure 4.2: Examples of formwork required for both minor and major concrete patch repairs

Self-consolidating concrete is often used in patch repair so that vibration is not required and so the material can be easily compacted into corners and around reinforcing steel. 


\subsubsection{Polymer Concrete Repair}

Polymer concrete is often desirable for patch repairs due to its low permeability. Polymer concrete patch repairs are often applied by hand. Thick repairs are built up in layers that are allowed to reach initial set before the next layer is placed. It is good practice to roughen the surface of each layer to increase bond.

\subsubsection{Crack Injection}

Epoxies, polyesters, methacrylates, and polyurethanes have all been used to fill cracks in concrete structures. The governing factors that determine the appropriate filling material are crack width, whether structural bond is necessary, and whether the crack is live. A "live" crack continues to open and/or close under the action of loading or thermal and shrinkage effects (ACI, 2003).

While some cracks in bridge repair can be filled using a gravity-fed system, most are filled using pressurized equipment. For pressure injection, ports must first be placed at required intervals along each crack. Ports can be installed at the crack surface or inserted through drilled holes. The portions of the crack away from the injection ports must be sealed with putty. Epoxy can be injected via a hand gun or a mechanical pump. The injection equipment is first attached to the port along the crack that is lowest in elevation. Injection continues until a consistent continuous flow is observed out of the next highest port. The injection equipment is then removed from the lower port and the lower port is sealed. The injection equipment is inserted in the next highest port and the process is repeated until all portions of the crack are filled (see Figure 4.3). 


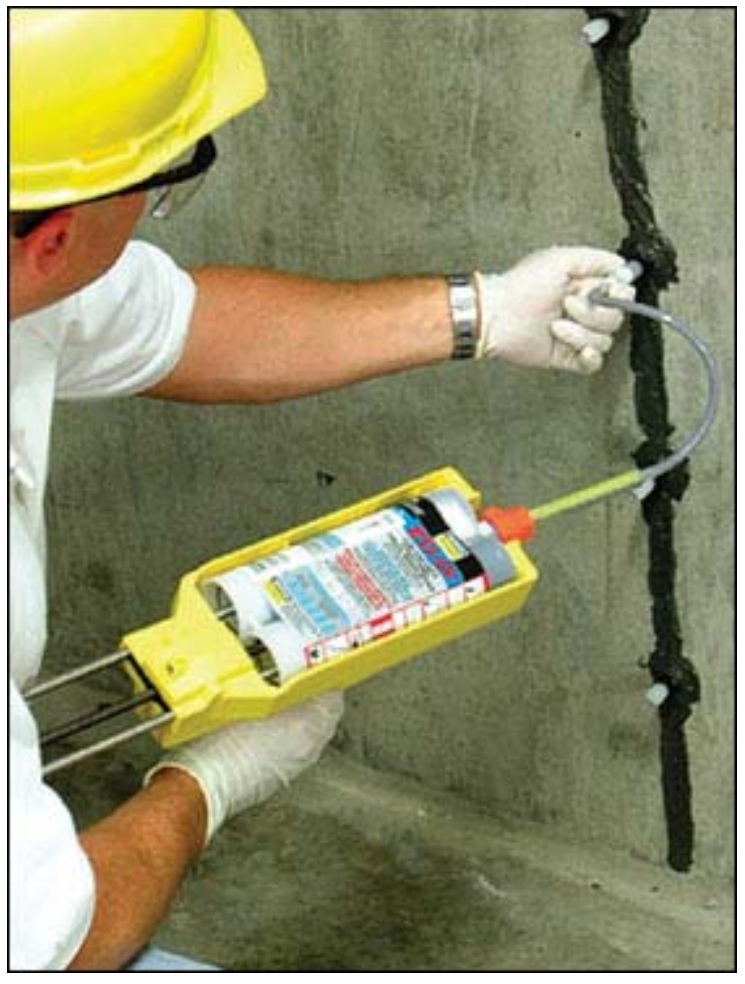

Figure 4.3: Epoxy crack injection (www.simpsonanchors.com)

Perhaps a preferred alternative to conventional pressure injection is negative pressure vacuum injection. First ports are inserted at intervals along the crack as described above. For the negative pressure vacuum injection method, however, a vacuum is connected to all ports except for one which is connected to a reservoir of mixed resin. The vacuums are allowed to suck the resin into the crack, and when a steady flow of resin appears in an adjacent port, the first port is sealed and the resin source is moved to the adjacent port. This process is continued until all portions of the crack are injected. This alternative method is sometimes preferred because it is easier to control and is less damaging to the structure. 


\subsubsection{Coatings and Sealers}

There are three primary types of material that are used to seal concrete and prevent ingress of contaminants: film-forming coatings, pore liners/blockers, and sealers. Filmforming coatings typically consist of epoxies, acrylics, polyurethanes and polymercement slurries and are used to provide a physical barrier on the concrete surface. Pore liners/blockers have a low viscosity and penetrate minute capillary pores where they solidify and form "plugs" which physically block the pores. Pore liners/blockers are beneficial since they do not affect the aesthetic appearance of the concrete. Sealers contain penetrating solvents but also form a thin film on the concrete surface. Mostly all coatings can be applied using either brush, roller, or spray.

\subsubsection{Steel Reinforcement Repair}

\subsubsection{Cleaning}

When concrete patch repair is implemented, steel reinforcement bars must first be cleaned to remove adhered contaminants from the steel surface. If these bars are not cleaned, the source of the corrosion is not removed and the steel will continue to actively corrode and will eventually destroy the concrete patch. Cleaning the reinforcement bars also promotes adhesion between the steel and the concrete.

Reinforcing steel is typically cleaned by some mechanical method. Wire wheel brushes can be used for small jobs, but abrasive blasting is preferred. It is recommended by ACI that, prior to patch repair, steel is cleaned down to a white metal surface. 


\subsubsection{Rebar Splicing}

If corrosion has caused significant section loss of reinforcing steel, new portions of steel rebar may need to be added it its place. This can be done by tying in new sections of steel rebar to restore the member to its original or to a desired capacity. All standards and specifications must be followed to ensure that the splice lengths, tying procedures, and subsequent concrete patching procedures are appropriate.

On beams being retrofitted with FRP, steel rebar addition may still be needed. This is because, in an FRP design, the FRP should not be relied upon completely. If the FRP fails, it should not lead to the brittle and catastrophic failure of a structure. By replacing some of the missing steel before patch repair (where applicable), a more ductile failure mode will likely result. If additional steel is added prior to an FRP retrofit, however, it should be checked that the cumulative effect of the repair materials will not yield an over-reinforced concrete member.

\subsubsection{Coatings}

A fusion-bonded epoxy coating is most suitable for steel rebar in concrete structures. Fusion bonded coatings, which consist of thermoset polymers in powder form, provide a cross-linked molecular matrix and undergo an irreversible chemical reaction that causes them to strongly adhere to the steel. This method of coating, however, is difficult to perform in field applications since temperatures of $360-480^{\circ} \mathrm{F}$ are needed to initiate the reaction. 
As an alternative, liquid epoxy coatings are available in industry. Most of these two-part epoxies can be mixed and then painted onto the steel. Product specifications must be carefully reviewed when choosing an epoxy coating to ensure that the coating is nonpermeable, non-conductive, and compatible with alkaline solutions present in concrete.

One must be careful when using epoxy coatings on rebar. Due to an incipient anode effect, if any part of the coating becomes damaged and even a small area of steel is exposed, corrosion can be accelerated in that location. A small area of accelerated corrosion can lead to a "domino effect", and the corrosion area can spread. This incipient anode effect is explained in an earlier section of this paper.

\subsubsection{FRP Repair}

When using any type of FRP system, it must first be ensured that a sound concrete substrate is provided onto or into which to apply the FRP. The FRP-concrete bond is essential for the success of the FRP system and for the safety of those traveling over the structure. Bond failures are the most commonly reported mode of FRP failure in research, and since the FRP and epoxy materials are generally stronger than the concrete to which they are bonded, failure usually occurs first in the concrete substrate layer. Concrete repair techniques required for most FRP repairs were discussed earlier in this chapter. 


\subsubsection{FRP Fabric}

Bridge repair with FRP fabric sheets involves first applying an epoxy primer coat to the prepared concrete substrate. Next, dry FRP fabrics are saturated in epoxy and placed onto the tension face of the bridge girder. It is essential that the FRP fabrics are completely saturated allowing no air voids so that proper bond is achieved and potential areas of stress concentration in a cured system are eliminated. Likewise, when placing the FRP via the wet lay-up method, it is important to remove all air bubbles. After placement, the FRP system should be allowed to cure according to manufacturers' specifications. Since repair with FRP fabric was used for this research, more extensive details are provided in Chapter 5.

\subsubsection{FRP Plates}

The application of a precured FRP system is similar to that of FRP sheets. FRP plates are essentially FRP fabric that has already been impregnated and cured by the manufacturer. First, a primer coat is applied to a sound concrete substrate. Next, the plates are cut to the desired dimensions and are placed onto the concrete member with epoxy adhesives. The systems are finally allowed to cure according to manufacturers' specifications.

\subsubsection{Near Surface Mounted (NSM) FRP Bars}

NSM bars are made of the same constituents as the FRP described above, but they are long and cylindrical like rebar. The first step when installing NSM bars is neatly cutting a shallow groove into a sound concrete substrate using a diamond-blade saw. Next, an 
embedding paste is used to half-fill the grooves. The bars are then lightly pressed into the groves so that the embedding paste completely fills the space between the FRP and the groove. Additional paste is placed to completely fill the groove, and the surface of the repair is leveled.

\subsubsection{Electrochemical Maintenance and Repair}

\subsubsection{Cathodic Protection - Sacrificial Anode}

Since the 1970 's, cathodic protection has been used to reduce corrosion in reinforced concrete structures. One method of cathodic protection is by the use of a sacrificial anode. In this method, a "sacrificial" metal with a higher galvanic corrosion potential is attached to the structure. A chart showing the galvanic series can be seen in Figure 4.4. The metals listed become less reactive as the chart is followed from top to bottom.

Since the sacrificial metal is more reactive than the steel reinforcement, the steel actually becomes the cathode and the sacrificial metal becomes the actively corroding anode. Common sacrificial metals used to protect steel are zinc and magnesium. In reinforced concrete structures, the sacrificial anode must be spread out and distributed over the concrete surface due to concrete's poor conductive properties. Some common forms of sacrificial anode material are mesh or conductive coatings.

One must be careful when using certain sacrificial anode techniques to protect steel, such as a zinc coating. Because of an incipient anode effect, accelerated corrosion can take place in adjacent areas of the steel if the entire bar is not coated. Also, as with 
conventional steel coatings, if a sacrificial anode coating becomes damaged, accelerated corrosion can occur. The incipient anode effect is described in an earlier section of this paper.

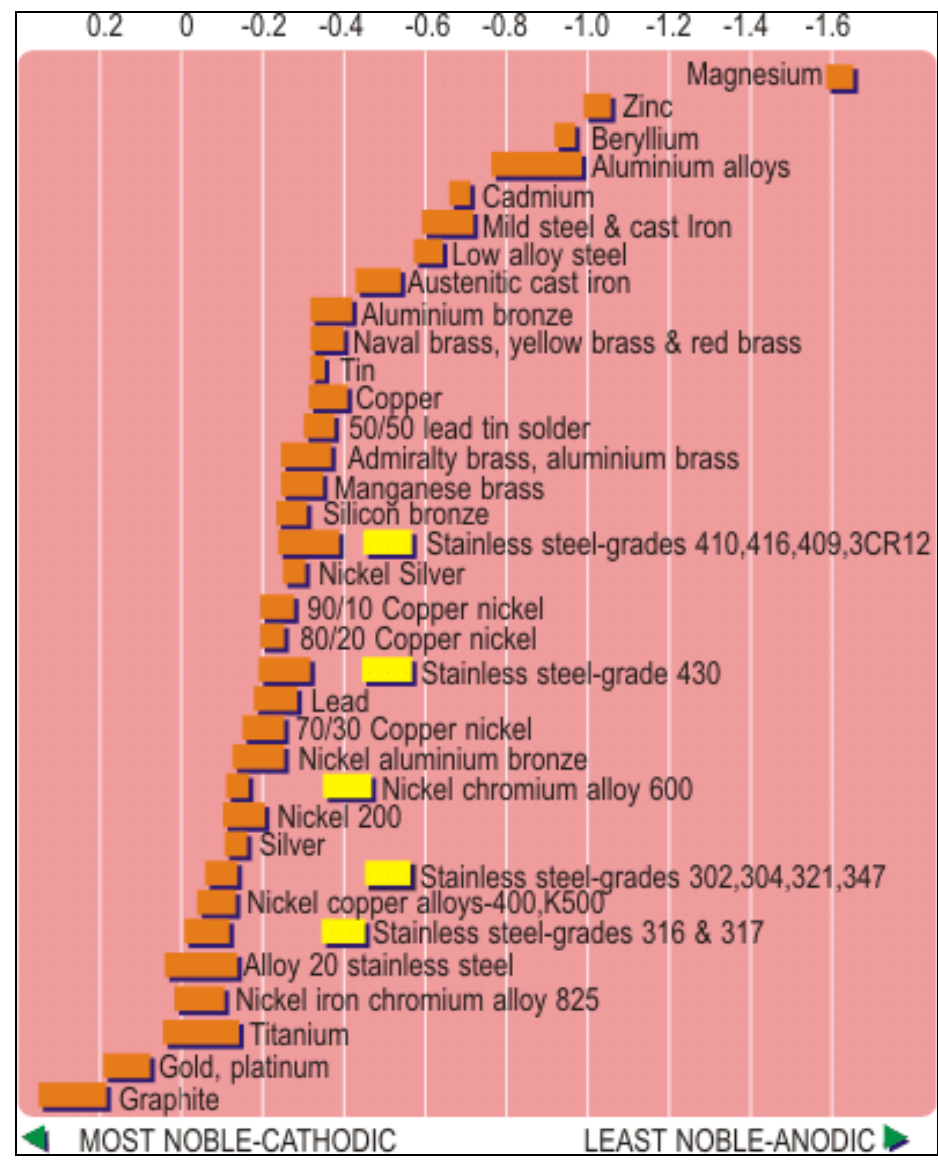

Figure 4.4: Galvanic Series (aZo)

\subsubsection{Cathodic Protection - Impressed Current}

Cathodic protection can also be achieved by an impressed current method. In this method, a direct current power supply is attached with the negative lead to the reinforcing steel and the positive lead to the anode material. Even an inert "anode material" can be used because it is kept in an anodic state in relation to the structure. As mentioned previously, the anode material must be spread out over the surface of the concrete in 
either the form of a mesh or a coating. It is interesting to note that the cathodic protection procedure is the exact reverse of the accelerated aging procedure that is described later in this paper.

\subsubsection{Electrochemical Chloride Extraction}

Although Electrochemical Chloride Extraction (ECE) was not used in this research project, it will be discussed in great detail in this section. This is because, after an extensive literature review, the West Virginia University research team believes that ECE prior to FRP repair has the potential to bring more confidence and long-term success to a strengthened regular reinforced concrete structure. This is because ECE removes the "source" of the corrosive activity, free chloride ions, instead of just the "symptoms". It is a relatively new technology and has been performed with great success as will be illustrated. A laboratory-scale experiment to study the advantages of combining ECE with FRP repair has been designed and will be implemented later in this project by another graduate student.

Electrochemical chloride extraction is similar to cathodic protection, only higher currents are used and the process only lasts for eight weeks. The total amp-hours applied through an ECE system in 8 weeks is the equal to that applied via cathodic protection over a period of ten years. ECE is advantageous over cathodic protection since it does not require continuous maintenance and monitoring of a power supply and wiring system throughout the life of a structure. ECE has been used mostly in bridge decks, but has also been applied to girders, capbeams, and columns. To perform ECE, damaged concrete 
must first be removed and patch repaired. Steel or titanium mesh (functioning as the cathode) is wrapped around the beam, while wooden spacers are used to suspend the mesh about an inch above the concrete surface ensuring that the concrete and the mesh itself do not make direct contact. Next, a power supply is connected to the system with the positive lead connected to the cathode mesh and the negative lead connected to exposed reinforcing steel. Only the reinforcing steel continuous with the section attached to the power supply will benefit from the ECE process.

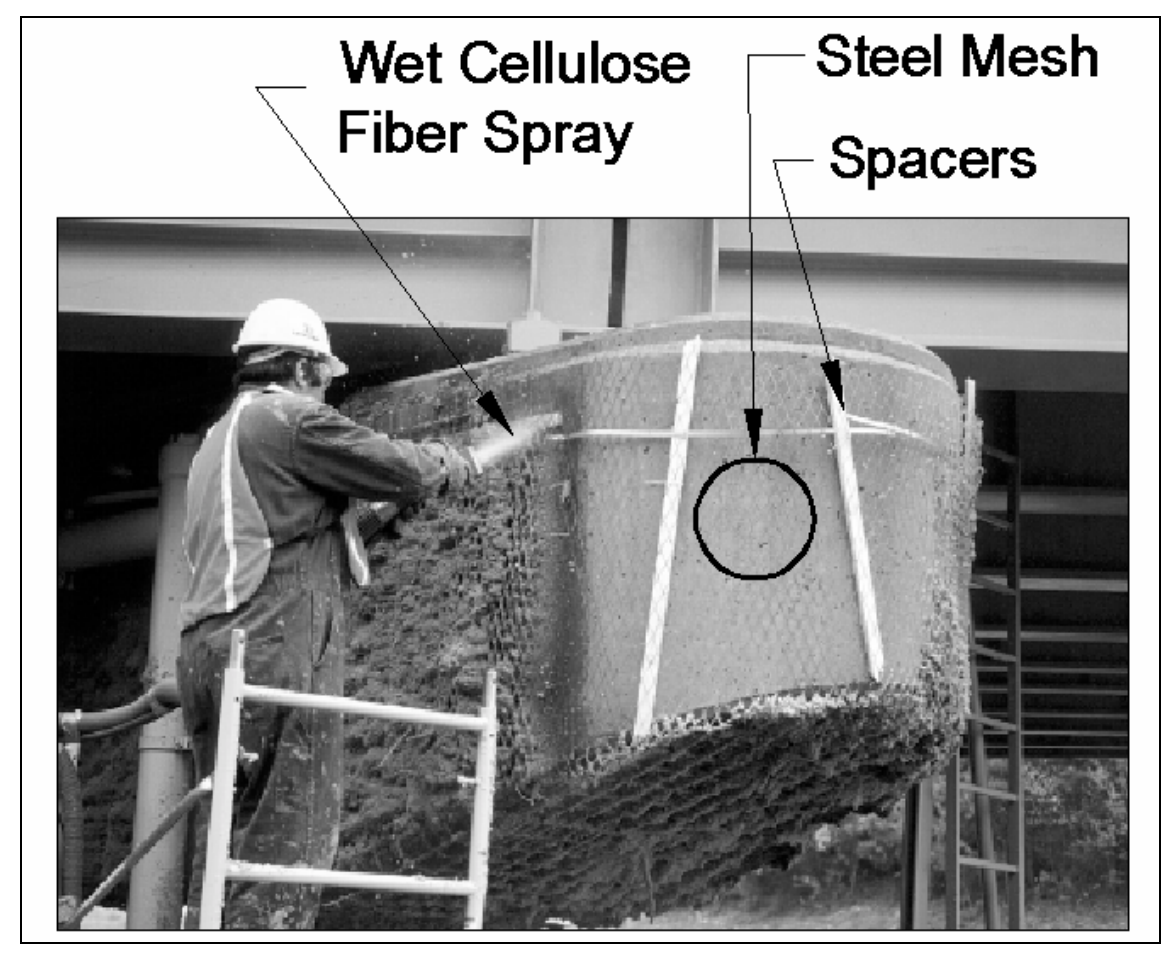

Figure 4.5: ECE setup in progress on a pier capbeam in Charlottesville, VA (Clemena, 2000)

Next, wet cellulose fibers are sprayed over and through the mesh so that electrical contact between the mesh and the concrete is ensured (see Figure 4.5). The water held by the wet cellulose fibers serves as the electrolyte. Finally, the mesh / wet cellulose fiber matrix is wrapped with plastic to prevent the escape of moisture (see Figure 4.6). It is extremely 
important to keep the electrolyte wet and non-acidic to prevent the formation of chlorine gas during the ECE process. ECE is feasible for a chloride/hydroxyl ion ration $\left(\mathrm{Cl}^{-} / \mathrm{OH}^{-}\right)$ of less than 0.61 , the threshold limit for corrosion of steel reinforcement in concrete.

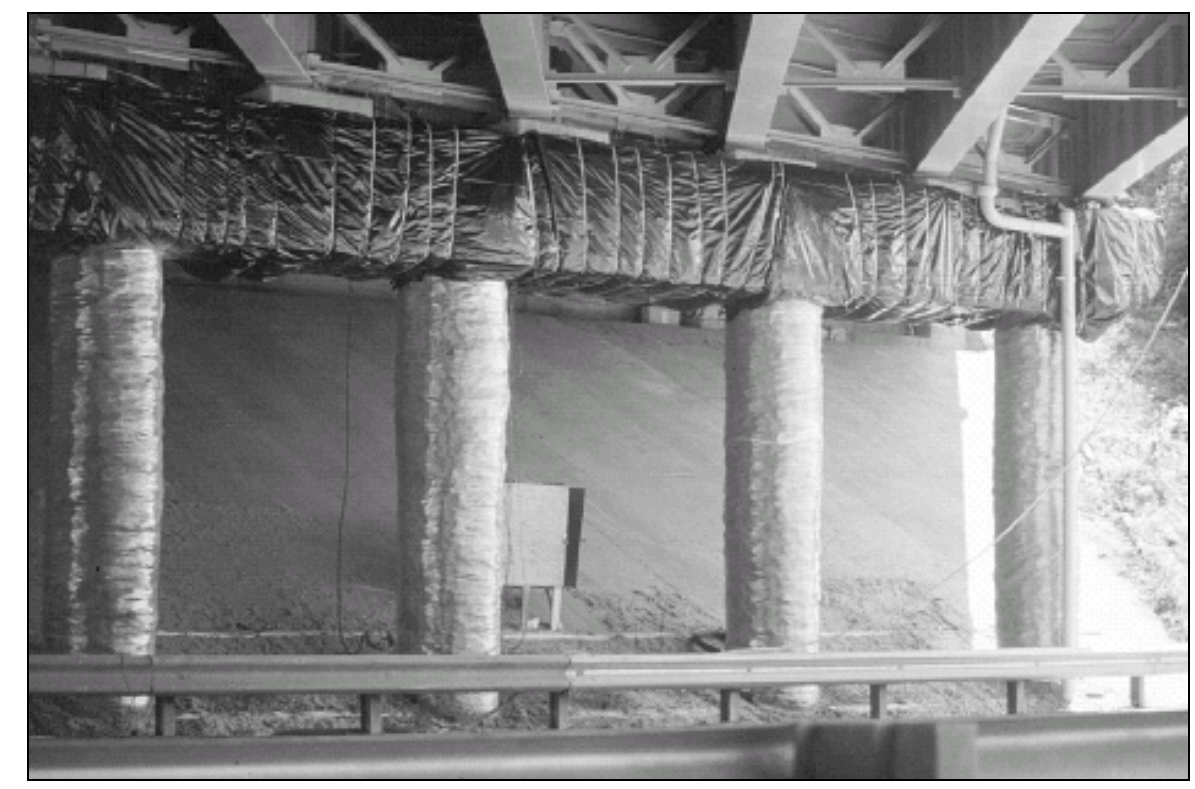

Figure 4.6: Completed ECE setup on pier columns and their capbeam in Charlottesville, VA (Clemena, 2000)

When the current $\left(1.0 \mathrm{~A} / \mathrm{m}^{2}-5.0 \mathrm{~A} / \mathrm{m}^{2}\right)$ is applied to the system, chloride ions are repelled from concrete regions surrounding the reinforcing steel due to the negative lead-to-anode/ positive lead-to-cathode wiring scheme (which is the opposite of the wiring scheme used to induce corrosion). This phenomenon occurs for the same reason that similar poles of a magnet repel. Consequently, electrolysis occurs at the surface of the reinforcing steel and produces a highly alkaline environment.

Research has proven ECE effective in both the laboratory and the field. Clemena, 2000 reported $33-76 \%$ of the chlorides were removed from regions surrounding the reinforcing 
steel in a laboratory experiment simulating bridge decks (Clemena, 2000). In a trial application to a beam element exposed to marine field conditions for 40 years, $42 \%$ of the overall free chloride content was removed. Free chlorides were extracted within a range of about $70 \%$ close to the steel, $50 \%$ in the intermediate cover, and $5 \%$ at the concrete surface (Clemena, 2000). When ECE was performed on the piers and pier capbeam of the 5th Street Bridge over I-64 in Charlottesville, VA, 13\% to 53\% of the chloride ions were removed from the concrete near the steel bars. When performed on the deck of the 34th Street Bridge over I-395 in Arlington, VA, $72 \%$ to $82 \%$ of the chloride ions were removed from the concrete at the depth of the first mat of steel bars (Clemena, 2000).

The disadvantage of ECE is that its protection life can be ensured for only ten to fifteen years. This is because ECE only removes chloride from regions surrounding reinforcing steel; it does not remove all chloride ions from the entire concrete section. After a number of years, chloride ions can migrate back to the steel regions, once again increasing the risk of corrosion. ECE has been "re-performed" on structures that have not been repaired with FRP. However, research is needed to determine if the process could be re-performed on an FRP-retrofitted structure. If this re-performance can be proven effective, ECE will become an extremely attractive option to be used in conjunction with FRP repair. If ECE could be applied every ten to fifteen years or more on an FRP-retrofitted structure as part of a maintenance plan, the long-term durability of that structure could be greatly enhanced. 
Table 4.1: ECE Treatment on Selected North American Structures (Sharp, 2002)

\begin{tabular}{|c|c|c|c|c|}
\hline Location & Date & $\begin{array}{c}\text { Area } \\
\text { Treated }\end{array}$ & $\begin{array}{c}\text { Chloride } \\
\text { Removed }(\%)\end{array}$ & $\begin{array}{c}\text { Current } \\
\text { Efficiency } \\
(\%)\end{array}$ \\
\hline Hwy \#192 Bridge Substructure, Council Bluffs, Iowa & 2000 & $1209 \mathrm{~m}^{2}$ & N/A & N/A \\
\hline Highway 11 Bridge Abutments, North Bay, Ontario & 2000 & $646 \mathrm{~m}^{2}$ & N/A & $\mathrm{N} / \mathrm{A}$ \\
\hline Eastern Avenue Bridge \#576 Abutments, Washington DC & 2000 & $220 \mathrm{~m}^{2}$ & N/A & $\mathrm{N} / \mathrm{A}$ \\
\hline $3^{\text {rd }}$ St. Viaduct, Bridge Substructure, Minot, North Dakota & 1999 & $100 \mathrm{~m}^{2}$ & $\mathrm{~N} / \mathrm{A}$ & N/A \\
\hline St. Adolphe Bridge Deck, St. Adolphe, Manitoba & 1999 & $14704 \mathrm{~m}^{2}$ & $\mathrm{~N} / \mathrm{A}$ & N/A \\
\hline S02 of 38061 Substructure, Jackson County, Michigan & 1999 & $109 \mathrm{~m}^{2}$ & N/A & N/A \\
\hline I-480 Bridge Substructure, Omaha, Nebraska & 1999 & $1400 \mathrm{~m}^{2}$ & N/A & N/A \\
\hline Burlington Skyway Substructure, Burlington, Ontario & 1999 & $1533 \mathrm{~m}^{2}$ & N/A & N/A \\
\hline Hwy \#192 Bridge Substructure, Council Bluffs, Iowa & 1998 & $463 \mathrm{~m}^{2}$ & $\mathrm{~N} / \mathrm{A}$ & $\mathrm{N} / \mathrm{A}$ \\
\hline I-480 Bridge Substructure, Omaha, Nebraska & 1998 & $1525 \mathrm{~m}^{2}$ & $\begin{array}{l}74 \text { (at } 0-25 \mathrm{~mm}) \\
63 \text { (at } 50-75 \mathrm{~mm})\end{array}$ & N/A \\
\hline St. Adolphe Bridge Deck, St. Adolphe, Manitoba & 1998 & $1115 \mathrm{~m}^{2}$ & $\begin{array}{l}84 \text { (at } 0-25 \mathrm{~mm}) \\
70 \text { (at } 25-51 \mathrm{~mm})\end{array}$ & N/A \\
\hline Pembina Highway Overpass Structure, Winnipeg, Manitoba & 1998 & $220 \mathrm{~m}^{2}$ & N/A & N/A \\
\hline Industrial Spur Bridge Substructure, Peoria, Illinois & 1998 & $462 \mathrm{~m}^{2}$ & N/A & N/A \\
\hline Starbuck Bridge Deck, Winnipeg, Manitoba & 1997 & $270 \mathrm{~m}^{2}$ & N/A & N/A \\
\hline I-395 \& Dunwoody Substructure, Minneapolis, Minnesota & 1997 & $225 \mathrm{~m}^{2}$ & N/A & N/A \\
\hline Carousel Center Parking Deck, Syracuse, New York & 1997 & $100 \mathrm{~m}^{2}$ & $\mathrm{~N} / \mathrm{A}$ & $\mathrm{N} / \mathrm{A}$ \\
\hline Islington Ave. Bridge Interceptor Chambers, Toronto, Ontario & 1997 & $180 \mathrm{~m}^{2}$ & N/A & N/A \\
\hline Burlington Skyway Substructure, Burlington, Ontario & 1997 & $268 \mathrm{~m}^{2}$ & N/A & N/A \\
\hline Tulls Highway Overpass Deck, Seaford, Delaware & 1997 & $1550 \mathrm{~m}^{2}$ & N/A & $\mathrm{N} / \mathrm{A}$ \\
\hline Hwy \#6 \& \#11 Overpass Piers, Regina, Saskatchewan & 1995 & $180 \mathrm{~m}^{2}$ & Up to 80 & N/A \\
\hline $5^{\text {ta }}$ Street \& I-64 Substructure, Charlottesville, Virginia & 1995 & $488 \mathrm{~m}^{2}$ & $\begin{array}{l}27-60 \text { (at } 6-19 \mathrm{~mm}) \\
13-53(\text { at } 25-38 \mathrm{~mm})\end{array}$ & 9 to 12 \\
\hline Hwy \#1 \& \#6 Overpass Piers, Regina, Saskatchewan & 1995 & $370 \mathrm{~m}^{2}$ & $\mathrm{~N} / \mathrm{A}$ & $\mathrm{N} / \mathrm{A}$ \\
\hline Hwy \#2 Overpass Piers, Morinville, Alberta & 1995 & $55 \mathrm{~m}^{2}$ & $62-96$ & $\mathrm{~N} / \mathrm{A}$ \\
\hline 34th Street \& I-395 Bridge Deck, Arlington, Virginia & 1995 & $733 \mathrm{~m}^{2}$ & $\begin{array}{l}76-82 \text { (at } 6-19 \mathrm{~mm}) \\
72-32 \text { (at } 19-32 \mathrm{~mm})\end{array}$ & 11 to 15 \\
\hline Hwy \#11 \& \#16 Overpass Piers, Saskatoon, Saskatchewan & 1994 & $150 \mathrm{~m}^{2}$ & $62-88$ & N/A \\
\hline Pier Columns, SHRP, USA & 1992 & $49 \mathrm{~m}^{2}$ & N/A & 7 to 13 \\
\hline Abutment Area, SHRP, USA & 1992 & $17 \mathrm{~m}^{2}$ & $\mathrm{~N} / \mathrm{A}$ & 12 to 19 \\
\hline Deck Area, SHRP, USA & 1991 & $136 \mathrm{~m}^{2}$ & 60 (25 mm from bars) & 20 \\
\hline Portage Avenue \& Rt. 90 Retaining Wall, Winnipeg, Manitoba & 1991 & $\mathrm{~N} / \mathrm{A}$ & $20-76$ & $\mathrm{~N} / \mathrm{A}$ \\
\hline Burlington Skyway Pier, Burlington, Ontario & 1989 & $31 \mathrm{~m}^{2}$ & $\begin{array}{l}27 \text { (East Face) } \\
59-60 \text { (West Face) } \\
57 \text { (South Face) } \\
\end{array}$ & \begin{tabular}{|l|}
11 (East) \\
$32-33$ (West) \\
30 (South) \\
\end{tabular} \\
\hline $\begin{array}{l}\text { U.S. Route No. } 33 \text { Bridge Deck (ODOT No. UNI-33.1138-R) } \\
\text { Marysville, Ohio }\end{array}$ & 1975 & $18 \mathrm{~m}^{2}$ & $\begin{array}{l}31 \mathrm{in} 12 \mathrm{hr}(\text { at } 0-25 \mathrm{~mm}) \\
51 \mathrm{in} 24 \mathrm{hr}(\text { at } 0-25 \mathrm{~mm}) \\
59 \mathrm{in} 12 \mathrm{hr} \text { (at } 25-51 \mathrm{~mm}) \\
70 \mathrm{in} 24 \mathrm{hr} \text { (at } 25-51 \mathrm{~mm})\end{array}$ & N/A \\
\hline
\end{tabular}

$\mathrm{N} / \mathrm{A}=$ Not Available

First it must be determined if sufficient electrical continuity can be achieved between the electrolyte and the concrete surface of a structure that is partially covered with FRP.

Secondly, a tightly-adhering substance composed of calcium carbonate, calcium chloride, 
and small quantities of undefined substances can form on the concrete surface as a byproduct of ECE (Clemena, 2000). The formation of this substance within an FRPretrofitted structure could potentially affect the concrete-FRP interface.

Concerns about ECE also include hydrogen evolution at cathode, bond strength loss between concrete and reinforcement, and ASR susceptibility. Research shows that hydrogen evolution won't affect a structure by causing embrittlement of the steel if current densities are kept at $1 \mathrm{~A} / \mathrm{m}^{2}$. Low strength steel is not as susceptible to this as high strength steel. Therefore ECE is not a viable option for prestressed concrete. Table 4.1 provides a list of selected ECE projects in North America. ECE projects have also been completed in Vancouver, Colorado, Texas, and New York.

\subsubsection{Re-alkalization}

The re-alkalization process is very similar to the ECE. The objective of re-alkalization is to restore alkalinity to carbonated concrete and to provide a passive layer around the steel reinforcement. This is accomplished by attaching a power supply to the reinforcement and an external anode, as in ECE. An alkaline electrolyte such as sodium carbonate solution is used and is drawn into the concrete, restoring the concrete's alkalinity. 


\subsection{Literature Review of Experiments Conducted to Examine FRP- Repair of Flexure Members}

\subsubsection{Laboratory-Scale Research}

\subsubsection{Laboratory Testing: Large-Scale Repair}

\subsection{Maaddawy,2005}

Maddaawy (2005) explored the short- and long-term performance of corrosion-damaged reinforced concrete beams repaired with CFRP laminates.

\section{Table 4.2: Grouping of Maddaawy (2005) Beam Specimens}

\begin{tabular}{|c|c|c|c|c|c|}
\hline Group & Specimen $^{\mathrm{a}}$ & $\begin{array}{c}\text { Total time of } \\
\text { exposure (days) }\end{array}$ & $\begin{array}{l}\text { Loading condition } \\
\text { during corrosion }\end{array}$ & $\begin{array}{l}\text { Repair } \\
\text { scheme }\end{array}$ & $\begin{array}{l}\text { Average degree } \\
\text { of corrosion } \\
(\% \text { mass loss })\end{array}$ \\
\hline \multirow{6}{*}{ A } & Virgin (UU) & - & - & - & - \\
\hline & UR-I & - & - & I & - \\
\hline & UR-II & - & - & II & - \\
\hline & CUN-50 & 50 & No Load & - & 8.9 \\
\hline & CRN-50-I & 50 & No Load & I & 8.5 \\
\hline & CRN-50-II & 50 & No Load & II & 8.8 \\
\hline \multirow{8}{*}{ B } & CUS-50 & 50 & Sustained Load & - & 9.7 \\
\hline & CUS-110 & 110 & Sustained Load & - & 15.4 \\
\hline & CUS-210 & 210 & Sustained Load & - & 22.8 \\
\hline & CUS-310 & 310 & Sustained Load & - & 30.0 \\
\hline & CRS-50-I & 50 & Sustained Load & I & 9.5 \\
\hline & CRS-110-I & 110 & Sustained Load & I & 15.7 \\
\hline & CRS-210-I & 210 & Sustained Load & I & 23.7 \\
\hline & CRS-310-I & 310 & Sustained Load & I & 31.0 \\
\hline \multicolumn{6}{|c|}{ 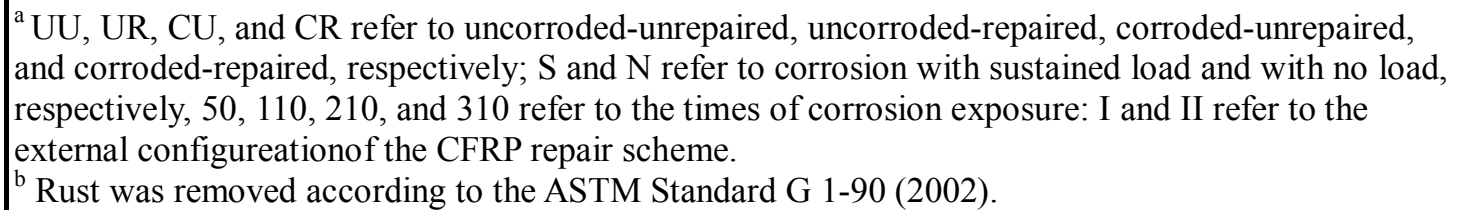 } \\
\hline
\end{tabular}


Both pristine and aged specimens were aged using induced electrical current along with chloride addition to the concrete mix, wet/dry cycling, and preloading/pre-cracking, all prior to FRP repair. Fourteen beam specimens were divided into two groups, as shown in Table 4.2. The specimens had a cross section of 6"x10" and were 10'-6" long. Two unique FRP wrapping schemes shown in Figure 4.7 were investigated. Midspan displacement and load were recorded during 4-point bending tests to failure.

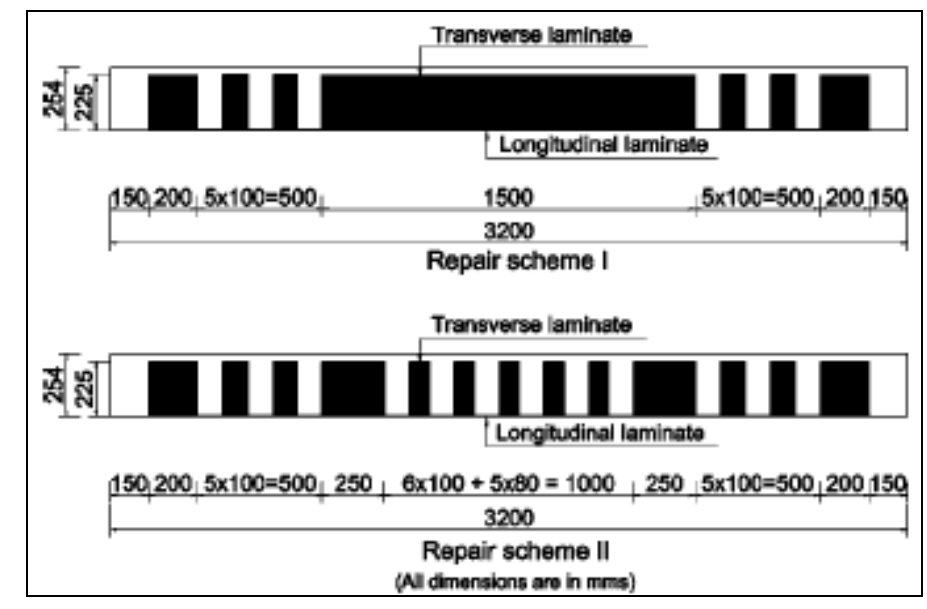

Figure 4.7: Maddaawy (2005) FRP Repair Schemes

For accelerated aging information from this study, please see Section 6.1.2.2. For crack measurement results from this study, please see Section 6.2.1.2.1. For static flexural testing procedures and results, please see Section 6.3.2.2.1.

\subsection{Bonacci, 2000}

The objective of this research was to study the effect of corrosion damage on the shortterm effectiveness of FRP for strengthening reinforced concrete beams. Variables in the test plan included the extent of corrosion, the external reinforcing scheme, and the 
loading-repair history for the seven beams tested. Four 14'-3" long reinforced concrete beams with cross-sections of 10.6"x15.7" (see Figure 4.8) were subjected to accelerated aging.

FRP was installed under sustained loading. Table 4.3 presents a summary of the testing plan and the extent of FRP repair. A schematic diagram of the B5 wrapping scheme with U-wraps is shown in Figure 4.9.

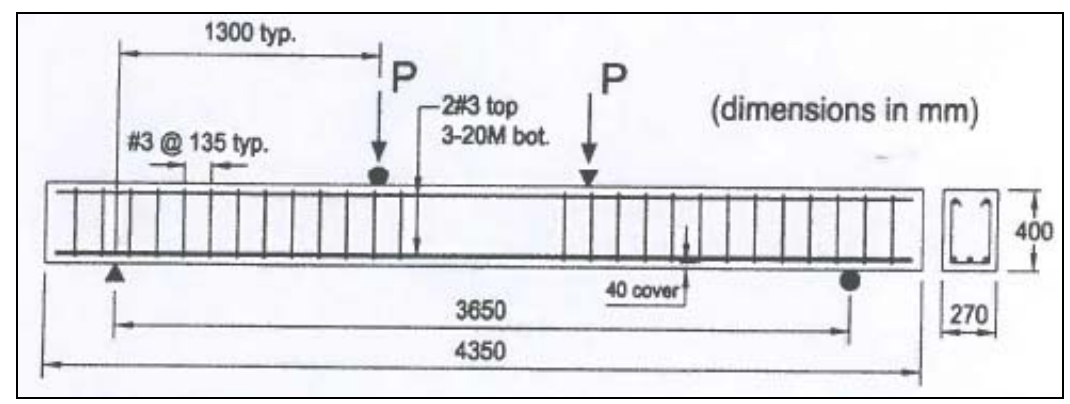

Figure 4.8: Bonacci (2000) Test Specimen

Table 4.3: Summary of Bonacci (2000) Testing Plan. (The term "long” represents longitudinal CFRP reinforcement)

\begin{tabular}{|c|c|c|c|c|}
\hline $\begin{array}{c}\text { Specimen } \\
\text { Designation }\end{array}$ & Corrosion & CFRP & Loading/CFRP History & Identify \\
\hline B1 & None & None & Monotonic & Control \\
\hline B2 & None & 2 long. & CFRP Monotonic & Strengthened \\
\hline B3 & None & 2 long. & $\begin{array}{c}\text { Cycle - Sustain for CFRP } \\
- \text { Monotonic }\end{array}$ & $\begin{array}{c}\text { Strengthened } \\
\text { Under Load }\end{array}$ \\
\hline B4 & $10 \%$ & None & Monotonic & Heavy Damaged \\
\hline B5 & $10 \%$ & $\begin{array}{c}\text { 1 long. }+ \\
\text { U-straps }\end{array}$ & $\begin{array}{c}\text { Cycle - Sustain for CFRP } \\
\text { - Monotonic } \\
\text { Optimized } \\
\text { Repair Under } \\
\text { Load }\end{array}$ \\
\hline B6 & $10 \%$ & 2 long. & $\begin{array}{c}\text { Cycle - Sustain for CFRP } \\
\text { - Monotonic }\end{array}$ & $\begin{array}{c}\text { Repaired Under } \\
\text { Load }\end{array}$ \\
\hline B7 & $5 \%$ & None & Monotonic & $\begin{array}{c}\text { Moderately } \\
\text { Damaged }\end{array}$ \\
\hline
\end{tabular}




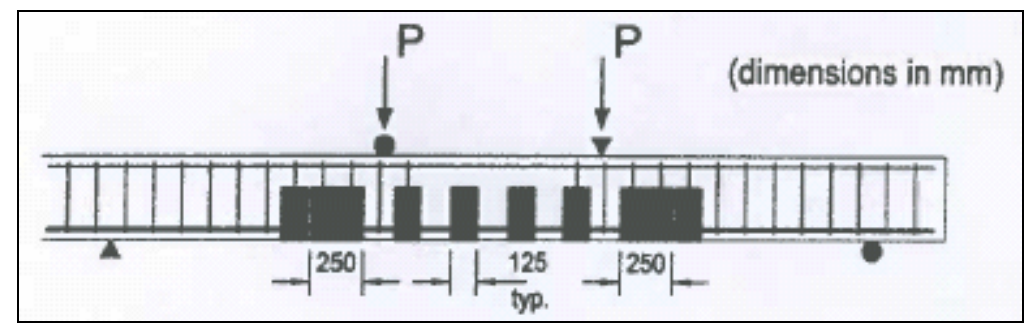

Figure 4.9: Bonacci (2000) B5 wrapping scheme

For accelerated aging information from this study, please see Section 6.1.2.4. For static flexural testing procedures and results, please see Section 6.3.2.2.2.

\subsection{Masoud, 2005 \& Masoud, 2006}

These research experiments focused on the corrosion activity in both FRP repaired and unrepaired large-scale reinforced concrete beam specimens. Ten 10'-6" beams with a 6"x10" cross section were tested. A diagram of the test specimen can be seen in Figure 4.10. The objective of Masoud 1 was to study corrosion in the reinforcing steel and to repair the beam specimens with FRP.

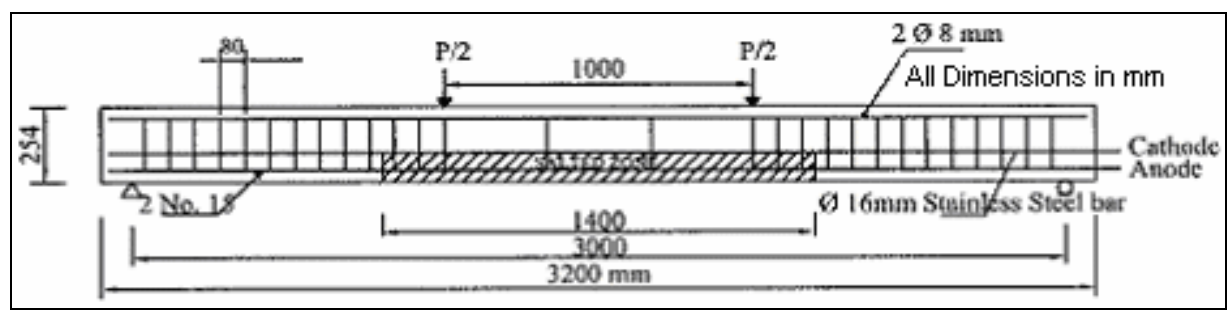

Figure 4.10: Masoud (2006) and Masoud (2005) Test Specimen

After an accelerated corrosion process, the cracks were sealed using a structural epoxy paste adhesive. An interesting variation in this research was that, after routine surface cleaning, the FRP sheets were directly applied. The deteriorated cover wasn't replaced 
and the corroded reinforcement was not cleaned. Two unique FRP wrapping schemes were studied. A summary of the testing plan is presented in Table 4.4.

Table 4.4: Masoud (2005) testing plan

\begin{tabular}{|c|c|c|c|c|c|}
\hline \multirow{2}{*}{\multicolumn{2}{|c|}{ Specimen }} & \multicolumn{4}{|c|}{ Level of corrosion exposure } \\
\hline & & $\begin{array}{c}\text { No } \\
\text { corrosion } \\
(0 \%)\end{array}$ & $\begin{array}{c}\text { Minor } \\
\text { corrosion } \\
(5 \%)\end{array}$ & $\begin{array}{c}\text { Medium } \\
\text { corrosion } \\
(10 \%)\end{array}$ & $\begin{array}{c}\text { Severe } \\
\text { corrosion } \\
(15 \%)\end{array}$ \\
\hline Unrepaired & & $00-\mathrm{U}$ & $11-\mathrm{U}$ & $22-U$ & $33-U$ \\
\hline \multirow{2}{*}{$\begin{array}{l}\text { after minor } \\
\text { corrosion } \\
\text { damage) }\end{array}$} & $\begin{array}{l}\text { FRP repair } \\
\text { scheme I }\end{array}$ & - & 11-RI & 12-RI & 13-RI \\
\hline & $\begin{array}{l}\text { FRP repair } \\
\text { scheme II }\end{array}$ & - & 11-RII & 12-RII & 13-RII \\
\hline \multicolumn{6}{|c|}{$\begin{array}{l}\text { Note: Specimen designated is as follows: First letter: Level of corrosion exposure ( } 0 \text { for } \\
\text { no corrosion, 1, 2, and 3, for minor, medium, and severe degrees of corrosion); Second } \\
\text { letter: Level of corrosion exposure at time of test to failure ( } 0,1,2 \text {, and } 3) \text {; Third letter: } \\
\text { U for unrepaired, RI or RII for FRP repaired specimens using scheme I and scheme II, } \\
\text { respectively. } \\
\text { Specimen groups: First group: Control; 00-U; Second group: Corroded unrepaired, 11- } \\
\text { U, 22-U, and 33-U; Third group: FRP repaired (short-term), 11-RI, and 11-RII; Fourth } \\
\text { group: FRP repaired (long-term), 12-RI, 13-RI, 12-RII, and 13-RII. }\end{array}$} \\
\hline
\end{tabular}

FRP repair scheme I incorporated GFRP U-wraps for shear strengthening only, and the second incorporated CFRP laminates for flexural strengthening in addition to the GFRP U-wrap shear reinforcement. It should be noted that the amount of flexural strengthening was chosen so that the beam specimen remained under-reinforced. The two wrapping schemes are illustrated in Figure 4.11.

For accelerated aging information from this study, please see Section 6.1.2.3. For crack measurement results from this study, please see Section 6.2.1.2.2. For cyclic flexural testing procedures and results, please see Section 6.3.1.2.1. 


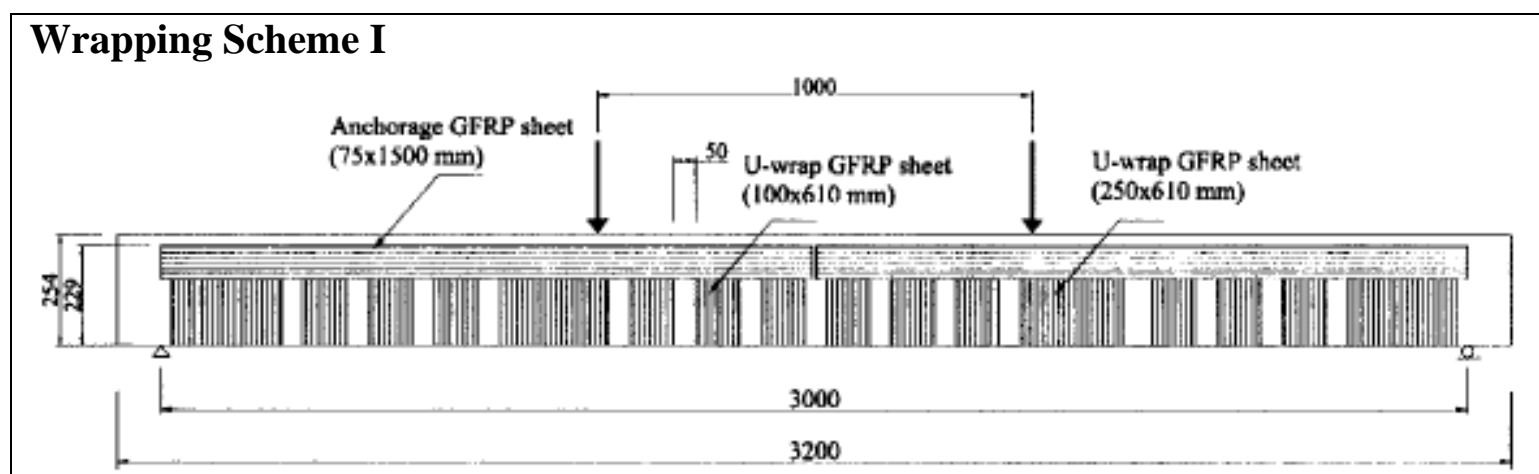

Wrapping Scheme II

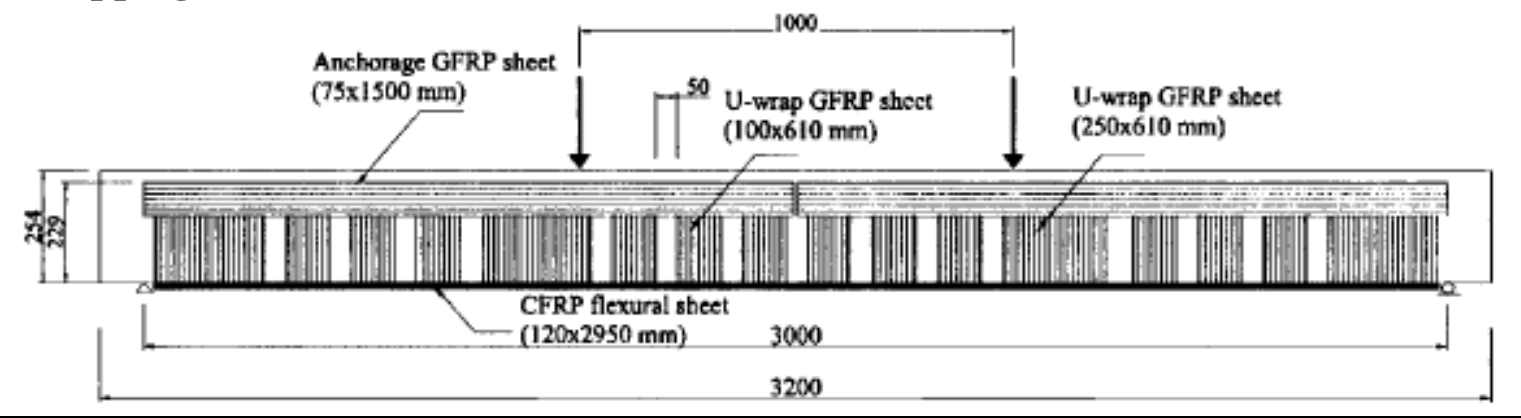

Figure 4.11: Schematic of Masoud (2005) and Masoud (2006) Wrapping Schemes I and II

\subsection{Wang, K., 2006}

Wang , K. (2006) experimentally and analytically studied the behavior of corroded and FRP-repaired reinforced concrete beams under static loading. Each of the 24 large-scale reinforced concrete beam was $11^{\prime}-6$ " long and had a cross-section of 7.9"x13.8". A diagram of the test specimen is provided in Figure 4.12.

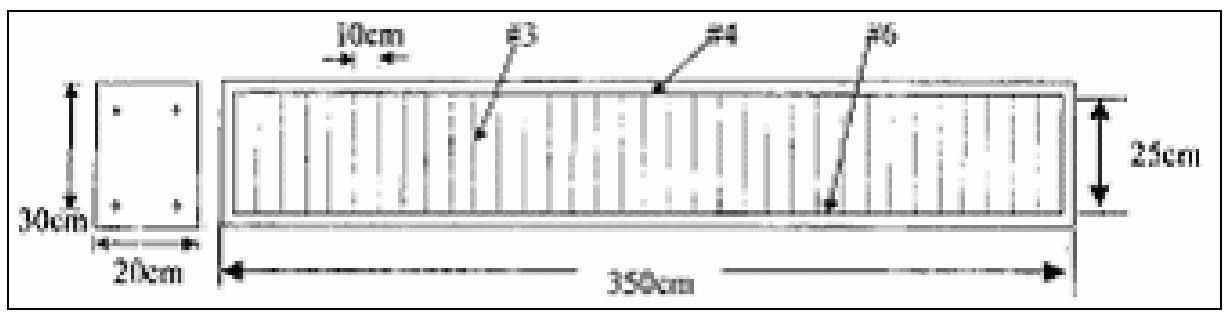

Figure 4.12: Wang, K. (2006) Test Specimen 
Four unique wrapping schemes were applied to the beam specimens. These schemes are illustrated and described in Figure 4.13.

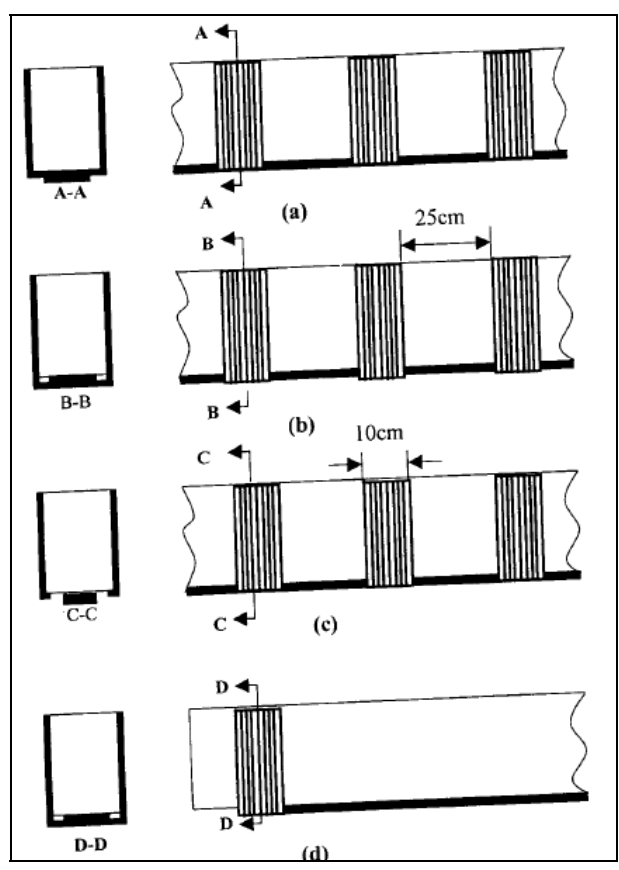

Figure 4.13: Various FRP

Wrapping Schemes in Wang, K., (2006) (a) Longitudinal strips over U-wrap anchors; (b) Longitudinal strips wrapped beneath $\mathrm{U}$-wrap anchors; (c) Longitudinal strip wrapped in discontinuous shear reinforcement; (d) U-wrap anchors applied only at ends of the longitudinal strips.

For accelerated aging information from this study, please see Section 6.1.2.6. For static flexural testing procedures and results, please see Section 6.3.2.2.3. 


\subsection{Kutarba, 2004}

Thirty total beams were tested, 26 of which were repaired with CFRP laminates. Each beam was 9'-6" long and had a cross-section of 8"x12". A diagram of the test specimen can be seen in Figure 4.14.

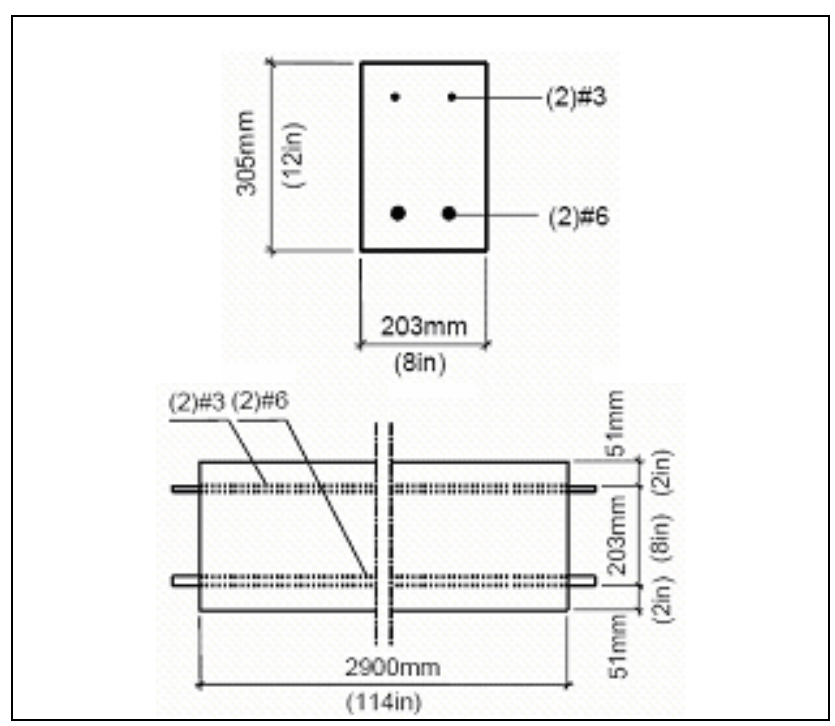

Figure 4.14: Kutarba (2004) Test Specimen

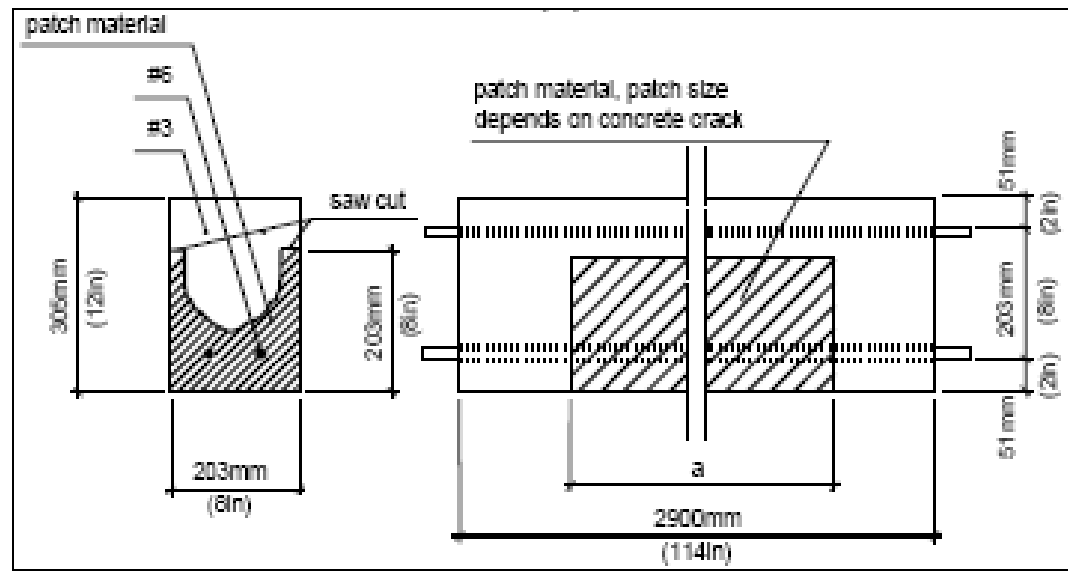

Figure 4.15: Schematic of Kutarba (2006) Concrete Repair 
Corroded beams were first repaired with normal concrete $(6,700$ psi compressive strength) containing superplasticizer. A schematic of Kutarba's (2006) concrete repair can be seen in Figure 4.15.

Table 4.5: Summary of Kutarba (2004) test specimens (Post-repair is abbreviated as “PR")

\begin{tabular}{|c|c|c|c|}
\hline Beam & $\begin{array}{c}\text { Strengthening } \\
\text { scheme }\end{array}$ & $\begin{array}{c}\text { Load tested } \\
\text { after }\end{array}$ & Repair \\
\hline C1 & none & initial corrosion & n/a \\
\hline C2 & none & initial corrosion & n/a \\
\hline 1 A-S & none & PR Corrosion & repaired \\
\hline 2 A-D & none & initial corrosion & repaired \\
\hline 2 B-S & none & initial corrosion & repaired \\
\hline 3 B-D & scheme III & PR Corrosion & unrepaired \\
\hline 3 B-S & scheme I & PR Corrosion & repaired \\
\hline 4 A-D & control & PR Corrosion & repaired \\
\hline 4 A-S & scheme III & PR Corrosion & repaired \\
\hline 4 B-D & scheme II & PR Corrosion & repaired \\
\hline 4 B-S & scheme III & initial corrosion & repaired \\
\hline 5 A-D & scheme I & initial corrosion & repaired \\
\hline 5 B-D & scheme III & PR Corrosion & repaired \\
\hline 5 B-S & scheme II & PR Corrosion & repaired \\
\hline 7 A-S & scheme II & initial corrosion & repaired \\
\hline 7 B-S & scheme I & initial corrosion & repaired \\
\hline $\begin{array}{l}\text { Numbers indicate the set of test specimen. The letter A or B the } \\
\text { position in the corrosion racks. The letters S or D describe the } \\
\text { number of ponding areas (single or double)during the initial } \\
\text { corrosion process. }\end{array}$ \\
\hline
\end{tabular}

Next, three FRP composite strengthening schemes were applied to the beams. Scheme I beams were strengthened in both flexure and shear. Eight non-U-wrap FRP stirrups with a center-to-center spacing of 12 in were applied to each side of each beam. Scheme II beams had the same FRP layout as scheme I except that U-wraps were used to anchor the flexural sheet. U-wrap anchors were fixed at solely the beam ends or for each of the 
eight stirrups over the length of the beam. Scheme III beams were U-wrapped over the length of the beam using a continuous FRP sheet. The various FRP arrangements are shown in Figure 4.16. A summary of the test specimens used in this study are provided in Table 4.5.

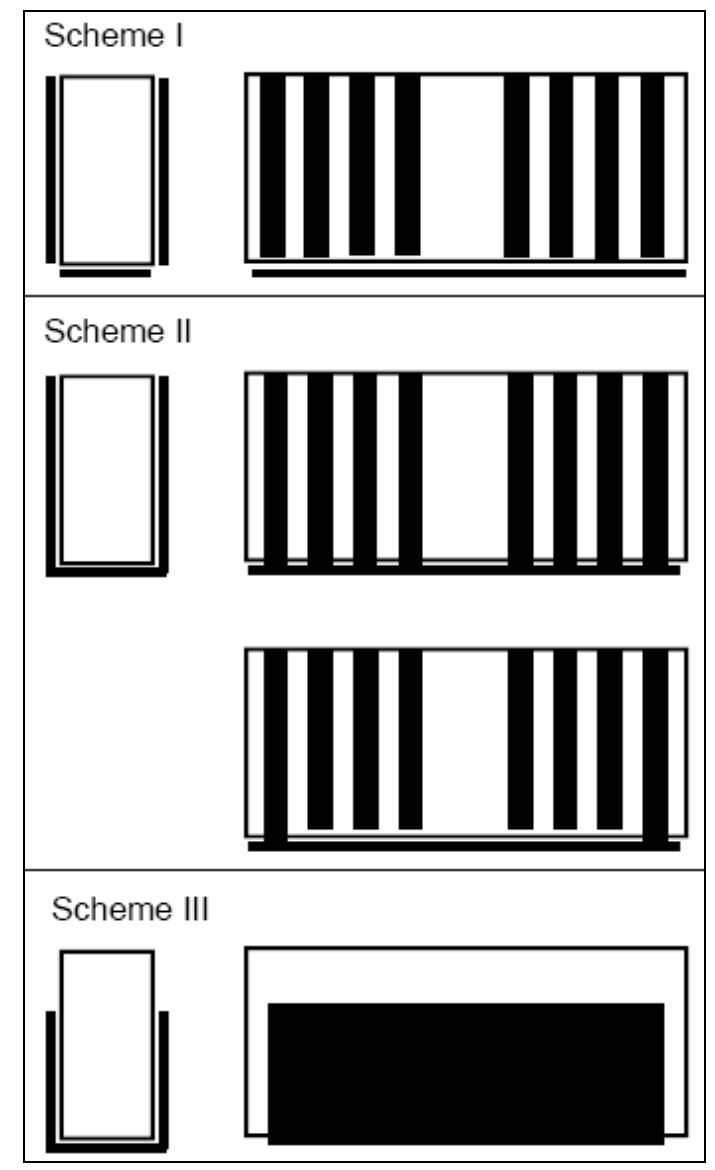

Figure 4.16: Kutarba (2004) Repair Schemes

For accelerated aging information from this study, please see Section 6.1.2.5. For static flexural testing procedures and results, please see Section 6.3.2.2.4. 


\subsection{Kachlakev, 2001}

Four 20'-long reinforced concrete beams designed to model the geometry and material properties of a historic bridge in Portland, OR were studied in this research. Beam specimens consisted of one control with no shear stirrups, one repaired with CFRP for flexure only, one repaired with GFRP for shear only, and one repaired with both CFRP for flexure and GFRP for shear. Type-I ready mix concrete with a compressive strength of 3000psi was used to cast each beam specimen. A schematic of the test specimen can be seen in Figure 4.17. Steel reinforcement with a smaller-than-required cross section was chosen to compensate for the higher tensile strength of today's steel as opposed to the steel found in the historic bridge. No beams were aged in this study.

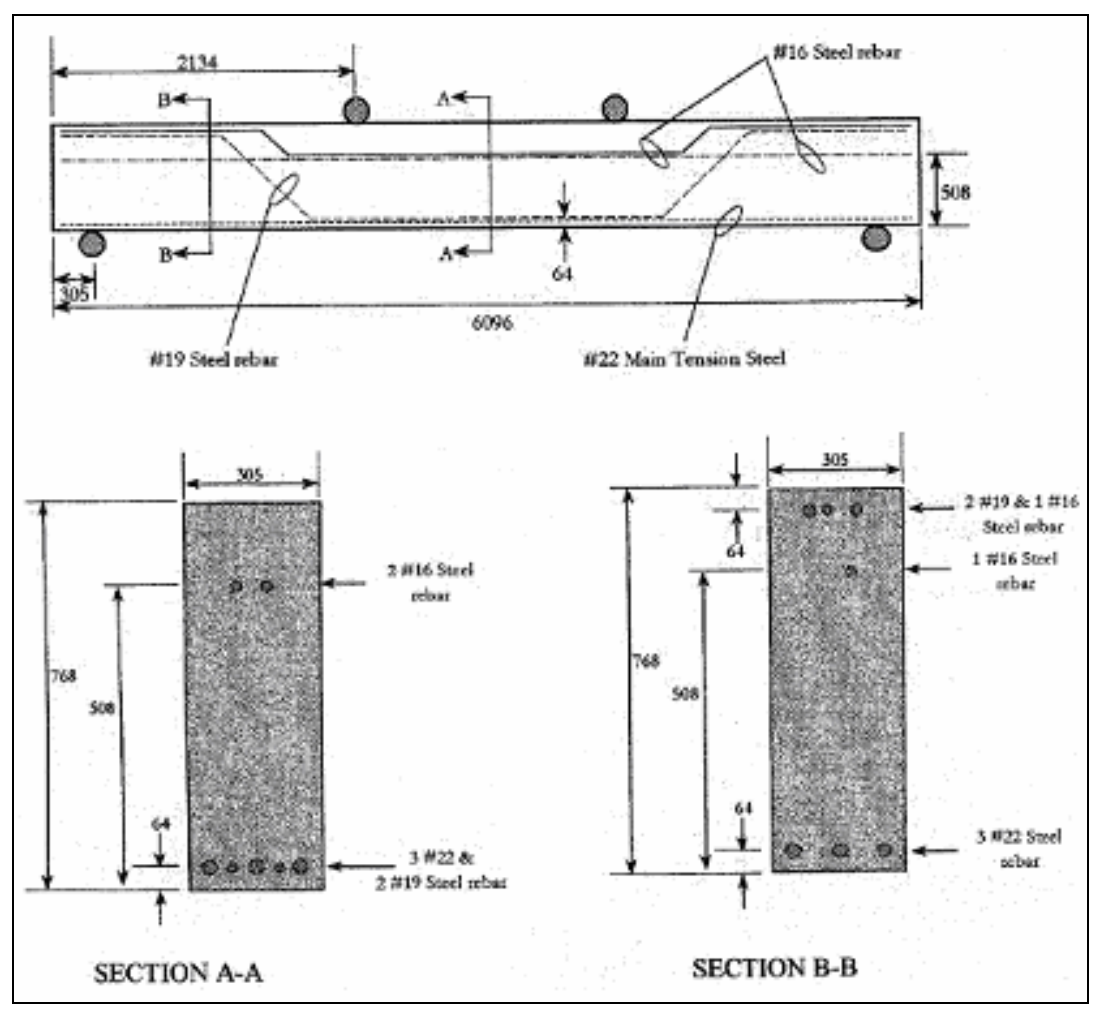

Figure 4.17: Kachlakev (2001) Test Specimen

For static flexural testing procedures and results, please see Section 6.3.2.2.5. 


\subsection{Leung, 2006}

This research investigated whether it is optimal to place FRP anchorage near the ends of the flexural reinforcement, as is commonly done for an FRP repair. Figure 4.18 shows the variation of interfacial shear stress obtained from numerical differentiation of experimental data that was performed by Leung, 2006. It is interesting to note that, for loads up to $260 \mathrm{kN}$, the shear stresses near the plate end are very high. However, at higher loads when cracking occurs near the plate end, a completely different distribution of shear stresses is present in the FRP plate with the maximum stresses located at a distance away from the plate end. This cracking has been found to occur at about $75 \%$ of a beam's ultimate load. The actual debonding of the FRP was observed to be crackinduced and occurred at the location of flexure cracks away from the beam end, as depicted in Figure 4.19. This observation led to the exploration of the optimal location for anchor stirrups.

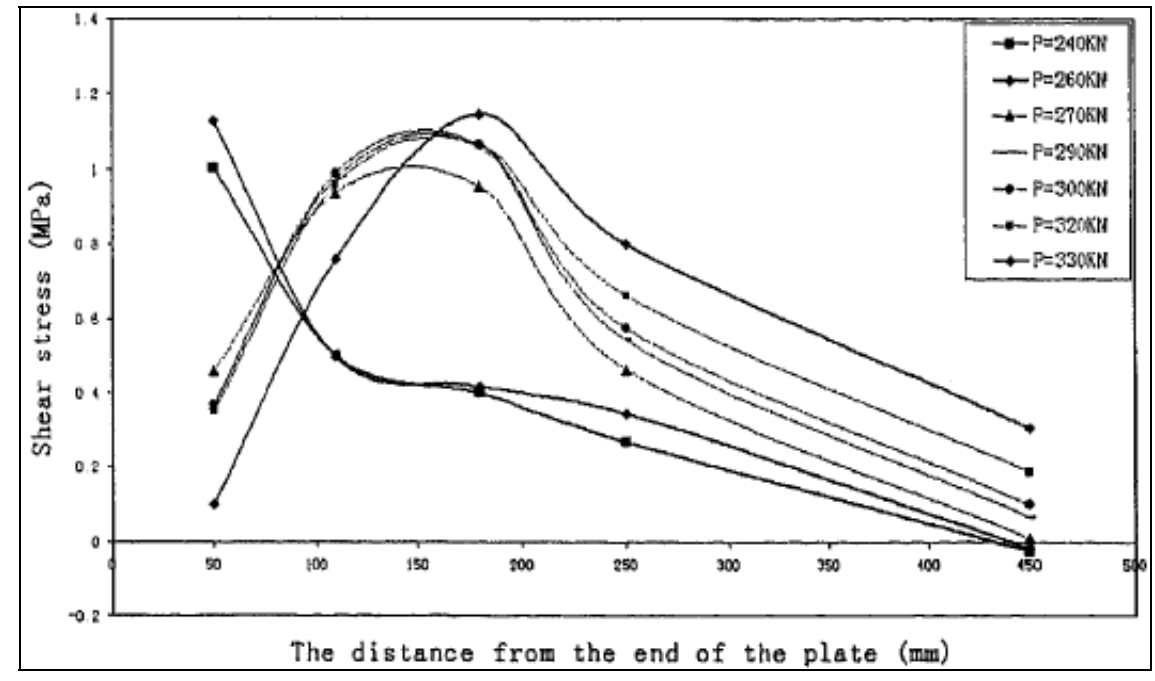

Figure 4.18: Variation of Interfacial Shear Stress Obtained from Numerical Differentiation of Experimental Data (Leung, 2006) 


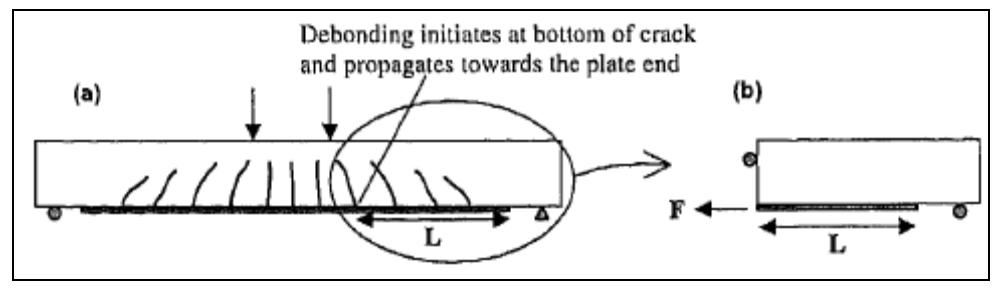

Figure 4.19: Illustration of Crack-Induced Debonding (Leung, 2006)

Beam specimens with cross-sectional dimensions of 6"x15-3/4" and a span length of $11^{\prime}-10^{\prime \prime}$ were used for this experiment. Three different anchor locations were tested. The value of " $x$ " indicates the distance from the end of the flexural FRP plate to the edge of the FRP stirrup, as shown in Figure 4.20. Table 4.6 shows the three locations tested.

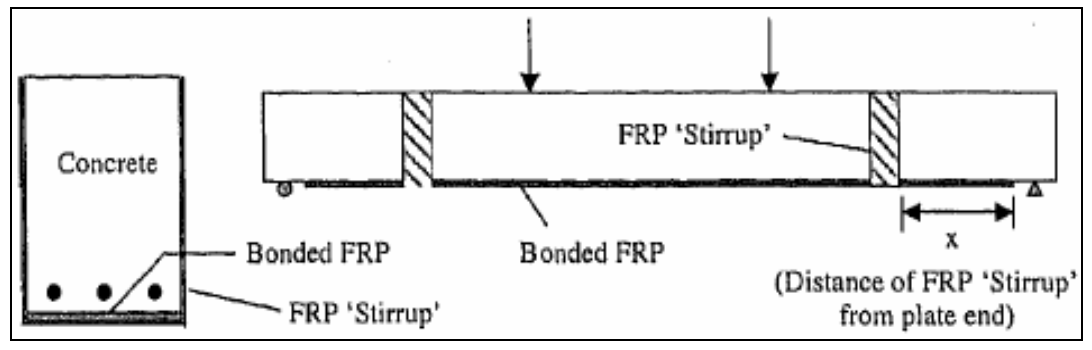

Figure 4.20: Leung (2006) Test Specimen

Table 4.6: Anchor Locations Tested in Leung (2006)

\begin{tabular}{|l|l|}
\hline Specimen & Location of anchor from plate end “x"(in) \\
\hline Control & N/A: No anchors for the control \\
\hline U1 & 0 \\
\hline U2 & 21 \\
\hline U3 & 30 \\
\hline
\end{tabular}

Four plies of CFRP plate ( $0.44 \mathrm{~mm}$ thick) was first bonded to the test specimens followed by the U-shaped anchor stirrups.

For static flexural testing procedures and results, please see Section 6.3.2.2.6. 


\subsection{Grace, 2004}

In this research, seventy-eight beams with a cross section of 6"x10" and a length of 9'-0" were tested. The concrete had a strength of 5,000psi. A schematic of a beam specimen can be seen in Figure 4.21.

Two were unstrengthened and four were unconditioned reference beams (2 strengthened with CFRP plates and 2 with CFRP fabrics). Thirty-six beams were strengthened with 1 layer of CFRP plates and 36 beams were strengthened with 2 layers of CFRP fabric. Beams were divided into sets of 4: 2 with plates and 2 with fabric. These sets of beams were exposed to three duration levels of the following environmental conditions: $100 \%$ humidity, dry heat, alkaline solution, saltwater solution, freeze/thaw cycles, and thermal expansion cycles.

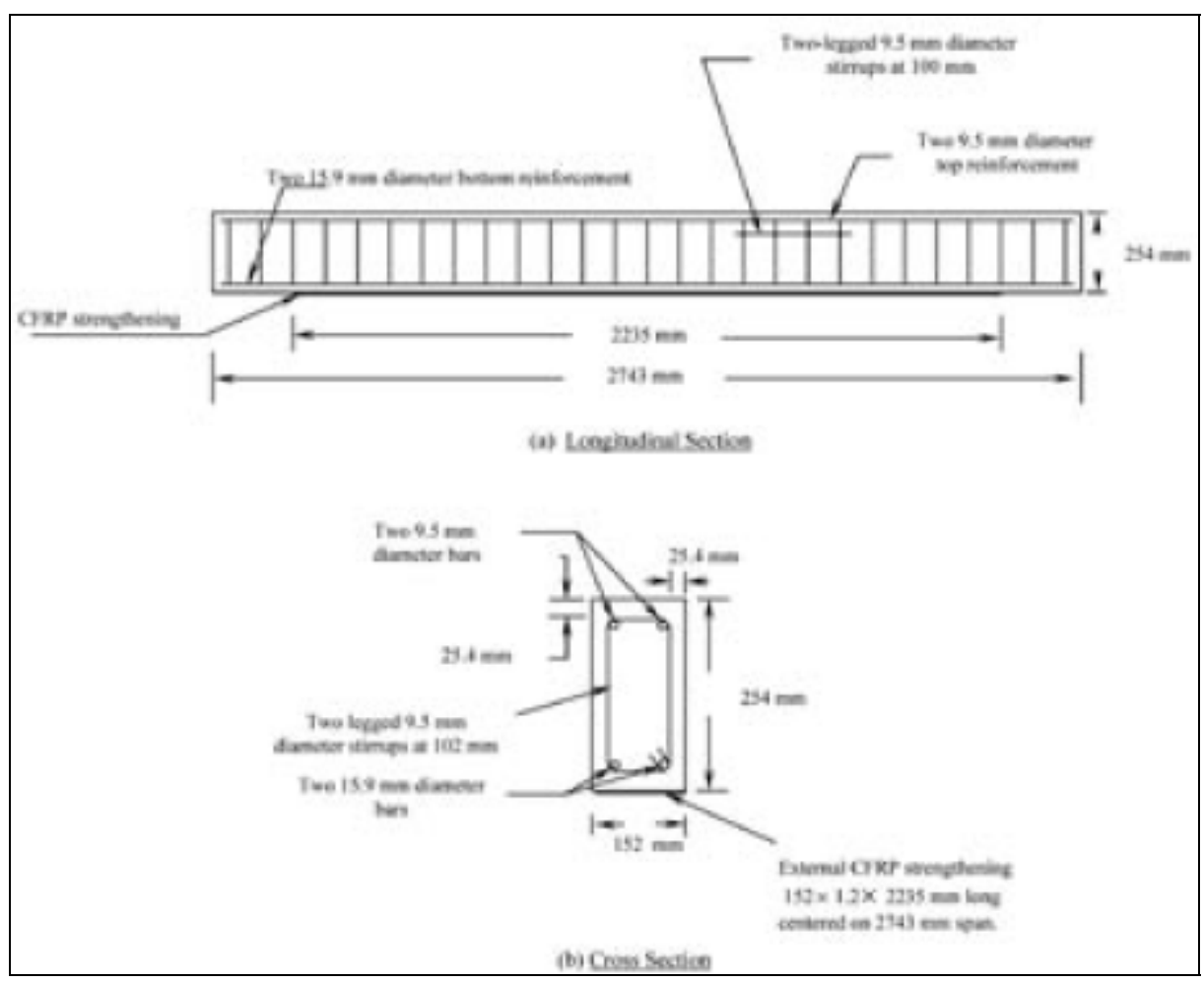

Figure 4.21: Grace (2004) Test Specimen 
To prepare the concrete substrate, a hand grinder and a masonry grinding wheel were used to remove all irregularities on the concrete surface of the beam. Next, the surfaces were sand-blasted. Epoxy was used to fill voids and low spots on the beam surface and cured for 24 hours prior to CFRP application. Fabric layers 0.007" in thickness were bonded to the concrete. Hand rollers were used to properly bond the laminates together and to remove any trapped air between them. CFRP plates were bonded using structural epoxy while CFRP fabric was bonded using saturating epoxy.

For accelerated aging information from this study, please see Section 6.1.2.7. For cyclic flexural testing procedures and results from this study, please see Section 6.3.1.2.2. For static flexural testing procedures and results, please see Section 6.3.2.2.7.

\subsection{Aidoo}

Two 30'-long beams were recovered from a 40-year old decommissioned interstate bridge and were retrofitted using externally bonded CFRP strips. The cover concrete was in sound structural condition and provided a good bonding surface for the concrete. Figure 4.22 shows a diagram of Aidoo's (2004) test specimen. These specimens were tested under both monotonic and cyclic loads.

For cyclic flexural testing procedures and results, please see Section 6.3.1.2.3. For static flexural testing procedures and results, please see Section 6.3.2.2.9. 


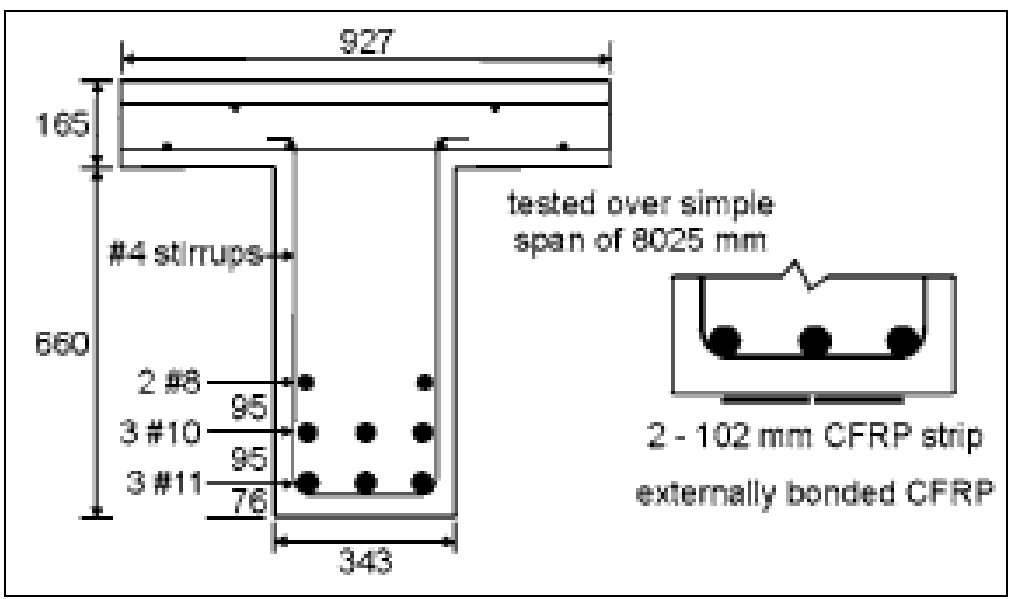

Figure 4.22: Aidoo (2004) test specimen

\subsection{Quattlebaum, 2005}

Three 15'-6" beam specimens were cast in the lab and were retrofitted with externallybonded CFRP. The first specimen was immediately tested to failure under static loading, the second specimen was subjected to low-stress cyclic loading, and the third specimen was subjected to high-stress cyclic loading. Figure 4.23 illustrates the Quattlebaum (2005) test specimen.

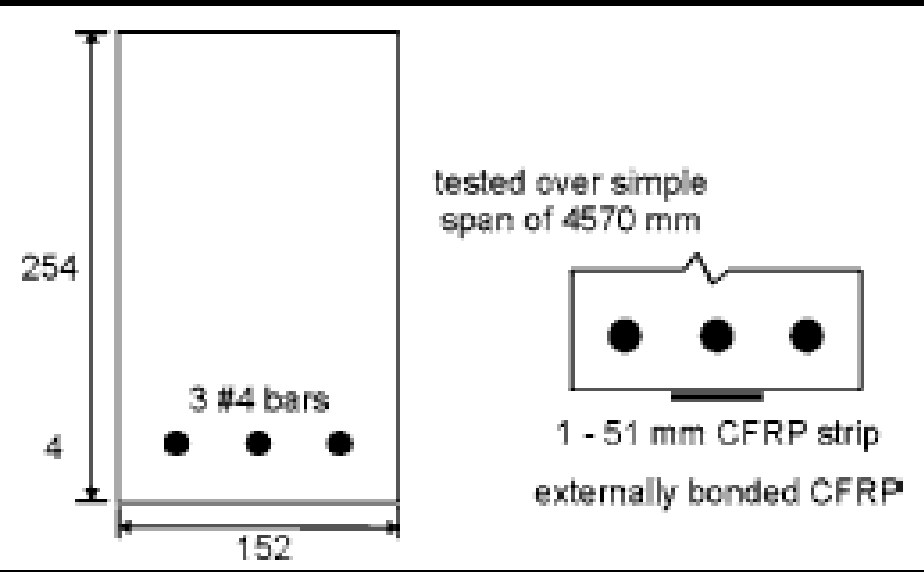

Figure 4.23: Quattlebaum, 2005 test specimen 
For cyclic flexural testing procedures and results, please see Section 6.3.1.2.4. For static flexural testing procedures and results, please see Section 6.3.2.2.10.

\subsubsection{Laboratory Testing: Small-Scale Repair}

\subsection{Soudki, 2000}

Ten small-scale beams with cross-sectional dimensions of 4"x6" and a length of 1'-11" were studied in this research. A schematic of the test specimen can be seen in Figure 4.24 .

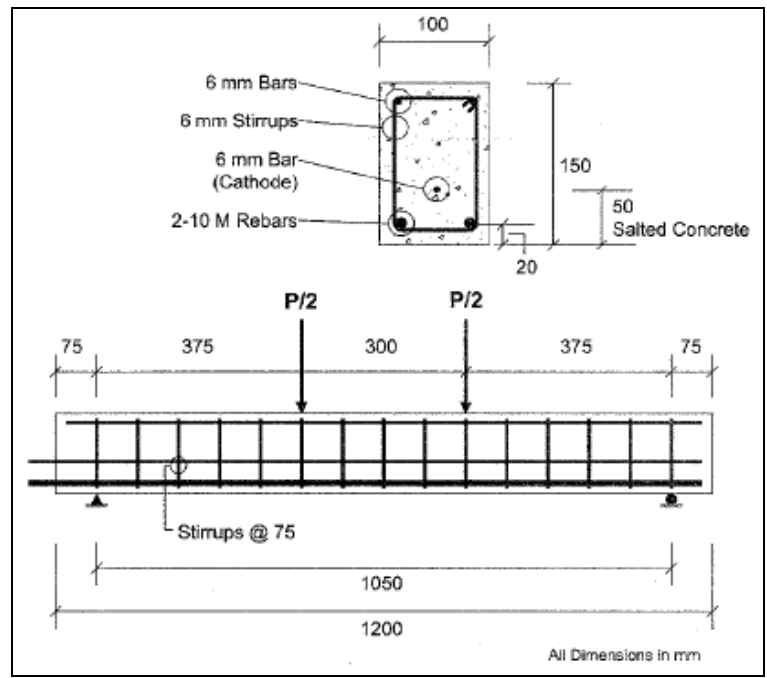

Figure 4.24: Soudki, 2000 test specimen

One ply of CFRP laminate was adhered to the bottom of each test specimen. CFRP laminates oriented with their fibers in the transverse direction were then bonded across the flexural FRP and up the sides to form a U-wrap. These anchors were placed to prevent premature debonding from the concrete substrate. The repair scheme can be seen in Figure 4.25. 


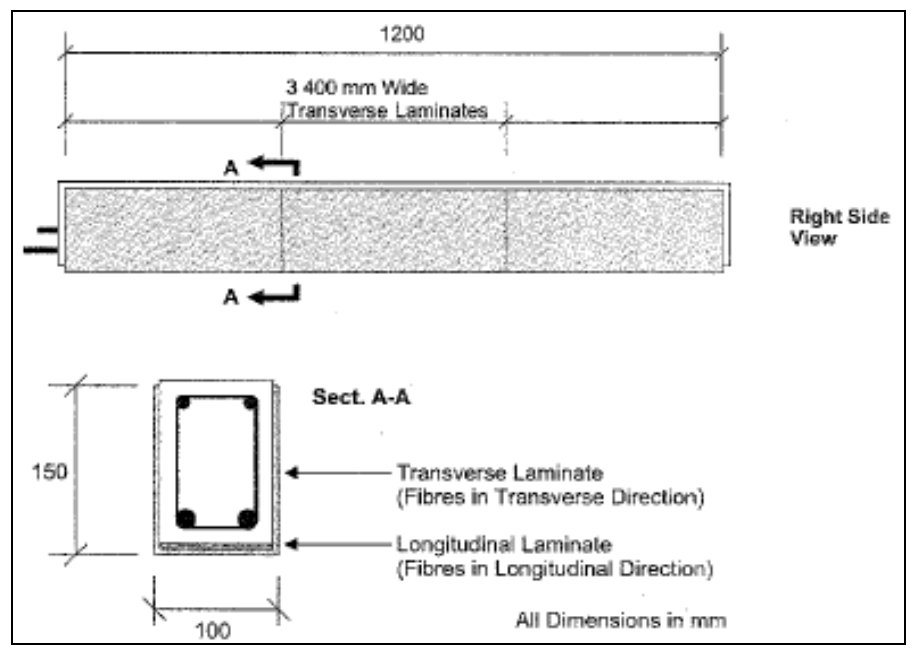

Figure 4.25: Soudki (2000) repair scheme

After repair, beam specimens were subjected to accelerated aging to observe the durability characteristics of the repair.

\subsubsection{Studies on Bridge Repair in the Field}

There is some well-written literature on full-scale bridge repair in the field, although it is beyond the scope of this research to discuss in detail. The following presents a bibliography for some excellent sources that were reviewed when designing this research project that describe studies conducted on FRP-strengthened bridges in the field:

Bank, Dr. Lawrence C, et al. Rapid Strengthening of Reinforced Concrete Bridges. Rolla, MO: University of Missouri-Rolla, 2002.

Hag-Elsafi, O., et al. "Application of Load Testing for Evaluation of FRP Retrofit Systems and Monitoring for Superloads." Transportation R\&D Bureau, NYSDOT, Albany, NY, April 2002.

Hag-Elsafi, Osman, Sreenivas Alampalli, and Jonathan Kunin. "In-Service Evaluation of a Reinforced Concrete T-Beam Bridge FRP Strengthening System." Composite Structures 64. (2004): Pages 179-188. Elsevier Science Ltd. $<$ www.elsevier.com/locate.compstruct $>$ 
Hag-Elsafi, Osman, Sreenivas Alampalli, and Jonathan Kunin. "Strengthening of a Bridge Pier Capbeam Using Bonded FRP Composite Plates." Composite Structures 57. (2002): Pages 393-403. Elsevier Science Ltd. $<$ www.elsevier.com/locate.compstruct $>$

Reay, Jaron T., et al. "Long Term Durability of Carbon FRP Composites Applied to RC Bridges: State Street Bridge on Interstate 80." Journal of Bridge Engineering. ASCE. March/April (2006): Pages 205-216.

Rizzo, Andrea, Nestore Galati, and Antonio Nanni. Design and In-Situ Load Testing of Bridge No. 1330005 Route 3560 - Phelps County, MO. Rolla, MO: University of Missouri-Rolla, 2005.

Sen, Rajan. "Issues Related to the FRP Wrap of Corroded Piling." COMPOSITES 2004 Convention and Trade Show. American Composites Manufacturers Association. Tampa, FL: October 6-8 (2004).

University of Missouri-Rolla. Preservation of Missouri Transportation Infrastructures; Validation of FRP Composite Technology Through Field Testing; Strengthening of Bridge P-0962 Vol. I: Bridge Design \& Load Rating. Rolla, MO: University of Missouri-Rolla, 2004.

University of Missouri-Rolla. Preservation of Missouri Transportation Infrastructures; Validation of FRP Composite Technology Through Field Testing; Strengthening of Bridge P-0962 Vol. II: Materials \& Construction. Rolla, MO: University of Missouri-Rolla, 2004.

University of Missouri-Rolla. Preservation of Missouri Transportation Infrastructures; Validation of FRP Composite Technology Through Field Testing; Strengthening of Bridge T-0530 Vol. I: Bridge Design \& Load Rating. Rolla, MO: University of Missouri-Rolla, 2004.

University of Missouri-Rolla. Preservation of Missouri Transportation Infrastructures; Validation of FRP Composite Technology Through Field Testing; Strengthening of Bridge X-0495 Vol. I: Bridge Design \& Load Rating. Rolla, MO: University of Missouri-Rolla, 2004.

University of Missouri-Rolla. Preservation of Missouri Transportation Infrastructures; Validation of FRP Composite Technology Through Field Testing; Strengthening of Bridge X-0495 Vol. II: Materials and Construction. Rolla, MO: University of Missouri-Rolla, 2004.

University of Missouri-Rolla. Preservation of Missouri Transportation Infrastructures; Validation of FRP Composite Technology Through Field Testing; Strengthening of 
Bridge X-0596 Vol. I: Bridge Design \& Load Rating. Rolla, MO: University of Missouri-Rolla, 2004.

University of Missouri-Rolla. Preservation of Missouri Transportation Infrastructures; Validation of FRP Composite Technology Through Field Testing; Strengthening of Bridge X-0596 Vol. II: Materials and Construction. Rolla, MO: University of Missouri-Rolla, 2004.

University of Missouri-Rolla. Preservation of Missouri Transportation Infrastructures; Validation of FRP Composite Technology Through Field Testing; Strengthening of Bridge Y-0298 Vol. I: Bridge Design \& Load Rating. Rolla, MO: University of Missouri-Rolla, 2004.

University of Missouri-Rolla. Preservation of Missouri Transportation Infrastructures; Validation of FRP Composite Technology Through Field Testing; Strengthening of Bridge Y-0298 Vol. II: Materials and Construction. Rolla, MO: University of Missouri-Rolla, 2004.

\subsection{Selection of Preferred Combination of Methods for Experimental Program}

Table 4.7 presents a list of some of the literature reviewed in this research and provides a quick summary of the details of the work. Obviously, this experiment could not include all the parameters listed in Table 4.7, so it had to be determined what voids were present in the current research. Of the 51 papers and books listed in the table, 30 studied FRP repair (listed in Table 4.8) and 15 discussed experiments with FRP repair of laboratoryscale beam specimens. Only 10 of these experiments included the repair large-scale specimens, only 5 of which incorporated transverse FRP in at least one wrapping scheme (highlighted in red in Table 4.8) and only 2 of which incorporated fatigue of the FRP system (with stars beside the author's name in Table 4.8). Only 3 of these 10 experiments applied additional corrosion current after FRP repair. For accelerated aging, 22 of the 51 papers incorporated accelerated aging of reinforced concrete, 20 of which 
added chlorides to the concrete mix and 12 of which used an induced electric current method.

From this analysis of literature, it was determined that large scale specimens should be used, various wrapping schemes should be examined, fatigue effects on FRP systems should be studied, and specimens should be subjected to accelerated corrosion after FRP repair. It was also concluded that the addition of chlorides to the concrete mix coupled with the application of electric current to the reinforcing steel would provide a successful method of accelerated aging. The experimentation plan for this research was designed to incorporate these key parameters. 
Table 4.7: Literature review summary

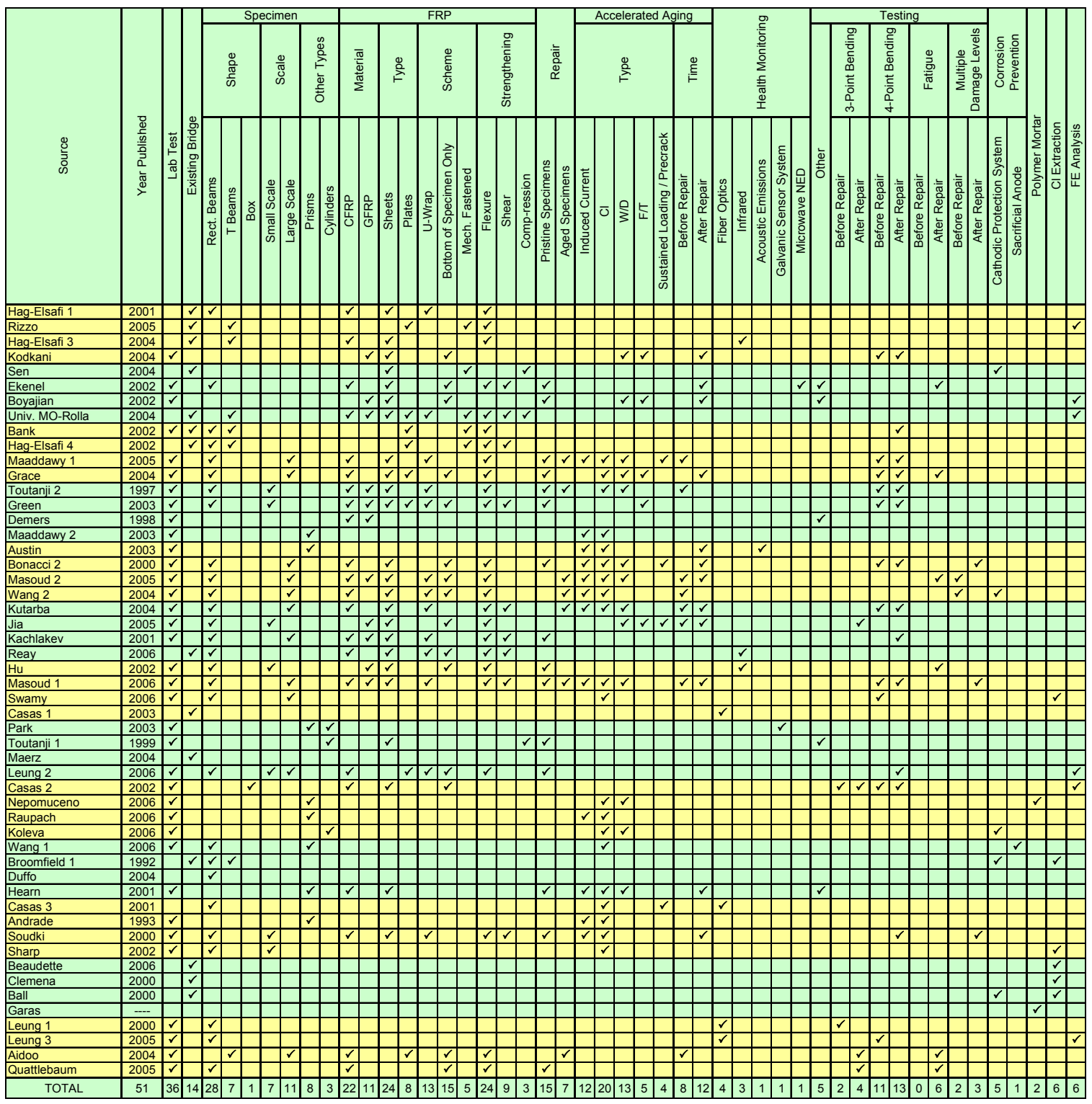


Table 4.8: Breakdown of literature review summary

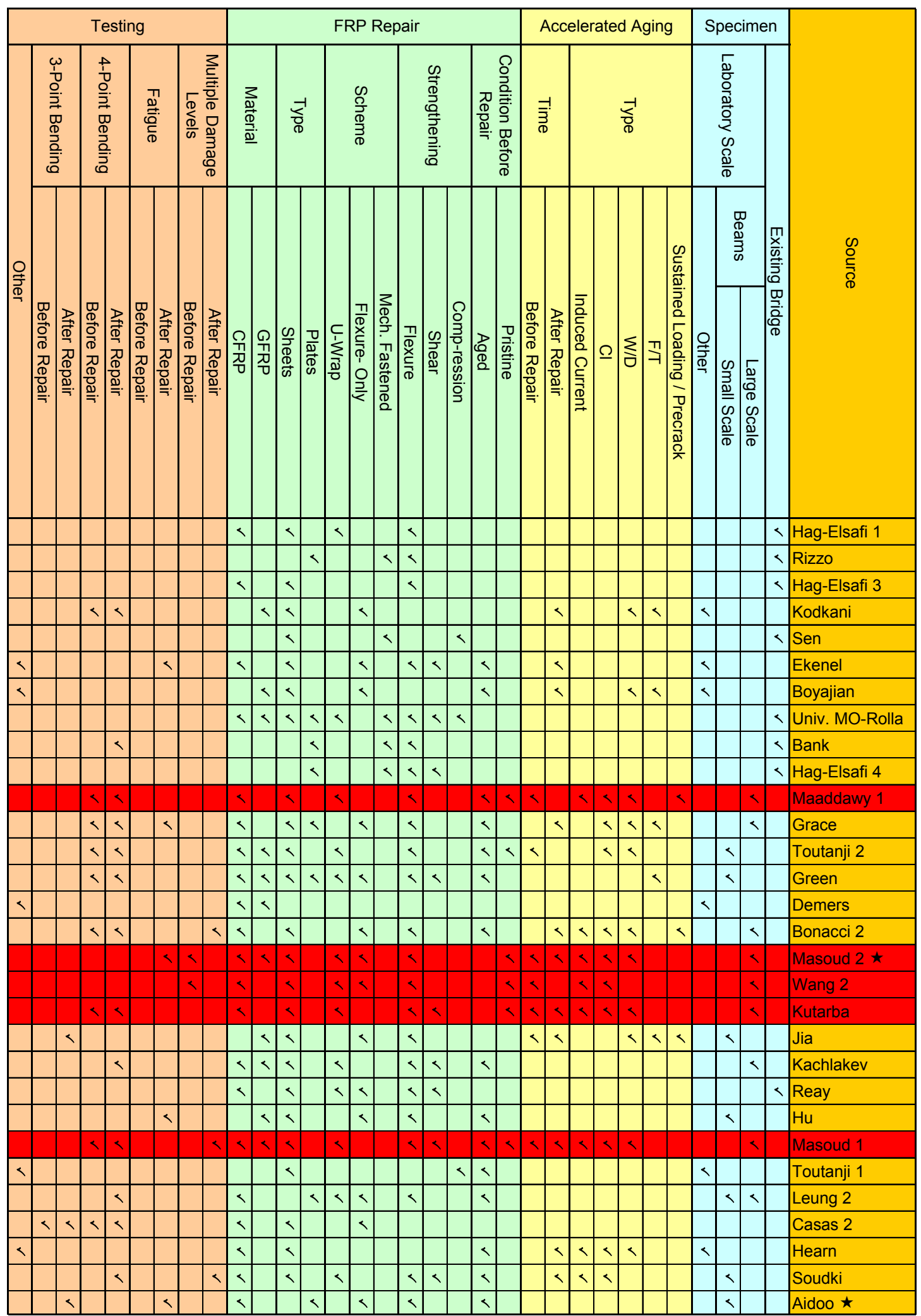




\section{Chapter 5: Experimental Program}

\subsection{Introduction and Overview of Laboratory Testing Plan}

As previously stated, the goal of this research was to determine the most durable, reliable, and economical currently available method of repairing concrete bridge girders. Therefore, a laboratory testing plan needed to be designed that would provide insight into the best methods of substrate repair, the best FRP wrapping scheme, and the long-term performance of complete repairs.

This two-part study consisted of 36 large-scale reinforced concrete beam specimens which were cast using chloride contaminated, low-strength, highly porous concrete. In both parts of experimentation, an electrochemical accelerated corrosion technique was applied to the beams. Part I consisted of 15 beams with dimensions 6" x 8" x 108 " and Part II consisted of 21 beams with dimensions 6" x 8" x 78". The objectives of Part I were to compare two different substrate repair methods and to study the long-term durability by inducing additional corrosion after repair. Part I was broken down into two branches. In the first branch, the concrete cover of the initially corroded beams was removed and the beams were patch repaired along their entire length. In the second branch, the deteriorated concrete cover was not removed, but instead, all cracks were injected with epoxy. The objective of Part II was to compare the performance of three unique FRP anchorage schemes under both static and cyclic loading. Scheme 1 consisted 
of flexural FRP only, scheme 2 consisted of flexural FRP plus two strategically placed anchor stirrups, and scheme 3 consisted of flexural FRP plus eight evenly spaced anchor stirrups.

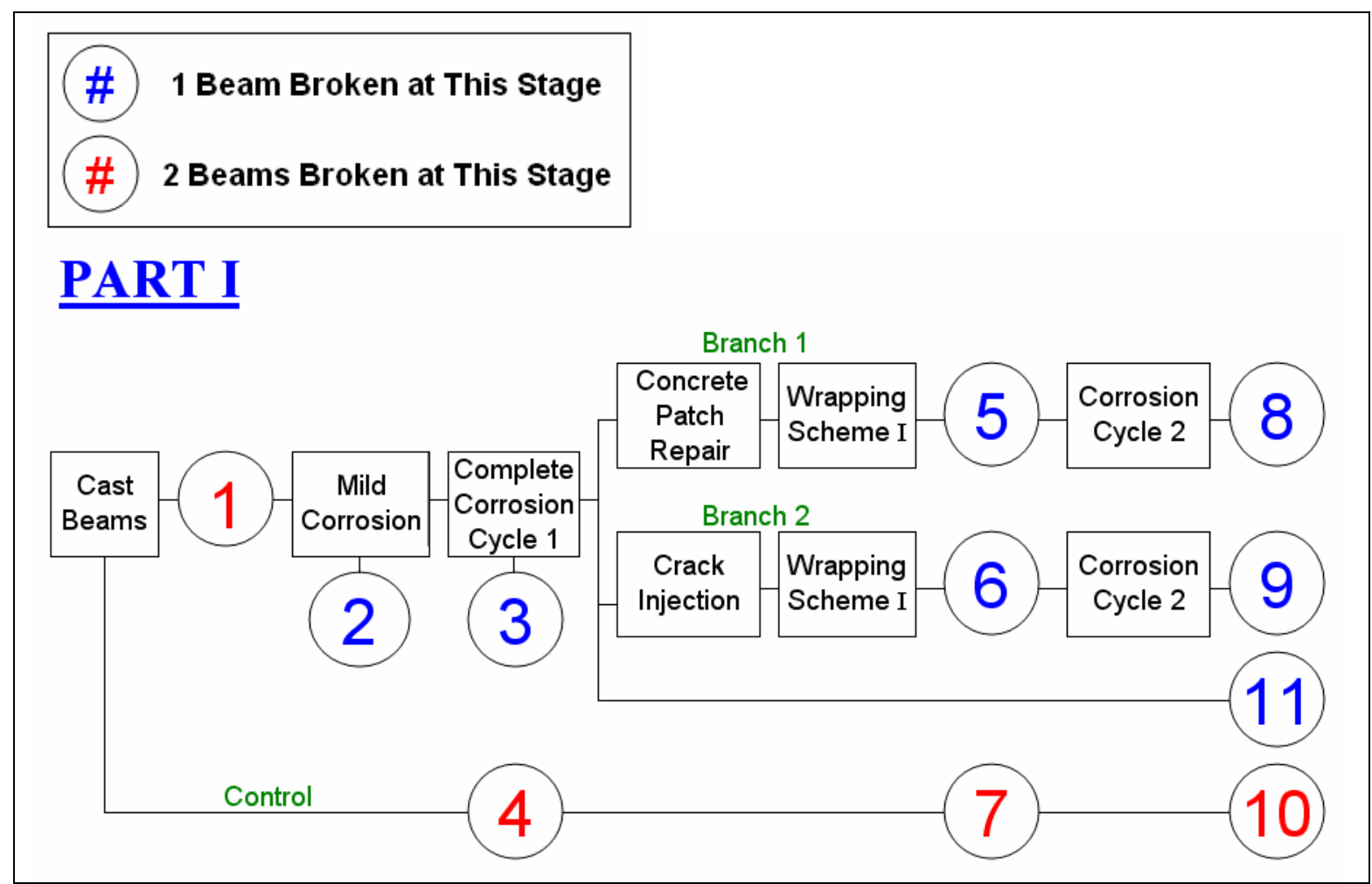

Figure 5.1: Schematic of experimental testing plan Part I

Figure 5.1 and Figure 5.2 show schematic drawings of Parts I and II of the experimental testing plan, respectively. The circled numerals indicate points in which static load tests were performed to failure. The color of each numeral indicates the number of specimens tested at each given stage. Circles which are lined up vertically in the figures indicate those beams were flexure tested at the same age (for example, the control beam breaks indicated by the number 7 were conducted at the same age as were the breaks indicated 
by the numbers 5 and 6 in Figure 5.1). Please refer to these schematics as you read the remainder of this document.

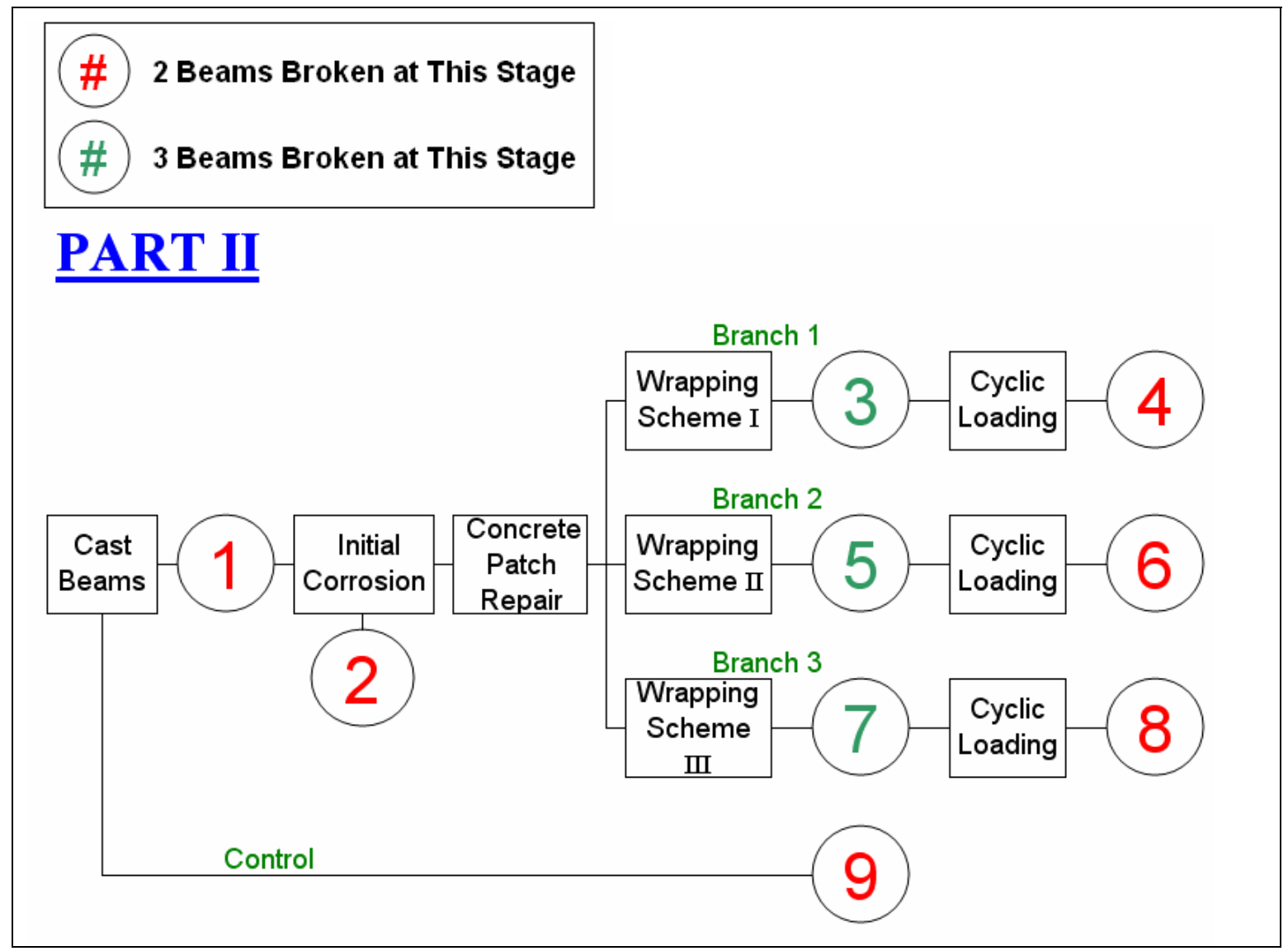

Figure 5.2: Schematic of experimental testing plan Part II

\subsection{Test Specimen}

\subsubsection{Design Philosophy}

As mentioned earlier, it was desired to create a corroded beam specimen that simulated the common conditions found in an actual aged, chloride-contaminated, reinforced concrete bridge girder. The primary step, therefore, was to determine the most 
destructive sources of deterioration that are common in most deteriorated bridges. To obtain direct insight, the material samples from PennDOT Bridge \#49-4012-0250-1032 were analyzed. Scanning electron microscope (SEM) images revealed that the deck and girders consisted of a very porous concrete that was saturated with deicing salts and other contaminants. Chloride content analysis confirmed what was observed in these images. Chloride-induced pitting corrosion was present on tension steel samples extracted from one of the bridge girders.

Figure 5.3, Figure 5.4, and Figure 5.5 are taken from the analysis of a beam sample obtained from PennDOT Bridge \#49-4012-0250-1032. SEM and EDX techniques were used to determine the morphology and qualitative compositions of hydrated pastes in concrete beam samples. The fractured concrete beam specimens were prepared by heating in an oven at $105^{\circ} \mathrm{C}$ for 24 hours, and then were vacuumed and gold coated. SEM and EDX analyses were performed using a Hitachi S 4700 model scanning electron microscope.

These figures indicate that chloride-based de-icing salt exposure for long periods of time may have reacted with aluminous phases and calcium hydroxide crystals in the cement paste and formed the platy crystals shown in Figure 5.3. The solubility of calcium hydroxide increases when exposed to saline solutions. Figure 5.4 indicates the substantial leaching of calcium hydroxide due to the presence of chloride solutions in the concrete. Stacked prismatic crystals with needle-shaped morphology, indicating the 
formation of calcite, can also be seen in Figure 5.4. The EDX data shown in Figure 5.5 strongly confirms what is observed in the SEM photo.

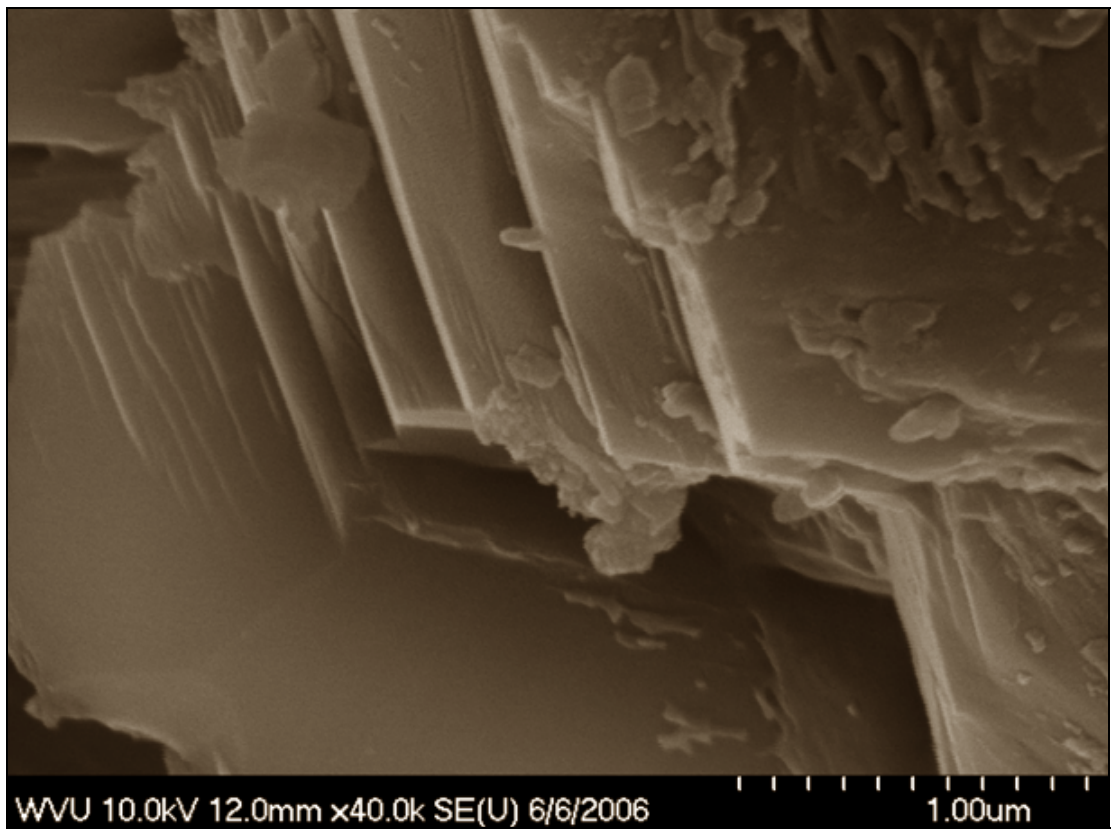

Figure 5.3: SEM photo of concrete extracted from an exterior girder of the PennDOT test bridge showing degradation due to deicing salts

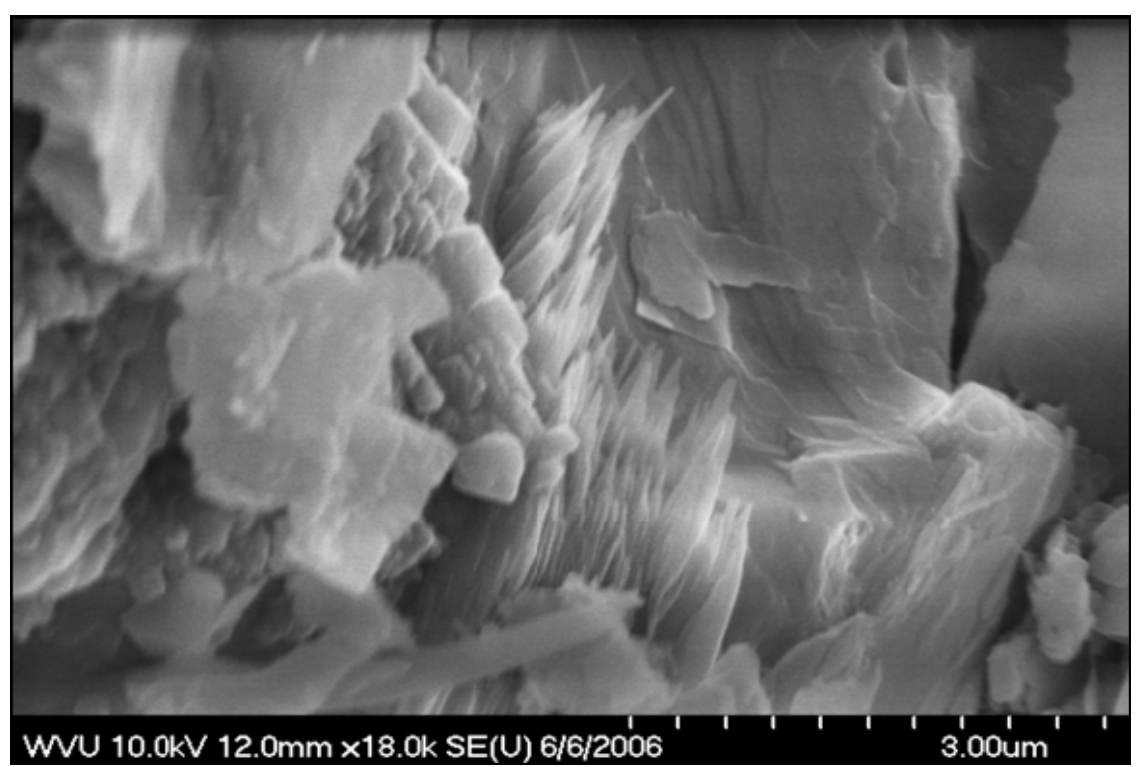

Figure 5.4: SEM photo of concrete extracted from an exterior girder of the PennDOT test bridge showing degradation due to deicing salts 
The EDX data in Figure 5.5 confirmed the formation of calcite, mostly at the expense of calcium hydroxide. Traces of sodium were detected in the EDX spectrum due to the effect of sodium chloride de-icing salts.

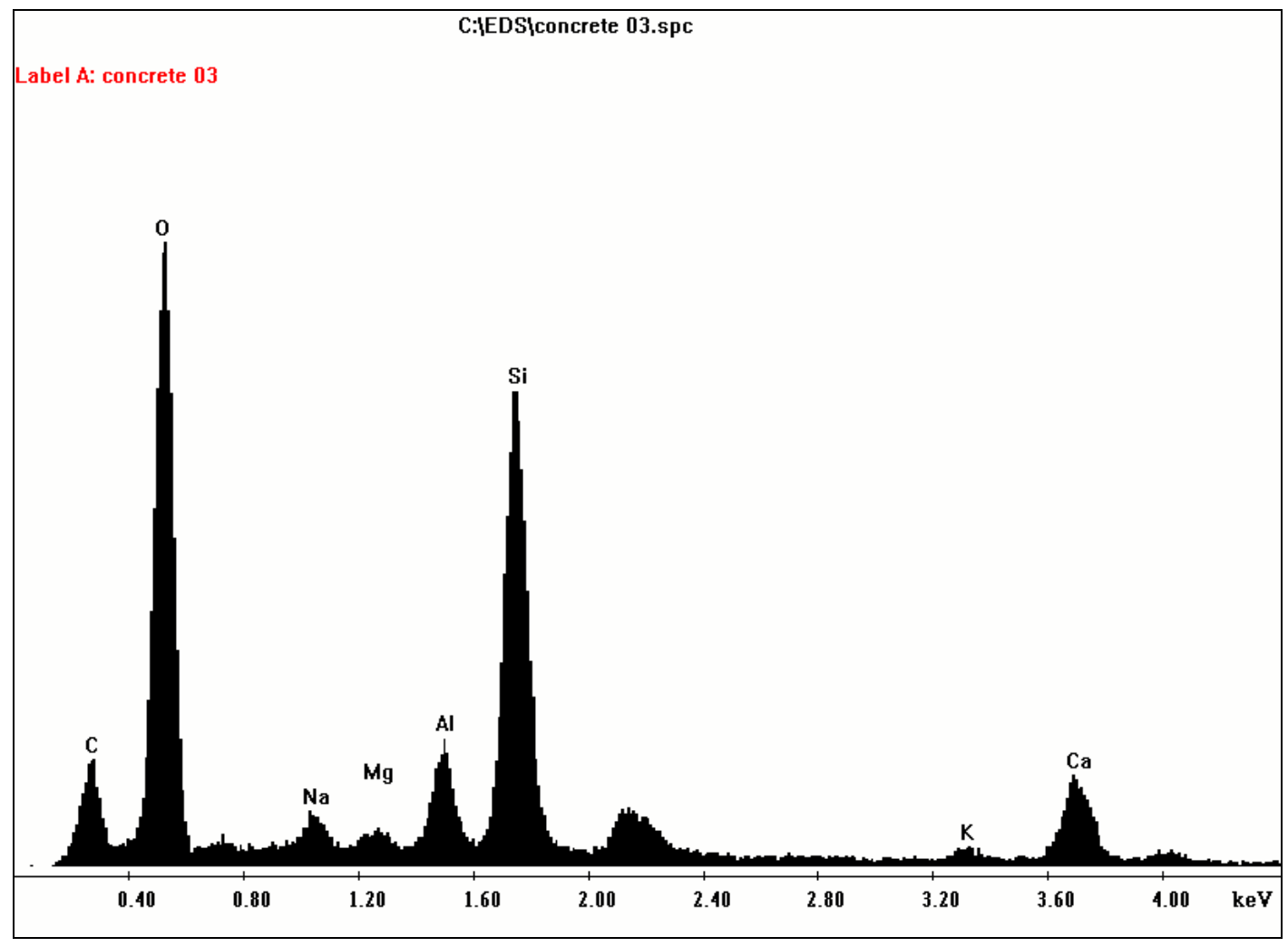

Figure 5.5: EDX spectrum of concrete extracted from an exterior girder of the PennDOT test bridge showing degradation due to deicing salts

Chemical analysis tests conducted on concrete powder samples indicate that a great deal of C-S-H gel and calcium hydroxide had leached from the concrete beams throughout the life of the structure. The SEM-EDX and carbonation tests indicated the probable causes of corrosion-initiated deterioration were carbonation and severe chloride attack. C-S-H gel and calcium hydroxide were converted to mainly calcite and chloroaluminates, which are weak byproducts of the reaction. 
In addition to Bridge \#49-4012-0250-1032, several other similar bridges near Morgantown, WV were visually observed. Concrete cracking, spalling and delamination in the cover layer were common in every deteriorating bridge that was visited. It was also observed that bridge girders in the field had significant moisture contents as evidenced by the prevalent seepage of water, steel corrosion products, and efflorescence, even during relatively dry summer months.

Based on visual observations and the study of corrosion in reinforced concrete, it was determined that the test specimens should have the following deteriorated properties that are common to an aged concrete beam before repair:

- The concrete should be low-strength and porous

- The concrete should be contaminated with embedded chloride salts

- The reinforcing steel should be corroded with pitting

- The concrete cover layer should be cracked and/or delaminated due to expansive corrosion of the reinforcing steel

- The specimens should have a high moisture content

Once these properties were determined, methods were sought to obtain them in the beam specimens. Basic fundamentals of concrete mix technology were applied to produce a concrete that was low strength, porous, and contaminated in order to provide a very favorable environment for reinforcement corrosion within. Details of this concrete are discussed in a later section. 


\subsubsection{Part I Test Specimen}

\subsubsection{Dimensions}

The beams used in Part I had the dimensions 6"x 8"x108" and were tested on a span of 96". This specimen size was chosen for two reasons. First, these dimensions were similar to those used in many related studies. By using a similar scale of specimen, comparisons could more easily and effectively be made. Second, these dimensions yielded a beam in which two tension bars were ideal in satisfying the required crosssectional steel area requirement by ACI (two bars were preferred for the accelerated aging procedure). Steel reinforcement consisted of two \#5 bars (5/8"diameter) for tension, two \#3 bars ( $3 / 8$ " diameter) for compression, and twenty-two \#3 stirrups for shear. The depth of the tension steel was 6-5/16" and the depth of the compression steel was 1-9/16". One inch of concrete cover was provided around the perimeter of each rectangular stirrup bent to the outside dimensions of 4 "x6" with inner radii of $13 / 16$ " at each bend location. (It should be noted here that the ACI guidelines call for at leaset $1 \frac{1}{2}$ " of clear cover. However, for this experiment, this clear cover was scaled down for three reasons. The first reason was the relatively small overall scale of the specimen compared to real-world structures for which the ACI guidelines were written. The second reason was that, with a thinner reinforced concrete cover, the ingress of moisture and contaminants was expedited. The third reason was that, on most aged bridge structures, a large quantity of cover concrete is missing, and therefore a cover thinner than $1 \frac{1 / 2}{2}$ is actually present.) A smooth stainless steel tube with an outer diameter of $3 / 8$ " and a wall thickness of 0.065 " was placed above and between the tension reinforcing bars to serve as the cathode in the accelerated corrosion process. A hook made by bending a \#3 bar was attached to the top 
of the cage on either side. These hooks projected out of the top of the concrete beams so that they could easily be lifted and transported with an overhead crane. The hooks were tied into the rebar cage so that they did not pull out during transport. Diagrams of a Part I beam are provided in Figure 5.6, Figure 5.7, and Figure 5.8.

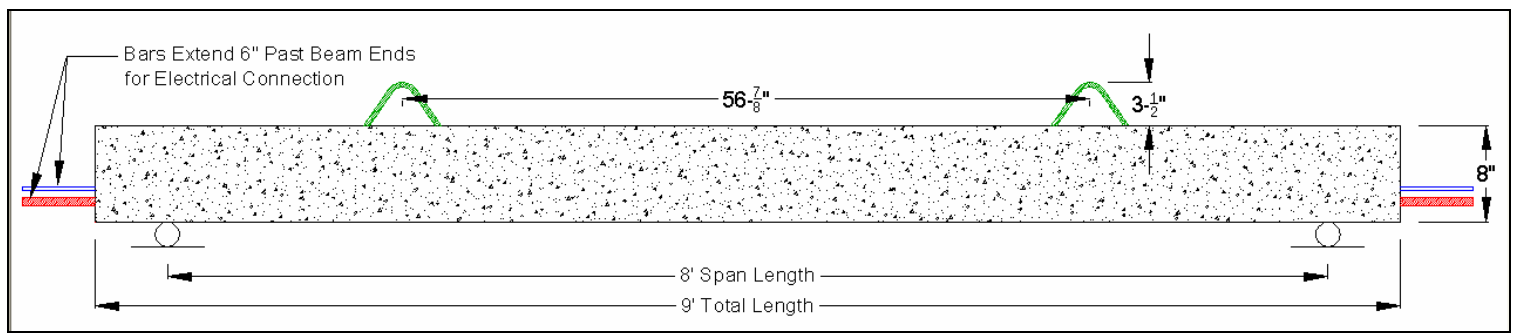

Figure 5.6: Part I Beam Specimen (Profile Dimensions)

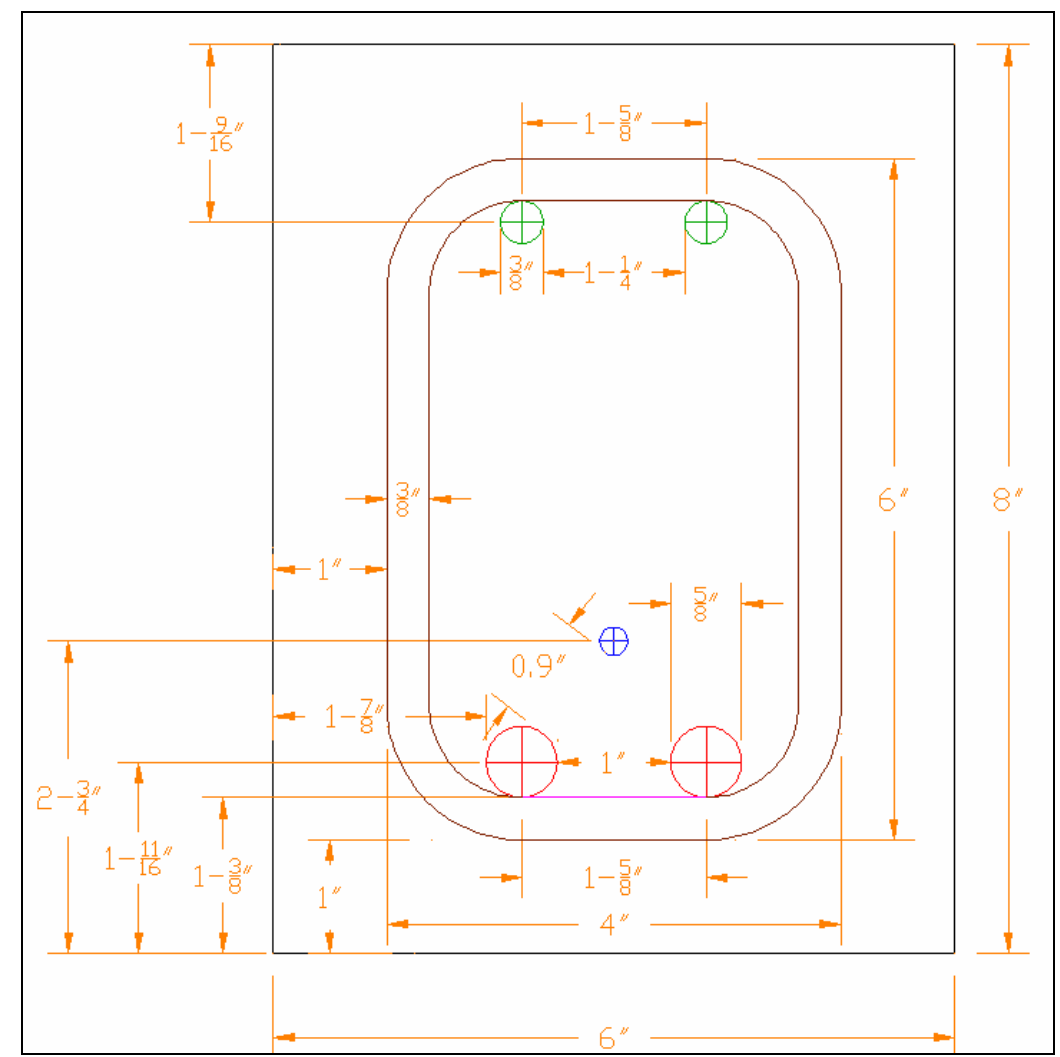

Figure 5.7 Part I Beam Specimen (Cross-Sectional Dimensions) 


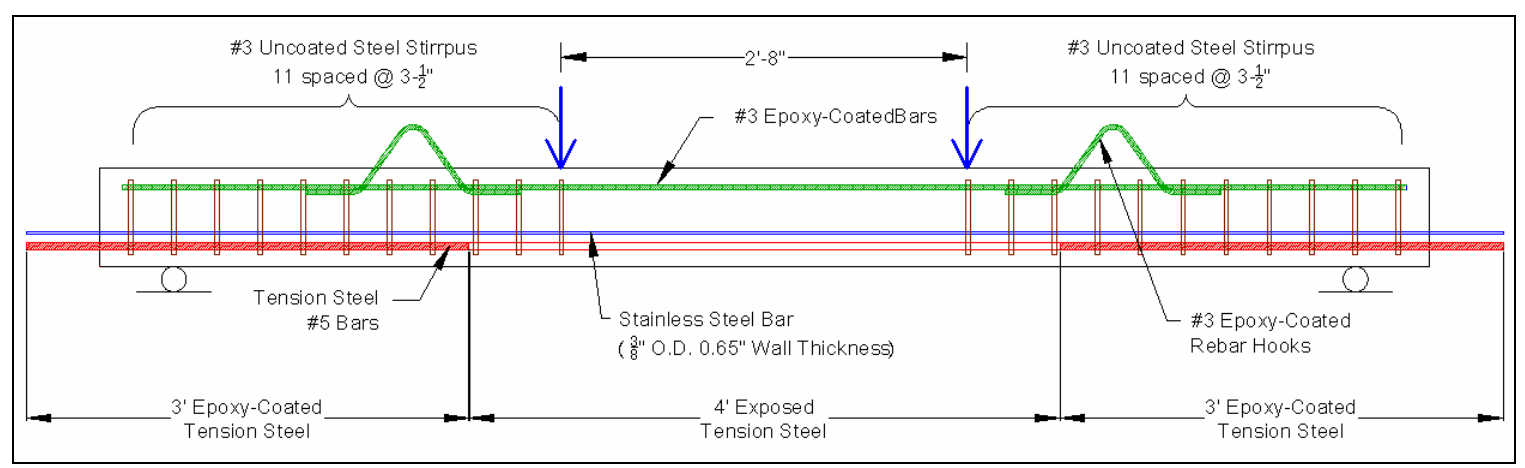

Figure 5.8: Part I Beam Specimen (Reinforcement Diagram)

\subsubsection{Materials}

As mentioned previously, the concrete mix was intentionally designed to simulate the deteriorated concrete found in many aged reinforced concrete bridge girders. The ideal concrete would be low-strength, highly porous, and chloride-contaminated. The concrete's low strength and high porosity were achieved by employing a high water cement ratio of 0.60 . Sodium chloride crystals ( $5 \%$ by weight of cement) were added directly to and dissolved into the mix water to create a corrosive environment for the reinforcing steel. In this concrete, 5\% sodium chloride by weight of cement was equivalent to about $31.23 \mathrm{lbs} / \mathrm{cy}$, a value that far exceeds the commonly accepted corrosion threshold quantity of $1 \mathrm{lb} / \mathrm{cy}$ (for when $\mathrm{NaCl}$ is added directly to the mix). The estimated soluble chloride content of the beam concrete samples extracted from PennDOT Bridge \#49-4012-0250-1032 was $0.164 \%$ by mass of cement, while a commonly acceptable threshold limit for reinforcement corrosion is $0.15 \%$. The mix proportions for the intentionally poor-quality concrete can be seen in Table 5.1. 
All steel reinforcement consisted of Grade $60(60 \mathrm{ksi})$ steel $^{\dagger}$. All tension steel except for that within a 4' section at the midspan was epoxy coated in the laboratory using Wabo MBrace Saturant epoxy. This was done in an attempt to confine the corrosion to the tension reinforcement (which failed, as will be discussed later). The compression steel was coated with standard fusion-bonded epoxy before purchase. The tubing was made of seamless Type 304 stainless steel. The coarse aggregate was \#8 limestone. Technical grade sodium chloride crystals were dissolved in the mix water before adding to the concrete. The air entrainer was Master Builders Technologies MB-VR Standard AirEntraining Admixture.

Table 5.1: Concrete Mix Proportions

\begin{tabular}{|l|l|}
\hline Material & $\begin{array}{l}\text { Material/Cement } \\
\text { Ratio }\end{array}$ \\
\hline \# 8 Coarse Aggregate & 2.42 \\
\hline Sand & 1.92 \\
\hline Water & 0.6 \\
\hline Sodium Chloride & 0.05 \\
\hline $\begin{array}{l}\text { Air Entraining } \\
\text { Admixture }\end{array}$ & $(22.4 \mathrm{~mL} / \mathrm{cu} . \mathrm{ft})$. \\
\hline
\end{tabular}

$\dagger$ The reinforcing steel in PennDOT Bridge \#49-4012-0250-1032 was found to have a strength of 36ksi. Either 36 or $40 \mathrm{ksi}$ steel exists in many old concrete bridges. It should be noted that $40 \mathrm{ksi}$ steel was sought for use in this experiment, but it was not readily available. 


\subsubsection{Construction}

All stirrup-bending was done professionally due to the large quantity, the necessity for all stirrups to effectively have the same dimensions, and the time constraints of the project.

Electrical tape was wrapped around the four corners of each stirrup at locations where the tension or compression steel were to make contact (see Figure 5.9). This was done as an effort to prevent direct electrical contact between reinforcing steel components. The stirrups were not insulated at any other location (which also proved to be problematic as will be seen later).
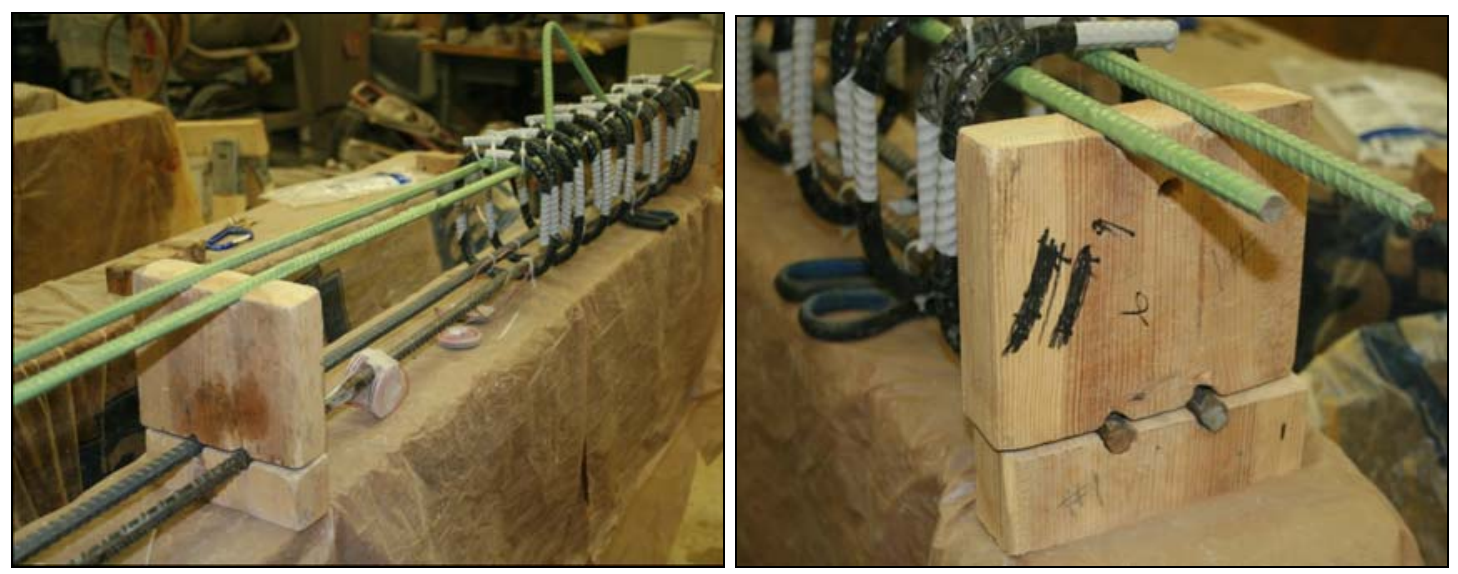

Figure 5.9: Wooden jigs used in assembly of rebar cages. Also seen is the electrical tape around corners of stirrups at contact points with longitudinal bars.

A rebar cage was assembled for each beam using wooden jigs to ensure all reinforcement dimensions were the same for each beam (see Figure 5.9). The reinforcement cages were tied together using plastic cable ties to prevent electrical contact between tension, compression, and shear reinforcing steel components. Eleven stirrups were placed in each of the shear regions and were evenly spaced at $3 \frac{1}{2}$ ". No stirrups were placed within 
constant moment region. The hollow stainless steel tube was set into the jig and suspended from the compression steel by nylon fishing line to a height of $1-1 / 16$ " above the centroid of the tension steel. Finally, the wooden jigs were removed and the cages were ready to be placed in the molds (see Figure 5.10).

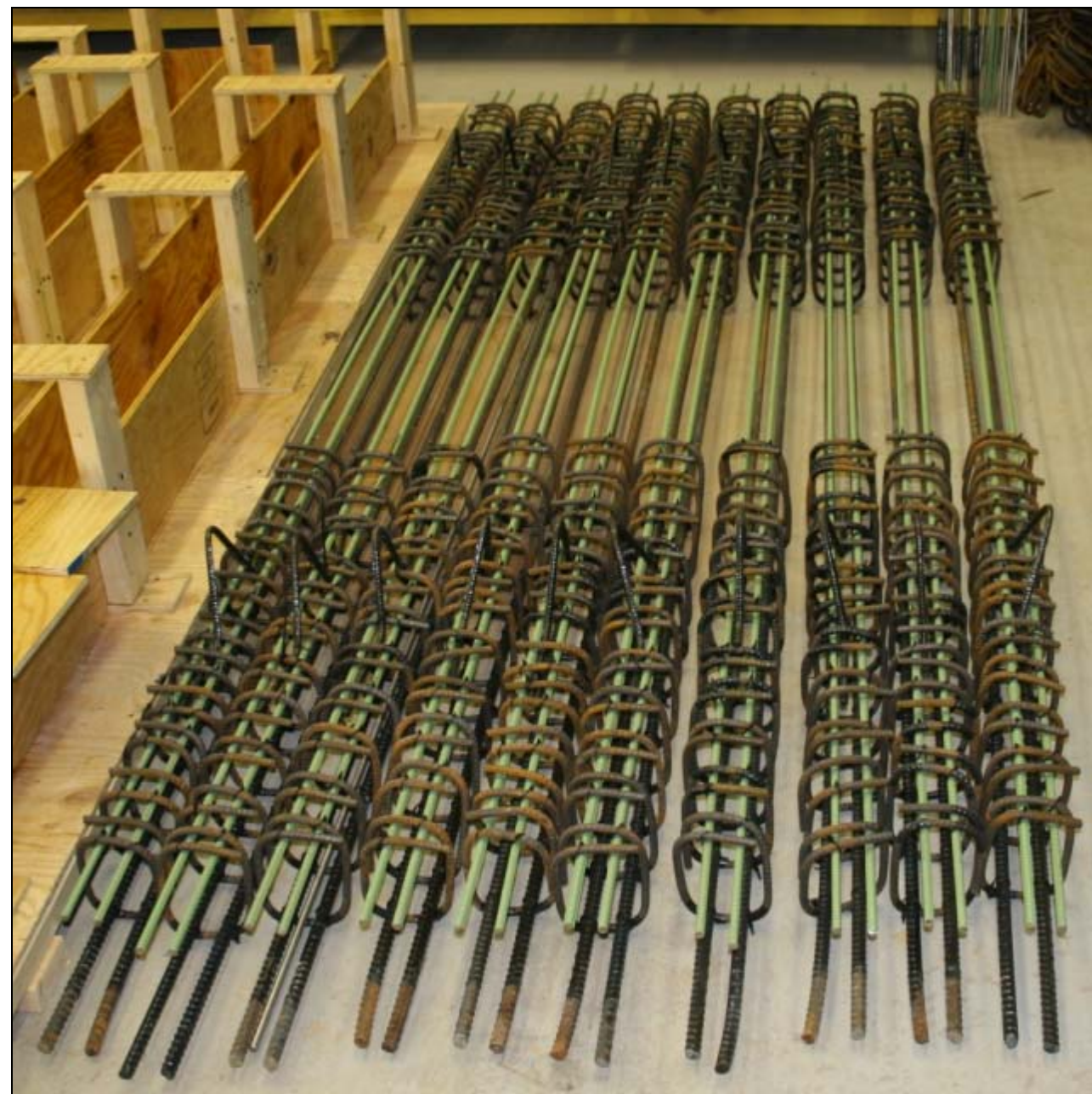

Figure 5.10: Completed rebar cages

The forms used to cast the beams were made of $1 / 2$ " thick plywood and reinforced with wooden 2x4's. The forms were designed so that they could be quickly and easily assembled and disassembled. The forms were required to be robust since they would be needed several times for reuse. The bottoms of the forms were reinforced with both 
longitudinal and transverse $2 \times 4$ 's to resist against warping. The sides of the molds were reinforced with five evenly spaced wooden $2 \times 4$ ribs to prevent warping and bending due to the weight of the concrete (see Figure 5.11). Holes were drilled in the wooden end walls of each form to allow the protrusion of the reinforcing steel from the ends. The reinforcement was projected out of each beam, not only to support the cages within the forms, but also to provide easy access points at which to make electrical connections to the steel. Before inserting the rebar cages into their respective forms, 1" plastic rebar chairs were placed between the floor of the molds and the bottoms of the stirrups to support the reinforcing steel at a proper and constant depth.

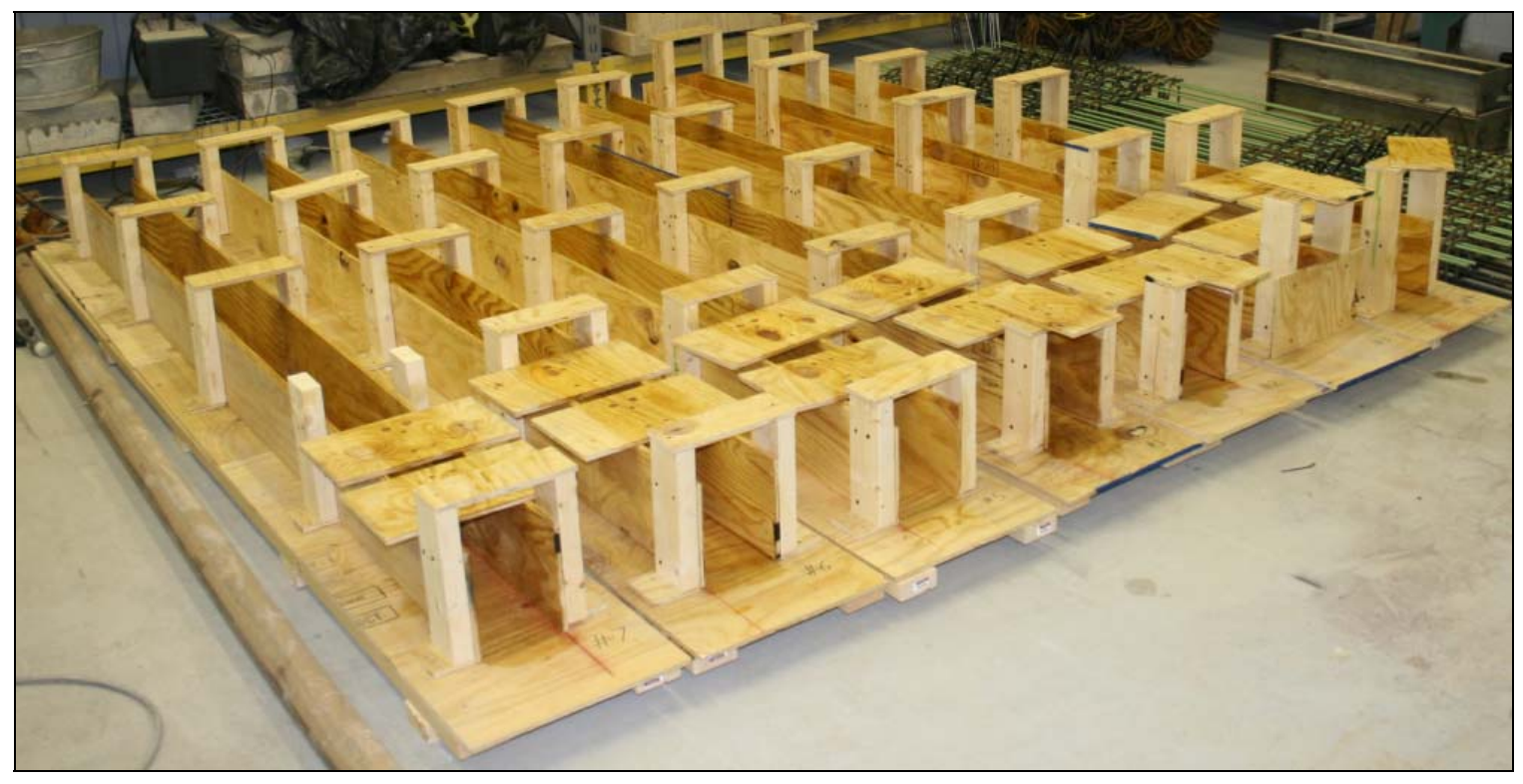

Figure 5.11: Wooden concrete forms built in the WVU laboratory

Once the cages were secured in the forms, the cross sectional dimensions were carefully checked to be within a tolerance of $\pm 1 / 16$ over the length of each beam. If the dimensions were outside of this tolerance, additional supports were added to the form as needed. 
Concrete was mixed using a Stow paddle mixer with a capacity of $3 f t^{3}$ and reconfigured by WVU technicians operate at variable speeds. To begin, the walls and paddles of the mixer were wetted and excess water was removed. First, approximately half the water needed for the batch was added to the mixer. Next, the coarse aggregate was added and mixed to enable wetting of all coarse aggregate surface area. The prescribed amount of air entraining admixture was added and mechanically mixed into the sand before it was placed into the mixer. After adding the sand and air entrainer, the mixer was once again run until the mixture was well blended. Surface moisture readings were recorded for both coarse and fine aggregate using a T-90 Trident Microwave Moisture Meter. The quantity of water present in the aggregate in the form of surface moisture was added to the total weight of water and subtracted from the total weight of aggregate. Before adding the remaining mix water, sodium chloride crystals were added to and dissolved into the water by vigorously stirring water for five minutes. Once the $\mathrm{NaCl}$ was completely dissolved, the cement and the remaining mix water were placed into the mixer. The concrete was mixed until uniformly blended.

The concrete was carefully and gently placed into the forms using buckets and shovels. Since the concrete had such a high water cement ratio, it was extremely workable and essentially self-consolidated around the rebar cages. When the forms were completely filled with concrete, a 13,000VPM concrete vibrator was touched to the sides of the forms at the locations of the $2 \times 4$ ribs for only a few seconds at each location. Vibration was applied only briefly so that the low-viscosity concrete mixture did not segregate. 


\subsubsection{Part II Test Specimen}

\subsubsection{Dimensions}

The beams used in Part II had the dimensions 6"x 8"x78" and were tested on a span of 72". The Part II specimens were shortened and the rebar size was reduced (compared to the Part I specimens) in order to expediate the accelerated aging process. By decreasing the total steel surface area within the concrete, the same electric current would result in more rapid corrosion. This is discussed further in Section 6.1.1. Steel reinforcement consisted of two \#4 bars (1/2"diameter) for tension, two \#3 bars (3/8" diameter) for compression, and \#3 stirrups for shear. The depth of the tension steel was $63 / 8$ " and the depth of the compression steel was 1-9/16". The dimensions of the stirrups, the stainless steel tubes, and the hooks were the same as that described for Part I specimens. Diagrams of the Part II beams are given in Figure 5.12, Figure 5.13, and Figure 5.14.

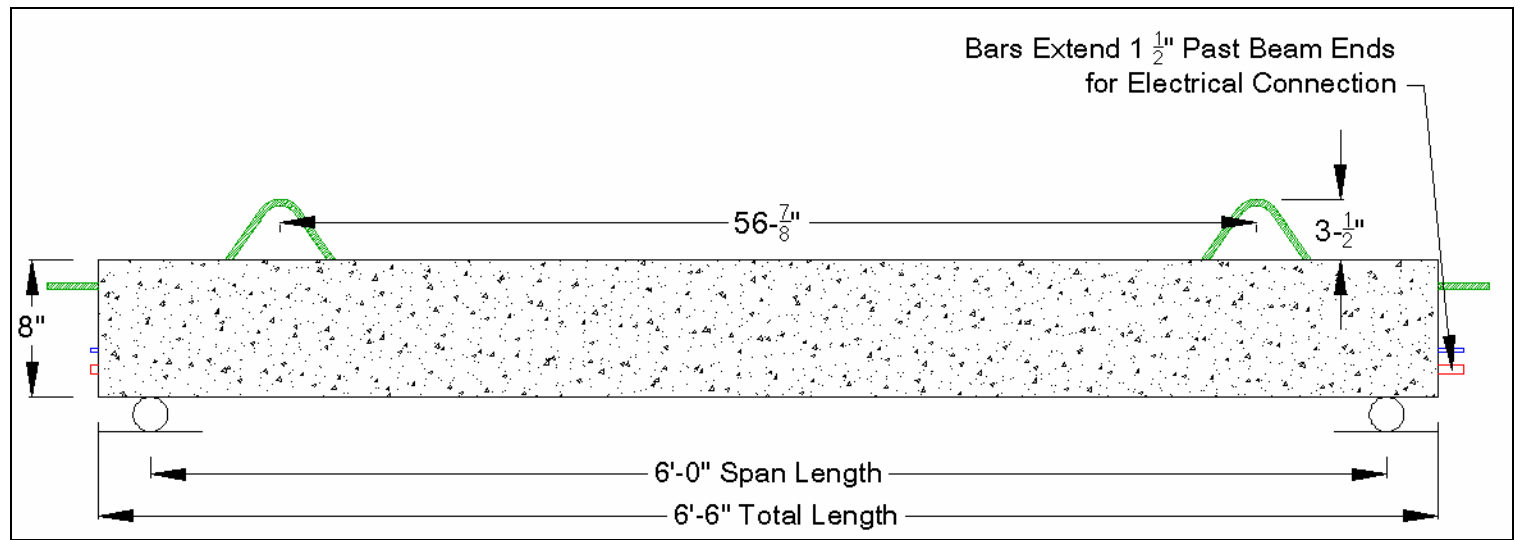

Figure 5.12: Part II Beam Specimen (Profile Dimensions) 


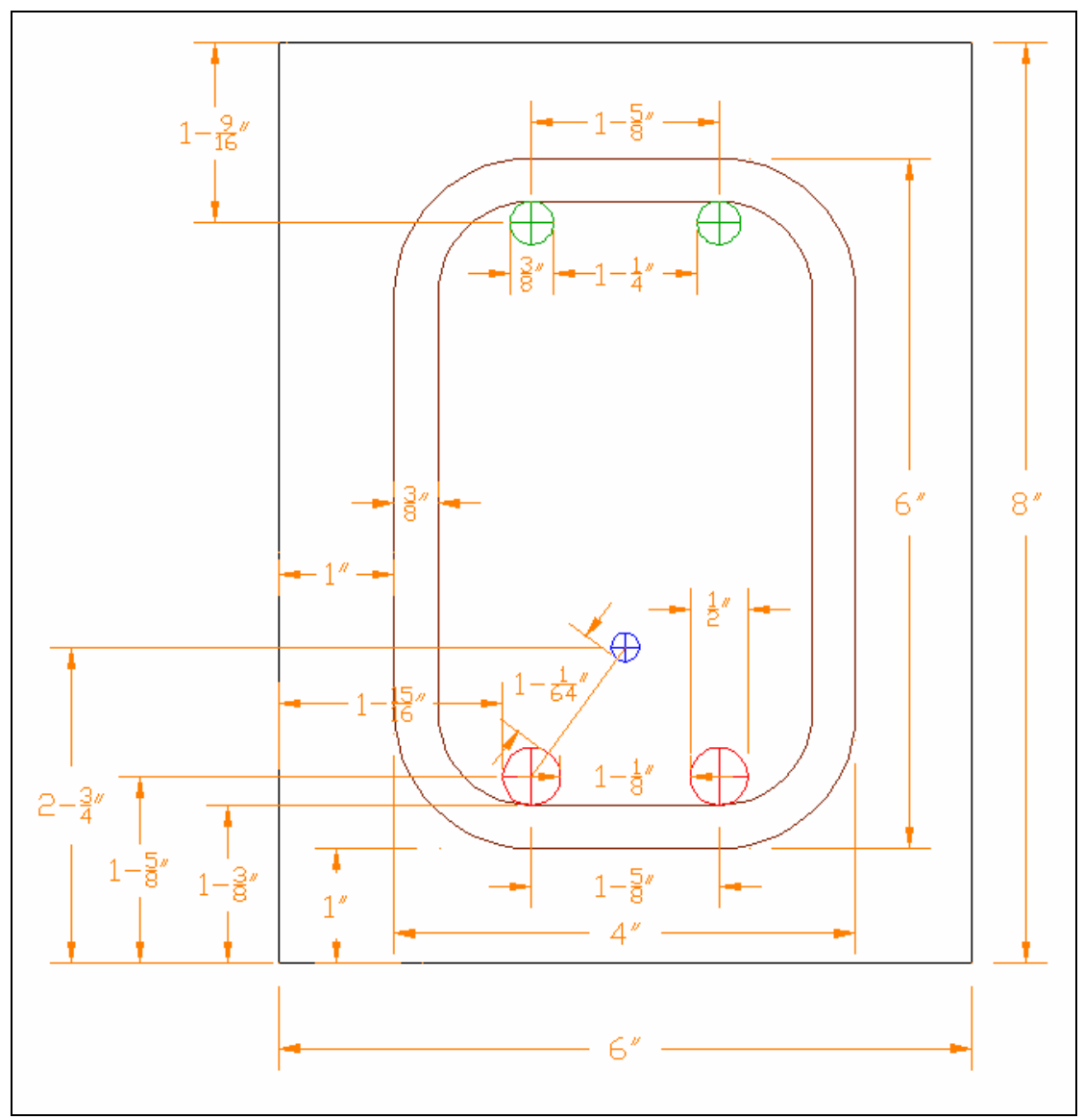

Figure 5.13: Part II Beam Specimen (Cross-Sectional Dimensions)

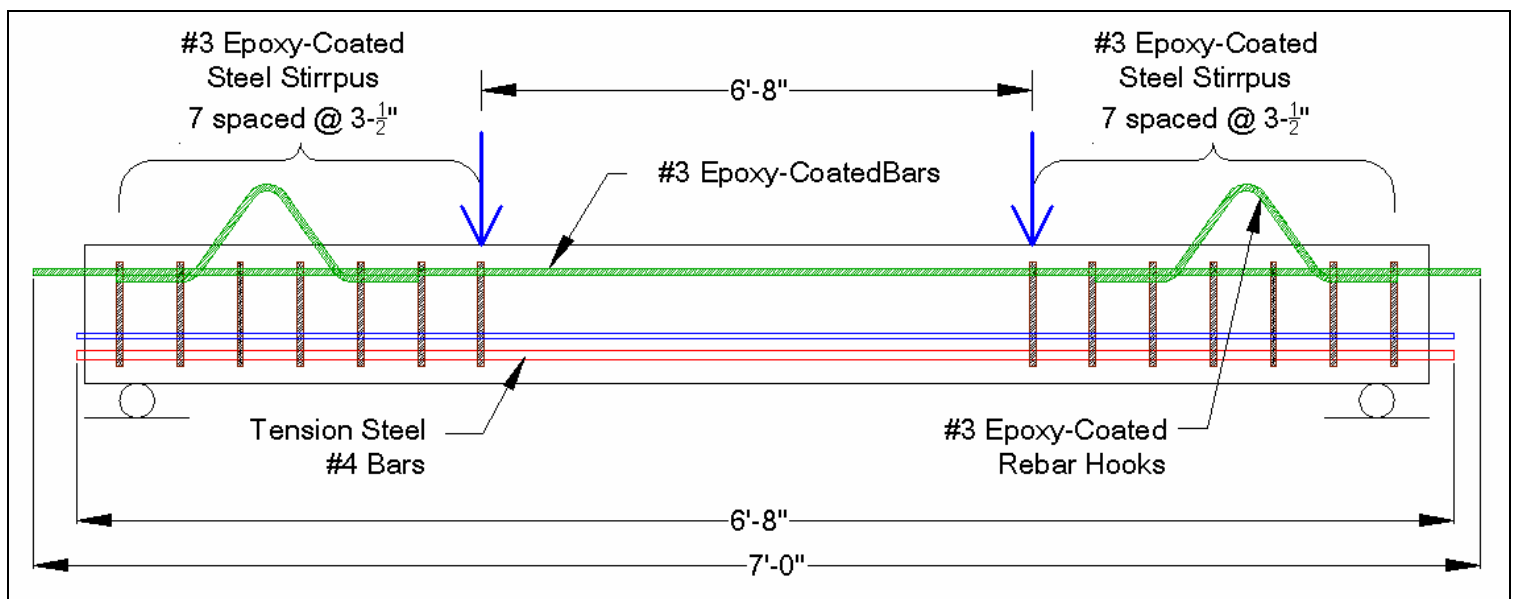

Figure 5.14: Part II Beam Specimen (Reinforcement Diagram) 


\subsubsection{Materials}

Mix proportions and materials in the concrete as well as the types and grades of steel and stainless steel were the same as those described for Part I specimens. In Part II, however, the entire surface area tension steel was exposed to the surrounding concrete over the entire length of each beam and no epoxy coating was used. As in Part I, the compression steel was coated with standard fusion-bonded epoxy before purchase.

\subsubsection{Construction}

Due to corrosion of the shear reinforcement in Part I, it was decided that all stirrups in Part II specimens would be epoxy coated. Due to the large quantity and necessity for quality and uniform coating, the epoxy coating was sub-contracted to KTA Tator in Pittsburgh, PA. Three-hundred fifty stirrups were dry abrasive blast cleaned using G40 grit to a cleanliness grade of SSPC SP-10/NACE No. 2 (Near-White Blast). The specimens were stored in an oven at a temperature of approximately $60^{\circ} \mathrm{C}$ until the coating was applied. The blast-cleaned stirrups were allowed to cool to room temperature prior to coating. Two coats of Sikagard® 62 were applied by brush to each stirrup. Electrical tape was then wrapped around the four corners of each stirrup at locations where the tension or compression steel were to make contact. This step was no longer an attempt to prohibit electrical contact, but instead, was implemented to protect epoxy coatings from abrasion during assembly of the reinforcing cages. Figure 5.15 shows a shear region of one of the new and improved Part II rebar cages. 


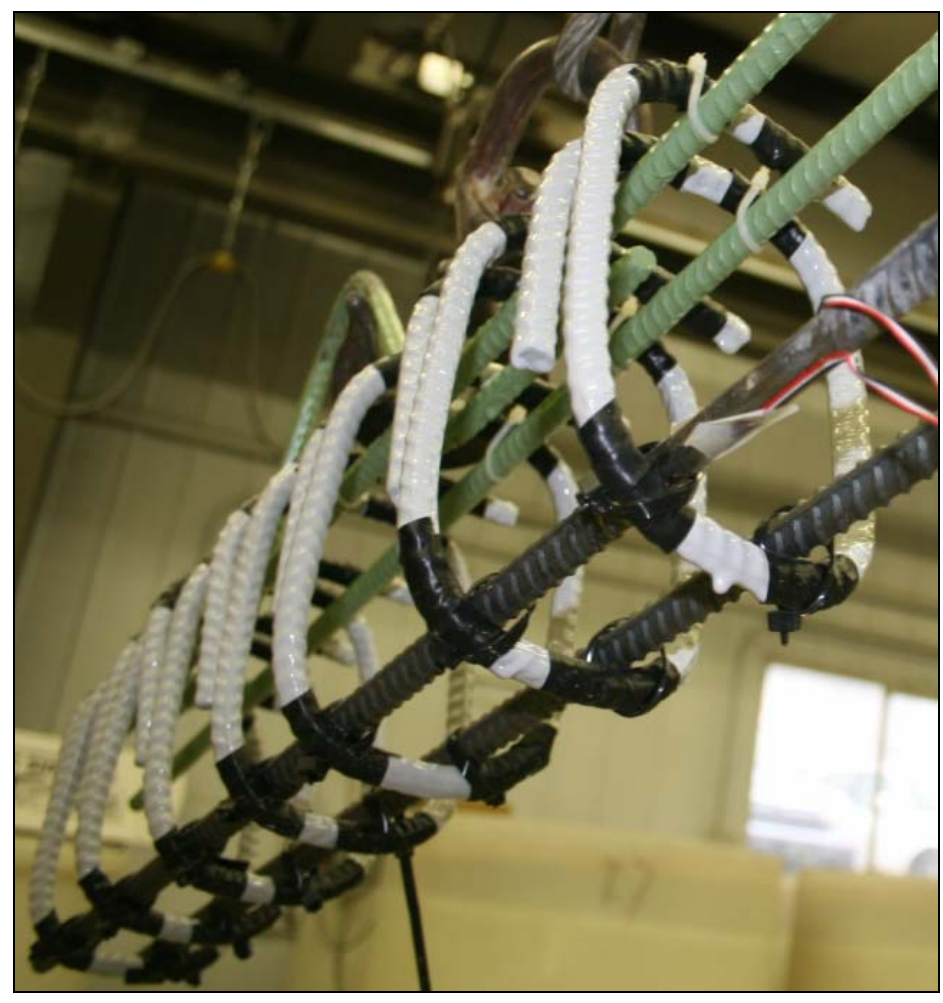

Figure 5.15: Improved Part II rebar cages with epoxy-coated shear stirrups

The procedure for tying the reinforcing cages was the same as that described for Part I. In Part II, fourteen stirrups were placed in the shear regions only, seven spaced at 3.5 " on either side of the 32 " constant moment region.

The same forms that were used for Part I were used for Part II. However, they were modified by shortening the bases and by replacing the 9' long sides with 6'-6"' long sides. All other details about the construction and adjustment of the forms and the production and placing of the concrete are the same as those described for Part I. 


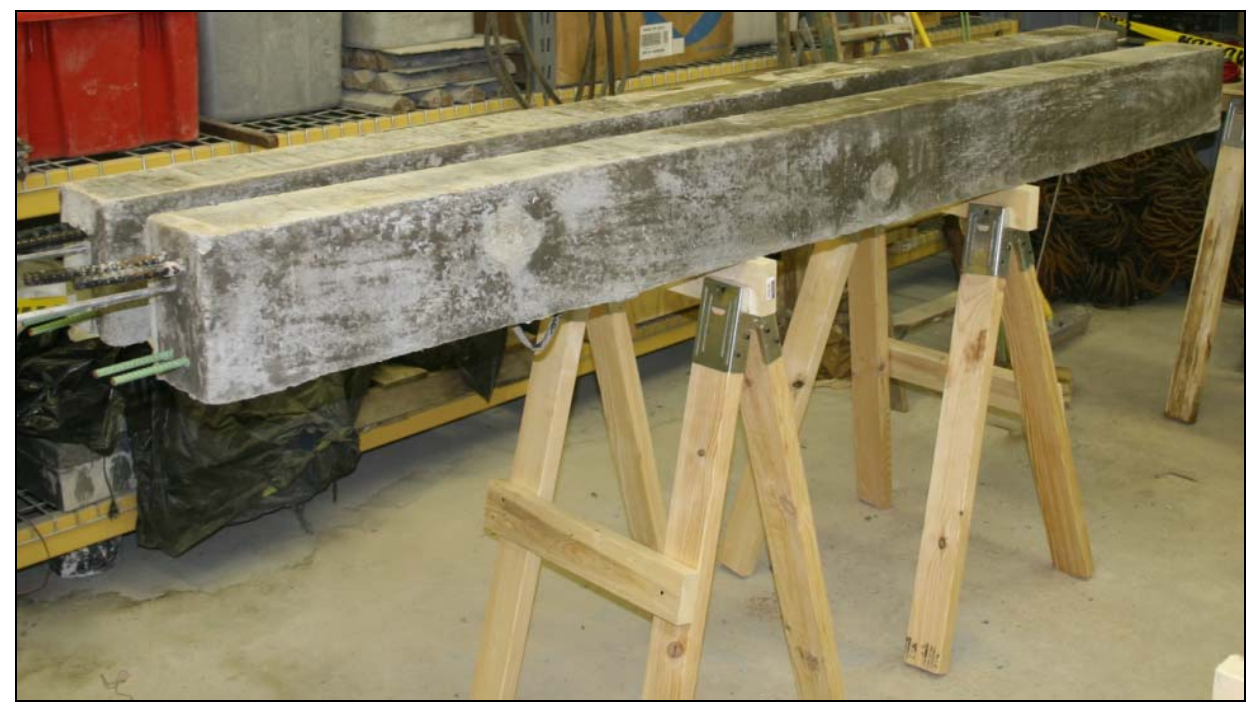

Figure 5.16: Sawhorses holding beams spaced to minimize dead load moments and creep strain

The sawhorses on which all beams sat in the laboratory were spaced at a distance that minimized the positive and negative dead load moments and resulting creep strain, as shown in Figure 5.16. The beams were placed inverted (tension steel side facing upward) so that crack measurements and observations could be easily made and so that the beams could be kept moist (which will be further discussed later). The \#3 compression bars were more than adequate to resist the small bending moments due to self weight while the beams were inverted.

\subsection{Accelerated Aging}

\subsubsection{Introduction}

An accelerated aging technique was needed to produce steel reinforcement corrosion, concrete cover cracking, and possible cover delamination over a period of only several weeks. Various aging methods were studied in literature, including wet/dry cycling, 
freeze/thaw cycling, sustained loading, pre-cracking, chemical soaking, and applying electrical current. It was determined, that for this research, the most effective method of accelerated aging would be via the application of electric current, the addition of chloride to the concrete mix, and a form of wet/dry cycling.

During the planning stages of this experiment, it was contemplated wheter a correlation could be made between the extents of corrosion caused by accelerated aging and natural aging processes. However, it was determined that if such a correlation was discovered, the large quantity of variables present in a large sample set of naturally aging structures would certainly impede its reliability. Some of these variables include climate, average daily traffic, type and amount of deicing salt, construction quality, reinforcement ratio and location, concrete type and quality, cover thickness, type and thickness of deck, drainage mechanism, and previous maintenance, just to name a few. It is because of these variables that some bridges between 20 and 50 years old, for example, are in poor condition while other bridges between 70 and 100 years old are in relatively good condition. For this reason, it would be highly non-conservative, very risky, and irresponsible to attempt assertion that " $\mathrm{x}$ " weeks of accelerated aging is equivalent to " $\mathrm{y}$ " years of naturally occoring corrosion.

\subsubsection{Procedure for Experimental Testing}

\subsubsection{Trial Testing of Impressed Current Method}

To obtain first-hand insight into the effectiveness of the induced current method (which is discussed in detail in the next section), a trial test was done with four small beam 
specimens with the dimensions 6"x 6"x 36". Each beam contained two \#3 rebar spaced so that one inch of concrete cover was provided on each corner. Neither beam contained compression nor shear reinforcement. Two beams had a w/c ratio of 0.55 and two had a w/c ratio of 0.65 . These beams were divided into two sets and were subjected to two unique variations of wetting and drying. One $0.55 \mathrm{w} / \mathrm{c}$ beam and one $0.65 \mathrm{w} / \mathrm{c}$ beam were placed in Group 1 and the remaining $0.55 \mathrm{w} / \mathrm{c}$ and $0.65 \mathrm{w} / \mathrm{c}$ beams were placed in Group 2. Group 1 beams were wrapped in a single layer of wet burlap followed by a layer of plastic during wet cycles. An 0.236 " thick acrylic trough was assembled on the tops of the beams in Group 2 and was made watertight around the concrete using silicone. The troughs were filled with 1" of water during wet cycles. The beams in Group 2 were pre-coated with an all-purpose non-permeable epoxy on all surface areas except for that within the trough, as is standard when building a wetting trough. During dry cycles, the burlap and plastic were removed from Group 1 beams and the troughs were drained with a hand pump from Group 2 beams. Wet/dry cycles were applied in increments of two days wet and two days dry. Table 5.2 provides an overview of these preliminary trial specimens.

\section{Table 5.2: Preliminary Trial Specimens}

\begin{tabular}{|c|c|c|l|}
\hline Group & Beam & w/c Ratio & Method of Wetting \\
\hline \multirow{2}{*}{1} & 1 & 0.55 & \multirow{2}{*}{ Wet Burlap Covered with Plastic } \\
\cline { 2 - 4 } & 2 & 0.65 & \\
\hline \multirow{2}{*}{2} & 3 & 0.55 & \multirow{2}{*}{ Acrylic Trough Filled with 1" of Water } \\
\cline { 2 - 4 } & 4 & 0.65 & \\
\hline
\end{tabular}

After approximately 5 weeks, all beams had undergone severe cracking of the cover layer. Group 1 beams were much more severely corroded and cracked than Group 2 
beams, indicating that the wet burlap method of wetting provided the more effective results. The cover layers on the Group 1 beams were even beginning to spall and delaminate. It was determined that moisture would be introduced to the beam specimens by draping wet burlap over the beams and covering them with plastic.

\subsubsection{Impressed Current Method used in Experimental Testing Plan}

Since the impressed current method for quickly aging reinforced concrete was proven effective for the trial specimens, it was incorporated into the experimental testing plan. Bio-Rad model 1000 power supplies were used to supply a constant electric current to each beam. These sophisticated power supplies were capable of applying constant current by automatically varying voltage and power output. Maximum outputs for these power supplies are given in Table 5.3.

Table 5.3: Maximum Outputs of Bio-Rad 1000 Power Supplies

\begin{tabular}{|l|l|}
\hline Parameter & Maximum Output \\
\hline Current & $500 \mathrm{~mA}$ \\
\hline Voltage & $1000 \mathrm{~V}$ \\
\hline Power & $250 \mathrm{~W}$ \\
\hline
\end{tabular}

Either two or three beams were wired to each power supply as shown in Figure 5.19 and Figure 5.20 using gage-12 rubber-coated solid copper wire. Rebar ground clamps provided a solid electrical connection between the wire and the steel and stainless steel bars. Before connecting any wires, the projecting ends of the tension steel were grinded down to white metal and the stainless steel bars were cleaned by lightly sanding to provide a clean surface on which to fix the clamps (see Figure 5.17). The ends of the copper wire were stripped and sanded before connections were made. An aluminum 
splice connector was used to split the single wire leading to the tension steel into two. This equally divided the current between the two longitudinal tension bars. Before starting the power supplies, all exposed steel was wrapped with electrical tape for the safety of others working in the laboratory (see Figure 5.18).

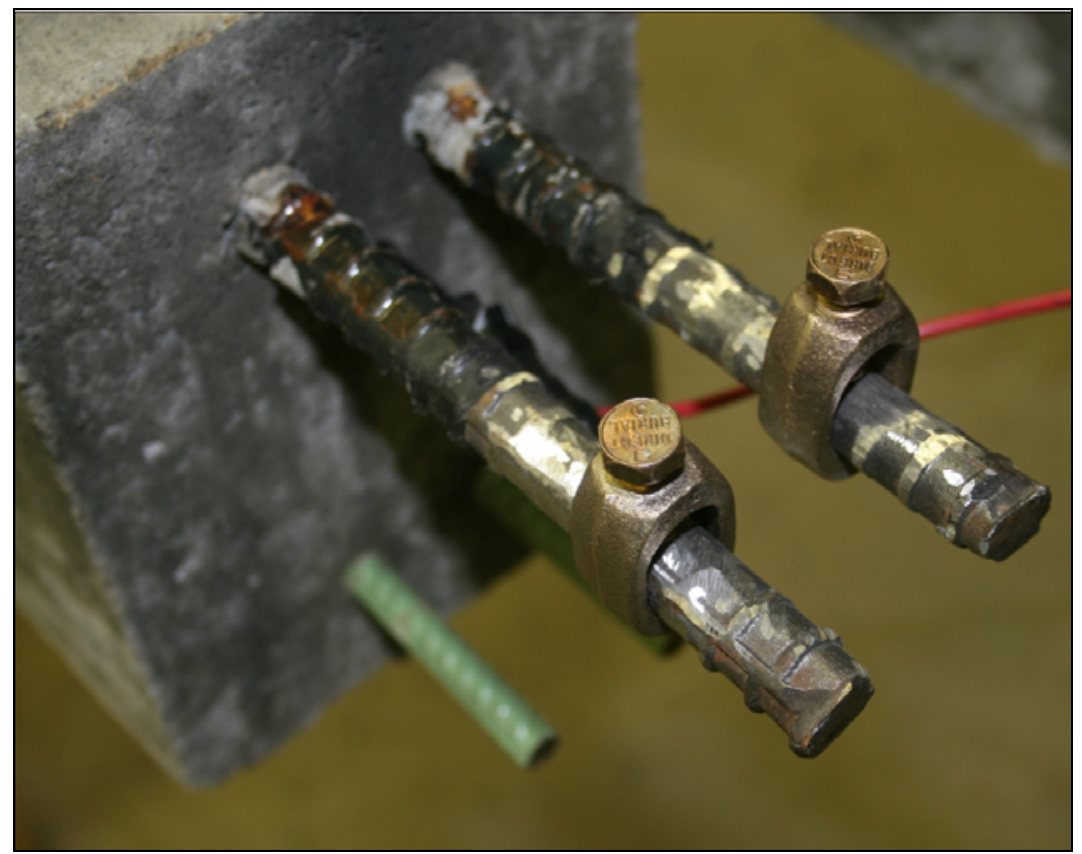

Figure 5.17: Rebar ground clamps attached to steel rebar that was grinded to white metal

In this accelerated aging process, the tension steel acted as the anode, of the actively corroding metal. The stainless steel acted as the cathode and did not corrode. The current entered the beam's stainless steel tube, passed through the concrete, and exited through the beam's tension reinforcing steel. The concrete beams acted as resistors and provided an electrical load within the circuit. 


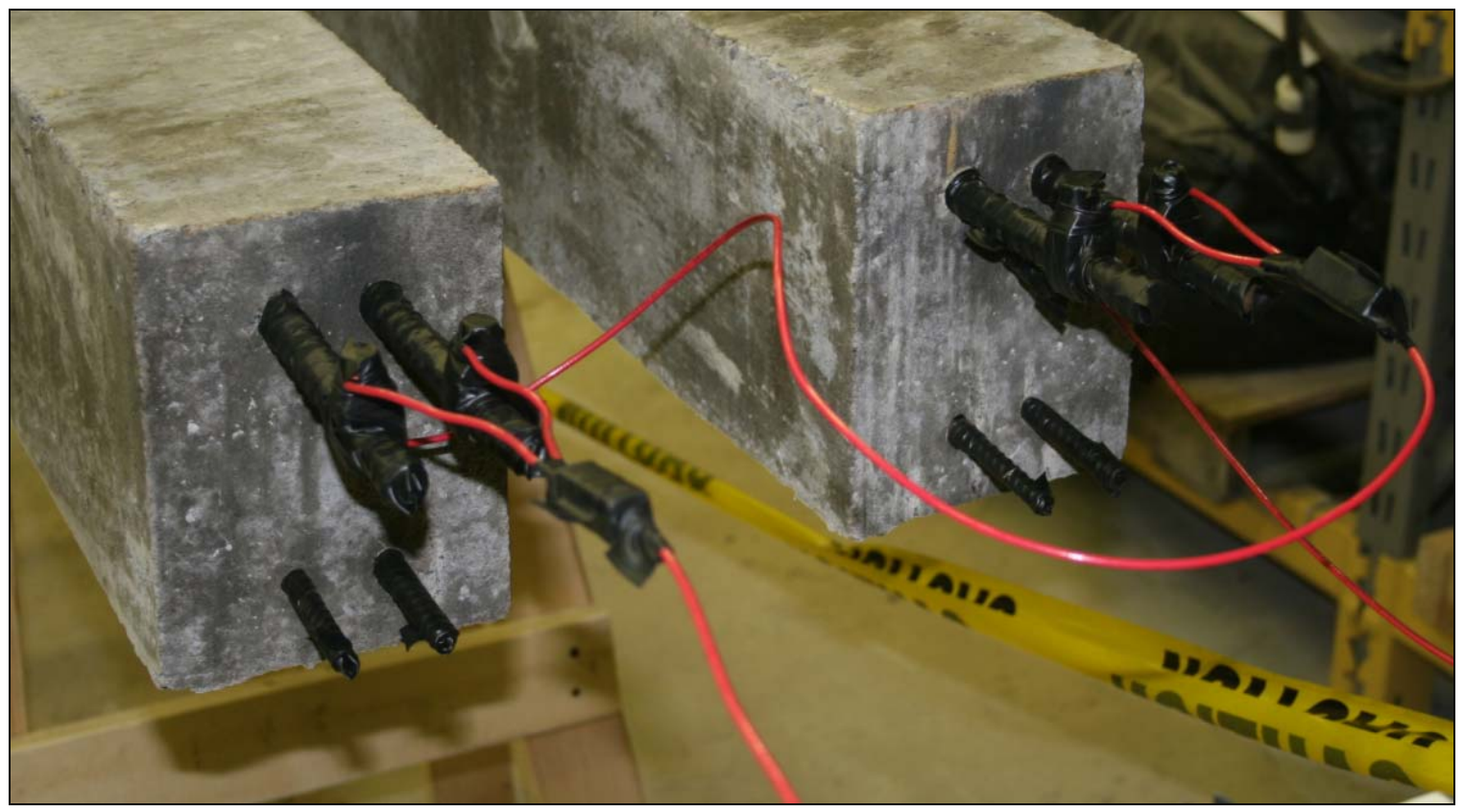

Figure 5.18: Insulation over connections and exposed reinforcing steel

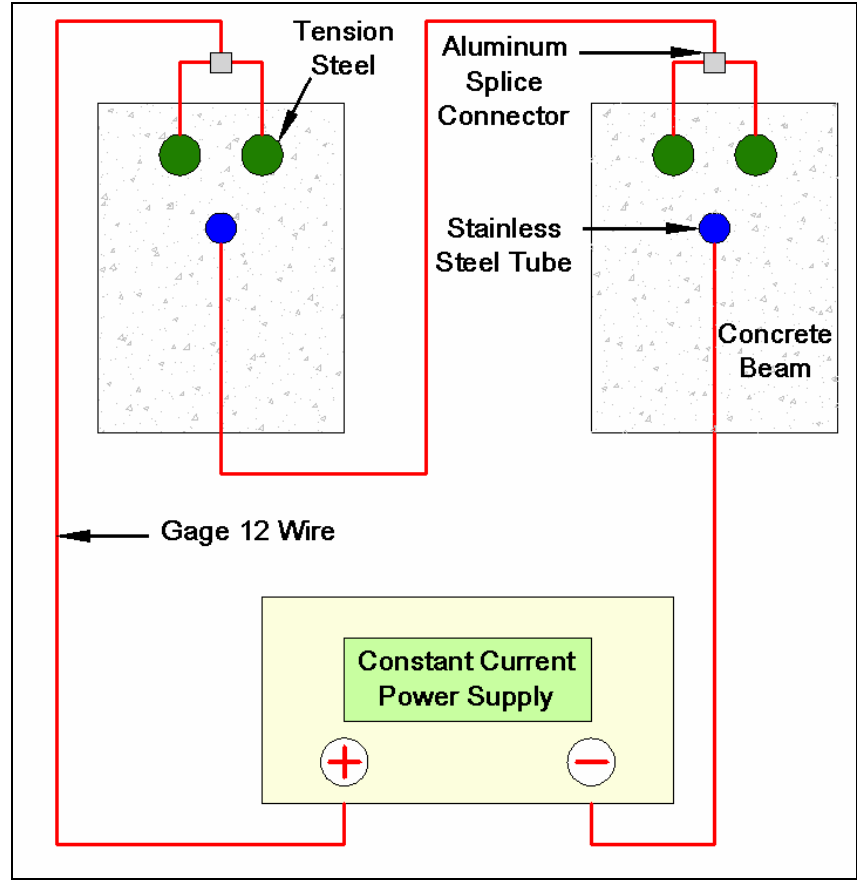

Figure 5.19: Wiring scheme for accelerated aging via induced electric current 


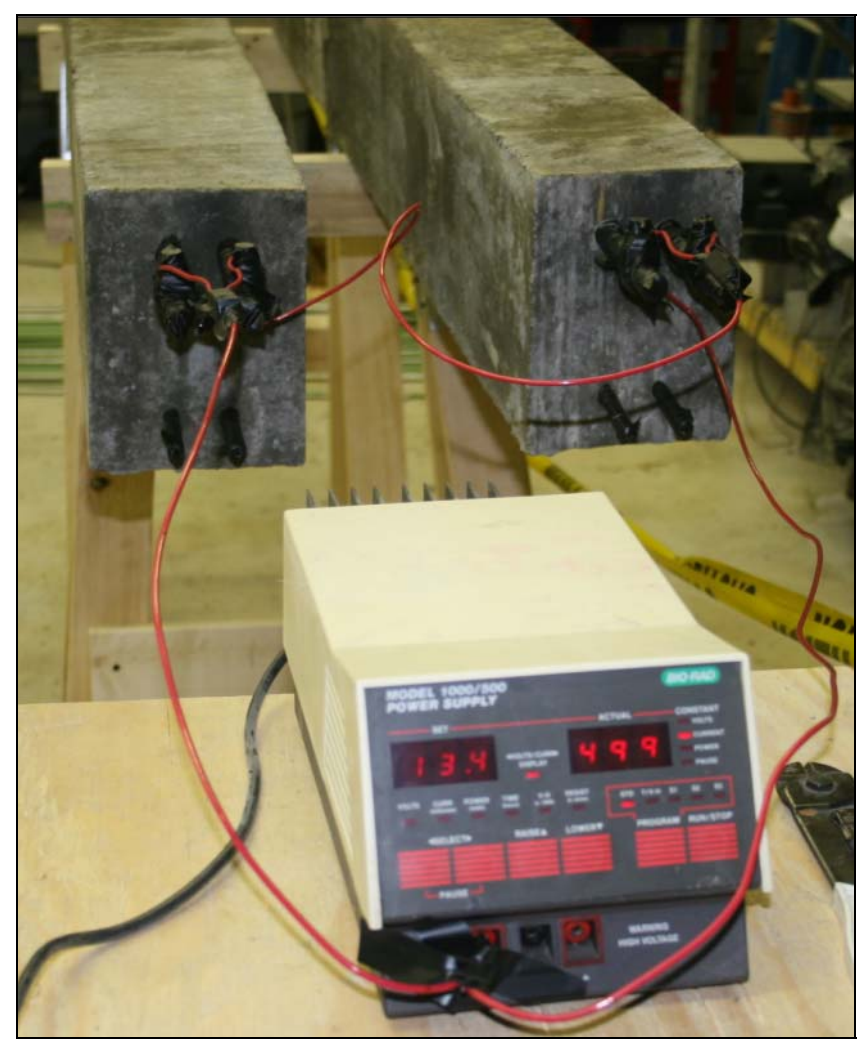

Figure 5.20: Beams wired to power supply

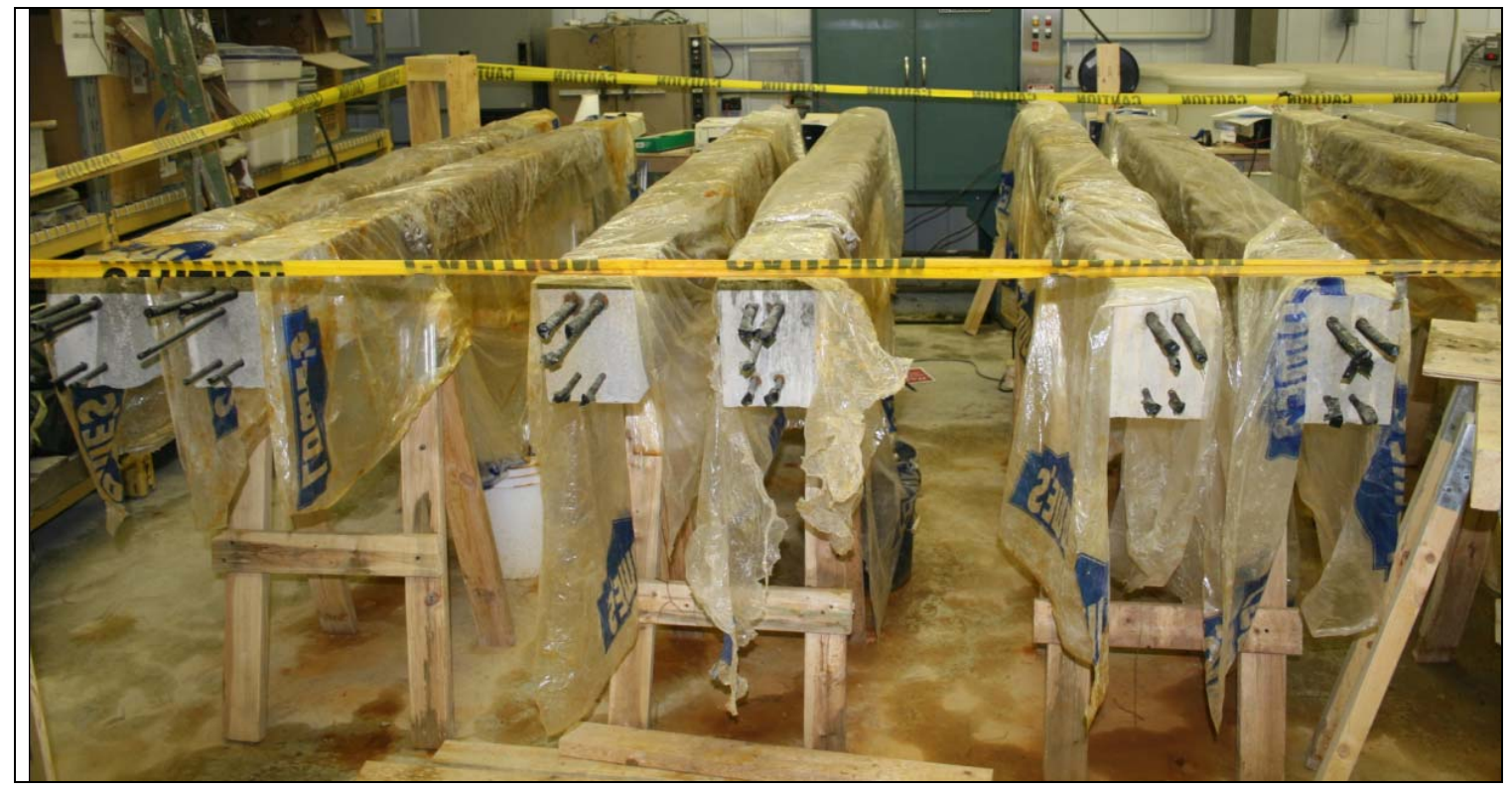

Figure 5.21: Beams covered with wet burlap and plastic during accelerated aging 
In attempt to maintain a constant moisture level within the beams, they were each partially covered with three layers of wet burlap and then were loosely covered with a plastic sheet. The wet burlap was draped over the tension face (which was facing upward) and hung 3" over each side of the beam. The reasoning behind this method was, while the concrete between the tension steel and stainless steel would remain moist to allow for electrical conductivity, the beam would also be exposed to the air from underneath. This would allow the access of oxygen needed for the expansive corrosion reactions to occur as desired. Covered beams can be seen in Figure 5.21. A dry cycle was also incorporated for two days per week since research has shown that wet/dry cycling provides a harsher environment than does a continually saturated condition.

Since concrete has highly-localized variability, and since the steel actively corrodes during the applied current process, the resistance provided by the beams constantly changes. At times during testing, the resistance provided by the beams did not provide enough of a load for the power supplies to stabilize and run. Therefore, additional resistance was provided by adding $200 \Omega / 100 \mathrm{~W}$ variable resistors to each circuit. The variable resistors were placed between the power supply and the final stainless steel tube in each circuit.

In contrast, as the steel corrosion products formed and accumulated around the tension reinforcement, the beams sometimes provided too much resistance for the power supplies to run at a constant current. This occurred because the power capacity of the beam would be exceeded and the power supply would begin to run in its constant power mode at its 
maximum power capacity of $250 \mathrm{~W}$. When this occurred, the same $200 \Omega / 100 \mathrm{~W}$ variable resistors were added between the tension steel and the stainless steel tube of each beam to act as a parallel resistor with the concrete. This troubleshooting method was found to effective reduce the total resistance of each beam and allowed the power supplies to resume functioning on the desired constant current control setting. It is important to note these paralleling resistors were added to the opposite end of the beam from power supply connection to ensure that the current had the opportunity to pass through the entire length of the tension steel before flowing through the concrete to the stainless steel.

The magnitude of current density governs the corrosion rate of reinforcing steel. Current density can be defined as the quotient of the magnitude of the applied current to the total surface area of exposed steel. Corrosion rate increases as current density increases. A current density of $178 \mathrm{~mA} / \mathrm{cm}^{2}$ was applied to Part I beams and a current density of $316 \mathrm{~mA} / \mathrm{cm}^{2}$ was applied to Part II beams.

The first corrosion cycle subjected Part I beams to 1,200amp-hours of constant current, while the second corrosion cycle subjected some of the beams to an additional 1,200amphours of constant current. It should be noted that the accelerated aging process was the same for both corrosion cycles except for beam orientation. During the first corrosion cycle, the beams were inverted, as shown in Figure 5.19. However, during the second corrosion cycle, the beams were turned so that the tension side faced the floor due to the presence of FRP. If the beams had remained inverted (with the tension FRP on top facing upward), then the waterproof composite layer would have prevented water from 
passing from the wet burlap and into the concrete. By placing the beams "right-side-up", the water could enter the beam through the compression face amd percolate through the concrete via gravity. This also simulated the mode of water entry in an actual FRPrepaired bridge girder.

The only corrosion cycle applied to Part II beams subjected them to 1,100amp-hours of constant current. The accelerated corrosion process and setup for Part II was the same as that used for the first corrosion cycle for Part I.

For more detailed information on these corrosion processes and results, please refer to Section 6.1.1.

\subsection{Repair of Beam Specimens}

\subsubsection{Part I Beam Repair}

For Part I, two unique substrate repair methods were incorporated and compared while the FRP wrapping scheme was the same for all beams. The performance difference between an FRP-system coupled with a minimum type substrate repair and one coupled with the most substantial type of substrate repair was examined. A total of four beams were repaired with FRP in Part I, two of which had minimum substrate repair and two of which had substantial substrate repair. 


\subsubsection{Two Different Substrate Repair Techniques}

Substrate Repair Method 1: For Substrate Repair Method 1, which was performed on Beams I-9 and I-10, none of the old deteriorated concrete was removed prior to FRP repair. Instead, Sikadur 52, which is described by Sika as an advanced, very-lowviscosity, moisture-tolerant epoxy injection adhesive, was used to fill and structurally repair the corrosion-induced cracks. Sikadur 52 (ASTM C-881, AASHTO M-235) is a 2component, $100 \%$ solids moisture-tolerant epoxy adhesive. It is a high-strength adhesive that can be used to grout both dry and damp cracks. Sikadur 52 Component A consists of a modified epoxy resin of the diglycidiether bisphenol-A type and viscosity control agents. Component B consisted primarily of an amine blend reaction product with an epoxy resin of the diglycidiether bisphenol-A type with viscosity control agents, pigments, and accelerators.

To begin the crack-injection substrate repair method, a $1 / 16$ " diameter steel pin punch was used as a stylus to lightly scrape the edges of each crack and to remove any lose or unsound material (see Figure 5.22). Next, compressed air was discharged into the cracks to remove dust, free corrosion product, or any loose debris (see Figure 5.23). In order to keep the extent of crack preparation compatible with that which an effectively be performed in the field, no additional measures were taken to clean or dry the cracks. 


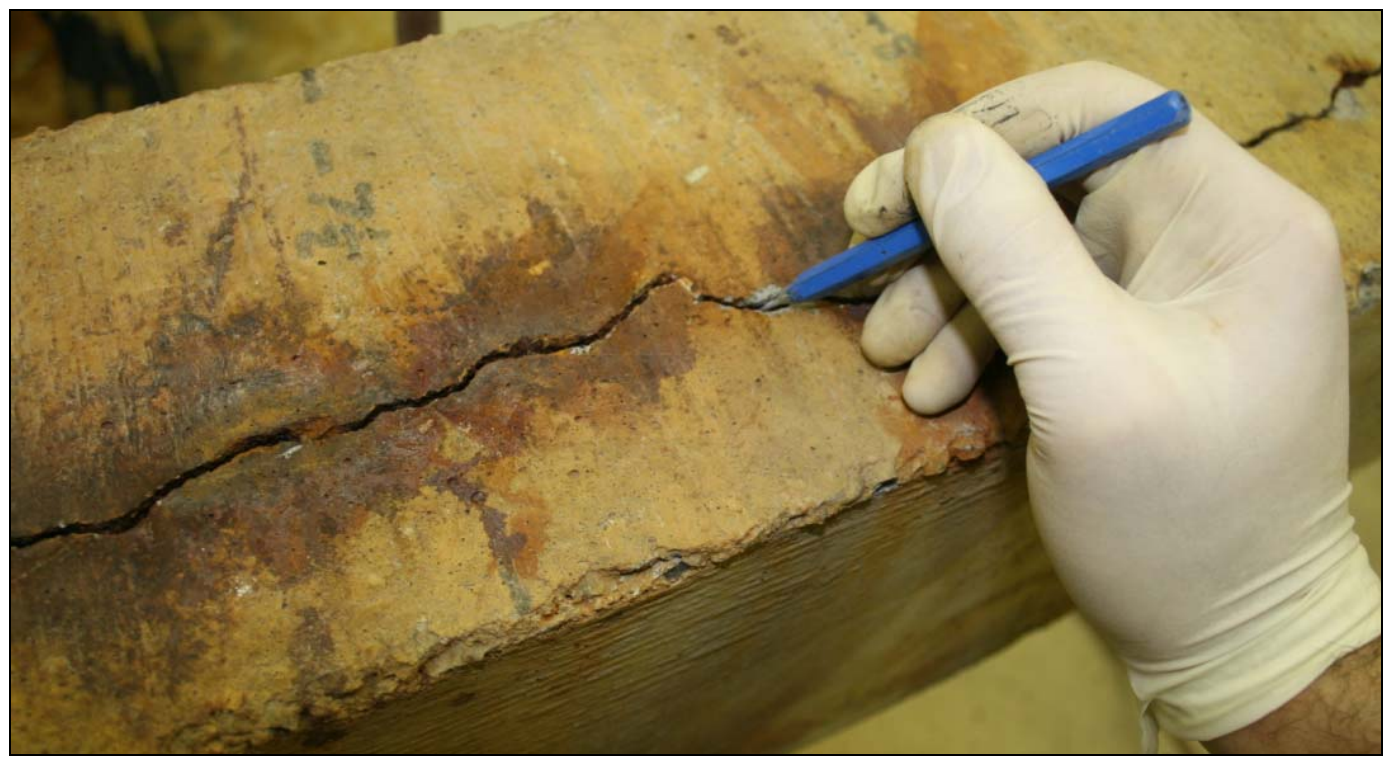

Figure 5.22: Pin punch used to remove loose material from around the crack edges prior to epoxy injection
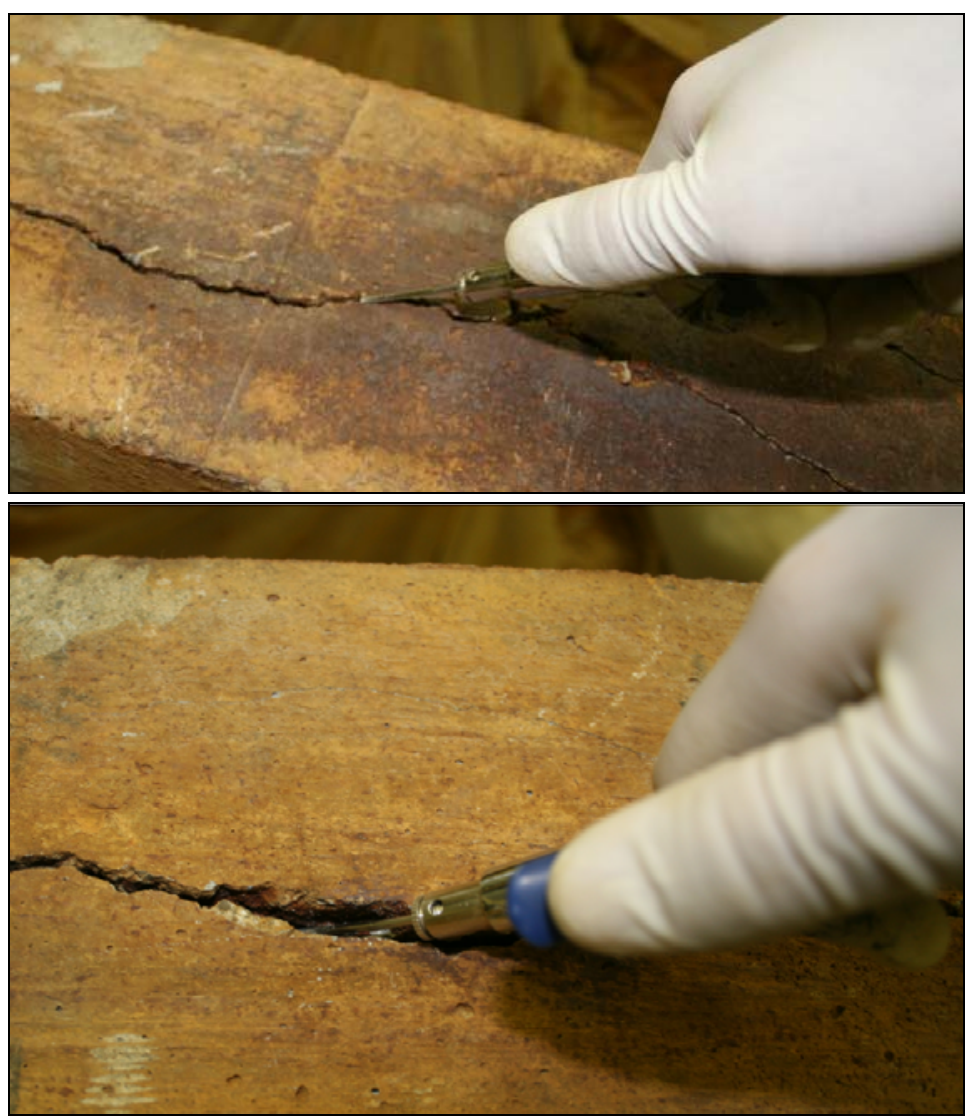

Figure 5.23: Needle attachment through which compressed air was used to clean cracks 
Initially, the cracks were covered with duct tape with periodically spaced holes through which the epoxy could be injected. The largest diameter plastic-needled syringes that could fit into the average crack were intended to be used for manual injection. These syringes had a capacity of $50 \mathrm{cc}$ and had an outside and inside needle diameter of 0.040 " 0.028 ", respectively. However, although the repair epoxy had a low viscosity of $200 \mathrm{cps}$, it was still too viscous to be easily passed through the needle. Therefore, the crack grouting method had to be changed. It should be noted that, due to the small size of the beam specimens, pressure injection equipment was not used. This equipment is made for large-scale structures and would not have been practical for the scaled-down specimens. Pressure-injection would have likely done more damage to the beam specimens than it would restoration.

Even though it was much more time consuming, gravity feeding the epoxy was determined to be the best alternative crack filling method (see Figure 5.25). First, the beams were inverted so that the cracks on the bottom face could be fed first. The duct tape was removed from the bottom-face cracks, and new duct tape was placed over all cracks on the remaining five faces of the beam, including the ends. This new tape was used to dam the wet epoxy and to prevent it from leaching out the sides. Next, the plastic needles were removed from the syringes so that the $1 / 8$ " diameter opening at the discharge end of the syringe shaft could be used to controllably administer a narrow line of epoxy. It should be noted that, for this application, the cracks were not vee-notched, as was recommended by ACI (2003). Vee-notching may have caused additional damage to the already intentionally poor concrete cover on the lab-scale specimen. The epoxy was 
mixed in small increments (according to the specified weight proportions) since the pot life was only 25-30 minutes. The epoxy was suctioned into the syringe, was applied in a neat, continuous line over the cracks, and was allowed to infiltrate via gravity. This procedure was very time consuming because, after each crack was traced with a single line of epoxy, it took several minutes for it to completely leach in. The largest cracks required re-applying epoxy at least 10 to 15 times until they were completely filled. Figure 5.24 shows a needle-less syringe setting next to a fresh epoxy-filled crack. The duct tape dams were not completely watertight due to the irregularities of the concrete, so some epoxy was able to slowly escape adding to the filling time. In field applications where vee-notching the cracks would be more practical, this gravity-fed grouting process is likely to be much more rapid and less tedious. Once the cracks on the bottom face of Beams 9 and 10 were completely filled, the epoxy was allowed to cure for 5 to 7 hours until becoming tack-free. This procedure was then repeated on both the left and right sides of the beam, leaving all major cracks completely filled with epoxy. 


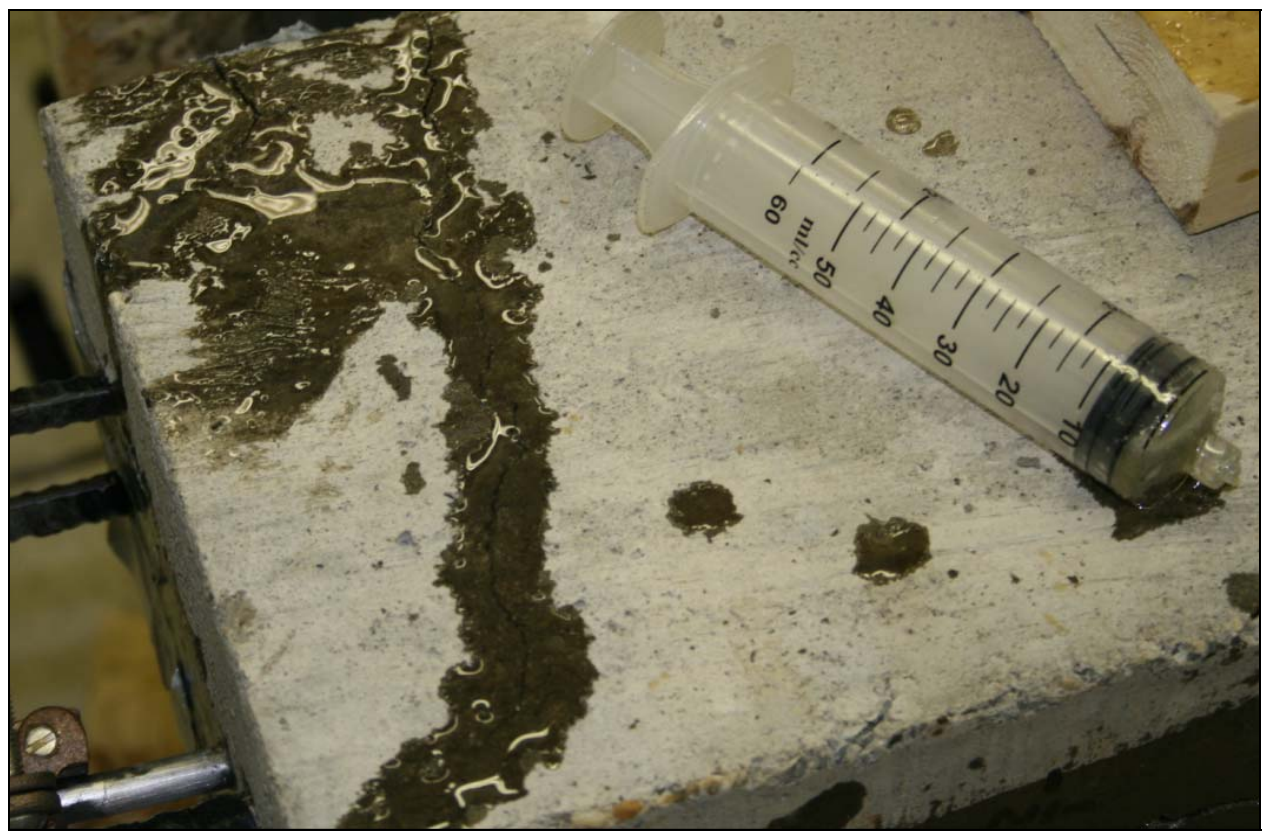

Figure 5.24: Plastic syringe next to gravity-fed epoxy-filled cracks 


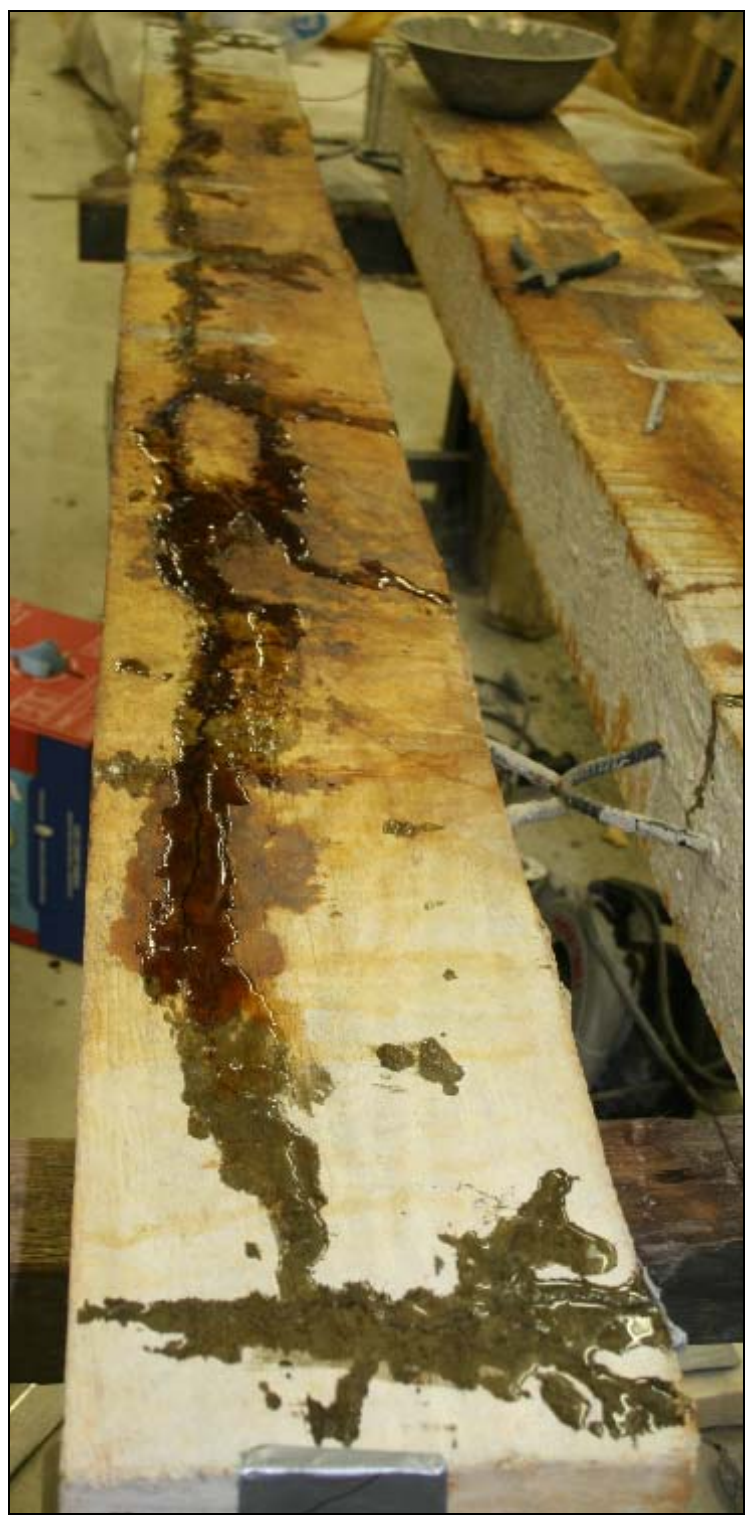

Figure 5.25: Cracks filled with epoxy

Once all the epoxy was cured, the surfaces accepting FRP repair were made level using a 3"x18" belt grinder and a handheld angle grinder with a 4⿳1⁄2" " concrete/masonry grinding wheel. At locations of U-wrapped FRP anchors, the two edges between the tension-face and the sides of the specimen were filleted to a radius of 1" using the handheld angle grinder. Creating a 1" radius with the handheld grinder was not difficult on the crackinjection substrate since the concrete was of poor quality. It should be noted that most 
substrate repair manuals recommend sandblasting the concrete surface to create a roughened surface profile. However, sandblasting was beyond the scope of capability due to a lack of the necessary equipment and a containment facility large enough to accommodate the large-scale beam specimen. Therefore, the final profile created by the angle grinder was deemed sufficient for the scope of this work.

Substrate Repair Method 2: For Substrate Repair Method 2, which was performed on Beams 7 and 8, old concrete was removed and replaced with high-strength polymer concrete containing corrosion inhibitors. First, deteriorated cover concrete was removed from each beam. Second, corrosion product was removed from the tension steel. Next, new polymer repair concrete was used to replace the old concrete which was removed. Finally, the surface of the repair concrete was prepared for FRP application. The following will describe each of these steps in detail and will provide photos of each step so that the reader can clearly understand.

First, all old concrete between the tension steel and the bottom face of each beam was removed using a light-duty air-powered hammer with a standard 0.401 " shank flatheaded chisel attachment. The air hammer was set to a high frequency and a low stroke so that the chiseling motion was nonviolent and that no sound concrete was damaged. Concrete was removed to a level even with the tension steel in shear regions and was removed beneath the tension bars in the constant moment region to a depth even with the stainless steel bar, as seen in the bottom photo in Figure 5.26. 

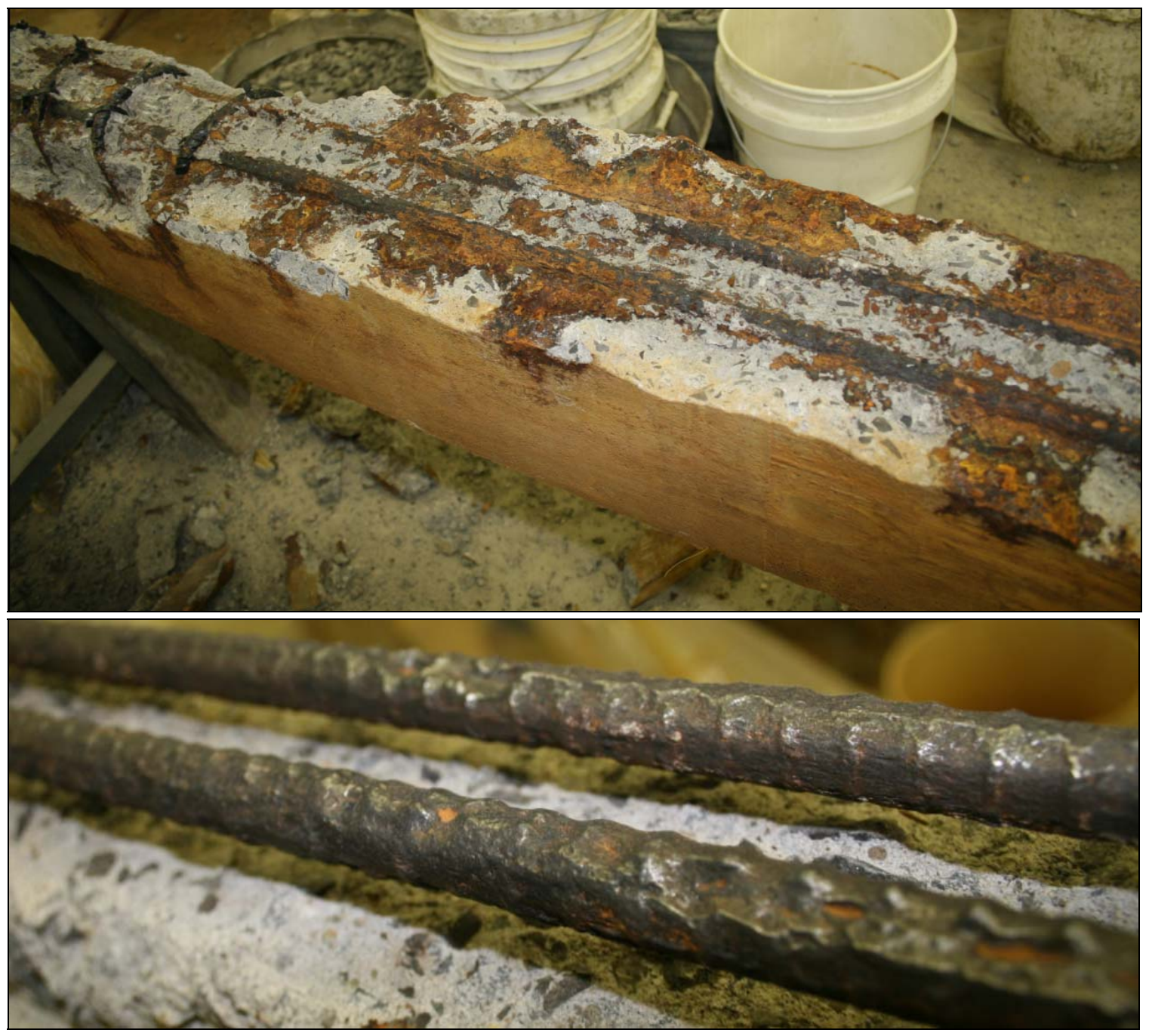

Figure 5.26: Inverted beam (tension steel facing upward) after air-chiseling

Next, a circular saw with a 7" diamond masonry blade was used to make a $3 / 4$ " deep cut longitudinally along the side of each beam. Saw-cutting is necessary to prevent the edges of the concrete removal from feathering or flaking. Saw-cutting was accomplished by first clamping a wooden $2 \times 4$ horizontally to each side of each beam at a height of 3 " above the tension face, as shown in Figure 5.27. This $2 \times 4$ would act as a guide for the saw to ensure a straight cut. Figure 5.28 shows a cut being made. A completed saw-cut can be seen in Figure 5.29. 
The saw-cuts were completed with relative speed and ease once the proper saw-guiding techniques were determined. Once all the cuts were made, the air-powered chisel hammer was used to remove all concrete between the cut and the tension face of the beam. Concrete was then also removed from around the tension steel in the constant moment region where no stirrups were present. Concrete could not be chiseled deeper than the tension steel in the shear regions since it would have likely resulted in damage of the test specimen due to the confinement provided by the stirrups. After air-chiseling was complete, a handheld chisel and hammer were used to remove all loose remaining concrete and to clean the chiseled surfaces.

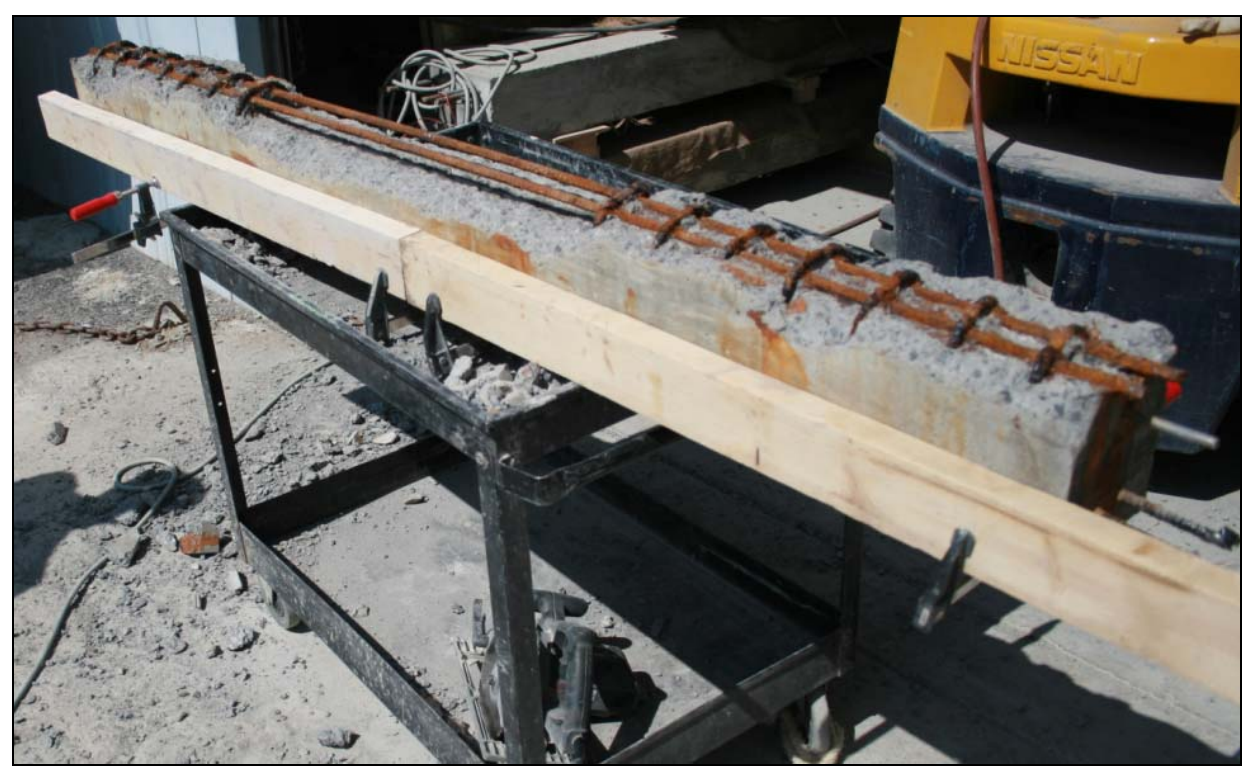

Figure 5.27: 2x4's used as a guide for saw-cutting

Next, the corrosion products and other contaminants were removed from the tension steel by first using a 4" diameter full cable twist wire wheel brush attached to a handheld electric drill (see Figure 5.30). The steel had to be brushed over several times at different angles. The brush removed a satisfactory amount of the corrosion product from the steel 
surface, but was less effective in removing the contaminants from the chloride-induced pits.

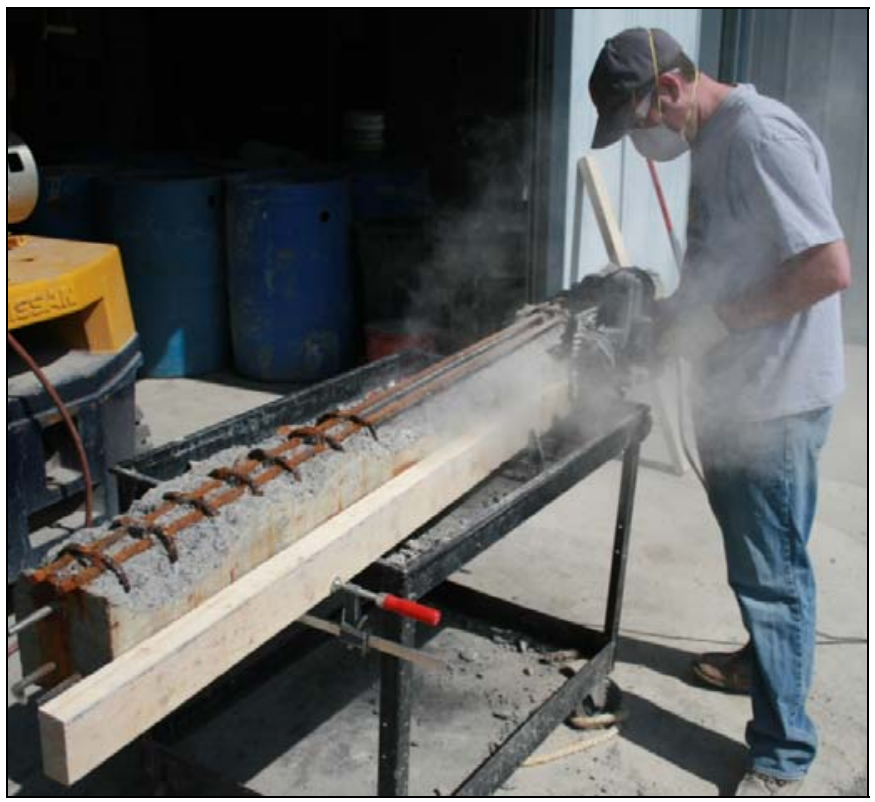

Figure 5.28: Saw cutting

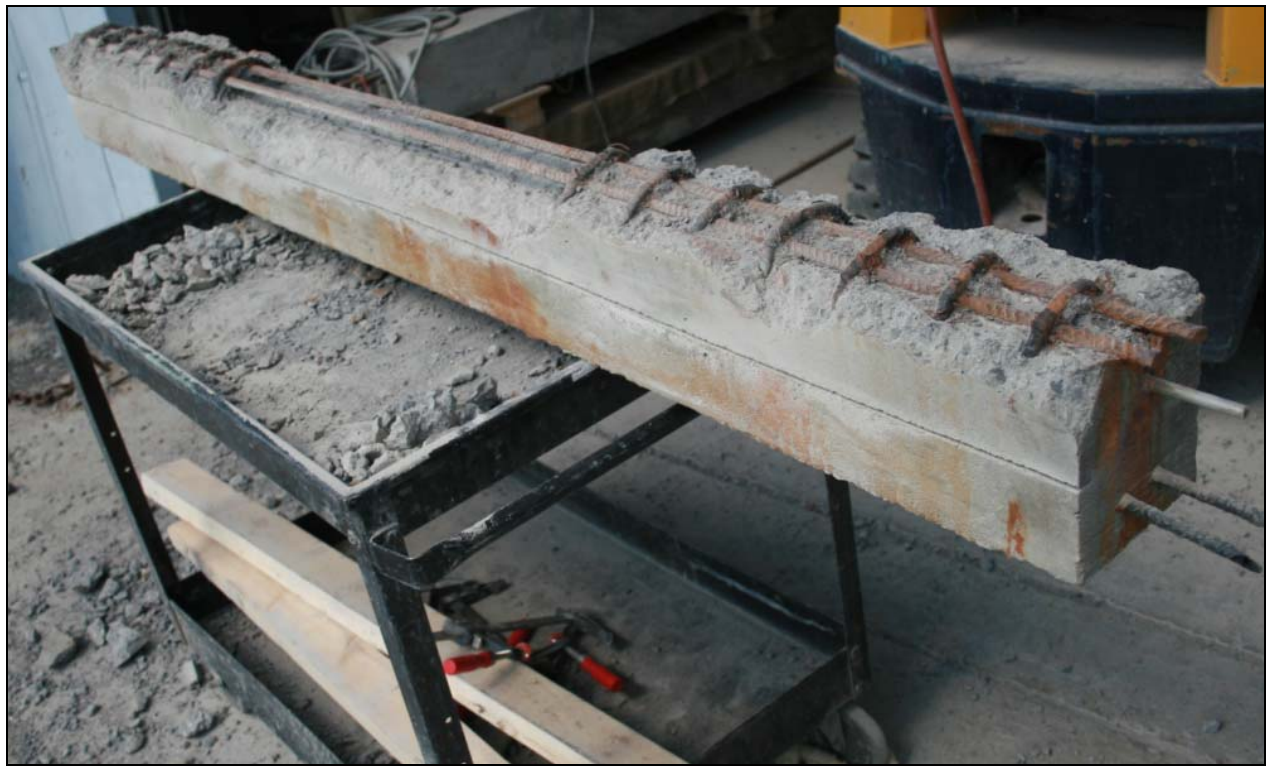

Figure 5.29: Completed saw cut 
The air-powered hammer was adjusted to its lowest stroke setting and a round pointed chisel attachment was used to loosen contaminants by vibration, which removed corrosion products from the pits surprisingly well. Steel cleaning was time consuming since it was difficult to guide both the wire wheel brush and the pointed air-chisel.

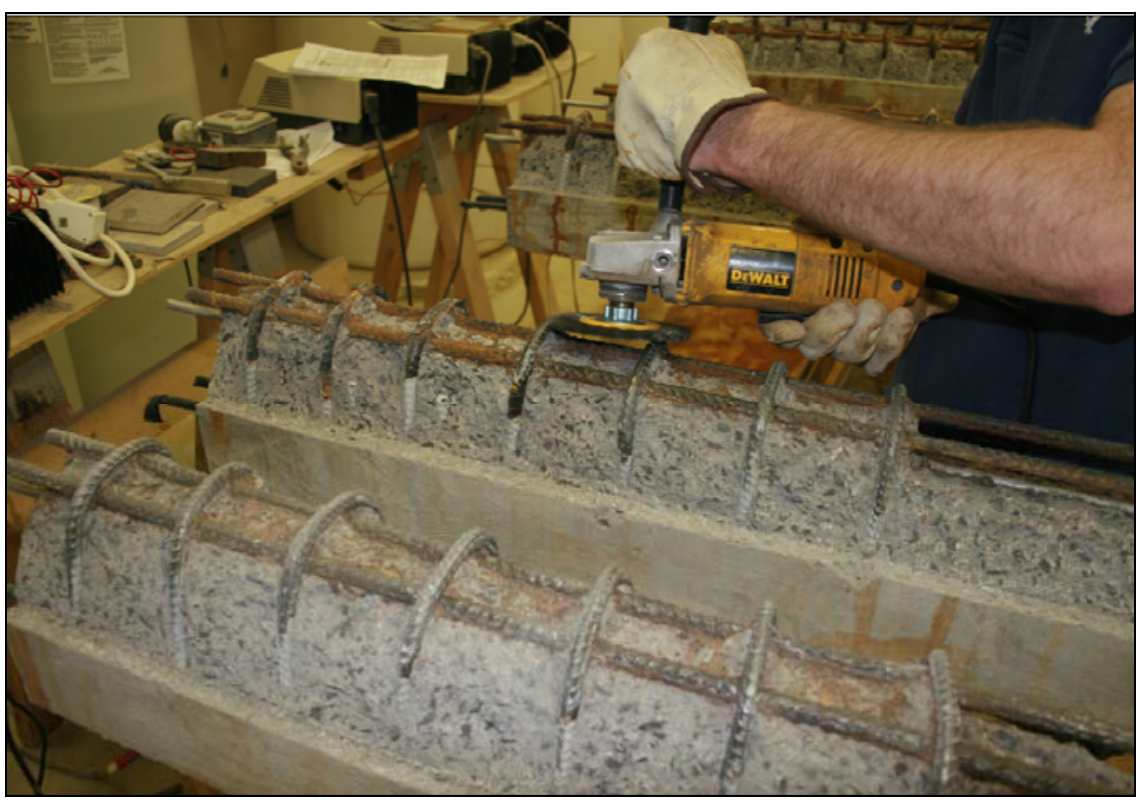

Figure 5.30: Steel cleaning with wire wheel brush

It should be noted that most substrate repair manuals strongly recommend sandblasting the steel down to white metal. However, sandblasting was beyond the scope of capability due to a lack of the necessary equipment and a containment facility large enough to accommodate the large-scale beam specimen. Therefore, while small amounts of corrosion products remained tightly adhered to the steel after preparation (see Figure 5.31), the quality of rust removal was deemed satisfactory for the scope of this work. It was determined that, even in a field repair, not all contaminants or corrosion products can realistically be completely removed. Therefore, the extent of steel preparation in this project may not be significantly different from that observed in a field application. 
To complete preparation for concrete patch repair, the repair surfaces were pressurewashed and then allowed to dry as a last effort to remove additional contaminants and loose concrete. Finally, the steel and concrete were air-jetted several times from shortrange in order to remove any dust or debris from the prepared surface.

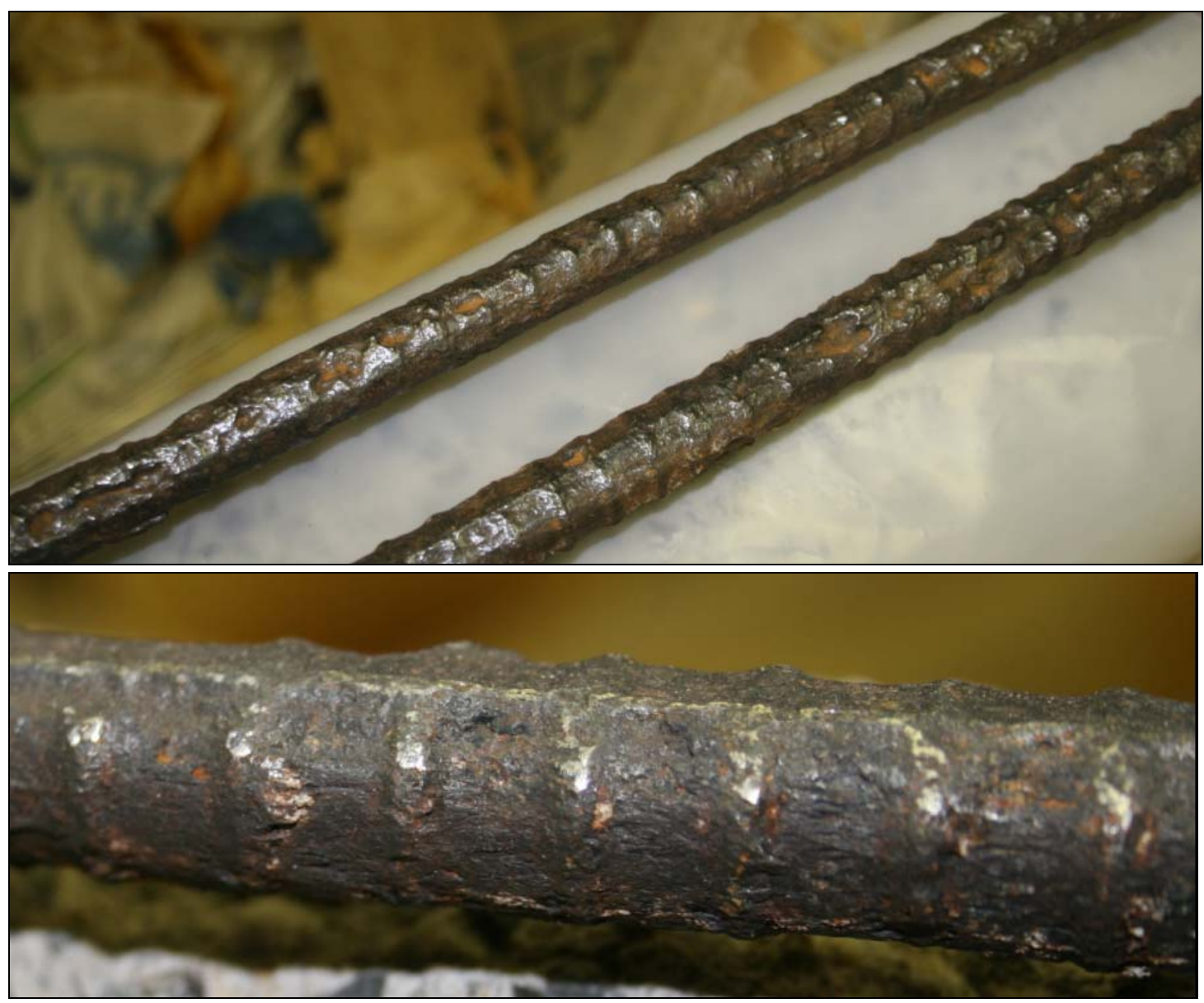

Figure 5.31: Small amounts of corrosion product remaining on steel after mechanical cleaning

In order to neatly replace the old concrete, wooden formwork had to be constructed around the beam. The sides of the formwork that had been previously used to cast the beams were removed and clamped to the sides of each beam using clutch-style bar clamps, as shown in Figure 5.32. The widths of the wooden formwork could be precisely 
adjusted to the 6" desired width by loosening or tightening additional bar clamps that were placed along the top of the formwork. The ends of the formwork, with holes drilled to allow the passage of the extruding reinforcement, were attached and the dimensions were double-checked.

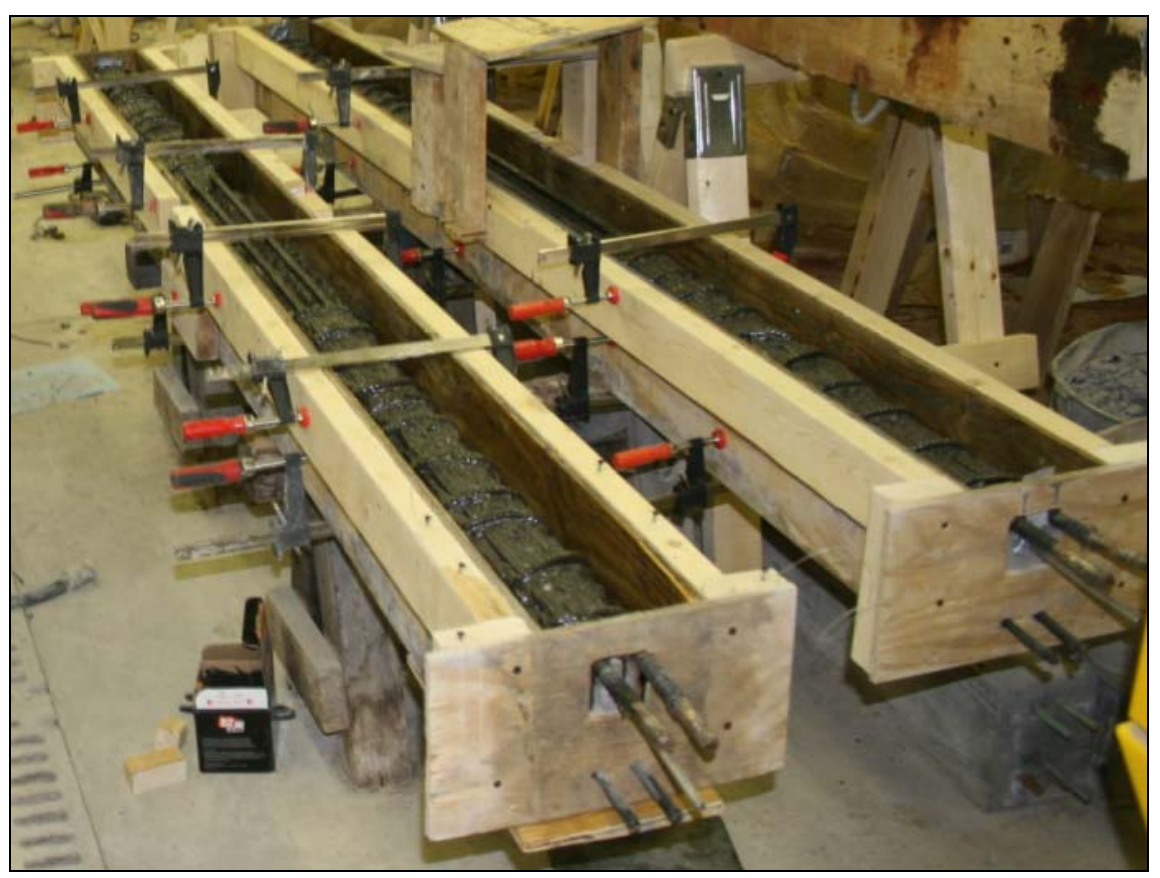

Figure 5.32: Clutch-style bar clamps used to secure molds and to adjust the cross-sectional width

Prior to applying the repair concrete, a "scrub coat" of Tyfo CB Epoxy Cement Bonding Agent / Corrosion Protection was applied with a paint brush at a thickness of about 15 mils to the surface of the concrete to be repaired and over the reinforcing steel. It was ensured that all voids and recesses were coated with this scrub-epoxy. Tyfo Fibrwrap products are distributed by the Fyfe Company. Tyfo CB is described by Fyfe as a threecomponent bonding agent composed of a specialty water-based epoxy and selected cementitious components. Tyfo CB serves as a bonding agent for repair concrete and also as a corrosion inhibitor. Once the first coating of Tyfo CB began to cure, a second 
coating was applied to the steel for additional corrosion protection. This product was easy to mix and apply because of its thin consistency and long 90 minute working time of the Tyfo CB scrub coat. Tyfo $\mathrm{CB}$ has an open time of about 12 hours at room temperature and must become tack-free before the repair concrete is applied. Therefore, the Tyfo CB was allowed to cure for about 3 hours before the repair concrete was poured.

The two-component SikaTop 111 PLUS polymer-modified, cementitious repair concrete with FerroGard 901 penetrating corrosion inhibitor was used to replace the old concrete on each beam. This product is described by Sika as a Portland-cement-based, fastsetting, screed mortar. It is a performance repair mortar for horizontal, vertical, and overhead applications or for form and pour applications. It also contains FerroGard 901, which is a penetrating corrosion inhibitor. This product was selected because of its high early compressive and flexural strength, compatible coefficient of thermal expansion, increased density, and corrosion-inhibiting properties. SikaTop 111 PLUS is also desirable for field applications because of its superior abrasion resistance, fast allowable opening time to traffic (4-12 hours), excellent freeze/thaw durability, resistance to deicing salts, and resistance to carbonation. SikaTop 111 PLUS Component A consisted of a jug of liquid polymer emulsion of an acrylic copolymer base and additives such as the organic corrosion inhibitor. SikaTop 111 PLUS Component B was packaged in a cement bag and consisted of a blend of Portland cements, specially graded aggregates, admixtures for controlling setting time, water reducers for workability, and an organic accelerator. In order to conform to the specifications for SikaTop 111, aggregate was added to the mortar mix to allow for placement of lifts greater than 1" in depth. 
Therefore, 42lbs of clean, well-graded, No. 8 (3/8") limestone aggregate was added to each unit of the SikaTop 111 to produce a polymer-modified Portland cement concrete. It is imperative to note that the aggregate used for this concrete was approved by the production plant and verified to be non-reactive. The technical specifications for SikaTop 111 oppose the use of limestone aggregates unless they are approved by an engineer since some types of limestone undergo an expansive alkali reaction which results in poor bond strength and cracking.

SikaTop 111 was very easy to mix since each unit came in pre-measured quantities. The repair concrete was mixed in a mechanical rotary mixer and was carried to the beam specimens in buckets. The low workability, high density, and short working time of 30 minutes made the concrete repair somewhat strenuous. Therefore, only two beam specimens could be repaired per one batch of concrete. The SikaTop 111 concrete finished neatly (see Figure 5.33), and the finishing time was around 45 minutes. Representative concrete cylinders were made for some batches of SikaTop 111 to ensure quality control.

After about 90 minutes, the beam specimens were covered with wet burlap and then a plastic sheet to prevent moisture from escaping. After one day, the reusable forms were unassembled and removed. The beams were allowed to cure for two days under wet burlap, as specified by Sika. 


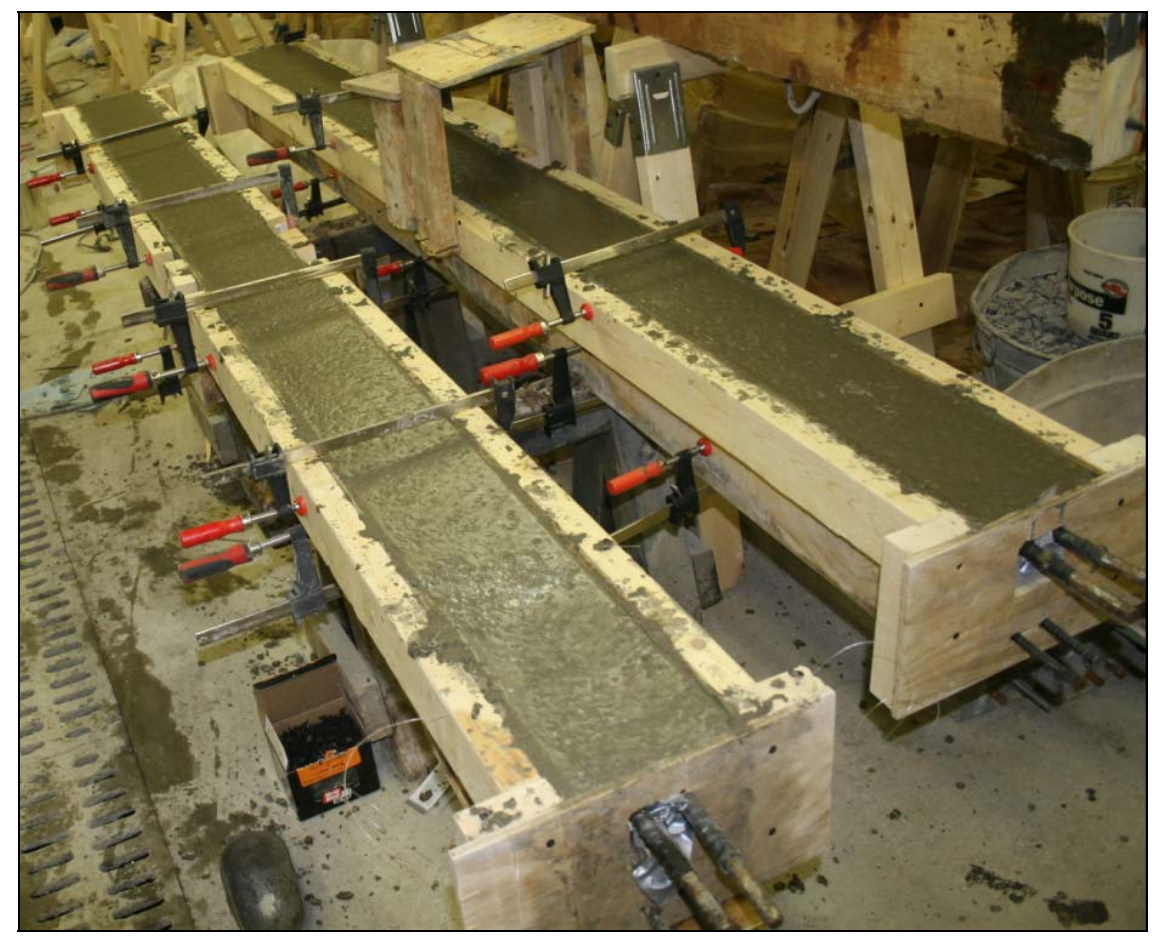

Figure 5.33: Freshly finished SikaTop 111 patch repair

Once the concrete was cured, the surfaces accepting FRP repair were made level with a 3"x18" belt grinder and a handheld angle grinder with a $4 \frac{1}{2}$ " concrete/masonry grinding wheel. At locations of U-wrapped FRP anchors, the two tension-face edges were rounded to a fillet radius of 1" using the angle grinder. Creating the 1" radius with the angle grinder was an arduous task for specimens with polymer concrete substrate repair due to the high strength and density of the patch material.

It should be noted that most substrate repair manuals recommend sandblasting the concrete surface to create a roughened surface profile. However, sandblasting was beyond the scope of capability due to a lack of the necessary equipment and a containment facility large enough to accommodate the large-scale beam specimen. Therefore, the final profile created by the angle grinder was deemed sufficient for the 
scope of this work. Sandblasting, however, should be performed during actual repairs in the field. FRP was not applied for at least seven days after substrate repair. A completed polymer-modified concrete substrate repair can be seen in Figure 5.35.

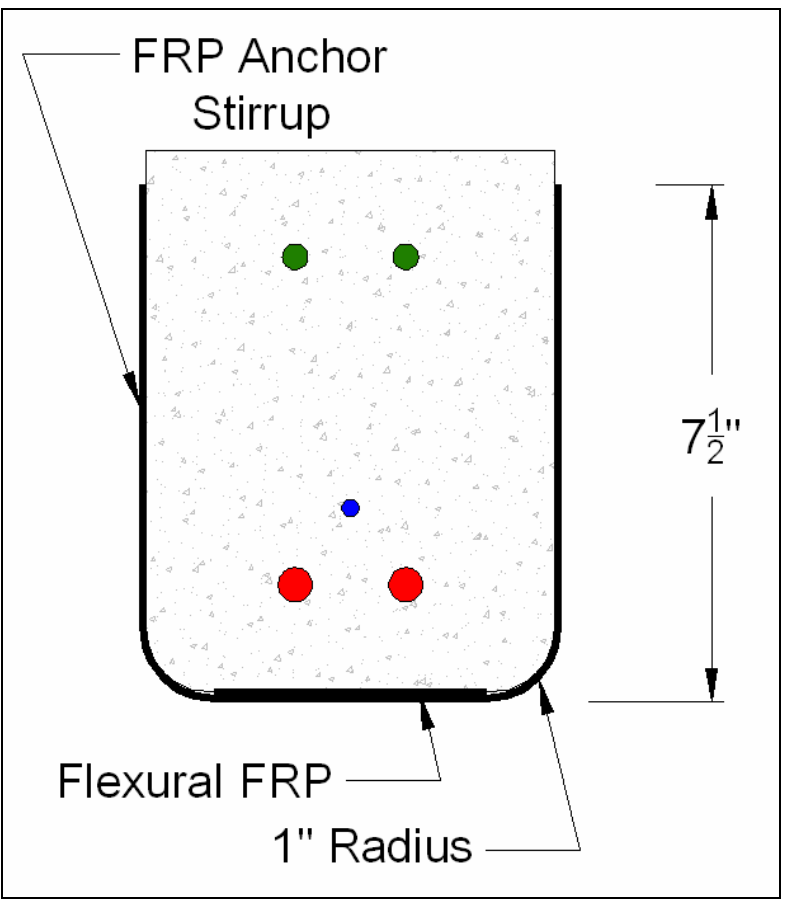

Figure 5.34: Beam cross-section at anchor locations

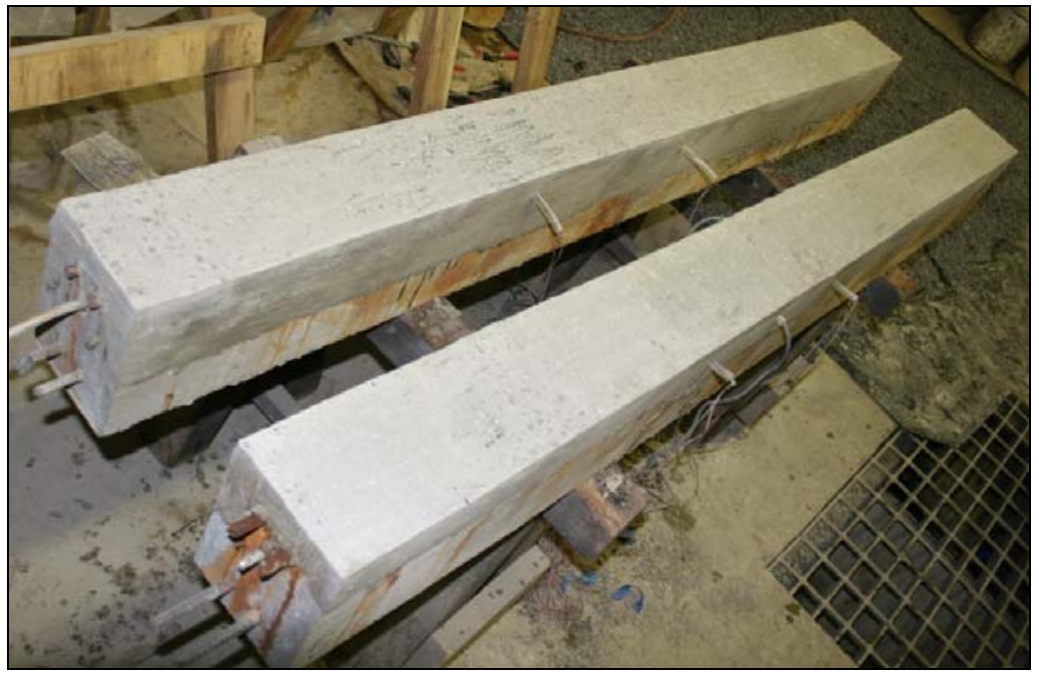

Figure 5.35: Completed polymer-modified concrete substrate repair 


\subsubsection{FRP Repair}

The FRP wrapping scheme used in Part I consisted of one layer of flexural CFRP and one CFRP U-wrapped anchor located at a strategic distance from the end of each specimen. The use of U-wrap anchors is common for FRP repair of reinforced concrete girders, but little research has been conducted to find an optimal location for these anchors, which have traditionally been placed near the FRP termination points at the beam ends. However, when FRP sheets are thin, crack-induced debonding is likely to occur at a distance away from the beam ends toward the center of the beam. Therefore, U-wraps located at the beam ends only may offer no benefit to the performance of the girder. Leung (2006) states that "to maximize the total load carrying capacity, the 'stirrup' should be placed close to the initiation point of debonding so that the stirrup's resistance is activated before significant debonding (and/or interfacial softening) has occurred." In an email conversation (Leung, 2008), Dr. Chris Leung stated that, in what he has learned from personal experience, debonding initiates from a flexural or a flexural-shear crack that forms near the load application point. The crack propagates downward from the load application point at roughly 30 to the vertical. Therefore, he suggested that the anchor stirrups be placed at a location slightly beyond the point where this $30^{\circ}$ line meets the tension face of the beam (see Figure 5.36). Dr. Leung's suggestion was followed for Part I of this research. The FPR wrapping scheme used for Part I of this research can be seen in Figure 5.37.

The extent of FRP repair was designed according to ACI guidelines to restore Part I beams to $94 \%$ the capacity of the original capacity predicted for a pristine beam. Beams 
were not designed to fully restore the beams to their original capacities since it was feared that the poor-quality compression concrete would crush with the addition of too much FRP. Concrete crushing would have resulted in inadequate data for the intentions of this project, so it had to be ensured this failure mode did not occur.

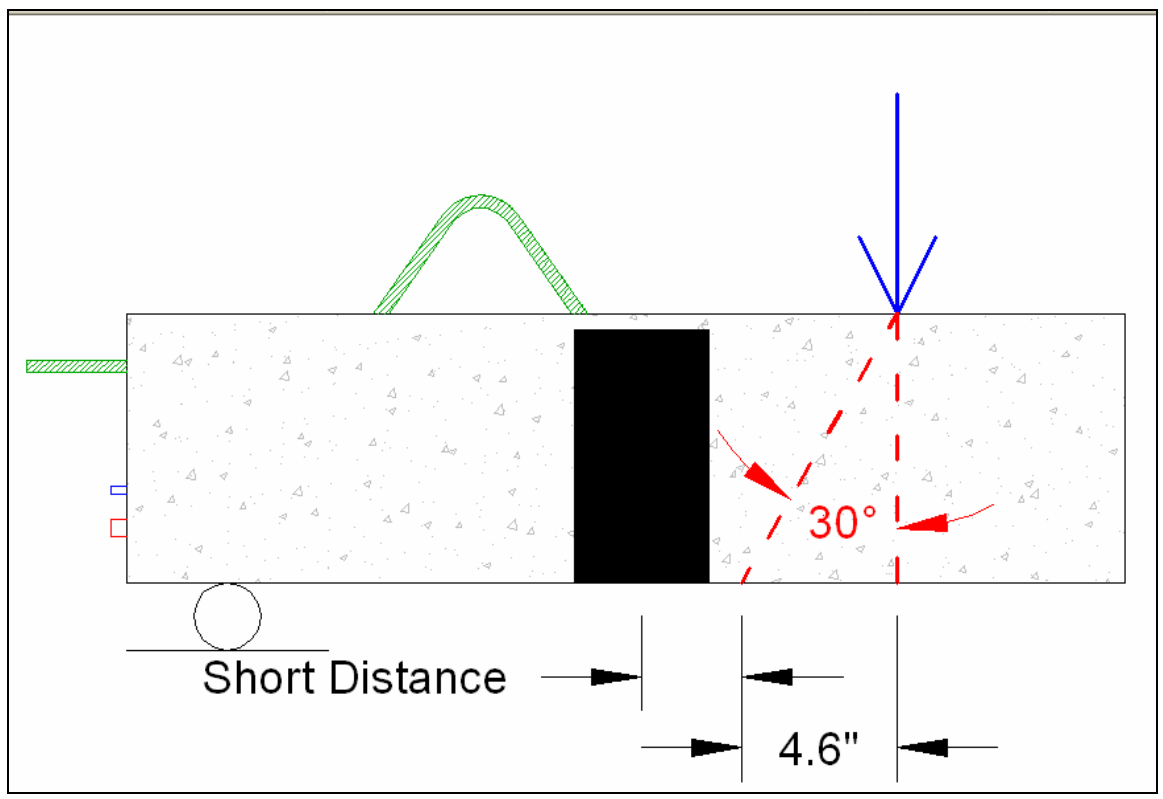

Figure 5.36: Illustration of Dr. Leung's suggested stirrup location

Layout lines were first measured and drawn on the concrete surface with a sharpie marker. The flexural FRP sheets were terminated exactly 4" from the end of each beam to yield a distance of 1 " between the termination points and the support locations during flexural testing. The FRP sheets were also 4" wide since the localized 1" radii fillets were grinded into the edges of each beam. The anchors were 4" wide and were terminated $1 / 4 "$ from the compression face of each specimen. 


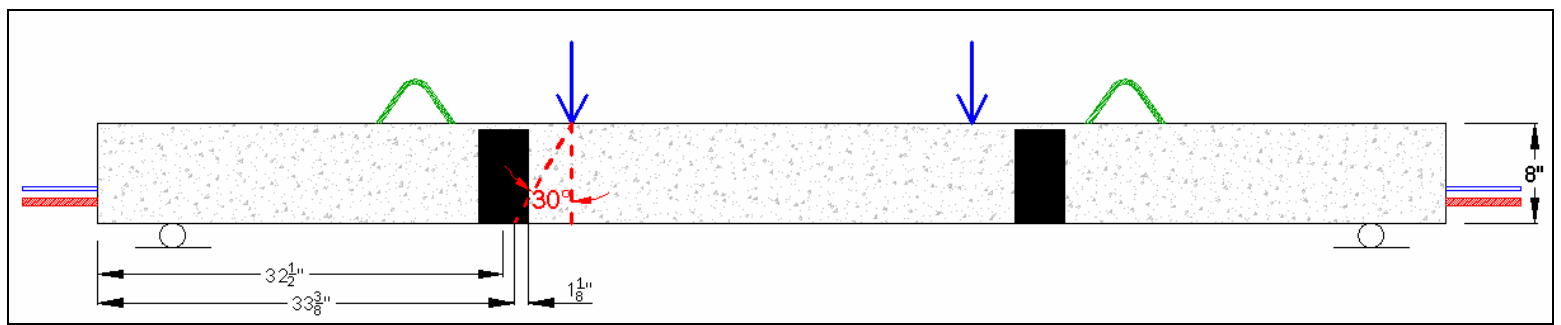

Figure 5.37: Part I FRP Wrapping Scheme

Next, Tyfo WS All Purpose Epoxy was mixed according to specifications. Tyfo Fibrwrap Systems describes Tyfo WS as a two-component, hi-build, 100\% solids developed for bonding applications. It can be used as a final protective coating or as a fill-and-level undercoat over which a Tyfo Fibrwrap FRP system may be applied. It can also be used to fill voids in concrete up to $1 / 2$ " depth (see Figure 5.39). Since it is a thickened epoxy, Tyfo WS is ideal for vertical and overhead applications. A layer of Tyfo WS was applied to all surfaces of the beam that would accept FRP using a paint brush. Care was taken to fill all pinholes and surface irregularities. Tyfo WS has a pot life of 3 to 6 hours, so there was plenty of time during which to apply the primer coat. This epoxy's drawback was that it took about 10 hours to become tacky. Because of this, the Tyfo WS primer coat had to be applied to the beam specimen early in the morning and the FRP repair and cleanup had to be completed very late at night. However, for field applications, it is specified that Tyfo WS should be applied within 72 hours of the application of the outer layer of fabric to ensure a proper bond. Therefore, it would have likely been sufficient to apply the Tyfo WS epoxy and to allow it to become tacky overnight before completing the FRP repair the following day. In Figure 5.38, the primer layer of Tyfo WS can be seen, and beneath it the FRP layout lines can also be seen. 


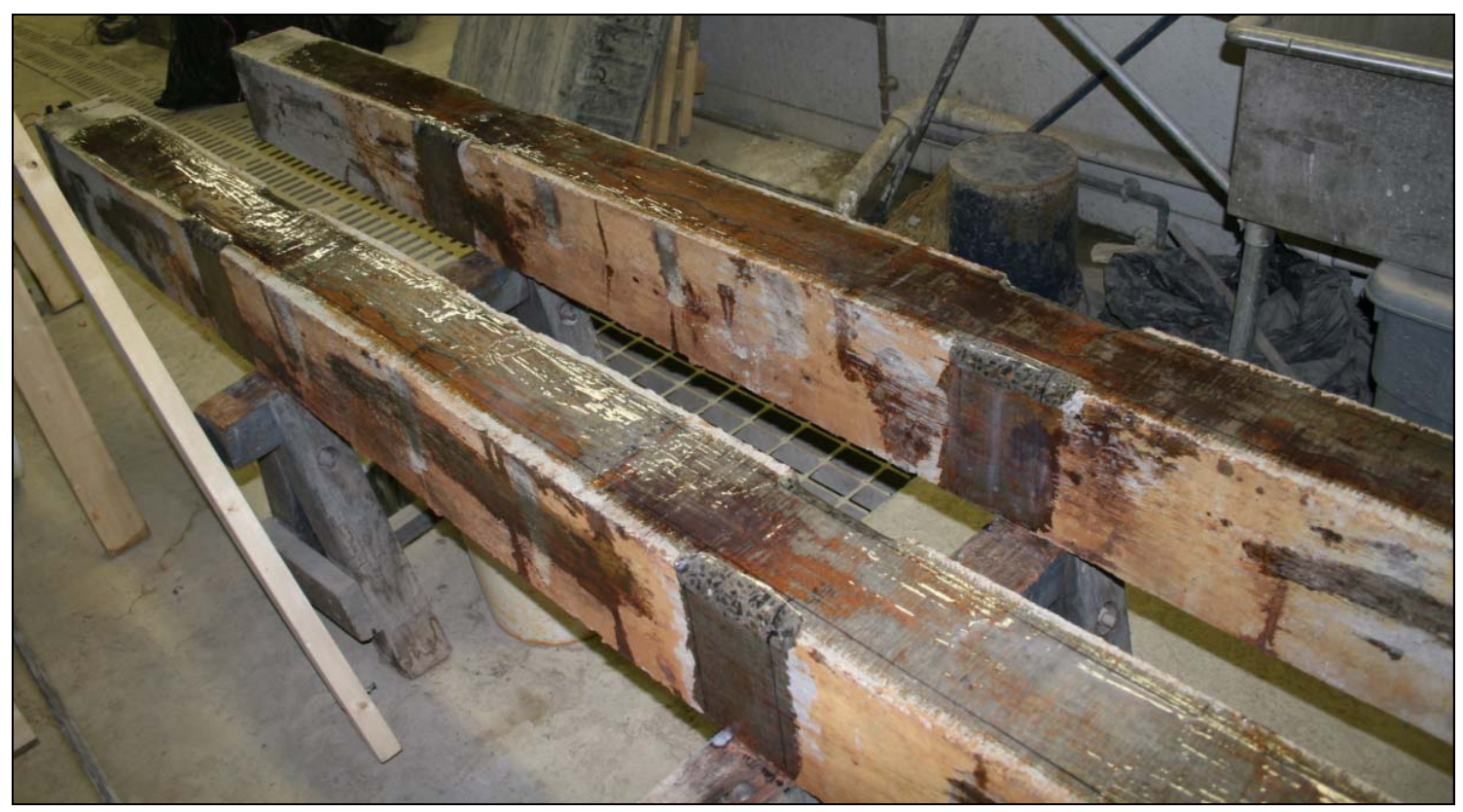

Figure 5.38: Primer coat and FRP layout lines on Part I beams

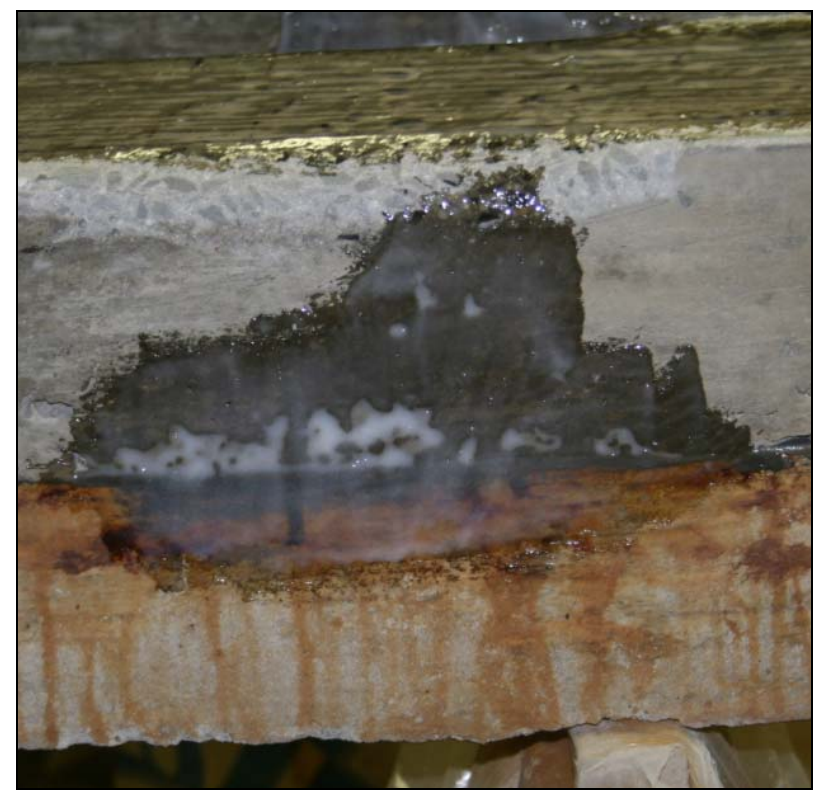

Figure 5.39: Tyfo WS epoxy used to fill voids on the sides of the beam specimens over which FRP would be placed

While the Tyfo WS primer coat was curing, the carbon fiber was cut to its appropriate length. Plastic sheeting (16mil thick) was rolled out on the floor and the carbon fiber, 
which was shipped on a 36 " wide roll much like gift-wrap, was rolled out over the plastic. The fibers were held together by a network of thin plastic strings evenly spaced in each direction to form a grid of $1 / 2$ " squares through which the fibers were stitched. Cutting the fiber sheet in the fiber direction was done with great ease.

Table 5.4: Material Properties for Gross SCH-7UP Laminate and its Components

\begin{tabular}{|l|l|l|}
\hline Material & Property & Value \\
\hline \multirow{5}{*}{ SCH-7UP Carbon Fiber } & Tensile Strength & $550,000 \mathrm{psi}$ \\
\cline { 2 - 3 } & Tensile Modulus & $33,500 \mathrm{psi}$ \\
\cline { 2 - 3 } & Ultimate Elongation & $1.6 \%$ \\
\cline { 2 - 3 } & Density & $0.065 \mathrm{lbs} / \mathrm{in}^{3}$ \\
\cline { 2 - 3 } & Weight per Square Yard & $8.1 \mathrm{oz}$. \\
\hline \multirow{5}{*}{ Tyfo S Saturant Epoxy } & Tensile Strength & $10,500 \mathrm{psi}$ \\
\cline { 2 - 3 } & Tensile Modulus & $461,000 \mathrm{psi}$ \\
\cline { 2 - 3 } $\begin{array}{l}\text { Gross Laminate Properties } \\
\text { (Design Values) }\end{array}$ & Elongation Percent & $5.0 \%$ \\
\cline { 2 - 3 } & Flexural Strength & $17,900 \mathrm{psi}$ \\
\cline { 2 - 3 } & Flexural Modulus & $425,000 \mathrm{psi}$ \\
\hline & $\begin{array}{l}\text { Ultimate Tensile Strength } \\
\text { (Fiber Direction) }\end{array}$ & $130,900 \mathrm{psi}$ \\
\cline { 2 - 3 } & $\begin{array}{l}\text { Ultimate Tensile Strength } \\
\text { (Perpendicular to Fiber) }\end{array}$ & 0 \\
\cline { 2 - 3 } & Elongation at Break & $1.05 \%$ \\
\cline { 2 - 3 } & Tensile Modulus & $12,600 \mathrm{psi}$ \\
\cline { 2 - 3 } & Laminate Thickness & $0.007 \mathrm{in}$ \\
\hline
\end{tabular}

A metal yardstick was placed as a guide along the desired cutting line as and held in place while a utility knife was used to cut the thin plastic grid and separate the fiber into the desired 4" wide strips. Cutting the fiber sheet perpendicular to the fiber direction took some additional effort and care, but was relatively effortless A metal ruler was placed perpendicular to the fiber direction as a guide at the desired laminate length of 8'4", and a utility knife was slid along the guide. It was found best if several cutting strokes were gently made along the guide until all the fibers were severed. If too much pressure was applied in an attempt to cut the fibers quickly, the knife blade would snag 
and fray the ends of the fiber fabric. A particle mask, goggles, and gloves were worn when cutting the fabric. Fabric strips with the dimensions 4"x201/2" for the U-wrap anchors and 12"x12" panels for sample coupons were also cut.

After 10 hours, the Tyfo WS primer layer was tacky enough on which to apply the FRP laminate. The requirements of the FRP design (see Appendix B.1 for detailed design calculations) were met by using one ply of Tyfo SCH-7UP Composite. This unidirectional carbon fiber composite laminate is $0.007^{\prime \prime}$ thick. It was saturated with Tyfo S Saturant Epoxy, as specified. Tyfo S epoxy is a high-elongation material which makes it an ideal FRP saturant. The advantages of this carbon fiber composite system are performance at extreme temperatures, long working time, high tensile modulus and strength, and ambient cure. Material properties of the fiber, the epoxy and the saturated and cured gross laminate are given in Table 5.4. It should be noted that the values provided for the fiber and the epoxy represent typical test values and the values given for the gross laminate are conservative design values specified by Tyfo Fibrwrap Systems. Tyfo Fibrwrap Systems reports the typical test values of $154,000 p s i$ for fiber-directional tensile strength and 14,800psi for tensile modulus for its gross SCH-7UP Composite laminate. However, the design values and not the test values should always be used and accepted since they conservatively account for possible variation in materials or workmanship. It should also be noted that FRP systems should only be installed at temperatures above $40^{\circ} \mathrm{F}$, as specified by most manufacturers. A trough was built using wooden $2 \times 4$ sides and a plywood base to serve as the FRP saturating bath (see Figure 5.40). It was lined with 16 mil plastic sheeting which was stapled onto the wood to 
prevent movement during saturation. The Tyfo $\mathrm{S}$ epoxy was mixed according to specification. Half of it was poured into the saturation trough and half into a stainless steel paint tray lined with plastic sheeting.

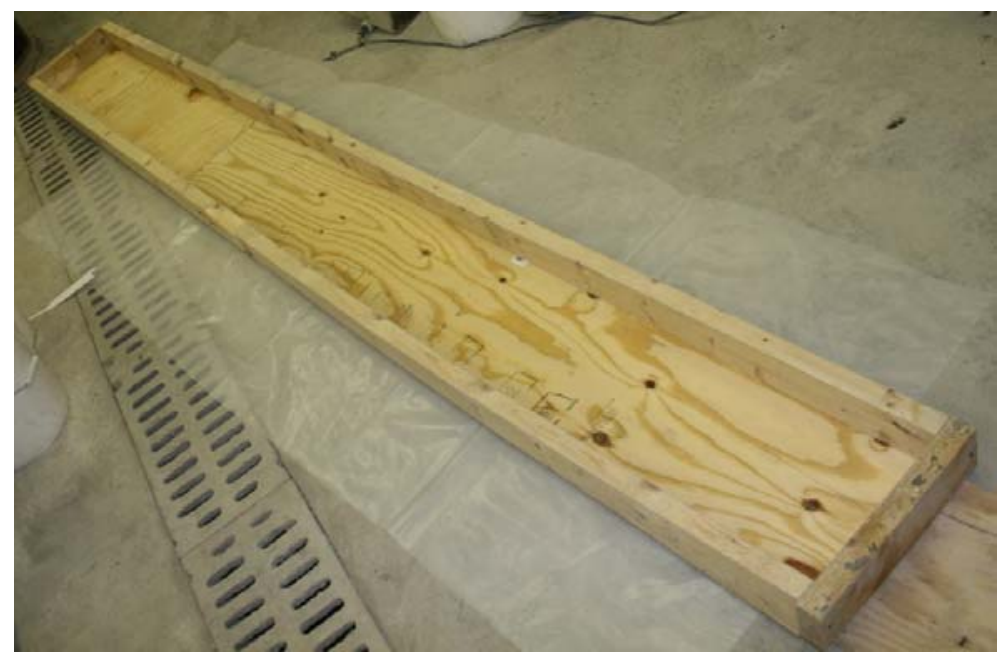

Figure 5.40: Trough built and used as FRP saturating bath

Next, the carbon fiber strips were rolled onto a homemade roller made out of 4 " diameter PVC pipe. Drilled wooden sides were inserted into each end of the pipe section, and a wooden dowel rod was placed through the center of the pipe and passed through the holes in the wooden sides (like a rolling pin). This homemade roller allowed for easy transportation and placement of the composite strip. The strips were transported to and rolled out in the saturation trough. Paint rollers were used to manually saturate the fibers with the epoxy. They were saturated with epoxy from the paint tray and were gently rolled along the carbon fiber sheet. Once the composite strip appeared to be saturated on the first side, it was flipped onto its other side and rolled again by the same procedure. The composite was deemed adequately saturated when no dry spots were visible. Once saturation was complete, the composite strip was again spooled onto the PVC roller and 
transported to the beam. The end of the strip was aligned to the layout lines and was then slowly rolled out over the tension face of the inverted beam specimen with special care taken to disallow the formation of air pockets. Once fully unrolled, paint rollers were used to apply pressure to the laminate and to squeegee out undesirable excess epoxy in all directions. Excess epoxy was wiped from the beam with a paper or cloth towel. Next, the 4"x21" fabric strips were saturated by the same method and were rolled out over the beam to form a U-wrap anchor at all predetermined locations using the same methods as described above. FRP application was easily and neatly completed since the beam specimen was inverted at the time of repair. It can be imagined that FRP repair would be considerably more demanding and messy if application was from below, as in bridge repair fieldwork.

It is required in FRP fieldwork to make representative composite coupon samples for quality control. Therefore, representative coupons from each batch were made and several were cut into smaller samples and tested in direct tension. Coupons were made by first cutting four 12 "x12" composite fiber panels. Two panels at a time were placed into the saturation bath and completely saturated from both sides as previously described. One panel was then laid out on a flat and clean 16 mil plastic sheet. Next, the second panel was placed exactly over top the first and pressed together with great care to ensure the fiber direction of each panel was perfectly aligned. Paint rollers were used to apply pressure and squeegee out excess epoxy. A second plastic sheet was placed over the sample panel. Finally, the sample panel was placed into an FRP sample box. The homemade FRP sample box was constructed so that multiple compartments used to house 
a sample panel could be stacked together as one unit. Two sample panels were made for each batch of FRP. These samples were left in the sample box to cure for at least 48 hours before removal. Once removed, they were cut into coupons and tested, as will be discussed later.

From this first-hand experience with FRP saturation and placement, it is recommended that the entire work area be covered with plastic since epoxy is difficult to remove from almost any surface. Also, it is recommended that protective clothing be worn to keep epoxy off of skin and clothes. Disposable coveralls were sufficient for this research. Other safety equipment used that is common for FRP work includes goggles, an organic respirator, and chemically resistant gloves*.

\subsubsection{Part II Beam Repair}

\subsubsection{Substrate Repair}

The substrate repair method for the Part II beam repairs was identical to the polymermodified concrete patch repair for Part I beams.

\footnotetext{
* The importance of using adequate chemical resistant gloves was directly learned in this project. Common latex laboratory gloves were used during the repair of the beam in Part 1 of the experimentation. Once work was completed and the gloves were removed, it was discovered that the epoxy had diffused through within the two hours it took for the repair. Epoxy penetration could not be detected during the work, but redness and a tingling sensation resulted for several days after the exposure since epoxy resin just as easily diffuses into skin. No glove is completely resistant to epoxy resin, but some glove material provides more time of resistance than do others. To avoid this problem after the first repair session, Silvershield gloves were used for all other FRP applications. Silvershield gloves are epoxy resistant and are guaranteed to provide many hours of protection. The Silvershield gloves worked very well and are strongly recommended for all future work requiring the handling of epoxy and FRP materials.
} 


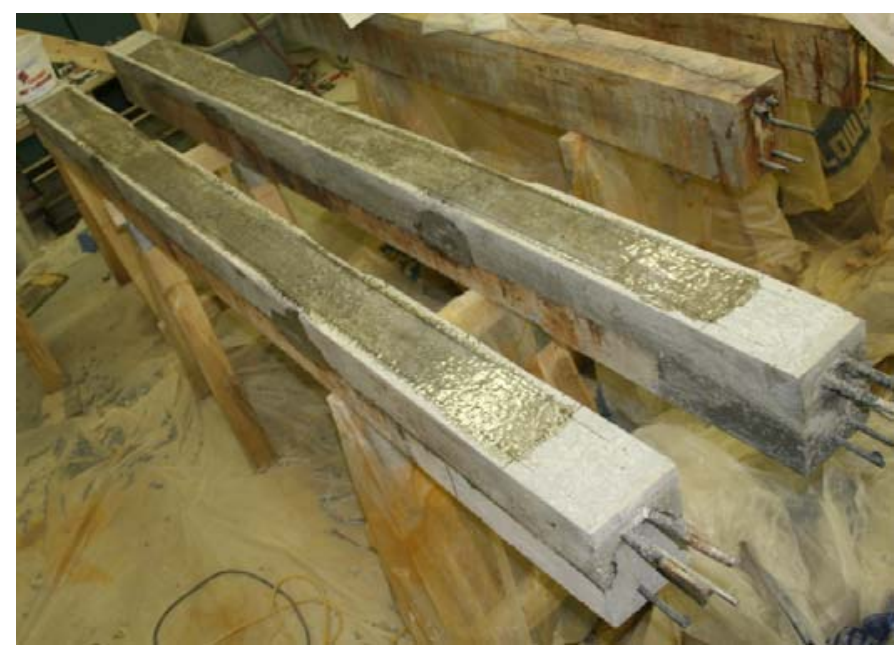

\section{Figure 5.41: Part II beams with finished} substrate repair and primed with Tyfo WS epoxy

First, deteriorated cover concrete was removed from each beam. Second, corrosion product was removed from the tension steel. Next, new polymer repair concrete was used to replace the old concrete that was removed. Finally, the surface of the repair concrete was prepared for the application of FRP. Figure 5.41 shows two Part II beams with completed substrate repair and primed with Tyfo WS epoxy.

\subsubsection{FRP Repair Using Three Unique Wrapping Schemes}

The effectiveness of three unique wrapping schemes was studied in Part II of this research. The variable was the extent of U-wrap anchorage provided. Flexural FRP strengthening consisted of one ply of Tyfo SCH-7UP Composite for all Part II beams. Wrapping Scheme 1 consisted of flexural FRP with no U-wrap anchors. Wrapping Scheme 2 consisted of flexural FRP with only one strategically placed U-wrap anchor on each side of the beam's midspan. Wrapping Scheme 3 consisted of flexural reinforcement with eight evenly spaced FRP U-wrap anchors. The U-wrap anchors were 
made of 4"x201/2" strips of Tyfo SCH-7UP Composite, the same material used for flexural strengthening. The main objective of Part II was to develop insight into an optimum FRP anchoring scheme and to compare the differences between the trial schemes.

The same procedures that were used to repair Part I specimens with polymer-modified concrete repair were used to repair all Part II specimens. Five beams were repaired with each wrapping scheme.

\subsection{Wrapping Scheme I}

Wrapping Scheme 1 consisted of one 4" wide ply of Tyfo SCH-7UP Composite, which is 0.007 " thick, for flexural strengthening. No anchorage system was used so that the beam specimens with Wrapping Scheme 1 would serve as a base comparison to the anchored schemes 2 and 3. A schematic of Wrapping Scheme 1 is provided in Figure 5.42.

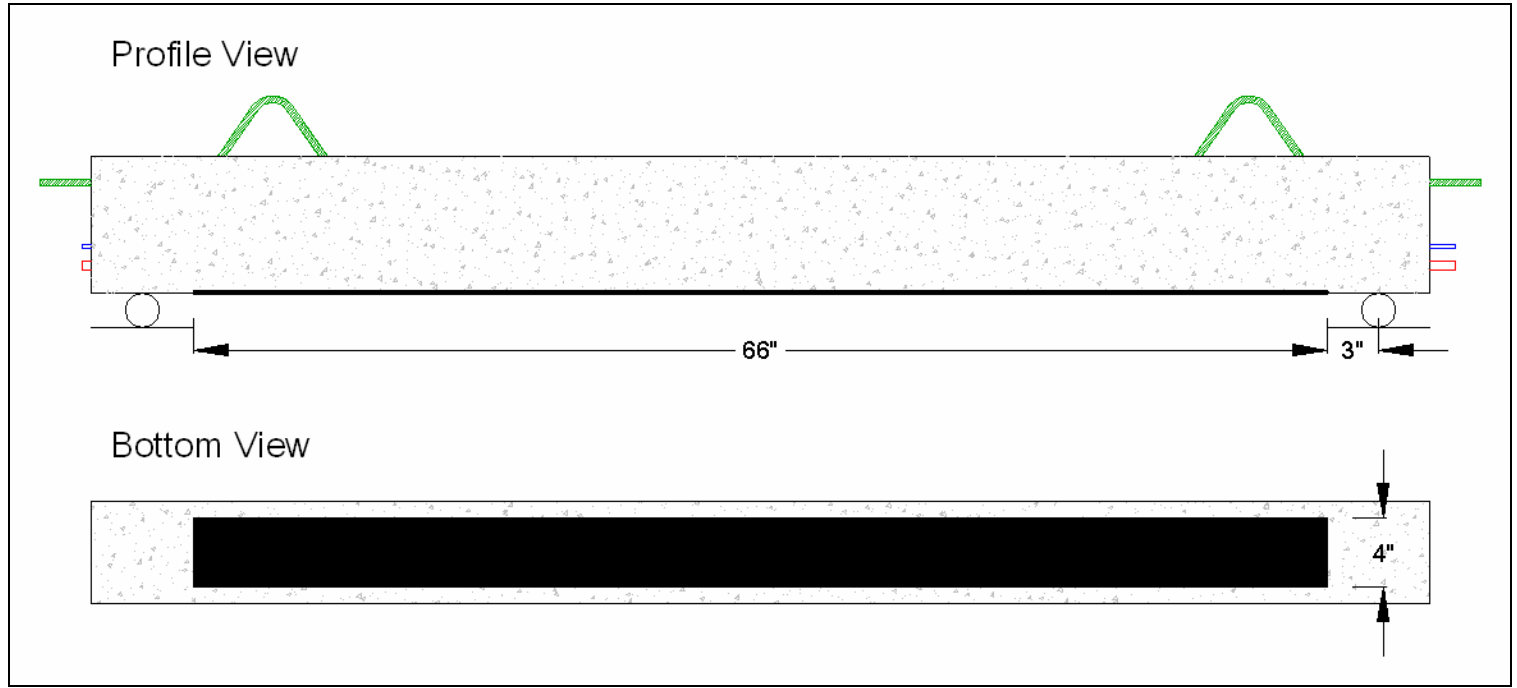

Figure 5.42: Schematic of Wrapping Scheme I 
The extent of FRP repair was designed according to ACI guidelines to restore Part I beams to $92 \%$ of the original capacity predicted for a pristine beam (the difference between 92 and $100 \%$ is $1,083 \mathrm{lbs}$ total load). Beams were not designed to fully restore the beams to their original capacities since it was feared that the poor-quality compression concrete would crush with the addition of too much FRP. Concrete crushing would have resulted in inadequate data for the intentions of this project, so it had to be ensured this failure mode did not occur.

\subsection{Wrapping Scheme 2}

Wrapping Scheme 2 consisted of one 4" wide ply of Tyfo SCH-7UP Composite, which is 0.007" thick, for flexural strengthening. Two 4" wide U-wrap anchors, one on either side of the beam's midspan, were installed at strategic locations. The same Tyfo SCH-7UP Composite was used to make the anchor stirrups. The concept behind Dr. Chris Leung's advice regarding the location of these stirrups (Leung, 2006) was the basis of the locations chosen for this wrapping scheme. The locations were not decided upon until the Wrapping Scheme 1 beams were tested in 4-point bending and the rupture and debonding locations were discovered. It was finally decided that the U-wrap anchors be placed at locations of 17 " from the supports (14" from the FRP termination points). This anchor location was slightly inside location Dr. Leung suggested (refer to Part I), because this appeared to be the initiation point of debonding for beams repaired using Scheme 1 .

A schematic of Wrapping Scheme 2 is provided in Figure 5.44. 


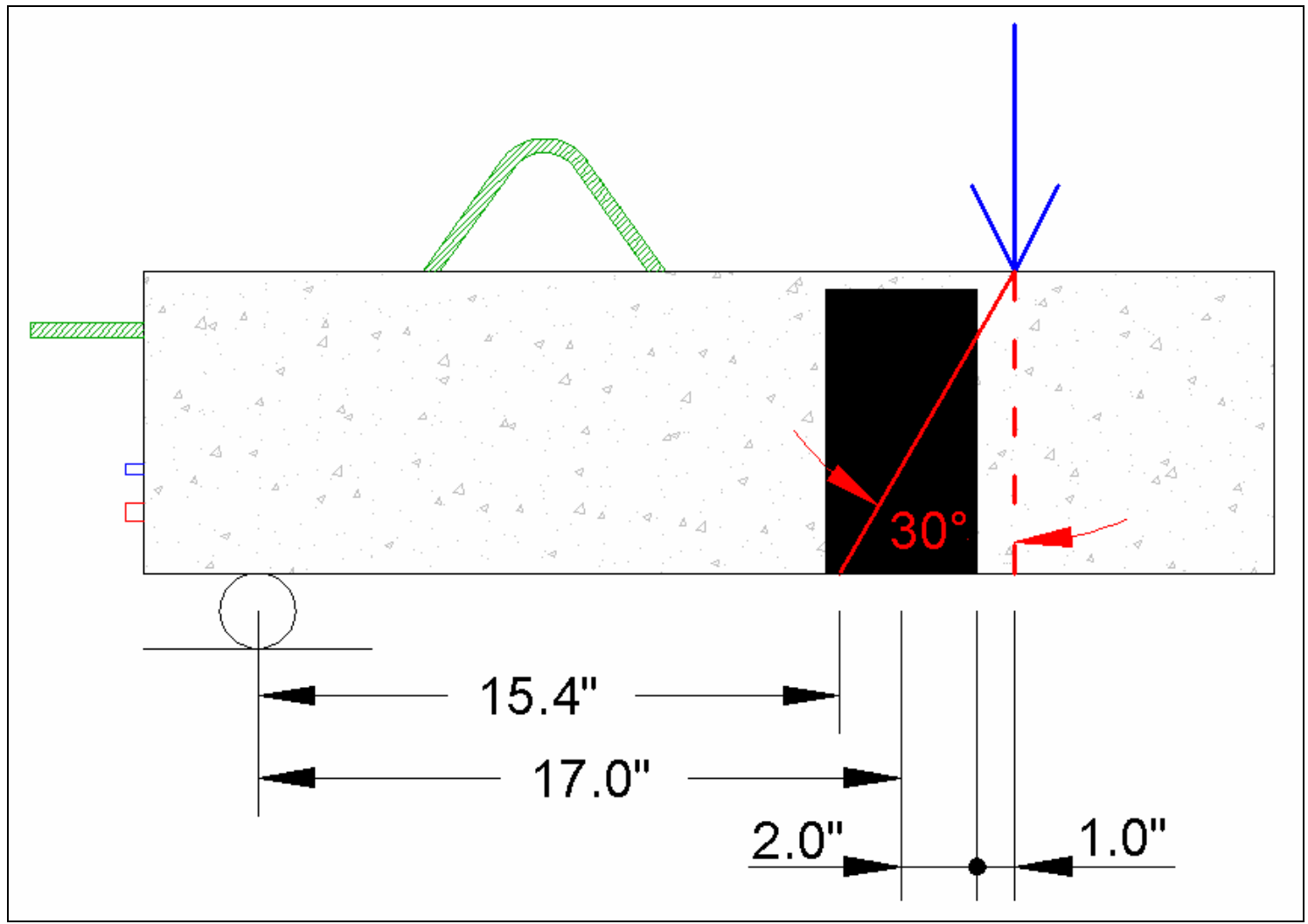

Figure 5.43: Stirrup Location for Wrapping Scheme II

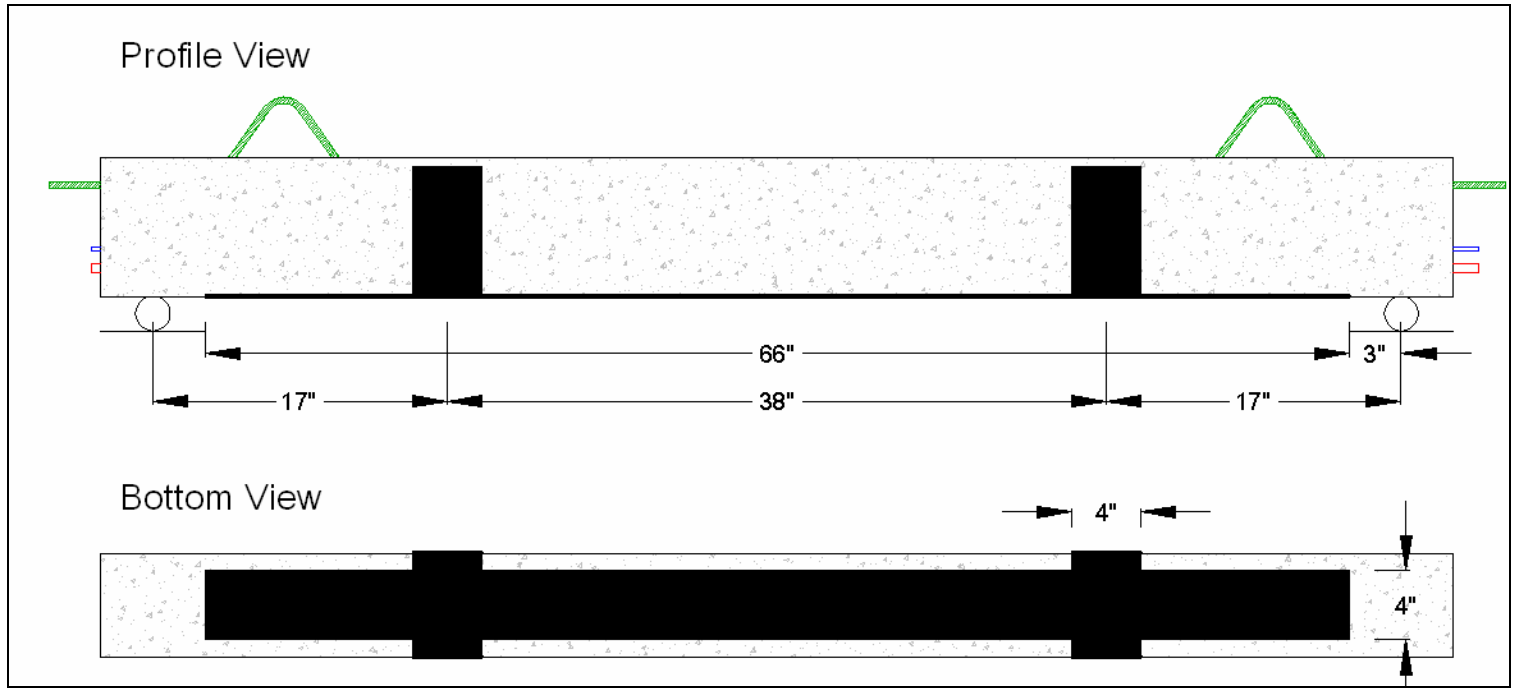

Figure 5.44: Schematic of Wrapping Scheme 2 


\subsection{Wrapping Scheme 3}

Wrapping Scheme 3 consisted of one 4" wide ply of Tyfo SCH-7UP Composite, which is 0.007" thick, for flexural strengthening.

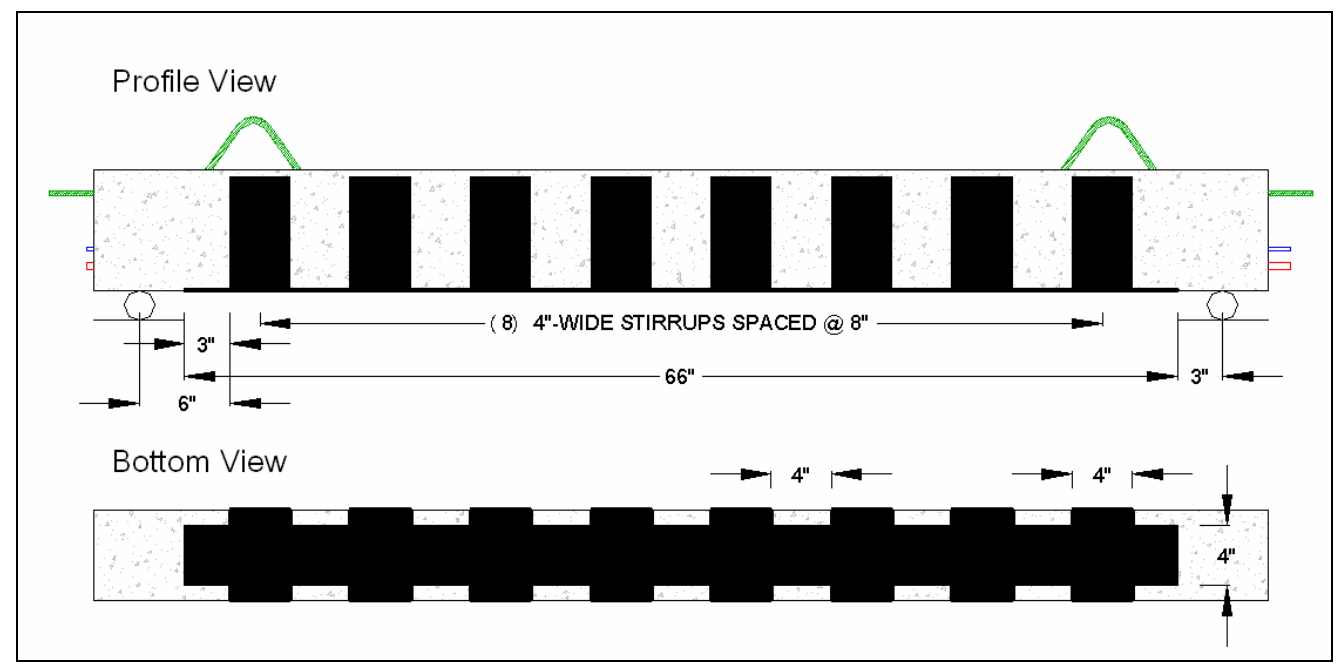

Figure 5.45: Schematic of Wrapping Scheme 3

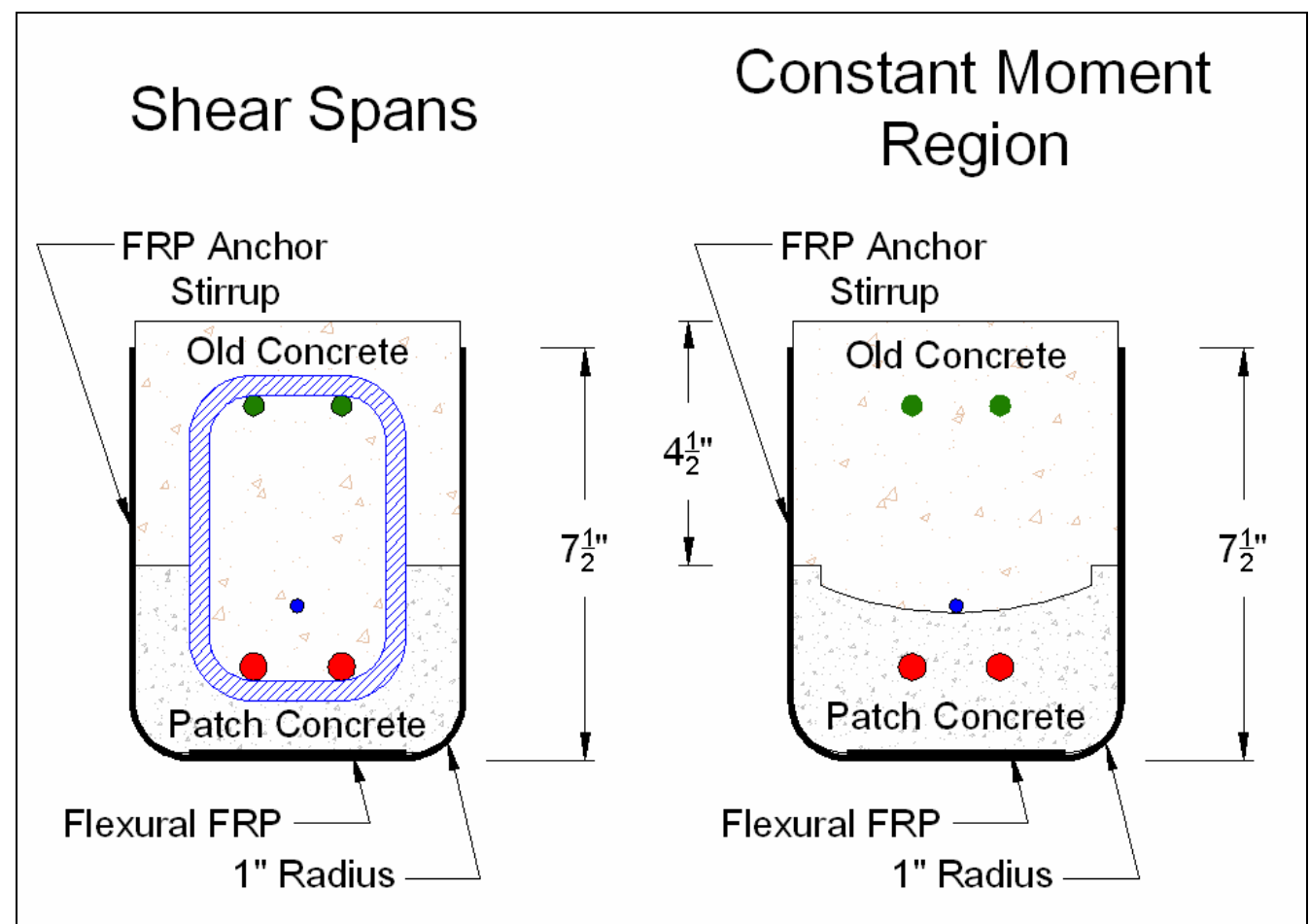

Figure 5.46: Cross-section of patch repaired beams with FRP at both shear and constant moment regions 
Eight 4"-wide U-wrap anchors were evenly spaced 8" apart over the length of the span. The same Tyfo SCH-7UP Composite was used to make the anchor stirrups. A schematic of Wrapping Scheme 3 is provided in Figure 5.45.

Figure 5.46 shows the cross-section of patch repaired beams strengthened with FRP at both the shear and constant moment regions.

\subsection{Non-Destructive Testing}

\subsubsection{Crack Measurement}

\subsubsection{Theory and Significance}

Crack measurement is very important because it can provide an engineer with insight into the rate of expansive corrosion. Cracks that grow significantly in length or width between field inspections can indicate problematic areas that may require more investigation. For inspectibility, crack formation imparts a safety feature in a reinforced concrete element since it provides early signs of a long-term problem.

\subsubsection{Application}

Cracks on all beams were measured weekly throughout the accelerated corrosion process. This was done by using a Mastrad crack width gage (see Figure 5.47). The data recorded provides values indicating representative width of each visible crack. Crack length was also measured weekly to reveal propagation rates. 


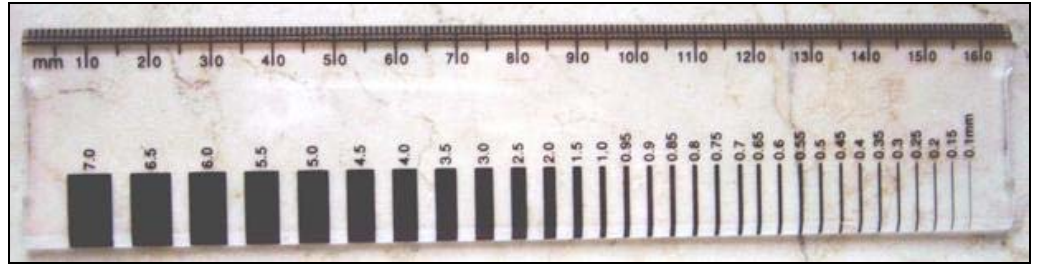

Figure 5.47: Mastrad crack width gage (http://rissmonitor.com)

Due to a substantial amount of crack data obtained, only the final crack patterns and measurements obtained at the commencement of the accelerated corrosion process are presented in Appendix $\mathrm{C}$ and discussed in the results section of this document.

\subsubsection{Half-Cell Potential}

\subsubsection{Theory and Significance}

Half-cell potential measurements serve as an inspection tool when it is suspected that concrete reinforcement is corroding. The negativity of the values obtained from this nondestructive test provides an indication of the likelihood and severity of corrosion activity within. Half-cell testing equipment simply consists of a half-cell electrode and a high-impedance voltmeter. A half-cell electrode consists of a tube with a porous media on one end. It contains a metal rod submersed in a saturated solution of one of its own salts. For example, in this research, a copper rod was used with copper sulfate solution. The negative voltmeter terminal is then connected to the half-cell electrode and the positive terminal is connected to exposed reinforcement. It should be noted that the concrete must be sufficiently moist to obtain accurate half-cell potential data. 
As mentioned previously, the process of iron atoms losing electrons is called a half-cell oxidation reaction. The electrons flow to cathodic areas where they combine with water and oxygen to produce hydroxyl ions. The electrons in the bar give yield negative charge when corrosion occurs, and the half-cell potential equipment detects it since the electrons flow from the bar to the half cell tube. Inside the tube, electrons are consumed and copper ions in the copper sulfate solution are transformed into copper atoms and are attach to the copper rod. Table 5.5 shows how to interpret these half-cell potential measurements.

\section{Table 5.5: Interpretation of Half-Cell Potential Data} (ASTM C 876-02)

\begin{tabular}{|l|l|}
\hline Half-Cell Potential Reading & Likelihood of Corrosion Activity \\
\hline$>-200 \mathrm{mV}$ & Low Risk of Corrosion $(<10 \%)$ \\
\hline-200 to $-350 \mathrm{mV}$ & Intermediate Risk of Corrosion \\
\hline-350 to $-500 \mathrm{mV}$ & High Risk of Corrosion $(>90 \%)$ \\
\hline$<-500 \mathrm{mV}$ & Severe Risk of Corrosion \\
\hline
\end{tabular}

Localized pitting corrosion is indicated by severe potential gradients exist across the reinforced concrete surface. A greater risk of corrosion exists in areas between where two measurements indicate a rapid change. It should also be noted that very negative potentials can be erroneously observed in saturated conditions where there is no oxygen.

It is suggested that, for field measurements, representative steel areas that were indicated as mild, intermediate, and severe be exposed and their conditions be verified to ensure the data correlates with what actually exists. 


\subsubsection{Application to this Research}

Half-cell potential was used in this research to compare the risk of corrosion in the seven beams aged in Part I of the testing plan. It is important in this research to show that an extra and unwanted variable was not introduced by varying degrees of corrosion between beams similar in age and applied amp-hours. While half-cell potential readings may yield obvious results and conclusions when taken from beam specimens subjected to accelerated aging, they were performed in this research to demonstrate the usefulness of half-cell data in conventional reinforced concrete bridge inspection to detect corrosion risk prior to visible symptoms of corrosion.

When subjected to electric current, the bars need time to depolarize after the corrosion current is turned off and the half-cell readings are taken. If the bars are not completely depolarized, the half-cell readings could be significantly affected. The reinforcing bars were given at least 30 minutes to depolarize after the power supplies were turned off.

Half-cell potential readings were taken weekly at the locations shown in Figure 5.48.

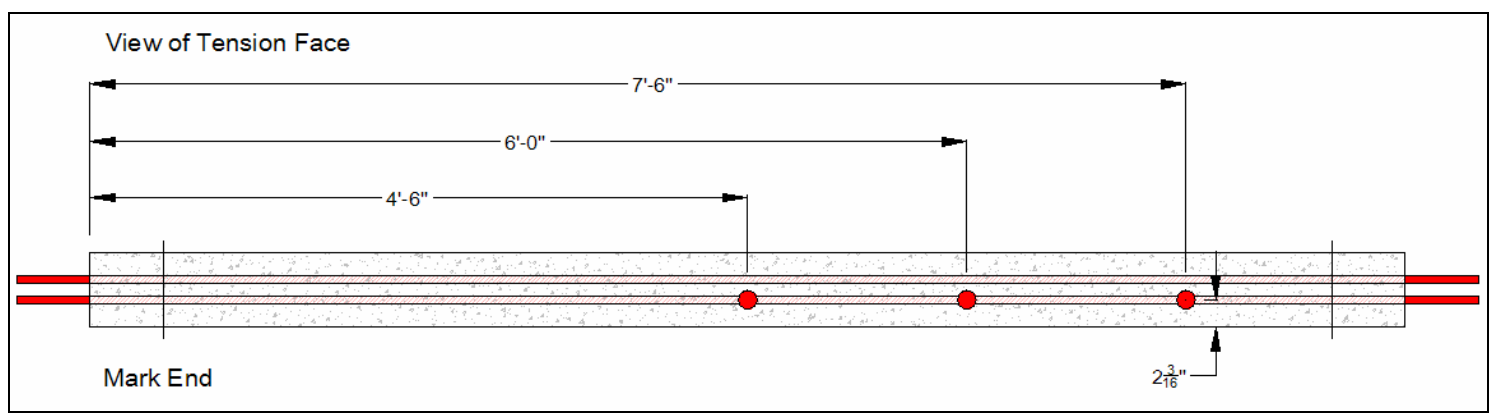

Figure 5.48: Location of half-cell potential readings on Part I beams 


\subsubsection{Rebound Hammer (ASTM C 805-2)}

\subsubsection{Theory and Significance}

Rebound hammer (Schmidt hammer), testing is one of the most widespread methods of estimating concrete quality, strength, and uniformity. It should be noted that, while rebound hammer data should not be relied upon to provide an accurate value for compressive strength, it can be acceptably used to measure the variations of strength in different concrete areas within a structure. Even for a well-calibrated hammer, the concrete strength estimated by rebound numbers is typically only accurate to $\pm 25 \%$ (Malhotra, 2004). The rebound hammer is more readily used to determine regions of poor quality and deteriorated concrete and to monitor in situ strength development.

The Schmidt hammer apparatus consists of a mass which slides on a plunger housed within a metal cylinder. The mass is initially held at a given location along the plunger by a catch with a self release mechanism. When the plunger is placed and pushed against the concrete surface, the plunger moves into the housing cylinder and a spring within the apparatus is extended. When the plunger is retracted, the self release catch is tripped and the mass accelerates toward the concrete surface under the force of the spring. When the mass strikes an enlarged area of the plunger, it rebounds a certain distance that is measured and recorded on a sliding scale that ranges from 10 to 100 . Due to gravity effects, the rebound number will be different for the same concrete when the angle of testing is changed. 
It is important to note that the results of a rebound hammer test can be significantly affected by the smoothness and finishing quality of the test surface, the size, shape, and rigidity of the specimens, the age of the concrete, moisture in the concrete, type of aggregates and cement, type of mold, and carbonation of the concrete surface. The concrete being tested should be at least 4 " thick and fixed within the structure. Rebound hammer readings should never be taken on frozen concrete, nor should they be taken directly over reinforcing bars with cover less than 3/4" (ASTM C 805-02).

\subsubsection{Application to this Research}

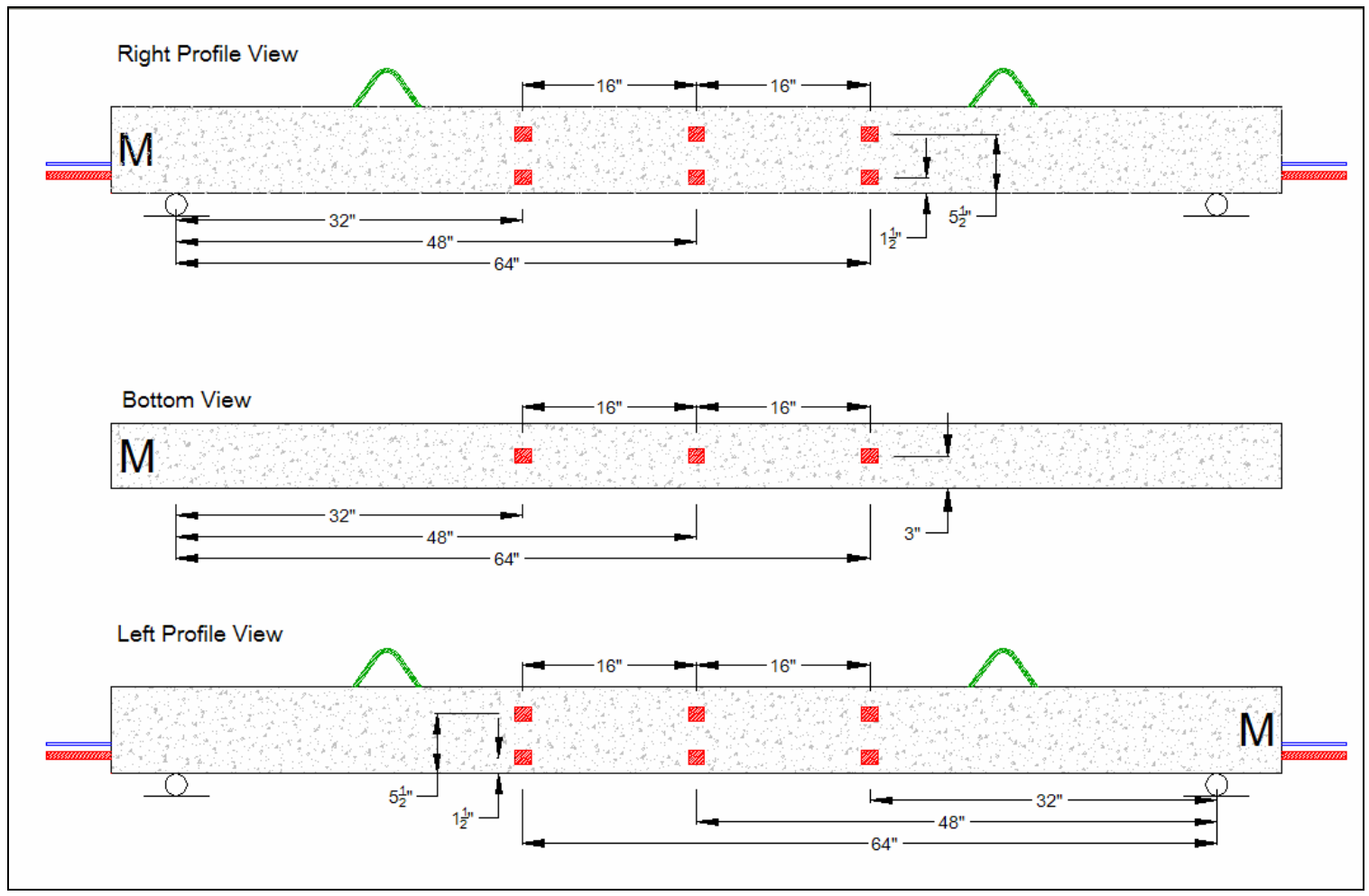

Figure 5.49: Rebound hammer test locations for Part I beams 
Rebound hammer testing was used in this research to estimate the homogeneity between the many batches of concrete used, to compare the qualities of the pristine, degraded, and patch repair concrete. It is important for this research to show that concrete material does not introduce an extra and unwanted variable. All normal concrete, all patch repair concrete, and all deteriorated concrete must have comparable quality, respectively. Comparisons between pristine and deteriorated concrete were made using the rebound hammer to demonstrate that it is useful in conventional reinforced concrete bridge inspection to detect and evaluate the extent of degradation of concrete member.

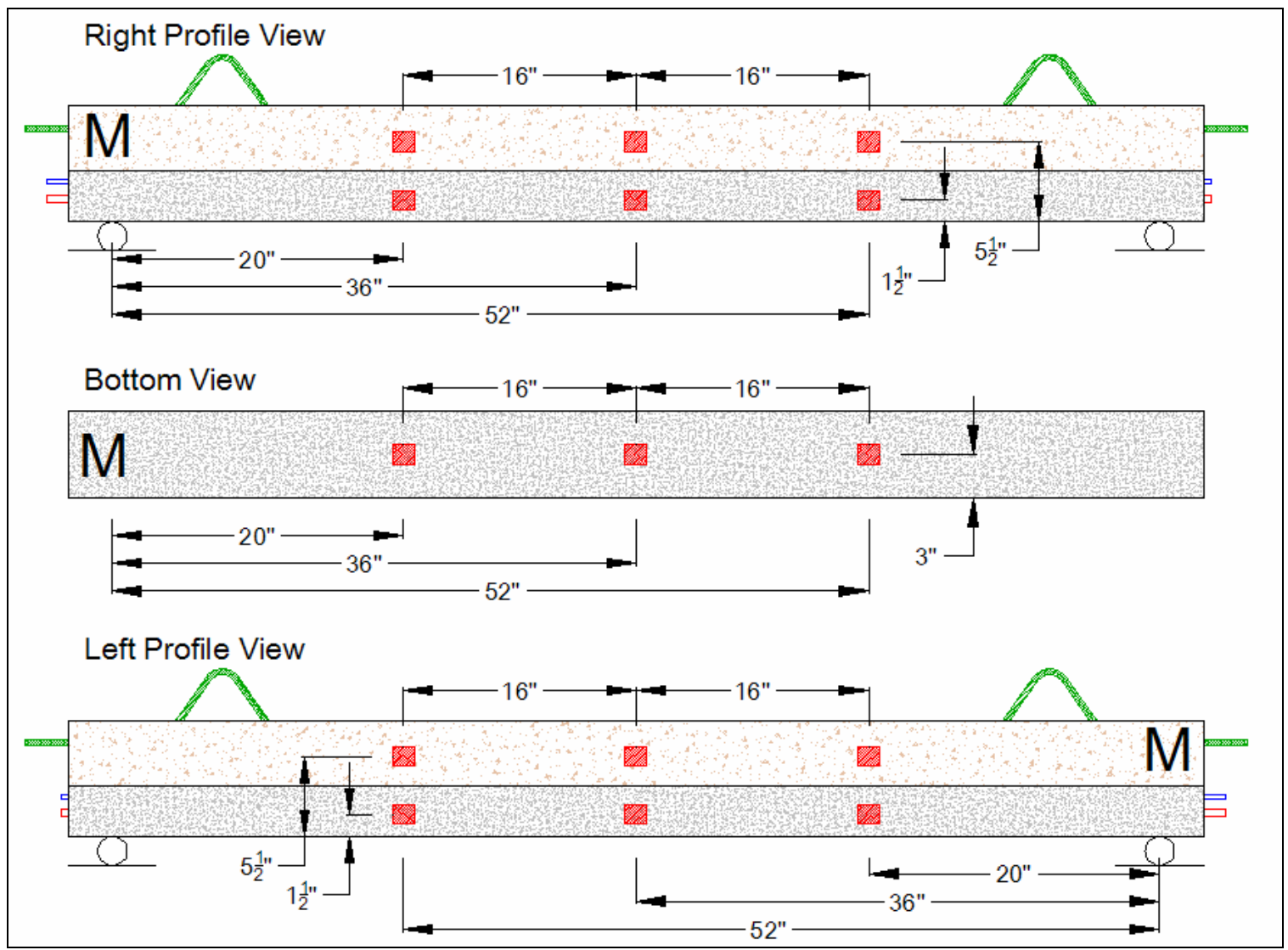

Figure 5.50: Rebound hammer test locations for Part II beams without externally bonded concrete strain gages 
For Part II unrepaired beams, a total of twelve locations were tested: six on each side. These locations for beams with no externally bonded concrete strain gages are illustrated in Figure 5.50. It should be noted that, for beams repaired with FRP, the readings on the bottom face of the beam were omitted. For beams with externally bonded concrete strain gages, the gage locations at the mark end and midspan were offset to the locations shown in Figure 5.51.

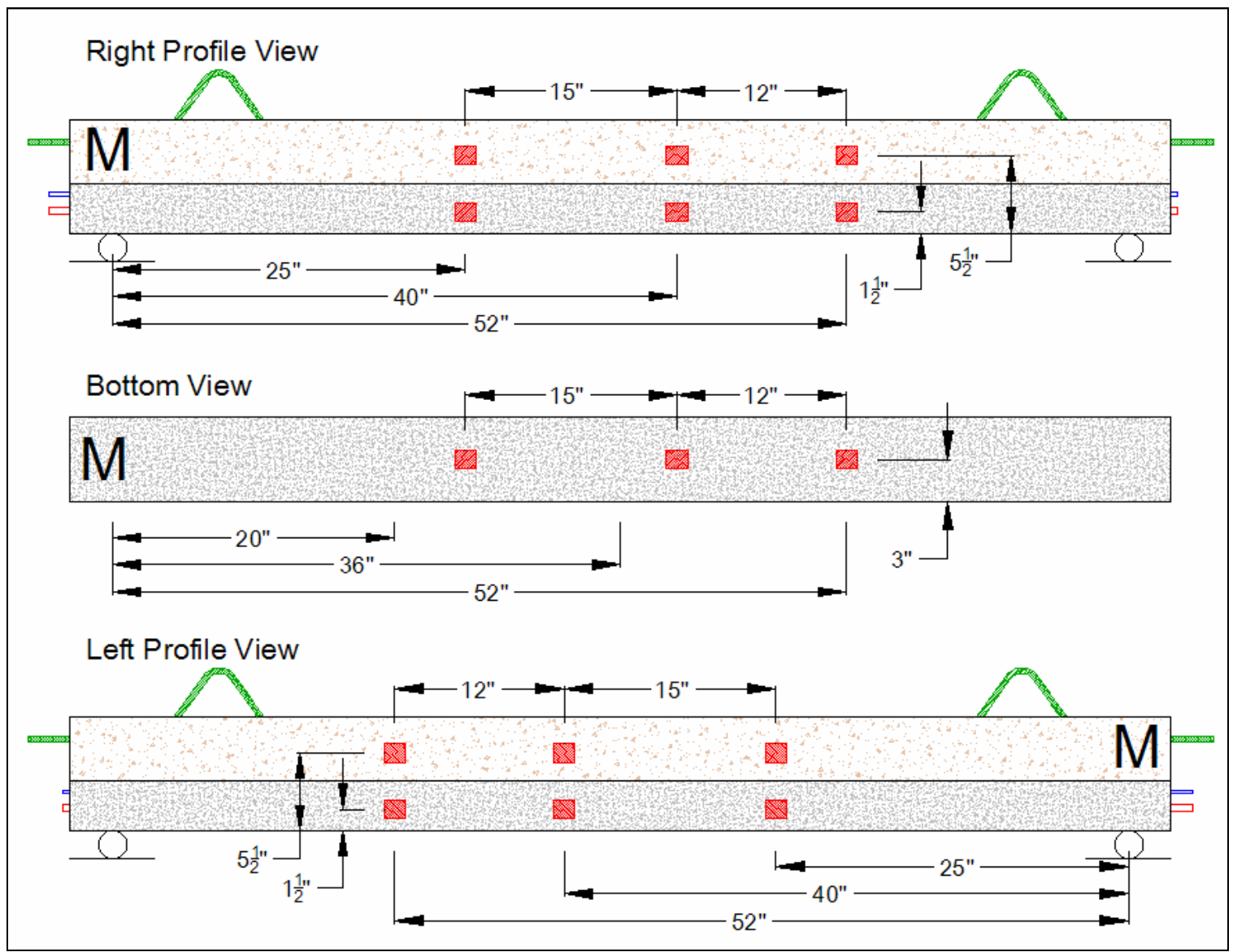

Figure 5.51: Rebound hammer test locations for Part II beams with externally bonded concrete strain gages

A total of eight rebound hammer measurements were taken at each testing location and were averaged together to obtain a rebound number for the concrete in each testing location. 


\subsubsection{Ultrasonic Pulse Velocity (ASTM C 597-02)}

\subsubsection{Theory and Significance}

Ultrasonic pulse velocity testing is used to estimate concrete strength, elasticity, uniformity, durability, and the presence of and depth of cracks, voids, honeycombing, or other irregularities. Like rebound hammer testing, ultrasonic pulse velocity is correctly used as a method of assessing variations in the quality of concrete instead as a means of attaining accurate values of concrete strength.

Ultrasonic pulse velocity equipment includes two transducers and a control box containing a pulse generator, a timing circuit, and a digital display. One cylindrical metal transducer is connected to the transmitter and the other is connected to the receiver. Transducers with frequencies between 25 and $100 \mathrm{kHz}$ are generally used when testing concrete. Petroleum jelly is spread over the transducer surfaces and the testing areas and is used as a coupling agent between the transducers and the concrete. The transducers are then pressed firmly against the concrete surface, and ultrasonic compression waves are passed into the concrete via the transmitter. The waves pass through the concrete, in much the same way that sound waves propagate through air, and are detected by the receiving transducer. The digital display indicates the travel time of the pulse between the transducers. The velocity of the pulse is simply found by dividing the distance between the transducers by the pulse's time of travel.

There are three possible configurations for ultrasonic pulse velocity: direct, indirect, and semi-direct. For the direct configuration, the transducers are placed on opposite faces of 
the member and the pulse travels through the member. For the indirect configuration, the transducers are placed on the same face of the member and the pulse travels just below the surface. For the semi-direct configuration, the transducers are placed on faces which are perpendicular to each other. Please refer to Figure 5.52 for diagrams of these three configurations. The direct configuration is the most accurate since it allows for maximum energy transfer.

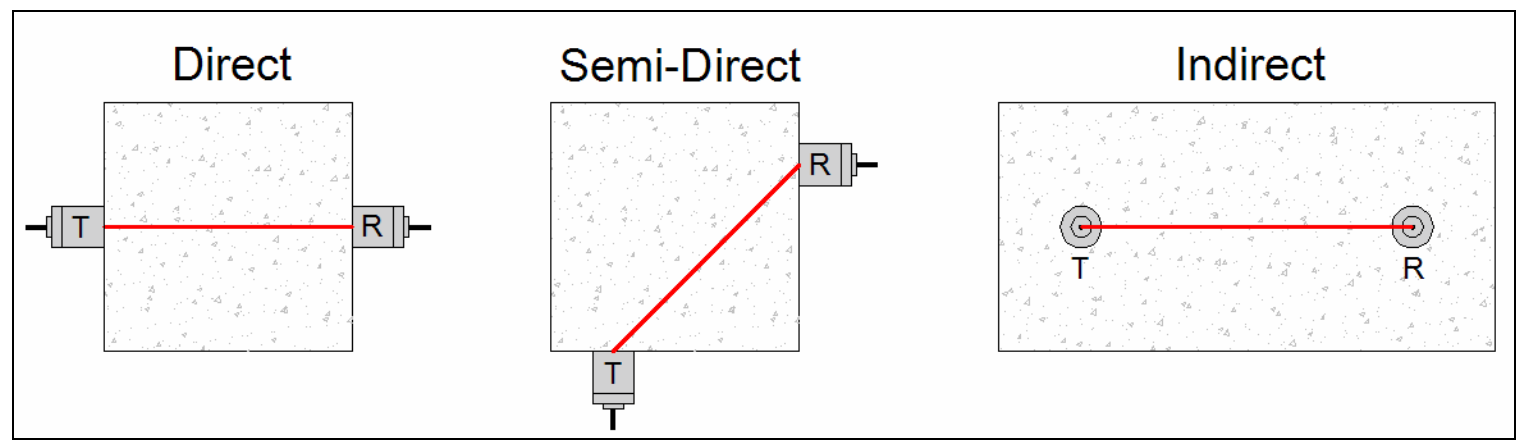

Figure 5.52: Three configurations for an ultrasonic pulse velocity test

The velocity of a wave is a function of the elastic properties and density of the concrete, as can be seen in the equation below. Therefore, empirical relationships can be used to compare the ultrasonic pulse velocity to the concrete's mechanical properties. It should be noted, however, that cement type, aggregate size and type, w/c ratio, reinforcement, moisture content, admixtures used, and concrete age can all affect the pulse velocity.

$V=\sqrt{\frac{E(1-\mu)}{\rho(1+\mu)(1-2 \mu)}}$

(Malhotra, 2004; ASTM C 597-02)

where:

$V=$ Compression Wave Velocity

$E=$ Dynamic Modulus of Elasticity

$\rho=$ Density

$\mu=$ Dynamic Poisson's Ratio 


\subsubsection{Application}

In this research, the ultrasonic pulse velocity was used to estimate the homogeneity of the many batches of concrete used, to detect the presence of cracks within the concrete, and to compare the qualities of the pristine, degraded, and patch repair concrete. As discussed previously, it is important to show that concrete material does not introduce a variable to the testing plan. All normal concrete, all patch repair concrete, and all deteriorated concrete must have comparable quality, respectively. When no cracks are present within the concrete, the ultrasonic wave can travel directly in line between the transmitter and the receiver. However, when a crack is present within this line, the pulse must travel a longer path around the crack which results in a lower perceived value for pulse velocity. A lesser perceived value of pulse velocity means that cracks are more likely present within the concrete. Comparisons between pristine and deteriorated concrete were made using the pulse velocity method to demonstrate that it is useful in conventional reinforced concrete bridge inspection to detect and evaluate the extent of degradation of a concrete member.

The pulse velocity configurations shown in Figure 5.53 were applied between the locations indicated by the red dots on Figure 5.54 for beams without externally bonded strain gages and between the offset dots on Figure 5.55 for beams with externally bonded strain gages. Note that for beams repaired with FRP, the semi-direct readings were omitted due to the presence of the repair material. Also note that pulse velocity readings were obtained at the same locations as were the rebound hammer readings. 


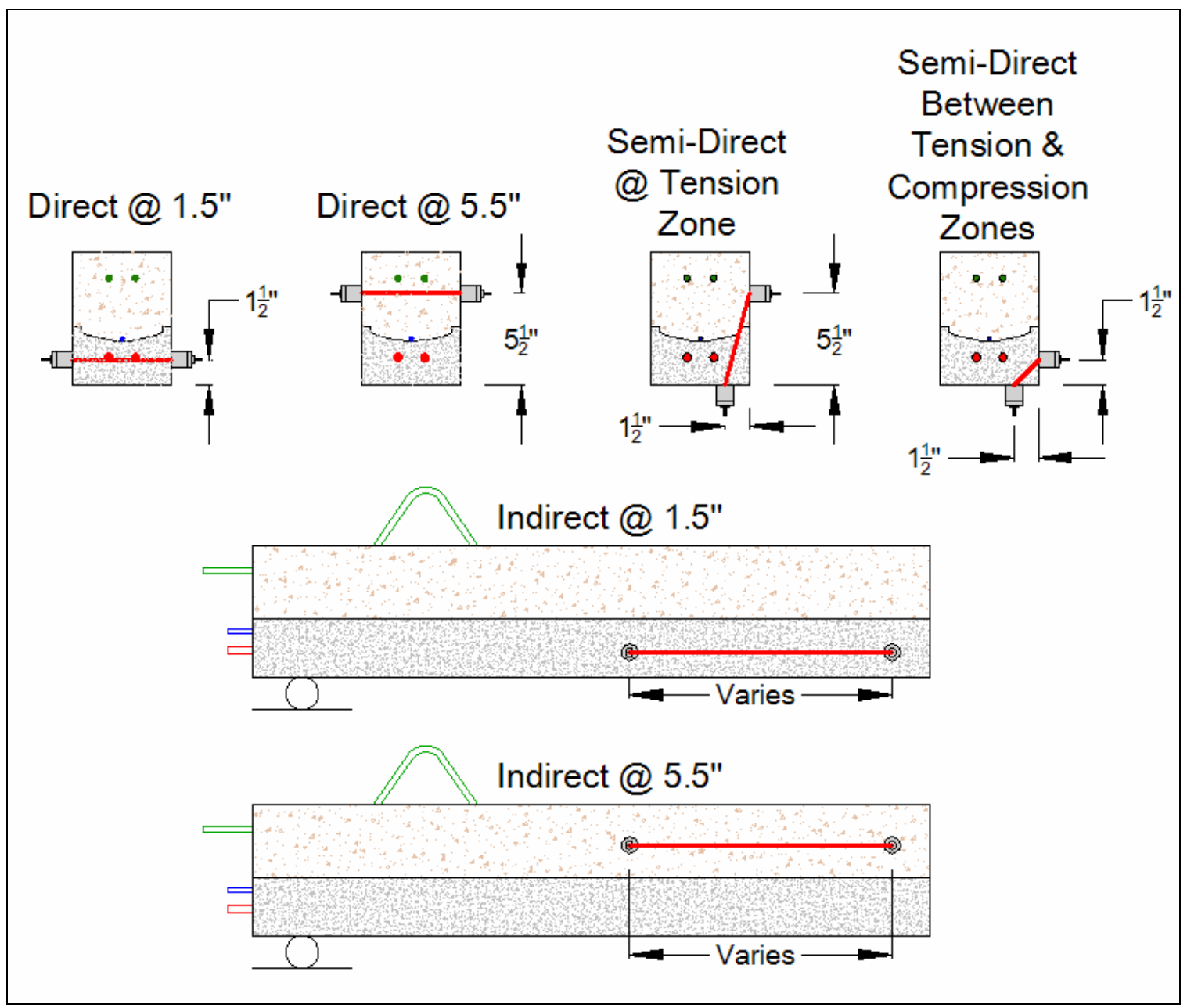

Figure 5.53: Pulse velocity configurations 


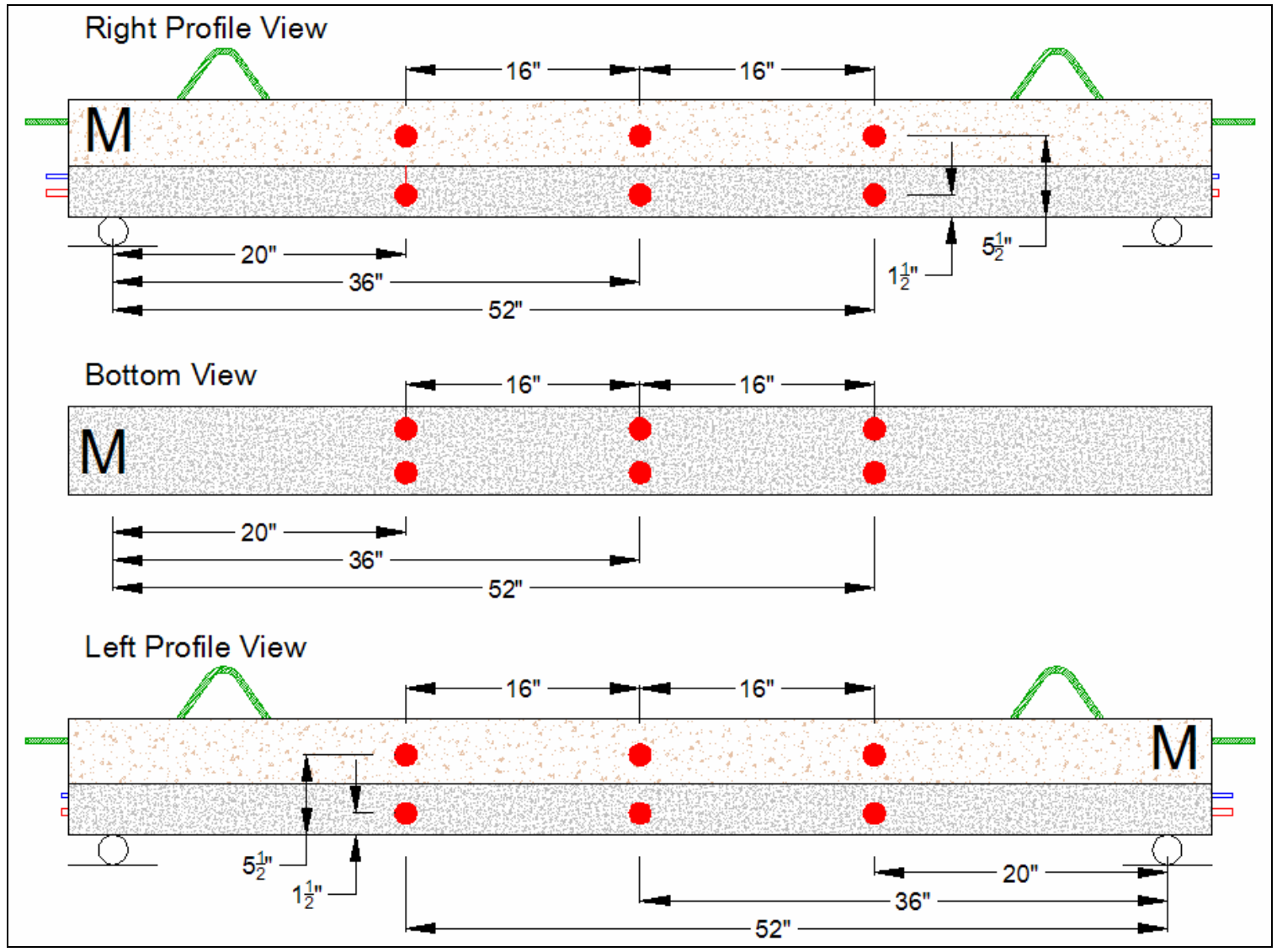

Figure 5.54: Pulse velocity testing locations on beams without externally bonded strain gages 


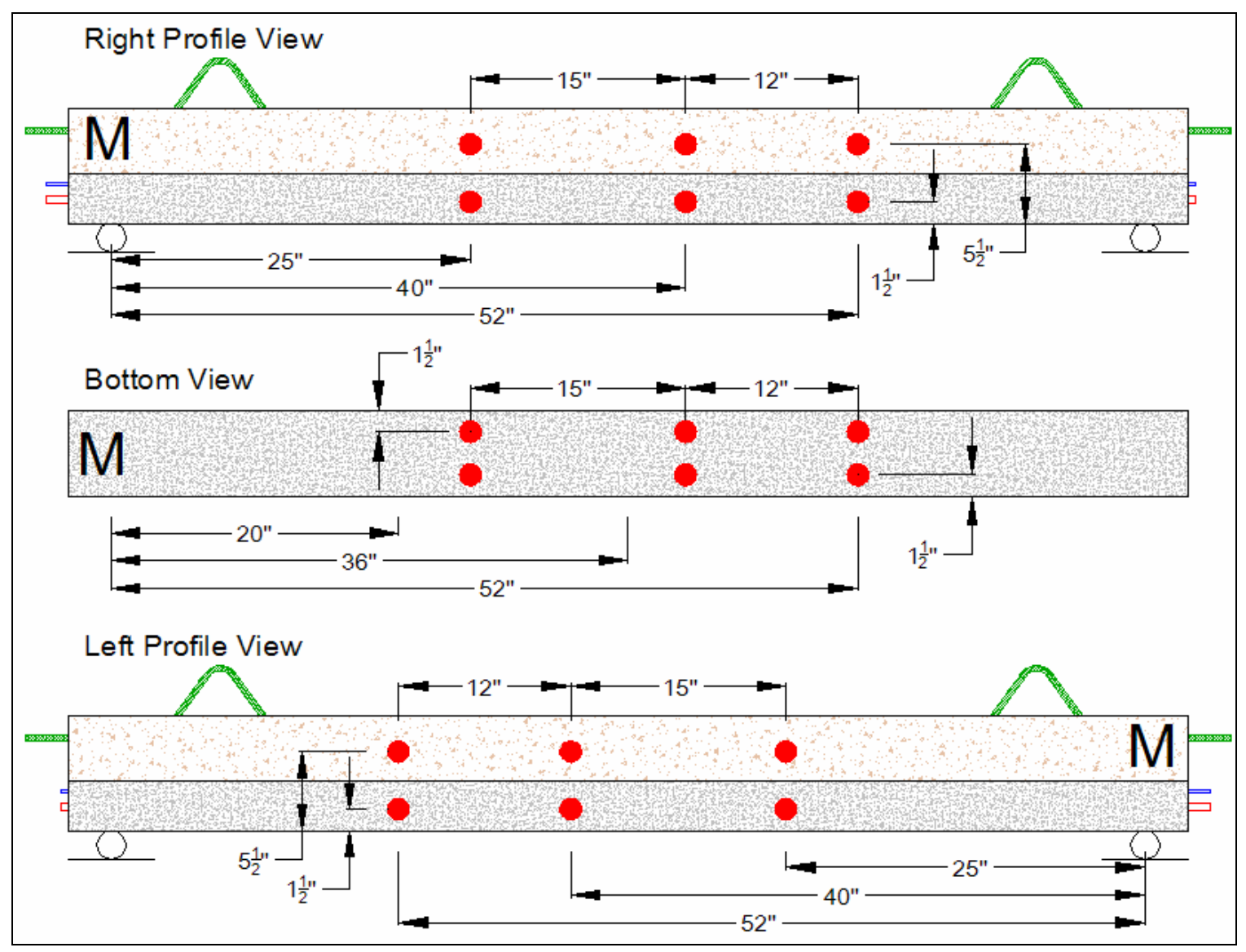

Figure 5.55: Pulse velocity testing locations on beams with externally bonded concrete strain gages

\subsection{Destructive Testing}

\subsubsection{Static Flexural Testing}

\subsubsection{Equipment}

The primary equipment used in static flexural testing is presented in this section. An MTS Single Ended Actuator (Model 243.40, 12.0” Stroke) capable of producing 110kips of compressive force was used to apply load to the beam specimens. An MTS SilentFlo ${ }^{\circledR}$ Hydraulic Power Unit (Model 505.90, 3000 psi working pressure, 90GPM 
flow rate) powered the hydraulic actuator. An MTS 290 Hydraulic Service Manifold was used to regulate flow and control the pressure to the test station.

TestStar System Software (Model 793.00, Version 3.4B) was used along with a TestStar IIm Digital Controller to control the functions of the actuator arm.

\subsubsection{Instrumentation}

\subsection{Part I}

Instrumentation for Part II of the experiment included three Honeywell VL7A-1000 LVDT's to measure displacement, as shown in Figure 5.56.

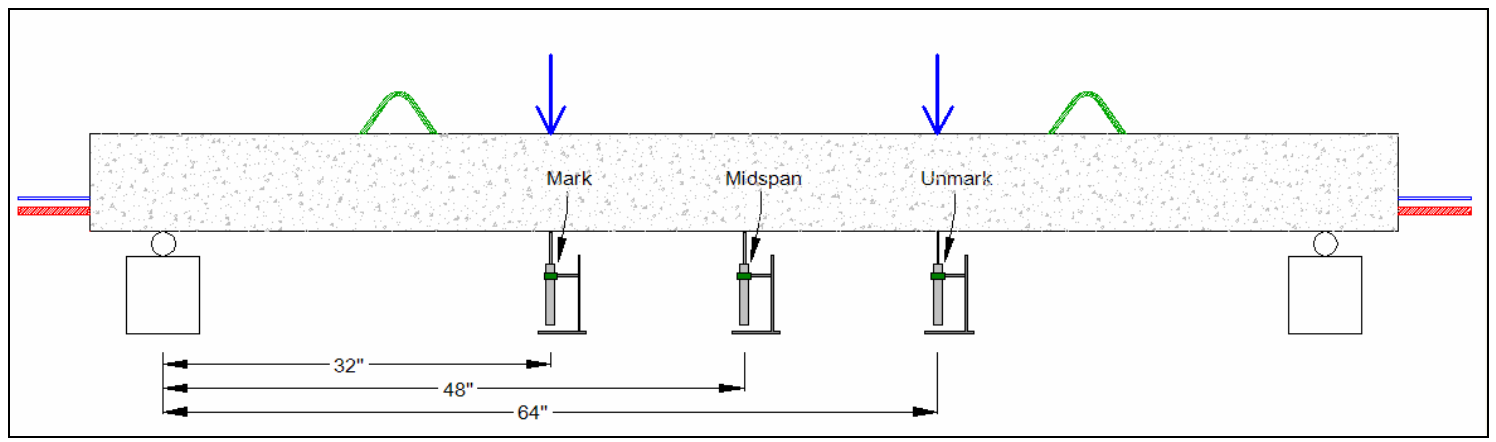

Figure 5.56: Part I LVDT Locations

\subsection{Part II}

Instrumentation for Part II of the experiment included three Honeywell VL7A-1000 LVDT's to measure displacement, Vishay N2A-06-250UN-120/P2 externally bonded 2" strain gages to measure concrete strain, Vishay EGP-5-120 4" concrete embedment gages to measure concrete strain at reinforcement levels, and Vishay N2A-06-20CBW-120/P 
0.25 " strain gages to measure both steel and FRP strain. A fully instrumented beam consisted of all of the instruments listed above.

A total of ten beams were instrumented with strain gages for this experiment. The remaining beams were instrumented with only the three LVDT's due to cost and time constraints. Table 5.6 provides an overview of the instrumentation plan. "Fully Instrumented" means that the beam was instrumented with LVDT's, bonded concrete strain gages, embedded concrete strain gages, steel strain gages, and FRP strain gages.

\section{Table 5.6: Part II Instrumentation Plan}

\begin{tabular}{|c|c|c|}
\hline Description & Beam & Instrumentation \\
\hline \multirow{2}{*}{ 28-day Pristine } & 1 & LVDT's Only \\
\hline & 2 & Fully Instrumented \\
\hline \multirow{2}{*}{ Long-Term Pristine } & 11 & \multirow{2}{*}{ LVDT's, Concrete Embedment, Steel } \\
\hline & 12 & \\
\hline \multirow[t]{2}{*}{ Corroded Unrepaired } & 3 & $\begin{array}{l}\text { LVDT's, Concrete Embedment, } \\
\text { Steel, Externally-Bonded Concrete }\end{array}$ \\
\hline & 4 & LVDT's Only \\
\hline \multirow{3}{*}{ Repaired with Wrapping Scheme 1} & 5 & Fully Instrumented \\
\hline & 8 & \multirow{2}{*}{ LVDT's Only } \\
\hline & 9 & \\
\hline \multirow{2}{*}{$\begin{array}{l}\text { Repaired with Wrapping Scheme } 1 \\
\text { and Subjected to Cyclic Load }\end{array}$} & 7 & Fully Instrumented \\
\hline & 14 & LVDT's Only \\
\hline \multirow{3}{*}{ Repaired with Wrapping Scheme 2} & 13 & \multirow{2}{*}{ LVDT's Only } \\
\hline & 15 & \\
\hline & 17 & Fully Instrumented \\
\hline \multirow{2}{*}{$\begin{array}{l}\text { Repaired with Wrapping Scheme } 2 \\
\text { and Subjected to Cyclic Load }\end{array}$} & 18 & Fully Instrumented \\
\hline & 20 & LVDT's Only \\
\hline \multirow{3}{*}{ Repaired with Wrapping Scheme 3} & 21 & \multirow{2}{*}{ LVDT's Only } \\
\hline & 22 & \\
\hline & 24 & Fully Instrumented \\
\hline \multirow{2}{*}{$\begin{array}{l}\text { Repaired with Wrapping Scheme } 3 \\
\text { and Subjected to Cyclic Load }\end{array}$} & 19 & Fully Instrumented \\
\hline & 23 & LVDT's Only \\
\hline
\end{tabular}


Three LVDT's were used to measure displacement during each load test, one beneath each load point and one at the midspan (See Figure 5.57).

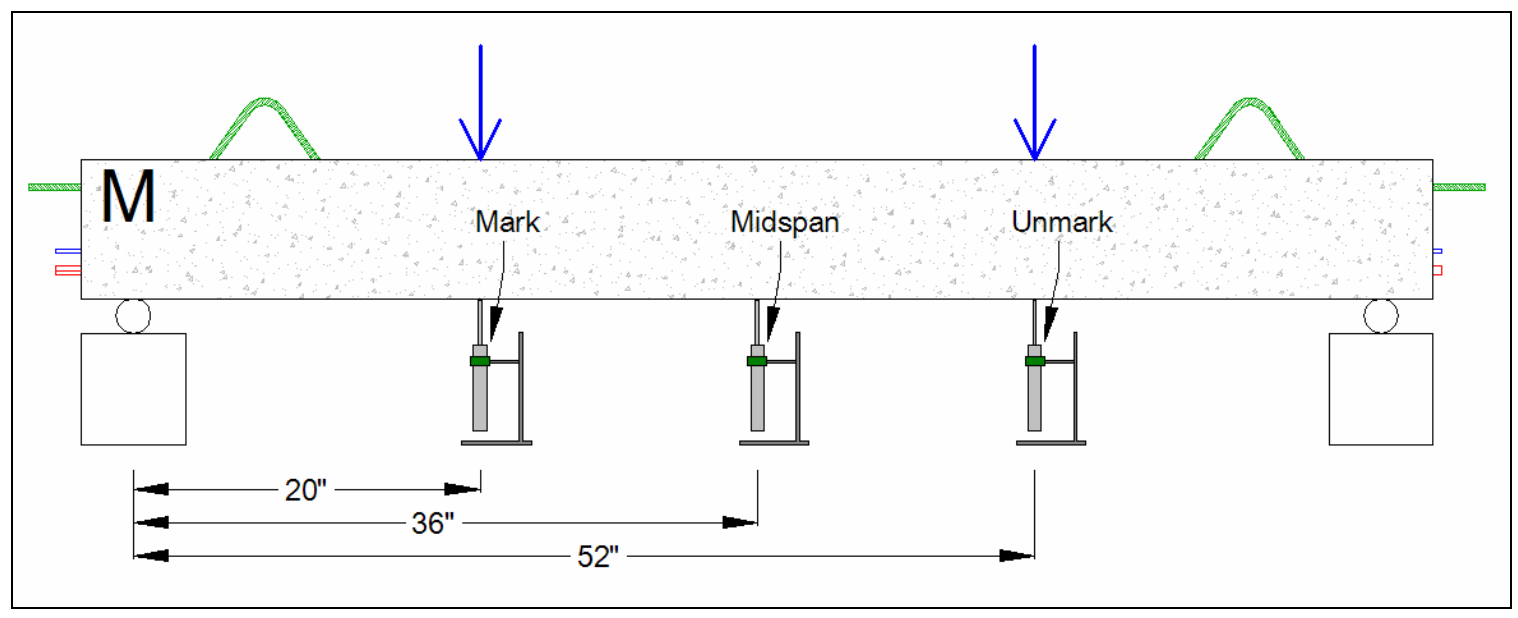

Figure 5.57: Part II LVDT locations

When preparing the surfaces for strain gage bonding, the surface of choice was sanded down to a surface profile produced by 320 -grit sandpaper. Next, the area was cleaned and primed with epoxy (Note: steel surfaces were not primed with epoxy). It was found that it was useful to place a layer of scotch tape loosely over the freshly-placed primer epoxy to reduce the thickness after curing (see Figure 5.58). This greatly reduced the time required for sanding down the primer layers prior to placing the strain gages. After the primer layers were cured, they were sanded down to a surface profile produced by 320-grit sandpaper, and layout lines were marked. All surfaces were then carefully cleaned immediately prior to placing the strain gages. Vishay-brand M-Bond AE-10 epoxy was used for all strain gage bonding and priming applications.

Two of the externally bonded concrete strain gages were placed at the midspan and two were placed at load application point on the side of the marked end immediately before 
testing. One gage in each pair was placed on the right side of the beam over the centerline of the tension steel reinforcement and the other gage was placed as close to the tension face of the beam as possible (See Figure 5.59).

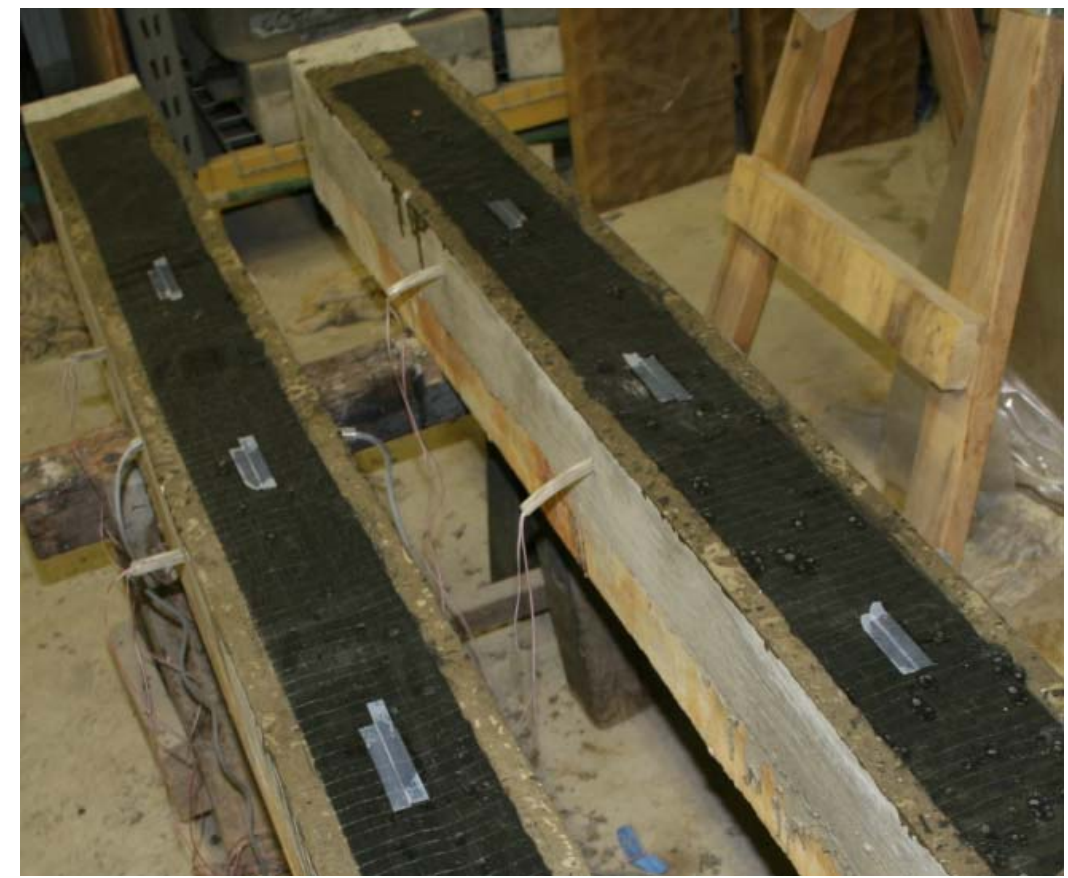

Figure 5.58: Scotch tape placed over freshly-placed strain gage primer epoxy

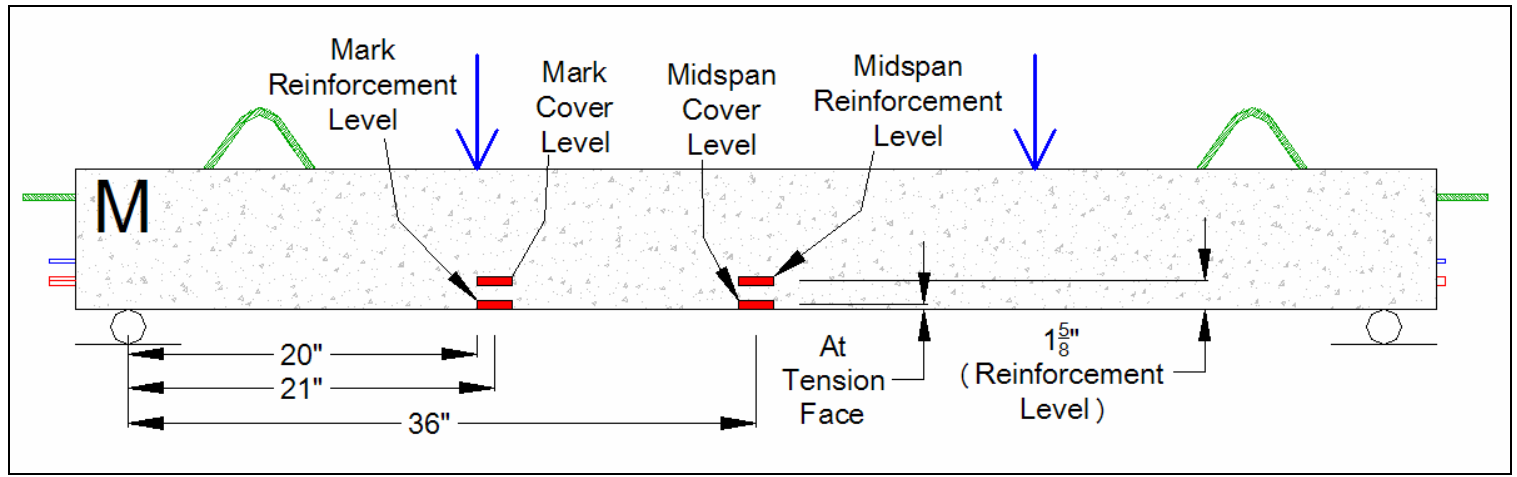

Figure 5.59: Externally-bonded concrete strain gage locations

Two concrete embedment gages were suspended between the two tension bars at the centerline level of the tensile reinforcement after the application of corrosion current and 
prior to concrete patch repair. Thin steel wire was used to suspend the gages. One of the gages was centered at the midspan and the other was placed as close as possible to the location of the load application point on the side of the marked end. The gage locations are shown in Figure 5.60. A photograph of a gage suspended from the rebar cage can be seen in Figure 5.61.

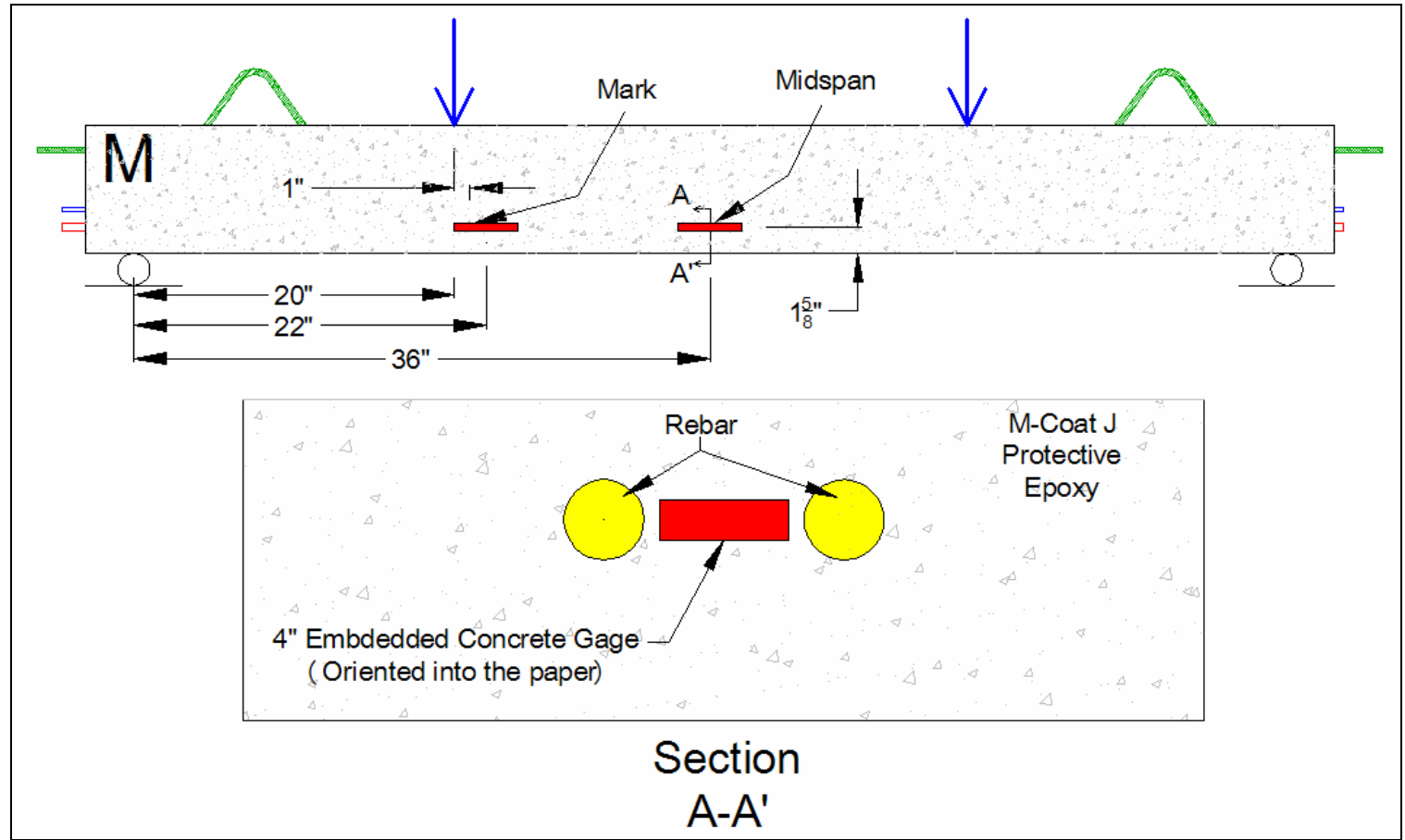

Figure 5.60: Externally-bonded concrete strain gage locations

The 0.25 " steel strain gages were applied after the application of corrosion current and before concrete repair. The steel was grinded and to smooth using an angle grinder before sanding. A pair of gages was placed across from each other on either side of one of the tension bars. These gages were even with the centerline depth of the tension steel (see Figure 5.62). One pair of gages was centered at the midspan and the other pair was placed beneath the load application point on the side of the marked end. 


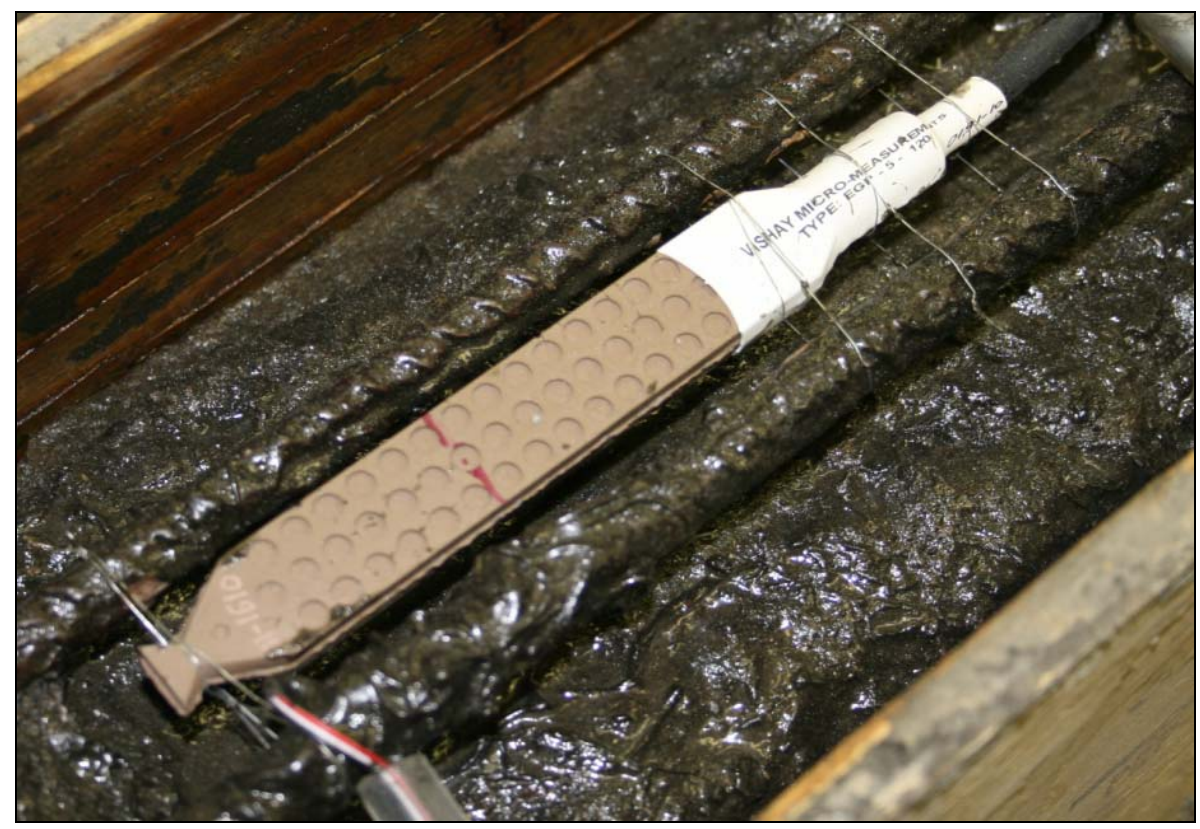

Figure 5.61: Concrete embedment gage tied between tension steel

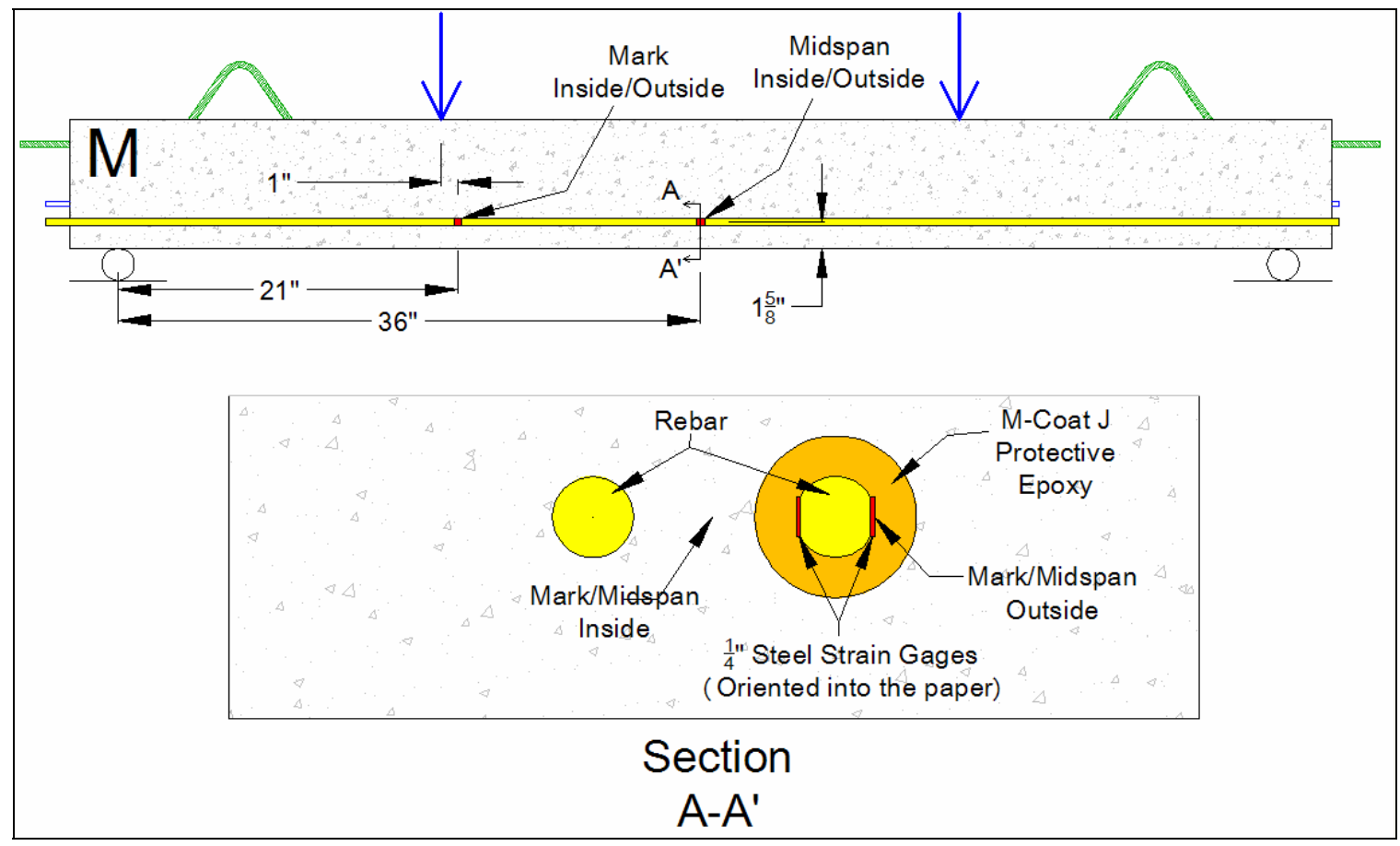

Figure 5.62: Steel strain gage locations

The 0.25 " FRP strain gages were applied immediately before testing. The gages were applied to the FRP tensile reinforcement along the longitudinal centerline of the beam 
(see Figure 5.63). The Tyfo S epoxy was sanded down until the outermost fibers were exposed during gage preparation. One gage was centered at the midspan while the other two were placed beneath the load application points, one on the side of the marked end and one on the side of the unmarked end.

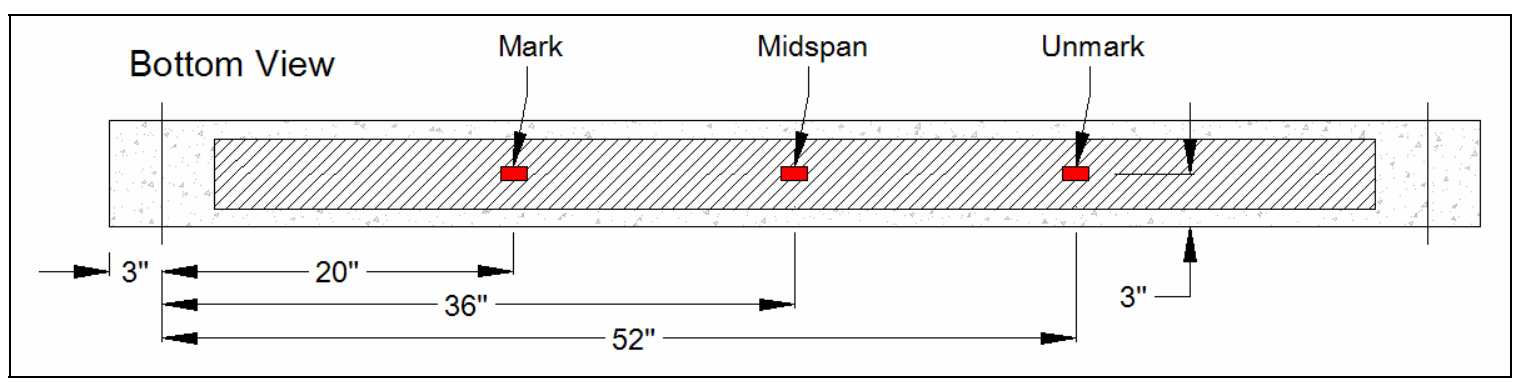

Figure 5.63: FRP strain gage locations

The leadwires from the steel strain gages and concrete embedment gages exited the beam from the side. This was accomplished by drilling $1 / 2$ " diameter holes at the gage depths and locations and inserting polyurethane tubing with an outside and inside diameter of $7 / 16 "$ and $1 / 4 "$, respectively. The leadwires were threaded through the tubes to prevent damage during the demolding process. It was important to coat the circumference of the hole with oil so that concrete paste did not bind the polyurethane tube to the wooden mold. The leadwires were also marked so that it could be determined which wires were attached to each gage after concrete repair.

For the fully-instrumented pristine Beam 2, the externally bonded concrete gages and the concrete embedment gages were placed at the exact same locations as those beams with FRP repair. Two additional concrete embedment gages were attached between the compression steel bars to capture the compression strain at that depth. One gage was centered at the midspan and the other was placed at the load application point. 


\subsubsection{Testing Setup}

Each beam was tested in 4-point bending. The Part I beams were tested across a span of 8'-6" and the Part II beams were tested across a span of 6'-0". Figure 5.64 shows the testing setup for Part I beams and Figure 5.65 shows the setup for Part II beams and displays labels on each item of the test setup.

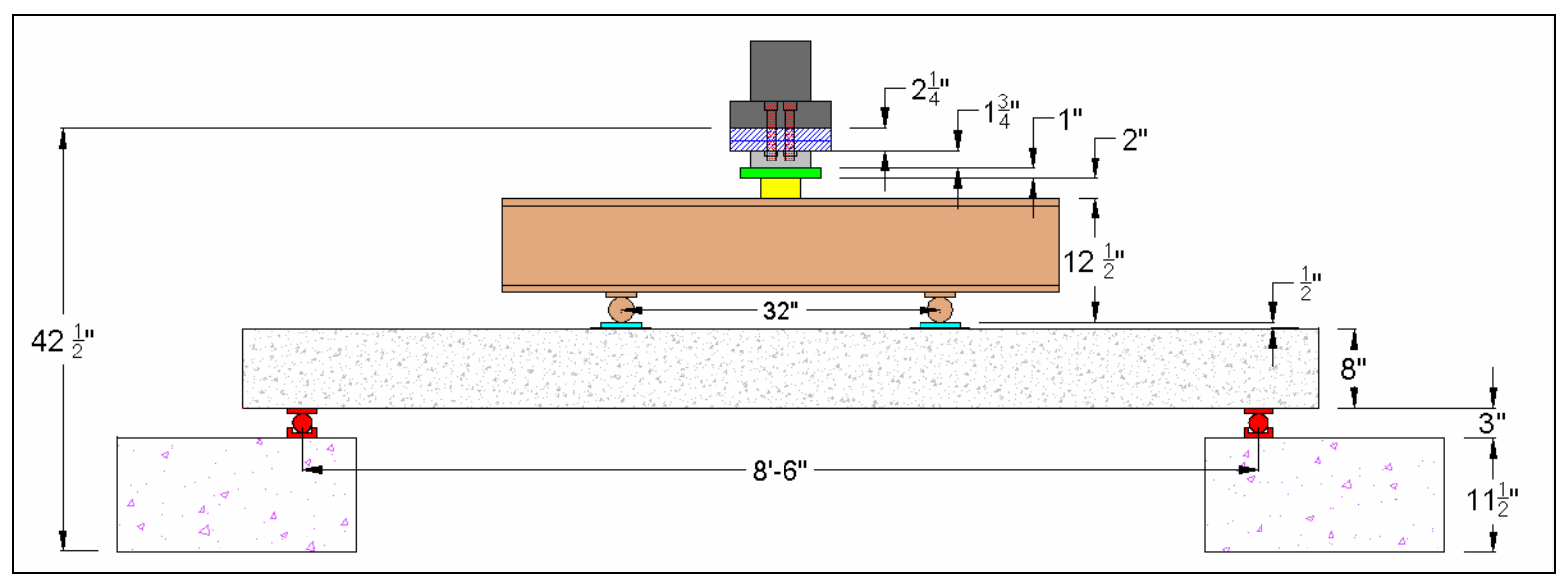

Figure 5.64: Part I Testing Setup

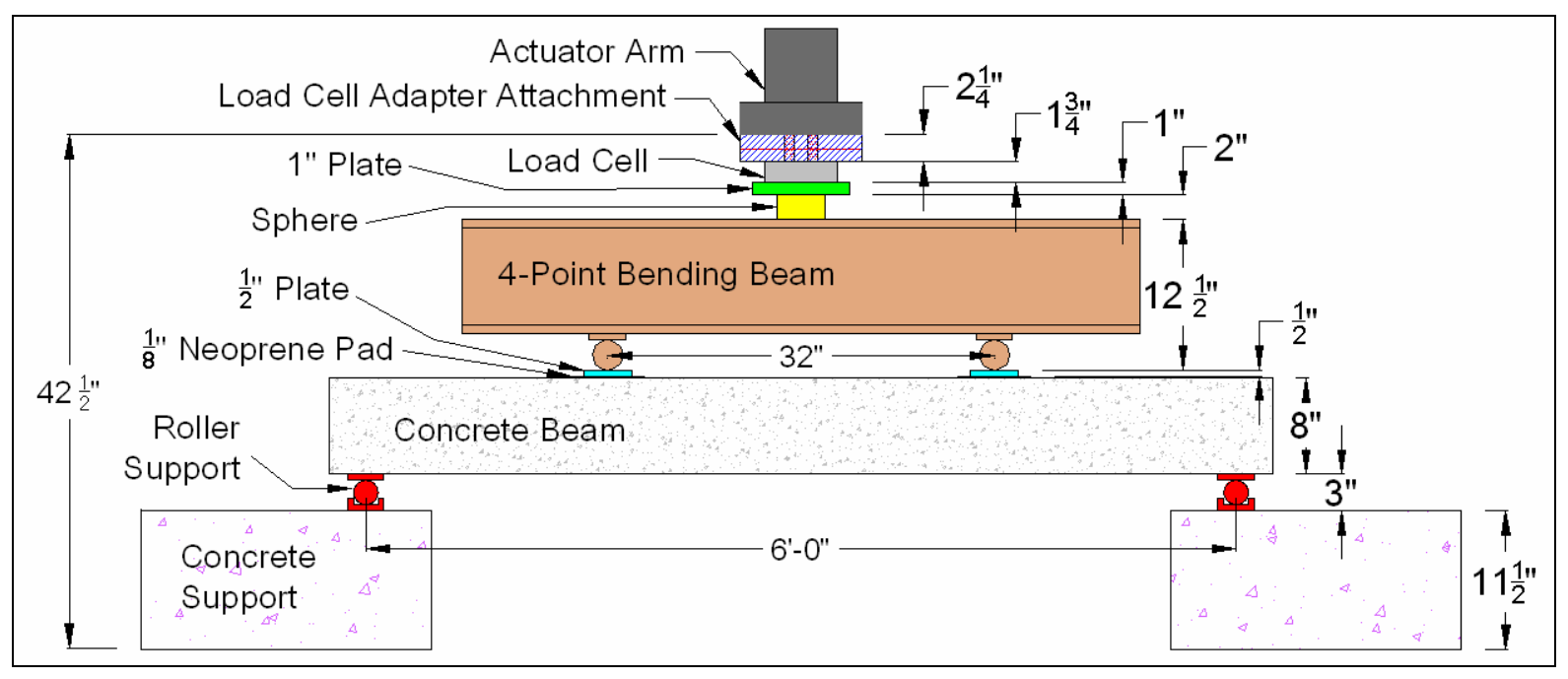

Figure 5.65: Part II Testing Setup

To begin, the actuator arm was plumbed. The supports, consisting of 11/1/2" high concrete blocks with freely placed steel roller supports, were symmetrically aligned to either side of the actuator arm to provide the desired span length. Before each beam was placed into 
the loading frame, it was marked with a sharpie marker. One-foot increments were marked along each side of each beam from the marked to the unmarked end. LVDT locations were marked at the three desired locations on the underside of each beam and load points spaced at 32 " were marked 16 " to either side of the midspan mark. Once the concrete beam was placed on the supports, it was ensured that the steel roller supports were aligned perfectly parallel to each other and perfectly perpendicular to the longitudinal axis of the beam. It was also ensured that the midspan of the beam was perfectly centered beneath the actuator arm using a plumb bob. An angle grinder was used to smooth the top surface of the beam in the load point locations. Next, $1 / 8$ "x6"x 10 " neoprene pads were centered over the load application points, over which $1 / 2$ " $x 4$ "x6" bearing plates were centered. Roller supports were welded to the bottom of a steel Ibeam at a distance of 32" apart to produce a 4-point bending beam. The I-beam used to apply 4-point bending was stiff and underwent a negligible amount deflection when subjected to the maximum load.

The 4-point bending beam was placed so that the supports sat directly on top of the centers of the $1 / 2$ " bearing plates. Next, very thin cardboard shims were inserted between the welded supports and the bearing plates where needed to ensure that the 4-point bending beam was not allowed to move laterally. Shims were also used as needed between the concrete beam and the steel roller supports to prevent undesired movement of the specimen and consistent loading. Centered between the load application points was a 4" diameter 2" high steel sphere apparatus (see Figure 5.66) to correct any unevenness of the bottom of the actuator arm with respect to the bearing area on the 4- 
point bending beam. A 1"x6"x10" steel plate was centered over the sphere to provide a wide enough bearing area for the 6" diameter load cell. A homemade load cell adapter attachment was fabricated and bolted to the bottom of the actuator arm. This adapter attachment consisted of steel plates with a threaded rod welded to the exact center of the bottom of the circular actuator arm. The threaded load cell was screwed onto the threaded rod and was thus suspended from the actuator arm to prevent it from falling at the moment of specimen failure.

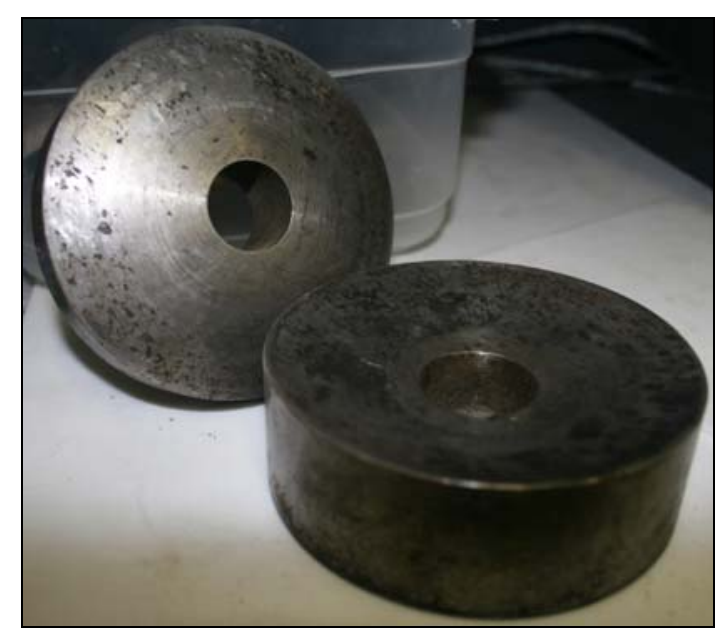

Figure 5.66: Steel sphere apparatus

\subsubsection{Testing Procedure}

Static load tests were performed at a constant load rate of $0.5 \mathrm{~mm} / \mathrm{min}(0.02 \mathrm{in} / \mathrm{min})$ using displacement control mode, as specified by ASTM. Each sensor recorded two data points per second. Beam specimens were tested to failure. After failure, the static load was removed, the cracks were traced, and photos were taken. 


\subsubsection{Cyclic Flexural Testing}

\subsubsection{Equipment}

Please refer to the equipment used for static flexural testing.

\subsubsection{Instrumentation}

Please refer to the instrumentation descriptions provided for static flexural testing.

\subsubsection{Testing Setup}

The same testing setup described for static flexural testing was first attempted to be used for cyclic load testing. However, when the cyclic loading was begun, one of the concrete blocks was freely sliding approximately $1 / 2$ " back and forth along the floor in the longitudinal direction of the beam. This motion was slowly moving the beam out of line with the actuator arm. Therefore, a stiffer support system had to be constructed.

In an attempt to stiffen the support system, four $3 / 8$ "x 12 "x 48 " plates were bolted to the lab floor. Next, steel I-beams with stiffening plates were welded to the floor plates at a distance of 6'-0" from each other and centered about the plumbed actuator arm. Cchannels were welded directly above the webs of these I-beam supports to confine the roller supports. The concrete beam was placed on top of the roller supports and the remaining part of the test setup described for static flexural testing was kept constant. Plates with a $3 / 8$ " thickness were placed directly beneath the bearing areas of the concrete beam to prevent deflection of the support beams spanning the $3 / 8$ " floor plates. 
When the cyclic loading was once again applied, the web of each I-beam freely bent back and forth like a cantilever and the steel support rollers were not moving properly. It was determined that one end of the beam specimen had to be freed to move longitudinally over the support to provide a true free-roller condition. It was also decided to further stiffen the system.

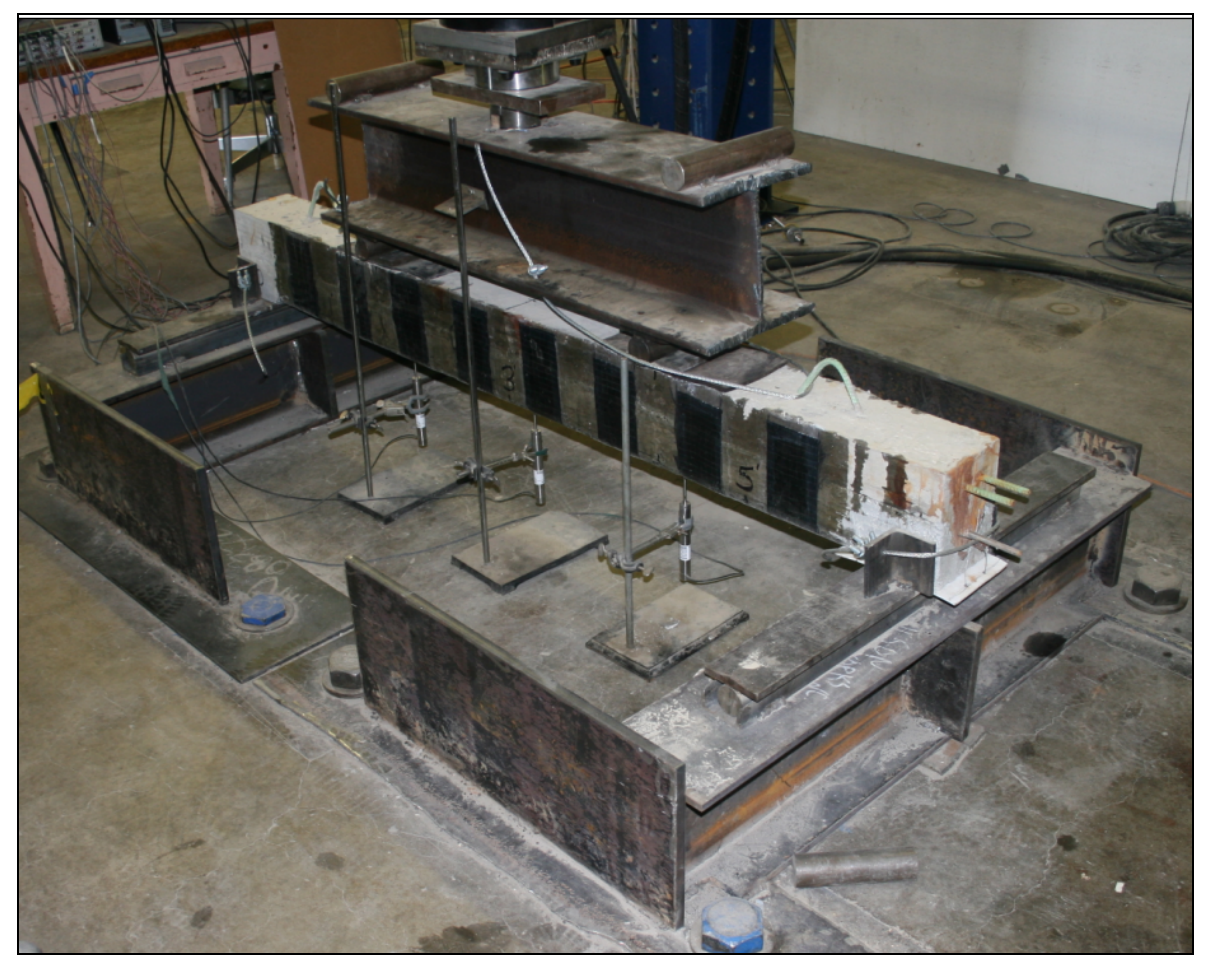

Figure 5.67: Final beam specimen support system for cyclic flexural testing

To first stiffen the existing support system, 1/2"x12"x36" steel plates were used to stiffen the webs of the I-beams. They were welded to the support system as shown in Figure 5.67. 

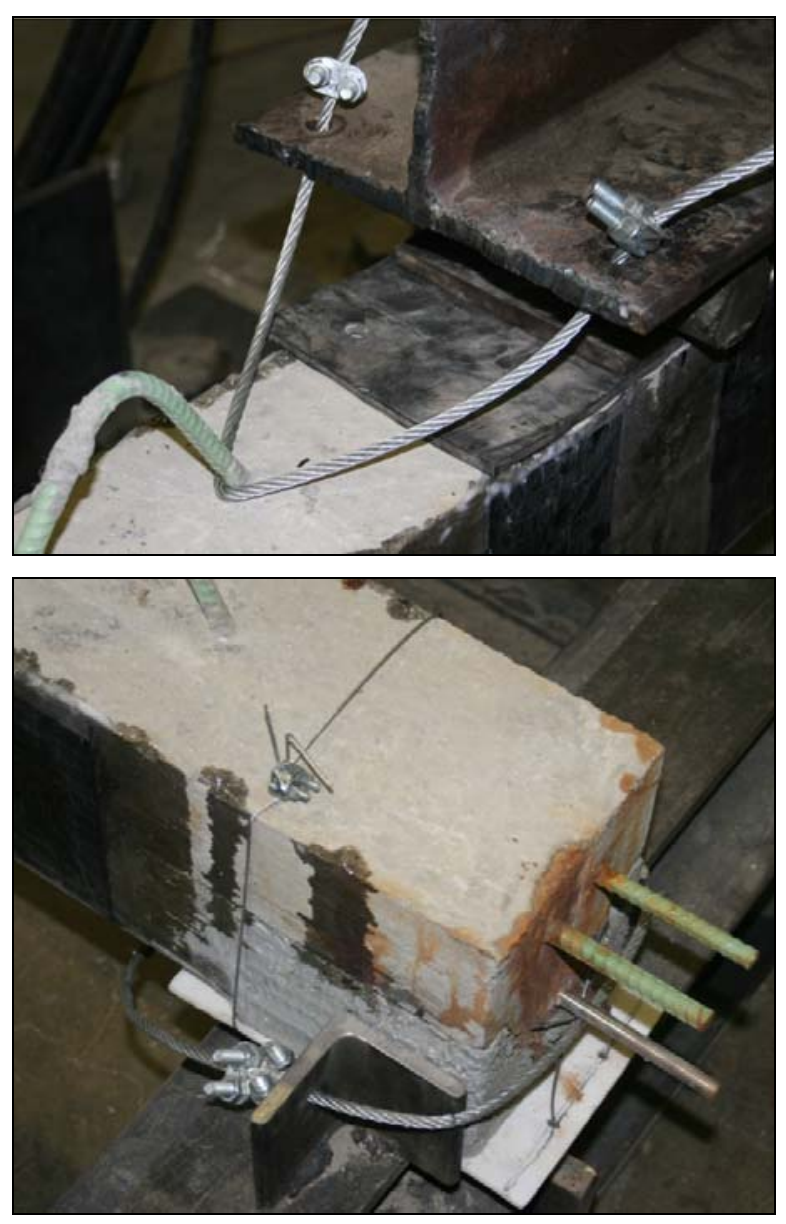

Figure 5.68: Loose cables used to secure beam specimens to both the supports and the 4-point bending beam in case of movement due to cyclic loading

Loose cables were used as a precaution in case movement occurred between the test specimen and either the 4-point bending beam or the supports. These cables were used to tie the beam specimens to both the supports and the 4-point bending beam as shown in Figure 5.68. No forces were placed on these loosely-attached cables; they were simply used as a precaution and to function only if there was movement in the system due to the cyclic loading or to sudden beam failure. Appropriate measures were also taken to properly secure the 4-point bending beam and the loading sphere to ensure they could not move throughout the duration of the 8-day cyclic load test. Tabs were welded to the top 
and center of the 4-point bending beam to provide a resting place for the sphere apparatus. Tabs were also welded to the bottom of the plate that sits on top of the test sphere to lock the components of the test setup and prevent their lateral movement (see Figure 5.69). The modified test setup now functioned as planned and cyclic testing proceeded.

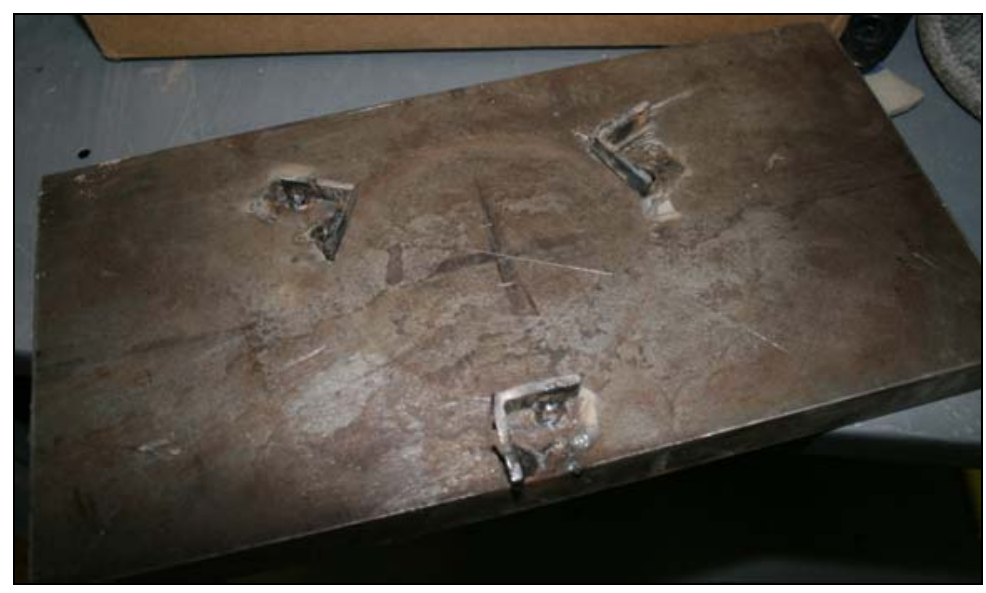

Figure 5.69: Tabs welded to the 4-point bending beam and to the steel plate to prevent movement of the steel sphere apparatus

\subsubsection{Testing Procedure}

Cyclic testing was performed as a part of only Part II testing. The first cyclic load test was performed on Beam II-6. The test parameters were set up so that the actuator provided a sinusoidal cyclic load with a frequency of $3.0 \mathrm{~Hz}$ and a range between $1,600 \mathrm{lbs}$ and $9,600 \mathrm{lbs}$, corresponding to 10 and $60 \%$ of the ultimate load recorded from the three static tests of Beams 5, 8, and 9. The peak load was chosen because the load-deflection curves for Beams 5, 8, and 9 appeared to all follow the same path within the postcracking serviceability region up to about $60 \%$ ultimate load, as can be seen in Figure 5.70 . 


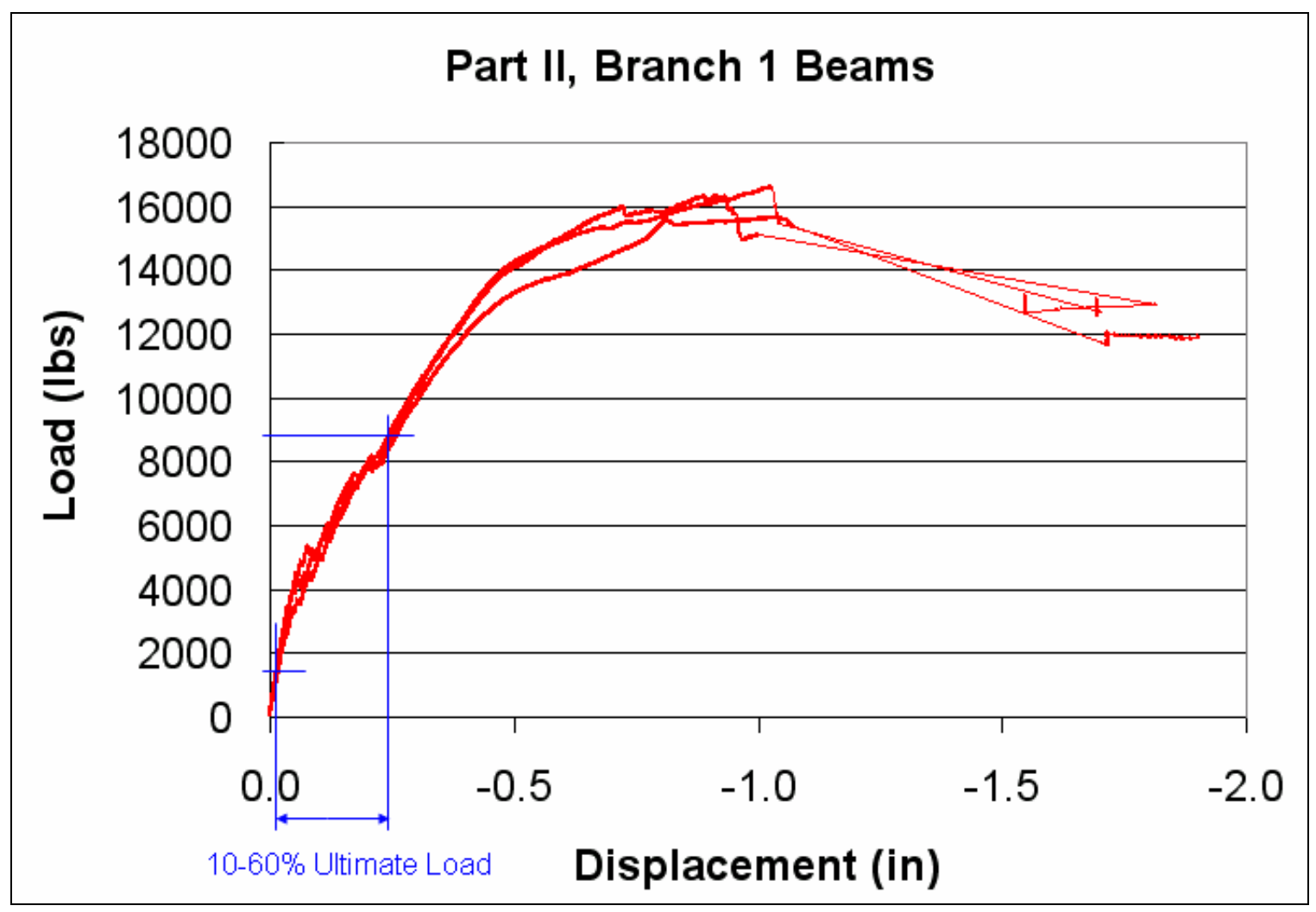

Figure 5.70: Load deflection curves for static tests of Beams 5, 8, and 9 showing 10$60 \%$ Ultimate Load

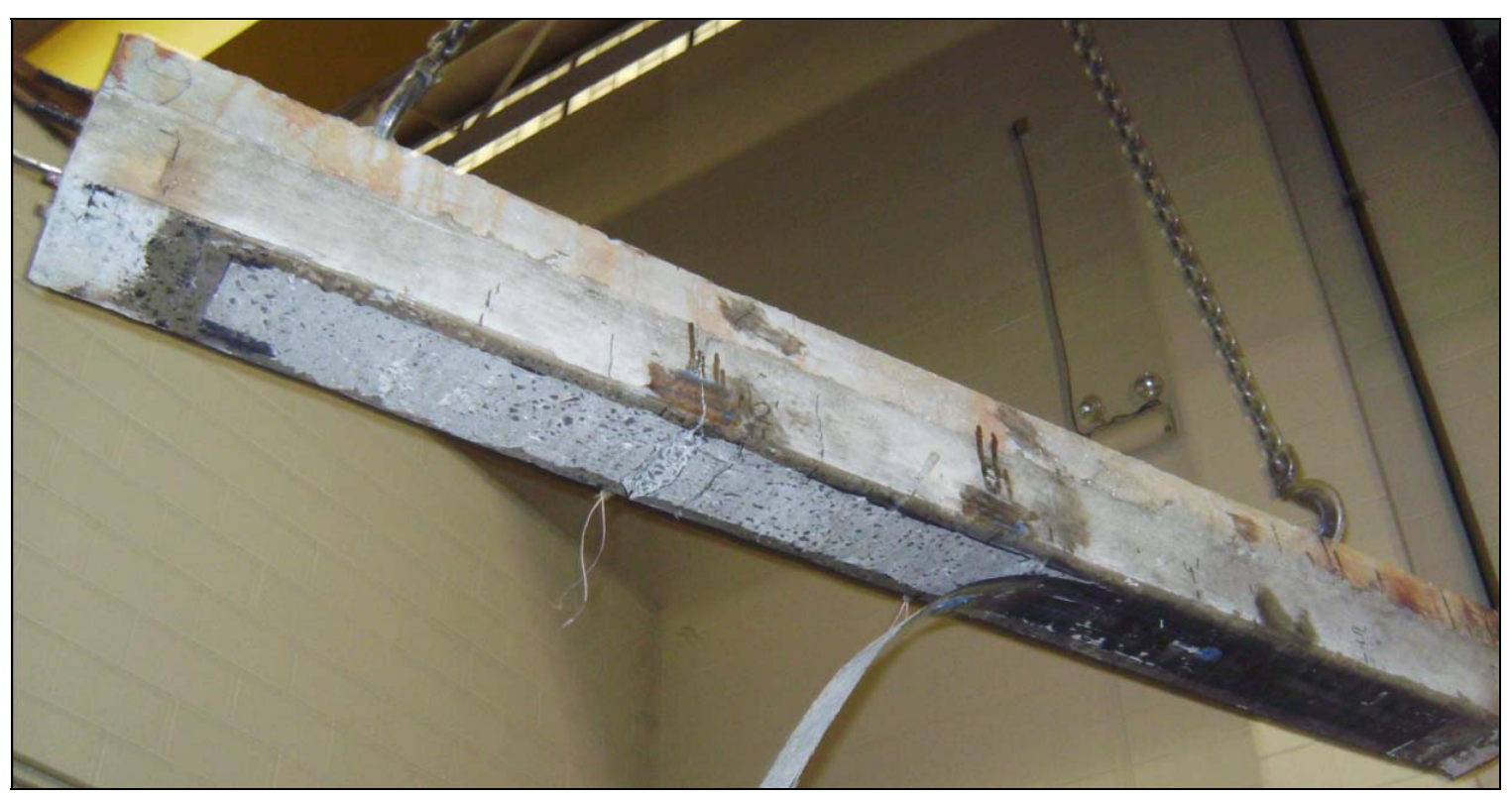

Figure 5.71: Delaminated FRP on Beam 6 after just 110,000 cycles due to the high load range 
The cyclic testing was scheduled for 2,000,000 cycles in 250,000 daily increments. However, after 110,000 cycles, the FRP delaminated from the beam at the marked end due to the high load range (see Figure 5.71).

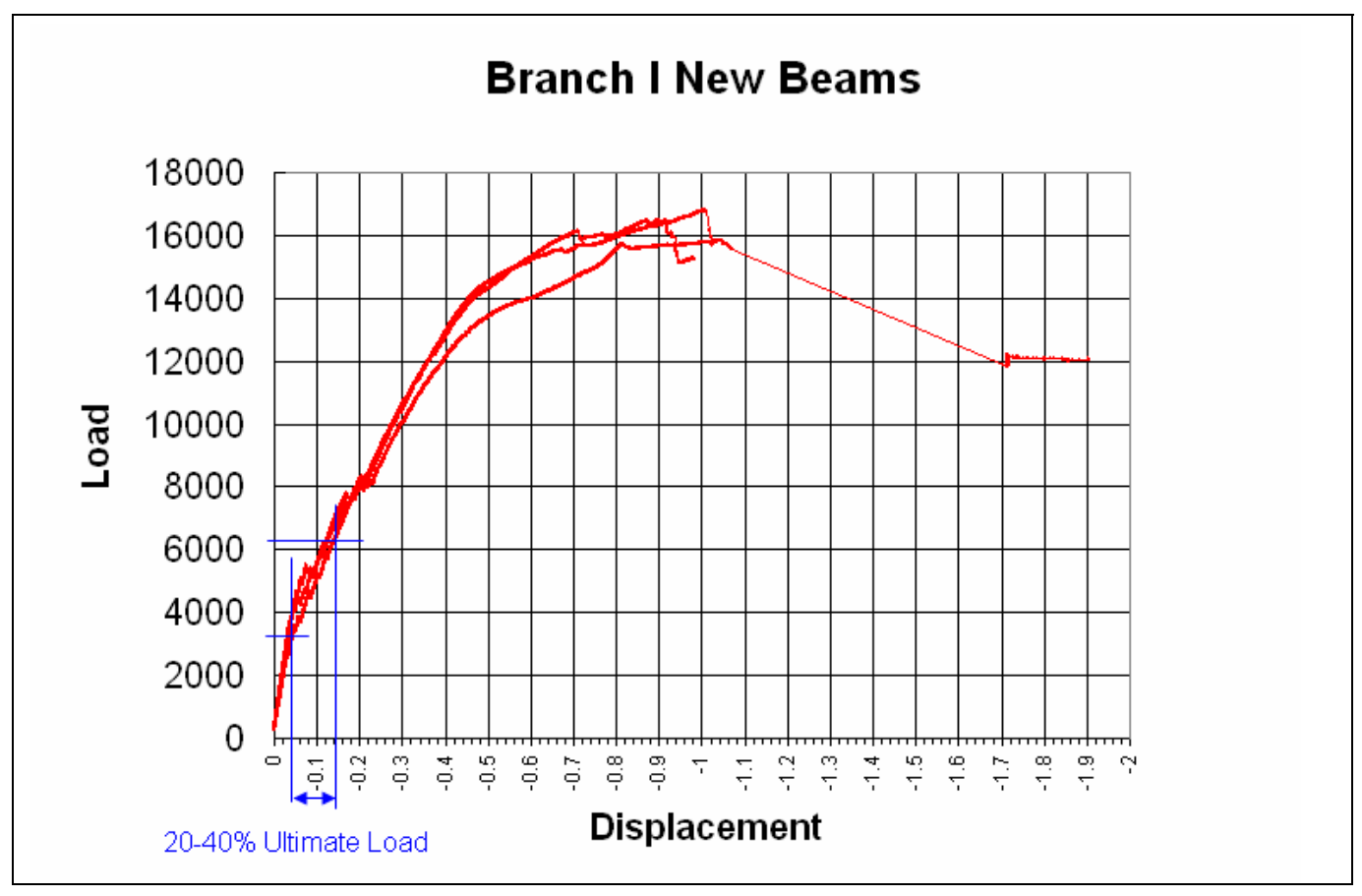

Figure 5.72: Load deflection curves for static tests of Beams 5, 8, and 9 showing $20-40 \%$ Ultimate Load

It was decided that the load range be reduced to between 20 and $40 \%$ ultimate load, corresponding to maximum and minimum loads of $3,200 \mathrm{lbs}$ and $6,400 \mathrm{lbs}$, respectively (see Figure 5.72). The loading frequency was to repair at $3.0 \mathrm{~Hz}$ for $2,000,000$ cycles.

At 250,000 cycle increments, the cyclic loading was paused and a static load was applied to the peak load of $6,400 \mathrm{lbs}$ and then removed at a rate of $0.5 \mathrm{~mm} / \mathrm{min}$ (the same rate as used for static tests to failure) while data was recorded. These static load tests provided insight into the decay of the beam specimens at various stages during fatigue loading. 


\subsubsection{Compression Cylinder Testing (ASTM C 39/C 39M - 05)}

As mentioned previously, six 4"x8" representative cylinders were made alongside each beam. Three of these cylinders were broken 28 days after casting. The remaining three cylinders were broken at the time their beam was broken under static load.

A Forney compression testing machine was used to break each cylinder. Before each cylinder was broken, its ends were grinded where necessary using an angle grinder with a masonry grinding wheel to ensure a relatively flat and smooth surface. Steel end caps cushioned with neoprene pads were placed on each end of the concrete cylinder, which was then centered beneath the loading apparatus. The compressive load was applied at a constant rate of $35 \mathrm{lbs} / \mathrm{s}$ until cylinder failure. The average values from each set of three cylinder breaks were averaged together to obtain the concrete strength.

\subsubsection{Pull-Off Testing (ASTM D 4541-02)}

Pull-off testing was performed on Part II beam II-16 at the locations shown in Figure 5.73. Pull-off testing measures the bond strength of the FRP-to-concrete interface. It is routinely performed on representative prism samples in FRP field repair as a quality control measure. For this experiment, two different pull-off testers were required due to the high tensile strength of the polymer concrete patch repair material.

To begin, the surface of the FRP was cleaned. The loading fixtures used were $50 \mathrm{~mm}$ diameter metal dollies with smooth faces (see Figure 5.74). The face of the dolly was 
first lightly abraded using an abrasive pad, and then epoxy was applied to both it and the FRP surface. The dolly was pressed firmly against the FRP, excess epoxy was removed using a cotton swab, and the epoxy was allowed to cure. A 2" diameter cobalt hole saw blade was attached to a power drill and was used to make a neat cut completely through the FRP and epoxy layers and to scrape the surface of the concrete substrate without damaging the bond between the dolly and the FP.

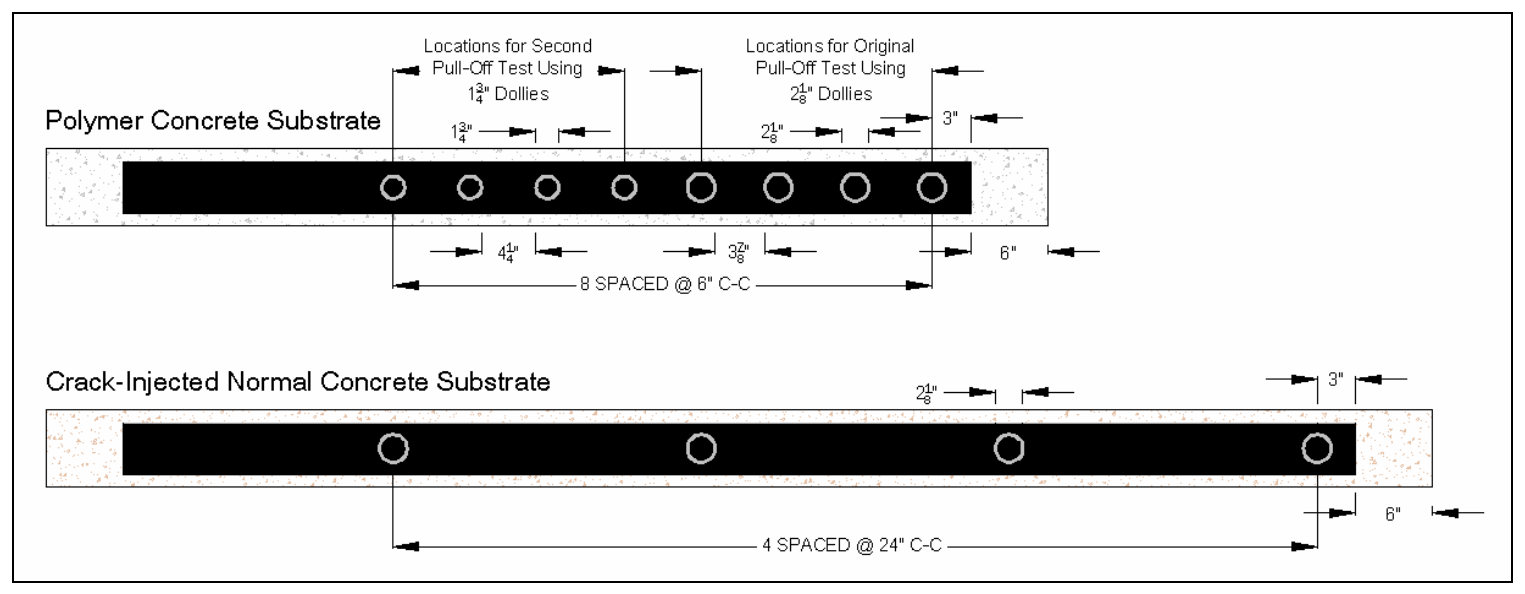

Figure 5.73: FRP-to-patch concrete pull-off test locations

After curing and cutting, the DeFelsko PosiTest AT Digital Coating pull-off adhesion tester was placed over the dolly and locked around the dolly head. Next, the loading apparatus was pumped by hand at a constant rate of approximately $150 \mathrm{psi} / \mathrm{s}$ until the dolly pulled the FRP circle off of the concrete. The pull-off strength and failure modes were recorded.

For beams repaired with patch repair, the DeFelsko pull-off tester did not have a high enough capacity due to the elevated compressive strength of the polymer concrete. 
Therefore, a Proceq Dyna Pull-Off Tester had to be used. The dollies for this tester were 2" in diameter and the cut FRP sample circles were 13/4" in diameter (see Figure 5.75). For these dollies, a precut hole had to be made using a diamond core drill and the dollies had to be bonded after cutting. Care was taken during bonding of the dollies not to allow excess epoxy into the cut groove around the separated FRP sample circle.

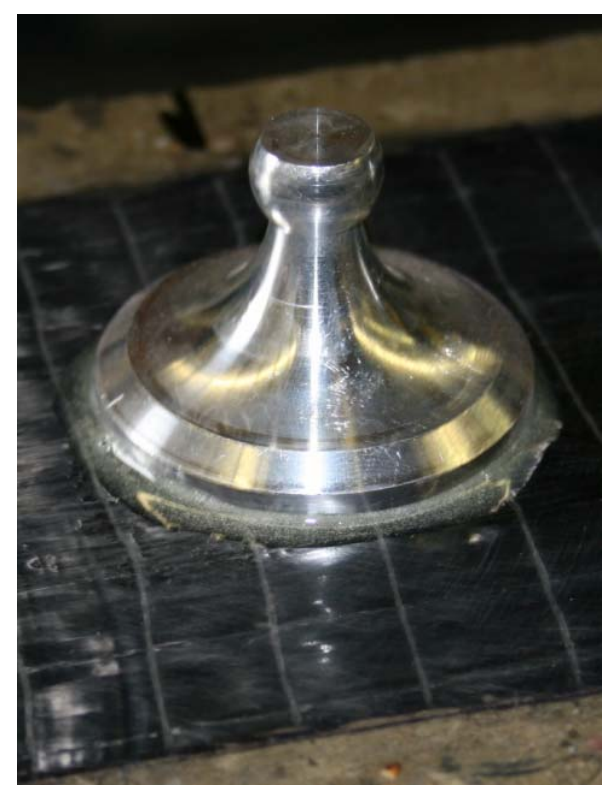

\section{Figure 5.74: First dolly used for FRP pull-off tests}

There are four possible failure modes as a result of a pull-off test: 1.) at the interface between the epoxy and the dolly, 2.) at the interface between the dolly epoxy and the FRP, 3.) at the FRP-concrete interface, or 4.) in the concrete substrate layer. The preferred mode of failure is in the concrete substrate layer, as it indicates a solid bond between the FRP and concrete substrate. If the concrete fails between the FRP and the concrete in the epoxy interface, the bond is likely insufficient and proper measures should be taken to ensure the safety of the structure. If the first or second mentioned failure 
modes occur, the test is inconclusive and the epoxy or the type of dolly should be changed and the assessment should be redone.

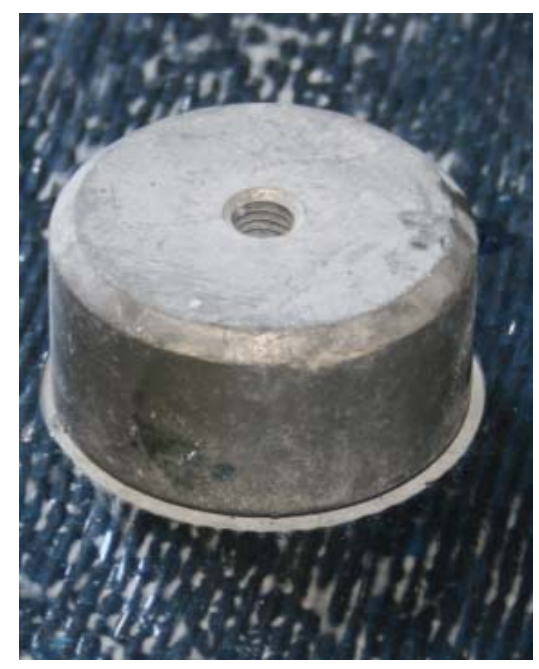

Figure 5.75: Second dolly used for FRP pull-off tests

\subsubsection{FRP Tension Coupon Testing (ASTM D3039/D 3039M-00)}

Direct tension testing of FRP materials is routinely performed on representative samples produced in the field during the time of an FRP repair. Tension test samples in this experiment were first made by first producing 12"x12" coupons that are two plies thick in which all unidirectional fibers have the same orientation (it was very difficult to perfectly align the fibers of the two-ply sample). These samples were placed in an FRP sample box and are left to cure for at least 48 hours. Once cured, the samples were cut into smaller test coupons.

The coupons were cut into strips which were 12" long and 1" wide. Next, grips were made from $1 / 8$ " aluminum sheets. The grips were each 4 " long and 1 " wide. A total of 
four grip plates were used for each coupon, with two placed on each side of each end. The grips were first lightly scoured on the side to face the FRP, and then epoxy was used to bond the grips to each coupon. This epoxy was allowed to cure, and the samples were ready to be tested. The gage length of each tension specimen was 4". Each specimen was tested to failure at a constant rate of $1,000 \mathrm{lbs} / \mathrm{min}$ using an MTS 810 Material Test System tension testing machine with hydraulic wedge grips.

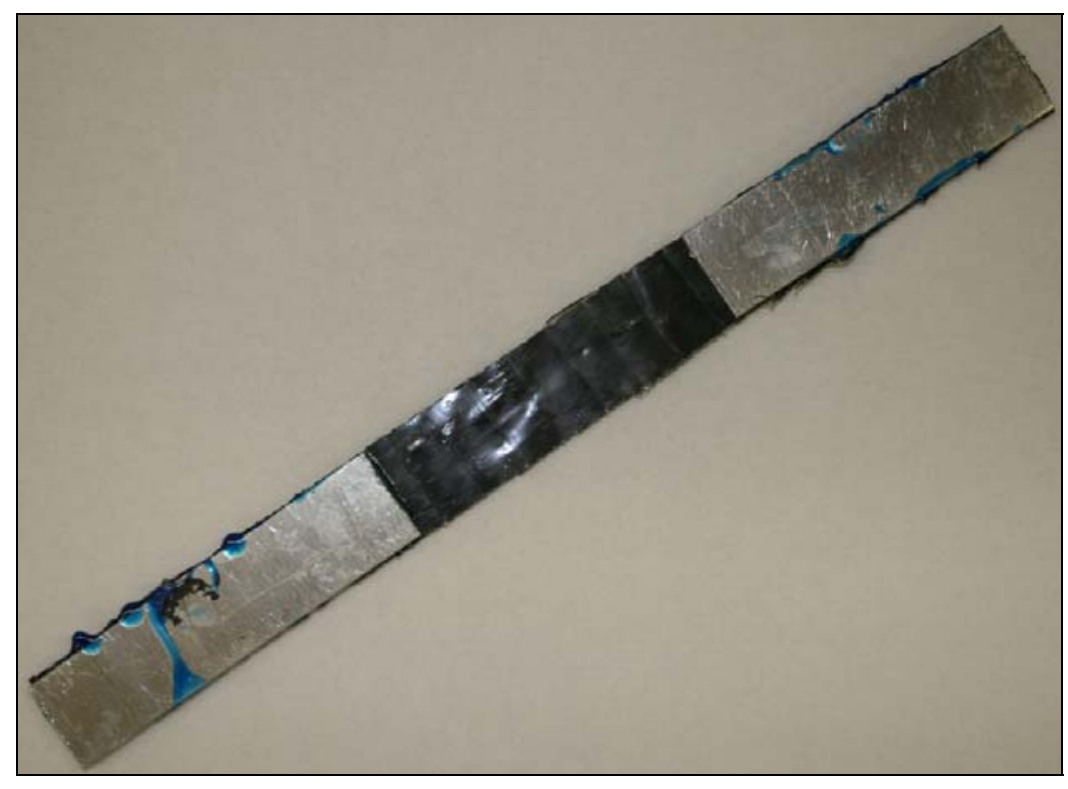

Figure 5.76: FRP Tension Coupon

\subsection{Beam Specimen Summary}

Table 5.7 presents a summary of all beam specimens included in the analysis of this paper. Beam designations highlighted in red indicate that those beams were instrumented with strain gages. 
Table 5.7: Specimen Summary

\begin{tabular}{|c|c|}
\hline 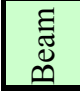 & \multirow{2}{*}{$\begin{array}{l}\text { Description } \\
\text { Part I }\end{array}$} \\
\hline & \\
\hline $\mathrm{I}-3$ & 28-Day Pristine \\
\hline $\mathrm{I}-1$ & \multirow{2}{*}{ Mildly Corroded Unrepaired } \\
\hline $\mathrm{I}-2$ & \\
\hline $\mathrm{I}-5$ & Corroded Unrepaired After 1 Full Corrosion Cycle \\
\hline I-15 & \multirow{2}{*}{ Pristine Control broken at same age as Beam I-5 } \\
\hline I-16 & \\
\hline $\mathrm{I}-17$ & \multirow{2}{*}{ Pristine Control broken at same age as Beams I-7 and I-10 } \\
\hline $\mathrm{I}-18$ & \\
\hline $\mathrm{I}-7$ & Polymer Concrete Patch Repair / FRP Repaired After Initial Corrosion Cycle \\
\hline I-10 & Crack Injection / FRP Repaired After Initial Corrosion Cycle \\
\hline $\mathrm{I}-8$ & Polymer Concrete Patch Repair / FRP Repaired and Subjected to an Additional Corrosion Cycle \\
\hline I-9 & Crack Injection / FRP Repaired and Subjected to an Additional Corrosion Cycle \\
\hline I-6 & Corroded Unrepaired After 2 Corrosion Cycles \\
\hline $\mathrm{I}-13$ & \multirow{2}{*}{ Pristine Control broken at same age as Beams I- 8 and I-9 } \\
\hline $\mathrm{I}-14$ & \\
\hline \multicolumn{2}{|r|}{ Part II } \\
\hline II-1 & \multirow{2}{*}{ 28-Day Pristine } \\
\hline II-2 & \\
\hline II-3 & \multirow{2}{*}{ Corroded Unrepaired } \\
\hline II-4 & \\
\hline$\frac{\mathrm{II}-11}{\mathrm{II}-12}$ & \multirow{2}{*}{ Pristine Control broken at same age as all FRP-Repaired Beams } \\
\hline$\frac{11-12}{112}$ & \\
\hline II-5 & \multirow{3}{*}{ FRP Repaired with Wrapping Scheme 1} \\
\hline II-8 & \\
\hline II-9 & \\
\hline II-7 & \multirow{2}{*}{ FRP Repaired with Wrapping Scheme 1 and Fatigued } \\
\hline II-14 & \\
\hline II-13 & \multirow{3}{*}{ FRP Repaired with Wrapping Scheme 2} \\
\hline II-15 & \\
\hline II-17 & \\
\hline II-18 & \multirow{2}{*}{ FRP Repaired with Wrapping Scheme 2 and Fatigued } \\
\hline II-20 & \\
\hline II-21 & \multirow{3}{*}{ FRP Repaired with Wrapping Scheme 3} \\
\hline II-22 & \\
\hline III-24 & \\
\hline II-19 & \multirow{2}{*}{ FRP Repaired with Wrapping Scheme 3 and Fatigued } \\
\hline II-23 & \\
\hline
\end{tabular}




\section{Chapter 6: Test Results and Discussion}

\subsection{Accelerated Aging Results}

\subsubsection{Results}

\subsubsection{Part I}

\subsection{Initial Corrosion Prior to FRP Repair}

As mentioned previously, based on the preliminary accelerated corrosion tests with 36 "'long samples, it was expected that the accelerated aging process would sufficiently age each beam within 5 to 6 weeks (350-450amp-hours). However, it was learned that this was an inaccurate estimate. Once the current was applied, the first visible signs of corrosion were not observed until between the $8^{\text {th }}$ and $13^{\text {th }}$ days (112-125amp-hours), when small amounts of corrosion product were secreting from and staining the concrete only in localized areas. No cracking was observed until day 15 (179amp-hours) on Beam I-10. By day 18 (202amp-hours), at least one crack was observed on each beam except Beam I-6, on which no crack was observed until Day 29 (347amp-hours). All beams cracked near the ends first, and then the cracks propagated inward. This raised the warning signs that the corrosion may not be confined to within the constant moment region alone. When Beams I-1 and I-2 were broken after 55 days (575amp-hours), the widest crack on each beam measured between only 0.5 and $0.6 \mathrm{~mm}$. 
Even prior to testing the corroded and unrepaired beams to failure and obtaining the mass loss, it was obvious that the corrosion process had not yielded sufficient mass loss and expansive corrosion for the testing plan to be successful. It was discovered that, although the steel stirrups were insulated from the tension steel with electrical tape, the presence of vertical cracks within the shear regions of the beam specimens was observed. Furthermore, although all portions of the tension steel outside of the constant moment region were coated with epoxy, longitudinal cracks were present within the shear regions, sometimes even more prevalently than the cracking observed within the constant moment regions.

In addition to the observations above, cracks generated in the 3'-long prism samples, which were subjected to the same current density of $178 \mu \mathrm{A} / \mathrm{cm}^{2}$, measured up to $3-6 \mathrm{~mm}$ wide at 57 days and 608amp-hours. It was pondered whether the size of a test specimen, in addition to the magnitude of current density, might play a significant role in determining the rate of accelerated corrosion when using such high current densities. Plans were made to further investigate the source of these observations after Beams I-1 and I-2 were tested.

At this point, it was decided to add Part II of the testing plan which would use shorter beams with smaller-diameter steel reinforcement. By decreasing the surface area of the steel, the current density could be increased. The current density could not be increased by raising the current level of the power supply, as the power supply was already running 
at its maximum capacity of $500 \mathrm{~mA}$. The scope of the experimentation plan would need to be modified to meet time constraints.

Following the static testing of Beams I-1 and I-2, steel coupons were removed and cleaned (see Figure 6.1). It was found that the mass loss was only 5.6 and $6.8 \%$ for Beams I-1 and I-2 (respectively), which is equivalent to a cross-sectional loss of only about $0.04 \mathrm{in}^{2}$ loss from the steel cross-section. This was nowhere near the level of simulated long-term aging that was initially desired.

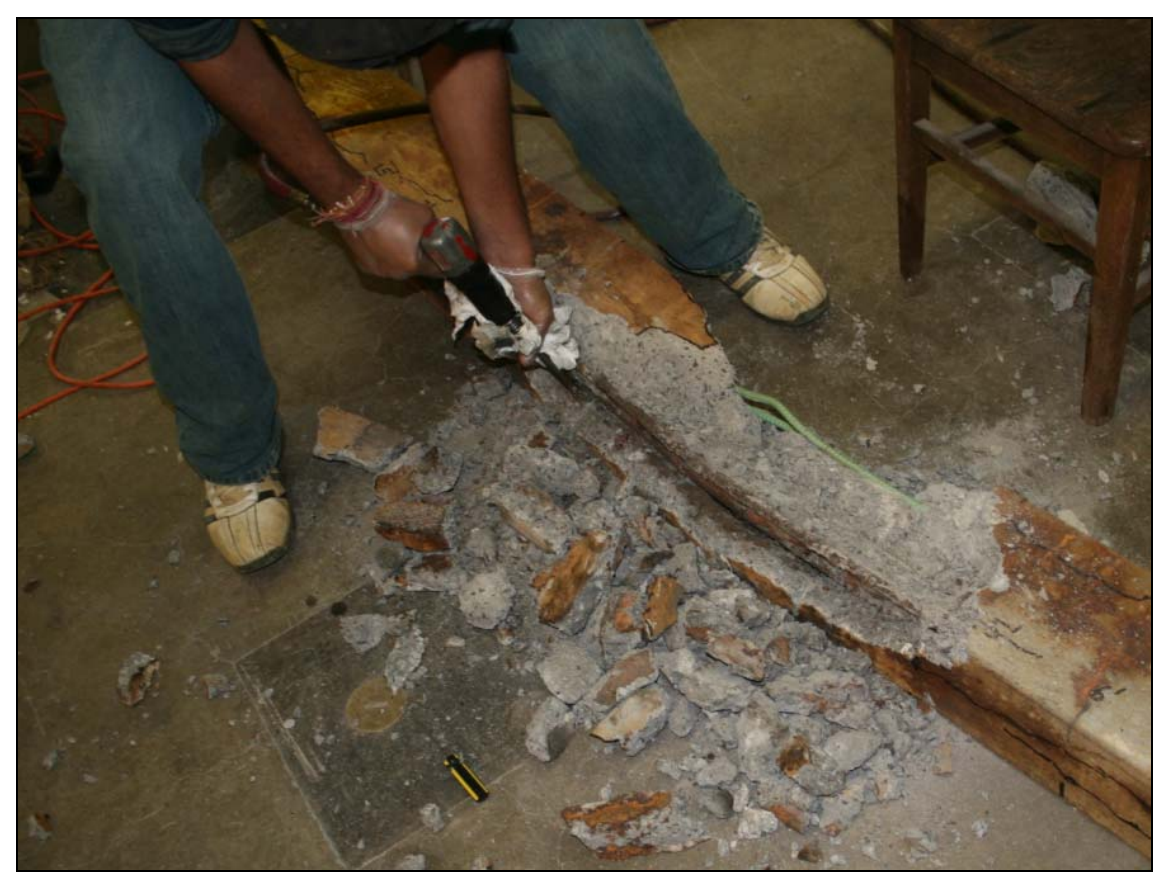

Figure 6.1: Extraction of steel rebar for mass loss analysis

After removing the concrete from the entire shear span of Beam I-1, it was discovered that the extent of corrosion in the steel stirrups and portions of epoxy-coated tension steel was the same as that within the uncoated constant moment region. On the tension bars, the epoxy actually peeled off of the steel over the entire length of the shear span. Perhaps the epoxy coating was conductive, allowing the electric current to flow freely through it 
and to corrode the steel beneath. Perhaps, also, the epoxy was not completely impermeable, and allowed access moisture and oxygen to the steel beneath. The most likely reason for the failure of the epoxy coating, however, was that the electric current was being fed directly into the steel bars through the exposed constant moment region. Therefore, it had to flow through at least one coated portion in the shear span before exiting the beam, and obviously flowed through both since corrosion was constant over the entire length of the beam. Due to an incipient anode effect, the epoxy likely started to fail near the interfaces between coated and uncoated steel, progressing in a domino effect down the lengths of the shear spans toward each end. This may have occurred rapidly since cracking was first observed near the beam ends. Although the average extent of corrosion was the same over the length of each bar, there was less confinement near the beam ends causing those areas to crack first.

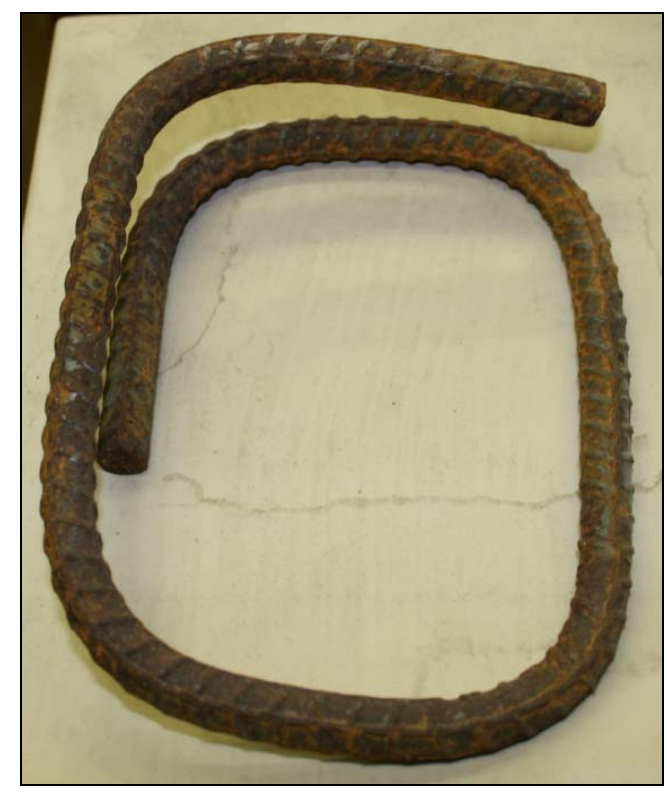

Figure 6.2: Typical corroded steel stirrup extracted from Part I beam 
What almost certainly occurred in the shear reinforcement was, even though the stirrups were insulated from the tension steel at the points of contact, the electric current was able to flow through the concrete and into the shear reinforcing steel. The electric current was, therefore, spread over not only the surface area of the exposed tension steel, but also the entire surface area of all 22 stirrups. The stirrups were corroded to the same extent as the tension steel (see Figure 6.2).
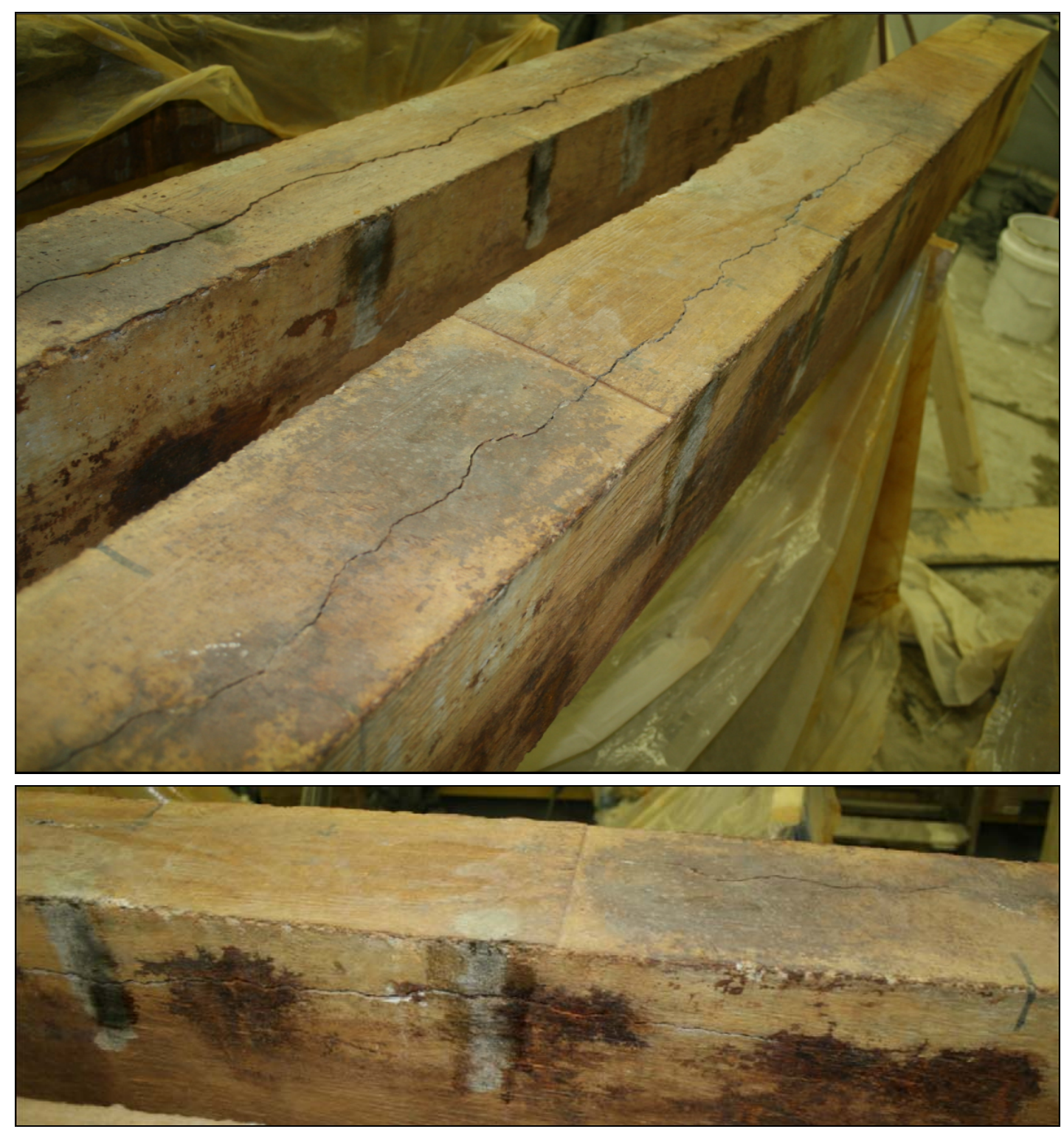

Figure 6.3: Typical extent of deterioration observed on Part I beams after initial corrosion 
Because of the unexpected results, it was decided to modify the experimental plan to the form which is presented in this paper. The beams would be kept and labeled "Part I" beams. They would be subjected to accelerated corrosion for several more weeks until approximately 1,200amp-hours was achieved, and hopefully this would provide a sufficient level of corrosion before FRP repair. An addition to the experimental program, which became Part II, will be described later.

Part I Beams I-5, I-7, I-8, I-9, and I-10 were subjected to electric current for another 111 days until 1,200amp hours was reached. At this time, the largest crack in each beam ranged from 1 to $2 \mathrm{~mm}$. A significantly higher level of deterioration had occurred since 608amp-hours. The typical level of deterioration can be seen in Figure 6.3.

After Beam I-5 was tested under static loading, it was broken open and steel coupons were extracted. The mass loss in Beam I-5 was determined to be $15.6 \%$, from which an estimated $0.10 \mathrm{in}^{2}$ could be assumed lost from the total steel cross-section. At this point, the accelerated corrosion process was temporarily stopped and the beam repair phase of Part I was launched.

The photo in Figure 6.4 is of a hooks on Beam I-8 and was taken after completion of the corrosion cycle and provides indisputable evidence that portions of the reinforcement other than just the tension steel were undesirably receiving electric current. 


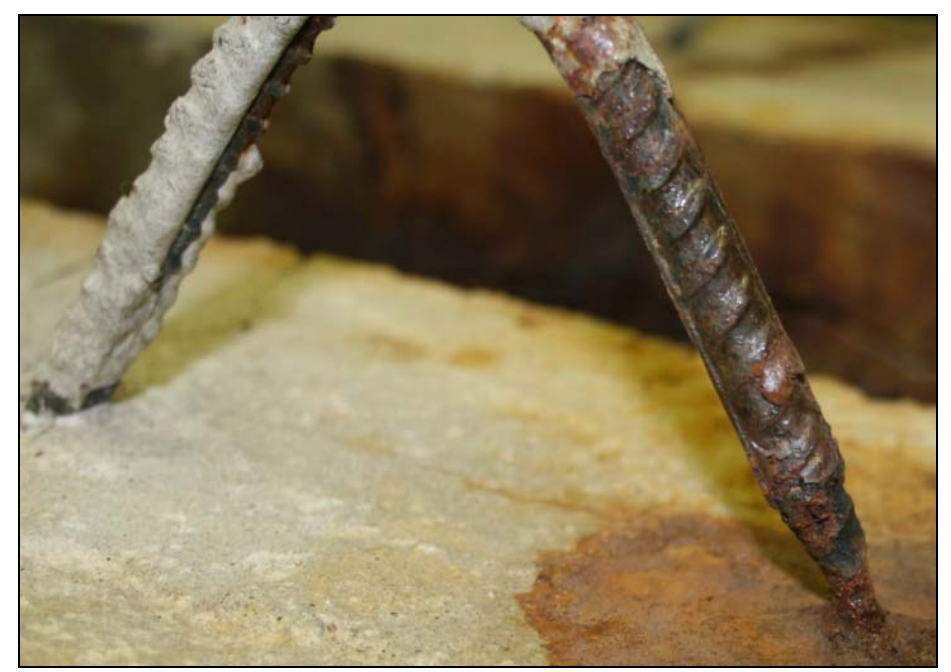

Figure 6.4: The only significant crack observed within polymer patch-repair concrete material FRESHIY REMOVED 2500 HOURS WIRE BRUSHED 2500 HOURS WIRE BRUSHED 1250 HOURS

Figure 6.5: Comparison of extent corrosion damage on reinforcing steel extracted from Beams I-1 and I-5. 


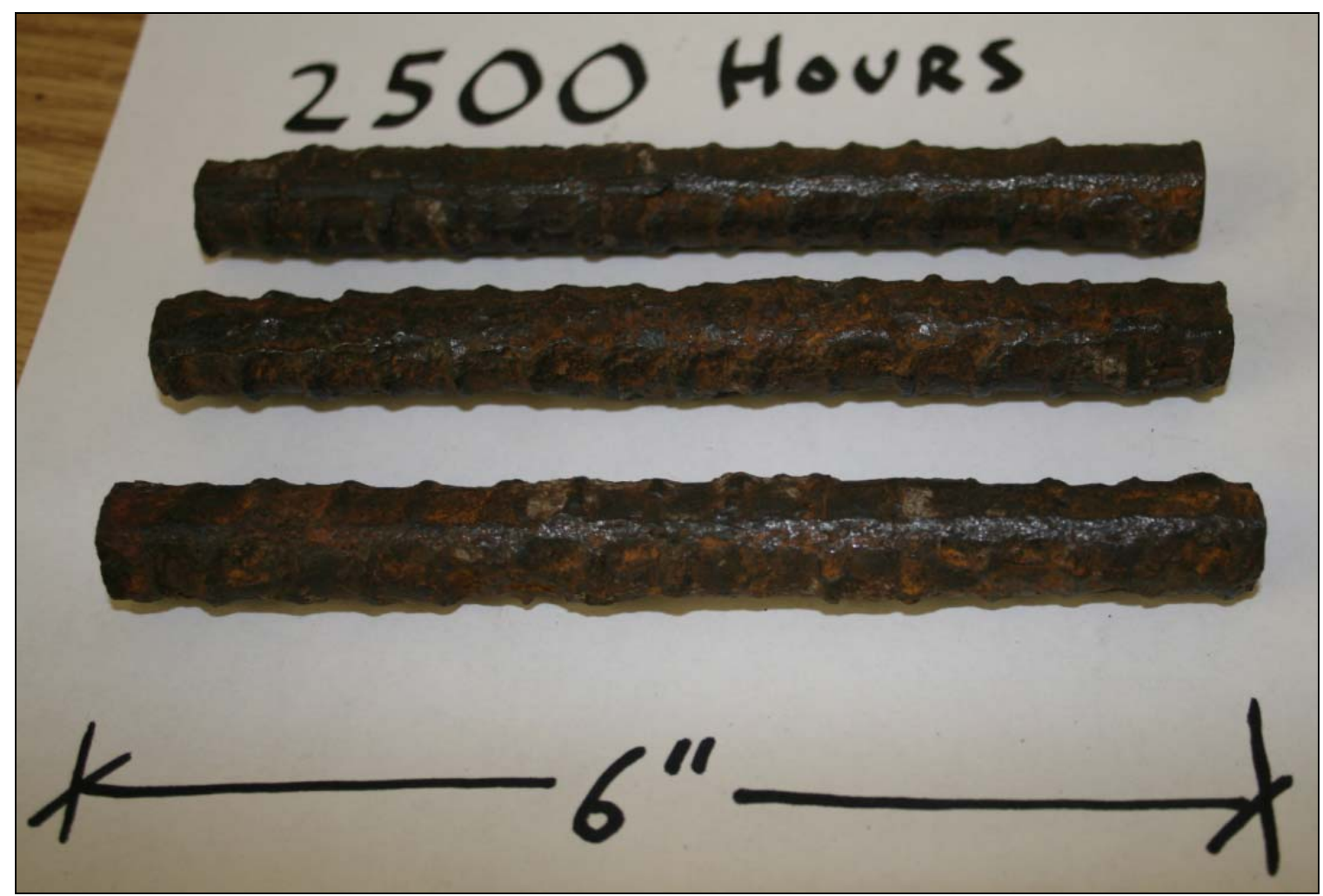

Figure 6.6: Steel coupon samples cut from Beam I-5 rebar at 1,200amp•hours

Figure 6.5 shows rebar samples extracted from Beams I-1 and I-5. The bar labeled "wire brushed 1250 hours" at the bottom was extracted from Beam I-1 at 608amp.hours. The bar labeled "wire brushed 2500 hours" in the middle was extracted from Beam I-5 at 1,200amp.hours and was cleaned with a wire wheel brush. The bar labeled "freshly removed 2500 hours" at the top was also extracted from Beam I-5 at 1,200amp.hours and is in its as-removed condition. Notice the significant difference between $5.6 \%$ and $15.6 \%$ mass loss. At 5.6\% mass loss, the bar is almost in its pristine state with the exception of some small localized pits. For the most part, its ribs are intact. Significant pitting, some moderately deep, is present on the bar with $15.6 \%$ mass loss. The pitting can also be seen in Figure 6.6, which shows the cleaned 6" coupon samples cut from Beam I-5 steel. Notice the large amount of expansive corrosion product that was adhered to the freshly 
removed steel by comparing to the freshly removed uncleaned steel to the wire-brushed steel.

A reassuring quality control observation was that the extent of mass loss was the comparable in both the left and the right tension bars. At the onset of the experiment, it was feared that a significant difference in mass loss might be observed between the left and right bars as a result of an uneven current distribution through the aluminum splice box. However, the wiring configuration proved to be effective and reliable, removing a potential unwanted variable from the experiment. It should also be noted that the same amount of mass loss occurred at both ends of the tension steel.

\subsection{Secondary Corrosion Following FRP Repair}

Table 6.1 provides a summary of the average mass loss values recorded in Part II. The values provided for Beams I-6, 8, and 9 were obtained after the second corrosion cycle $(2,400 \mathrm{amp} \cdot$ hours $)$. The values for all other beams were obtained after the first corrosion cycle (1,200amp hours). It should be noted that all extracted steel samples were cleaned using a solution of hydrochloric acid and hexameythylene tetramine, as specified in ASTM G1-03.

Steel was extracted from pristine control Beam I-14 at the same time as it was from the corroded and repaired beams (at 62 weeks of age). A mass loss of only $0.8 \%$ was attained which showed that the natural unaccelerated corrosion process did not produce a significant amount of mass loss in just over one year. It appears that steel from pristine 
Beam 14 experienced lesser mass loss than that in Beam 17. However, these values are both very small and the difference may be regarded as insignificant. Tightly adhered concrete was very difficult to remove from the specimens from the pristine beams, so a small amount of this extra concrete on specimens from Beam 14 is likely what caused this difference. Tightly adhered concrete was not an issue with the corroded beams.

Table 6.1: Part I Mass Loss Summary

\begin{tabular}{|c|c|c|c|c|}
\hline Description & 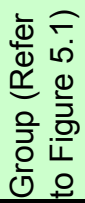 & \begin{tabular}{|l}
$E$ \\
$\mathbb{\varpi}$ \\
$ٍ$ \\
$\infty$
\end{tabular} & $\begin{array}{c}\text { Average } \\
\text { Mass Loss } \\
(\%)\end{array}$ & $\begin{array}{c}\text { Average } \\
\text { Mass Loss } \\
\text { by Group } \\
(\%)\end{array}$ \\
\hline \multirow{2}{*}{ Mildly Corroded Unrepaired } & \multirow{2}{*}{2} & 1 & 5.6 & \multirow{2}{*}{6.2} \\
\hline & & 2 & 6.8 & \\
\hline Pristine Control (After 1 Corr. Cyc.) & 4 & 17 & 1.8 & 1.8 \\
\hline Corroded Unrepaired (After 1 Corr. Cyc.) & 3 & 5 & 15.6 & 15.6 \\
\hline \multirow{2}{*}{$\begin{array}{l}\text { After Initial Corrosion Process } \\
\text { (Repaired) }\end{array}$} & \multirow{2}{*}{5,6} & 7 & 17.4 & \multirow{2}{*}{17.3} \\
\hline & & 10 & 17.2 & \\
\hline \multirow{2}{*}{ After Second Corrosion Process (Repaired) } & \multirow{2}{*}{8,9} & 8 & 17.1 & 17.1 \\
\hline & & 9 & 26.5 & 26.5 \\
\hline Corroded Unrepaired (After 2 Corr. Cyc.) & 11 & 6 & 24.2 & 24.2 \\
\hline Pristine Control (After 2 Corr. Cyc.) & 10 & 14 & 0.8 & 0.8 \\
\hline
\end{tabular}

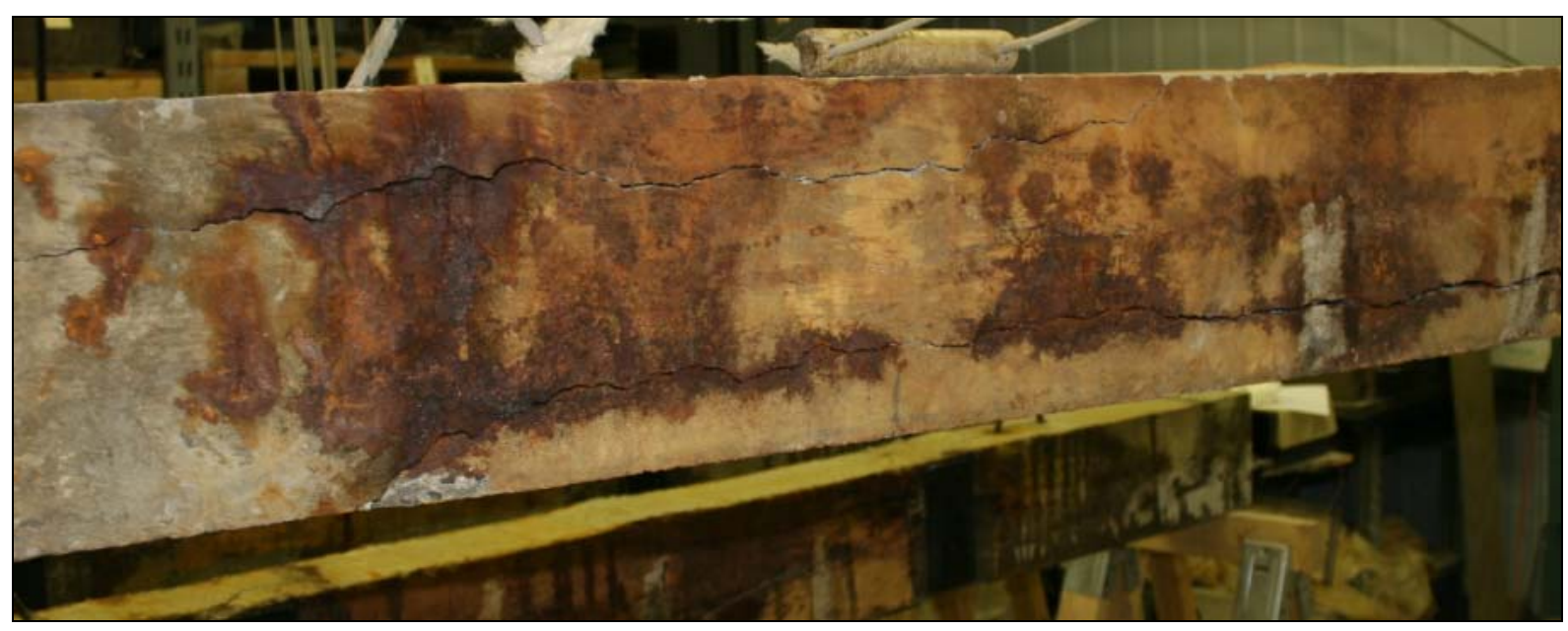

Figure 6.7: Cracking in constant moment region of corroded unrepaired Beam I-6 after two corrosion cycles 
Beam I-6 (after two corrosion cycles) had a mass loss of $24.2 \%$, a 55 percent increase compared to the corroded unrepaired Beam I-5 (after only one corrosion cycle). This level of corrosion caused the existing cracks grow and widen, resulting in the formation of new cracks. Figure 6.7 illustrates the extent of damage observed within the constant moment region. There was also severe web-shaped cracking in a pattern at the beam ends (see Figure 6.8).
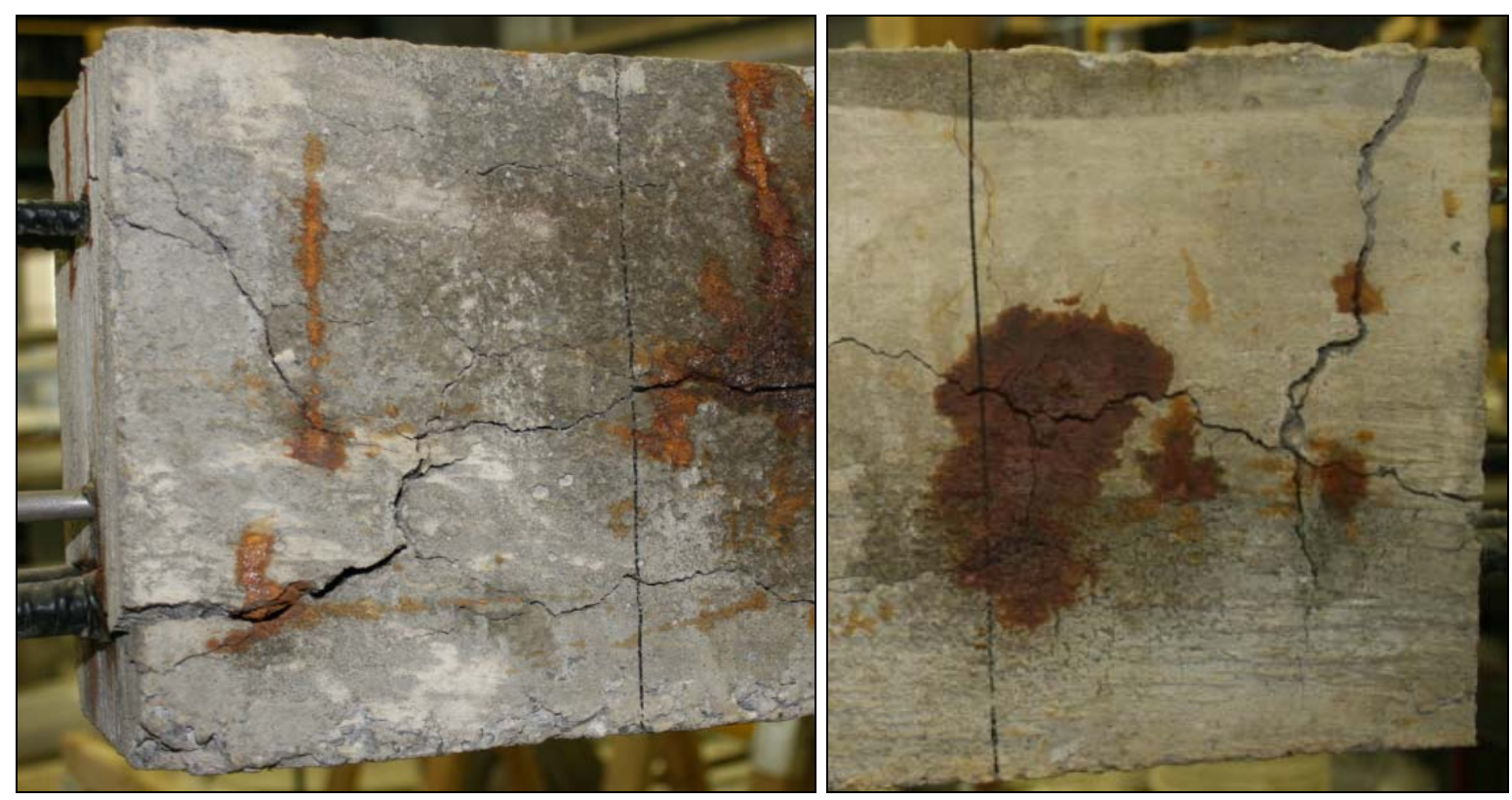

Figure 6.8: End cracking in Part I control beam subjected to two corrosion cycles

Additional accelerated aging caused longitudinal cracking on Beam I-8, which was patch repaired prior to FRP repair. This longitudinal cracking occurred mostly within the old concrete and ran along the length of the beam at a height of $1 / 2$ to $1 \frac{1}{2}$ " above and parallel to the interface of old and patch-repair concrete, as shown in Figure 6.9.

The patch repair material containing corrosion inhibitor that was used for Beam I-8 proved to very effectively prevent further corrosion and deterioration. The mass loss 
after repair for Beams I-7 and I-10 was 17.4 and 17.2\%, respectively. For Beam I-8, the recorded mass loss was only 17.1. Virtually no additional mass loss resulted from the second corrosion process within the constant moment region. This was a very significant and a better-than-expected result that strongly favors the use of complete polymer patch repair.
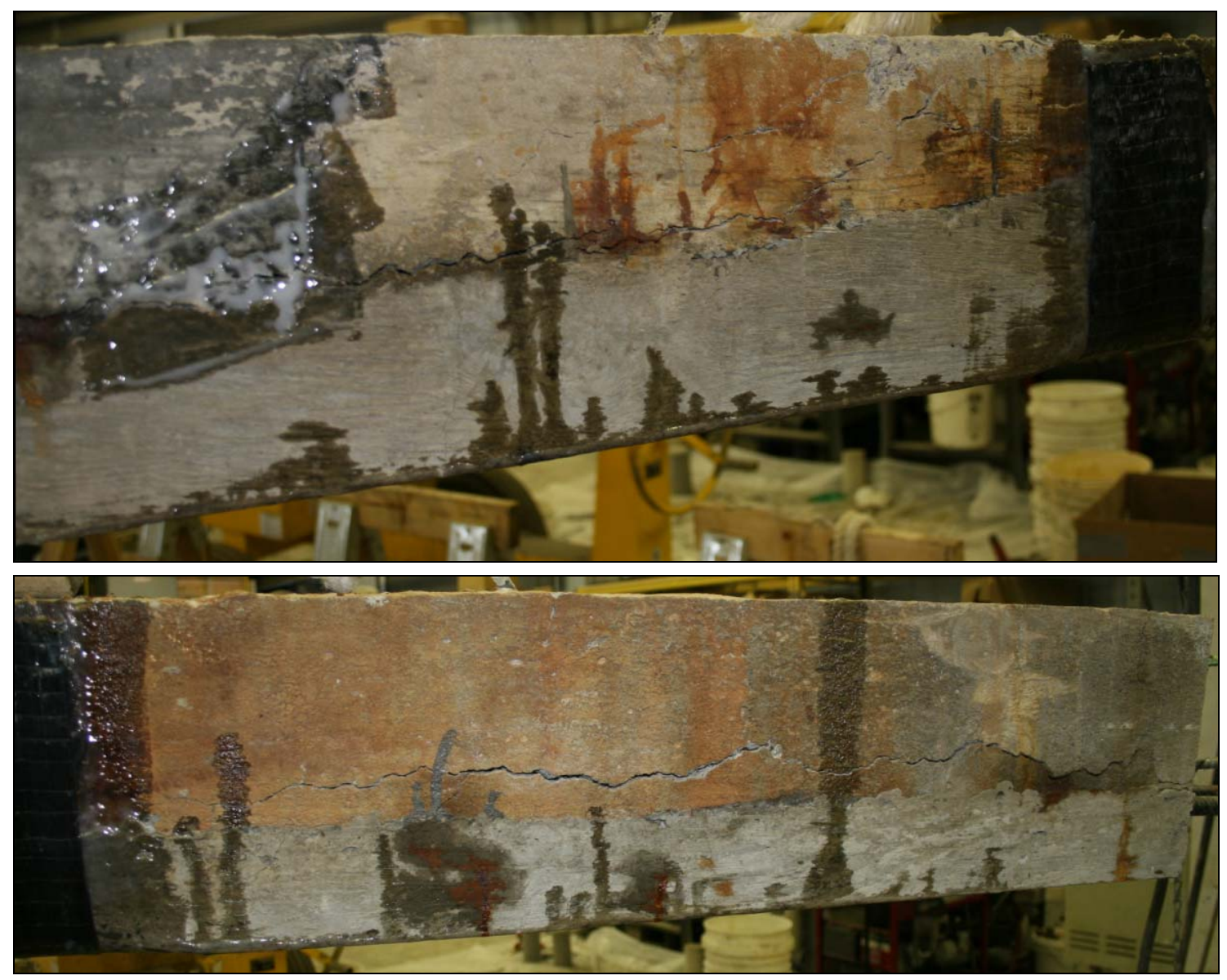

Figure 6.9: Cracks in Beam I-8 within the old concrete running parallel to the oldto-patch concrete interface

Although no significant damage was observed within the polymer-modified concrete material or at the interface between the old and new concrete, the old-to-patch concrete interface did show signs of failure near one end of the specimen (see Figure 6.10). The 
only significant crack observed within the patch concrete itself can be seen in Figure 6.11 .

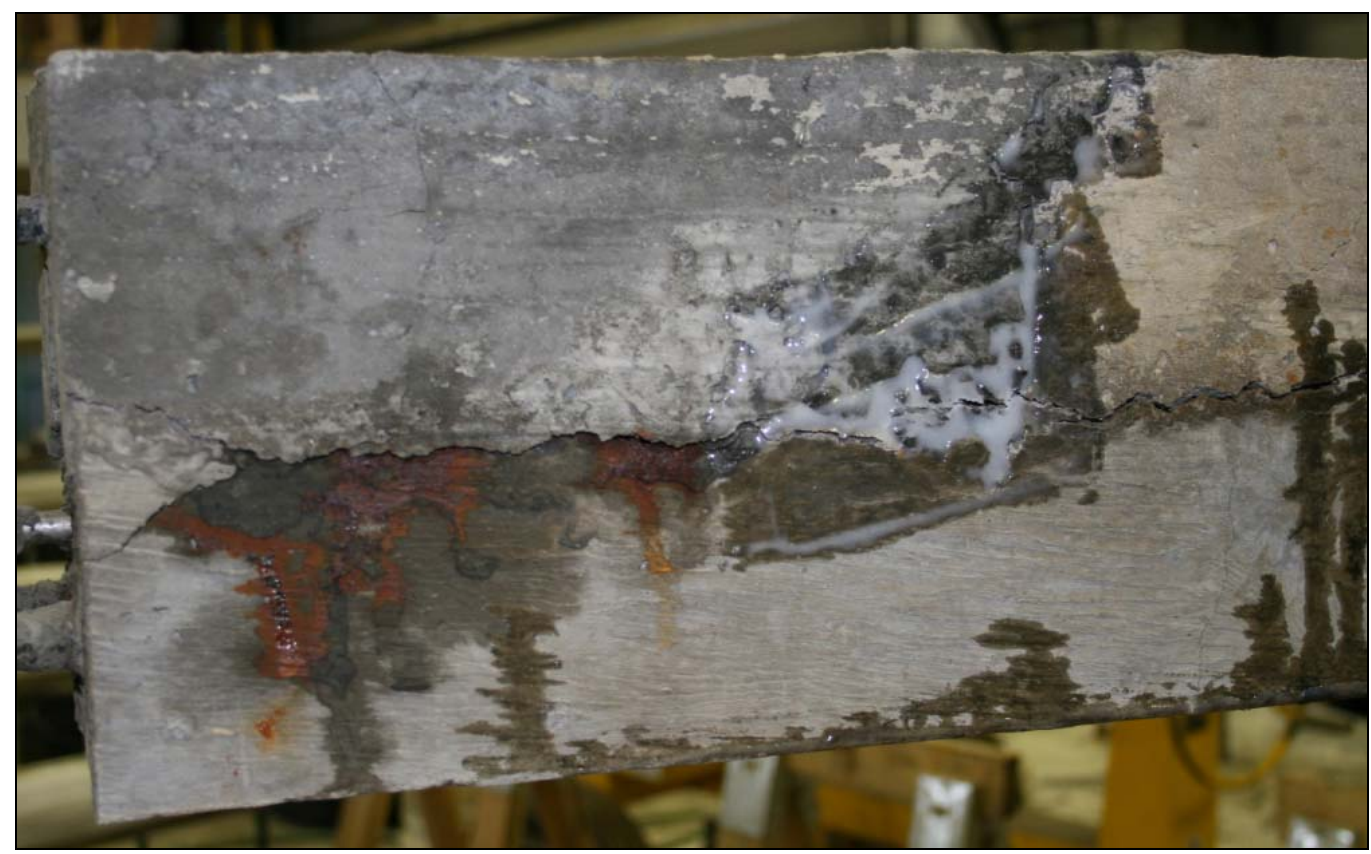

Figure 6.10: Damage of old-new concrete interface at the mark end of Beam I-8

At least some corrosion took place within the shear regions of Beam I-8, as was evident by deterioration at the beam ends. This could be because of one or both of the following reasons: 1.) the steel stirrups likely continued to corrode within the remaining portions of old concrete and 2.) only half of the surface area of the steel was encased in polymermodified concrete within the shear regions. This may have led to the formation of an incipient anode or simply to continued corrosion of the steel adjacent to the remaining portions of old concrete. This observation suggests that all steel requiring the prevention of additional corrosion should be completely encased in polymer-modified concrete containing corrosion inhibitor to obtain optimum results from concrete patch repair. 
Recall that Beam I-8's steel had also been cleaned prior to patch repair which also contributed to the prevention of additional corrosion.

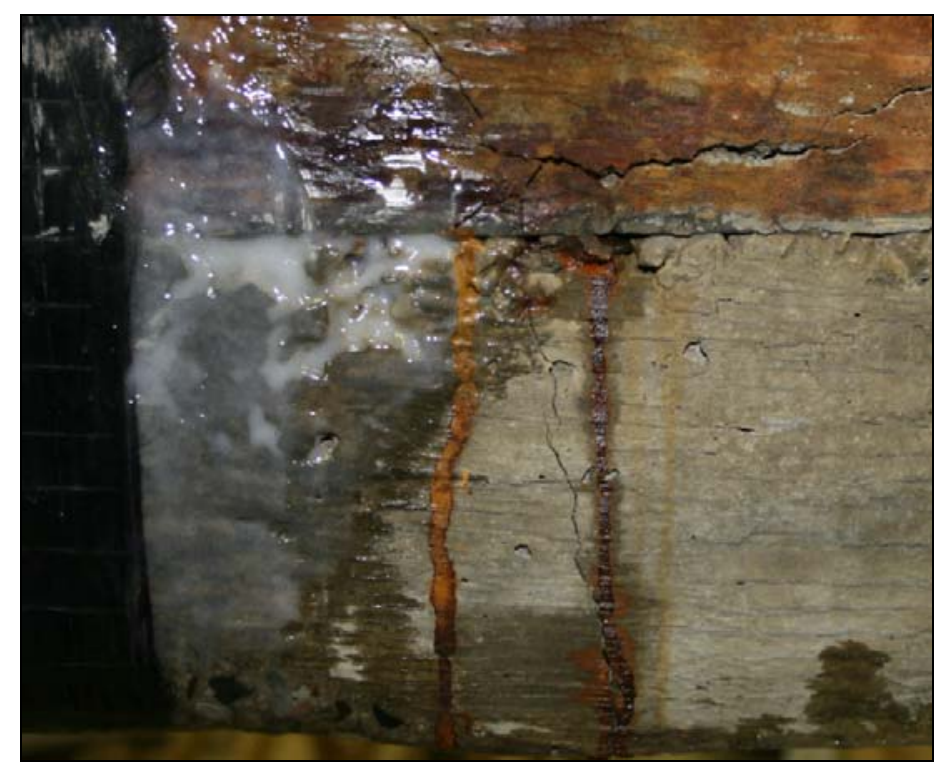

Figure 6.11: The only significant crack observed within polymer patch-repair concrete material

Many new cracks formed on Beam I-9, which was crack injected prior to FRP repair and subjected to additional corrosion. The most common evidence of new deterioration as a result of the additional corrosion cycle was the formation of new horizontal corrosion cracks that ran parallel to the repaired crack. These cracks were located anywhere between $1 / 2$ " and 2 " above the crack that was epoxy injected (see Figure 6.12). Cracks did not form below the injected cracks because there are minimal stresses in the regions below the level of tension reinforcement. The epoxy performed well at these locations as the repair areas were stronger than the once-sound concrete. However, due to the continued formation of expansive corrosive forces, the sound concrete became the "weak link" and failed. 
Another form of new deterioration can be seen in Figure 6.13. Certain cracks actually reopened and failed in the epoxy-concrete interface, likely because the crack faces were weak.

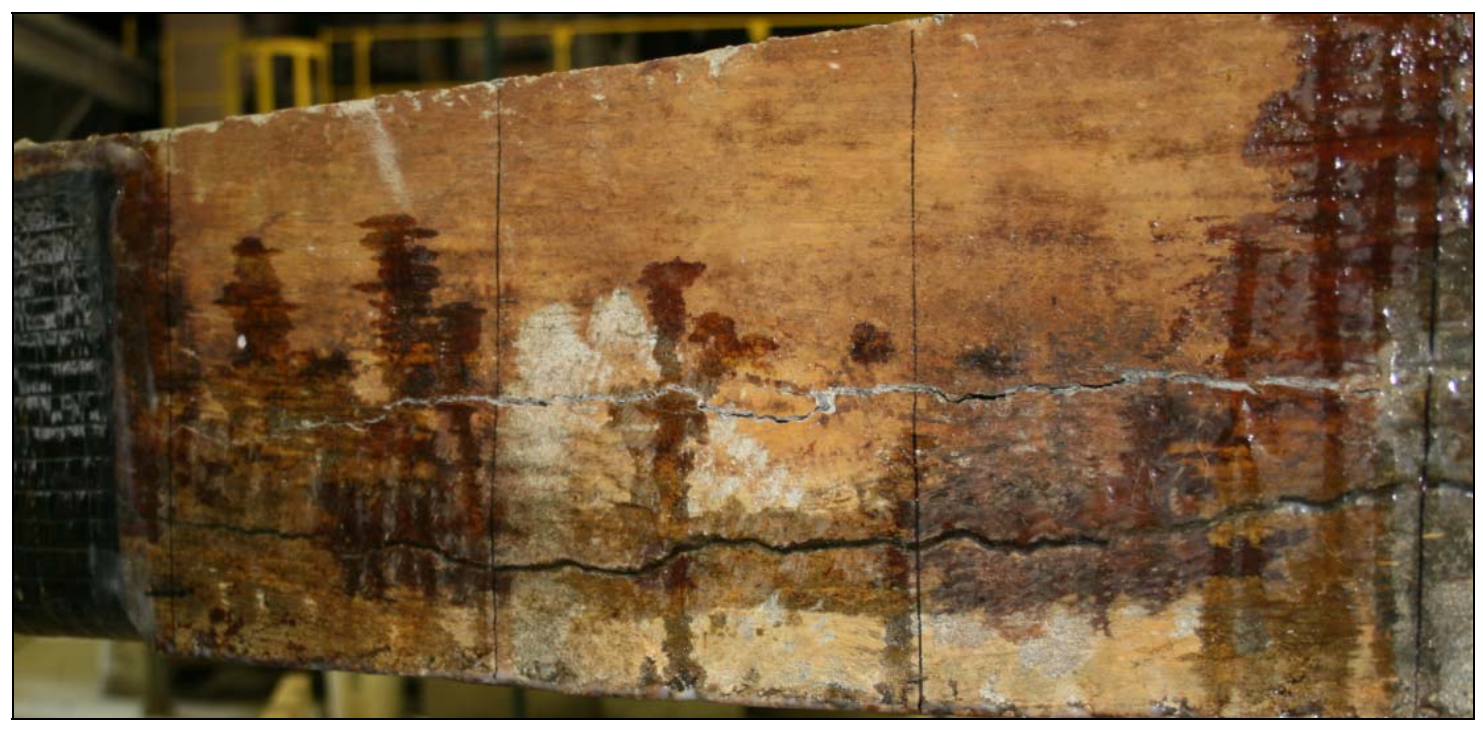

Figure 6.12: New crack running parallel to injection-repaired crack on Beam I-9

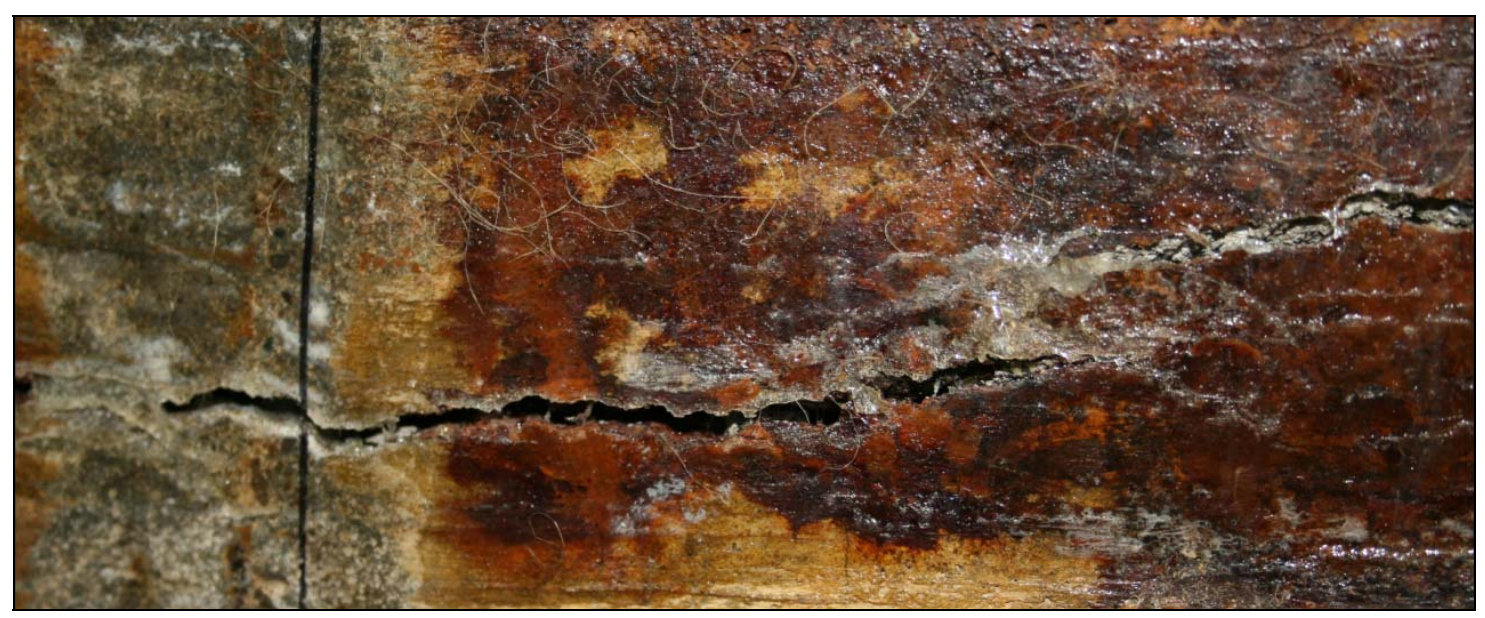

Figure 6.13: Re-opening of epoxy-injected crack on Beam I-9

Steel extracted from Beam I-9 yielded a mass loss of $26.5 \%$, a $53 \%$ increase compared to the average mass loss observed in repaired Beams I-7 and I-10. Beam I-9 had a 10\% greater mass loss than did corroded unrepaired Beam I-6 of the same age. This indicates 
that the FRP material may have actually assisted in the corrosion process by retaining contaminants within the beam and not allowing them to precipitate out in solution.

The mass loss differences in the cleaned steel coupons can be easily observed in Figure 6.14, Figure 6.15, and Figure 6.16. Figure 6.14 provides a comparison of the extent of corrosion on steel extracted from Beam I-7 after one corrosion process (top photo) and from Beam I-8 after two corrosion processes (bottom photo). No visual differences exsit between these two samples.

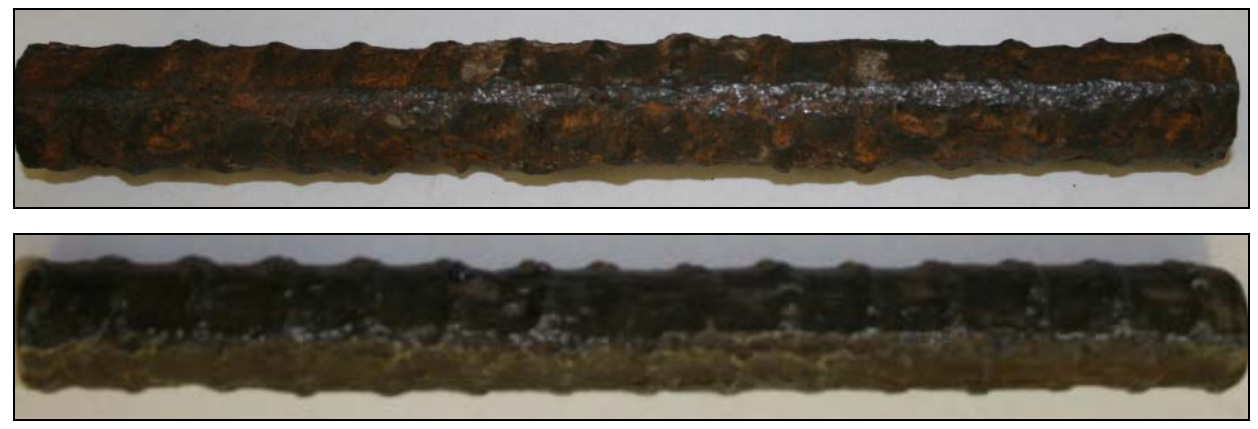

Figure 6.14: Steel coupon samples cut from Beams I-7 and I-8 at 1,200 and 2,400amp-hours, respectively

In Figure 6.15, Specimen 14 is a nearly pristine reference while only minor corrosion is observed in Specimen 8. Specimens 6 and 9 were both very severely corroded with the presence of large pits. A closer observation suggests that Specimen 9 was even slightly more corroded and more dramatically pitted than was Specimen 6. 


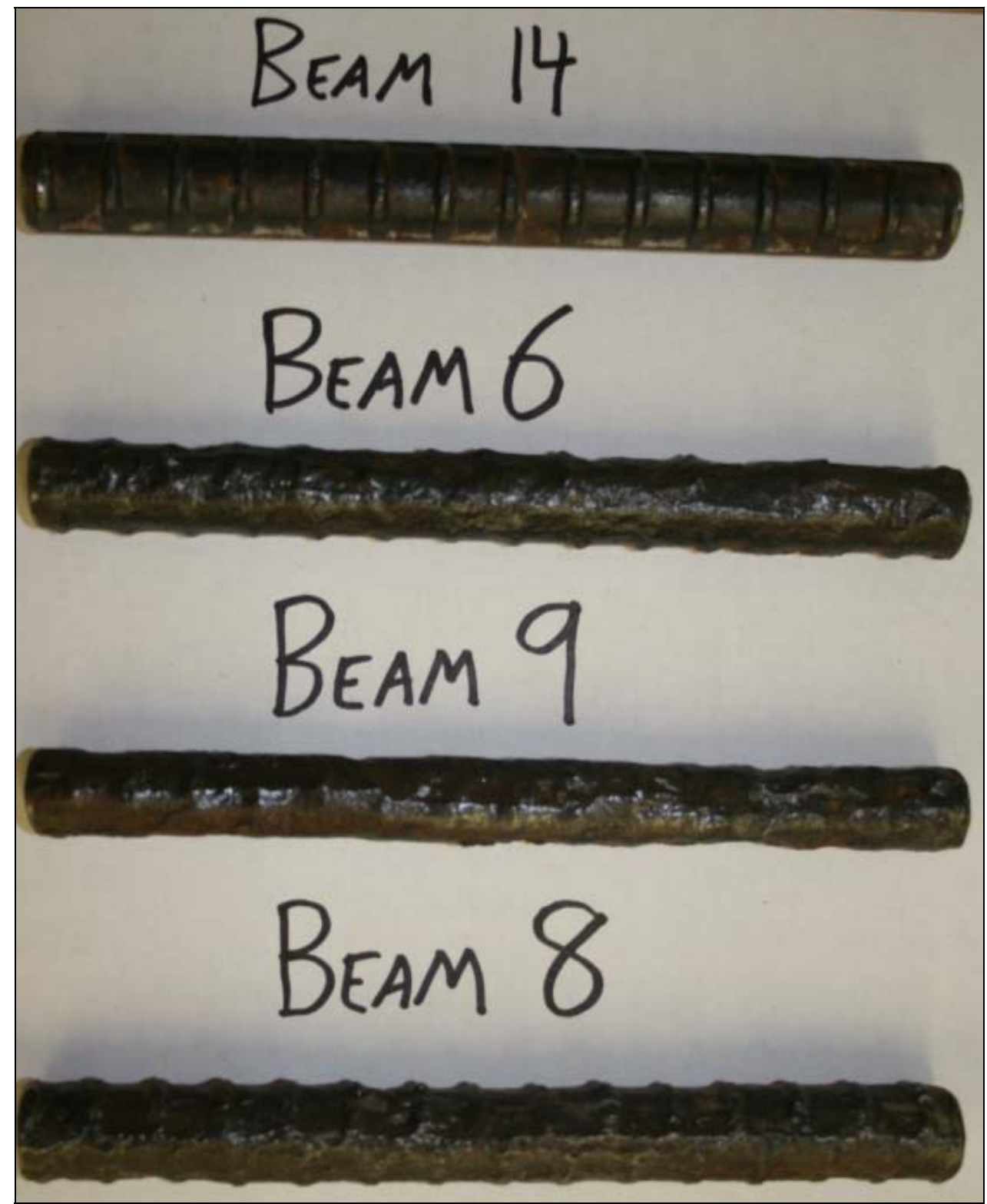

Figure 6.15: Profile view of steel coupon samples extracted from pristine control Beam I-14 and Beams I-6, I-9 and I-8 at 2,400amphours

Figure 6.16 provides a close-up of the cross-sections of the extracted steel samples. From left to right, the samples in the photo were extracted from Beam 14, I-6, I-9, and I-8. 


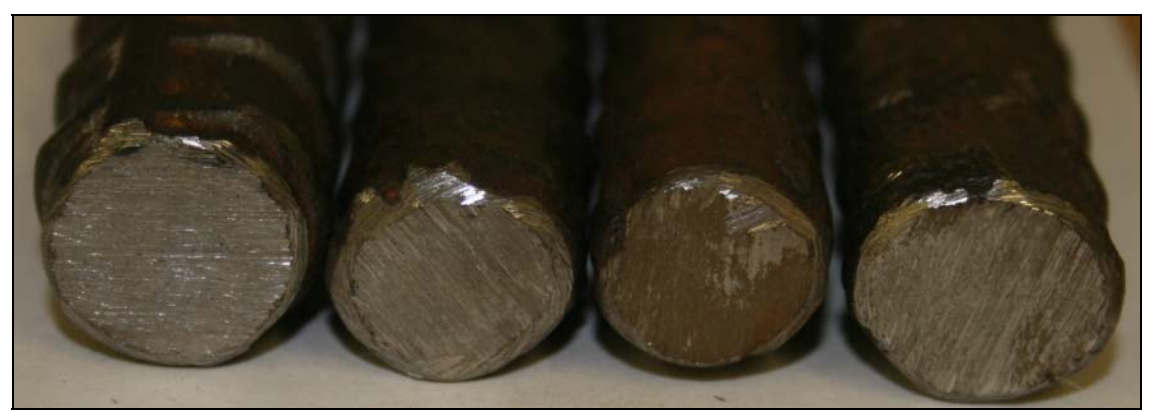

Figure 6.16: Cross-section view of steel coupon samples extracted from pristine control Beam I-14 and Beams I-6, I-9 and I-8 at 2,400amp-hours

\subsubsection{Part II}

The outstanding observation in Table 6.2 is the consistency of the accelerated aging process.

Table 6.2: Part II Mass Loss Summary

\begin{tabular}{|c|c|c|c|c|c|c|c|c|c|}
\hline Description & 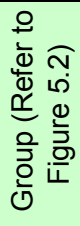 & $\begin{array}{l}\mathcal{E} \\
\underset{\Phi}{\Phi} \\
\infty\end{array}$ & $\begin{array}{c}\text { Mass Loss } \\
(\%)\end{array}$ & $\begin{array}{c}\text { Average } \\
\text { Mass Loss } \\
\text { by Group } \\
(\%)\end{array}$ & $\begin{array}{c}\text { Range of } \\
\text { Mass Loss } \\
\text { by Group } \\
(\%)\end{array}$ & $\begin{array}{c}\text { Percent } \\
\text { Difference } \\
\text { by Group } \\
(\%)\end{array}$ & $\begin{array}{c}\text { Total } \\
\text { Average } \\
\text { Mass Loss } \\
(\%)\end{array}$ & $\begin{array}{c}\text { Total } \\
\text { Range of } \\
\text { Mass Loss } \\
(\%)\end{array}$ & $\begin{array}{c}\text { Total } \\
\text { Percent } \\
\text { Difference } \\
(\%)\end{array}$ \\
\hline Pristine (28-day) & 1 & 2 & 0.5 & - & - & - & & & \\
\hline Pristine (Long-Term) & 9 & 12 & 0.7 & - & - & - & & & \\
\hline \multirow{2}{*}{ Corroded Unrepaired } & \multirow{2}{*}{2} & 3 & 24.2 & \multirow{2}{*}{24.2} & \multirow{2}{*}{0.2} & \multirow{2}{*}{0.6} & & & \\
\hline & & 4 & 24.3 & & & & & & \\
\hline \multirow{5}{*}{$\begin{array}{c}\text { Repaired with } \\
\text { Wrapping Scheme } 1\end{array}$} & \multirow{3}{*}{3} & 5 & 22.5 & \multirow{5}{*}{22.6} & \multirow{5}{*}{2.6} & \multirow{5}{*}{11.4} & \multirow{15}{*}{22.5} & \multirow{15}{*}{2.7} & \multirow{15}{*}{11.9} \\
\hline & & 8 & 22.3 & & & & & & \\
\hline & & 9 & 21.3 & & & & & & \\
\hline & \multirow{2}{*}{4} & 7 & 23.9 & & & & & & \\
\hline & & 14 & 23.2 & & & & & & \\
\hline \multirow{5}{*}{$\begin{array}{c}\text { Repaired with } \\
\text { Wrapping Scheme } 2\end{array}$} & \multirow{3}{*}{5} & 13 & 22.1 & \multirow{5}{*}{22.2} & \multirow{5}{*}{2.4} & \multirow{5}{*}{10.5} & & & \\
\hline & & 15 & 21.2 & & & & & & \\
\hline & & 17 & 21.7 & & & & & & \\
\hline & \multirow{2}{*}{6} & 18 & 23.5 & & & & & & \\
\hline & & 20 & 22.2 & & & & & & \\
\hline \multirow{5}{*}{$\begin{array}{c}\text { Repaired with } \\
\text { Wrapping Scheme } 3\end{array}$} & \multirow{3}{*}{7} & 21 & 22.6 & \multirow{5}{*}{22.6} & \multirow{5}{*}{1.2} & \multirow{5}{*}{5.1} & & & \\
\hline & & 22 & 22.4 & & & & & & \\
\hline & & 24 & 22.4 & & & & & & \\
\hline & \multirow{2}{*}{8} & 20 & 22.2 & & & & & & \\
\hline & & 23 & 23.4 & & & & & & \\
\hline
\end{tabular}



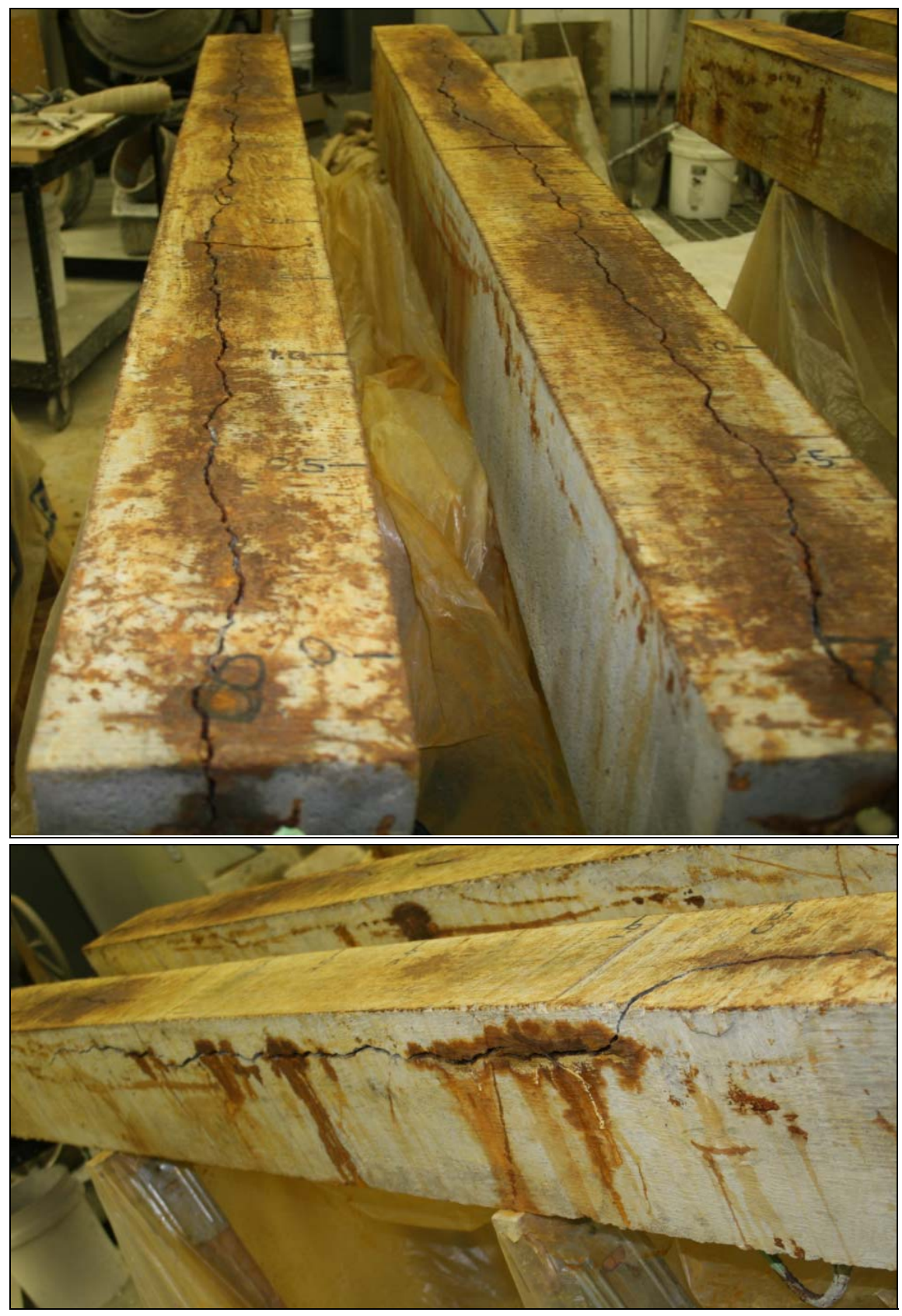

Figure 6.17: Typical deterioration of Part II beams prior to repair

The range of total percent mass loss for all fifteen FRP-repaired beam specimens was only $2.7 \%$ with a percent difference of $11.9 \%$. This data shows that the modified 
specimen and the finely-tuned accelerated aging procedure for Part II is a very dependable method for creating low-variability aged reinforced concrete beam samples.

The average percent mass loss for the FRP repaired beams subjected to 1,100amp hours $(2,200$ hours at a current of $500 \mathrm{~mA})$ was $22.5 \%$. This magnitude of mass loss of produced a substantial amount of concrete cover cracking and deterioration of steel-toconcrete bond (see Figure 6.17). It should be noted that the average mass loss observed in the corroded unrepaired Beams II-3 and II-4 averaged a 1.7\% greater mass loss than did the repaired beams. This difference is probably because these bars were encased in the chloride-contaminated concrete for a slightly longer amount of time than were the fifteen repaired beams. A photo of Beam II-3 prior to concrete removal and steel extraction is provided in Figure 6.18. It should be noted that a natural mass loss of only $0.7 \%$ was observed in the long-term pristine beam at 34 weeks of age.

The steel was extracted from Beams II-3 and II-4 at the same age as the steel from the repaired beams. The cleaned steel combined with the corrosion inhibitor and high alkalinity in the repair concrete prevented any additional corrosion after repair in the fifteen strengthened beams. However, the chloride-contaminated beams sat in storage while the strengthened beams were cleaned, patched, retrofitted with FRP, and then tested. This extra time (approximately one month) that the steel sat encased in a corrosive environment likely caused the small additional mass loss. 
Photos of typical extracted bars can be seen in Figure 6.19. The top photo shows a bar freshly removed from a corroded unrepaired beam that had not been cleaned. The middle photo shows a cleaned bar with exposed pits from a corroded unrepaired beam. The bottom is a photo of bars that were extracted from a polymer-modified concrete-repaired beam after wire brushing. Notice the excellent bond between the polymer patch concrete and the steel; the wire brush was not able to remove most of the concrete. This concrete was removed, however, during the chemical cleaning process and prior to weighing for mass loss.

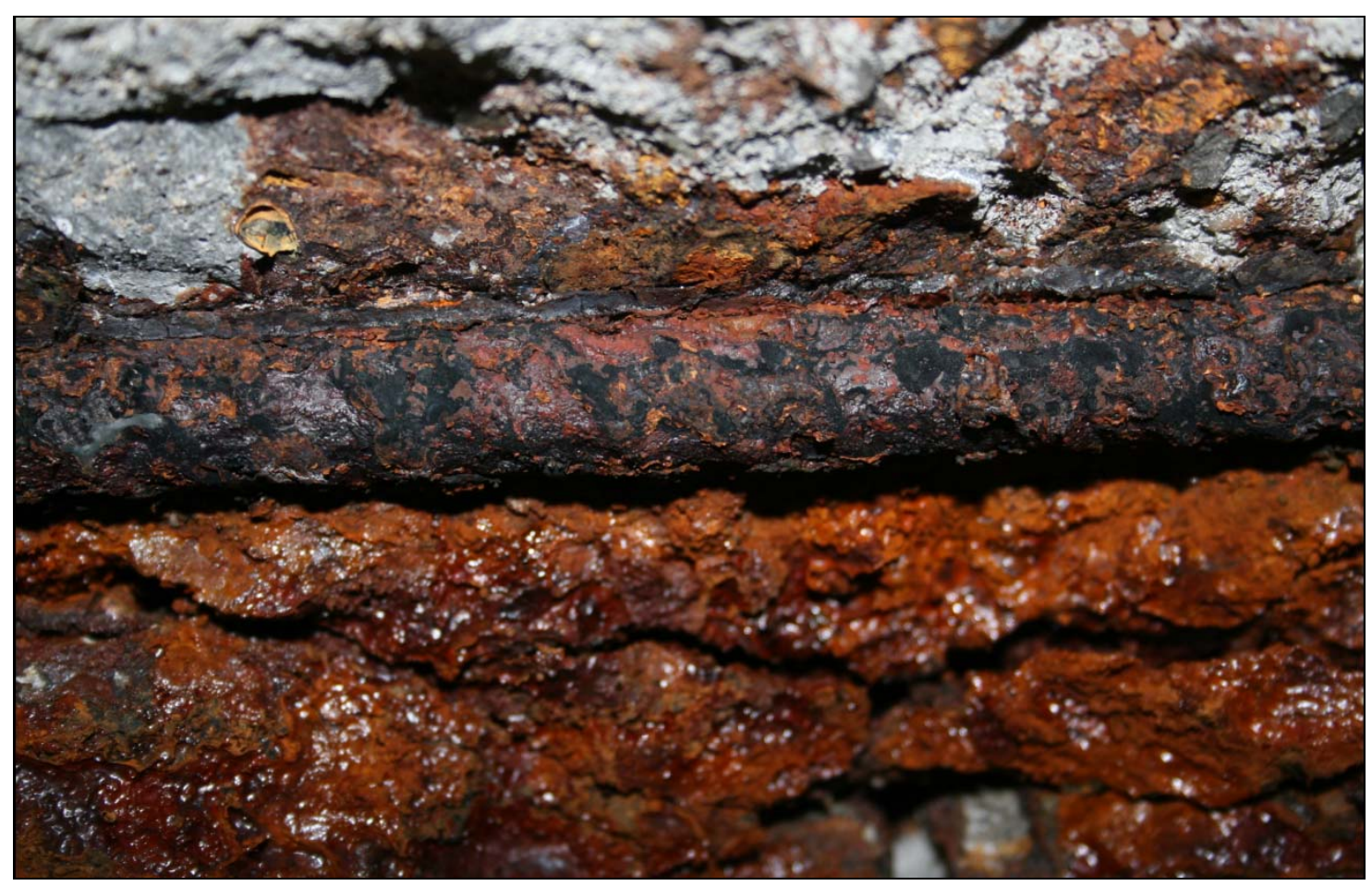

Figure 6.18: Corrosion observed in Beam II-3 after cover delamination

In addition to the seeping corrosion product, other undefined substances were found leaching from the concrete of several beams. These substances can be seen in Figure 6.20 

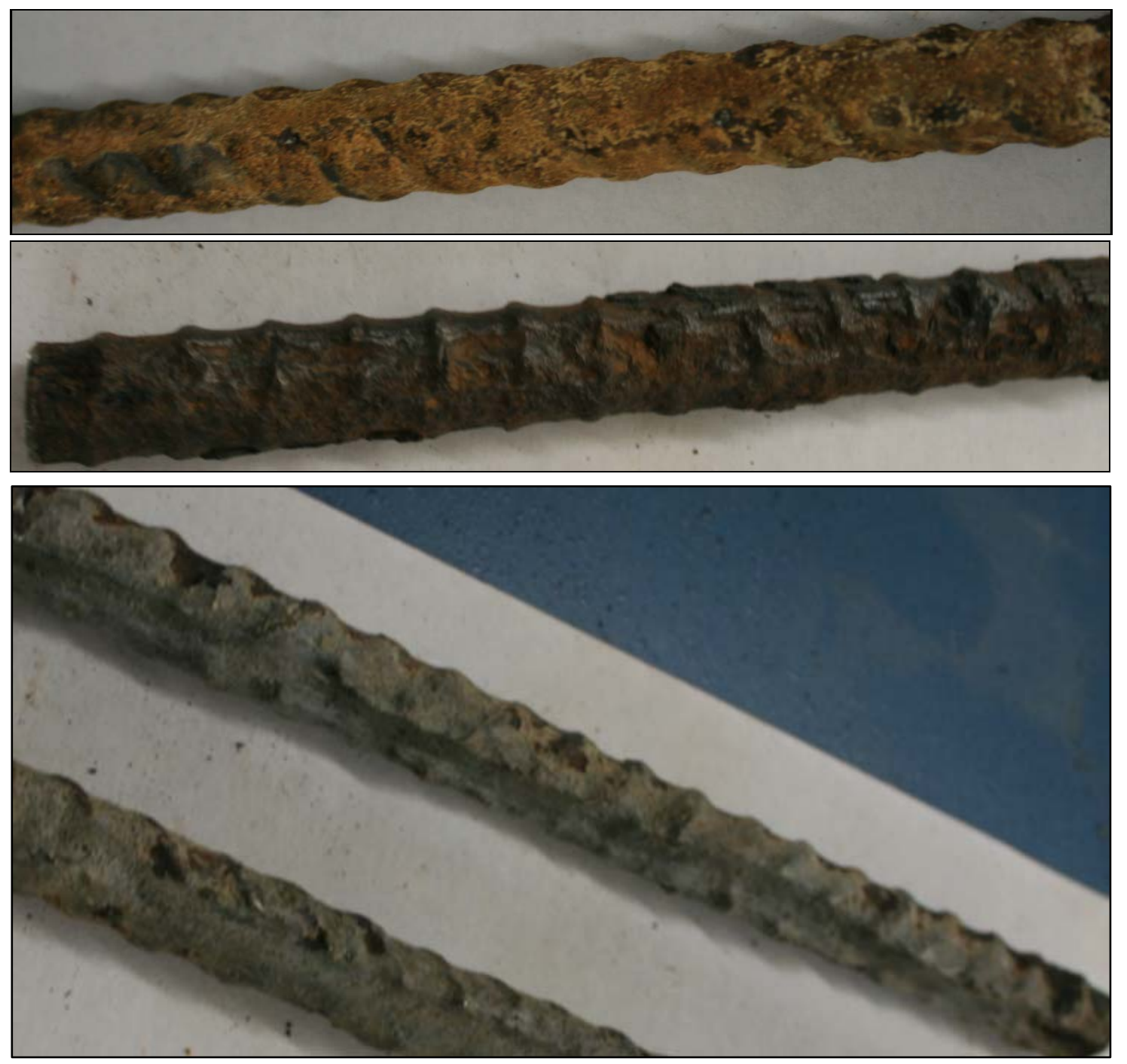

Figure 6.19: Part II pitting corrosion on extracted rebar

Also found leaching from some Part II beams was what appeared to be efflorescence, which consists of salt deposits. Recall that, while the leaching of efflorescence is mainly an aesthetic problem, its presence can indicate an increase in porosity, a reduction of strength, and an increase in vulnerability to chemical attack. It is possible that the substance in Figure 6.20 is actually efflorescence tainted with a small amount of green rust. The material was likely drawn from the beam ends by the flow of the current. 
Chemical analysis will be performed on this substance to determine its definite constituents.
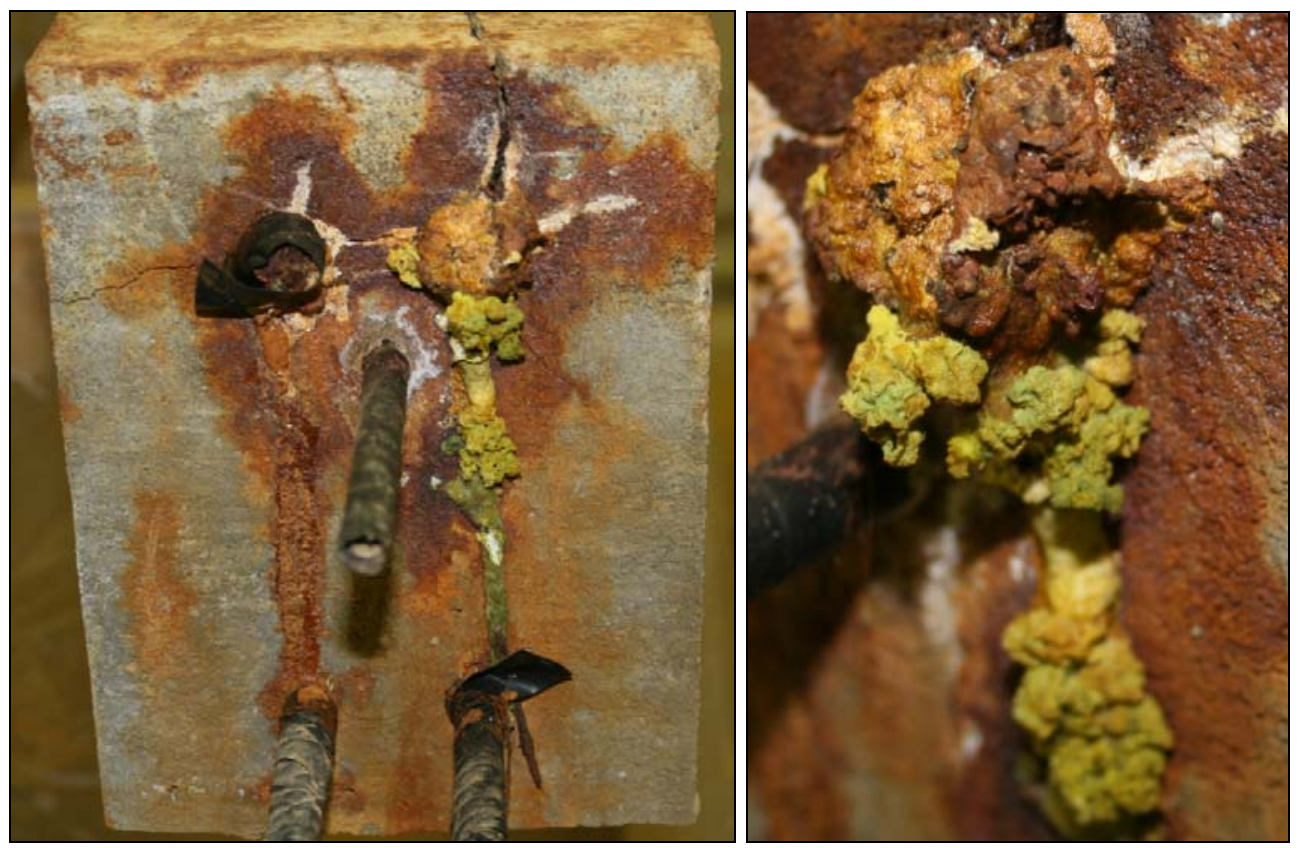

Figure 6.20: Unknown substance precipitating from Part II Beams
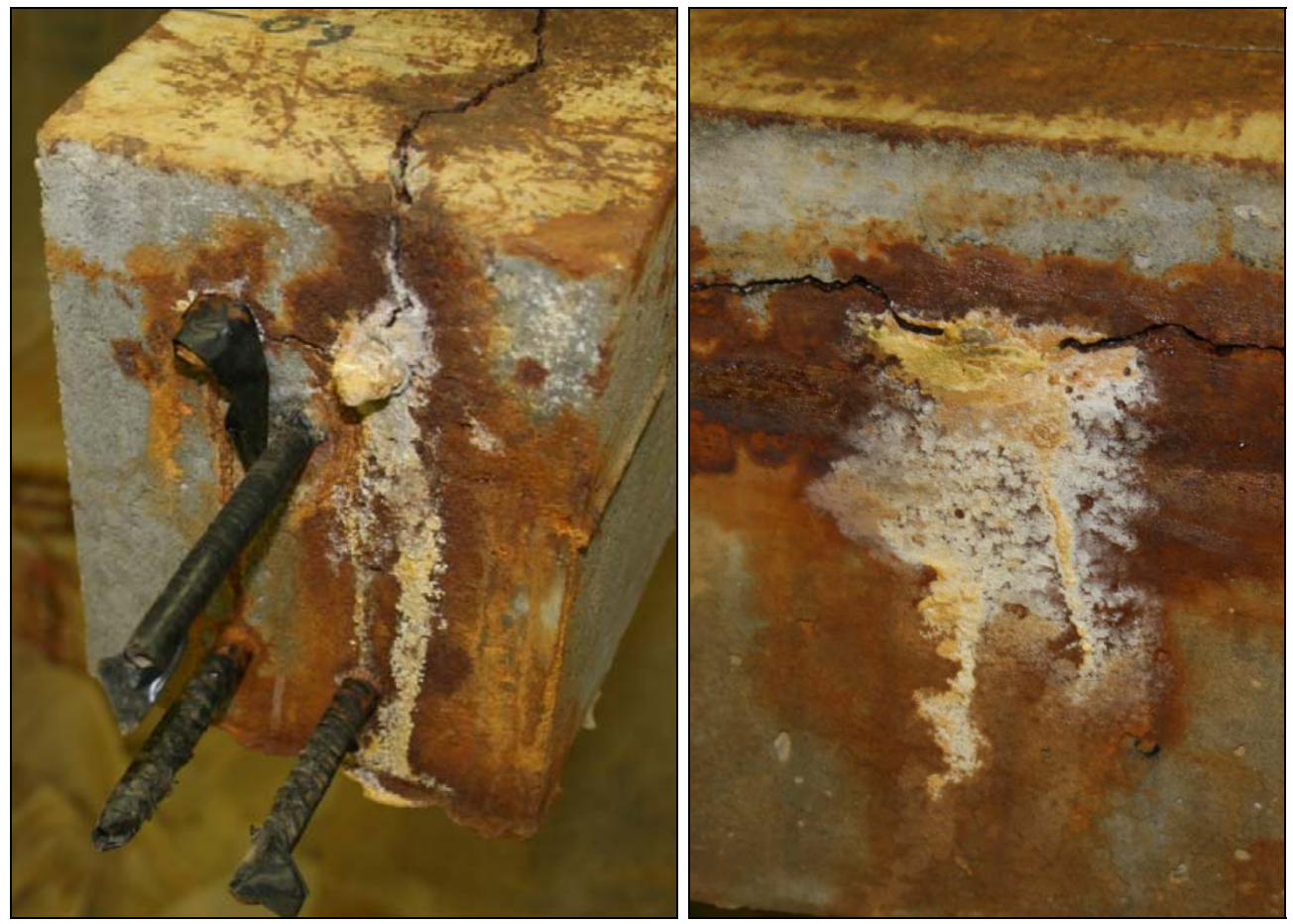

Figure 6.21: Efflorescence leaching from Part II Beams 


\subsubsection{Literature Review of Accelerated Aging Results}

Literature from twenty-four research projects that included some form of accelerated aging on reinforced concrete was reviewed (please refer to Table 4.7). Twelve of these projects employed an impressed electric current technique. In all twelve of these, chlorides were introduced to the reinforced concrete, while thirteen subjected its specimens wet/dry cycling. Eight of the research projects involved quickly aging largescale reinforced concrete beams. A method of impressed electrical current was used in six of them, and chloride was added in all eight. Some of the aging methods and their combinations will be analyzed and discussed in this literature review.

\subsubsection{Maddaawy, 2003}

In Maddaawy (2003), twelve reinforced concrete prism specimens were aged using an impressed current technique. Each specimen was about 12" long with a 6"x10" crosssection and had 5\% sodium chloride by weight of cement added to its concrete mix. Each prism was singly reinforced with two Canadian standard \#10M $(\approx 0.44$ " diameter) steel bars with 1" clear cover. One 1/4" diameter Type 304 stainless steel bar, which acted as a cathode in the accelerated corrosion setup, was placed above the steel bars. A diagram of the test specimen can be seen in Figure 6.22 (all dimensions are in millimeters). 


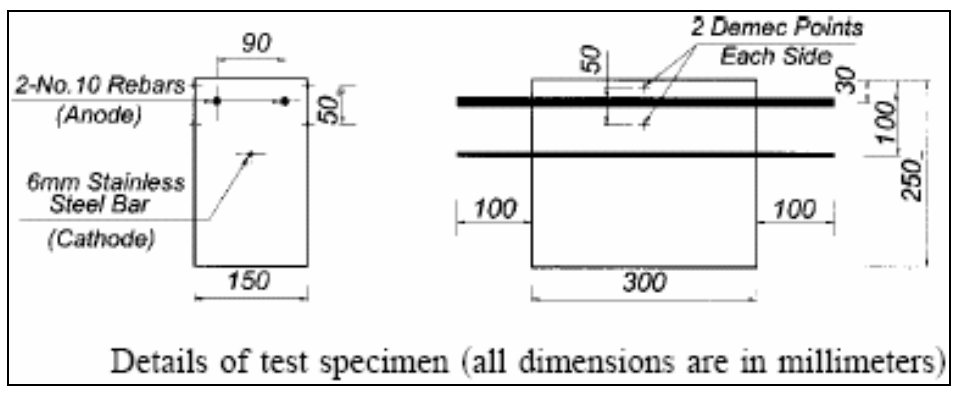

Figure 6.22: Maddaawy (2003) Test Specimen

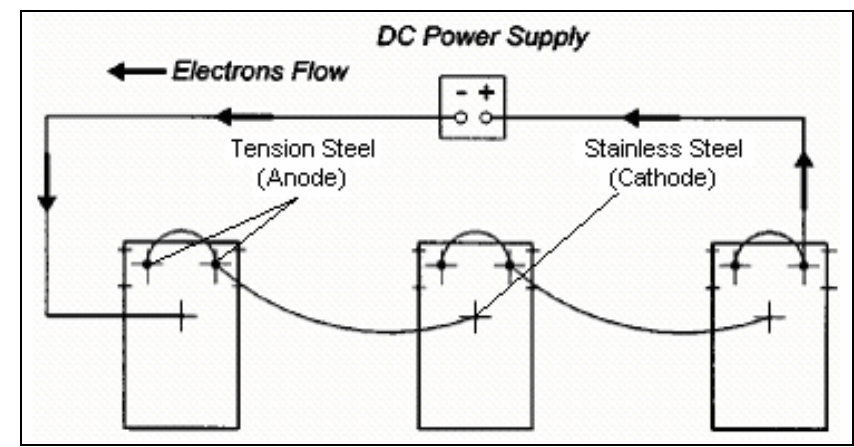

Figure 6.23: Maddaawy (2003) Wiring Scheme

The reinforcing steel and stainless steel bar extended from the ends of the specimen to allow for electrical connection, and a Bio-Rad 500 Power supply was wired into the circuit as shown in Figure 6.23.

The beams were wrapped in burlap sheets and were wetted daily to provide moisture to allow the corrosion reactions to take place. Table 6.3 presents a summary of the accelerated corrosion plan and the resulting mass losses.

It can be clearly seen in Figure 6.24 that, as the current density increased, the concrete side strain due to expansive corrosion increased. The most significant strain development rate increase occurred between current densities of 200 and $350 \mu \mathrm{A} / \mathrm{cm}^{2}$. 
Table 6.3: Summary of Accelerated Corrosion Schedule and Resulting Mass Losses

\begin{tabular}{|c|c|c|c|c|c|c|}
\hline \multirow[t]{2}{*}{ Group } & \multirow[t]{2}{*}{ Specimen } & \multirow{2}{*}{$\begin{array}{c}\text { Level of } \\
\text { impressed current } \\
\text { density } \\
\left(\mu \mathrm{A} / \mathrm{cm}^{2}\right)\end{array}$} & \multirow{2}{*}{$\begin{array}{l}\text { Time for } \\
\text { induced } \\
\text { corrosion (b) }\end{array}$} & \multicolumn{2}{|c|}{$\begin{array}{l}\text { Actual Degrees of Corrosion } \\
\text { (\% Mass Loss) }\end{array}$} & \multirow{2}{*}{$\begin{array}{c}\text { Actual degrees of } \\
\text { corrosion (average) } \\
(\% \text { mass loss })\end{array}$} \\
\hline & & & & $\operatorname{Bar}(1)$ & $\operatorname{Bar}(2)$ & \\
\hline \multirow{3}{*}{ A } & P-D & 100 & 815 & 3.87 & 5.57 & \multirow[t]{3}{*}{ 4.38; SD 0.63} \\
\hline & K-R & 100 & 815 & 4.13 & 4.12 & \\
\hline & $\mathrm{H}-\mathrm{G}$ & 100 & 815 & 3.87 & 4.55 & \\
\hline \multirow{3}{*}{ B } & $\mathrm{M}-\mathrm{Z}$ & 200 & 766 & 7.75 & 7.29 & \multirow[t]{3}{*}{ 7.30; SD 0.43} \\
\hline & $\mathrm{X}-\mathrm{B}$ & 200 & 766 & 6.57 & 7.30 & \\
\hline & $\mathrm{C}-\mathrm{O}$ & 200 & 766 & 7.17 & 7.73 & \\
\hline \multirow{3}{*}{$\mathrm{C}$} & $\mathrm{N}-\mathrm{A}$ & 350 & 380 & 6.63 & 7.01 & \multirow[t]{3}{*}{$6.50 ;$ SD 0.32} \\
\hline & E-I & 350 & 380 & 6.16 & 6.58 & \\
\hline & $\mathrm{T}-\mathrm{Y}$ & 350 & 380 & 6.14 & 6.46 & \\
\hline \multirow{3}{*}{$\mathrm{D}$} & U-F & 500 & 306 & 8.35 & 5.98 & \multirow[t]{3}{*}{ 7.26; SD 0.798} \\
\hline & L-V & 500 & 306 & 7.36 & 6.98 & \\
\hline & $\mathrm{J}-\mathrm{Q}$ & 500 & 306 & 7.11 & 7.76 & \\
\hline
\end{tabular}

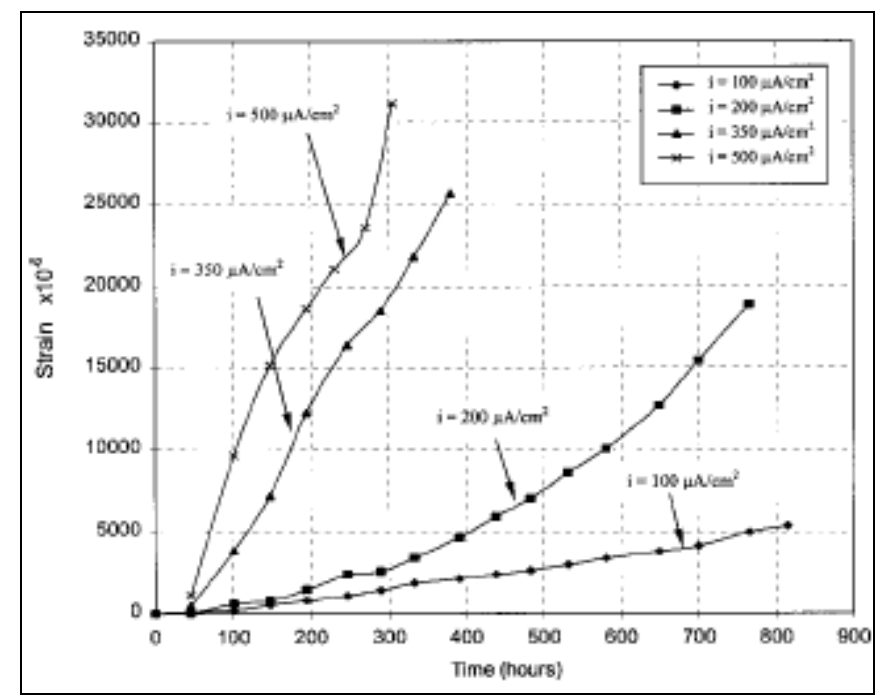

\section{Figure 6.24: Concrete Side Strain vs. Time Relationship (Maddaawy 2003)}

\subsubsection{Maddaawy, 2005}

Maddaawy (2005) employed induced electrical current along with chloride addition, wet/dry cycling, and preloading/pre-cracking prior to FRP repair. The applied current method was performed using the same techniques as in Maddaawy (2003). 
Specimens had cross sections of 6"x10" and were 10'-6" long. Each was reinforced with two \#15M Canadian standard bars (approximately $5 / 8$ " in diameter) in the tension zone and two 0.31 " diameter plain bars in the compressive zone. Plain stirrups were used in the shear span. A Type 304 stainless steel tube with an external diameter of $3 / 8$ " and a wall thickness of 0.95 " was placed above the tension steel to serve as the cathode. A diagram of the test specimen can be seen in Figure 6.25 (all dimensions are in millimeters).

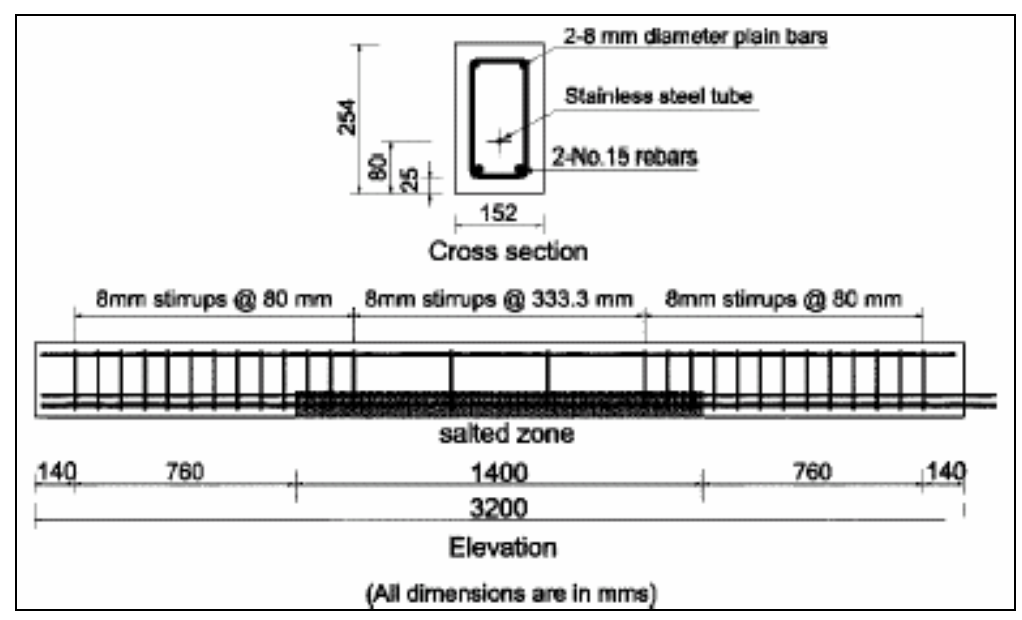

Figure 6.25: Maddaawy (2005) Test Specimen

Corrosion was restricted to the tensile steel reinforcement in the middle 55" zone by adding $2.25 \% \mathrm{Cl}^{-}$by weight of cement to this portion of the concrete. The stirrups were coated with epoxy and plastic tape was wrapped around the stirrups' corners at the contact points between the longitudinal steel bars to prevent corrosion of the shear reinforcement. The tensile steel bars and the stainless steel tube were extended out of one end of the specimen and wired to a Bio-Rad PowerPac 1000 constant-current power supply. A current density of about $150 \mu \mathrm{A} / \mathrm{cm}^{2}$ was applied constantly to the steel bars to 
accelerate the corrosion process. A diagram of the wiring scheme can be seen in Figure 6.23

Two fogging mist nozzles were used to constantly spray mist over the test specimens and to provide the moisture required for the corrosion process. Specimens were encased in a polyethylene cover to control humidity. No wet/dry cycling was employed.

Table 6.4 presents a summary of the accelerated corrosion plan and the resulting mass losses. In addition to accelerated corrosion, Group B beams were subjected to sustained loading in order to produce a bending moment equivalent to about $60 \%$ of the ultimate load. Reductions in ultimate strength of $12,14,14.5$ and $24 \%$ were recorded at steel mass losses of 9.7, 15.4, 22.8, and 30\%, respectively.

Table 6.4: Summary of accelerated corrosion schedule and resulting mass losses

\begin{tabular}{|c|c|c|c|c|c|}
\hline Group & Specimen $^{\mathrm{a}}$ & $\begin{array}{l}\text { Total time of } \\
\text { exposure (days) }\end{array}$ & $\begin{array}{l}\text { Loading condition during } \\
\text { corrosion }\end{array}$ & Repair scheme & $\begin{array}{c}\text { Average degree of corrosion }{ }^{\mathrm{b}} \\
\text { (\% mass loss) }\end{array}$ \\
\hline \multirow{6}{*}{ A } & Virgin (UU) & - & - & - & - \\
\hline & UR-I & - & - & I & - \\
\hline & UR-II & - & - & II & - \\
\hline & CUN-50 & 50 & No Load & - & 8.9 \\
\hline & CRN-50-I & 50 & No Load & I & 8.5 \\
\hline & CRN-50-II & 50 & No Load & II & 8.8 \\
\hline \multirow{8}{*}{ B } & CUS-50 & 50 & Sustained Load & - & 9.7 \\
\hline & CUS-110 & 110 & Sustained Load & - & 15.4 \\
\hline & CUS-210 & 210 & Sustained Load & - & 22.8 \\
\hline & CUS-310 & 310 & Sustained Load & - & 30.0 \\
\hline & CRS-50-I & 50 & Sustained Load & I & 9.5 \\
\hline & CRS-110-I & 110 & Sustained Load & I & 15.7 \\
\hline & CRS-210-I & 210 & Sustained Load & I & 23.7 \\
\hline & CRS-310-I & 310 & Sustained Load & I & 31.0 \\
\hline \multicolumn{6}{|c|}{$\begin{array}{l}{ }^{\text {a } U U, ~ U R, ~ C U, ~ a n d ~ C R ~ r e f e r ~ t o ~ u n c o r r o d e d-u n r e p a i r e d, ~ u n c o r r o d e d-r e p a i r e d, ~ c o r r o d e d-u n r e p a i r e d, ~ a n d ~ c o r r o d e d-r e p a i r e d, ~} \\
\text { respectively; S and N refer to corrosion with sustained load and with no load, respectively, 50, 110, 210, and } 310 \text { refer to the times } \\
\text { of corrosion exposure: I and II refer to the external configuration of the CFRP repair scheme. } \\
{ }^{b} \text { Rust was removed according to the ASTM Standard G 1-90 (2002). }\end{array}$} \\
\hline
\end{tabular}


For specimen details and repair methods used in this study, please see Section 4.2.1.1.1.

For crack measurement results from this study, please see Section 6.2.1.2.1. For static flexural testing procedures and results, please see Section 6.3.2.2.1.

\subsubsection{Masoud,2005 \& Masoud, 2006}

These research experiments focused on the corrosion activity in both FRP repaired and unrepaired large-scale reinforced concrete beam specimens. Ten 10'-6" long beams with a 6" 10 " cross section were tested. Tension reinforcement consisted of two Canadian standard \#15M bars $(\approx 0.63$ " diameter). Compression and shear reinforcement consisted of 0.31 " diameter plain bars. An 0.63 " diameter Type 316 stainless steel bar was placed above the tension steel to serve as the cathode in the accelerated corrosion process. Salt was added to the concrete mix at the level of tension reinforcement so that there were about $2.15 \%$ chlorides per weight of cement. Shear stirrups within this region were epoxy-coated to limit the corrosion to the tension steel only. A diagram of the test specimen can be seen in Figure 6.26 (all dimensions are in millimeters).

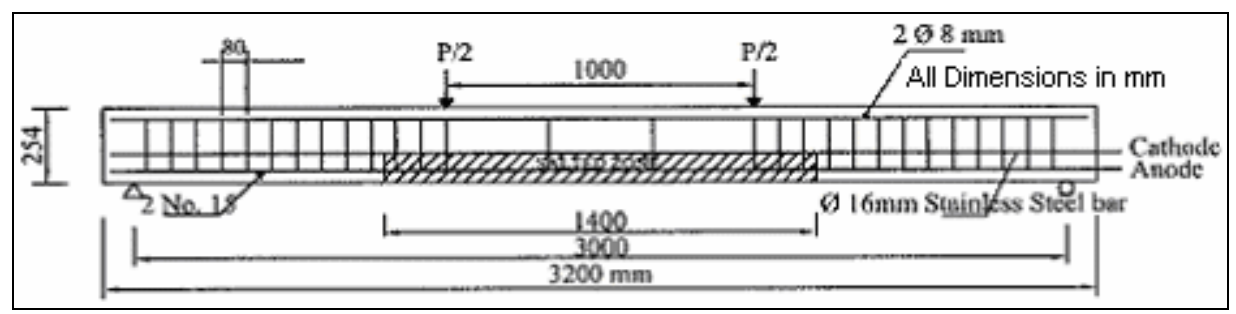

Figure 6.26: Masoud (2005) and Masoud (2006) Test Specimen

A constant current density of $140 \mu \mathrm{A} / \mathrm{cm}^{2}$ was applied to each specimen for 48,100 , and 200 days. After 48 days some beams were repaired with FRP. At this time, the average mass loss was $5.5 \%$, ranging from $5.1-5.8 \%$. Corroding specimens were subjected to 2 
wet/dry cycles per week in a large-scale corrosion chamber at increments of $2 \frac{1}{2}$ days wet and 1 day dry. Mass losses were determined by extracting twelve steel coupons from the tension reinforcement (see Figure 6.27). and cleaning them with a solution of hydrochloric acid and hexameythylene tetramine prior to weighing.

Table 6.5 summarizes the quantity of mass loss observed throughout the experiment, and Figure 6.28 shows a histogram of mass loss over time. The FRP repair appeared to slightly retard the rate of mass loss within the beam specimens. Masoud attributed this corrosion rate decrease to the fact that the FRP layer likely lowered the diffusion rate of moisture and oxygen. This differed from the findings in the West Virginia University research project, probably because of the method used to soak the beams. Masoud used a "corrosion chamber" and West Virginia University allowed the moisture to percolate through the concrete (from the compression face where there was no FRP layer) via gravity on repaired beams in Part I.

For specimen details and repair methods used in this study, please see Section 4.2.1.1.3. For crack measurement testing results from this study, please see Section 6.2.1.2.2. For cyclic flexural testing procedures and results, please see Section 6.3.1.2.1. 


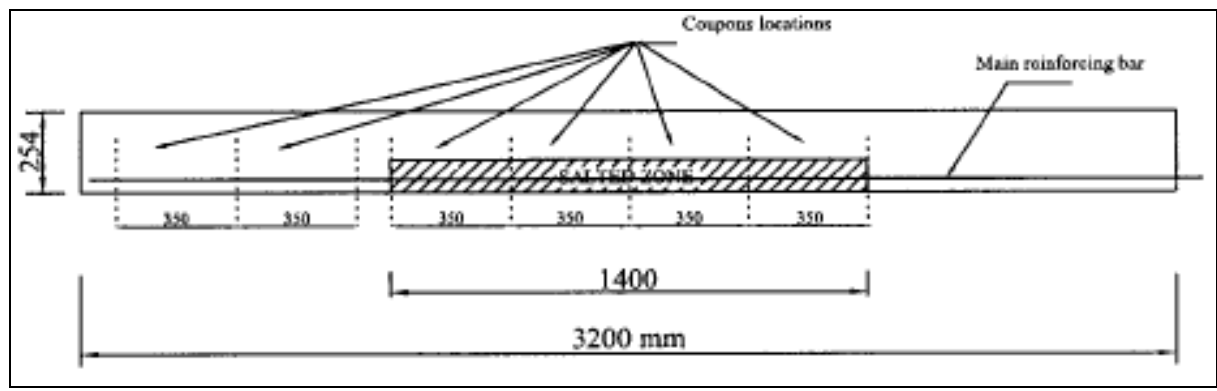

Figure 6.27: Location of sample coupons to determine mass loss for Masoud (2006)

Table 6.5: Masoud (2006) Mass Loss Summary

\begin{tabular}{|c|c|c|c|c|}
\hline \multirow[b]{2}{*}{ Days of Corrosion } & \multicolumn{2}{|l|}{ Unrepaired Specimens } & \multicolumn{2}{|c|}{ FRP-Repaired Specimens } \\
\hline & Average Mass Loss (\%) & $\begin{array}{l}\text { Range of Mass Loss } \\
(\%)\end{array}$ & $\begin{array}{l}\text { Average Mass Loss } \\
(\%)\end{array}$ & $\begin{array}{l}\text { Range of Mass Loss } \\
(\%)\end{array}$ \\
\hline 48 & 5.5 & $5.1-5.8$ & --- & --- \\
\hline 100 & 9.2 & $8.8-9.6$ & 9.0 & $8 . .7-9.4$ \\
\hline 200 & 12.5 & $10.7-14.0$ & 10.5 & $9.1-11.8$ \\
\hline
\end{tabular}

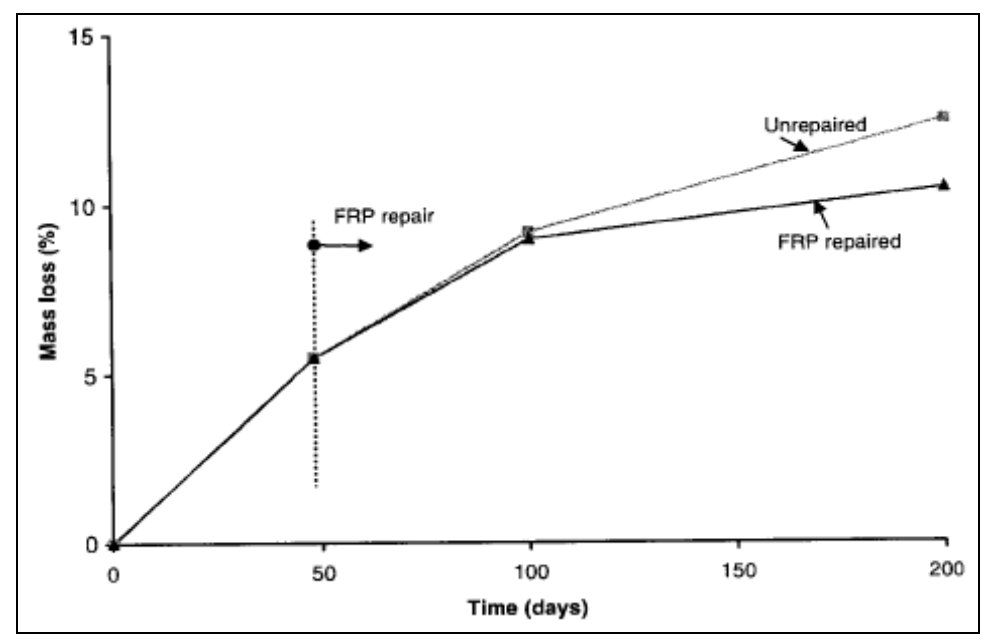

Figure 6.28: Timeline of Average Mass Loss observed in Masoud (2006)

\subsubsection{Bonacci, 2000}

Four 14'-3" long reinforced concrete beams with cross-sections of 10.6"x15.7" were subjected to accelerated aging. The tension steel consisted of three \#20M $(\approx 3 / 4$ " 
diameter) deformed bars. Compression and shear reinforcement consisted of \#3 deformed bars. The end regions of each cage were epoxy-coated to contain the corrosion to within the midspan. An 0.12 " diameter wire mesh with an average spacing of 1 " was placed in a small gap below the constant moment region of each specimen. Sodium chloride crystals were added to the concrete mix in constant moment regions of each beam. The $\mathrm{NaCl}$ produced an approximate $2 \%$ chloride ion concentration by weight of cement.

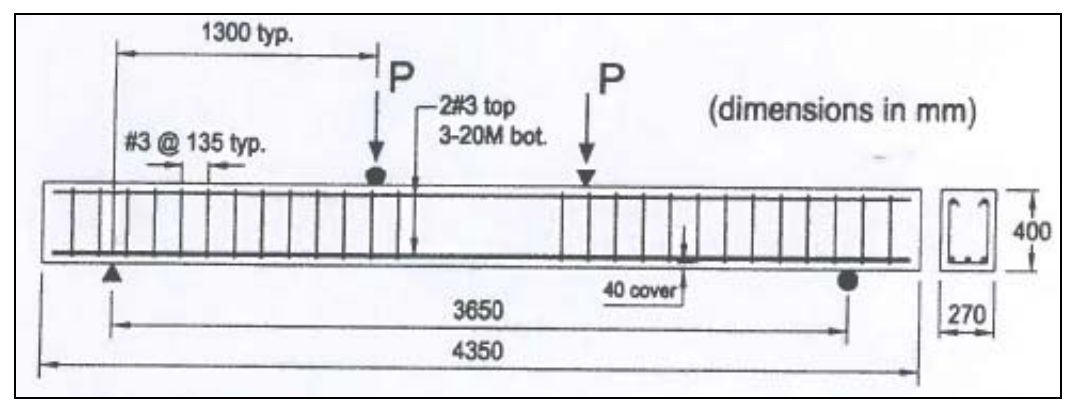

Figure 6.29: Bonacci (2000) Test Specimen

Each specimen was initially placed in a separate corrosion tank so that the bottom third $\left(5^{1 / 4}\right)$ of each beam soaked in a $3 \% \mathrm{NaCl}$ solution. A constant voltage of $12 V^{\ddagger}$ was

* The report of a constant voltage is meaningless when attempting to control or predict the rate of steel mass loss. This is because mass loss is directly related to the amount of current supplied to the steel. Since the resistance in the circuit constantly changes as the beam corrodes, a constant voltage must yield a variable current based on the fundamental equation $\mathrm{I}=\mathrm{V} / \mathrm{R}$. This is evidenced when Bonacci (2000) reports an average $1,700 \mathrm{~mA}$ during wet cycles and an average $300 \mathrm{~mA}$ during dry cycles. Because of this, the required time reported by Bonacci (2000) to reach a specified mass loss may not be reliable. 
applied to the steel. A small pump was used to supply oxygen from the air to the external cathode region to promote the formation of hydroxyl ions.

Initially, the specimens were subjected to two cycles wetting and drying per week at increments of 3.5 days wet and 3.5 days dry for 56 days. Bonacci (2000) reports that, during the wet phase, the current averaged $1,700 \mathrm{~mA}$ on average, and during the drying phase, it was $300 \mathrm{~mA}$ on average. Later in the testing, to further accelerate the rate of corrosion, the water level was lowered to $1 / 2 "$ to increase oxygen availability and the drying phase was omitted.

Sixty days of accelerated aging yielded a 5\% steel mass loss and 140 days yielded a 10\% mass loss.

For specimen details and repair methods used in this study, please see Section 4.2.1.1.2. For static flexural testing procedures and results, please see Section 6.3.2.2.2.

\subsubsection{Kutarba, 2004}

Twenty-six beams were subjected to accelerated corrosion via induced electric current. Each beam was 9'-6" long and had a cross-section of 8"x12". Steel reinforcement consisted of two \#6 tension bars and two \#3 compression bars. 
The beams were first pre-cracked and then a $5 \% \mathrm{NaCl}$ solution was continuously dripped over the side and bottom of the beam in the cracked region during wet cycles. The beams were cycled in increments of one week wet and one week dry.

For pre-repaired corrosion specimens, a $5 V^{\S}$ constant potential was applied to the tension steel. The corrosion process lasted 18 weeks and resulted in severe corrosion damage to the beams.

For post-repaired corrosion specimens beams, corrosion cycling consisted of one week of wetting with a $3.5 \% \mathrm{NaCl}$ solution under a constant potential of $5 \mathrm{~V}$ followed by 1 week of drying over a 22-week span.

Kutarba (2004) observed that the post-repair corrosion rates were less than the pre-repair corrosion rates.

For specimen details and repair methods used in this study, please see Section 4.2.1.1.5. For static flexural testing procedures and results, please see Section 6.3.2.2.4.

\footnotetext{
$\S$ The report of a constant voltage is meaningless when attempting to control or predict the rate of steel mass loss. This is because mass loss is directly related to the amount of current supplied to the steel. Since the resistance in the circuit constantly changes as the beam corrodes, a constant voltage must yield a variable current based on the fundamental equation $I=V / R$. Because of this, the required time reported by Kutarba (2004) to reach a specified mass loss may not be reliable.
} 


\subsubsection{Wang, K., 2006}

Each large-scale reinforced concrete beam was 11'-6" long and had a cross-section of 7.9"x13.8". Tension steel consisted of two \#6 bars, compression steel consisted of two \#4 bars, and shear reinforcement consisted of \#3 bars. Nine beams were constructed using normal-strength concrete $(3,164 p s i)$ and fifteen were made using low-strength concrete $(1,067 p s i)$. The surface of each beam was coated with a conductive material through which an electric current was passed. A diagram of the test specimen can be seen in Figure 6.30.

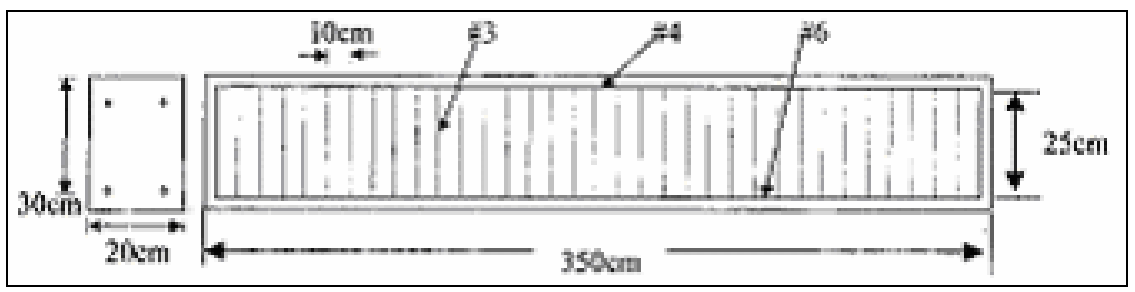

Figure 6.30: Wang, K. (2006) Test Specimen

Table 6.6: Summary of corrosion procedures used in Wang, K. (2006)

Normal-Strength Concrete

\begin{tabular}{|l|c|c|c|c|c|c|c|c|c|c|c|}
\hline \multirow{2}{*}{ Beam Position } & \multicolumn{2}{|c|}{ H-A2-T0 } & \multicolumn{3}{|c|}{ H-A2-ET1U10 } & \multicolumn{3}{c|}{ H-A1-T0 } & \multicolumn{3}{c|}{ H-A1-ET1U10 } \\
\cline { 2 - 13 } & Left & Center & Left & Center & Right & Left & Center & Right & Left & Center & Right \\
\hline $\begin{array}{l}\text { Total corrosion power } \\
\text { (Ah) }\end{array}$ & 5,868 & 9,081 & $\begin{array}{c}1,296- \\
2,792\end{array}$ & 11,538 & $\begin{array}{c}3,003- \\
9,985\end{array}$ & $\begin{array}{c}2,444- \\
10,549\end{array}$ & $\begin{array}{c}1,047- \\
3,145\end{array}$ & $\begin{array}{c}1,863- \\
3,260\end{array}$ & $\begin{array}{c}1,301- \\
3,166\end{array}$ & $\begin{array}{c}1,011- \\
3,864\end{array}$ & 2,700 \\
\hline $\begin{array}{l}\text { Diameter reduction of } \\
\text { number 6 (mm) }\end{array}$ & 1.37 & 2.2 & $\begin{array}{c}0.4- \\
0.7\end{array}$ & 2.8 & $\begin{array}{c}0.7- \\
2.4\end{array}$ & $0.6-2.6$ & $0.2-0.7$ & $0.4-0.7$ & $0.3-0.7$ & $0.2-0.9$ & 0.6 \\
\hline $\begin{array}{l}\text { Diameter reduction of } \\
\text { number 4 (mm) }\end{array}$ & 1.4 & 2.2 & $\begin{array}{c}0.4- \\
0.7\end{array}$ & 2.9 & $\begin{array}{c}0.7- \\
2.5\end{array}$ & $0.6-2.7$ & $0.2-0.7$ & $0.4-0.7$ & $0.3-0.7$ & $0.2-0.9$ & 0.6 \\
\hline $\begin{array}{l}\text { Diameter reduction of } \\
\text { number 3 (mm) }\end{array}$ & 1.4 & 2.3 & $\begin{array}{c}0.4- \\
0.7\end{array}$ & 3.1 & $\begin{array}{c}0.7- \\
2.6\end{array}$ & $0.6-2.8$ & $0.2-0.7$ & $0.4-0.8$ & $0.3-0.7$ & $0.2-0.9$ & 0.6 \\
\hline
\end{tabular}

Low-Strength Concrete

\begin{tabular}{|l|c|c|c|c|c|c|c|c|}
\hline \multirow{2}{*}{ Beam Position } & L-A2-T0 & L-A2-T2U2 & L-A2-T2D10 & L-A1-T0 & \multicolumn{2}{|c|}{ L-A1-T2U2 } & \multicolumn{2}{|c|}{ L-A1-T2D10 } \\
\cline { 2 - 9 } & Center & Center & Center & Center & Center & Right & Center & Right \\
\hline $\begin{array}{l}\text { Total corrosion power } \\
\text { (Ah) }\end{array}$ & 3,201 & 3,083 & 2,715 & 1,107 & 628 & $\begin{array}{c}1,112- \\
5,164\end{array}$ & 1,051 & 583 \\
\hline $\begin{array}{l}\text { Diameter reduction of } \\
\text { number 6 (mm) }\end{array}$ & 0.7 & 0.7 & 0.6 & 0.3 & 0.1 & $0.3-12$ & 0.2 & 0.1 \\
\hline $\begin{array}{l}\text { Diameter reduction of } \\
\text { number 4 (mm) }\end{array}$ & 0.7 & 0.7 & 0.6 & 0.3 & 0.1 & $0.3-1.2$ & 0.2 & 0.1 \\
\hline $\begin{array}{l}\text { Diameter reduction of } \\
\text { number 3 (mm) }\end{array}$ & 0.7 & 0.7 & 0.6 & 0.3 & 0.1 & $0.3-1.2$ & 0.2 & 0.1 \\
\hline
\end{tabular}


When the coating became brittle and began to peel off easily when subjected to a high current, the specimens were partially immersed in fiberglass tanks containing a sodiumchloride solution, and titanium mesh was then used for the cathode. Beams were corroded to two different damage levels using electric current prior to FRP repair. Steel loss results can be seen in Table 6.6.

For specimen details and repair methods used in this study, please see Section 4.2.1.1.4. For static flexural testing procedures and results, please see Section 6.3.2.2.3.

\subsubsection{Grace, 2004}

The sets of beam specimens were exposed for $1,000,3,000$, and 10,000 hours to the following environmental conditions: $100 \%$ humidity, dry heat, alkaline solution, and saltwater solution. The specimens were also exposed to 350 and 700 freeze/thaw cycles and 35 thermal expansion cycles.

Environmental conditioning was administered in 3 stainless steel tanks containing either 100\% humidity (ASTM D2247-02), alkaline solution, or saltwater solution (ASTM C 581, ASTM D1141) (pH 9.5, 1500ppm, SG 1.022). A heating blanket placed under each tank maintained the temperature of the solutions. Pumps in the bottom of the tank continually circulated the water. Dry heat $\left(60^{\circ} \mathrm{C}\right)$ was applied in a specially-designed chamber and according to ASTM D3045. Freeze/thaw cycles (350 and 700 cycles) were applied in a chamber designed according to ASTM C666 Procedure B. The total duration of each freeze/thaw cycle was 4 hours. Thirty-five thermal expansion cycles were 
performed in the same chamber with a maximum temperature of $75.5^{\circ} \mathrm{C}$ and maximum humidity of $100 \%$. Each cycle raised the temperature of the beam to $48.9^{\circ} \mathrm{C}$ and cooled it to $26.7^{\circ} \mathrm{C}$ according to ASTM C531 over a total period of 5 hours.

The $100 \%$ humidity conditioning and freeze/thaw cycling were most successful in deteriorating the beam specimens while dry heat and thermal expansion were the least successful. It is interesting to note that humidity and saltwater conditioning decreased the specimen strength, but the time in which the process was applied had no effect.

For specimen details and repair methods used in this study, please see Section 4.2.1.1.8. For cyclic flexural testing procedures and results, please see Section 6.3.1.2.2. For static flexural testing procedures and results, please see Section 6.3.2.2.7.

\subsubsection{Soudki, 2000}

Accelerated corrosion was induced via an impressed electric current technique. Specimen nomenclature and the accelerated corrosion plan are given in Table 6.7.

Table 6.7: Soudki (2000) specimen nomenclature and accelerated corrosion

\begin{tabular}{|c|c|c|c|c|}
\hline \multicolumn{5}{|c|}{ Corrosion plan } \\
\hline \multirow{2}{*}{$\begin{array}{l}\text { Strengthening } \\
\text { scheme }^{\mathrm{a}}\end{array}$} & \multicolumn{4}{|c|}{ Corrosion level $^{b}$} \\
\hline & $0 \%$ & $5 \%$ & $10 \%$ & $15 \%$ \\
\hline No wrap & $\mathrm{N}-0$ & $\mathrm{~N}-5$ & $\mathrm{~N}-10$ & $\mathrm{~N}-15$ \\
\hline \multirow{2}{*}{ CFRP wrapped } & $\mathrm{CF}-0$ & $\mathrm{CF}-5$ & CF-10 & CF-15 \\
\hline & CF-S- $0^{\mathrm{C}}$ & & CF-S- $10^{\mathrm{c}}$ & \\
\hline \multicolumn{5}{|c|}{$\begin{array}{l}\text { a } \mathrm{N}=\text { no CFRP strengthening; } \mathrm{CF}=\text { continuous + flexural CFRP strengthening scheme. } \\
{ }^{\mathrm{b}} \text { Corrosion level in percent mass loss. } \\
{ }^{\mathrm{c}} \text { Specimens constructed with no stirrups. }\end{array}$} \\
\hline
\end{tabular}


One $1 / 4$ " diameter stainless steel bar was cast into the concrete above the tension steel to act as the cathode in the accelerated corrosion process. The bottom third depth of the concrete contained $3 \%$ chloride ions by weight of cement. Specimens were placed in a tank with a small amount of water in the bottom. The tank was covered and sealed to ensure a high-humidity environment of between 75 and $95 \%$. A current density of $140 \mu \mathrm{A} / \mathrm{cm}^{2}$ was applied to the beams for a period of 84 days. This current density corresponded to a theoretically predicted mass loss of $15 \%$. A schematic of the accelerated corrosion setup can be seen in Figure 6.31. Less corrosion was observed in the FRP-strengthened specimens than in the unrepaired specimens.

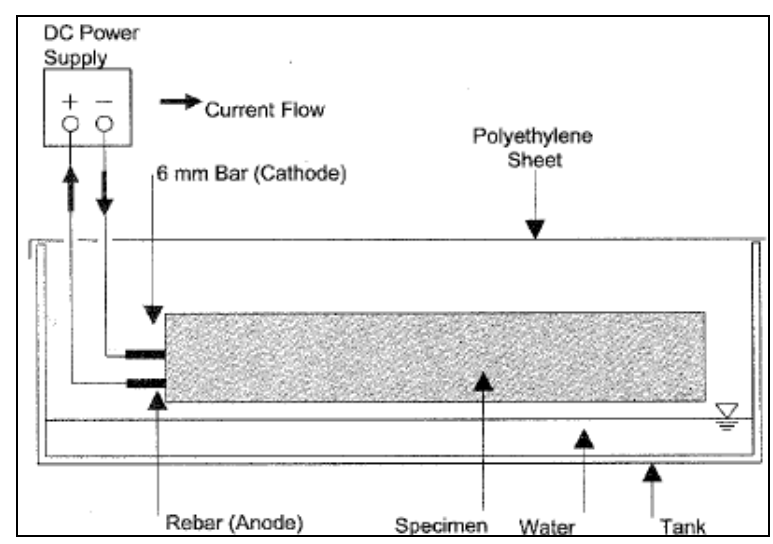

\section{Figure 6.31: Schematic of Soudki (2000) accelerated corrosion setup}

For specimen details and repair methods used in this study, please see Section 4.2.1.2.1. For crack measurement results, please see Section 6.2.1.2.3. For static flexural testing procedures and results, please see Section 6.3.2.2.8. 


\subsubsection{Austin, 20003}

In this research, prism specimens were subjected to accelerated corrosion via induced electrical current. A constant current of $100 \mu \mathrm{A} / \mathrm{cm}^{2}$, which is the maximum reported current density found in corroding structures in the field, was applied to the steel reinforcement. Austin's (2003) results indicate that the corrosion in his experiment replicated the corrosion found in real structures. He observed that, just as in natural corrosion, the corrosion process initiated at only a small number of localized areas on the reinforcement.

\subsubsection{Suggestions for Improvement}

Even for the Part II beams, small localized areas of corrosion were observed on the shear reinforcing steel at the areas of contact between the tension steel and the stirrups. Recall that two coats of Sikagard 62 were applied professionally to the steel stirrups prior to placement. Corrosion of the stirrups is undesirable since the electric current is intended to flow only through the tension steel. It is likely that, even though electrical tape was wrapped around contact points and care was taken to protect the coating during rebar cage assembly, small areas of the epoxy were scraped and slightly damaged. Therefore, additional measures should be taken to prevent mechanical damage to the rebar coatings. One suggestion is to develop a new jig system for assembling the cages. An ideal jig would hold all the steel stirrups firmly in place at the desired spacing. The inner circumference of each steel stirrup should be temporarily covered, and the longitudinal bars should be inserted through the center of the stirrup arrangement. Once the longitudinal bars are placed at their desired locations, the covering could be removed and 
the cages could be tied, thus prohibiting any contact between steel components until all bars were in place.

\begin{abstract}
Although most corrosion product observed in this experiment was in the form of expansive rust, some "green" corrosion was observed. Remember that "green" corrosion indicates a lack of oxygen at the steel reinforcement level. To prevent the formation of green rust, longer or more frequent dry cycles should be introduced to the accelerated aging process.
\end{abstract}

Another very interesting addition would be to designate several beams for corrosion rate monitoring. Perhaps steel could be extracted from these beams and examined at weekly intervals. A corrosion rate histogram could then be constructed to predict corrosion levels for future work.

Since freeze/thaw cycling is such a major component of reinforced concrete bridge deterioration in cold climates like in Pennsylvania or West Virginia, it would be a very practical and necessary addition to future research. The effects of wet/dry cycling and the inclusion variable temperature also need to be studied.

Lastly, it would be interesting to design beam specimens varying in size. By subjecting these beams to accelerated corrosion for the same amount of time and then examining the steel, it could be determined whether specimen size plays a significant role in the corrosion rate. 


\subsection{Non-Destructive Testing Results}

\subsubsection{Crack Measurement}

\subsubsection{Results}

Crack widths and lengths were measured at least once per week on all beams in this experiment. This, of course, resulted in massive amounts of data. To report all this data, even in an appendix, would be beyond the scope of this project. This data can be used in the future, however, to model the corrosion and cracking process in reinforced concrete. It was determined that, since this project focuses on reinforced concrete repair, the final crack patterns, lengths, and widths were most important. A brief summary of observed cracking is presented here, additional information is provided within the accelerated aging results section, and exact final crack drawings (including major crack widths) are provided for each beam in Appendix C. This final crack data may be similar to what a bridge inspector would record during the preliminary qualitative stages in determining a bridge's candidacy for repair.

\subsection{Part I}

Table 6.8 displays a summary of the cracking damage observed on each Part I beam specimen after each corrosion cycle. The maximum crack width on each beam and the faces on which major cracks were present are listed in this table. Typically, at least one horizontal crack extended over the entire length of each beam. Individual crack drawings for each beam are provided in Appendix C. 
The maximum crack width observed on mildly corroded Beams I-1 and I-2 ranged between only 0.5 and $0.6 \mathrm{~mm}$. The maximum crack width after the first corrosion cycle widely ranged between 1.2 and $5.0 \mathrm{~mm}$, although mass losses were very similar. Maximum crack width after the second corrosion cycle also varied greatly between 3.0 and $6.0 \mathrm{~mm}$. Crack patterns, however, were very similar on all beams. These results suggest that no correlation between crack width and mass loss can be made in this work.

Primary cracking occurred on all three primary faces (left face, right face, and tension face) of the beam for most specimens. The widest crack on each beam almost always occurred near the midspan instead of the ends, probably due to the extra confinement provided by the stirrups in the shear regions. Most Part I beams subjected to the first corrosion cycle had between one and three primary flexure cracks that ran parallel to the longitudinal axis, and usually the number of primary cracks on a single beam face was limited to one. After the second corrosion cycle, there were occasionally multiple primary cracks per single beam face. For all Part I beams, webbed cracks were present within 1' of the beam ends, almost certainly as a result of the corroding anchor stirrups. Please refer to the accelerated aging results for more detailed information on cracking, as the two topics are concurrent.

It would be irresponsible to attempt to conclude how each repair technique affected crack width since only one specimen of each repair type was subjected to additional corrosion. Localized corrosion cells, among other variables, could affect the crack widths observed 
on these beams. More specimens using each repair techniques should be tested in the future to study the correlation between repair method and crack widths. It should also be noted that crack width cannot be directly related to mass loss.

Table 6.8: Part I Cracking Summary

\begin{tabular}{|c|c|c|}
\hline & $\begin{array}{c}\text { Maximum } \\
\text { Crack } \\
\text { Width } \\
(\mathrm{mm})\end{array}$ & $\begin{array}{c}\text { Face Containing } \\
\text { Primary Cracks }\end{array}$ \\
\hline \multicolumn{3}{|c|}{ After Mild Corrosion Cycle } \\
\hline 1 & 0.6 & Tension, Left \\
\hline 2 & 0.5 & Right, Tension, Left \\
\hline \multicolumn{3}{|c|}{ After First Corrosion Cycle } \\
\hline 5 & 5.0 & Right, Tension, Left \\
\hline 7 & 1.2 & Right, Tension, Left \\
\hline 10 & 2.5 & Right, Tension, Left \\
\hline 6 & 2.0 & Tension \\
\hline 8 & 3.0 & Right, Tension, Left \\
\hline 9 & 2.6 & Right, Tension, Left \\
\hline \multicolumn{3}{|c|}{ After Second Corrosion Cycle } \\
\hline 6 & 6.0 & Right, Tension, Left \\
\hline 8 & 5.0 & Right, Left \\
\hline 9 & 3.0 & Right, Left \\
\hline
\end{tabular}

\subsection{Part II}

Table 6.9 displays a summary of the final cracking observed on each Part II beam specimen. The maximum crack width found on each beam and the faces on which primary cracks were present are listed in this table. Typically, at least one horizontal crack spanned the entire length of each beam. Individual crack drawings for each beam are provided in Appendix C. 
The cracking observed on the beam specimens was much more uniform for Part II than it was for Part I. With the exception of Beam II-4, all maximum crack widths were between 4.0 and $5.0 \mathrm{~mm}$. With the exception of only four beams, all cracking in Part II was confined to the tension face of the beam specimen. Please refer to the accelerated aging results section for more detailed information on cracking since the two topics are concurrent.

Table 6.9: Part II Cracking Summary

\begin{tabular}{|c|c|c|}
\hline Beam & $\begin{array}{c}\text { Maximum } \\
\text { Crack } \\
\text { Width } \\
(\mathrm{mm})\end{array}$ & $\begin{array}{c}\text { Face Containing } \\
\text { Primary Cracks }\end{array}$ \\
\hline 3 & 4.5 & Tension \\
\hline 4 & 3.0 & Right, Tension, Left \\
\hline 5 & 4.5 & Right, Tension \\
\hline 7 & 5.0 & Tension \\
\hline 8 & 5.0 & Tension \\
\hline 9 & 5.0 & Right, Tension \\
\hline 13 & 4.5 & Tension \\
\hline 14 & 5.0 & Tension \\
\hline 15 & 4.0 & Tension \\
\hline 17 & 5.0 & Tension \\
\hline 18 & 4.5 & Tension \\
\hline 19 & 4.5 & Tension \\
\hline 20 & 4.5 & Right, Tension \\
\hline 21 & 5.0 & Tension \\
\hline 22 & 4.0 & Tension \\
\hline 23 & 4.5 & Tension \\
\hline 24 & 4.0 & Tension \\
\hline
\end{tabular}

\subsubsection{Comparison to Literature}

\subsection{Maddaawy, 2005}

Steel coupons were extracted from the maximum moment region of each specimen. The coupons were cleaned and weighed to determine the extents of corrosion, which are seen 
in Table 6.4. Maximum crack width for the first group was $0.9 \mathrm{~mm}$. Maximum crack widths for the second group were 1.1, 1.4, 2.5, and 3.1 $\mathrm{mm}$ for 9.6, 15.6, 23.3, and $30.5 \%$ steel mass loss, respectively. Three typical corrosion crack patterns were observed. Most resembled pattern A.

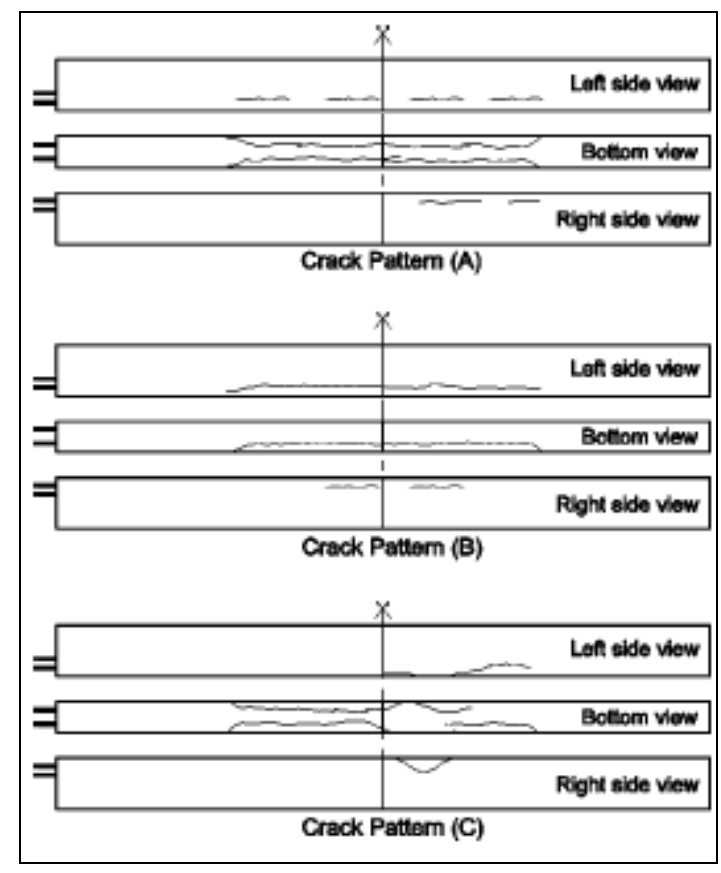

Figure 6.32: Typical crack patterns caused by corrosion (Maddaawy, 2005)

For specimen details and repair methods used in this study, please see Section 4.2.1.1.1. For accelerated aging information, please see Section 6.1.2.2. For static flexural testing procedures and results, please see Section 6.3.2.2.1.

\subsection{Masoud, 2005 \& Masoud, 2006}

The important crack measurement finding provided was that cracks up to $1 \mathrm{~mm}$ in width were observed. 
For specimen details and repair methods used in this study, please see Section 4.2.1.1.3.

For accelerated aging information, please see Section 6.1.2.3. For cyclic flexural testing procedures and results, please see Section 6.3.1.2.1.

\subsection{Soudki, 2000}

In the unrepaired specimens, continuous longitudinal cracks with widths up to $1.0 \mathrm{~mm}$ formed at the location of the tension steel and extended over the length of the specimen. Some additional cracks were present along the sides of the beams, possibly due to the small scale of the beam specimens. The corrosion products also stained the concrete. No spalling or delamination occurred.

On FRP-strengthened specimens, some cracking was observed along the cross-section, but the maximum crack width was only $0.3 \mathrm{~mm}$. The FRP laminates prevented visual observation of the tension faces and sides of the beam specimens. However, after load testing the beams, it was discovered that longitudinal cracking patterns (similar to those observed on the unstrengthened specimens) spanned the length of the beams.

Strain gages were placed on the FRP to record tensile strains due to the expansive corrosion products. Figure 6.33 shows the extent of expansion observed in four of the strengthened specimens. This figure shows that there was a nonlinear relationship between the degree of corrosion and expansive strain. Specimen CF-S-10 was constructed without steel stirrups. It can be seen that, without the restraint from the steel, 
the expansive forces are much higher. At the maximum 15\% corrosion level, the maximum recorded strain was only $36 \%$ of the FRP's strain capacity.

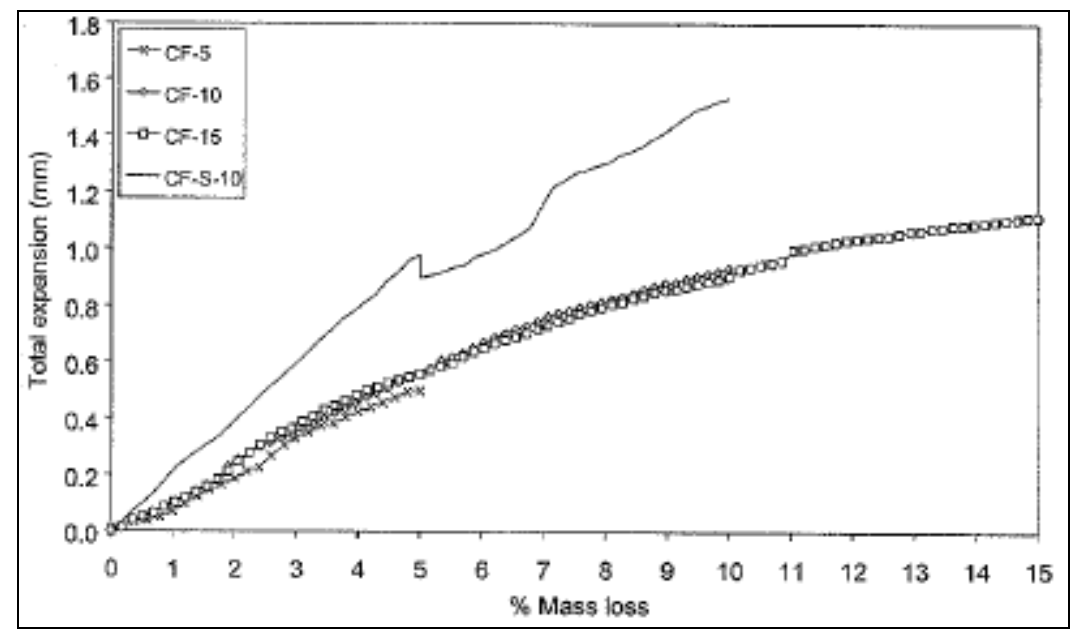

Figure 6.33: Total expansion in the transverse laminate due to corrosion for Soudki (2000) test specimens CF-5, CF-10, CF-S-10 and CF-15

For specimen details and repair methods used in this study, please see Section 4.2.1.2.1. For accelerated aging information, please see Section 6.1.2.8. For static flexural testing procedures and results, please see Section 6.3.1.2.8.

\subsection{Andrade, 1993}

In this research, cracking of reinforced concrete prism specimens (containing \#5 rebar) subjected to accelerated aging via electric current was studied. Andrade concluded that concrete may crack (0.05-0.1 $\mathrm{mm}$ width), even with a negligible loss of bar cross section. The crack widths grew relatively slowly until they reached a maximum of $0.3 \mathrm{~mm}$. Andrade determined that the appearance of cracks in carbonated concrete did not necessarily represent an increase in corrosion rate and total mass loss. He suggested that, 
when cracks measuring $0.3-0.4 \mathrm{~mm}$ in width are observed in chloride-contaminated concrete, a severe risk of localized pitting corrosion is present within the structure.

\subsubsection{Suggestions for Improvement}

Crack lengths and widths were measured up to three times a week for some beams in this experiment. However, due to the large number of beam specimens, the large quantity of cracks, and the substantial amount of data, detailed information from these incremental crack measurements are not provided in this document. The data will be useful, however, in future studies dealing with accelerated corrosion.

\subsubsection{Half-Cell Potential}

\subsubsection{Results}

The most reliable set of data obtained from the half-cell potential readings is that at time 0 hours. These readings were taken between 30 and 40 days after the beam specimens were cast and immediately before the power supplies were turned on for the first time. As can be seen in Table 6.10, the average potential recorded for all seven beams tested was $-463 \mathrm{mV}$ with a range of only $39 \mathrm{mV}$ (please refer to Table 5.5 , which provides information on interpreting half-cell potential readings). Note that a value of $-493 \mathrm{mV}$ indicates that a high risk of corrosion already existed within the beams' reinforcing steel. This is reasonable since the beam was intentionally contaminated with chloride and had been cured under wet burlap for 28 days. Although the corrosion risk was high, the extent of corrosion at this time was likely relatively low. 
After just 168 hours of induced electric current, half-cell potential readings averaging $593 \mathrm{mV}$ with a range of only $41 \mathrm{mV}$ were obtained. This indicates a severe risk of corrosion, which was expected due to the accelerated corrosion process. Readings taken at 294, 462, and 622 hours also fell within this high-to-severe risk zone.

Table 6.10: Average Half-cell potential readings for Part I Test specimens

\begin{tabular}{|c|c|c|c|c|c|c|c|c|c|}
\hline $\begin{array}{l}\text { ⿳亠口 } \\
\text { ㄷ }\end{array}$ & $\begin{array}{l}\bar{\varepsilon} \\
\overline{\mathbb{E}} \\
\stackrel{\Phi}{\infty}\end{array}$ & $\begin{array}{l}\mathbb{N} \\
\mathcal{E} \\
\mathbb{\Phi} \\
\Phi\end{array}$ & $\begin{array}{c}10 \\
\mathcal{E} \\
\mathbb{\Phi} \\
\mathbb{\infty}\end{array}$ & $\begin{array}{l}\hat{\Sigma} \\
\varepsilon \\
\mathbb{\Phi} \\
\mathbb{D} \\
\infty\end{array}$ & 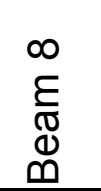 & 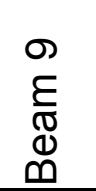 & $\begin{array}{l}\text { 으 } \\
\varepsilon \\
\mathbb{\Phi} \\
\Phi \\
\infty\end{array}$ & 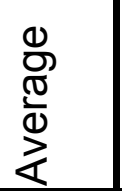 & 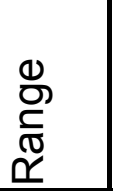 \\
\hline$\overline{0}$ & -461 & -473 & -454 & -488 & -456 & $-\overline{-449}$ & -461 & -463 & 3 \\
\hline 168 & $-5 !$ & 503 & -609 & -599 & -5 & & -57 & & 41 \\
\hline 294 & -54 & -562 & -554 & -566 & -586 & -564 & -554 & -56 & 41 \\
\hline 462 & -459 & -481 & -507 & -496 & -522 & -493 & -481 & -49 & 64 \\
\hline 622 & -502 & -525 & -548 & -555 & -549 & -521 & -506 & -529 & 53 \\
\hline 782 & -376 & -425 & -453 & -476 & -414 & -372 & -413 & -418 & 104 \\
\hline$\overline{934}$ & -424 & -463 & -467 & -547 & -447 & -419 & -438 & -458 & 128 \\
\hline 1,097 & -324 & -340 & -389 & -537 & -454 & -367 & -354 & -395 & 213 \\
\hline 2,354 & - & - & -397 & -334 & -283 & -504 & -269 & -357 & 235 \\
\hline 2,467 & & & & -455 & -411 & -358 & -330 & -388 & 126 \\
\hline
\end{tabular}

As can be seen in the data obtained at hours 622 and beyond, half-cell potential readings appear to become quite arbitrary. The average values tend to decrease, which would indicate that the corrosion risk is lessening. The range of values expanded between 622 and 2,354 hours, and then decreased in the last testing interval at 2,467 hours. This is obviously not a logical conclusion since visual observations of the beam indicated that the corrosion was becoming more severe. The most likely explanation is that at this time, significant deposits of corrosion product formed and jacketed the steel reinforcement. Simultaneously, cracks in the concrete cover layer began to form and grow. As a result of these two occurrences, the electric connectivity between the half-cell, concrete cover 
layer, and steel reinforcement was probably significantly reduced, resulting in consistently lower potential values as time increased. The mass loss can be seen for Beams I-1 and I-2 at time $\approx 2,500$ hours in Figure 6.1. The average mass loss of about $6.2 \%$ shows that significant corrosion was indeed occurring withing the reinforcing steel.

\subsubsection{Suggestions for Improvement}

An improvement to the half-cell potential testing conducted in this experiment would be to stop the accelerated aging process multiple times per day for the first several days of accelerated aging. Since the first readings (after the ones at time 0) weren't taken until seven days after the accelerated aging process begun, the probability of corrosion was already in the severe region by hour 168 . If readings were taken at short intervals during the first week, a more meaningful corrosion-risk timeline could be constructed.

Another interesting addition would be to make extra samples and break one open after each set of readings was taken to observe the actual condition of the steel and to see if it corresponds whit is indicated by the half-cell readings.

\subsubsection{Rebound Hammer (ASTM C 805-02)}

\subsubsection{Results}

\subsection{Part I}

Table 6.11 provides a summary of the rebound hammer testing results obtained in Part I. Eight rebound hammer readings were taken at each location shown in Figure 5.49, and 
these individual values can be seen in Appendix D. Next, in the tables of Appendix D, these 8 values were averaged at each location. This average value was the rebound number for that location. Therefore, totals of six readings were taken at a height of 1.5" above the tension face and six readings were taken at a height of 5.5" above the tension face of each beam. It should be noted that, for FRP-repaired beams, polymer-modified repair concrete was present at a height of 1.5 " and deteriorated concrete was present at a height of 5.5". There were three sets of vertical inverted readings taken on the tension face of each beam without FRP (listed in the "Compression Face" column). The "Average" columns in Table 6.11 show the average rebound number at each respective height above the compression face. The "Range" columns show the range of these sets of rebound numbers. The rightmost column presents a "corrected" rebound number for the vertical inverted readings taken on the compression face of the beam by interpolating between points in Figure 6.34 (Figure 6.34 shows the rebound hammer calibration curves provided by Proceq and their polynomial equations). This "correction" was made by first plugging the vertical inverted rebound number into the polynomial equation for vertical inverted readings, by next setting the polynomial equations for horizontal and vertical inverted readings equal to each other, and by finally solving the system for " $\mathrm{x}$ ". This "correction" made the horizontal and vertical inverted rebound numbers compatible for comparison purposes.

Also presented in Table 6.11 is the average and range of the rebound numbers at each vertical location for each set of similar beams (highlighted in beige). These rebound 
hammer readings can be used to compare the quality of the pristine, the deteriorated, and the polymer-modified patch repair concretes.

Table 6.11: Summary of Rebound Numbers for Part I Beams

\begin{tabular}{|c|c|c|c|c|c|c|c|c|}
\hline Description & Beam & $\begin{array}{c}\text { Average } \\
@ 1.5^{\prime \prime} \\
\text { Height }\end{array}$ & $\begin{array}{c}\text { Range @ } \\
1.5^{\prime \prime} \\
\text { Height }\end{array}$ & $\begin{array}{c}\text { Average } \\
@ 5.5 " \\
\text { Height }\end{array}$ & $\begin{array}{c}\text { Range @ } \\
5.5 " \\
\text { Height }\end{array}$ & $\begin{array}{c}\text { Average } \\
@ \text { Comp. } \\
\text { Face }\end{array}$ & $\begin{array}{c}\text { Range @ } \\
\text { Comp. } \\
\text { Face }\end{array}$ & $\begin{array}{c}\text { Corrected } \\
\text { to } \\
\text { Compare } \\
\text { to Horiz. }\end{array}$ \\
\hline \multirow{4}{*}{ Corroded Unrepaired } & 1 & 29 & 8 & 29 & 7 & 34 & 1 & 29 \\
\hline & 2 & 33 & 6 & 30 & 8 & 37 & 7 & 32 \\
\hline & Average & \multicolumn{2}{|c|}{31} & \multicolumn{2}{|c|}{29} & \multicolumn{2}{|c|}{$\frac{1}{35}$} & 31 \\
\hline & Range & \multicolumn{2}{|c|}{4} & \multicolumn{2}{|c|}{1} & \multicolumn{2}{|c|}{3} & 3 \\
\hline \multirow{4}{*}{1 - Corrosion Control } & 17 & 32 & 1 & 30 & 4 & 38 & 1 & 33 \\
\hline & 18 & 30 & 3 & 30 & 4 & 36 & 3 & 31 \\
\hline & Average & \multicolumn{2}{|c|}{31} & \multicolumn{2}{|c|}{30} & \multicolumn{2}{|c|}{$\frac{1}{37}$} & 32 \\
\hline & Range & \multicolumn{2}{|c|}{2} & \multicolumn{2}{|c|}{0} & \multicolumn{2}{|c|}{2} & 2 \\
\hline \multirow{4}{*}{2 - Corrosion Control } & 13 & 29 & 6 & 28 & 5 & 32 & 2 & 27 \\
\hline & 14 & 29 & 8 & 29 & 5 & 32 & 0 & 27 \\
\hline & Average & \multicolumn{2}{|c|}{$\frac{1}{29}$} & \multicolumn{2}{|c|}{28} & \multicolumn{2}{|c|}{$\frac{1}{32}$} & 27 \\
\hline & Range & \multicolumn{2}{|c|}{0} & \multicolumn{2}{|c|}{1} & \multicolumn{2}{|c|}{1} & 1 \\
\hline Add. Corr. Unrepaired & 6 & 27 & 15 & 28 & 9 & 31 & 5 & 26 \\
\hline \multirow{2}{*}{$\begin{array}{c}\text { After Initial Corrosion } \\
\text { Process }\end{array}$} & 7 & 35 & 9 & 26 & 4 & \multicolumn{3}{|c|}{ with Patch Repair } \\
\hline & 10 & 26 & 4 & 31 & 4 & \multicolumn{3}{|c|}{ w/out Patch Repair } \\
\hline \multirow{2}{*}{$\begin{array}{l}\text { After Secondary } \\
\text { Corrosion Process }\end{array}$} & 8 & 33 & 7 & 24 & 10 & \multicolumn{3}{|c|}{ with Patch Repair } \\
\hline & 9 & 28 & $\overline{6}$ & 29 & $\overline{8}$ & \multicolumn{3}{|c|}{ w/out Patch Repair } \\
\hline
\end{tabular}

The rebound numbers indicate that the concrete quality for beams I-1, I-2, I-17, I-18, I-13 and I-14 were all very similar. This could be expected when comparing the Beams I-1 and I-2 to the pristine samples since no significant deterioration was observed as a result of the mild corrosion. These results also indicate that the quality of concrete in the uncorroded beams did not change significantly over time.

Beams I-7 and I-8 were patched with polymer concrete in the tension zone (@ 1.5" height). As expected, the rebound numbers obtained from the polymer patch concrete were much higher than those obtained from the poor-quality normal concrete. 
Interestingly, the rebound numbers for corroded unrepaired beam I-6 were only slightly less than the rebound numbers obtained for the normal concrete in both the control and repaired beams. Visual observation of the significantly deteriorated quality concrete led to the expectation that rebound numbers would be significantly lower. This further indicates that rebound number should not be solely relied upon as an accurate means of assessing concrete quality and strength. Do notice, though, how the ranges for each set of 8 readings for beam I-6 concrete are very high. This signifies highly localized differences in concrete quality.

Also notice how, for corroded beams without patch repair (I-1, I-2, I-6, I-7, and I-8), similar values were obtained at both the level of tension reinforcement and in the compression zone. This could also be expected since the shear stirrups were actively corroding and damaging the concrete "uniformly" over the entire depth of the beam

Table 6.14 compares the concrete strength estimated from the rebound numbers to the actual concrete strength obtained from compression cylinder testing. It can be seen that, for all beam specimens except Beam I-18, the calibration information in Figure 6.34 significantly underestimates the actual normal concrete compressive strength by an average of 934 psi and by a maximum of 2,326psi for Beam I-8. The rebound hammer data grossly underestimated the compressive strength of the polymer-modified repair concrete by values of 6,211 and 6,543psi for Beams I-7 and I-8, respectively. These considerable differences are common when using the calibration data supplied by a rebound hammer manufacturer. Because of these differences, it is strongly recommended 
by Malhotra (2004) to cast prism specimens with different compressive strengths within the range of the actual concrete being studied. By recording the rebound numbers obtained from these prism samples and fitting a curve to the results, a self-calibration of the rebound hammer can be achieved. The homemade curve can then be used to more accurately predict the compressive strength of the concrete under examination.

These estimated strengths, when compared to the actual strengths, show that the calibration data provided by Proceq was very conservative. These findings reinforce the fact that the rebound hammer is a tool for comparing concrete quality and not for obtaining its material properties.

Table 6.12: Comparison of concrete strength estimated by the rebound hammer to actual concrete strength for Part I Beams

\begin{tabular}{|c|c|c|c|c|c|c|c|c|c|}
\hline Description & $\begin{array}{l}E \\
\widetilde{\Phi} \\
\Phi \\
\mathscr{D} \\
\end{array}$ & 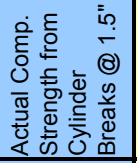 & 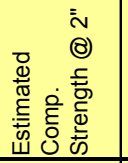 & 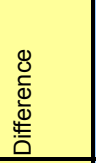 & 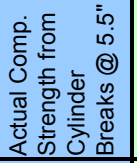 & 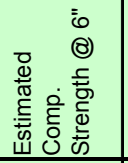 & 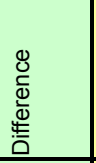 & 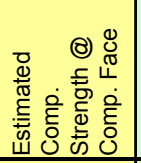 & 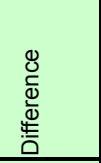 \\
\hline \multirow{4}{*}{ Corroded Unrepaired } & 1 & 3,495 & 2,337 & $-1,158$ & 3,495 & 2,257 & $-1,238$ & 2,318 & $-1,177$ \\
\hline & 2 & 3,515 & 2,985 & -530 & 3,515 & 2,468 & $-1,047$ & 2,874 & -641 \\
\hline & Avg. & 3,505 & 2,661 & -844 & 3,505 & 2,363 & $-1,142$ & 2,596 & -909 \\
\hline & Range & 20 & 648 & 628 & 20 & 211 & 191 & 557 & 537 \\
\hline \multirow{4}{*}{1 - Corrosion Control } & 17 & 3,634 & 2,848 & -786 & 3,634 & 2,519 & $-1,115$ & 3,020 & -614 \\
\hline & 18 & 3,581 & 2,471 & $-1,110$ & 3,581 & 2,471 & $-1,110$ & 2,674 & 3,784 \\
\hline & Avg. & 3,608 & 2,660 & -948 & 3,608 & 2,495 & $-1,113$ & 2,847 & 1,585 \\
\hline & Range & 53 & 377 & 324 & 53 & 47 & 6 & 346 & 4,398 \\
\hline \multirow{4}{*}{2 - Corrosion Control } & 13 & 3,860 & 2,277 & $-1,583$ & 3,860 & 2,188 & $-1,672$ & 2,066 & $-1,794$ \\
\hline & 14 & 3,769 & 2,260 & $-1,509$ & 3,769 & 2,270 & $-1,499$ & 1,986 & 3,494 \\
\hline & Avg. & 3,815 & 2,269 & $-1,546$ & 3,815 & 2,229 & $-1,585$ & 2,026 & 850 \\
\hline & Range & 91 & 17 & 74 & 91 & 83 & 174 & 80 & 5,288 \\
\hline Add. Corr. Unrepaired & 6 & 3700 & 2,031 & $-1,669$ & 3,634 & 2,231 & $-1,403$ & 1,886 & $-1,814$ \\
\hline \multirow{2}{*}{$\begin{array}{c}\text { After Initial Corrosion } \\
\text { Process } \\
\end{array}$} & 7 & 9,563 & 3,352 & $-6,211$ & 3,249 & 1,873 & $-1,376$ & \multicolumn{2}{|c|}{ with Patch Repair } \\
\hline & 10 & 3,846 & 1,861 & $-1,985$ & 3,846 & 2,662 & $-1,184$ & \multicolumn{2}{|c|}{ w/out Patch Repair } \\
\hline \multirow{2}{*}{$\begin{array}{c}\text { After Secondary } \\
\text { Corrosion Process }\end{array}$} & 8 & 9,563 & 3,020 & $-6,543$ & 3,846 & 1,520 & $-2,326$ & \multicolumn{2}{|c|}{ with Patch Repair } \\
\hline & 9 & 3,780 & 2,129 & $-1,651$ & 3,780 & 2,394 & $-1,386$ & \multicolumn{2}{|c|}{ w/out Patch Repair } \\
\hline
\end{tabular}




\subsection{Part II}

Table 6.13 provides a summary of the rebound hammer testing results obtained in Part II of the experiment. Eight rebound hammer readings were taken at each location shown in Figure 5.50 or Figure 5.51, and these individual values can be seen in Appendix D. Next, in the Appendix D tables, these 8 values were averaged at each location, and this average is the rebound number at that location. Therefore, there were totals of six readings taken at a height of 1.5 " above the tension face and six readings taken at a height of 5.5" above the tension face on each beam. It should be noted that, for FRP-repaired beams, polymer patch repair concrete was present at a height of 1.5 " and the remaining deteriorated concrete was present at a height of 5.5". There were three sets of vertical inverted readings taken on the tension face of each beam without FRP (listed in the "Compression Face" column). The "Average" columns in Table 6.13 show the average rebound number at each respective height above the compression face. The "Range" columns show the range of these sets of rebound numbers. The rightmost column presents a "corrected" rebound number for the vertical inverted readings taken on the compression face of the beam by interpolating between points in Figure 6.34 (Figure 6.34 shows the rebound hammer calibration curves provided by Proceq and their polynomial equations). Refer to the section discussing Part I rebound hammer data for an explanation of how this correction was derived. Also presented in Table 6.13 is the average and range of the rebound numbers at each vertical location for each set of duplicate beams (highlighted in beige). These rebound hammer readings can be used to compare the quality of the pristine, the deteriorated, and the polymer patch repair concrete. 
Table 6.13: Summary of Rebound Numbers for Part II Beams

\begin{tabular}{|c|c|c|c|c|c|c|c|c|}
\hline Group & Beam & $\begin{array}{c}\text { Average } \\
\text { @ 1.5" } \\
\text { Height }\end{array}$ & $\begin{array}{c}\text { Range @ } \\
1.5^{\prime \prime} \\
\text { Height }\end{array}$ & $\begin{array}{c}\text { Average } \\
\text { @ 5.5" } \\
\text { Height }\end{array}$ & $\begin{array}{c}\text { Range @ } \\
5.5^{\prime \prime} \\
\text { Height }\end{array}$ & $\begin{array}{c}\text { Average } \\
@ \text { Comp. } \\
\text { Face }\end{array}$ & $\begin{array}{c}\text { Range @ } \\
\text { Comp. } \\
\text { Face }\end{array}$ & $\begin{array}{c}\text { Corrected } \\
\text { to } \\
\text { Compare } \\
\text { to Horiz. }\end{array}$ \\
\hline \multirow{4}{*}{ 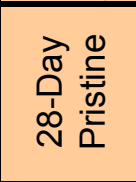 } & 1 & 19 & 5 & 17 & 3 & 27 & 5 & 22 \\
\hline & 2 & 17 & 3 & 16 & 3 & 37 & 7 & 33 \\
\hline & Average & \multicolumn{2}{|c|}{18} & \multicolumn{2}{|c|}{16} & \multicolumn{2}{|c|}{32} & 27 \\
\hline & Range & \multicolumn{2}{|c|}{2} & \multicolumn{2}{|c|}{1} & \multicolumn{2}{|c|}{10} & 11 \\
\hline \multirow{4}{*}{ 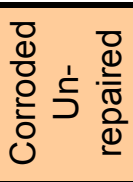 } & 3 & 26 & 1 & 29 & 2 & 32 & 1 & 27 \\
\hline & 4 & 27 & 3 & 30 & 3 & 35 & 4 & 30 \\
\hline & Average & \multicolumn{2}{|c|}{27} & \multicolumn{2}{|c|}{30} & \multicolumn{2}{|c|}{33} & 28 \\
\hline & Range & \multicolumn{2}{|c|}{1} & \multicolumn{2}{|c|}{2} & \multicolumn{2}{|c|}{3} & 3 \\
\hline \multirow{4}{*}{ 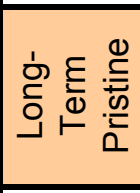 } & 11 & 23 & 2 & 22 & 4 & 30 & 2 & 25 \\
\hline & 12 & 18 & 9 & 17 & 5 & 32 & 2 & 27 \\
\hline & Average & \multicolumn{2}{|c|}{21} & \multicolumn{2}{|c|}{20} & \multicolumn{2}{|c|}{31} & 26 \\
\hline & Range & \multicolumn{2}{|c|}{5} & \multicolumn{2}{|c|}{5} & \multicolumn{2}{|c|}{2} & 2 \\
\hline \multirow{7}{*}{ 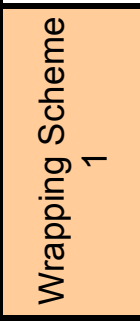 } & 5 & 35 & 4 & 26 & 12 & & & \\
\hline & 8 & 34 & 5 & 28 & 2 & & & \\
\hline & 9 & 35 & 7 & 25 & 4 & & & \\
\hline & 7 & 35 & 4 & 26 & 3 & & & \\
\hline & 14 & 35 & 3 & 24 & 3 & & & \\
\hline & Average & \multicolumn{2}{|c|}{35} & \multicolumn{2}{|c|}{26} & & & \\
\hline & Range & \multicolumn{2}{|c|}{1} & \multicolumn{2}{|c|}{4} & & & \\
\hline \multirow{7}{*}{ 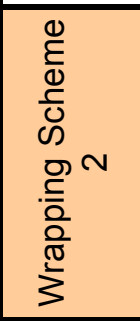 } & 13 & 34 & 4 & 23 & 3 & & & \\
\hline & 15 & 36 & 6 & 21 & 5 & & & \\
\hline & 17 & 34 & 7 & 23 & 3 & & & \\
\hline & 18 & 36 & 3 & 21 & 3 & & & \\
\hline & 20 & 35 & 5 & 26 & 5 & & & \\
\hline & Average & \multicolumn{2}{|c|}{35} & & 23 & & & \\
\hline & Range & & 3 & & 5 & & & \\
\hline$\stackrel{0}{\varepsilon}$ & 21 & 38 & 3 & 27 & 5 & & & \\
\hline$\frac{c}{0}$ & 22 & 38 & 7 & 24 & 6 & & & \\
\hline 등 & 24 & 36 & 3 & 25 & 3 & & & \\
\hline o & 19 & 36 & 2 & 23 & 4 & & & \\
\hline 등 & 23 & 39 & 3 & 26 & 5 & & & \\
\hline 윤 & Average & & 37 & & 25 & & & \\
\hline 3 & Range & & 4 & & 4 & & & \\
\hline
\end{tabular}




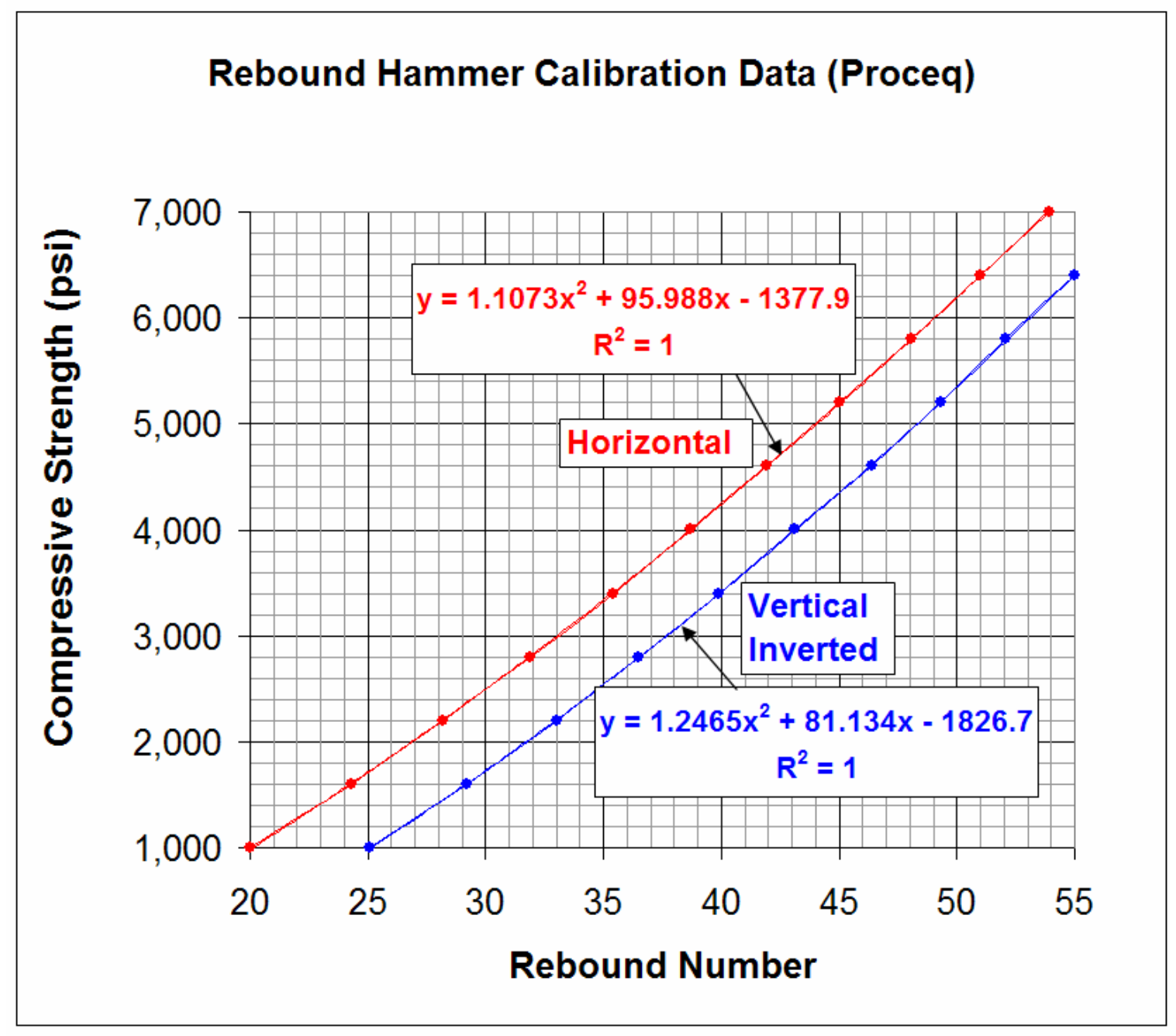

Figure 6.34: Rebound hammer calibration data provided by Proceq

As was originally desired, the average quality of each type of concrete was consistent. The polymer-modified concrete (at a height of 1.5 " above the tension face) yielded rebound numbers of 35, 35, and 37 for Wrapping Schemes 1, 2, and 3, respectively, while the ranges were just 1,3 , and 3 . The deteriorated concrete that remained in the compression zone after repair (at a height of 5.5" above the tension face) yielded rebound numbers for Wrapping schemes 1, 2, and 3 of 26, 23, and 25, respectively. As expected, the ranges of values for the more variable deteriorated concrete were slightly more 
variable than for the patch concrete: 4,5 , and 4 . Also, as expected, the rebound numbers obtained from the polymer patch concrete were much higher than those obtained from the poor quality normal concrete.

The rebound hammer data also shows that the concrete became harder between 28 days and the time the FRP-repaired beams were tested, as was expected.

One unexpected result was that the deteriorated concrete yielded higher rebound numbers than did the concrete on either of the long-term pristine beams (tested at the same approximate age). This indicates that, although the rebound hammer is a very useful tool for comparing concrete qualities, its results cannot be solely relied upon to estimate compressive strength or to independently determine what concrete should be removed when planning for a bridge repair.

Table 6.14 compares the concrete strength estimated from the rebound numbers to the actual concrete strength obtained from compression cylinder testing. It can be seen that, for all beam specimens except Beam II-2, the calibration information in Figure 6.34 significantly underestimated the actual normal concrete compressive strength by an average of 959psi and by a maximum of 2,017psi for Beam II-1. The rebound hammer data grossly underestimated the compressive strength of the polymer patch repair concrete by an average of 4,684psi and a maximum of 5,028psi for Beam II-17. These 
considerable differences are common when using the calibration data provided with a rebound hammer.

\section{Table 6.14: Comparison of concrete strength estimated by the rebound hammer to actual concrete strength for Part II Beams}

\begin{tabular}{|c|c|c|c|c|c|c|c|}
\hline Beam & $\begin{array}{l}\text { Actual Comp. } \\
\text { Strength from } \\
\text { Cylinder } \\
\text { Breaks } \\
\text { (psi) }\end{array}$ & $\begin{array}{c}\text { Estimated } \\
\text { Comp. } \\
\text { Strength @ } \\
1.5^{\prime \prime} \\
\text { (psi) }\end{array}$ & $\begin{array}{l}\text { Difference } \\
\quad(p s i)\end{array}$ & $\begin{array}{c}\text { Estimated } \\
\text { Comp. } \\
\text { Strength @ } \\
5.5^{\prime \prime} \\
\text { (psi) }\end{array}$ & $\begin{array}{l}\text { Difference } \\
\quad(p s i)\end{array}$ & $\begin{array}{c}\text { Estimated } \\
\text { Comp. } \\
\text { Strength @ } \\
\text { Comp. Face } \\
\text { (psi) }\end{array}$ & $\begin{array}{l}\text { Difference } \\
\quad(p s i)\end{array}$ \\
\hline 1 & 2,546 & 846 & $-1,700$ & 529 & $-2,017$ & 1,273 & $-1,273$ \\
\hline 2 & 1,976 & 619 & $-1,358$ & 398 & $-1,578$ & 2,940 & 963 \\
\hline Avg. & 2,261 & 732 & $-1,529$ & 464 & $-1,797$ & 2,106 & -155 \\
\hline Range & 570 & 227 & 343 & 132 & 438 & 1,667 & 2,237 \\
\hline 3 & 3,011 & 1,918 & $-1,093$ & 2,284 & -727 & 1,993 & $-1,018$ \\
\hline 4 & 3,170 & 2,047 & $-1,123$ & 2,553 & -617 & 2,484 & -686 \\
\hline$\overline{A v g .}$ & 3,091 & 1,982 & $-1,108$ & 2,418 & $\overline{-672}$ & 2,238 & -852 \\
\hline Range & 159 & 129 & 30 & 269 & 110 & 491 & 332 \\
\hline 11 & 2,387 & 1,416 & -971 & 1,246 & $-1,141$ & 1,677 & -710 \\
\hline 12 & 2,493 & 731 & $-1,762$ & 596 & $-1,897$ & 1,993 & -500 \\
\hline$\overline{A v g .}$ & 2,440 & 1,073 & $-1,367$ & 921 & $-1,519$ & 1,835 & -605 \\
\hline \begin{tabular}{|l} 
Range \\
\end{tabular} & 106 & 684 & 790 & 649 & 755 & 315 & 209 \\
\hline
\end{tabular}

\begin{tabular}{|c|c|c|c|c|c|c|}
\hline Beam & $\begin{array}{l}\text { Actual Comp. } \\
\text { Strength from } \\
\text { Cylinder } \\
\text { Breaks }\end{array}$ & $\begin{array}{c}\text { Estimated } \\
\text { Comp. } \\
\text { Strength @ } \\
1.5 "\end{array}$ & Difference & $\begin{array}{c}\text { Actual Comp. } \\
\text { Strength from } \\
\text { Cylinder } \\
\text { Breaks } \\
\end{array}$ & $\begin{array}{c}\text { Estimated } \\
\text { Comp. } \\
\text { Strength @ } \\
5.5^{\prime \prime} \\
\end{array}$ & Difference \\
\hline 5 & 8,137 & 3,338 & $-4,799$ & 2,493 & 1,790 & -703 \\
\hline 8 & 8,137 & 3,223 & $-4,914$ & 2,653 & 2,152 & -501 \\
\hline 9 & 8,137 & 3,252 & $-4,885$ & 2,679 & 1,714 & -965 \\
\hline 7 & 8,137 & 3,338 & $-4,799$ & 2,639 & 1,892 & -747 \\
\hline 14 & 8,137 & 3,309 & $-4,828$ & 2,401 & 1,564 & -837 \\
\hline Avg. & 8,137 & 3,292 & $-4,845$ & 2,573 & 1,822 & -751 \\
\hline Range & - & 115 & 115 & 278 & 588 & 464 \\
\hline 13 & 8,137 & 3,166 & $-4,971$ & 2,265 & 1,367 & -898 \\
\hline 15 & 8,137 & 3,571 & $-4,566$ & 2,361 & 1,126 & $-1,235$ \\
\hline 17 & 8,137 & 3,109 & $-5,028$ & 2,454 & 1,416 & $-1,038$ \\
\hline 18 & 8,137 & 3,425 & $-4,712$ & 2,321 & 1,150 & $-1,171$ \\
\hline 20 & 8,137 & 3,367 & $-4,770$ & 2,546 & 1,841 & -705 \\
\hline Avg. & 8,137 & 3,328 & $-4,809$ & 2,389 & 1,380 & $-1,010$ \\
\hline Range & - & 463 & 463 & 281 & 715 & 530 \\
\hline 21 & 8,137 & 3,809 & $-4,328$ & 2,507 & 1,995 & -512 \\
\hline 22 & 8,137 & 3,929 & $-4,208$ & 2,427 & 1,514 & -913 \\
\hline 24 & 8,137 & 3,483 & $-4,654$ & 2,401 & 1,714 & -687 \\
\hline 19 & 8,137 & 3,425 & $-4,712$ & 2,401 & 1,440 & -961 \\
\hline 23 & 8,137 & 4,050 & $-4,087$ & 2,427 & 1,866 & -561 \\
\hline$\overline{A v g .}$ & 8,137 & 3,739 & $-4,398$ & 2,433 & 1,706 & -727 \\
\hline Range & - & 625 & 625 & 106 & 555 & 449 \\
\hline
\end{tabular}

Because of these differences, it is strongly recommended by Malhotra (2004) to cast

prism specimens with different compressive strengths within the range of the actual 
concrete being studied. By recording the rebound numbers obtained from these prism samples and fitting a curve, a self-calibration can be executed. The homemade curve can then be used to more accurately predict the compressive strength of the concrete under examination. These estimated strengths, when compared to actual strengths, show that the calibration data provided by Proceq was very conservative.

\subsubsection{Suggestions for Improvement}

As discussed previously, prisms with varying concrete strengths should be made and hammer tested. Then, representative concrete cylinders from each of the concrete prisms should be compression tested so that an accurate calibration curve could be constructed for the rebound hammer. If this were done, concrete compressive strength could be more accurately estimated.

\subsubsection{Ultrasonic Pulse Velocity}

\subsubsection{Results}

Table 6.17 presents a summary of results obtained from ultrasonic pulse velocity testing in Part II of the experiment. No pulse velocity readings were taken in Part I of this experiment. Three direct readings were taken at a height of 1.5 " and three direct readings were taken at a height of 5.5" above the tension face at the locations shown in Figure 5.53, Figure 5.54, or Figure 5.55. A total of four indirect readings were taken at each a height of 1.5 " and 5.5", between the locations shown in Figure 5.53, Figure 5.54 or Figure 5.55. On unrepaired beams only, a total of six semi-direct readings were taken 
between the tension face and 1.5 " above the tension face and six semi-direct readings were taken between the tension face and 5.5" above the tension face, as shown in Figure 5.53 and Figure 5.54 or Figure 5.55. These individual values can be seen in Appendix D. It should be noted that, for FRP-repaired beams, polymer-modified repair concrete was present at a height of 1.5 " and deteriorated concrete was present at a height of 5.5".

No semi-direct readings were taken on the repaired beams, as their tension faces were covered with FRP. No pulse velocity readings were taken for Beams II-19 or II-24 since they contained FRP anchors spaced at 4" apart and were instrumented with externally bonded concrete strain gages in the same locations as where the readings needed to be taken. The locations of the pulse velocity readings could not be offset, as shown in Figure 5.55, since the FRP anchor stirrups covered the offset locations.

First, to obtain the pulse velocities, the total path length was simply divided by the time required for the pulse to travel between the transmitting and the receiving transducers:

$$
\begin{aligned}
& V=\frac{L}{t}, \text { where: } \quad \begin{aligned}
V & =\text { Pulse Velocity } \quad \text { (Malhotra, 2004; ASTM C 597-02) } \\
L & =\text { Total Path Length }
\end{aligned} \\
& t=\text { Time }
\end{aligned}
$$

Next, corrections were made to account for the presence of the reinforcing bars. First, the total lengths of steel " $L_{S}$ " within the path of the pulse were calculated. Next, the correction factor " $V_{C} / V$ ", which is a function of total path length, total steel in path, pulse velocity in un-reinforced concrete, and pulse velocity in steel was calculated. It should be noted that the pulse velocity in non-reinforced concrete was not known for this 
experiment. Therefore, the pulse velocity " $V$ " through the reinforced concrete was used in place of " $V_{C}$ " in the equation for " $V_{C} / V$ ". It was determined that, for the intentions of this test, this value would provide a result very close to the actual. It should also be noted that the value used for $V_{S}$ was recommended by Malhotra (2004) for steel rebar and was not directly measured. Finally, the pulse velocity in non-reinforced concrete " $V_{C}$ " was found by simply multiplying the pulse velocity measured " $V$ " by the correction factor. For the direct configuration at 5.5", two \#3 rebar were present. Although these bars were not directly in line with the transducers (see Figure 5.53), they were within close enough proximity to have an effect on the readings. For the direct configuration at 1.5", two \#4 rebar were present. For the semi-direct configurations, one of the $\# 4$ tension reinforcing bars were taken in account, although, once again not directly in line. Please refer to the diagrams in Figure 6.35 when reviewing the subsequent calculations.

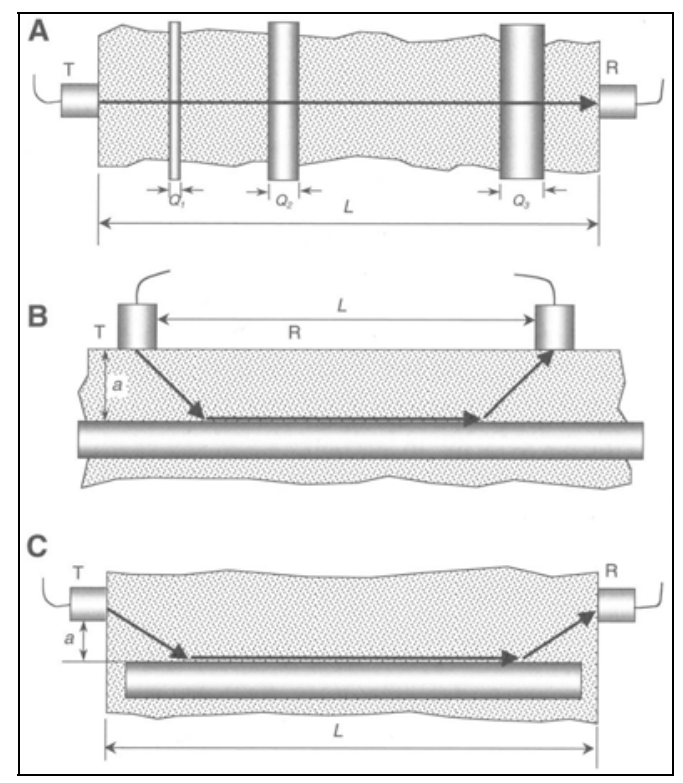

Figure 6.35: Variables used for correction of ultrasonic pulse velocity in steel-reinforced concrete (Malhotra, 2004) 


$$
\begin{aligned}
& L_{S}=\sum_{1}^{n} Q_{i}, \text { where: } \\
& L_{S}=\text { Time } \\
& Q_{i}=\text { Individual Steel Rebar Diameters } \\
& \frac{V_{C}}{V}=1-\frac{L_{S}}{L}\left(1-\frac{V_{C}}{V_{S}}\right) \quad \begin{array}{l}
V_{C}=\text { Pulse Velocity in Plain Concrete } \\
V_{S}=\text { Pulse Velocity in Steel }
\end{array} \\
& V_{c}=\frac{V_{C}}{V} \times V
\end{aligned}
$$

For Direct @ 1.5" at Mark End Readings on Beam II-5:

$$
\begin{aligned}
& L_{S}=Q_{1}+Q_{2}=0.5 \mathrm{in}+0.5 \mathrm{in}=1.0 \mathrm{in} \\
& \frac{V_{C}}{V}=1-\frac{1.0 \mathrm{in}}{6 \mathrm{in}}\left(1-\frac{3,440 \frac{\mathrm{m}}{\mathrm{s}}}{5,200 \frac{\mathrm{m}}{\mathrm{s}}}\right)=0.93 \\
& V_{c}=\frac{V_{C}}{V} \times V=0.93 \times 3,440 \frac{\mathrm{m}}{\mathrm{s}}=3,198 \frac{\mathrm{m}}{\mathrm{s}}
\end{aligned}
$$

For Direct @ 1.5” at Mark End Readings on Beam II-5:

$$
\begin{aligned}
& L_{S}=Q_{1}+Q_{2}=0.375 \mathrm{in}+0.375 \mathrm{in}=0.750 \mathrm{in} \\
& \frac{V_{C}}{V}=1-\frac{0.750 \mathrm{in}}{6 \mathrm{in}}\left(1-\frac{2,544 \frac{\mathrm{m}}{\mathrm{s}}}{5,200 \frac{\mathrm{m}}{\mathrm{s}}}\right)=0.93 \\
& V_{c}=\frac{V_{C}}{V} \times V=0.93 \times 2,544 \frac{\mathrm{m}}{\mathrm{s}}=2,365 \frac{\mathrm{m}}{\mathrm{s}}
\end{aligned}
$$

For Semi-Direct@,Tension Zone Mark End Right on Beam II-1:

$$
\begin{aligned}
& L_{S}=Q_{1}=0.50 \mathrm{in} \\
& \frac{V_{C}}{V}=1-\frac{0.50 \mathrm{in}}{2.12 \mathrm{in}}\left(1-\frac{2,721 \frac{\mathrm{m}}{\mathrm{s}}}{5,200 \frac{\mathrm{m}}{\mathrm{s}}}\right)=0.90 \\
& V_{c}=\frac{V_{C}}{V} \times V=0.90 \times 2,721 \frac{\mathrm{m}}{\mathrm{s}}=2,450 \frac{\mathrm{m}}{\mathrm{s}}
\end{aligned}
$$

For Semi-Direct Between Tension and Compression Zones Mark End Right on Beam II-1

$$
\begin{aligned}
& L_{S}=Q_{1}=0.50 \mathrm{in} \\
& \frac{V_{C}}{V}=1-\frac{0.50 \mathrm{in}}{5.70 \mathrm{in}}\left(1-\frac{3,694 \frac{\mathrm{m}}{\mathrm{s}}}{5,200 \frac{\mathrm{m}}{\mathrm{s}}}\right)=0.96 \\
& V_{c}=\frac{V_{C}}{V} \times V=0.96 \times 3,694 \frac{\mathrm{m}}{\mathrm{s}}=2,450 \frac{\mathrm{m}}{\mathrm{s}}
\end{aligned}
$$


For the indirect configuration, it had to be determined whether the steel would have an effect on the pulse velocity reading. If $\frac{a}{L} \leq \frac{1}{2} \sqrt{\frac{V_{S}-V_{C}}{V_{S}+V_{C}}}$, then the effect of the steel must be accounted for (Malhotra, 2004). Therefore, for Beam II-6 Indirect @ 5.5” Mark Right:

$a=1.875^{\prime \prime}$

$L=16^{\prime}$

$$
\frac{1.875^{\prime \prime}}{16^{\prime \prime}} \leq \frac{1}{2} \sqrt{\frac{5,200 \frac{m}{s}-2,708 \frac{m}{s}}{5,200 \frac{m}{s}+2,708 \frac{m}{s}}}
$$

$0.12 \leq 0.28, \therefore$ The steel does have an effect and must be accounted for. Table 6.15 was provided by (Malhotra, 2004) and was used to determine the steel correction factor

“ $V_{C} / V . "$ For $L=16$ " readings, $\frac{a}{L}=0.117$; for $L=15$ " readings, $\frac{a}{L}=0.125$, and for $L=12$ " readings, $\frac{a}{L}=0.156$. For the normal concrete, $\frac{V_{C}}{V_{S}} \approx 0.46$, and for polymer patch repair concrete, $\frac{V_{C}}{V_{S}} \approx 0.60$.

Table 6.15: Values for $V_{C} / V$ for ultrasonic pulse velocity readings when using the indirect configuration with the presence of longitudinal reinforcing steel (Malhotra, 2004)

\begin{tabular}{|c|c|c|c|c|}
\hline$\frac{a}{L}$ & $\frac{V_{C}}{V_{S}}=0.90$ & $\frac{V_{C}}{V_{S}}=0.80$ & $\frac{V_{C}}{V_{S}}=0.71$ & $\frac{V_{C}}{V_{S}}=0.60$ \\
\hline 0 & 0.90 & 0.80 & 0.71 & 0.60 \\
\hline $1 / 20$ & 0.94 & 0.86 & 0.78 & 0.68 \\
\hline $1 / 15$ & 0.96 & 0.88 & 0.80 & 0.71 \\
\hline $1 / 10$ & 0.99 & 0.92 & 0.85 & 0.76 \\
\hline $1 / 7$ & 1.00 & 0.97 & 0.91 & 0.83 \\
\hline $1 / 5$ & 1.00 & 1.00 & 0.99 & 0.92 \\
\hline $1 / 4$ & 1.00 & 1.00 & 1.00 & 1.00 \\
\hline
\end{tabular}


Therefore, the following values shown in Table 6.16 were interpolated from Table 6.15 and used for " $V_{C} / V$ ":

Table 6.16: Values used for $V_{C} / V$

\begin{tabular}{|c|c|c|c|}
\hline$\frac{V_{C}}{V_{S}}$ & $L=16 ”$ & $L=15 ”$ & $L=12 ”$ \\
\hline Normal Concrete & 0.64 & 0.63 & 0.72 \\
\hline Polymer Patch Concrete & 0.80 & 0.79 & 0.85 \\
\hline
\end{tabular}

Each set of pulse velocity was averaged and is presented in the "Individual" columns of Table 6.17. The "Average" columns in Table 6.17 show the average pulse velocities obtained for each defined group of beams (pristine, repaired, etc.). The "Range" columns show the range of these sets for each group.

Pulse velocity results were as expected. As indicated by rebound hammer testing, the average qualities of the separate concrete types (pristine normal concrete, deteriorated normal concrete, and polymer patch concrete) were quite consistent. As expected, the pulse velocity through the polymer-modified concrete was much higher than through the intentionally poor quality normal concrete because it was much denser and since its properties were far superior to those of the normal concrete.

The average velocities in the 28-day pristine beams and the long-term pristine beams were comparable indicating that no significant cracking occurred in the long-term pristine beams due to normal corrosion. Also, the average velocities in the control beams were 
comparable to the average velocities in the remaining normal concrete in the repaired beams, indicating that no significant cracking or irregularity was present within the compression concrete of the repaired beams.

\section{Table 6.17: Summary of Ultrasonic Pulse Velocity Results}

\begin{tabular}{|c|c|c|c|c|c|c|c|c|c|c|c|c|c|c|c|c|c|c|c|}
\hline \multirow[b]{2}{*}{ 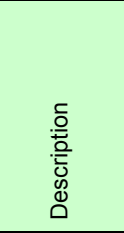 } & \multirow[b]{2}{*}{$\begin{array}{l}E \\
\mathbb{\Phi} \\
\Phi \\
\Phi\end{array}$} & \multicolumn{3}{|c|}{ Direct @ 1.5" } & \multicolumn{3}{|c|}{ Direct @ 5.5" } & \multicolumn{3}{|c|}{ Indirect @ 1.5" } & \multicolumn{3}{|c|}{ Indirect @ 5.5" } & \multicolumn{3}{|c|}{$\begin{array}{l}\text { Semi-Direct @ } \\
\text { Tension Zone }\end{array}$} & \multicolumn{3}{|c|}{\begin{tabular}{|c|} 
Semi-Direct \\
Between Tension \& \\
Compression \\
Zones \\
\end{tabular}} \\
\hline & & $\begin{array}{l}\bar{\pi} \\
\stackrel{0}{0} \\
\stackrel{0}{\overline{2}} \\
\underline{\underline{D}}\end{array}$ & $\begin{array}{l}\stackrel{0}{\mathscr{D}} \\
\frac{\pi}{0} \\
\stackrel{0}{\rightleftarrows}\end{array}$ & 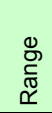 & 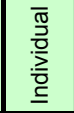 & 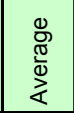 & 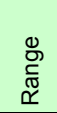 & 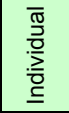 & 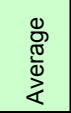 & 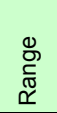 & 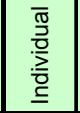 & 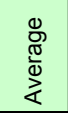 & 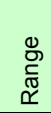 & 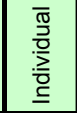 & 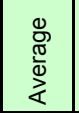 & $\begin{array}{l}\mathscr{0} \\
\stackrel{0}{\widetilde{\pi}} \\
\widetilde{\Upsilon}\end{array}$ & 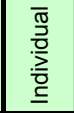 & 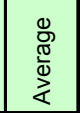 & 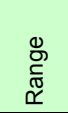 \\
\hline $\begin{array}{l}\text { 28-Day } \\
\text { Pristine }\end{array}$ & $\begin{array}{l}1 \\
2 \\
\end{array}$ & \begin{tabular}{|l|}
2,617 \\
2,459 \\
\end{tabular} & 2,538 & 157 & \begin{tabular}{|l|}
2,629 \\
2,522 \\
\end{tabular} & 2,576 & 108 & $\begin{array}{l}1,556 \\
2,376 \\
\end{array}$ & 1,966 & 819 & \begin{tabular}{|l|}
2,119 \\
1,829 \\
\end{tabular} & 1,974 & 289 & \begin{tabular}{|l|}
2,433 \\
2,123 \\
\end{tabular} & 2,278 & 310 & \begin{tabular}{|l|}
3,616 \\
2,184 \\
\end{tabular} & 2,900 & 1,431 \\
\hline $\begin{array}{c}\text { Long-Term } \\
\text { Pristine } \\
\end{array}$ & $\begin{array}{l}11 \\
12 \\
\end{array}$ & \begin{tabular}{|l|}
2,568 \\
2,299 \\
\end{tabular} & 2,433 & 268 & \begin{tabular}{|l|}
2,619 \\
2,377 \\
\end{tabular} & 2,498 & 242 & \begin{tabular}{|l|}
1,673 \\
1,503 \\
\end{tabular} & 1,588 & 170 & \begin{tabular}{|l|}
1,578 \\
1,420 \\
\end{tabular} & 1,499 & 157 & \begin{tabular}{|l|}
2,441 \\
2,207 \\
\end{tabular} & 2,324 & 235 & \begin{tabular}{|l|}
2,441 \\
2,084 \\
\end{tabular} & 2,263 & 358 \\
\hline $\begin{array}{c}\text { Corroded } \\
\text { Unrepaired } \\
\end{array}$ & $\begin{array}{l}3 \\
4 \\
\end{array}$ & \begin{tabular}{|l|}
1,317 \\
2,016 \\
\end{tabular} & 1,666 & 699 & \begin{tabular}{|l|}
2,323 \\
2,397 \\
\end{tabular} & 2,360 & 75 & \begin{tabular}{|l|}
2,563 \\
1,984 \\
\end{tabular} & 2,273 & 579 & \begin{tabular}{|l|}
2,019 \\
1,792 \\
\end{tabular} & 1,906 & 227 & \begin{tabular}{|l|}
2,515 \\
2,377 \\
\end{tabular} & 2,446 & 138 & \begin{tabular}{|l|}
3,045 \\
2,314 \\
\end{tabular} & 2,680 & 731 \\
\hline $\begin{array}{l}\text { Wrapping } \\
\text { Scheme } 1\end{array}$ & \begin{tabular}{|c|}
5 \\
8 \\
9 \\
7 \\
14 \\
\end{tabular} & \begin{tabular}{|l|}
3,174 \\
3,247 \\
3,137 \\
3,171 \\
2,606 \\
\end{tabular} & 3,067 & 641 & \begin{tabular}{|l|}
2,299 \\
2,357 \\
2,194 \\
2,260 \\
2,934 \\
\end{tabular} & 2,409 & 740 & \begin{tabular}{|l|}
3,479 \\
3,392 \\
3,767 \\
3,314 \\
3,360 \\
\end{tabular} & 3,462 & 454 & \begin{tabular}{|l|}
1,811 \\
1,753 \\
1,869 \\
1,712 \\
1,855 \\
\end{tabular} & 1,800 & 157 & & & & & & \\
\hline $\begin{array}{l}\text { Wrapping } \\
\text { Scheme } 2\end{array}$ & \begin{tabular}{|l|}
13 \\
15 \\
17 \\
18 \\
20 \\
\end{tabular} & \begin{tabular}{|l|}
3,122 \\
3,093 \\
3,135 \\
3,143 \\
3,858 \\
\end{tabular} & 3,270 & 764 & \begin{tabular}{|l|}
2,214 \\
2,115 \\
2,170 \\
2,366 \\
2,167 \\
\end{tabular} & 2,207 & 251 & \begin{tabular}{|l|}
3,341 \\
3,399 \\
3,314 \\
3,317 \\
2,741 \\
\end{tabular} & 3,222 & 658 & \begin{tabular}{|l|}
1,400 \\
1,887 \\
1,711 \\
1,669 \\
1,761 \\
\end{tabular} & 1,685 & 488 & & & & & & \\
\hline $\begin{array}{l}\text { Wrapping } \\
\text { Scheme } 3\end{array}$ & \begin{tabular}{|l|}
21 \\
22 \\
24 \\
19 \\
23 \\
\end{tabular} & \begin{tabular}{|c|}
3,320 \\
3,123 \\
- \\
- \\
3,407 \\
\end{tabular} & 3,284 & 283 & \begin{tabular}{|c|}
2,010 \\
2,116 \\
- \\
- \\
2,138 \\
\end{tabular} & 2,088 & 128 & \begin{tabular}{|c|}
3,463 \\
3,337 \\
- \\
- \\
3,100 \\
\end{tabular} & 3,300 & 363 & \begin{tabular}{|c|}
1,762 \\
1,637 \\
- \\
- \\
1,715 \\
\end{tabular} & 1,705 & 125 & & & & & & \\
\hline
\end{tabular}

The pulse velocity through the tension zone of the corroded unrepaired beams was much less than through the pristine control beams, indicating that significant cracking was present. However, for the remaining normal concrete in the repaired beams, the velocity through the compression zone of the corroded unrepaired beams was similar to that of the pristine control beams, suggesting that the compressive concrete remained in good condition.

These results were very favorable for this experiment because they helped confirm that no extra variable was introduced into the testing plan due to significantly differing 
concrete qualities. The results also confirm that ultrasonic pulse velocity testing is an excellent tool for comparing the qualities of differing concrete.

Another observation is that the direct, semi-direct, and indirect configurations all yielded comparable pulse velocity results. This indicates that the correction factors calculated to correct for the presence of steel were reasonably accurate. The indirect readings for the normal concrete were slightly lower than those obtained from the direct and semi-direct configurations, but the indirect configuration is expected to be the least reliable and accurate according to Malhotra (2004). When comparing concrete quality during bridge evaluation, the same configuration should be used for all tests to ensure that no undesired variability will be introduced.

\subsubsection{Suggestions for Improvement}

An interesting addition to this experiment would be to use the indirect configuration to determine the location and depth of cracks and to estimate the depth of deteriorated concrete. Crack locations can be estimated by placing the transmitting transducer at a fixed location and taking evenly spaced readings along a straight line by moving the receiving transducer. By plotting velocity vs. distance, approximate locations of cracks or other irregularities can be determined by noting the locations of slope change on the plotted curve (see Figure 6.37).

Crack depth can be estimated by the following equation (also see Figure 6.36): 
$h=\frac{X}{T_{2}} \sqrt{T_{1}^{2}-T_{2}^{2}}$, where:

$X=$ Distance to the transducer from the crack (both transducers must be placed

(Malhotra, 2004) equidistant on each side of the crack)

$T_{l}=$ Transit time around the crack

$T_{2}=$ Transit time between transducers over the same distance between which there are no cracks

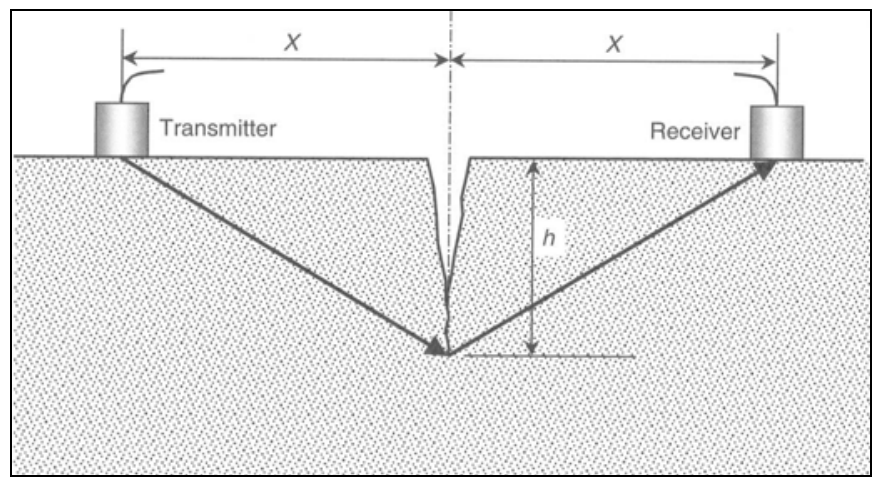

Figure 6.36: Scheme for measuring surface crack depth using ultrasonic pulse velocity testing (Malhotra, 2004)

Depth of deterioration can be determined by using the same procedure as described for determining the location of cracks or irregularities as long as the deteriorated layer is distinct and is of reasonable uniform thickness (see Figure 6.37). This is accomplished by first determining the distance from the transmitting transducer in which the velocity vs. distance curve changes slope. The depth of deterioration can be estimated by using the following equation:

$t=\frac{X}{2} \sqrt{\frac{V_{2}-V_{1}}{V_{2}-V_{1}}}$, where:

$t=$ Estimated depth of deterioration

(Malhotra, 2004)

$X=$ Distance from the transducer to which the velocity vs. distance curve changes slope

$V_{l}=$ Pulse velocity through the upper layer

$V_{2}=$ Pulse velocity through the lower layer 


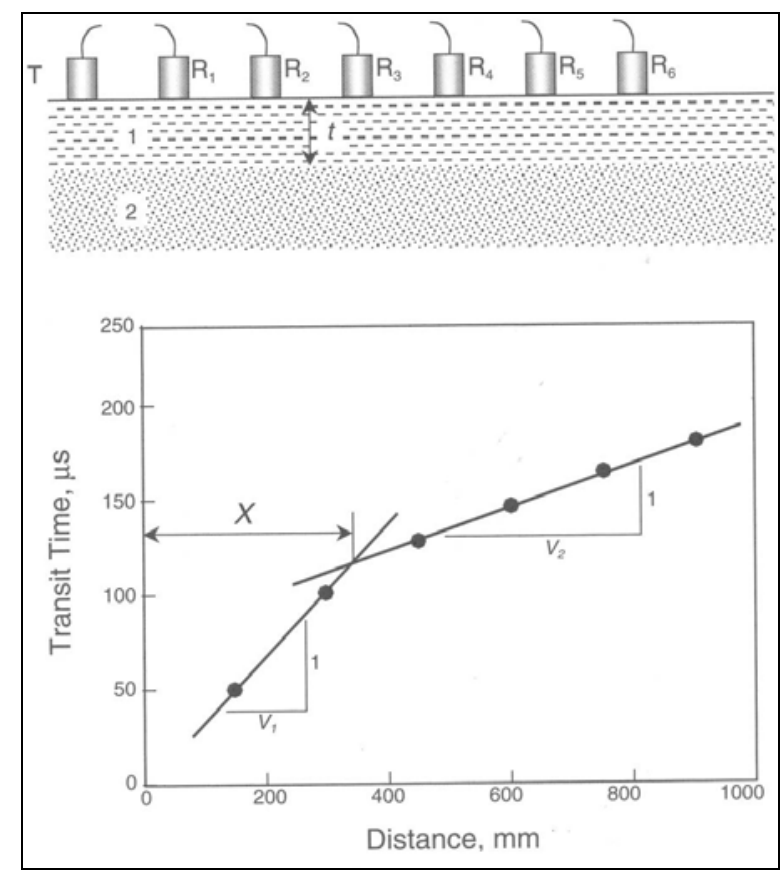

Figure 6.37: Use of surface method to determine depth of concrete deterioration and to determine approximate location of cracks or irregularities

\subsection{Destructive Testing Results}

\subsubsection{Cyclic Flexural Testing}

\subsubsection{Results}

Figure 6.38 presents the normalized maximum deflection obtained during each static load test within the serviceability region up to $7,000 \mathrm{lbs}$. Normalized deflection is calculated by dividing the actual maximum deflection at " $i$ " cycles by the initial maximum deflection at 0 cycles. It should be noted that, due to the size constraints of the beam cross section and rebar area in the relatively small laboratory scale specimens, these deflections exceeded the L/800 service limit. For the purposes and goals of this project, however, this was acceptable. The specimen size, reinforcement ratio, and deflections 
were similar to those studied in the literature. Data sets from beams repaired using Wrapping Schemes 1, 2, and 3 are presented in red, blue, and green, respectively.

The maximum deflection increase due to fatigue occurred during the first 250,000 cycles for all specimens. On average, the second largest increase occurred between 250,000 and 500,000 cycles. Between 500,000 and 2,000,000 cycles, the maximum deflection increased more uniformly. A significant increase in maximum deflection occurred between 750,000 and 1,000,000 cycles for Beam II-14 and between 1,000,000 and 1,250,000 cycles for Beam II-7, each of which were repaired using Wrapping Scheme 1. A similar increase was not noticed within these intervals for the other four fatigue-loaded beams repaired using Wrapping Schemes 2 or 3.

The maximum deflection for beams repaired using Wrapping Scheme 1 were significantly higher than for beams repaired using Wrapping Schemes 2 or 3 . The average normalized maximum deflection for Wrapping Scheme 1 beams was 2.38, while the average normalized maximum deflections for Wrapping Schemes 2 and 3 were 2.01 and 1.93, respectively. Therefore, when at least minimum anchorage was provided, deflections due to fatigue loading decreased significantly. More anchorage further reduced deflections, but only by a small amount. The range was largest for beams repaired with Scheme 1 and smallest for beams repaired with Scheme 3. 


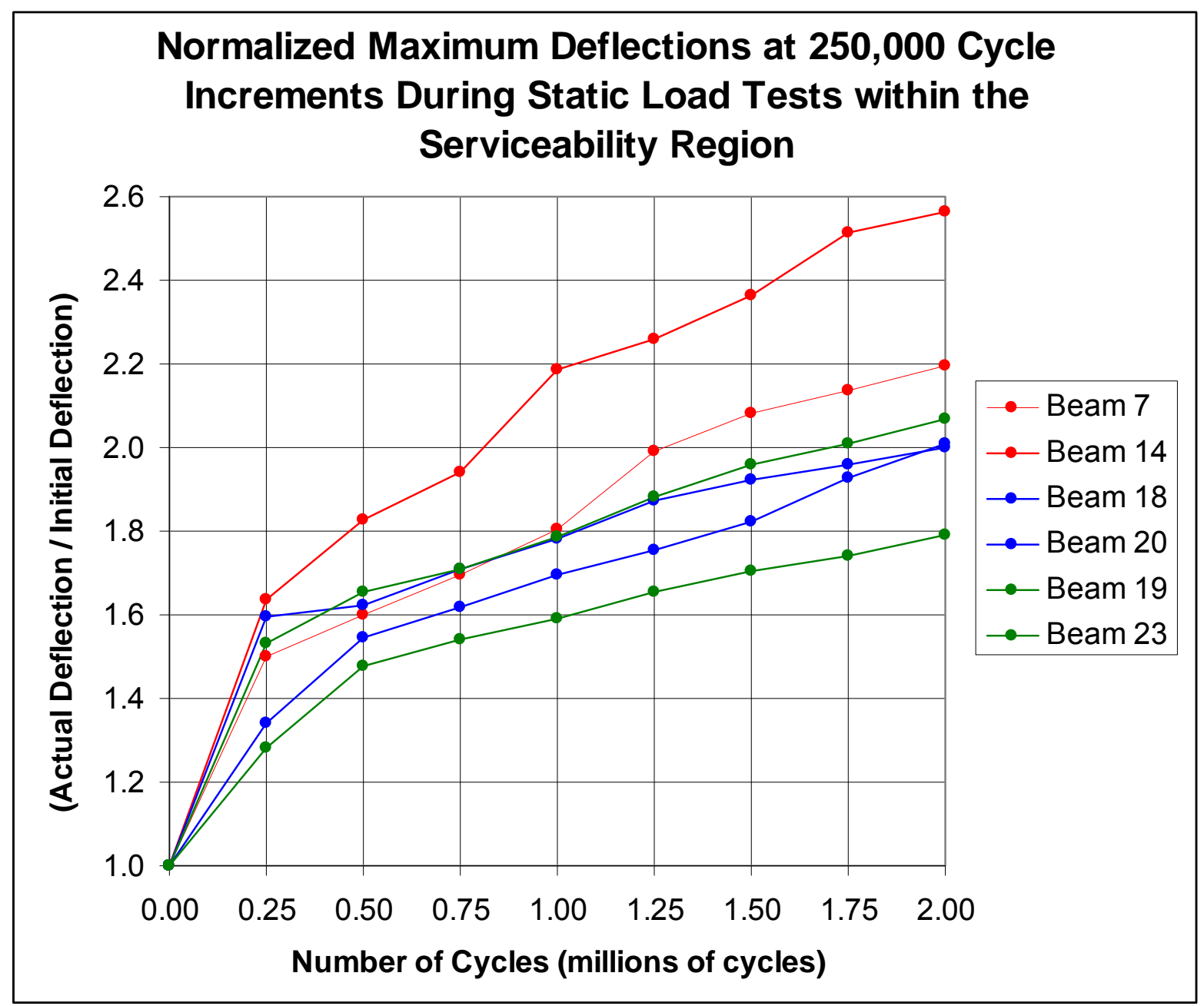

Figure 6.38: Decay of Part II fatigue-loaded beams as illustrated by normalized deflections at 250,000 cycle increments during static load tests within the serviceability region (see graphs in Section F.1.2.1 for actual deflections)

Figure 6.39 presents the permanent deflections observed at each 250,000 cycle increment. Data sets from beams repaired using Wrapping Schemes 1, 2, and 3 are presented in red, blue, and green, respectively.

The trends observed in Figure 6.38 and Figure 6.39 were very similar. The maximum permanent deflection increase occurred within the first 250,000 cycles for all fatigued 
specimens. Between 250,000 and 2,000,000 cycles, the permanent deflection increased more uniformly. A significant increase in maximum deflection occurred between 750,000 and 1,000,000 cycles for Beam II-14 and between 1,000,000 and 1,250,000 cycles for Beam II-7, each of which were repaired using Wrapping Scheme 1. This jump was not observed for Wrapping Schemes 2 or 3.

As were the maximum deflections, the average permanent deflections for Wrapping Scheme 1 beams were significantly higher than for beams repaired using Wrapping Schemes 2 or 3. Again, when at least minimum anchorage was provided, deflections due to fatigue loading decreased. Overall, the final average permanent deflection observed for Wrapping Scheme 1 beams was 0.174 in, which was $12 \%$ larger than for Scheme 2 beams and 14\% larger than for Scheme 3 beams. More anchors did not appear to further reduce the permanent deflection, as Schemes 2 and 3 had similar averages. The range was largest for beams repaired with Scheme 2 and smallest for beams repaired with Scheme 3.

Figure 6.40 presents the normalized stiffness obtained during each static load test within the serviceability region up to $7,000 \mathrm{lbs}$. Normalized stiffness is calculated by dividing actual stiffness at " $i$ " cycles (given in Table F.1) by initial stiffness at 0 cycles. Data sets from beams repaired using Wrapping Schemes 1, 2, and 3 are presented in red, blue, and green, respectively. 


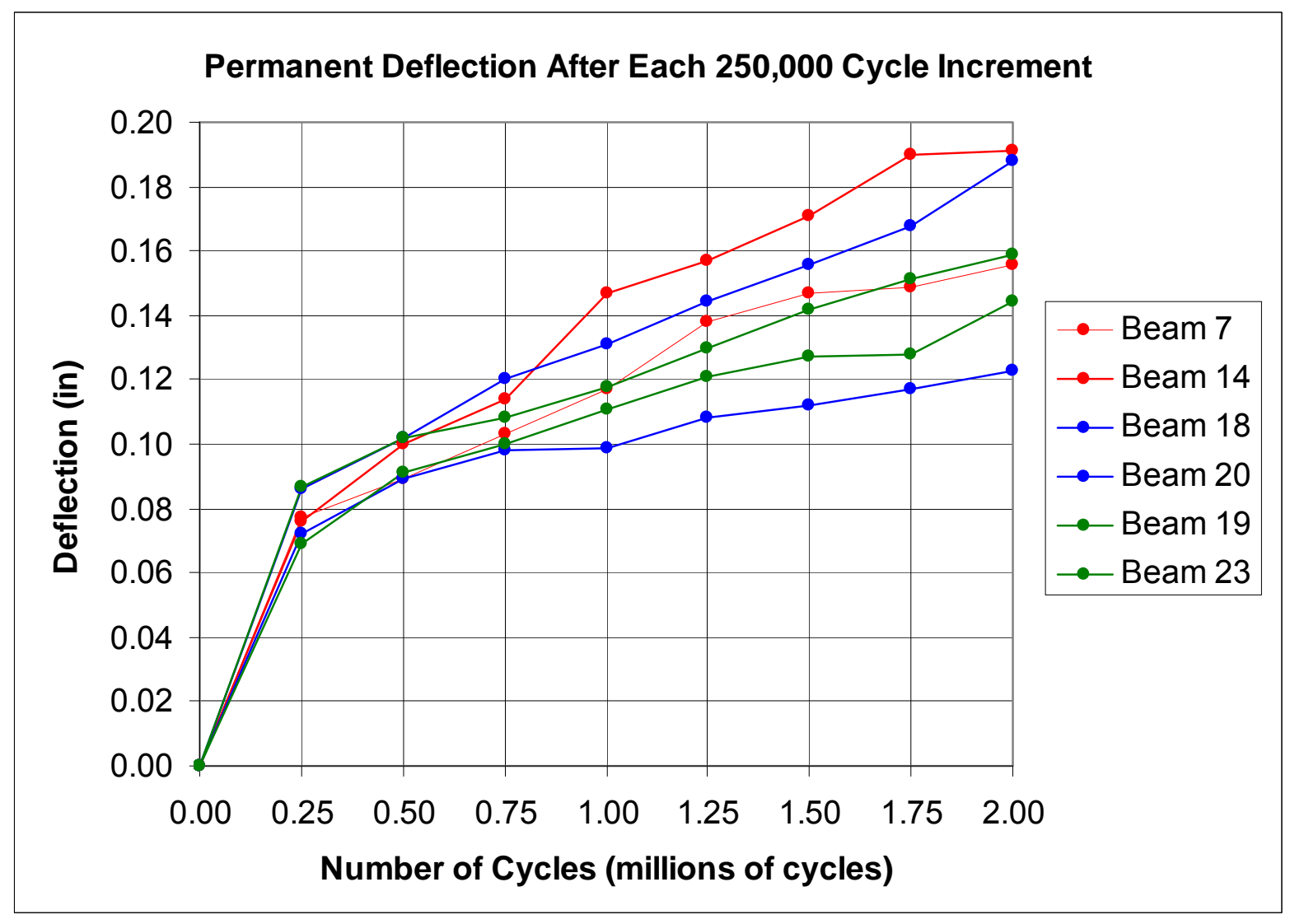

Figure 6.39: Decay of Part II fatigue-loaded beams as illustrated by permanent deflections after each 250,000 cycle increment

The stiffness of all beams decreased by $55-60 \%$ between the static test at 0 cycles and the incremental static test at 250,000 cycles. A majority of this stiffness loss occurred because the concrete cracked at around 4,000lbs load, as is seen in the load-deflection decay curves presented in Appendix F. For beams 19 and 20, a second static load test was performed at 0 cycles. The results from these additional static tests showed that between 65 and $72 \%$ of the total stiffness loss observed between 0 and 250,000 cycles was due to the fatigue loading (the remaining $28-35 \%$ was due to cracking during static loading at zero cycles). 


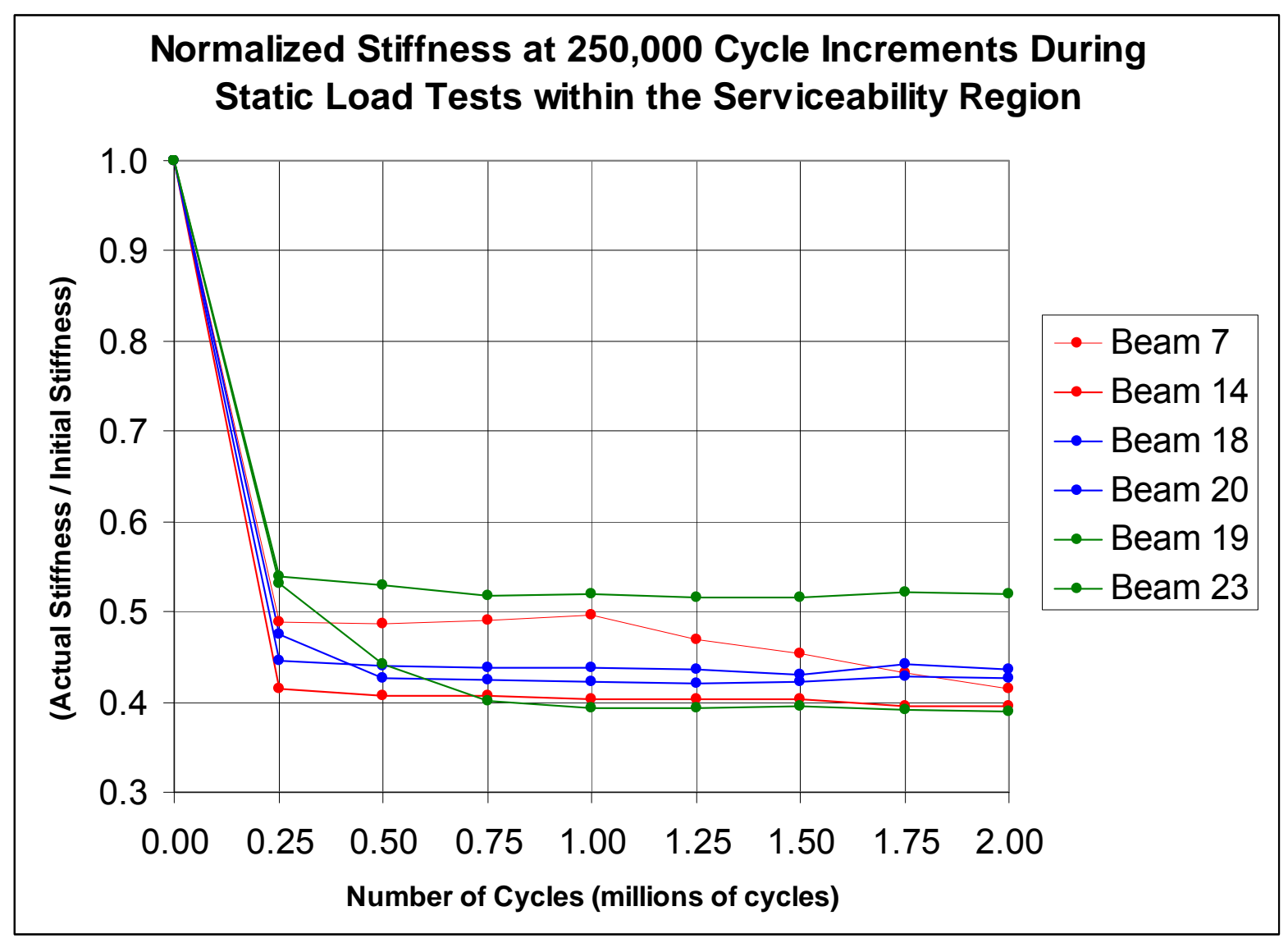

Figure 6.40: Decay of Part II fatigue-loaded beams as illustrated by normalized stiffness at 250,000 cycle increments during static load tests within the serviceability region (see Table F.1 for actual stiffness values)

Stiffness remained fairly constant (perhaps decreasing only slightly) between 250,0002,000,000 cycles for Beams II-14, II-18, II-19, and II-20. Beam II-23 stiffness decreased between 250,000 and 750,000 cycles before becoming fairly constant up to 2,000,000 cycles. Beam II-7 exhibited a fairly constant stiffness between 250,000 and 1,000,000 cycles, but then began to decrease (and almost linearly) between 1,000,000 and 2,000,000 cycles. 
All fatigued beams had a similar average stiffness after 2,000,000 cycles that ranged between 39,000 and 43,000lbs/in. The range of values for Wrapping Schemes 1 and 2 was very small, while the range for Wrapping Scheme 3 was much larger.

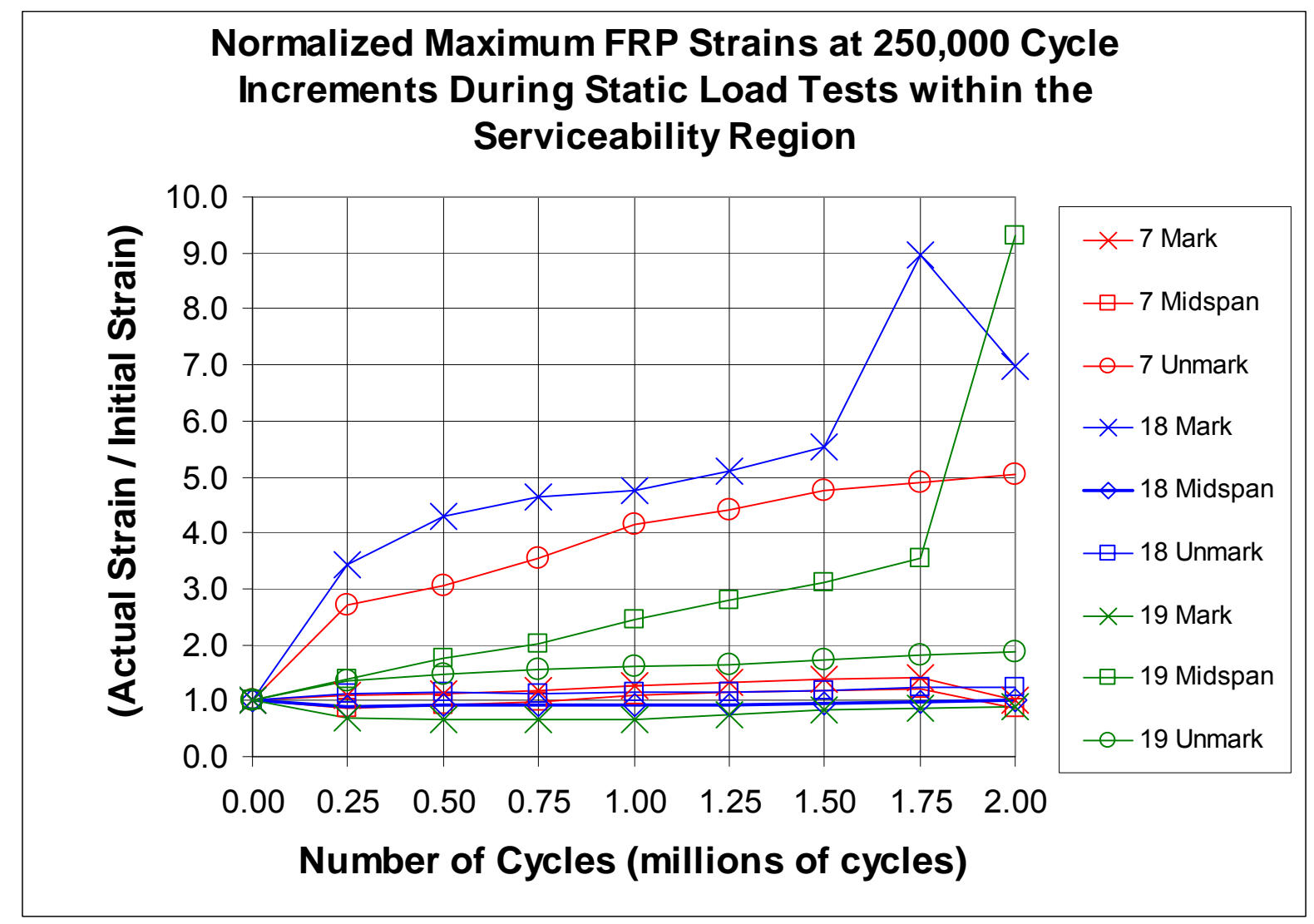

Figure 6.41: Decay of Part II fatigue-loaded beams as illustrated by normalized FRP Strain at 250,000 cycle increments during static load tests within the serviceability region (with outliers) (see graphs in Section F.1.2.3 for actual FRP strain values)

Figure 6.41 and Figure 6.42 shows the normalized FRP strains obtained during the static load tests conducted at every 250,000 cycles. "Mark" strain gages were located at the loading point toward the marked end of the beam, midspan strain gages were located at the midspan of the beam, and "unmark" strain gages were located at the load point toward the unmarked end of the beam. One FRP strain gage from each beam provided 
outlying results. These outliers are shown in Figure 6.41, however, to illustrate the necessity of using many FRP strain gages on actual field tests due to high variability. If only few strain gages are used during testing, very inaccurate results will likely be obtained. Outliers are eliminated from the same plot in Figure 6.42.

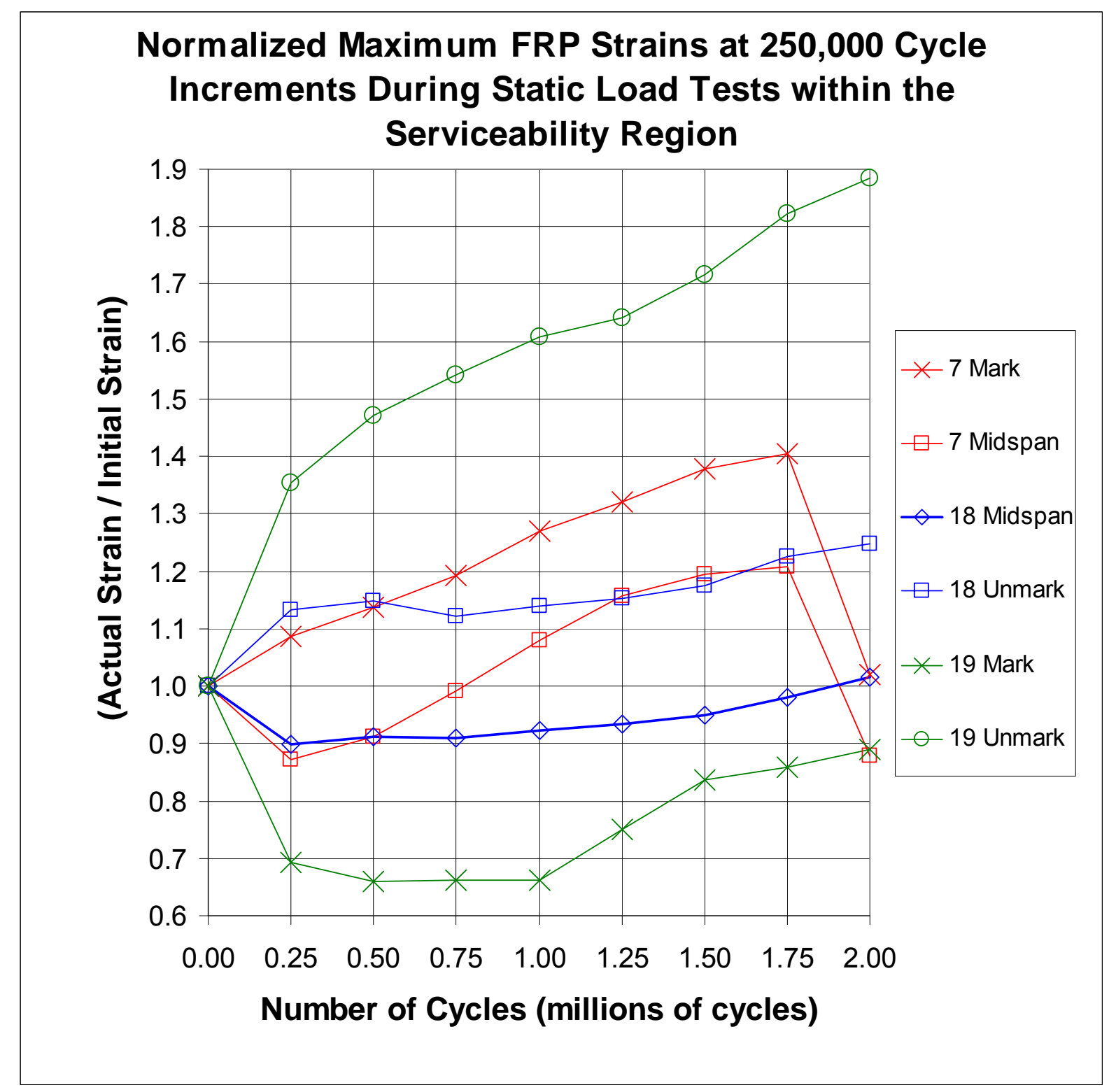

Figure 6.42: Decay of Part II fatigue-loaded beams as illustrated by normalized FRP Strain at 250,000 cycle increments during static load tests within the serviceability region (outliers removed) (see graphs in Section F.1.2.3 for actual FRP strain values) 
The FRP strain gages yielded inconsistent values for fatigue-loaded beams. However, a general trend of increasing FRP strains with an increasing number of cycles can be seen, with a maximum normalized FRP strain of 1.88. FRP strains on Beam II-7 (repaired with Wrapping Scheme 1) tended to steadily increase up to $1,750,000$ cycles and then decrease at 2,000,000 cycles. FRP strains on Beam II-18 (repaired with Wrapping Scheme 2) tended to steadily increase over 2,000,000 cycles. This indicates that strains may not be uniform (as in theory) across the entire constant moment region of the beam, but instead may be highly localized due to cracking. This is illustrated more emphatically when comparing the "mark" and "unmark" strain results for Beam II-19 (repaired with Wrapping Scheme 3).

Figure 6.43 shows the normalized steel strains obtained during the static load tests that were conducted every 250,000 cycles. "Mark inside" and outside "mark outside" gages were located beneath the load point toward the marked end of the beam on the vertical centerline of the rebar. Midspan inside and outside strain gages were located at the midspan of the beam on the vertical centerline of the rebar.

Most normalized steel strains increased to a range of 1.20 and 1.45 after the first 250,000 cycles and then tended to continue increasing less dramatically to a range of 1.45 and 1.80. Several outlying curves that may be attributed to localized strain differences due to cracking or to statistical variability of the strain gages were obtained. Again, the presence of these outliers emphasizes the necessity of using a large quantity of steel strain gages during actual field tests. Also, gages with $350 \Omega$ resistance are more accurate and 
consistent than gages with $120 \Omega$ resistance like the ones used in this research and should be used in field studies.

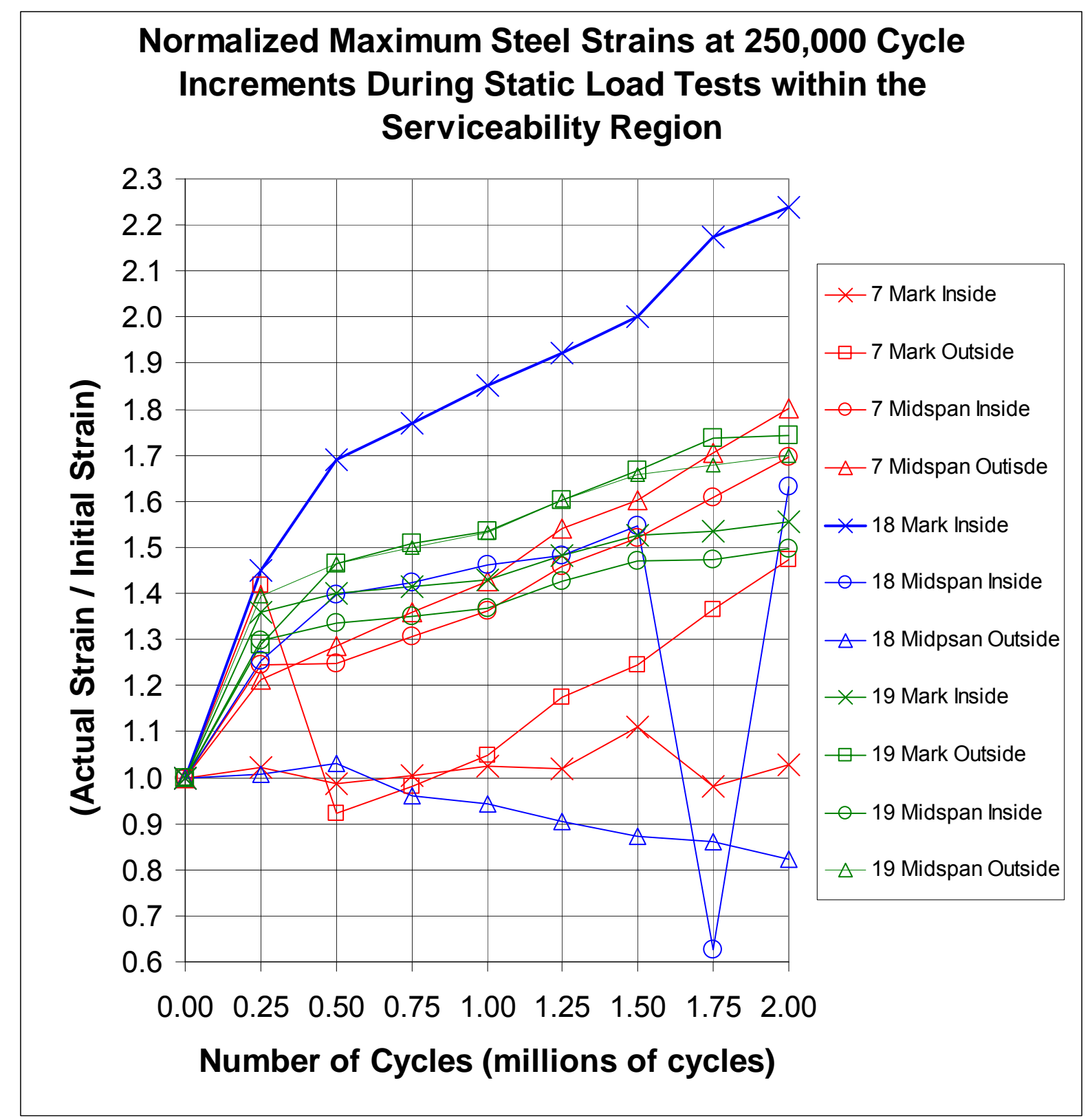

Figure 6.43: Decay of Part II fatigue-loaded beams as illustrated by normalized steel strain at 250,000 cycle increments during static load tests within the serviceability region (see graphs in Section F.1.2.2 for actual steel strain values) 


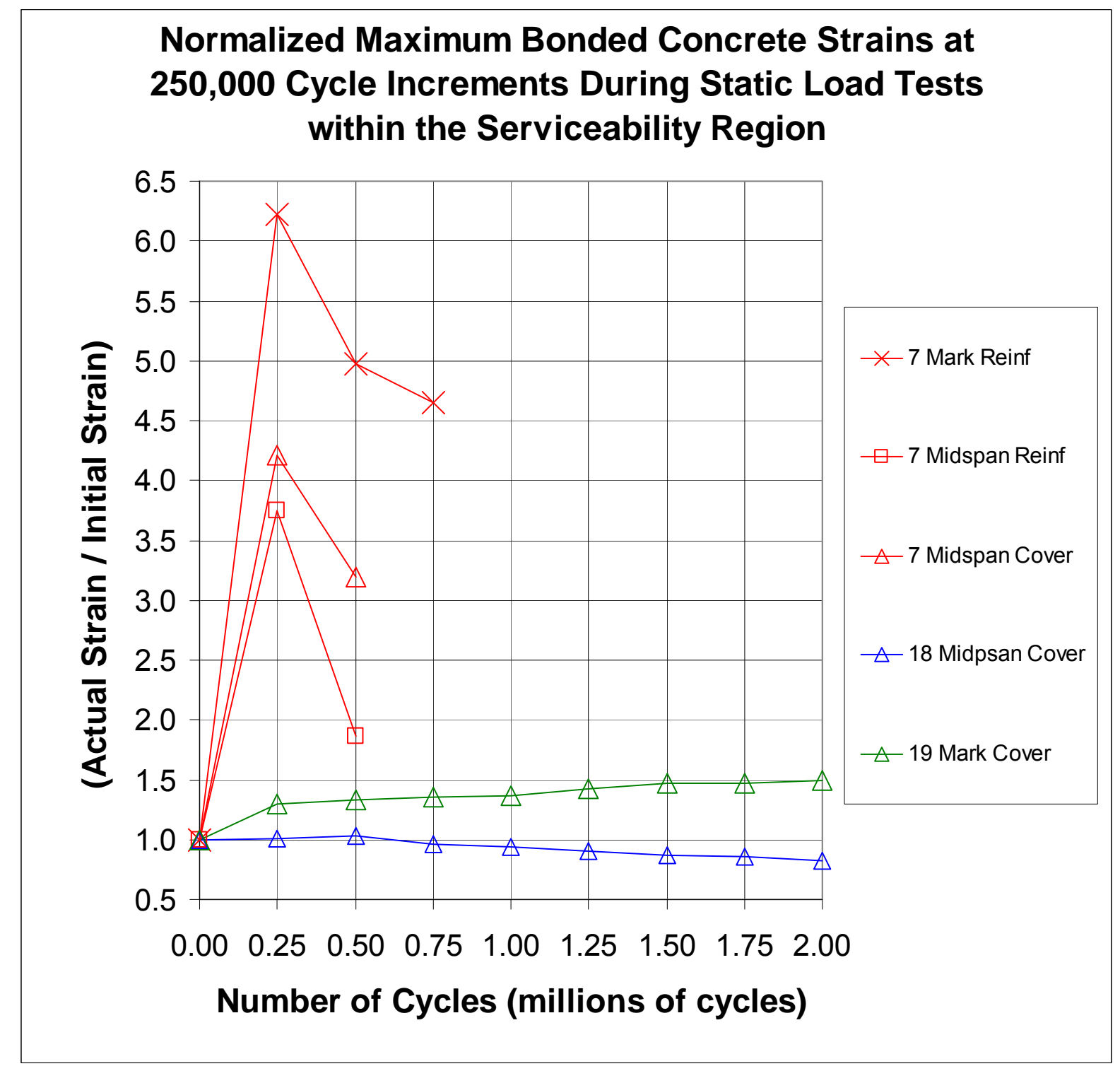

Figure 6.44: Decay of Part II fatigue-loaded beams as illustrated by normalized bonded concrete strain at 250,000 cycle increments during static load tests within the serviceability region (see graphs in Section F.1.2.4 for actual externally bonded concrete strain values)

Figure 6.44 presents normalized concrete strains obtained from surface-bonded gages during the static load tests performed at every 250,000 cycles. "Mark reinf" and "midspan reinf" gages were bonded to the concrete at the depth as the tension steel centerline at the "mark" load point and at midspan, respectively. "Mark cover" and 
"midspan cover" gages were bonded to the concrete at the tension face of the beam at the mark load point and at the midspan, respectively.

Again, highly variable results were obtained from the concrete strain gages with many outliers due to cracking. These outliers are not shown in Figure 6.44. In fact, many of these bonded gages failed during the static load test at 0 cycles due to the formation of cracks beneath the gages.

Meaningful results were obtained, however, from several concrete strain gages. Beam II7 (repaired with Scheme 1) gages showed large maximum strain increases, Beam II-18 (repaired with Scheme 2) gages showed slowly increasing maximum strains, and Beam II-19 (repaired with Scheme 3) gages showed slightly decreasing maximum concrete strains. These results are logical since the least-confined concrete in Wrapping Scheme 1 beams yielded the most dramatic increase in concrete strain and the most-confined concrete in Wrapping Scheme 3 beams yielded a slight decrease in concrete strain.

Embedded concrete strain gages did not perform well in fatigued beams and failed within the first 250,000 cycles.

Table 6.18 presents the permanent microstrains recorded after 2,000,000 fatigue loading cycles in all materials. Beam II-18 yielded the largest average permanent FRP microstrain of 2,019. All permanent microstrain values were similar. The permanent 
strain at midspan was slightly larger than at the load points on each of the gaged and fatigued beams. Average permanent steel strains were similar at all locations. Beam II-7 yielded the largest average permanent steel microstrain of 802 .

Table 6.18: Part II permanent strains after 2,000,000 loading cycles

\begin{tabular}{|c|c|c|c|c|c|}
\hline \multirow{3}{*}{ Gage } & Location & \multicolumn{3}{|c|}{ Part II Beam } & \multirow{2}{*}{ Average } \\
\cline { 3 - 6 } & Mark & 1,171 & 1,442 & 1,407 & 1,340 \\
\hline \multirow{4}{*}{ FRP } & Midspan & 2,625 & 1,937 & 1,527 & 2,030 \\
\cline { 2 - 5 } & Unmark & 1,174 & 2,678 & 1,136 & 1,663 \\
\cline { 2 - 5 } & Average & 1,657 & 2,019 & 1,357 & \\
\cline { 2 - 5 } Steel & Mark Inside & 78 & 1,089 & 757 & 641 \\
\cline { 2 - 5 } & Mark Outside & 684 & - & 905 & 795 \\
\cline { 2 - 6 } & Midspan Inside & 736 & 672 & 615 & 674 \\
\cline { 2 - 6 } & Midspan Outside & 986 & 267 & 742 & 665 \\
\cline { 2 - 6 } & Average & 802 & 470 & 754 & \\
\hline
\end{tabular}

\subsubsection{Literature Review on Cyclic Loading}

\subsection{Masoud, 2005}

Beam specimens subjected to fatigue loading were tested in 4-point bending along a span of 9'-10" and a constant moment region of $3^{\prime}-3$ '. All specimens failed due to tension steel rupture. For wrapping scheme II beams, which were strengthened in flexure, the FRP laminate ruptured immediately after tension steel failure. The CFRP laminates did increase the fatigue life of the beam specimens by a factor of about 2.5 since it reduced the stress range in the tension steel. A summary of cyclic loading test results is presented in Table 6.19.

Interestingly, it was found that just a small amount of pitting corrosion in the reinforcing steel significantly reduced the fatigue life of a reinforced concrete beam. However, 
fatigue life was not further reduced at more severe levels of pitting corrosion, indicating that the life of a reinforced concrete structure may be significantly reduced at the time pitting corrosion initiates. The onset of delamination was the primary failure mode of strengthened beams with and without exposure to environmental conditions.

Table 6.19: Summary of Masoud (2005) Test Results

\begin{tabular}{|c|c|c|c|c|c|c|c|}
\hline \multirow[t]{2}{*}{ Specimen } & \multirow[t]{2}{*}{ ID } & \multirow{2}{*}{$\begin{array}{c}\text { Mass loss } \\
(\%)\end{array}$} & \multirow{2}{*}{$\begin{array}{c}\text { Fatigue } \\
\text { life } \\
\text { (cycles) }\end{array}$} & \multicolumn{2}{|c|}{ Maximum deflection } & \multicolumn{2}{|c|}{ Maximum concrete strain } \\
\hline & & & & $\begin{array}{l}\text { Start } \\
(\mathrm{mm})\end{array}$ & $\begin{array}{l}\text { End } \\
(\mathrm{mm})\end{array}$ & $\begin{array}{l}\text { Start } \\
(\mu \varepsilon)\end{array}$ & $\begin{array}{l}\text { End } \\
(\mu \varepsilon)\end{array}$ \\
\hline Control & $00-\mathrm{U}$ & 0.0 & 337,200 & 13.04 & 14.23 & 896 & 1020 \\
\hline Corroded & $11-\mathrm{U}$ & 5.5 & 109,400 & 12.3 & 13.05 & 914 & 926 \\
\hline \multirow[t]{2}{*}{ unrepaired } & $22-U$ & 9.2 & 8,300 & 12.94 & 14.58 & 924 & 956 \\
\hline & $33-U$ & 12.5 & 75,400 & 13.17 & 14.9 & 944 & 1053 \\
\hline FRP-repaired & $11-\mathrm{RI}^{\mathrm{a}}$ & 5.5 & 118,000 & 12.63 & 13.33 & 897 & 1038 \\
\hline \multirow[t]{2}{*}{ (scheme I) } & $12-\mathrm{RI}^{\mathrm{b}}$ & 9.0 & 94,800 & 12.8 & 14 & 928 & 949 \\
\hline & $13-\mathrm{RI}^{\mathrm{b}}$ & 10.5 & 101,000 & 12.48 & 13.96 & 921 & 1041 \\
\hline FRP repaired & $11-\mathrm{RII}^{\mathrm{a}}$ & 5.5 & 232,000 & 9.62 & 10.7 & 777 & 884 \\
\hline \multirow[t]{2}{*}{ (scheme II) } & $12-\mathrm{RII}^{\mathrm{b}}$ & 9.0 & 209,000 & 9.76 & 11.15 & 766 & 911 \\
\hline & $13-\mathrm{RII}^{\mathrm{b}}$ & 10.5 & 216,000 & 9.15 & 11 & 738 & 820 \\
\hline \multicolumn{8}{|l|}{$\begin{array}{l}\text { a Short term. } \\
{ }^{b} \text { Long term. }\end{array}$} \\
\hline \multirow[t]{2}{*}{ Specimen } & ID & \multicolumn{2}{|c|}{ Nominal stress } & $\begin{array}{l}\text { Maximum } \\
\text { local stress } \\
(\mathrm{MPa})\end{array}$ & \multicolumn{2}{|c|}{ Local change } & $\mathrm{K}_{\mathrm{f}}$ \\
\hline & & $\begin{array}{l}\text { Maximum } \\
(\mathrm{MPa})\end{array}$ & $\begin{array}{l}\text { Minimum } \\
(\mathrm{MPa})\end{array}$ & & $\begin{array}{l}\text { Stress } \\
(\mathrm{MPa})\end{array}$ & $\begin{array}{c}\text { Strain } \\
(\mu \varepsilon)\end{array}$ & \\
\hline Control & 00-UF & 363 & 40 & 470 & 608 & 3230 & 1.94 \\
\hline Corroded & $11-\mathrm{U}$ & 380 & 42 & 494 & 681 & 3875 & 2.15 \\
\hline \multirow[t]{2}{*}{ unrepaired } & $22-U$ & 386 & 43 & 500 & 700 & 4076 & 2.2 \\
\hline & $33-U$ & 397 & 44 & 503 & 709 & 4178 & 2.18 \\
\hline FRP-repaired & $11-\mathrm{RI}$ & 378 & 42 & 475 & 679 & 3845 & 2.15 \\
\hline \multirow[t]{2}{*}{ (scheme I) } & 12-RI & 389 & 43 & 497 & 693 & 3995 & 2.15 \\
\hline & 13-RI & 392 & 44 & 497 & 689 & 3959 & 2.12 \\
\hline FRP repaired & 11-RII & 316 & 35 & 478 & 631 & 3414 & 2.34 \\
\hline \multirow[t]{2}{*}{ (scheme II) } & 12-RII & 321 & 36 & 480 & 638 & 3465 & 2.33 \\
\hline & 13-RII & 322 & 36 & 479 & 636 & 3453 & 2.32 \\
\hline \multicolumn{8}{|c|}{$\begin{array}{l}\text { Note: Specimen designated is as follows: First letter: Level of corrosion exposure ( } 0 \text { for no corrosion, } 1,2 \text {, and } 3 \text { for minor, } \\
\text { medium, and severe degrees of corrosion); Second letter: Level of corrosion exposure at time of test to failure }(0,1,2 \text {, and } 3) \text {; Thir } \\
\text { letter: U for unrepaired, RI or RII for FRP repaired specimens using scheme I and scheme II, respectively. Specimen groups: First } \\
\text { group: Control; 00-U; Second group: Corroded unrepaired, 11-U, 22-U, and 33-U; Third group: FRP repaired (short-term), 11-RI, } \\
\text { and 11-RII; Fourth group: FRP-repaired (long-term), 12-RI, 13-RI, 12-RII, and 13-RII. }\end{array}$} \\
\hline
\end{tabular}


For specimen details and repair methods used in this study, please see Section 4.2.1.1.3.

For accelerated aging information, please see Section 6.1.2.3. For crack measurement information, please see Section 6.2.1.2.2.

\subsection{Grace, 2004}

Cyclic load tests were conducted in 4-point bending along a span of 7'-4" and with a constant moment region of 2'-8'. Cyclic loads of 15,25 , and $40 \%$ ultimate were applied at a frequency of $3.25 \mathrm{~Hz}$ for duration of $2,000,000$ cycles. Cyclic loading did not have a significant effect on the flexural strength of the CFRP strengthened beams $(7.5 \%$ for plates and $2.5 \%$ for fabric). As in the static tests, the onset of delamination was the primary failure mode. Table 6.20 shows the ultimate loads observed after cyclic testing was complete.

Table 6.20: Ultimate failure loads observed by Grace (2004) after cyclic loading was complete. "P" stands for plates and " $F$ " stands for fabric.

\begin{tabular}{|l|c|}
\hline \multicolumn{1}{|c|}{ Beam } & $\begin{array}{c}\text { Ultimate failure load, } \\
\text { kN }\end{array}$ \\
\hline Unstrengthened & 85.9 \\
\hline Plate reference & 138.4 \\
\hline P-R15 & 126.4 \\
\hline P-R25 & 129.9 \\
\hline P-R40 & 146.9 \\
\hline Fabric reference & 129.5 \\
\hline F-R15 & 125.9 \\
\hline F-R25 & 125.9 \\
\hline F-R40 & 130.4 \\
\hline
\end{tabular}


For specimen details and repair methods used in this study, please see Section 4.2.1.1.8.

For accelerated aging information, please see Section 6.1.2.7. For static flexural testing procedures and results, please see section 6.3.2.2.7.

\subsection{Aidoo, 2004}

Beams were fatigued in 3-point bending over a span of 29'. The fatigued specimen was subjected to 2,000,000 cycles of loading corresponding to the application of dead load plus an HS25 service load (plus impact factor). The frequency of loading was $1.2 \mathrm{~Hz}$. This specimen exhibited intermediate crack-induced debonding as its initial failure mode. The observed strain in the CFRP immediately before debonding was $6,760 \mu \varepsilon$, compared to the $9,400 \mu \varepsilon$ observed in the duplicate non-fatigued specimen. During the fatigue conditioning, no significant degradation was observed in the specimens.

For specimen details and repair methods used in this study, please see Section 4.2.1.1.9. For static flexural testing procedures and results, please see section 6.3.2.2.9.

\subsection{Quattlebaum, 2005}

Two beams were fatigued in 3-point bending over a span of 15'. The first beam was subjected to high stress fatigue loading to failure at a frequency of $1.2 \mathrm{~Hz}(6,000,000$ cycles). The second beam was subjected to $2,000,000$ cycles of low stress fatigue loading at a frequency of $1.2 \mathrm{~Hz}$ and was then fatigued to failure under the high-stress load level. These specimens exhibited intermediate crack-induced debonding as its initial 
failure mode. The observed strains in the CFRP immediately before debonding were $3,750 \mu \varepsilon$ and $2,520 \mu \varepsilon$ for the high-stress loaded and low-stress loaded specimens, respectively, compared to the $6,400 \mu \varepsilon$ observed in the duplicate non-fatigued specimen.

For specimen details and repair methods used in this study, please see Section 4.2.1.1.10. For static flexural testing procedures and results, please see section 6.3.2.2.10.

\subsubsection{Suggestions for Improvement}

Due to time constraints, only 2,000,000 cycles were applied to each fatigue-loaded beam in this experiment. Ideally, each specimen should be subjected to at least $10,000,000$ cycles in order to observe the full effects of fatigue on the FRP repair system.

A larger number of beam specimens should be added to future cyclic loading plans. These beams should be fatigued to failure using different maximum loads so that different beams fail at different numbers of cycles. S-N curves, where stress is plotted against the number of cycles required to fail the specimens, could then be plotted on a logarithmic scale. It is important to maintain the same amplitude for all tests when developing S-N curves.

S-N curves are important because they provide information on both the fatigue strength and the fatigue life of a specimen. Fatigue strength can be defined as the stress at which 
failure occurs for a given number of cycles, and fatigue life can be defined as the number of cycles required for a material to fail at a certain stress.

A fatigue threshold could also be obtained by finding the highest stress at which no failure occurs. For stresses below the fatigue threshold, the specimen will never fail, regardless of the number of applied load cycles. Due to the typical large scatter of fatigue data, a reduction factor should be incorporated into the S-N curve results to provide conservative values for future design.

It is recommended that a backup actuator system be availabe in case the main actuator requires maintenance, as was the case several times during this experiment which resulted in significant delays. Future researchers should plan ahead assuming that all equipment may be temporarily disabled during at least some portion of the project. 


\subsubsection{Static Flexural Testing}

\subsubsection{Results}

\subsection{Part I}

Figure 6.45, Figure 6.46, Figure 6.47, Figure 6.48, and Figure 6.49 show various sets of load-deflection curves grouped together for comparison. Figure 6.45 shows the superposition of all curves obtained in Part I. Figure 6.46 and Figure 6.47 display comparisons of FRP-repaired beams. Figure 6.48 and Figure 6.49 display curves for corroded and unrepaired beams and pristine control beams, respectively. The curves in these figures are analyzed in the following commentary.

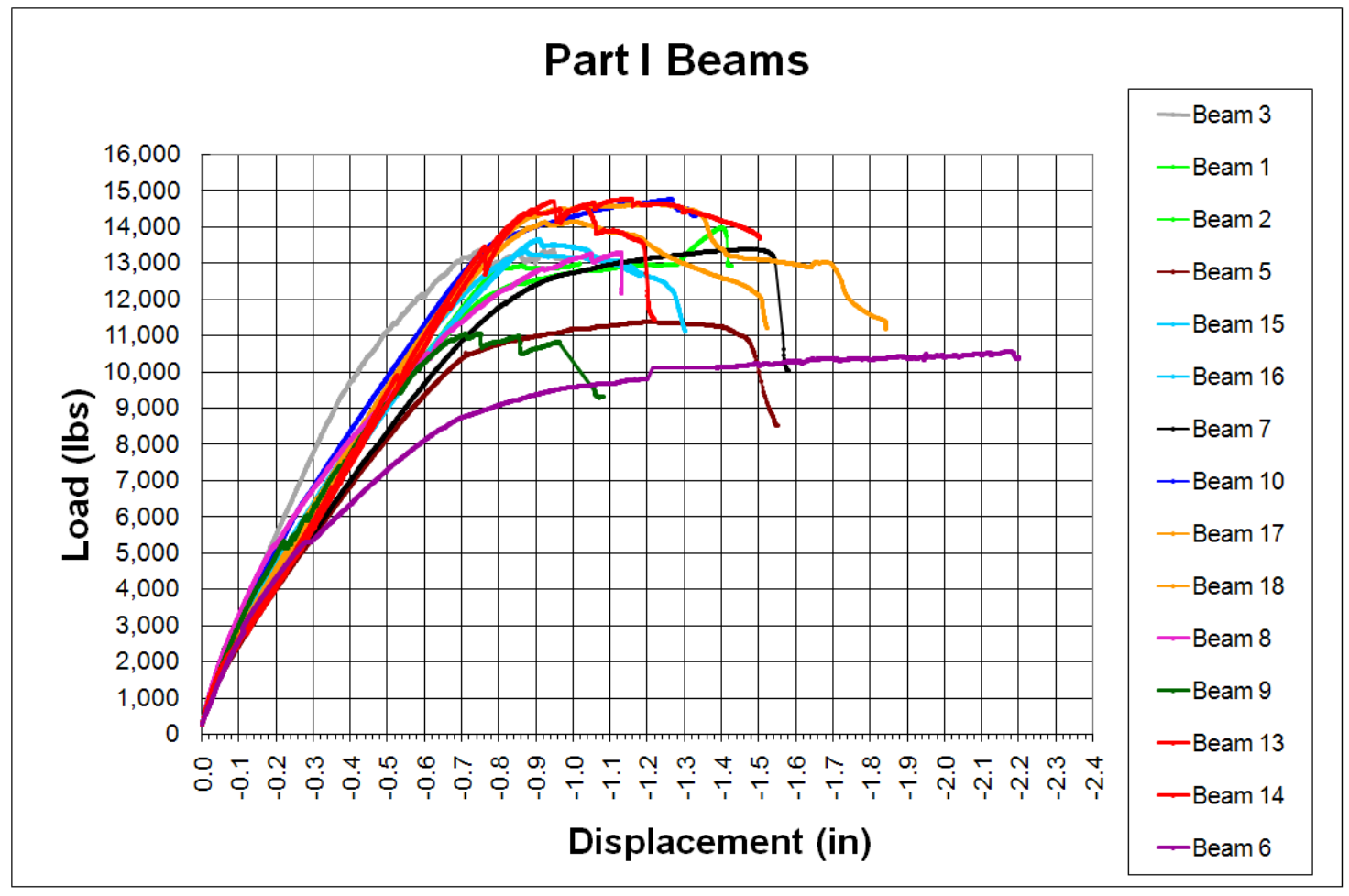

Figure 6.45: Part I load-deflection curves 


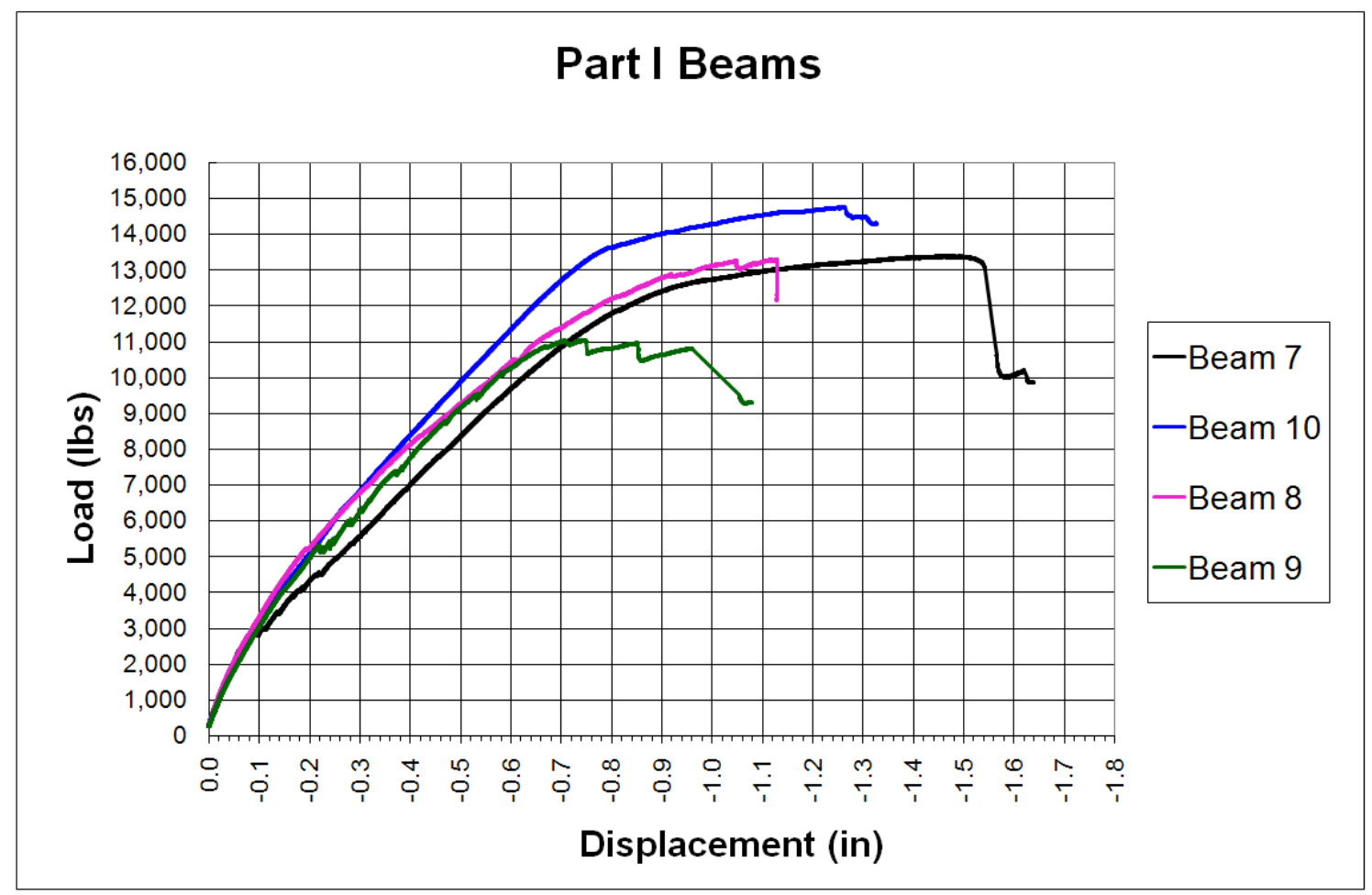

Figure 6.46: Comparison of Part I load-deflection curves for beams repaired with FRP

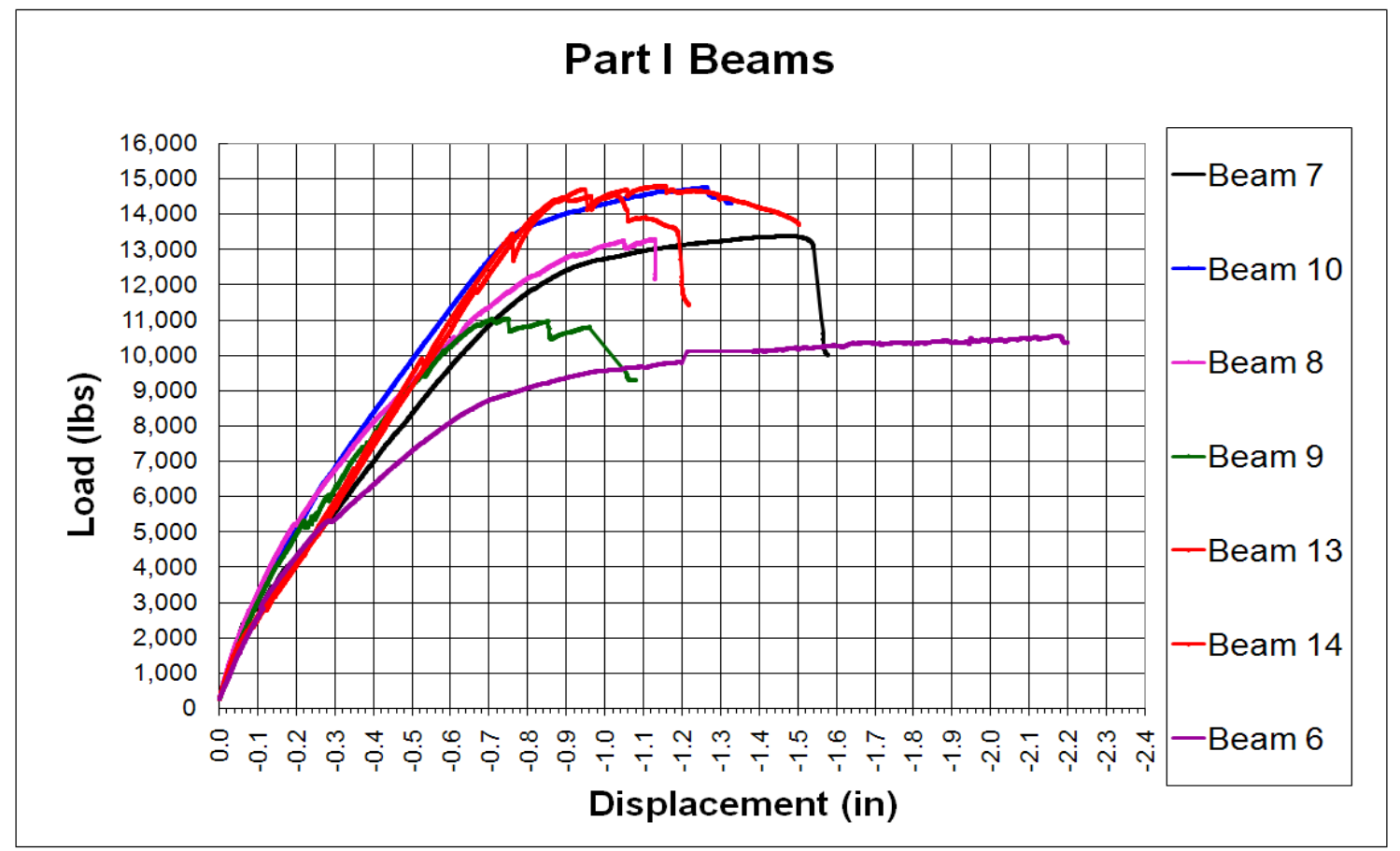

Figure 6.47: Comparison of Part I load-deflection curves for beams repaired with FRP and both pristine and aged control beams 


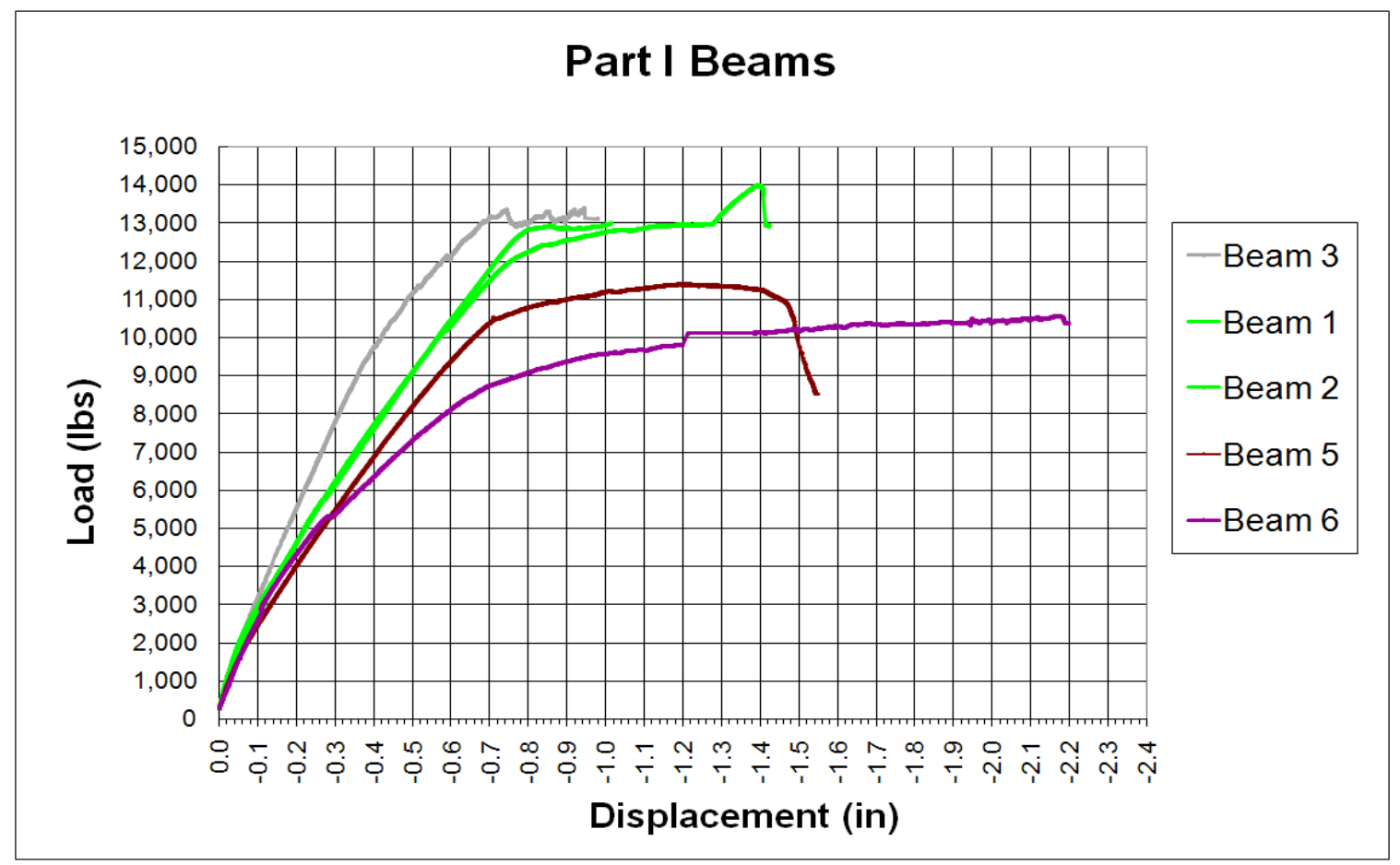

Figure 6.48: Comparison of Part I load-deflection curves for beams repaired with FRP and both pristine and aged control beams

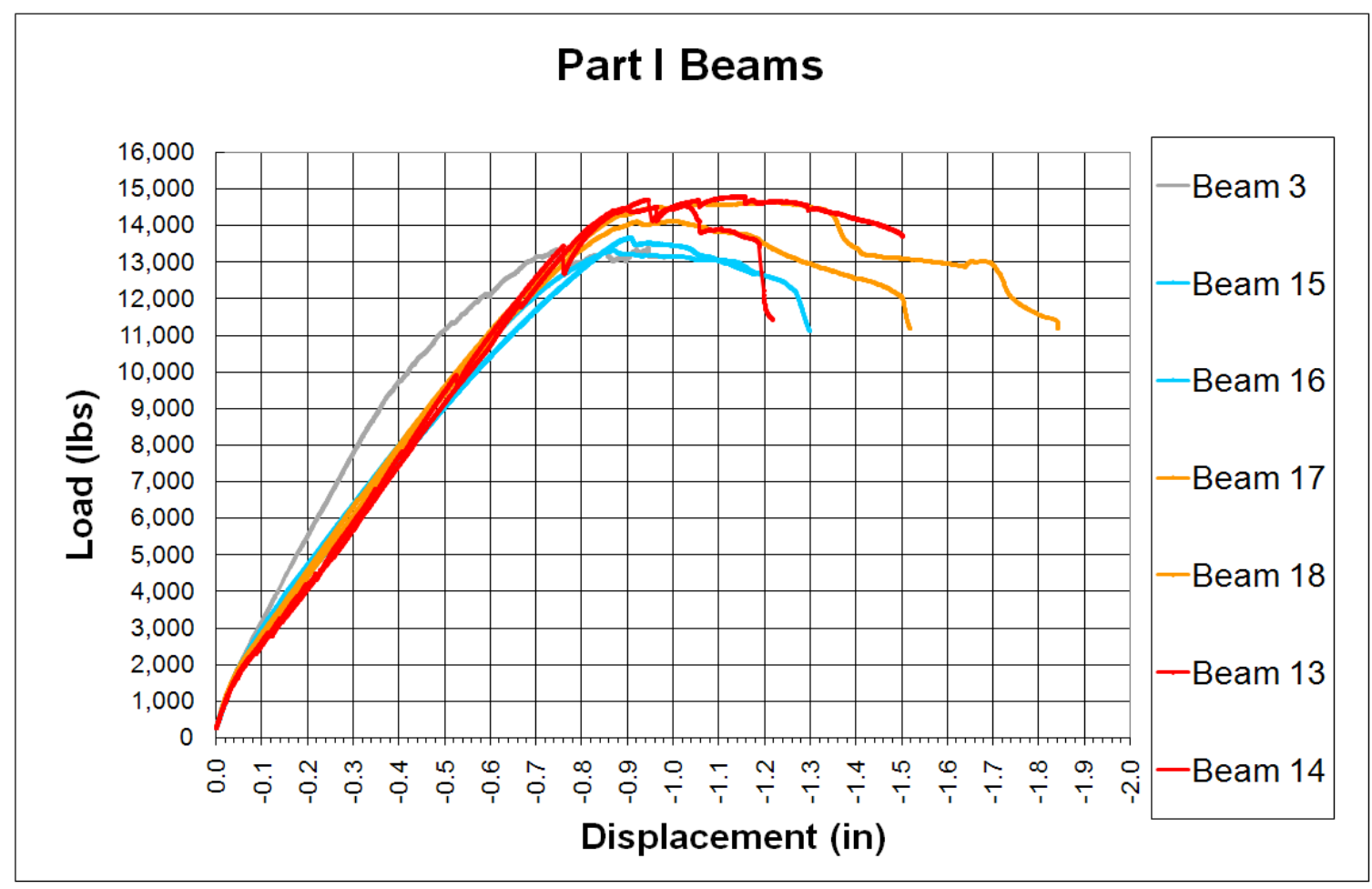

Figure 6.49: Comparison of Part I load-deflection curves for pristine control beams 
Table 6.22 presents a summary of both maximum service and failure loads. This data is also plotted in a stacked bar graph in Figure 6.50. The maximum service load is defined as the highest load observed within the nearly-linear post-cracking region on the loaddeflection curve. All loads presented in this table were rounded to the nearest $100 \mathrm{lbs}$.

Table 6.21: Part I Load Capacity Summary

\begin{tabular}{|c|c|c|c|c|c|}
\hline Description & Beam & 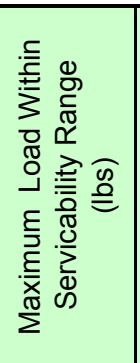 & 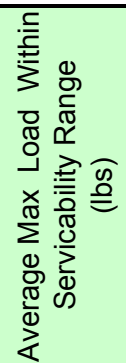 & 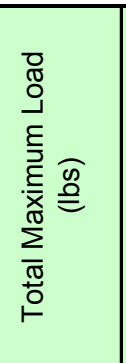 & 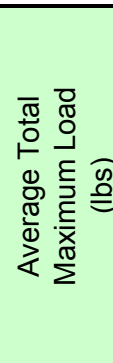 \\
\hline 28-Day Pristine & 3 & 11,300 & 11,300 & 13,300 & 13,300 \\
\hline Mildly Corroded Unrepaired & $\frac{1}{2}$ & \begin{tabular}{l|}
11,200 \\
12,600 \\
\end{tabular} & 11,900 & \begin{tabular}{r|}
14,000 \\
13,000 \\
\end{tabular} & 13,500 \\
\hline Corroded Unrepaired After Initial Corrosion Process & 5 & 10,300 & 10,300 & 11,400 & 11,400 \\
\hline Pristine Control After Initial Corrosion & $\begin{array}{l}15 \\
16 \\
\end{array}$ & $\begin{array}{l}11,800 \\
11,900 \\
\end{array}$ & 11,850 & $\begin{array}{l}13,400 \\
13,600 \\
\end{array}$ & 13,500 \\
\hline Patch Repair + FRP Repair (After Initial Corrosion) & 7 & 11,600 & 11,600 & 13,300 & 13,300 \\
\hline Crack Injection + FRP Repair (After Initial Corrosion) & 10 & 12,800 & 12,800 & 14,800 & 14,800 \\
\hline Pristine Control at Time of FRP Repair & $\begin{array}{l}17 \\
18 \\
\end{array}$ & $\begin{array}{l}13,100 \\
12,900 \\
\end{array}$ & 13,000 & \begin{tabular}{r|}
14,600 \\
14,100 \\
\end{tabular} & 14,350 \\
\hline Patch Repair + FRP Repair (After Post-Repair Corrosion) & 8 & 10,500 & 10,500 & 13,300 & 13,300 \\
\hline Crack Injection + FRP Repair (After Post-Repair Corrosion) & 9 & 9,600 & 9,600 & 11,000 & 11,000 \\
\hline Severely Corroded Unrepaired (Second Corrosion Process) & 6 & 8,300 & 8,300 & 10,500 & 10,500 \\
\hline Pristine Control After Second Corrosion Process & $\frac{13}{14}$ & \begin{tabular}{|l|}
13,300 \\
13,400
\end{tabular} & 13,350 & \begin{tabular}{r|}
14,500 \\
14,700 \\
\end{tabular} & 14,600 \\
\hline
\end{tabular}

ACI deflection analysis equations predicted an ultimate load of 6,198lbs at each load point, or approximately $12,400 \mathrm{lbs}$ total. The pristine beams yielded average maximum service loads of 11,300lbs (28-day), 11,850lbs (25 weeks), 13,000lbs (40 weeks), and $13,350 \mathrm{lbs}$ ( 66 weeks), all of which average to $12,529 \mathrm{lbs}$. This is a good quality control observation as it verifies the beam specimens performed as designed. 
As can be seen, the mild corrosion in Beams I-1 and I-2 did not negatively affect flexural strength. This supports the decision to extend the corrosion process on the Part I beams as was discussed in the accelerated aging results section.

The complete initial corrosion cycle applied to Beam I-5 resulted in a $13 \%$ reduction in service load capacity and a $16 \%$ reduction in maximum load capacity compared to the average of the equivalent-age pristine Beams I-15 and I-16.

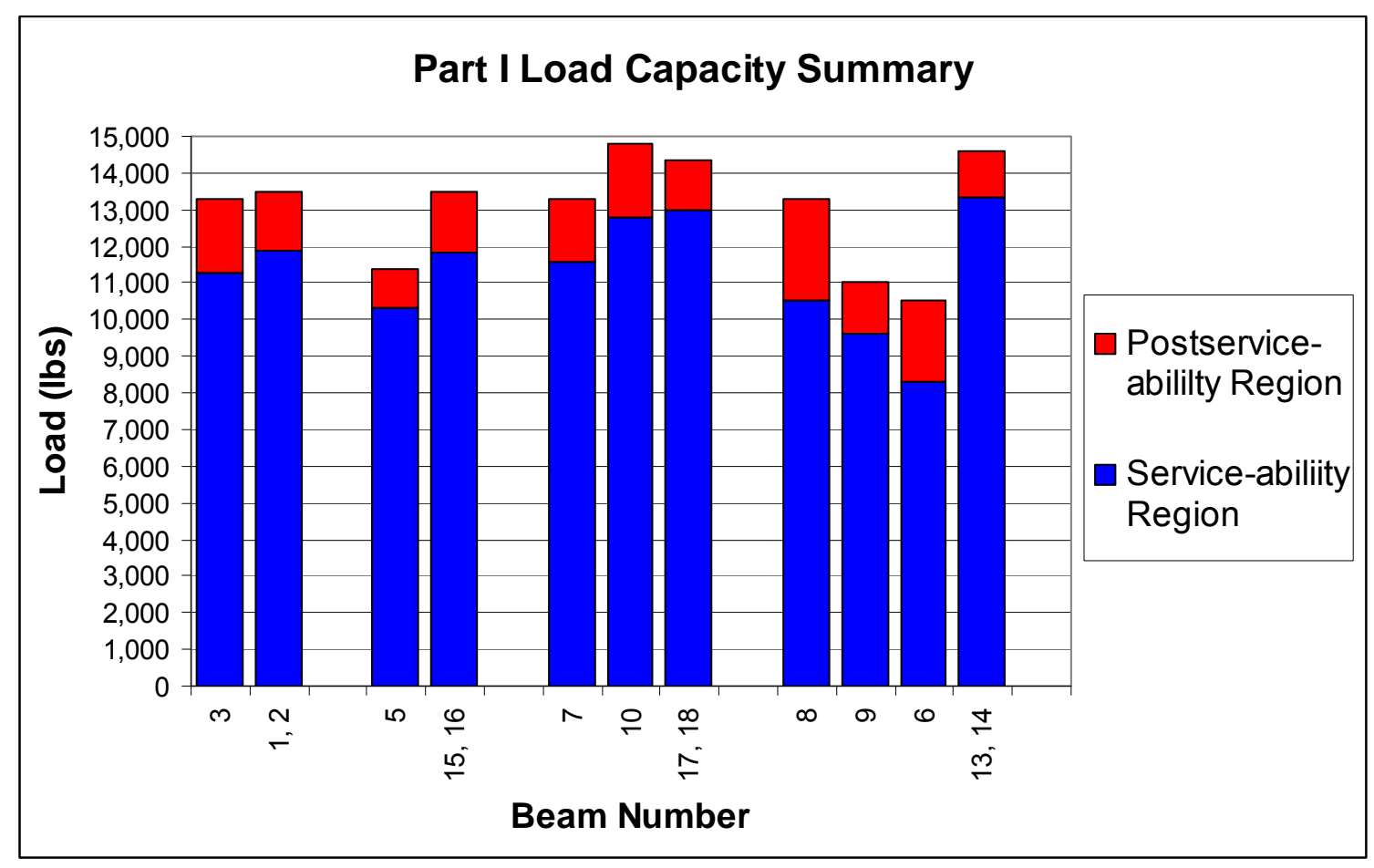

Figure 6.50: Part I Load Capacities

FRP analysis calculations show that the FRP-repaired beam should withstand an unfactored service load of approximately 11,630lbs. This was slightly less than the original pristine design capacity, but to ensure valuable data from this research, it was essential that the repaired beams fail in tension. For this reason, the beam repairs were 
not intended to fully restore original capacity to the specimens, as would be expected for an actual bridge repair. The focus was, instead, to observe the long-term durability and behavior of the repair schemes. The two FRP-repaired beams yielded maximum service loads of $11,600 \mathrm{lbs}$ and $12,800 \mathrm{lbs}$, exhibiting excellent correlation with the analysis. The maximum service load of the FRP-repaired beams was slightly less than that of the pristine control beams of the same age. The maximum total loads were approximately the same as those of the pristine control beams. Even though the beams were slightly under-reinforced, the FRP system in Beam I-7 provided a 3\% service load increase and an equal failure load compared to 28-day pristine Beam I-3. Surprisingly, Beam I-7, which was completely patch repaired, yielded a $9 \%$ lesser service and ultimate strength than did Beam I-10, in which the cracks were simply epoxy-injected and no deteriorated concrete was removed. Beam I-10 showed more dramatic increases in load capacity of $13 \%$ and $11 \%$ for maximum service and failure loads, respectively, when compared to 28-day pristine Beam I-3. The service load for Beam I-7 was $0.3 \%$ less than the predicted value and the service load for Beam I-10 was $10 \%$ higher than the predicted value.

Beam I-6, which was subjected to two corrosion cycles, yielded a maximum service load of only $8,300 \mathrm{lbs}$ and a total maximum load of only $10,500 \mathrm{lbs}$ (reductions of $38 \%$ and $28 \%$, respectively) when compared to the pristine control beams of the same age. Beam I-6 also yielded maximum service and failure loads of $19 \%$ and $8 \%$ less than initiallycorroded unrepaired Beam I-5. 
Beam I-9, with substrate crack injection prior to FRP repair, exhibited significant strength decrease when subjected to additional corrosion after repair. Its service and failure loads were $25 \%$ and $29 \%$ less than those of duplicate Beam I-10 which were tested immediately after repair. Beam I-9 exhibited service and failure loads of $28 \%$ and $25 \%$ less than did the pristine control beams of the same age. Interestingly, Beam I-9 had maximum service and failure loads of just $16 \%$ and $5 \%$ higher than did equally-corroded unrepaired Beam I-6. Beam I-9 actually exhibited service and failure loads that were 7\% and $4 \%$ less than those of initially-corroded unrepaired Beam I-5. In summary, the result of additional accelerated aging was an FRP-repaired beam with a lesser capacity than the corroded unrepaired beam for which the FRP system was designed to strengthen. The repair of Beam I-9 can be considered a failure for long-term durability. Although the lesser substrate repair was adequate immediately after strengthening, the system did not perform well at all when subjected to continued aging.

Beam I-8, which was completely patch repaired with polymer concrete containing corrosion inhibitors, proved to be more durable. It too, however, exhibited some deterioration compared to its duplicate beam I-7, which was tested immediately after FRP repair. Beam I-8 had a maximum service load that was $9 \%$ less than that of I-7 and exhibited an equal failure load of 13,300lbs. The maximum service and failure loads of Beam I- 8 , however, were still $21 \%$ and $9 \%$ less than the pristine control beams of the same age. The maximum service load for Beam I-8 was only 7\% less than that of I-3, and the failure loads of the two were equivalent. Overall, the repair of Beam I- 8 can be considered a success, although it also shows the necessity of using conservative safety 
factors when designing an FRP strengthening system since some strength loss due to continuing deterioration is inevitable.

Beams I-8 and I-9 had service load capacities of 10 and 17\% (respectively) less than those predicted for a beam immediately after repair.

Table 6.22 presents a summary of the maximum service and failure deflections. The maximum service load deflection is the largest deflection observed in the post-cracking region of the load-deflection curve. All deflections presented in this table were rounded to the nearest $0.01 \mathrm{in}$.

Reinforced concrete beam deflection analysis equations predicted a maximum service load deflection of $0.53 \mathrm{in}$. The 28-day-old Beam I-3 exhibited a maximum service load deflection of $0.52 \mathrm{in}$, showing excellent compatibility between actual and predicted results. Other pristine beams exhibited slightly larger service load deflections at later ages, ranging between 0.67 and 0.77 in. Part of this difference can be attributed to some of the load-deflection curves having postservicability transition zones with locations that were difficult to precisely define. The 28-day pristine Beam I-3 deflected a maximum of $0.95 \mathrm{in}$ at failure.

The mildly-corroded Beams I-1 and I-2 and the more severely-corroded Beam I-5 all exhibited average maximum service deflections of approximately $0.7 \mathrm{in}$ and failure 
deflections of 1.21in. The pristine controls at the same age (Beams I-15 and I-16) deflected an average 0.70in at maximum the service load as well, but the average failure deflection was only $0.88 \mathrm{in}$. It should be noted that there was excellent consistency between control Beams I-15 and 16: both sets of deflections were within \pm 0.05 in of each other.

Table 6.22: Part I Deflection Summary

\begin{tabular}{|c|c|c|c|c|c|}
\hline Description & Beam & 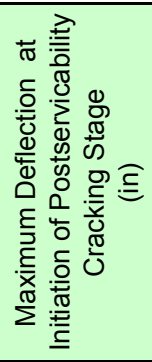 & 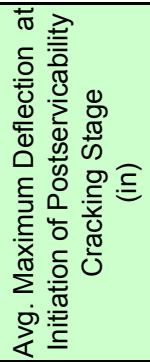 & 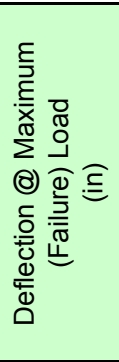 & 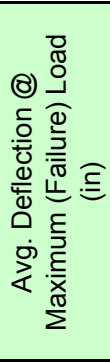 \\
\hline 28-Day Pristine & 3 & 0.52 & 0.52 & 0.95 & 0.95 \\
\hline \multirow{2}{*}{ Mildly Corroded Unrepaired } & 1 & 0.66 & \multirow{2}{*}{0.72} & 1.40 & \multirow{2}{*}{1.21} \\
\hline & 2 & 0.77 & & 1.02 & \\
\hline Corroded Unrepaired After Initial Corrosion Process & 5 & 0.70 & 0.70 & 1.21 & 1.21 \\
\hline \multirow{2}{*}{ Pristine Control After Initial Corrosion } & 15 & 0.67 & \multirow{2}{*}{0.70} & 0.86 & \multirow{2}{*}{0.88} \\
\hline & 16 & 0.72 & & 0.90 & \\
\hline Patch Repair + FRP Repair (After Initiail Corrosion) & 7 & 0.78 & 0.78 & 1.51 & 1.51 \\
\hline Crack Injection + FRP Repair (After Initial Corrosion) & 10 & 0.72 & 0.72 & 1.26 & 1.26 \\
\hline \multirow{2}{*}{ Pristine Control at Time of FRP Repair } & 17 & 0.77 & \multirow{2}{*}{0.77} & 1.25 & \multirow{2}{*}{1.13} \\
\hline & 18 & 0.77 & & 1.01 & \\
\hline Patch Repair + FRP Repair (After Post-Repair Corrosion) & 8 & 0.62 & 0.62 & 1.13 & 1.13 \\
\hline Crack Injection + FRP Repair (After Post-Repair Corrosion) & 9 & 0.53 & 0.53 & 0.75 & 0.75 \\
\hline Severely Corroded Unrepaired (Second Corrosion Process) & 6 & 0.62 & 0.62 & 2.18 & 2.18 \\
\hline \multirow{2}{*}{ Pristine Control After Second Corrosion Process } & 13 & 0.76 & \multirow{2}{*}{0.76} & 1.03 & \multirow{2}{*}{0.99} \\
\hline & 14 & 0.76 & & 0.95 & \\
\hline
\end{tabular}

Beam I-7 yielded a maximum service deflection of 0.78in, while Beam I-10 yielded a slightly lesser service deflection of 0.72in. A similar trend was observed for failure deflection; Beam I-7 deflected a maximum of 1.51in while Beam I-10 deflected a 17\% less 1.26in. Pristine control beams of equivalent age (Beams I-17 and 18) had service and failure deflections of $0.77 \%$ and $1.13 \%$, respectively. There was excellent comparability between the service regions of control Beams I-17 and I-18, as the service 
load deflections were identical. No significant difference was detected between the deflections of the repaired beams and of the pristine control beams after the intital corrosion cycle.

Interesting results were obtained when comparing the deflections of the FRPstrengthened beams immediately after repair and the ones tested after the addional corrosion cycle. Beam I-8 (patch repair/additional corrosion) had service and failure deflections of 0.62 and $1.13 \mathrm{in}$, respectively, which were $21 \%$ and $25 \%$ less than those of Beam I-7 (patch repair/no additional corrosion). Beam I-9 (crack injection/additional corrosion) had service and failure deflections of 0.53 and $0.75 \mathrm{in}$, respectively, which were $26 \%$ and $50 \%$ less than those of Beam I-10 (crack injection/no additional corrosion). The fact that the beams repaired using polymer-modified concrete yielded higher deflections both before and after additional corrosion suggests that patch-repair before FRP strengthening results in a more ductile failure mode. Although both of the repaired beams which were subjected to additional accelerated aging exhibited reduced service and failure deflections, the effects were not as great for beams repaired with polymer-modified concrete. Again, these results show the necessity of using conservative safety factors when designing FRP strengthening systems since they apparently lose ductility over time. Pristine control beams of equivalent age (Beams I-13 and I-14) exhibited defections similar to those of the other pristine control beams. Beam I-8 exhibited service load and failure deflections of $18 \%$ and $14 \%$ less (respectively) than those of the pristine control beams. Beam I-9 exhibited even lesser service load and failure deflections of $30 \%$ and $24 \%$, respectively. There was excellent comparability 
between both the service and failure deflections of control Beams I-17 and I-18; the service deflections were equivalent and the failure deflections differed by only $\pm 0.08 \mathrm{in}$.

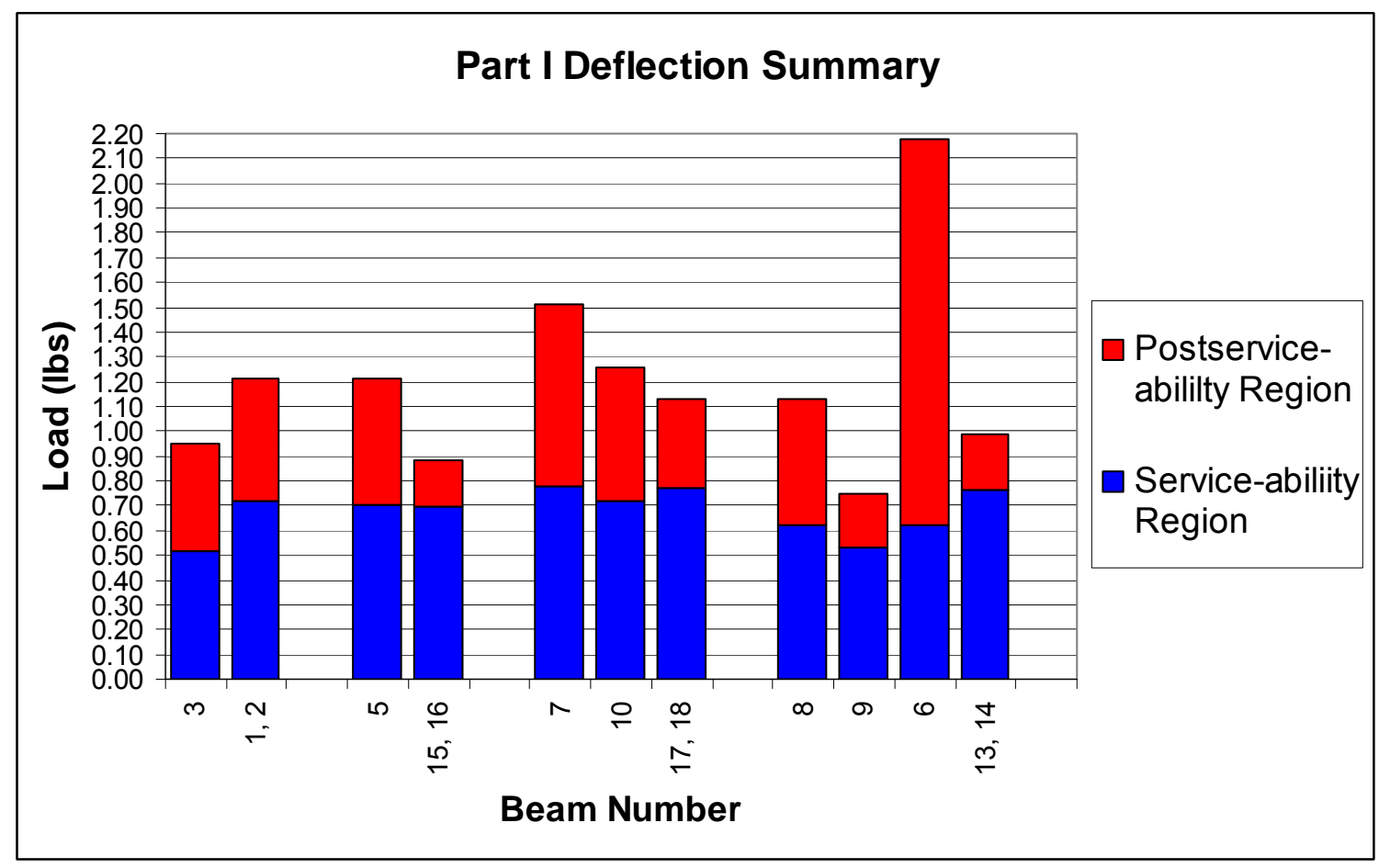

Figure 6.51: Part I Deflections

Beam I-6 had maximum service and failure deflections of 0.62 and $2.18 \mathrm{in}$, respectively. It should be noted that these large deflections in Beam I-6 occurred at loads much less than the design loads. Therefore, it should not be implied that a corroded and unrepaired beam is "safer" than a repaired beam since it is extremely ductile. A reinforced concrete member must have favorable strength and ductility. While its service load was $18 \%$ less than pristine controls of equivalent age, its maximum deflection was $120 \%$ greater. Beam I-8 had a maximum service deflection equivalent to Beam I-6, while Beam I-9 had a service deflection that was $15 \%$ less than that of Beam I-6. 
Table 6.23 presents a summary of both the post-cracking and the post-serviceability stiffness. The stiffness values reported in this table were obtained by adding linear trend lines to the linear portions of the load-deflection curves and obtaining the slopes of these segments. The stiffness value was only used if the linear regression value " $R$ " was $\geq 0.99$.

Table 6.23: Part I Stiffness Summary

\begin{tabular}{|c|c|c|c|c|c|}
\hline \multirow[b]{2}{*}{ Description } & \multirow[b]{2}{*}{ Beam } & \multicolumn{2}{|c|}{$\begin{array}{l}\text { Post-Cracking } \\
\text { Stiffness } \\
\text { (Ibs/in) }\end{array}$} & \multicolumn{2}{|c|}{$\begin{array}{c}\text { Postservicability } \\
\text { Cracking } \\
\text { Stiffness } \\
\text { (lbs/in) }\end{array}$} \\
\hline & & Indiv. & Avg. & Indiv. & Avg. \\
\hline 28-Day Pristine & 3 & 22,201 & 22,201 & 11,829 & 11,829 \\
\hline \multirow{2}{*}{ Mildly Corroded Unrepaired } & 1 & 13,484 & \multirow{2}{*}{13,943} & 2,238 & \multirow{2}{*}{1,265} \\
\hline & 2 & 14,401 & & 292 & \\
\hline Corroded Unrepaired After Initial Corrosion Process & 5 & 13,448 & 13,448 & 1,413 & 1,413 \\
\hline \multirow{2}{*}{ Pristine Control After Initial Corrosion } & 15 & 15,792 & \multirow{2}{*}{15,246} & 6,774 & \multirow{2}{*}{8,500} \\
\hline & 16 & 14,700 & & 10,226 & \\
\hline Patch Repair + FRP Repair (After Initiail Corrosion) & 7 & 13,358 & 13,358 & 1,571 & 1,571 \\
\hline Crack Injection + FRP Repair (After Initial Corrosion) & 10 & 14,942 & 14,942 & 2,882 & 2,882 \\
\hline \multirow{2}{*}{ Pristine Control at Time of FRP Repair } & 17 & 16,774 & \multirow{2}{*}{16,708} & 1,625 & \multirow{2}{*}{3,286} \\
\hline & 18 & 16,642 & & 4,947 & \\
\hline Patch Repair + FRP Repair (After Post-Repair Corrosion) & 8 & 11,378 & 11,378 & 6,826 & 6,826 \\
\hline Crack Injection + FRP Repair (After Post-Repair Corrosion) & 9 & 12,969 & 12,969 & 2,668 & 2,668 \\
\hline Severely Corroded Unrepaired (Second Corrosion Process) & 6 & 9,730 & 9,730 & 1,208 & 1,208 \\
\hline \multirow{2}{*}{ Pristine Control After Second Corrosion Process } & 13 & 16,451 & \multirow{2}{*}{16,577} & 10,525 & \multirow{2}{*}{12,134} \\
\hline & 14 & 16,703 & & 13,742 & \\
\hline
\end{tabular}

The post-cracking stiffness of corroded unrepaired Beam I-5 was $11.8 \%$ less than that of the pristine control Beams I-15 and I-16. The differences in post-cracking stiffness between each set of pristine control beams in Part I were similar, but the postservicability cracking stiffness of the sets of pristine beams appeared to be random. It can still clearly be seen, however, that the postservicability stiffness was greatly reduced for corroded Beam I-5 compared to that of the pristine beams. 
The post-cracking stiffness of Beam I-7 (patch repair) was 11\% less than that of Beam I10 (crack injection). Although it is often reported that FRP strengthening yields a stiffer beam, the post-cracking stiffness was $20 \%$ and $11 \%$ less (for Beams I-7 and I-10, respectively) than the pristine control beams of equal age (Beams I-17 and I-18). It can also be seen that the stiffness of Beams I-7 and I-10 were within the same range as those of corroded unrepaired Beam I-5. It was unexpected that the FRP did not appear to stiffen the specimens. This observation is favorable to the FRP repair, however, since no ductility was lost. The postservicability stiffness of Beams I-7, I-10, I-17, and I-18 were random. It is important to note that the FRP repair of the actual bridge in the PennDOT field study led to deflection decreases of only, 10.4 and $13.4 \%$. This shows that FRP does not have an extremem effect on ductility in laboratory specimens or on actual bridge girders. It also suggests, hoever, that beam length could play a role in determining the magnitude of deflection reduction since the bridge girders exhibited a more noticeable loss of ductility. Further study of this size effect is needed.

The post-cracking stiffness of Beam I-6 (subjected to 2 corrosion cycles) was $41 \%$ less than that of the pristine control beams of equivalent age (Beams I-13 and I-14). It was also $28 \%$ less than that of Beam I-5, which was subjected to only one corrosion cycle. It should be noted that the first corrosion process subjected the beams to 2,000amp hrs of current and the second corrosion process subjected the beams to 2,500amp $h \mathrm{hrs}$ of current. It can be seen that much more stiffness was lost during the second corrosion cycle than during the first. The postservicability stiffness of Beam I-6 was also much less than that of the equal-age control beams. 
The post-cracking stiffness of Beam I-8 (patch repair/additional corrosion) was $12 \%$ less than that of Beam I-9 (crack injection/additional corrosion), similar to the difference between that of Beams I-7 and I-10. Beams I-8 and I-9 had a post-cracking stiffness of $31 \%$ and $23 \%$ less than the pristine control beams, respectively. Beams I-8 and I-9 exhibited a $17 \%$ and $33 \%$ higher post-cracking stiffness than did Beam I-6. Accelerated corrosion after FRP repair resulted in a loss of stiffness in the repaired beams. Beams I-8 and I-9 (after additional corrosion) each had a 15\% lower post-cracking stiffness than did Beams I-7 and Beam I-10 (immediately after repair), respectively.

Table 6.24 shows the locations of FRP rupture. Beams I-7 and I-8 with patch repair tended to rupture nearer to the anchor stirrups and Beams I-8 and I-9 tended to rupture nearer to the midspan.

Table 6.24: Part I FRP Rupture Locations

\begin{tabular}{|c|c|c|}
\hline Description & Beam & $\begin{array}{l}\text { Distance from the Mark } \\
\text { End to the Primary } \\
\text { Location of FRP Failure }\end{array}$ \\
\hline $\begin{array}{l}\text { Patch Repair + FRP Repair (After } \\
\text { Initiail Corrosion) }\end{array}$ & 7 & 2'-8" -- 3'-1" \\
\hline $\begin{array}{c}\text { Crack Injection + FRP Repair } \\
\text { (After Initial Corrosion) }\end{array}$ & 10 & 3'-5" -- 4'-11/2" \\
\hline $\begin{array}{c}\text { Patch Repair + FRP Repair (After } \\
\text { Post-Repair Corrosion) }\end{array}$ & 8 & 2'-6" -- 2'-101/2" \\
\hline $\begin{array}{l}\text { Crack Injection + FRP Repair } \\
\text { (After Post-Repair Corrosion) }\end{array}$ & 9 & 3'-41/2" -- 4'-01/2" \\
\hline
\end{tabular}

Photos of the FRP rupture of Beams I-7, I-10, I-8, and I-9 are shown in Figure 6.52, Figure 6.53, Figure 6.54, and Figure 6.55, respectively. 


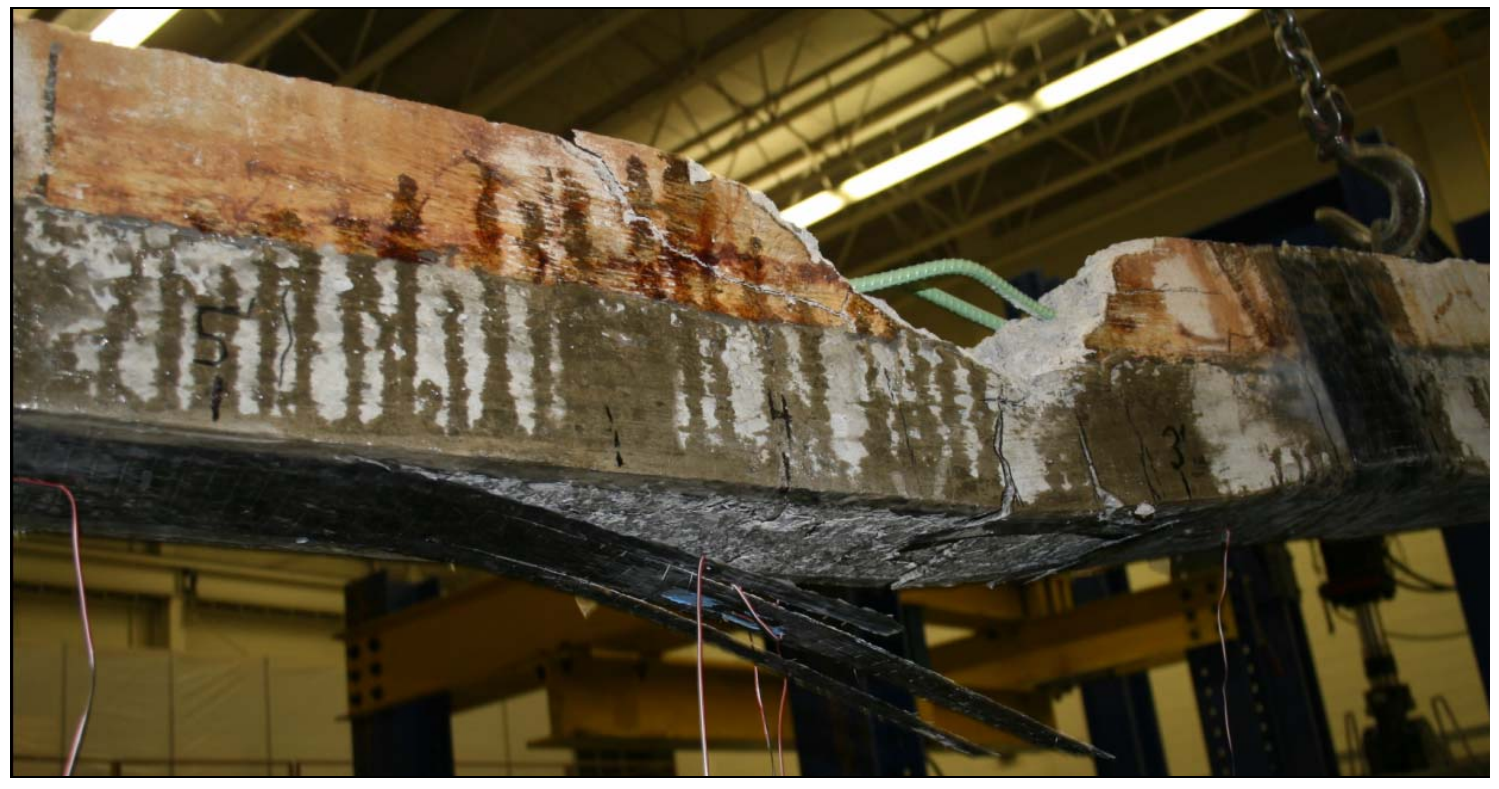

Figure 6.52: FRP Rupture on Beam I-7

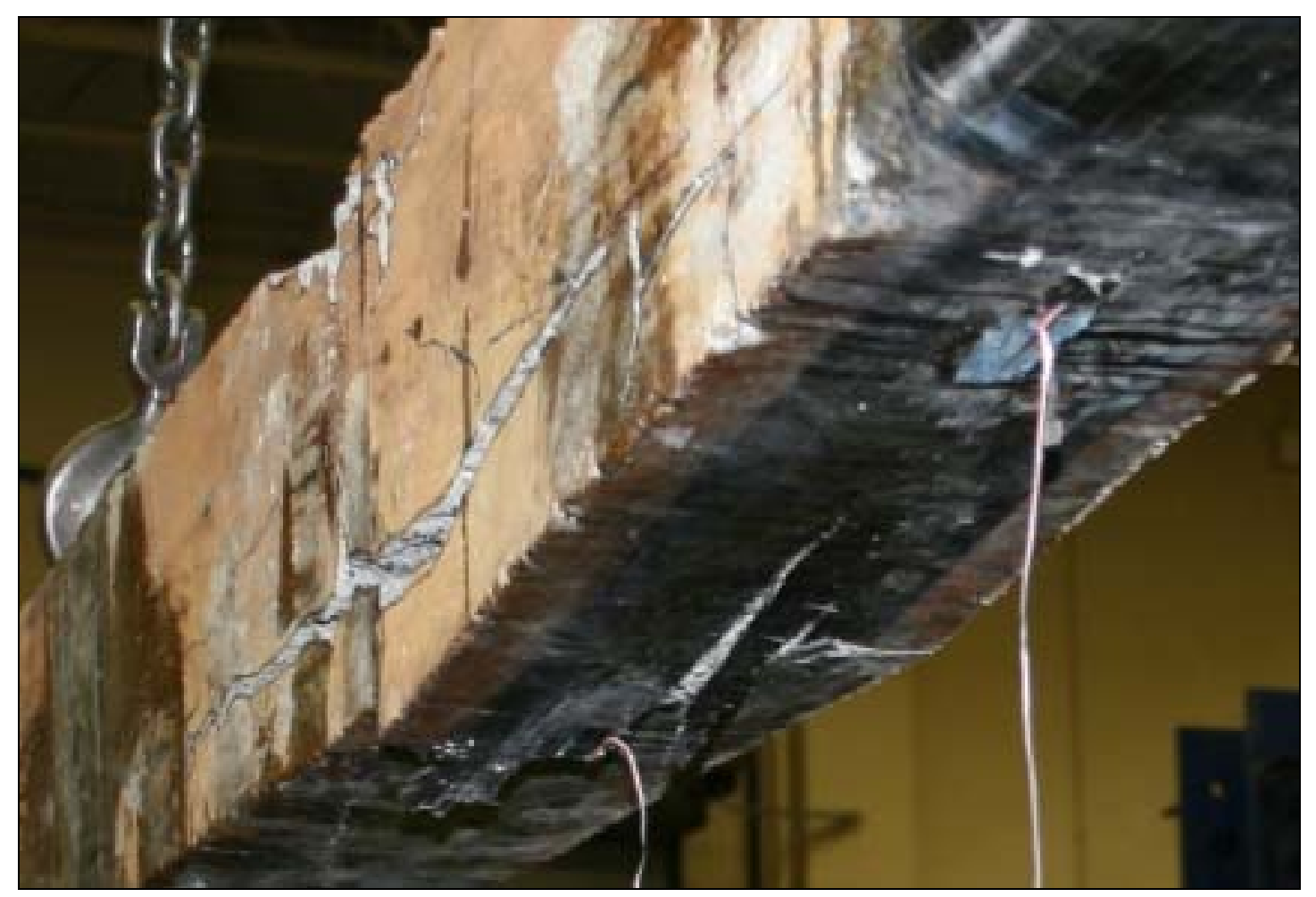

Figure 6.53: FRP Rupture on Beam I-10 


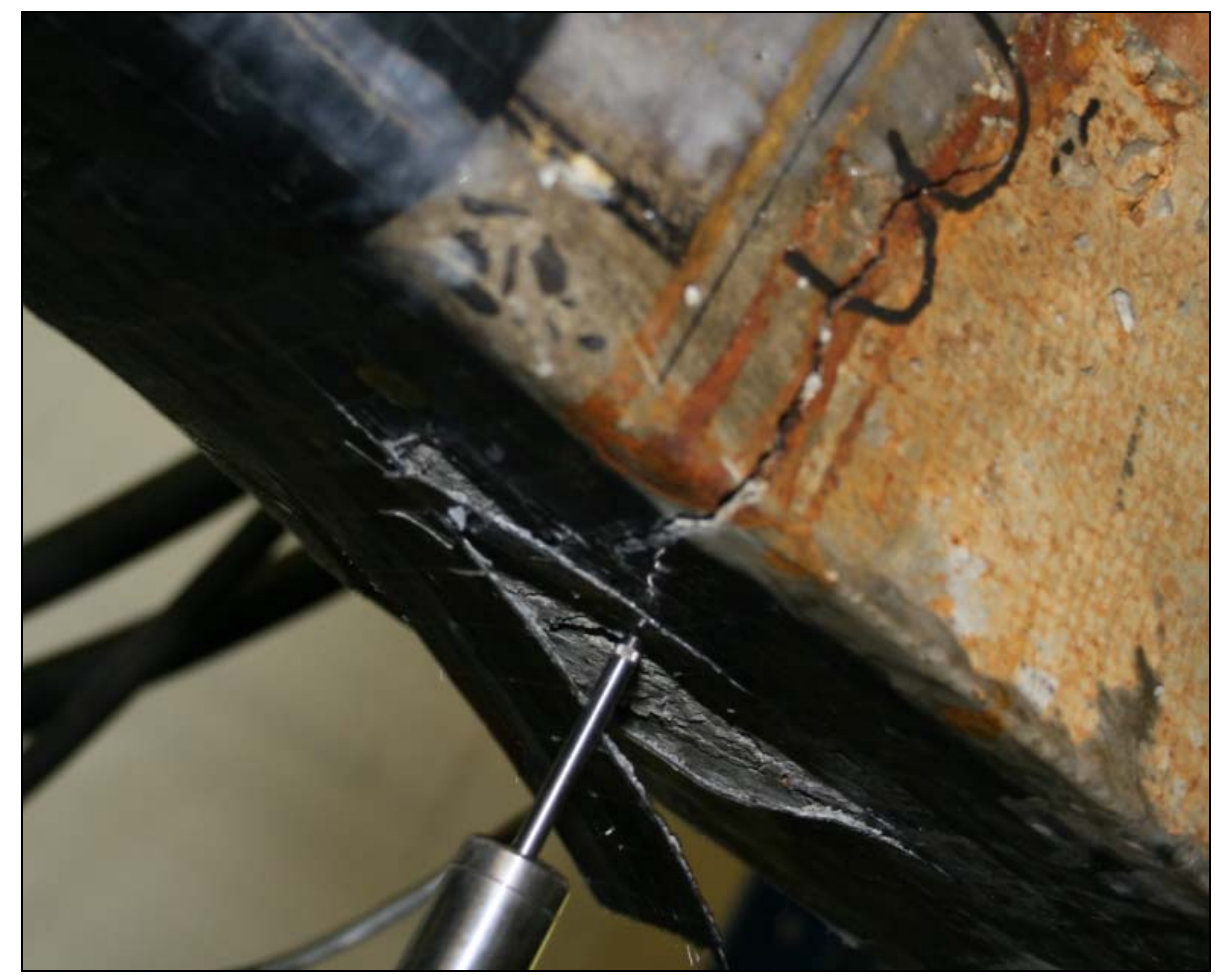

Figure 6.54: FRP Rupture on Beam I-8

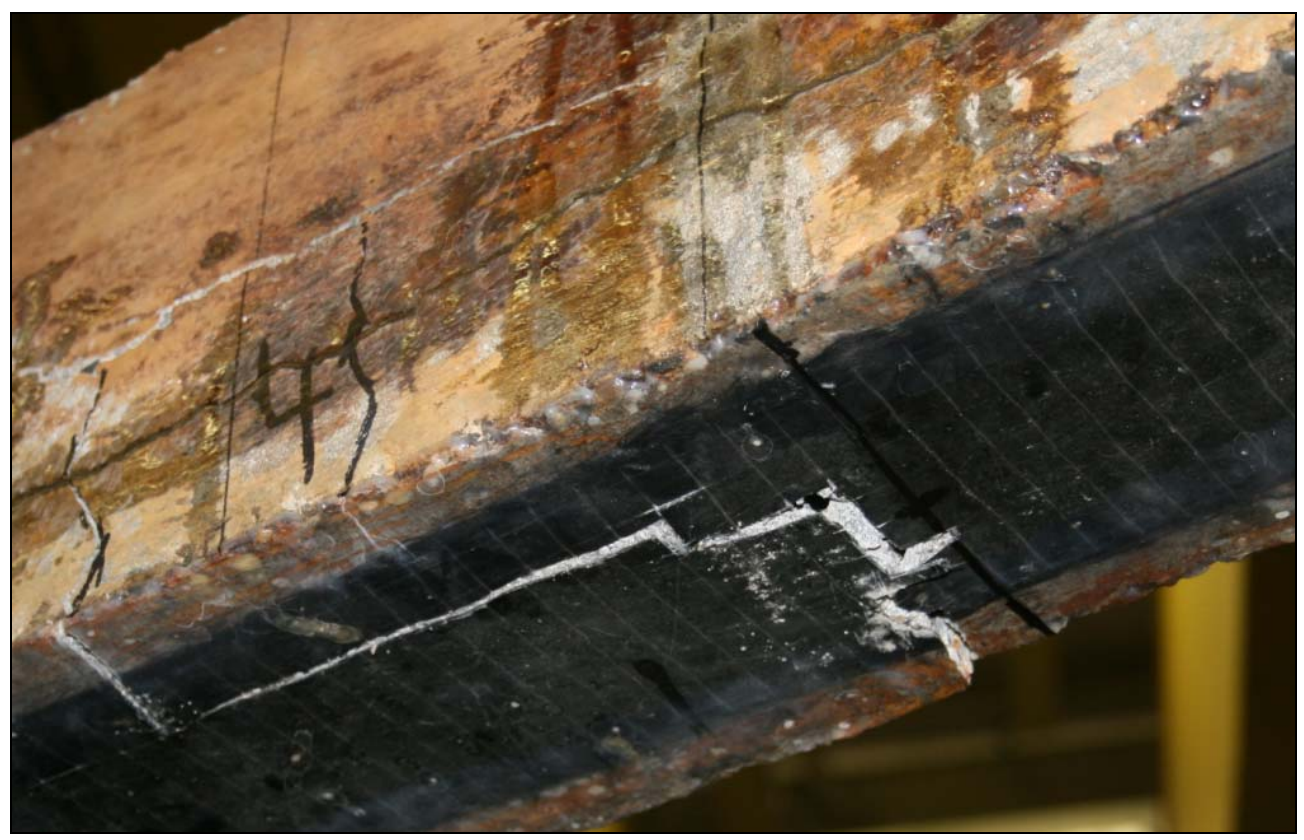

Figure 6.55: FRP Rupture on Beam I-9 
Both polymer-modified concrete-repaired beams failed via crack-induced debonding and subsequent FRP rupture. Crack-induced debonding initiates at the location of a flexure crack where there is a high stress concentration at the FRP-concrete interface. When the stress level reaches a critical point, the crack instantly propagates along the FRP-concrete interface resulting in dramatic debonding of the FRP from the concrete. Due to the rapid redistribution of stress, the FRP ruptures at a location near the original concrete flexure crack. It is typically not favorable for failure to occur within the epoxy layer as it did for Beams I-7 and I-8; it would be more favorable for the failure to occur within the concrete cover layer, showing that the FRP-concrete bond is stronger than the concrete itself. This debonding, however, can be attributed to the extremely high strength of the polymer patch repair concrete. The bond between the FRP and the concrete was likely sufficient. This issue was further investigated by examining the results of the FRP-concrete pull-off tests, which will be discussed later.

It is important to notice, however, that dramatic debonding did not occur on beams with a crack-injected normal concrete substrate (examine Figure 6.52, Figure 6.53, Figure 6.54, and Figure 6.55). Instead, debonding occurred at the steel-concrete interface with subsequent cover delamination. This can be seen in Figure 6.56, where the top and bottom photos are of Beams I- 10 and 9, respectively, during static testing just before FRP rupture. This was certainly aided by the fact that the steel-concrete bond was already weakened by corrosion cracking prior to static testing and by the presence of corrosion product around the steel. It appeared that FRP rupture via direct tension, 
instead of crack-induced debonding, was the failure mode for the crack-injected Beams I9 and $\mathrm{I}-10$.
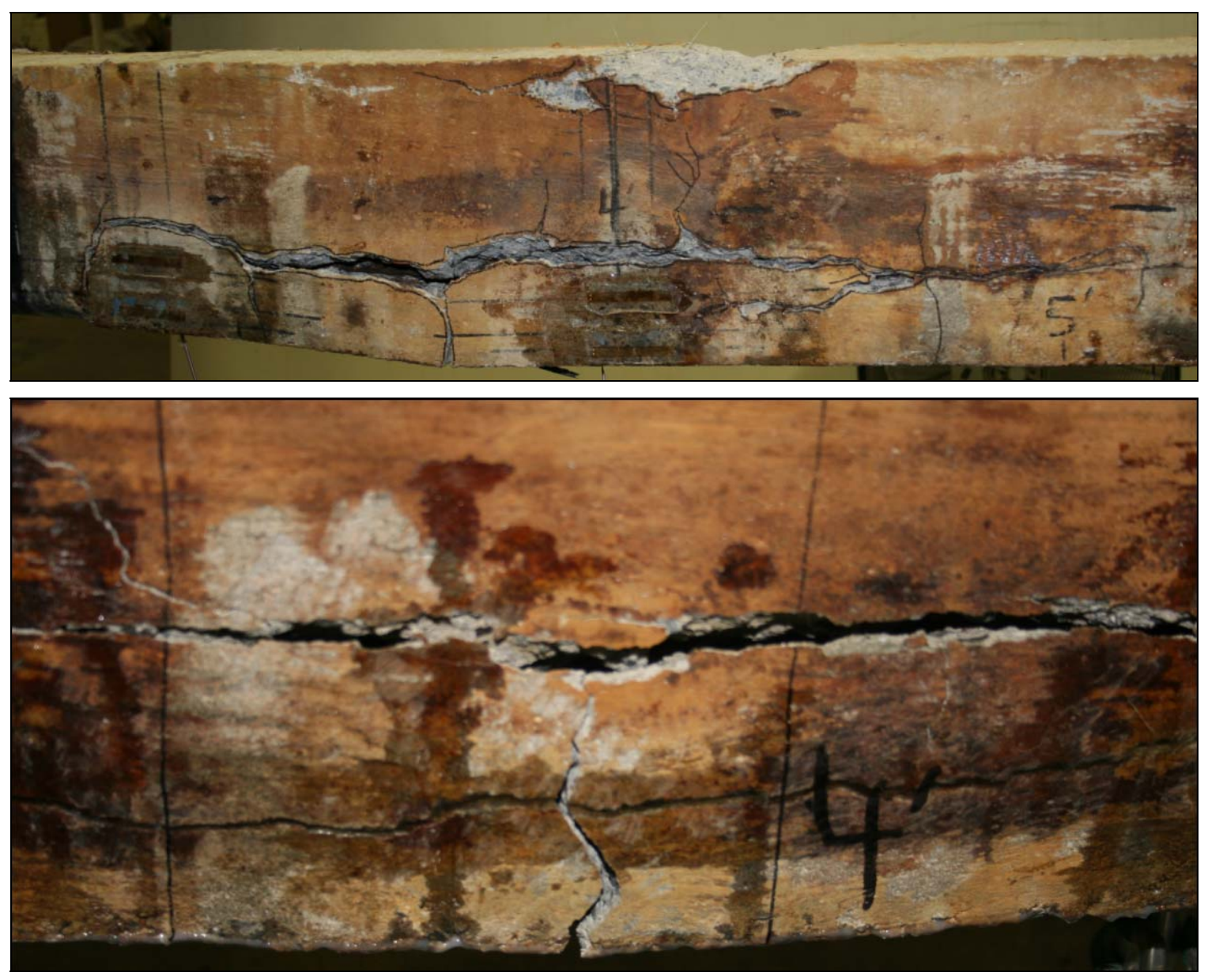

Figure 6.56: Concrete cover delamination on Beams I-9 and I-10 during static testing

\subsection{Part II}

Figure 6.57, Figure 6.58, Figure 6.59, and Figure 6.60 show various sets of loaddeflection curves grouped together for comparison. Figure 6.57 provides the superposition of all curves obtained in Part II. Figure 6.58 displays comparisons of all pristine and corroded unrepaired control beams. 


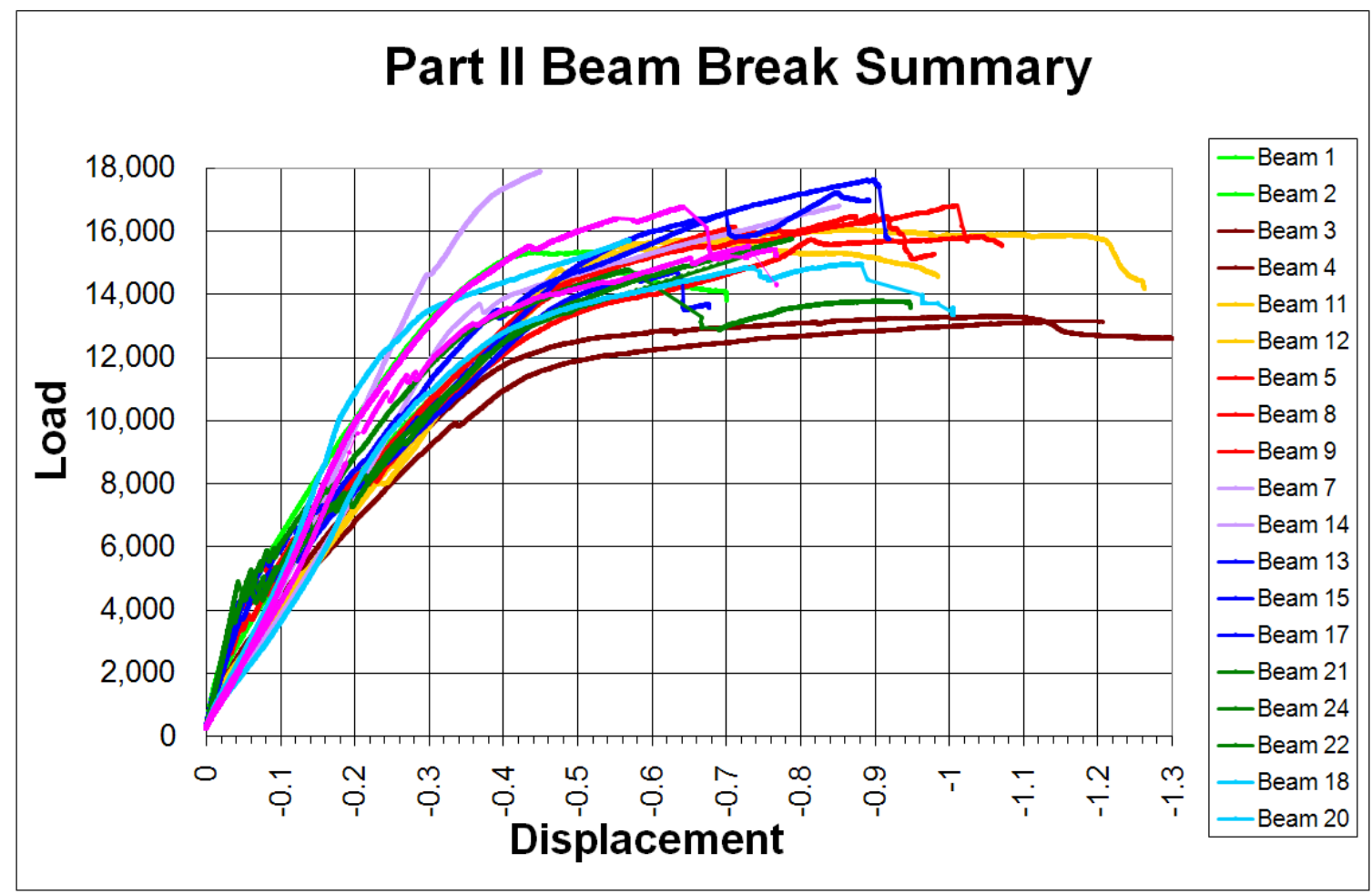

Figure 6.57: Part II load-deflection curves

Figure 6.59 shows load-deflection curves for the Part II beams repaired with FRP Wrapping Schemes 1, 2, and 3. Figure 6.60 shows a comparison of all beams subjected to cyclic loading before repair. The curves in these figures are analyzed in the following commentary. 


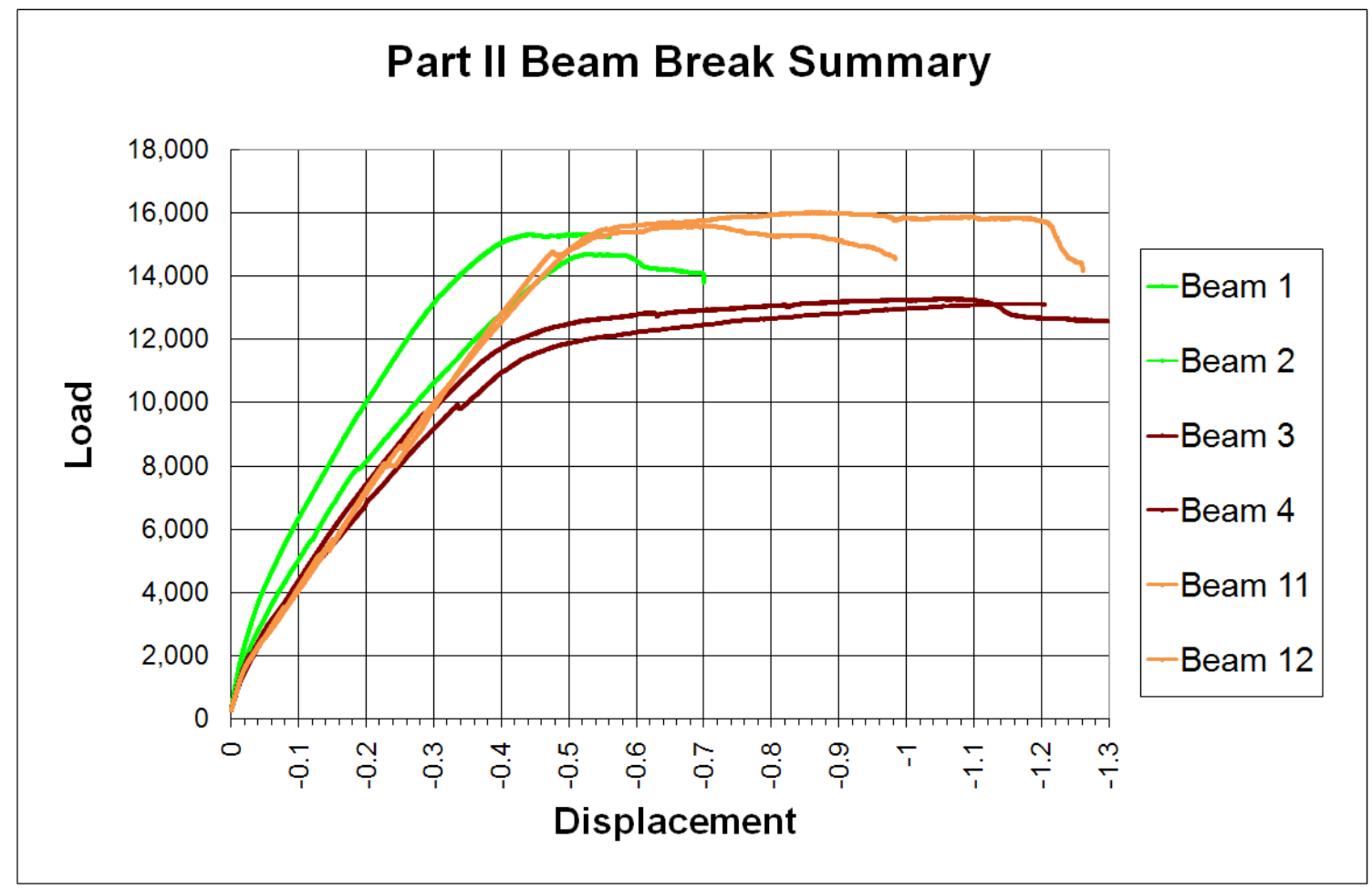

Figure 6.58: Comparison of Part II load-deflection curves for both pristine and corroded unrepaired control beams

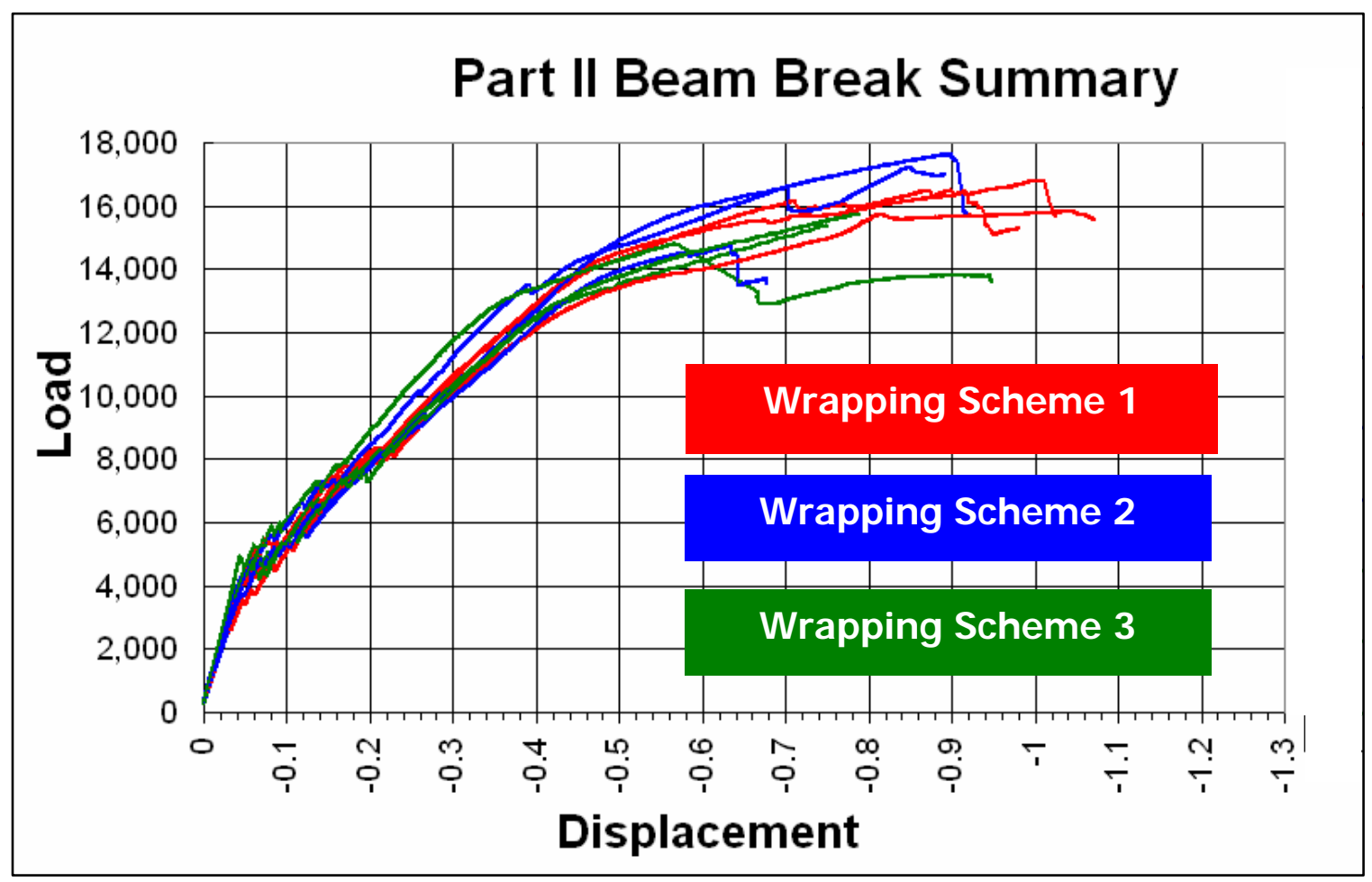

Figure 6.59: Comparison of Part II load-deflection curves 


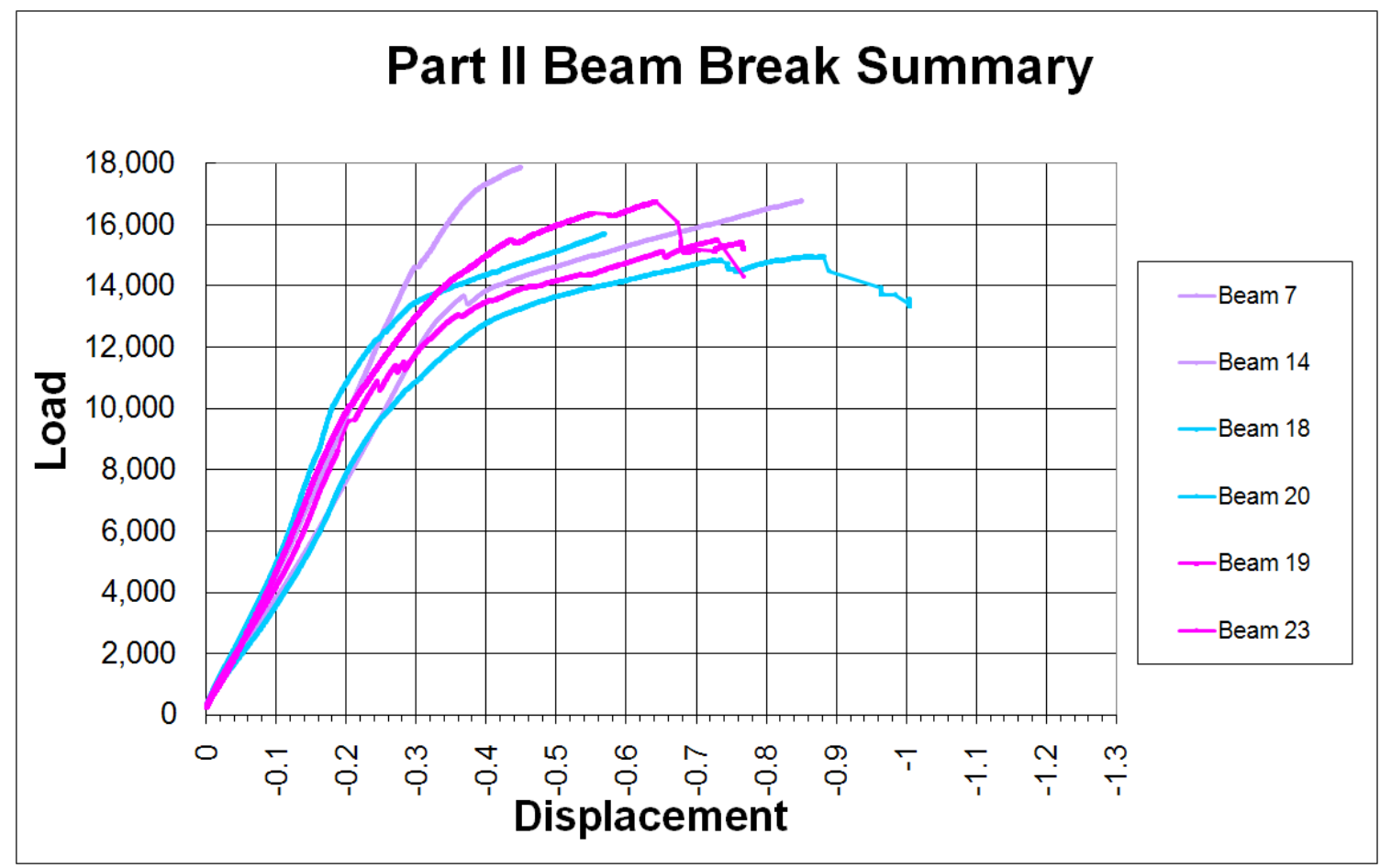

Figure 6.60: Comparison of Part II load-deflection curves for repaired beams subjected to fatigue loading prior to loading statically to failure

Table 6.25 presents a summary of both maximum service load and maximum load at failure. The maximum service load is the highest load observed within the post-cracking region of the load-deflection curve. All loads presented in this table were rounded to the nearest 100lbs. Figure 6.61 presents these values in a stacked bar graph.

Reinforced concrete beam deflection analysis equations predicted an ultimate load of $6,488 \mathrm{lbs}$ applied at each load points, or approximately $12,976 \mathrm{lbs}$ total. The pristine beams yielded average maximum service loads of 13,500lbs (28-day) and 15,100lbs (27 weeks). These were good for quality control since they verified the beam specimens performed according to the conservative ACI design guidelines. 
Table 6.25: Part II Load Capacity Summary

\begin{tabular}{|c|c|c|c|c|c|c|c|c|c|}
\hline \multirow[t]{2}{*}{ Description } & \multirow[t]{2}{*}{ 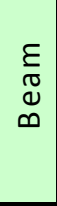 } & \multicolumn{4}{|c|}{$\begin{array}{l}\text { Maximum Load Within } \\
\text { S ervicability Range } \\
\text { (Ibs) }\end{array}$} & \multicolumn{4}{|c|}{$\begin{array}{l}\text { Total Maximum Load } \\
\text { (lbs) }\end{array}$} \\
\hline & & Load & Mean & Range & \% Diff. & Load & Mean & Range & \% Diff. \\
\hline \multirow{2}{*}{ 28-D ay $P$ ris tine } & 1 & 13,000 & \multirow{2}{*}{13,500} & \multirow{2}{*}{1,000} & \multirow{2}{*}{7.41} & 15,300 & \multirow{2}{*}{15,000} & \multirow{2}{*}{600} & \multirow{2}{*}{4.00} \\
\hline & 2 & 14,000 & & & & 14,700 & & & \\
\hline \multirow{2}{*}{ Corroded Unrepaired } & 3 & 9,700 & \multirow{2}{*}{9,850} & \multirow{2}{*}{300} & \multirow{2}{*}{3.05} & 13,200 & \multirow{2}{*}{13,150} & \multirow{2}{*}{100} & \multirow{2}{*}{0.76} \\
\hline & 4 & 10,000 & & & & 13,100 & & & \\
\hline \multirow{2}{*}{ Long-Term $\mathrm{P}$ ris tine Control } & 11 & 14,600 & \multirow{2}{*}{15,100} & \multirow{2}{*}{1,000} & \multirow{2}{*}{6.62} & 16,000 & \multirow{2}{*}{15,100} & \multirow{2}{*}{1,800} & \multirow{2}{*}{11.92} \\
\hline & 12 & 15,600 & & & & 14,200 & & & \\
\hline \multirow{3}{*}{$\begin{array}{l}\text { Repaired using Wrapping } \\
\text { Scheme } 1\end{array}$} & 5 & 10,100 & \multirow{3}{*}{12,233} & \multirow{3}{*}{3,400} & \multirow{3}{*}{28.81} & 15,700 & \multirow{3}{*}{16,300} & \multirow{3}{*}{1,100} & \multirow{3}{*}{6.77} \\
\hline & 8 & 13,100 & & & & 16,400 & & & \\
\hline & 9 & 13,500 & & & & 16,800 & & & \\
\hline \multirow{2}{*}{$\begin{array}{l}\text { Repaired using Wrapping } \\
\text { Scheme } 1+\text { Cyclic Load }\end{array}$} & 7 & 14,600 & 13850 & 1500 & 1083 & 17,900 & 17350 & 1100 & 6.34 \\
\hline & 14 & 13,100 & 13,050 & 1,300 & 10.85 & 16,800 & 17,350 & 1,100 & 0.34 \\
\hline & 13 & 13,500 & & & & 17,400 & & & \\
\hline Repaıred usıng Wrappıng & 15 & 14,100 & 13,700 & 600 & 4.35 & 17,600 & 16,533 & 3,000 & 18.63 \\
\hline & 17 & 13,500 & & & & 14,600 & & & \\
\hline Repaired using Wrapping & 18 & 12,400 & & 700 & 5.49 & 15,000 & 15350 & 700 & 4.56 \\
\hline Scheme $2+$ Cyclic Load & 20 & 13,100 & 12,150 & 100 & 5.49 & 15,700 & 15,350 & 100 & 4.50 \\
\hline & 21 & 12,300 & & & & 15,700 & & & \\
\hline Repaired using Wrapping & 22 & 12,000 & 12,267 & 500 & 4.08 & 15,400 & 15,300 & 900 & 5.90 \\
\hline scneme 3 & 24 & 12,500 & & & & 14,800 & & & \\
\hline Repaired using Wrapping & 19 & 14,000 & 12450 & 3.10 & & 16,800 & & & 8.05 \\
\hline Scheme $3+$ Cyclic Load & 23 & 10,900 & 12,450 & 3,100 & 24.90 & 15,500 & 10,130 & 1,300 & 0.05 \\
\hline
\end{tabular}

On average, corroded unrepaired Beams II-3 and II-4 suffered a 35\% decrease in service load capacity and a $13 \%$ decrease of failure load compared to the long-term control specimens II-11 and II-12.

ACI design equations predicted that the FRP-repaired beams in Part II would have a maximum service load capacity of 11,893lbs. Beams repaired with Wrapping Scheme 1 (II-5, II-8, and II-9) had an average maximum service load of 12,233lbs and an average failure load of 16,300lbs. Beams repaired with Wrapping Scheme 2 (II-13, II-15, and II17) had an average maximum service load of $13,700 \mathrm{lbs}$ and an average failure load of 
16,533lbs. Beams repaired using Wrapping Scheme 3 (II-21, II-22, and II-24) had an average maximum service load of $12,267 \mathrm{lbs}$ and an average failure load of $15,300 \mathrm{lbs}$.

FRP strengthening with Wrapping Schemes 1, 2, and 3 yielded maximum service load increases of 24,39 , and $25 \%$ compared to the corroded unrepaired samples. One of the three beams repaired with Scheme 1 and all three of the beams repaired with Scheme 2 were restored to at least their original service capacities, although the specimens were not designed to fully restore these capacities. Recall that this silght under-reinforcement guarded against possible crushing of the intentionally poor-quality concrete if too much tension reinforcement was provided. Beams II-5 and II- 8 had service capacities that were $75 \%$ and $97 \%$ that of the 28 -day pristine beams, respectively. Beams II-9, II-13, and II17 had service capacities equaling that of the 28-day pristine specimens, and Beam II-15 had a capacity of $104 \%$ that of the 28 -day pristine specimens. Beams repaired using Wrapping Scheme 3 had service load capacities less than that of the 28-day pristine beams (91, 89, and $93 \%$ that of the 28-day pristine beams). Wrapping Schemes 1, 2, and 3 yielded percent increases in service load of 24,39 , and $12 \%$ compared to the corroded unrepaired Beams II-3 and II-4, respectively.

FRP-repair of beams using Wrapping Schemes 1, 2, and 3 yielded 9, 10, and 2\% increases in failure load compared to the 28-day pristine specimens, respectively. These wrapping schemes yielded 24,26 , and $16 \%$ increases in failure load compared to corroded unrepaired Beams II-3 and II-4, respectively. FRP repair of beams using 
Schemes 1, 2, and 3 had service load capacities that were 3, 15, and 3\% higher than predicted, respectively.

Cyclic loading did not appear to have a significant effect on load capacity. There was not consistency between duplicate beams in Part II of this experiment. The capacity difference between most specimens in defined beam groups was less than $10 \%$.

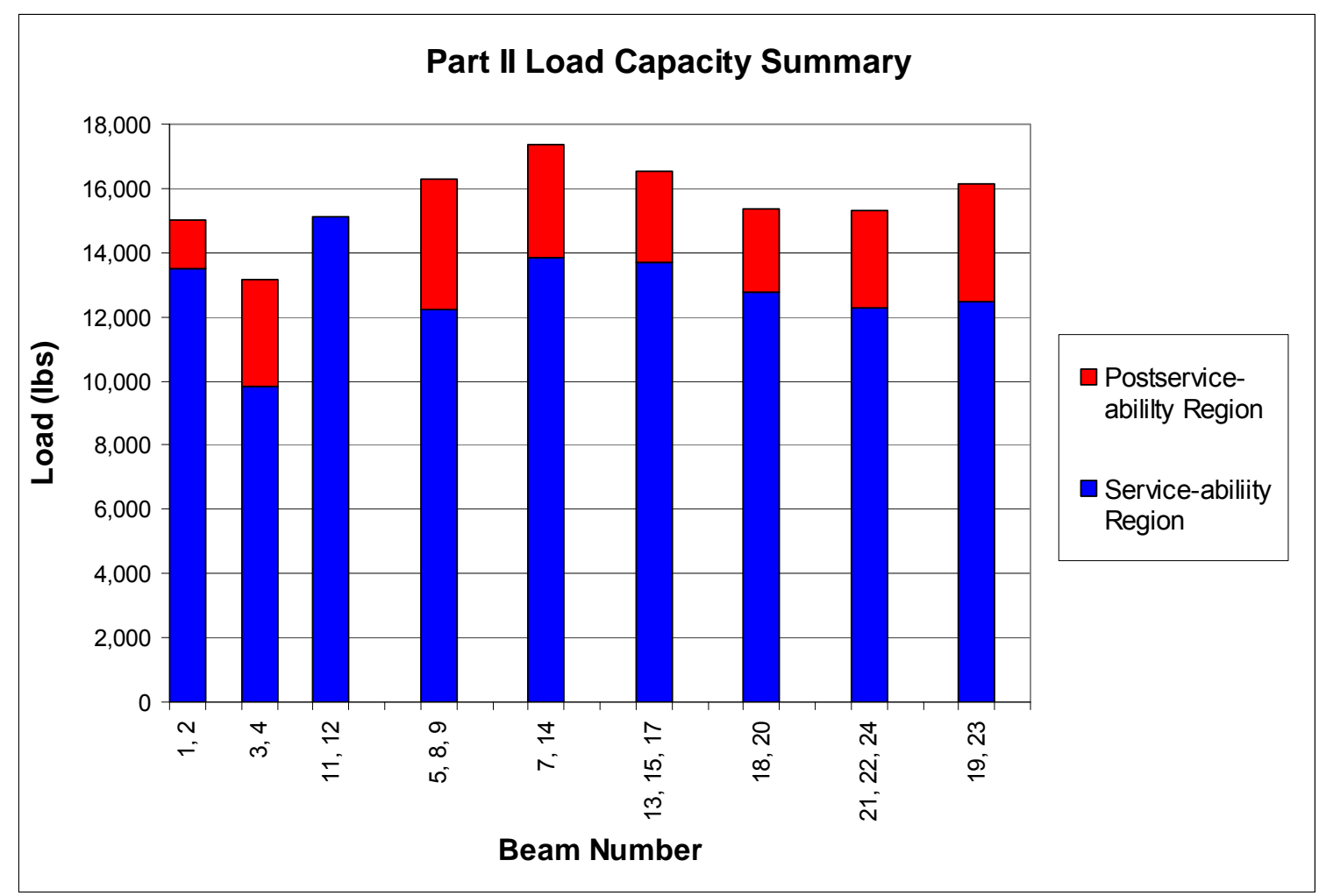

Figure 6.61: Part II load capacities

Table 6.26 shows the Part II service and failure deflections. Figure 6.62 presents this data in the form of a stacked bar graph. The predicted service deflection was 0.37in and the average deflection of the 28-day pristine specimen was $0.38 \mathrm{in}$, a good result for quality control showing that the beams were performing as designed. The average 
service deflection of the long-term control beams was a larger 0.48in. The corroded unrepaired beams II-3 and II-4 each exhibited an average service deflection of $0.32 \mathrm{in}$. Large differences existed between the failure deflections of duplicate beam specimens.

\section{Table 6.26: Part II Deflection Summary}

\begin{tabular}{|c|c|c|c|c|c|c|c|c|c|}
\hline \multirow[t]{2}{*}{ Description } & \multirow[t]{2}{*}{$\begin{array}{l}\varepsilon \\
\tilde{O} \\
\stackrel{D}{\infty}\end{array}$} & \multicolumn{4}{|c|}{$\begin{array}{l}\text { Maximum Deflection at Initiation } \\
\text { of Posts ervicability C racking } \\
\text { S tage } \\
\text { (in) }\end{array}$} & \multicolumn{4}{|c|}{$\begin{array}{c}\text { Deflection@ } \begin{array}{c}\text { Maximum (Failure) } \\
\text { Load } \\
\text { (in) }\end{array}\end{array}$} \\
\hline & & $\Delta$ & Mean & Range & $\%$ Diff. & $\Delta$ & Mean & Range & $\%$ Diff. \\
\hline \multirow{2}{*}{ 28-Day $P$ ris tine } & 1 & 0.30 & \multirow{2}{*}{0.38} & \multirow{2}{*}{0.16} & \multirow{2}{*}{42.1} & 0.53 & \multirow{2}{*}{0.56} & \multirow{2}{*}{0.05} & \multirow{2}{*}{9.0} \\
\hline & 2 & 0.46 & & & & 0.58 & & & \\
\hline \multirow{2}{*}{ Corroded Unrepaired } & 3 & 0.29 & \multirow{2}{*}{0.32} & \multirow{2}{*}{0.06} & \multirow{2}{*}{18.8} & 1.10 & \multirow{2}{*}{1.12} & \multirow{2}{*}{0.03} & \multirow{2}{*}{2.7} \\
\hline & 4 & 0.35 & & & & 1.13 & & & \\
\hline \multirow{2}{*}{ Long-Term P ristine Control } & 11 & 0.48 & \multirow{2}{*}{0.48} & \multirow{2}{*}{0.01} & \multirow{2}{*}{2.1} & 1.17 & \multirow{2}{*}{0.95} & \multirow{2}{*}{0.45} & \multirow{2}{*}{47.6} \\
\hline & 12 & 0.47 & & & & 0.72 & & & \\
\hline \multirow{3}{*}{$\begin{array}{l}\text { Repaired using Wrapping } \\
\text { Scheme } 1\end{array}$} & 5 & 0.30 & \multirow{3}{*}{0.38} & \multirow{3}{*}{0.13} & \multirow{3}{*}{35.6} & 1.05 & \multirow{3}{*}{0.80} & \multirow{3}{*}{0.60} & \multirow{3}{*}{80.0} \\
\hline & 8 & 0.41 & & & & 0.91 & & & \\
\hline & 9 & 0.43 & & & & 0.45 & & & \\
\hline \multirow{2}{*}{$\begin{array}{l}\text { Repaired using Wrapping } \\
\text { Scheme } 1+\text { Cyclic Load }\end{array}$} & 7 & 0.52 & 0.43 & 0.18 & 41.9 & 0.60 & 0.73 & 0.25 & 34.5 \\
\hline & 14 & 0.34 & & & & 0.85 & & & \\
\hline & 13 & 0.39 & & & & 0.84 & & & \\
\hline nepaile using vo & 15 & 0.46 & 0.44 & 0.07 & 16.5 & 0.90 & 0.79 & 0.26 & 33.8 \\
\hline & 17 & 0.46 & & & & 0.64 & & & \\
\hline Repaired using Wrapping & 18 & 0.37 & 033 & 0,09 & 7. & 0.88 & O 73 & & 428 \\
\hline S cheme $2+$ Cyclic Load & 20 & 0.28 & 0.33 & 0.09 & 27.1 & 0.57 & 0.13 & 0.31 & 42.8 \\
\hline & 21 & 0.39 & & & & 0.79 & & & \\
\hline Kepairea using vorapping & 22 & 0.37 & 0.36 & 0.06 & 16.7 & 0.75 & 0.70 & 0.22 & 32.4 \\
\hline & 24 & 0.33 & & & & 0.57 & & & \\
\hline Repaired using Wrapping & 19 & 0.34 & 0.29 & 0.10 & 34.5 & 0.64 & 0.69 & 0.09 & 13.1 \\
\hline Scheme $3+$ Cyclic Load & 23 & 0.24 & & & & 0.73 & & & \\
\hline
\end{tabular}

Non-fatigued beams repaired with Wrapping Schemes 1, 2, and 3 yielded service deflections of $0.38,0.44$, and $0.36 \mathrm{in}$, respectively. Fatigue loading appeared to reduce the service deflection for Schemes 2 and 3. The service defection of Scheme 1 beams was not significantly affected by fatigue loading. 
The average failure deflection for 28-day pristine beams was $0.56 \mathrm{in}$. Long-term pristine control beams exhibited a scattered average failure deflection ranging between 0.72 and 1.17in. Corroded unrepaired beams yielded a $100 \%$ increase in failure deflection compared to that of the 28-day pristine beams.

The average failure deflections for non-fatigued beams repaired with Schemes 1, 2, and 3 were 0.80, 0.79, and 0.70in, respectively. Cyclic loading reduced the failure deflection for Schemes 1, 2, and 3 by 9,8 , and $1 \%$, respectively.

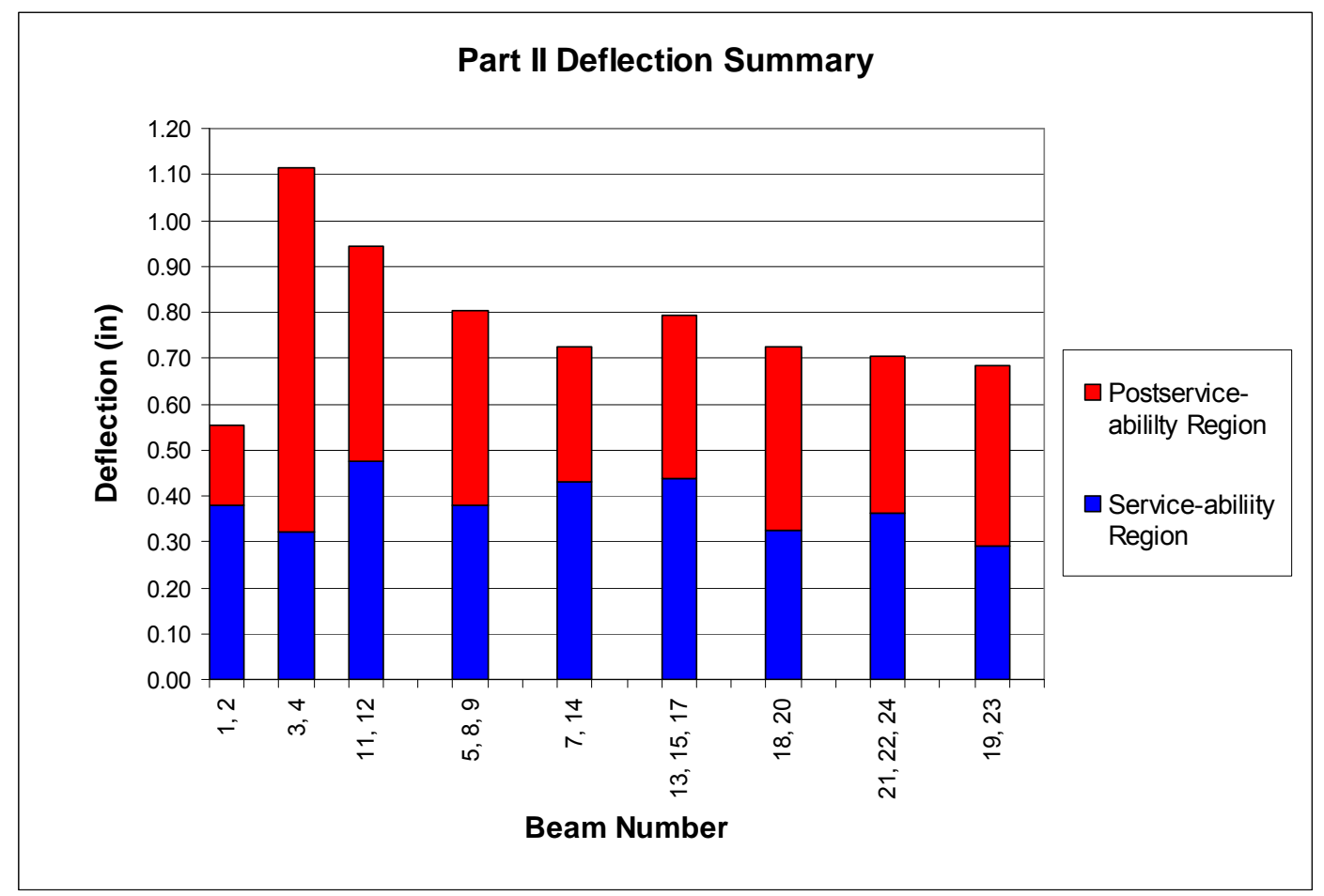

\section{Figure 6.62: Part II deflections}

Table 6.27 presents both the post-cracking and the post-serviceability stiffness observed for each Part II beam. The average 28-day pristine post-cracking stiffness was 
29,280lbs/in. The average post-cracking stiffness for the corroded unrepaired beam was $26,360 \mathrm{lbs} / \mathrm{in}$, a $7 \%$ decrease compared to that of the long-term pristine control specimens. Large differences were observed between the stiffness of two 28-day pristine beams.

\section{Table 6.27: Part II Stiffness Summary}

\begin{tabular}{|c|c|c|c|c|c|c|c|c|c|}
\hline \multirow{2}{*}{ Description } & \multirow{2}{*}{$\begin{array}{l}\varepsilon \\
\tilde{\sigma} \\
\mathbb{\infty} \\
\infty\end{array}$} & \multicolumn{4}{|c|}{ Initial S tiffness (Ibs/in) } & \multicolumn{4}{|c|}{ S econdary S tiffness (lbs/in) } \\
\hline & & Stiffness & Mean & Range & $\%$ Diff. & Stiffness & Mean & Range & $\%$ Diff. \\
\hline \multirow{2}{*}{ 28-Day $P$ ris tine } & 1 & 34,550 & \multirow{2}{*}{29,280} & \multirow{2}{*}{10,541} & \multirow{2}{*}{36.00} & 2,012 & \multirow{2}{*}{1,969} & \multirow{2}{*}{87} & \multirow{2}{*}{4.42} \\
\hline & 2 & 24,009 & & & & 1,925 & & & \\
\hline \multirow{2}{*}{ Corroded Unrepaired } & 3 & 27,751 & \multirow{2}{*}{26,360} & \multirow{2}{*}{2,782} & \multirow{2}{*}{10.55} & 1,199 & \multirow{2}{*}{1,505} & \multirow{2}{*}{611} & \multirow{2}{*}{40.61} \\
\hline & 4 & 24,969 & & & & 1,810 & & & \\
\hline \multirow{2}{*}{ Long-Term $P$ ris tine $C$ ontrol } & 11 & 28,634 & \multirow{2}{*}{28,236} & \multirow{2}{*}{797} & \multirow{2}{*}{2.82} & 1,658 & \multirow{2}{*}{1,251} & \multirow{2}{*}{814} & \multirow{2}{*}{65.07} \\
\hline & 12 & 27,837 & & & & 844 & & & \\
\hline \multirow{3}{*}{$\begin{array}{l}\text { Repaired using Wrapping } \\
\text { S cheme } 1\end{array}$} & 5 & 21,864 & \multirow{3}{*}{24,483} & \multirow{3}{*}{3,928} & \multirow{3}{*}{16.48} & 6,021 & \multirow{3}{*}{7,076} & \multirow{3}{*}{2,470} & \multirow{3}{*}{34.04} \\
\hline & 8 & 25,792 & & & & 8,491 & & & \\
\hline & 9 & 25,792 & & & & 6,717 & & & \\
\hline \multirow{2}{*}{$\begin{array}{l}\text { Repaired using Wrapping } \\
\text { S cheme } 1+C \text { yclic Load }\end{array}$} & 7 & 51,655 & 46950 & 9410 & בח & 11,744 & רחת 9 & 5485 & 6093 \\
\hline & 14 & 42,245 & 40,950 & $y, 4 \perp 0$ & 20.04 & 6,259 & 9,0U2 & 5,485 & 00.93 \\
\hline & 13 & 27,494 & & & & 9,422 & & & \\
\hline Repaired using Wrapping & 15 & 24,330 & 24,712 & 5,181 & 20.80 & 5,576 & 7,350 & 3,846 & 51.29 \\
\hline scrieme 2 & 17 & 22,313 & & & & 7,053 & & & \\
\hline R epaired using Wrapping & 18 & 42,409 & $53 \cap 04$ & 21190 & 3998 & 5,623 & 6772 & 2297 & 3397 \\
\hline S cheme $2+$ Cyclic Load & 20 & 63,599 & 53,004 & 21,190 & & 7,920 & $6,1 / 2$ & 2,291 & 33.92 \\
\hline & 21 & 26,573 & & & & 6,240 & & & \\
\hline Kepaliea using virapping & 22 & 26,014 & 27,191 & 2,971 & 10.80 & 7,414 & 7,414 & 2,348 & 31.67 \\
\hline & 24 & 28,985 & & & & 8,588 & & & \\
\hline Repaired using Wrapping & 19 & 31,429 & 42837 & 27806 & 5325 & 8,784 & 7293 & 2982 & ח 90 \\
\hline Scheme $3+$ Cyclic Load & 23 & 54,235 & 42,032 & $\angle 2,0 \cup 0$ & & 5,802 & 1,293 & 2,902 & 40.90 \\
\hline
\end{tabular}

The average post-cracking stiffness increased as more anchorage was added. Beams repaired with Schemes 2 and 3 exhibited 1 and 11\% post-cracking stiffness increases (respectively) over those repaired with Scheme 1.

Perhaps the most unanticipated result of this experiment appeared when comparing the post-cracking stiffness of fatigue-loaded and non-fatigue-loaded beams prior to static flexural testing. The post-cracking stiffness of these fatigued beams appeared to have 1.9, 2.1 and 1.6 times the stiffness of their duplicate non-fatigued beams for Schemes 1, 
2 , and 3 , respectively. This is obviously not a logical outcome, as fatigue loading is expected to either reduce or at least have no effect on stiffness. Further observing the load-deflection curves obtained for cyclic loading, it can be seen that the pre-cracking stiffness of the fatigued beams are either equal to or less than those of non-fatigued beams up to about 3,000-3,500lbs of static loading. After reaching the "post cracking" region, the slopes begin to increase, where they become steeper than those of their nonfatigued duplicates. Interestingly, if Beam II-7 data is eliminated, the post-serviceability stiffness of the fatigued beams are actually less than those of the non-fatigued beams. Not including Beam II-7, cyclic loading resulted in a percent decrease of 12,8 , and $2 \%$ in post-serviceability stiffness for Schemes 1,2, and 3, respectively.

The mysterious "increase" in post-cracking stiffness may be attributed to a pre-tensioning effect that was a result of permanent beam deflection produced by the cyclic loading process. The permanent deflection result in FRP that was already under tension at zero load. The "pre-tensioned" FRP sheet may have caused the beam to appear as if it wasstiffer than a repaired beam without a permanent deflection. It is very important to note that great care was taken to ensure continuity between all test setups. Support conditions, instrumentation setup, data acquisition setting, load rate, etc. were all exactly the same for all static tests. This peculiar observation will be further studied in the future.

Table 6.28 presents a summary of strains and corresponding loads recorded during the Part II static tests. The average strain at peak of the linear region and its corresponding load is given in the "max in linear region" rows. The average maximum strain recorded 
and its corresponding load is provided in the "failure" rows. These values are the average of all gages in similar locations by material. Values recorded from the four steel gages, the three FRP gages, the two bonded concrete reinforcement level gages, the two bonded concrete cover level gages, and the two embedded concrete gages were each averaged together, respectively. Each respective group of gages should theoretically have the same strain at the same load since they were all located within the constant moment region of the beam specimen.

Table 6.28: Part II Strain Summary

\begin{tabular}{|c|c|c|c|c|c|c|c|c|c|c|c|c|}
\hline \multirow{3}{*}{ 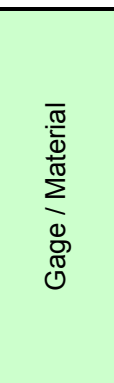 } & & & \multicolumn{10}{|c|}{ Part II Beam and Description } \\
\hline & & & 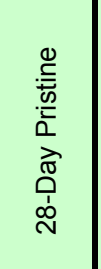 & ह & 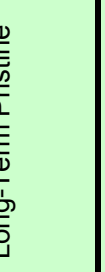 & 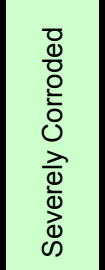 & 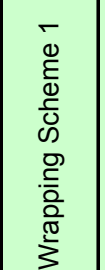 & 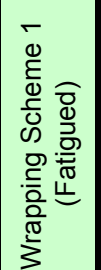 & 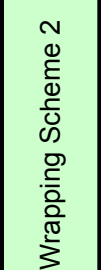 & 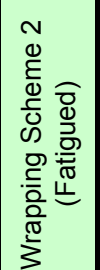 & 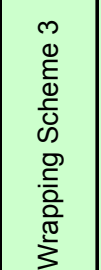 & 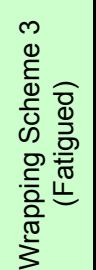 \\
\hline & & & 2 & 11 & 12 & 3 & 5 & 7 & 17 & 18 & 24 & 19 \\
\hline \multirow{4}{*}{$\begin{array}{l}\bar{\Phi} \\
\frac{\Phi}{\omega}\end{array}$} & \multirow{2}{*}{$\begin{array}{l}\text { Max in } \\
\text { Linear } \\
\text { Region }\end{array}$} & Microstrain & 2,466 & 2,439 & 2,465 & - & 2,358 & 3,172 & 1,791 & 2,390 & 2,286 & 2,911 \\
\hline & & Load (lbs) & 14,321 & 14,724 & 14,331 & - & 11,293 & 16,652 & 13,381 & 11,703 & 11,946 & 11,837 \\
\hline & \multirow{2}{*}{ Failure } & Microstrain & 8,050 & 16,986 & 10,629 & - & 11,085 & 4,527 & 5,117 & 9,218 & 8,641 & 11,820 \\
\hline & & Load (Ibs) & 13,830 & 15,777 & 14,546 & - & 14,601 & 17,878 & 14,436 & 14,043 & 14,128 & 16,074 \\
\hline \multirow{4}{*}{$\frac{0}{\frac{0}{\sim}}$} & \multirow{2}{*}{$\begin{array}{l}\text { Max in } \\
\text { Linear } \\
\text { Region }\end{array}$} & Microstrain & - & - & - & - & 299 & 5,830 & 211 & 6,902 & 247 & 3,903 \\
\hline & & Load (Ibs) & - & - & - & - & 9,510 & 16,775 & 8,717 & 12,281 & 5,284 & 11,013 \\
\hline & \multirow{2}{*}{ Failure } & Microstrain & - & - & - & - & 9,731 & 6,803 & 3,377 & 10,755 & 8,954 & 7,320 \\
\hline & & Load (Ibs) & - & - & - & - & 15,513 & 17,879 & 14,471 & 14,830 & 14,784 & 15,724 \\
\hline \multirow{4}{*}{ 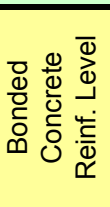 } & \multirow{2}{*}{$\begin{array}{l}\text { Max in } \\
\text { Linear } \\
\text { Region }\end{array}$} & Microstrain & 2,529 & - & - & 141 & 88 & - & 174 & - & 108 & - \\
\hline & & Load (lbs) & 14,459 & - & - & 1,866 & 3,370 & - & 5,736 & - & 4,930 & - \\
\hline & \multirow{2}{*}{ Failure } & Microstrain & 8,050 & - & - & 9,303 & 6,220 & - & 4,601 & - & 10,793 & - \\
\hline & & Load (Ibs) & 13,830 & - & - & 11,124 & 10,615 & - & 13,994 & - & 9,711 & - \\
\hline \multirow{4}{*}{ 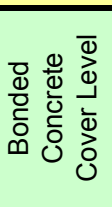 } & \multirow{2}{*}{$\begin{array}{l}\text { Max in } \\
\text { Linear } \\
\text { Region }\end{array}$} & Microstrain & 2,425 & - & - & 152 & 88 & - & 154 & - & - & - \\
\hline & & Load (Ibs) & 14,680 & - & - & 1,195 & 3,370 & - & 5,669 & - & - & - \\
\hline & \multirow{2}{*}{ Failure } & Microstrain & - & - & - & 15,844 & 5,488 & - & 6,734 & - & - & - \\
\hline & & Load (Ibs) & - & - & - & 3,945 & 5,353 & - & 13,578 & - & - & - \\
\hline \multirow{4}{*}{ 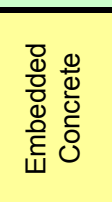 } & \multirow{2}{*}{$\begin{array}{l}\text { Max in } \\
\text { Linear } \\
\text { Region }\end{array}$} & Microstrain & - & 660.5 & 391 & - & 57 & - & 90 & - & 106 & - \\
\hline & & Load (Ibs) & - & 12771 & 8492 & - & 3,362 & - & 4,382 & - & 7,122 & - \\
\hline & \multirow{2}{*}{ Failure } & Microstrain & 846 & 1521 & 588 & - & 248 & - & 660 & - & 8,959 & - \\
\hline & & Load (Ibs) & 14,216 & 15413 & 15438 & - & 15,430 & - & 10,434 & - & 11,525 & - \\
\hline
\end{tabular}


Figure 6.63 , Figure 6.65 , Figure 6.67 , Figure 6.69 show the points of maximum strain recorded within the linear regions of the load-strain curve from tension steel, FRP, externally bonded concrete, and embedded concrete gages, respectively. Figure 6.64, Figure 6.66, Figure 6.68, and Figure 6.70 show the points of maximum total strain observed on the entire load-strain curve from tension steel, FRP, externally bonded concrete, and embedded concrete gages, respectively.

In Figure 6.63, it can be seen that the maximum steel strain within the linear region for both the 28-day pristine Beam II-2 and the long-term pristine Beams II-11 and II-12 were very closely bunched which showed good correlation between specimens. The average maximum linear steel strain for fatigued beams was higher than for non-fatigued beams for all wrapping schemes. FRP-repair did not significantly affect the maximum linear steel strain, but it did tend to reduce the load at which the load-strain relationship became non-linear. The strains and loads at failure were widely scattered for all beams. The largest maximum linear and failure steel strains on non-fatigued beams were observed on Beam II-5 (Scheme 1) and the smallest was observed on Beam II-17 (Scheme 2). 


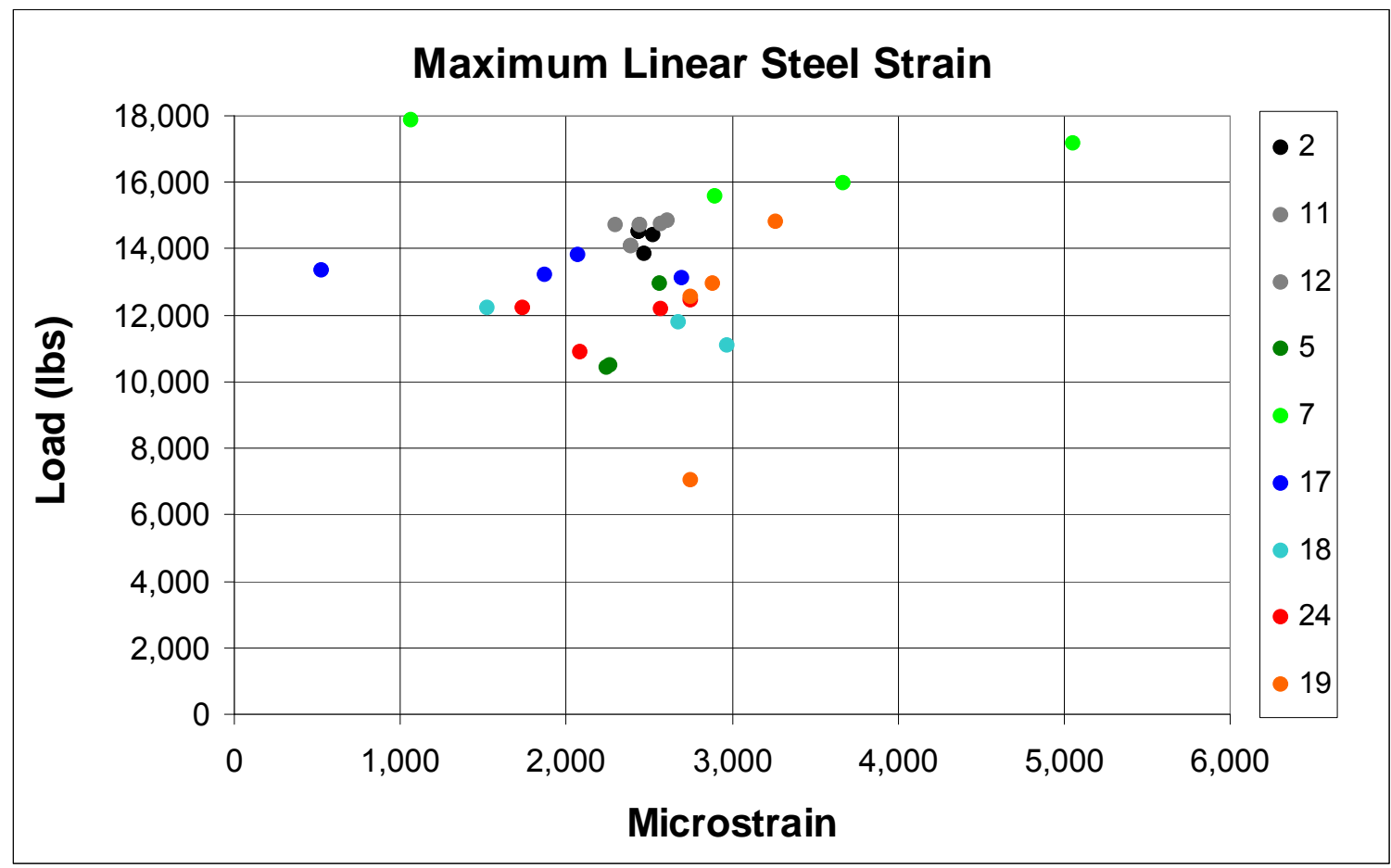

Figure 6.63: Individual maximum overall steel strains and corresponding loads

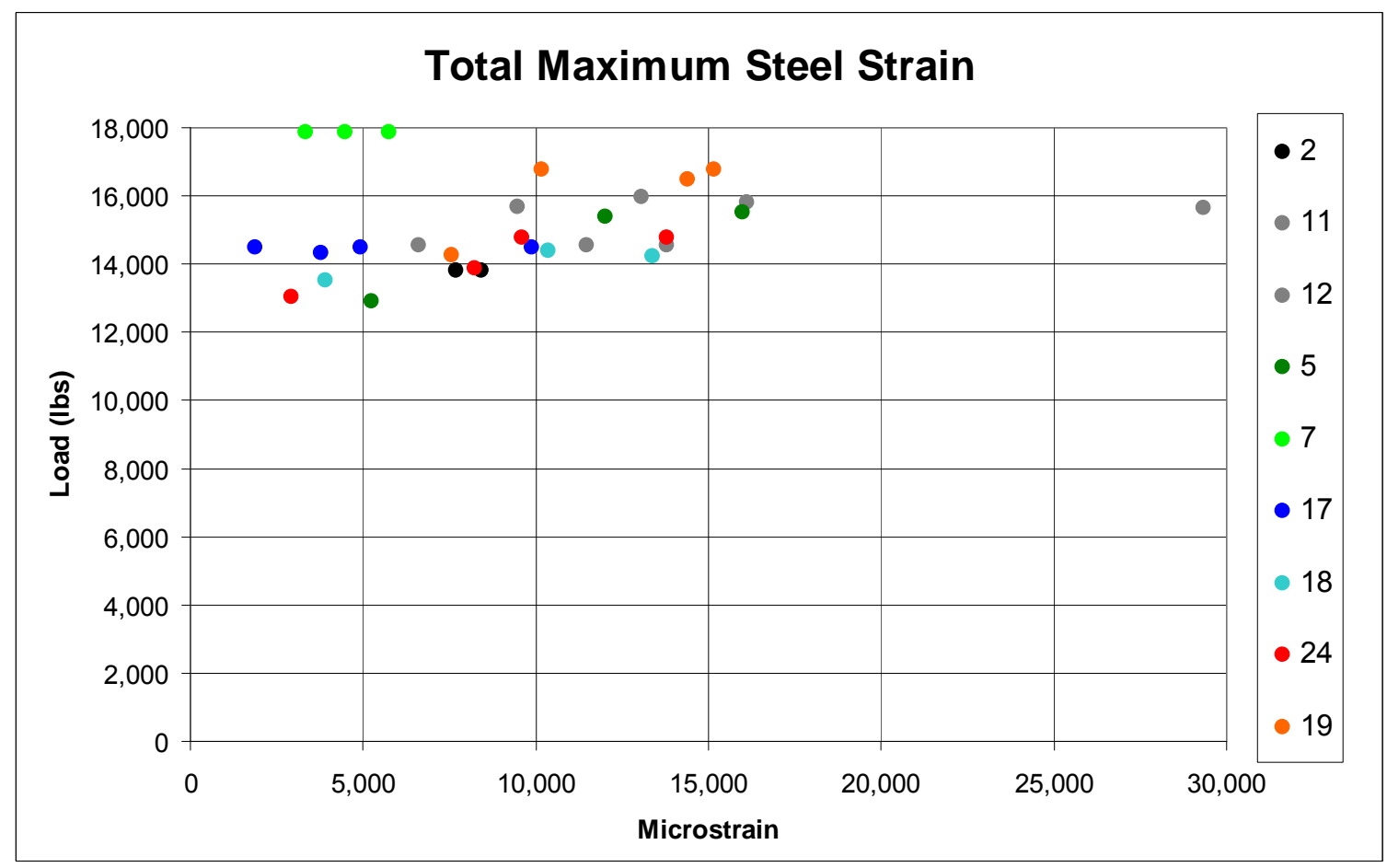

Figure 6.64: Individual maximum steel strains and corresponding loads within the linear region 
The maximum linear FRP strains ${ }^{* *}$ were very similar amongst the three wrapping schemes, but the loads at which the linearity of the strain was terminated varied significantly. For both fatigued and non-fatigued beams, FRP strains remained linear to the highest load for Scheme 1 and to the lowest load for Scheme 3. As for the steel, the FRP strains were widely scattered at failure.

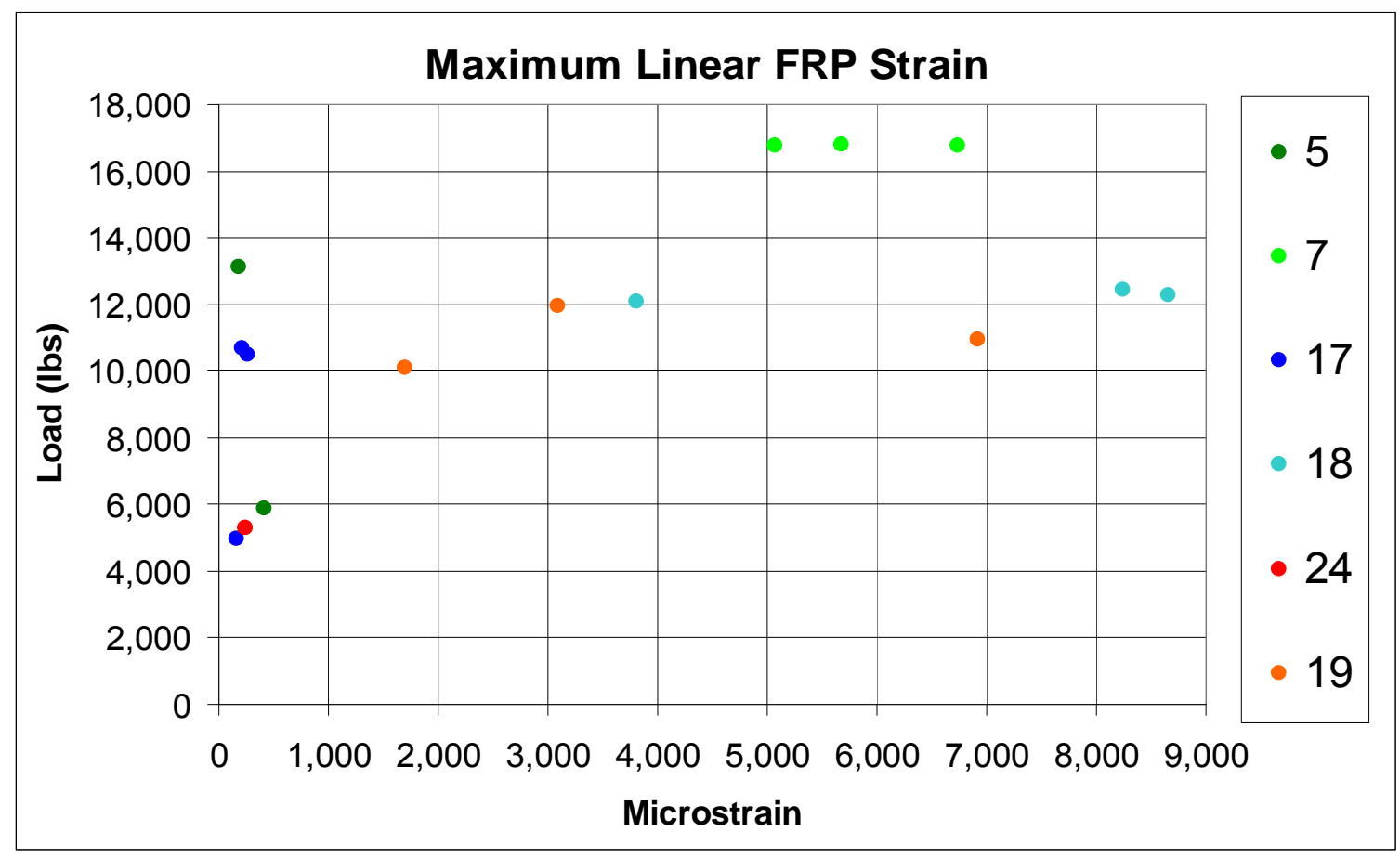

Figure 6.65: Individual maximum FRP strains and corresponding loads within the linear region

\footnotetext{
${ }^{* *}$ Please note that FRP strain is linear to rupture for direct tension coupon tests involving the FRP alone. However, when FRP is bonded to the concrete, the two materials behave compositely, resulting in a nonlinear portion of the FRP load-strain curve.
} 


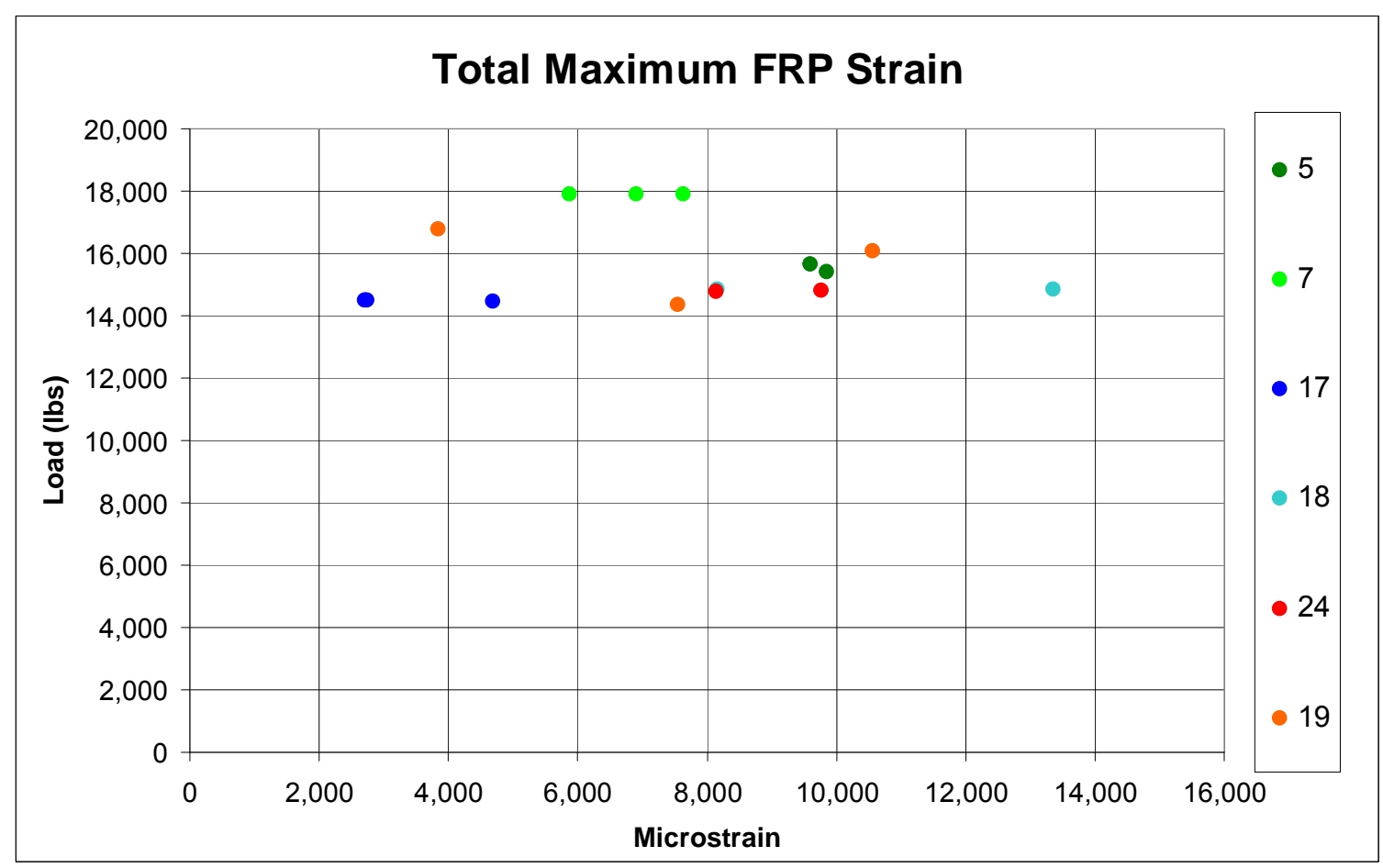

Figure 6.66: Individual maximum overall FRP strains and corresponding loads

Maximum linear bonded concrete strains were all similar, but the loads at which they occurred were widely scattered. Bonded concrete strain remained linear to much higher strain values and loads on unrepaired beams than they did on repaired beams. Total maximum linear concrete strains were all widely scattered due to the formation of cracks, and the bonded gages failed at a wide variety of loads which were well below the failure load of the beam specimens. 


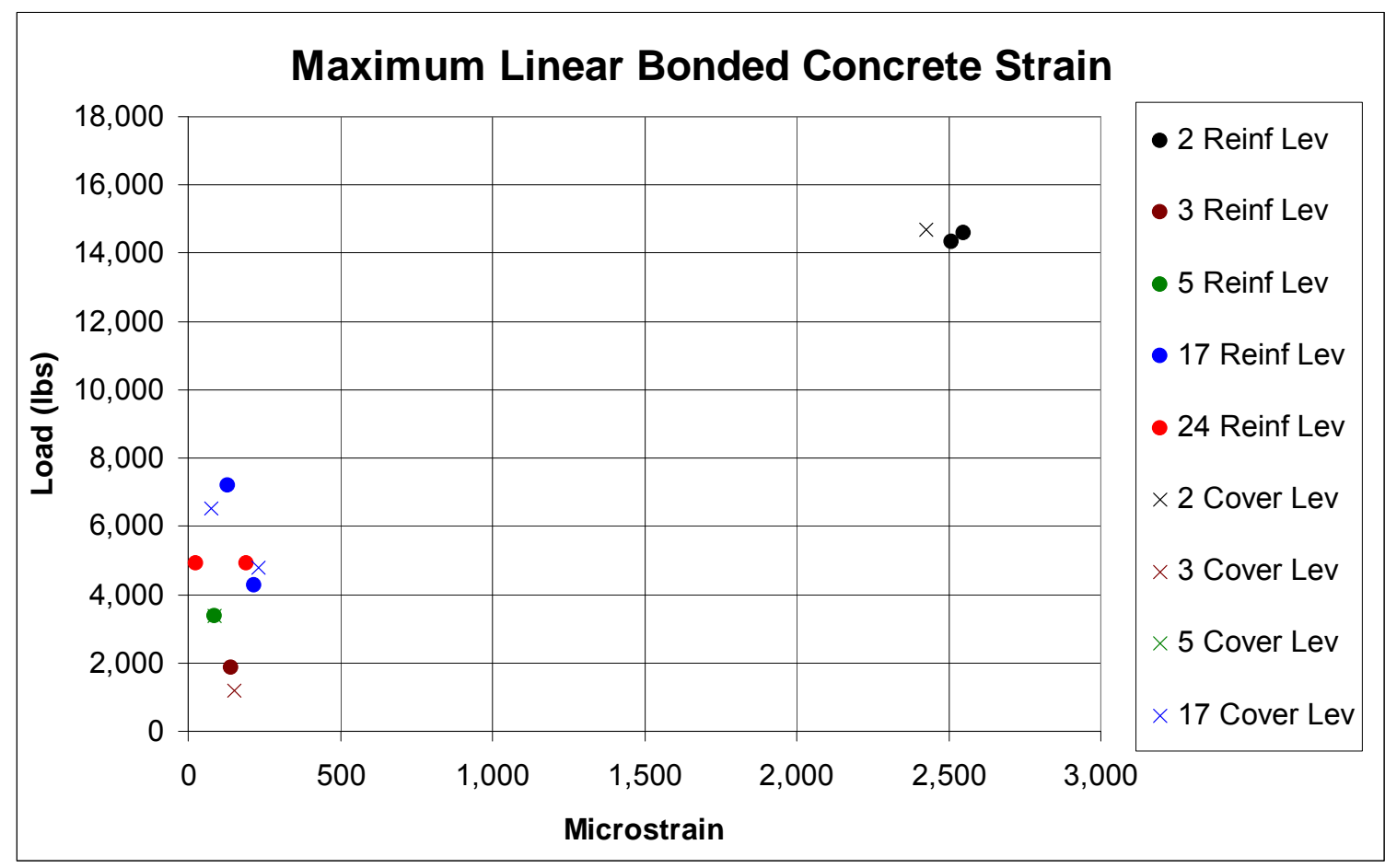

Figure 6.67: Individual maximum bonded concrete strains (both at reinforcement level and at concrete cover level) and corresponding loads within the linear region

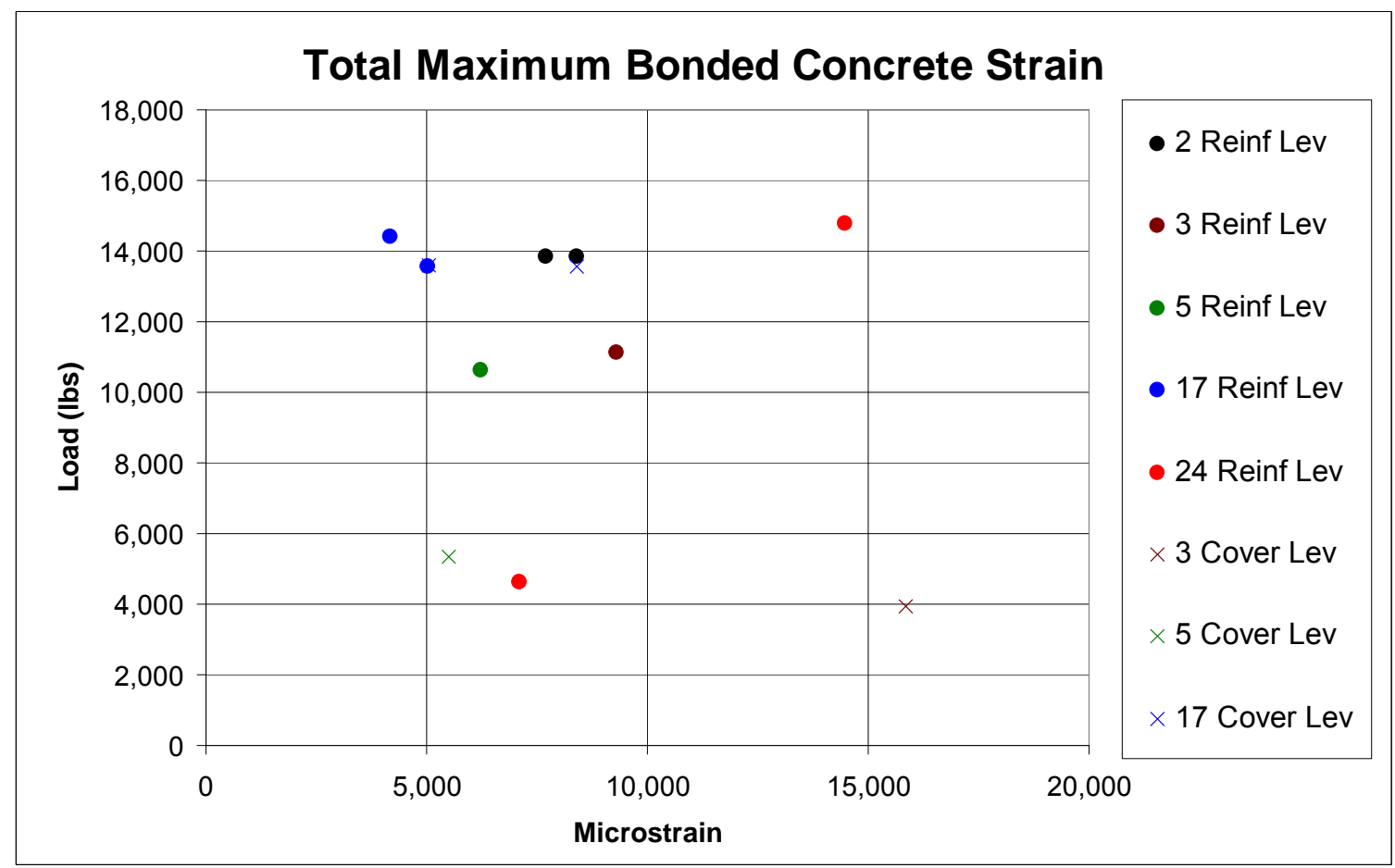

Figure 6.68: Individual maximum overall bonded concrete strains (both at reinforcement level and at concrete cover level) and corresponding loads 


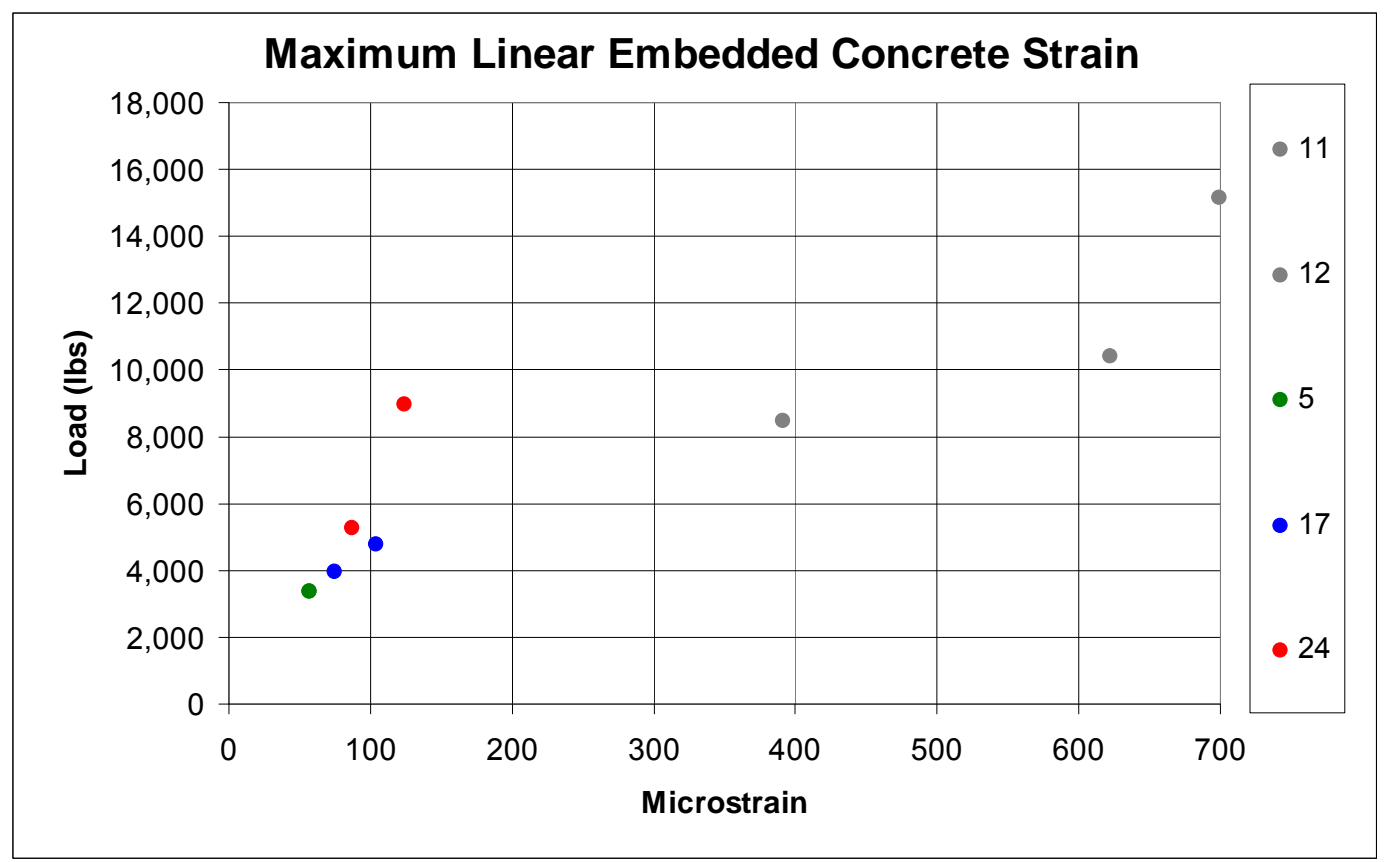

Figure 6.69: Individual maximum embedded concrete strains and corresponding loads within the linear region

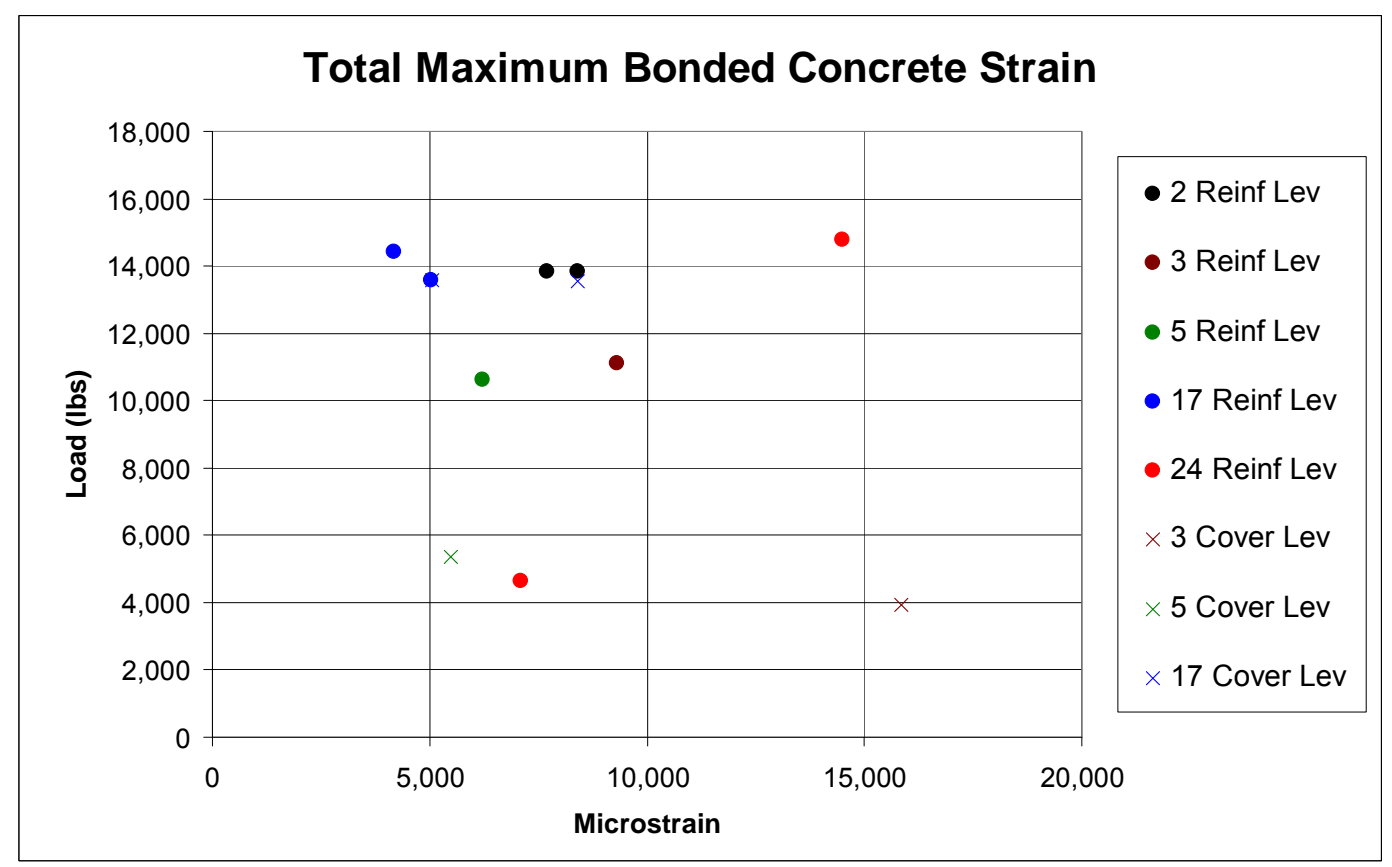

Figure 6.70: Individual maximum recorded bonded concrete strains (both at reinforcement level and at concrete cover level) and corresponding loads 
Embedded concrete strains remained linear to much higher strain values on unrepaired beams than they did on repaired beams. However, these gages did not perform well as evidenced by the vast difference in strain values.

All beams failed via crack-induced debonding and subsequent FRP rupture. Recall that crack-induced debonding initiates at the location of a flexure crack where there is a high stress concentration at the FRP-concrete interface. When the stress level reaches a critical point, the crack instantly propagates along the FRP-concrete interface. Due to the rapid redistribution of stress, the FRP ruptures at a location near the original concrete flexure crack.

Table 6.30 shows the primary locations of FRP rupture on Part II beams. The reported locations were measured from the marked end support location. Please note that the marked end support was located 3" from the beam ends and the FRP termination points were located 3" to the inside of each support. Therefore, a reported FRP rupture location of 3'-9" would have been located 3'-6" from the FRP termination point. Recall that the locations of the beams' midspan are 3'-0". 
Table 6.29: Part II FRP Rupture Locations

\begin{tabular}{|c|c|c|c|}
\hline \multicolumn{2}{|l|}{ Description } & Beam & $\begin{array}{l}\text { Distance from the Mark } \\
\text { Support to the Primary } \\
\text { Location of FRP Failure }\end{array}$ \\
\hline \multirow{5}{*}{ Wrapping Scheme 1} & \multirow{3}{*}{$\begin{array}{c}\text { Non- } \\
\text { Fatigued }\end{array}$} & 5 & $1^{\prime}-6^{3 / 4} 4^{\prime \prime}-1^{\prime}-10^{1 / 2}$ \\
\hline & & 8 & $1^{\prime}-113 / 8 "--2^{\prime}-37 / 8 "$ \\
\hline & & 9 & $1^{\prime}-4^{3} / 4^{\prime \prime}-2^{\prime}-3^{\prime \prime}$ \\
\hline & \multirow{2}{*}{ Fatigued } & 7 & $2^{\prime}-3^{\prime \prime}--2^{\prime}-9^{1} / 2^{\prime \prime}$ \\
\hline & & 14 & $3^{\prime}-9^{\prime \prime}$ \\
\hline \multirow{5}{*}{ Wrapping Scheme 2} & \multirow{3}{*}{$\begin{array}{c}\text { Non- } \\
\text { Fatigued }\end{array}$} & 13 & $2^{\prime}-6^{\prime \prime}--2^{\prime}-9^{\prime \prime}$ \\
\hline & & 15 & $3^{\prime}-61^{1} 2^{\prime \prime}-3^{\prime}-9^{1} / 2^{\prime \prime}$ \\
\hline & & 17 & 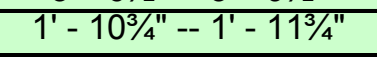 \\
\hline & \multirow{2}{*}{ Fatigued } & 18 & $1^{\prime}-81^{1} 4^{\prime \prime}-2^{\prime}-6{ }^{\prime \prime} 4^{\prime \prime}$ \\
\hline & & 20 & $3^{\prime}-8^{\prime \prime}--3^{\prime}-11^{\prime \prime}$ \\
\hline \multirow{4}{*}{ Wrapping Scheme 3} & \multirow{2}{*}{\begin{tabular}{|c|} 
Non- \\
Fatigued
\end{tabular}} & 21 & $2^{\prime}-71 / 2^{\prime \prime}-2^{\prime}-8^{\prime \prime}$ \\
\hline & & 24 & $1^{\prime}-7^{\prime \prime}--1^{\prime}-8^{\prime \prime}$ \\
\hline & \multirow{2}{*}{ Fatigued } & 19 & $2^{\prime}-11 \frac{1}{2 \prime}{ }^{\prime \prime}--3^{\prime}-2^{1} \frac{1}{\prime \prime}$ \\
\hline & & 23 & $3^{\prime}-8^{\prime}$ \\
\hline
\end{tabular}

The FRP rupture locations for non-fatigued Scheme 1 beams ranged between 1'-43/4" and 2-37/8". Non-fatigued Scheme 2 rupture locations ranged between $1^{\prime}-10^{3} / 4^{\prime \prime}$ and 3'-91/2". Recall that, for Scheme 2, a 4"-wide FRP anchor stirrup was located at locations of 1'-3" $-1 '-7$ ' and at 4'-3" - 4'-7" (measured from the marked end support). These failure locations (including debonding) were contained to within the regions between the two anchor stirrups. Scheme 2 ruptures tended to occur nearer to the midspan than did Scheme 1 ruptures. Non-fatigued Scheme 3 rupture locations ranged between 1'-7" and 2'-8". Recall that for Scheme 3, 4" wide FRP anchor stirrup were present at locations between 0'-6" and 0'-10", 1'-2"' and 1'-6”, 1'-10" and 2'-2", 2'-6" and 2'-10", 3'-2" and 3'-6", 3'-10" and 4'-2', 4'-6" and 4'-10", and 5'-2" and 5'6". Scheme 3 rupture locations were scattered. 
The FRP rupture locations for fatigued Scheme 1, 2, and 3 beams ranged between 2'-3'" and 3-9", $1^{\prime}-81 / 4^{\prime \prime}$ and $3^{\prime}-11^{\prime \prime}$, and $2^{\prime}-11^{1 / 2}$ ' and $3^{\prime}-8$ ', respectively. These ruptures were nearer to the midspan than for the non-fatigued ruptures of the same scheme.

Figure 6.71 displays photos of the statically-failed non-fatigued beams that were repaired using Wrapping Scheme 1. Top left is Beam II-5, top right is Beam II-8, bottom left is Beam II-9, bottom center shows a typical FRP failure surface, and bottom right shows a vee-shaped crack that will be discussed next. As evidenced in the photos, widespread delamination occurred due to crack-induced debonding. The vee-shaped crack is also visible at the initiation point of crack-induced debonding in the top left photo. Similar pronounced vee-shaped cracking was very common among most of the non-fatigued FRP-repaired beams. Debonding occurred primarily within the epoxy-concrete interface, with very thin localized patches of concrete remaining adhered to the FRP. The debonding would have likely occurred within the concrete cover layer if normal concrete were used for repair, but due to the high strength of the polymer concrete, failure occurred primarily at the bonded interface.

Figure 6.72 presents photos of the statically-failed beams that were fatigued and beams that were repaired using Wrapping Scheme 1. The photo on the left is of Beam II-7 and the photo on the right is of Beam II-14. For the fatigued beams, vee-shaped cracking was not as prevalent (there were still very small $\mathrm{v}$-shaped patches, but they were not nearly as pronounced as those observed on the non-fatigued beams). A possible reason for this was that either localized debonding or weakening of the epoxy-concrete interface 
occurred within the constant moment region during fatigue loading, which caused noncomposite behavior. The strong bond closer to the beam ends may have held the FRP system in place, resembling the behavior of the prestressed beam. It should be noted that no visual observation could be made that suggested the weakening of the bond during fatigue loading or during static loading prior to failure.
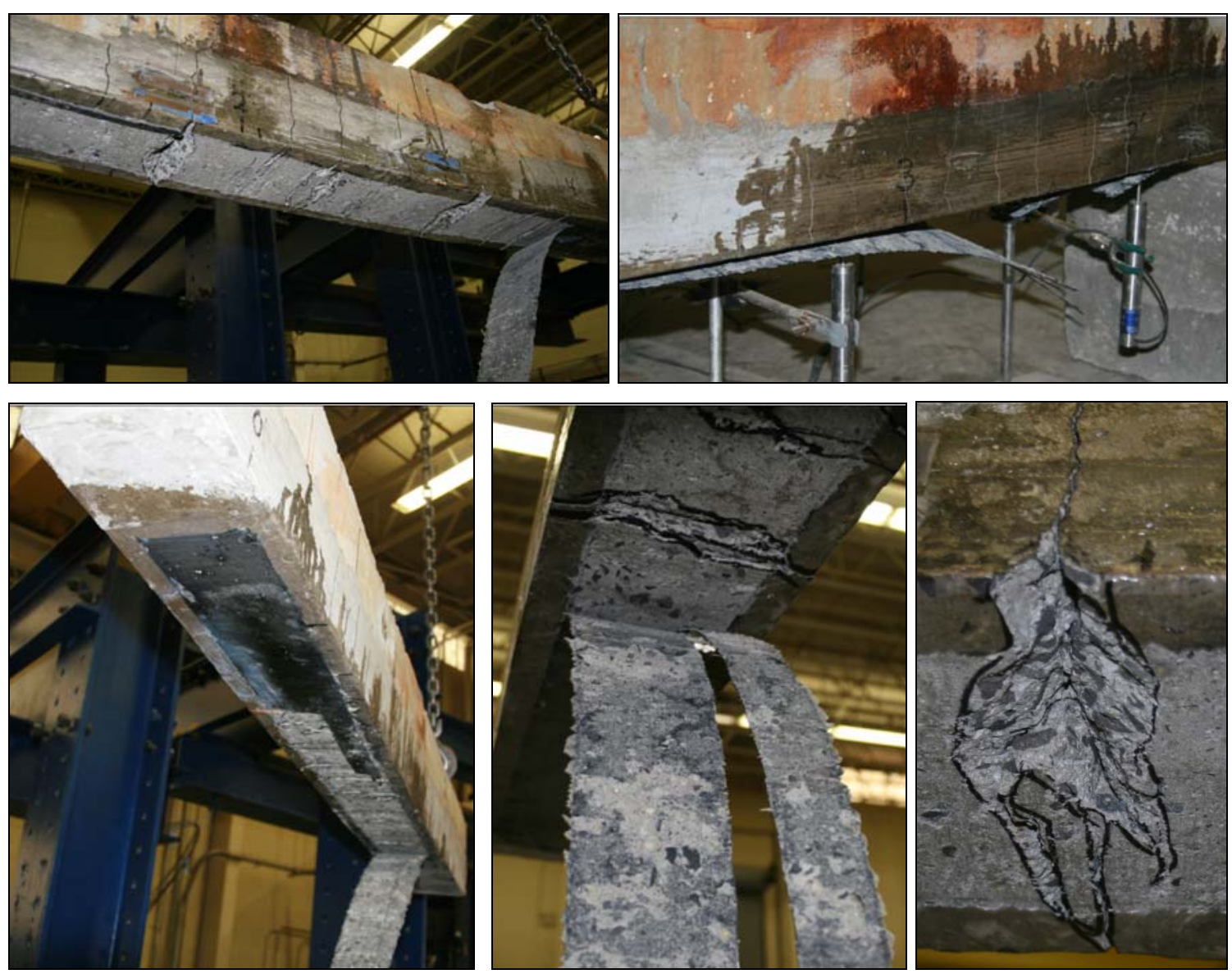

Figure 6.71: Photos of non-fatigued Part II beams repaired using Wrapping Scheme 1 after failure 

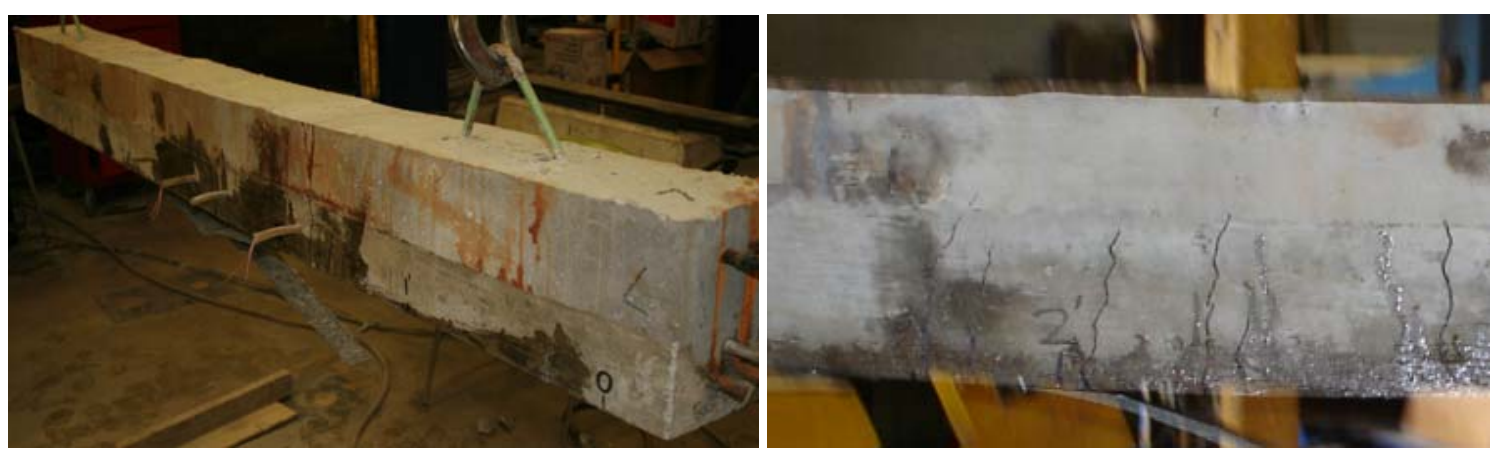

Figure 6.72: Photos of fatigued Part II beams repaired using Wrapping Scheme 1 after failure

Figure 6.73 shows photos of the statically-failed non-fatigued beams that were repaired using Wrapping Scheme 2. The top photo is of Beam II-13, the middle photo is of Beam II-15, and the bottom photo is of Beam II-17. Regions of dramatic delamination, as for Scheme 1, were also observed to either side of the crack where crack-induced debonding occured on Beams II-13 and 15. The anchors prevented the delamination from continuing beyond the stirrup locations. A very small area of delamination was observed adjacent to the rupture location on Beam II-17, which was near the anchor stirrup. Figure 6.74 displays photos of the statically-failed fatigued beams that were repaired using Wrapping Scheme 2. The photo on the left is of Beam II-18 and the photo on the right is of Beam II-20. The FRP rupture and delamination on these beams support the conjecture proposed for the fatigued Wrapping Scheme 1 beams. Notice how the FRP freely delaminated from Beams II-18 over almost the entire constant moment region and had multiple locations of partial rupture. Also, observe the lack of pronounced vee-shaped notches on the concrete tension face of Beam II-20. 

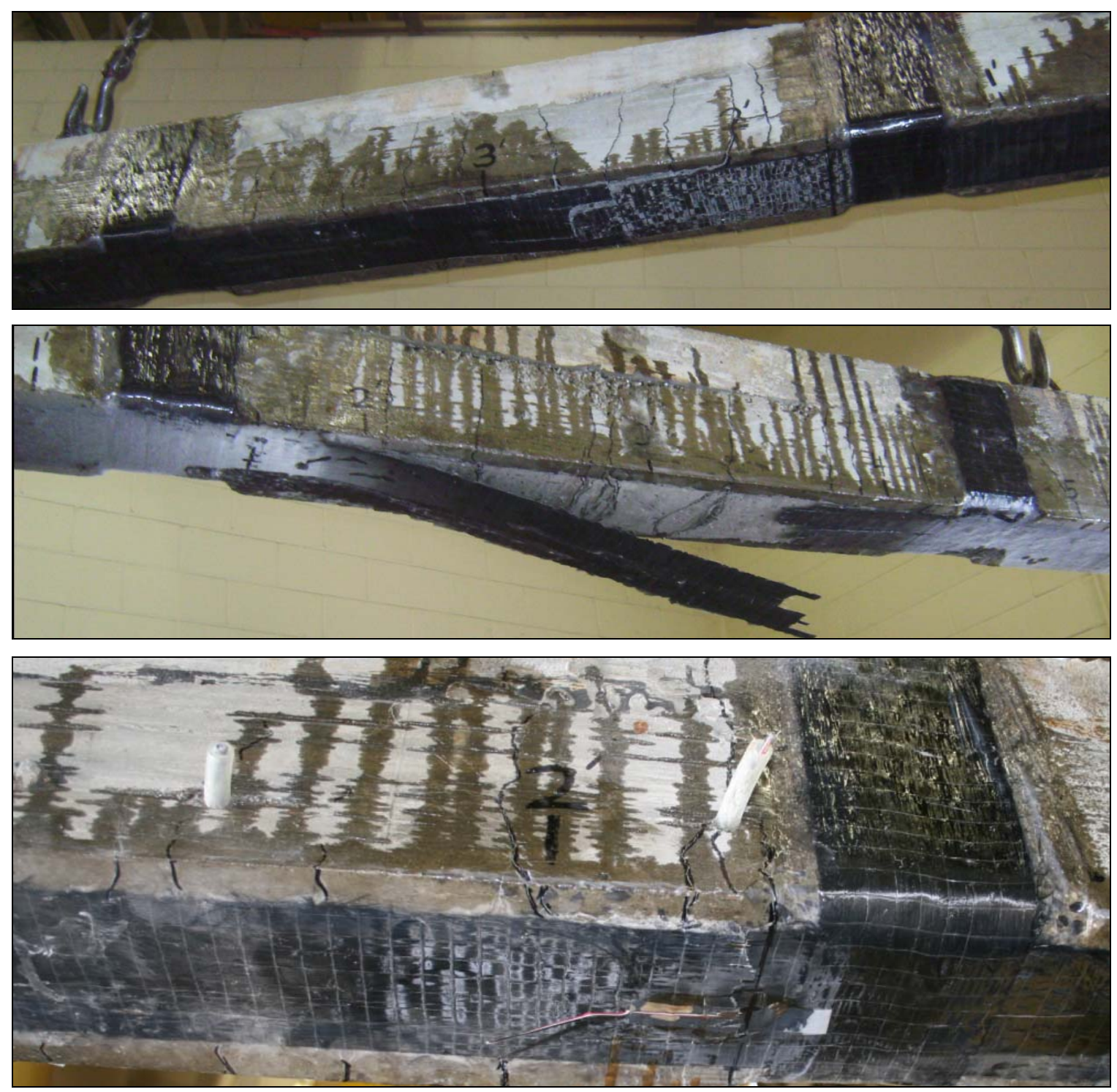

Figure 6.73: Photos of non-fatigued Part II beams repaired using Wrapping Scheme 2 after failure

Figure 6.75 presents photos of the statically-failed non-fatigued beams that were repaired using Wrapping Scheme 3. The top left photo is of Beam II-21, the top right photo is of Beam II-24, the bottom left photo is of Beam II-23, and the bottom right photo shows the pronounced vee-shaped crack on beam II-24 after the FRP was locally removed. The evenly spaced anchors greatly limited the size of FRP debonding areas at the time of 
failure. Failure in Beam II-21 occurred directly beneath the anchor stirrup, so no delamination was observed. The anchor stirrups confined the delamination on Beams II22 and II- 24 to within the 4 in region between the transverse reinforcement.
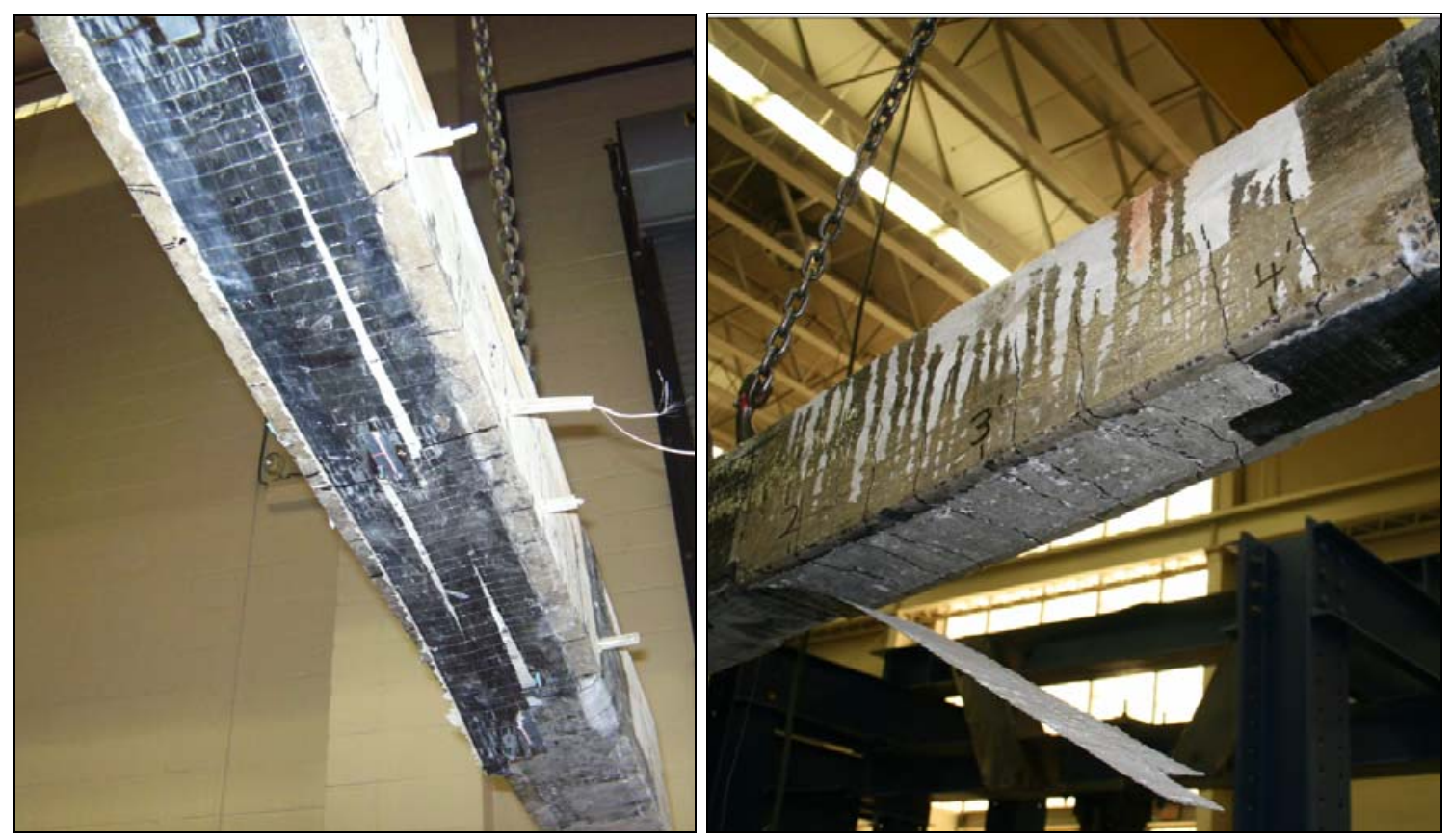

Figure 6.74: Photos of fatigued Part II beams repaired using Wrapping Scheme 2 after failure

Figure 6.76 displays photos of the statically-failed fatigued beams that were repaired using Wrapping Scheme 3. The photo on the left is of Beam II-19 and the photo on the right is of Beam II-23. Again, the pronounced vee-shaped cracking is not prevalent in the fatigue-loaded beams, suggesting that a localized weakening of the bond layer may have still occurred between the anchor stirrups as a result of fatigue. 

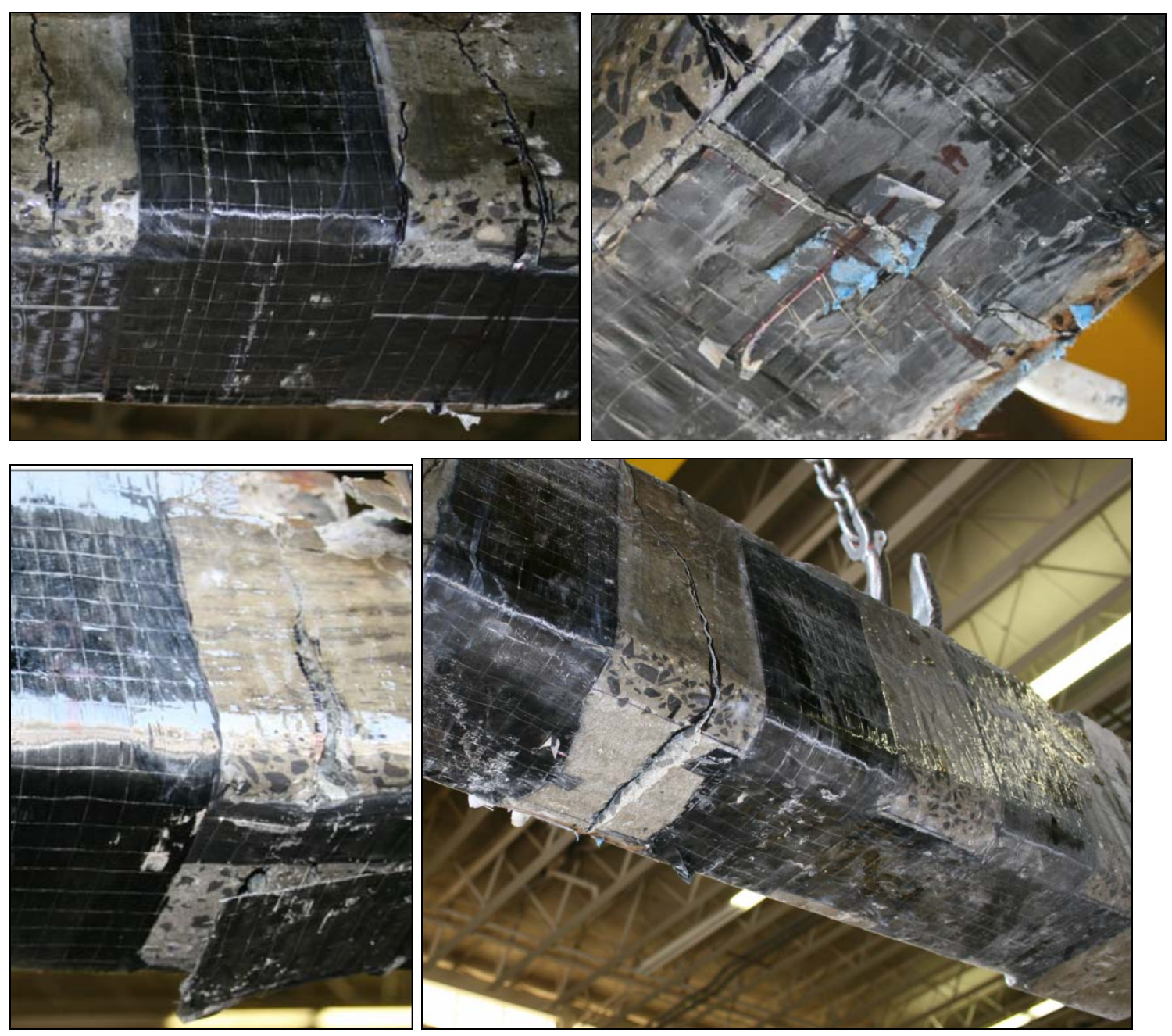

Figure 6.75: Photos of non-fatigued Part II beams repaired using Wrapping Scheme 3 after failure
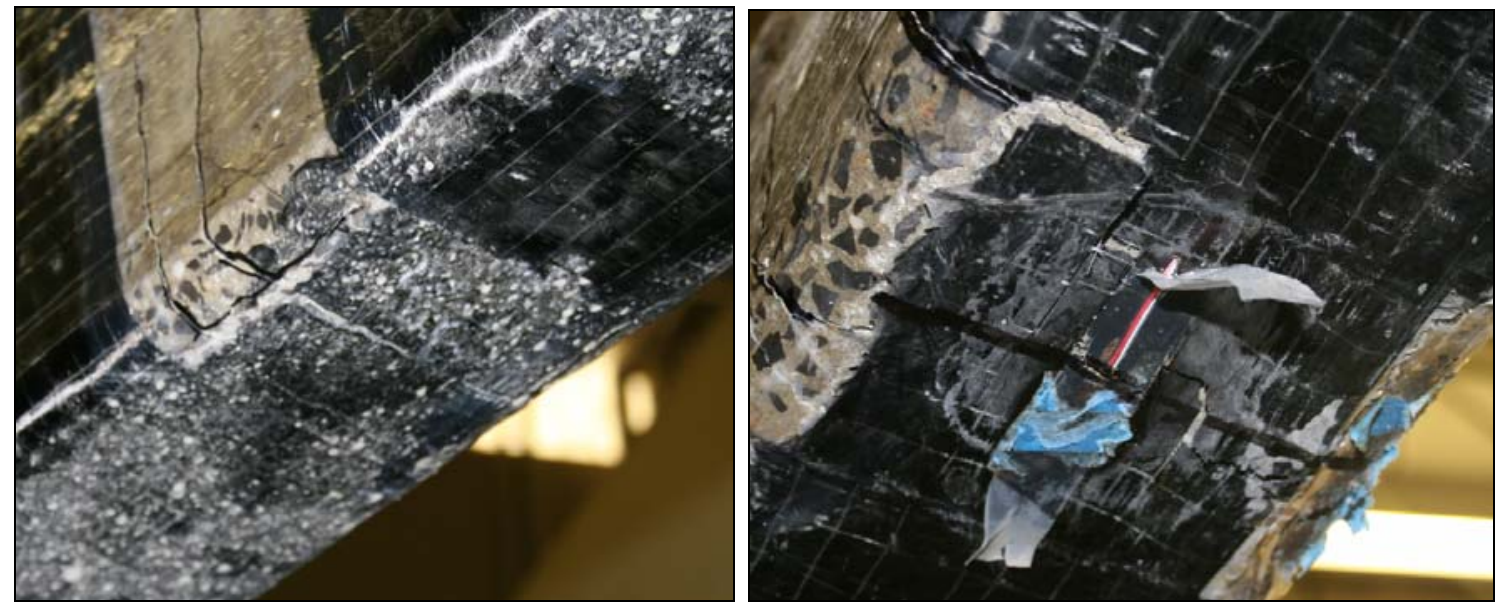

Figure 6.76: Photos of fatigued Part II beams repaired using Wrapping Scheme 3 after failure 

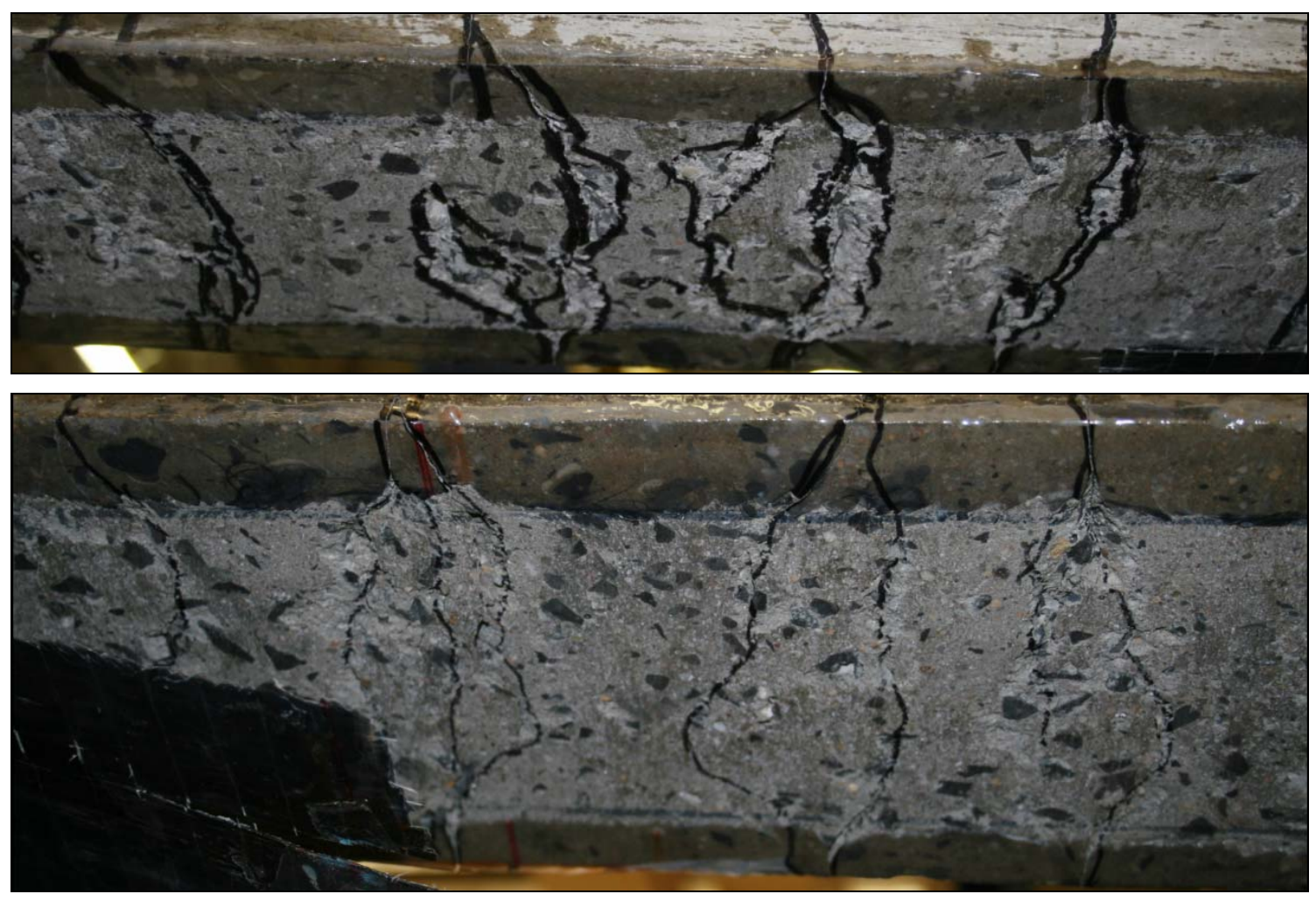

Figure 6.77: Comparison between fracture surfaces of non-fatigued and fatigued beams repaired with Wrapping Scheme 1

To effectively illustrate the differences in cracking to the reader, Figure 6.77, Figure 6.78, Figure 6.79 present close-up views of the fracture surface of one non-fatigued beam and one fatigued beam for Wrapping Schemes 1, 2, and 3 respectively. In Figure 6.77, nonfatigued Beam II-8 is shown at the top and fatigued Beam II-14 is shown at the bottom. In Figure 6.78, non-fatigued Beam II-17 is shown at the top and fatigued Beam II-18 is shown at the bottom. In Figure 6.79, non-fatigued Beam II-24 is shown to the left and fatigued beam II-19 is shown to the right.. 

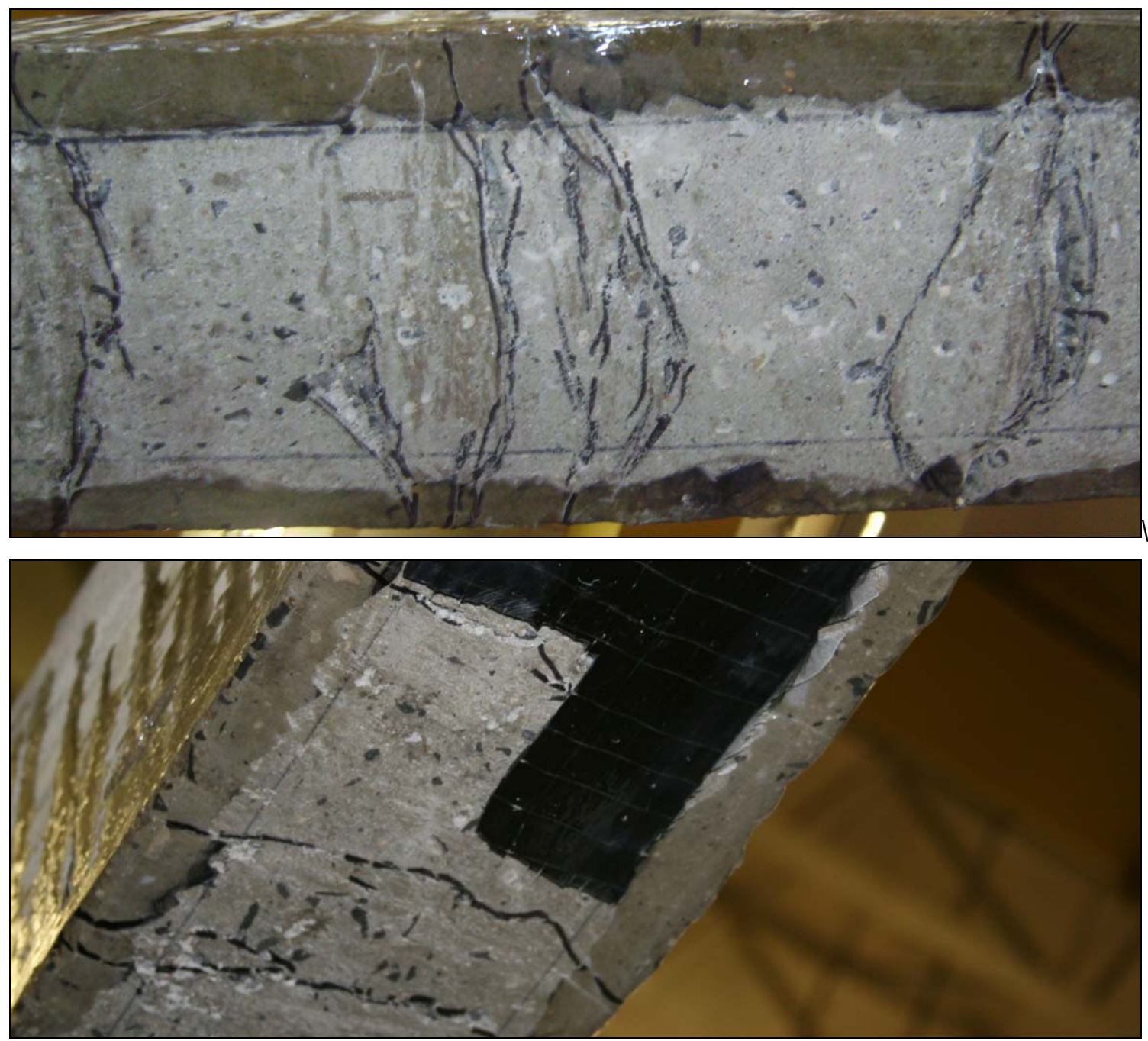

Figure 6.78: Comparison between fracture surfaces of non-fatigued and fatigued beams repaired with Wrapping Scheme 2 

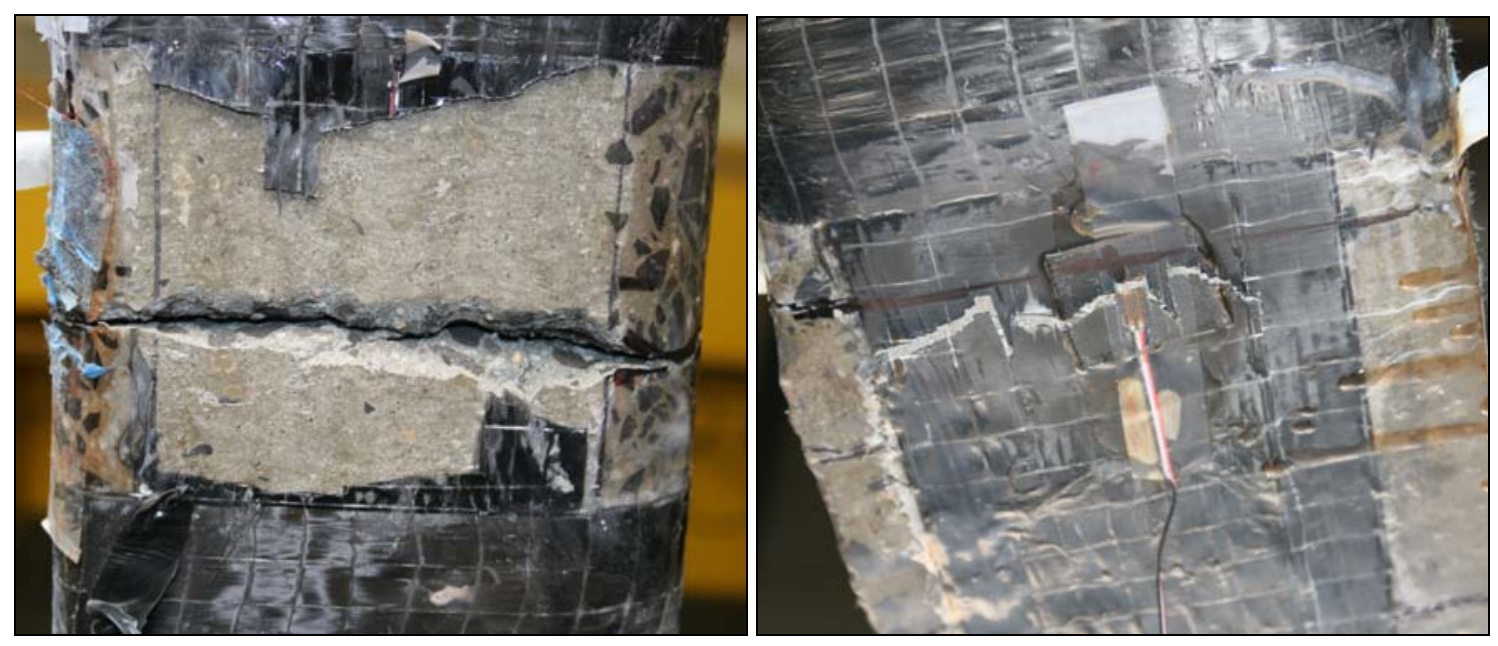

Figure 6.79: Comparison between fracture surfaces of non-fatigued and fatigued beams repaired with Wrapping Scheme 2

Figure 6.80 shows the typical fracture surface including the pronounced vee-shaped portions of concrete adhered to the FRP that was observed on the non-fatigued beams repaired with Wrapping Scheme 1.

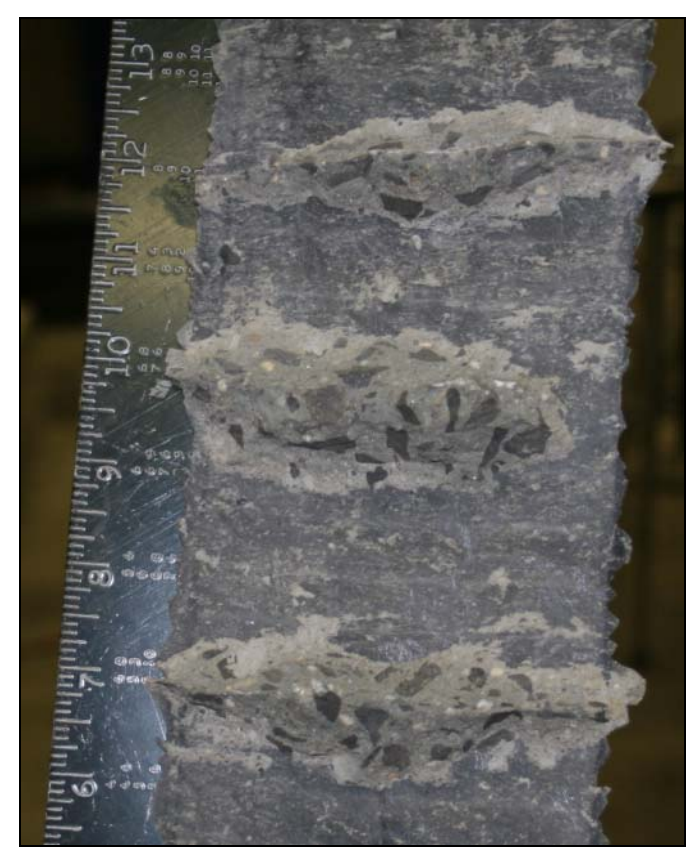

Figure 6.80: Typical fracture surface of non-fatigued beam specimens with polymer concrete substrate repair 

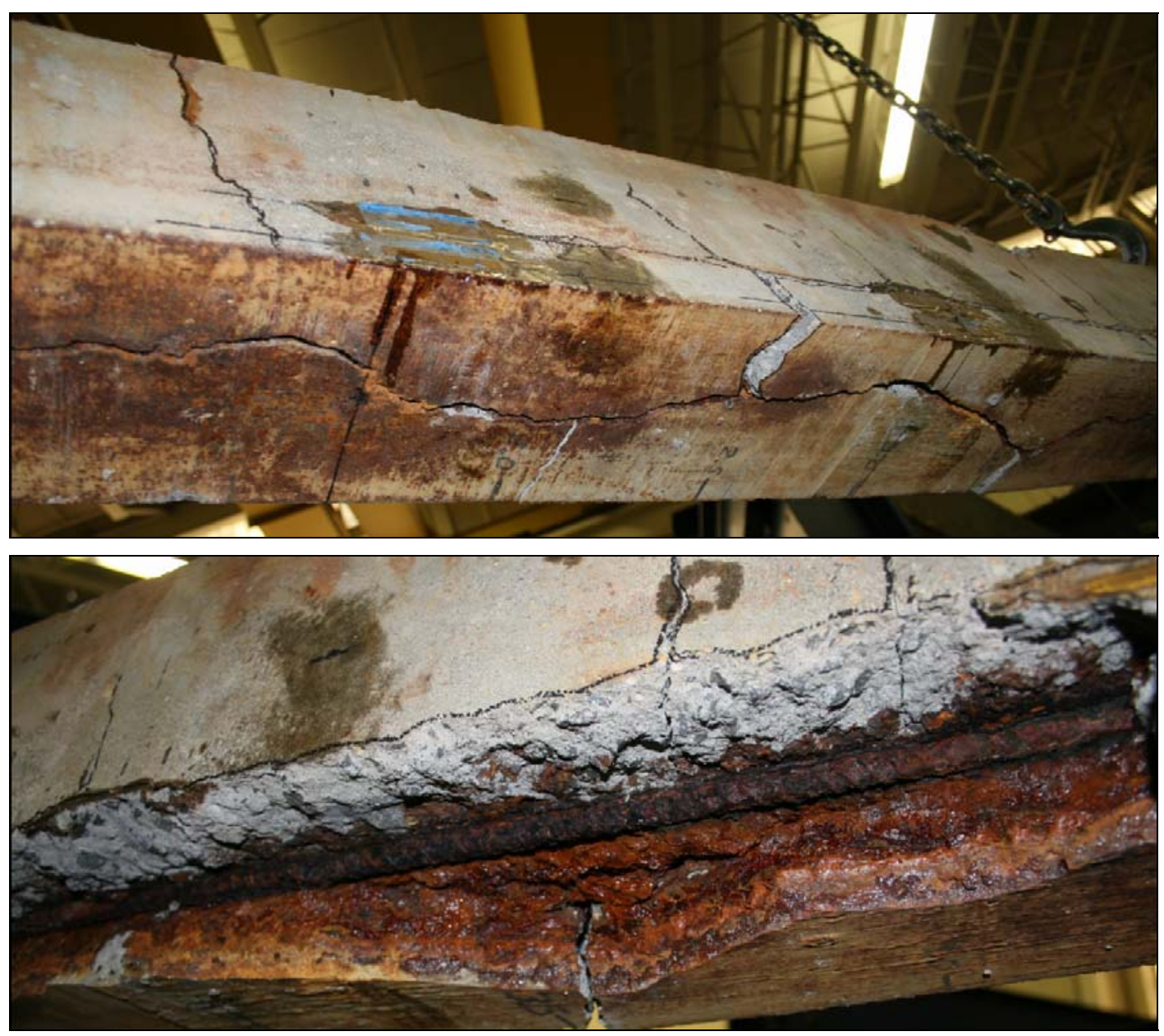

Figure 6.81: Failure of Beam II-3

Observations of the corroded unrepaired beams during static flexure testing were very interesting since the deterioration closely resembled that typically seen in the field. Figure 6.81 and Figure 6.82 show the failure of Beams II-3 and II-4, respectively. Beam II-3 had a horizontal crack on its tension face that ran parallel to the longitudinal axis, a type of crack that is commonly observed on bridges in the field. Finally, half the cover layer completely debonded and fell. The entire cover layer of Beam II-4 debonded and fell. 

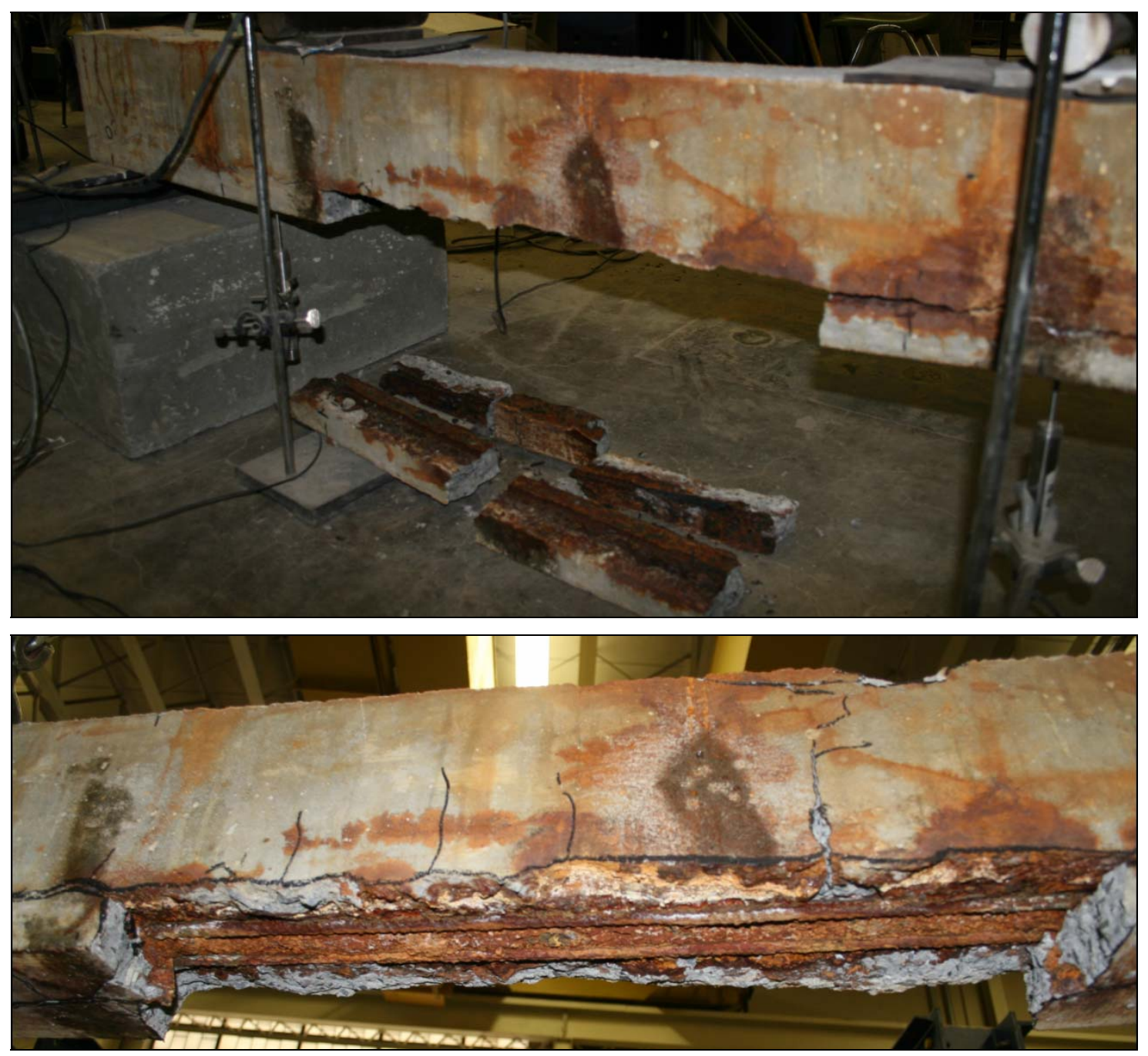

Figure 6.82: Failure of Beam II-4

Be sure to compare the photos in Figure 6.81 and Figure 6.82 to that in Figure 6.83 which depicts what was observed on the severely-deteriorated exterior girder of \#49-4012-02501032. 


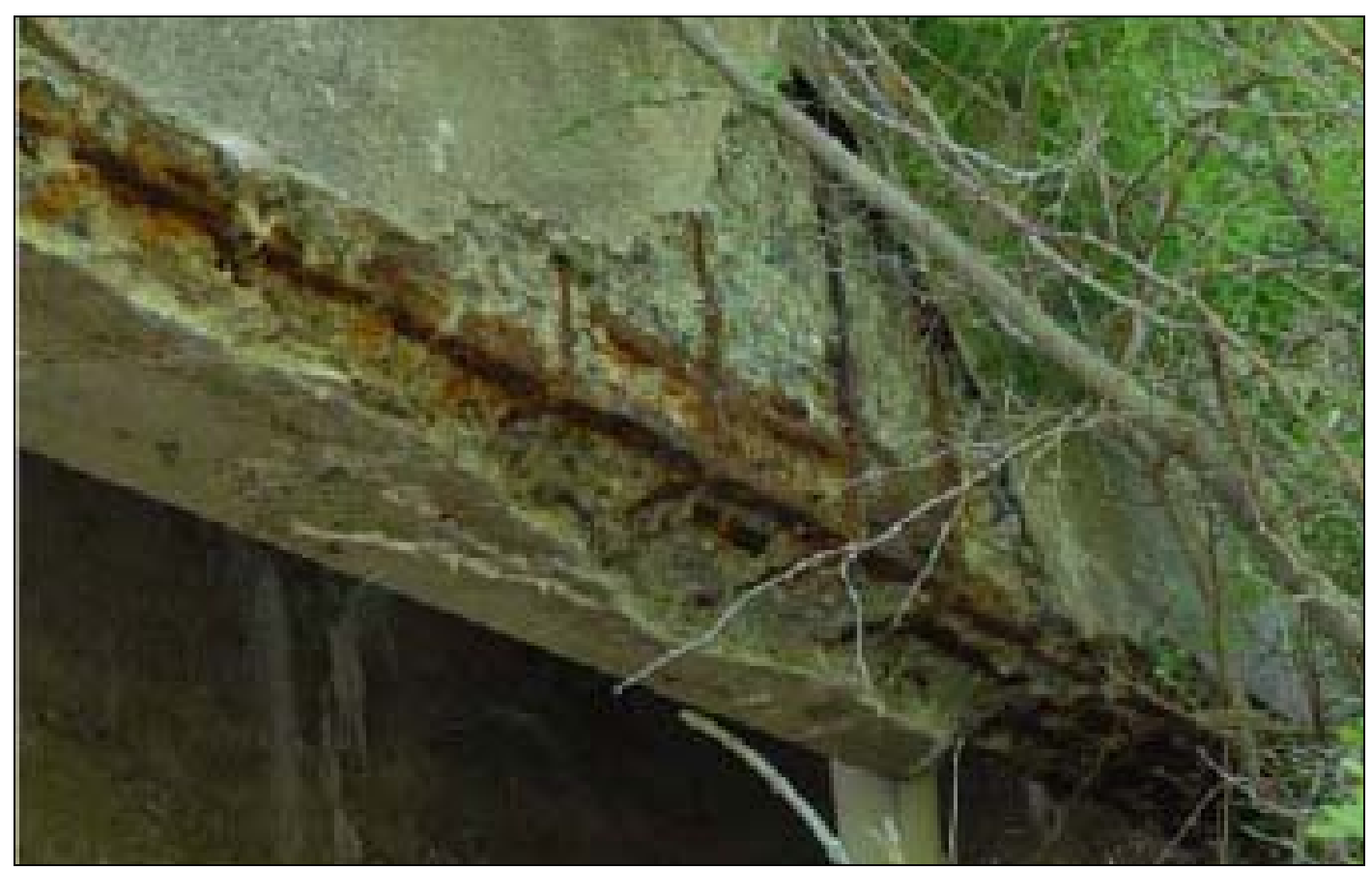

Figure 6.83: Corroded exterior girder of PennDOT Bridge \#49-4012-0250-1032

Another observation to note is the formation of a shear-flexure crack on most beams. This crack would begin on most beams as a flexure crack, and then begin to propagate at a $45^{\circ}$ upward and toward the midspan as the load increased. Some examples of these shear-flexure cracks are displayed in Figure 6.84; from top to bottom are photos of Beams II-1, II-11, II-15, and II-21 respectively. Interestingly, these shear-flexure cracks were not observed in the corroded unrepaired specimens nor were they observed in the non-fatigued beams repaired with Wrapping Scheme 1 (they were observed on fatigued Scheme 1 beams). For beams repaired with Scheme 3, as in the bottom photo of Figure 6.84, multiple shear-flexure cracks were typically observed within the same region. The transverse FRP, however, appeared to terminate the growth of these cracks once they reached and propagated beneath the stirrups. 

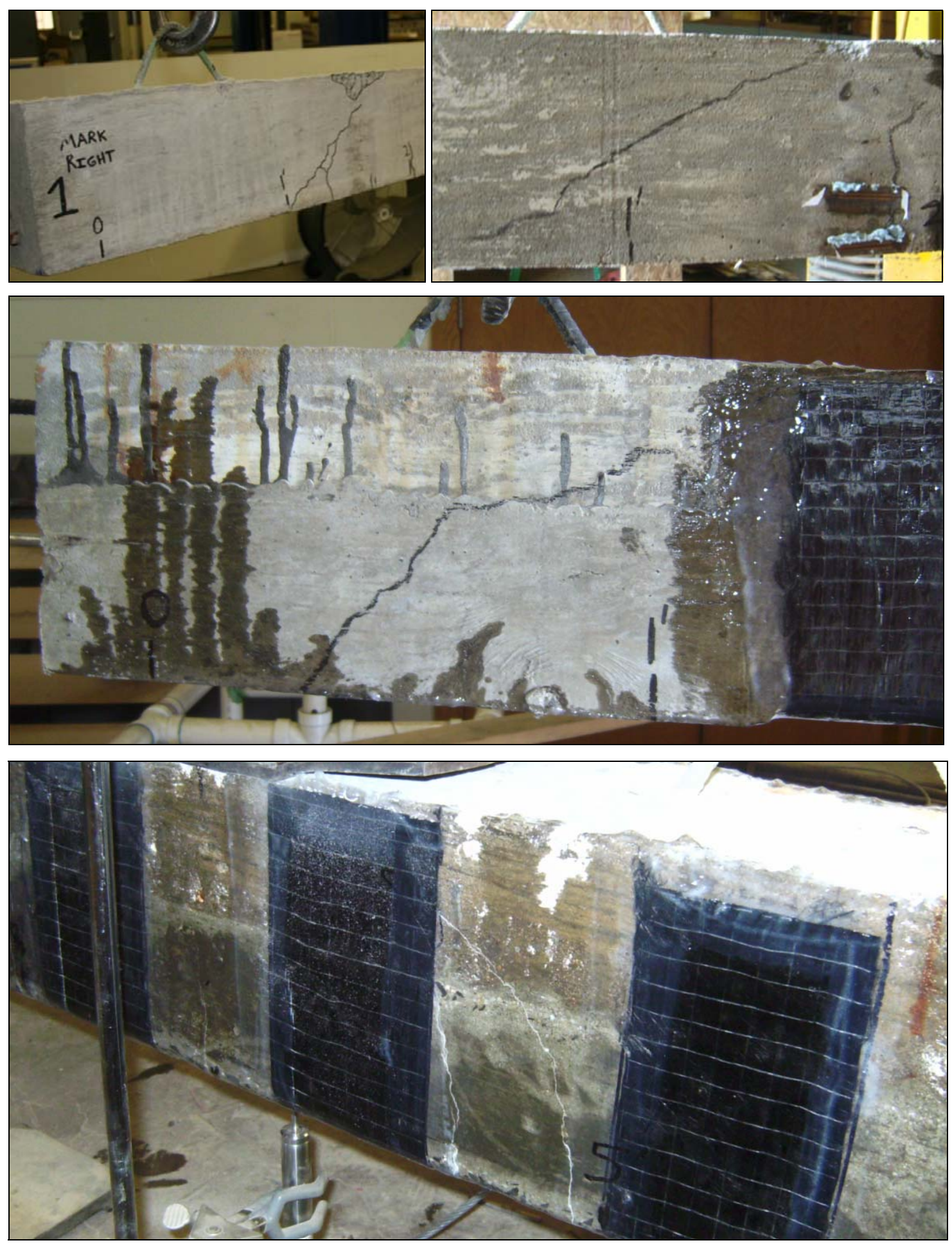

Figure 6.84: Typical shear flexure cracks observed on Part II beams 
Further analysis will need to be completed in order to determine the cause of the shear flexure cracking and to clarify the reason it did not appear on all beam specimens.

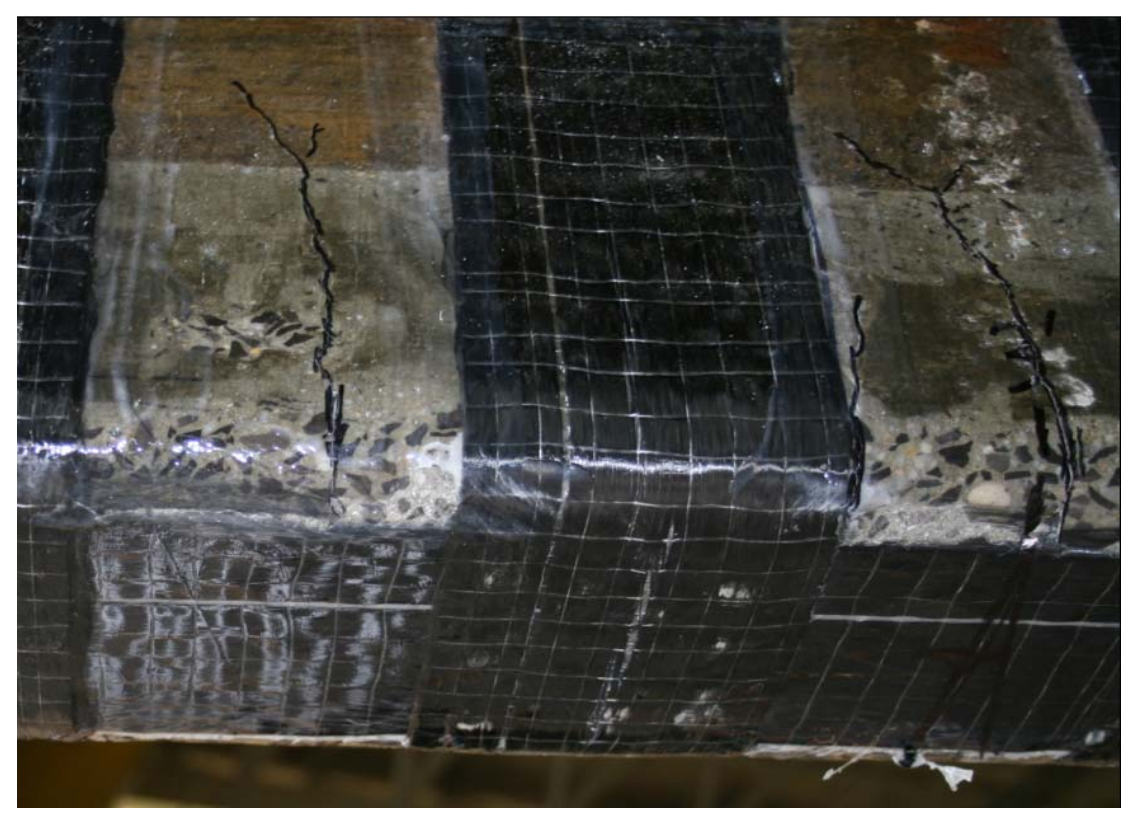

Figure 6.85: Composite action between old and new concrete on Part II beams as evidenced by cracking continuity across interface

After witnessing all the Part II static tests, it was determined that there was an excellent bond and composite action between old concrete and the polymer-modified repairconcrete. This is illustrated by the cracking seen in Figure 6.85. Cracks propagated across the interface of the two materials as if they were one material. Even in the shear spans where the patch material did not completely encase the steel, no horizontal cracking was observed along the interface and no debonding of the patch material was detected. 


\subsubsection{Literature Review on Static Flexural Testing of Large-Scale FRP-Repaired Beams}

\subsection{Maddaawy, 2005}

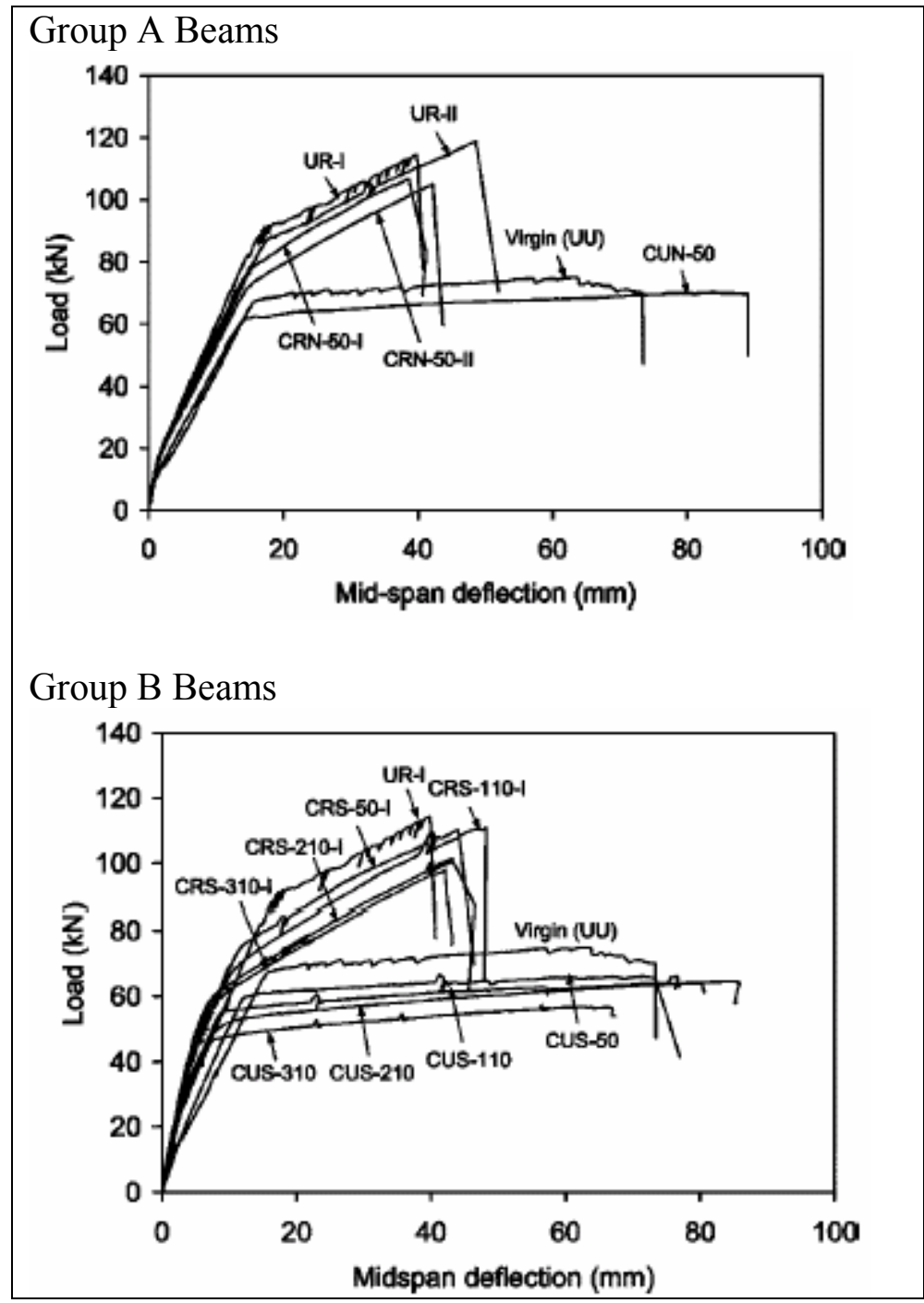

Figure 6.86: Static flexural test results for Maddaawy (2005)

Pristine and corroded beams failed via concrete crushing and FRP-strengthened beams failed via FRP rupture. Wrapping Schemes I and II increased the stiffness of the pristine beam specimens by $25 \%$ and $13 \%$, respectively. The deflection capacities for Wrapping 
Schemes I and II were $26 \%$ and $34 \%$, respectively. A summary of all static load results can be seen in Table 6.30 .

Table 6.30: Test results for Maddaawy (2005)

\begin{tabular}{|c|c|c|c|c|c|c|c|c|}
\hline \multirow[t]{2}{*}{ Group } & \multirow[t]{2}{*}{ Specimen } & \multicolumn{2}{|c|}{ Cracking } & \multicolumn{2}{|c|}{ Yield } & \multicolumn{2}{|c|}{ Ultimate } & \multirow[t]{2}{*}{ Failure Mode $\mathrm{a}^{\mathrm{a}}$} \\
\hline & & $\begin{array}{c}\mathrm{P}_{\sigma} \\
(\mathrm{kN})\end{array}$ & $\begin{array}{c}\Delta_{\sigma} \\
(\mathrm{mm})\end{array}$ & $\begin{array}{c}\mathrm{P}_{\mathrm{y}} \\
(\mathrm{kN})\end{array}$ & $\begin{array}{c}\Delta_{\mathrm{y}} \\
(\mathrm{mm})\end{array}$ & $\begin{array}{c}\mathrm{P}_{\mathrm{u}} \\
(\mathrm{kN})\end{array}$ & $\begin{array}{c}\Delta_{\mathrm{u}} \\
(\mathrm{mm})\end{array}$ & \\
\hline \multirow{6}{*}{ A } & Virgin (UU) & 10.79 & 0.92 & 67.2 & 15.63 & 75 & 73.33 & Concrete crushing \\
\hline & UR-I & 17.05 & 1.4 & 88.5 & 16.46 & 114.33 & 39.79 & CFRP rupture \\
\hline & UR-II & 17.28 & 1.43 & 87.86 & 18.05 & 118.79 & 48.55 & CFRP rupture \\
\hline & CUN-50 & 11.02 & 1.07 & 61.71 & 14.39 & 70.22 & 88.96 & Concrete crushing \\
\hline & CRN-50-I & 17.8 & 1.64 & 75.96 & 14.51 & 106.82 & 38.6 & CFRP rupture \\
\hline & CRN-50-II & 17.62 & 1.76 & 72.83 & 15.28 & 105.07 & 42.19 & CFRP rupture \\
\hline \multirow{8}{*}{$\mathrm{B}$} & CUS-50 & - & - & 59.88 & 12.34 & 66.08 & 73.41 & Concrete crushing \\
\hline & CUS-110 & - & - & 55.1 & 8.93 & 64.59 & 85.86 & Concrete crushing \\
\hline & CUS-210 & - & - & 50.1 & 8.41 & 64.18 & 76.9 & Concrete crushing \\
\hline & CUS-310 & - & - & 46.14 & 7.42 & 56.87 & 66.82 & Concrete crushing \\
\hline & CRS-50-I & - & - & 74.33 & 11.48 & 110.34 & 44.05 & CFRP rupture \\
\hline & CRS-110-I & - & - & 67.2 & 10.29 & 110.92 & 48.2 & CFRP rupture \\
\hline & CRS-210-I & - & - & 60.04 & 7.82 & 101.67 & 43.25 & CFRP rupture \\
\hline & CRS-310-I & - & - & 57.05 & 7.47 & 98.12 & 42.07 & CFRP rupture \\
\hline
\end{tabular}

For specimen details and repair methods used in this study, please see Section 4.2.1.1.1.

For accelerated aging information, please see Section 6.1.2.2. For crack measurement results, please see Section 6.2.1.2.1.

\subsection{Bonacci, 2000}

Specimens B1 and B7 failed via flexural compression, B4 failed due to steel rupture, B2, B3, and B6 failed due to FRP debonding, and B5 failed via FRP rupture. The loaddeflection curves recorded in Bonacci (2000) are shown in Figure 6.87 and a summary of 
the test results is presented in Table 6.31. It should be noted that localized crack-induced debonding was observed in the static load tests.

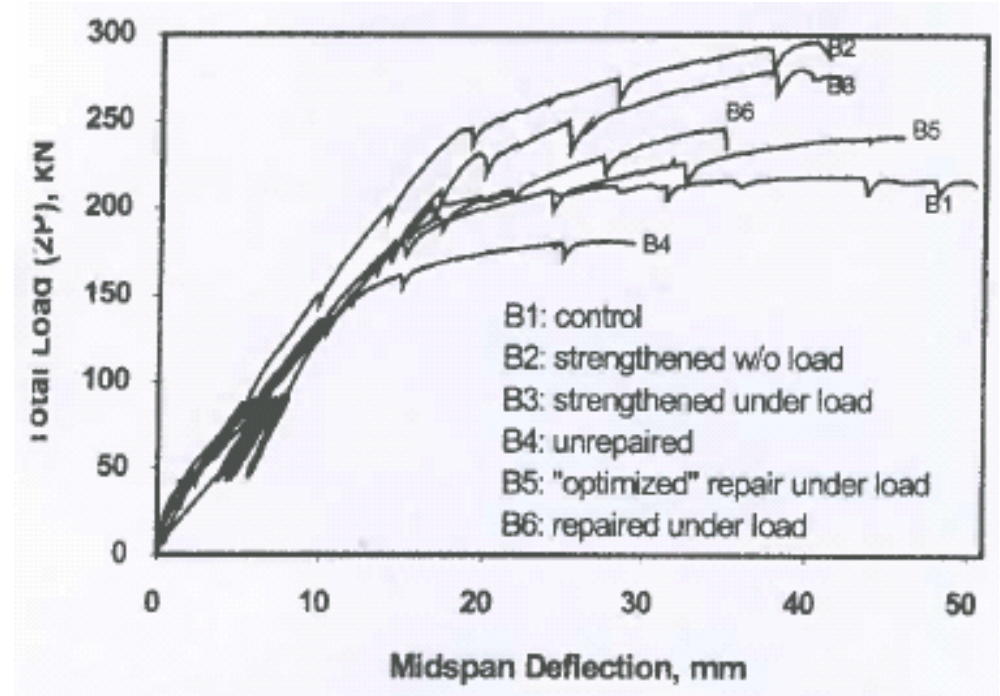

Figure 6.87: Load-deflection curves for Bonacci (2000)

Table 6.31: Summary of Test Results for Bonacci (2000)

\begin{tabular}{|c|c|c|c|c|c|c|c|c|}
\hline \multirow[t]{2}{*}{ Specimen ID } & \multirow{2}{*}{$\begin{array}{l}\mathrm{P}_{\text {yields }} \\
\mathrm{kN}^{\mathrm{a}}\end{array}$} & \multicolumn{2}{|c|}{ Load at Failure } & \multicolumn{2}{|c|}{ Deflection at failure } & \multirow[t]{2}{*}{$\Delta_{\text {fail }} / \mathrm{L}, \%$} & \multirow[t]{2}{*}{$\varepsilon^{\mathrm{CFRP}}$ fail } & \multirow[t]{2}{*}{ Failure mode } \\
\hline & & $\mathrm{P}_{\text {fail }} \mathrm{kN}$ & $\begin{array}{l}\% \text { of } \\
\text { control }\end{array}$ & $\Delta_{\text {fail }} \mathrm{mm}$ & $\begin{array}{l}\% \text { of } \\
\text { control }\end{array}$ & & & \\
\hline B1 & 202 & 219 & 100 & 51 & 100 & 1.4 & - & $\begin{array}{c}\text { Flexural } \\
\text { compression }\end{array}$ \\
\hline B2 & 242 & 296 & 135 & 41 & 81 & 1.1 & 0.0080 & Debonding \\
\hline B3 & 231 & 280 & 128 & 42 & 83 & 1.2 & 0.0064 & Debonding \\
\hline B4 & 155 & 181 & 83 & 29 & 58 & 0.8 & - & Steel rupture \\
\hline B5 & 179 & 242 & 111 & 46 & 90 & 1.3 & 0.0098 & CFRP rupture \\
\hline B6 & 194 & 246 & 112 & 35 & 69 & 1 & 0.0061 & Debonding \\
\hline B7 & 183 & 200 & 91 & 67 & 133 & 1.8 & - & $\begin{array}{l}\text { Flexural } \\
\text { compression }\end{array}$ \\
\hline
\end{tabular}

Results also indicated that there was strain compatibility between the steel and FRP materials until steel yielding, as can be seen in Figure 6.88. 


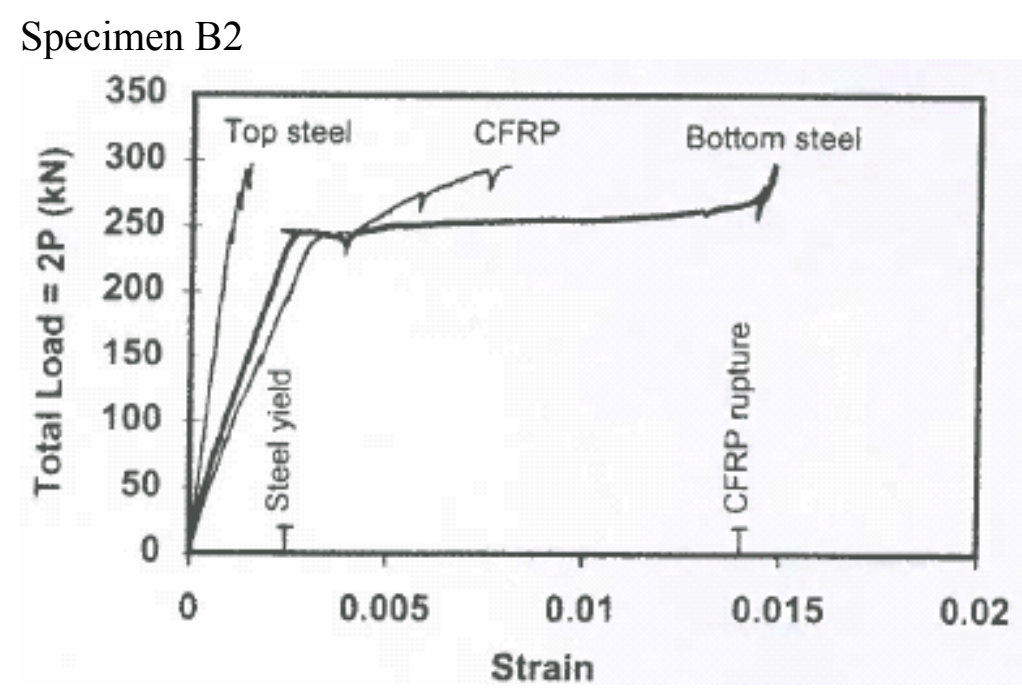

Specimen B3

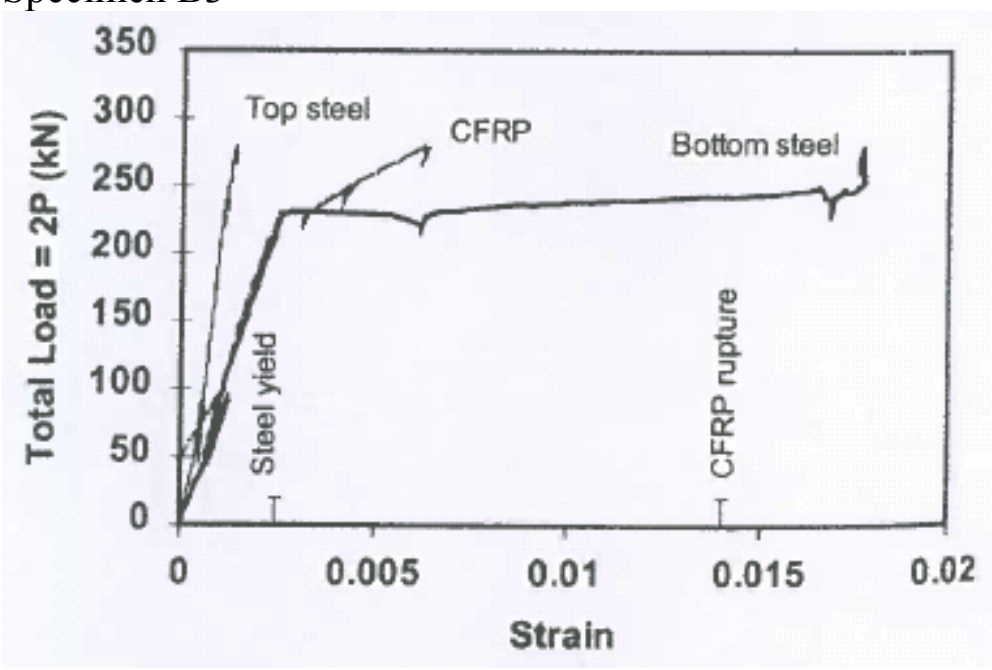

Figure 6.88: Illustration of apparent strain compatibility observed by Bonacci (2000)

For specimen details and repair methods used in this study, please see Section 4.2.1.1.2. For accelerated aging information, please see Section 6.1.2.4.

\subsection{Wang, K., 2006}

Table 6.32 defines the five failure modes observed, and Table 6.33 defines the nomenclature system used to label the beam specimens in Wang, K. (2006). 
Table 6.32: Modes of Failure Observed in Wang, K. (2006)

\begin{tabular}{|c|l|}
\hline $\begin{array}{l}\text { Failure } \\
\text { Mode }\end{array}$ & Description \\
\hline 1 & Tensile steel yielding followed by concrete compression crushing \\
\hline 2 & Tensile steel yielding followed by longitudinal FRP rupture \\
\hline 3 & Flexural FRP debonding followed by anchor debonding \\
\hline 4 & Flexural FRP debonding \\
\hline 5 & Concrete compression crushing \\
\hline
\end{tabular}

Table 6.33: Wang, K. (2006) Beam Specimen Coding System

\begin{tabular}{|c|c|c|}
\hline Code & Beam & Description \\
\hline \multirow[t]{2}{*}{ I } & $\mathrm{H}$ & Compression strength of concrete $=222.5 \mathrm{~kg} / \mathrm{cm}^{2}$ \\
\hline & $\mathrm{L}$ & Compression strength of concrete $=75 \mathrm{~kg} / \mathrm{cm}^{2}$ \\
\hline \multirow[t]{6}{*}{ II } & A1 & Low input of accelerated corrosion power \\
\hline & A2 & High input of accelerated corrosion power \\
\hline & $\mathrm{P} 1$ & Cathodic protection (with one $10 \mathrm{~cm}$ wide longitudinal FRP strip) \\
\hline & $\mathrm{P} 2$ & Cathodic protection (with two $5 \mathrm{~cm}$ wide longitudinal FRP strip) \\
\hline & $\mathrm{N}$ & Naturally corroded under room environmental \\
\hline & $\mathrm{O}$ & No chloride content in the specimen \\
\hline \multirow[t]{7}{*}{ III } & T0 & No longitudinal FRP strip on tension side \\
\hline & $\mathrm{T} 1$ & One layer of $10 \mathrm{~cm}$ wide longitudinal FRP strip on tension side \\
\hline & $\mathrm{T} 2$ & Two layers of $10 \mathrm{~cm}$ wide longitudinal FRP strip on tension side \\
\hline & $\mathrm{E}$ & Cracks sealed by epoxy injection \\
\hline & $\mathrm{U} 2$ & $10 \mathrm{~cm}$ wide U-shaped anchorage at the ends of longitudinal FRP strip \\
\hline & $\mathrm{U} 10$ & $\begin{array}{l}\text { U-shaped FRP strips of width } 10 \mathrm{~cm} \text { at a spacing of } 20 \mathrm{~cm} \text { along the } \\
\text { beam }\end{array}$ \\
\hline & D10 & $\begin{array}{l}\text { All U-shaped FRP strips of width } 10 \mathrm{~cm} \text { at a spacing of } 20 \mathrm{~cm} \text { along } \\
\text { the beam axis were cut at both corners of the beam's tensile side }\end{array}$ \\
\hline \multicolumn{3}{|c|}{ Note: I (concrete strength), II (corrosion state), and III (FRP patching style) } \\
\hline
\end{tabular}

For specimen details and repair methods used in this study, please see Section 4.2.1.1.4.

For accelerated aging information, please see Section 6.1.2.6..

\subsection{Kutarba, 2004}

After each corrosion cycle, eight beams were tested to failure in 4-point bending at a load rate of 50lbf/s and with a constant moment region of 3'-0" for specimens C 1 and 2 A-D and a constant moment region of 1'-0" for all other specimens. Table 6.34 provides the nomenclature used for the Kutarba (2004) test specimens. Table 6.35 and Table 6.36 
present Kutarba's (2004) static load test results after initial corrosion and after post-repair corrosion, respectively.

Table 6.34: Summary of Kutarba (2004) test specimens (PR=Post

Repair)

\begin{tabular}{|c|c|c|c|}
\hline Beam & $\begin{array}{l}\text { Strengthening } \\
\text { scheme }\end{array}$ & Load tested after & Repair \\
\hline $\mathrm{C} 1$ & none & Initial corrosion & $\mathrm{n} / \mathrm{a}$ \\
\hline $\mathrm{C} 2$ & none & Initial corrosion & $\mathrm{n} / \mathrm{a}$ \\
\hline $1 \mathrm{~A}-\mathrm{S}$ & none & PR Corrosion & repaired \\
\hline $2 \mathrm{~A}-\mathrm{D}$ & none & Initial corrosion & repaired \\
\hline $2 \mathrm{~B}-\mathrm{S}$ & none & Initial corrosion & repaired \\
\hline $3 \mathrm{~B}-\mathrm{D}$ & scheme III & PR Corrosion & unrepaired \\
\hline $3 \mathrm{~B}-\mathrm{S}$ & scheme I & PR Corrosion & repaired \\
\hline $4 \mathrm{~A}-\mathrm{D}$ & control & PR Corrosion & repaired \\
\hline $4 \mathrm{~A}-\mathrm{S}$ & scheme III & PR Corrosion & repaired \\
\hline 4 B-D & scheme II & PR Corrosion & repaired \\
\hline $4 \mathrm{~B}-\mathrm{S}$ & scheme III & Initial corrosion & repaired \\
\hline $5 \mathrm{~A}-\mathrm{D}$ & scheme I & Initial corrosion & repaired \\
\hline $5 \mathrm{~B}-\mathrm{D}$ & scheme III & PR Corrosion & repaired \\
\hline $5 \mathrm{~B}-\mathrm{S}$ & scheme II & PR Corrosion & repaired \\
\hline $7 \mathrm{~A}-\mathrm{S}$ & scheme II & Initial corrosion & repaired \\
\hline $7 \mathrm{~B}-\mathrm{S}$ & scheme I & Initial corrosion & repaired \\
\hline \multicolumn{4}{|c|}{$\begin{array}{l}\text { Numbers indicate the set of test specimen, the letter A or B the position in } \\
\text { the corrosion racks. The letters S or D describe the number of ponding } \\
\text { areas (single or double) during the initial corrosion process. }\end{array}$} \\
\hline
\end{tabular}

Table 6.35: Load test results reported by Kutarba (2004) after initial corrosion

\begin{tabular}{|c|c|c|c|}
\hline Beam & $\begin{array}{c}\text { Test results } \\
\text { kN (kip) }\end{array}$ & $\begin{array}{c}\text { PC } \\
\text { slope in } \\
\text { kip/in }\end{array}$ & $\begin{array}{c}\text { Capacity change to } \\
\text { beam C2 }\end{array}$ \\
\hline C1 & $\begin{array}{c}104.3 \\
(23.4)\end{array}$ & 37 & not compared \\
\hline 2 A-D & $128(28.8)$ & 35 & not compared \\
\hline C2 & $\begin{array}{c}96.1 \\
(21.6)\end{array}$ & 36 & $0 \%$ \\
\hline 2 B-S & 88.1 & 29 & $-8 \%$ \\
\hline 5 A-D & $124.5(28)$ & 41 & $30 \%$ \\
\hline 7 B-S & $111.2(25)$ & 36 & $14 \%$ \\
\hline 7 A-S & 141.4 & 42 & $47 \%$ \\
\hline 4 B-S & $137.9(31)$ & 37 & $44 \%$ \\
\hline
\end{tabular}

FRP-repaired beams increased the capacity of the beam specimens, as expected. Beams repaired with schemes 1 and 2 demonstrated less post-cracking stiffness than the control beams, but beams repaired with scheme 3 had a post-cracking stiffness similar to that of 
the control beams. Table 6.37 provides a summary of the failure modes observed by Kutarba (2004).

Beam 3B-D was repaired by placing FRP scheme III over the corrosion cracks without concrete repair. Large areas of localized debonding were observed on the specimen after post-repair corrosion, however, this beam still failed in sudden concrete crushing. This beam had an increased load capacity of $18 \%$ over the control beam and a $9 \%$ lesser load capacity compared to the scheme III beam on which the concrete was repaired.

The initial corrosion process yielded between a loss of between 8 and 15\% in unrepaired load capacity. Scheme I beams had an increase of $27 \%$ load capacity compared to control beams. Post-repair corrosion had little effect on the load capacity. Scheme II beams had an increase in load capacity between 30 and 31\% higher than the control. Post-repair corrosion resulted in a load capacity decrease $12 \%$. Scheme II Beams had a load capacity increase between 30 and $32 \%$, and post-repair corrosion caused a decrease between 9 and $12 \%$.

\begin{tabular}{|c|c|c|c|}
\hline \multicolumn{4}{|c|}{$\begin{array}{l}\text { Table 6.36: Load test results reported by } \\
\text { Kutarba (2004) after initial corrosion }\end{array}$} \\
\hline Beam & $\begin{array}{l}\text { Test results } \\
\text { kN (kip) }\end{array}$ & $\begin{array}{c}\mathrm{PC} \\
\text { slope in } \\
\text { kip/in }\end{array}$ & $\begin{array}{l}\text { Capacity change to } \\
\text { beam C2 }\end{array}$ \\
\hline $1 \mathrm{~A}-\mathrm{S}$ & 81.8 (18.4) & 31 & $-15 \%$ \\
\hline $4 \mathrm{~A}-\mathrm{D}$ & $87.6(19.7)$ & 25 & $-8 \%$ \\
\hline 3 B-S & $\begin{array}{l}121.9 \\
(27.4)\end{array}$ & 36 & $27 \%$ \\
\hline 4 B-D & $\begin{array}{l}125.4 \\
(28.2)\end{array}$ & 30 & $31 \%$ \\
\hline $5 \mathrm{~B}-\mathrm{S}$ & $124.5(28)$ & 29 & $30 \%$ \\
\hline $3 \mathrm{~B}-\mathrm{D}$ & $\begin{array}{l}113.4 \\
(25.5)\end{array}$ & 40 & $18 \%$ \\
\hline $4 \mathrm{~A}-\mathrm{S}$ & $\begin{array}{l}125.4 \\
(28.2)\end{array}$ & 36 & $31 \%$ \\
\hline 5 B-D & $\begin{array}{l}127.2 \\
(28.6)\end{array}$ & 36 & $32 \%$ \\
\hline
\end{tabular}




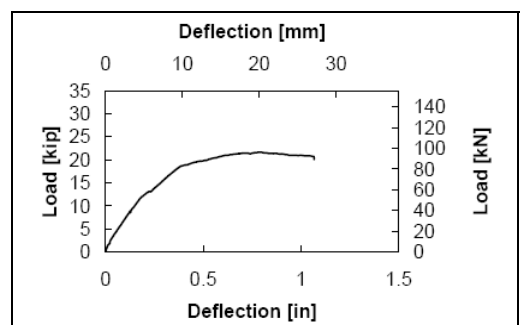

Figure 6.89: Loaddisplacement curve for Kutarba (2004) beam C2

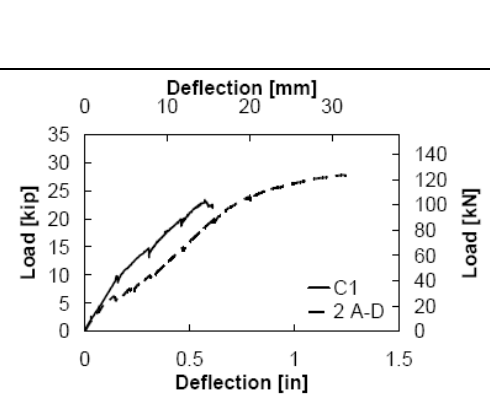

Figure 6.92: Loaddisplacement curve for Kutarba (2004) beams C2, 2A-D

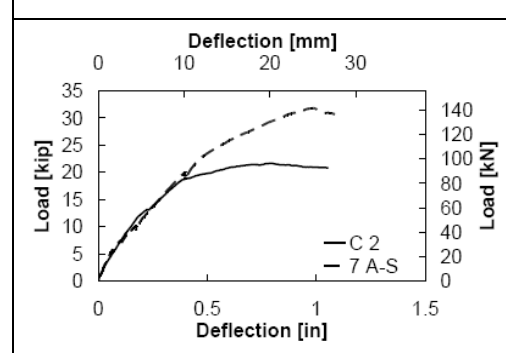

Figure 6.95: LoadDisplacement curve for Kutarba (2004) beams C2, 7A-S

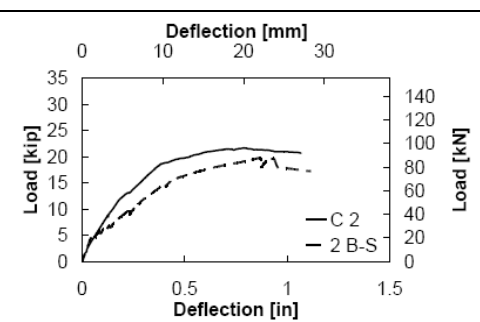

Figure 6.90: Loaddisplacement curve for Kutarba (2004) beams C2, 2B-S

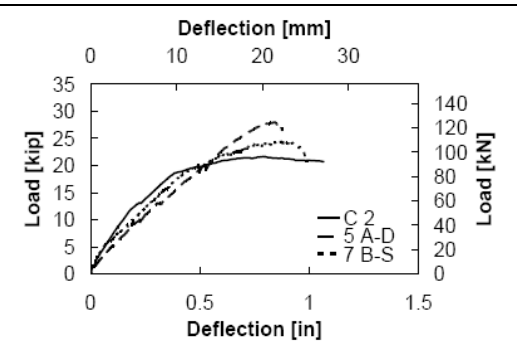

Figure 6.93: LoadDisplacement curve for Kutarba (2004) beams C2, 5A-D

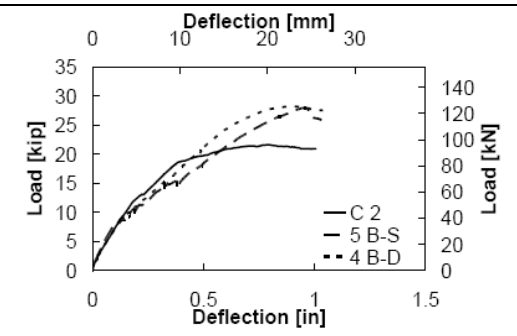

Figure 6.96: Loaddisplacement curve for Kutarba beams C2, 5B-S, 4B-D

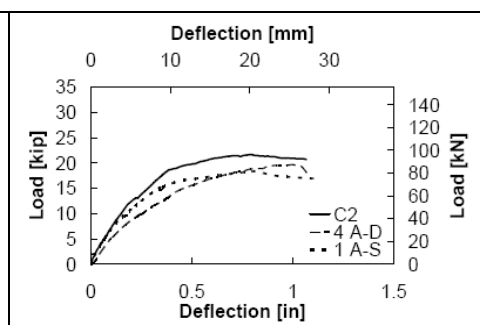

Figure 6.91: Loaddisplacement curve for Kutarba (2004) beams C2, 4A-D, 1A-S

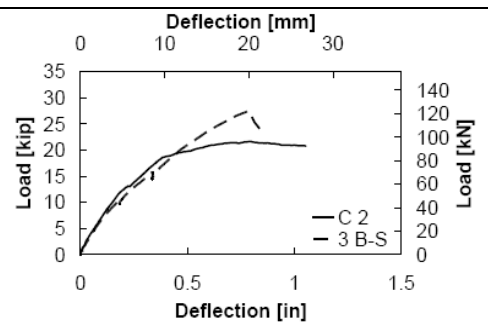

Figure 6.94: Loaddisplacement curve for Kutarba (2004) beams C2, 3B-S

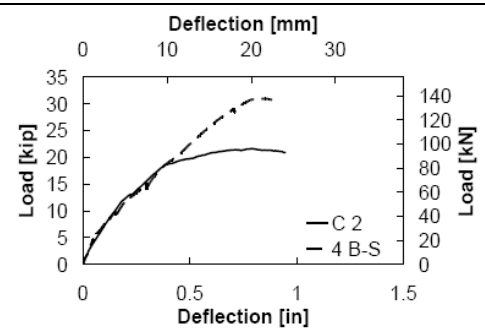

Figure 6.97: Load-

Displacement curve for Kutarba (2004) beams C2, 4B-S

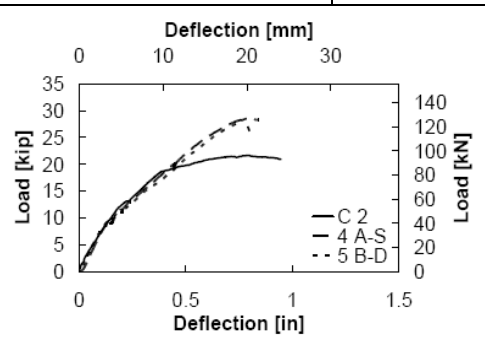

Figure 6.98: Load-displacement curve for Kutarba (2004) beams C2, 4A-S, 5B-D

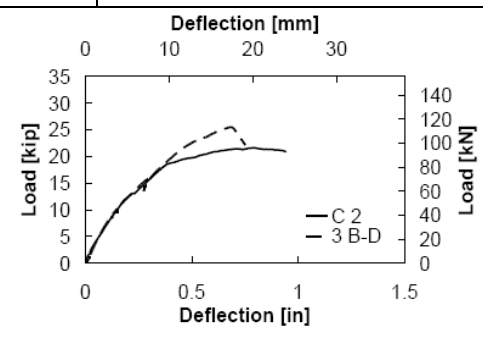

Figure 6.99: Load-displacement curve for Kutarba (2004) beams C2, 3B-D 
Table 6.37: Failure modes observed by Kutarba (2004) (Schematics of wrapping schemes can be viewed in Figure 4.16)

\begin{tabular}{|c|c|c|}
\hline Repair Scheme & Beam & Failure Mode \\
\hline \multirow{2}{*}{ Control } & $\mathrm{C}-1$ & \multirow{2}{*}{ Shear } \\
\hline & 2A-D & \\
\hline \multirow{3}{*}{ Scheme I } & 3B-S & \multirow{3}{*}{ Concrete crushing } \\
\hline & 5A-D & \\
\hline & $7 \mathrm{~B}-\mathrm{S}$ & \\
\hline \multirow{3}{*}{ Scheme II } & $7 \mathrm{~A}-\mathrm{S}$ & \multirow[t]{2}{*}{ Concrete crushing followed by FRP debonding at midspan between anchors } \\
\hline & $5 B-S$ & \\
\hline & 4B-D & Concrete crushing followed by concrete delamination from end \\
\hline \multirow{4}{*}{ Scheme III } & $4 \mathrm{~A}-\mathrm{S}$ & \multirow{4}{*}{ Concrete Crushing } \\
\hline & 5B-D & \\
\hline & 4B-S & \\
\hline & 3B-D & \\
\hline
\end{tabular}

This research also showed that stiffness loss caused by corrosion can be regained by the application of FRP. The post-repair corrosion rates were less than the pre-repair corrosion rates.

For specimen details and repair methods used in this study, please see Section 4.2.1.1.5. For accelerated aging information, please see Section 6.1.2.5.

\subsection{Kachlakev, 2001}

Beams in this experiment were tested in 4-point bending on a span of $18^{\prime}-0$ " and a constant moment region of 6'-0". A summary of load and deflection results is given in Table 6.38 and a summary of observed failure modes is given in Table 6.39 .

Table 6.38: Summary of load-deflection results observed by Kachlakev (2001)

\begin{tabular}{|l|c|c|c|c|}
\hline Measurement & Control & F-only & S-only & S \& F \\
\hline Max. deflection, mm & 24.5 & 30.3 & 35 & 25 \\
\hline Failure load, kN & 476 & 689 & 689 & Not observed \\
\hline First cracking load, kN & 78.3 & 96.5 & 87.6 & 96.1 \\
\hline Max. moment, kN-m & 435 & 630 & 630 & $651(868)$ \\
\hline Max. shear force, $\mathrm{kN}$ & 234 & 345 & 345 & 356 \\
\hline
\end{tabular}


Table 6.39: Failure modes observed by Kachlakev (2001)

\begin{tabular}{|l|l|}
\hline Beam & Failure Mode \\
\hline Control & Diagonal tension crack (shear failure) \\
\hline Flexure-Only & Diagonal tension crack (shear failure) \\
\hline Shear-Only & Yielding of tension steel followed by crushing of compression concrete after extended deflections \\
\hline Flexure \& Shear & $\begin{array}{l}\text { No failure observed. Believed to be yielding of tension steel followed by concrete crushing. FRP } \\
\text { rupture might occur after significant deflections due to failure of the concrete. }\end{array}$ \\
\hline
\end{tabular}

When testing the specimen reinforced in both flexure and shear, the capacity of the testing equipment was exceeded and no failure was observed. The load was then removed and the load points were moved closer together to increase moment. Still, however, no signs of failure were apparent.

The load vs. deflection and load vs. midspan strain curves are presented in Figure 6.100 and Figure 6.101, respectively.

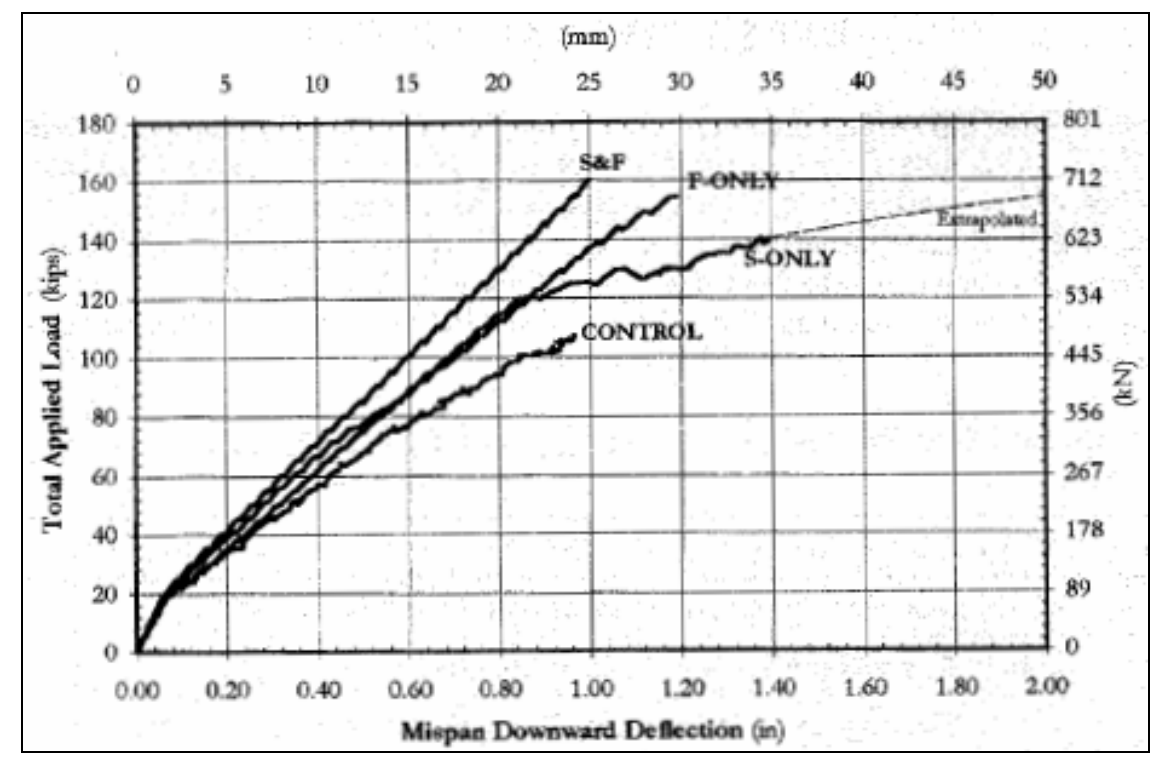

Figure 6.100: Load vs. deflection results observed by Kachlakev (2001) for the specimen strengthened in both flexure and shear

Interestingly, both the flexure-only and the shear-only strengthened beams achieved an equivalent load capacity of $45 \%$ greater than the control beam, although they exhibited 
different failure modes. It is predicted that the beam strengthened in both flexure and shear would have greatly exceeded this as it sustained at least $49 \%$ higher capacity with no indications of pending failure. In fact, during the second static load test using a higher moment, the beam withstood a moment $98 \%$ higher than that of the control beams without an indication of pending failure. Comparisons of the three strengthened beams to the control beam are provided in Table 6.40 .

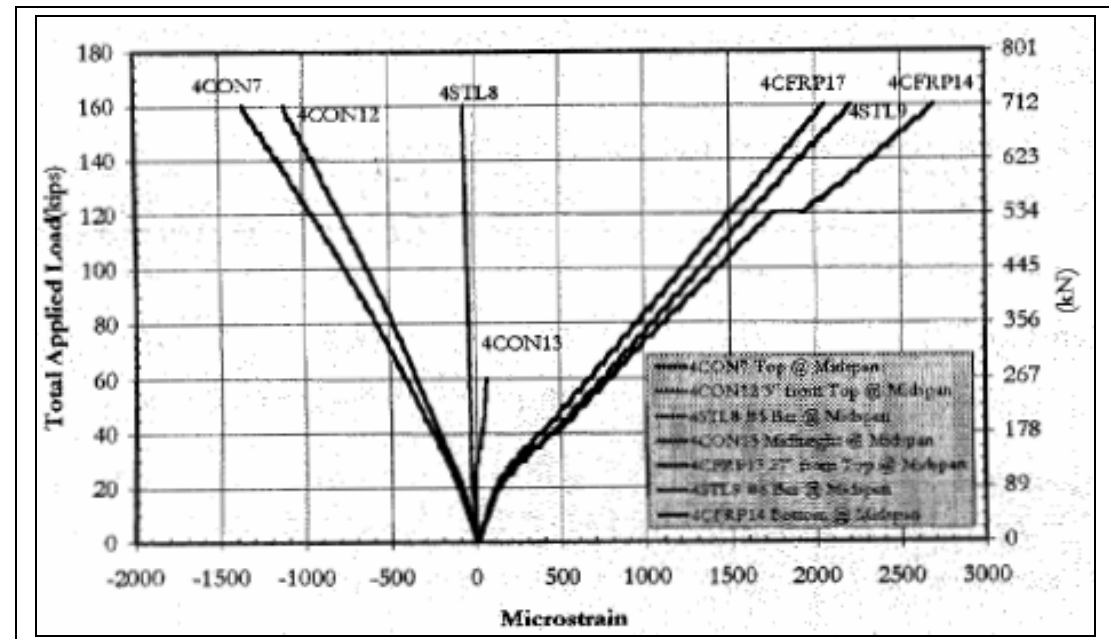

Figure 6.101: Load vs. midspan strain results observed by Kachlakev (2001) for the specimen strengthened in both flexure and shear

(Legend: 4CON7=concrete top @ midspan; 4CON12= concrete 3” from top @ midspan; 4STL8=\#5 bar @ midspan; 4CON13=concrete mid-height @ midspan; 4CFRP17=FRP 27” from top @ midspan; 4STL 9=\#6 bar @ midspan; 4CFRP14=FRP bottom @ midspan)

Table 6.40: Comparison of loads and deflections observed by Kachlakev (2001)

\begin{tabular}{|l|c|c|c|c|}
\hline \multirow{2}{*}{ Item } & \multirow{2}{*}{$\begin{array}{c}\text { Control Beam } \\
\text { Data }\end{array}$} & \multicolumn{3}{c|}{ Percent Gain Over Control Beam } \\
\cline { 3 - 5 } & 24.5 & F-only & S-only & S\&F \\
\hline Max. deflection, mm & 24.5 & 24 & 44 & 3.8 \\
\hline $\begin{array}{l}\text { Midspan deflection @ failure, } \\
\mathrm{mm}\end{array}$ & 476 & 45 & 45 & No failure \\
\hline Load at failure, $\mathrm{kN}$ & 78.3 & 23 & 110 & 49 \\
\hline Load at first cracking, $\mathrm{kN}$ & & & & 23 \\
\hline
\end{tabular}


FRP-strengthened beams were stiffer than the control specimens, resulting in lesser strains. The post-cracking stiffness was increased by $21 \%$ for the flexure-only beam and by $30 \%$ for the beam strengthened in both flexure and shear.

For specimen details and repair methods used in this study, please see Section 4.2.1.1.6.

\subsection{Leung, 2006}

The beam specimens in this study were tested in 4-point bending over a span of 11'-10" with a constant moment region of 1'-4'. On beams where the stirrup was placed at the beam end, no increase in capacity was observed. Very importantly, however, test results indicated that the load capacity of an FRP-strengthened beam increase as the anchor stirrups are moved away from the plate ends. This is because crack-induced debonding occurs near the load point. At a certain load, the crack instantly propagated into the epoxy or concrete cover layer and ran toward the end of the FRP plate, causing debonding. When the anchor was placed at the extreme end of the FRP plate, the contribution of the anchor stirrup to the total bond force was decreased due to shear softening along the debonded interface. In other words, the debonding had to reach the stirrup location before the stirrup could have any effect. However, when the stirrup was placed closer to the cracks that induced debonding, the stirrup's resistance was activated before significant debonding and shear softening had occurred (Leung, 2006). Although Leung made it clear that debonding could in fact initiate at the plate end, his results showed that it always initiated near each load point. 
In a follow-up to the review of this paper, an email was sent to Dr. Christopher Leung requesting more information on the optimum location for the anchor stirrups. His response indicated that, while he does not have a method of accurately predicting the exact optimal location, he could give some insight into how to choose a location. Dr. Leung said that if the failure is dominated by plate end failure via peel-off of the concrete cover, then the best location for the U-shaped anchor should obviously be at the plate end. He said that plate end failure usually occurs when relatively thick FRP plates are used. Dr. Leung continued to explain that, if failure is dominated by crack-induced debonding initiating below a flexural or shear-flexure crack away from the plate end, then the anchor should be placed close to the location of crack initiation. His experience has showed that, for beams between 6 and 10" deep and strengthened with four layers or less of thin $(\leq 0.11 \mathrm{~mm})$ CFRP laminates, crack-induced debonding has been likely to occur. In Dr. Leung's study, crack induced debonding mostly initiated near a shear crack near the load application point. He suggested that, for a 4-point bending test, it can be assumed that a shear-flexure crack will extend downward from the loading point toward the beam ends at approximately $30^{\circ}$ diagonal-to-the-vertical. As discussed earlier, Dr. Leung recommended that a good location for the anchor stirrup would be at a location slightly beyond where this $30^{\circ}$ reaches the bottom of the beam (see Figure 5.36).

For specimen details and repair methods used in this study, please see Section 4.2.1.1.7. 


\subsection{Grace, 2004}

Each beam was tested in 4-point bending along a span of $7^{\prime}-4$ "' and with a constant moment region of $2^{\prime}-8$ '. Beams were first loaded to a total of $12,000 \mathrm{lbs}$ and unloaded to zero. Next, they were loaded to $24,0001 \mathrm{bs}$ and unloaded to zero. Finally, the beams were loaded to failure.

For CFRP plates, the strength of the reference beam increased by $59 \% . \quad 10,000$ hours of $100 \%$ humidity reduced the ultimate load by $33 \%$ ( $87 \%$ loss of the strength gain from FRP). The reduction in strength from dry heat was not significant. Thermal expansion decreased the strength by $15 \%$. 350 and $700 \mathrm{~F} / \mathrm{T}$ cycles decreased the capacity by 3.3 and $9.5 \%$.

For CFRP fabric, dry heat increased the strength of the beams. Humidity and saltwater decreased the strength (saltwater by 5.3\%), but interestingly, the time extent of conditioning had no effect. Thermal expansion had no effect and freeze/thaw cycling decreased strength by $13 \%$. 


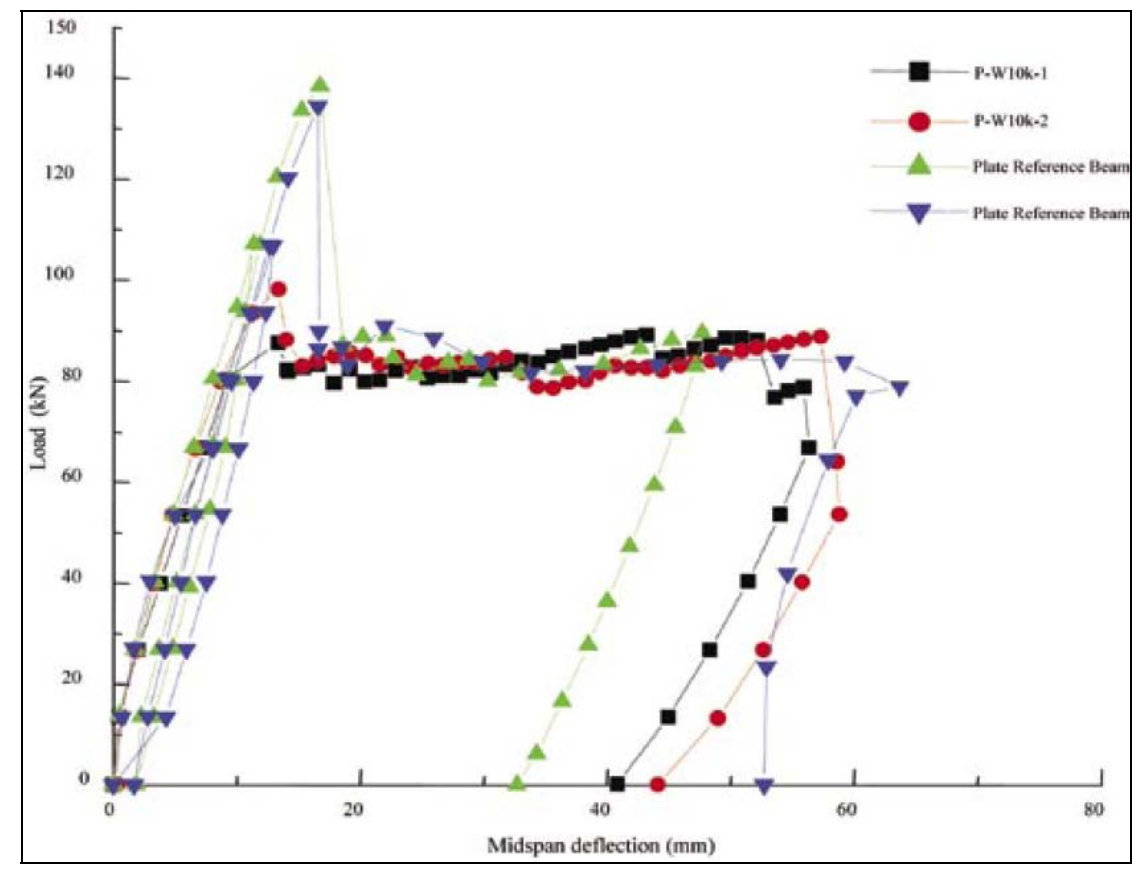

Figure 6.102: Load-deflection curves observed by Grace (2004) for beams strengthened with CFRP. Specimens were subjected to $100 \%$ humidity at $38^{\circ} \mathrm{C}$.

Figure 6.102 shows load-deflection curves observed by Grace (2004) for beams repaired with CFRP plates. Interestingly, after reaching a high load, a sudden drop in load followed by a large deflection at a constant load occurred before their failure. Grace attributed this behavior to the failure of the beams by the onset CFRP plate delamination at a load close to the observed ultimate load. Grace (2004) noted that a similar loaddeflection response was observed for each of the other test beams, except that other environmental exposures did not cause as great of a load reduction effect. Figure 6.103 and Figure 6.105 show the ultimate loads categorized by aging method and extent of aging for beams repaired with CFRP plates and sheets, respectively. 

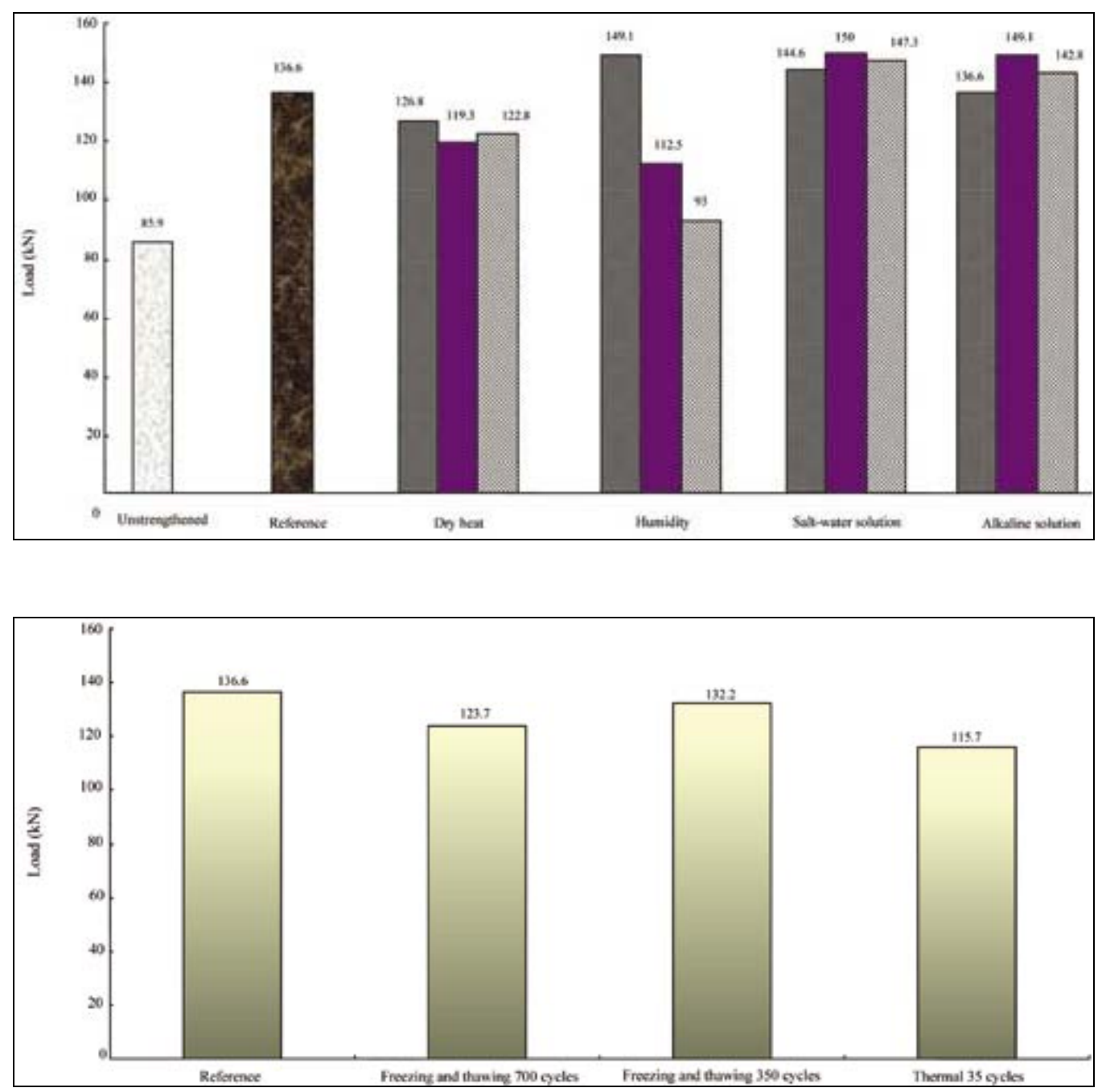

Figure 6.103: Average ultimate failure loads observed by Grace (2004) for beams strengthened with CFRP plates. Notice that the bars are grouped in sets of three according to their conditioning method. From left to right, the bars represent specimens conditioned for 1,000, 3,000, and 10,000 hours, respectively 

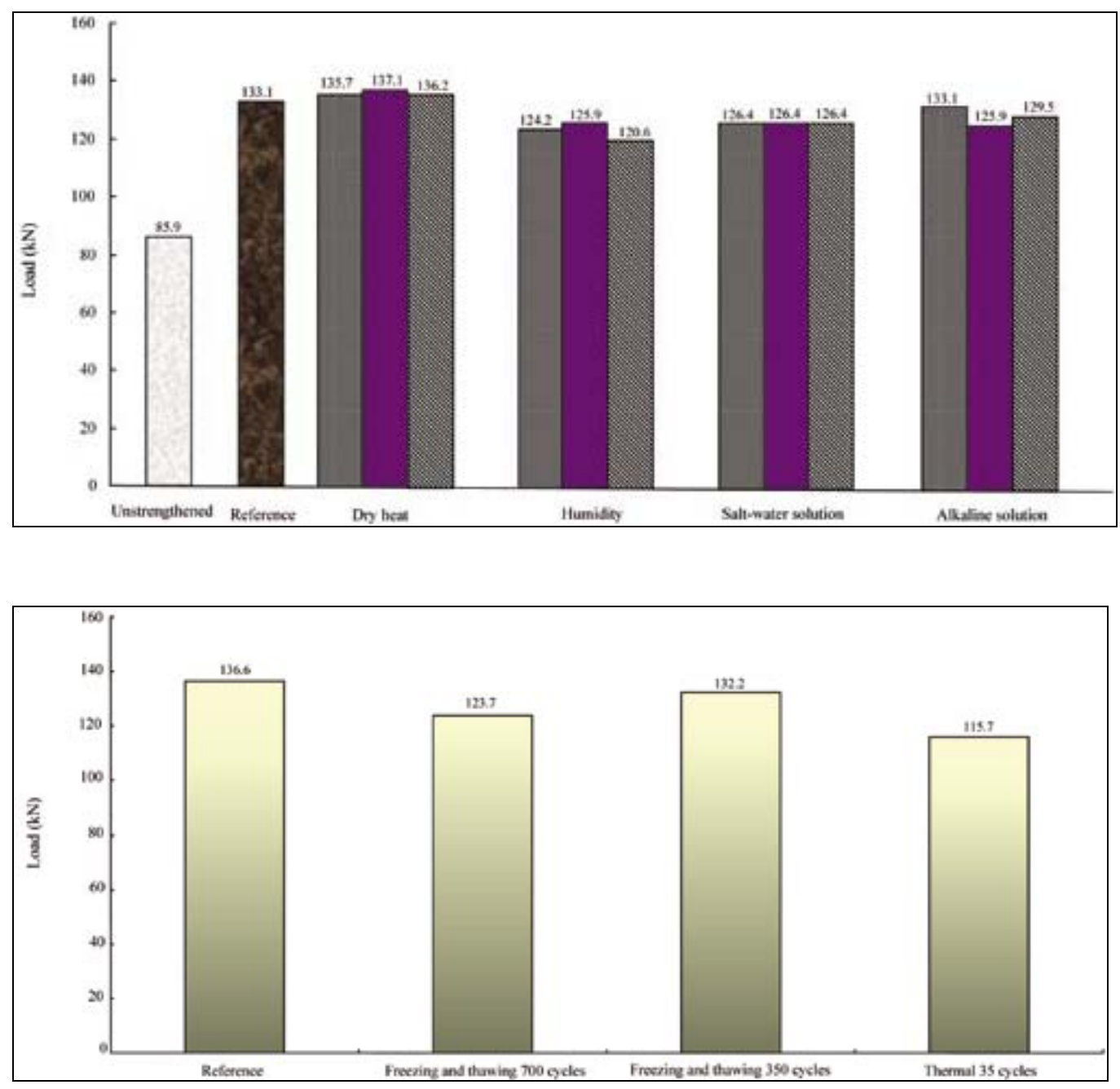

Figure 6.104: Average ultimate failure loads observed by Grace (2004) for beams strengthened with CFRP laminates. Notice that the bars are grouped in sets of three according to their conditioning method. From left to right, the bars represent specimens conditioned for $1,000,3,000$, and 10,000 hours, respectively

For specimen details and repair methods used in this study, please see Section 4.2.1.1.8. For accelerated aging information, please see Section 6.1.2.7. For cyclic flexure testing procedure and results, please see section 6.3.1.2.2. 


\subsection{Soudki, 2000}

Small-scale beam specimens were tested in 4-point bending along a span of 3'-5" and with a constant moment region of 1'-0". The FRP-strengthened beams failed by yielding of the tension steel followed by concrete crushing and then FRP rupture at the midspan. Figure 6.105 and Figure 6.106 show the load-deflection curves for the unstrengthened beams and FRP-strengthened beams, respectively. Figure 6.107 compares the loaddeflection relationships between FRP-strengthened and unstrengthened specimens with mass losses of 5 and $10 \%$. It can be seen that the FRP-strengthened beams were less ductile than the unstrengthened beams. A numerical summary of flexural test results is also provided in Table 6.41

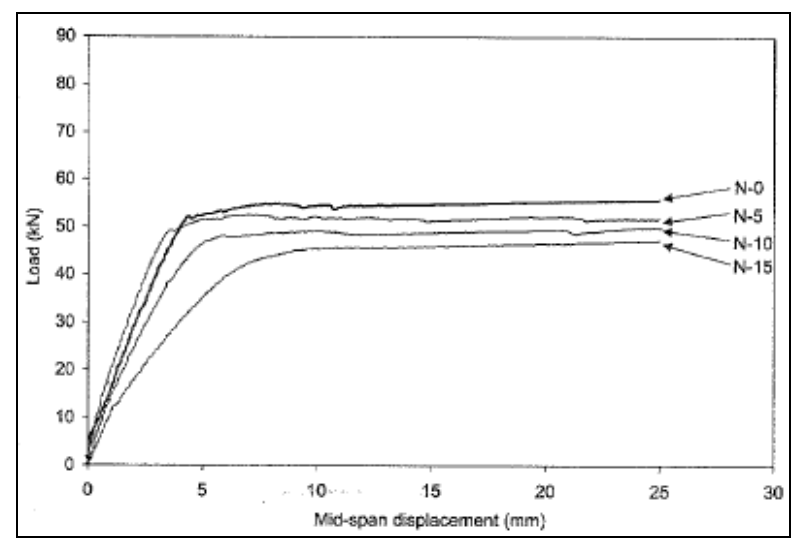

Figure 6.105: Load-deflection curves observed by Soudki (2000) for corroded and unstrengthened specimens. The numeral after the letter " $N$ " represents the \% corrosion in the specimen 


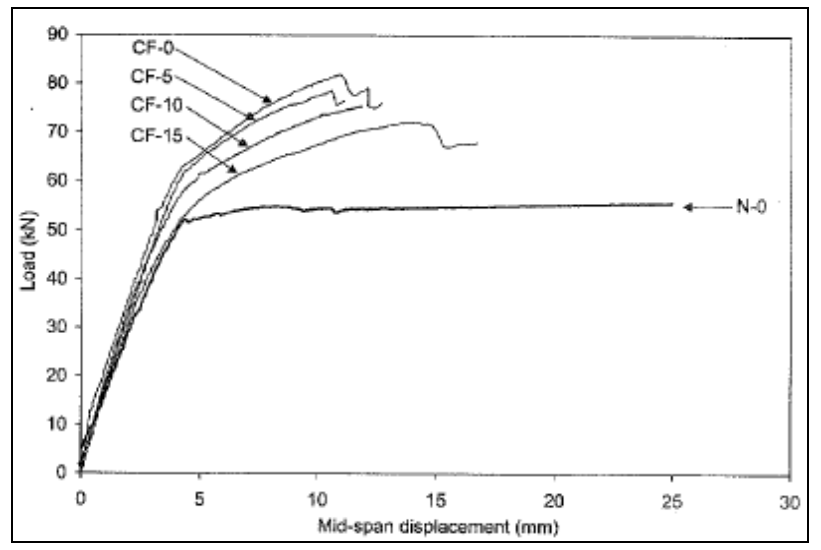

Figure 6.106: Load-deflection curves observed by Soudki (2000) for FRPstrengthened specimens. The numeral after the letter " $N$ " represents the \% corrosion in the specimen

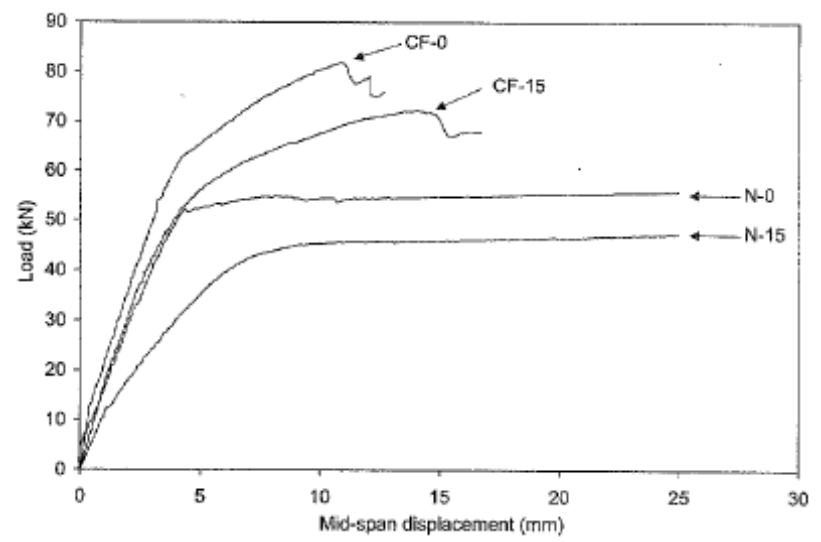

Figure 6.107: Soudki (2000) load-deflection comparison between FRP-strengthened and unstrengthened specimens at mass losses of 5 and $10 \%$. The numeral after the letter " $N$ " represents the \% corrosion in the specimen

For specimen details and repair methods used in this study, please see Section 4.2.1.2.1.

For accelerated aging information, please see Section 6.1.2.8. For crack measurement results, please see section 6.2.1.2.3. 


\section{Table 6.41: Summary of Soudki (2000) flexural test results}

\begin{tabular}{|c|c|c|c|c|c|}
\hline \multicolumn{6}{|c|}{ Unstrengthened Specimens } \\
\hline $\begin{array}{l}\text { Specimen } \\
\text { ID }\end{array}$ & $\begin{array}{l}\% \\
\text { mass } \\
\text { loss }\end{array}$ & $\begin{array}{l}\text { Yield } \\
\text { load } \\
(\mathrm{kN})\end{array}$ & $\begin{array}{l}\% \text { loss in } \\
\text { yield } \\
\text { strength vs. } \\
\mathrm{N}-0\end{array}$ & $\begin{array}{l}\text { Ultimate } \\
\text { load } \\
(\mathrm{kN})\end{array}$ & $\begin{array}{l}\text { \% loss in } \\
\text { ultimate } \\
\text { strength vs. } \mathrm{N} \text { - } \\
0\end{array}$ \\
\hline $\mathrm{N}-0$ & 0 & 51.7 & & 55.8 & \\
\hline $\mathrm{N}-5$ & 5 & 49 & 5 & 51.9 & 7 \\
\hline $\mathrm{N}-10$ & 10 & 47.3 & 9 & 50 & 10 \\
\hline N-15 & 15 & 44.1 & 15 & 47.3 & 15 \\
\hline \multicolumn{6}{|c|}{ FRP-Strengthened Specimens } \\
\hline $\begin{array}{l}\text { Specimen } \\
\text { ID }\end{array}$ & $\begin{array}{l}\% \\
\text { mass } \\
\text { loss }\end{array}$ & $\begin{array}{l}\text { Yield } \\
\text { load } \\
(\mathrm{kN})\end{array}$ & $\begin{array}{l}\% \text { loss in } \\
\text { yield } \\
\text { strength vs. } \\
\mathrm{N}-0\end{array}$ & $\begin{array}{l}\text { Ultimate } \\
\text { load } \\
(\mathrm{kN})\end{array}$ & $\begin{array}{l}\% \text { loss in } \\
\text { ultimate } \\
\text { strength vs. N- }- \\
0\end{array}$ \\
\hline CF-0 & 0 & 62.9 & & 81.8 & \\
\hline CF-5 & 5 & 62 & 1 & 78.7 & 4 \\
\hline CF-10 & 10 & 58.4 & 7 & 75.5 & 8 \\
\hline CF-15 & 15 & 56 & 11 & 72.2 & 12 \\
\hline
\end{tabular}

\subsection{Aidoo, 2004}

The T-beam specimens were tested in three-point bending over a 29' span. One of the two specimens was immediately tested to static failure. The other specimen was subjected to cyclic loading and then was tested to static failure. All specimens exhibited intermediate crack-induced debonding as their initial failure mode. The strain observed in the CFRP immediately before debonding failure was $9400 \mu \varepsilon$ on the beam tested to cyclic failure.

For specimen details and repair methods used in this study, please see Section 4.2.1.1.9.

For cyclic flexural testing procedures and results, please see section 6.3.1.2.3. 


\subsection{Quattlebaum}

One beam specimen was tested in 3-point bending over a span of $15^{\prime}$ immediately after repair. The observed strain in the CFRP immediately before debonding failure was $6,400 \mu \varepsilon$ for the beam tested to failure without static loading.

For specimen details and repair methods used in this study, please see Section 4.2.1.1.10. For cyclic flexural testing procedures and results, please see section 6.3.1.2.4.

\subsubsection{Suggestions for Improvement}

The most significant improvement would be to stop the test at various increments (such as at every 1,000 lbs) to record crack locations, lengths, and widths. By doing so, a better understanding of the global specimen failure could be obtained.

Another interesting addition would be to incorporate beam specimens of differing size to determine size effect on the behavior of an FRP repair system. To do so, all parameters other than beam length should be held constant.

Lastly, it is strongly suggested that a backup actuator system be available in case the primary actuator requires maintenance. This resulted in significant delays several times throughout this experiment. Future researchers should plan ahead and expect that equipment will be temporarily disabled during at least a portion of the project. 


\subsubsection{Compression Cylinder Testing}

\subsubsection{Results}

\subsection{Part I}

Results for Part I cylinder tests are provided in Table 6.42. Part I cylinders were broken on the same day as their corresponding beam specimens were tested to static failure.

Table 6.42: Part I 28-day compression cylinder tests

\begin{tabular}{|c|c|c|c|c|c|c|}
\hline Age & $\begin{array}{l}\text { Corresponds to the } \\
\text { Following Set of } \\
\text { Beams }\end{array}$ & Beam & $\begin{array}{l}\text { Compressive } \\
\text { Strength } \\
\text { (psi) }\end{array}$ & $\begin{array}{c}\text { Average } \\
\text { Compressive } \\
\text { Strength by } \\
\text { Group } \\
\text { (psi) }\end{array}$ & $\begin{array}{l}\text { Range of } \\
\text { Compressive } \\
\text { Strength } \\
\text { (psi) }\end{array}$ & $\begin{array}{c}\text { Percent } \\
\text { Difference } \\
\text { by Group } \\
(\%)\end{array}$ \\
\hline 28 Days & 28-Day Pristine & 3 & 3,501 & 3,501 & - & - \\
\hline \multirow{2}{*}{8 Weeks } & \multirow{2}{*}{$\begin{array}{l}\text { Mild Corrosion } \\
\text { Unrepaired }\end{array}$} & 1 & 3,495 & \multirow{2}{*}{3,505} & \multirow{2}{*}{20} & \multirow{2}{*}{1} \\
\hline & & 2 & 3,515 & & & \\
\hline \multirow{3}{*}{25 Weeks } & \multirow{3}{*}{$\begin{array}{l}\text { Severe Corrosion } \\
\text { Unrepaired }\end{array}$} & 5 & 3,674 & \multirow{3}{*}{3,444} & \multirow{3}{*}{424} & \multirow{3}{*}{12} \\
\hline & & 15 & 3,249 & & & \\
\hline & & 16 & 3,409 & & & \\
\hline \multirow{4}{*}{40 Weeks } & \multirow{2}{*}{$\begin{array}{c}\text { After First Corrosion } \\
\text { Cycle }\end{array}$} & 7 & 3,249 & \multirow{4}{*}{3,578} & \multirow{4}{*}{597} & \multirow{4}{*}{17} \\
\hline & & 10 & 3,846 & & & \\
\hline & \multirow{2}{*}{ Pristine Controls } & 17 & 3,634 & & & \\
\hline & & 18 & 3,581 & & & \\
\hline \multirow{5}{*}{66 Weeks } & \multirow{3}{*}{$\begin{array}{l}\text { After Second } \\
\text { Corrosion Cycle }\end{array}$} & 6 & 3,700 & \multirow{5}{*}{3,791} & \multirow{5}{*}{159} & \multirow{5}{*}{4} \\
\hline & & 8 & 3,846 & & & \\
\hline & & 9 & 3,780 & & & \\
\hline & \multirow{2}{*}{ Pristine Controls } & 13 & 3,860 & & & \\
\hline & & 14 & 3,769 & & & \\
\hline 28 Days & Patch Concrete & - & 9,563 & 9,563 & - & - \\
\hline
\end{tabular}

Beam specimens were broken at ages 28 days, 8 weeks, 25 weeks, 40 weeks, and 66 weeks. Cylinders made from polymer-modified repair concrete were broken after 28days. Please note that none of the cylinders were subjected to corrosion. The description of the corresponding beam specimen is given as a reference only. All cylinders were 
stored in the laboratory in open air at room temperature near their corresponding beam specimens.

It can be seen that values were relatively consistent for different concrete batches at the same age. It is important to remember that concrete is a highly variable material and small differences were to be expected.

It is interesting to note that the concrete did not gain appreciable strength between 28 days and 66 weeks of age. This was expected, however, since the cylinders were stored in open air and were not exposed to high amounts of moisture. The polymer-modified repair concrete exhibited a superior compressive strength of 9,563psi.

\subsection{Part II}

Strengths were recorded in Part II at ages of both 28 days and at the times the respective beam specimens were tested to static failure. Results are provided in Table 6.43 (28-day strengths) and Table 6.44 (long-term strengths). Figure 6.108 shows two typical failure modes of the compression cylinders.

It can be seen that the value ranges were relatively small for different concrete batches at 28 days. These 28-day breaks were conducted for quality control purposes to ensure that all concrete batches were essentially comparable. All individual 28-day compressive strengths fell within $\pm 413 p s i$ of the total average. Again, since concrete is a highly 
variable material, the differences observed in the compressive strengths were to be expected.
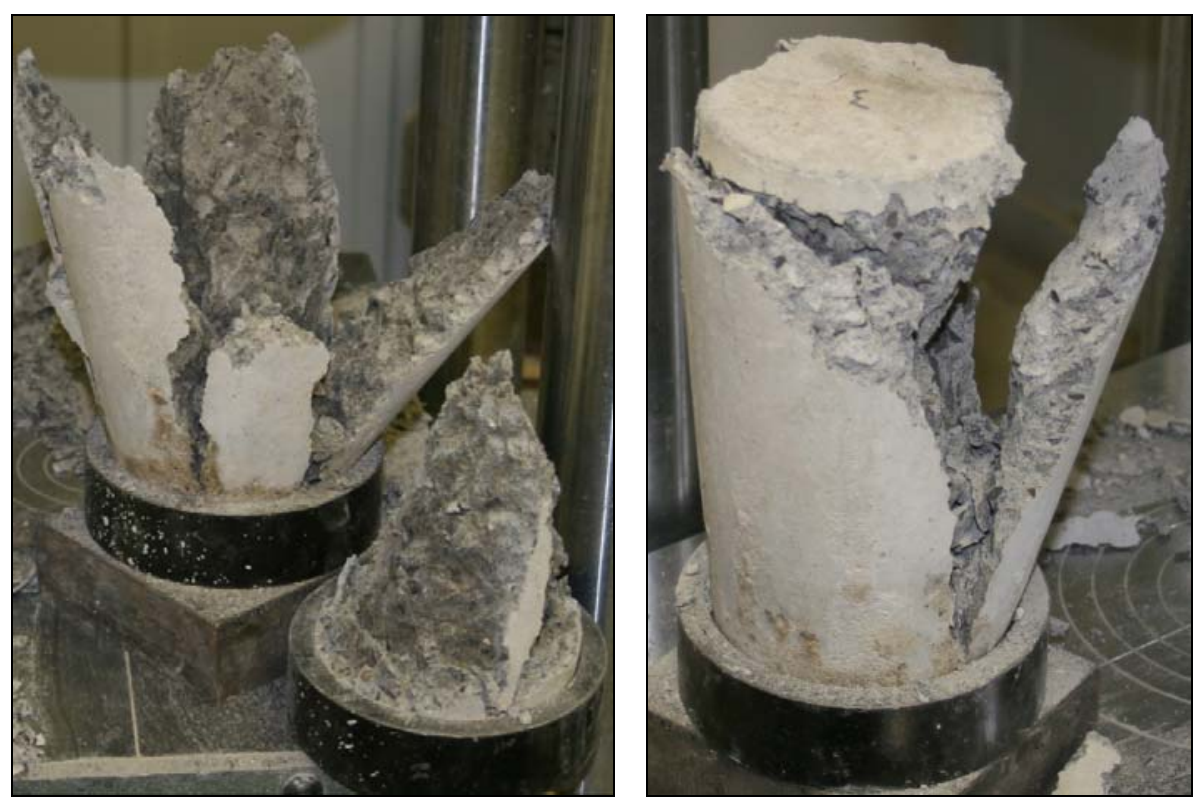

Figure 6.108: Typical Compression Cylinders Failures

Table 6.43: Part II Compression Cylinder Test Results at 28 Days

\begin{tabular}{|c|c|c|c|c|c|c|c|c|}
\hline Description & Beam & $\begin{array}{l}\text { Compressive } \\
\text { Strength } \\
\text { (psi) }\end{array}$ & $\begin{array}{c}\text { Average } \\
\text { Compressive } \\
\text { Strength by } \\
\text { Group } \\
\text { (psi) }\end{array}$ & $\begin{array}{c}\text { Range of } \\
\text { Compressive } \\
\text { Strength by } \\
\text { Group } \\
\text { (psi) }\end{array}$ & $\begin{array}{c}\text { Percent } \\
\text { Difference by } \\
\text { Group } \\
(\%)\end{array}$ & $\begin{array}{l}\text { Total Average } \\
\text { Compressive } \\
\text { Strength } \\
\text { (psi) }\end{array}$ & $\begin{array}{c}\text { Total Range of } \\
\text { Compressive } \\
\text { Strength } \\
\text { (psi) }\end{array}$ & $\begin{array}{l}\text { Total Percent } \\
\text { Difference } \\
(\%)\end{array}$ \\
\hline \multirow{2}{*}{$\begin{array}{l}\text { 28-Day } \\
\text { Pristine }\end{array}$} & 1 & 2,546 & \multirow{2}{*}{2,261} & \multirow{2}{*}{570} & \multirow{2}{*}{25} & \multirow{21}{*}{2,389} & \multirow{21}{*}{769} & \multirow{21}{*}{33} \\
\hline & 2 & 1,976 & & & & & & \\
\hline Long-Term & 11 & 2,321 & 2,361 & 80 & 3 & & & \\
\hline Pristine & 12 & 2,401 & 2,001 & 00 & 3 & & & \\
\hline \multirow{2}{*}{$\begin{array}{c}\text { Corroded } \\
\text { Unrepaired }\end{array}$} & 3 & 2,082 & \multirow{2}{*}{2,361} & \multirow{2}{*}{557} & \multirow{2}{*}{24} & & & \\
\hline & 4 & 2,639 & & & & & & \\
\hline \multirow{5}{*}{$\begin{array}{l}\text { Repaired } \\
\text { with } \\
\text { Wrapping } \\
\text { Scheme } 1\end{array}$} & 5 & 2,215 & \multirow{5}{*}{2,417} & \multirow{5}{*}{358} & \multirow{5}{*}{15} & & & \\
\hline & 8 & 2,573 & & & & & & \\
\hline & 9 & 2,401 & & & & & & \\
\hline & 7 & 2,401 & & & & & & \\
\hline & 14 & 2,493 & & & & & & \\
\hline \multirow{5}{*}{$\begin{array}{l}\text { Repaired } \\
\text { with } \\
\text { Wrapping } \\
\text { Scheme } 2\end{array}$} & 13 & 2,255 & \multirow{5}{*}{2,332} & \multirow{5}{*}{623} & \multirow{5}{*}{26} & & & \\
\hline & 15 & 2,135 & & & & & & \\
\hline & 17 & 2,122 & & & & & & \\
\hline & 18 & 2,401 & & & & & & \\
\hline & 20 & 2,745 & & & & & & \\
\hline \multirow{5}{*}{$\begin{array}{l}\text { Repaired } \\
\text { with } \\
\text { Wrapping } \\
\text { Scheme } 3\end{array}$} & 21 & 2,533 & \multirow{5}{*}{2,493} & \multirow{5}{*}{451} & \multirow{5}{*}{18} & & & \\
\hline & 22 & 2,546 & & & & & & \\
\hline & 24 & 2,294 & & & & & & \\
\hline & 19 & 2,745 & & & & & & \\
\hline & 23 & 2,348 & & & & & & \\
\hline
\end{tabular}


Table 6.44: Part II Compression Cylinder Test Results at the Time the Corresponding Beam was Tested to Static Failure

\begin{tabular}{|c|c|c|c|c|c|}
\hline Description & Beam & $\begin{array}{l}\text { Compressive } \\
\text { Strength } \\
\text { (psi) }\end{array}$ & $\begin{array}{c}\text { Average } \\
\text { Compressive } \\
\text { Strength by } \\
\text { Group } \\
\text { (psi) }\end{array}$ & $\begin{array}{l}\text { Range of } \\
\text { Compressive } \\
\text { Strength by } \\
\text { Group } \\
\text { (psi) }\end{array}$ & $\begin{array}{c}\text { Percent } \\
\text { Difference by } \\
\text { Group } \\
(\%)\end{array}$ \\
\hline $\begin{array}{l}\text { Long-Term } \\
\text { Pristine }\end{array}$ & $\frac{11}{12}$ & $\begin{array}{l}2,387 \\
2,493\end{array}$ & 2,440 & 106 & 4 \\
\hline $\begin{array}{l}\text { Corroded } \\
\text { Unrepaired }\end{array}$ & $\frac{3}{4}$ & $\begin{array}{l}3,011 \\
3,170\end{array}$ & 3,090 & 159 & 5 \\
\hline $\begin{array}{l}\text { Repaired } \\
\text { with } \\
\text { Wrapping } \\
\text { Scheme } 1\end{array}$ & \begin{tabular}{c|}
5 \\
8 \\
9 \\
7 \\
14
\end{tabular} & \begin{tabular}{|l|}
2,493 \\
2,653 \\
2,679 \\
2,639 \\
2,401
\end{tabular} & 2,573 & 279 & 11 \\
\hline $\begin{array}{l}\text { Repaired } \\
\text { with } \\
\text { Wrapping } \\
\text { Scheme } 2\end{array}$ & \begin{tabular}{|l|}
$\frac{13}{15}$ \\
17 \\
18 \\
20
\end{tabular} & \begin{tabular}{|l|}
2,265 \\
2,361 \\
2,454 \\
2,321 \\
2,546
\end{tabular} & 2,389 & 281 & 12 \\
\hline $\begin{array}{l}\text { Repaired } \\
\text { with } \\
\text { Wrapping } \\
\text { Scheme } 3\end{array}$ & $\frac{\frac{21}{22}}{\frac{24}{19}}$ & $\begin{array}{l}\frac{2,507}{2,427} \\
2,401 \\
2,401 \\
2,427\end{array}$ & 2,432 & 106 & 4 \\
\hline
\end{tabular}

The values were also relatively consistent for concrete at different respective ages. The small percent differences attest to the fact that the concrete in all the beams was similar in quality. All individual compressive strengths at the time that repaired beams were tested in static failure fell within $\pm 214 p s i$ of the total average of $2,465 p s i$.

It can also be seen that, for the most part, the concrete compression cylinders did not gain appreciable strength over time. This was expected, however, since the cylinders were stored in open air and were not exposed to high amounts of moisture. Table 6.45 shows the strength gain observed both individually and by group of compression cylinder ages. Not including the corroded unrepaired beam, the average strength gain by group at the 
time the repaired beams were tested in static failure (including the long-term control Beams II-11 and II-12) was only 54psi, with a maximum gain of only 332psi. Some long-term compression cylinders actually yielded lesser strengths than did their corresponding 28-day cylinders. This result is likely due to experimental or statistical error.

Table 6.45: Compressive strength gain over time

\begin{tabular}{|c|c|c|c|}
\hline Description & Beam & $\begin{array}{l}\text { Individual } \\
\text { Increase in } \\
\text { Strength } \\
\text { (psi) }\end{array}$ & $\begin{array}{c}\text { Increase in } \\
\text { Strength By } \\
\text { Group } \\
\text { (psi) }\end{array}$ \\
\hline \multirow{2}{*}{$\begin{array}{c}\text { Long-Term } \\
\text { Pristine }\end{array}$} & 11 & 66 & \multirow{2}{*}{80} \\
\hline & 12 & 93 & \\
\hline \multirow{2}{*}{$\begin{array}{c}\text { Corroded } \\
\text { Unrepaired }\end{array}$} & 3 & 928 & \multirow{2}{*}{729} \\
\hline & 4 & 531 & \\
\hline \multirow{5}{*}{$\begin{array}{c}\text { Repaired } \\
\text { with } \\
\text { Wrapping } \\
\text { Scheme } 1\end{array}$} & 5 & 279 & \multirow{5}{*}{157} \\
\hline & 8 & 80 & \\
\hline & 9 & 279 & \\
\hline & 7 & 239 & \\
\hline & 14 & -93 & \\
\hline \multirow{5}{*}{$\begin{array}{c}\text { Repaired } \\
\text { with } \\
\text { Wrapping } \\
\text { Scheme } 2\end{array}$} & 13 & 11 & \multirow{5}{*}{58} \\
\hline & 15 & 225 & \\
\hline & 17 & 332 & \\
\hline & 18 & -80 & \\
\hline & 20 & -199 & \\
\hline \multirow{5}{*}{$\begin{array}{c}\text { Repaired } \\
\text { with } \\
\text { Wrapping } \\
\text { Scheme } 3\end{array}$} & 21 & -27 & \multirow{5}{*}{-61} \\
\hline & 22 & -119 & \\
\hline & 24 & 106 & \\
\hline & 19 & -345 & \\
\hline & 23 & 80 & \\
\hline
\end{tabular}

The conclusion that the compressive strength did not significantly increase over time was very helpful in the analysis of the flexural tests since concrete of all ages could be assumed comparable. 


\subsubsection{Suggestions for Improvement}

A good addition to this experiment would have been to break concrete cylinders at additional constant intervals so that the rate of concrete strength gain could be determined. In addition, it would have been interesting to extract core samples from one of the specimens and compare their strength to that of the compression cylinders.

Also, it must always be made certain that the tops and bottoms of the cylinder molds are relatively smooth and level. Several compression test results had to be discarded at the beginning of this experiment due to inaccurate compression readings resulting from an unlevel top surface. These tests significantly underestimated the strength of the concrete.

\subsubsection{Pull-Off Testing}

\subsubsection{Results}

Pull-off tests were first performed on an extra duplicate FRP-repaired Part I beam with only a crack-injected substrate repair. A total of four tests were completed over the length of the beam. The failure was completely within the concrete, which is the desired mode (see Figure 6.109). This failure mode was expected due to the low-strength normal concrete substrate.

When the same test was attempted on an extra Part II beam with concrete patch repair, it was found that the 500psi capacity of the DeFelsko pull-off was not enough to fail either 
the concrete-FRP bond or the concrete itself. Therefore, new test dollies had to be bonded and pulled off with the new Proceq pull-off tester.
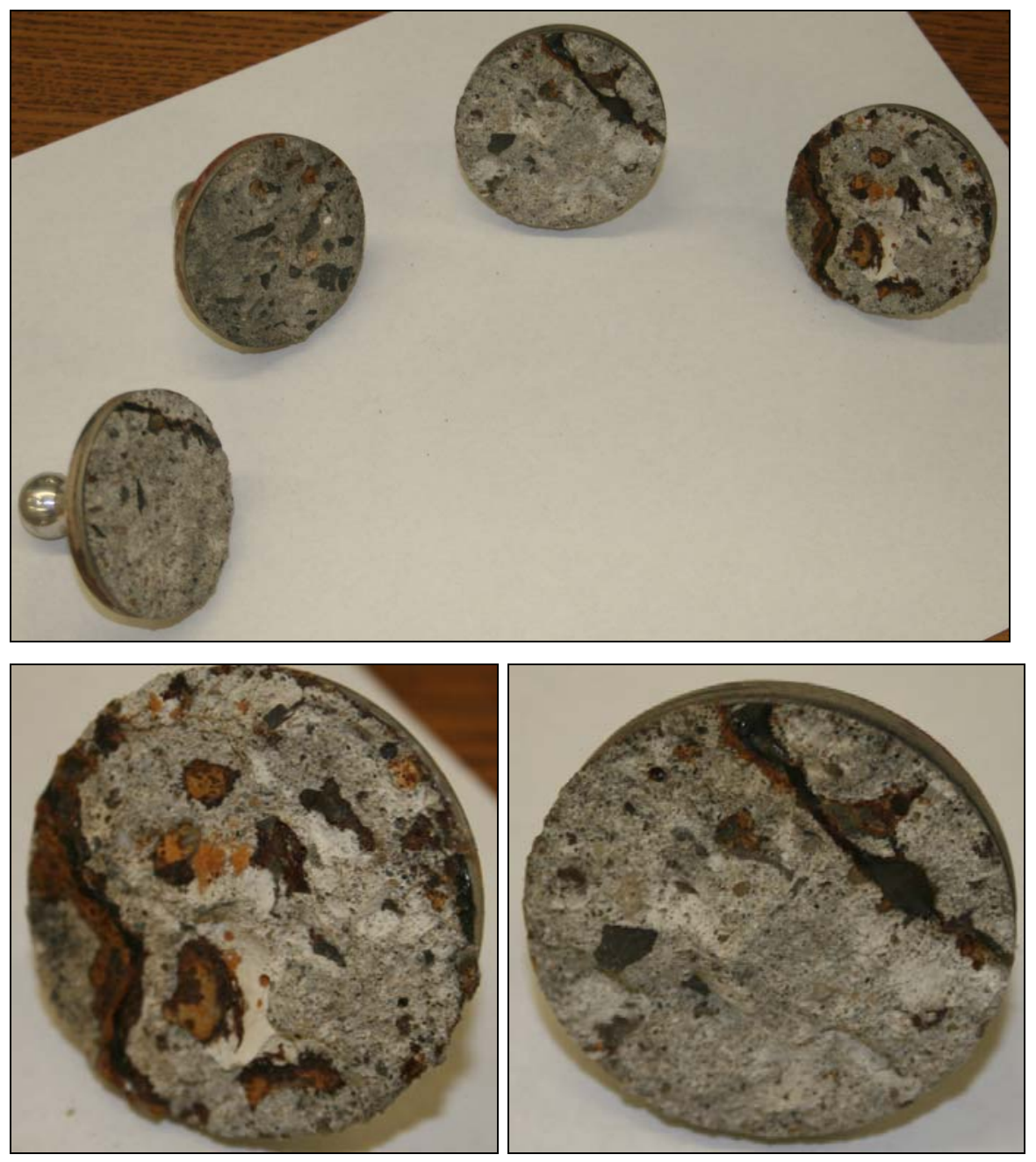

Figure 6.109: Pull-off failure of beams having crack-injected normal concrete substrates

A total of four pull-off tests were performed on the polymer-modified repair-concrete on the extra Part II beam. In three of the four specimens, failure using the new dollies and pull-off tester occurred within the epoxy-concrete interface with just small particles of concrete remaining adhered to the test dollies (see Figure 6.110). This is, of course, not a favorable failure mode under normal circumstances. However, since the failure occurred 
at such a high pressure, the bond was determined to be satisfactory for this experiment. The high tensile strength of the polymer patch material forced the failure to occur within the epoxy-concrete interface. The acceptability of this failure result when using highstrength concrete will need to be further investigated. As can be seen in the bottom right photo in Figure 6.110, one specimen even failed in the epoxy between the dolly and the FRP, indicating that the strength of the FRP-concrete bond is very high.
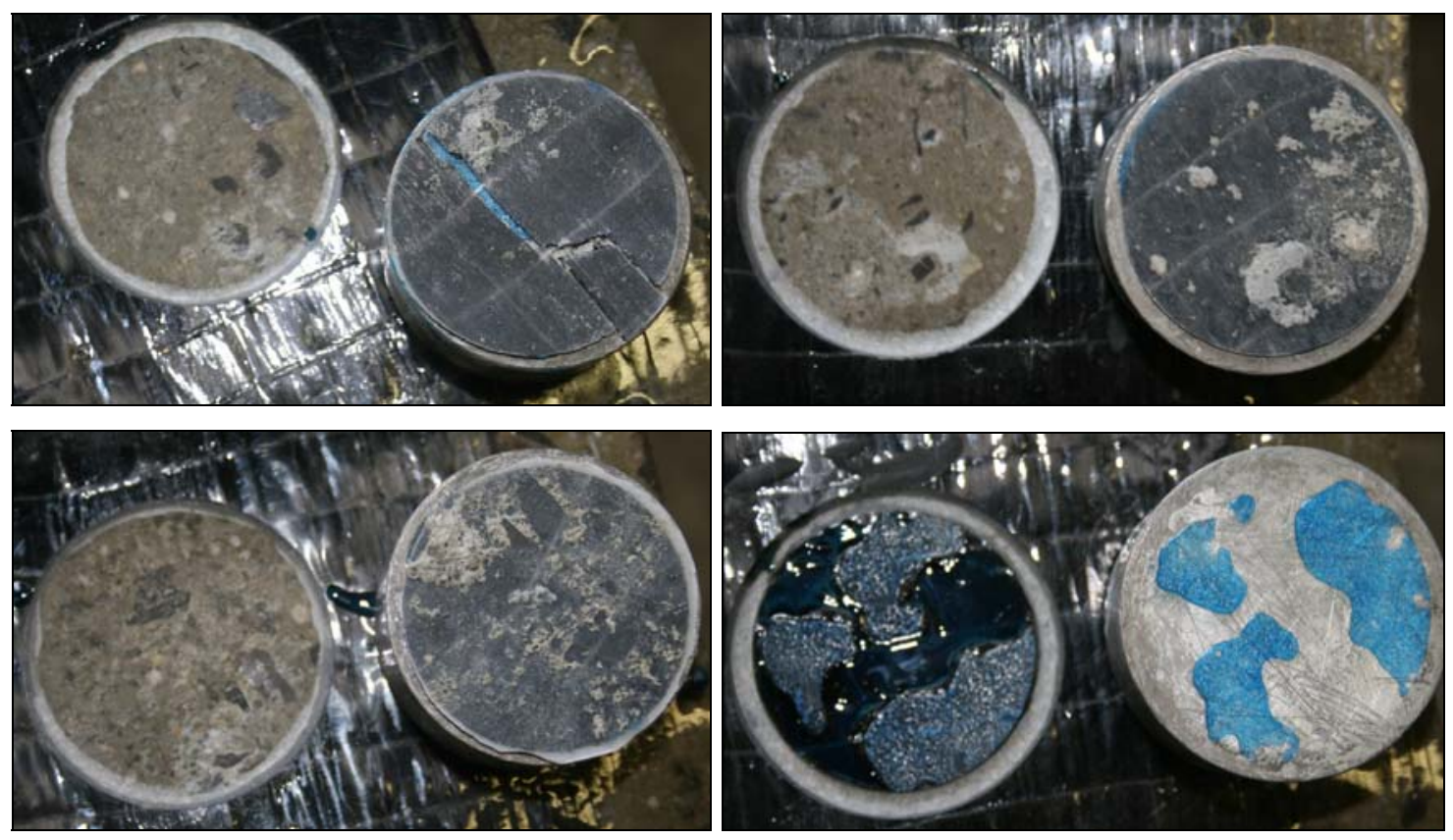

Figure 6.110: Pull-off failure of beams having patch-repaired polymer concrete substrates

Compare the FRP failure surfaces in Figure 6.110 to a typical failure surface observed on the FRP after failing in flexure and debonding from polymer patch concrete which can be seen in Figure 6.111. The fracture surfaces look exactly the same. This also supports the theory of mixed-mode failure in externally bonded FRP sheets. It was traditionally believed that mode II (shear) failure was the primary failure mode when FRP debonded from the tension face of a member in flexure. However, it is now known that the failure 
mode is actually a combination of modes I (tensile) and II. The comparison of these fracture surfaces in the two figures supports the theory that mode I direct tension failure contributed to the overall failure of the FRP system. Further research on this topic will be completed later, and discussion of FRP fracture mechanics is not within the scope of this project.

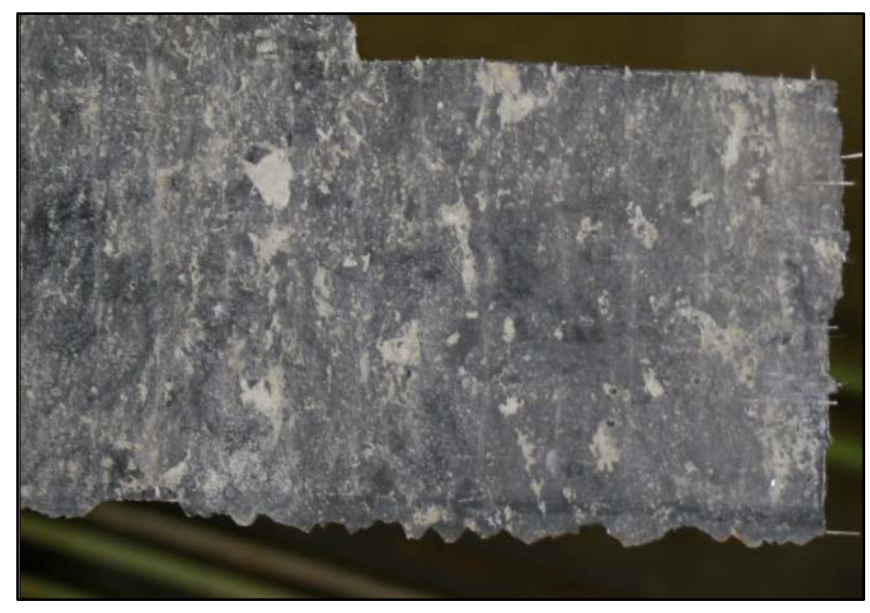

Figure 6.111: Typical FRP fracture surface after debonding from polymer patch repair concrete

Table 6.46 provides a summary of the pull-off test results. The average pull-off strength for the normal concrete was 464psi. Recall that the 500psi was not a high enough capacity to fail the specimen when using the Proceq pull-off tester. Surprisingly, the average pull-off strength on the polymer-modified concrete using the Defelsko pull-off tester was only 495psi. This may be because it was difficult to completely fill all voids between the dolly and the FRP without excess epoxy seeping into the pre-cut groove around the FRP sample circle. An unbalanced bond could result in the premature pull-off failure. Nonetheless, an average pull-off strength of 495psi indicates a reasonably favorable bond. 
Table 6.46: Pull-off test results

\begin{tabular}{|c|c|c|c|}
\hline 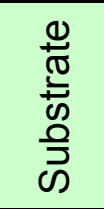 & 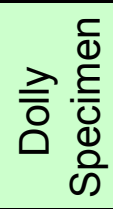 & 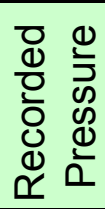 & 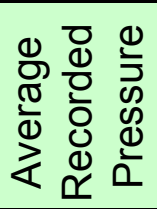 \\
\hline \multirow{4}{*}{ 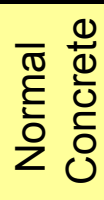 } & 1 & 408 & \multirow{4}{*}{464} \\
\hline & 2 & 512 & \\
\hline & 3 & 476 & \\
\hline & 4 & 458 & \\
\hline \multirow{4}{*}{ 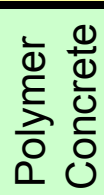 } & 1 & 501 & \multirow{4}{*}{495} \\
\hline & 2 & 498 & \\
\hline & 3 & 523 & \\
\hline & 4 & 456 & \\
\hline
\end{tabular}

\subsubsection{Suggestions for Improvement}

It would be very beneficial to perform pull-off tests on beams patch repaired with normal-strength concrete. Obviously the failure was within the concrete on the corroded and crack-injected beam, but it would be valuable to know whether the same result would occur in pristine normal concrete.

Another good addition could be to fatigue extra beams and then perform FRP-concrete pull-off tests within the constant moment region. Recall how it was suggested that the fatigue loading weakened the FRP-concrete bond within this region in the static loading results. Pull-off tests immediately after fatiguing would provide insight into this supposition. It may also be very interesting to perform pull-off tests on areas of FRP that appear to remain strongly bonded to the concrete after loading statically to failure. This would provide indication as to whether there was damage in locations away from the ruptured and debonded areas that were not visible. 
Finally, it would be a useful quality control tool to successfully perform a pull-off test to investigate the old concrete-patch concrete bond. As discussed earlier, this could not be done on the beams in this experiment because the concrete core kept breaking off in the bit due to the presence of the stainless steel bar. Representative specimens should be made with no steel so that the cores could be successfully drilled and tested.

\subsubsection{FRP Direct Tension Tests}

\subsubsection{Results}

Table 6.47 presents details of the FRP direct tension tests. The Part I Beams had a much lesser thickness since they were sanded prior to the application of strain gages. The manufacturer reported a design tensile strength of 130,900psi and a typical actual tensile strength of $154,000 \mathrm{psi}$. The tensile strength values for the sample coupons in this experiment were lower than expected since the coupons were not completely flat and had small ripples as a result of curing between plastic sheets. This almost certainly resulted in a reduction of the tensile strength values obtained.

Table 6.47: Direct tension test results for FRP coupon samples

\begin{tabular}{|c|r|r|r|r|r|r|}
\hline & \multicolumn{5}{|c|}{ Specimen } \\
\cline { 2 - 7 } & Part I (1) & Part I (2) & Part II (1) & Part II (2) & Part II (3) & Part II (3) \\
\hline Thickness (in) & 0.019 & 0.023 & 0.027 & 0.029 & 0.028 & 0.026 \\
\hline Width (in) & 1.000 & 1.000 & 1.000 & 1.000 & 1.000 & 1.000 \\
\hline Area (in ${ }^{2}$ ) & 0.019 & 0.023 & 0.027 & 0.029 & 0.028 & 0.026 \\
\hline Load (Ibs) & 1,258 & 2,404 & 3,067 & 2,984 & 3,055 & 3,390 \\
\hline Tensile Strength (psi) & 66,190 & 104,540 & 113,580 & 102,892 & 109,117 & 130,394 \\
\hline $\begin{array}{c}\text { Average Tensile } \\
\text { Strength (psi) }\end{array}$ & \multicolumn{3}{|c|}{85,365} & \multicolumn{5}{|c}{113,996} \\
\hline
\end{tabular}




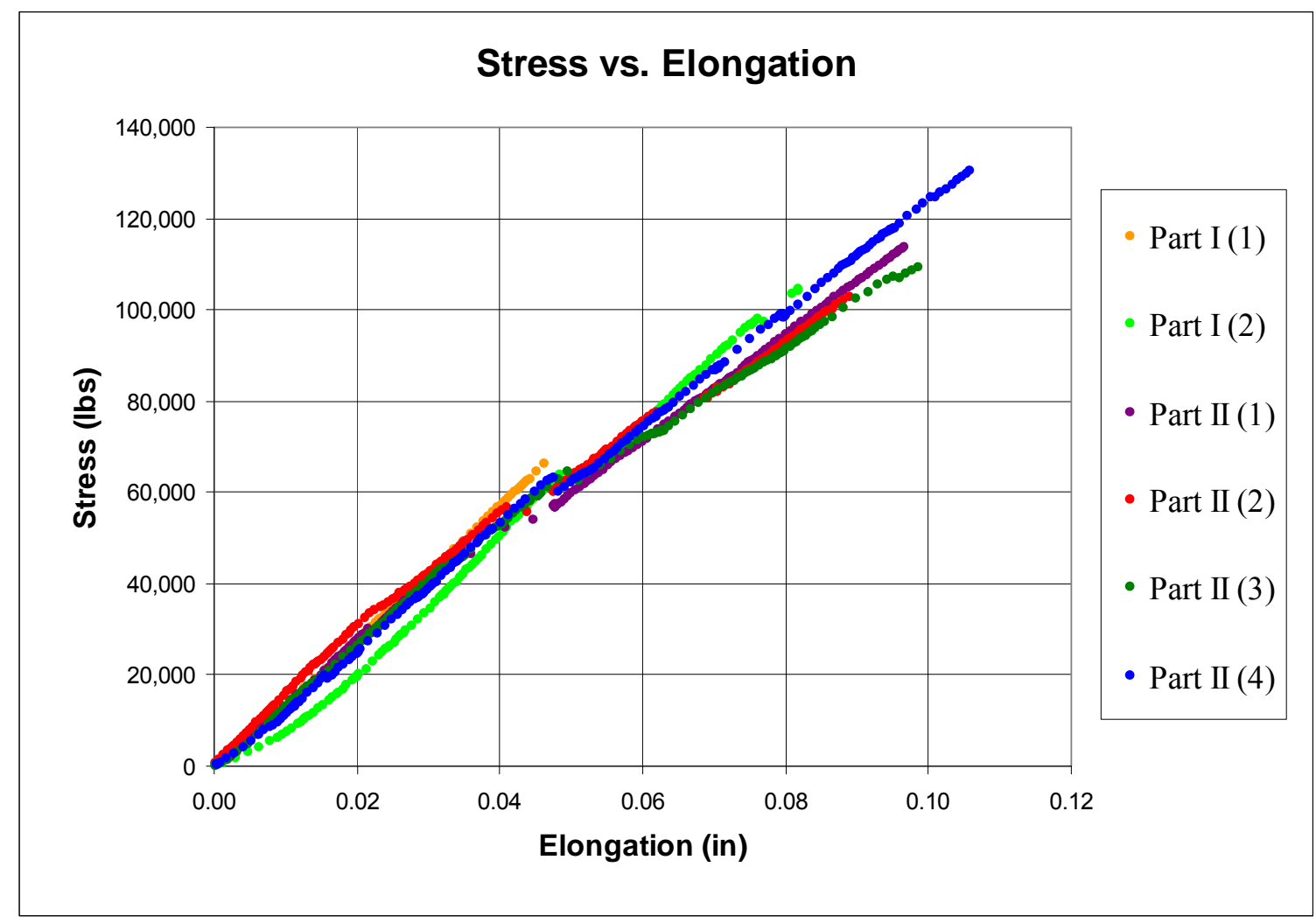

Figure 6.112: Stress vs. Elongation curves for FRP Direct Tension Tests

As expected, the coupons exhibited linear-elastic behavior to a brittle failure, as can be seen in Figure 6.112. A photo of some of the failed tension coupon specimens can be viewed in Figure 6.113, where the small ripples can be easily seen because of the lighting.

Three strain gages were placed at the middle of the gage length of both Part I samples. One was located on the longitudinal centerline and two were located at distances $w / 8$ away from the coupon edges ( $w$ is the width of the tension coupon), as specified by ASTM D3039/D3039M-00. All gages yielded consistent values, which proved that the gripping system was satisfactory. 

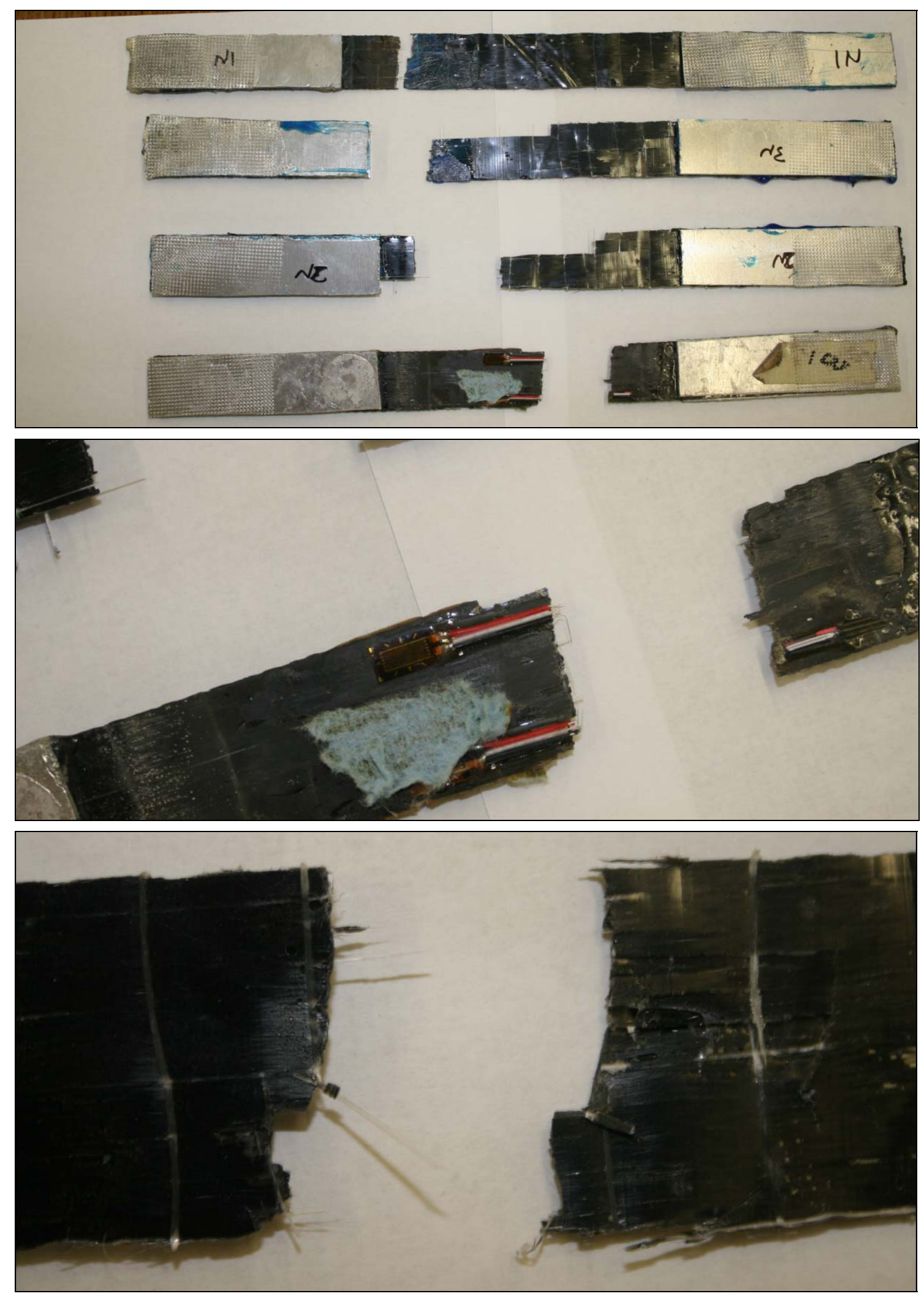

Figure 6.113: Failed FRP tension coupon samples 


\subsubsection{Suggestions for Improvement}

The surface on which the FRP coupons are placed to cure needs to be modified. In this experiment, the coupons were placed on a sheet of $16 \mathrm{mil}$-thick plastic and then were covered with a second sheet of plastic. Specimens were then placed in the wooden FRP sample box to cure. However, after curing, it was found that the coupons were not completely flat, but instead containted small ripples. The ripples almost certainly resulted in a reduction in the tensile strength values obtained. Also, since the coupons were slightly rippled, the grips actually came loose when clamped into the testing machine due to the eccentricity generated. It can be seen in Figure 6.113 that one specimen even partially ruptured within the grips. An improvement would be to place a relatively heavy weight on top of the FRP coupon surrounded in plastic. It must be ensured that no ripples or folds are present in the plastic. The weight must be completely flat and must be at least the size of the $12 \times 12$ in FRP coupon. This would produce a completely flat coupon in which the fibers are perfectly straight. 


\section{Chapter 7: Conclusions}

\subsection{Laboratory Testing}

\subsubsection{Accelerated Aging}

Corrosion produced by the accelerated aging technique resulted in deterioration of the laboratory specimens that was very similar to what was observed on bridges in the field. Pitting corrosion, severe mass loss, significant cracking, and the beginnings of concrete cover delamination resulted.

The high water-cement ratio resulted in a concrete that was very porous and low strength, much like the concrete which was extracted from PennDOT Bridge \#49-4012-0250-1032. The addition of sodium chloride to the concrete mix resulted in a chloride-hydroxyl ion ratio greater than 0.6 produced a very harsh corrosive environment for the reinforcing steel. This duplicated the chloride-saturated conditions found within the PennDOT bridge, which was caused by deicing salts.

Very important details of successfully using electric current to accelerate aging in reinforced concrete members were learned in Part I of this research. It is an absolute necessity that, when desiring to confine corrosion to tension steel only, that all other exposed steel (stirrups, compression bars, etc.) be completely epoxy coated. Any uncoated steel was found to corrode at nearly the same rate as the tension steel. The actual corrosion rate in these specimens was much lower than the originally anticipated 
rate since the surface area of corroding steel was dramatically increased. It was also found that, when applying electric current, corrosion cannot be confined to select regions of exposed reinforcement bar by epoxy coating regions along the same bar that are not desired for corrosion. When this was done, the epoxy layer simply peeled off. From literature review, it was found that the best way to confine corrosion to within a desired region is to add salt only to the concrete that encases regions of steel where corrosion is desired.

When FRP-repaired beams with only crack-injected concrete substrates were subjected to an additional accelerated corrosion cycle, severe cracking, mass loss, and reduction in flexural strength ensued. However, when FRP-repaired beams with complete steel cleaning and complete polymer-modified concrete repair (which included corrosion inhibitors) of the concrete cover were subjected to the same additional corrosion cycle, virtually no additional mass loss was observed. The polymer concrete substrate repair proved to have superior durability compared to the epoxy crack injection substrate repair.

Mass losses obtained from Part II beams were more consistent that those from Part I beams. This is because all steel except for the tension bars was coated using a nonporous non-conductive epoxy, and corrosion was confined to only the exposed steel. Even though great care was taken to protect the coated steel during the construction of the rebar cages, some localized areas of the coated shear reinforcement were scraped and localized patches of corrosion on these stirrups ensued. Overall, the coated steel performed exceptionally well, however, and the shear and compression steel did not 
consume any of the applied electric current. The result was a severe average mass loss of $22.5 \%$ in only 13 weeks of accelerated aging. Even more impressive was that the range of mass loss observed for fifteen specimens was only $2.7 \%$, which is a small $0.054 \mathrm{in}^{2}$ difference in section loss.

The accelerated corrosion method used in this research proved to be extremely effective and consistent. It is strongly recommended that this procedure be followed in future studies.

\subsubsection{Crack Measurement}

In Part I, crack widths did not correspond with mass loss. Cracking was typically observed on all three primary faces (right, tension, and left) of each specimen with few exceptions. In Part II, the maximum crack widths were uniform between 4.0 and $5.0 \mathrm{~mm}$. It should not be concluded, however, that a direct correlation can be made between crack width and mass loss for several reasons. First, all concrete is different. The more porous the concrete, the more minute voids the expansive corrosion products have to fill before causing cracking. The denser the concrete, the more likely it is that larger cracks will form more rapidly. Second, the formation of non-expansive green rust can contribute to mass loss without contributing to cracking. Third, even small cracks can provide exit routes for expansive corrosion products, halting crack growth. For these reasons, an inspector evaluating a bridge should not rely on crack widths to effectively quantify the level of structural deterioration. 


\subsubsection{Half-Cell Potential Testing}

Half-cell potential readings proved effective during the early stages of accelerated corrosion. However, half-cell potential readings later became more positive, suggesting a reduction in corrosion risk (which was obviously not correct). These false readings were likely due to the accumulation of corrosion products around the steel and to significant cracks in the concrete between the half-cell electrode and the steel below. Therefore, it can be concluded that half-cell readings may be non-conservatively skewed for considerably deteriorated concrete. Half-cell data, however, is reliable in evaluating reinforced concrete in early stages of deterioration, even when no damage is visible.

\subsubsection{Rebound Hammer Testing}

On average, rebound numbers obtained from deteriorated concrete were lower than those obtained from pristine concrete. Localized differences in quality, however, were observed in some readings taken from the deteriorated concrete in Part II. Part I specimens yielded very consistent rebound numbers for each individual type and condition of concrete. The rebound numbers obtained from the high-strength polymer patch concrete were much higher than either the pristine normal concrete or the deteriorated concrete, as expected. Rebound hammer data also indicated that the quality of pristine concrete did not change significantly over time. Overall, it can be concluded that the rebound hammer was extremely effective in comparing concrete qualities, and that it is a useful tool in determining the areas in need of repair during the inspection of a reinforced concrete bridge which is a candidate for rehabilitation. 
Another important observation was the severe lack of accuracy in calibration data provided with the rebound hammer. This calibration data grossly underestimated the strength of all concrete, especially the high-strength patch concrete. For this reason, prisms with varying concrete strengths should be made and hammer tested, as discussed earlier. The representative concrete cylinders from each of the concrete prisms should be compression tested so that an accurate homemade calibration curve could be constructed for the rebound hammer. By doing so, concrete compressive strength could be more accurately estimated.

It can be concluded that, although the rebound hammer is a very useful tool for comparing concrete qualities, its results cannot be solely relied upon to estimate compressive strength or to independently determine what concrete should be removed when planning for a bridge repair.

\subsubsection{Ultrasonic Pulse Velocity Testing}

As indicated by rebound hammer testing, the average qualities of the separate concrete types (pristine normal concrete, deteriorated normal concrete, and polymer patch concrete) were consistent. Also as expected, the pulse velocity in the polymer patch concrete was much higher than through the intentionally poor quality normal concrete, since it was much denser and since its properties were far superior to the normal concrete. No significant cracking or irregularity was present in the compression concrete of the corroded beams, indicating that the epoxy-coated shear and compression reinforcement did not corrode before the beam was actually broken open and the steel was observed. 
All three transducer configurations yielded comparable corrected pulse velocity results, indicating that the steel reinforcement correction factors presented in this paper are reasonably accurate.

Ultrasonic pulse velocity proved to be a powerful tool in this research for assessing and comparing concrete quality. Its incorporation into the inspection of candidate bridges for rehabilitation could produce extremely valuable information in the comparison of concrete qualities.

\subsubsection{Cyclic Flexural Testing}

It was found that the largest deflection increase occurred after the first 250,000 cycles. After 2,000,000 cycles, average normalized maximum deflections of $2.38,2.01$, and 1.93in were observed for Wrapping Schemes 1, 2, and 3, respectively. This indicates that, as more anchorage was added, the level of structural deterioration caused by fatigue loading was reduced; the most significant reduction in deterioration occurred by simply using two anchors as opposed to no anchorage.

As were the maximum deflections, the permanent deflections for beams repaired using Wrapping Scheme 1 were significantly higher, on average, than for beams repaired using Wrapping Schemes 2 or 3. These results support that, when at least minimum anchorage is provided, deflections due to fatigue loading will decrease. 
The stiffness of all fatige-loaded beams decreased by $55-60 \%$ between at 0 and 250,000 cycles (obtained from the the incremental static test results at every 250,000 cycles). A majority of this stiffness loss occurred because the concrete cracked during static loading at 0 cycles, as can be clearly seen in all load-deflection decay curves in Appendix F. It was discovered that between 65 and $72 \%$ of this total stiffness loss within the first 250,000 cycles was due to the fatigue loading. Most beams had a fairly constant stiffness after the first 250,000 cycles while others experienced a relatively small amount of additional stiffness loss.

All strains tended to increase after each 250,000 cycle increment, but many gages yielded inconsistent values. This suggests that highly localized strains were present in the beams' constituent materials. The FRP gages bore the most highly localized differences in strain while the steel strains were more consistent. Concretegages provided a variety of localized strain trends due to cracking.

\subsubsection{Static Flexural Testing}

\subsubsection{Part I}

It was concluded that the maximum service loads and deflections were very close to what was predicted by the ACI design guidelines. A mild corrosion level of around 5\% mass loss yielded no significant loss in flexural strength, and the more significant deterioration mass loss of $15 \%$ after the first complete corrosion cycle resulted in a $13 \%$ reduction in service load capacity. Actual service moments immediately after repair either 
approximately matched or exceeded the value predicted by the ACI design equations, indicating that the guidelines are likely conservative for newly repaired FRP strengthening systems. Although the beams were strengthened to just below their original pristine capacities to ensure the prevention of concrete crushing, the actual service loads both exceeded those observed in 28-day pristine Beam I-3.

Although it was expected that the polymer patch repaired Beam I-7 would outperform the crack-injected Beam I-10, the reverse was true for load capacity. This would dramatically change, however, for the long-term durability study.

Beam I-6, which was unrepaired and subjected to both corrosion cycles, exhibited large reductions in service load and failure load of 28 and $38 \%$, respectively, demonstrating that the accelerated aging process was highly successful.

Although both beams subjected to a second corrosion cycle after repair experienced at least some strength loss, Beam I-8 with polymer patch repair proved to be much more durable than crack-injected Beam I-9. Beam I-8 had only a 9\% reduction of service load capacity compared to I-7, and experienced no decrease in failure load. However, Beam I9 lost an overwhelming 25 and $29 \%$ of its service and failure load capacities, respectively, as a result of the second corrosion cycle. After the second corrosion cycle, service load capacities of Beams I-8 and I-9 were 10 and $17 \%$ less than the ACI predicted value, respectively. It can be concluded that, while the ACI guidelines may be 
conservative for newly repaired beams, they may not be conservative for long-term performance.

Somewhat surprisingly, Beam I-7 (repaired with polymer-modifeid concrete) yielded larger deflections than did crack-injected Beam I-10, which favors polymer concrete repair since it yielded a more ductile failure. Additionally corroded Beams I-8 and I-9 followed the same trend. Another interesting observation was that Beam I-8 had a service deflection equivalent to that of severely corroded unrepaired Beam I-6. It can be concluded that, for this experiment, complete polymer patch repair prior to FRP strengthening produces a much more durable and ductile failure than does crack-injection alone.

The accelerated corrosion process reduced specimen stiffness, as expected. Surprisingly, the stiffness of the FRP-repaired beams was less than that of the pristine beams, although this could be partly attributed to the intended under-reinforcement of the specimens which was discussed earlier. The stiffness of the FRP-repaired beams was actually similar to the stiffness of the corroded unrepaired beams.

It was observed that the second corrosion cycle produced an even greater loss in relative stiffness than did the first corrosion cycle. For both aged and unaged repairs, crackinjected specimens exhibited a greater stiffness than did polymer-modified concreterepaired specimens. This supports the conclusion that polymer concrete substrate repair 
prior to FRP application yields the more ductile failure. Beams I-8 and I-9 retained more stiffness than the equivalent corroded unrepaired Beam I-6, as expected.

Polymer-modified concrete-repaired beams failed via crack-induced debonding and FRP rupture while crack-injected beams encountered debonding of the concrete cover and subsequent FRP rupture. The FRP rupture on the crack-injected beams likely occurred because of localized direct tension in areas of high stress concentration due to the failing substrate. No significant debonding occurred between the concrete and the FRP. An additional observation was that the FRP sheets tended to rupture closer to the midspan of crack-injected beams and closer to the anchor stirrups on patch-repaired beams.

Overall, the polymer-modified concrete repair was superior to the crack-injection repair. When coupled with FRP sheets, it produced the most ductile failure and certainly provided the most durability.

\subsubsection{Part II}

Pristine beams performed slightly better than predicted by ACI guidelines. The accelerated corrosion process yielded a $13 \%$ decrease in failure load and a substantial $35 \%$ loss of service load capacity. As the corroded unrepaired beams were statically tested to failure, they had the appearance of deteriorated concrete bridge girders in the field. Longitudinal cracks grew, cover delamination occurred, and corroded rebar 
became exposed. Again, this substantiates the successfulness of the accelerated aging process as it simulated field conditions in a laboratory environment.

Beams repaired with Wrapping Schemes 1, 2, and 3 had service load capacities between 3 and $15 \%$ higher than that predicted by ACI design equations. The average failure load for each group of the FRP-repaired beams was also higher than that of the pristine control samples of equivalent age. Although these equations are conservative immediately after repair, they may be somewhat non-conservative for long-term performance, as demonstrated in Part I.

No clear trend was observed in either failure or service load capacity as more anchorage was added, as was expected since flexural performance is not at all related to extent or quality of anchorage used in ACI's flexure FRP design. Cyclic loading did not appear to significantly affect the flexural strength capacity of the beams for any of the three schemes, and no clear trend in load capacity was detected as more anchorage was added. Duplicate FRP-repaired beams showed excellent consistency in service load capacity and deflection, as evidenced by the comparison tables and curves presented in Chapter 6 .

The extent of anchorage did not significantly influence the maximum service deflection, but the addition of evenly spaced anchors tended to reduce the failure deflection. For fatigued beams, the maximum service deflections were reduced as more anchorage was 
added. As expected, the corroded unrepaired beams yielded much higher deflections than did the pristine beams.

The accelerated aging process resulted in a $7 \%$ decrease in stiffness for unrepaired beams. The average post-cracking stiffness increased as more anchorage was added with the greatest increase between Schemes 2 and 3. Post-cracking stiffness of fatigued beams appeared to be double that of non-fatigued beams. Although this needs to be further investigated, it is initially theorized that the permanent deflection caused by fatigue created an artificial pre-tensioning of the linear-elastic FRP sheet, causing the stiffness to appear much greater than non-fatigued duplicates.

Pristine beams showed very uniform steel strains, but steel strains in repaired beams were more scattered. It could be seen that, although FRP repair did not significantly affect the maximum linear steel strain, it did tend to reduce the load at which the strain became non-linear. The maximum linear steel strain was also higher for fatigued beams than it was for non-fatigued beams. 
The maximum linear FRP strains ${ }^{\dagger \dagger}$ were very similar amongst the three wrapping schemes, but the loads at which the linearity of the strain was terminated varied significantly. FRP strains tended to remain linear to a higher flexural load for beams with less anchorage.

Both the bonded and the embedded concrete gages provided very inconsistent strain data, which was likely due to the variable location of crack formation within the gage length on different beams.

All beams failed via some extent of crack-induced debonding and subsequent FRP rupture. It was found that FRP rupture was contained between the anchor stirrups for beams repaired with Schemes 2 and 3. Rupture of Scheme 2 beams occurred closer to the midspan than for Scheme 1 beams. Dramatic debonding occurred in unanchored Scheme 1, dramatic debonding occurred in Scheme 2 but was contained to between the anchors, and small areas of debonding occurred between anchors in Scheme 3.

It can be concluded that vee-shaped portions of concrete remaining adhered to the FRP coupled with bond failure at the FRP-concrete interface provides an indicative sign of

\footnotetext{
${ }^{\dagger}$ Please note that FRP strain is linear to rupture for direct tension coupon tests involving the FRP alone. However, when FRP is bonded to the concrete, the two materials behave compositely, resulting in a nonlinear portion of the load-strain curve.
} 
crack-induced debonding. Pronounced vee-shaped notches were prevalently observed in all non-fatigued beams. The vee-shaped cracking was not nearly as prevalent in fatigued beams, although very small vee-shaped notches were still present on the concrete substrate. While further investigation is necessary, it is theorized that the fatigue loading weakened the epoxy-concrete interface within the constant moment region, and perhaps even caused some localized debonding. This yielded non-composite action between the FRP and the concrete, and the FRP failure was more due to direct tension than actual instantaneous crack-induced debonding.

Contrary to hypothesis, the presence of shear-flexure cracks actually appeared to increase as more transverse stirrups were added. This will need to be further investigated.

Overall, the wrapping scheme did not appear to cause dramatic differences in overall performance. More anchorage was found to reduce the area of FRP debonding, but also to create a slightly stiffer reinforced concrete member. Cyclic loading seemed to shift the failure mode from instantaneous crack-induced debonding to weakening of the FRPconcrete interface and then tension failure of the FRP for all wrapping schemes. It is extremely important to note that, since all these beams were tested immediately after repair, that additional aging would very possibly yield widespread differences between the performances of the wrapping schemes. Additional corrosion on the three schemes could not be investigated in this research due to time constraints, but the results of Part I prove that additional aging definitely changes the performance of an FRP repair. It can be very easily hypothesized that more anchorage would provide a safer long-term repair. 


\subsubsection{Compression Cylinder Testing}

For Part I, the compressive strength values of all equivalently-aged cylinders were consistent. It was concluded that the concrete did not gain significant strength between the age of 28 days and 66 weeks. This was likely due to the presence of chlorides, which produce a high early strength, and to the fact that the cylinders were stored in open air and were not exposed to high moisture levels after 28 days. The compressive strength of the intentionally poor-quality concrete was approximately $3,500 \mathrm{psi}$, comparable to the compressive strength of cylinders extracted from PennDOT Bridge \#49-4012-0250-1032.

For Part II, all individual 28-day compressive strengths fell within $\pm 413 p s i$, and all individual compressive strengths at the time the repaired beams were broken were within $\pm 214 p s i$. It can be concluded from these results that all concrete used in this experiment was very consistent, which was essential for the integrity of all results discussed for other tests. A different brand of Type I cement was used for Part II beams, and the average compressive strength was just below 2,500psi. It can also be concluded that, like Part I cylinders, Part II cylinders did not exhibit significant strength gain over time. This was important since it allows meaningful comparison between the analyses of beams of all ages in this research.

\subsubsection{FRP-Concrete Pull-Off Testing}

On a beam with substrate repair consisting only of epoxy-crack injection, pull-off testing resulted in an average strength of $464 p s i$ and failure occurred completely within the 
concrete. This concludes that there was a good bond between the FRP and the concrete for beams with a crack-injected substrate.

The bond between the FRP and concrete was stronger than the 500psi capacity of the original pull-off tester for beams with complete polymer patch concrete repair. Therefore, a higher-capacity tester had to be used. The failure occurred at the epoxyconcrete interface which is usually not favorable. However, since the failure occurred at such a high average pressure of $495 p s i$, the bond was determined to be satisfactory for this experiment. The actual pull-off strength for these samples was likely even higher, but since it was difficult to sufficiently bond the new dollies, an unbalanced bond could have resulted in eccentricity during the test.

The contribution of mode I failure to the ultimate failure of the FRP-concrete bond for the static flexure tests was demonstrated in the mode I pull-off tests. The fracture surfaces of both the pull-off test circles and the delaminated FRP sheet appeared to be the same.

\subsubsection{FRP Direct Tension Testing}

Tensile strengths of the FRP coupons were less than the values reported by the manufacturer. This was because, as the sample coupons cured in the sample box, they were placed between two plastic sheets which wrinkled and formed small ripples in the 
FRP. It is likely that, had the coupons been perfectly flat, the test values would have been within the range reported by the manufacturer.

\subsubsection{Summary}

The primary objective of this research was to determine the most durable, reliable, and economical method of deteriorated concrete bridge girder rehabilitation that is currently available in the engineering industry. Through literature review, it was determined that repair using CFRP sheets would be the focus. CFRP sheets had been shown to demonstrate many favorable properties, and since the relative quantity of material required for a bridge repair is small, it had proven to be a cost-efficient choice. Laboratory-scale experimentation involved two different substrate repair techniques (complete polymer patch repair and crack injection only), the effects of additional corrosion after FRP repair, the behavior beams repaired using different anchorage schemes, and the effects of fatigue loading on an FRP-strengthening system.

It was concluded that, for best results, old concrete should first be completely removed from regions surrounding the tension steel. Next, the steel should be well-cleaned. An epoxy "scrub coat" should be applied to all concrete and steel to which the repair concrete will be adhered. New high-performance concrete, preferably polymer-modified concrete, should be used to replace the old concrete. Care should be taken when using the new concrete to patch only certain areas around the tension steel, as an incipient anode forms causing accelerated corrosion in regions adjacent to the patch repair. Next, the substrate should be sandblasted to a specified surface profile. FRP should be applied 
with sufficient transverse anchorage, and it is likely that more anchorage is better for long-term performance.

The bond between FRP and concrete will likely be deteriorated by fatigue during the service life of a bridge structure. Permanent strain and deflection due to fatigue is also to be expected. Higher-amplitude fatigue loading during a relatively small time interval can result in brittle failure of the FRP system. FRP systems are brittle by nature, and the maximum load they can accept is typically the same load at which the FRP debonds and/or ruptures.

The ACI design guidelines are conservative for newly FRP-repaired bridge girders. More long-term durability studies, however, need to be completed to determine the reliability of the guidelines over time. This experiment showed that the guidelines are certainly not always conservative after continued deterioration of the repaired reinforced concrete members.

The second objective of this research was to establish an effective, consistent, rapid and reliable way to simulate the aged conditions of deteriorated reinforced concrete members in a laboratory. By using a high water-cement ratio and by adding sodium chloride to the concrete mix, a concrete simulating that found in deteriorated bridge structures can be simulated. Accelerated aging via electric current applied to the reinforcing steel proved to be effective, consistent, rapid, and reliable. The overall simulation of field conditions 
was extremely accurate, as proved by a series of supplementary material tests and visual observations. This research certainly provided further insight into future bridge rehabilitation and will contribute to creating practical guidelines for concrete patch-repair and CFRP retrofit of concrete girders to assure long-term adequate performance under environmental and mechanical loads.

\subsection{Recommendations for future work}

There are many topics in the field of bridge rehabilitation and strengthening which need to be studied further. FRP repair is a relatively new technology with a small knowledge base compared to that of the other major materials used in the structural engineering industry.

Since it is a fairly new technology, knowledge about the long-term performance of FRP repairs is deficient. There are many variables in an existing bridge which determine how the structure will behave when FRP is added. The quality of existing concrete, the quantity of deicing salt used on a bridge, the extent and frequency of loading placed on the structure, the harshness of the environment, and the quality of workmanship while performing the repair are just some of the hundreds of items that determine the durability of a repaired bridge. For this reason, it is not possible to provide an exact correlation between the duration of accelerated corrosion in the laboratory and the amount of time required to obtain an equivalent level of corrosion in the field. This is evidenced by observing existing bridges. Some bridges are 50 years old and are in excellent condition 
while others are 30 years old and in very poor condition. Because of all the external and uncontrollable variables, research needs to focus on 1.) repairing concrete structures assuming worst-case long-term environments and 2.) "curing" the structures by eliminating the sources of corrosion instead of just "temporarily alleviating the symptoms," which will be explained later in this section..

The durability of the FRP-concrete bond is essential for the long-term success and safety of the repair. Further research needs to be conducted on this topic. It is known that alkaline solutions and UV light degrade epoxy. Since alkaline solutions will definitely precipitate out of concrete and since sunlight will definitely access at least the exterior girders, it must be determined whether the bond will deteriorate over time. Also, much more work needs to be conducted on continued deterioration of the reinforced concrete member on which the FRP is bonded. It can be guaranteed that beams will continue to corrode after repair. The effects of various corrosion levels applied after repair need to be examined in order to begin to predict the service life of a repair. If adequate thought is not put into what should be the design service life of a repair, the bridge engineering industry will be faced with the unexpected problem of deteriorated FRP-repaired beams in the future.

Since concrete patch repair is often used to restore only localized areas, great care must be taken to ensure that an incipient anode doesn't form and cause accelerated corrosion in locations adjacent to the repair. More research needs done on the formation of an incipient anode after concrete patch repair and its effects on an FRP system. 
Freeze/thaw is one of the leading causes of reinforced concrete deterioration in coldclimate environments, such as in Pennsylvania or West Virginia. No reviewed literature, however, included freeze/thaw cycling of large-scale specimens repaired with FRP. Such an important parameter should not be overlooked and more work on large-scale freeze/thaw needs to be conducted. Wet/dry with varying temperature effects has also been proven to negatively affect reinforced concrete. More work needs to be done to investigate the effect of this aging mechanism on FRP repairs.

The performance of FRP repair on beams corroded to different extents should be evaluated and compared. Perhaps this could lead to the conclusion of an "optimum deterioration level" of a structure on which to perform a repair.

In this research, only a small number of beams were fatigued. More research needs to be conducted that focuses only on the fatigue performance of FRP repairs. Variable frequencies, amplitudes, load levels, wave shapes, and number of cycles should be incorporated into the experimental plan. It is important that S-N curves be constructed and analyzed.

If someone has a disease and is given medicine to alleviate the symptoms, they will still suffer from the disease at a later time. However, if a cure is found for the disease, it will never reoccur and the person will maintain a healthy life. This medical analogy can be easily related to reinforced concrete repair. New ways to "cure" a structure from further 
deterioration instead of just "temporarily alleviating the symptoms" need to be sought. Electrochemical chloride extraction is one example of how this is possible. Please refer to the detailed explanation of ECE in Chapter 4. The chloride ions, which initiate corrosion, are repelled away from the reinforcing steel, which are re-passivated. The $\mathrm{pH}$ of the concrete becomes more alkaline and corrosion is prevented. If this technology were coupled with FRP technology, the risk of additional corrosion could be greatly reduced. It needs to be determined whether or not ECE could be re-performed on an FRP-strengthened structure. This is because, after about 10 to 15 years, contaminants could precipitate back to the level of the reinforcing bars. No research was found in the literature review which examined the possibilities of re-performing ECE on an FRPrepaired beam.

Perhaps most importantly, ways to monitor the health of structures repaired with FRP need to be studied. Long-term health monitoring techniques, such as the use of fiber optic strain gages that can detect crack location and width, need continued development and released commercially. This would assist bridge inspectors in detecting structural changes which are invisible to the naked eye. New "smart structures" need to be constructed and analyzed. The structural engineering industry needs to utilize available multidisciplinary technologies to more effectively understand, monitor, and care for its bridges. 


\section{References}

ACI Committee 440. Guide for the Design and Construction of Externally Bonded FRP Systems for Strengthening Concrete Structures. Farmington Hills, MI: American Concrete Institute, 2002.

Aidoo, J. 2004_. "Flexural retrofit of reinforced concrete bridge girders using three CFRP systems." PhD dissertation, Dept. of Civil and Environmental Engineering, Univ. of South Carolina, Columbia, S.C.

Andrade, C. "Cover Cracking as a Function of Bar Corrosion; Part I - Experimental Test." Materials and Structures 26. (1993): 453-464.

Austin, S.A., R. Lyons, and J.J. Ing. "Electrochemical Behavior of Steel-Reinforced Concrete During Accelerated Corrosion Testing." Corrosion. 60. No. 2 (2003): Pages 203-212.

AZo Journal of Materials Online. 2008. AZoM. 3 Mar 2008. $<$ http://www.azom.com/work/ycdTWC207CJUrDMpADF3_files/image003.gif $>$

Ball, Chris. "Corrosion Mitigation Strategies for FRP Composite Strengthening Systems." ACI Fall Convention. Toronto, 2000.

Bank, Dr. Lawrence C, et al. Rapid Strengthening of Reinforced Concrete Bridges. Rolla, MO: University of Missouri-Rolla, 2002.

Barbero, Ever J. Introduction to Composite Materials Design. New York, NY: Taylor \& Francis Group, 1999.

Bonacci, J. F., and M. Maalej. "Behavioral Trends of RC Beams Strengthened with Externally Bonded FRP.” Journal of Composites for Construction. May (2001): Pages 102-113.

Bonacci, John F., and Mohamed Maalej. "Externally Bonded Fiber-Reinforced Polymer for Rehabilitation of Corrosion Damaged Concrete Beams." Journal. September/October (2000): Pages 703-711.

Boyajian, David M., Mode I Fracture and Durability of the CFRP-Concrete Interface Bond. Dissertation. Morgantown, WV: West Virginia University, 2002.

Brayack, Daniel A. Technical and Economic Effectiveness for Repair with FRP of Concrete T-Beam Bridges: Case Study for PennDOT-District 3. M.S. Thesis. Morgantown, WV: West Virginia University, 2006. 
Broomfield, John P., and John S. Tinnea. "Cathodic Protection of Reinforced Concrete Bridge Components." Washington DC: Strategic Highway Research Program, National Research Council, 1992.

Broomfield, John P. Corrosion of Steel in Concrete. London: E\&FN Spon, 1997.

Calvert, Sean, and Jason Mooney. "Bridge Structural Health Monitoring Using Fiber Grating Sensors: Development and Preparation for a Permanent Insulation." Blue Road Research. (2002).

Casas, Joan R., and Paulo J.S. Cruz. "Fiber Optic Sensors for Bridge Monitoring." Journal of Bridge Engineering Vol. 8. No. 6. ASCE. November/December (2003): Pages 362-373.

Casas, Joan R., and Gonzalo Ramos. "Intelligent Repair of Existing Concrete Structures." Computer-Aided Civil and Infrastructure Engineering 17. (2002): Pages 43-52.

Casas, Joan R. "Monitoring and Reliability Management of Deteriorating Concrete Bridges." Maintaining the Safety of Deteriorating Civil Infrastructures; Proceedings of the $2^{\text {nd }}$ International Workshop on Life-Cycle Cost Analysis and Design. (2001): Pages 127-141.

Chen, Yi, Julio F. Davalos, and Indrajit Ray. "Durability of GFRP Reinforcing Bars in Concrete Environment.” Morgantown, WV: West Virginia University, 2006.

Chen, Yi, Julio F. Davalos, and Indrajit Ray. "Using Short-Term Data of Accelerated Aging Tests." Journal of Composites for Construction. ASCE. July/August (2006): 279-286.

Chloride Extraction. Ed. Martin Beaudette. 2006. 28 Dec. 2006. $<$ http://www.norcure.com/chloride.htm $>$.

Clemeña, Gerardo G., and Donald R. Jackson. "Final Report; Trial Application of Electrochemical Chloride Extraction on Concrete Bridge Components in Virginia." Virginia Transportation Research Council, April, 2000.

Concrete Repair Manual. Second Edition. Volumes 1 and 2. ACI International, BRE, Concrete Society, and International Concrete Institute. May 2003.

Construction Materials Institute at the University of Tehran. 2007. University of Tehran, Iran. 5 Feb 2008. < http://cmi.ut.ac.ir/Newweb/ENProOxygen.aspx>

Corrosion-Club. M. Tullmin. Jan 2008. 5 Feb 2008. <http://www.corrosionclub.com/concreteintro4.htm> 
Davalos, Dr. Julio F., et al. District 3-0 Investigation of Fiber-Wrap Technology for Bridge Repair and Rehabilitation (Phase-I). Morgantown, WV: West Virginia University, 2006.

Demers, Cornelia E. "Fatigue Strength Degradation of E-glass FRP Composites and Carbon FRP Composites." Construction and Building Materials 12. (1998): 311318.

Duffo, G.S., et al. "A Study of Steel Rebar Embedded in Concrete During 65 Years." Corrosion Science 46. (2004): Pages 2143-2157.

Ecosmart Concrete. 2007. EcoSmart Foundation. 10 Feb 2008. $<$ http://www.ecosmartconcrete.com/enviro_statistics.cfm>

Ekenel, M., et at. Microwave NED of RC Beams Strengthened with CFRP Laminates Containing Surface Defects and Tested Under Cyclic Loading. Rolla, MO: University of Missouri-Rolla.

Epoxy Systems Product \#680. MMA Polymer Concrete. 2006. 28 Dec. 2006. $<\mathrm{http}: / /$ www.epoxy.com/680.htm>

GangaRao, Hota V.S, Narendra Taly, P.V. Vijay. Reinforced Concrete Design with FRP Composites. Boca Raton, FL: CRC Press, Taylor \& Francis Group, 2007.

Garas, Victor Y, and C. Vipulanandan. "Review of Polyseter Polymer Concrete Properties." Houston, TX: University of Houston.

Grace, Nabil F., “Concrete Repair with CFRP.” Concrete International. (2004): Pages4552.

Green, Mark F., Aaron J.S. Dent, and Luke A. Bisby. "Effect of Freeze-Thaw Cycling on the Behavior of Reinforced Concrete Beams Strengthened in Flexure with Fibre Reinforced Polymer Sheets." Canadian Journal of Civil Engineering 30. (2003): Pages 1081-1088.

Hag-Elsafi, O., et al. "Application of Load Testing for Evaluation of FRP Retrofit Systems and Monitoring for Superloads." Transportation R\&D Bureau, NYSDOT, Albany, NY, April 2002.

Hag-Elsafi, Osman, Sreenivas Alampalli, and Jonathan Kunin. "Application of FRP Laminates for Strengthening of a Reinforced-Concrete T-Beam Bridge Structure." Composite Structures. (2001): Pages 454-466. Elsevier Science Ltd. $<$ www.elsevier.com/locate.compstruct $>$ 
Hag-Elsafi, Osman, Sreenivas Alampalli, and Jonathan Kunin. "In-Service Evaluation of a Reinforced Concrete T-Beam Bridge FRP Strengthening System." Composite Structures 64. (2004): Pages 179-188. Elsevier Science Ltd. $<$ www.elsevier.com/locate.compstruct $>$

Hag-Elsafi, Osman, Sreenivas Alampalli, and Jonathan Kunin. "Strengthening of a Bridge Pier Capbeam Using Bonded FRP Composite Plates." Composite Structures 57. (2002): Pages 393-403. Elsevier Science Ltd. $<$ www.elsevier.com/locate.compstruct $>$

Hamilton III, HR, and CW Dolan. "Durability of FRP Reinforcements for Concrete." Progressive Structural Engineering Materials. John Wiley \& Sons, Ltd., 2000. Pages 139-145.

Harries, Kent A. "Debonding- and Fatigue-Related Strain Limits for Externally Bonded FRP." Journal of Composites for Construction. (January/February): Pages 87-90.

Hearn, N. "Effect of Mechanical Restraint on the Rate of Corrosion in Concrete." Canadian Journal of Civil Engineering 24. (1998): Pages 81-88.

Hu, C.W., et al. "Detection of Air Blisters and Crack Propatation in FRP Strengthened Concrete Elements Using Infrared Thermography." InfraMation.

Jia, Junhui, et al. "Durability Evaluation of Glass Fiber Reinforced-Polymer-Concrete Bonded Interfaces." Journal of Composites for Construction. ASCE. July/August (2005): Pages 348-359.

Kachlakev, Damian I. "Experimental Results and Deisgn Methods of Structural Strengthening of RC Beams Using Composite Laminates." $33^{\text {rd }}$ International SAMPE Technical Conference. (November 5-8, 2001): Pages 792-807.

Kayyali, O.A., and M.N. Haque. "The Cl-/OH- Ratio in Chloride-Contaminated Concrete - A Most Important Criterion." Magazine of Concrete Research 47. No. 172 (1995): Pages 235-242.

Kodkani, Shilpa. Interface Durability of Externally Bonded GFRP to Normal and HighPerformance Concrete. M.S. Thesis. Morgantown, WV: West Virginia University, 2004.

Koleva, D.A., et al. "Cathodic Protection Revisited: Impact on Structural Morphology Sheds New Light on its Efficiency." Cement \& Concrete Composites 28. (2006): Pages 696-706. 
Kumahara, S.; Masuda, Y.; and Tanano, Y., 1993, "Tensile Strength of Continuous Fiber Bar Under High Temperature," International Symposium on Fiber-Reinforced Plastic Reinforcement for Concrete Structures, SP-138, American Concrete Institute, Farmington Hills, Mich., pp. 731-742.

Kutarba, M.P., J.R. Brown, and H.R. Hamilton. "Repair of Corrosion Damaged Concrete Beams with Carbon Fiber-Reinforced Polymer Composites." COMPOSITES 2004 Convention and Trade Show. American Composites Manufacturers Association. Tampa, FL: October 6-8 (2004).

Leung, Christopher. Email conversation. 21 Jan 2008.

Leung, Christopher K.Y. "FRP Debonding from a Concrete Substrate: Some Recent Findings Against Conventional Belief." Cement \& Concrete Composites 28. (2006): Pages 742-748.

Littles, Jr., Jerrol W., Laurence J. Jacobs, and abdul-Hamid Zureick. "Single-Sided Ultrasonic Technique to Characterize Thick FRP Composites." Journal of Nondestructive Evaluation. Vol. 17. No. 4. (1998): Pages 223-230.

Maddaawy, Tamer El, and Khaled Soudki. "Carbon-Fiber-Reinforced Polymer Repair to Extend Service Life of Corroded Reinforced Concrete Beams." Journal of Composites for Construction. ASCE. March/April (2005): Pages 187-194.

Maddaawy, Tamer El, and Khaled Soudki. "Effectiveness of Impressed Current Technique to Simulate Corrosion of Steel Reinforcement in Concrete." Journal of Materials in Civil Engineering. January/February (2003): Pages 41-47.

Maerz, N., G. Galecki, and A. Nanni. "Experimental Non-Destructive Testing of FRP Materials, Installation, and Performance, Dallas County Bridge, Missouri, USA." Rolla, MO: University of Missouri-Rolla.

Mailvaganam, Noel P. "Structural and Patch Repair in Concrete Structures." Cement \& Concrete Composites 28. (2006): Pages 669-670.

Masoud, Sobhy, and Khaled Soudki. "Evaluation of Corrosion Activity in FRP Repaired RC Beams." Cement \& Concrete Composites 28. (2006): Paves 969-977.

Masoud, Sobhy, Khaled Soudki, and Timothy Topper. "Postrepair Fatigue Performance of FRP-Repaired Corroded RC Beams: Experimental and Analytical Investigation.” Journal of Composites for Construction. ASCE. September/October (2005): Pages 441-449.

Mindess, Sidney, J. Francis Young, and David Darwin. Concrete. Second Edition. Pearson Education, Inc. Upper Saddle River, NJ: Prentice Hall, 2003. 
Mufti, Aftab A., et al. "Are Civil Structural Engineers "Risk Averse"? Can Civionics Help?" Ansari, Farhad, ed. Sensing Issues in Civil Structural Health Monitoring. The Netherlands: Springer, 2005.

Nawy, Edward G. Reinforced Concrete: A Fundamental Approach. Upper Saddle River, NJ: Prentice Hall, Pearson Education, Inc., 2003.

Nepomuceno, Antonio A. "Steel Protection Capacity of Polymaric Based Cement Mortars Against Chloride and Carbonation Attacks Studied Using Electrochemical Polarization Resistance." Cement \& Concrete Composites 28. (2006): 716-721.

Nilson, Arthur H. Design of Prestressed Concrete. New York: John Wiley \& Sons, Inc., 1987.

Oh, B.H., S.Y. Jang, and Y.S. Shin. "Experimental Investigation of the Threshold Chloride Concentration for Corrosion Initiation in Reinforced Concrete Structures." Magazine of Concrete Research 55. No. 2 (2003): Pages 117-124.

Park, Zin-Taek, et al. "Development of a Galvanic Sensor System for Detecting the Corrosion Damage of the Steel Embedded in Concrete Structure Part 2. Laboratory Electrochemical Testing of Sensors in Concrete." Suwon, South Korea: Sungkyunkwan University, 2003.

Malhotra, V.M. and N.J. Carino. Handbook on Nondestructive Testing of Concrete. West Conshohocken, PA: CRC Press LLC, 2004.

PCI Design Handbook, Sixth Edition. U.S.A.: Precast/Prestressed Concrete Institute, 2004.

Phares, Brent M., et al. "Health Monitoring of Bridge Structures and Components Using Smart Structure Technology Volume 1." Wisconsin Highway Research Plan. January (2005).

Phares, Brent M., et al. "Health Monitoring of Bridge Structures and Components Using Smart Structure Technology Volume 2." Wisconsin Highway Research Plan. January (2005).

Polymer Concrete. ABT, Inc. 2006. 28 Dec. 2006.

$<$ http://www.abtdrains.com/PolyDrain/Polymer_Concrete>

Quattlebaum, J., Harries, K. A., and Petrou, M. F._2005_. “Comparison

of three CFRP flexural retrofit systems under monotonic and fatigue

loads." J. Bridge Eng., 10_6_, 731-740. 
Raupach, M. "Patch Repairs on Reinforced Concrete Structures - Model Investigations on the Required Size and Practical Consequences." Cement \& Concrete Composites 28. (2006): 679-684.

Reay, Jaron T., et al. "Long Term Durability of Carbon FRP Composites Applied to RC Bridges: State Street Bridge on Interstate 80." Journal of Bridge Engineering. ASCE. March/April (2006): Pages 205-216.

Rizzo, Andrea, Nestore Galati, and Antonio Nanni. Design and In-Situ Load Testing of Bridge No. 1330005 Route 3560 - Phelps County, MO. Rolla, MO: University of Missouri-Rolla, 2005.

Sebastian's Technical Glossaries: Building \& general construction technology dictionary: technology, architecture, civil, structural, forensic, mechanical, pavement and materials engineering, roofing, and masonry with elements of testing and quality science. A. Sebastian. 2008. A. Sebastian Engineering \& Investigation Services. 10 Feb 2008.

$<$ http://www.angelfire.com/biz/BuildingPathology/ConstrEFRglossA.html $>$

Sen, Rajan. "Issues Related to the FRP Wrap of Corroded Piling." COMPOSITES 2004 Convention and Trade Show. American Composites Manufacturers Association. Tampa, FL: October 6-8 (2004).

Sharp, Stephen R, et al. "Electrochemical Chloride Extraction: Influence of Concrete Surface on Treatment." Charlottesville, VA: Virginia Transportation Research Council, 2002.

Soudki, K.A. "Behavior of Reinforced Concrete Beams Strengthened with Carbon Fiber Reinforced Polymer Laminates Subjected to Corrosion Damage." Canadian Journal of Civil Engineering 27. (2000): Pages 1005-1010.

Strength of Continuous Fiber Bar Under High Temperature," International Symposium on Fiber-Reinforced Plastic

Reinforcement for Concrete Structures, SP-138, American

Concrete Institute, Farmington Hills, Mich., pp. 731-742.

Swamy, R.N., and Stephen McHugh. "Effectiveness and Structural Implications of Electrochemical Chloride Extraction from Reinforced Concrete Beams." Cement \& Concrete Composites 28. (2006): Pages 722-733.

Toutanji, Houssam A. "Characteristics of Concrete Columns Confined with Advanced Composite Materials." Composite Structures 44. (1999): 155-161.

Toutanji, Houssam A., and William Gómez. "Durability Characteristics of Concrete Beams Externally Bonded with FRP Composite Sheets." Cement and Concrete Composites 19. (1997): Pages 351-358. 
University of Missouri-Rolla. Preservation of Missouri Transportation Infrastructures; Validation of FRP Composite Technology Through Field Testing; Strengthening of Bridge P-0962 Vol. I: Bridge Design \& Load Rating. Rolla, MO: University of Missouri-Rolla, 2004.

University of Missouri-Rolla. Preservation of Missouri Transportation Infrastructures; Validation of FRP Composite Technology Through Field Testing; Strengthening of Bridge P-0962 Vol. II: Materials \& Construction. Rolla, MO: University of Missouri-Rolla, 2004.

University of Missouri-Rolla. Preservation of Missouri Transportation Infrastructures; Validation of FRP Composite Technology Through Field Testing; Strengthening of Bridge T-0530 Vol. I: Bridge Design \& Load Rating. Rolla, MO: University of Missouri-Rolla, 2004.

University of Missouri-Rolla. Preservation of Missouri Transportation Infrastructures; Validation of FRP Composite Technology Through Field Testing; Strengthening of Bridge X-0495 Vol. I: Bridge Design \& Load Rating. Rolla, MO: University of Missouri-Rolla, 2004.

University of Missouri-Rolla. Preservation of Missouri Transportation Infrastructures; Validation of FRP Composite Technology Through Field Testing; Strengthening of Bridge X-0495 Vol. II: Materials and Construction. Rolla, MO: University of Missouri-Rolla, 2004.

University of Missouri-Rolla. Preservation of Missouri Transportation Infrastructures; Validation of FRP Composite Technology Through Field Testing; Strengthening of Bridge X-0596 Vol. I: Bridge Design \& Load Rating. Rolla, MO: University of Missouri-Rolla, 2004.

University of Missouri-Rolla. Preservation of Missouri Transportation Infrastructures; Validation of FRP Composite Technology Through Field Testing; Strengthening of Bridge X-0596 Vol. II: Materials and Construction. Rolla, MO: University of Missouri-Rolla, 2004.

University of Missouri-Rolla. Preservation of Missouri Transportation Infrastructures; Validation of FRP Composite Technology Through Field Testing; Strengthening of Bridge Y-0298 Vol. I: Bridge Design \& Load Rating. Rolla, MO: University of Missouri-Rolla, 2004.

University of Missouri-Rolla. Preservation of Missouri Transportation Infrastructures; Validation of FRP Composite Technology Through Field Testing; Strengthening of Bridge Y-0298 Vol. II: Materials and Construction. Rolla, MO: University of Missouri-Rolla, 2004. 
Vaysburd, Alexander M. "Holistic System Approach to Design and Implementation of Concrete Repair." Cement \& Concrete Composites 28. (2006): Pages 671-678.

Wang, Chung-Yue, et al. "Rehabilitation of Cracked and Corroded Reinforced Concrete Beams with Fiber-Reinforced Plastic Patches." Journal of Composites for Construction May/June (2004): Pages 219-228.

Wang, K., P.R.L. Helene, and P.J.M. Monteiro. "Potential Use of Zinc in the Repair of Corroded Reinforced Concrete." Cement \& Concrete Composites 28. (2006): Pages 707-715.

Wang, N., and Evans, J. T., 1995, "Collapse of Continuous Fiber Composite Beam at Elevated Temperatures," Composites, V. 26, No. 1, pp. 56-61.

Wu, W. Thermomechanical Properties of Fiber Reinforced Plastics (FRP) Bars. PhD Dissertation. Morgantown, WV: West Virginia University, 1990. 


\section{Appendix A: Reinforced Concrete Beam Design Calculations}

\section{A.1 Definition of Variables}

$A_{S}=$ Actual area of tension steel reinforcement $\left(\mathrm{in}^{2}\right)$

$A_{S}{ }^{\prime}=$ Actual area of compression steel reinforcement $\left(\mathrm{in}^{2}\right)$

$A_{s 1}=$ Difference between areas of tension and compression steel reinforcement $\left(\mathrm{in}^{2}\right)$

$A_{s, r e q}=$ Area of steel reinforcement required $\left(\mathrm{in}^{2}\right)$

$A_{v}=$ Area of shear steel reinforcement $\left(\mathrm{in}^{2}\right)$

$A_{s t}=$ Total area of longitudinal reinforcement $\left(\mathrm{in}^{2}\right)$

$a=$ Depth of equivalent rectangular stress block (in)

$b=$ Width of rectangular cross section (in)

$c=$ Distance from extreme compression fiber to the neutral axis (in)

$C=$ Resultant compressive force in concrete (lbs)

$c_{b}=$ Neutral axis depth for balanced failure (in)

$d=$ Distance from extreme compression fiber to centroid of tension steel (in)

$d^{\prime}=$ Distance from extreme compression fiber to centroid of compression steel (in)

$d_{\min }=$ Minimum allowable distance from extreme compression fiber to neutral axis (in)

$d_{M A X}=$ Maximum allowable distance from extreme compression fiber to neutral axis (in)

$E_{c}=$ Modulus of elasticity of concrete (psi)

$E_{S}=$ Modulus of elasticity of steel (psi)

$f_{c},=$ Compressive strength of concrete (psi)

$f_{r}=$ Modulus of rupture

$f_{s}^{\prime}=$ Stress in steel reinforcement (psi)

$f_{\text {s,artificial }}=$ Initial estimate of stress in steel reinforcement in an iterative process(psi)

$f_{y}=$ Specified yield strength of steel reinforcement (psi)

$h=$ Total height of beam (in)

$I_{c r}=$ Moment of inertia of cracked section transformed to concrete (in $\left.{ }^{4}\right)$

$I_{e}=$ Effective moment of inertia $\left(\mathrm{in}^{4}\right)$

$I_{g t}=$ Gross moment of inertia $\left(\mathrm{in}^{4}\right)$

$L=$ Span length (in)

$M_{a}=$ Service load bending moment (in $\left.\cdot 1 \mathrm{~b}\right)$

$M_{c r}=$ Cracking moment (in $\left.\cdot \mathrm{lb}\right)$

$M_{D}=$ Dead Load Moment

$M_{L}=$ Live Load Moment

$M_{n}=$ Nominal moment strength (in $\left.\cdot \mathrm{lb}\right)$

$M_{u}=$ Factored ultimate moment (in $\left.\cdot \mathrm{lb}\right)$

$n=$ Modular ratio

$P=$ Live point load (lbs)

$P_{c r}=$ Live point load required for cracking (lbs)

$s \quad=$ Stirrup spacing (in)

$T=$ Resultant tensile force in concrete (lbs) 
$V_{c}=$ Nominal shear resistance of plain concrete web (lbs)

$V_{u}=$ Factored shear force (lbs)

$y_{t}=\mathrm{h}-\bar{y}$

$\bar{y}=$ Depth of center of gravity (in)

$\beta_{1}=$ Stress block depth factor

$\Delta_{\mathrm{L}}=$ Live load deflection (in)

$\varepsilon_{t}=$ Strain level in the steel reinforcement (in/in)

$\lambda=$ Factor dependent on type of concrete in a shear member

$\rho=$ Tension steel reinforcement ratio

$\rho^{\prime}=$ Compression steel reinforcement ratio

$\rho_{\text {min }}=$ Minimum allowable tension steel reinforcement ratio

$\omega_{\mathrm{c}}=$ Volumetric weight of concrete $\left(\mathrm{lbs} / \mathrm{ft}^{3}\right)$

$\omega_{\mathrm{D}}=$ Unit dead load $(\mathrm{lbs} / \mathrm{ft})$

\section{A.2 Part I Specimen Design and Commentary}

\section{Material Properties and Geometry:}

$$
\begin{aligned}
& f_{c}^{\prime}=3,500 \mathrm{psi} \\
& f_{\gamma}=60,000 \mathrm{psi} \\
& \omega_{c}=150 \mathrm{lbs} / \mathrm{ft}^{3} \\
& E_{s}=29,000,000 \mathrm{psi} \\
& E_{c}=33 \omega_{c} \sqrt{f_{c}^{\prime}}=33\left(150 \frac{\mathrm{lbs}}{f^{3}}\right) \sqrt{3,500 \mathrm{psi}}=3,586,616 \mathrm{psi} \\
& E_{c}=3,586,616 p s i \\
& L=96 \text { in } \\
& h=8 \text { in } \\
& b=6 \text { in } \\
& \text { Stirrup Diameter }=0.375 \text { in } \\
& d_{\min }=6 \text { in } \\
& d=6.3125 \mathrm{in} \\
& b / d=0.95
\end{aligned}
$$


Find Loads and Moments:

$$
\begin{aligned}
& \omega_{D}=\omega_{c} \times b \times h=150 \frac{\mathrm{lbs}}{f t^{3}} \times 6 \mathrm{in} \times 8 \mathrm{in} \\
& \omega_{D}=50 \frac{\mathrm{lbs}}{\mathrm{ft}} \\
& P=3,000 \mathrm{lbs} \\
& 1.2 \omega_{D}=1.2\left(50.0 \frac{\mathrm{lbs}}{\mathrm{ft}}\right)=60.0 \frac{\mathrm{lbs}}{\mathrm{ft}} \\
& 1.2 \omega_{D}=60.0 \frac{\mathrm{lbs}}{\mathrm{ft}} \\
& P_{L}=1.6 P=1.6(3,000 \mathrm{lbs}) \\
& P_{L}=4,800 \mathrm{lbs} \\
& M_{L}=\frac{P L}{3}=\frac{(4,800 \mathrm{lbs})(96 \mathrm{in})}{3} \\
& M_{L}=153,600 \mathrm{in} \cdot \mathrm{lbs} \\
& M_{D}=\frac{\omega_{D} L^{2}}{8}=\frac{\left(60 \frac{l b s}{f t} \times \frac{1 f t}{12 i n}\right)(96 i n)^{2}}{8} \\
& M_{D}=5,760 \mathrm{in} \cdot \mathrm{lbs} \\
& M_{u}=M_{D}+M_{L}=(5,760 \mathrm{in} \cdot \mathrm{lbs})(153,600 \mathrm{in} \cdot \mathrm{lbs}) \\
& M_{u}=159,360 \mathrm{in} \cdot \mathrm{lbs} \\
& M_{n}=\frac{M_{u}}{\phi}=\frac{159,360 \mathrm{in} \cdot \mathrm{lbs}}{0.87} \\
& M_{n}=182,735 \mathrm{in} \cdot \mathrm{lbs}
\end{aligned}
$$

\section{Design Reinforced Concrete Beam:}

$$
\begin{aligned}
& c_{b}=d\left(\frac{0.003}{0.003+\frac{f_{y}}{E_{s}}}\right)=6.3125 \mathrm{in}\left(\frac{0.003}{0.003+\frac{60,000 p s i}{29,000,000 p s i}}\right) \\
& c_{b}=3.74 \mathrm{in} \\
& c=0.5 c_{b}=0.5(3.74 \mathrm{in}) \\
& c=1.87 \mathrm{in}
\end{aligned}
$$


$\beta_{1}=0.85$

$a=\beta_{1} c=0.85(1.87 \mathrm{in})$

$a=1.59 \mathrm{in}$

$C=0.85 f_{c}^{\prime} b a=0.85(3,500 p s i)(6 i n)(1.59 i n)$

$C=28,342 \mathrm{lbs}$

$C=T=28,342 \mathrm{lbs}$

$A_{s, r e q}=\frac{T}{f_{y}}=\frac{28,342 \mathrm{lbs}}{60,000 \mathrm{psi}}$

$A_{\text {s, req }}=0.47 \mathrm{in}^{2}$

Number of Bars $=2$ bars

Bar Diameter $=0.625$ in

$d_{M A X}=h-$ cover thickness - stirrup diameter $-($ tension bar diameter / 2)

$$
=8 \text { in }-1 \text { in }-0.375 \text { in }-\frac{0.625 i n}{2}
$$

$d_{\text {MAX }}=6.3125$ in

Minimum Allowable Spacing $=1 \mathrm{in}$

Spacing $=1$ in

Allowable Cover that applies $=1$ in

Total width of bars, stirrups, and cover $=5.88 \mathrm{in}<b=6 \mathrm{in} \quad \checkmark$ O.K

$A_{S}=2 \times 0.31 \mathrm{in}^{2}$

$A_{S}=0.62 \mathrm{in}^{2}$

$a=\frac{A_{S} f_{y}}{0.85 f_{c}^{\prime} b}=\frac{\left(0.62 i n^{2}\right)(60,000 p s i)}{0.85(3500 p s i)(6 i n)}$

$a=2.08 \mathrm{in}$

$c=\frac{a}{\beta_{1}}=\frac{2.08 \mathrm{in}}{0.85}$

$c=2.45 \mathrm{in}$ 


$$
\begin{aligned}
& \varepsilon_{t}=0.003\left(\frac{d-c}{c}\right)=0.003\left(\frac{6.3125 i n-2.45 i n}{2.45 i n}\right) \\
& \varepsilon_{t}=0.0065 \\
& \varepsilon_{t}=0.0065>0.005 \therefore \phi=0.9 \text { since steel reinforcement yielded }
\end{aligned}
$$

\section{Analyze Doubly Reinforced Beam:}

$d^{\prime}=1.562$ in

Diameter of Compression Steel $=0.375 \mathrm{in}$

$$
\begin{aligned}
& A_{S}{ }^{\prime}=2 \times 0.11 \mathrm{in}^{2} \\
& A_{S}{ }^{\prime}=0.22 \mathrm{in}^{2} \\
& \rho_{\text {min }}=\left\{\begin{array}{l}
3 \sqrt{\frac{f_{c}^{\prime}}{f_{y}}}=3 \sqrt{\frac{3,500 p s i}{60,000 p s i}}=0.0030 \\
200 f_{y}=200(60,000 \text { psi })=0.0033
\end{array}\right\} \text { Greater of } 2 \text { Values } \\
& \rho_{\min }=0.0033 \\
& \rho=\frac{A_{S}}{b d}=\frac{0.62 i^{2}}{(6 i n)(6.3125 i n)} \\
& \rho=0.0164 \\
& \rho^{\prime}=\frac{A_{S}^{\prime}}{b d}=\frac{0.22 \mathrm{in}^{2}}{(6 \mathrm{in})(6.3125 \mathrm{in})} \\
& \rho=0.0058 \\
& \begin{array}{l}
A_{S 1}=A_{S}-A_{S}{ }^{\prime}=0.62 \mathrm{in}^{2}-0.22 \mathrm{in}^{2} \\
A_{S 1}=0.40 \mathrm{in}^{2}
\end{array} \\
& \begin{array}{l}
\rho-\rho^{\prime}=0.0164-0.0058 \\
\rho-\rho=0.01056
\end{array} \\
& f_{S, \text { artificial }}=87,000\left[\frac{1-0.85 \beta_{1} f_{c}^{\prime} d^{\prime}}{\left(\rho-\rho^{\prime}\right) f_{y} d}\right]=87,000\left[1-\frac{0.85(0.85)(3,500 p s i)(1.5625 \mathrm{in})}{(0.01056)(60,000 \mathrm{psi})(6.3125 \mathrm{in})}\right] \\
& f_{\text {S,artificial }}=1,062 p \text { si }
\end{aligned}
$$




$$
\begin{aligned}
& a=\frac{A_{S} f_{y}-A_{S}^{\prime} f_{y}^{\prime}}{0.85 f_{c}^{\prime} b}=\frac{\left(0.62 \mathrm{in}^{2}\right)(60,000 \mathrm{psi})-\left(0.22 \mathrm{in}^{2}\right)(60,000 \mathrm{psi})}{0.85(3,500 \mathrm{psi})(6 \mathrm{in})} \\
& a=2.07 \mathrm{in} \\
& c=\frac{a}{\beta_{1}}=\frac{2.07 \mathrm{in}}{0.85} \\
& c=2.44 \mathrm{in}
\end{aligned}
$$

Strain at tension face of beam $=0.003$

$$
\begin{aligned}
& \varepsilon_{S}{ }^{\prime}=\frac{0.003-d^{\prime}}{c}=\frac{0.003-1.562 \text { in }}{2.44 i n} \\
& \varepsilon_{S}{ }^{\prime}=0.00108
\end{aligned}
$$$$
\begin{aligned}
& f_{S}{ }^{\prime}=\varepsilon_{s}{ }^{\prime} E_{s}=0.00108(29,000,000) \\
& f_{S}^{\prime}=31,206 p s i
\end{aligned}
$$$$
a=\frac{A_{S} f_{y}-A_{S}^{\prime} f_{S}^{\prime}}{0.85 f_{c}^{\prime} b}=\frac{\left(0.62 i n^{2}\right)(60,000 p s i)-\left(0.22 i n^{2}\right)(31,206 p s i)}{0.85(3,500 p s i)(6 i n)}
$$$$
a=1.70 \mathrm{in}
$$$$
c=\frac{a}{\beta_{1}}=\frac{1.70 \mathrm{in}}{0.85}
$$$$
c=2.00 \mathrm{in}
$$$$
\varepsilon_{t}=0.003\left(\frac{d-c}{c}\right)=0.003\left(\frac{i n-i n}{i n}\right)
$$

$\varepsilon_{t}=0.0065 \geq 0.005 \therefore \quad \phi=0.9$ since steel reinforcement yielded

$$
\begin{aligned}
M_{n}= & \left(A_{S} f_{y}-A_{S}^{\prime} f_{S}^{\prime}\right)\left(d-\frac{a}{2}\right)+A_{S}^{\prime} f_{S}^{\prime}\left(d-d^{\prime}\right) \\
= & \left(0.62 \mathrm{in}^{2}\right)(60,000 \mathrm{psi})-\left(0.22 \mathrm{in}^{2}\right)(31,206 \mathrm{psi})\left(6.3125 \mathrm{in}-\frac{2.07 \mathrm{in}}{2}\right) \\
& \quad+\left(0.22 \mathrm{in}^{2}\right)(1,062 \mathrm{psi})(6.3125 \mathrm{in}-1.562 \mathrm{in}) \\
& M_{n}=198,322 \mathrm{in} \mathrm{lbs} \\
M_{n}= & 16.5 f \mathrm{t} \mathrm{k}
\end{aligned}
$$




$$
\begin{aligned}
& P=\frac{3}{L}\left(M_{n}-\frac{\omega_{D} L^{2}}{8}\right)=\frac{3}{96 i n}\left[(198,322 \mathrm{in} \cdot \mathrm{lbs})-\frac{\left(4.17 \frac{\mathrm{lbs}}{\mathrm{in}}\right)(96 \mathrm{in})^{2}}{8}\right] \\
& P=6,198 \mathrm{lbs} \\
& M_{u}=\phi M_{n}=0.90(198,322 \mathrm{in} \cdot \mathrm{lbs}) \\
& M_{u}=178,490 \mathrm{in} \mathrm{lbs}
\end{aligned}
$$

\section{Calculate cracking moment, load, and moment of inertia:}

$$
\begin{aligned}
& n=\frac{E_{S}}{E_{C}}=\frac{29,000,000 p s i}{3,586,616 p s i} \\
& n=8.09 \\
& \bar{y}=\frac{\left(\frac{b h^{2}}{2}\right)+(n+1) A_{S} d}{b h+(n-1) A_{S}}=\frac{\left[\frac{(6 i n)(8 i n)^{2}}{2}\right]+(8.09+1)\left(0.62 i n^{2}\right)(6.3125 i n)}{(6 i n)(8 i n)+(8.09+1)\left(0.62 i n^{2}\right)} \\
& \bar{y}=4.19 i n \\
& I_{g t}=\frac{b h^{3}}{12}+b h\left(\bar{y}-\frac{h}{2}\right)^{2}+(n-1) A_{S}(d-\bar{y})^{2} \\
& =\frac{(6 i n)(8 i n)^{3}}{12}+(6 i n)(8 i n)\left(4.19 i n-\frac{8 i n}{2}\right)^{2}+(8.09-1)\left(0.62 i^{2}\right)(6.3125 i n-4.19 i n)^{2} \\
& I_{g t}=278 \mathrm{in}^{4} \\
& y_{t}=h-\bar{y}=8 \mathrm{in}-4.19 \mathrm{in} \\
& y_{t}=3.81 \mathrm{in} \\
& f_{r}=7.5 \sqrt{f_{c}^{\prime}}=7.5 \sqrt{3,500 p s i} \\
& f_{r}=443.7 p s i \\
& M_{c r}=\frac{I_{g t} f_{r}}{y_{t}}=\frac{\left(278 \mathrm{in}^{4}\right)(443.7 \mathrm{psi})}{3.81 \mathrm{in}} \\
& M_{c r}=32,353 \mathrm{in} \mathrm{lbs} \\
& M_{c r}=2.7 f t k \\
& P_{c r}=\frac{3}{L}\left(M_{c r}-\frac{\omega_{D} L^{2}}{8}\right)=\frac{3}{96 i n}\left[(32,353 \mathrm{in} \cdot l b s)-\frac{\left(4.17 \frac{\mathrm{lbs}}{\mathrm{in}}\right)(96 \mathrm{in})^{2}}{8}\right] \\
& P_{c r}=1,011 \mathrm{lbs}
\end{aligned}
$$


"c" is found by solving the following quadratic equation:

$$
\begin{aligned}
& \frac{b c^{2}}{2}+\left[n A_{S}+(n-1) A_{S}^{\prime}\right] c-n A_{S} d-(n-1) A_{S}^{\prime} d^{\prime}=0 \\
& \frac{6(i n)}{2} c^{2}+\left[(8.09)\left(0.62 i n^{2}\right)+(8.09-1)\left(0.22 i n^{2}\right)\right] c-(8.09)\left(0.62 i^{2}\right)(6.3125 i n) \\
& \quad-(8.09-1)\left(0.22 i n^{2}\right)(1.562 i n)=0 \\
& (3.00 i n) c^{2}+\left(5.01 i^{2}\right) c+\left(31.6 i n^{3}\right)=0 \\
& \begin{array}{c}
c=2.52 i n \\
I_{c r}=\frac{b c^{3}}{3}+n A_{S}(d-c)^{2}+(n-1) A_{S}\left(c-d^{\prime}\right)^{2} \\
=\frac{(6 i n)(2.52 i n)^{3}}{3}+(8.09)\left(0.62 i n^{2}\right)(6.3125 i n-2.52 i n)^{2} \\
\quad+(8.09-1)\left(0.22 i n^{2}\right)(2.52 i n-1.562 i n)^{2}
\end{array} \\
& \begin{array}{l}
I_{c r}=104 i n^{4}
\end{array}
\end{aligned}
$$

Find the effective moment inertia of the cracked section:

\section{Dead Load:}

Dead Load: $M_{a}=\frac{\omega L^{2}}{8}=\frac{\left(4.17 \frac{\mathrm{lbs}}{\mathrm{in}}\right)(96 \mathrm{in})^{2}}{8}$ $M_{a}=4,800$ in lbs

$\frac{M_{c r}}{M_{a}}=\frac{M_{c r}}{M_{a}}=\frac{32,353 \mathrm{in} \cdot \mathrm{lbs}}{4,800 \mathrm{in} \cdot \mathrm{lbs}}$

$\frac{M_{c r}}{M_{a}}=6.74>1.0, \therefore$ the beam will not crack under its own self-weight

$$
\therefore I_{e}=I_{g}=278 \text { in }^{4}
$$

\section{Dead Load + Live Load}

Live Load: $M_{a}=\frac{P L}{3}=\frac{\left(4.17 \frac{\mathrm{lbs}}{\mathrm{in}}\right)(96 \mathrm{in})}{3}$

$M_{a}=198,322$ in lbs

Dead Load + Live Load: $M_{a}=4,800 i n \cdot l b s+198,322 i n \cdot l b s$ $M_{a}=203,122$ in lbs 


$$
\begin{aligned}
& \frac{M_{c r}}{M_{a}}=\frac{M_{c r}}{M_{a}}=\frac{32,353 \mathrm{in} \cdot \mathrm{lbs}}{203,122 \mathrm{in} \cdot \mathrm{lbs}} \\
& \frac{M_{c r}}{M_{a}}=0.16 \\
& I_{e}=\left(\frac{M_{c r}}{M_{a}}\right)^{3} I_{g}+\left[1-\left(\frac{M_{c r}}{M_{a}}\right)^{3}\right] I_{c r}=(0.16)^{3}\left(278 \mathrm{in}^{4}\right)+\left[1-(0.16)^{3}\right]\left(104 \mathrm{in}^{4}\right) \\
& I_{e}=104.8 \mathrm{in}^{4}
\end{aligned}
$$

\section{Calculate Live Load Deflection:}

$\Delta_{L} M / I=\frac{L^{2}}{8 E_{c}}=\left[\frac{(96 \mathrm{in})^{2}}{8(3,586,616 p s i)}\right]$

$\Delta_{L} M / I=0.00027 \frac{\mathrm{lbs}}{\mathrm{in}}$

$\Delta_{L} M / I=\frac{5 L}{48 E_{c}}=\frac{5(96 \mathrm{in})}{48(3,586,616 p s i)}$

$\Delta_{L} M / I=0.00027 \frac{\mathrm{lbs}}{\mathrm{in}}$

$$
\begin{aligned}
\Delta_{L} & =\frac{\left(\Delta_{L} M / I\right)\left(M_{a, L L}\right)+\left(\Delta_{D} M / I\right)\left(M_{a, D L}\right)}{I_{e, L L}}-\frac{\left(\Delta_{D} M / I\right)\left(M_{a, D L}\right)}{I_{e, D L}} \\
& =\frac{\left(0.00027 \frac{\mathrm{lbs}}{\mathrm{in}}\right)(198,322 \mathrm{in} \cdot \mathrm{lbs})+(0.00027 \mathrm{in})(4,800 \mathrm{in} \cdot \mathrm{lbs})}{104.8 \mathrm{in}^{4}}-\frac{\left(0.00027 \frac{\mathrm{in}}{\mathrm{lbs}}\right)(4,800 \mathrm{in} \cdot \mathrm{lbs})}{278 \mathrm{in}^{4}} \\
\Delta_{L} & =0.53 \mathrm{in}
\end{aligned}
$$

\section{Design for Shear:}

(a) 6"from end:

(a) Critical Section 6":

$$
V_{u}=\left(\frac{\frac{L}{2}-6 i n}{\frac{L}{2}}\right)\left(\frac{1.2 \omega_{D} \frac{L}{2}}{2}\right)+1.6 P
$$

$$
=\left[\frac{\left(\frac{96 i n}{2}\right)-6 i n}{\left(\frac{96 i n}{2}\right)}\right]\left[\frac{1.2\left(50 \frac{\mathrm{lbs}}{f t}\right)(8 f t)}{2}\right]+1.6(3,000 \mathrm{lbs})
$$

$V_{u}=5,010 \mathrm{lbs}$ 
$\lambda=1$

$V_{c}=2 \lambda \sqrt{f_{c}} b d=2(1) \sqrt{3,500 p \sin }(6 \mathrm{in})(6.3125 \mathrm{in})$

$V_{c}=4,481 \mathrm{lbs}$

If $8 \sqrt{f_{c}{ }^{\prime}} b d>\frac{V_{u}}{\phi}-V_{c}$, then section is adequate for shear stirrups

$8 \sqrt{3,500 p s i}(6 i n)(6.3125 i n)=17,962 l b s>\frac{5,010 l b s}{0.75}-4,481 l b s=2,199 l b s$

$\therefore$ Section is adequate

If $V_{u}>\frac{0.75 V_{c}}{2}$, then stirrups are not necessary

$5,010 \mathrm{lbs}>\frac{0.75(4,481 \mathrm{lbs})}{2}=1,681 \mathrm{lbs}$

$\therefore$ Stirrups are necessary in this location

Check that $\phi V_{c}<V_{u}$

$0.75(4,481 l b s)=3,361 l b s<5,010 l b s \quad \checkmark$ O.K

*Use \#3 stirrups

$A_{v}=2\left(0.11 \mathrm{in}^{2}\right)$

$A_{v}=0.22 \mathrm{in}^{2}$

Check that $\left(\frac{V_{u}}{\phi}\right)-V_{c}<4 \sqrt{f_{c}{ }^{\prime}} b d$ $\left(\frac{5,010 l b s}{0.75}\right)-4,481 l b s=2,199 l b s<4 \sqrt{3,500 l b s}(6 i n)(6.3125 i n)=8,963 l b s \quad \checkmark$ O.K

$s=\left\{\begin{array}{l}\frac{A_{v} f_{v} d}{\frac{V_{u}}{0.75}-V_{c}}=\frac{\left(0.22 \mathrm{in}^{2}\right)(60,000 \mathrm{psi})(6.3125 \mathrm{in})}{\frac{5,010}{0.75}-4,481 \mathrm{lbs}}=37.90 \mathrm{in} \\ \frac{d}{2}=\frac{6.3125 \mathrm{in}}{2}=3.16 \mathrm{in}\end{array}\right\}$ Lesser of two values

$s=3.16 \mathrm{in}$ 
(a) 32" from end:

(a) Critical Section 32":

$$
V_{u}=\left(\frac{\frac{L}{2}-32 i n}{\frac{L}{2}}\right)\left(\frac{1.2 \omega_{D} \frac{L}{2}}{2}\right)+1.6 P
$$

$$
=\left[\frac{\left(\frac{96 i n}{2}\right)-32 i n}{\left(\frac{96 i n}{2}\right)}\right]\left[\frac{1.2\left(50 \frac{\mathrm{lbs}}{f t}\right)(8 f t)}{2}\right]+1.6(3,000 \mathrm{lbs})
$$

$V_{u}=4,880 \mathrm{lbs}$

$\lambda=1$

$V_{c}=2 \lambda \sqrt{f_{c}{ }^{\prime}} b d=2(1) \sqrt{3,500 p \sin }(6 \mathrm{in})(6.3125 \mathrm{in})$

$V_{c}=4,481 \mathrm{lbs}$

If $8 \sqrt{f_{c}{ }^{\prime}} b d>\frac{V_{u}}{\phi}-V_{c}$, then section is adequate for shear stirrups

$8 \sqrt{3,500 p s i}(6 i n)(6.3125 i n)=17,962 l b s>\frac{4,880 l b s}{0.75}-4,481 l b s=2,025 l b s$

$\therefore$ Section is adequate

If $V_{u}>\frac{0.75 V_{c}}{2}$, then stirrups are not necessary

$4,880 \mathrm{lbs}>\frac{0.75(4,481 \mathrm{lbs})}{2}=1,681 \mathrm{lbs}$

$\therefore$ Stirrups are necessary in this location

Check that $\phi V_{c}<V_{u}$

$0.75(4,481 l b s)=3,361 l b s<4,880 l b s \quad \checkmark$ O.K

*Use \#3 stirrups

$A_{v}=2\left(0.11 \mathrm{in}^{2}\right)$

$A_{v}=0.22 \mathrm{in}^{2}$

Check that $\left(\frac{V_{u}}{\phi}\right)-V_{c}<4 \sqrt{f_{c}{ }^{\prime}} b d$ 


$$
\begin{aligned}
& \left(\frac{4,880 l b s}{0.75}\right)-4,481 l b s=2,025 l b s<4 \sqrt{3,500 l b s}(6 \text { in })(6.3125 i n)=8,963 l b s \quad \checkmark \text { O.K } \\
& s=\left\{\begin{array}{l}
\frac{A_{v} f_{v} d}{\frac{V_{u}}{0.75}-V_{c}}=\frac{\left(0.22 \mathrm{in}^{2}\right)(60,000 \mathrm{psi})(6.3125 \mathrm{in})}{\frac{4,880}{0.75}-4,481 \mathrm{lbs}}=41.14 \mathrm{in} \\
\frac{d}{2}=\frac{6.3125 \mathrm{in}}{2}=3.16 \mathrm{in}
\end{array}\right\} \text { Lesser of two values } \\
& S=3.16 \mathrm{in}
\end{aligned}
$$

\section{A.3 Part II Specimen Design and Commentary}

\section{Material Properties and Geometry:}

$$
\begin{aligned}
& f_{c}^{\prime}=2,500 \mathrm{psi} \\
& f_{\gamma}=60,000 \mathrm{psi} \\
& \omega_{c}=150 \mathrm{lbs} / \mathrm{ft}^{3} \\
& E_{s}=29,000,000 \mathrm{psi} \\
& E_{c}=33 \omega_{c} \sqrt{f_{c}{ }^{\prime}}=33\left(150 \frac{\mathrm{lbs}}{f t^{3}}\right) \sqrt{2,500 p s i} \\
& E_{c}=3,031,244 \text { psi } \\
& L=72 \text { in } \\
& t_{\min }=6 \mathrm{in} \\
& h=8 \text { in } \\
& b=6 \text { in } \\
& \text { Stirrup Diameter }=0.375 \text { in } \\
& d_{\min }=6 \text { in } \\
& d=6.375 \text { in }
\end{aligned}
$$


$b / d=0.94$

Find Loads and Moments:

$\omega_{D}=\omega_{c} \times b \times h=150 \frac{\mathrm{lbs}}{f^{3}} \times 6$ in $\times 8$ in

$\omega_{D}=50 \frac{\mathrm{lbs}}{\mathrm{ft}}$

$P=3,150 \mathrm{lbs}$

$1.2 \omega_{D}=1.2\left(50.0 \frac{\mathrm{lbs}}{\mathrm{ft}}\right)=60.0 \frac{\mathrm{lbs}}{\mathrm{ft}}$

$1.2 \omega_{D}=60.0 \frac{\mathrm{lbs}}{\mathrm{ft}}$

$P_{L}=1.6 P=1.6(3,150 \mathrm{lbs})$

$P_{L}=5,040 \mathrm{lbs}$

$M_{L}=\frac{P L}{3}=\frac{(5,040 \mathrm{lbs})(72 \mathrm{in})}{3}$

$M_{L}=100,800 \mathrm{in} \cdot \mathrm{lbs}$

$M_{D}=\frac{\omega_{D} L^{2}}{8}=\frac{\left(60 \frac{\mathrm{lbs}}{\mathrm{ft}} \times \frac{1 \mathrm{ft}}{12 i n}\right)(72 \mathrm{in})^{2}}{8}$

$M_{D}=3,240 \mathrm{in} l b s$

$M_{u}=M_{D}+M_{L}=(3,240 \mathrm{in} \cdot \mathrm{lbs})(100,800 \mathrm{in} \cdot \mathrm{lbs})$

$M_{u}=104,040 \mathrm{in} \cdot \mathrm{lbs}$

$M_{n}=\frac{M_{u}}{\phi}=\frac{104,040 \mathrm{in} \cdot \mathrm{lbs}}{0.90}$

$M_{n}=115,600 \mathrm{in} \cdot \mathrm{lbs}$

Design Reinforced Concrete Beam:

$c_{b}=d\left(\frac{0.003}{0.003+\frac{f_{y}}{E_{s}}}\right)=6.375 \mathrm{in}\left(\frac{0.003}{0.003+\frac{60,000 p s i}{29,000,000 p s i}}\right)$

$\underline{c_{b}}=3.77 \mathrm{in}$ 
$c=0.5 c_{b}=0.5(3.74 i n) 7$

$c=1.89 \mathrm{in}$

$\beta_{1}=0.85$

$a=\beta_{1} c=0.85(1.89 \mathrm{in})$

$a=1.60 \mathrm{in}$

$C=0.85 f_{c}^{\prime} b a=0.85(2,500 p s i)(6 i n)(1.60 i n)$

$C=20,445 l b s$

$C=T=20,445 \mathrm{lbs}$

$A_{s, r e q}=\frac{T}{f_{y}}=\frac{20,445 \mathrm{lbs}}{60,000 \mathrm{psi}}$

$A_{\text {s,req }}=0.34 \mathrm{in}^{2}$

Number of Bars $=2$ bars

Bar Diameter $=0.500 \mathrm{in}$

$d_{M A X}=h-$ cover thickness - stirrup diameter $-($ tension bar diameter / 2$)$

$=8$ in -1 in $-0.375 i n-\frac{0.500 i n}{2}$

$d_{M A X}=6.375$ in

Minimum Allowable Spacing $=1$ in

Spacing $=1$ in

Allowable Cover that applies $=1$ in

Total width of bars, stirrups, and cover $=5.75 \mathrm{in}<b=6 \mathrm{in} \quad \checkmark$ O.K

$A_{S}=2 \times 0.20 \mathrm{in}^{2}$
$A_{S}=0.40 \mathrm{in}^{2}$

$a=\frac{A_{S} f_{y}}{0.85 f_{c}^{\prime} b}=\frac{\left(0.40 \mathrm{in}^{2}\right)(60,000 \mathrm{psi})}{0.85(2,500 \mathrm{psi})(6 \mathrm{in})}$

$a=1.88 \mathrm{in}$ 


$$
\begin{aligned}
& c=\frac{a}{\beta_{1}}=\frac{1.88 \mathrm{in}}{0.85} \\
& c=2.21 \mathrm{in} \\
& \varepsilon_{t}=0.003\left(\frac{d-c}{c}\right)=0.003\left(\frac{6.375 \mathrm{in}-2.21 \mathrm{in}}{2.21 \mathrm{in}}\right) \\
& \varepsilon_{t}=0.0056 \\
& \varepsilon_{t}=0.0056>0.005 \therefore \phi=0.9 \text { since steel reinforcement yielded }
\end{aligned}
$$

\section{Analyze Doubly Reinforced Beam:}

$d^{\prime}=1.562$ in

Diameter of Compression Steel $=0.375 \mathrm{in}$

$$
\begin{aligned}
& \begin{array}{l}
A_{S}{ }^{\prime}=2 \times 0.11 \mathrm{in}^{2} \\
A_{S}{ }^{\prime}=0.22 \mathrm{in}^{2}
\end{array} \\
& \rho_{\text {min }}=\left\{\begin{array}{l}
3 \sqrt{\frac{f_{c}^{\prime}}{f_{y}}}=3 \sqrt{\frac{2,500 p s i}{60,000 p s i}}=0.0025 \\
200 f_{y}=200(60,000 p s i)=0.0033
\end{array}\right\} \text { Greater of 2 Values } \\
& \rho_{\min }=0.0033 \\
& \rho=\frac{A_{S}}{b d}=\frac{0.40 \mathrm{in}^{2}}{(6 \mathrm{in})(6.375 \mathrm{in})} \\
& \rho=0.0105 \\
& \rho^{\prime}=\frac{A_{S}^{\prime}}{b d}=\frac{0.22 \mathrm{in}^{2}}{(6 \mathrm{in})(6.375 \mathrm{in})} \\
& \rho=0.0058 \\
& A_{S 1}=A_{S}-A_{S}{ }^{\prime}=0.40 i n^{2}-0.22 i n^{2} \\
& A_{S 1}=0.18 \mathrm{in}^{2} \\
& \begin{array}{l}
\rho-\rho^{\prime}=0.0105-0.0058 \\
\rho-\rho=0.00471
\end{array}
\end{aligned}
$$


$f_{S, \text { artificial }}=87,000\left[\frac{1-0.85 \beta_{1} f_{c}^{\prime} d^{\prime}}{\left(\rho-\rho^{\prime}\right) f_{y} d}\right]=87,000\left[1-\frac{0.85(0.85)(2,500 \mathrm{psi})(1.5625 \mathrm{in})}{(0.0047)(60,000 \mathrm{psi})(6.375 \mathrm{in})}\right]$

$f_{s, \text { artificial }}=-49,410 p$ si

$a=\frac{A_{S} f_{y}-A_{S}^{\prime} f_{s}^{\prime}}{0.85 f_{c}^{\prime} b}=\frac{\left(0.40 \mathrm{in}^{2}\right)(60,000 \mathrm{psi})-\left(0.22 \mathrm{in}^{2}\right)(-49,410 \mathrm{psi})}{0.85(2,500 \mathrm{psi})(6 \mathrm{in})}$

$a=2.73 \mathrm{in}$

$c=\frac{a}{\beta_{1}}=\frac{2.73 \mathrm{in}}{0.85}$

$c=3.22$ in

Strain at tension face of beam $=0.003$

$\varepsilon_{S}{ }^{\prime}=\frac{0.003-d^{\prime}}{c}=\frac{0.003-1.562 \mathrm{in}}{3.22 \mathrm{in}}$

$\varepsilon_{S}=0.00154$

$f_{S}^{\prime}=\varepsilon_{s}{ }^{\prime} E_{s}=0.00154(29,000,000)$

$f_{S}^{\prime}=44,751 p s i$

$a=\frac{A_{S} f_{y}-A_{S}^{\prime} f_{S}^{\prime}}{0.85 f_{c}^{\prime} b}=\frac{\left(0.40 \mathrm{in}^{2}\right)(60,000 \mathrm{psi})-\left(0.22 \mathrm{in}^{2}\right)(44,751 \mathrm{psi})}{0.85(2,500 \mathrm{psi})(6 \mathrm{in})}$

$a=1.11$ in

$c=\frac{a}{\beta_{1}}=\frac{1.11 \mathrm{in}}{0.85}$

$c=1.31$ in

$\varepsilon_{t}=0.003\left(\frac{d-c}{c}\right)=0.003\left(\frac{6.375 \mathrm{in}-1.31 \mathrm{in}}{1.31 \mathrm{in}}\right)$

$\varepsilon_{t}=0.0116 \geq 0.005 \therefore \phi=0.9$ since steel reinforcement yielded 


$$
\begin{aligned}
& M_{n}=\left(A_{S} f_{y}-A_{S}^{\prime} f_{S}^{\prime}\right)\left(d-\frac{a}{2}\right)+A_{S} f_{S}^{\prime}\left(d-d^{\prime}\right) \\
& =\left[\left(0.40 \mathrm{in}^{2}\right)(60,000 \mathrm{psi})-\left(0.22 \mathrm{in}^{2}\right)(44,751 \mathrm{psi})\right]\left(6.375 \mathrm{in}-\frac{1.1 \mathrm{in}}{2}\right) \\
& \quad+\left(0.22 \mathrm{in}^{2}\right)(44,750 \mathrm{psi})(6.375 \mathrm{in}-1.562 \mathrm{in}) \\
& \begin{array}{l}
M_{n}=129,760 \mathrm{lbs} \cdot \mathrm{in} \\
M_{n}=10.8 f t \mathrm{k}
\end{array} \\
& P=\frac{3}{L}\left(M_{n}-\frac{\omega_{D} L^{2}}{8}\right)=\frac{3}{72 \mathrm{in}}\left[(129,760 \mathrm{in} \cdot \mathrm{lbs})-\frac{\left(4.17 \frac{\mathrm{lbs}}{\mathrm{in}}\right)(72 \mathrm{in})^{2}}{8}\right] \\
& P=6,488 \mathrm{lbs} \\
& M_{u}=\phi M_{n}=0.90(129,760 \mathrm{in} \cdot \mathrm{lbs}) \\
& M_{u}=116,784 \mathrm{in} \mathrm{lbs}
\end{aligned}
$$

\section{Calculate cracking moment, load, and moment of inertia:}

$$
\begin{aligned}
& n=\frac{E_{S}}{E_{C}}=\frac{29,000,000 p s i}{3,031,244 p s i} \\
& n=9.57 \\
& \bar{y}=\frac{\left(\frac{b h^{2}}{2}\right)+(n+1) A_{S} d}{b h+(n-1) A_{S}}=\frac{\left[\frac{(6 i n)(8 i n)^{2}}{2}\right]+9.75\left(0.40 i^{2}\right)(6.375 i n)}{(6 i n)(8 i n)+(9.75+1)\left(0.40 i n^{2}\right)} \\
& \bar{y}=4.16 i n \\
& I_{g t}=\frac{b h^{3}}{12}+b h\left(\bar{y}-\frac{h}{2}\right)^{2}+(n-1) A_{S}(d-\bar{y})^{2} \\
& =\frac{(6 i n)(8 i n)^{3}}{12}+(6 i n)(8 i n)\left(4.16 i n-\frac{8 i n}{2}\right)^{2}+(9.75-1)\left(0.40 i n^{2}\right)(6.375 i n-4.16 i n)^{2} \\
& I_{g t}=274 i n^{4} \\
& y_{t}=h-\bar{y}=8 i n-4.16 i n \\
& y_{t}=3.84 i n \\
& f_{r}=7.5 \sqrt{f_{c}^{\prime}}=7.5 \sqrt{2,500 p s i} \\
& f_{r}=375.0 p s i
\end{aligned}
$$




$$
\begin{aligned}
& M_{c r}=\frac{I_{g t} f_{r}}{y_{t}}=\frac{\left(274 \mathrm{in}^{4}\right)(375.0 \mathrm{psi})}{3.84 i n} \\
& M_{c r}=26,750 \mathrm{in} l \mathrm{lbs} \\
& M_{c r}=2.2 \mathrm{ft} \mathrm{k} \\
& P_{c r}=\frac{3}{L}\left(M_{c r}-\frac{\omega_{D} L^{2}}{8}\right)=\frac{3}{72 i n}\left[(26,750 \mathrm{in} \cdot \mathrm{lbs})-\frac{\left(4.17 \frac{\mathrm{lbs}}{\mathrm{in}}\right)(72 \mathrm{in})^{2}}{8}\right] \\
& P_{c r}=1,115 \mathrm{lbs}
\end{aligned}
$$

"c" is found by solving the following quadratic equation:

$$
\begin{aligned}
& \frac{b c^{2}}{2}+\left[n A_{S}+(n-1) A_{S}^{\prime}\right] c-n A_{S} d-(n-1) A_{S}^{\prime} d^{\prime}=0 \\
& \frac{6(i n)}{2} c^{2}+\left[(9.57)\left(0.40 i^{2}\right)+(9.57-1)\left(0.40 i^{2}\right)\right] c-(9.57)\left(0.40 i^{2}\right)(6.375 i n) \\
& \quad-(9.57-1)\left(0.22 i n^{2}\right)(1.562 i n)=0 \\
& (3.00 i n) c^{2}+\left(3.83 i^{2}\right) c+\left(24.4 i^{3}\right)=0 \\
& \begin{array}{c}
c=2.28 i n \\
I_{c r}=\frac{b c^{3}}{3}+n A_{S}(d-c)^{2}+(n-1) A_{S}^{\prime}\left(c-d^{\prime}\right)^{2} \\
=\frac{(6 i n)(2.28 i n)^{3}}{3}+(9.57)\left(0.40 i n^{2}\right)(6.375 i n-2.28 i n)^{2} \\
\quad+(9.57-1)\left(0.22 i^{2}\right)(2.28 i n-1.562 i n)^{2}
\end{array} \\
& I_{c r}=88 i n^{4}
\end{aligned}
$$

Find the effective moment inertia of the cracked section:

\section{Dead Load:}

Dead Load: $M_{a}=\frac{\omega L^{2}}{8}=\frac{\left(4.17 \frac{\mathrm{lbs}}{i n}\right)(72 i n)^{2}}{8}$

$M_{a}=2,700 \mathrm{in} l b s$ 
$\frac{M_{c r}}{M_{a}}=\frac{M_{c r}}{M_{a}}=\frac{26,750 \mathrm{in} \cdot \mathrm{lbs}}{2,700 \mathrm{in} \cdot \mathrm{lbs}}$

$\frac{M_{c r}}{M_{a}}=9.91>1.0, \therefore$ the beam will not crack under its own self-weight

$\therefore I_{e}=I_{g}=274$ in $^{4}$

Dead Load + Live Load

Live Load: $M_{a}=\frac{P L}{3}=\frac{\left(4.17 \frac{\mathrm{lbs}}{\mathrm{in}}\right)(72 \mathrm{in})}{3}$

$M_{a}=155,712$ in lbs

Dead Load + Live Load: $M_{a}=2,700 \mathrm{in} \cdot l b s+155,712 \mathrm{in} \cdot l b s$

$M_{a}=158,412$ in lbs

$\frac{M_{c r}}{M_{a}}=\frac{M_{c r}}{M_{a}}=\frac{26,750 \mathrm{in} \cdot \mathrm{lbs}}{158,412 \mathrm{in} \cdot \mathrm{lbs}}$

$\frac{M_{c r}}{M_{a}}=0.17$

$I_{e}=\left(\frac{M_{c r}}{M_{a}}\right)^{3} I_{g}+\left[1-\left(\frac{M_{c r}}{M_{a}}\right)^{3}\right] I_{c r}=(0.17)^{3}\left(274 i i^{4}\right)+\left[1-(0.17)^{3}\right]\left(88 i n^{4}\right)$

$I_{e}=88.7 \mathrm{in}^{4}$

\section{Calculate Live Load Deflection:}

$\Delta_{L} M / I=\frac{L^{2}}{8 E_{c}}=\left[\frac{(72 i n)^{2}}{8(3,031,244 p s i)}\right]$

$\Delta_{L} M / I=0.00021 \frac{l b s}{i n}$

$\Delta_{L} M / I=\frac{5 L}{48 E_{c}}=\frac{5(72 \mathrm{in})}{48(3,031,244 p s i)}$

$\Delta_{L} M / I=0.00018 \frac{\mathrm{lbs}}{\mathrm{in}}$ 


$$
\begin{aligned}
\Delta_{L} & =\frac{\left(\Delta_{L} M / I\right)\left(M_{a, L L}\right)+\left(\Delta_{D} M / I\right)\left(M_{a, D L}\right)}{I_{e, L L}}-\frac{\left(\Delta_{D} M / I\right)\left(M_{a, D L}\right)}{I_{e, D L}} \\
& =\frac{\left(0.00021 \frac{\mathrm{lbs}}{\mathrm{in}}\right)(198,322 \mathrm{in} \cdot \mathrm{lbs})+(0.00018 \mathrm{in})(4,800 \mathrm{in} \cdot \mathrm{lbs})}{88.7 \mathrm{in}^{4}}-\frac{\left(0.00018 \frac{\mathrm{in}}{l b s}\right)(4,800 \mathrm{in} \cdot \mathrm{lbs})}{274 \mathrm{in}^{4}} \\
\Delta_{L} & =0.37 \mathrm{in}
\end{aligned}
$$

\section{Design for Shear:}

(a) 6rom end:

(a) Critical Section 6":

$$
V_{u}=\left(\frac{\frac{L}{2}-6 i n}{\frac{L}{2}}\right)\left(\frac{1.2 \omega_{D} \frac{L}{2}}{2}\right)+1.6 P
$$

$V_{u}=5,190 \mathrm{lbs}$

$$
=\left[\frac{\left(\frac{72 i n}{2}\right)-6 i n}{\left(\frac{72 i n}{2}\right)}\right]\left[\frac{1.2\left(50 \frac{\mathrm{lbs}}{\mathrm{ft}}\right)(8 \mathrm{ft})}{2}\right]+1.6(3,150 \mathrm{lbs})
$$

$\lambda=1$

$V_{c}=2 \lambda \sqrt{f_{c}{ }^{\prime}} b d=2(1) \sqrt{2,500 p \sin }(6 \mathrm{in})(6.375 \mathrm{in})$

$V_{c}=3,825 \mathrm{lbs}$

If $8 \sqrt{f_{c}{ }^{\prime}} b d>\frac{V_{u}}{\phi}-V_{c}$, then section is adequate for shear stirrups

$8 \sqrt{2,500 p s i}(6 \mathrm{in})(6.375 \mathrm{in})=15,300 \mathrm{lbs}>\frac{5,190 \mathrm{lbs}}{0.75}-3,825 \mathrm{lbs}=3,095 \mathrm{lbs}$

$\therefore$ Section is adequate

If $V_{u}>\frac{0.75 V_{c}}{2}$, then stirrups are not necessary

$5,190 \mathrm{lbs}>\frac{0.75(3,825 \mathrm{lbs})}{2}=1,434 \mathrm{lbs}$

$\therefore$ Stirrups are necessary in this location

Check that $\phi V_{c}<V_{u}$

$0.75(3,825 l b s)=2,869 l b s<5,190 l b s \quad \checkmark$ O.K 
*Use \#3 stirrups

$A_{v}=2\left(0.11 i n^{2}\right)$
$A_{v}=0.22 i n^{2}$

Check that $\left(\frac{V_{u}}{\phi}\right)-V_{c}<4 \sqrt{f_{c}{ }^{\prime}} b d$

$\left(\frac{5,190 l b s}{0.75}\right)-3,825 l b s=3,095 l b s<4 \sqrt{2,500 l b s}(6 i n)(6.375 i n)=7,650 l b s \quad \checkmark$ O.K

$s=\left\{\begin{array}{l}\frac{A_{v} f_{v} d}{\frac{V_{u}}{0.75}-V_{c}}=\frac{\left(0.22 \mathrm{in}^{2}\right)(60,000 \mathrm{psi})(6.375 \mathrm{in})}{\frac{5,190}{0.75}-3,825 \mathrm{lbs}}=27.19 \mathrm{in} \\ \frac{d}{2}=\frac{6.375 \mathrm{in}}{2}=3.19 \mathrm{in}\end{array}\right\}$ Lesser of two values

$s=3.19 \mathrm{in}$

(a) 24" from end:

(a) Critical Section 24":

$$
V_{u}=\left(\frac{\frac{L}{2}-32 i n}{\frac{L}{2}}\right)\left(\frac{1.2 \omega_{D} \frac{L}{2}}{2}\right)+1.6 P
$$

$V_{u}=5,100 \mathrm{lbs}$

$$
=\left[\frac{\left(\frac{72 i n}{2}\right)-32 i n}{\left(\frac{72 i n}{2}\right)}\right]\left[\frac{1.2\left(50 \frac{l b s}{f t}\right)(8 f t)}{2}\right]+1.6(3,150 l b s)
$$

$\lambda=1$

$V_{c}=2 \lambda \sqrt{f_{c}{ }^{\prime}} b d=2(1) \sqrt{2,500 p \sin }(6 \mathrm{in})(6.375 \mathrm{in})$

$V_{c}=3,825 \mathrm{lbs}$

If $8 \sqrt{f_{c}} b d>\frac{V_{u}}{\phi}-V_{c}$, then section is adequate for shear stirrups

$8 \sqrt{2,500 p s i}(6 \mathrm{in})(6.375 \mathrm{in})=15,300 \mathrm{lbs}>\frac{5,100 \mathrm{lbs}}{0.75}-3,825 \mathrm{lbs}=1,434 \mathrm{lbs}$

$\therefore$ Section is adequate 
If $V_{u}>\frac{0.75 V_{c}}{2}$, then stirrups are not necessary

$5,100 \mathrm{lbs}>\frac{0.75(3,825 \mathrm{lbs})}{2}=1,434 \mathrm{lbs}$

$\therefore$ Stirrups are necessary in this location

Check that $\phi V_{c}<V_{u}$

$0.75(3,825 \mathrm{lbs})=2,869 \mathrm{lbs}<5,100 \mathrm{lbs} \quad \checkmark$ O.K

*Use \#3 stirrups

$A_{v}=2\left(0.11 \mathrm{in}^{2}\right)$

$A_{v}=0.22 \mathrm{in}^{2}$

Check that $\left(\frac{V_{u}}{\phi}\right)-V_{c}<4 \sqrt{f_{c}{ }^{\prime}} b d$

$\left(\frac{5,100 l b s}{0.75}\right)-3,825 l b s=2,975 l b s<4 \sqrt{2,500 l b s}(6 i n)(6.375 i n)=7,650 l b s \quad \checkmark$ O.K

$s=\left\{\begin{array}{l}\frac{A_{v} f_{v} d}{\frac{V_{u}}{0.75}-V_{c}}=\frac{\left(0.22 \mathrm{in}^{2}\right)(60,000 \mathrm{psi})(6.375 \mathrm{in})}{\frac{5,100}{0.75}-3,825 \mathrm{lbs}}=28.29 \mathrm{in} \\ \frac{d}{2}=\frac{6.375 \mathrm{in}}{2}=3.19 \mathrm{in}\end{array}\right\}$ Lesser of two values

$s=3.16$ in 


\section{Appendix B: FRP Design Calculations}

\section{B.1 Definition of Variables}

$A_{f}=$ Area of FRP external reinforcement $\left(\mathrm{in}^{2}\right)$

$A_{f v}=$ Area of FRP shear reinforcement with spacing $s\left(\mathrm{in}^{2}\right)$

$A_{g}=$ Gross area of section $\left(\mathrm{in}^{2}\right)$

$A_{s}=$ Area of steel reinforcement $\left(\mathrm{in}^{2}\right)$

$A_{s, c}=$ Corroded area of steel $\left(\right.$ in $\left.^{2}\right)$

$A_{s t}=$ Total area of longitudinal reinforcement $\left(\mathrm{in}^{2}\right)$

$b=$ Width of rectangular cross section (in)

$c=$ Distance from extreme compression fiber to the neutral axis (in)

$C_{E}=$ Environmental-reduction factor

$d$ = Distance from extreme compression fiber to the neutral axis (in)

$d_{f}=$ Depth of FRP shear reinforcement (in)

$E_{c}=$ Modulus of elasticity of concrete (psi)

$E_{f}=$ Tensile modulus of elasticity of FRP (psi)

$E_{s}=$ Modulus of elasticity of steel (psi)

$f_{c}=$ Compressive stress in concrete (psi)

$f_{c}$, $=$ Specified compressive strength of concrete (psi)

$f_{f}=$ Stress level in the FRP reinforcement, psi (MPa)

$f_{f, s}=$ Stress level in the FRP caused by a moment within the elastic range of the member (psi)

$f_{f e}=$ Effective stress in the FRP; stress level attained at section failure (psi)

$f_{f u}{ }^{*}=$ Ultimate tensile strength of the FRP material as reported by the manufacturer (psi)

$f_{f u}=$ Design ultimate tensile strength of FRP (psi)

$\overline{f_{f u}}=$ Mean ultimate strength of FRP based on a population of 20 or more tensile tests per ASTM D 3039 (psi)

$f_{l}=$ Confining pressure due to FRP jacket (psi)

$f_{s}=$ Stress in steel reinforcement (psi)

$f_{s, s}=$ Stress level in steel reinforcement at service loads (psi)

$f_{y}=$ Specified yield strength of steel reinforcement (psi)

$h=$ Overall thickness of a member (in)

$I_{c r}=$ Moment of inertia of cracked section transformed to concrete $\left(\mathrm{in}^{4}\right)$

$k=$ Ratio of the depth of the neutral axis to the reinforcement depth measured on the same side of neutral axis

$k_{f}=$ Stiffness per unit width per ply of the FRP reinforcement (lb/in)

$k_{1}=$ Modification factor applied to $\mathrm{k}_{v}$ to account for the concrete strength

$k_{2}=$ Modification factor applied to $\mathrm{k}_{v}$ to account for the wrapping scheme

$L_{e}=$ Active bond length of FRP laminate (in)

$l_{d f}=$ Development length of FRP system (in) 
$M_{c r}=$ Cracking moment (in $\left.\cdot \mathrm{lb}\right)$

$M_{D L}=$ Dead Load Moment

$M_{L L}=$ Live Load Moment

$M_{n}=$ Nominal moment strength (in $\left.\cdot 1 \mathrm{~b}\right)$

$M_{s}=$ Moment within the elastic range of the member (in $\left.\cdot \mathrm{lb}\right)$

$M_{u}=$ Factored moment at section (in $\cdot 1 \mathrm{~b}$ )

$N=$ Number of plies of FRP reinforcement

$p_{f u}=$ Ultimate tensile strength per unit width per play of the FRP reinforcement (lb/in)

$\overline{p_{f u}}=$ Mean tensile strength per unit width per ply of the reinforcement (lb/in)

$P_{n}=$ Nominal axial load strength at given eccentricity (lb)

$S_{D L}=$ Dead load effects

$s_{f}=$ Spacing FRP shear reinforcing as (in)

$S_{L L}=$ Live load effects

$t_{f}=$ Nominal thickness of one ply of the FRP reinforcement (in)

$T_{g}=$ Glass-transition temperature $\left({ }^{\circ} \mathrm{F}\right)$

$V_{c}=$ Nominal shear strength provided by concrete with steel flexural reinforcement (lb)

$V_{n}=$ Nominal shear strength (lb)

$V_{s}=$ Nominal shear strength provided by steel stirrups (lb)

$V_{f}=$ Nominal shear strength provided by FRP stirrups, lb

$w_{f}=$ Width of the FRP reinforcing plies (in)

$a=$ Angle of inclination of stirrups or spirals, degrees

$a_{L}=$ Longitudinal coefficient of thermal expansion (in $\left./ \mathrm{in} /{ }^{\circ} \mathrm{F}\right)$

$a_{T}=$ Transverse coefficient of thermal expansion (in./in. $/{ }^{\circ} \mathrm{F}$ )

$b_{1}=$ Ratio of the depth of the equivalent rectangular stress block to the depth of the neutral axis

$\varepsilon_{b}=$ Strain level in the concrete substrate developed by a given bending moment [tension in positive] (in/in)

$\varepsilon_{b i}=$ Strain level in the concrete substrate at the time of the FRP installation [tension is positive] (in/in)

$\varepsilon_{c}=$ Strain level in the concrete, in./in. $(\mathrm{mm} / \mathrm{mm})$

$\varepsilon_{c c}{ }^{\prime}=$ Maximum usable compressive strain of FRP confined concrete (in/in)

$\varepsilon_{c u}=$ Maximum usable compressive strain of concrete (in/in)

$\varepsilon_{f}=$ Strain level in the FRP reinforcement (in/in)

$\varepsilon_{f e}=$ Effective strain level in FRP reinforcement; strain level attained at section failure (in/in)

$\varepsilon_{f u}=$ Design rupture strain of FRP reinforcement (in/in)

$\overline{\varepsilon_{f u}}=$ Mean rupture stain of FRP reinforcement based on a population of 20 or more tensile tests per ASTM D 3039 (in/in)

$\varepsilon_{f_{u}}{ }^{*}=$ Ultimate rupture strain of the FRP reinforcement (in/in)

$\varepsilon_{s}=$ Strain level in the steel reinforcement (in/in)

$\varepsilon_{s y}=$ Strain corresponding to the yield strength of steel reinforcement

$f=$ Strength reduction factor

$g=$ Multiplier on $f_{c}$ ' to determine the intensity of an equivalent rectangular stress distribution for concrete

$k_{a}=$ Efficiency factor for FRP reinforcement (based on the section geometry)

$k_{m}=$ bond-dependent coefficient for flexure 
$k_{v}=$ bond-dependent coefficient for shear

$\rho_{f}=$ FRP reinforcement ratio

$\rho_{g}=$ Ratio of the area of longitudinal steel reinforcement to the cross-sectional area of a compression member

$\rho_{s}=$ Ratio of reinforcement

$\mathrm{y}_{f}=$ Additional FRP strength-reduction factor

$\%_{\text {loss }}=$ Percent mass loss of tension steel

\section{B.2 Part I FRP Design and Commentary}

Material Properties

$f_{c}^{\prime}=3500 \mathrm{psi}$

$f_{y}=60,000 \mathrm{psi}$

$E_{S}=29,000,000 \mathrm{psi}$

$E_{c}=57,000 \sqrt{f_{c}{ }^{\prime}}=57,000 \sqrt{3,500} \mathrm{psi}$
$E_{c}=3,372,165 \mathrm{psi}$

Specimen Geometry

$A_{s}=0.62 \mathrm{in}^{2}$

$b=6$ in

$d=6.3125 \mathrm{in}$

$h=8 \mathrm{in}$

$$
\begin{gathered}
A_{s, c}=A_{s}\left(\frac{100-\%_{\text {loss }}}{100}\right)=0.62 \operatorname{in}^{2}\left(\frac{100-16}{100}\right) \\
A_{s, c}=0.52 \mathrm{in}^{2}
\end{gathered}
$$


Loads:

$M_{D L}=0.4 \mathrm{ft} \cdot \mathrm{k}$

$M_{L L}=16.528 \mathrm{ft} \cdot \mathrm{k}$

Hence, the service load moment applied to the beam is:

$$
\begin{aligned}
M_{s}= & M_{D L}+M_{L L} \\
& M_{S}=16.928 \mathrm{ft} \cdot \mathrm{k}
\end{aligned}
$$

Existing Flexural Unrepaired Capacity of Beam Specimen

Step 1: Determine the depth of the equivalent rectangular stress block assuming all rebar yields:

$0.85 f_{c}^{\prime} a b=A_{s, c} f_{y}$

$\beta_{1}=0.85-0.05 \frac{f_{c}^{\prime}-4000}{1000} \geq 0.85$

$\beta_{1}=0.85$ since $f_{c}$ ' is less than 4000

$a=\frac{A_{s} f_{y}}{0.85 f_{c}^{\prime} b}=\frac{\left(0.52 \mathrm{in}^{2}\right)(60,000 \mathrm{psi})}{0.85(3,500 \mathrm{psi})(6 \mathrm{in})}$

$a=1.75$ in

$c=\frac{a}{\beta_{1}}=\frac{1.75 \mathrm{in}}{0.85}$

$c=2.06$ in

$k=\frac{c}{d}=\frac{2.06 \mathrm{in}}{6.3125 \mathrm{in}}$

$k=0.3258$ 
Step 2: Calculate the Existing Moment Capacity

$$
\begin{aligned}
& M_{n}=A_{s} f_{y}\left(d-\frac{a}{2}\right)=\left(0.52 \mathrm{in}^{2}\right)(60,000 \mathrm{psi})\left(6.3125 \mathrm{in}-\frac{1.75 \mathrm{in}}{2}\right)=169,683 \mathrm{lb} \cdot \mathrm{in} \\
& M_{n}=14.1 \mathrm{ft} \cdot \mathrm{k} \\
& \rho_{s}=\frac{A_{s}}{b d}=\frac{0.52 i n^{2}}{(6 i n)(6.3125 i n)} \\
& \rho_{\mathrm{s}}=0.0137 \\
& \rho_{\min }=3 \frac{\sqrt{f_{c}^{\prime}}}{f_{y}}=3 \frac{\sqrt{3,500 p s i}}{60,000 p s i} \\
& \rho_{\min }=0.0030 \quad \therefore \text { Use } \rho_{s}=0.0074 \\
& \rho_{s}=0.0137>\rho_{\min }=0.0030 \quad \text { Good } \\
& \frac{c}{d}=\frac{2.06 i n}{6.3125 i n} \\
& \frac{c}{d}=0.326<0.375 \quad \text { Good; The following equation is valid } \\
& \varepsilon_{s}=0.003\left(\frac{d-c}{c}\right)=0.003\left(\frac{6.3125 i n-2.06 i n}{2.06 i n}\right) \\
& \varepsilon_{S}=0.0062 \mathrm{in} / \mathrm{in}>0.005 \mathrm{in} / \text { in Good } \\
& \varepsilon_{s y}=\frac{f_{y}}{E_{s}}=\frac{60,000 p s i}{29,000,000 p s i} \\
& \varepsilon_{\mathrm{sy}}=0.002 \mathrm{in} / \mathrm{in}<\varepsilon_{\mathrm{s}}=0.0062 \mathrm{in} / \mathrm{in} \text { Good }
\end{aligned}
$$


Since $\varepsilon_{\mathrm{sy}}<0.005<\varepsilon_{\mathrm{s}}$, The beam is ductile and a nominal strength reduction factor of $\Phi=$ 0.9 may be used.

$$
\begin{gathered}
\phi M_{n}=0.9(7.9 f t \cdot k) \\
M_{n}=14.1 \mathrm{ft} \cdot \mathrm{k}
\end{gathered}
$$

$$
\phi M_{n}=12.7 f t \cdot k<1.2 M_{D L}+0.85 M_{L L}=1.2(0.4 f t \cdot k)+0.85(16.5 f t \cdot k)=14.5 f t \cdot k \quad \text { N.G. }
$$

$\therefore$ The level of strengthening is not acceptable because the criterion of the strength limit is not satisfied. FRP strengthening is needed.

Flexural Strengthening with CFRP

Step 3: Define Material Properties of FRP and Perform Preliminary Calculations The selected composite material is TYFO SCH-7 UP Composite Laminate.

The following material properties are reported by the manufacturer:

$$
\begin{aligned}
f_{f u}^{*} & =130,900 \mathrm{psi} \\
E_{f}^{*} & =12,600,000 \mathrm{psi} \\
\varepsilon_{f_{u}}^{*} & =0.0105 \mathrm{in} / \mathrm{in} \\
t_{f}^{*} & =0.007 \mathrm{in}
\end{aligned}
$$

The material properties provided by the manufacturer do not account for the long-term exposure to environmental conditions that the repair material will eventually undergo. This exposure can cause degrade the tensile properties, the fatigue performance properties, and the creep-rupture of the FRP. Therefore, the initial values of the material 
properties should be reduced by an environmental reduction factor, $C_{E}$. This factor should be selected from ACI 440.2R Table 8.1, which is given below in Table B.1of this paper.

Table B.1: Environmental-Reduction Factor for Various FRP Systems and Exposure Conditions (ACI 440.2R, Table 8.1)

\begin{tabular}{|c|c|c|}
\hline Exposure conditions & Fiber and resin type & $\begin{array}{c}\text { Environmental-reduction } \\
\text { factor } C_{E}\end{array}$ \\
\hline \multirow[t]{3}{*}{ Interior exposure } & Carbon/epoxy & 0.95 \\
\hline & Glass/epoxy & 0.75 \\
\hline & Aramid/epoxy & 0.85 \\
\hline \multirow{3}{*}{$\begin{array}{c}\text { Exterior exposure } \\
\text { (bridges, piers, and } \\
\text { unenclosed parking } \\
\text { garages) }\end{array}$} & Carbon/epoxy & 0.85 \\
\hline & Glass/epoxy & 0.65 \\
\hline & Aramid/epoxy & 0.75 \\
\hline \multirow{3}{*}{$\begin{array}{c}\text { Aggressive } \\
\text { environment (chemical } \\
\text { plants and wastewater } \\
\text { treatment plants) }\end{array}$} & Carbon/epoxy & 0.85 \\
\hline & Glass/epoxy & 0.50 \\
\hline & Aramid/epoxy & 0.70 \\
\hline
\end{tabular}

Since the beam specimens are in a laboratory-controlled environment (interior exposure) and are being strengthened with a carbon/epoxy FRP system,

$C_{E}=0.95$

was selected. In this experimental plan, environmental degradation to the FRP material itself is not planned or expected, so a factor conforming exterior exposure conditions was not needed.

Multiply the tensile strength and strain by the selected environmental reduction factor:

$$
\begin{gathered}
f_{f u}=C_{E} f_{f u}{ }^{*}=0.95(0.0105 \mathrm{in} / \mathrm{in}) \quad \text { (ACI 440-2R Eq. 8-3) } \\
f_{f u}=124,355 \mathrm{psi}
\end{gathered}
$$




$$
\begin{gathered}
\varepsilon_{f u}=C_{E} \varepsilon_{f u}^{*}=0.95(0.0105 \mathrm{in} / \mathrm{in}) \quad \text { (ACI 440-2R Eq. 8-4) } \\
E_{f u}=0.0998 \mathrm{in} / \mathrm{in} \\
\varepsilon_{f u}=\frac{f_{f u}}{\varepsilon_{f u}}=\frac{124,355 \mathrm{psi}}{0.0998} \quad \text { (ACI 440-2R Eq. 8-5) } \\
E_{f}=12,466,667 \mathrm{psi} \\
N=1 \text { Layer }
\end{gathered}
$$

An FRP laminate width was selected to allow concrete edges to either side of the sheet to be grinded to a 1" radius in locations where anchorage stirrups were to be placed:

$w_{f}=4 \mathrm{in}$

Find total the area of the FRP reinforcement and the corresponding FRP reinforcement ratio:

$$
\begin{gathered}
A_{f}=N t_{f} w_{f}=1(0.007 i n)(4 i n) \\
\mathrm{A}_{f}=0.028 \mathrm{in}^{2} \\
\rho_{f}=\frac{A_{f}}{b d}=\frac{0.007 \mathrm{in}^{2}}{(6 i n)(6.3125 \mathrm{in})} \\
\rho_{f}=0.00074
\end{gathered}
$$

Step 4: Determine the Existing State of Strain on the Soffit

The existing state of strain is calculated assuming the beam is cracked and the only loads acting on the beam at the time of the FRP installation are dead loads.

$n_{s}=\frac{E_{s}}{E_{c}}=\frac{29,000,000 p s i}{3,372,165 p s i}$ 


$$
\begin{gathered}
\underline{n_{s}=8.5998} \\
\rho_{s} n_{s}=(0.0137)(8.5998) \\
\rho_{s} n_{s}=0.1181
\end{gathered}
$$

From a cracked section analysis of the pristine beam, the cracked neutral axis depth can be calculated:

$$
\begin{aligned}
& k=\sqrt{\left(\rho_{s} n_{s}\right)^{2}+2\left(\rho_{s} n_{s}\right)}-\left(\rho_{s} n_{s}\right)=\sqrt{(0.1181)^{2}+2(0.1181)}-0.1181 \\
& k=0.382 \\
& c=k d=(0.382)(6.3125 i n) \\
& c=2.41 \mathrm{in}
\end{aligned}
$$

The cracked moment of inertia can then be determined:

$$
\begin{gathered}
I_{c r}=\frac{1}{3} b c^{3}+n_{s} A_{s}(d-c)^{2}=\frac{1}{3}(6 i n)(2.41 i n)^{3}+(8.5998)\left(0.52 i n^{2}\right)(6.3125 i n-2.41 i n)^{2} \\
I_{c r}=96.10 \mathrm{in}^{4}
\end{gathered}
$$

Finally, the initial strain level on the bonded substrate can be ascertained:

$$
\begin{gathered}
\varepsilon_{b i}=\frac{M_{D L}(h-c)}{I_{c r} E_{c}}=\frac{(0.4 k \cdot f t)(8 i n-2.41 i n)}{\left(96.10 i^{4}\right)(3,372,165 p s i)} \\
\varepsilon_{b i}=8.28 \times 10^{-5}
\end{gathered}
$$

Step 5: Determine the Bond-Dependent Coefficient of the FRP System

If the force in the FRP laminate cannot be sustained by the concrete substrate, concrete cover delamination or FRP debonding can occur. The following limitation is placed on 
the strain level developed in the FRP in order to prevent debonding. The dimensionless bond-dependent coefficient for flexure is calculated as follows:

$$
\kappa_{m}=\left\{\begin{array}{l}
\frac{1}{60 \varepsilon_{f u}}\left(1-\frac{n E_{f} t_{f}}{2,000,000}\right) \leq 0.90: n E_{f} t_{f} \leq 1,000,000 \\
\frac{1}{60 \varepsilon_{f u}}\left(\frac{500,000}{n E_{f} t_{f}}\right) \leq 0.90: n E_{f} t_{f}>1,000,000
\end{array}\right.
$$

This equation takes account that stiffer FRP systems have a high tendency to delaminate. As the stiffness increases, the strain limitation escalates. The $n E_{f} t_{f}$ expression represents the unit stiffness of the system. If the unit stiffness is greater than $1,000,000$, the bonddependent coefficient limits force in the laminate instead of the strain level. This factor places an upper limit on the total force allowed in the FRP regardless of the thickness of the laminate system.

$$
n E_{f} t_{f}=2(12,666,667 \text { psi })(0.007 i n)=88,200 \leq 1,000,000
$$

Since in this design $n E_{f} t_{f}<1,000,000$, the strain limit controls and the first equation is used:

$$
\kappa_{m}=\frac{1}{60 \varepsilon_{f u}}\left(1-\frac{n E_{f} t_{f}}{2,000,000}\right)=\frac{1}{60(0.0998)}\left[1-\frac{2(12,466,667 \mathrm{psi})(0.007 \mathrm{in})}{2,000,000}\right]=1.60 \leq 0.9
$$

A greater than 0.9 is not permitted, therefore:

$$
\boldsymbol{\kappa}_{m}=0.9
$$


Step 6: Estimate the Depth to the Neutral Axis

The depth of the neutral axis must be found by trial and error. A good initial estimate for " $c$ " can be found by:

$$
c=\left(1.33 \frac{\varepsilon_{c u}}{\varepsilon_{c u}+\varepsilon_{f u}}\right) d \quad \text { or } \quad c=0.20 d
$$

However, in this example, it was found that:

$c=2.24$ in

This will be the initial "Guess" in this example to demonstrate the design procedure. It will later be verified. It should be noted that this is an iterative process where initially knowing the correct value for " $c$ " is not a luxury.

Step 7: Determine the Effective Level of Strain in the FRP Reinforcement

First, it must be seen if the following equations are valid:

$$
\begin{aligned}
& \frac{c}{d}=\frac{2.24 i n}{3.3125 i n} \\
& \frac{c}{d}=0.355<0.375 \quad \text { Good; The following equation is valid } \\
& \left.\varepsilon_{f e}=0.003\left(\frac{h-c}{c}\right)-\varepsilon_{b i} \leq \kappa_{m} \varepsilon_{f u}\right)
\end{aligned}
$$

If the left-hand side of the expression in this equation controls, it is assumed that the failure mode would be concrete crushing. If the right-hand side controls, then it is presumed that the failure mode would be FRP rupture. 


$$
\begin{aligned}
& \varepsilon_{f e}=0.003\left(\frac{h-c}{c}\right)-\varepsilon_{b i}=0.003\left(\frac{8 i n-6.3125 i n}{6.3125 i n}\right)-8.28 \times 10^{-5}=0.00771 \\
& \varepsilon_{f e}=\kappa_{m} \varepsilon_{f u}=(0.9)(0.00998)=0.00898
\end{aligned}
$$

Since $\varepsilon_{f e}=0.00771<0.00898$, the left-hand side controls and concrete crushing is predicted.

$$
\varepsilon_{f e}=0.00771
$$

Step 8: Calculate the Strain in the Existing Reinforcing Steel

From strain compatibility using similar triangles, the strain in the tension reinforcing steel is calculated:

$$
\begin{gathered}
\varepsilon_{s}=\left(\varepsilon_{f e}+\varepsilon_{b i}\right)\left(\frac{d-c}{h-c}\right)=\left(0.00771+8.28 \times 10^{-5}\right)\left(\frac{6.3125 i n-2.24 i n}{8 i n-2.24 i n}\right) \\
\varepsilon_{s}=0.00551 \mathrm{in} / \mathrm{in} \quad \text { (ACI 440-2R Eq. 9-8) }
\end{gathered}
$$

Step 9: Calculate the Stress Level in Reinforcing Steel and FRP

Stress in the reinforcement is calculated from the strain level in the steel assuming elastic-plastic behavior:

$$
\begin{aligned}
& f_{s}=E_{s} \varepsilon_{s} \leq f_{y} 0-2 \text { R Eq. 9-9) } \\
& f_{s}=E_{s} \varepsilon_{s}=(29,000,000 \mathrm{psi})(0.00551) \times \frac{1 \mathrm{ksi}}{1,000 \mathrm{psi}}=160 \mathrm{ksi} \leq f_{y}=60 \mathrm{ksi}
\end{aligned}
$$

Since steel stress is governed by the yield stress of the reinforcing bars:

$$
f_{s}=60 \mathrm{ksi}
$$


The effective stress level in the FRP reinforcement is the maximum level of stress that can be developed in the FRP reinforcement before flexural failure of the section. Perfectly elastic behavior is assumed:

$$
\begin{gathered}
f_{f e}=E_{f} \varepsilon_{f e}=(12,466,667 p s i)(0.00771) \times \frac{1 k s i}{1,000 p s i} \\
f_{f e}=97.20 \mathrm{ksi}
\end{gathered}
$$

Step 10-Calculate the internal force resultants and check equilibrium

Internal force equilibrium and strain compatibility is verified by checking the initial estimate of the neutral axis depth with the following equation. If concrete crushing is the controlling mode of failure (before or after steel yielding), $\gamma$ and $\beta_{1}$ can be taken as the values associated with the Whitney stress block $\left(\gamma=0.85\right.$ and $\beta_{1}$ from Section 10.2.7.3 of ACI 318-99). If FRP rupture, cover delamination, or FRP-debonding control failure occur, the Whitney stress block yields reasonably accurate results. It should be noted that the actual design process is iterative and the initial "Guess" must be changed until its value equals that given by the following equation:

$$
\begin{aligned}
& c=\frac{A_{s} f_{s}+A_{f} f_{f e}}{\gamma \beta_{1} f_{c}^{\prime} b}=\frac{\left(0.52 \mathrm{in}^{2}\right)(60 \mathrm{ksi})+\left(0.028 \mathrm{in}^{2}\right)(97.20 \mathrm{ksi})}{0.85(0.85)(3,500)(6 \mathrm{in})} \\
& c=2.24 \mathrm{in}=\text { Guess: } 2.24 \mathrm{in} \mathrm{Good;} 2.24 \text { in is the correct neutral axis depth. } \\
& a=\beta_{1} c=0.85(2.24 \mathrm{in}) \\
& a=1.90 \mathrm{in}
\end{aligned}
$$


Step 11-Calculate design flexural strength of the section

First, the strain in the steel at yielding is established:

$$
\begin{gathered}
\varepsilon_{s y}=\left(\frac{f_{y}}{E_{s}}\right)=\frac{60,000 p s i}{29,000,000 p s i} \\
\varepsilon_{s y}=0.00207
\end{gathered}
$$

The strain level in the steel at the ultimate limit state must be checked to ensure sufficient ductility. Adequate ductility is achieved if the strain in the steel at the point of concrete crushing or failure of the FRP, including delamination or debonding, is at least 0.005 , according to the definition of a tension-controlled section as given in Chapter 2 of ACI 318. Because $\varepsilon_{s}=0.00551>0.005$, a strength-reduction factor of $\phi=0.90$ is selected and applied:

$$
\begin{aligned}
\phi=\left\{\begin{array}{l}
0.90: \varepsilon_{s} \geq 0.005 \\
0.70+0.20\left(\frac{\varepsilon_{s}-\varepsilon_{s y}}{0.005-\varepsilon_{s y}}\right)=0.70+0.20\left(\frac{0.00551-0.00207}{0.005-0.00207}\right)=0.935: \varepsilon_{s y}<\varepsilon_{s}<0.005 \\
0.70: \varepsilon_{s} \leq \varepsilon_{s y}
\end{array}\right. \\
\therefore \Phi=0.90
\end{aligned}
$$

An additional reduction factor is applied to the contribution of the FRP system:

$$
\psi=0.85
$$


Finally, the nominal flexural strength of the FRP-strengthened section can be determined:

$$
\begin{aligned}
& \phi M_{n}=\phi\left[A_{s} f_{y}\left(d-\frac{a}{2}\right)+\psi_{f} A_{f r p}\left(E_{f r p} \kappa_{m} \varepsilon_{f r p u}\right)\left(h-\frac{a}{2}\right)\right] \\
& =0.90\left[\begin{array}{l}
\left(0.52 i^{2}\right)(60,000 p s i)\left(6.3125 i n-\frac{1.90 i n}{2}\right)+ \\
(0.85)(0.007 i n)(12,466,667 p s i)\left(8 i n-\frac{1.90 i n}{2}\right)
\end{array}\right] \times \frac{1 f t}{12 i n} \times \frac{1 k i p}{1,000 l b s} \\
& \phi M_{n}=14.0 \mathrm{ft} \cdot \mathrm{k}
\end{aligned}
$$

Step 12-Check service stresses in the reinforcing steel and the FRP

The stress level in the steel reinforcement can be calculated based on a cracked elastic analysis of the FRP-strengthened section, as follows.

First, the elastic depth to the cracked neutral axis can be obtained by adding the first moment of the areas of the transformed section. This value can be sought by the following simplified equation for a rectangular beam:

$$
\begin{aligned}
& k=\sqrt{\left(\rho_{s} n_{s}+\rho_{f} n_{f}\right)^{2}+2\left(\rho_{s} n_{s}+\rho_{f} n_{f}\left(\frac{h}{d}\right)\right)}-\left(\rho_{s} n_{s}+\rho_{f} n_{f}\right) \\
&=\sqrt{(0.1181+0.00276)^{2}+2\left(0.1181+0.00276\left(\frac{8 i n}{6.3125 i n}\right)\right)}-(0.1181+0.00276) \\
& k=0.387
\end{aligned}
$$

The distribution of strain and stress in the reinforced concrete section is illustrated in Figure B.1. As in regular reinforced concrete analysis, the depth to the neutral axis under service loads can be ascertained by taking the first moment of the areas of the transformed section. Although this method ignores the difference in the initial strain 
level of the FRP, the initial strain level does not greatly influence the depth to the neutral axis in the elastic response range of the member.

$k d=(0.387 i n)(6.3125 i n)$

$k d=2.442$ in for service conditions.

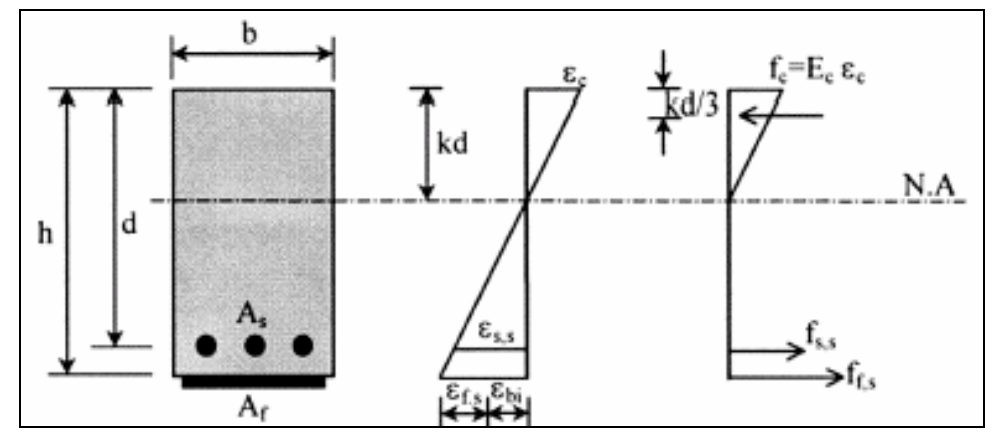

Figure B.1: Elastic Strain and Stress Distribution (ACI 220-R, Fig. 9.3)

Next, the stress level in the reinforcing steel is calculated and it is verified that it is less than recommended limit. The term " $M_{s}$ " represents the moment due to all sustained loads, that is dead loads and the sustained portion of the live load, plus the maximum moment induced in a fatigue loading cycle as shown in Figure B.1.

$$
\begin{aligned}
& f_{s, s}=\frac{\left[M_{s}+A_{f} E_{f} \varepsilon_{b i}\left(h-\frac{k d}{3}\right)\right](d-k d) E_{s}}{A_{s} E_{s}\left(d-\frac{k d}{3}\right)(d-k d)+A_{f} E_{f}\left(h-\frac{k d}{3}\right)(h-k d)} \quad \text { (ACI 440-2R Eq. 9-12) } \\
& f_{s, s}=\frac{\left[16.928 f t \cdot k+\left(0.028 i^{2}\right)(12,466.667 k s i)\left(8.25 \times 10^{-5}\right)\left(8 i n-\frac{2.44 i n}{3}\right)\right](6.3125 i n-2.44 i n)(29,000 k s i)}{\left(0.52 i n^{2}\right)(29,000 k s i)\left(6.3125 i n-\frac{2.44 i n}{3}\right)(6.3125 i n-2.44 i n)+\left(0.028 i^{2}\right)(12,466.667 k s i)\left(8 i n-\frac{2.44 i n}{3}\right)(8 i n-2.44 i n)} \\
& f_{s, s}=68.16 \mathrm{ksi}
\end{aligned}
$$




$$
\begin{gathered}
f_{s, s}=0.80 f_{y}=0.80(60 \mathrm{ksi})=48.00 \mathrm{ksi} \\
f_{s, s}=68.16 \mathrm{ksi}>48.00 \mathrm{ksi} \quad \text { N.G. }
\end{gathered}
$$

The stress in the reinforcing steel at service load conditions is not less than the recommended limit.

Equation (9-13) gives the stress level in the FRP reinforcement under an applied moment within the elastic response range of the member.

$$
\begin{aligned}
& f_{f, s}=f_{s, s}\left(\frac{E_{f}}{E_{s}}\right)\left(\frac{h-k d}{d-k d}\right)-\varepsilon_{b i} E_{f} \\
& f_{f, s}=68.16 k s i\left(\frac{12,466,667 p s i}{29,000,000 p s i}\right)\left(\frac{8 i n-2.44 i n}{6.3125 i n-2.44 i n}\right)-\left(8.28 \times 10^{-5}\right)(12,466.667 k s i) \\
& f_{f, s}=41.04 \\
& f_{f, s}=0.55 f_{f u}=0.55\left(124,355 \mathrm{psi} \times \frac{1 \mathrm{ksi}}{1,000 \mathrm{psi}}\right)=68.40 \mathrm{ksi} \\
& f_{f, s}=41.04 \mathrm{ksi}<68.40 \mathrm{ksi} \quad \text { Good }
\end{aligned}
$$

\section{B.3 Part II FRP Design and Commentary}

$$
\begin{aligned}
& \text { Material Properties } \\
& \begin{array}{l}
f_{c}^{\prime}=2,500 \mathrm{psi} \\
f_{y}=60,000 \mathrm{ps} \\
E_{s}=29,000,000 \mathrm{psi}
\end{array}
\end{aligned}
$$




$$
\begin{gathered}
E_{c}=57,000 \sqrt{f_{c}{ }^{\prime}}=57,000 \sqrt{2,500} \mathrm{psi} \\
E_{c}=2,850,000 \mathrm{psi}
\end{gathered}
$$

Specimen Geometry

$$
\begin{aligned}
& A_{s}=0.40 \mathrm{in}^{2} \\
& b=6 \mathrm{in} \\
& d=6.375 \mathrm{in} \\
& h=8 \mathrm{in} \\
& A_{s, c}=A_{s}\left(\frac{100-\%_{\text {loss }}}{100}\right)=0.40 \mathrm{in}^{2}\left(\frac{100-25}{100}\right) \\
& A_{s, c}=0.30 \mathrm{in}^{2}
\end{aligned}
$$

Loads

$M_{D L}=0.4 \mathrm{ft} \cdot \mathrm{k}$

$M_{L L}=15.0 \mathrm{ft} \cdot \mathrm{k}$

Hence, the service load moment applied to the beam is:

$$
\begin{array}{r}
M_{s}=M_{D L}+M_{L L} \\
M_{s}=15.4 \mathrm{ft} \cdot \mathrm{k}
\end{array}
$$

Existing Flexural Unrepaired Capacity of Beam Specimen

Step 1: Determine the depth of the equivalent rectangular stress block assuming all rebar yields:

$$
\begin{aligned}
& 0.85 f_{c}^{\prime} a b=A_{s, c} f_{y} \\
& \beta_{1}=0.85-0.05 \frac{f_{c}^{\prime}-4000}{1000} \geq 0.85 \\
& \beta_{1}=0.85 \text { since } f_{c}^{\prime} \text { ' is less than } 4000
\end{aligned}
$$




$$
\begin{gathered}
a=\frac{A_{s} f_{y}}{0.85 f_{c}^{\prime} b}=\frac{\left(0.30 \mathrm{in}^{2}\right)(60,000 \mathrm{psi})}{0.85(2,500 \mathrm{psi})(6 \mathrm{in})} \\
a=1.41 \mathrm{in} \\
c=\frac{a}{\beta_{1}}=\frac{1.41 \mathrm{in}}{0.85} \\
c=1.66 \mathrm{in} \\
k=\frac{c}{d}=\frac{1.66 \mathrm{in}}{6.375 \mathrm{in}} \\
k=0.2605
\end{gathered}
$$

Step 2: Calculate the Existing Moment Capacity

$$
\begin{aligned}
& M_{n}=A_{s} f_{y}\left(d-\frac{a}{2}\right)=\left(0.30 \mathrm{in}^{2}\right)(60,000 \mathrm{psi})\left(6.375 \mathrm{in}-\frac{1.41 \mathrm{in}}{2}\right)=102,044 \mathrm{lb} \cdot \mathrm{in} \\
& M_{n}=8.5 \mathrm{ft} \cdot \mathrm{k} \\
& \rho_{s}=\frac{A_{s}}{b d}=\frac{0.30 \mathrm{in}^{2}}{(6 \mathrm{in})(6.375 \mathrm{in})} \\
& \underline{\rho_{\mathrm{s}}=0.0078} \\
& \rho_{\min }=3 \frac{\sqrt{f_{c}^{\prime}}}{f_{y}}=3 \frac{\sqrt{2,500 \mathrm{psi}}}{60,000 \mathrm{psi}} \\
& \rho_{\min }=0.0025 \quad \therefore \text { Use } \rho_{s}=0.0078 \\
& \rho_{s}=0.0078>\rho_{\min }=0.0025 \quad \text { Good } \\
& \frac{c}{d}=\frac{1.66 \mathrm{in}}{6.375 \mathrm{in}} \\
& \frac{c}{d}=0.261<0.375 \quad \text { Good; The following equation is valid }
\end{aligned}
$$




$$
\begin{aligned}
& \varepsilon_{s}=0.003\left(\frac{d-c}{c}\right)=0.003\left(\frac{6.375 i n-1.66 i n}{1.66 i n}\right) \\
& \varepsilon_{s}=0.0085 \mathrm{in} / \mathrm{in}>0.005 \mathrm{in} / \mathrm{in} \quad \text { Good } \\
& \varepsilon_{s y}=\frac{f_{y}}{E_{s}}=\frac{60,000 p s i}{29,000,000 p s i} \\
& \varepsilon_{\mathrm{sy}}=0.002 \mathrm{in} / \mathrm{in}<\varepsilon_{\mathrm{s}}=0.0085 \mathrm{in} / \mathrm{in} \text { Good }
\end{aligned}
$$

Since $\varepsilon_{\mathrm{sy}}<0.005<\varepsilon_{\mathrm{s}}$, The beam is ductile and a nominal strength reduction factor of $\Phi=$ 0.9 may be used.

$$
\begin{gathered}
\phi M_{n}=0.9(8.5 f t \cdot k) \\
\phi M_{n}=7.7 \mathrm{ft} \cdot \mathrm{k}
\end{gathered}
$$$$
\phi M_{n}=7.7 f t \cdot k<1.2 M_{D L}+0.85 M_{L L}=1.2(0.4 f t \cdot k)+0.85(15.0 f t \cdot k)=13.2 f t \cdot k \quad \text { N.G. }
$$

$\therefore$ The level of strengthening is not acceptable because the criterion of the strength limit is not satisfied. FRP strengthening is needed.

Flexural Strengthening with CFRP:

Step 3: Define Material Properties of FRP and Perform Preliminary Calculations The selected composite material is TYFO SCH-7 UP Composite Laminate.

The following material properties are reported by the manufacturer: 


$$
\begin{aligned}
& f_{f u}^{*}=130,900 \mathrm{psi} \\
& E_{f}^{*}=12,600,000 \mathrm{psi} \\
& \varepsilon_{f u}^{*}=0.0105 \mathrm{in} / \mathrm{in} \\
& t_{f}^{*}=0.007 \mathrm{in}
\end{aligned}
$$

The material properties provided by the manufacturer do not account for the long-term exposure to environmental conditions that the repair material will eventually undergo. This exposure can cause degrade the tensile properties, the fatigue performance properties, and the creep-rupture of the FRP. Therefore, the initial values of the material properties should be reduced by an environmental reduction factor, $C_{E}$. This factor should be selected from ACI 440.2R Table 8.1, which is given in Table B.1 of this paper.

Since the beam specimens are in a laboratory-controlled environment (interior exposure) and are being strengthened with a carbon/epoxy FRP system, $C_{E}=0.95$ was selected. In this experimental plan, environmental degradation to the FRP material itself is not planned or expected, so a factor conforming exterior exposure conditions was not needed.

Multiply the tensile strength and strain by the selected environmental reduction factor:

$$
\begin{aligned}
& f_{f u}=C_{E} f_{f u}{ }^{*}=0.95(0.0105 \mathrm{in} / \mathrm{in}) \quad \text { (ACI 440-2R Eq. 8-3) } \\
& f_{f u}=124,355 \mathrm{psi} \\
& \varepsilon_{f u}=C_{E} \varepsilon_{f u}{ }^{*}=0.95(0.0105 i n / i n) \quad(\text { ACI } 440-2 R \text { Eq. } 8-4)
\end{aligned}
$$




$$
\begin{aligned}
& \varepsilon_{f u}=0.0998 \mathrm{in} / \mathrm{in} \\
& E_{f}=\frac{f_{f u}}{\varepsilon_{f u}}=\frac{124,355 \mathrm{psi}}{0.0998} \quad \text { (ACI 440-2R Eq. 8-5) } \\
& E_{f}=12,466,667 \mathrm{psi} \\
& N=1 \text { Layer }
\end{aligned}
$$

An FRP laminate width was selected to allow concrete edges to either side of the sheet to be grinded to a 1" radius in locations where anchorage stirrups were to be placed:

$w_{f}=4$ in

Find total the area of the FRP reinforcement and the corresponding FRP reinforcement ratio:

$$
\begin{gathered}
A_{f}=N t_{f} w_{f}=1(0.007 \mathrm{in})(4 \mathrm{in}) \\
\mathrm{A}_{f}=0.028 \mathrm{in}^{2} \\
\rho_{f}=\frac{A_{f}}{b d}=\frac{0.028 \mathrm{in}^{2}}{(6 \mathrm{in})(6.375 \mathrm{in})} \\
\rho_{f}=0.00073
\end{gathered}
$$

Step 4: Determine the Existing State of Strain on the Soffit

The existing state of strain is calculated assuming the beam is cracked and the only loads acting on the beam at the time of the FRP installation are dead loads.

$$
\begin{gathered}
n_{s}=\frac{E_{s}}{E_{c}}=\frac{29,000,000 p s i}{2,850,000 p s i} \\
n_{s}=10.1754
\end{gathered}
$$




$$
\begin{gathered}
\rho_{s} n_{s}=(0.0078)(10.1754) \\
\rho_{s} n_{s}=0.0798
\end{gathered}
$$

From a cracked section analysis of the pristine beam, the cracked neutral axis depth can be calculated:

$$
\begin{gathered}
k=\sqrt{\left(\rho_{s} n_{s}\right)^{2}+2\left(\rho_{s} n_{s}\right)}-\left(\rho_{s} n_{s}\right)=\sqrt{(0.0798)^{2}+2(0.0 .0798)}-0.0798 \\
k=0.328 \\
c=k d=(0.328)(6.375 \mathrm{in}) \\
c=2.09 \mathrm{in}
\end{gathered}
$$

The cracked moment of inertia can then be determined:

$$
\begin{gathered}
I_{c r}=\frac{1}{3} b c^{3}+n_{s} A_{s}(d-c)^{2}=\frac{1}{3}(6 i n)(1.66 i n)^{3}+(10.1754)\left(0.30 i n^{2}\right)(6.375 i n-1.66 i n)^{2} \\
I_{c r}=74.31 \mathrm{in}^{4}
\end{gathered}
$$

Finally, the initial strain level on the bonded substrate can be ascertained:

$$
\begin{gathered}
\varepsilon_{b i}=\frac{M_{D L}(h-c)}{I_{c r} E_{c}}=\frac{(0.4 k \cdot f t)(8 i n-2.41 i n)}{\left(96.10 i n^{4}\right)(3,372,165 p s i)} \\
\varepsilon_{b i}=0.00013
\end{gathered}
$$

Step 5: Determine the Bond-Dependent Coefficient of the FRP System

If the force in the FRP laminate cannot be sustained by the concrete substrate, concrete cover delamination or FRP debonding can occur. The following limitation is placed on 
the strain level developed in the FRP in order to prevent debonding. The dimensionless bond-dependent coefficient for flexure is calculated as follows:

$$
\kappa_{m}=\left\{\begin{array}{l}
\frac{1}{60 \varepsilon_{f u}}\left(1-\frac{n E_{f} t_{f}}{2,000,000}\right) \leq 0.90: n E_{f} t_{f} \leq 1,000,000 \\
\frac{1}{60 \varepsilon_{f u}}\left(\frac{500,000}{n E_{f} t_{f}}\right) \leq 0.90: n E_{f} t_{f}>1,000,000
\end{array}\right.
$$

This equation takes account that stiffer FRP systems have a high tendency to delaminate. As the stiffness increases, the strain limitation escalates. The $n E_{f} t_{f}$ expression represents the unit stiffness of the system. If the unit stiffness is greater than $1,000,000$, the bonddependent coefficient limits force in the laminate instead of the strain level. This factor places an upper limit on the total force allowed in the FRP regardless of the thickness of the laminate system.

$$
n E_{f} t_{f}=2(12,666,667 p s i)(0.007 i n)=87,267 \leq 1,000,000
$$

Since in this design $n E_{f} t_{f}<1,000,000$, the strain limit controls and the first equation is used:

$$
\kappa_{m}=\frac{1}{60 \varepsilon_{f u}}\left(1-\frac{n E_{f} t_{f}}{2,000,000}\right)=\frac{1}{60(0.0998)}\left[1-\frac{2(12,466,667 \mathrm{psi})(0.007 \mathrm{in})}{2,000,000}\right]=1.60 \leq 0.9
$$

A greater than 0.9 is not permitted, therefore:

$$
\boldsymbol{\kappa}_{m}=0.9
$$


Step 6: Estimate the Depth to the Neutral Axis

The depth of the neutral axis must be found by trial and error. A good initial estimate for "c" can be found by:

$c=\left(1.33 \frac{\varepsilon_{c u}}{\varepsilon_{c u}+\varepsilon_{f u}}\right) d \quad$ or $c=0.20 d$

However, in this example, it was found that:

$c=1.95$ in

This will be the initial "Guess" in this example to demonstrate the design procedure. It will later be verified. It should be noted that this is an iterative process where initially knowing the correct value for " $c$ " is not a luxury.

Step 7: Determine the Effective Level of Strain in the FRP Reinforcement

First, it must be seen if the following equations are valid:

$$
\begin{aligned}
& \frac{c}{d}=\frac{1.95 \text { in }}{3.375 \text { in }} \\
& \frac{c}{d}=0.310<0.375 \quad \text { Good; The following equation is valid }
\end{aligned}
$$$$
\left.\varepsilon_{f e}=0.003\left(\frac{h-c}{c}\right)-\varepsilon_{b i} \leq \kappa_{m} \varepsilon_{f u}\right)
$$

If the left-hand side of the expression in this equation controls, it is assumed that the failure mode would be concrete crushing. If the right-hand side controls, then it is presumed that the failure mode would be FRP rupture. 


$$
\begin{aligned}
& \varepsilon_{f e}=0.003\left(\frac{h-c}{c}\right)-\varepsilon_{b i}=0.003\left(\frac{8 i n-6.375 i n}{6.375 i n}\right)-0.00013=0.00917 \\
& \varepsilon_{f e}=\kappa_{m} \varepsilon_{f u}=(0.9)(0.00998)=0.00898
\end{aligned}
$$

Since $\varepsilon_{f e}=0.00917<0.00898$, the right-hand side controls and FRP failure is the predicted failure mode.

$$
\varepsilon_{f e}=0.00898
$$

Step 8: Calculate the Strain in the Existing Reinforcing Steel

From strain compatibility using similar triangles, the strain in the tension reinforcing steel is calculated:

$$
\begin{gathered}
\varepsilon_{s}=\left(\varepsilon_{f e}+\varepsilon_{b i}\right)\left(\frac{d-c}{h-c}\right)=(0.008978+0.00013)\left(\frac{6.375 i n-1.66 i n}{8 i n-1.66 i n}\right) \\
\varepsilon_{s}=0.00666 \mathrm{in} / \mathrm{in} \quad \text { (ACI 440-2R Eq. 9-8) }
\end{gathered}
$$

Step 9: Calculate the Stress Level in Reinforcing Steel and FRP

Stress in the reinforcement is calculated from the strain level in the steel assuming elastic-plastic behavior:

$$
\begin{aligned}
& f_{s}=E_{s} \varepsilon_{s} \leq f_{y} 0-2 \mathrm{R} \text { Eq. 9-9) } \\
& f_{s}=E_{s} \varepsilon_{s}=(29,000,000 \mathrm{psi})(0.00666) \times \frac{1 \mathrm{ksi}}{1,000 \mathrm{psi}}=193 \mathrm{ksi} \leq f_{y}=60 \mathrm{ksi}
\end{aligned}
$$

Since steel stress is governed by the yield stress of the reinforcing bars:

$$
f_{s}=60 \mathrm{ksi}
$$


The effective stress level in the FRP reinforcement is the maximum level of stress that can be developed in the FRP reinforcement before flexural failure of the section. Perfectly elastic behavior is assumed:

$$
\begin{gathered}
f_{f e}=E_{f} \varepsilon_{f e}=(12,466,667 p s i)(0.00898) \times \frac{1 k s i}{1,000 p s i} \\
f_{f e}=111.92 \mathrm{ksi}
\end{gathered}
$$

(ACI 440-2R Eq. 9-4)

Step 10-Calculate the internal force resultants and check equilibrium

Internal force equilibrium and strain compatibility is verified by checking the initial estimate of the neutral axis depth with the following equation. If concrete crushing is the controlling mode of failure (before or after steel yielding), $\gamma$ and $\beta_{1}$ can be taken as the values associated with the Whitney stress block $\left(\gamma=0.85\right.$ and $\beta_{1}$ from Section 10.2.7.3 of ACI 318-99). If FRP rupture, cover delamination, or FRP-debonding control failure occur, the Whitney stress block yields reasonably accurate results. It should be noted that the actual design process is iterative and the initial "Guess" must be changed until its value equals that given by the following equation:

$$
\begin{aligned}
& c=\frac{A_{s} f_{s}+A_{f} f_{f e}}{\gamma \beta_{1} f_{c}^{\prime} b}=\frac{\left(0.30 \mathrm{in}^{2}\right)(60 \mathrm{ksi})+\left(0.028 \mathrm{in}^{2}\right)(111.92 \mathrm{ksi})}{0.85(0.85)(2,500)(6 \mathrm{in})} \\
& c=1.95 \mathrm{in}=\text { Guess: } 1.95 \mathrm{in} \quad \checkmark \text { Good; } 1.95 \text { in is the correct neutral axis depth. } \\
& a=\beta_{1} c=0.85(1.95 \mathrm{in}) \\
& a=1.66 \mathrm{in}
\end{aligned}
$$


Step 11-Calculate design flexural strength of the section

First, the strain in the steel at yielding is established:

$$
\begin{gathered}
\varepsilon_{s y}=\left(\frac{f_{y}}{E_{s}}\right)=\frac{60,000 p s i}{29,000,000 p s i} \\
\varepsilon_{s y}=0.00207
\end{gathered}
$$

The strain level in the steel at the ultimate limit state must be checked to ensure sufficient ductility. Adequate ductility is achieved if the strain in the steel at the point of concrete crushing or failure of the FRP, including delamination or debonding, is at least 0.005 , according to the definition of a tension-controlled section as given in Chapter 2 of ACI 318. Because $\varepsilon_{s}=0.00551>0.005$, a strength-reduction factor of $\phi=0.90$ is selected and applied:

$$
\begin{aligned}
\phi= & \left\{\begin{array}{l}
0.90: \varepsilon_{s} \geq 0.005 \\
0.70+0.20\left(\frac{\varepsilon_{s}-\varepsilon_{s y}}{0.005-\varepsilon_{s y}}\right)=0.70+0.20\left(\frac{0.00666-0.00207}{0.005-0.00207}\right)=1.014: \varepsilon_{s y}<\varepsilon_{s}<0.005 \\
0.70: \varepsilon_{s} \leq \varepsilon_{s y}
\end{array}\right. \\
& \therefore \Phi=0.90
\end{aligned}
$$

An additional reduction factor is applied to the contribution of the FRP system:

$\psi=0.85$

Finally, the nominal flexural strength of the FRP-strengthened section can be determined:

(ACI 440-2R Eq. 9-11) 


$$
\begin{aligned}
& \phi M_{n}=\phi\left[A_{s} f_{y}\left(d-\frac{a}{2}\right)+\psi_{f} A_{f r p}\left(E_{f r p} \kappa_{m} \varepsilon_{f r p u}\right)\left(h-\frac{a}{2}\right)\right] \\
& =0.90\left[\begin{array}{l}
\left(0.30 \mathrm{in}^{2}\right)(60,000 \mathrm{psi})\left(6.375 \mathrm{in}-\frac{1.66 \mathrm{in}}{2}\right)+ \\
(0.85)(0.007 \mathrm{in})(12,466,667 \mathrm{psi})\left(8 \mathrm{in}-\frac{1.66 \mathrm{in}}{2}\right)
\end{array}\right] \times \frac{1 \mathrm{ft}}{12 \mathrm{in}} \times \frac{1 \mathrm{kip}}{1,000 \mathrm{lbs}} \\
& \phi M_{n}=8.9 \mathrm{ft} \cdot \mathrm{k}
\end{aligned}
$$

Step 12-Check service stresses in the reinforcing steel and the FRP

The stress level in the steel reinforcement can be calculated based on a cracked elastic analysis of the FRP-strengthened section, as follows.

First, the elastic depth to the cracked neutral axis can be obtained by adding the first moment of the areas of the transformed section. This value can be sought by the following simplified equation for a rectangular beam:

$$
\begin{aligned}
& k=\sqrt{\left(\rho_{s} n_{s}+\rho_{f} n_{f}\right)^{2}+2\left(\rho_{s} n_{s}+\rho_{f} n_{f}\left(\frac{h}{d}\right)\right)}-\left(\rho_{s} n_{s}+\rho_{f} n_{f}\right) \\
&= \sqrt{(0.0798+0.00320)^{2}+2\left(0.0798+0.00320\left(\frac{8 i n}{6.375 i n}\right)\right)}-(0.0798+0.00320) \\
& k=0.335
\end{aligned}
$$

The distribution of strain and stress in the reinforced concrete section is illustrated in Figure B.1. As in regular reinforced concrete analysis, the depth to the neutral axis under service loads can be ascertained by taking the first moment of the areas of the transformed section. Although this method ignores the difference in the initial strain 
level of the FRP, the initial strain level does not greatly influence the depth to the neutral axis in the elastic response range of the member.

$$
\begin{gathered}
k d=(0.335 \mathrm{in})(6.375 \mathrm{in}) \\
k d=2.1342 \mathrm{in} \text { for service conditions. }
\end{gathered}
$$

Next, the stress level in the reinforcing steel is calculated and it is verified that it is less than recommended limit. The term " $M_{s}$ " represents the moment due to all sustained loads, that is dead loads and the sustained portion of the live load, plus the maximum moment induced in a fatigue loading cycle as shown in Figure B.1.

$$
\begin{aligned}
& f_{s, s}=\frac{\left[M_{s}+A_{f} E_{f} \varepsilon_{b i}\left(h-\frac{k d}{3}\right)\right](d-k d) E_{s}}{A_{s} E_{s}\left(d-\frac{k d}{3}\right)(d-k d)+A_{f} E_{f}\left(h-\frac{k d}{3}\right)(h-k d)} \quad \text { (ACI 440-2R Eq. 9-12) } \\
& f_{s . s}=\frac{\left[15.4 f t \cdot k+\left(0.028 i^{2}\right)(12,466.667 k s i)(0.00013)\left(8 i n-\frac{2.13 i n}{3}\right)\right](6.375 i n-2.13 i n)(29,000 k s i)}{\left(0.30 i^{2}\right)(29,000 k s i)\left(6.375 i n-\frac{2.13 i n}{3}\right)(6.375 i n-2.13 i n)+\left(0.028 i^{2}\right)(12,466.667 k s i)\left(8 i n-\frac{2.13 i n}{3}\right)(8 i n-2.13 i n)} \\
& \\
& f_{s, s}=101.70 \mathrm{ksi}
\end{aligned}
$$$$
f_{s, s}=0.80 f_{y}=0.80(60 k s i)=48.00 k s i
$$

$$
f_{s, s}=101.70 \mathrm{ksi}>48.00 \mathrm{ksi} \quad \text { N.G. }
$$

The stress in the reinforcing steel at service load conditions is not less than the recommended limit.

Equation (9-13) gives the stress level in the FRP reinforcement under an applied moment within the elastic response range of the member. 


$$
\begin{gathered}
f_{f, s}=f_{s, s}\left(\frac{E_{f}}{E_{s}}\right)\left(\frac{h-k d}{d-k d}\right)-\varepsilon_{b i} E_{f} \\
f_{f, s}=101.70 k s i\left(\frac{12,466,667 p s i}{29,000,000 p s i}\right)\left(\frac{8 i n-2.13 i n}{6.3125 i n-2.13 i n}\right)-(0.00013)(12,466.667 k s i) \\
\quad \frac{f_{f, s}=58.80}{f_{f, s}}=0.55 f_{f u}=0.55\left(124,355 p s i \times \frac{1 \mathrm{ksi}}{1,000 \mathrm{psi}}\right)=68.40 \mathrm{ksi} \\
f_{f, s}=58.80 \mathrm{ksi}<68.40 \mathrm{ksi} \quad \mathrm{Good}
\end{gathered}
$$




\section{Appendix C: Final Beam Cracking Widths and Patterns}

Diagrams of the final cracking patterns are provided in the figures in this appendix. Widths of major cracks are also labeled on the drawings. The specimens' numbers are provided next to the mark end of each beam drawing. Beams are drawn as if the sides were unfolded like a box. The right side of the beam is located at the top of each diagram, the bottom face of the beam is located at the middle of each diagram, the left side of the beam is located at the bottom of the diagram (and is inverted), and the beam ends project outward to the left and right of the bottom face. A 1"x1" grid was drawn over the sides of the beam so that the observer can easily distinguish the exact locations of the cracks. Both the "after corrosion cycle 1" and "after corrosion cycle 2" diagrams are provided for Beams I-6, 8, and 9. Existing cracks from the first corrosion process were not redrawn on the diagram for the second corrosion process for Beam I-6. Existing repaired cracks were not redrawn for Beam I-9. Also, remember that Beam I-8 was already repaired with polymer concrete material after the second corrosion cycle. 


\section{C.1 Part I}

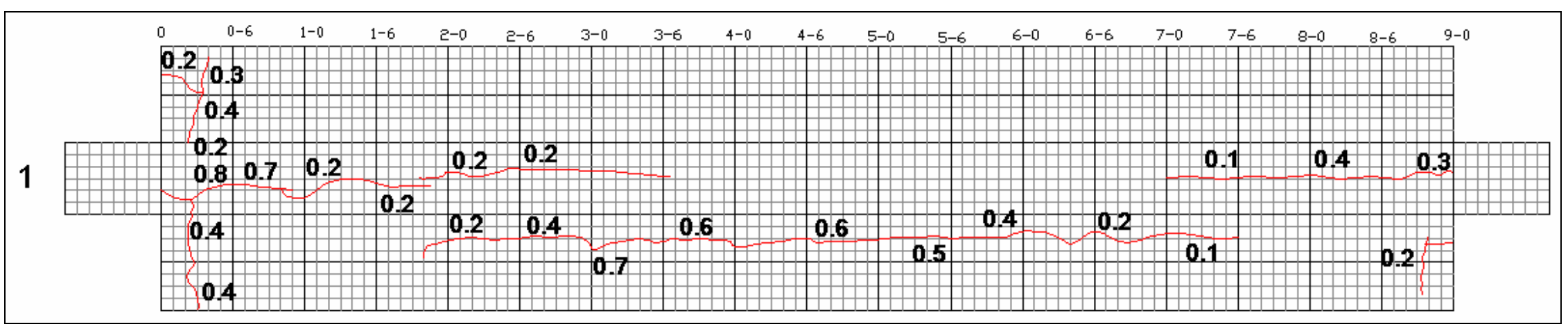

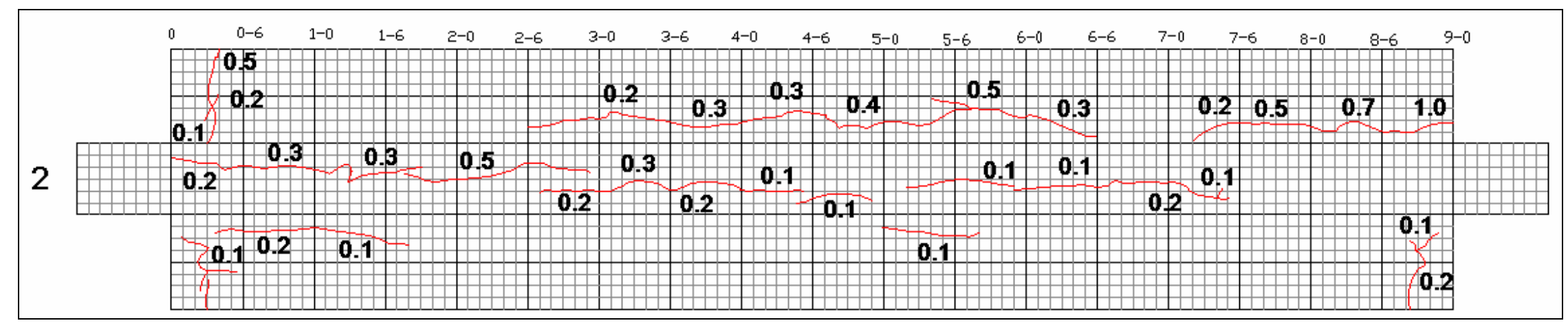




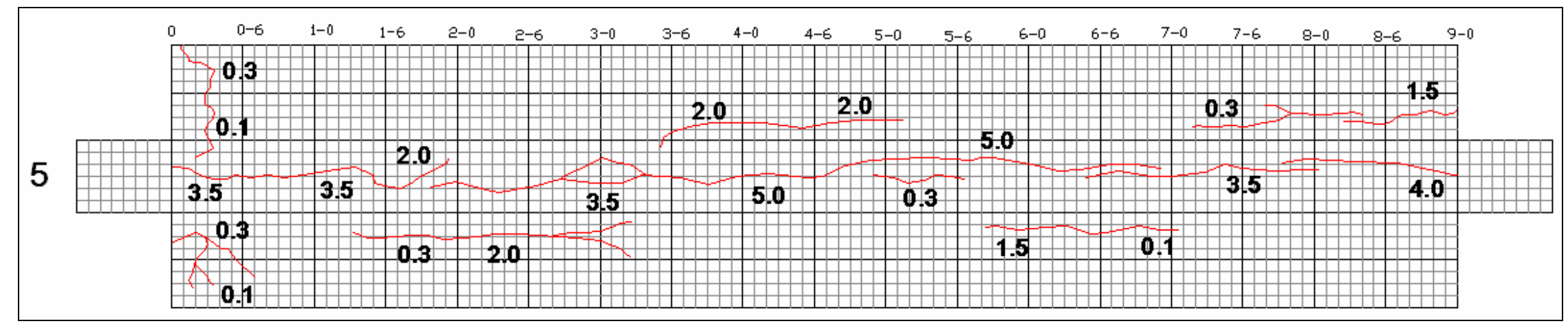



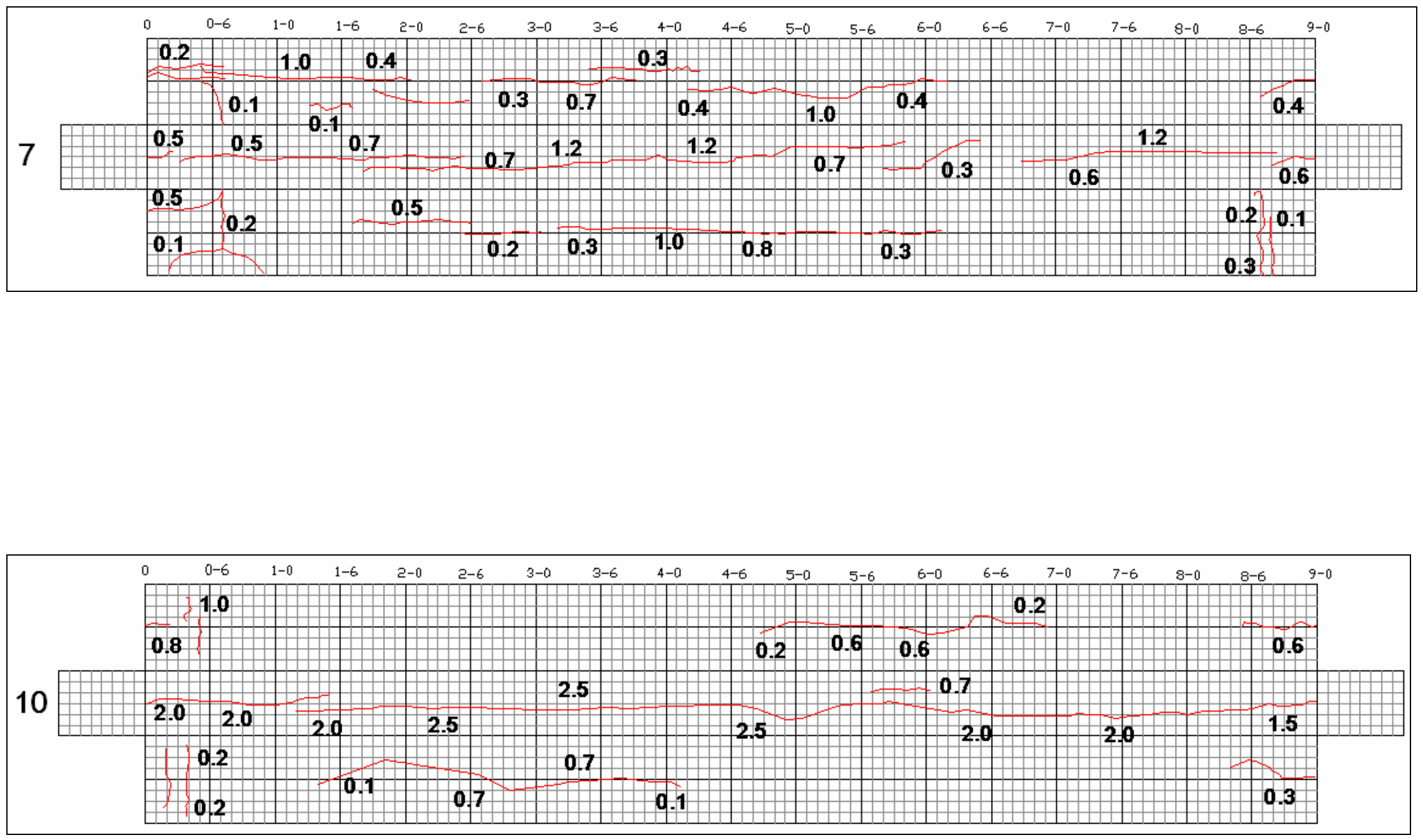

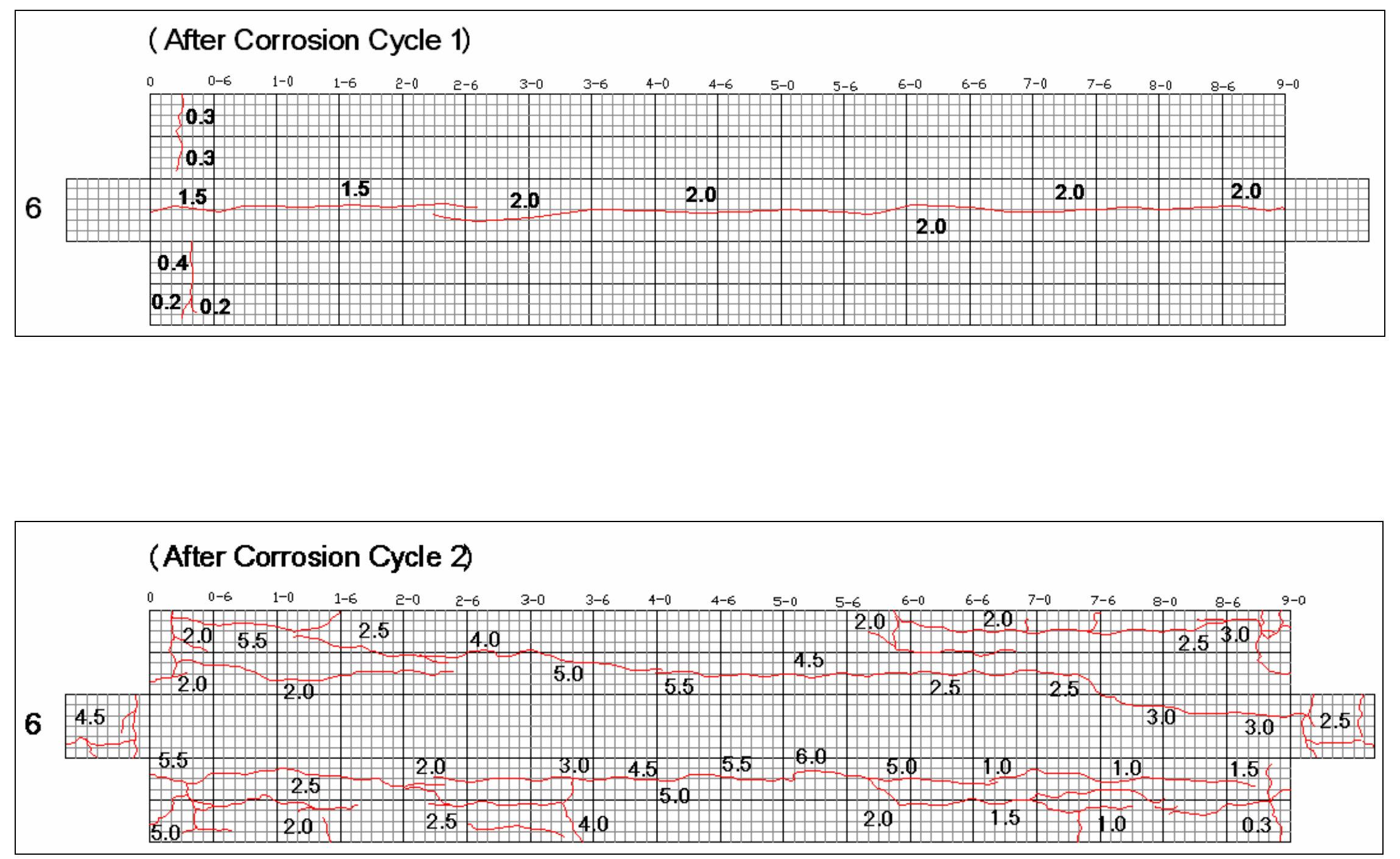


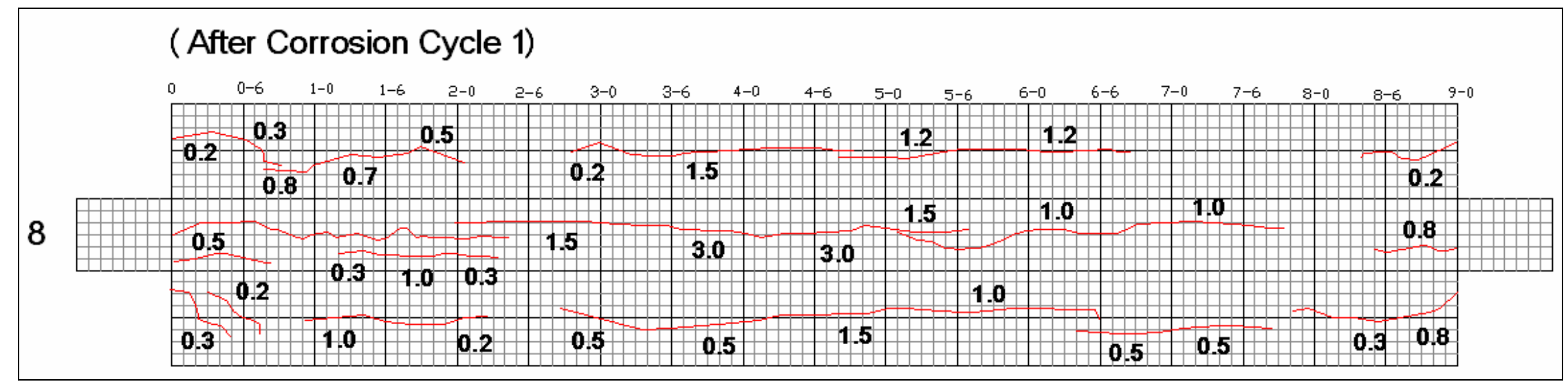




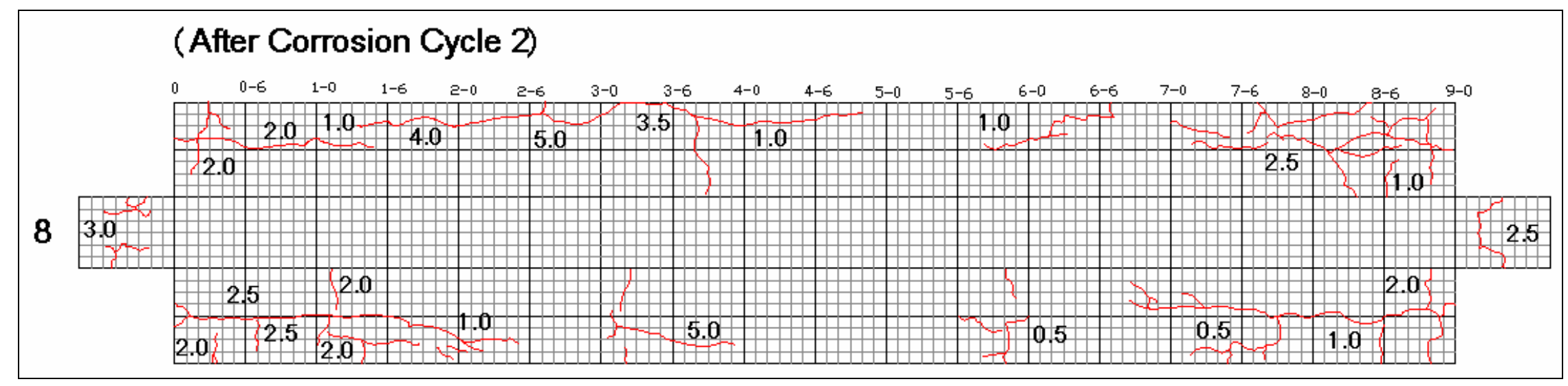

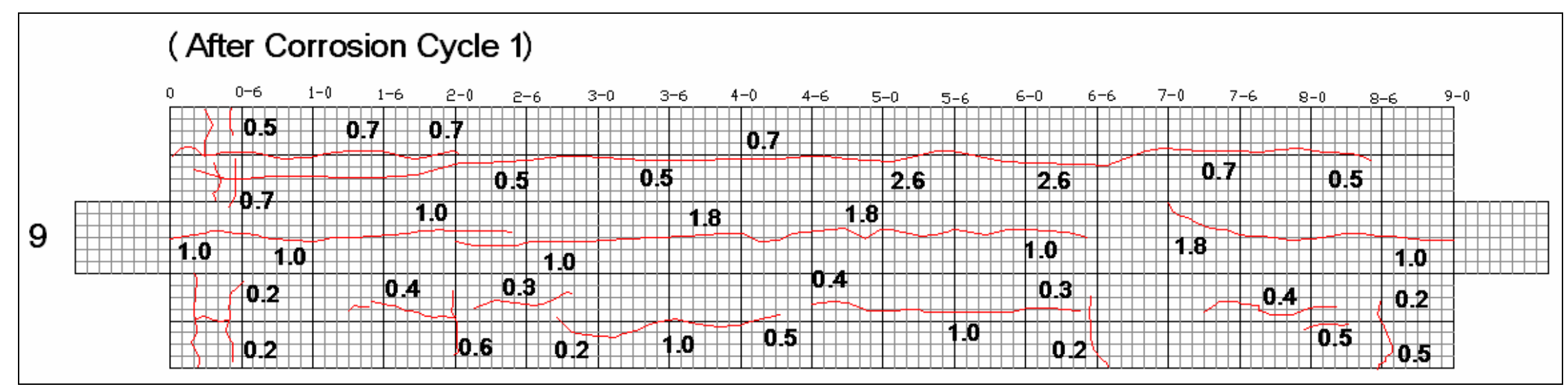




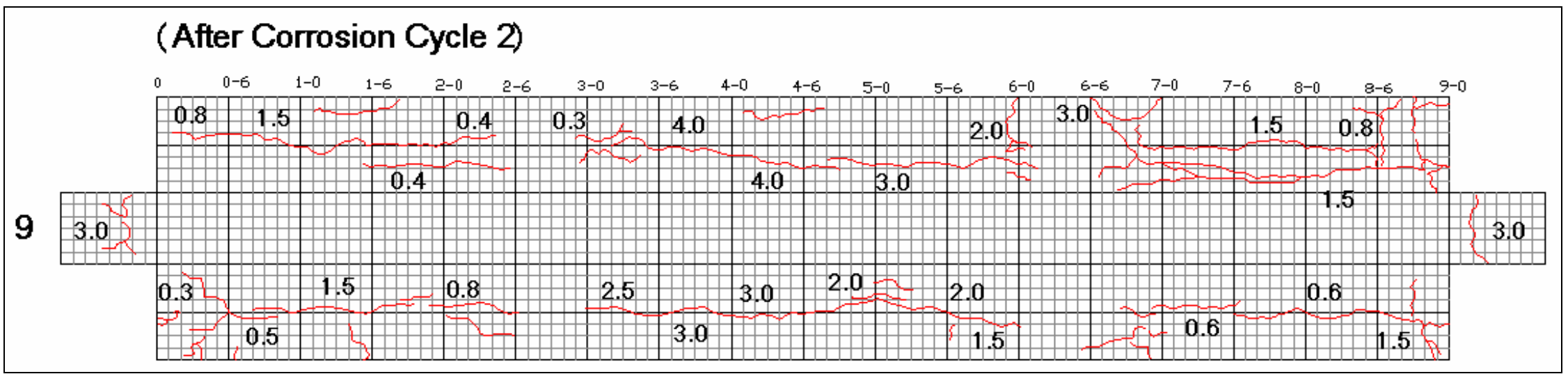

\section{C.2 Part II}

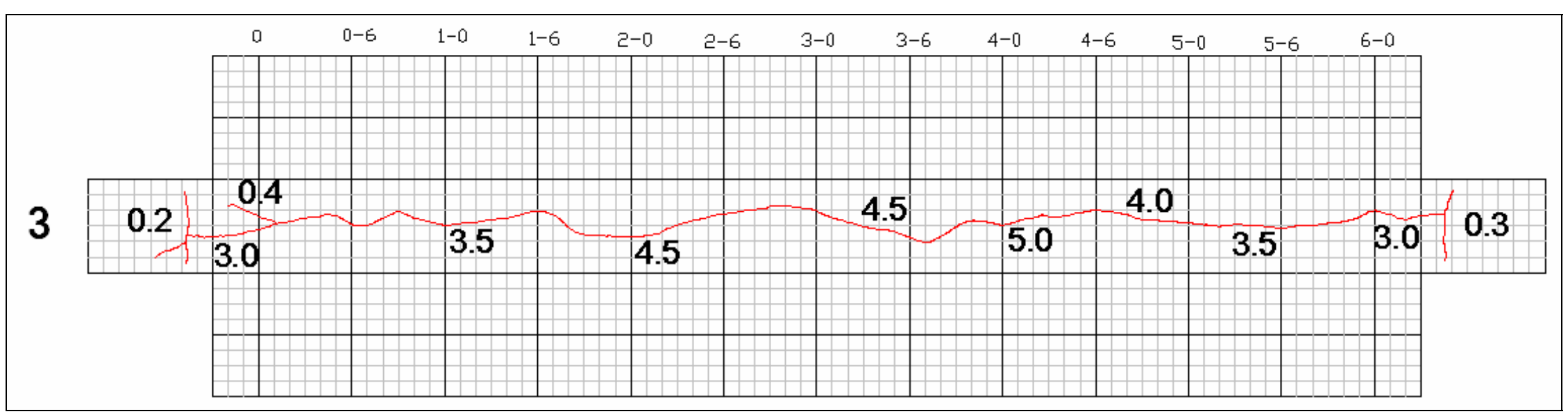



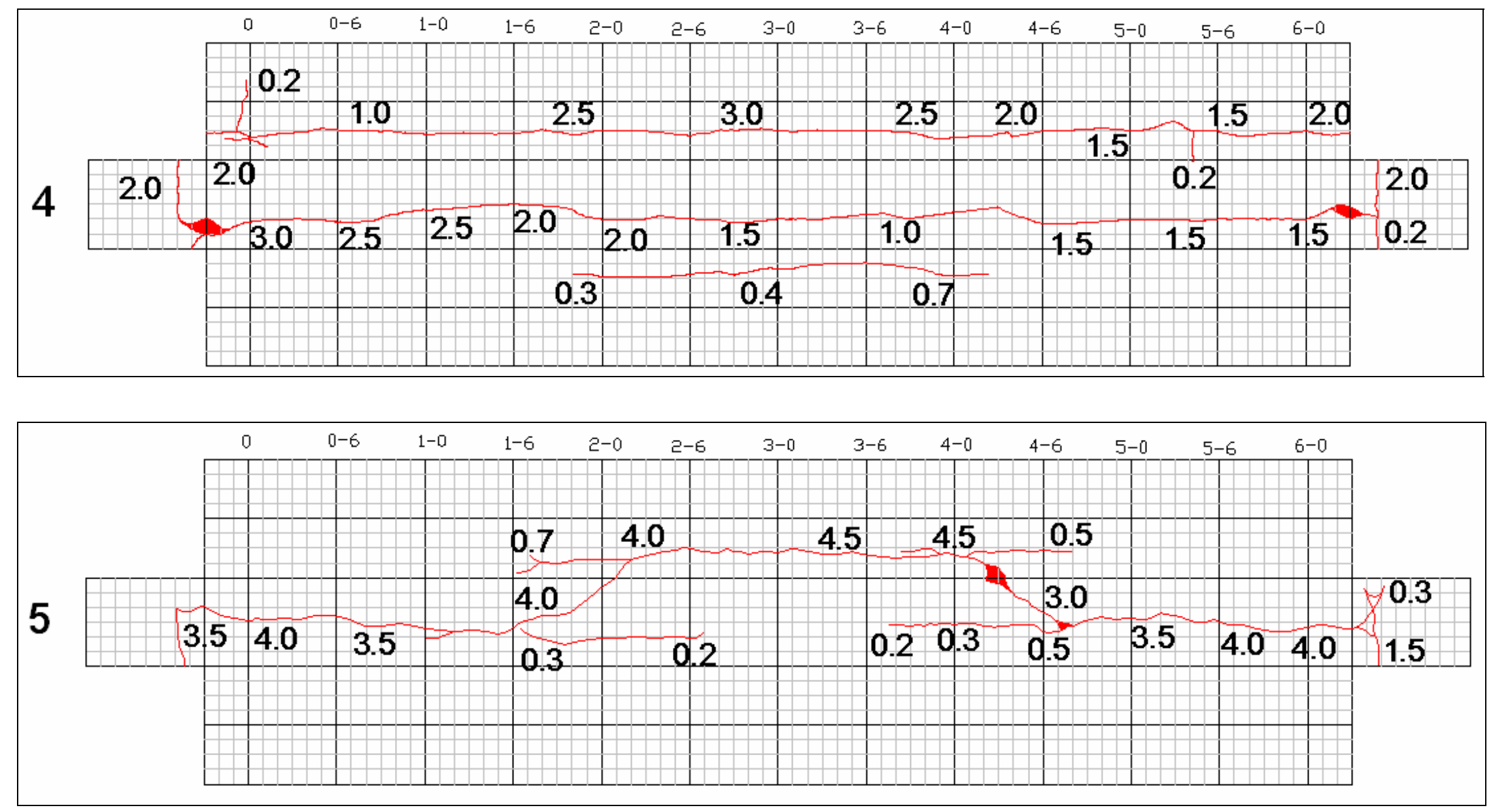


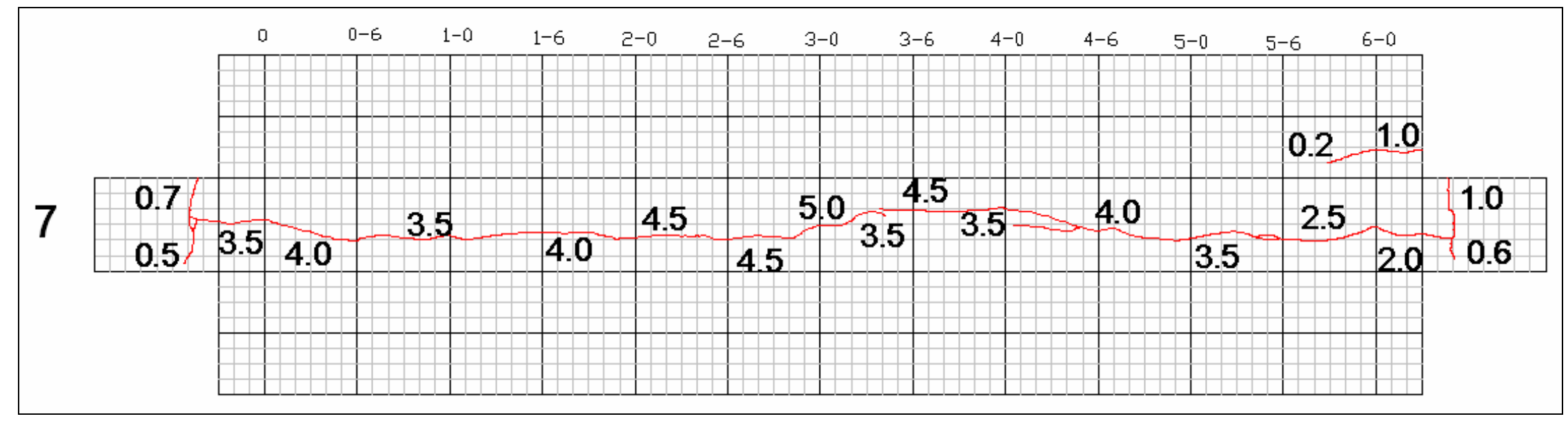

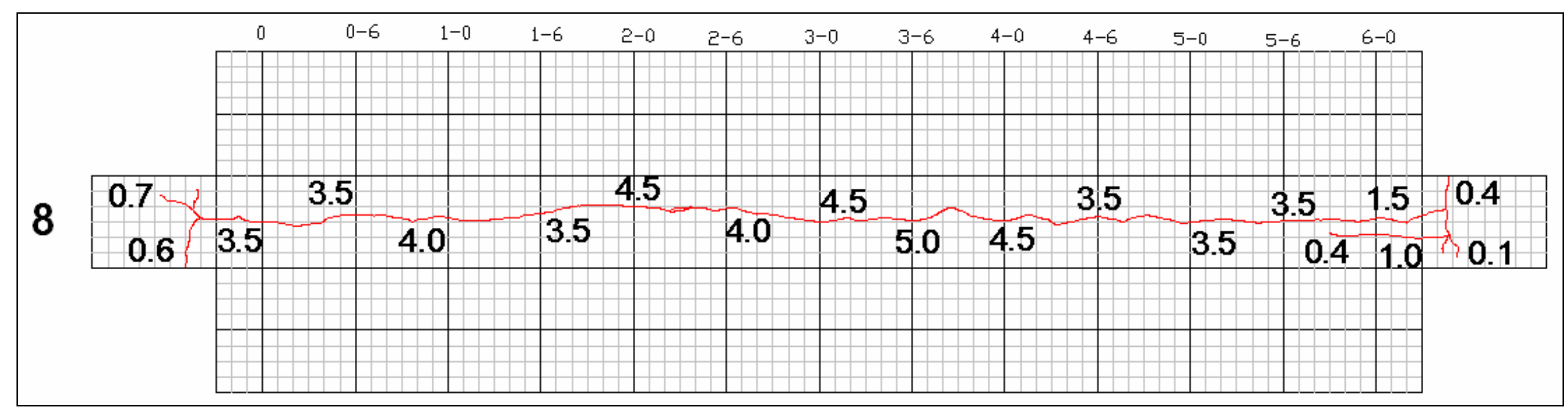



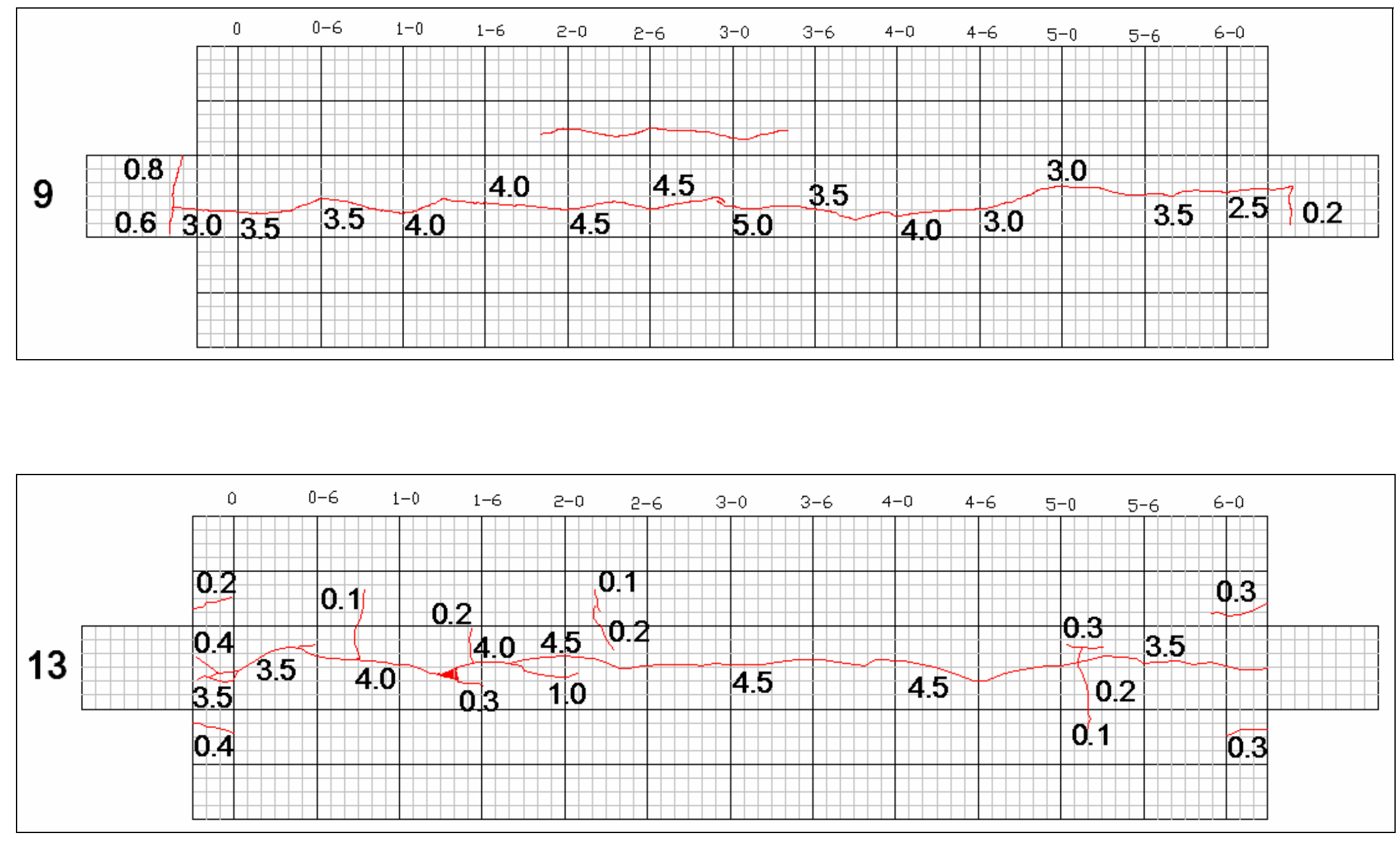


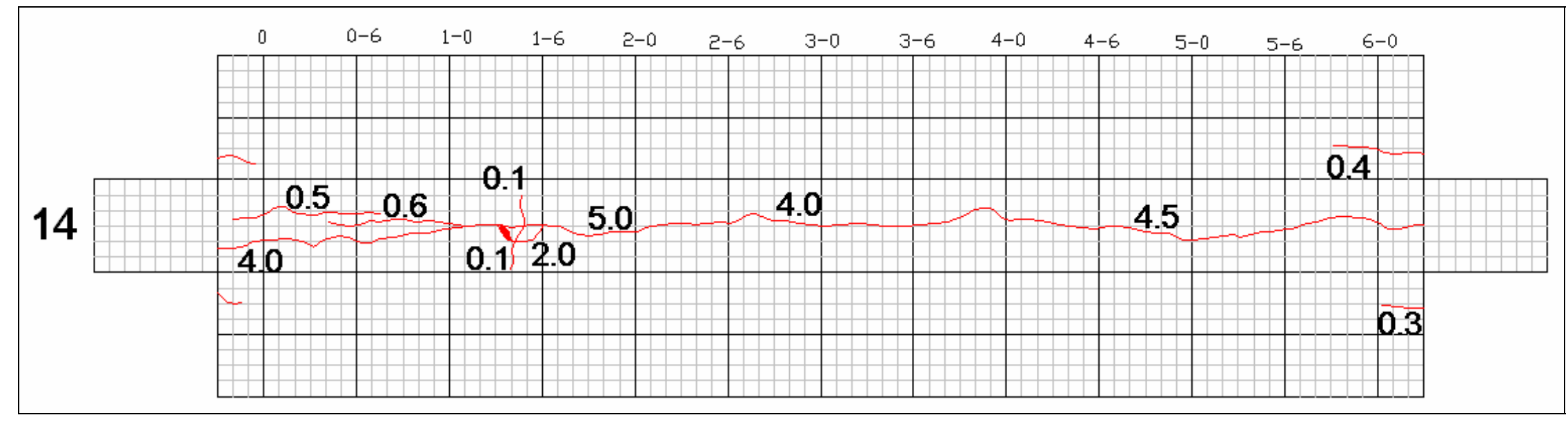

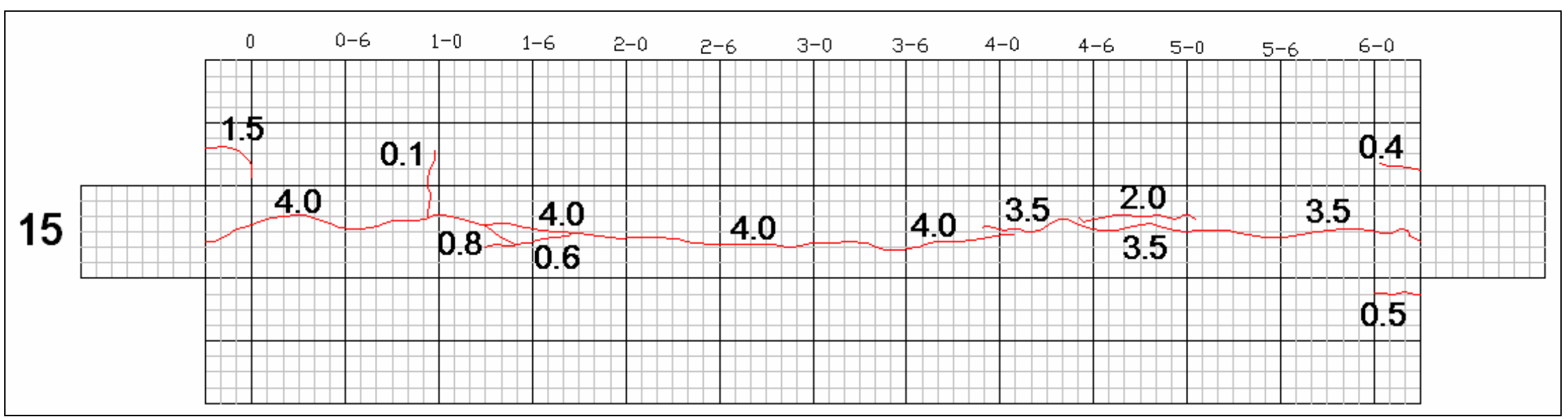



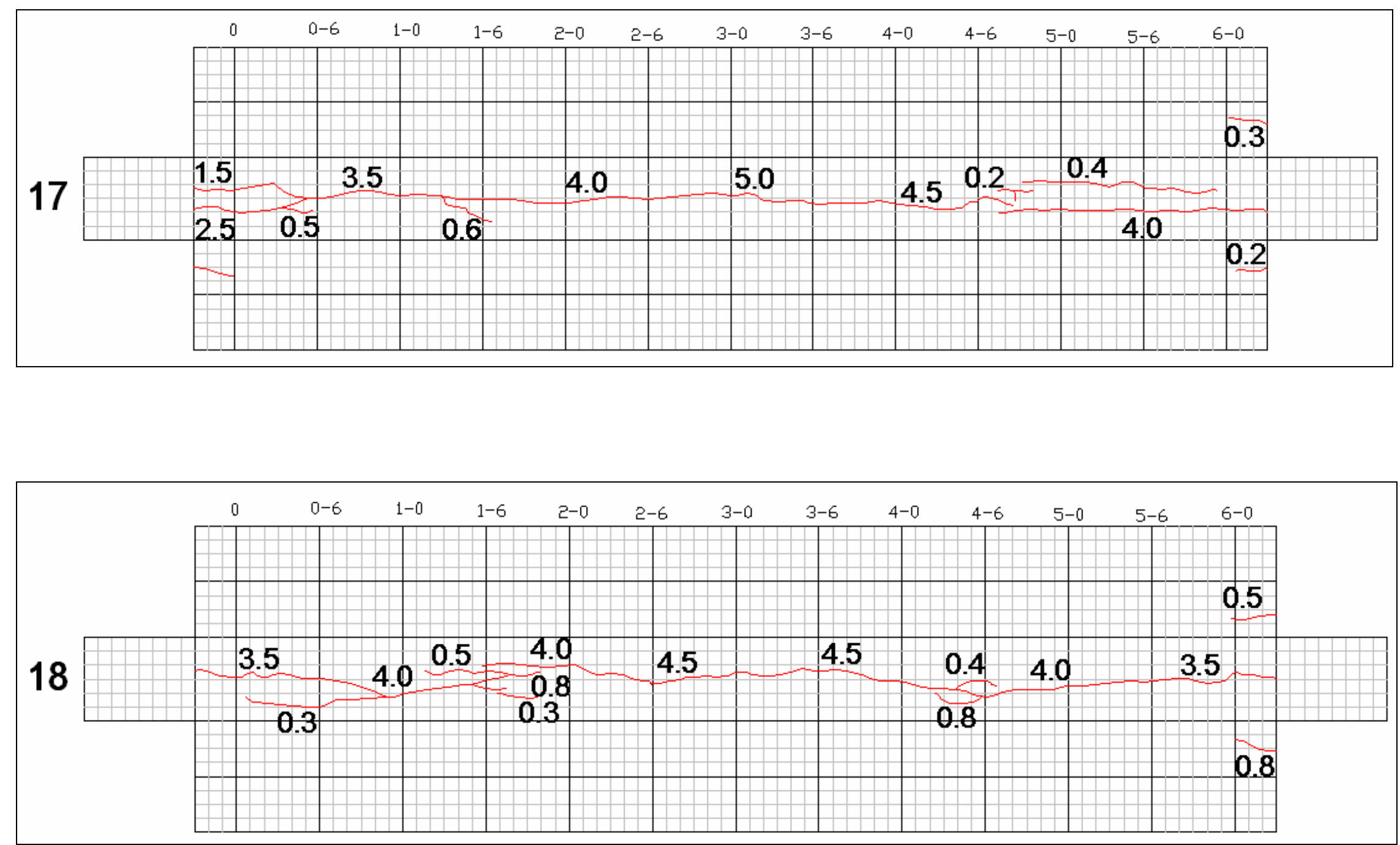

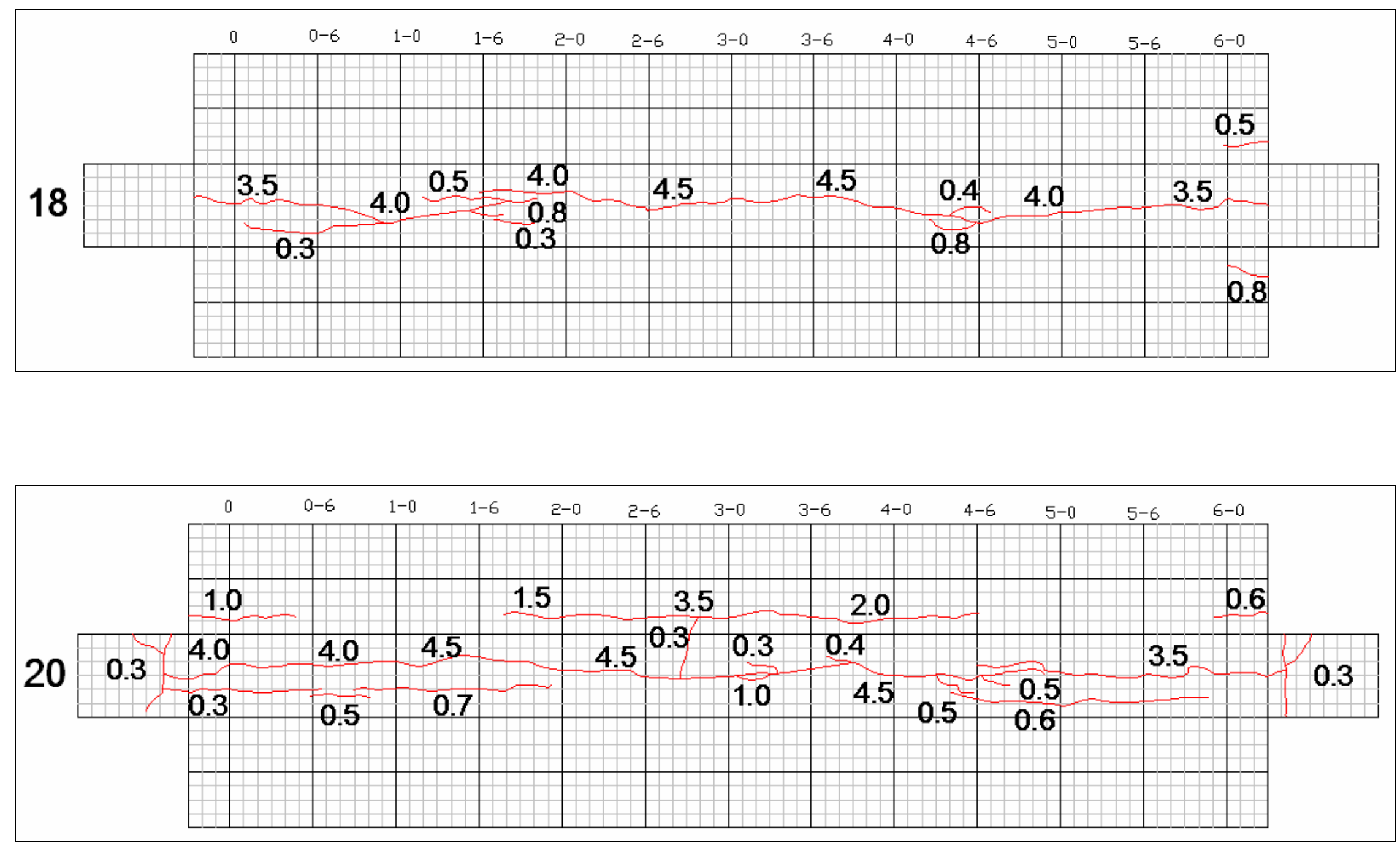

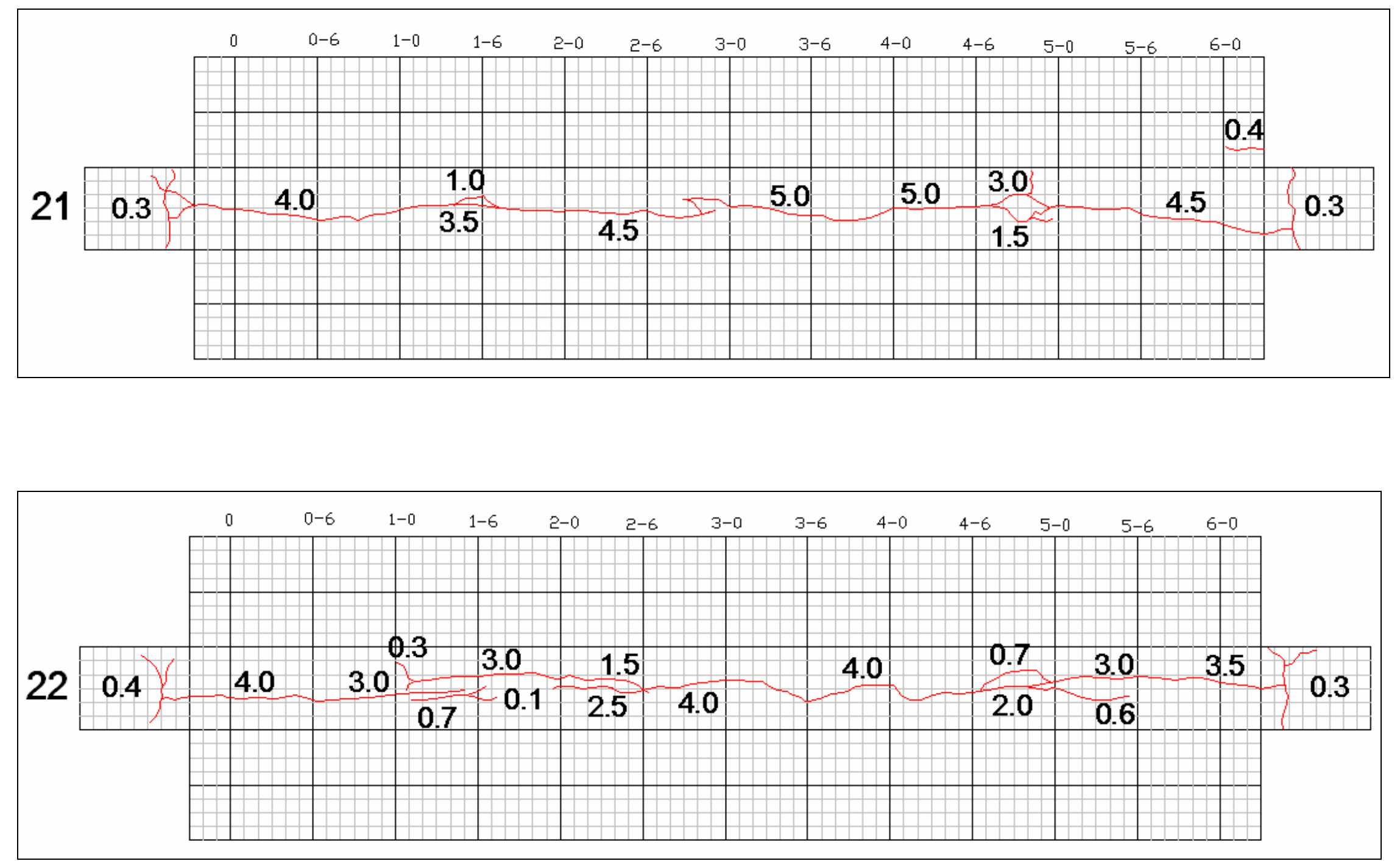

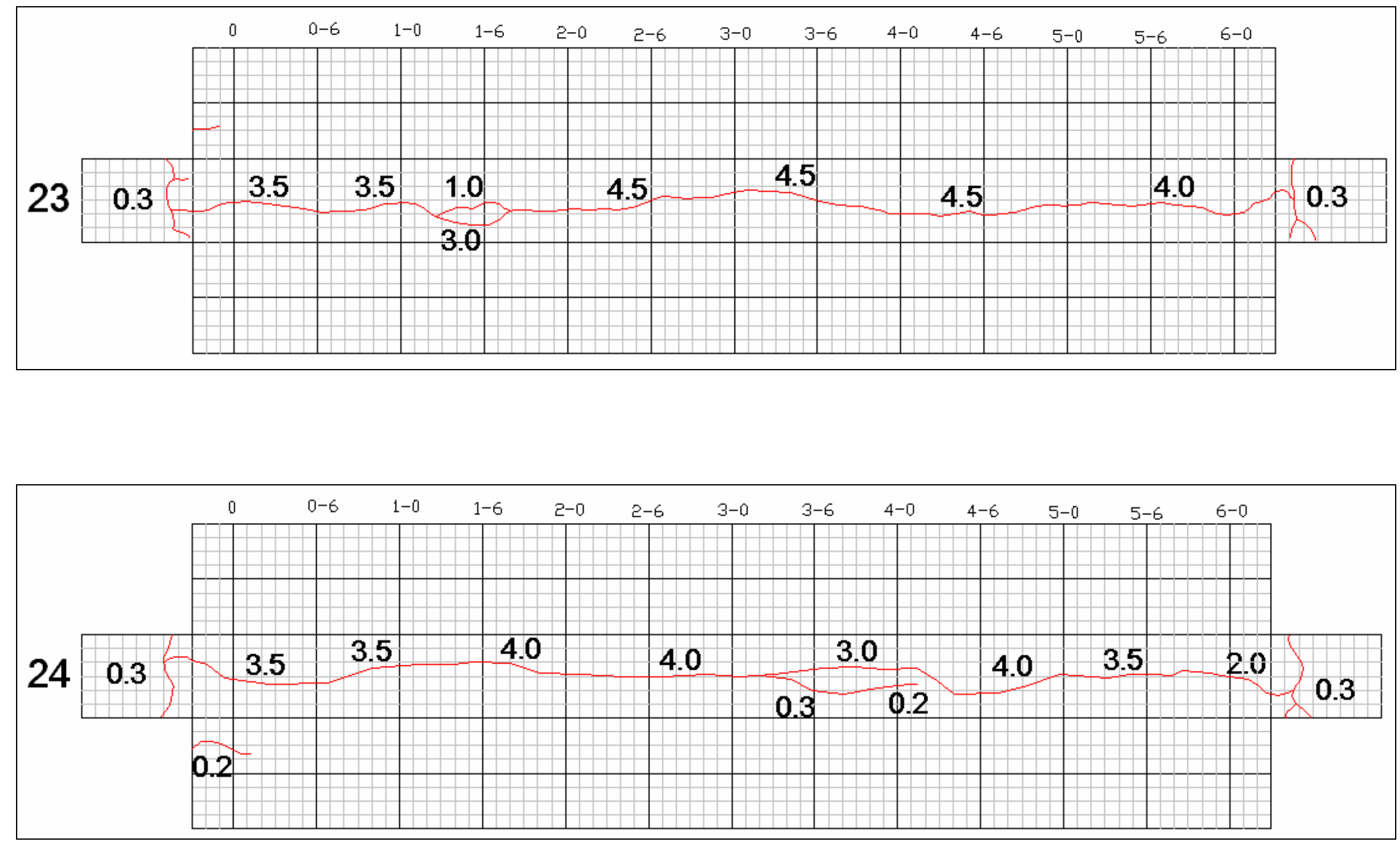


\section{Appendix D: Raw Data}

\section{D.1 Half-Cell Potential Raw Data}

\begin{tabular}{|r|r|r|r|r|r|r|}
\hline \multicolumn{1}{|l|}{ Time of Reading } & \multicolumn{5}{|c|}{ Beam 1 } \\
\hline \multicolumn{1}{l|}{ Date } & Hour & $4^{\prime}-6 "$ & $6^{\prime}-0^{\prime \prime}$ & $7^{\prime}-6^{\prime \prime}$ & Average & Range \\
\hline $4 / 26 / 2007$ & 0 & -445 & -463 & -476 & -461 & 31 \\
\hline $5 / 4 / 2007$ & 167.5 & -596 & -675 & -516 & -596 & 159 \\
\hline $5 / 11 / 2007$ & 294 & -558 & -595 & -481 & -545 & 114 \\
\hline $5 / 18 / 2007$ & 462 & -476 & -553 & -347 & -459 & 206 \\
\hline $5 / 25 / 2007$ & 621.5 & -458 & -517 & -531 & -502 & 73 \\
\hline $6 / 1 / 2007$ & 781.5 & -358 & -426 & -344 & -376 & 82 \\
\hline $6 / 8 / 2007$ & 933.5 & -388 & -444 & -441 & -424 & 56 \\
\hline $6 / 18 / 2007$ & 1096.5 & -250 & -341 & -381 & -324 & 131 \\
\hline $10 / 10 / 2007$ & 2354 & - & - & - & - & - \\
\hline $10 / 17 / 2007$ & 2467 & - & - & - & - & - \\
\hline
\end{tabular}

\begin{tabular}{|r|r|r|r|r|r|r|}
\hline \multicolumn{2}{|l|}{ Time of Reading } & \multicolumn{5}{|c|}{ Part I Beam 2 } \\
\hline Date & Hour & $4^{\prime}-6^{\prime \prime}$ & $6^{\prime}-0^{\prime \prime}$ & $7^{\prime}-6 "$ & Average & Range \\
\hline $4 / 26 / 2007$ & 0 & -459 & -470 & -490 & -473 & 31 \\
\hline $5 / 4 / 2007$ & 167.5 & -598 & -639 & -571 & -603 & 68 \\
\hline $5 / 11 / 2007$ & 294 & -521 & -615 & -549 & -562 & 94 \\
\hline $5 / 18 / 2007$ & 462 & -427 & -525 & -492 & -481 & 98 \\
\hline $5 / 25 / 2007$ & 621.5 & -485 & -541 & -548 & -525 & 63 \\
\hline $6 / 1 / 2007$ & 781.5 & -394 & -427 & -454 & -425 & 60 \\
\hline $6 / 8 / 2007$ & 933.5 & -433 & -477 & -478 & -463 & 45 \\
\hline $6 / 18 / 2007$ & 1096.5 & -296 & -352 & -371 & -340 & 75 \\
\hline $10 / 10 / 2007$ & 2354 & - & - & - & - & - \\
\hline $10 / 17 / 2007$ & 2467 & - & - & - & - & - \\
\hline
\end{tabular}

\begin{tabular}{|r|r|r|r|r|r|r|}
\hline \multicolumn{2}{|l|}{ Time of Reading } & \multicolumn{5}{|c|}{ Part I Beam 5 } \\
\hline Date & Hour & $4^{\prime}-6 "$ & $6{ }^{\prime}-0 "$ & $7^{\prime}-6 "$ & Average & Range \\
\hline $4 / 26 / 2007$ & 0 & -454 & -451 & -456 & -454 & 5 \\
\hline $5 / 4 / 2007$ & 167.5 & -605 & -609 & -614 & -609 & 9 \\
\hline $5 / 11 / 2007$ & 294 & -570 & -597 & -494 & -554 & 103 \\
\hline $5 / 18 / 2007$ & 462 & -485 & -518 & -519 & -507 & 34 \\
\hline $5 / 25 / 2007$ & 621.5 & -534 & -533 & -577 & -548 & 44 \\
\hline $6 / 1 / 2007$ & 781.5 & -391 & -484 & -483 & -453 & 93 \\
\hline $6 / 8 / 2007$ & 933.5 & -421 & -472 & -509 & -467 & 88 \\
\hline $6 / 18 / 2007$ & 1096.5 & -330 & -401 & -435 & -389 & 105 \\
\hline $10 / 10 / 2007$ & 2354 & -484 & -504 & -203 & -397 & 301 \\
\hline $10 / 17 / 2007$ & 2467 & - & - & - & - & - \\
\hline
\end{tabular}




\begin{tabular}{|r|r|r|r|r|r|r|}
\hline \multicolumn{2}{|l|}{ Time of Reading } & \multicolumn{5}{|c|}{ Part I Beam 7 } \\
\hline Date & Hour & $4^{\prime}-6^{\prime \prime}$ & $6^{\prime}-0^{\prime \prime}$ & $7^{\prime}-6{ }^{\prime \prime}$ & Average & Range \\
\hline $4 / 26 / 2007$ & 0 & -470 & -480 & -513 & -488 & 43 \\
\hline $5 / 4 / 2007$ & 167.5 & -605 & -618 & -574 & -599 & 44 \\
\hline $5 / 11 / 2007$ & 294 & -605 & -618 & -476 & -566 & 142 \\
\hline $5 / 18 / 2007$ & 462 & -540 & -566 & -381 & -496 & 185 \\
\hline $5 / 25 / 2007$ & 621.5 & -553 & -558 & -553 & -555 & 5 \\
\hline $6 / 1 / 2007$ & 781.5 & -503 & -497 & -428 & -476 & 75 \\
\hline $6 / 8 / 2007$ & 933.5 & -571 & -549 & -521 & -547 & 50 \\
\hline $6 / 18 / 2007$ & 1096.5 & -528 & -507 & -575 & -537 & 68 \\
\hline $10 / 10 / 2007$ & 2354 & -265 & -242 & -495 & -334 & 253 \\
\hline $10 / 17 / 2007$ & 2467 & -435 & -345 & -586 & -455 & 241 \\
\hline
\end{tabular}

\begin{tabular}{|r|r|r|r|r|r|r|}
\hline \multicolumn{4}{|l|}{ Time of Reading } & \multicolumn{5}{|c|}{ Part I Beam 8 } \\
\hline Date & Hour & $4^{\prime}-6^{\prime \prime}$ & $6^{\prime}-0^{\prime \prime}$ & $7^{\prime}-6^{\prime \prime}$ & Average & Range \\
\hline $4 / 26 / 2007$ & 0 & -448 & -452 & -467 & -456 & 19 \\
\hline $5 / 4 / 2007$ & 167.5 & -616 & -637 & -538 & -597 & 99 \\
\hline $5 / 11 / 2007$ & 294 & -593 & -617 & -548 & -586 & 69 \\
\hline $5 / 18 / 2007$ & 462 & -527 & -577 & -463 & -522 & 114 \\
\hline $5 / 25 / 2007$ & 621.5 & -568 & -570 & -508 & -549 & 62 \\
\hline $6 / 1 / 2007$ & 781.5 & -402 & -501 & -339 & -414 & 162 \\
\hline $6 / 8 / 2007$ & 933.5 & -419 & -485 & -437 & -447 & 66 \\
\hline $6 / 18 / 2007$ & 1096.5 & -405 & -463 & -493 & -454 & 88 \\
\hline $10 / 10 / 2007$ & 2354 & -445 & -107 & -296 & -283 & 338 \\
\hline $10 / 17 / 2007$ & 2467 & -406 & -370 & -456 & -411 & 86 \\
\hline
\end{tabular}

\begin{tabular}{|r|r|r|r|r|r|r|}
\hline \multicolumn{2}{|l|}{ Time of Reading } & \multicolumn{5}{|c|}{ Part I Beam 9 } \\
\hline Date & Hour & $4^{\prime}-6^{\prime \prime}$ & $6^{\prime}-0^{\prime \prime}$ & $7^{\prime}-6^{\prime \prime}$ & Average & Range \\
\hline $4 / 26 / 2007$ & 0 & -459 & -440 & -448 & -449 & 19 \\
\hline $5 / 4 / 2007$ & 167.5 & -629 & -619 & -456 & -568 & 173 \\
\hline $5 / 11 / 2007$ & 294 & -613 & -607 & -472 & -564 & 141 \\
\hline $5 / 18 / 2007$ & 462 & -531 & -537 & -412 & -493 & 125 \\
\hline $5 / 25 / 2007$ & 621.5 & -516 & -560 & -487 & -521 & 73 \\
\hline $6 / 1 / 2007$ & 781.5 & -375 & -451 & -289 & -372 & 162 \\
\hline $6 / 8 / 2007$ & 933.5 & -354 & -475 & -427 & -419 & 121 \\
\hline $6 / 18 / 2007$ & 1096.5 & -321 & -407 & -373 & -367 & 86 \\
\hline $10 / 10 / 2007$ & 2354 & -509 & -496 & -507 & -504 & 13 \\
\hline $10 / 17 / 2007$ & 2467 & -402 & -426 & -246 & -358 & 180 \\
\hline
\end{tabular}

\begin{tabular}{|r|r|r|r|r|r|r|}
\hline \multicolumn{2}{|l|}{ Time of Reading } & \multicolumn{5}{|c|}{ Part I Beam 10 } \\
\hline Date & Hour & $4^{\prime}-6^{\prime \prime}$ & $6^{\prime}-0 "$ & $7^{\prime}-6 "$ & Average & Range \\
\hline $4 / 26 / 2007$ & 0 & -460 & -455 & -469 & -461 & 14 \\
\hline $5 / 4 / 2007$ & 167.5 & -631 & -629 & -476 & -579 & 155 \\
\hline $5 / 11 / 2007$ & 294 & -586 & -592 & -484 & -554 & 108 \\
\hline $5 / 18 / 2007$ & 462 & -493 & -535 & -415 & -481 & 120 \\
\hline $5 / 25 / 2007$ & 621.5 & -493 & -522 & -502 & -506 & 29 \\
\hline $6 / 1 / 2007$ & 781.5 & -370 & -446 & -424 & -413 & 76 \\
\hline $6 / 8 / 2007$ & 933.5 & -390 & -469 & -455 & -438 & 79 \\
\hline $6 / 18 / 2007$ & 1096.5 & -269 & -388 & -406 & -354 & 137 \\
\hline $10 / 10 / 2007$ & 2354 & -358 & -322 & -126 & -269 & 232 \\
\hline $10 / 17 / 2007$ & 2467 & -302 & -285 & -402 & -330 & 117 \\
\hline
\end{tabular}




\section{D.2 Rebound Hammer Raw Data}

\section{D.2.1 Part I}

Note: Abbreviations for Direction of Impact: H = Horizontal; V.I. =Vertical Inverted

Beam numbers shown to the left of each dataset represent Beams I-\#.

\begin{tabular}{|c|c|c|c|c|c|c|c|c|c|c|c|c|c|}
\hline $\begin{array}{l}E \\
\Phi \\
\Phi \\
\infty\end{array}$ & \multirow[t]{2}{*}{$\frac{1}{0}$} & 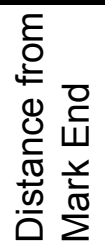 & 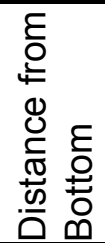 & 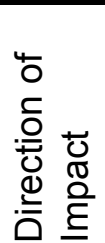 & \multicolumn{8}{|c|}{ Readings } & \multirow[t]{2}{*}{ 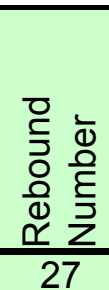 } \\
\hline & & \multirow{2}{*}{ 2'-6" } & $5.5^{\prime \prime}$ & $\mathrm{H}$ & 24 & 27 & 33 & 29 & 24 & 28 & 24 & 30 & \\
\hline & \multirow{5}{*}{ Right } & & $1.5^{\prime \prime}$ & $\bar{H}$ & 30 & 24 & 32 & 24 & 28 & 26 & 24 & 30 & 27 \\
\hline & & \multirow{2}{*}{ 4'-6" } & $5.5^{\prime \prime}$ & $\overline{\mathrm{H}}$ & 18 & 22 & 26 & 28 & 27 & 24 & 30 & 27 & 25 \\
\hline & & & $1.5^{\prime \prime}$ & $\mathrm{H}$ & 30 & 30 & 32 & 30 & 24 & 22 & 30 & 24 & 28 \\
\hline & & \multirow{2}{*}{ 6'-6" } & $5.5^{\prime \prime}$ & $\overline{\mathrm{H}}$ & 34 & 29 & 33 & \begin{tabular}{l|}
36 \\
\end{tabular} & 28 & 33 & 32 & 30 & 32 \\
\hline & & & $1.5^{\prime \prime}$ & $\bar{H}$ & 30 & 25 & 32 & 26 & 23 & 30 & 22 & 27 & 27 \\
\hline & \multirow{6}{*}{ Left } & \multirow{2}{*}{ 2'-6" } & $5.5^{\prime \prime}$ & $\bar{H}$ & 30 & 28 & 27 & 30 & 31 & 32 & 32 & 26 & 30 \\
\hline 1 & & & $1.5^{\prime \prime}$ & $\mathrm{H}$ & 28 & 24 & 28 & 27 & 27 & 28 & 26 & 24 & 27 \\
\hline & & \multirow{2}{*}{ 4'-6" } & $5.5^{\prime \prime}$ & $\bar{H}$ & 26 & 28 & 26 & 29 & 26 & 32 & 26 & 27 & 28 \\
\hline & & & $1.5^{\prime \prime}$ & $\mathrm{H}$ & 28 & 29 & 32 & 28 & 32 & 30 & 28 & 29 & 30 \\
\hline & & \multirow{2}{*}{ 6'-6" } & $5.5^{\prime \prime}$ & $\overline{\mathrm{H}}$ & 28 & 26 & 26 & 30 & 32 & 28 & 30 & 30 & 29 \\
\hline & & & $1.5^{\prime \prime}$ & $\mathrm{H}$ & 42 & 37 & 40 & \begin{tabular}{l|}
32 \\
\end{tabular} & 34 & 31 & 31 & 32 & 35 \\
\hline & \multirow{3}{*}{ Bottom } & $2^{\prime \prime}-6 "$ & --- & $\begin{array}{l}\text { V.I. } \\
\text { V. }\end{array}$ & 34 & 27 & 33 & 33 & 39 & 34 & 29 & 38 & 33 \\
\hline & & 4'-6" & - & V.I. & 34 & 32 & 33 & \begin{tabular}{l|l}
32 \\
\end{tabular} & 32 & 34 & 37 & 37 & 34 \\
\hline & & 6 6'-6" & $\overline{---}$ & $\overline{\text { V.I. }}$ & 36 & 32 & 36 & 35 & 34 & 34 & 32 & 36 & 34 \\
\hline
\end{tabular}




\begin{tabular}{|c|c|c|c|c|c|c|c|c|c|c|c|c|c|}
\hline 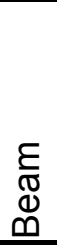 & $\frac{0}{0}$ & 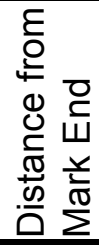 & 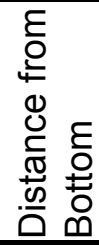 & 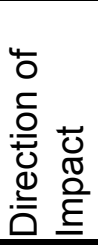 & \multicolumn{8}{|c|}{ Readings } & 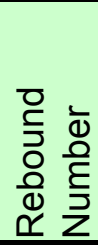 \\
\hline \multirow{15}{*}{2} & \multirow{6}{*}{ Right } & \multirow{2}{*}{$2^{\prime}-6 "$} & $5.5^{\prime \prime}$ & $\mathrm{H}$ & 30 & 32 & 32 & 30 & 33 & 28 & 34 & 29 & 31 \\
\hline & & & $1.5^{\prime \prime}$ & $\mathrm{H}$ & 32 & 33 & 36 & 32 & 34 & 34 & 38 & 34 & 34 \\
\hline & & \multirow{2}{*}{ 4'-6" } & $5.5^{\prime \prime}$ & $\mathrm{H}$ & 38 & 34 & 34 & 38 & 27 & 34 & 36 & 36 & 35 \\
\hline & & & $1.5^{\prime \prime}$ & $\mathrm{H}$ & 34 & 35 & 36 & 37 & 38 & 37 & 34 & 36 & 36 \\
\hline & & \multirow{2}{*}{ 6'-6" } & $5.5^{\prime \prime}$ & $\overline{\mathrm{H}}$ & 26 & 26 & 29 & 28 & 30 & 32 & 33 & 30 & 29 \\
\hline & & & $1.5 "$ & $\mathrm{H}$ & 34 & 31 & 29 & 34 & 30 & 30 & 32 & 31 & 31 \\
\hline & \multirow{6}{*}{ Left } & \multirow{2}{*}{ 2'-6" } & $5.5^{\prime \prime}$ & $\mathrm{H}$ & 28 & 35 & 26 & 28 & 34 & 33 & 29 & 30 & 30 \\
\hline & & & $1.5^{\prime \prime}$ & $\mathrm{H}$ & 21 & 20 & 30 & 36 & 39 & 36 & 34 & 27 & 30 \\
\hline & & \multirow{2}{*}{ 4'-6" } & $5.5^{\prime \prime}$ & $\mathrm{H}$ & 25 & 24 & 26 & 28 & 32 & 26 & 26 & 26 & 27 \\
\hline & & & $1.5^{\prime \prime}$ & $\mathrm{H}$ & 33 & 30 & 37 & 30 & 34 & 32 & 34 & 33 & 33 \\
\hline & & \multirow{2}{*}{ 6'-6" } & $5.5^{\prime \prime}$ & $\mathrm{H}$ & 33 & 24 & 27 & 27 & 26 & 27 & 26 & 26 & 27 \\
\hline & & & $1.5^{\prime \prime}$ & $\mathrm{H}$ & 24 & 38 & 36 & 32 & 38 & 34 & 28 & 34 & 33 \\
\hline & \multirow{3}{*}{ Bottom } & 2'-6" & --- & V.I. & 42 & 40 & 39 & 32 & 41 & 41 & 37 & 44 & 40 \\
\hline & & $4^{\prime}-6 "$ & --- & V.I. & 34 & 38 & 37 & 43 & 41 & 40 & 37 & 38 & 39 \\
\hline & & 6'-6" & --- & V.I. & 31 & 31 & 31 & 32 & 35 & 33 & 32 & 38 & 33 \\
\hline
\end{tabular}

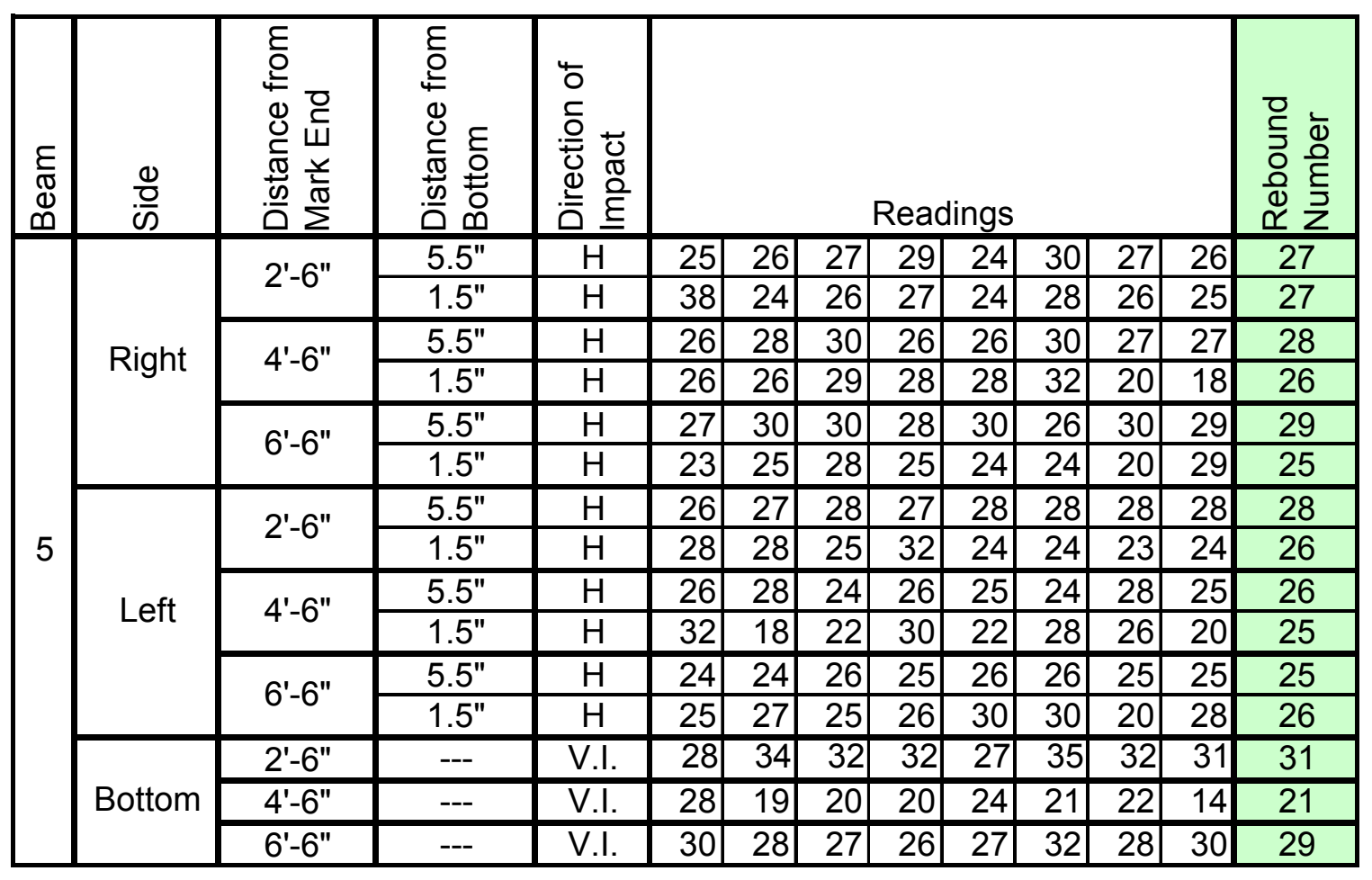




\begin{tabular}{|c|c|c|c|c|c|c|c|c|c|c|c|c|c|}
\hline 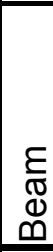 & $\frac{0}{0}$ & 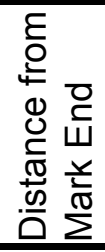 & 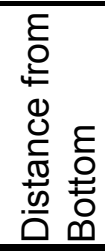 & 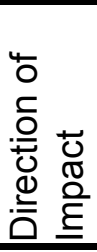 & \multicolumn{8}{|c|}{ Readings } & 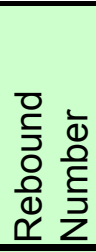 \\
\hline \multirow{15}{*}{6} & \multirow{6}{*}{ Right } & \multirow{2}{*}{ 2'-6" } & $5.5^{\prime \prime}$ & $\mathrm{H}$ & 23 & 24 & 23 & 23 & 24 & 24 & 25 & 24 & 24 \\
\hline & & & $1.5^{\prime \prime}$ & $\mathrm{H}$ & 32 & 23 & 32 & 22 & 26 & 36 & 27 & 24 & 28 \\
\hline & & \multirow{2}{*}{ 4'-6" } & $5.5^{\prime \prime}$ & $\mathrm{H}$ & 30 & 29 & 38 & 33 & 35 & 26 & 32 & 37 & 33 \\
\hline & & & $1.5^{\prime \prime}$ & $\mathrm{H}$ & 23 & 23 & 20 & 22 & 20 & 20 & 18 & 22 & 21 \\
\hline & & \multirow{2}{*}{ 6'-6" } & $5.5^{\prime \prime}$ & $\overline{\mathrm{H}}$ & 28 & 25 & 32 & 27 & 24 & 31 & 29 & 29 & 28 \\
\hline & & & $1.5^{\prime \prime}$ & $\mathrm{H}$ & 27 & 30 & 27 & 32 & 32 & 24 & 29 & 26 & 28 \\
\hline & \multirow{6}{*}{ Left } & \multirow{2}{*}{ 2'-6" } & $5.5^{\prime \prime}$ & $\mathrm{H}$ & 21 & 22 & 28 & 22 & 24 & 20 & 23 & 26 & 23 \\
\hline & & & $1.5^{\prime \prime}$ & $\mathrm{H}$ & 30 & 29 & 30 & 34 & 37 & 38 & 32 & 30 & 33 \\
\hline & & \multirow{2}{*}{ 4'-6" } & $5.5^{\prime \prime}$ & $\overline{\mathrm{H}}$ & 30 & 26 & 30 & 30 & 27 & 28 & 32 & 36 & 30 \\
\hline & & & $1.5^{\prime \prime}$ & $\mathrm{H}$ & 16 & 18 & 20 & 20 & 22 & 19 & 18 & 20 & 19 \\
\hline & & \multirow{2}{*}{ 6'-6" } & $5 . \mathrm{St}^{\prime \prime}$ & $\mathrm{H}$ & 35 & 22 & 34 & 36 & 36 & 34 & 28 & 35 & 33 \\
\hline & & & $1.5^{\prime \prime}$ & $\bar{H}$ & 34 & 38 & 33 & 37 & 30 & 24 & 37 & 36 & 34 \\
\hline & \multirow{3}{*}{ Bottom } & $2^{\prime}-6 "$ & --- & V.I. & 28 & 34 & 32 & 32 & 38 & 35 & 32 & 37 & 34 \\
\hline & & $4^{\prime}-6 "$ & $\overline{---}$ & V.I. & 28 & 29 & 30 & 30 & 34 & 31 & 32 & 34 & 31 \\
\hline & & 6'-6" & --- & V.I. & 30 & 28 & 27 & 26 & 27 & 32 & 28 & 30 & 29 \\
\hline
\end{tabular}

\begin{tabular}{|c|c|c|c|c|c|c|c|c|c|c|c|c|c|}
\hline 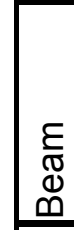 & \multirow[t]{2}{*}{$\frac{0}{0}$} & 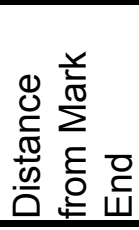 & 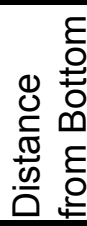 & 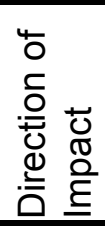 & \multicolumn{8}{|c|}{ Readings } & \multirow[t]{2}{*}{ 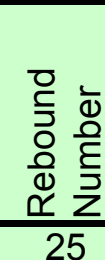 } \\
\hline \multirow{12}{*}{7} & & \multirow{2}{*}{ 2'-6" } & $5.5^{\prime \prime}$ & $\mathrm{H}$ & 24 & 24 & 24 & 24 & 26 & 22 & 27 & 28 & \\
\hline & \multirow{5}{*}{ Right } & & $1.5^{\prime \prime}$ & $\mathrm{H}$ & 40 & 36 & 32 & 36 & 35 & 35 & 38 & 34 & 36 \\
\hline & & \multirow{2}{*}{ 4'-6" } & $5.5^{\prime \prime}$ & $\overline{\mathrm{H}}$ & 27 & 29 & 28 & 28 & 27 & 28 & 28 & 28 & 28 \\
\hline & & & $1.5^{\prime \prime}$ & $\mathrm{H}$ & 25 & 29 & 38 & 32 & 24 & 32 & 30 & 29 & 30 \\
\hline & & $61-6 "$ & $5.5^{\prime \prime}$ & $\bar{H}$ & 29 & 28 & 26 & 26 & 26 & 30 & 27 & 28 & 28 \\
\hline & & & $1.5^{\prime \prime}$ & $\mathrm{H}$ & 32 & 28 & 38 & 35 & 26 & 41 & 39 & 28 & 33 \\
\hline & \multirow{6}{*}{ Left } & \multirow{2}{*}{ 2'-6" } & $5.5^{\prime \prime}$ & $\overline{\mathrm{H}}$ & 28 & 24 & 26 & 28 & 26 & 26 & 29 & 28 & 27 \\
\hline & & & $1.5^{\prime \prime}$ & $\mathrm{H}$ & 37 & 45 & 40 & 36 & 33 & 39 & 43 & 35 & 39 \\
\hline & & \multirow{2}{*}{ 4'-6" } & $5.5^{\prime \prime}$ & $\bar{H}$ & 23 & 28 & 24 & 27 & 27 & 24 & 26 & 26 & 26 \\
\hline & & & 1. I" $^{\prime}$ & $\mathrm{H}$ & 32 & 39 & 37 & 38 & 36 & 38 & 39 & 38 & 37 \\
\hline & & \multirow{2}{*}{ 6'-6" } & $5.5^{\prime \prime}$ & $\bar{H}$ & 24 & 27 & 20 & 23 & 22 & 21 & 26 & 25 & 24 \\
\hline & & & $1.5^{\prime \prime}$ & $\mathrm{H}$ & 36 & 40 & 38 & 34 & 39 & 31 & 33 & - & 36 \\
\hline
\end{tabular}




\begin{tabular}{|c|c|c|c|c|c|c|c|c|c|c|c|c|c|}
\hline $\begin{array}{l}\frac{\varepsilon}{\mathbb{D}} \\
\mathbb{D} \\
\infty\end{array}$ & $\frac{0}{\frac{0}{0}}$ & 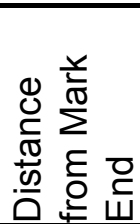 & 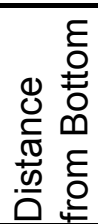 & 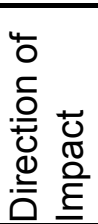 & \multicolumn{8}{|c|}{ Readings } & 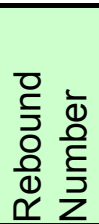 \\
\hline \multirow{12}{*}{8} & \multirow{6}{*}{ Right } & \multirow{2}{*}{ 2'-6" } & $5.5^{\prime \prime}$ & $\mathrm{H}$ & 22 & 24 & 21 & 22 & 23 & 26 & 23 & 19 & 23 \\
\hline & & & 1.5" & $\mathrm{H}$ & 30 & 38 & 32 & 30 & 30 & 37 & 30 & 39 & 33 \\
\hline & & \multirow{2}{*}{ 4'-6" } & $5.5^{\prime \prime}$ & $\overline{\mathrm{H}}$ & 27 & 28 & 28 & 28 & 29 & 28 & 24 & 32 & 28 \\
\hline & & & $1.5^{\prime \prime}$ & $\mathrm{H}$ & 37 & 33 & 34 & 29 & 37 & 34 & 33 & 35 & 34 \\
\hline & & 6' & $5.5^{\prime \prime}$ & $\overline{\mathrm{H}}$ & 24 & 22 & 25 & 22 & 17 & 21 & 17 & 20 & 21 \\
\hline & & $6-6$ & $1.5^{\prime \prime}$ & $\mathrm{H}$ & 25 & 30 & 35 & 22 & 28 & 38 & 21 & 34 & 29 \\
\hline & \multirow{6}{*}{ Left } & \multirow{2}{*}{ 2'-6" } & $5.5^{\prime \prime}$ & $\mathrm{H}$ & 26 & 26 & 24 & 26 & 29 & 24 & 25 & 26 & 26 \\
\hline & & & $1.5^{\prime \prime}$ & $\mathrm{H}$ & 35 & 36 & 26 & 32 & 34 & 34 & 34 & 37 & 34 \\
\hline & & \multirow{2}{*}{ 4'-6" } & $5.5^{\prime \prime}$ & $\mathrm{H}$ & 28 & 28 & 24 & 28 & 26 & 25 & 26 & 28 & 27 \\
\hline & & & $1.5^{\prime \prime}$ & $\mathrm{H}$ & 33 & 36 & 35 & 38 & 35 & 37 & 33 & 38 & 36 \\
\hline & & \multirow{2}{*}{ 6'-6" } & $5.5^{\prime \prime}$ & $\overline{\mathrm{H}}$ & 16 & 16 & 17 & 18 & 24 & 22 & 16 & 18 & 18 \\
\hline & & & 1.5" & $\mathrm{H}$ & 40 & 39 & 28 & 36 & 26 & 38 & 30 & 30 & 33 \\
\hline
\end{tabular}

\begin{tabular}{|c|c|c|c|c|c|c|c|c|c|c|c|c|c|}
\hline 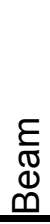 & $\frac{0}{0}$ & 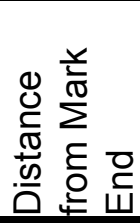 & 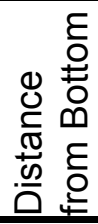 & 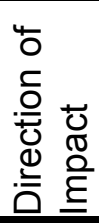 & \multicolumn{8}{|c|}{ Readings } & 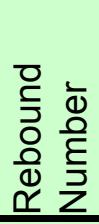 \\
\hline \multirow{12}{*}{9} & \multirow{6}{*}{ Right } & \multirow{2}{*}{ 2'-6" } & $5.5^{\prime \prime}$ & $\mathrm{H}$ & 28 & 26 & 22 & 25 & 24 & 21 & 24 & 22 & 24 \\
\hline & & & $1.5^{\prime \prime}$ & $\mathrm{H}$ & 29 & 34 & 30 & 27 & 27 & 31 & 30 & 33 & 30 \\
\hline & & \multirow{2}{*}{ 4'-6" } & $5.5^{\prime \prime}$ & $\overline{\mathrm{H}}$ & 30 & 28 & 31 & 29 & 33 & 30 & 35 & 29 & 31 \\
\hline & & & $1.5^{\prime \prime}$ & $\mathrm{H}$ & 29 & 32 & 30 & 30 & 26 & 28 & 27 & 30 & 29 \\
\hline & & \multirow{2}{*}{ 6'-6" } & $5.5^{\prime \prime}$ & $\mathrm{H}$ & 30 & 30 & 26 & 30 & 30 & 30 & 31 & 26 & 29 \\
\hline & & & $1.5 "$ & $\mathrm{H}$ & 28 & 23 & 30 & 28 & 27 & 28 & 30 & 32 & 28 \\
\hline & \multirow{6}{*}{ Left } & \multirow{2}{*}{ 2'-6" } & $5.5 "$ & $\mathrm{H}$ & 27 & 32 & 33 & 32 & 29 & 26 & 30 & 28 & 30 \\
\hline & & & 1.5" & $\mathrm{H}$ & 24 & 26 & 28 & 22 & 25 & 22 & 24 & 22 & 24 \\
\hline & & \multirow{2}{*}{ 4'-6" } & $5.5^{\prime \prime}$ & $\mathrm{H}$ & 34 & 36 & 30 & 28 & 30 & 34 & 33 & 34 & 32 \\
\hline & & & 1.5" & $\mathrm{H}$ & 26 & 19 & 27 & 30 & 29 & 23 & 26 & 27 & 26 \\
\hline & & \multirow{2}{*}{ 6'-6" } & $5.5 "$ & $\mathrm{H}$ & 30 & 22 & 62 & 29 & 21 & 25 & 27 & 27 & 30 \\
\hline & & & $1.5^{\prime \prime}$ & $\mathrm{H}$ & 30 & 25 & 28 & 32 & 29 & 30 & 26 & 30 & 29 \\
\hline
\end{tabular}




\begin{tabular}{|c|c|c|c|c|c|c|c|c|c|c|c|c|c|}
\hline $\begin{array}{l}\varepsilon \\
\widetilde{్} \\
\mathscr{ల} \\
\end{array}$ & $\frac{0}{0}$ & 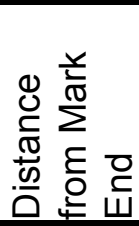 & 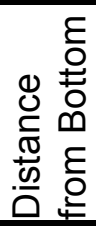 & 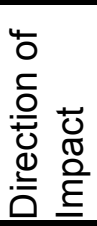 & \multicolumn{8}{|c|}{ Readings } & 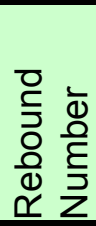 \\
\hline \multirow{12}{*}{10} & \multirow{6}{*}{ Right } & \multirow{2}{*}{ 2'-6" } & $5.5^{\prime \prime}$ & $\mathrm{H}$ & 34 & 29 & 32 & 29 & 33 & 32 & 29 & 29 & 31 \\
\hline & & & $1.5^{\prime \prime}$ & $\mathrm{H}$ & 32 & 36 & 29 & 35 & 27 & 28 & 30 & 29 & 31 \\
\hline & & \multirow{2}{*}{ 4'-6" } & $5.5^{\prime \prime}$ & $\bar{H}$ & 29 & 28 & 29 & 27 & 30 & 30 & 29 & 29 & 29 \\
\hline & & & $1.5^{\prime \prime}$ & $\mathrm{H}$ & 32 & 32 & 27 & 34 & 30 & 28 & 30 & 30 & 30 \\
\hline & & \multirow{2}{*}{ 6'-6" } & $5.5^{\prime \prime}$ & $\overline{\mathrm{H}}$ & 28 & 32 & 33 & 35 & 34 & 35 & 32 & 36 & 33 \\
\hline & & & $1.5^{\prime \prime}$ & $\mathrm{H}$ & 30 & 30 & 30 & 29 & 24 & 30 & 33 & 34 & 30 \\
\hline & \multirow{6}{*}{ Left } & \multirow{2}{*}{ 2'-6" } & $5.5^{\prime \prime}$ & $\overline{\mathrm{H}}$ & 28 & 34 & 32 & 30 & 32 & 30 & 33 & 30 & 31 \\
\hline & & & $1.5^{\prime \prime}$ & $\mathrm{H}$ & 27 & 28 & 30 & 32 & 29 & 32 & 33 & 33 & 31 \\
\hline & & \multirow{2}{*}{ 4'-6" } & $5.5^{\prime \prime}$ & $\overline{\mathrm{H}}$ & 32 & 31 & 34 & 36 & 30 & 30 & 29 & 30 & 32 \\
\hline & & & $1.5^{\prime \prime}$ & $\mathrm{H}$ & 28 & 33 & 33 & 32 & 30 & 30 & 27 & 31 & 31 \\
\hline & & \multirow{2}{*}{ 6'-6" } & $5.5^{\prime \prime}$ & $\overline{\mathrm{H}}$ & 27 & 30 & 38 & 24 & 32 & 30 & 33 & 30 & 31 \\
\hline & & & $1.5^{\prime \prime}$ & $\mathrm{H}$ & 30 & 29 & 31 & 30 & 28 & 30 & 30 & 29 & 30 \\
\hline
\end{tabular}

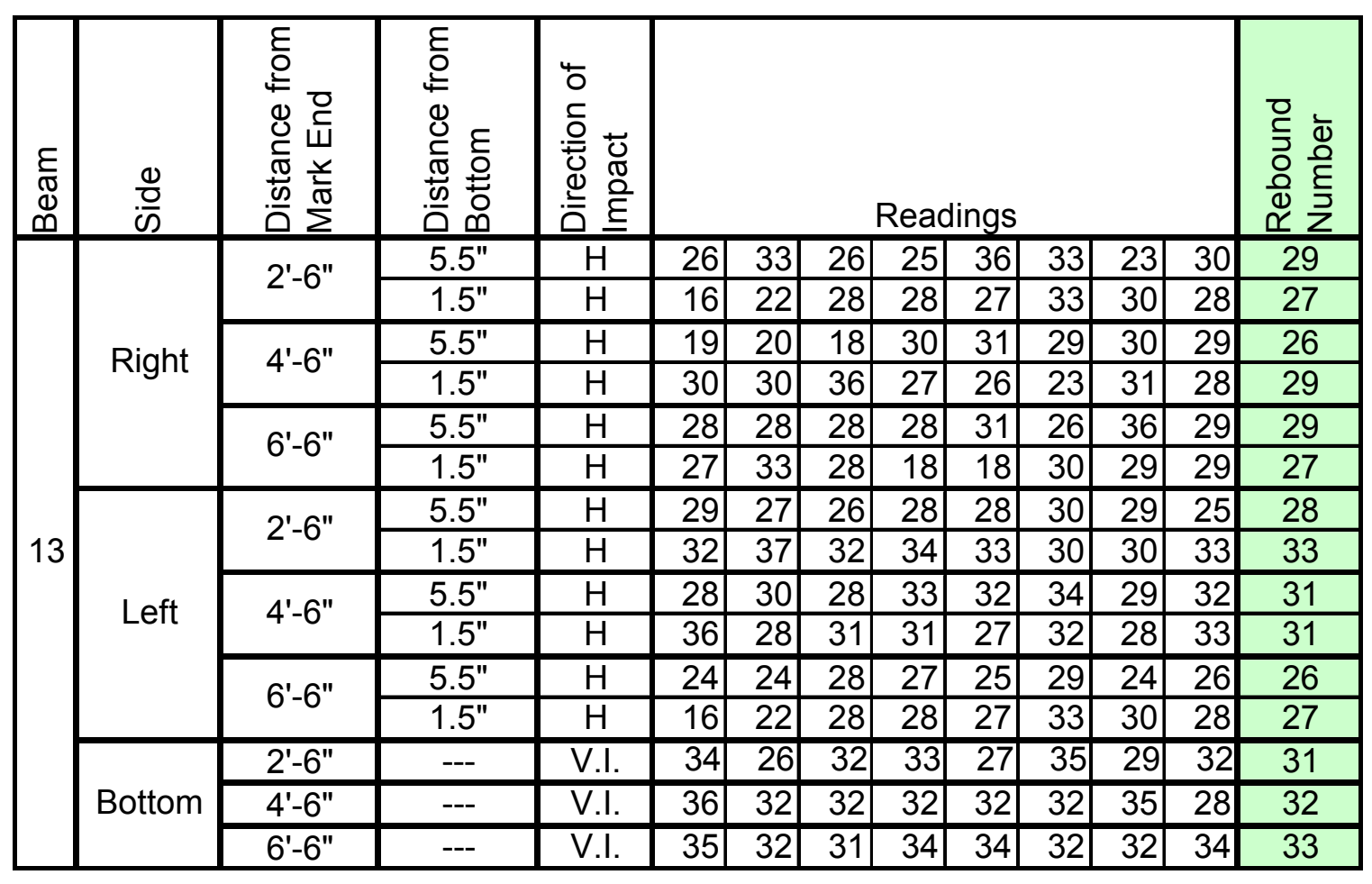




\begin{tabular}{|c|c|c|c|c|c|c|c|c|c|c|c|c|c|}
\hline $\begin{array}{l}\tilde{E} \\
\mathbb{\Phi} \\
\Phi \\
\Phi\end{array}$ & $\frac{0}{0}$ & 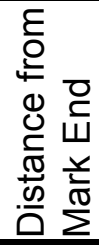 & 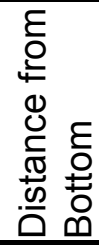 & 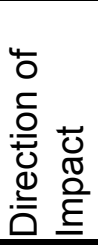 & \multicolumn{8}{|c|}{ Readings } & 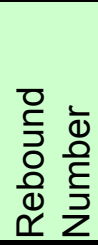 \\
\hline \multirow{15}{*}{14} & \multirow{6}{*}{ Right } & \multirow{2}{*}{ 2'-6" } & $5.5^{\prime \prime}$ & $\mathrm{H}$ & 27 & 32 & 27 & 24 & 36 & 35 & 29 & 29 & 30 \\
\hline & & & $1.5^{\prime \prime}$ & $\mathrm{H}$ & 20 & 22 & 27 & 27 & 29 & 29 & 30 & 31 & 27 \\
\hline & & \multirow{2}{*}{ 4'-6" } & $5.5^{\prime \prime}$ & $\mathrm{H}$ & 18 & 24 & 24 & 26 & 31 & 29 & 30 & 29 & 26 \\
\hline & & & $1.5^{\prime \prime}$ & $\mathrm{H}$ & 29 & 29 & 37 & 28 & 27 & 22 & 30 & 30 & 29 \\
\hline & & \multirow{2}{*}{ 6'-6" } & $5.5^{\prime \prime}$ & $\overline{\mathrm{H}}$ & 28 & 30 & 32 & 28 & 32 & 24 & 30 & 28 & 29 \\
\hline & & & $1.5 "$ & $\mathrm{H}$ & 24 & 29 & 32 & 24 & 24 & 30 & 29 & 30 & 28 \\
\hline & \multirow{6}{*}{ Left } & \multirow{2}{*}{ 2'-6" } & $5.5^{\prime \prime}$ & $\mathrm{H}$ & 27 & 27 & 26 & 28 & 28 & 27 & 29 & 29 & 28 \\
\hline & & & $1.5^{\prime \prime}$ & $\mathrm{H}$ & 30 & 37 & 35 & 34 & 33 & 31 & 31 & 29 & 33 \\
\hline & & $4^{\prime \prime}-6 "$ & $5.5^{\prime \prime}$ & $\mathrm{H}$ & 30 & 30 & 30 & 30 & 32 & 34 & 28 & 33 & 31 \\
\hline & & $4-6$ & $1.5^{\prime \prime}$ & $\mathrm{H}$ & 24 & 28 & 31 & 31 & 33 & 32 & 30 & 33 & 30 \\
\hline & & $61-6 "$ & $5.5^{\prime \prime}$ & $\mathrm{H}$ & 26 & 24 & 28 & 27 & 25 & 25 & 29 & 26 & 26 \\
\hline & & $0-0$ & $1.5^{\prime \prime}$ & $\mathrm{H}$ & 29 & 18 & 26 & 18 & 27 & 26 & 26 & 28 & 25 \\
\hline & & 2'-6" & --- & V.I. & 32 & 26 & 32 & 31 & 27 & 30 & 30 & 32 & 30 \\
\hline & Bottom & $4^{\prime}-6 "$ & --- & V.I. & 30 & 32 & 34 & 33 & 32 & 32 & 36 & 29 & 32 \\
\hline & & 6'-6" & --- & V.I. & 29 & 32 & 32 & 34 & 33 & 34 & 34 & 33 & 33 \\
\hline
\end{tabular}

\begin{tabular}{|c|c|c|c|c|c|c|c|c|c|c|c|c|c|}
\hline $\begin{array}{l}\mathbb{E} \\
\mathbb{D} \\
\Phi \\
\Phi\end{array}$ & $\frac{0}{0}$ & 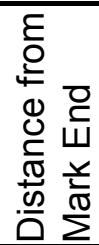 & 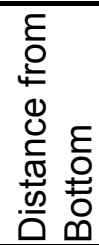 & 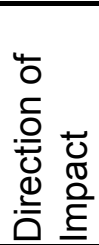 & \multicolumn{8}{|c|}{ Readings } & 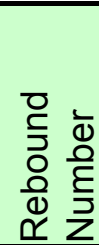 \\
\hline \multirow{15}{*}{17} & \multirow{6}{*}{ Right } & \multirow{2}{*}{ 2'-6" } & $5.5^{\prime \prime}$ & $\mathrm{H}$ & 28 & $\overline{31}$ & 25 & 26 & 24 & 29 & 26 & 32 & 28 \\
\hline & & & $1.5^{\prime \prime}$ & $\mathrm{H}$ & 28 & 30 & 34 & 30 & 36 & 34 & 33 & 34 & 32 \\
\hline & & \multirow{2}{*}{ 4'-6" } & $5.5^{\prime \prime}$ & $\mathrm{H}$ & 33 & 30 & 30 & 31 & 29 & 33 & 37 & 27 & 31 \\
\hline & & & 1.5" & $\mathrm{H}$ & 34 & 34 & 29 & 31 & 30 & 34 & 26 & 34 & 32 \\
\hline & & $6{ }^{\prime}-6 "$ & $5.5^{\prime \prime}$ & $\mathrm{H}$ & 34 & 27 & 37 & 30 & 31 & 33 & 30 & 30 & 32 \\
\hline & & $6-6$ & $1.5^{\prime \prime}$ & $\mathrm{H}$ & 33 & 34 & 28 & 36 & 31 & 34 & 33 & 31 & 33 \\
\hline & \multirow{6}{*}{ Left } & \multirow{2}{*}{ 2'-6" } & $5.5^{\prime \prime}$ & $\mathrm{H}$ & - & - & - & - & - & - & - & - & - \\
\hline & & & $1.5^{\prime \prime}$ & $\mathrm{H}$ & - & - & - & - & - & - & - & - & - \\
\hline & & \multirow{2}{*}{ 4'-6" } & $5.5^{\prime \prime}$ & $\mathrm{H}$ & - & - & - & - & - & - & - & - & - \\
\hline & & & $1.5^{\prime \prime}$ & $\mathrm{H}$ & - & - & - & - & - & - & - & - & - \\
\hline & & \multirow{2}{*}{ 6'-6" } & $5.5^{\prime \prime}$ & $\mathrm{H}$ & - & - & - & - & - & - & - & - & - \\
\hline & & & $1.5^{\prime \prime}$ & $\mathrm{H}$ & - & - & - & - & - & - & - & - & - \\
\hline & \multirow{3}{*}{ Bottom } & $2^{\prime}-6 "$ & -- & V.I. & 36 & 38 & 36 & 38 & 34 & 34 & 50 & 30 & 37 \\
\hline & & $44^{\prime}-6 "$ & $\overline{---}$ & V.I. & 40 & 38 & 38 & 40 & 33 & 40 & 37 & 40 & 38 \\
\hline & & $6^{\prime}-6^{\prime \prime}$ & $\overline{---}$ & V.I. & 40 & 40 & 35 & 40 & 38 & 37 & 40 & 35 & 38 \\
\hline
\end{tabular}




\begin{tabular}{|c|c|c|c|c|c|c|c|c|c|c|c|c|c|}
\hline $\begin{array}{l}\tilde{E} \\
\mathbb{\Phi} \\
\Phi \\
\Phi\end{array}$ & $\frac{0}{0}$ & 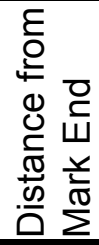 & 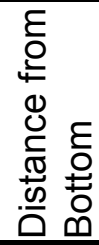 & 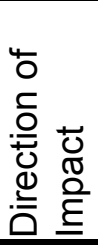 & \multicolumn{8}{|c|}{ Readings } & 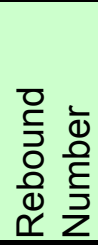 \\
\hline \multirow{15}{*}{18} & \multirow{6}{*}{ Right } & \multirow{2}{*}{ 2'-6" } & $5.5^{\prime \prime}$ & $\mathrm{H}$ & 30 & 25 & 38 & 29 & 29 & 29 & 28 & 30 & 30 \\
\hline & & & $1.5^{\prime \prime}$ & $\mathrm{H}$ & 34 & 28 & 28 & 29 & 30 & 32 & 28 & 28 & 30 \\
\hline & & \multirow{2}{*}{ 4'-6" } & $5.5^{\prime \prime}$ & $\mathrm{H}$ & 31 & 30 & 30 & 34 & 34 & 35 & 30 & 32 & 32 \\
\hline & & & $1.5^{\prime \prime}$ & $\mathrm{H}$ & 38 & 34 & 34 & 34 & 28 & 29 & 28 & 28 & 32 \\
\hline & & $61-6 "$ & $5.5^{\prime \prime}$ & $\mathrm{H}$ & 30 & 26 & 27 & 28 & 29 & 29 & 28 & 25 & 28 \\
\hline & & $0-0$ & $1.5 "$ & $\mathrm{H}$ & 28 & 29 & 28 & 30 & 24 & 29 & 28 & 30 & 28 \\
\hline & \multirow{6}{*}{ Left } & \multirow{2}{*}{ 2'-6" } & $5.5^{\prime \prime}$ & $\mathrm{H}$ & - & - & - & - & - & - & - & - & - \\
\hline & & & $1.5^{\prime \prime}$ & $\mathrm{H}$ & - & - & - & - & - & - & - & - & - \\
\hline & & \multirow{2}{*}{ 4'-6" } & $5.5^{\prime \prime}$ & $\mathrm{H}$ & - & - & - & - & - & - & - & - & - \\
\hline & & & $1.5^{\prime \prime}$ & $\mathrm{H}$ & - & - & - & - & - & - & - & - & - \\
\hline & & \multirow{2}{*}{ 6'-6" } & $5.5^{\prime \prime}$ & $\mathrm{H}$ & - & - & - & - & - & - & - & - & - \\
\hline & & & $1.5^{\prime \prime}$ & $\mathrm{H}$ & - & - & - & - & - & - & - & - & - \\
\hline & \multirow{3}{*}{ Bottom } & 2'-6" & --- & V.I. & 34 & 36 & 38 & 37 & 34 & 38 & 44 & 40 & 38 \\
\hline & & $4^{\prime}-6 "$ & --- & V.I. & 32 & 34 & 32 & 34 & 34 & 36 & 37 & 38 & 35 \\
\hline & & 6'-6" & --- & V.I. & 36 & 30 & 33 & 36 & 35 & 35 & 40 & 36 & 35 \\
\hline
\end{tabular}

\section{D.2.2 Part II}

Note: Abbreviations for Direction of Impact: $\mathrm{H}=$ Horizontal; V.I. = Vertical Inverted

Beam numbers shown to the left of each dataset represent Beams II-\#. 


\begin{tabular}{|c|c|c|c|c|c|c|c|c|c|c|c|c|c|}
\hline 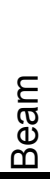 & $\frac{0}{\frac{0}{0}}$ & 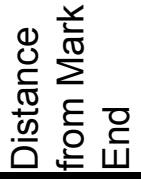 & 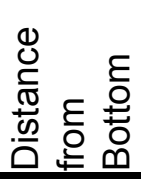 & 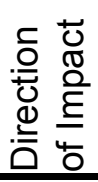 & \multicolumn{8}{|c|}{ Readings } & 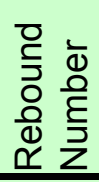 \\
\hline \multirow{15}{*}{1} & \multirow{6}{*}{ Right } & \multirow{2}{*}{ 1'-6" } & $5.5^{\prime \prime}$ & $\mathrm{H}$ & 14 & 18 & 15 & 16 & 15 & 17 & 24 & 20 & 17 \\
\hline & & & $1.5^{\prime \prime}$ & $\mathrm{H}$ & 22 & 23 & 18 & 18 & 22 & 23 & 22 & 21 & 21 \\
\hline & & \multirow{2}{*}{ 3'-0" } & $5.5^{\prime \prime}$ & $\overline{\mathrm{H}}$ & 16 & 17 & 14 & 12 & 16 & 16 & 14 & 14 & 15 \\
\hline & & & $1.5^{\prime \prime}$ & $\mathrm{H}$ & 20 & 17 & 17 & 22 & 20 & 22 & 21 & 20 & 20 \\
\hline & & \multirow{2}{*}{ 4'-6" } & $5.5 "$ & $\overline{\mathrm{H}}$ & 19 & 18 & 16 & 20 & 17 & 16 & 20 & 15 & 18 \\
\hline & & & 1.5" & $\mathrm{H}$ & 14 & 13 & 16 & 15 & 17 & 18 & 19 & 14 & 16 \\
\hline & \multirow{6}{*}{ Left } & \multirow{2}{*}{ 1'-6" } & $5.5^{\prime \prime}$ & $\overline{\mathrm{H}}$ & - & - & - & - & - & - & - & - & - \\
\hline & & & $1.5^{\prime \prime}$ & $\mathrm{H}$ & - & - & - & - & - & - & - & - & - \\
\hline & & \multirow{2}{*}{ 3'-0" } & $5.5^{\prime \prime}$ & $\mathrm{H}$ & - & - & - & - & - & - & - & - & - \\
\hline & & & 1.5" & $\mathrm{H}$ & - & - & - & - & - & - & - & - & - \\
\hline & & \multirow{2}{*}{ 4'-6" } & $5.5^{\prime \prime}$ & $\mathrm{H}$ & - & - & - & - & - & - & - & - & - \\
\hline & & & $1.5^{\prime \prime}$ & $\mathrm{H}$ & - & - & - & - & - & - & - & - & - \\
\hline & \multirow{3}{*}{ Bottom } & 1'-6" & --- & V.I. & 27 & 32 & 28 & 26 & 31 & 28 & 24 & 29 & 28 \\
\hline & & 3'-0" & --- & V.I. & 28 & 36 & 28 & 28 & 30 & 30 & 28 & 26 & 29 \\
\hline & & 4'-6" & --- & V.I. & 20 & 25 & 24 & 24 & 19 & 27 & 33 & 22 & 24 \\
\hline
\end{tabular}

\begin{tabular}{|c|c|c|c|c|c|c|c|c|c|c|c|c|c|}
\hline $\begin{array}{l}\varepsilon \\
\mathbb{\sigma} \\
\mathbb{D} \\
\infty\end{array}$ & $\frac{0}{\infty}$ & 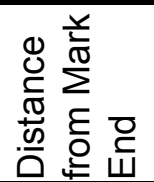 & 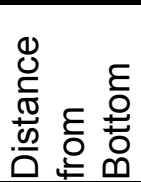 & 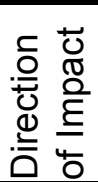 & \multicolumn{8}{|c|}{ Readings } & 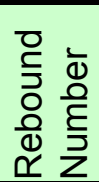 \\
\hline \multirow{15}{*}{2} & \multirow{6}{*}{ Right } & \multirow{2}{*}{ 1'-10" } & $5.5^{\prime \prime}$ & $\mathrm{H}$ & 15 & 16 & 17 & 18 & 15 & 16 & 16 & 14 & 16 \\
\hline & & & $1.5^{\prime \prime}$ & $\mathrm{H}$ & 12 & 20 & 15 & 22 & 18 & 20 & 16 & 20 & 18 \\
\hline & & \multirow{2}{*}{ 3'-4" } & $5.5^{\prime \prime}$ & $\overline{\mathrm{H}}$ & 16 & 18 & 14 & 15 & 14 & $\overline{14}$ & 14 & 12 & 15 \\
\hline & & & $1.5^{\prime \prime}$ & $\mathrm{H}$ & 20 & 16 & 16 & 16 & 20 & 18 & 14 & 14 & 17 \\
\hline & & \multirow{2}{*}{ 4'-6" } & $5.5^{\prime \prime}$ & $\overline{\mathrm{H}}$ & 18 & 14 & 18 & 16 & 17 & $\overline{16}$ & 16 & 10 & 16 \\
\hline & & & $1.5^{\prime \prime}$ & $\overline{\mathrm{H}}$ & 18 & 16 & 20 & 19 & 19 & 16 & 20 & 20 & 19 \\
\hline & \multirow{6}{*}{ Left } & \multirow{2}{*}{ 1'-10" } & $5.5^{\prime \prime}$ & $\overline{\mathrm{H}}$ & 14 & 16 & 17 & 18 & 17 & 20 & 18 & 17 & 17 \\
\hline & & & $1.5^{\prime \prime}$ & $\mathrm{H}$ & 16 & 16 & 17 & 16 & 12 & 18 & 14 & 17 & 16 \\
\hline & & "4" & $5.5^{\prime \prime}$ & $\overline{\mathrm{H}}$ & 16 & 16 & 17 & 16 & 17 & 15 & 14 & 16 & 16 \\
\hline & & $3-4$ & 1.5" & $\mathrm{H}$ & 17 & 15 & 16 & 19 & 18 & 16 & 16 & 16 & 17 \\
\hline & & 1' 6" & $5.5^{\prime \prime}$ & $\overline{\mathrm{H}}$ & 16 & 12 & 12 & 14 & $\overline{10}$ & $\overline{18}$ & 17 & 16 & $\overline{14}$ \\
\hline & & $4-0$ & 1.5" & $\overline{\mathrm{H}}$ & 19 & 15 & 18 & 18 & 15 & 17 & 14 & 16 & 17 \\
\hline & & 1'-10" & --- & V.I. & \begin{tabular}{l|}
42 \\
\end{tabular} & 40 & 39 & 32 & 41 & 41 & 37 & 44 & 40 \\
\hline & Bottom & $3^{\prime}-4 "$ & $\overline{---}$ & V.I. & 34 & 38 & 37 & 43 & $\overline{41}$ & $\overline{40}$ & 37 & 38 & $\overline{39}$ \\
\hline & & $\overline{4 '-6 "}$ & $\overline{---}$ & V.I. & 31 & 31 & 31 & 32 & 35 & $\overline{33}$ & 32 & 38 & $\overline{33}$ \\
\hline
\end{tabular}




\begin{tabular}{|c|c|c|c|c|c|c|c|c|c|c|c|c|c|}
\hline $\begin{array}{l}\mathbb{E} \\
\mathbb{\mathbb { N }} \\
\Phi \\
\oplus\end{array}$ & $\frac{0}{\circ}$ & 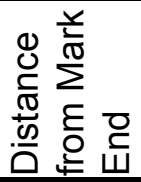 & 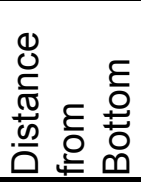 & 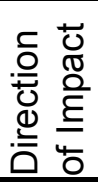 & \multicolumn{8}{|c|}{ Readings } & 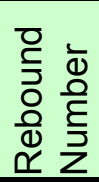 \\
\hline \multirow{15}{*}{3} & \multirow{6}{*}{ Right } & \multirow{2}{*}{ 1'-10" } & $5.5^{\prime \prime}$ & $\mathrm{H}$ & - & - & - & - & - & - & - & - & - \\
\hline & & & $1.5^{\prime \prime}$ & $\mathrm{H}$ & - & - & - & - & - & - & - & - & - \\
\hline & & \multirow{2}{*}{ 3'-4" } & $5.5^{\prime \prime}$ & $\overline{\mathrm{H}}$ & - & - & - & - & - & - & - & - & - \\
\hline & & & $1.5^{\prime \prime}$ & $\mathrm{H}$ & - & - & - & - & - & - & - & - & - \\
\hline & & \multirow{2}{*}{ 4'-6" } & $5.5^{\prime \prime}$ & $\overline{\mathrm{H}}$ & - & - & - & - & - & - & - & - & - \\
\hline & & & 1.5" & $\mathrm{H}$ & - & - & - & - & - & - & - & - & - \\
\hline & \multirow{6}{*}{ Left } & \multirow{2}{*}{ 1'-10" } & $5.5^{\prime \prime}$ & $\mathrm{H}$ & 29 & 33 & 28 & 27 & 26 & 24 & 28 & 26 & 28 \\
\hline & & & $1.5^{\prime \prime}$ & $\mathrm{H}$ & 29 & 26 & 24 & 25 & 26 & 24 & 26 & 25 & 26 \\
\hline & & \multirow{2}{*}{ 3'-4" } & $5.5 "$ & $\mathrm{H}$ & 28 & 27 & 28 & 30 & 29 & 26 & 27 & 28 & 28 \\
\hline & & & $1.5^{\prime \prime}$ & $\mathrm{H}$ & 26 & 28 & 25 & 26 & 26 & 26 & 24 & 28 & 26 \\
\hline & & \multirow{2}{*}{ 4'-6" } & $5.5^{\prime \prime}$ & $\overline{\mathrm{H}}$ & 28 & 30 & 30 & 29 & 29 & 29 & 32 & 29 & 30 \\
\hline & & & $1.5^{\prime \prime}$ & $\mathrm{H}$ & 23 & 34 & 30 & 27 & 25 & 26 & 25 & 27 & 27 \\
\hline & \multirow{3}{*}{ Bottom } & 1'-10" & --- & V.I. & 37 & 32 & 28 & 27 & 27 & 32 & 36 & 34 & 32 \\
\hline & & 3'-4" & $\overline{---}$ & V.I. & 33 & 30 & 29 & 29 & 32 & 29 & 30 & 32 & 31 \\
\hline & & 4'-6" & --- & V.I. & 36 & 30 & 32 & 37 & 34 & 30 & 29 & 30 & 32 \\
\hline
\end{tabular}

\begin{tabular}{|c|c|c|c|c|c|c|c|c|c|c|c|c|c|}
\hline $\begin{array}{l}E \\
\mathbb{\Phi} \\
\Phi\end{array}$ & $\frac{8}{0}$ & 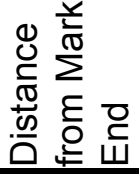 & 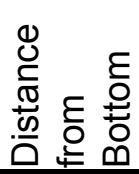 & 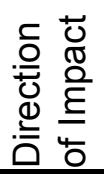 & \multicolumn{8}{|c|}{ Readings } & 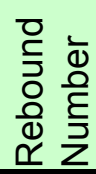 \\
\hline \multirow{15}{*}{4} & \multirow{6}{*}{ Right } & \multirow{2}{*}{ 1'-6" } & $5.5^{\prime \prime}$ & $\mathrm{H}$ & 29 & 30 & 32 & 30 & 28 & 28 & 34 & 31 & 30 \\
\hline & & & $1.5^{\prime \prime}$ & $\mathrm{H}$ & 32 & 30 & 30 & 28 & 28 & 28 & 27 & 28 & 29 \\
\hline & & \multirow{2}{*}{ 3'-0" } & $5.5^{\prime \prime}$ & $\overline{\mathrm{H}}$ & 34 & 28 & 35 & 30 & 29 & 33 & 34 & 31 & 32 \\
\hline & & & $1.5^{\prime \prime}$ & $\mathrm{H}$ & 23 & 25 & 30 & 25 & 26 & 26 & 29 & 25 & 26 \\
\hline & & \multirow{2}{*}{ 4'-6" } & $5.5^{\prime \prime}$ & $\overline{\mathrm{H}}$ & 33 & 31 & 32 & 36 & 32 & 32 & 32 & 30 & 32 \\
\hline & & & $1.5^{\prime \prime}$ & $\mathrm{H}$ & 30 & 28 & 30 & 24 & 24 & 27 & 28 & 30 & 28 \\
\hline & \multirow{6}{*}{ Left } & \multirow{2}{*}{ 1'-6" } & $5.5^{\prime \prime}$ & $\mathrm{H}$ & 28 & 32 & 29 & 28 & 32 & 30 & 32 & 27 & 30 \\
\hline & & & $1.5^{\prime \prime}$ & $\mathrm{H}$ & 28 & 31 & 28 & 24 & 27 & 26 & 30 & 32 & 28 \\
\hline & & \multirow{2}{*}{ 3'-0" } & $5.5^{\prime \prime}$ & $\overline{\mathrm{H}}$ & 29 & 26 & 25 & 30 & 28 & 28 & 28 & 34 & 29 \\
\hline & & & $1.5^{\prime \prime}$ & $\mathrm{H}$ & 26 & 30 & 23 & 26 & 22 & 28 & 26 & 25 & 26 \\
\hline & & \multirow{2}{*}{ 4'-6" } & $5.5^{\prime \prime}$ & $\overline{\mathrm{H}}$ & 30 & 28 & 27 & 28 & 32 & 30 & 29 & 28 & 29 \\
\hline & & & $1.5^{\prime \prime}$ & $\mathrm{H}$ & 30 & 27 & 23 & 26 & 24 & 29 & 21 & 24 & 26 \\
\hline & \multirow{3}{*}{ Bottom } & 1'-6" & -- & V.I. & 33 & 34 & 32 & 33 & 33 & 32 & 32 & 35 & 33 \\
\hline & & $3^{\prime}-0 "$ & $\overline{---}$ & $\overline{\text { V.I. }}$ & 34 & 34 & 38 & 35 & 30 & 32 & 30 & 36 & 34 \\
\hline & & 4'-6" & -- & V.I. & 40 & 34 & 35 & 37 & 34 & 42 & 38 & 37 & 37 \\
\hline
\end{tabular}




\begin{tabular}{|c|c|c|c|c|c|c|c|c|c|c|c|c|c|}
\hline $\begin{array}{l}\text { E } \\
\mathbb{D} \\
0\end{array}$ & $\frac{\infty}{0}$ & 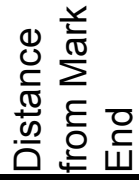 & 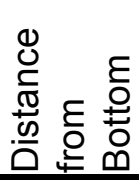 & 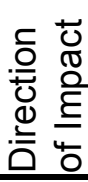 & \multicolumn{8}{|c|}{ Readings } & 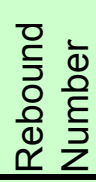 \\
\hline \multirow{12}{*}{5} & \multirow{6}{*}{ Right } & \multirow{2}{*}{ 1'-10" } & $5.5^{\prime \prime}$ & $\mathrm{H}$ & 27 & 30 & 26 & 28 & 27 & 29 & 29 & 26 & 28 \\
\hline & & & $1.5^{\prime \prime}$ & $\mathrm{H}$ & 36 & 36 & 28 & 25 & 36 & 40 & 37 & 37 & 34 \\
\hline & & \multirow{2}{*}{$3^{\prime}-4 "$} & $5.5^{\prime \prime}$ & $\bar{H}$ & 26 & 28 & 30 & 33 & 27 & 28 & 28 & 28 & 29 \\
\hline & & & $1.5^{\prime \prime}$ & $\mathrm{H}$ & 36 & 30 & 32 & 38 & 36 & 35 & 33 & 34 & 34 \\
\hline & & \multirow{2}{*}{ 4'-6" } & $5.5^{\prime \prime}$ & $\overline{\mathrm{H}}$ & 30 & 30 & 26 & 27 & 30 & 25 & 26 & 26 & 28 \\
\hline & & & $1.5^{\prime \prime}$ & $\mathrm{H}$ & 40 & 36 & 38 & 35 & 33 & 38 & 39 & 39 & 37 \\
\hline & \multirow{6}{*}{ Left } & \multirow{2}{*}{ 1'-10" } & $5.5^{\prime \prime}$ & $\overline{\mathrm{H}}$ & 13 & 15 & 13 & 29 & 13 & 13 & 29 & 14 & 17 \\
\hline & & & $1.5^{\prime \prime}$ & $\mathrm{H}$ & 32 & 36 & 36 & 36 & 37 & 30 & 32 & 39 & 35 \\
\hline & & \multirow{2}{*}{ 3'-4" } & $5.5^{\prime \prime}$ & $\overline{\mathrm{H}}$ & 24 & 23 & 24 & 25 & 26 & 25 & 27 & 27 & 25 \\
\hline & & & $1.5^{\prime \prime}$ & $\mathrm{H}$ & 30 & 34 & 30 & 30 & 34 & 34 & 36 & 37 & 33 \\
\hline & & \multirow{2}{*}{ 4'-6" } & $5.5^{\prime \prime}$ & $\overline{\mathrm{H}}$ & 28 & 30 & 28 & 25 & 30 & 24 & 19 & 27 & 26 \\
\hline & & & $1.5^{\prime \prime}$ & $\mathrm{H}$ & 38 & 36 & 35 & 40 & 38 & 38 & 36 & 38 & 37 \\
\hline
\end{tabular}

\begin{tabular}{|c|c|c|c|c|c|c|c|c|c|c|c|c|c|}
\hline $\begin{array}{l}E \\
\mathbb{\varpi} \\
\Phi\end{array}$ & $\frac{\infty}{0}$ & 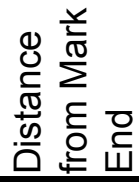 & 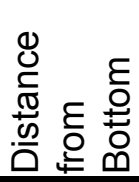 & 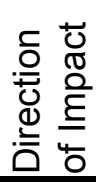 & \multicolumn{8}{|c|}{ Readings } & 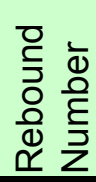 \\
\hline \multirow{12}{*}{7} & \multirow{6}{*}{ Right } & \multirow{2}{*}{$1^{\prime}-10^{\prime \prime}$} & $5.5^{\prime \prime}$ & $\mathrm{H}$ & 23 & 26 & 25 & 25 & 25 & 23 & 30 & 25 & 25 \\
\hline & & & $1.5^{\prime \prime}$ & $\mathrm{H}$ & 36 & 38 & 37 & 25 & 36 & 39 & 35 & 37 & 35 \\
\hline & & \multirow{2}{*}{ 3'-4" } & $5.5^{\prime \prime}$ & $\overline{\mathrm{H}}$ & 27 & 26 & 27 & 28 & 27 & 30 & 30 & 24 & 27 \\
\hline & & & $1.5^{\prime \prime}$ & $\mathrm{H}$ & 34 & 35 & 33 & 36 & 33 & 33 & 38 & 37 & 35 \\
\hline & & \multirow{2}{*}{ 4'-6" } & $5.5^{\prime \prime}$ & $\overline{\mathrm{H}}$ & 26 & 32 & 24 & 29 & 26 & 29 & 23 & 22 & 26 \\
\hline & & & $1.5^{\prime \prime}$ & $\bar{H}$ & 34 & 40 & 36 & 30 & 33 & 34 & 35 & 38 & 35 \\
\hline & \multirow{6}{*}{ Left } & \multirow{2}{*}{ 1'-10" } & $5.5^{\prime \prime}$ & $\overline{\mathrm{H}}$ & 28 & 26 & 25 & 27 & 26 & 24 & 27 & 27 & 26 \\
\hline & & & $1 . \mathrm{s}^{\mathrm{n}}$ & $\mathrm{H}$ & 34 & 37 & 35 & 35 & 37 & 40 & 29 & 34 & 35 \\
\hline & & \multirow{2}{*}{ 3'-4" } & $5 . \mathrm{n}^{\mathrm{n}}$ & $\overline{\mathrm{H}}$ & 26 & 22 & 26 & 22 & 24 & 26 & 25 & 28 & 25 \\
\hline & & & $1.5^{\prime \prime}$ & $\bar{H}$ & 39 & 37 & 36 & 40 & 38 & 35 & 34 & 37 & 37 \\
\hline & & \multirow{2}{*}{ 4'-6" } & $5.5^{\prime \prime}$ & $\overline{\mathrm{H}}$ & 30 & 27 & 28 & 29 & 26 & 27 & 30 & 27 & 28 \\
\hline & & & 1. " $^{\prime \prime}$ & $\bar{H}$ & 34 & 33 & 32 & 33 & 36 & 33 & 31 & 32 & 33 \\
\hline
\end{tabular}




\begin{tabular}{|c|c|c|c|c|c|c|c|c|c|c|c|c|c|}
\hline $\begin{array}{r}E \\
0 \\
0 \\
0\end{array}$ & $\frac{0}{0}$ & 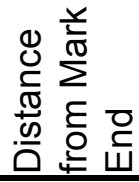 & 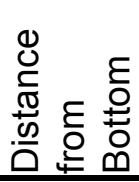 & 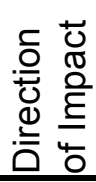 & \multicolumn{8}{|c|}{ Readings } & 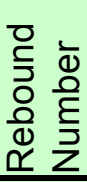 \\
\hline \multirow{12}{*}{8} & \multirow{6}{*}{ Right } & \multirow{2}{*}{$1^{\prime}-6 "$} & $5.5^{\prime \prime}$ & $\mathrm{H}$ & 30 & 27 & 27 & 29 & 27 & 28 & 26 & 26 & 28 \\
\hline & & & $1.5^{\prime \prime}$ & $\mathrm{H}$ & 33 & 32 & 35 & 35 & 34 & 36 & 35 & 32 & 34 \\
\hline & & \multirow{2}{*}{ 3'-0" } & $5.5^{\prime \prime}$ & $\overline{\mathrm{H}}$ & 29 & 25 & 30 & 30 & 26 & 27 & 26 & 25 & 27 \\
\hline & & & $1.5^{\prime \prime}$ & $\mathrm{H}$ & 34 & 34 & 34 & 33 & 33 & 36 & 34 & 33 & 34 \\
\hline & & \multirow{2}{*}{ 4'-6" } & $5.5^{\prime \prime}$ & $\overline{\mathrm{H}}$ & 32 & 26 & 28 & 30 & 30 & 27 & 28 & 30 & 29 \\
\hline & & & $1.5^{\prime \prime}$ & $\mathrm{H}$ & 34 & 35 & 34 & 31 & 32 & 32 & 31 & 30 & 32 \\
\hline & \multirow{6}{*}{ Left } & \multirow{2}{*}{ 1'-6" } & $5.5^{\prime \prime}$ & $\overline{\mathrm{H}}$ & 32 & 28 & 27 & 29 & 30 & 25 & 29 & 29 & 29 \\
\hline & & & $1.5^{\prime \prime}$ & $\mathrm{H}$ & 40 & 38 & 35 & 35 & 33 & 37 & 34 & 33 & 36 \\
\hline & & \multirow{2}{*}{ 3'-0" } & $5.5^{\prime \prime}$ & $\overline{\mathrm{H}}$ & 26 & 28 & 28 & 27 & 27 & 28 & 26 & 26 & 27 \\
\hline & & & $1.5^{\prime \prime}$ & $\mathrm{H}$ & 32 & 38 & 36 & 36 & 38 & 35 & 38 & 39 & 37 \\
\hline & & \multirow{2}{*}{ 4'-6" } & $5.5^{\prime \prime}$ & $\overline{\mathrm{H}}$ & 28 & 27 & 26 & 28 & 24 & 29 & 28 & 26 & 27 \\
\hline & & & $1.5^{\prime \prime}$ & $\mathrm{H}$ & 26 & 32 & 34 & 33 & 38 & 36 & 33 & 28 & 33 \\
\hline
\end{tabular}

\begin{tabular}{|c|c|c|c|c|c|c|c|c|c|c|c|c|c|}
\hline $\begin{aligned} E \\
0 \\
0 \\
0\end{aligned}$ & $\frac{\Phi}{0}$ & 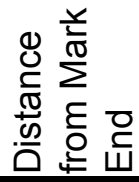 & 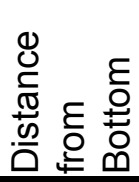 & 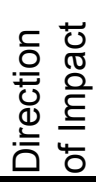 & \multicolumn{8}{|c|}{ Readings } & 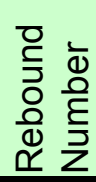 \\
\hline \multirow{12}{*}{9} & \multirow{6}{*}{ Right } & \multirow{2}{*}{ 1'-6" } & $5.5^{\prime \prime}$ & $\mathrm{H}$ & 26 & 24 & 30 & 25 & 24 & 24 & 19 & 24 & 25 \\
\hline & & & $1.5^{\prime \prime}$ & $\mathrm{H}$ & 38 & 38 & 42 & 41 & 37 & 34 & 37 & 34 & 38 \\
\hline & & \multirow{2}{*}{ 3'-0" } & $5.5^{\prime \prime}$ & $\overline{\mathrm{H}}$ & 22 & 22 & 21 & 21 & 23 & 26 & 25 & 24 & 23 \\
\hline & & & $1.5^{\prime \prime}$ & $\mathrm{H}$ & 28 & 33 & 31 & 36 & 36 & 32 & 30 & 34 & 33 \\
\hline & & \multirow{2}{*}{ 4'-6" } & $5.5^{\prime \prime}$ & $\overline{\mathrm{H}}$ & 30 & 28 & 27 & 27 & 30 & 24 & 28 & 25 & 27 \\
\hline & & & $1.5^{\prime \prime}$ & $\bar{H}$ & 36 & 33 & 36 & 38 & 35 & 35 & 35 & 38 & 36 \\
\hline & \multirow{6}{*}{ Left } & \multirow{2}{*}{ 1'-6" } & $5.5^{\prime \prime}$ & $\overline{\mathrm{H}}$ & 29 & 26 & 28 & 28 & 26 & 25 & 23 & 27 & 27 \\
\hline & & & $1.5^{\prime \prime}$ & $\mathrm{H}$ & 30 & 34 & 29 & 34 & 34 & 34 & 37 & 37 & 34 \\
\hline & & \multirow{2}{*}{ 3'-0" } & $5 . \mathrm{m}^{\mathrm{\prime \prime}}$ & $\overline{\mathrm{H}}$ & 22 & 23 & 24 & 23 & 24 & 25 & 26 & 20 & 23 \\
\hline & & & $1.5^{\prime \prime}$ & $\bar{H}$ & 36 & 36 & 35 & 36 & 34 & 37 & 35 & 30 & 35 \\
\hline & & \multirow{2}{*}{ 4'-6" } & $5.5^{\prime \prime}$ & $\overline{\mathrm{H}}$ & 25 & 26 & 25 & 26 & 23 & 27 & 24 & 26 & 25 \\
\hline & & & 1. " $^{\prime \prime}$ & $\bar{H}$ & 28 & 29 & 30 & 34 & 30 & 32 & 30 & 31 & 31 \\
\hline
\end{tabular}




\begin{tabular}{|c|c|c|c|c|c|c|c|c|c|c|c|c|c|}
\hline $\begin{array}{r}E \\
0 \\
0 \\
0\end{array}$ & $\frac{0}{0}$ & 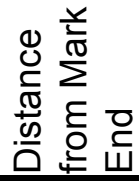 & 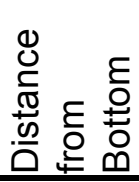 & 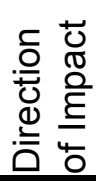 & \multicolumn{8}{|c|}{ Readings } & 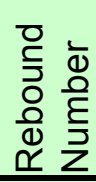 \\
\hline \multirow{12}{*}{10} & \multirow{6}{*}{ Right } & \multirow{2}{*}{$1^{\prime}-6 "$} & $5.5^{\prime \prime}$ & $\mathrm{H}$ & 25 & 28 & 24 & 24 & 21 & 21 & 24 & 22 & 24 \\
\hline & & & $1.5^{\prime \prime}$ & $\mathrm{H}$ & 40 & 36 & 36 & 36 & 40 & 37 & 37 & 40 & 38 \\
\hline & & \multirow{2}{*}{ 3'-0" } & $5.5^{\prime \prime}$ & $\overline{\mathrm{H}}$ & 25 & 27 & 25 & 28 & 25 & 25 & 26 & 23 & 26 \\
\hline & & & $1.5^{\prime \prime}$ & $\mathrm{H}$ & 36 & 37 & 38 & 36 & 37 & 38 & 36 & 37 & 37 \\
\hline & & \multirow{2}{*}{ 4'-6" } & $5.5^{\prime \prime}$ & $\overline{\mathrm{H}}$ & 24 & 25 & 26 & 24 & 23 & 27 & 26 & 25 & 25 \\
\hline & & & $1.5^{\prime \prime}$ & $\mathrm{H}$ & 39 & 36 & 42 & 39 & 38 & 35 & 36 & 36 & 38 \\
\hline & \multirow{6}{*}{ Left } & \multirow{2}{*}{ 1'-6" } & $5.5^{\prime \prime}$ & $\bar{H}$ & 26 & 25 & 25 & 26 & 24 & 25 & 25 & 25 & 25 \\
\hline & & & $1.5^{\prime \prime}$ & $\mathrm{H}$ & 30 & 34 & 28 & 36 & 37 & 35 & 35 & 35 & 34 \\
\hline & & \multirow{2}{*}{ 3'-0" } & $5.5^{\prime \prime}$ & $\overline{\mathrm{H}}$ & 26 & 24 & 27 & 25 & 25 & 27 & 25 & 29 & 26 \\
\hline & & & $1.5^{\prime \prime}$ & $\mathrm{H}$ & 34 & 37 & 37 & 30 & 35 & 32 & 34 & 36 & 34 \\
\hline & & \multirow{2}{*}{ 4'-6" } & $5.5^{\prime \prime}$ & $\overline{\mathrm{H}}$ & 28 & 25 & 24 & 21 & 23 & 25 & 26 & 25 & 25 \\
\hline & & & $1.5^{\prime \prime}$ & $\vec{H}$ & 32 & 46 & 39 & 38 & 40 & 38 & 38 & 34 & 38 \\
\hline
\end{tabular}

\begin{tabular}{|c|c|c|c|c|c|c|c|c|c|c|c|c|c|}
\hline $\begin{array}{l}E \\
\mathbb{D} \\
\Phi\end{array}$ & $\frac{0}{0}$ & 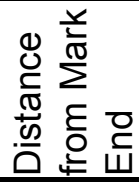 & 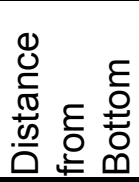 & 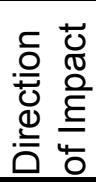 & \multicolumn{8}{|c|}{ Readings } & 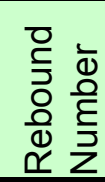 \\
\hline \multirow{15}{*}{11} & \multirow{6}{*}{ Right } & \multirow{2}{*}{ 1'-10" } & $5.5^{\prime \prime}$ & $\mathrm{H}$ & 18 & 23 & 26 & 22 & 20 & 22 & 20 & 22 & 22 \\
\hline & & & $1.5^{\prime \prime}$ & $\mathrm{H}$ & 25 & 24 & 25 & 23 & 24 & 22 & 23 & 24 & 24 \\
\hline & & \multirow{2}{*}{ 3'-4" } & $5.5^{\prime \prime}$ & $\overline{\mathrm{H}}$ & 18 & 20 & 16 & 24 & 20 & 22 & 20 & 18 & 20 \\
\hline & & & $1.5^{\prime \prime}$ & $\mathrm{H}$ & 24 & 28 & 22 & 20 & 21 & 21 & 23 & 20 & 22 \\
\hline & & \multirow{2}{*}{ 4'-6" } & $5.5^{\prime \prime}$ & $\overline{\mathrm{H}}$ & 26 & 24 & 23 & 22 & 22 & 24 & 24 & 25 & 24 \\
\hline & & & $1 . \mathrm{s}^{\prime \prime}$ & $\mathrm{H}$ & 22 & 25 & 20 & 24 & 20 & 23 & 25 & 23 & 23 \\
\hline & \multirow{6}{*}{ Left } & \multirow{2}{*}{ 1'-10" } & $5.5^{\prime \prime}$ & $\bar{H}$ & 24 & 20 & 22 & 25 & 20 & 23 & 20 & 22 & 22 \\
\hline & & & $1 . \mathrm{F}^{\mathrm{\prime}}$ & $\mathrm{H}$ & 29 & 24 & 24 & 22 & 26 & 22 & 22 & 24 & 24 \\
\hline & & \multirow{2}{*}{ 3'-4" } & $5.5^{\prime \prime}$ & $\overline{\mathrm{H}}$ & 22 & 22 & 22 & 22 & 20 & 22 & 19 & 18 & 21 \\
\hline & & & $1.5^{\prime \prime}$ & $\mathrm{H}$ & 22 & 21 & 24 & 24 & 22 & 20 & 23 & 23 & 22 \\
\hline & & \multirow{2}{*}{ 4'-6" } & $5.5^{\prime \prime}$ & $\overline{\mathrm{H}}$ & 24 & 22 & 20 & 20 & 24 & 24 & 21 & 23 & 22 \\
\hline & & & $1.5^{\prime \prime}$ & $\overline{\mathrm{H}}$ & 20 & 25 & 22 & 24 & 24 & 24 & 24 & 24 & 23 \\
\hline & \multirow{3}{*}{ Bottom } & 1'-10" & $\overline{---}$ & V.I. & 30 & 28 & 26 & 28 & 31 & 28 & 34 & 30 & 29 \\
\hline & & $3^{\prime}-4 "$ & -- & V.I. & 27 & 30 & 32 & 31 & 38 & 33 & 27 & 28 & 31 \\
\hline & & 4'-6" & - & V.I. & 29 & 29 & 28 & 29 & 29 & 29 & 29 & 29 & 29 \\
\hline
\end{tabular}




\begin{tabular}{|c|c|c|c|c|c|c|c|c|c|c|c|c|c|}
\hline $\begin{array}{l}\varepsilon \\
\mathbb{D} \\
\Phi \\
\oplus \\
\end{array}$ & $\frac{0}{\frac{0}{0}}$ & 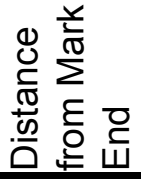 & 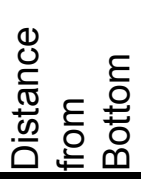 & 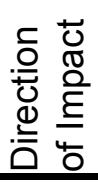 & \multicolumn{8}{|c|}{ Readings } & 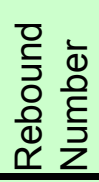 \\
\hline \multirow{15}{*}{12} & \multirow{6}{*}{ Right } & \multirow{2}{*}{ 1'-10" } & $5.5^{\prime \prime}$ & $\mathrm{H}$ & 18 & 24 & 23 & 20 & 19 & 18 & 20 & 16 & 20 \\
\hline & & & $1.5^{\prime \prime}$ & $\mathrm{H}$ & 21 & 29 & 18 & 24 & 20 & 23 & 28 & 20 & 23 \\
\hline & & \multirow{2}{*}{ 3'-4" } & $5.5^{\prime \prime}$ & $\bar{H}$ & 24 & 15 & 19 & 14 & 13 & 14 & 14 & 24 & 17 \\
\hline & & & $1.5^{\prime \prime}$ & $\mathrm{H}$ & 24 & 22 & 18 & 16 & 20 & 16 & 19 & 21 & 20 \\
\hline & & \multirow{2}{*}{ 4'-6" } & $5.5 "$ & $\overline{\mathrm{H}}$ & 20 & 14 & 17 & 22 & 15 & 14 & 13 & 20 & 17 \\
\hline & & & $1.5^{\prime \prime}$ & $\mathrm{H}$ & 21 & 18 & 18 & 18 & 19 & 17 & 19 & 17 & 18 \\
\hline & \multirow{6}{*}{ Left } & \multirow{2}{*}{ 1'-10" } & $5.5^{\prime \prime}$ & $\overline{\mathrm{H}}$ & 20 & 20 & 20 & 17 & 17 & 18 & 16 & 19 & 18 \\
\hline & & & $1.5^{\prime \prime}$ & $\mathrm{H}$ & 20 & 16 & 20 & 20 & 22 & 20 & 18 & 18 & 19 \\
\hline & & \multirow{2}{*}{$3^{\prime}-$} & $5.5^{\prime \prime}$ & $\mathrm{H}$ & 21 & 14 & 15 & 17 & 13 & 12 & 13 & 14 & 15 \\
\hline & & & 1.5" & $\mathrm{H}$ & 17 & 10 & 15 & 12 & 19 & 12 & 10 & 15 & 14 \\
\hline & & \multirow{2}{*}{ 4'-6" } & $5.5 "$ & $\overline{\mathrm{H}}$ & 20 & 14 & 18 & 14 & 12 & 15 & 17 & 14 & 16 \\
\hline & & & $1.5^{\prime \prime}$ & $\mathrm{H}$ & 17 & 15 & 12 & 11 & 18 & 15 & 12 & 16 & 15 \\
\hline & \multirow{3}{*}{ Bottom } & 1'-10" & --- & V.I. & 29 & 28 & 33 & 30 & 32 & 42 & 36 & 33 & 33 \\
\hline & & 3'-4" & -- & V.I. & 26 & 30 & 30 & 37 & 35 & 32 & 29 & 31 & 31 \\
\hline & & 4'-6" & --- & V.I. & 34 & 32 & 32 & 36 & 30 & 28 & 30 & 27 & 31 \\
\hline
\end{tabular}

\begin{tabular}{|c|c|c|c|c|c|c|c|c|c|c|c|c|c|}
\hline $\begin{array}{l}\mathcal{E} \\
\mathbb{D} \\
\mathbb{\Phi} \\
\Phi\end{array}$ & $\frac{0}{0}$ & 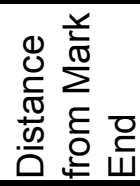 & 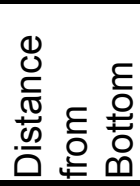 & 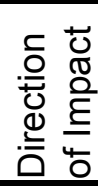 & \multicolumn{8}{|c|}{ Readings } & 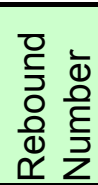 \\
\hline \multirow{12}{*}{13} & \multirow{6}{*}{ Right } & \multirow{2}{*}{ 1'-6" } & $5.5^{\prime \prime}$ & $\mathrm{H}$ & 26 & 23 & 24 & 22 & 24 & 22 & 24 & 23 & 24 \\
\hline & & & $1.5^{\prime \prime}$ & $\mathrm{H}$ & 34 & 37 & 36 & 37 & 30 & 33 & 32 & 36 & 34 \\
\hline & & \multirow{2}{*}{ 3'-0" } & $5.5^{\prime \prime}$ & $\mathrm{H}$ & 24 & 24 & 23 & 24 & 24 & 24 & 24 & 24 & 24 \\
\hline & & & $1.5^{\prime \prime}$ & $\mathrm{H}$ & 31 & 39 & 29 & 34 & 36 & 38 & 37 & 36 & 35 \\
\hline & & \multirow{2}{*}{ 4'-6" } & $5.5^{\prime \prime}$ & $\overline{\mathrm{H}}$ & 18 & 20 & 26 & 23 & 22 & 24 & 22 & 23 & 22 \\
\hline & & & 1.5" & $\mathrm{H}$ & 35 & 32 & 33 & 36 & 37 & 34 & 36 & 36 & 35 \\
\hline & \multirow{6}{*}{ Left } & \multirow{2}{*}{ 1'-6" } & $5.5^{\prime \prime}$ & $\overline{\mathrm{H}}$ & 20 & 22 & 20 & 23 & 18 & 20 & 24 & 20 & 21 \\
\hline & & & $1.5 "$ & $\mathrm{H}$ & 34 & 34 & 34 & 35 & 32 & 40 & 34 & 36 & 35 \\
\hline & & \multirow{2}{*}{ 3'-0" } & $5.5^{\prime \prime}$ & $\mathrm{H}$ & 17 & 28 & 20 & 16 & 18 & 25 & 20 & 22 & 21 \\
\hline & & & $1.5^{\prime \prime}$ & $\mathrm{H}$ & 36 & 30 & 30 & 32 & 35 & 28 & 26 & 32 & 31 \\
\hline & & \multirow{2}{*}{ 4'-6" } & $5.5^{\prime \prime}$ & $\mathrm{H}$ & 24 & 24 & 26 & 22 & 27 & 23 & 24 & 22 & 24 \\
\hline & & & $1.5^{\prime \prime}$ & $\mathrm{H}$ & 32 & 34 & 35 & 30 & 35 & 35 & 36 & 32 & 34 \\
\hline
\end{tabular}




\begin{tabular}{|c|c|c|c|c|c|c|c|c|c|c|c|c|c|}
\hline $\begin{array}{l}\text { E } \\
\mathbb{D} \\
0\end{array}$ & $\frac{0}{0}$ & 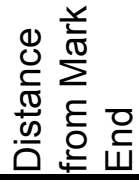 & 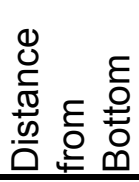 & 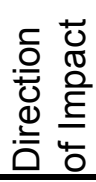 & \multicolumn{8}{|c|}{ Readings } & 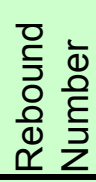 \\
\hline \multirow{12}{*}{14} & \multirow{6}{*}{ Right } & \multirow{2}{*}{$1^{\prime}-6 "$} & $5.5^{\prime \prime}$ & $\mathrm{H}$ & 22 & 23 & 22 & 18 & 21 & 25 & 22 & 22 & 22 \\
\hline & & & $1.5^{\prime \prime}$ & $\mathrm{H}$ & 34 & 33 & 34 & 37 & 36 & 35 & 39 & 32 & 35 \\
\hline & & \multirow{2}{*}{ 3'-0" } & $5.5^{\prime \prime}$ & $\overline{\mathrm{H}}$ & 24 & 24 & 29 & 24 & 24 & 24 & 22 & 24 & 24 \\
\hline & & & $1.5^{\prime \prime}$ & $\mathrm{H}$ & 35 & 37 & 37 & 38 & 35 & 32 & 36 & 35 & 36 \\
\hline & & \multirow{2}{*}{ 4'-6" } & $5.5^{\prime \prime}$ & $\overline{\mathrm{H}}$ & 25 & 25 & 26 & 25 & 22 & 27 & 25 & 25 & 25 \\
\hline & & & $1.5^{\prime \prime}$ & $\mathrm{H}$ & 38 & 35 & 38 & 35 & 38 & 38 & 32 & 37 & 36 \\
\hline & \multirow{6}{*}{ Left } & \multirow{2}{*}{ 1'-6" } & $5.5^{\prime \prime}$ & $\overline{\mathrm{H}}$ & 24 & 23 & 22 & 26 & 26 & 24 & 24 & 26 & 24 \\
\hline & & & $1.5^{\prime \prime}$ & $\mathrm{H}$ & 33 & 32 & 35 & 33 & 34 & 37 & 38 & 33 & 34 \\
\hline & & \multirow{2}{*}{ 3'-0" } & $5.5^{\prime \prime}$ & $\overline{\mathrm{H}}$ & 25 & 26 & 25 & 24 & 20 & 24 & 24 & 24 & 24 \\
\hline & & & $1.5^{\prime \prime}$ & $\mathrm{H}$ & 37 & 36 & 32 & 32 & 34 & 35 & 34 & 36 & 35 \\
\hline & & \multirow{2}{*}{ 4'-6" } & $5.5^{\prime \prime}$ & $\overline{\mathrm{H}}$ & 24 & 26 & 24 & 27 & 23 & 26 & 26 & 24 & 25 \\
\hline & & & $1.5^{\prime \prime}$ & $\mathrm{H}$ & 32 & 35 & 32 & 36 & 31 & 29 & 35 & 30 & 33 \\
\hline
\end{tabular}

\begin{tabular}{|c|c|c|c|c|c|c|c|c|c|c|c|c|c|}
\hline $\begin{array}{l}\varepsilon \\
\mathbb{\Phi} \\
\Phi \\
0\end{array}$ & $\frac{\infty}{0}$ & 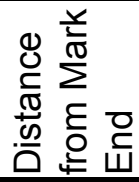 & 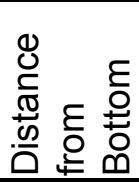 & 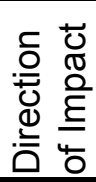 & \multicolumn{8}{|c|}{ Readings } & 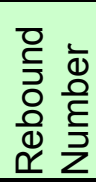 \\
\hline \multirow{12}{*}{15} & \multirow{6}{*}{ Right } & \multirow{2}{*}{ 1'-6" } & $5.5^{\prime \prime}$ & $\mathrm{H}$ & 18 & 18 & 22 & 25 & 22 & 29 & 21 & 19 & 22 \\
\hline & & & $1.5^{\prime \prime}$ & $\mathrm{H}$ & 31 & 34 & 32 & 37 & 36 & 32 & 39 & 34 & 34 \\
\hline & & \multirow{2}{*}{ 3'-0" } & $5.5^{\prime \prime}$ & $\overline{\mathrm{H}}$ & 16 & 18 & 18 & 16 & 19 & 18 & 20 & 23 & 19 \\
\hline & & & $1.5^{\prime \prime}$ & $\mathrm{H}$ & 36 & 35 & 35 & 38 & 40 & 24 & 37 & 33 & 35 \\
\hline & & \multirow{2}{*}{ 4'-6" } & $5.5^{\prime \prime}$ & $\overline{\mathrm{H}}$ & 20 & 18 & 20 & 22 & 16 & 15 & 16 & 21 & 19 \\
\hline & & & $1.5^{\prime \prime}$ & $\mathrm{H}$ & 39 & 35 & 29 & 36 & 30 & 34 & 35 & 34 & 34 \\
\hline & \multirow{6}{*}{ Left } & \multirow{2}{*}{ 1'-6" } & $5.5^{\prime \prime}$ & $\overline{\mathrm{H}}$ & 29 & 20 & 22 & 22 & 27 & 20 & 29 & 22 & 24 \\
\hline & & & $1.5^{\prime \prime}$ & $\mathrm{H}$ & 42 & 34 & 32 & 42 & 40 & 42 & 44 & 42 & 40 \\
\hline & & \multirow{2}{*}{ 3'-0" } & $5.5^{\prime \prime}$ & $\overline{\mathrm{H}}$ & 22 & 22 & 18 & 23 & 28 & 21 & 24 & 20 & 22 \\
\hline & & & $1.5^{\prime \prime}$ & $\overline{\mathrm{H}}$ & 39 & 35 & 34 & 40 & 43 & 36 & 36 & 40 & 38 \\
\hline & & \multirow{2}{*}{ 4'-6" } & $5.5^{\prime \prime}$ & $\overline{\mathrm{H}}$ & 20 & 19 & 18 & 20 & 24 & 20 & 22 & 19 & 20 \\
\hline & & & $1.5^{\prime \prime}$ & $\mathrm{H}$ & 37 & 35 & 38 & 35 & 40 & 39 & 38 & 34 & 37 \\
\hline
\end{tabular}




\begin{tabular}{|c|c|c|c|c|c|c|c|c|c|c|c|c|c|}
\hline $\begin{array}{r}E \\
0 \\
0 \\
0\end{array}$ & $\frac{0}{0}$ & 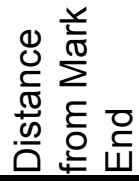 & 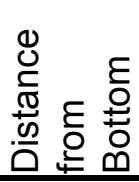 & 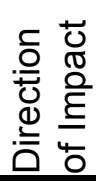 & \multicolumn{8}{|c|}{ Readings } & 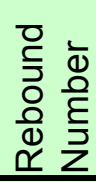 \\
\hline \multirow{12}{*}{17} & \multirow{6}{*}{ Right } & \multirow{2}{*}{ 1'-10" } & $5.5^{\prime \prime}$ & $\mathrm{H}$ & 22 & 23 & 23 & 21 & 19 & 25 & 22 & 20 & 22 \\
\hline & & & $1.5^{\prime \prime}$ & $\mathrm{H}$ & 34 & 31 & 34 & 33 & 36 & 35 & 34 & 30 & 33 \\
\hline & & \multirow{2}{*}{ 3'-4" } & $5.5^{\prime \prime}$ & $\overline{\mathrm{H}}$ & 24 & 22 & 26 & 20 & 23 & 21 & 25 & 25 & 23 \\
\hline & & & $1.5^{\prime \prime}$ & $\mathrm{H}$ & 36 & 34 & 34 & 37 & 36 & 35 & 34 & 37 & 35 \\
\hline & & \multirow{2}{*}{ 4'-6" } & $5.5^{\prime \prime}$ & $\overline{\mathrm{H}}$ & 26 & 24 & 25 & 23 & 24 & 25 & 26 & 24 & 25 \\
\hline & & & $1 . \mathrm{F}^{\mathrm{\prime}}$ & $\bar{H}$ & 34 & 32 & 31 & 36 & 34 & 32 & 32 & 31 & 33 \\
\hline & \multirow{6}{*}{ Left } & \multirow{2}{*}{ 1'-10" } & $5.5^{\prime \prime}$ & $\overline{\mathrm{H}}$ & 24 & 25 & 24 & 24 & 22 & 23 & 26 & 20 & 24 \\
\hline & & & $1.5^{\prime \prime}$ & $\mathrm{H}$ & 30 & 36 & 40 & 42 & 37 & 36 & 37 & 36 & 37 \\
\hline & & \multirow{2}{*}{ 3'-4" } & $5.5^{\prime \prime}$ & $\overline{\mathrm{H}}$ & 22 & 23 & 23 & 24 & 22 & 21 & 20 & 21 & 22 \\
\hline & & & $1.5^{\prime \prime}$ & $\mathrm{H}$ & 36 & 30 & 27 & 32 & 30 & 30 & 34 & 24 & 30 \\
\hline & & \multirow{2}{*}{ 4'-6" } & $5.5^{\prime \prime}$ & $\overline{\mathrm{H}}$ & 24 & 22 & 19 & 20 & 20 & 29 & 22 & 23 & 22 \\
\hline & & & $1.5^{\prime \prime}$ & $\mathrm{H}$ & 30 & 36 & 38 & 33 & 32 & 36 & 34 & 36 & 34 \\
\hline
\end{tabular}

\begin{tabular}{|c|c|c|c|c|c|c|c|c|c|c|c|c|c|}
\hline $\begin{array}{l}E \\
\mathbb{\varpi} \\
\infty\end{array}$ & $\frac{8}{0}$ & 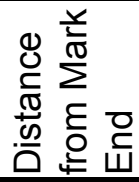 & 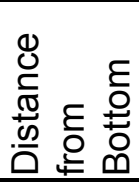 & 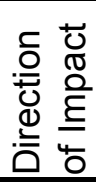 & \multicolumn{8}{|c|}{ Readings } & 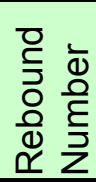 \\
\hline \multirow{12}{*}{18} & \multirow{6}{*}{ Right } & \multirow{2}{*}{$1^{\prime}-10^{\prime \prime}$} & $5.5^{\prime \prime}$ & $\mathrm{H}$ & 19 & 18 & 16 & 20 & 20 & 20 & 17 & 20 & 19 \\
\hline & & & $1.5^{\prime \prime}$ & $\mathrm{H}$ & 36 & 34 & 37 & 32 & 35 & 34 & 31 & 31 & 34 \\
\hline & & \multirow{2}{*}{ 3'-4" } & $5.5^{\prime \prime}$ & $\overline{\mathrm{H}}$ & 20 & 20 & 18 & 20 & 27 & 20 & 24 & 21 & 21 \\
\hline & & & $1.5^{\prime \prime}$ & $\mathrm{H}$ & 36 & 40 & 36 & 36 & 40 & 36 & 36 & 39 & 37 \\
\hline & & \multirow{2}{*}{ 4'-6" } & $5.5^{\prime \prime}$ & $\overline{\mathrm{H}}$ & 22 & 24 & 20 & 21 & 22 & 21 & 22 & 16 & 21 \\
\hline & & & $1.5^{\prime \prime}$ & $\mathrm{H}$ & 34 & 34 & 40 & 38 & 36 & 36 & 38 & 38 & 37 \\
\hline & \multirow{6}{*}{ Left } & \multirow{2}{*}{ 1'-10" } & $5.5^{\prime \prime}$ & $\overline{\mathrm{H}}$ & 22 & 22 & 27 & 23 & 19 & 22 & 23 & 21 & 22 \\
\hline & & & $1.5^{\prime \prime}$ & $\mathrm{H}$ & 34 & 33 & 35 & 36 & 35 & 37 & 32 & 33 & 34 \\
\hline & & \multirow{2}{*}{$3^{\prime}-4 "$} & $5.5^{\prime \prime}$ & $\overline{\mathrm{H}}$ & 20 & 20 & 25 & 20 & 22 & 21 & 21 & 23 & 22 \\
\hline & & & $1.5^{\prime \prime}$ & $\overline{\mathrm{H}}$ & 34 & 37 & 32 & 36 & 34 & 34 & 34 & 38 & 35 \\
\hline & & \multirow{2}{*}{ 4'-6" } & $5.5^{\prime \prime}$ & $\overline{\mathrm{H}}$ & 20 & 22 & 23 & 21 & 21 & 20 & 22 & 23 & 22 \\
\hline & & & $1.5^{\prime \prime}$ & $\mathrm{H}$ & 38 & 35 & 39 & 39 & 34 & 35 & 36 & 30 & 36 \\
\hline
\end{tabular}




\begin{tabular}{|c|c|c|c|c|c|c|c|c|c|c|c|c|c|}
\hline $\begin{array}{r}E \\
0 \\
0 \\
0\end{array}$ & $\frac{0}{0}$ & 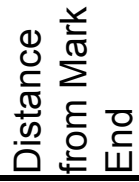 & 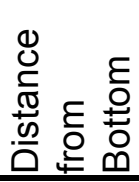 & 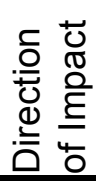 & \multicolumn{8}{|c|}{ Readings } & 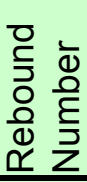 \\
\hline \multirow{12}{*}{19} & \multirow{6}{*}{ Right } & \multirow{2}{*}{$1^{\prime}-6 "$} & $5.5^{\prime \prime}$ & $\mathrm{H}$ & 21 & 23 & 26 & 18 & 18 & 26 & 25 & 26 & 23 \\
\hline & & & $1.5^{\prime \prime}$ & $\mathrm{H}$ & 33 & 34 & 34 & 37 & 38 & 37 & 37 & 37 & 36 \\
\hline & & \multirow{2}{*}{ 3'-0" } & $5.5^{\prime \prime}$ & $\overline{\mathrm{H}}$ & 22 & 22 & 25 & 19 & 25 & 19 & 19 & 22 & 22 \\
\hline & & & $1.5^{\prime \prime}$ & $\mathrm{H}$ & 36 & 36 & 34 & 32 & 33 & 33 & 33 & 34 & 34 \\
\hline & & \multirow{2}{*}{ 4'-6" } & $5.5^{\prime \prime}$ & $\overline{\mathrm{H}}$ & 27 & 28 & 30 & 27 & 32 & 18 & 20 & 24 & 26 \\
\hline & & & $1.5^{\prime \prime}$ & $\mathrm{H}$ & 38 & 38 & 36 & 36 & 35 & 34 & 37 & 30 & 36 \\
\hline & \multirow{6}{*}{ Left } & \multirow{2}{*}{ 1'-6" } & $5.5^{\prime \prime}$ & $\overline{\mathrm{H}}$ & 20 & 20 & 22 & 26 & 24 & 24 & 24 & 22 & 23 \\
\hline & & & $1.5^{\prime \prime}$ & $\mathrm{H}$ & 38 & 36 & 34 & 36 & 35 & 35 & 35 & 38 & 36 \\
\hline & & \multirow{2}{*}{ 3'-0" } & $5.5^{\prime \prime}$ & $\overline{\mathrm{H}}$ & 22 & 22 & 22 & 26 & 24 & 25 & 24 & 20 & 23 \\
\hline & & & $1.5^{\prime \prime}$ & $\mathrm{H}$ & 36 & 36 & 36 & 35 & 34 & 31 & 32 & 38 & 35 \\
\hline & & \multirow{2}{*}{ 4'-6" } & $5.5^{\prime \prime}$ & $\overline{\mathrm{H}}$ & 16 & 24 & 20 & 20 & 20 & 24 & 24 & 26 & 22 \\
\hline & & & $1.5^{\prime \prime}$ & $\mathrm{H}$ & 39 & 39 & 33 & 36 & 36 & 34 & 34 & 36 & 36 \\
\hline
\end{tabular}

\begin{tabular}{|c|c|c|c|c|c|c|c|c|c|c|c|c|c|}
\hline $\begin{array}{l}\varepsilon \\
\mathbb{\Phi} \\
\Phi \\
0\end{array}$ & $\frac{\infty}{0}$ & 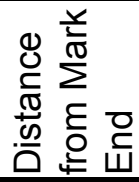 & 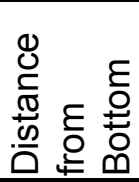 & 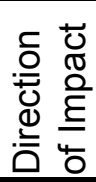 & \multicolumn{8}{|c|}{ Readings } & 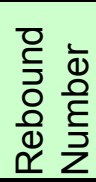 \\
\hline \multirow{12}{*}{20} & \multirow{6}{*}{ Right } & \multirow{2}{*}{ 1'-6" } & $5.5^{\prime \prime}$ & $\mathrm{H}$ & 23 & 30 & 23 & 21 & 26 & 26 & 29 & 30 & 26 \\
\hline & & & $1.5^{\prime \prime}$ & $\mathrm{H}$ & 43 & 37 & 42 & 37 & 40 & 34 & 32 & 34 & 37 \\
\hline & & \multirow{2}{*}{ 3'-0" } & $5.5^{\prime \prime}$ & $\overline{\mathrm{H}}$ & 42 & 20 & 24 & 18 & 22 & 20 & 25 & 25 & 25 \\
\hline & & & $1.5^{\prime \prime}$ & $\mathrm{H}$ & 38 & 40 & 36 & 36 & 32 & 33 & 26 & 36 & 35 \\
\hline & & \multirow{2}{*}{ 4'-6" } & $5.5^{\prime \prime}$ & $\overline{\mathrm{H}}$ & 26 & 27 & 28 & 30 & 26 & 28 & 32 & 26 & 28 \\
\hline & & & $1.5^{\prime \prime}$ & $\mathrm{H}$ & 32 & 36 & 36 & 36 & 32 & 37 & 37 & 32 & 35 \\
\hline & \multirow{6}{*}{ Left } & \multirow{2}{*}{ 1'-6" } & $5.5^{\prime \prime}$ & $\overline{\mathrm{H}}$ & 25 & 25 & 26 & 30 & 26 & 28 & 27 & 29 & 27 \\
\hline & & & $1.5^{\prime \prime}$ & $\mathrm{H}$ & 28 & 38 & 36 & 34 & 36 & 38 & 35 & 34 & 35 \\
\hline & & \multirow{2}{*}{ 3'-0" } & $5.5^{\prime \prime}$ & $\overline{\mathrm{H}}$ & 23 & 23 & 24 & 21 & 23 & 20 & 21 & 26 & 23 \\
\hline & & & $1.5^{\prime \prime}$ & $\overline{\mathrm{H}}$ & 34 & 30 & 35 & 30 & 35 & 28 & 32 & 35 & 32 \\
\hline & & \multirow{2}{*}{ 4'-6" } & $5.5^{\prime \prime}$ & $\overline{\mathrm{H}}$ & 24 & 26 & 25 & 26 & 27 & 28 & 26 & 24 & 26 \\
\hline & & & $1.5^{\prime \prime}$ & $\mathrm{H}$ & 38 & 47 & 30 & 32 & 35 & 40 & 36 & 40 & 37 \\
\hline
\end{tabular}




\begin{tabular}{|c|c|c|c|c|c|c|c|c|c|c|c|c|c|}
\hline $\begin{array}{l}\text { E } \\
\mathbb{D} \\
0\end{array}$ & $\frac{\infty}{0}$ & 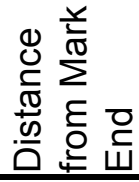 & 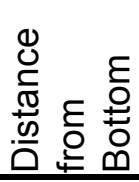 & 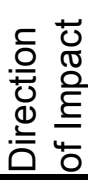 & \multicolumn{8}{|c|}{ Readings } & 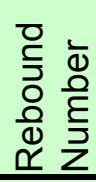 \\
\hline \multirow{12}{*}{21} & \multirow{6}{*}{ Right } & \multirow{2}{*}{$1^{\prime}-6 "$} & $5.5^{\prime \prime}$ & $\mathrm{H}$ & 27 & 29 & 36 & 27 & 30 & 24 & 29 & 28 & 29 \\
\hline & & & $1.5^{\prime \prime}$ & $\mathrm{H}$ & 36 & 39 & 37 & 40 & 29 & 39 & 36 & 39 & 37 \\
\hline & & \multirow{2}{*}{ 3'-0" } & $5.5^{\prime \prime}$ & $\overline{\mathrm{H}}$ & 24 & 22 & 24 & 20 & 24 & 26 & 28 & 24 & 24 \\
\hline & & & $1.5^{\prime \prime}$ & $\mathrm{H}$ & 40 & 42 & 37 & 40 & 37 & 42 & 37 & 39 & 39 \\
\hline & & \multirow{2}{*}{ 4'-6" } & $5.5^{\prime \prime}$ & $\overline{\mathrm{H}}$ & 26 & 32 & 26 & 24 & 30 & 26 & 24 & 24 & 27 \\
\hline & & & $1.5^{\prime \prime}$ & $\mathrm{H}$ & 41 & 38 & 39 & 40 & 38 & 37 & 38 & 36 & 38 \\
\hline & \multirow{6}{*}{ Left } & \multirow{2}{*}{ 1'-6" } & $5.5^{\prime \prime}$ & $\overline{\mathrm{H}}$ & 28 & 26 & 25 & 30 & 29 & 29 & 25 & 28 & 28 \\
\hline & & & $1.5^{\prime \prime}$ & $\mathrm{H}$ & 39 & 42 & 40 & 35 & 36 & 40 & 41 & 34 & 38 \\
\hline & & \multirow{2}{*}{ 3'-0" } & $5.5^{\prime \prime}$ & $\overline{\mathrm{H}}$ & 24 & 26 & 28 & 26 & 24 & 26 & 25 & 25 & 26 \\
\hline & & & $1.5^{\prime \prime}$ & $\mathrm{H}$ & 40 & 30 & 40 & 37 & 34 & 36 & 34 & 37 & 36 \\
\hline & & \multirow{2}{*}{ 4'-6" } & $5.5^{\prime \prime}$ & $\overline{\mathrm{H}}$ & 24 & 26 & 28 & 30 & 30 & 25 & 28 & 25 & 27 \\
\hline & & & $1.5^{\prime \prime}$ & $\mathrm{H}$ & 39 & 38 & 39 & 39 & 40 & 34 & 35 & 39 & 38 \\
\hline
\end{tabular}

\begin{tabular}{|c|c|c|c|c|c|c|c|c|c|c|c|c|c|}
\hline $\begin{array}{l}\varepsilon \\
\mathbb{\Phi} \\
\Phi \\
0\end{array}$ & $\frac{\infty}{0}$ & 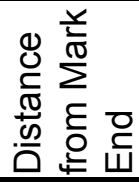 & 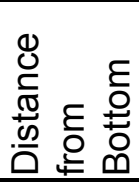 & 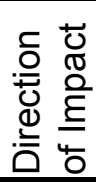 & \multicolumn{8}{|c|}{ Readings } & 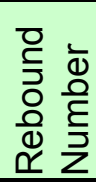 \\
\hline \multirow{12}{*}{22} & \multirow{6}{*}{ Right } & \multirow{2}{*}{ 1'-6" } & $5.5^{\prime \prime}$ & $\mathrm{H}$ & 24 & 22 & 22 & 21 & 20 & 20 & 15 & 25 & 21 \\
\hline & & & $1.5^{\prime \prime}$ & $\mathrm{H}$ & 42 & 40 & 38 & 43 & 37 & 40 & 39 & 39 & 40 \\
\hline & & \multirow{2}{*}{ 3'-0" } & $5.5^{\prime \prime}$ & $\overline{\mathrm{H}}$ & 19 & 19 & 20 & 20 & 20 & 16 & 22 & 23 & 20 \\
\hline & & & $1.5^{\prime \prime}$ & $\bar{H}$ & 37 & 36 & 40 & 40 & 35 & 35 & 39 & 39 & 38 \\
\hline & & \multirow{2}{*}{ 4'-6" } & $5.5^{\prime \prime}$ & $\overline{\mathrm{H}}$ & 22 & 27 & 23 & 28 & 21 & 21 & 26 & 24 & 24 \\
\hline & & & $1 . \mathrm{s}^{\prime \prime}$ & $\mathrm{H}$ & 44 & 32 & 41 & 40 & 33 & 30 & 35 & 38 & 37 \\
\hline & \multirow{6}{*}{ Left } & \multirow{2}{*}{ 1'-6" } & $5.5^{\prime \prime}$ & $\overline{\mathrm{H}}$ & 24 & 25 & 22 & 29 & 23 & 25 & 26 & 30 & 26 \\
\hline & & & $1.5^{\prime \prime}$ & $\mathrm{H}$ & 32 & 36 & 34 & 39 & 34 & 37 & 32 & 31 & 34 \\
\hline & & \multirow{2}{*}{ 3'-0" } & $5.5^{\prime \prime}$ & $\overline{\mathrm{H}}$ & 22 & 32 & 20 & 34 & 20 & 24 & 26 & 22 & 25 \\
\hline & & & $1.5^{\prime \prime}$ & $\overline{\mathrm{H}}$ & 38 & 39 & 46 & 44 & 39 & 42 & 38 & 41 & 41 \\
\hline & & \multirow{2}{*}{ 4'-6" } & $5.5^{\prime \prime}$ & $\overline{\mathrm{H}}$ & 24 & 26 & 26 & 28 & 25 & 26 & 24 & 26 & 26 \\
\hline & & & $1.5^{\prime \prime}$ & $\mathrm{H}$ & 36 & 41 & 39 & 39 & 40 & 40 & 40 & 42 & 40 \\
\hline
\end{tabular}




\begin{tabular}{|c|c|c|c|c|c|c|c|c|c|c|c|c|c|}
\hline 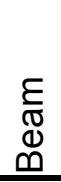 & $\frac{1}{0}$ & 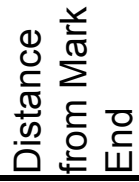 & 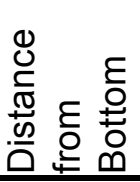 & 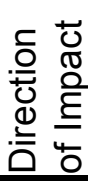 & \multicolumn{8}{|c|}{ Readings } & 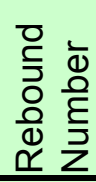 \\
\hline \multirow{12}{*}{23} & \multirow{6}{*}{ Right } & \multirow{2}{*}{ 1'-10" } & $5.5^{\prime \prime}$ & $\mathrm{H}$ & 26 & 27 & 26 & 26 & 29 & 32 & 27 & 23 & 27 \\
\hline & & & $1.5^{\prime \prime}$ & $\mathrm{H}$ & 39 & 35 & 38 & 36 & 39 & 43 & 44 & 39 & 39 \\
\hline & & \multirow{2}{*}{ 3'-4" } & $5.5^{\prime \prime}$ & $\overline{\mathrm{H}}$ & 23 & 26 & 30 & 27 & 28 & 23 & 24 & 28 & 26 \\
\hline & & & $1.5^{\prime \prime}$ & $\mathrm{H}$ & 38 & 36 & 39 & 40 & 37 & 36 & 39 & 38 & 38 \\
\hline & & \multirow{2}{*}{ 4'-6" } & $5.5^{\prime \prime}$ & $\overline{\mathrm{H}}$ & 35 & 29 & 28 & 29 & 24 & 26 & 29 & 33 & 29 \\
\hline & & & $1.5^{\prime \prime}$ & $\mathrm{H}$ & 45 & 44 & 38 & 39 & 40 & 42 & 36 & 35 & 40 \\
\hline & \multirow{6}{*}{ Left } & \multirow{2}{*}{ 1'-10" } & $5.5^{\prime \prime}$ & $\bar{H}$ & 20 & 24 & 26 & 28 & 28 & 28 & 21 & 23 & 25 \\
\hline & & & $1.5^{\prime \prime}$ & $\mathrm{H}$ & 45 & 29 & 37 & 46 & 40 & 45 & 44 & 36 & 40 \\
\hline & & \multirow{2}{*}{ 3'-4" } & $5.5^{\prime \prime}$ & $\overline{\mathrm{H}}$ & 29 & 25 & 20 & 24 & 22 & 23 & 23 & 27 & 24 \\
\hline & & & $1.5^{\prime \prime}$ & $\mathrm{H}$ & 40 & 43 & 42 & 40 & 37 & 42 & 38 & 40 & 40 \\
\hline & & \multirow{2}{*}{ 4'-6" } & $5.5^{\prime \prime}$ & $\overline{\mathrm{H}}$ & 25 & 28 & 24 & 21 & 22 & 30 & 23 & 27 & 25 \\
\hline & & & $1.5^{\prime \prime}$ & $\mathrm{H}$ & 35 & 37 & 39 & 33 & 35 & 38 & 38 & 43 & 37 \\
\hline
\end{tabular}

\begin{tabular}{|c|c|c|c|c|c|c|c|c|c|c|c|c|c|}
\hline $\begin{array}{l}\varepsilon \\
\mathbb{\Phi} \\
\Phi\end{array}$ & $\frac{0}{0}$ & 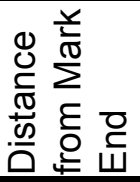 & 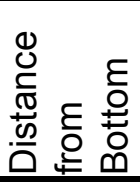 & 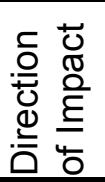 & \multicolumn{8}{|c|}{ Readings } & 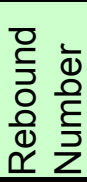 \\
\hline \multirow{12}{*}{24} & \multirow{6}{*}{ Right } & \multirow{2}{*}{$1^{\prime}-10^{\prime \prime}$} & $5 . \mathrm{5}^{\mathrm{m}}$ & $\mathrm{H}$ & 24 & 20 & 23 & 28 & 25 & 20 & 29 & 24 & 24 \\
\hline & & & $1.5^{\prime \prime}$ & $\mathrm{H}$ & 40 & 36 & 32 & 38 & 34 & 38 & 34 & 30 & 35 \\
\hline & & \multirow{2}{*}{ 3'-4" } & $5.5^{\prime \prime}$ & $\overline{\mathrm{H}}$ & 24 & 25 & 29 & 25 & 26 & 21 & 23 & 30 & 25 \\
\hline & & & $1.5^{\prime \prime}$ & $\mathrm{H}$ & 36 & 35 & 38 & 36 & 30 & 37 & 38 & 33 & 35 \\
\hline & & \multirow{2}{*}{ 4'-6" } & $5.5^{\prime \prime}$ & $\mathrm{H}$ & 25 & 30 & 28 & 26 & 26 & 23 & 25 & 27 & 26 \\
\hline & & & $1.5^{\prime \prime}$ & $\mathrm{H}$ & 31 & 37 & 34 & 34 & 37 & 36 & 27 & 33 & 34 \\
\hline & \multirow{6}{*}{ Left } & \multirow{2}{*}{ 1'-10" } & $5.5^{\prime \prime}$ & $\overline{\mathrm{H}}$ & 22 & 29 & 25 & 27 & 26 & 27 & 24 & 24 & 26 \\
\hline & & & $1.5^{\prime \prime}$ & $\mathrm{H}$ & 35 & 35 & 38 & 40 & 42 & 36 & 36 & 34 & 37 \\
\hline & & \multirow{2}{*}{ 3'-4" } & $5.5^{\prime \prime}$ & $\mathrm{H}$ & 24 & 28 & 22 & 17 & 23 & 20 & 26 & 24 & 23 \\
\hline & & & $1.5^{\prime \prime}$ & $\mathrm{H}$ & 34 & 36 & 40 & 36 & 42 & 36 & 38 & 37 & 37 \\
\hline & & \multirow{2}{*}{ 4'-6" } & $5.5^{\prime \prime}$ & $\overline{\mathrm{H}}$ & 26 & 26 & 33 & 22 & 24 & 27 & 25 & 24 & 26 \\
\hline & & & $1.5^{\prime \prime}$ & $\mathrm{H}$ & 38 & 38 & 34 & 39 & 35 & 36 & 38 & 36 & 37 \\
\hline
\end{tabular}




\section{D.3 Ultrasonic Pulse Velocity Raw Data}

Note: Pulse velocity readings were only taken on Part II beam specimens. Beam numbers at the top of each dataset represent Beams II-\#.

\begin{tabular}{|c|c|c|c|c|c|c|c|c|c|c|c|c|c|c|c|}
\hline \multirow[b]{2}{*}{ End } & \multirow[b]{2}{*}{ Path } & \multicolumn{7}{|c|}{1} & \multicolumn{7}{|c|}{2} \\
\hline & & 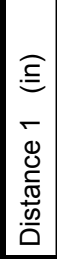 & 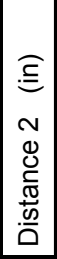 & 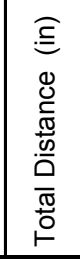 & 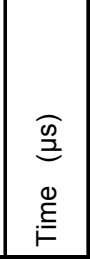 & $\begin{array}{l}\text { के } \\
\text { है } \\
0 \\
\frac{0}{0} \\
\frac{0}{0}\end{array}$ & ${ }_{j}^{>}$ & 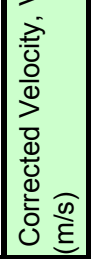 & 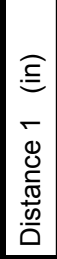 & 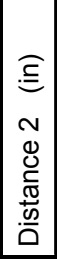 & 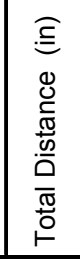 & 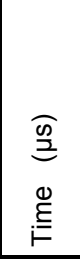 & $\begin{array}{l}\frac{\pi}{0} \\
\text { है } \\
0 \\
> \\
\frac{\vec{\pi}}{0} \\
\frac{0}{0} \\
>\end{array}$ & > & 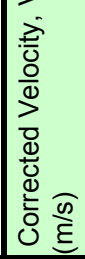 \\
\hline \multirow{6}{*}{ Mark } & Direct @ 1.5" & - & - & 6.00 & 56.1 & 2,717 & 0.93 & 2,525 & - & - & 6.00 & 57.0 & 2,674 & 0.93 & 2,485 \\
\hline & Direct @ 5.5" & - & - & 6.00 & 55.5 & 2,746 & 0.95 & 2,601 & - & - & 6.00 & \begin{tabular}{|l|}
56.2 \\
\end{tabular} & 2,712 & 0.95 & 2,568 \\
\hline & Semi-Direct @ Ten Right & 1.5 & 1.5 & 2.12 & 19.8 & 2,721 & 0.90 & 2,450 & 1.5 & 1.5 & 2.12 & \begin{tabular}{|l}
24.9 \\
\end{tabular} & 2,164 & 0.90 & 1,948 \\
\hline & Semi-Direct @ Ten Left & - & - & - & - & - & - & - & 1.5 & 1.5 & 2.12 & 22.3 & 2416 & 0.90 & 2,175 \\
\hline & Semi-Direct Bot-Top Right & 1.5 & 5.5 & 5.70 & 39.2 & 3,694 & 0.96 & 3,557 & 1.5 & 5.5 & 5.70 & \begin{tabular}{|l}
61.7 \\
\end{tabular} & 2,347 & 0.96 & 2,260 \\
\hline & Semi-Direct Bot-Top Left & - & - & - & - & - & - & - & 1.5 & 5.5 & 5.70 & 67.0 & 2161 & 0.96 & 2,081 \\
\hline \multirow{6}{*}{ Midspan } & Direct @ 1.5" & - & - & 6.00 & 53.4 & 2,854 & 0.93 & 2,653 & - & - & 6.00 & 57.8 & 2,637 & 0.93 & 2,451 \\
\hline & Direct @ 5.5" & - & - & 6.00 & 55.0 & 2,771 & 0.95 & 2,624 & - & - & 6.00 & 59.0 & 2,583 & 0.95 & 2,446 \\
\hline & Semi-Direct @ Ten Right & 1.5 & 1.5 & 2.12 & 18.7 & 2,881 & 0.90 & 2,594 & 1.5 & 1.5 & 2.12 & 23.4 & 2,303 & 0.90 & 2,073 \\
\hline & Semi-Direct @ Ten Left & - & - & - & - & - & - & - & 1.5 & 1.5 & 2.12 & 24.5 & 2199 & 0.90 & 1,980 \\
\hline & Semi-Direct Bot-Top Right & 1.5 & 5.5 & 5.70 & 35.4 & 4,090 & 0.96 & 3,939 & 1.5 & 5.5 & 5.70 & 66.8 & 2,168 & 0.96 & 2,087 \\
\hline & Semi-Direct Bot-Top Left & - & - & - & - & - & - & - & 1.5 & 5.5 & 5.70 & 66.5 & 2177 & 0.96 & 2,097 \\
\hline \multirow{6}{*}{ Unmark } & Direct @ 1.5" & - & - & 6.00 & 53.0 & 2,875 & 0.93 & 2,673 & - & - & 6.00 & 58.0 & 2,628 & 0.93 & 2,442 \\
\hline & Direct @ 5.5" & - & - & 6.00 & 54.2 & 2,812 & 0.95 & 2,663 & - & - & 6.00 & 56.6 & 2,693 & 0.95 & 2,550 \\
\hline & Semi-Direct @ Ten Right & 1.5 & 1.5 & 2.12 & 21.5 & 2,506 & 0.90 & 2,256 & 1.5 & 1.5 & 2.12 & 20.4 & 2,641 & 0.90 & 2,378 \\
\hline & Semi-Direct @ Ten Left & 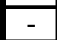 & - & - & - & - & - & - & 1.5 & 1.5 & 2.12 & 22.2 & 2427 & 0.90 & 2,185 \\
\hline & Semi-Direct Bot-Top Right & 1.5 & 5.5 & 5.70 & 41.6 & 3,481 & 0.96 & 3,352 & 1.5 & 5.5 & 5.70 & 63.1 & 2,295 & 0.96 & 2,210 \\
\hline & Semi-Direct Bot-Top Left & - & - & - & - & - & - & - & 1.5 & 5.5 & 5.70 & 58.8 & 2463 & 0.96 & 2,371 \\
\hline Mark & Indirect Right @ 1.5" & - & - & 16.00 & 194.7 & 2,087 & 0.80 & 1,670 & - & - & 15.00 & 129.3 & 2,947 & 0.79 & 2,328 \\
\hline Unmark & Indirect Right @ 1.5" & - & - & 16.00 & 225.3 & 1,804 & 0.80 & 1,443 & - & - & 12.00 & 107.4 & 2,838 & 0.85 & 2,412 \\
\hline Mark & Indirect Left @ 1.5" & - & - & - & - & - & - & - & - & - & 15.00 & 129 & 2953 & 0.79 & 2,333 \\
\hline Unmark & Indirect Left @ 1.5" & - & - & - & 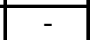 & - & - & - & - & - & 12.00 & 107 & 2859 & 0.85 & 2,430 \\
\hline Mark & Indire & - & - & 16.00 & 122.5 & 3,318 & 0.64 & 2,123 & 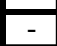 & - & 15.00 & 137 & 2791 & 0.63 & 1,758 \\
\hline Unmark & Indirect Right @ 5.5" & - & - & 16.00 & 123.0 & 3,304 & 0.64 & 2,115 & - & - & 12.00 & 114 & 2667 & 0.72 & 1,920 \\
\hline Mark & Indirect Left @ 5.5" & - & - & - & - & - & - & - & - & - & 15.00 & 137 & 2779 & 0.63 & 1,751 \\
\hline Unmark & Indirect Left @ 5.5" & - & - & - & - & - & - & - & - & - & 12.00 & 116 & 2623 & \begin{tabular}{|l|}
0.72 \\
\end{tabular} & 1,889 \\
\hline
\end{tabular}




\begin{tabular}{|c|c|c|c|c|c|c|c|c|c|c|c|c|c|c|c|}
\hline \multirow[b]{2}{*}{ End } & \multirow[b]{2}{*}{ Path } & \multicolumn{7}{|c|}{11} & \multicolumn{7}{|c|}{12} \\
\hline & & 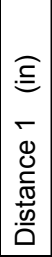 & 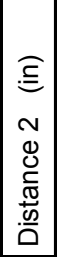 & 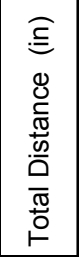 & 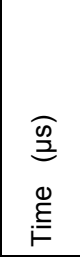 & $\begin{array}{l}\frac{\pi}{E} \\
0 \\
> \\
\frac{\pi}{0} \\
\frac{0}{0} \\
>\end{array}$ & \rangle$_{>}^{>}$ & 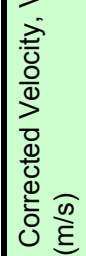 & 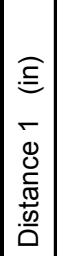 & 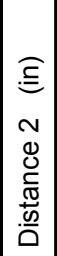 & $\begin{array}{l}\widehat{\Xi} \\
0 \\
0 \\
\frac{1}{0} \\
\frac{\pi}{00} \\
\frac{.0}{0} \\
\frac{\pi}{\pi} \\
\frac{0}{0}\end{array}$ & $\begin{array}{l}\frac{\widehat{D}}{2} \\
\stackrel{\Phi}{E} \\
i=\end{array}$ & $\begin{array}{l}\text { की } \\
\text { है } \\
0 \\
> \\
\frac{\vec{D}}{0} \\
\frac{0}{0}\end{array}$ & \rangle$_{j}^{>}$ & 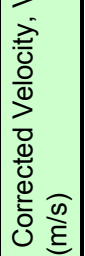 \\
\hline \multirow{6}{*}{ Mark } & Direct @ 1.5" & - & - & 6.00 & 59.1 & 2,579 & 0.93 & 2,397 & - & - & 6.00 & 63.6 & 2,396 & 0.93 & 2,227 \\
\hline & Direct @ 5.5" & - & - & 6.00 & 57.3 & 2,660 & 0.95 & 2,519 & - & - & 6.00 & \begin{tabular}{|l|}
61.4 \\
\end{tabular} & 2,482 & 0.95 & 2,351 \\
\hline & Semi-Direct @ Ten Right & 1.5 & 1.5 & 2.12 & 21.5 & 2,506 & 0.90 & 2,256 & - & - & - & - & \begin{tabular}{|l|}
- \\
-
\end{tabular} & -1 & - \\
\hline & Semi-Direct @ Ten Left & - & - & - & - & - & - & - & 1.5 & 1.5 & 2.12 & 20.7 & 2603 & 0.90 & 2,343 \\
\hline & Semi-Direct Bot-Top Right & 1.5 & 5.5 & 5.70 & 55.2 & 2,623 & 0.96 & 2,526 & - & - & - & - & - & - & - \\
\hline & Semi-Direct Bot-Top Left & - & - & - & - & - & - & - & 1.5 & 5.5 & 5.70 & 70.6 & 2051 & 0.96 & 1,975 \\
\hline \multirow{6}{*}{ Midspan } & Direct @ 1.5" & - & - & 6.00 & $\overline{53.8}$ & 2,833 & 0.93 & 2,633 & - & - & 6.00 & 62.4 & 2,442 & 0.93 & 2,270 \\
\hline & Direct @ 5.5" & - & - & 6.00 & 55.0 & 2,771 & 0.95 & 2,624 & - & - & 6.00 & 59.3 & 2,570 & 0.95 & 2,434 \\
\hline & Semi-Direct @ Ten Right & 1.5 & 1.5 & 2.12 & 18.1 & 2,977 & 0.90 & 2,680 & 1.5 & 1.5 & 2.12 & 24.2 & 2,227 & 0.90 & 2,004 \\
\hline & Semi-Direct @ Ten Left & - & 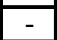 & - & - & - & - & 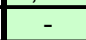 & - & - & - & - & - & - & - \\
\hline & Semi-Direct Bot-Top Right & 1.5 & 5.5 & 5.70 & 60.4 & 2,397 & 0.96 & 2,308 & 1.5 & 5.5 & 5.70 & 62.8 & 2,306 & 0.96 & 2,220 \\
\hline & Semi-Direct Bot-Top & - & - & - & - & - & - & - & - & - & - & - & - & - & - \\
\hline \multirow{6}{*}{ Unmark } & Direct @ 1.5" & - & - & 6.00 & 53.0 & 2,875 & 0.93 & 2,673 & - & - & 6.00 & 59.0 & 2,583 & 0.93 & 2,401 \\
\hline & Direct @ 5.5" & - & - & 6.00 & 53.2 & 2,865 & 0.95 & 2,713 & - & - & 6.00 & 61.5 & 2,478 & 0.95 & 2,347 \\
\hline & Semi-Direct @ Ten Right & 1.5 & 1.5 & 2.12 & 14.9 & 3,616 & 0.90 & 3,256 & 1.5 & 1.5 & 2.12 & 26.5 & 2,033 & 0.90 & 1,831 \\
\hline & Semi-Direct @ Ten Left & - & - & - & - & - & - & - & - & - & - & - & - & - & - \\
\hline & Semi-Direct Bot-Top Right & 1.5 & 5.5 & 5.70 & 56.0 & 2,586 & 0.96 & 2,490 & 1.5 & 5.5 & 5.70 & 67.8 & 2,136 & 0.96 & 2,056 \\
\hline & Semi-Direct Bot-Top Left & - & - & - & - & - & - & - & - & - & - & - & - & - & - \\
\hline$\overline{\text { Mark }}$ & Indirect Right @ 1.5" & - & - & 15.00 & $\overline{177.0}$ & 2,153 & 0.79 & 1,701 & - & - & 15.00 & 165.2 & 2,306 & 0.79 & 1,822 \\
\hline Unmark & Indirect Right @ 1.5" & - & - & 12.00 & 157.2 & 1,939 & 0.85 & 1,648 & - & - & 12.00 & 233.0 & 1,308 & 0.85 & 1,112 \\
\hline Mark & eft @ 1.5" & - & - & 15.00 & 207 & 1845 & 0.79 & 1,458 & - & - & 15.00 & 193 & 1978 & 0.79 & 1,563 \\
\hline Unmark & Indirect Left @ 1.5" & - & - & 12.00 & 137 & 2220 & 0.85 & 1,887 & - & - & 12.00 & 171 & 1783 & 0.85 & 1,516 \\
\hline Mark & Indirect Right @ 5.5" & - & - & 15.00 & 139 & 2739 & 0.63 & 1,726 & - & - & 15.00 & 164 & 2322 & \begin{tabular}{|l|l|}
0.63 \\
\end{tabular} & 1,463 \\
\hline Unmark & Indirect Right @ 5.5" & - & - & 12.00 & 157 & 1939 & 0.72 & 1,396 & - & - & 12.00 & 160 & 1903 & \begin{tabular}{|l|l|}
0.72 \\
\end{tabular} & 1,370 \\
\hline Mark & Indirect Left @ 5.5" & - & - & 15.00 & 153 & 2489 & 0.63 & 1,568 & - & - & 15.00 & 172 & 2215 & \begin{tabular}{|l|l|}
0.63 \\
\end{tabular} & 1,396 \\
\hline Unmark & Indirect Left @ 5.5" & 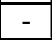 & - & 12.00 & 135 & 2251 & 0.72 & 1,621 & - & - & 12.00 & 151 & 2017 & \begin{tabular}{|l|l|}
0.72 \\
\end{tabular} & 1,452 \\
\hline
\end{tabular}




\begin{tabular}{|c|c|c|c|c|c|c|c|c|c|c|c|c|c|c|c|}
\hline \multirow[b]{2}{*}{ End } & \multirow[b]{2}{*}{ Path } & \multicolumn{7}{|c|}{3} & \multicolumn{7}{|c|}{4} \\
\hline & & 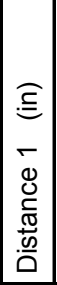 & 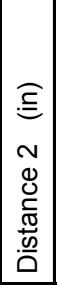 & 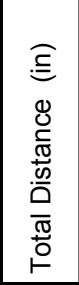 & $\begin{array}{l}\stackrel{\frac{0}{2}}{\mathcal{E}} \\
\stackrel{\oplus}{\xi} \\
i=\end{array}$ & 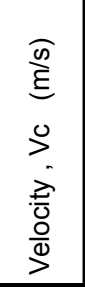 & خे & 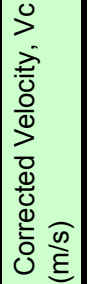 & 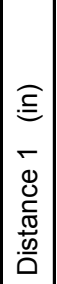 & 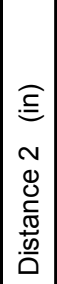 & 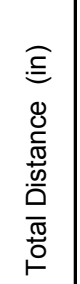 & 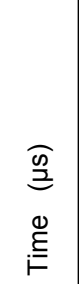 & $\begin{array}{l}\frac{0}{0} \\
\text { है } \\
0 \\
> \\
\frac{\vec{\pi}}{0} \\
\frac{0}{0} \\
>\end{array}$ & خे & 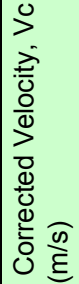 \\
\hline \multirow{6}{*}{ Mark } & Direct @ 1.5" & - & - & 6.00 & 154.9 & 984 & 0.93 & 914 & - & - & 6.00 & 76.3 & 1,997 & 0.93 & 1,857 \\
\hline & Direct @ 5.5" & - & - & 6.00 & 64.7 & 2,355 & 0.95 & 2,231 & - & - & 6.00 & 62.7 & 2,431 & 0.95 & 2,302 \\
\hline & Semi-Direct @ Ten Right & - & - & - & - & - & - & - & 1.5 & 1.5 & 2.12 & 21.0 & 2,566 & 0.90 & 2310 \\
\hline & Semi-Direct @ Ten Left & 1.5 & 1.5 & 2.12 & 18.6 & 2897 & 0.90 & 2608 & 1.5 & 1.5 & 2.12 & 19.8 & 2721 & 0.90 & 2,450 \\
\hline & Semi-Direct Bot-Top Right & - & - & - & - & - & - & - & 1.5 & 5.5 & 5.70 & 74.5 & 1,944 & 0.96 & 1872 \\
\hline & Semi-Direct Bot-Top Left & 1.5 & 5.5 & 5.70 & 69.0 & 2099 & 0.96 & 2021 & 1.5 & 5.5 & 5.70 & 44.3 & 3269 & 0.96 & 3,147 \\
\hline \multirow{6}{*}{ Midspan } & Direct @ 1.5" & - & - & 6.00 & 95.7 & 1,592 & 0.93 & 1,480 & - & - & 6.00 & 65.3 & 2,334 & 0.93 & 2,169 \\
\hline & Direct @ 5.5" & - & - & 6.00 & 61.4 & 2,482 & 0.95 & 2,351 & - & - & 6.00 & 58.1 & 2,623 & 0.95 & 2,484 \\
\hline & Semi-Direct @ Ten Right & - & - & - & - & - & - & - & 1.5 & 1.5 & 2.12 & 22.4 & 2,405 & 0.90 & 2,166 \\
\hline & Semi-Direct @ Ten Left & 1.5 & 1.5 & 2.12 & 19.9 & 2708 & 0.90 & 2438 & 1.5 & 1.5 & 2.12 & 22.6 & 2384 & 0.90 & 2146 \\
\hline & Semi-Direct Bot-Top Right & - & - & - & - & - & - & - & 1.5 & 5.5 & 5.70 & 74.0 & 1,957 & 0.96 & $\overline{1,884}$ \\
\hline & Semi-Direct Bot-Top Left & 1.5 & 5.5 & 5.70 & 38.8 & 3732 & 0.96 & 3594 & 1.5 & 5.5 & 5.70 & 84.7 & 1710 & 0.96 & 1646 \\
\hline \multirow{6}{*}{ Unmark } & Direct @ 1.5" & - & - & 6.00 & 91.1 & 1,673 & 0.93 & 1,555 & - & - & 6.00 & 70.1 & 2,174 & 0.93 & 2,021 \\
\hline & Direct @ 5.5" & - & - & 6.00 & 60.5 & 2,519 & 0.95 & 2,386 & - & - & 6.00 & 60.0 & 2,540 & 0.95 & 2,406 \\
\hline & Semi-Direct @ Ten Right & - & - & - & - & - & - & - & 1.5 & 1.5 & 2.12 & 22.6 & 2,384 & 0.90 & 2,146 \\
\hline & Semi-Direct @ Ten Left & 1.5 & 1.5 & 2.12 & 19.4 & 2777 & 0.90 & 2500 & 1.5 & 1.5 & 2.12 & 19.0 & 2836 & 0.90 & 2553 \\
\hline & Semi-Direct Bot-Top Right & & & & - & & 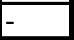 & & 1.5 & 5.5 & 5.70 & 41.5 & 3,489 & 0.96 & 3,360 \\
\hline & Semi-Direct Bot-Top Left & 1.5 & 5.5 & 5.70 & 39.6 & 3657 & 0.96 & 3521 & 1.5 & 5.5 & 5.70 & 70.6 & 2051 & 0.96 & 1975 \\
\hline Mark & Indirect Right @ 1.5" & - & - & 16.00 & 123.0 & 3,304 & 0.80 & 2,643 & - & - & 16.00 & 164.6 & 2,469 & 0.80 & 1,975 \\
\hline Unmark & Indirect Right @ 1.5" & - & - & 16.00 & 131.0 & 3,102 & 0.80 & \begin{tabular}{|l|}
2,482 \\
\end{tabular} & - & - & 16.00 & 163.2 & 2,490 & 0.80 & 1,992 \\
\hline Mark & Indirect Left @ 1.5" & - & - & - & - & - & - & - & - & - & - & - & - & - & - \\
\hline Unmark & Indirect Left @ 1.5" & - & - & - & - & - & - & - & - & - & - & - & - & - & - \\
\hline Mark & Indirect Right @ 5.5" & - & - & 16.00 & 128 & 3175 & 0.64 & 2,032 & - & - & 16.00 & 142 & 2864 & \begin{tabular}{|l|}
0.64 \\
\end{tabular} & 1,833 \\
\hline Unmark & Indirect Right @ 5.5" & - & - & 16.00 & 130 & 3136 & 0.64 & \begin{tabular}{|l|}
2,007 \\
\end{tabular} & - & - & 16.00 & 149 & 2737 & \begin{tabular}{|l|}
0.64 \\
\end{tabular} & 1,751 \\
\hline Mark & Indirect Left @ 5.5" & - & - & - & - & - & - & - & - & - & - & - & - & - & - \\
\hline Unmark & Indirect Left @ 5.5" & - & - & - & - & - & - & - & - & - & - & - & - & - & - \\
\hline
\end{tabular}




\begin{tabular}{|c|c|c|c|c|c|c|c|c|c|c|c|c|c|c|c|c|c|c|c|c|c|c|c|c|c|c|}
\hline \multirow[b]{2}{*}{ Location } & \multirow[b]{2}{*}{ Path } & \multicolumn{5}{|c|}{5} & \multicolumn{5}{|c|}{8} & \multicolumn{5}{|c|}{9} & \multicolumn{5}{|c|}{7} & \multicolumn{5}{|c|}{14} \\
\hline & & 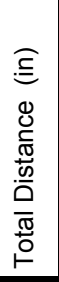 & $\begin{array}{l}\frac{\widehat{0}}{2} \\
\stackrel{\Phi}{\xi} \\
i=\end{array}$ & $\begin{array}{l}\frac{\widehat{o}}{\xi} \\
\text { है } \\
0 \\
\vdots \\
\frac{\overrightarrow{0}}{0} \\
\frac{0}{0}\end{array}$ & \rangle$_{>}^{>}$ & 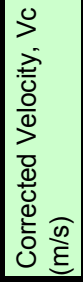 & 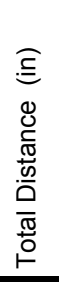 & 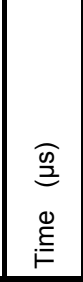 & $\begin{array}{l}\frac{\pi}{\text { है }} \\
0 \\
0 \\
\frac{\overrightarrow{0}}{0} \\
\frac{0}{0} \\
>\end{array}$ & >े & 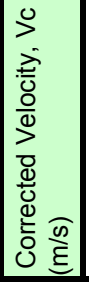 & 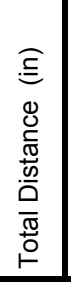 & 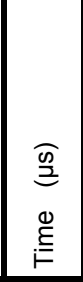 & $\begin{array}{l}\frac{0}{0} \\
\text { है } \\
0 \\
> \\
\frac{\overrightarrow{0}}{0} \\
\frac{0}{0} \\
\text { ग }\end{array}$ & > & 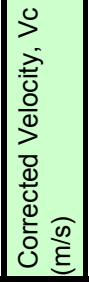 & 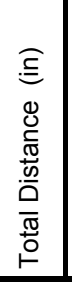 & 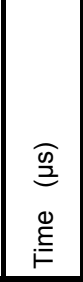 & 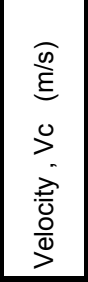 & >े & 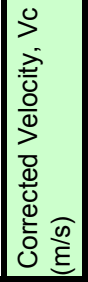 & 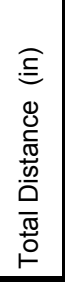 & $\begin{array}{l}\stackrel{0}{2} \\
\stackrel{\varrho}{E} \\
i=\end{array}$ & 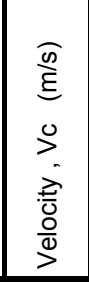 & ì & 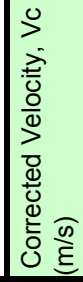 \\
\hline \multirow{2}{*}{ Mark } & Direct @1.5" & 6 & 44.3 & 3,440 & 0.93 & 3,198 & 6 & 43.5 & \begin{tabular}{|l|}
3,503 \\
\end{tabular} & 0.93 & 3,256 & 6 & 45.1 & \begin{tabular}{|l|}
3,379 \\
\end{tabular} & 0.93 & 3,141 & 6 & 44.6 & 3,417 & \begin{tabular}{|l|}
0.93 \\
\end{tabular} & 3,176 & 6 & 43.0 & 3,544 & 0.93 & 3,294 \\
\hline & Direct @ 5.5" & 6 & 59.9 & 2,544 & 0.93 & 2,365 & 6 & 62.4 & \begin{tabular}{|l|}
2,442 \\
\end{tabular} & 0.93 & 2,270 & 6 & 55.7 & \begin{tabular}{|l|}
2,736 \\
\end{tabular} & \begin{tabular}{|l|}
0.93 \\
\end{tabular} & 2,543 & 6 & 62.5 & 2,438 & 0.93 & 2,266 & 6 & 61.5 & 2,478 & 0.93 & 2,303 \\
\hline \multirow{2}{*}{ Midspan } & Direct @1.5" & 6 & 44.8 & 3,402 & 0.93 & 3,162 & $\overline{6}$ & 42.9 & \begin{tabular}{|l|}
3,552 \\
\end{tabular} & 0.93 & 3,302 & 6 & 44.4 & \begin{tabular}{|l|}
3,432 \\
\end{tabular} & \begin{tabular}{|l|}
0.93 \\
\end{tabular} & 3,190 & 6 & 44.6 & 3,417 & 0.93 & 3,176 & 6 & 69.5 & 2,193 & 0.93 & 2,038 \\
\hline & Direct @ 5.5" & 6 & 61.2 & 2,490 & 0.93 & 2,315 & 6 & 56.8 & 2,683 & 0.93 & 2,494 & 6 & \begin{tabular}{|l|}
70.7 \\
\end{tabular} & \begin{tabular}{|l|}
2,156 \\
\end{tabular} & \begin{tabular}{|l|}
0.93 \\
\end{tabular} & 2,004 & 6 & 61.9 & 2,462 & 0.93 & 2,288 & 6 & 42.9 & 3,552 & 0.93 & 3,302 \\
\hline \multirow{2}{*}{ Unmark } & Direct @1.5" & $\overline{6}$ & 44.8 & 3,402 & 0.93 & 3,162 & $\overline{6}$ & 44.5 & \begin{tabular}{|l|}
3,425 \\
\end{tabular} & 0.93 & 3,183 & 6 & 46.0 & \begin{tabular}{|l|}
3,313 \\
\end{tabular} & \begin{tabular}{|l|}
0.93 \\
\end{tabular} & 3,079 & 6 & 44.8 & 3,402 & 0.93 & 3,162 & 6 & 57.0 & \begin{tabular}{|l|}
2,674 \\
\end{tabular} & 0.93 & 2,485 \\
\hline & Direct @ 5.5" & 6 & 63.9 & 2,385 & 0.93 & 2,217 & 6 & 61.4 & \begin{tabular}{|l|}
2,482 \\
\end{tabular} & 0.93 & 2,307 & 6 & 69.6 & 2,190 & \begin{tabular}{|l|}
0.93 \\
\end{tabular} & 2,035 & 6 & 63.7 & 2,392 & 0.93 & 2,224 & 6 & 44.3 & 3,440 & 0.93 & 3,198 \\
\hline Mark & $\mid$ Indirect @ 1.5" & 15 & 72.3 & 5,270 & 0.79 & 4,163 & 16 & 96.0 & 4,233 & 0.80 & \begin{tabular}{|l|}
3,387 \\
\end{tabular} & 16 & 96.2 & \begin{tabular}{|l|}
4,225 \\
\end{tabular} & 0.80 & 3,380 & 15 & 93.8 & 4,062 & 0.79 & 3,209 & 16 & 93.8 & 4,333 & 0.80 & 3,466 \\
\hline Unmark & Indirect @ 1.5" & 12 & 74.7 & 4,080 & 0.85 & 3,468 & 16 & 96.6 & 4,207 & 0.80 & 3,366 & 16 & 80.9 & \begin{tabular}{|l|}
5,023 \\
\end{tabular} & \begin{tabular}{|l|}
0.80 \\
\end{tabular} & 4,019 & 12 & 74.5 & 4,091 & 0.85 & 3,478 & 16 & 98.3 & 4,134 & 0.80 & 3,307 \\
\hline Mark & |lndirect @ 1.5" & 15 & 98.3 & 3,876 & 0.79 & 3,062 & 16 & 94.7 & 4,291 & 0.80 & 3,433 & 16 & 96.0 & \begin{tabular}{|l|}
4,233 \\
\end{tabular} & \begin{tabular}{|l|}
0.80 \\
\end{tabular} & 3,387 & 15 & 92.0 & 4,141 & 0.79 & 3,272 & 16 & 96.9 & 4,194 & 0.80 & 3,355 \\
\hline Unmark & |ndirect @ 1.5" & 12 & 80.4 & 3,791 & 0.85 & 3,222 & 16 & 96.1 & 4,229 & 0.80 & 3,383 & 16 & 75.9 & \begin{tabular}{|l|}
5,354 \\
\end{tabular} & 0.80 & 4,284 & 12 & 78.6 & 3,878 & 0.85 & 3,296 & 16 & 98.2 & 4,138 & 0.80 & 3,311 \\
\hline Mark & |ndirect @ 5.5" & 15 & 127.3 & 2,993 & 0.63 & 1,886 & 16 & 150.1 & 2,708 & 0.64 & 1,733 & 16 & 141.6 & \begin{tabular}{|l|}
2,870 \\
\end{tabular} & 0.64 & 1,837 & 15 & 136.5 & 2,791 & 0.63 & 1,758 & 16 & 168.6 & 2,410 & 0.64 & 1,543 \\
\hline Unmark & Indirect @ 5.5" & 12 & 101.0 & 3,018 & 0.72 & 2,173 & 16 & 174.4 & 2,330 & 0.64 & 1,491 & 16 & 123.8 & \begin{tabular}{|l|}
3,283 \\
\end{tabular} & 0.64 & 2,101 & 12 & 110.2 & 2,766 & 0.72 & 1,991 & 16 & 131.3 & 3,095 & 0.64 & 1,981 \\
\hline Mark & @ 5.5" & 15 & 121.6 & 3,133 & 0.63 & 1,974 & 16 & 130.6 & \begin{tabular}{|l|}
3,112 \\
\end{tabular} & 0.64 & 1,992 & 16 & 132.5 & \begin{tabular}{|l|}
3,067 \\
\end{tabular} & \begin{tabular}{|l|}
0.64 \\
\end{tabular} & 1,963 & 15 & 146.0 & 2,610 & 0.63 & 1,644 & 16 & 143.1 & 2,840 & 0.64 & 1,818 \\
\hline Unmark & |Indirect @ 5.5" & 12 & 181.3 & 1,681 & 0.72 & 1,210 & 16 & 144.7 & 2,809 & 0.64 & 1,797 & 16 & 165.2 & \begin{tabular}{|l|}
2,460 \\
\end{tabular} & \begin{tabular}{|l|}
0.64 \\
\end{tabular} & 1,574 & 12 & 150.9 & 2,020 & 0.72 & 1,454 & 16 & 125.2 & 3,246 & 0.64 & 2,077 \\
\hline
\end{tabular}




\begin{tabular}{|c|c|c|c|c|c|c|c|c|c|c|c|c|c|c|c|c|c|c|c|c|c|c|c|c|c|c|}
\hline \multirow[b]{2}{*}{ Location } & \multirow[b]{2}{*}{ Path } & \multicolumn{5}{|c|}{13} & \multicolumn{5}{|c|}{15} & \multicolumn{5}{|c|}{17} & \multicolumn{5}{|c|}{18} & \multicolumn{5}{|c|}{20} \\
\hline & & 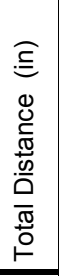 & 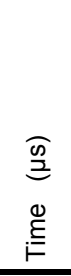 & $\begin{array}{l}\frac{\pi}{0} \\
\text { है } \\
0 \\
> \\
\frac{\overrightarrow{0}}{0} \\
\frac{0}{0} \\
>\end{array}$ & ì & 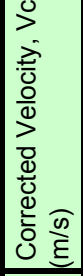 & 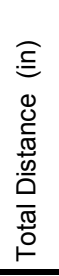 & 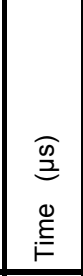 & $\begin{array}{l}\frac{\pi}{0} \\
\text { है } \\
0 \\
> \\
\frac{\overrightarrow{0}}{0} \\
\frac{0}{0} \\
>\end{array}$ & >े & 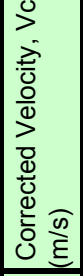 & 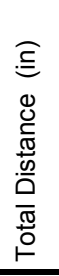 & $\begin{array}{l}\stackrel{0}{2} \\
\stackrel{0}{E} \\
\stackrel{\varrho}{E}\end{array}$ & $\begin{array}{l}\frac{\pi}{0} \\
\text { है } \\
0 \\
> \\
\frac{\overrightarrow{0}}{0} \\
\frac{0}{0} \\
>\end{array}$ & ì & 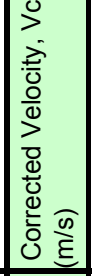 & 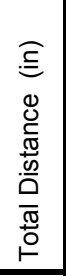 & $\begin{array}{l}\stackrel{\infty}{2} \\
\stackrel{0}{E} \\
\stackrel{0}{E}\end{array}$ & $\begin{array}{l}\frac{\pi}{0} \\
\text { है } \\
0 \\
> \\
\frac{\overrightarrow{0}}{0} \\
\frac{0}{0} \\
>\end{array}$ & गे & 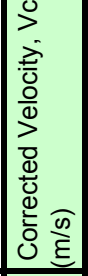 & 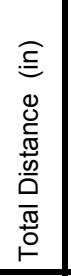 & $\begin{array}{l}\stackrel{\frac{0}{2}}{=} \\
\stackrel{0}{E} \\
i=\end{array}$ & $\begin{array}{l}\frac{\pi}{5} \\
\text { है } \\
0 \\
\frac{2}{0} \\
\frac{0}{0} \\
>\end{array}$ & > & 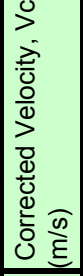 \\
\hline \multirow{2}{*}{ Mark } & Direct @1.5" & 6 & 45.1 & \begin{tabular}{|l|}
3,379 \\
02
\end{tabular} & 0.93 & 3,141 & 0 & 45.3 & 3,364 & 0.93 & 3,127 & 6 & 44.9 & 3,394 & 0.93 & 3,155 & 6 & 44.9 & \begin{tabular}{|l|}
3,394 \\
\end{tabular} & \begin{tabular}{|l|}
0.93 \\
\end{tabular} & 3,155 & 6 & 38.4 & 3,969 & 0.93 & 3,689 \\
\hline & Direct @ 5.5" & 6 & 62.9 & 2,423 & 0.93 & 2,252 & 6 & 63.6 & 2,396 & 0.93 & 2,227 & 6 & 61.4 & 2,482 & 0.93 & 2,307 & 6 & 71.3 & 2,137 & 0.93 & 1,987 & 6 & 67.4 & 2,261 & 0.93 & 2,102 \\
\hline \multirow{2}{*}{ Midspan } & Direct @1.5" & 6 & 45.4 & 3,357 & 0.93 & 3,120 & 6 & 45.4 & 3,357 & 0.93 & 3,120 & 6 & 44.6 & 3,417 & 0.93 & 3,176 & 6 & 45.3 & 3,364 & 0.93 & 3,127 & 6 & 35.2 & 4,330 & 0.93 & 4,024 \\
\hline & Direct @ 5.5" & 6 & 65.8 & 2,316 & 0.93 & 2,153 & 6 & 73.2 & 2,082 & 0.93 & 1,935 & 6 & 73.4 & 2,076 & 0.93 & 1,930 & 6 & 45.4 & 3,357 & 0.93 & 3,120 & 6 & 73.7 & 2,068 & 0.93 & 1,922 \\
\hline \multirow{2}{*}{ Unmark } & Direct @1.5" & 6 & 45.6 & 3,342 & 0.93 & 3,106 & $\overline{6}$ & 46.7 & 3,263 & 0.93 & 3,033 & 6 & 46.1 & 3,306 & 0.93 & 3,073 & 6 & 45.0 & \begin{tabular}{|l|}
3,387 \\
\end{tabular} & 0.93 & 3,148 & 6 & 36.7 & 4,153 & 0.93 & 3,860 \\
\hline & Direct @ 5.5" & 6 & 63.3 & 2,408 & 0.93 & 2,238 & 6 & 64.9 & 2,348 & 0.93 & 2,183 & 6 & 62.3 & 2,446 & 0.93 & 2,274 & 6 & 71.1 & 2,143 & 0.93 & 1,992 & 6 & 57.2 & 2,664 & 0.93 & 2,476 \\
\hline Mark & Indirect @ 1.5" & 16 & 98.1 & 4,143 & 0.80 & 3,314 & 16 & 97.7 & 4,160 & 0.80 & 3,328 & 15 & 92.4 & 4,123 & 0.79 & 3,257 & 15 & 90.1 & 4,229 & 0.79 & 3,341 & 16 & 135.3 & 3,004 & 0.80 & 2,403 \\
\hline Unmark & Indirect @ 1.5" & 16 & 97.7 & 4,160 & 0.80 & 3,328 & 16 & 96.9 & 4,194 & 0.80 & 3,355 & 12 & 75.5 & 4,037 & 0.85 & 3,432 & 12 & 78.0 & 3,908 & 0.85 & 3,322 & 16 & 149.8 & 2,713 & 0.80 & 2,170 \\
\hline Mark & Indirect @ 1.5" & 16 & 96.2 & 4,225 & 0.80 & 3,380 & 16 & 91.2 & 4,456 & 0.80 & 3,565 & 15 & 93.0 & 4,097 & 0.79 & 3,236 & 15 & 95.0 & 4,011 & 0.79 & 3,168 & 16 & 125.9 & 3,228 & 0.80 & 2,582 \\
\hline Unmark & Indirect @ 1.5" & 16 & 97.3 & 4,177 & 0.80 & 3,341 & 16 & 97.1 & 4,185 & 0.80 & 3,348 & 12 & 77.8 & 3,918 & 0.85 & 3,330 & 12 & 75.4 & \begin{tabular}{|l|}
4,042 \\
\end{tabular} & 0.85 & 3,436 & 16 & \begin{tabular}{|l|}
85.4 \\
\end{tabular} & 4,759 & 0.80 & 3,807 \\
\hline Mark & Indirec & 16 & 153 & 2,654 & 0.64 & 1,699 & 16 & 124.5 & 3,264 & 0.64 & 2,089 & 15 & 142.5 & 2,674 & 0.63 & 1,684 & 15 & 139.8 & \begin{tabular}{|l|}
2,725 \\
\end{tabular} & 0.63 & 1,717 & 16 & 199.7 & 2,035 & 0.64 & 1,302 \\
\hline Unmark & Indirect @ 5.5" & 16 & 241 & 1,686 & 0.64 & 1,079 & 16 & 129.6 & 3,136 & 0.64 & 2,007 & 12 & 215.2 & 1,416 & 0.72 & 1,020 & 12 & 203.4 & 1,499 & 0.72 & 1,079 & 16 & 141.3 & 2,876 & 0.64 & 1,841 \\
\hline Mark & Indirect @ 5.5" & 16 & 166 & 2,451 & 0.64 & 1,569 & 16 & 171.4 & 2,371 & 0.64 & 1,517 & 15 & 109.1 & 3,492 & 0.63 & 2,200 & 15 & 121.0 & 3,149 & 0.63 & 1,984 & 16 & 139.8 & 2,907 & 0.64 & 1,860 \\
\hline Unmark & Indirect @ 5.5" & 16 & 208 & 1,956 & 0.64 & 1,252 & 16 & 134.4 & 3,024 & 0.64 & 1,935 & 12 & 113.1 & 2,695 & 0.72 & 1,940 & 12 & 115.8 & 2,632 & 0.72 & 1,895 & 16 & 127.6 & 3,185 & 0.64 & 2,038 \\
\hline
\end{tabular}




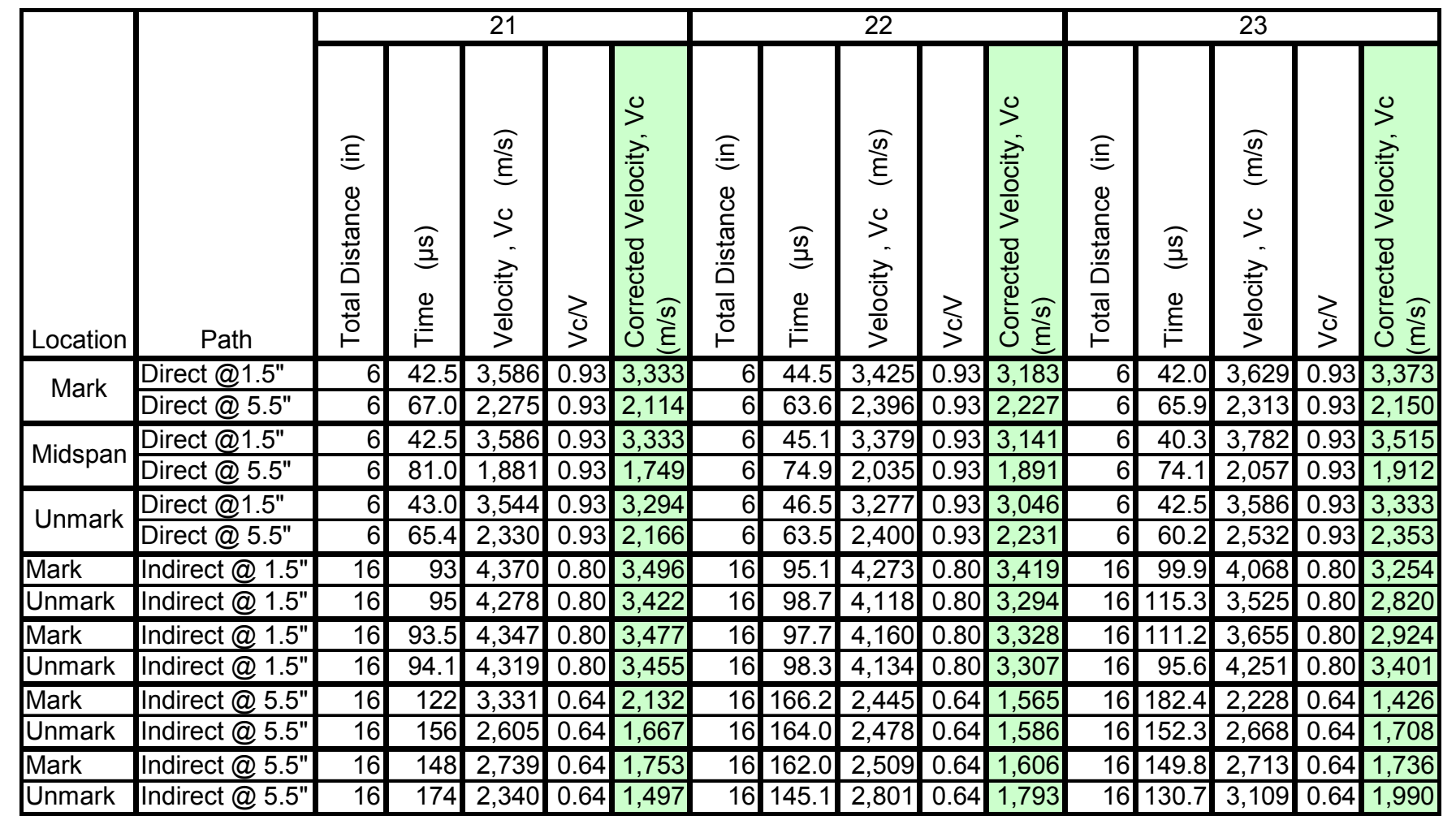




\section{D.4 Compression Cylinder Raw Data}

\section{D.4.1 Part I}

Please note that the specimen numbers listed in Table D.1 indicate that the cylinder was made from the same concrete batch as was its corresponding Part I beam. 
Table D.1: Part II Compressive Strengths

\begin{tabular}{|c|c|c|c|c|}
\hline Cylinder Set & Date & Force (lbs) & $\begin{array}{l}\text { Compressive } \\
\text { Strength (psi) }\end{array}$ & (Average psi) \\
\hline \multirow{3}{*}{1} & \multirow{3}{*}{$7 / 13 / 2007$} & 44,000 & 3,501 & \multirow{3}{*}{3,495} \\
\hline & & 39,750 & 3,163 & \\
\hline & & 48,000 & 3,820 & \\
\hline \multirow{3}{*}{2} & \multirow{3}{*}{$7 / 13 / 2007$} & 43,500 & 3,462 & \multirow{3}{*}{3,515} \\
\hline & & 44,500 & 3,541 & \\
\hline & & 44,500 & 3,541 & \\
\hline \multirow{3}{*}{3} & \multirow{3}{*}{ 4/4/2007 } & 43,000 & 3,422 & \multirow{3}{*}{3,501} \\
\hline & & 44,000 & 3,501 & \\
\hline & & 45,000 & 3,581 & \\
\hline \multirow{3}{*}{5} & \multirow{3}{*}{ 10/16/2007 } & 47,000 & 3,740 & \multirow{3}{*}{3,674} \\
\hline & & 45,500 & 3,621 & \\
\hline & & 46,000 & 3,661 & \\
\hline \multirow{3}{*}{15} & \multirow{3}{*}{$10 / 23 / 2007$} & 41,500 & 3,302 & \multirow{3}{*}{3,249} \\
\hline & & 41,000 & 3,263 & \\
\hline & & 40,000 & 3,183 & \\
\hline \multirow{3}{*}{16} & \multirow{3}{*}{$10 / 23 / 2007$} & 43,500 & 3,462 & \multirow{3}{*}{3,409} \\
\hline & & 43,000 & 3,422 & \\
\hline & & 42,000 & 3,342 & \\
\hline \multirow{3}{*}{7} & \multirow{3}{*}{$2 / 6 / 2008$} & 40,000 & 3,183 & \multirow{3}{*}{3,249} \\
\hline & & 41,500 & 3,302 & \\
\hline & & 41,000 & 3,263 & \\
\hline \multirow{3}{*}{10} & & 45,500 & 3,621 & \\
\hline & 2/1/2008 & 49,000 & 3,899 & 3,846 \\
\hline & & 50,500 & 4,019 & \\
\hline & & 43,500 & 3,462 & \\
\hline 17 & 2/5/2008 & 49,000 & 3,899 & 3,634 \\
\hline & & 44,500 & 3,541 & \\
\hline & & 45,000 & 3,581 & \\
\hline 18 & $2 / 5 / 2008$ & 44,000 & 3,501 & 3,581 \\
\hline & & 46,000 & 3,661 & \\
\hline & & 46,000 & 3,661 & \\
\hline 6 & $7 / 28 / 2008$ & 46,500 & 3,700 & 3,700 \\
\hline & & 47,000 & 3,740 & \\
\hline & & 48,000 & 3,820 & \\
\hline 8 & $7 / 25 / 2008$ & 49,000 & 3,899 & 3,846 \\
\hline & & 48,000 & 3,820 & \\
\hline & & 46,000 & 3,661 & \\
\hline 9 & $7 / 25 / 2008$ & 48,000 & 3,820 & 3,780 \\
\hline & & 48,500 & 3,860 & \\
\hline & & 49,000 & 3,899 & \\
\hline 13 & $7 / 28 / 2008$ & 48,500 & 3,860 & 3,860 \\
\hline & & 48,000 & 3,820 & \\
\hline & & 47,000 & 3,740 & \\
\hline 14 & $7 / 28 / 2008$ & 47,000 & 3,740 & 3,769 \\
\hline & & 48,100 & 3,828 & \\
\hline Patch & & 125,000 & 9,947 & \\
\hline Concrete & 2/7/2008 & 120,000 & 9,549 & 9,563 \\
\hline (28-day) & & 115,500 & 9,191 & \\
\hline
\end{tabular}




\section{D.4.2 Part II}

Please note that the specimen numbers listed in Table D.2, Table D.3, Table D.4, and Table D.5 indicate that the cylinder was made from the same concrete batch as was its corresponding Part II beam. The 28-day strengths are highlighted in yellow and the longterm strengths (cylinders were broken on same day as the beam was tested to static failure) are highlighted in green.

Table D.2: Part II Control Beam Compressive Strengths

\begin{tabular}{|c|c|c|c|c|}
\hline $\begin{array}{l}\text { Cylinder } \\
\text { Set }\end{array}$ & Date & Force (Ibs) & $\begin{array}{l}\text { Compressive } \\
\text { Strength (psi) }\end{array}$ & Average psi) \\
\hline \multirow{3}{*}{1} & \multirow{3}{*}{$10 / 1 / 2007$} & 31,000 & 2,467 & \multirow{3}{*}{2,546} \\
\hline & & 32,500 & 2,586 & \\
\hline & & 32,500 & 2,586 & \\
\hline \multirow{3}{*}{2} & \multirow{3}{*}{$6 / 3 / 2008$} & 25,000 & 1,989 & \multirow{3}{*}{1,976} \\
\hline & & 25,000 & 1,989 & \\
\hline & & 24,500 & 1,950 & \\
\hline \multirow{3}{*}{3} & \multirow{3}{*}{ 9/20/2007 } & 28,500 & 2,268 & \multirow{3}{*}{2,082} \\
\hline & & 26,500 & 2,109 & \\
\hline & & 23,500 & 1,870 & \\
\hline \multirow{3}{*}{3} & \multirow{3}{*}{$1 / 31 / 2008$} & 36,500 & 2,905 & \multirow{3}{*}{3,011} \\
\hline & & 39,500 & 3,143 & \\
\hline & & 37,500 & 2,984 & \\
\hline \multirow{3}{*}{4} & \multirow{3}{*}{ 9/20/2007 } & 32,500 & 2,586 & \multirow{3}{*}{2,639} \\
\hline & & 33,000 & 2,626 & \\
\hline & & 34,000 & 2,706 & \\
\hline \multirow{3}{*}{4} & \multirow{3}{*}{$1 / 31 / 2008$} & 39,000 & 3,104 & \multirow{3}{*}{3,170} \\
\hline & & 39,500 & 3,143 & \\
\hline & & 41,000 & 3,263 & \\
\hline \multirow{3}{*}{11} & \multirow{3}{*}{$9 / 25 / 2007$} & 28,000 & 2,228 & \multirow{3}{*}{2,321} \\
\hline & & 29,500 & 2,348 & \\
\hline & & 30,000 & 2,387 & \\
\hline \multirow{3}{*}{11} & \multirow{3}{*}{$6 / 17 / 2008$} & 31,500 & 2,507 & \multirow{3}{*}{2,387} \\
\hline & & 29,500 & 2,348 & \\
\hline & & 29,000 & 2,308 & \\
\hline \multirow{3}{*}{12} & \multirow{3}{*}{$9 / 25 / 2007$} & 29,500 & 2,348 & \multirow{3}{*}{2,401} \\
\hline & & 30,500 & 2,427 & \\
\hline & & 30,500 & 2,427 & \\
\hline \multirow{3}{*}{12} & \multirow{3}{*}{$6 / 18 / 2008$} & 32,000 & 2,546 & \multirow{3}{*}{2,493} \\
\hline & & 31,000 & 2,467 & \\
\hline & & 31,000 & 2,467 & \\
\hline
\end{tabular}


Table D.3: Part II Branch 1 Beam Compressive Strengths

\begin{tabular}{|c|c|c|c|c|}
\hline $\begin{array}{l}\text { Cylinder } \\
\text { Set }\end{array}$ & Date & Force (lbs) & $\begin{array}{l}\text { Compressive } \\
\text { Strength (psi) }\end{array}$ & Average psi) \\
\hline \multirow{3}{*}{5} & \multirow{3}{*}{$9 / 21 / 2007$} & 26,500 & 2,109 & \multirow{3}{*}{2,215} \\
\hline & & 27,500 & 2,188 & \\
\hline & & 29,500 & 2,348 & \\
\hline \multirow{3}{*}{5} & \multirow{3}{*}{$2 / 21 / 2008$} & 32,000 & 2,546 & \multirow{3}{*}{2,493} \\
\hline & & 31,000 & 2,467 & \\
\hline & & 31,000 & 2,467 & \\
\hline \multirow{3}{*}{7} & \multirow{3}{*}{$9 / 24 / 2007$} & 25,500 & 2,029 & \multirow{3}{*}{2,401} \\
\hline & & 32,000 & 2,546 & \\
\hline & & 33,000 & 2,626 & \\
\hline \multirow{3}{*}{7} & \multirow{3}{*}{ 4/18/2008 } & 34,000 & 2,706 & \multirow{3}{*}{2,639} \\
\hline & & 33,000 & 2,626 & \\
\hline & & 32,500 & 2,586 & \\
\hline \multirow{3}{*}{8} & \multirow{3}{*}{$9 / 24 / 2007$} & 30,000 & 2,387 & \multirow{3}{*}{2,573} \\
\hline & & 34,000 & 2,706 & \\
\hline & & 33,000 & 2,626 & \\
\hline \multirow{3}{*}{8} & \multirow{3}{*}{ 3/3/2008 } & 33,000 & 2,626 & \multirow{3}{*}{2,653} \\
\hline & & 33,500 & 2,666 & \\
\hline & & 33,500 & 2,666 & \\
\hline \multirow{3}{*}{9} & \multirow{3}{*}{ 9/27/2007 } & 30,500 & 2,427 & \multirow{3}{*}{2,401} \\
\hline & & 30,000 & 2,387 & \\
\hline & & 30,000 & 2,387 & \\
\hline \multirow{3}{*}{9} & \multirow{3}{*}{$3 / 4 / 2008$} & 33,500 & 2,666 & \multirow{3}{*}{2,679} \\
\hline & & 33,500 & 2,666 & \\
\hline & & 34,000 & 2,706 & \\
\hline \multirow{3}{*}{14} & \multirow{3}{*}{$11 / 26 / 2007$} & 32,000 & 2,546 & \multirow{3}{*}{2,493} \\
\hline & & 30,000 & 2,387 & \\
\hline & & 32,000 & 2,546 & \\
\hline \multirow{3}{*}{14} & \multirow{3}{*}{$5 / 6 / 2008$} & 30,500 & 2,427 & \multirow{3}{*}{2,401} \\
\hline & & 30,000 & 2,387 & \\
\hline & & 30,000 & 2,387 & \\
\hline
\end{tabular}


Table D.4: Part II Branch 2 Beam Compressive Strengths

\begin{tabular}{|c|c|c|c|c|}
\hline $\begin{array}{l}\text { Cylinder } \\
\text { Set }\end{array}$ & Date & Force (lbs) & \begin{tabular}{|l|} 
Compressive \\
Strength (psi)
\end{tabular} & Average psi) \\
\hline \multirow{3}{*}{13} & \multirow{3}{*}{$11 / 26 / 2007$} & 27,500 & 2,188 & \multirow{3}{*}{2,255} \\
\hline & & 29,000 & 2,308 & \\
\hline & & 28,500 & 2,268 & \\
\hline \multirow{3}{*}{13} & \multirow{3}{*}{ 4/23/2008 } & 27,400 & 2,180 & \multirow{3}{*}{2,265} \\
\hline & & 28,500 & 2,268 & \\
\hline & & 29,500 & 2,348 & \\
\hline \multirow{3}{*}{15} & \multirow{3}{*}{$11 / 27 / 2007$} & 26,000 & 2,069 & \multirow{3}{*}{2,135} \\
\hline & & 27,000 & 2,149 & \\
\hline & & 27,500 & 2,188 & \\
\hline \multirow{3}{*}{15} & \multirow{3}{*}{$5 / 6 / 2008$} & 29,500 & 2,348 & \multirow{3}{*}{2,361} \\
\hline & & 29,500 & 2,348 & \\
\hline & & 30,000 & 2,387 & \\
\hline \multirow{3}{*}{17} & \multirow{3}{*}{$1 / 29 / 2008$} & 27,000 & 2,149 & \multirow{3}{*}{2,122} \\
\hline & & 27,500 & 2,188 & \\
\hline & & 25,500 & 2,029 & \\
\hline \multirow{3}{*}{17} & \multirow{3}{*}{ 6/10/2008 } & 31,500 & 2,507 & \multirow{3}{*}{2,454} \\
\hline & & 31,000 & 2,467 & \\
\hline & & 30,000 & 2,387 & \\
\hline \multirow{3}{*}{18} & \multirow{3}{*}{ 1/29/2008 } & 29,500 & 2,348 & \multirow{3}{*}{2,401} \\
\hline & & 30,500 & 2,427 & \\
\hline & & 30,500 & 2,427 & \\
\hline \multirow{3}{*}{18} & \multirow{3}{*}{$5 / 30 / 2008$} & 29,500 & 2,348 & \multirow{3}{*}{2,321} \\
\hline & & 29,000 & 2,308 & \\
\hline & & 29,000 & 2,308 & \\
\hline \multirow{3}{*}{20} & \multirow{3}{*}{$1 / 15 / 2008$} & 34,500 & 2,745 & \multirow{3}{*}{2,745} \\
\hline & & 35,000 & 2,785 & \\
\hline & & 34,000 & 2,706 & \\
\hline \multirow{3}{*}{20} & \multirow{3}{*}{ 6/30/2008 } & 32,000 & 2,546 & \multirow{3}{*}{2,546} \\
\hline & & 31,000 & 2,467 & \\
\hline & & 33,000 & 2,626 & \\
\hline
\end{tabular}


Table D.5: Part II Branch 3 Beam Compressive Strengths

\begin{tabular}{|c|c|c|c|c|}
\hline $\begin{array}{l}\text { Cylinder } \\
\text { Set }\end{array}$ & Date & Force (lbs) & $\begin{array}{l}\text { Compressive } \\
\text { Strength (psi) }\end{array}$ & Average psi) \\
\hline \multirow{3}{*}{19} & \multirow{3}{*}{$1 / 15 / 2008$} & 30,000 & 2,387 & \multirow{3}{*}{2,387} \\
\hline & & 29,000 & 2,308 & \\
\hline & & 31,000 & 2,467 & \\
\hline \multirow{3}{*}{19} & \multirow{3}{*}{$8 / 10 / 2008$} & 30,500 & 2,427 & \multirow{3}{*}{2,401} \\
\hline & & 31,000 & 2,467 & \\
\hline & & 29,000 & 2,308 & \\
\hline \multirow{3}{*}{21} & \multirow{3}{*}{$1 / 17 / 2008$} & 31,500 & 2,507 & \multirow{3}{*}{2,533} \\
\hline & & 31,000 & 2,467 & \\
\hline & & 33,000 & 2,626 & \\
\hline \multirow{3}{*}{21} & \multirow{3}{*}{$6 / 5 / 2008$} & 31,500 & 2,507 & \multirow{3}{*}{2,507} \\
\hline & & 31,000 & 2,467 & \\
\hline & & 32,000 & 2,546 & \\
\hline \multirow{3}{*}{22} & \multirow{3}{*}{$1 / 17 / 2008$} & 33,500 & 2,666 & \multirow{3}{*}{2,546} \\
\hline & & 30,500 & 2,427 & \\
\hline & & 32,000 & 2,546 & \\
\hline \multirow{3}{*}{22} & \multirow{3}{*}{$6 / 12 / 2008$} & 30,500 & 2,427 & \multirow{3}{*}{2,427} \\
\hline & & 29,500 & 2,348 & \\
\hline & & 31,500 & 2,507 & \\
\hline \multirow{3}{*}{23} & \multirow{3}{*}{$1 / 18 / 2008$} & 28,000 & 2,228 & \multirow{3}{*}{2,348} \\
\hline & & 30,500 & 2,427 & \\
\hline & & 30,000 & 2,387 & \\
\hline \multirow{3}{*}{23} & \multirow{3}{*}{ 8/24/2008 } & 29,500 & 2,348 & \multirow{3}{*}{2,427} \\
\hline & & 30,500 & 2,427 & \\
\hline & & 31,500 & 2,507 & \\
\hline \multirow{3}{*}{24} & \multirow{3}{*}{ 1/18/2008 } & 30,000 & 2,387 & \multirow{3}{*}{2,294} \\
\hline & & 27,000 & 2,149 & \\
\hline & & 29,500 & 2,348 & \\
\hline \multirow{3}{*}{24} & \multirow{3}{*}{$6 / 19 / 2008$} & 30,000 & 2,387 & \multirow{3}{*}{2,401} \\
\hline & & 30,500 & 2,427 & \\
\hline & & 30,000 & 2,387 & \\
\hline
\end{tabular}


Table D.6: Part II Patch-Repair Polymer Concrete Compressive Strengths

\begin{tabular}{|c|c|c|c|c|}
\hline Cylinder Set & Date & Force (Ibs) & $\begin{array}{l}\text { Compressive } \\
\text { Strength (psi) }\end{array}$ & Average psi) \\
\hline \multirow{3}{*}{$\begin{array}{c}\text { Patch } \\
\text { Concrete }\end{array}$} & \multirow{3}{*}{$5 / 6 / 2008$} & 103,000 & 8,196 & \multirow{3}{*}{8,130} \\
\hline & & 102,000 & 8,117 & \\
\hline & & 101,500 & 8,077 & \\
\hline \multirow{6}{*}{$\begin{array}{c}\text { Patch } \\
\text { Concrete }\end{array}$} & \multirow{6}{*}{$8 / 24 / 2008$} & 103,500 & 8,236 & \multirow{6}{*}{8,137} \\
\hline & & 104,000 & 8,276 & \\
\hline & & 101,000 & 8,037 & \\
\hline & & 104,000 & 8,276 & \\
\hline & & 100,000 & 7,958 & \\
\hline & & 101,000 & 8,037 & \\
\hline
\end{tabular}




\section{D.5 Static Flexural Testing Observations}

\section{D.5.1 Part I Beams}

\begin{tabular}{|l|l|}
\hline Beam 6 \\
\hline Load (lbs) & Observation \\
\hline 4000 & Several flexure cracks \\
\hline 5000 & Horizontal delamination crack widening \\
\hline 6000 & Horizontal delamination crack continuing to widen \\
\hline 7000 & All cracks widening \\
\hline 8000 & No change \\
\hline 9000 & Crack widths growing significantly \\
\hline 10000 & Delamination layer now has no bond. \\
\hline
\end{tabular}

\begin{tabular}{|l|l|}
\hline \multicolumn{2}{|l|}{ Beam 7} \\
\hline Load (lbs) & Observation \\
\hline 6000 & Flexure crack in constant moment region \\
\hline 7000 & Few more flexure cracks \\
\hline 8000 & No change \\
\hline 9000 & Flexure crack @ 7 '-10' \\
\hline 10000 & No change \\
\hline 11000 & Few more flexure cracks \\
\hline 12000 & Flexure cracks propagating upward slightly \\
\hline 13000 & Crack widths growing slightly \\
\hline
\end{tabular}

\begin{tabular}{|l|l|}
\hline Beam 8 & \\
\hline Load (lbs) & Observation \\
\hline 7000 & Few hairline flexure cracks \\
\hline 8000 & Few more flexure cracks \\
\hline 9000 & Flexure crack @ 7'-11' \\
\hline 10000 & No change \\
\hline 11000 & Flexure cracks propagating upward slightly \\
\hline 12000 & Few more flexure cracks outside constant moment region \\
\hline 13000 & Crack widths growing very slightly; Partial failure @ 13,100 lbs \\
\hline
\end{tabular}




\begin{tabular}{|l|l|}
\hline Beam 9 \\
\hline Load (lbs) & Observation \\
\hline 5000 & $\begin{array}{l}\text { Some flexure cracks in constant moment region; Horizontal crack running } \\
\text { parallel to epoxy-filled crack }\end{array}$ \\
\hline 6000 & Flexure cracks widening slightly \\
\hline 7000 & No change \\
\hline 8000 & No change \\
\hline 9000 & Horizontal crack on right side elongating; Flexure crack @ 6'-7' and 2'-2'" \\
\hline 10000 & No change \\
\hline
\end{tabular}

\begin{tabular}{|l|l|}
\hline \multicolumn{2}{|l|}{ Beam 10} \\
\hline Load (lbs) & Observation \\
\hline 1,000 & No Change \\
\hline 2,000 & No Change \\
\hline 3,000 & No Change \\
\hline 4,000 & Flexure crack forming in constant moment region \\
\hline 5,000 & More flexural cracks forming \\
\hline 6,000 & No Change \\
\hline 7,000 & No Change \\
\hline 8,000 & No Change \\
\hline 9,000 & No Change \\
\hline 10,000 & No Change \\
\hline 11,000 & No Change \\
\hline 12,000 & New tensile crack formation / Upward crack propagation / Cracks widen \\
\hline 13,000 & Cracks widening slightly \\
\hline 14,000 & Cracks widening slightly, delamination of cover in constant moment sect. \\
\hline
\end{tabular}

\begin{tabular}{|l|l|}
\hline Beam 17 \\
\hline Load (lbs) & Observation \\
\hline 1,000 & No Change \\
\hline 2,000 & No Change \\
\hline 3,000 & No Change \\
\hline 4,000 & No Change \\
\hline 5,000 & No Change \\
\hline 6,000 & Initial flexure cracks forming \\
\hline 7,000 & More cracks forming \\
\hline 8,000 & More cracks forming \\
\hline 9,000 & No Change \\
\hline 10,000 & Cracks widening slightly \\
\hline 11,000 & Cracks widening slightly / Crack outside of const. mom. region on unmark \\
\hline 12,000 & Cracks widening / More cracks outside of constant moment region \\
\hline 13,000 & Cracks widening \\
\hline 14,000 & Cracks widening, especially initial flexure crack \\
\hline
\end{tabular}




\begin{tabular}{|l|l|}
\hline Beam 13 & \\
\hline Load (lbs) & Observation \\
\hline 4000 & Flexure crack @ midspan \\
\hline 5000 & No change \\
\hline 6000 & No change \\
\hline 7000 & Few more flexure cracks propagating upward \\
\hline 8000 & Few more flexure cracks \\
\hline 9000 & No change \\
\hline 10000 & Cracks widening slightly \\
\hline 11000 & Cracks continuing to widen slightly \\
\hline 12000 & Few more flexure cracks \\
\hline 13000 & No change \\
\hline 14000 & Flexure cracks @ midspan growing significantly \\
\hline
\end{tabular}

\begin{tabular}{|l|l|}
\hline Beam 14 \\
\hline Load (lbs) & Observation \\
\hline 5000 & Flexure crack @ midspan \\
\hline 6000 & Few more flexure cracks \\
\hline 7000 & No change \\
\hline 8000 & Crack widths growing slightly \\
\hline 9000 & Few more flexure cracks \\
\hline 10000 & Cracks propagating upward slightly \\
\hline 11000 & Cracks growing slightly \\
\hline 12000 & No change \\
\hline 13000 & No change \\
\hline 14000 & More flexure cracks \\
\hline
\end{tabular}

\begin{tabular}{|l|l|}
\hline Beam 18 & \\
\hline Load (lbs) & Observation \\
\hline 1,000 & No Change \\
\hline 2,000 & No Change \\
\hline 3,000 & No Change \\
\hline 4,000 & No Change \\
\hline 5,000 & Flexure cracks forming in constant moment region \\
\hline 6,000 & No Change \\
\hline 7,000 & More flexure cracks forming \\
\hline 8,000 & Cracks growing slightly \\
\hline 9,000 & More cracks forming both inside and outside of constant moment region \\
\hline 10,000 & More cracks forming both inside and outside of constant moment region \\
\hline 11,000 & More cracks forming both inside and outside of constant moment region \\
\hline 12,000 & Cracks widening \\
\hline 13,000 & More flexure cracks forming and slowly growing \\
\hline 14,000 & Cracks growing and widening \\
\hline 15,000 & \\
\hline 16,000 & \\
\hline
\end{tabular}




\section{D.5.2 Part II Beams}

\begin{tabular}{|l|l|}
\hline Beam 2 \\
\hline Load & Observation \\
\hline 8000 & First flexure crack in constant moment region \\
\hline 9000 & More flexure cracks forming in constant moment region \\
\hline 10000 & $\begin{array}{l}\text { Several more flexure cracks, some just outside of constant moment region. } \\
\text { Cracks propagating upward }\end{array}$ \\
\hline 11000 & No change \\
\hline 12000 & No change \\
\hline 13000 & More flexure cracks. Crack widths growing \\
\hline 14000 & Crack widths growing \\
\hline 14500 & Cracks still widening \\
\hline
\end{tabular}

\begin{tabular}{|l|l|}
\hline Beam 3 \\
\hline Load (lbs) & Observation \\
\hline 6,000 & T-crack in constant moment region \\
\hline 7,000 & Cracks continue to widen \\
\hline 8,000 & Cracks continue to widen \\
\hline 9,000 & No Change \\
\hline 10,000 & Delamination crack turns upward in constant moment region \\
\hline 11,000 & More flexural cracks forming \\
\hline 12,000 & Flexural crack rapidly propagating toward top of beam \\
\hline
\end{tabular}

\begin{tabular}{|l|l|}
\hline Beam 4 \\
\hline Load (lbs) & Observation \\
\hline 2,000 & Crack in constant moment region \\
\hline 3,000 & No Change \\
\hline 4,000 & Existing delamination crack widening / New flexure cracks forming \\
\hline 5,000 & No Change \\
\hline 6,000 & No Change \\
\hline 7,000 & No Change \\
\hline 8,000 & No Change \\
\hline 9,000 & No Change \\
\hline 10,000 & Flexural crack forming above delaminated zone \\
\hline 11,000 & No Change \\
\hline 12,000 & Cracks Widening \\
\hline 13,000 & Delamination Layer Falls and Beam Fails Shortly After \\
\hline
\end{tabular}




\begin{tabular}{|l|l|}
\hline Beam 5 & \\
\hline Load (lbs) & Observation \\
\hline 3,000 & Preliminary flexure cracks \\
\hline 4,000 & No Change \\
\hline 5,000 & No Change \\
\hline 6,000 & No Change \\
\hline 7,000 & No Change \\
\hline 8,000 & Several more cracks forming \\
\hline 9,000 & No Change \\
\hline 10,000 & More cracks / Crack widths growing slightly \\
\hline 11,000 & No Change \\
\hline 12,000 & More cracks / Crack widths growing \\
\hline 13,000 & More evenly spaced flexure cracks / Crack widths growing faster \\
\hline 14,000 & More cracks / Widths growing / Flexure cracks growing past 1' \& 5' marks \\
\hline 15,000 & Cracks widening \& forming / Cracks propagating up to old concrete \\
\hline
\end{tabular}

\begin{tabular}{|l|l|}
\hline Beam 7 \\
\hline Load (lbs) & Observation \\
\hline 4000 & Few evenly spaced flexure cracks \\
\hline 5000 & No change \\
\hline 6000 & No change \\
\hline 7000 & Few more cracks. Cracks widening slightly and propagating upward. \\
\hline 8000 & No change \\
\hline 9000 & Few more cracks. Cracks widening slightly and propagating upward. \\
\hline 10000 & Shear-flexure crack near 1'-0'. Cracks widening. \\
\hline 11000 & All cracks widening \\
\hline 12000 & Cracks continuing to widen \\
\hline 13000 & Cracks widening \\
\hline 14000 & More flexure cracks forming \\
\hline 15000 & More flexure cracks. Cracks widening significantly \\
\hline 16000 & Shear crack @ 5'-1'” \\
\hline 17000 & Some cracks widening \\
\hline 18,000 & Shear flexure cracks at 5'; Flexure crack at midspan widening significantly \\
\hline
\end{tabular}




\begin{tabular}{|l|l|}
\hline Beam 8 & \\
\hline Load (lbs) & Observation \\
\hline 1,000 & No Change \\
\hline 2,000 & No Change \\
\hline 3,000 & No Change \\
\hline 4,000 & Initial flexure cracking \\
\hline 5,000 & More cracks forming \\
\hline 6,000 & No Change \\
\hline 7,000 & More cracks / Some cracks widening slightly \\
\hline 8,000 & No Change \\
\hline 9,000 & No Change \\
\hline 10,000 & Some cracks outside of constant moment region \\
\hline 11,000 & No Change \\
\hline 12,000 & More flexure cracks \\
\hline 13,000 & More flexure cracks \\
\hline 14,000 & Some cracks widening slightly \\
\hline 15,000 & Shear flexure cracks at 5' / One flexure crack widening significantly \\
\hline 16,000 & Imminent fracture / Most cracks at unmark end widening \\
\hline
\end{tabular}

\begin{tabular}{|l|l|}
\hline Beam 9 \\
\hline Load (lbs) & Observation \\
\hline 1,000 & No Change \\
\hline 2,000 & No Change \\
\hline 3,000 & No Change \\
\hline 4,000 & Initial flexure cracks \\
\hline 5,000 & No Change \\
\hline 6,000 & More cracks forming \\
\hline 7,000 & More cracks forming \\
\hline 8,000 & No Change \\
\hline 9,000 & Few more flexure cracks forming \\
\hline 10,000 & Few more cracks / Cracks propagating \\
\hline 11,000 & No Change \\
\hline 12,000 & Some cracks forming \\
\hline 13,000 & No Change \\
\hline 14,000 & Cracks widening slightly \\
\hline 15,000 & Cracks widening significantly \\
\hline 16,000 & More evenly spaced flexure cracks / All cracks widening \\
\hline
\end{tabular}




\begin{tabular}{|l|l|}
\hline \multicolumn{2}{|l|}{ Beam 11} \\
\hline Load & Observation \\
\hline 2000 & First flexure cracks \\
\hline 3000 & No change \\
\hline 4000 & Few more flexure cracks \\
\hline 5000 & No change \\
\hline 6000 & Flexure cracks widening slightly \\
\hline 7000 & Large flexure crack propagating high towards compression zone at 3'-10" \\
\hline 8000 & Shear-flexure crack at 0'-9" \\
\hline 9000 & $\begin{array}{l}\text { Shear-flexure crack widening slightly. More flexure cracks. Cracks propagating } \\
\text { upward }\end{array}$ \\
\hline 10000 & $\begin{array}{l}\text { Shear-flexure crack widening slightly. More flexure cracks. Cracks propagating } \\
\text { upward }\end{array}$ \\
\hline 11000 & Shear-flexure crack widening and propagating to top of beam near load point \\
\hline 12000 & $\begin{array}{l}\text { Shear-flexure crack at 5'-5" propagating up toward load point. More flexure } \\
\text { cracks. Cracks widening }\end{array}$ \\
\hline 13000 & Shear-flexure cracks widening \\
\hline 14000 & Cracks widening and propagating upward \\
\hline 15000 & Additional shear cracking, more flexure cracks \\
\hline 15500 & Cracks widening \\
\hline 16000 & Cracks widen significantly \\
\hline
\end{tabular}

\begin{tabular}{|l|l|}
\hline \multicolumn{2}{|l|}{ Beam 13} \\
\hline Load & Observation \\
\hline 4000 & Initial flexure crack at midspan \\
\hline 5000 & No change \\
\hline 6000 & Cracks directly beneath each load plate \\
\hline 7000 & No change \\
\hline 8000 & Several more evenly spaced cracks in constant moment region \\
\hline 9000 & Several more evenly spaced cracks in constant moment region \\
\hline 10000 & Flexure cracks propagating upward \\
\hline 11000 & No change \\
\hline 12000 & Shear-flexure cracks around 1' and 5' outside of stirrup region \\
\hline 13000 & Cracks continuing to grow \\
\hline 14000 & $\begin{array}{l}\text { Large shear crack beginning around 0'-9' ' and moving toward load point. } \\
\text { Flexure cracks not widening }\end{array}$ \\
\hline 15000 & $\begin{array}{l}\text { Shear crack widening slightly. Crack near 1' on mark left side turned up into } \\
\text { anchor }\end{array}$ \\
\hline 16000 & Flexure cracks widening. Drop in load just over 16000 \\
\hline 17000 & Shear crack widening. All cracks widening \\
\hline
\end{tabular}




\begin{tabular}{|l|l|}
\hline \multicolumn{2}{|l|}{ Beam 12} \\
\hline Load & Observation \\
\hline 5000 & First flexural crack \\
\hline 6000 & No change \\
\hline 7000 & No change \\
\hline 8000 & More flexure cracks forming \\
\hline 9000 & No change \\
\hline 10000 & Few more flexure cracks propagating upward \\
\hline 11000 & Few more flexure cracks \\
\hline 12000 & More flexure cracks. Cracks propagating upward \\
\hline 13000 & More flexure cracks. Cracks propagating upward \\
\hline 14000 & Shear-flexure cracks on each side of each end \\
\hline 15000 & Cracks widening \\
\hline 15500 & Cracks widening significantly \\
\hline
\end{tabular}

\begin{tabular}{|l|l|}
\hline \multicolumn{2}{|l|}{ Beam 13} \\
\hline Load & Observation \\
\hline 4000 & Initial flexure crack at midspan \\
\hline 5000 & No change \\
\hline 6000 & Cracks directly beneath each load plate \\
\hline 7000 & No change \\
\hline 8000 & Several more evenly spaced cracks in constant moment region \\
\hline 9000 & Several more evenly spaced cracks in constant moment region \\
\hline 10000 & Flexure cracks propagating upward \\
\hline 11000 & No change \\
\hline 12000 & Shear-flexure cracks around 1' and 5' outside of stirrup region \\
\hline 13000 & Cracks continuing to grow \\
\hline 14000 & $\begin{array}{l}\text { Large shear crack beginning around 0'-9' and moving toward load point. } \\
\text { Flexure cracks not widening }\end{array}$ \\
\hline 15000 & $\begin{array}{l}\text { Shear crack widening slightly. Crack near 1' on mark left side turned up into } \\
\text { anchor }\end{array}$ \\
\hline 16000 & Flexure cracks widening. Drop in load just over 16000 \\
\hline 17000 & Shear crack widening. All cracks widening \\
\hline
\end{tabular}




\begin{tabular}{|l|l|}
\hline \multicolumn{2}{|l|}{ Beam 14} \\
\hline Load & Observation \\
\hline 5000 & Evenly spaced flexure cracks \\
\hline 6000 & No change \\
\hline 7000 & No change \\
\hline 8000 & No change \\
\hline 9000 & Few more cracks. Cracks widening slightly and propagating upward. \\
\hline 10000 & Few more cracks. Cracks widening slightly and propagating upward. \\
\hline 11000 & Shear-flexure crack near 1'-2". Cracks widening. \\
\hline 12000 & Shear-flexure crack growing and widening. Other flexure cracks widening \\
\hline 13000 & Cracks continuing to widen \\
\hline 14000 & Cracks widening \\
\hline 15000 & Cracks widening. More flexure cracks formed \\
\hline 16000 & More flexure cracks. Cracks widening significantly \\
\hline 16500 & Another shear crack and sudden FRP debonding and failure \\
\hline
\end{tabular}

\begin{tabular}{|l|l|}
\hline \multicolumn{2}{|l|}{ Beam 15} \\
\hline Load & Observation \\
\hline 4000 & First flexure cracks in constant moment region \\
\hline 5000 & No change \\
\hline 6000 & Some additional cracks in constant moment region \\
\hline 7000 & Flexure cracks propagating upward \\
\hline 8000 & Flexure cracks outside of constant moment \\
\hline 9000 & Shear-flexure crack at unmark end \\
\hline 10000 & Cracks all growing slightly \\
\hline 11000 & No change \\
\hline 12000 & No change \\
\hline 13000 & Additional flexure cracks in constant moment region \\
\hline 14000 & Some additional flexure cracks \\
\hline 14500 & Shear crack at 0 '-4" on mark end \\
\hline 15000 & No change \\
\hline 16000 & Shear crack propagated to FRP \\
\hline 17000 & No change \\
\hline
\end{tabular}




\begin{tabular}{|l|l|}
\hline \multicolumn{2}{|l|}{ Beam 17} \\
\hline Load & Observation \\
\hline 3000 & $\begin{array}{l}\text { First cracks visible, one to inside of unmarked anchor and one to outside. The } \\
\text { outside shear-flexure crack turns up and into the FRP. }\end{array}$ \\
\hline 4000 & Few more flexure cracks \\
\hline 5000 & Few more flexure cracks \\
\hline 6000 & Cracks propagating upward \\
\hline 7000 & Few more flexure cracks \\
\hline 8000 & New flexure-shear crack at unmarked end \\
\hline 9000 & Cracks propagating slowly \\
\hline 10000 & $\begin{array}{l}\text { Cracks propagating slowly. The shear-flexure crack outside of the anchor stirrup } \\
\text { at 5'-1" on the left side appears to only be a flexure crack on the right side }\end{array}$ \\
\hline 11000 & No change \\
\hline 12000 & Few more flexure cracks \\
\hline 13000 & Shear-flexure crack at 5'-1" propagating up into FRP stirrup on left side \\
\hline 14000 & Crack at 4'-11" on right side now shear-flexure. Shear flexure crack at 1'-0" \\
\hline
\end{tabular}

\begin{tabular}{|l|l|}
\hline \multicolumn{2}{|l|}{ Beam 18} \\
\hline Load & Observation \\
\hline 3000 & First flexure crack \\
\hline 4000 & Few more flexure cracks \\
\hline 5000 & Few more flexure cracks \\
\hline 6000 & Few flexure cracks in constant moment region \\
\hline 7000 & No change \\
\hline 8000 & Crack near 1'-0" outside of anchor \\
\hline 9000 & Some flexure cracks widening slightly \\
\hline 10000 & Several more flexure cracks \\
\hline 11000 & No change \\
\hline 12000 & More flexure cracks growing. Crack near 1'-0" turning toward FRP anchor \\
\hline 13000 & Flexure cracks widening and propagating upward \\
\hline 14000 & $\begin{array}{l}\text { Similar shear-flexure crack near 5'-0". Flexure cracks widening and propagating } \\
\text { upward }\end{array}$ \\
\hline
\end{tabular}




\begin{tabular}{|l|l|}
\hline \multicolumn{2}{|l|}{ Beam 20} \\
\hline Load & Observation \\
\hline 0 & Evenly spaced flexural cracks from cyclic loading \\
\hline 1000 & No change \\
\hline 2000 & No change \\
\hline 3000 & No change \\
\hline 4000 & No change \\
\hline 5000 & No change \\
\hline 6000 & No change \\
\hline 7000 & No change \\
\hline 8000 & Few more flexure cracks \\
\hline 9000 & No change \\
\hline 10000 & No change \\
\hline 11000 & Cracks propagating upward \\
\hline 12000 & Cracks widening slightly \\
\hline 13000 & No change \\
\hline 14000 & Cracks widening and propagating upward \\
\hline 15000 & Cracks widening and propagating upward \\
\hline
\end{tabular}

\begin{tabular}{|l|l|}
\hline Beam 21 \\
\hline Load & Observation \\
\hline 6000 & Initial flexure cracks \\
\hline 7000 & No change \\
\hline 8000 & More flexure cracks, cracks also at 1'-1' 'and 4'-6' \\
\hline 9000 & $\begin{array}{l}\text { More cracks, several more outside constant moment region, shear-flexure cracks } \\
\text { near each load point }\end{array}$ \\
\hline 10000 & More cracks, several more outside constant moment region \\
\hline 11000 & More flexure cracks \\
\hline 12000 & Cracks propagating upward \\
\hline 13000 & No change \\
\hline 14000 & More flexure cracks forming \\
\hline 14500 & More cracking \\
\hline
\end{tabular}

\begin{tabular}{|l|l|}
\hline \multicolumn{2}{|l|}{ Beam 22} \\
\hline Load & Observation \\
\hline 4000 & Initial flexure crack \\
\hline 5000 & Few more flexure cracks \\
\hline 6000 & No change \\
\hline 7000 & Shear-flexure crack at 4'11'" \\
\hline 8000 & No change \\
\hline 9000 & More flexure cracks, some outside of constant moment region \\
\hline 10000 & No change \\
\hline
\end{tabular}




\begin{tabular}{|l|l|}
\hline \multicolumn{2}{|l|}{ Beam 24} \\
\hline Load & Observation \\
\hline 5000 & First flexure cracks in constant moment region \\
\hline 6000 & More flexure cracks \\
\hline 7000 & More flexure cracks \\
\hline 8000 & No change \\
\hline 9000 & Few more flexure cracks \\
\hline 10000 & No change \\
\hline 11000 & Few more flexure cracks \\
\hline 12000 & Few more flexure cracks \\
\hline 13000 & No change \\
\hline 14000 & Cracks propagating upward \\
\hline 14500 & Failure at flexure crack directly below mark load point \\
\hline
\end{tabular}




\section{D.6 Mass Loss Data}

\section{D.6.1 Part I Beams}

\begin{tabular}{|c|c|c|c|c|c|c|c|c|c|}
\hline Beam & Side & Sample & $\begin{array}{c}\text { Initial } \\
\text { Weight } \\
\text { (g) }\end{array}$ & $\begin{array}{c}\text { Cleaned } \\
\text { Weight } \\
\text { (g) }\end{array}$ & $\begin{array}{l}\text { Average } \\
\text { Cleaned } \\
\text { Weight } \\
\text { per Side } \\
\text { (g) }\end{array}$ & $\begin{array}{l}\text { Average } \\
\text { Mass } \\
\text { Loss per } \\
\text { Side } \\
(\%)\end{array}$ & $\begin{array}{l}\text { Average } \\
\text { Cleaned } \\
\text { Weight } \\
\text { per } \\
\text { Beam } \\
\text { (g) }\end{array}$ & $\begin{array}{c}\text { Average } \\
\text { Mass } \\
\text { Loss per } \\
\text { Beam } \\
\text { (g) }\end{array}$ & $\begin{array}{c}\text { Average } \\
\text { Percent } \\
\text { Mass } \\
\text { Loss } \\
(\%)\end{array}$ \\
\hline \multirow{4}{*}{ Control } & \multirow{4}{*}{--- } & 1 & 229.82 & 228.20 & \multirow{4}{*}{228.48} & \multirow{4}{*}{--- } & \multirow{4}{*}{228.48} & \multirow{4}{*}{--- } & \multirow{4}{*}{---} \\
\hline & & 2 & 230.00 & 228.31 & & & & & \\
\hline & & 3 & 230.38 & 229.25 & & & & & \\
\hline & & 4 & 230.43 & 228.15 & & & & & \\
\hline \multirow{8}{*}{1} & \multirow{4}{*}{ Right } & 1 & 231.50 & 218.01 & \multirow{4}{*}{213.95} & \multirow{4}{*}{6.4} & \multirow{8}{*}{215.64} & \multirow{8}{*}{12.8} & \multirow{8}{*}{5.6} \\
\hline & & 2 & 229.19 & 216.83 & & & & & \\
\hline & & 3 & 221.03 & 211.52 & & & & & \\
\hline & & 4 & 220.76 & 209.44 & & & & & \\
\hline & \multirow{4}{*}{ Left } & 1 & 224.57 & 214.41 & \multirow{4}{*}{217.32} & \multirow{4}{*}{4.9} & & & \\
\hline & & 2 & 228.97 & 217.51 & & & & & \\
\hline & & 3 & 233.30 & 220.45 & & & & & \\
\hline & & 4 & 229.92 & 216.91 & & & & & \\
\hline \multirow{8}{*}{2} & \multirow{4}{*}{ Right } & $\overline{1}$ & 223.16 & 214.35 & \multirow{4}{*}{213.42} & \multirow{4}{*}{6.6} & \multirow{8}{*}{212.93} & \multirow{8}{*}{15.5} & \multirow{8}{*}{6.8} \\
\hline & & 2 & 225.67 & 215.44 & & & & & \\
\hline & & 3 & 217.22 & 209.44 & & & & & \\
\hline & & 4 & 222.18 & 214.43 & & & & & \\
\hline & \multirow{4}{*}{ Left } & 1 & 220.13 & 211.82 & & & & & \\
\hline & & 2 & 219.66 & 212.15 & 2124 & & & & \\
\hline & & 3 & 226.85 & 213.96 & 212.45 & 7.0 & & & \\
\hline & & 4 & 219.22 & 211.85 & & & & & \\
\hline & & $\overline{1}$ & 205.70 & 195.76 & & & & & \\
\hline & Right & 2 & 201.82 & 192.35 & 193.90 & 15.1 & & & \\
\hline 5 & & 3 & 202.99 & 193.58 & & & 1020 & 250 & 150 \\
\hline 5 & & 1 & 202.54 & 193.38 & & & 192.86 & 35.6 & 15.6 \\
\hline & Left & 2 & 198.51 & 191.30 & 191.82 & 16.0 & & & \\
\hline & & 3 & 197.45 & 190.78 & & & & & \\
\hline & & 1 & 226.34 & 224.66 & & & & & \\
\hline & Right & 2 & 227.10 & 225.41 & 225.21 & 1.4 & & & \\
\hline 17 & & 3 & 227.16 & 225.57 & & & 17 & 10 & 10 \\
\hline 17 & & 1 & 225.17 & 222.83 & & & $224.4 !$ & 4.0 & 1.8 \\
\hline & Left & 2 & 227.46 & 225.28 & 223.72 & 2.1 & & & \\
\hline & & 3 & 225.42 & 223.05 & & & & & \\
\hline & & 1 & 178.25 & 175.69 & & & & & \\
\hline & Right & 2 & 172.51 & 169.68 & 173.43 & 24.1 & & & \\
\hline 6 & & 3 & 177.85 & 174.93 & & & 173.17 & 55.3 & 24.2 \\
\hline & & 1 & 175.26 & 174.23 & & & & & \\
\hline & Left & 2 & 176.35 & 173.52 & 172.90 & 24.3 & & & \\
\hline & & 3 & 174.26 & 170.95 & & & & & \\
\hline
\end{tabular}




\begin{tabular}{|c|c|c|c|c|c|c|c|c|c|}
\hline Beam & Side & Sample & $\begin{array}{c}\text { Initial } \\
\text { Weight } \\
\text { (g) }\end{array}$ & $\begin{array}{c}\text { Cleaned } \\
\text { Weight } \\
\text { (g) }\end{array}$ & $\begin{array}{c}\text { Average } \\
\text { Cleaned } \\
\text { Weight } \\
\text { per Side } \\
\text { (g) }\end{array}$ & $\begin{array}{c}\text { Average } \\
\text { Mass } \\
\text { Loss per } \\
\text { Side } \\
(\%)\end{array}$ & $\begin{array}{c}\text { Average } \\
\text { Cleaned } \\
\text { Weight } \\
\text { per } \\
\text { Beam } \\
\text { (g) }\end{array}$ & $\begin{array}{l}\text { Average } \\
\text { Mass } \\
\text { Loss per } \\
\text { Beam } \\
\text { (g) }\end{array}$ & $\begin{array}{c}\text { Average } \\
\text { Percent } \\
\text { Mass } \\
\text { Loss } \\
(\%)\end{array}$ \\
\hline \multirow{6}{*}{7} & \multirow{3}{*}{ Right } & 1 & 197.23 & 195.21 & \multirow{3}{*}{188.96} & \multirow{3}{*}{17.3} & \multirow{6}{*}{188.76} & \multirow{6}{*}{39.7} & \multirow{6}{*}{17.4} \\
\hline & & 2 & 189.47 & 184.36 & & & & & \\
\hline & & 3 & 191.88 & 187.30 & & & & & \\
\hline & \multirow{3}{*}{ Left } & 1 & 190.36 & 187.85 & \multirow{3}{*}{188.57} & \multirow{3}{*}{17.5} & & & \\
\hline & & 2 & 186.21 & 183.85 & & & & & \\
\hline & & 3 & 197.41 & 194.01 & & & & & \\
\hline \multirow{6}{*}{10} & \multirow{3}{*}{ Right } & 1 & 198.04 & 193.54 & \multirow{3}{*}{188.20} & \multirow{3}{*}{17.6} & \multirow{6}{*}{189.25} & \multirow{6}{*}{39.2} & \multirow{6}{*}{17.2} \\
\hline & & 2 & 194.35 & 189.60 & & & & & \\
\hline & & 3 & 183.59 & 181.46 & & & & & \\
\hline & \multirow{3}{*}{ Left } & 1 & 193.64 & 190.92 & \multirow{3}{*}{190.29} & \multirow{3}{*}{16.7} & & & \\
\hline & & 2 & 188.74 & 186.36 & & & & & \\
\hline & & 3 & 197.55 & 193.60 & & & & & \\
\hline \multirow{6}{*}{8} & \multirow{3}{*}{ Right } & 1 & 203.72 & 189.54 & \multirow{3}{*}{189.60} & \multirow{3}{*}{17.0} & \multirow{6}{*}{189.47} & \multirow{6}{*}{39.0} & \multirow{6}{*}{17.1} \\
\hline & & 2 & 199.89 & 188.45 & & & & & \\
\hline & & 3 & 203.06 & 190.80 & & & & & \\
\hline & \multirow{3}{*}{ Left } & 1 & 202.35 & 189.80 & \multirow{3}{*}{189.34} & & & & \\
\hline & & 2 & 201.96 & 188.24 & & 17.1 & & & \\
\hline & & 3 & 203.65 & 189.98 & & & & & \\
\hline & & 1 & 186.15 & 182.91 & & & & & \\
\hline & Right & 2 & 165.05 & 159.23 & 168.28 & 26.3 & & & \\
\hline O & & 3 & 166.13 & 162.70 & & & 16701 & 505 & 265 \\
\hline 9 & & 1 & 178.12 & 171.21 & & & $16 \% .94$ & 60.5 & 26.5 \\
\hline & Left & 2 & 171.68 & 168.00 & 167.59 & 26.6 & & & \\
\hline & & 3 & 173.22 & 163.56 & & & & & \\
\hline & & 1 & 231.13 & 228.16 & & & & & \\
\hline & Right & 2 & 228.98 & 226.27 & 227.38 & 0.5 & & & \\
\hline 11 & & 3 & 231.24 & 227.70 & & & 22660 & 18 & 08 \\
\hline 14 & & 1 & 230.50 & 226.89 & & & $2 \angle 26.69$ & 1.8 & 0.8 \\
\hline & Left & 2 & 229.21 & 225.98 & 226.00 & 1.1 & & & \\
\hline & & 3 & 231.04 & 225.12 & & & & & \\
\hline
\end{tabular}




\section{D.6.2 Part II Beams}

\begin{tabular}{|c|c|c|c|c|c|c|c|c|}
\hline Beam & Side & Sample & $\begin{array}{l}\text { Initial } \\
\text { Weight } \\
\text { (g) }\end{array}$ & $\begin{array}{c}\text { Cleaned } \\
\text { Weight } \\
(\mathrm{g})\end{array}$ & $\begin{array}{c}\text { Average } \\
\text { Cleaned } \\
\text { Weight } \\
\text { per Side } \\
\text { (g) }\end{array}$ & \begin{tabular}{|c} 
Average \\
Mass Loss \\
per Side \\
$(\%)$
\end{tabular} & $\begin{array}{l}\text { Average } \\
\text { Cleaned } \\
\text { Weight } \\
\text { per Beam } \\
\text { (g) }\end{array}$ & $\begin{array}{c}\text { Average } \\
\text { Mass Loss } \\
\text { per Beam } \\
(\%)\end{array}$ \\
\hline \multirow{6}{*}{ Control } & \multirow{6}{*}{--- } & 1 & 144.08 & 143.20 & \multirow{6}{*}{142.40} & \multirow{6}{*}{---} & \multirow{6}{*}{142.40} & \multirow{6}{*}{---} \\
\hline & & 2 & 143.89 & 142.51 & & & & \\
\hline & & 3 & 143.77 & 142.48 & & & & \\
\hline & & 4 & 143.27 & 142.42 & & & & \\
\hline & & 5 & 143.38 & 141.86 & & & & \\
\hline & & 6 & 143.37 & 141.90 & & & & \\
\hline \multirow{6}{*}{2} & \multirow{3}{*}{ Right } & 1 & 146.24 & 144.99 & \multirow{3}{*}{140.91} & \multirow{3}{*}{1.0} & \multirow{6}{*}{141.68} & \multirow{6}{*}{0.5} \\
\hline & & 2 & 144.55 & 143.44 & & & & \\
\hline & & 3 & 135 & 134.29 & & & & \\
\hline & \multirow{3}{*}{ Left } & 1 & 148.25 & 142.67 & \multirow{3}{*}{142.46} & \multirow{3}{*}{0.0} & & \\
\hline & & 2 & 147.62 & 142.01 & & & & \\
\hline & & 3 & 148.24 & 142.69 & & & & \\
\hline \multirow{6}{*}{3} & \multirow{3}{*}{ Right } & 1 & 111.70 & 104.10 & \multirow{3}{*}{103.60} & \multirow{3}{*}{27.2} & \multirow{6}{*}{107.99} & \multirow{6}{*}{24.2} \\
\hline & & 2 & 111.54 & 109.09 & & & & \\
\hline & & 3 & 100.81 & 97.60 & & & & \\
\hline & \multirow{3}{*}{ Left } & 1 & 117.40 & 113.70 & \multirow{3}{*}{112.39} & & & \\
\hline & & 2 & 114.46 & 111.73 & & 21.1 & & \\
\hline & & 3 & 116.37 & 111.73 & & & & \\
\hline & & 1 & 108.24 & 107.32 & & & & \\
\hline & Right & 2 & 108.67 & 107.28 & 106.95 & 24.9 & & \\
\hline 1 & & 3 & 107.03 & 106.24 & & & 10777 & 213 \\
\hline 4 & & 1 & 109.01 & 108.09 & & & 107.17 & 24.3 \\
\hline & Left & 2 & 111.09 & 110.14 & 108.59 & 23.7 & & \\
\hline & & 3 & 108.30 & 107.55 & & & & \\
\hline & & 1 & 106.12 & 105.74 & & & & \\
\hline & Right & 2 & 103.20 & 102.96 & 105.65 & 25.8 & & \\
\hline 5 & & 3 & 108.60 & 108.25 & & & 11038 & 225 \\
\hline 5 & & 1 & 116.62 & 115.42 & & & 110.38 & $\angle 2.5$ \\
\hline & Left & 2 & 116.60 & 115.58 & 115.12 & 19.2 & & \\
\hline & & 3 & 115.31 & 114.35 & & & & \\
\hline & & 1 & 106 & 105.03 & & & & \\
\hline & Right & 2 & 116.84 & 115.61 & 110.56 & 22.4 & & \\
\hline 7 & & 3 & 111.97 & 111.03 & & & 10838 & 239 \\
\hline r & & 1 & 111.47 & 110.29 & & & 108.38 & 23.9 \\
\hline & Left & 2 & 105.8 & 105.14 & 106.21 & 25.4 & & \\
\hline & & 3 & 103.78 & 103.2 & & & & \\
\hline & & 1 & 115.41 & 114.36 & & & & \\
\hline & Right & 2 & 115.27 & 114.61 & 114.76 & 19.4 & & \\
\hline 8 & & 3 & 116.02 & 115.32 & & & 1107 & \\
\hline 8 & & 1 & 106.96 & 106.28 & & & 110.10 & 22.3 \\
\hline & Left & 2 & 106.08 & 105.41 & 106.64 & 25.1 & & \\
\hline & & 3 & 108.85 & 108.23 & & & & \\
\hline
\end{tabular}




\begin{tabular}{|c|c|c|c|c|c|c|c|c|}
\hline Beam & Side & Sample & $\begin{array}{l}\text { Initial } \\
\text { Weight } \\
\text { (g) }\end{array}$ & $\begin{array}{c}\text { Cleaned } \\
\text { Weight } \\
\text { (g) }\end{array}$ & $\begin{array}{c}\text { Average } \\
\text { Cleaned } \\
\text { Weight } \\
\text { per Side } \\
\text { (g) }\end{array}$ & $\begin{array}{c}\text { Average } \\
\text { Mass Loss } \\
\text { per Side } \\
(\%)\end{array}$ & $\begin{array}{l}\text { Average } \\
\text { Cleaned } \\
\text { Weight } \\
\text { per Beam } \\
\text { (g) }\end{array}$ & $\begin{array}{c}\text { Average } \\
\text { Mass Loss } \\
\text { per Beam } \\
(\%)\end{array}$ \\
\hline \multirow{6}{*}{9} & \multirow{3}{*}{ Right } & 1 & 108.71 & 108.18 & \multirow{3}{*}{110.37} & \multirow{3}{*}{22.5} & \multirow{6}{*}{112.06} & \multirow{6}{*}{21.3} \\
\hline & & 2 & 113.85 & 112.63 & & & & \\
\hline & & 3 & 111.85 & 110.29 & & & & \\
\hline & \multirow{3}{*}{ Left } & 1 & 118.82 & 116.84 & \multirow{3}{*}{113.74} & \multirow{3}{*}{20.1} & & \\
\hline & & 2 & 113.03 & 112.19 & & & & \\
\hline & & 3 & 112.94 & 112.2 & & & & \\
\hline \multirow{6}{*}{12} & \multirow{3}{*}{ Right } & 1 & 142.18 & 141.06 & \multirow{3}{*}{140.39} & \multirow{3}{*}{1.4} & \multirow{6}{*}{141.42} & \multirow{6}{*}{0.7} \\
\hline & & 2 & 141.16 & 141.13 & & & & \\
\hline & & 3 & 139.32 & 138.98 & & & & \\
\hline & \multirow{3}{*}{ Left } & 1 & 102.79 & 102.14 & \multirow{3}{*}{142.46} & \multirow{3}{*}{0.0} & & \\
\hline & & 2 & 103.81 & 103.08 & & & & \\
\hline & & 3 & 101.52 & 100.9 & & & & \\
\hline \multirow{6}{*}{13} & \multirow{3}{*}{ Right } & 1 & 115.39 & 113.86 & & & & \\
\hline & & 2 & 115.72 & 112.95 & 113.48 & 20.3 & & \\
\hline & & 3 & 115.23 & 113.62 & & & 11087 & 221 \\
\hline & & 1 & 109.96 & 109.28 & & & 170.87 & 22.1 \\
\hline & Left & 2 & 107.6 & 106.9 & 108.25 & 24.0 & & \\
\hline & & 3 & 109.6 & 108.58 & & & & \\
\hline & & 1 & 109.21 & 108.56 & & & & \\
\hline & Right & 2 & 106.82 & 106.11 & 107.91 & 24.2 & & \\
\hline 11 & & 3 & 109.79 & 109.05 & & & 10021 & ? ? ? \\
\hline 14 & & 1 & 112.52 & 111.81 & & & 109.34 & 23.2 \\
\hline & Left & 2 & 109.91 & 109.38 & 110.78 & 22.2 & & \\
\hline & & 3 & 111.68 & 111.15 & & & & \\
\hline & & 1 & 115.47 & 114.53 & & & & \\
\hline & Right & 2 & 115.37 & 114.3 & 114.06 & 19.9 & & \\
\hline & & 3 & 114.21 & 113.35 & & & 11201 & 210 \\
\hline 15 & & 1 & 108.71 & 108.18 & & & 112.21 & 21.2 \\
\hline & Left & 2 & 113.85 & 112.63 & 110.37 & 22.5 & & \\
\hline & & 3 & 111.85 & 110.29 & & & & \\
\hline & & 1 & 116.4 & 114.73 & & & & \\
\hline & Right & 2 & 115.71 & 113.97 & 113.85 & 20.0 & & \\
\hline 17 & & 3 & 114.55 & 112.85 & & & 11146 & 217 \\
\hline 17 & & 1 & 110.06 & 108.95 & & & 111.40 & 21.1 \\
\hline & Left & 2 & 111.73 & 109.37 & 109.08 & 23.4 & & \\
\hline & & 3 & 111.27 & 108.91 & & & & \\
\hline & & 1 & 109.6 & 107.89 & & & & \\
\hline & Right & 2 & 111.85 & 110.41 & 109.29 & 23.2 & & \\
\hline 18 & & 3 & 110.78 & 109.58 & & & 10887 & 235 \\
\hline 18 & & 1 & 108.5 & 107.12 & & & $108.8 /$ & 23.5 \\
\hline & Left & 2 & 108.25 & 106.99 & 108.44 & 23.8 & & \\
\hline & & 3 & 112.62 & 111.2 & & & & \\
\hline & & 1 & 116.74 & 114.43 & & & & \\
\hline & Right & 2 & 115.62 & 108.32 & 110.76 & 22.2 & & \\
\hline 19 & & 3 & 114.45 & 109.54 & & & 10999 & 228 \\
\hline 15 & & 1 & 110.56 & 108.65 & & & & \\
\hline & Left & 2 & 111.13 & 109.51 & 109.04 & 23.4 & & \\
\hline & & 3 & 111.64 & 108.95 & & & & \\
\hline
\end{tabular}




\begin{tabular}{|c|c|c|c|c|c|c|c|c|}
\hline Beam & Side & Sample & $\begin{array}{c}\text { Initial } \\
\text { Weight } \\
(\mathrm{g})\end{array}$ & $\begin{array}{c}\text { Cleaned } \\
\text { Weight } \\
\text { (g) }\end{array}$ & $\begin{array}{c}\text { Average } \\
\text { Cleaned } \\
\text { Weight } \\
\text { per Side } \\
\text { (g) }\end{array}$ & $\begin{array}{c}\text { Average } \\
\text { Mass Loss } \\
\text { per Side } \\
(\%)\end{array}$ & $\begin{array}{c}\text { Average } \\
\text { Cleaned } \\
\text { Weight } \\
\text { per Beam } \\
\text { (g) }\end{array}$ & $\begin{array}{c}\text { Average } \\
\text { Mass Loss } \\
\text { per Beam } \\
(\%)\end{array}$ \\
\hline \multirow{6}{*}{20} & \multirow{3}{*}{ Right } & 1 & 115.39 & 113.98 & \multirow{3}{*}{113.62} & \multirow{3}{*}{20.2} & \multirow{6}{*}{110.73} & \multirow{6}{*}{22.2} \\
\hline & & 2 & 115.72 & 113.02 & & & & \\
\hline & & 3 & 115.23 & 113.85 & & & & \\
\hline & \multirow{3}{*}{ Left } & 1 & 109.96 & 108.34 & \multirow{3}{*}{107.84} & \multirow{3}{*}{24.3} & & \\
\hline & & 2 & 107.6 & 106.87 & & & & \\
\hline & & 3 & 109.6 & 108.32 & & & & \\
\hline \multirow{6}{*}{21} & \multirow{3}{*}{ Right } & 1 & 111.03 & 110.03 & \multirow{3}{*}{109.93} & \multirow{3}{*}{22.8} & \multirow{6}{*}{110.22} & \multirow{6}{*}{22.6} \\
\hline & & 2 & 109.45 & 108.7 & & & & \\
\hline & & 3 & 112.22 & 111.07 & & & & \\
\hline & \multirow{3}{*}{ Left } & 1 & 111.53 & 110.71 & \multirow{3}{*}{110.51} & \multirow{3}{*}{22.4} & & \\
\hline & & 2 & 110.92 & 109.76 & & & & \\
\hline & & 3 & 112.67 & 111.05 & & & & \\
\hline \multirow{6}{*}{22} & \multirow{3}{*}{ Right } & 1 & 114.98 & 114.72 & \multirow{3}{*}{112.99} & \multirow{3}{*}{20.7} & \multirow{6}{*}{110.53} & \multirow{6}{*}{22.4} \\
\hline & & 2 & 118.67 & 116.89 & & & & \\
\hline & & 3 & 107.58 & 107.35 & & & & \\
\hline & \multirow{3}{*}{ Left } & 1 & 111.56 & 110.65 & \multirow{3}{*}{108.07} & \multirow{3}{*}{24.1} & & \\
\hline & & 2 & 107.16 & 106.84 & & & & \\
\hline & & 3 & 107.48 & 106.73 & & & & \\
\hline \multirow{6}{*}{23} & \multirow{3}{*}{ Right } & 1 & 109.56 & 108.32 & & & & \\
\hline & & 2 & 106.54 & 105.94 & 107.70 & 24.4 & & \\
\hline & & 3 & 109.65 & 108.83 & & & 10908 & 234 \\
\hline & & 1 & 112.57 & 110.99 & & & 109.08 & 23.4 \\
\hline & Left & 2 & 111.45 & 110.3 & 110.46 & 22.4 & & \\
\hline & & 3 & 110.98 & 110.08 & & & & \\
\hline & & 1 & 112.54 & 111.2 & & & & \\
\hline & Right & 2 & 111.14 & 110.54 & 111.00 & 22.0 & & \\
\hline 21 & & 3 & 112.88 & 111.27 & & & 11056 & 224 \\
\hline$\angle 4$ & & 1 & 108.21 & 107.2 & & & 170.56 & 22.4 \\
\hline & Left & 2 & 110.07 & 108.55 & 110.11 & 22.7 & & \\
\hline & & 3 & 116.22 & 114.59 & & & & \\
\hline
\end{tabular}




\section{Appendix E: FRP Failure Diagrams}

The following diagrams show the geometries and locations of FRP failure. Broken FRP edges that were relatively smooth are outlined with a red line and edges that were jagged are outlined with a green line.

The tick marks on the ruler provided above each diagram denote the locations along the beam. For Part I beams, 0' corresponds to the mark end of the beam and 6" corresponds to the mark support location. Likewise, 9' corresponds to the unmark end of the beam and 8'-6" corresponds to the unmark support location. For Part I, the FRP sheet was terminated at 7"' and at 8'-5". For Part II beams, 0' corresponds to the location of the mark support and 6' corresponds to the location of the For Part II, the FRP sheet was terminated at 3 " and at 5'-6".

As a reference, the hatched rectangles along the FRP sheet indicate the locations of the transverse FRP anchor stirrups. 


\section{E.1 Part I Beams}

Beam 7

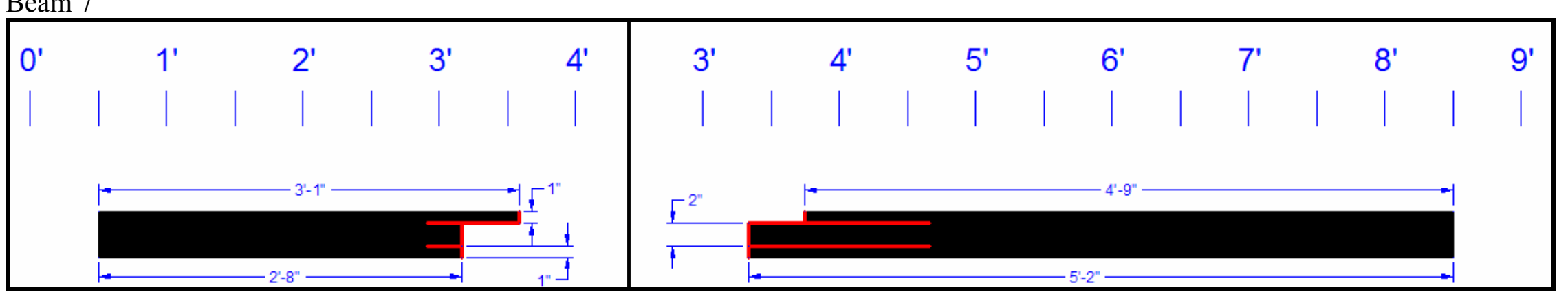

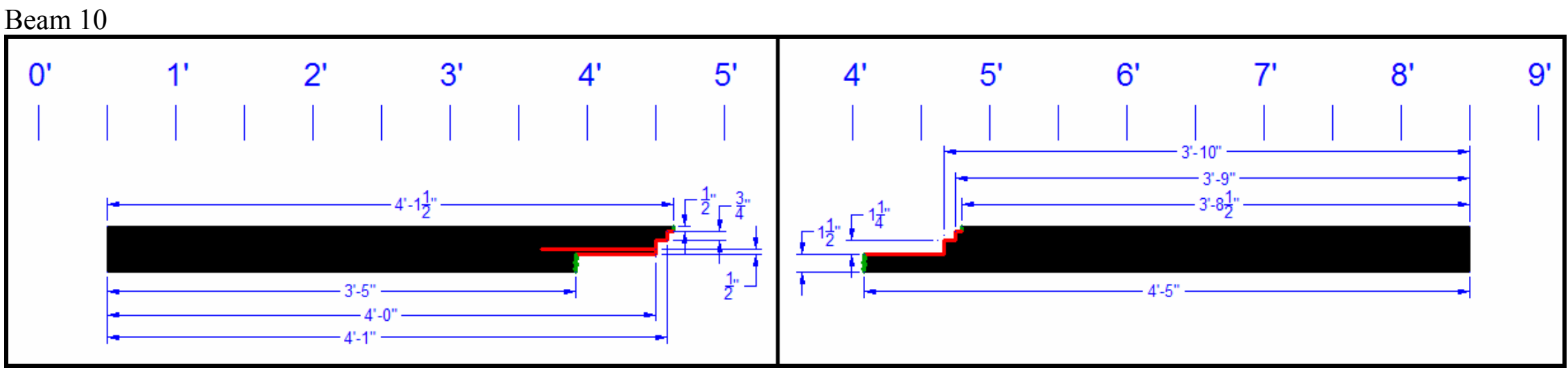



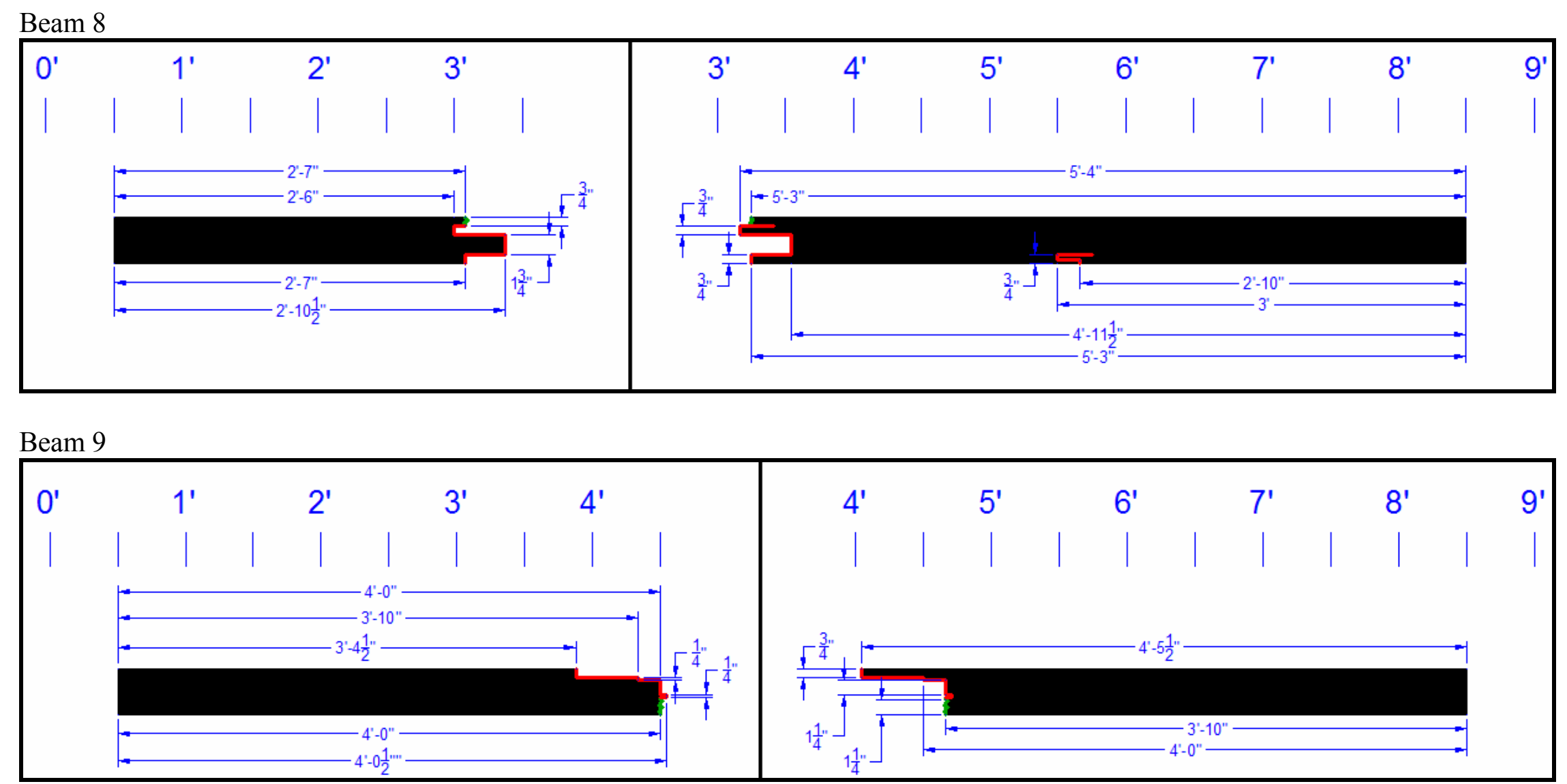


\section{E.2 Part II}

Beam 5

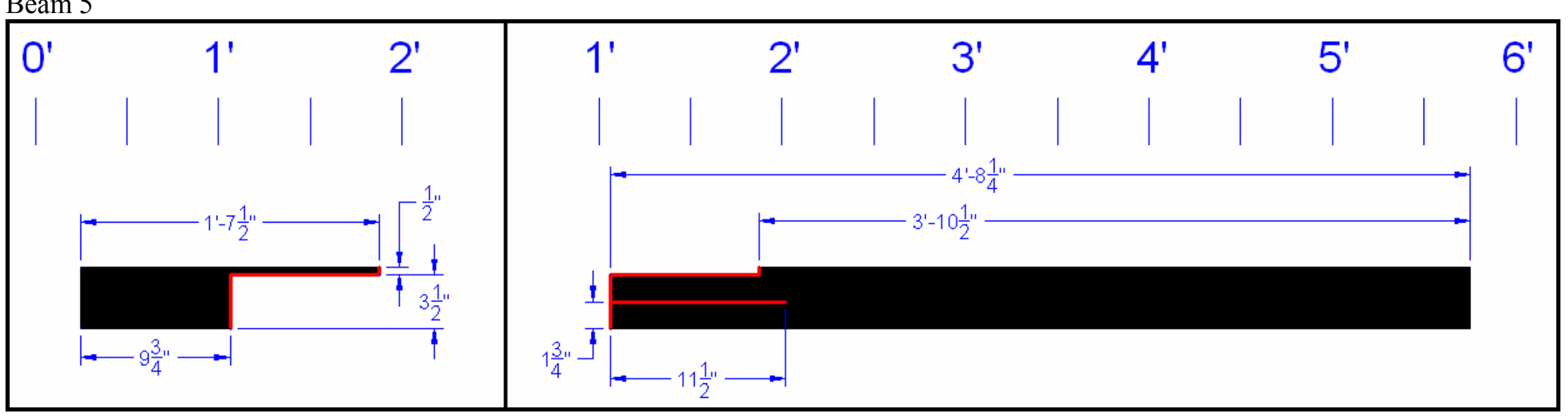



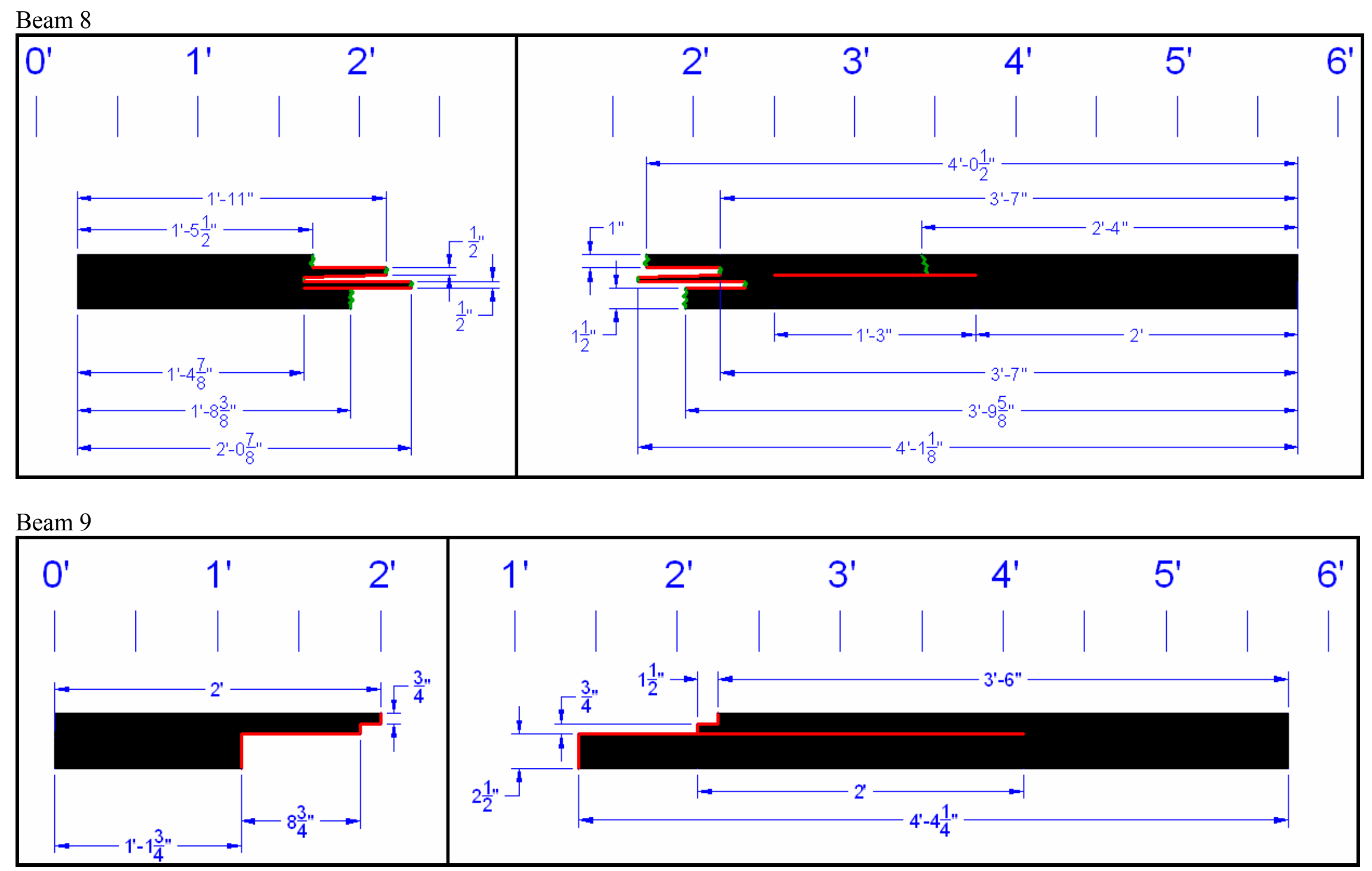
Beam 7

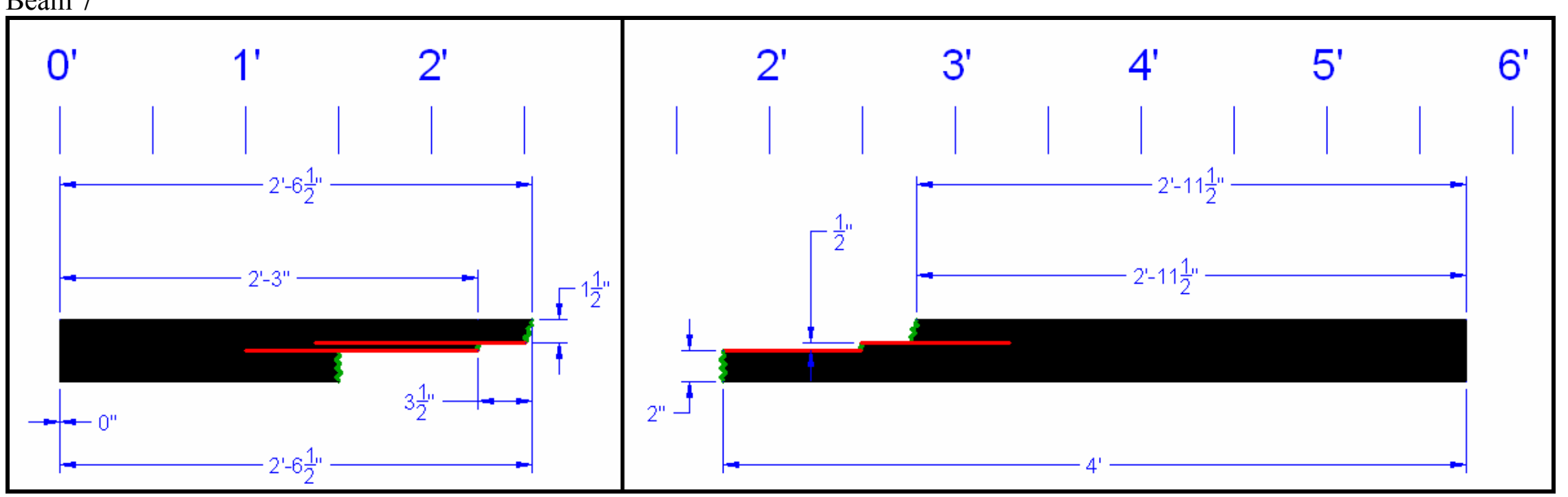

Beam 14

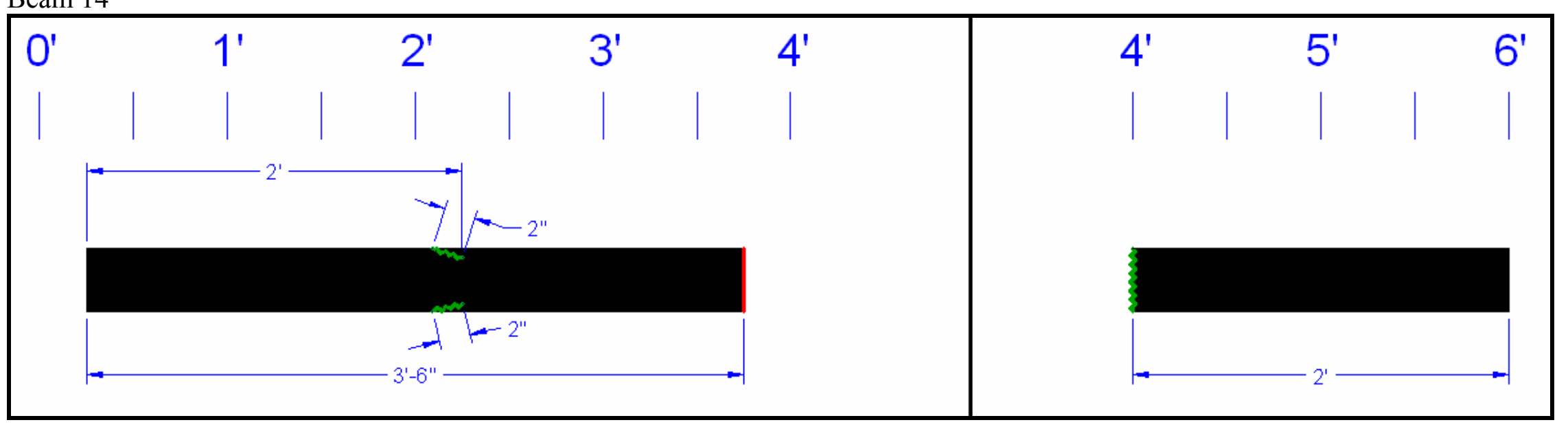




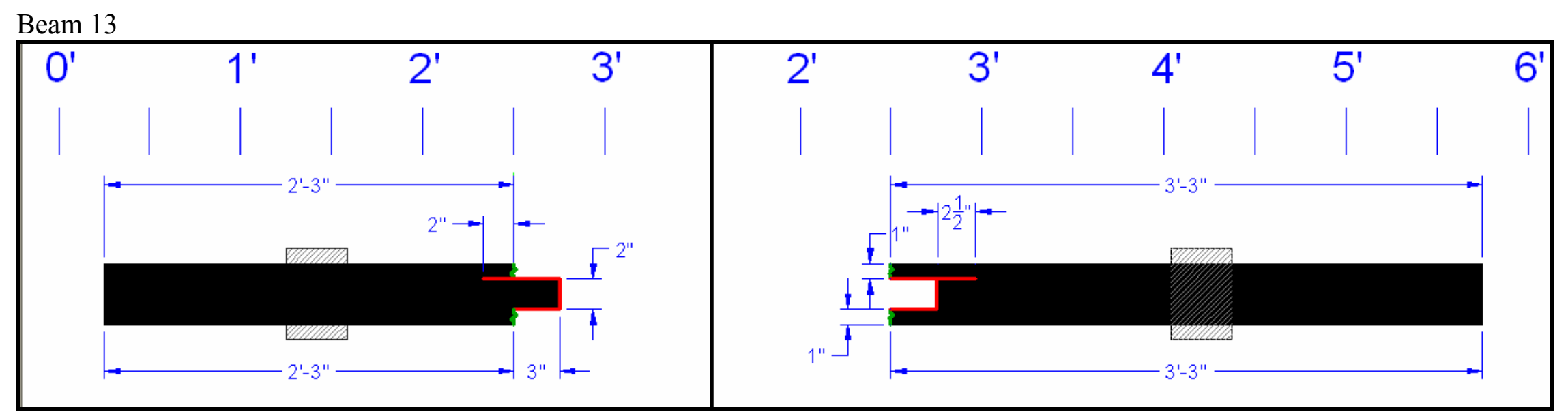

Beam 15

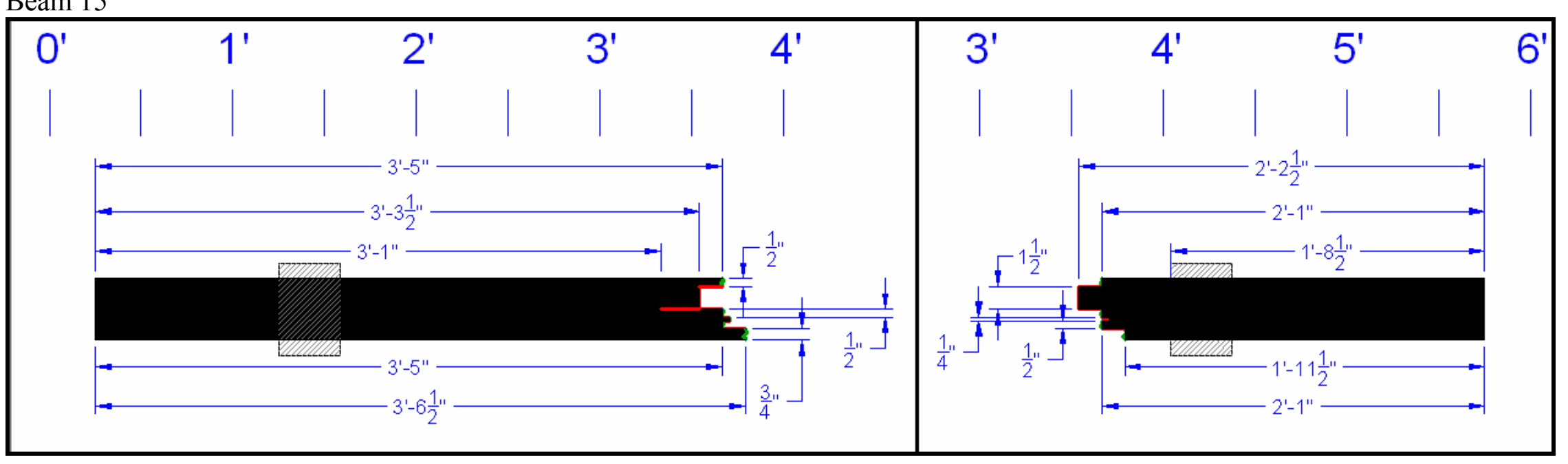




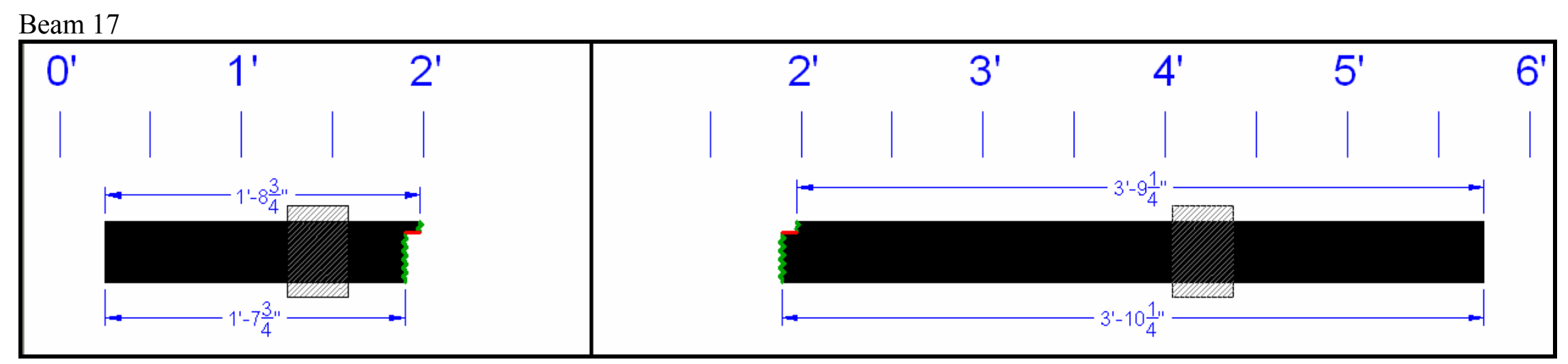




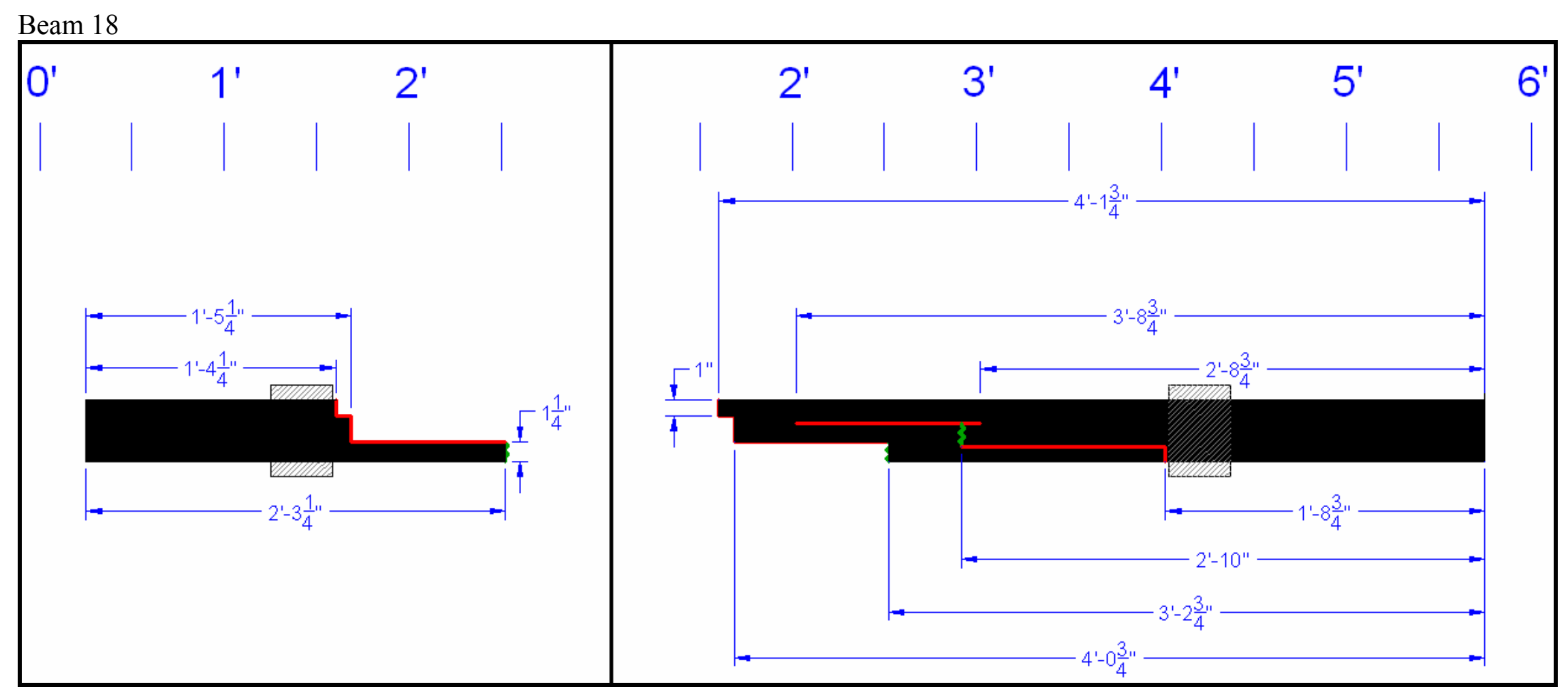



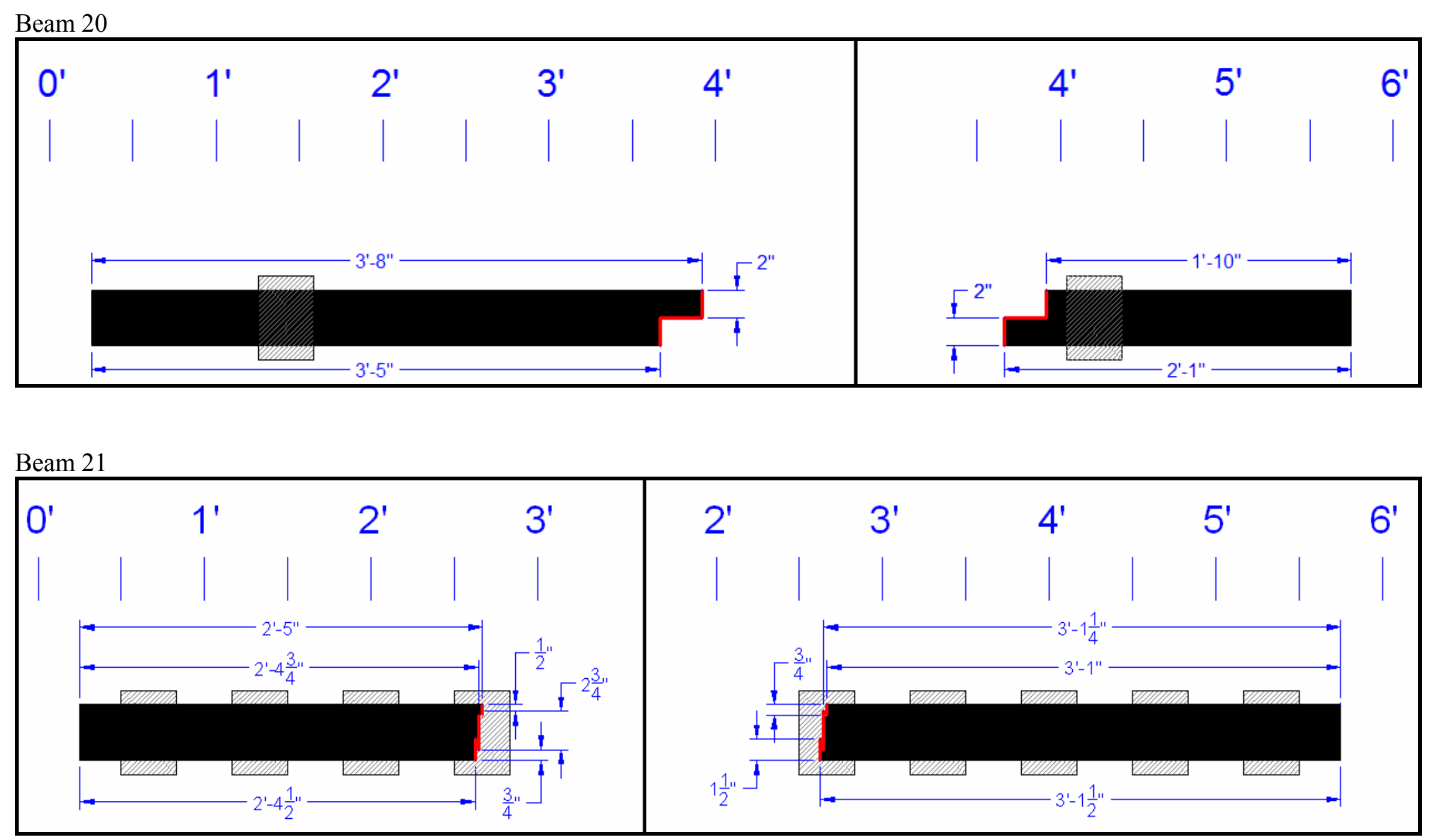


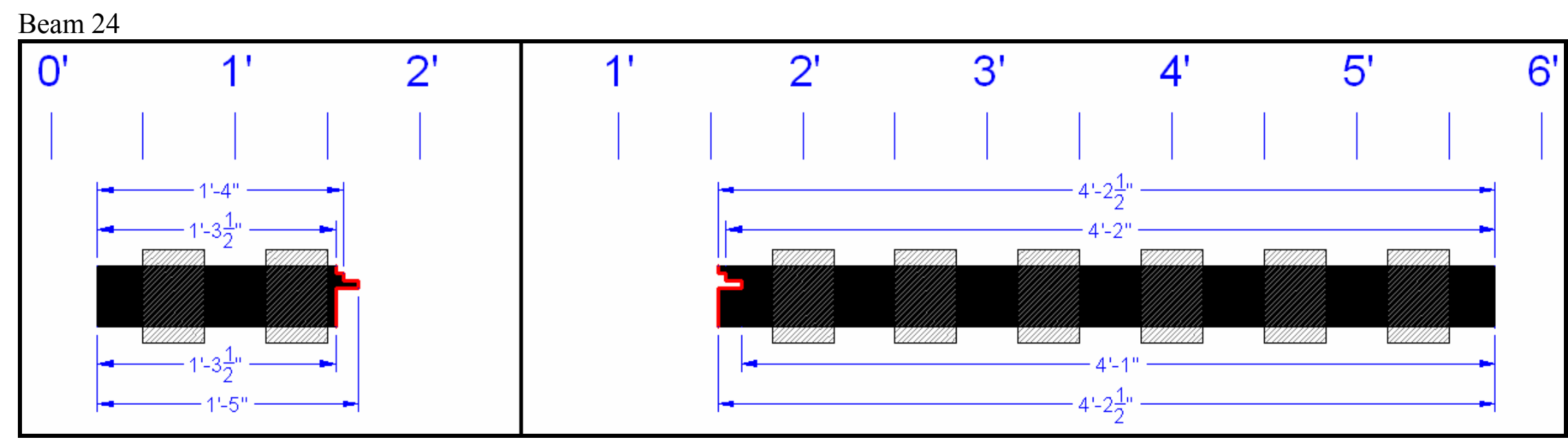

Beam 19

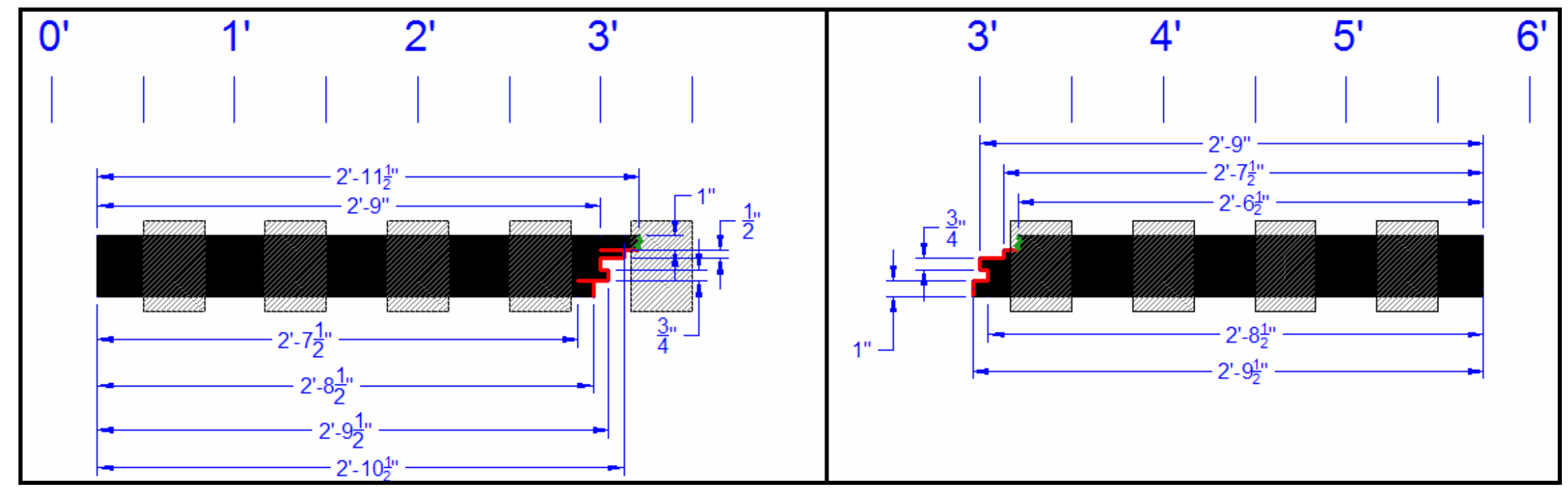


Beam 23

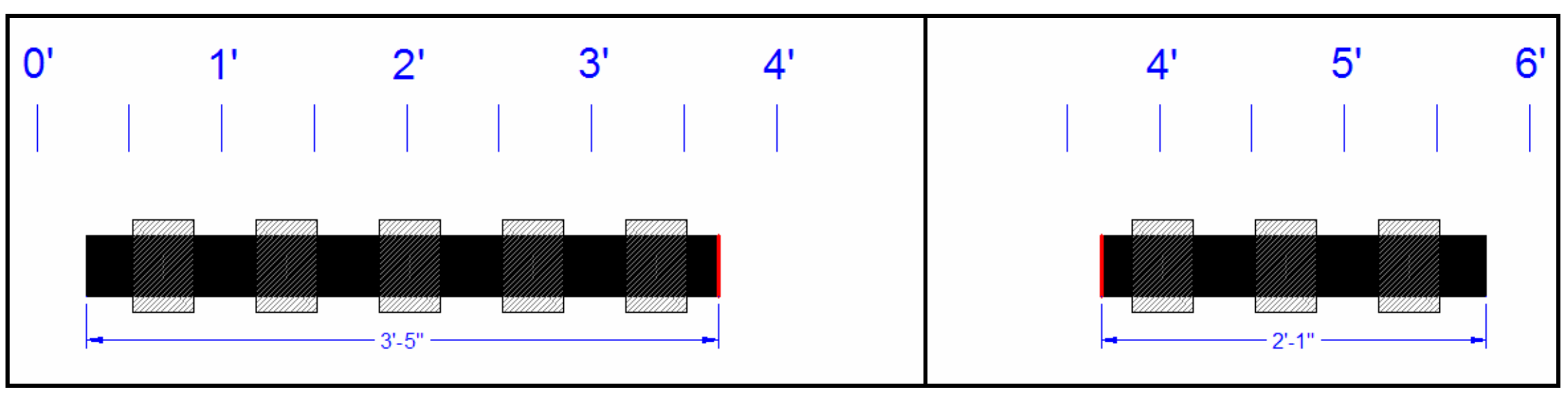




\title{
Appendix F: Load Test Results for Individual Beams
}

\author{
F.1 Static Load Tests
}

\section{F.1.1 Part I Beams}

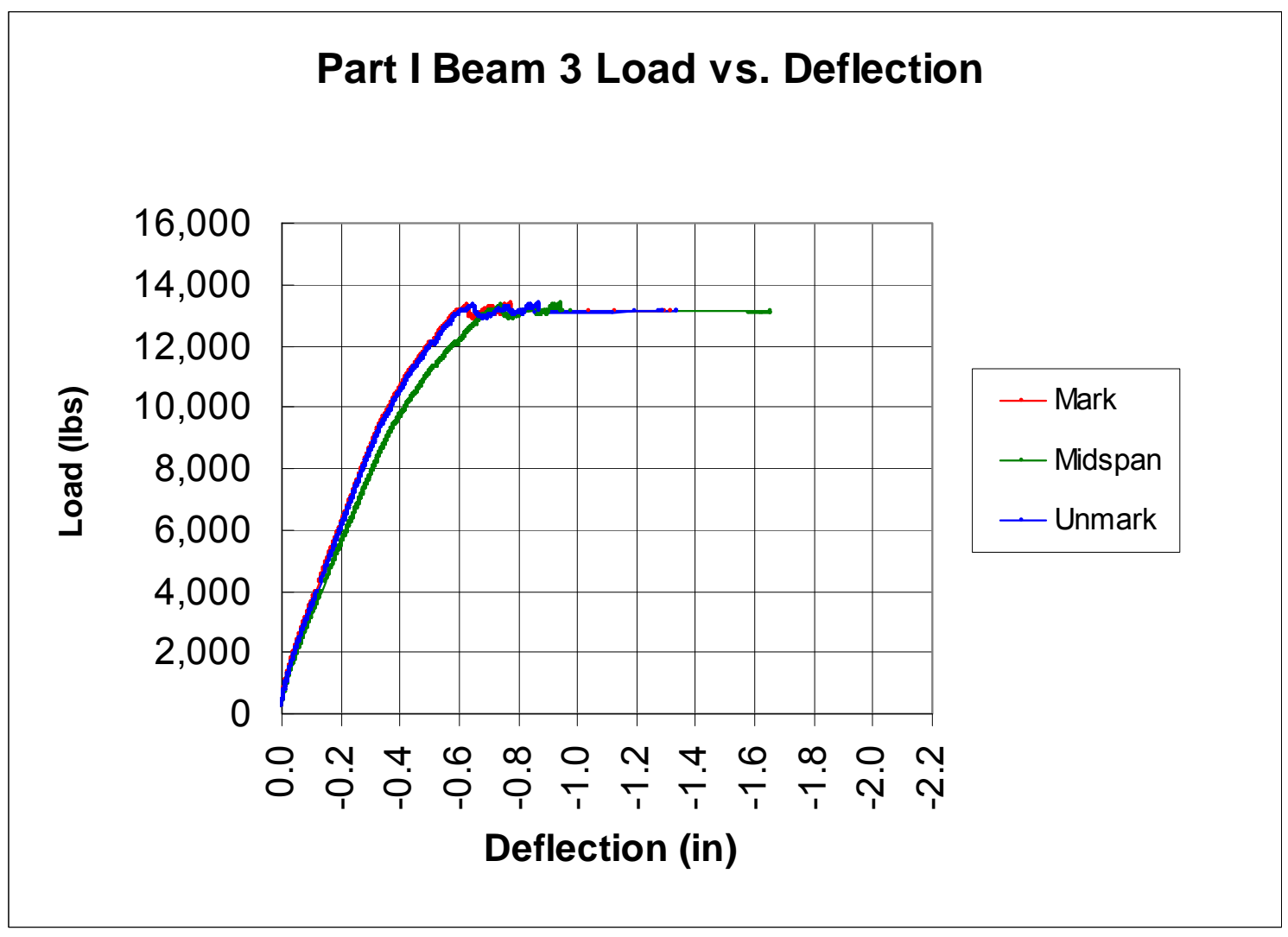



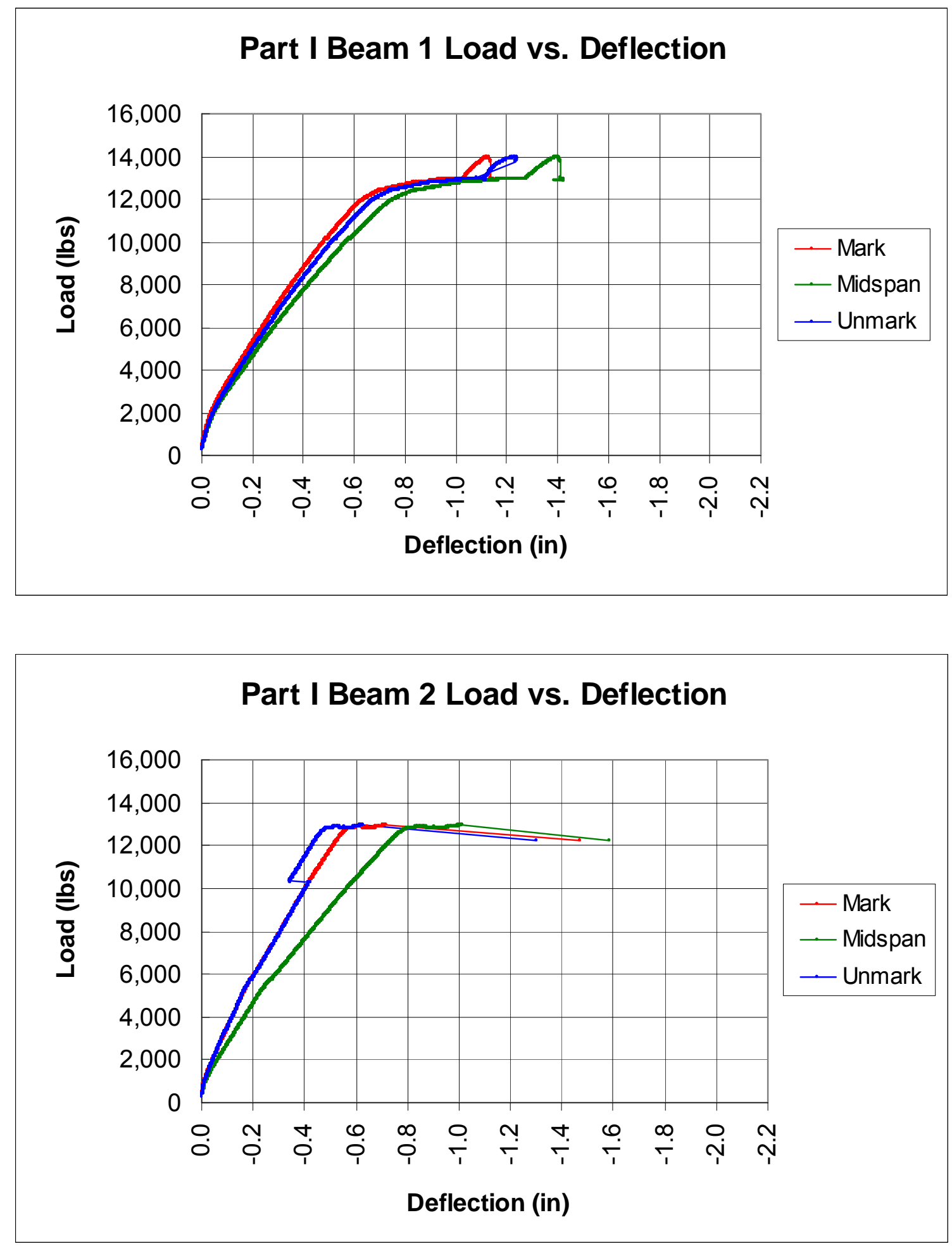

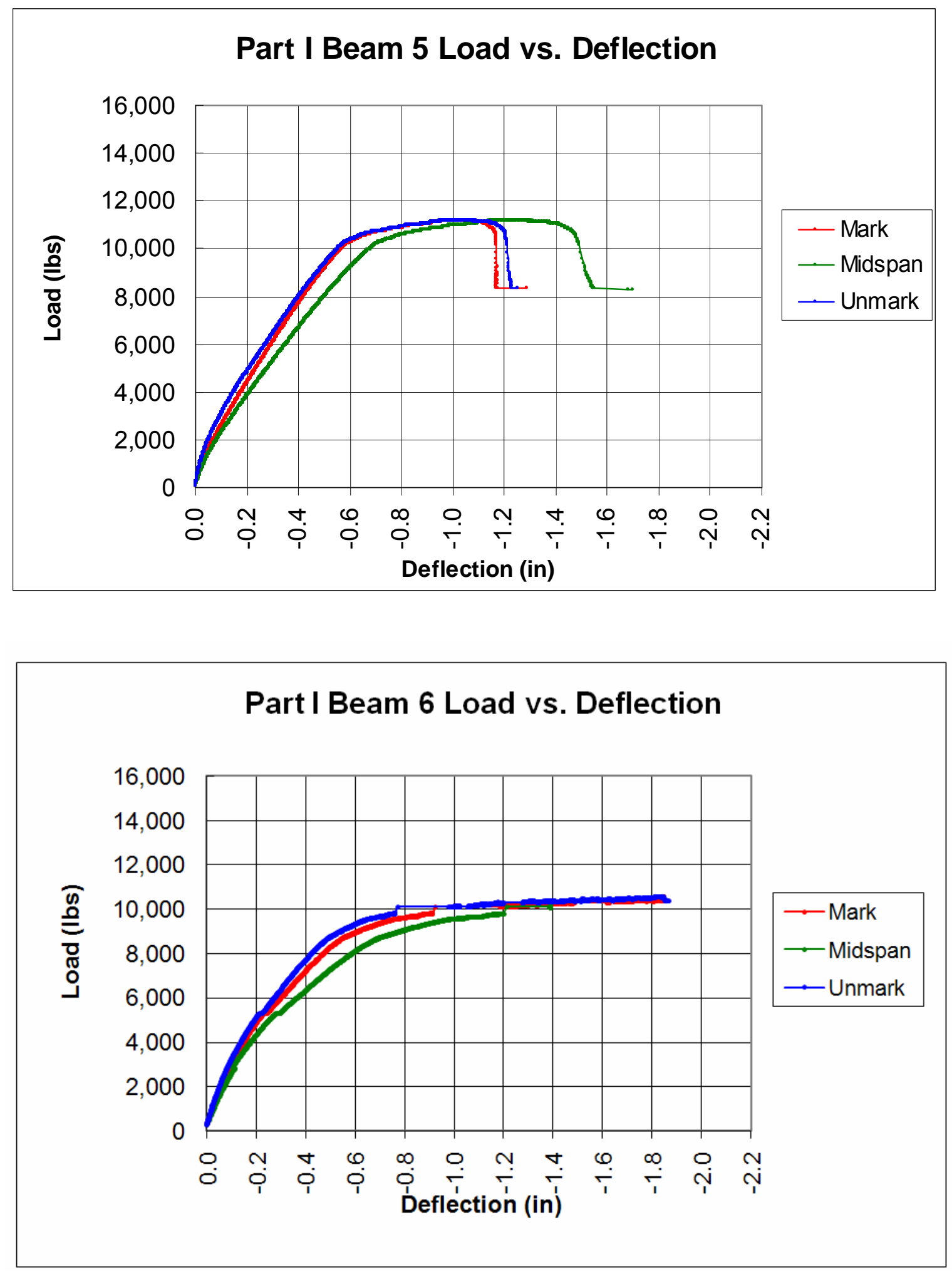

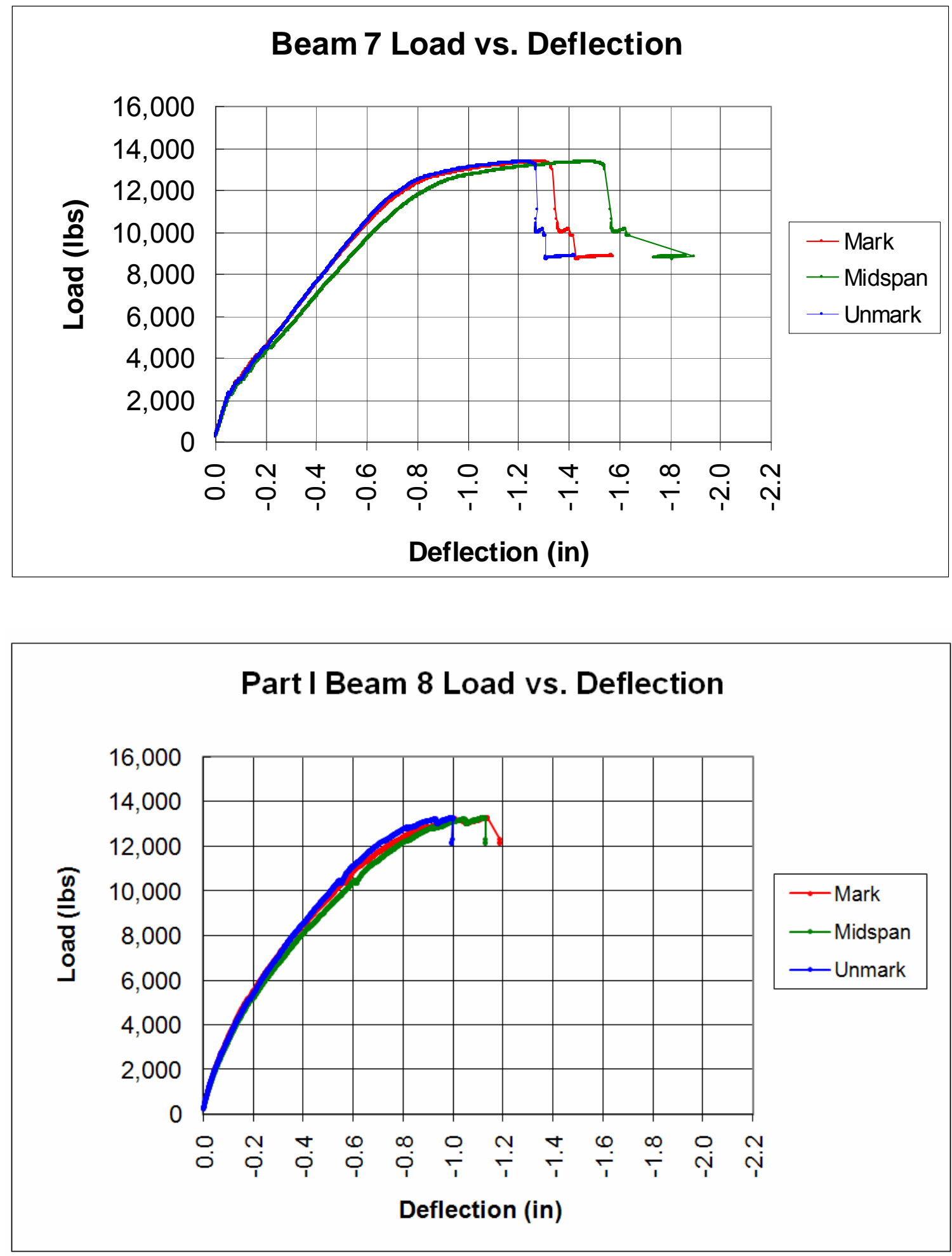

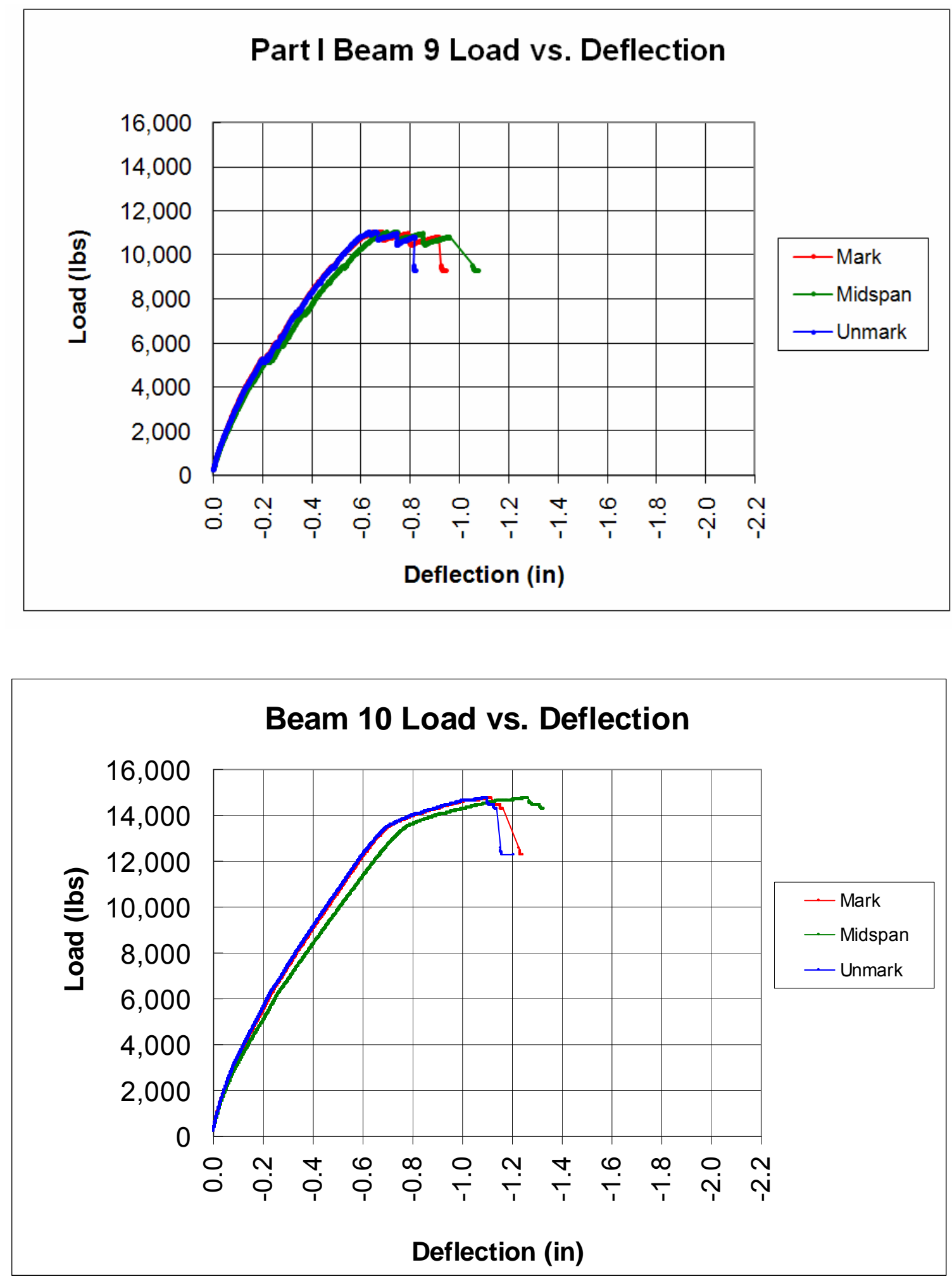


\section{Part I Beam 13 Load vs. Deflection}
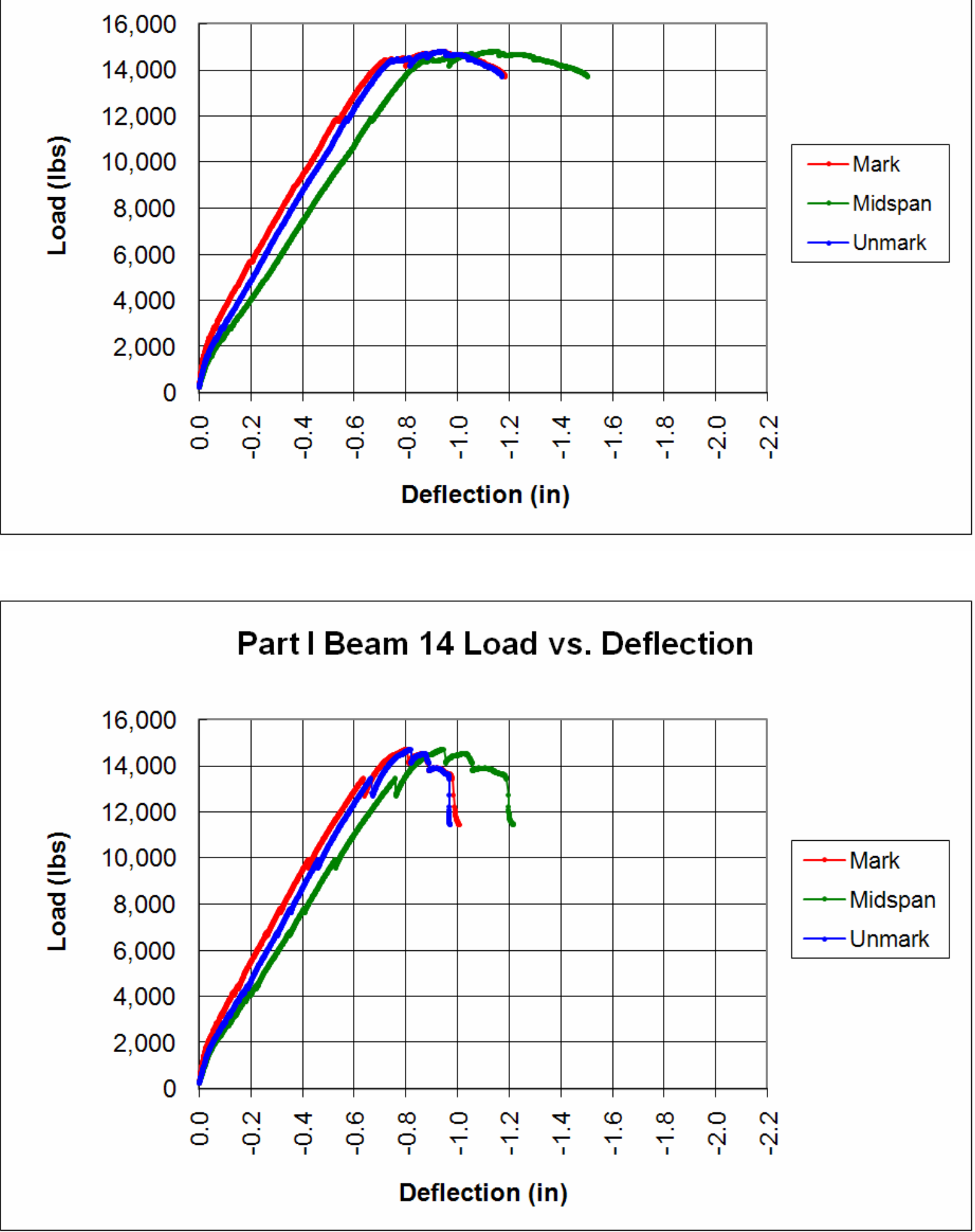

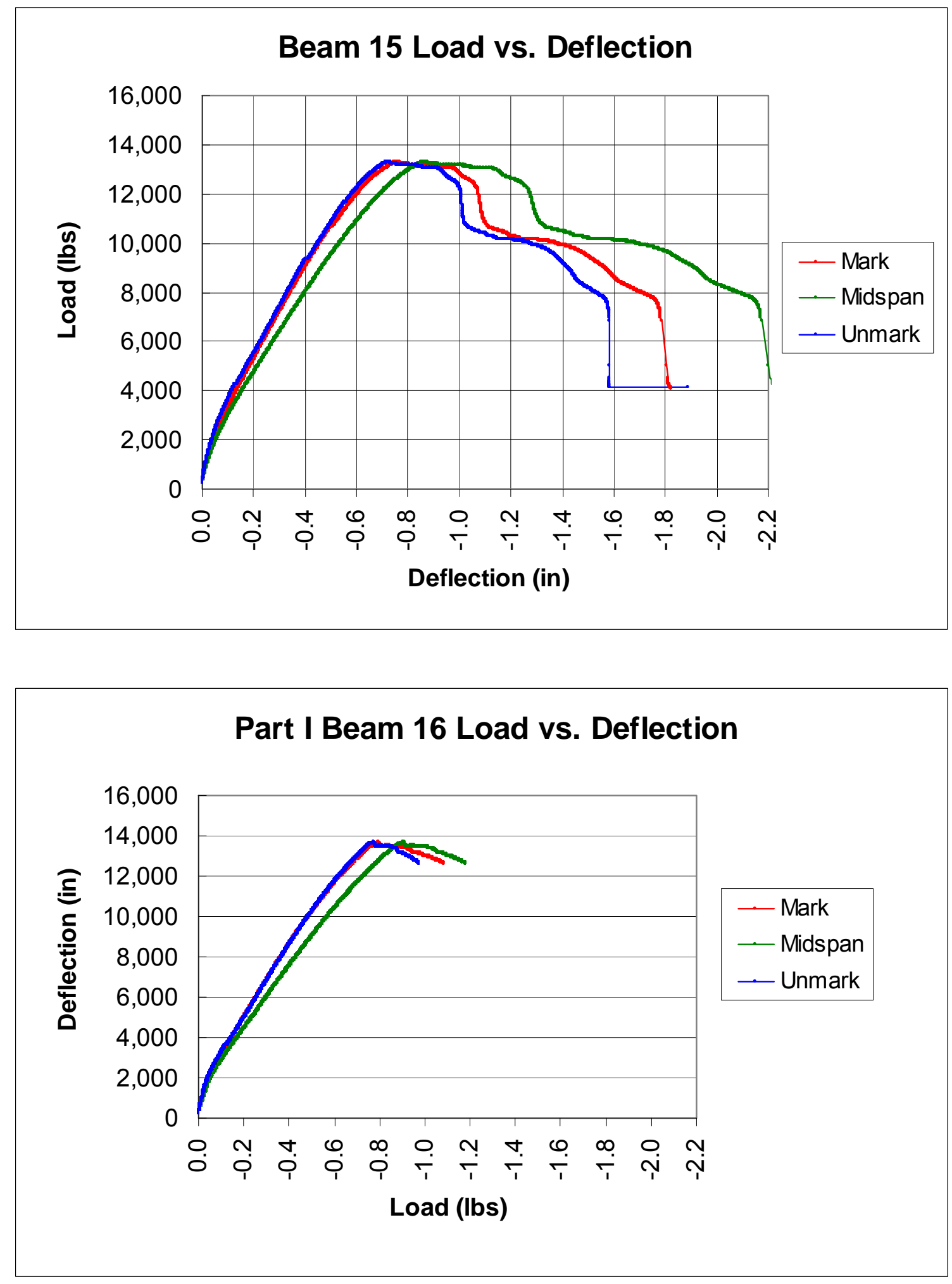

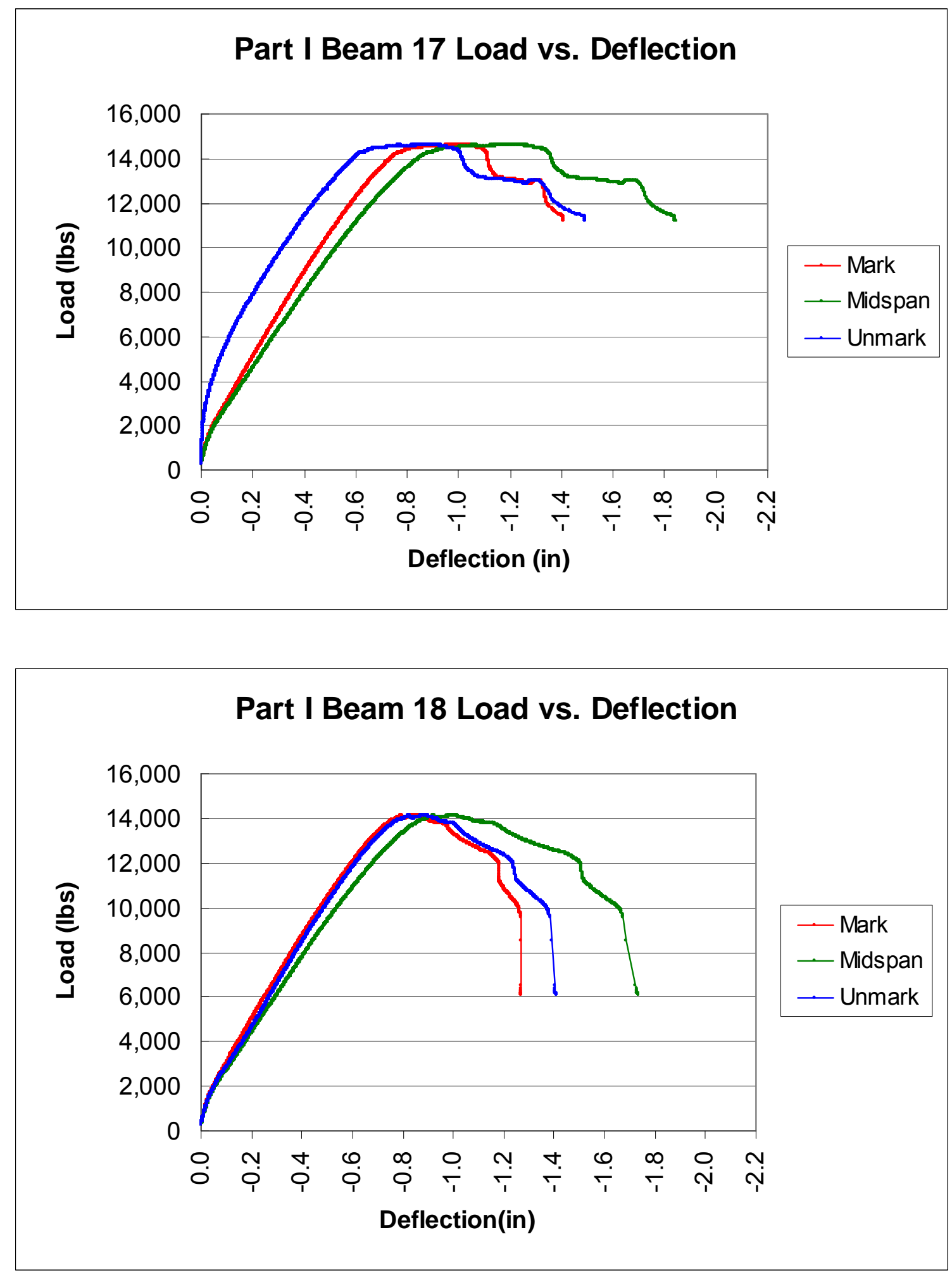


\section{F.1.2 Part II}

\section{F.1.2.1 Load-Deflection Curves}
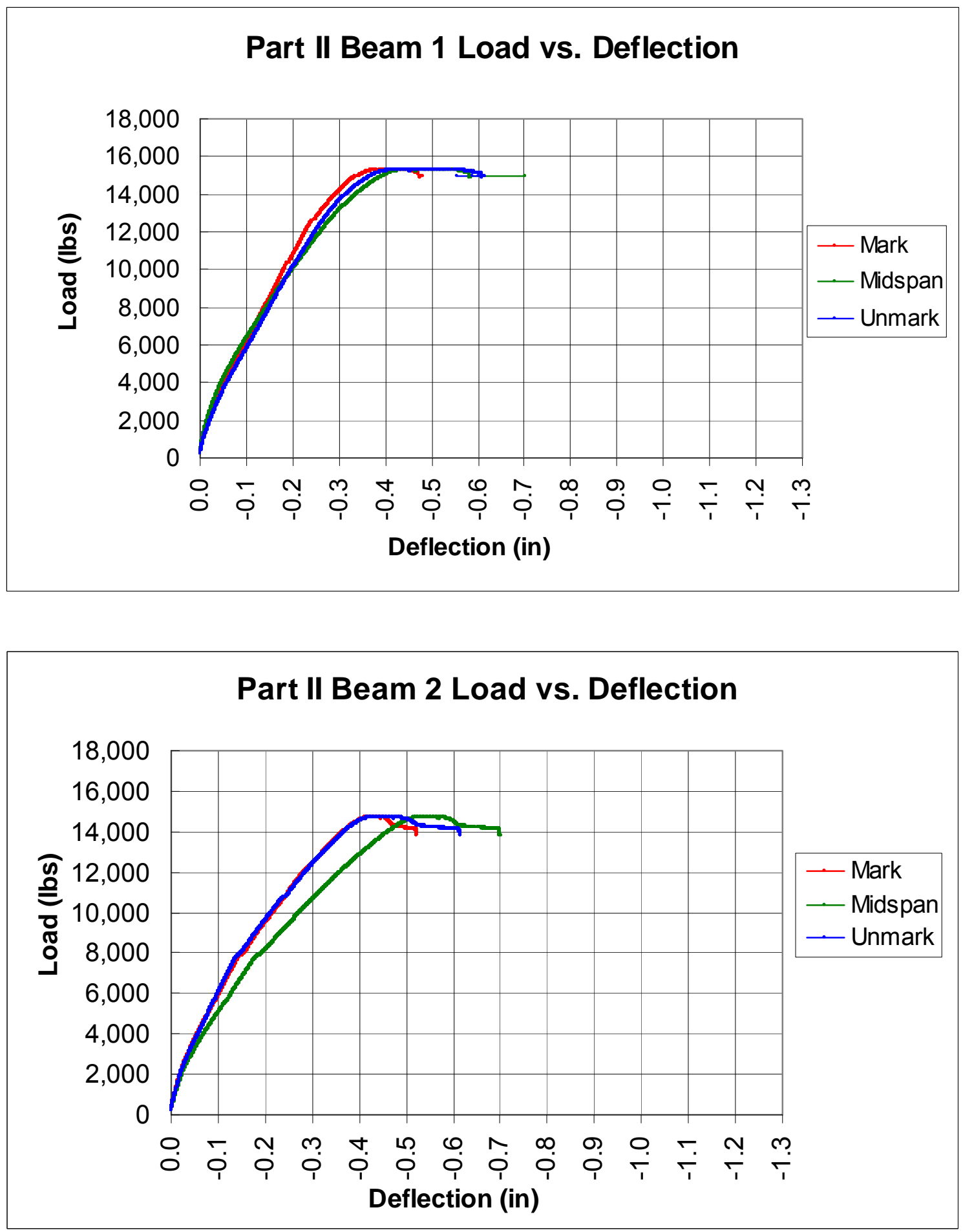

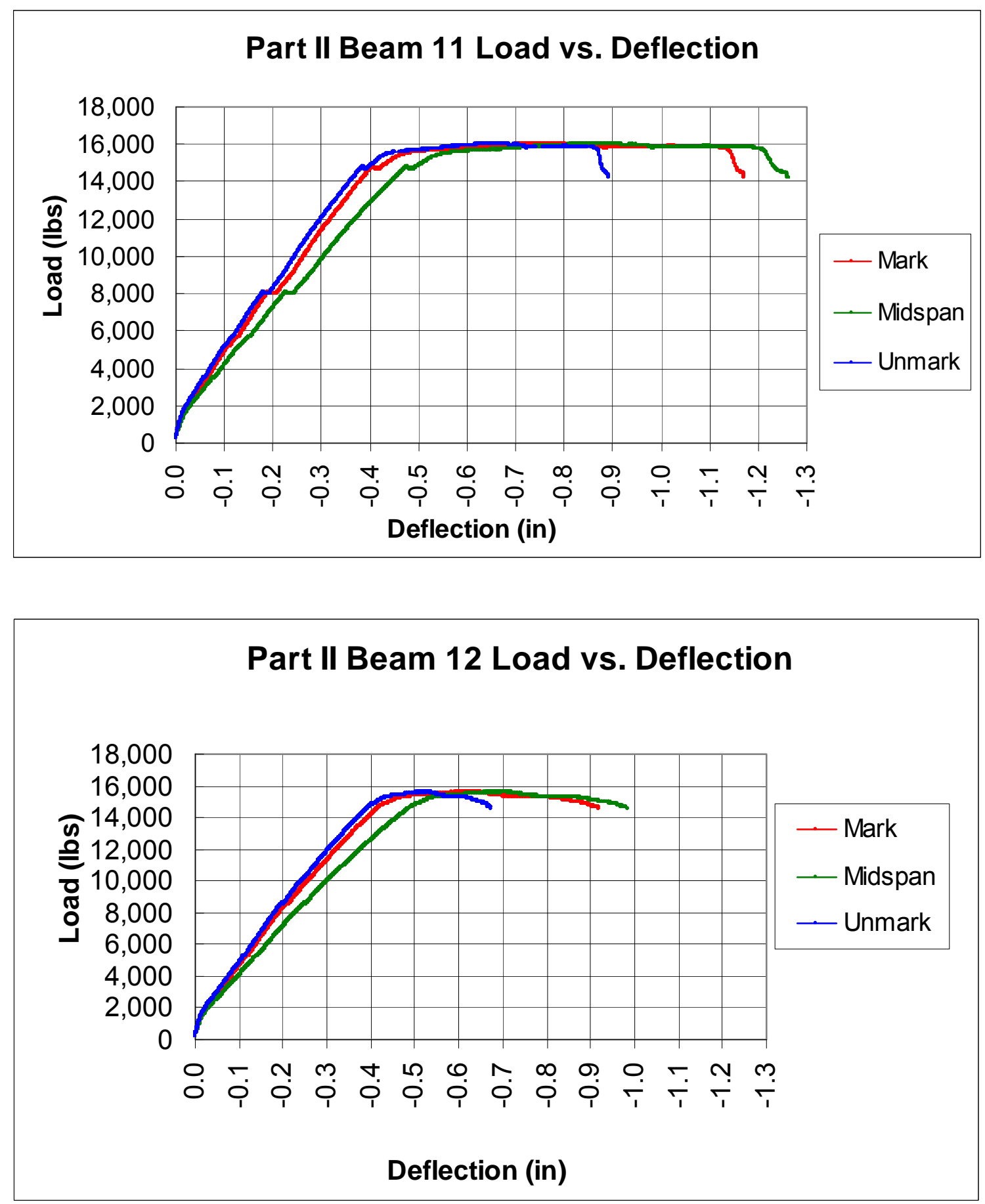

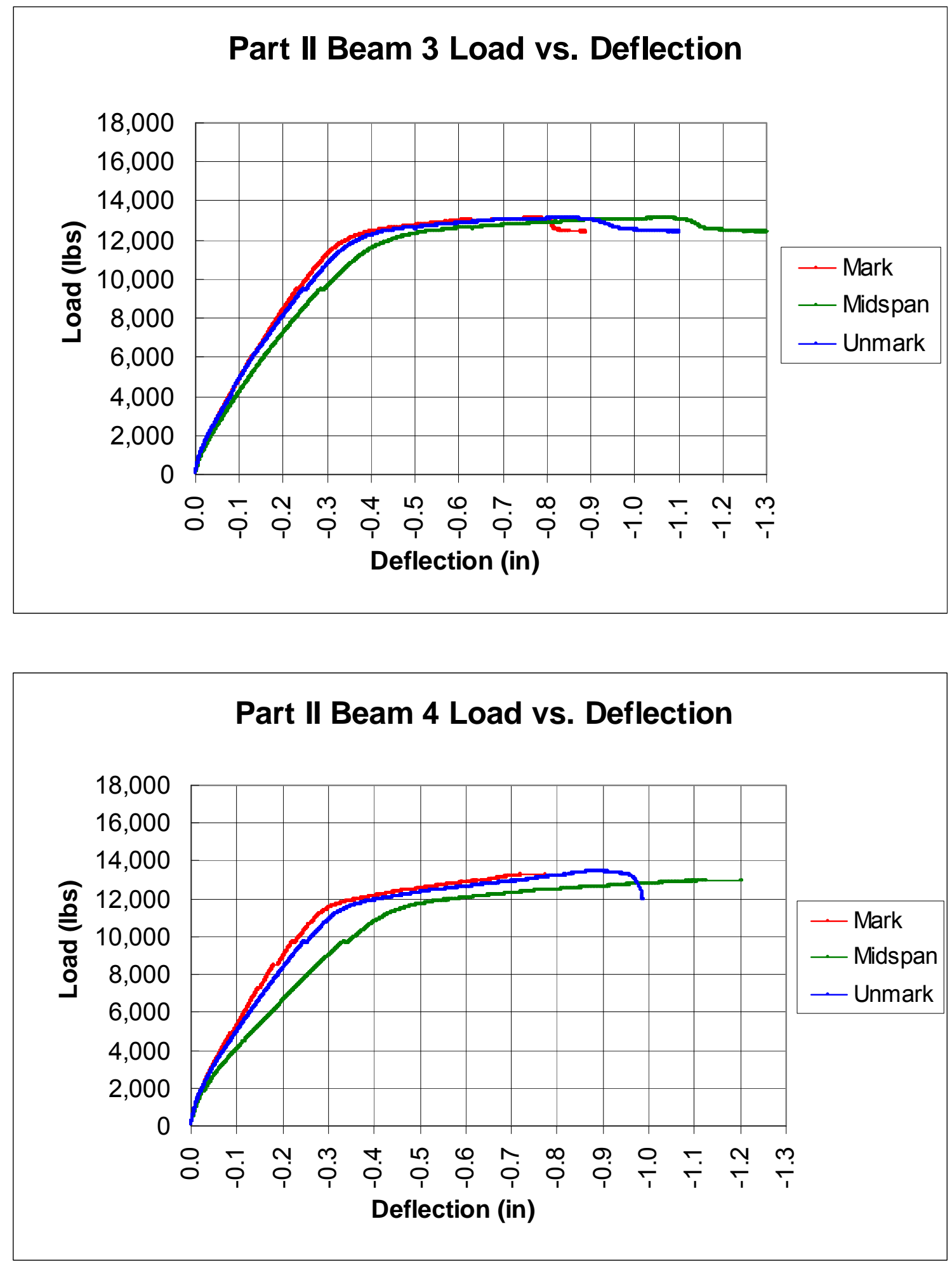

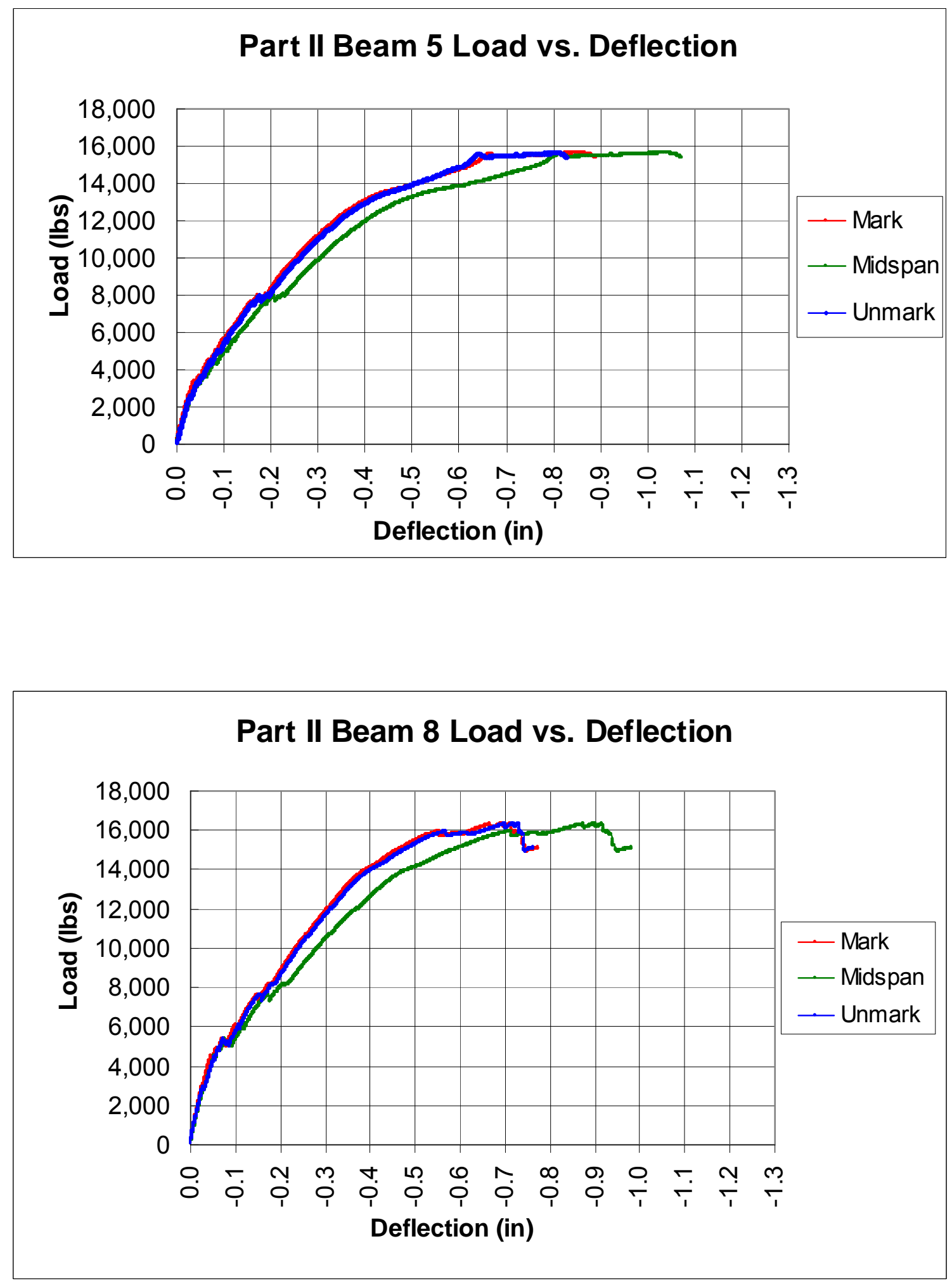

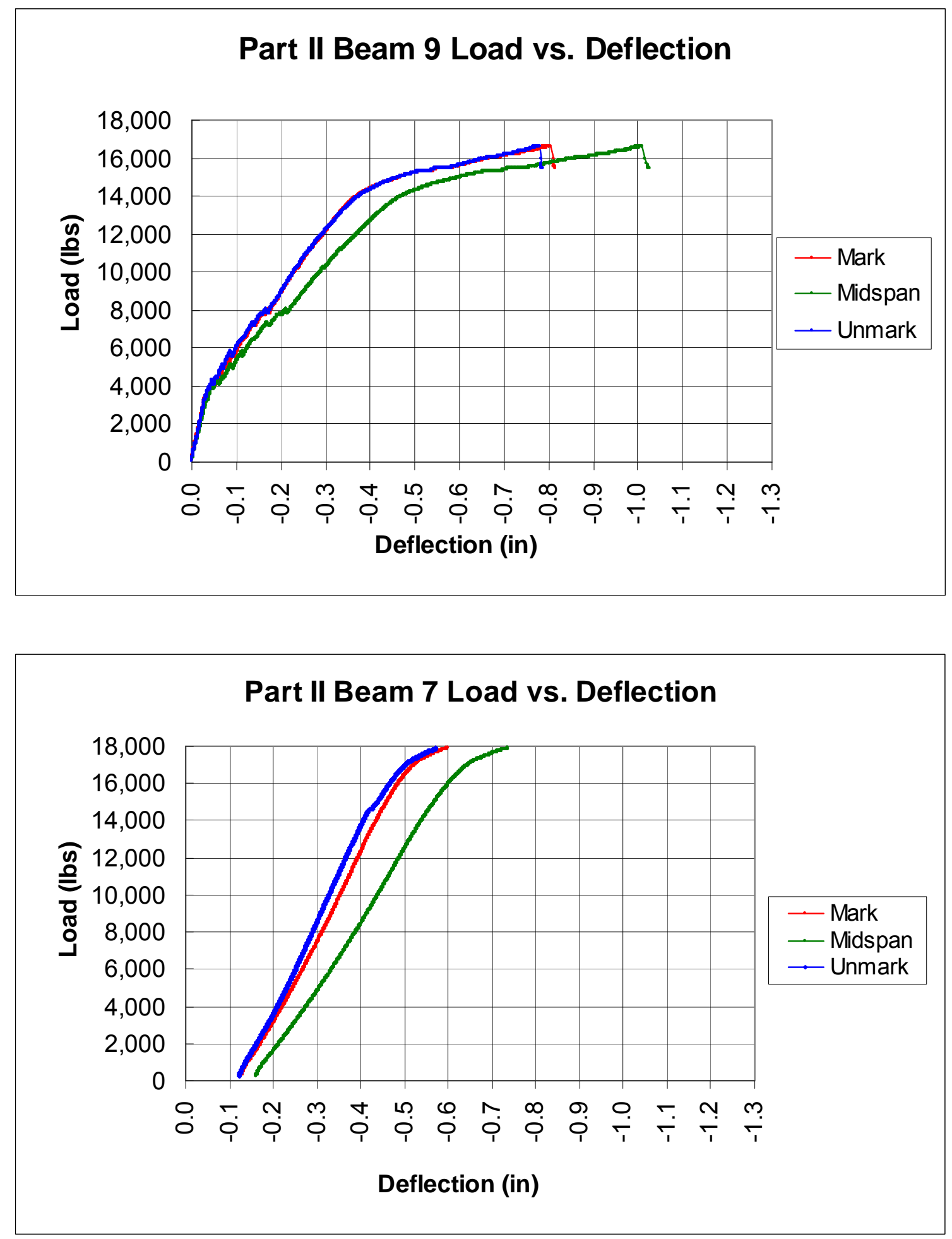

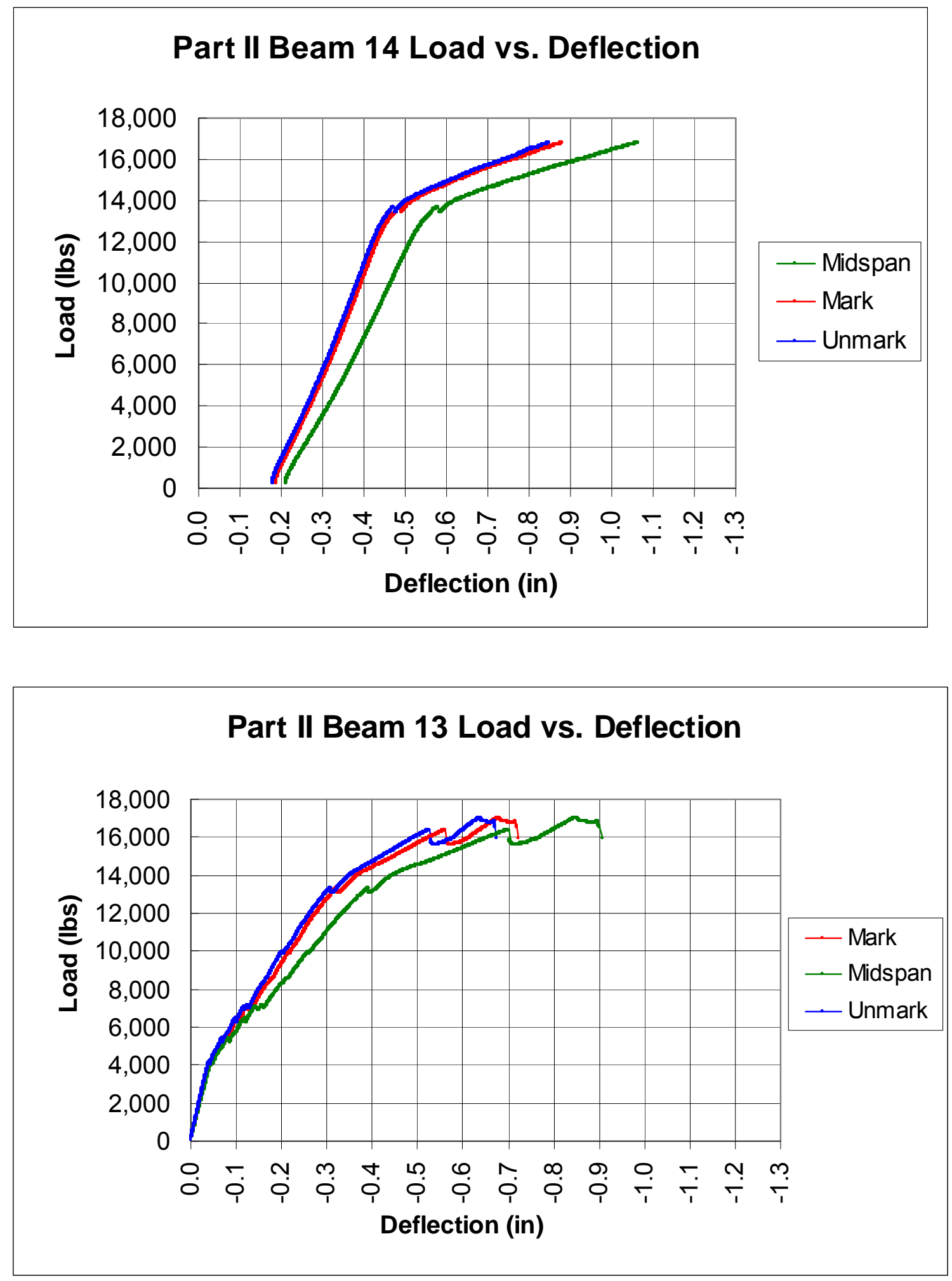

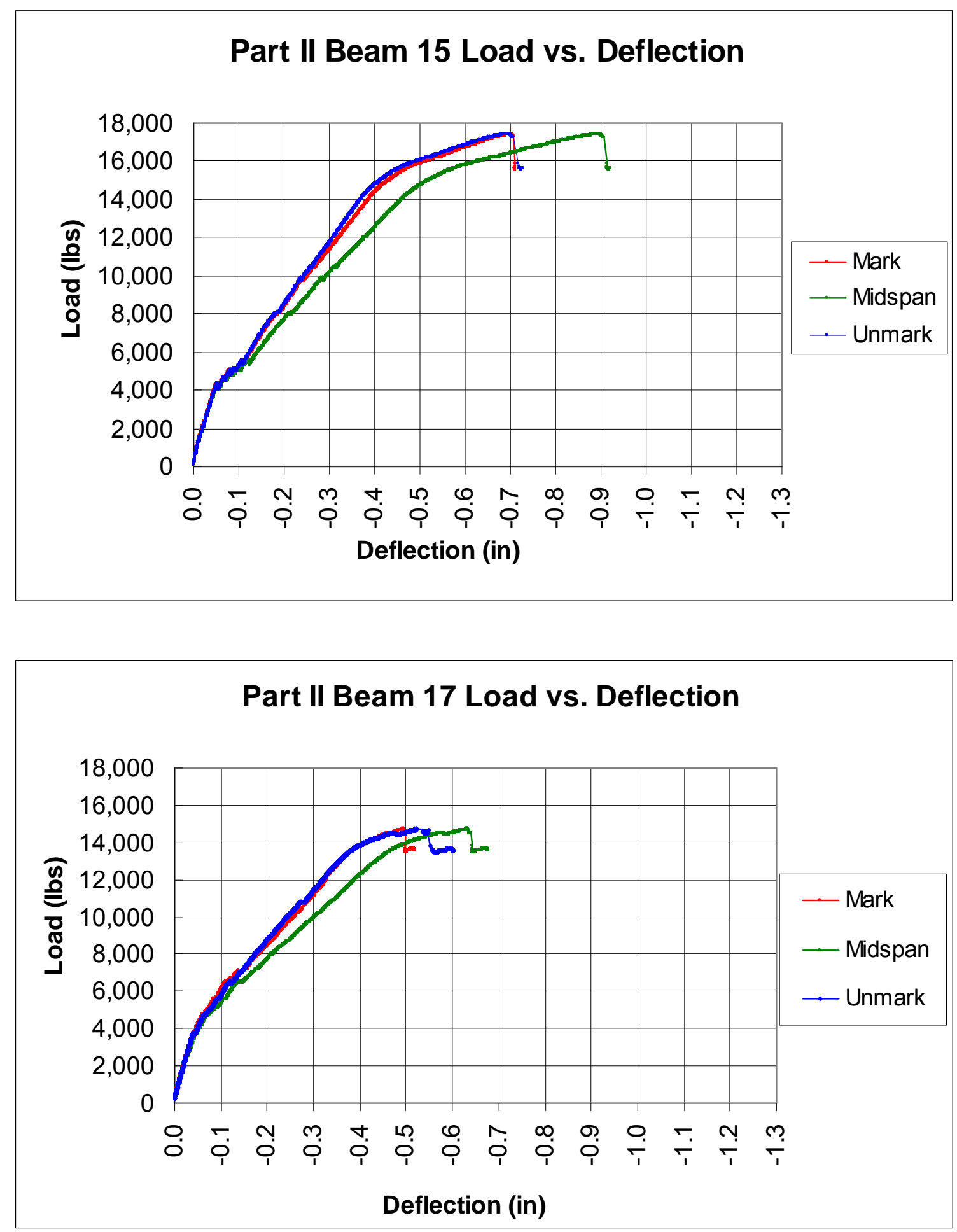

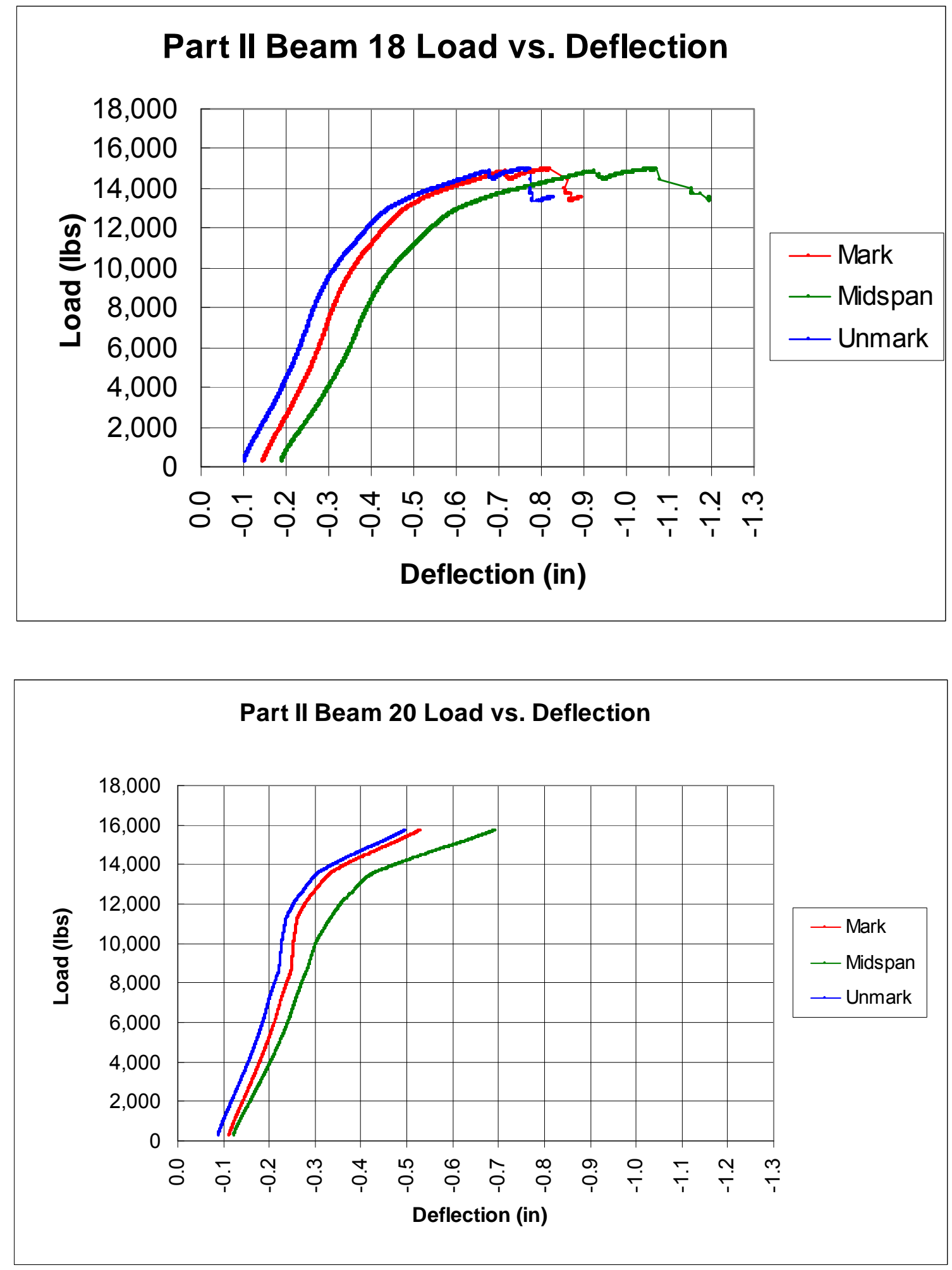

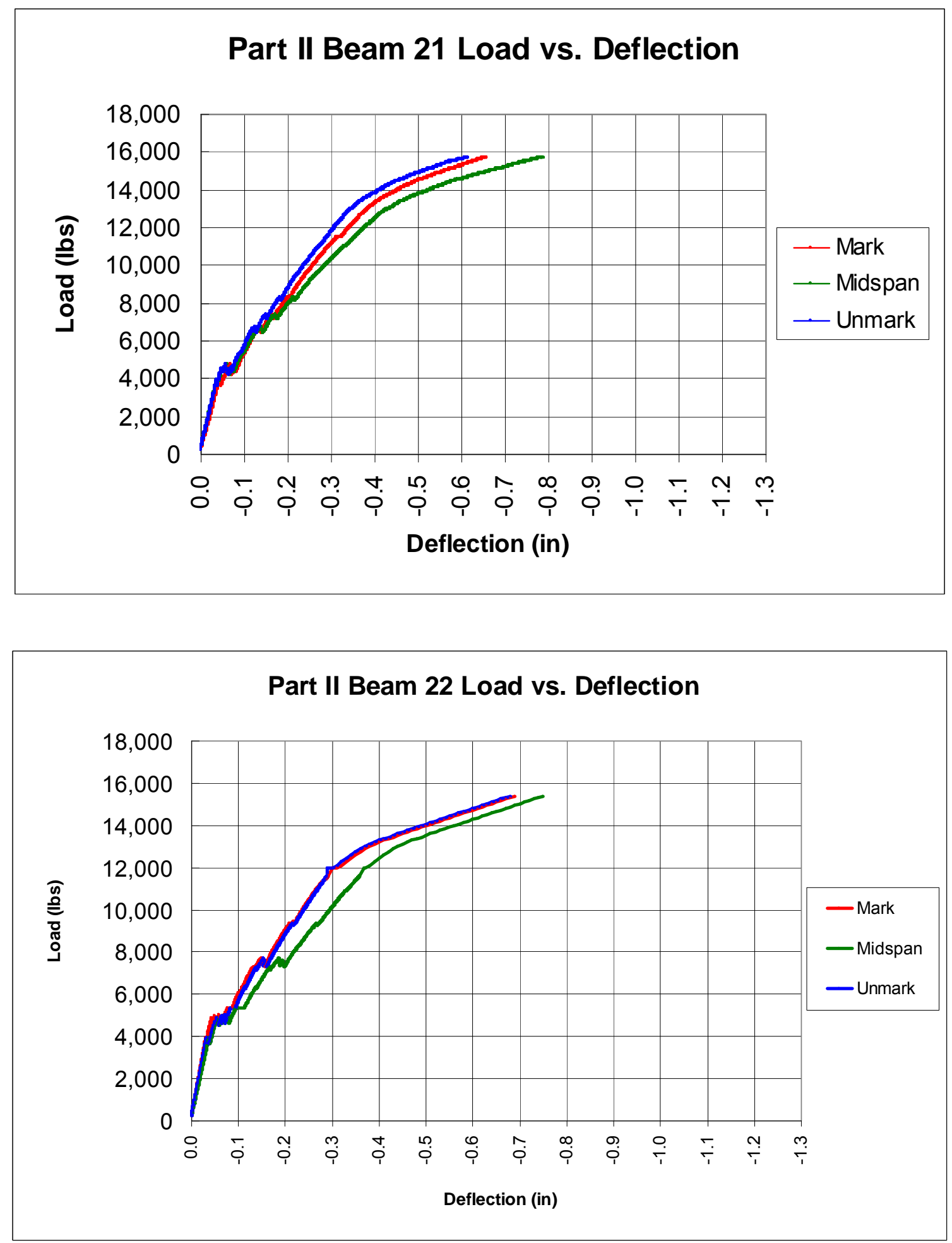


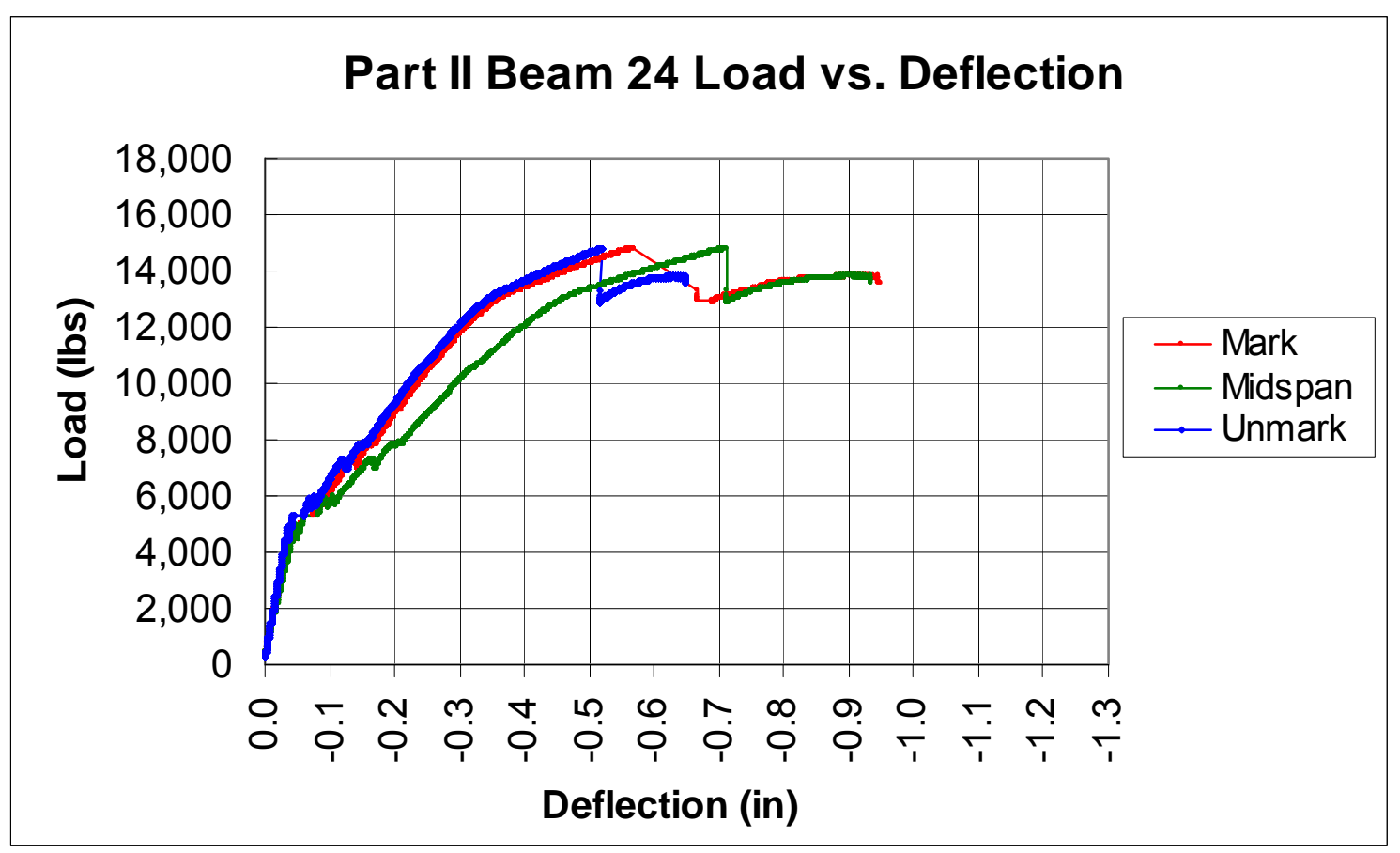



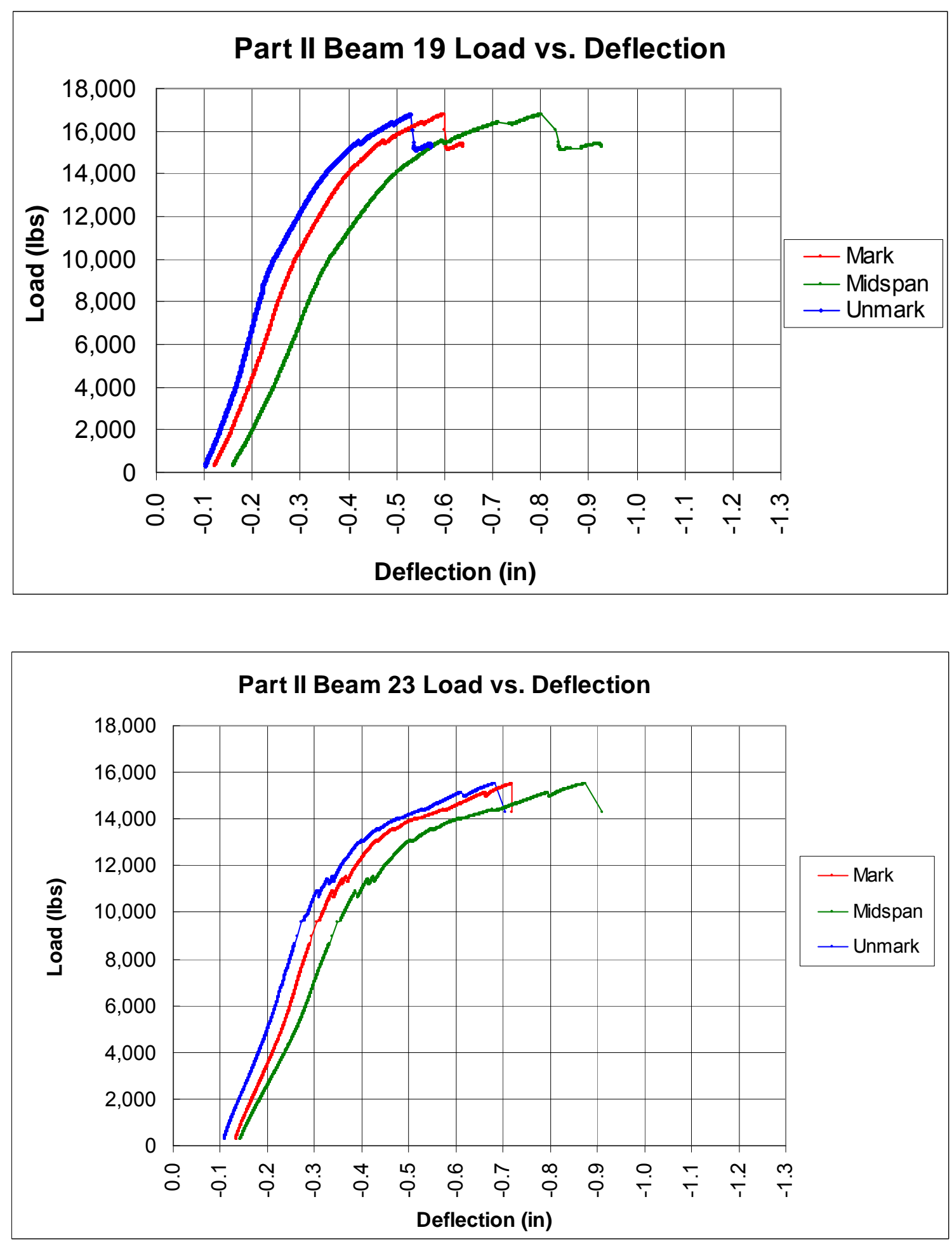


\section{F.1.2.2 Load vs. Steel Strain Diagrams}
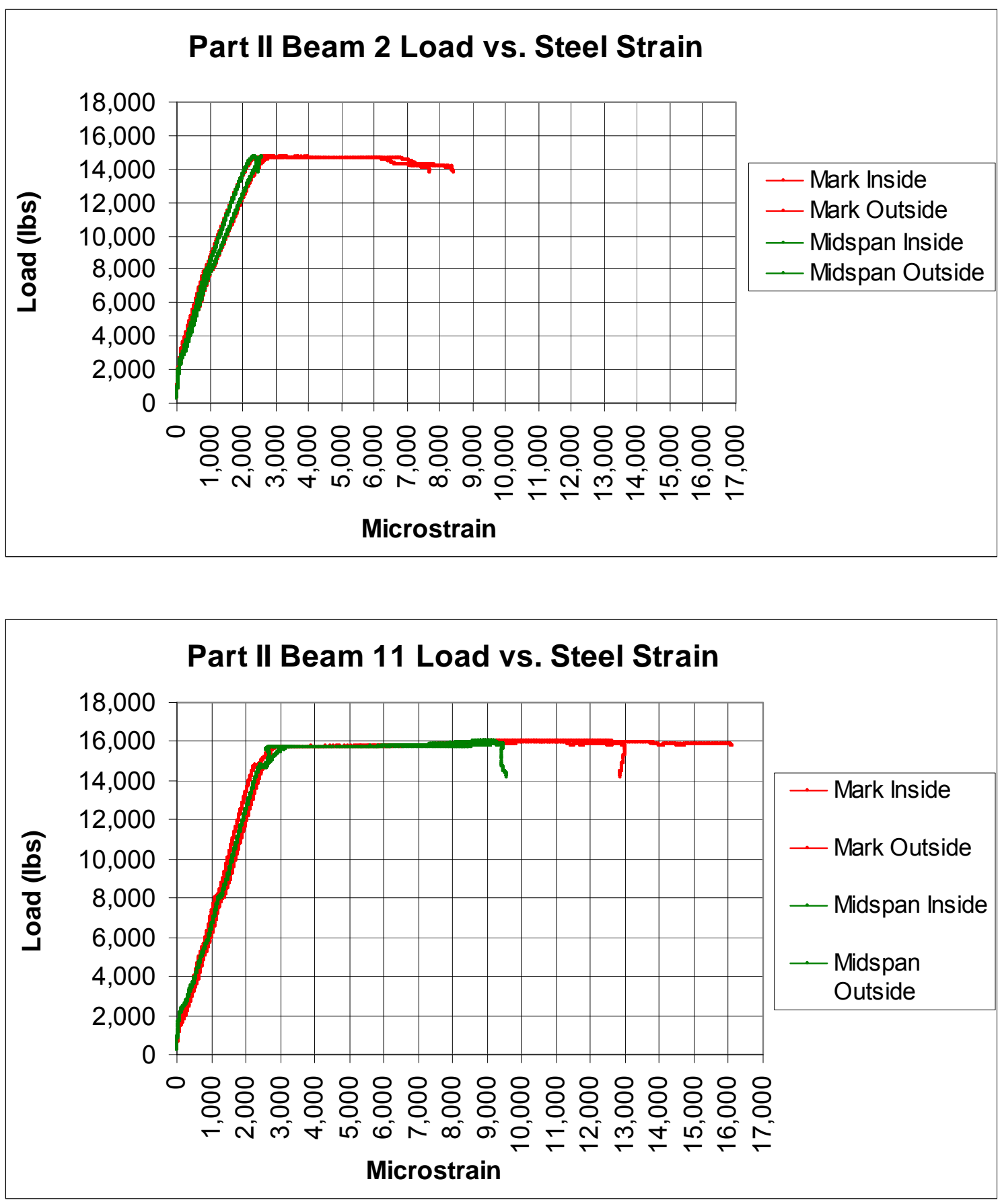

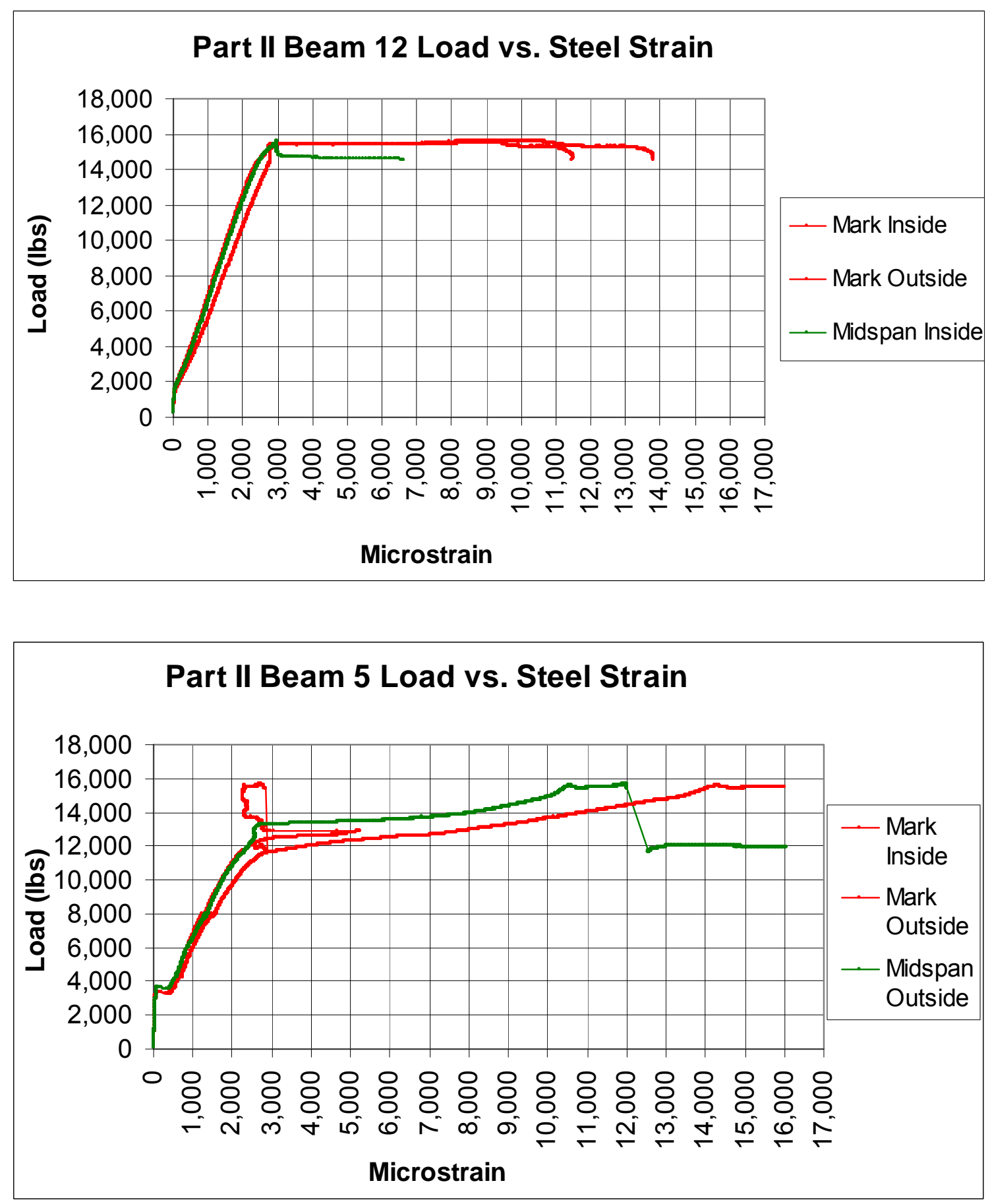

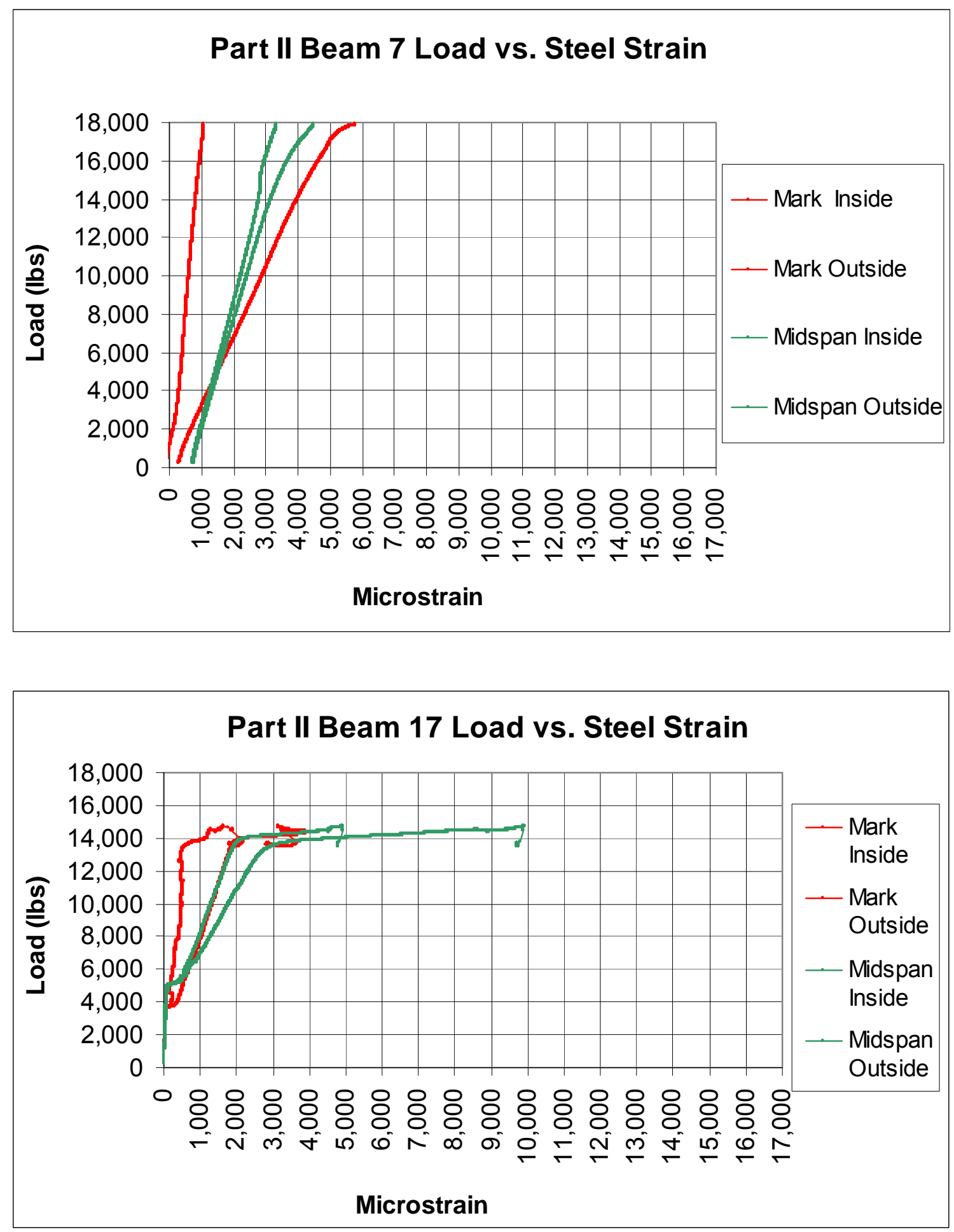

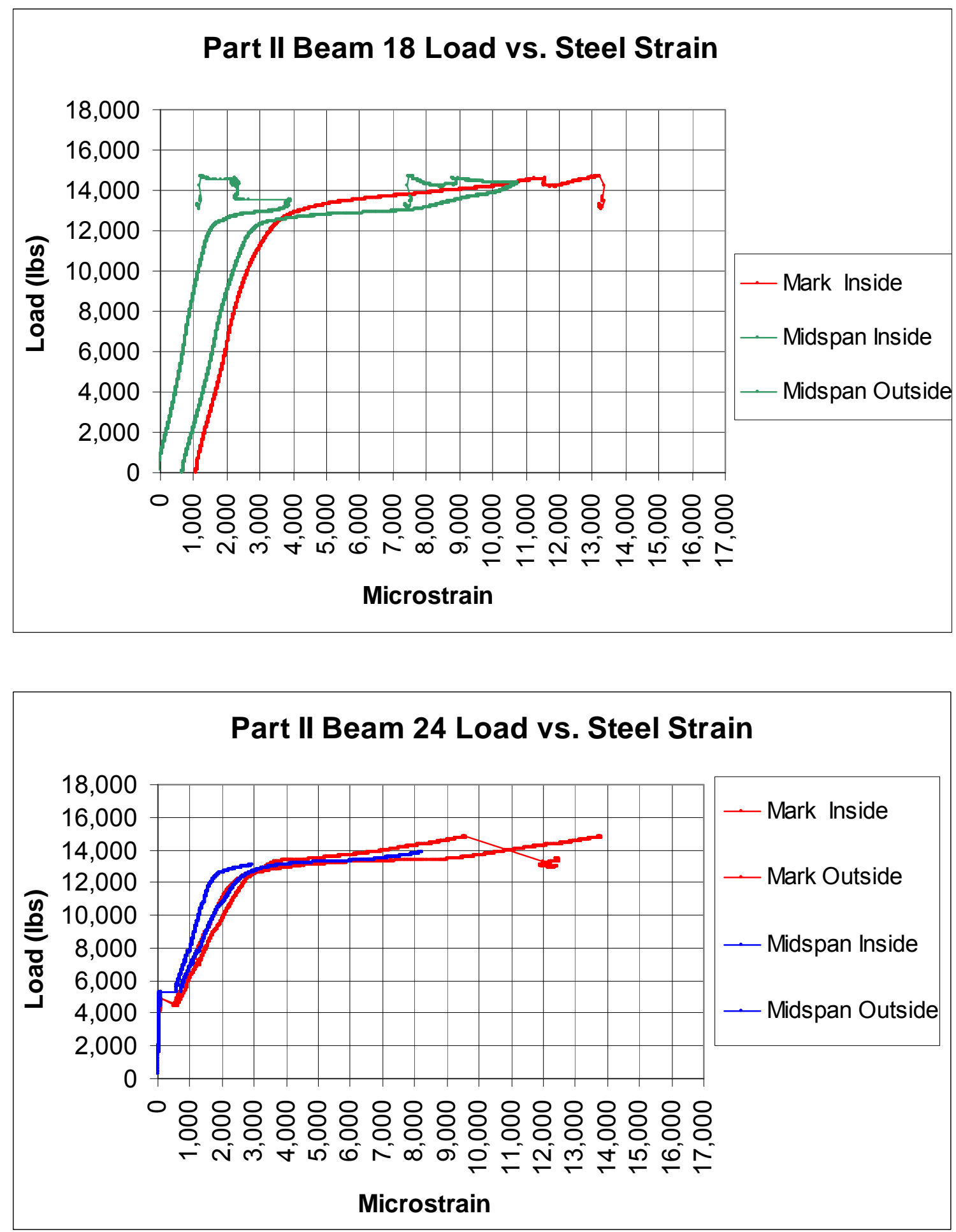


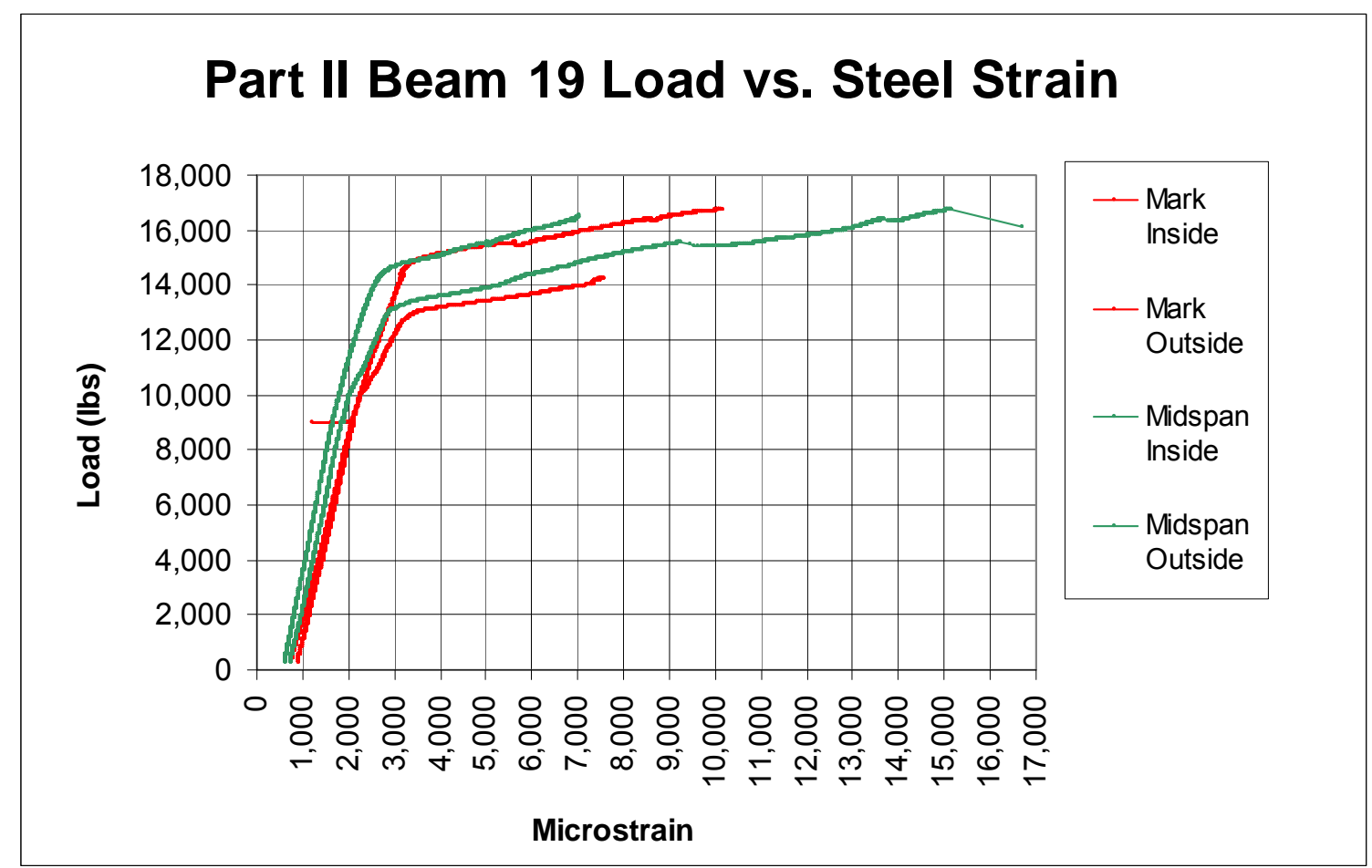

\section{F.1.2.3 Load vs. FRP Strain Diagrams}

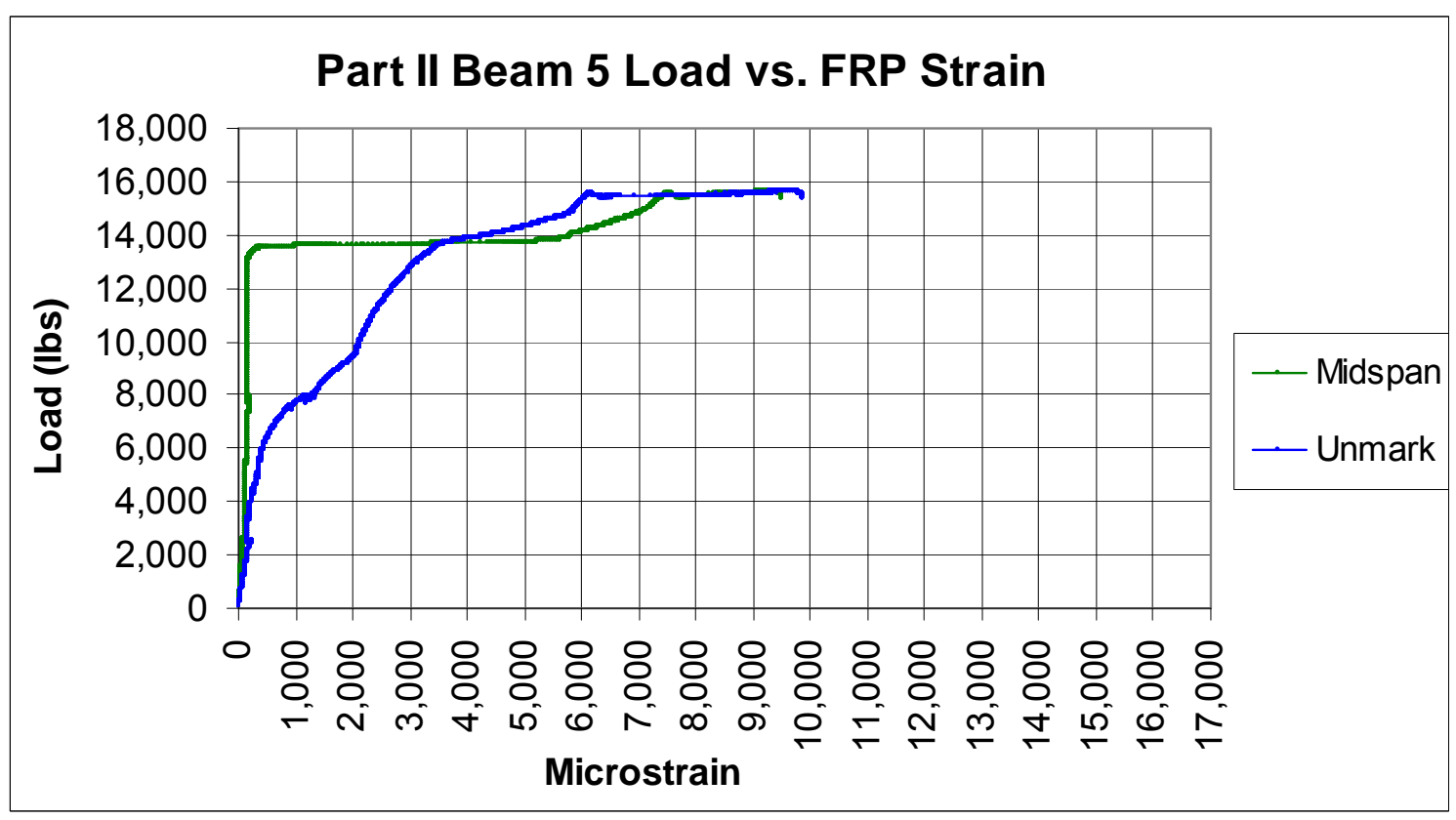



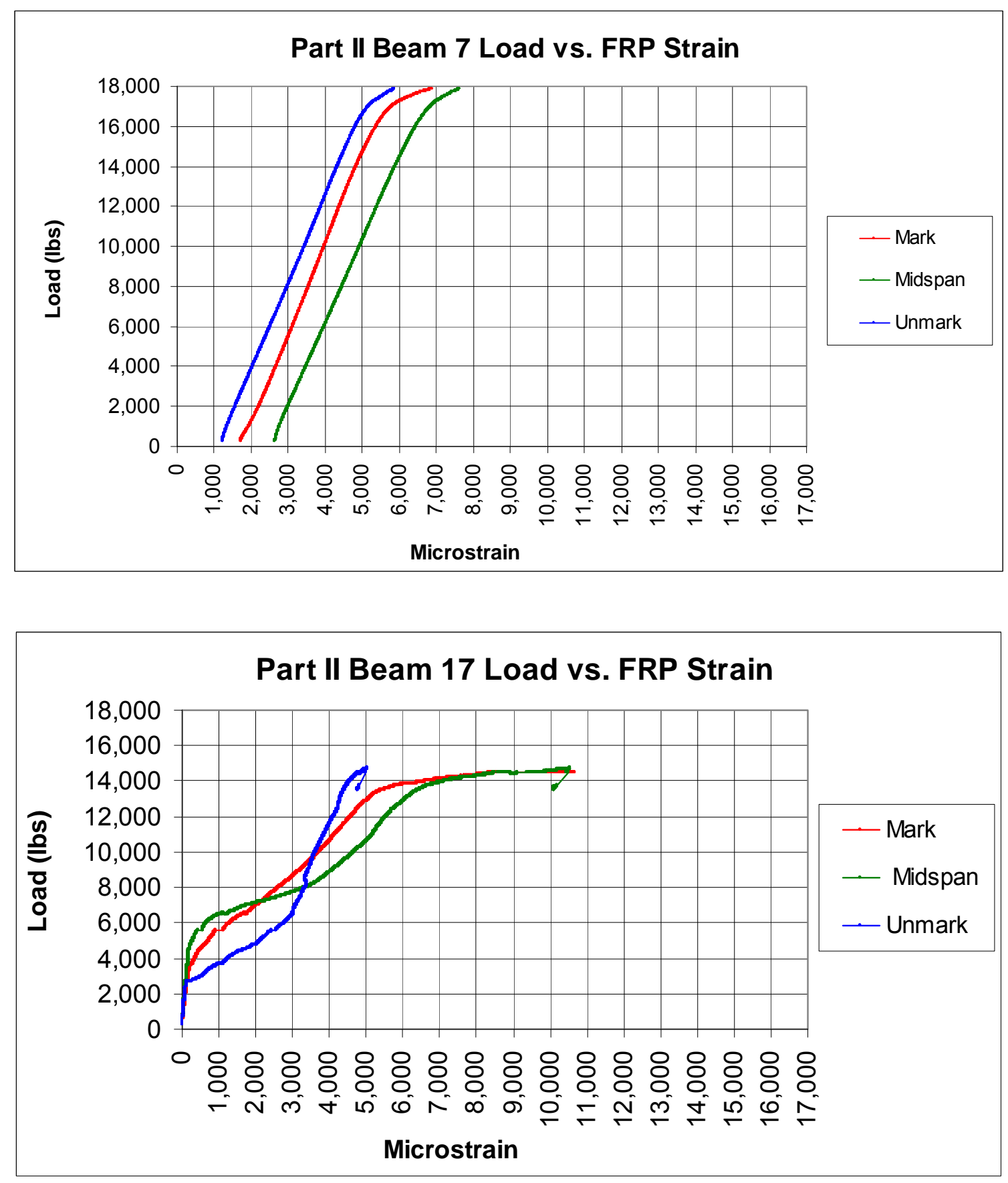

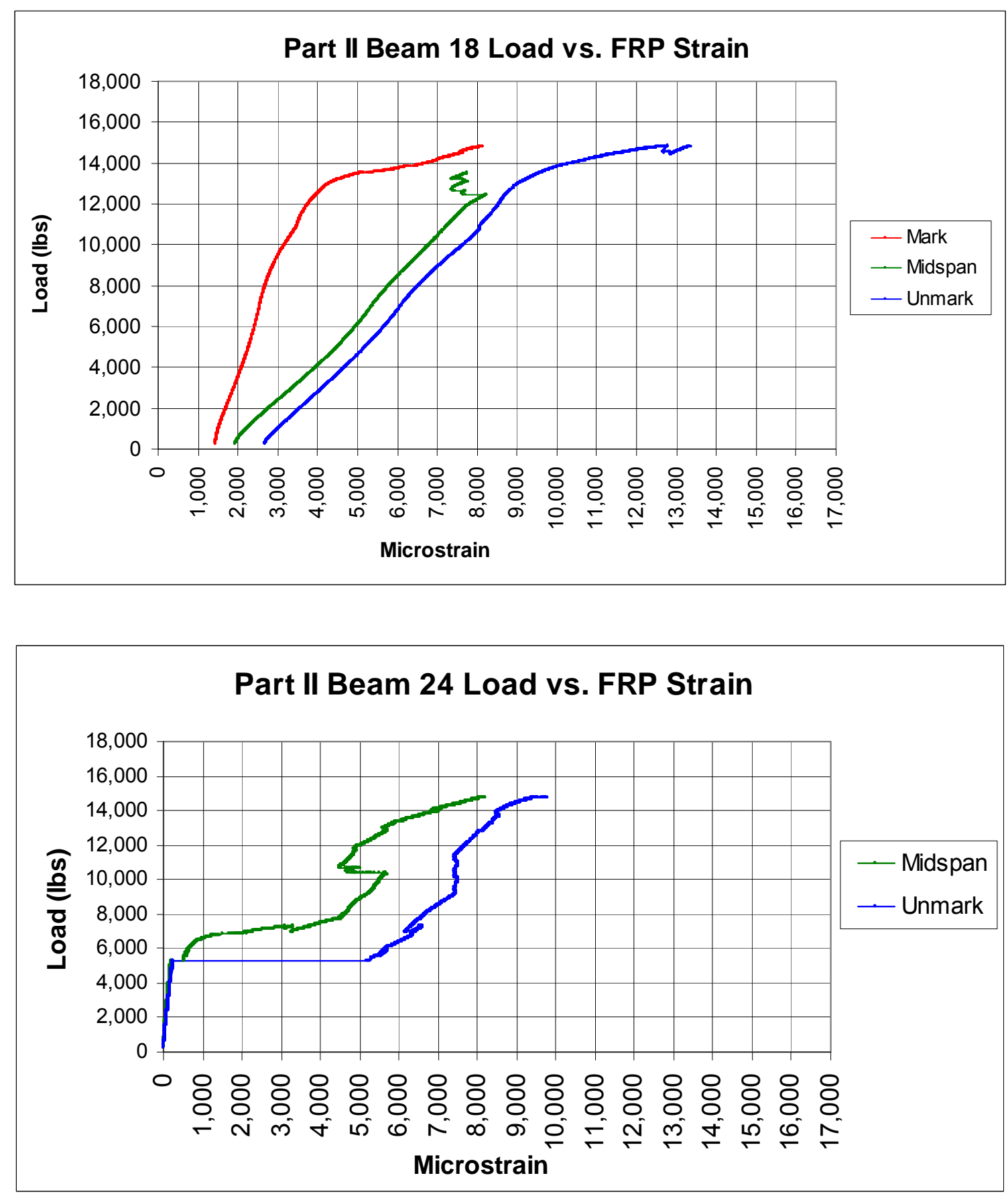


\section{F.1.2.4 Load vs. Externally Bonded Strain Gages}
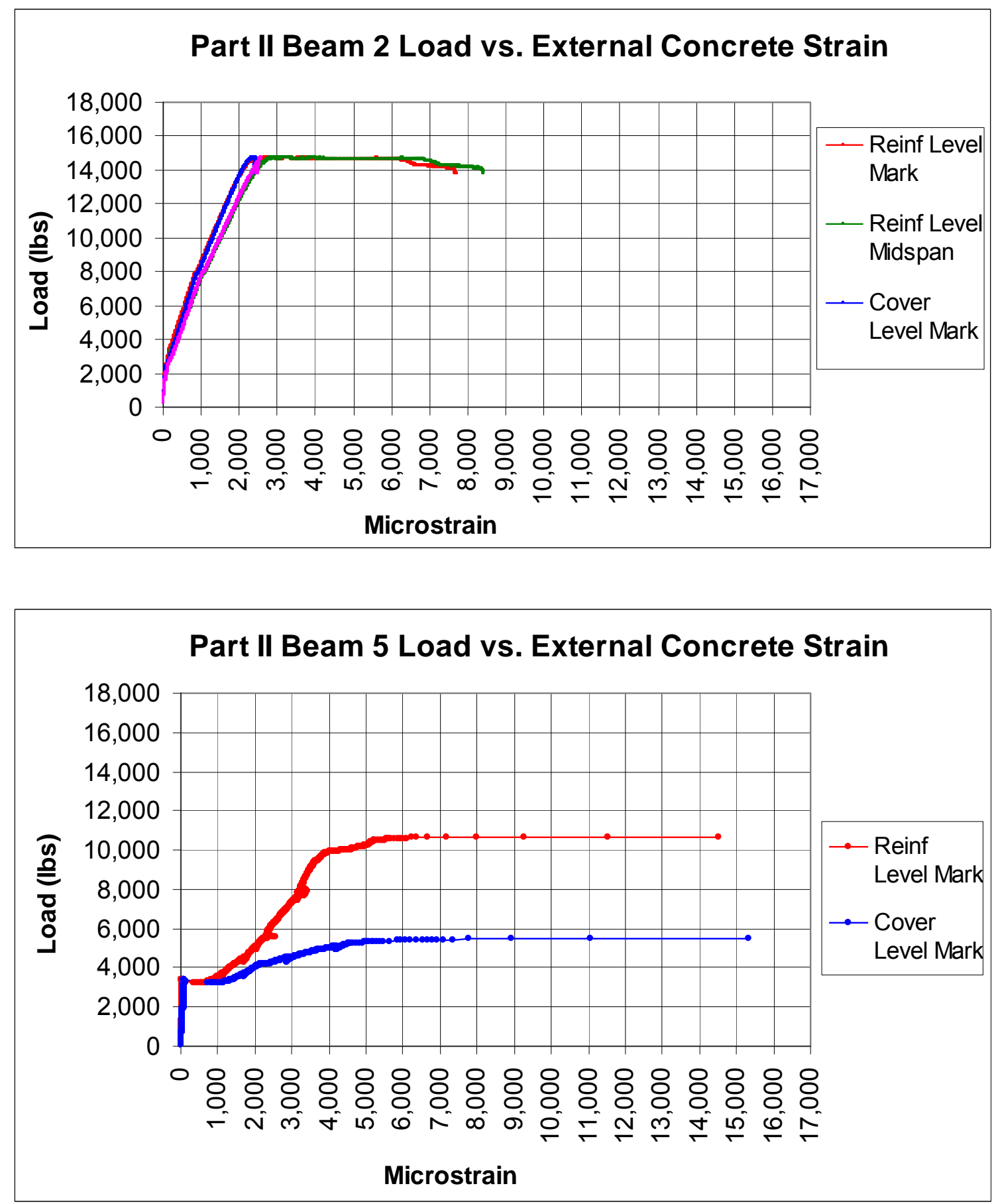

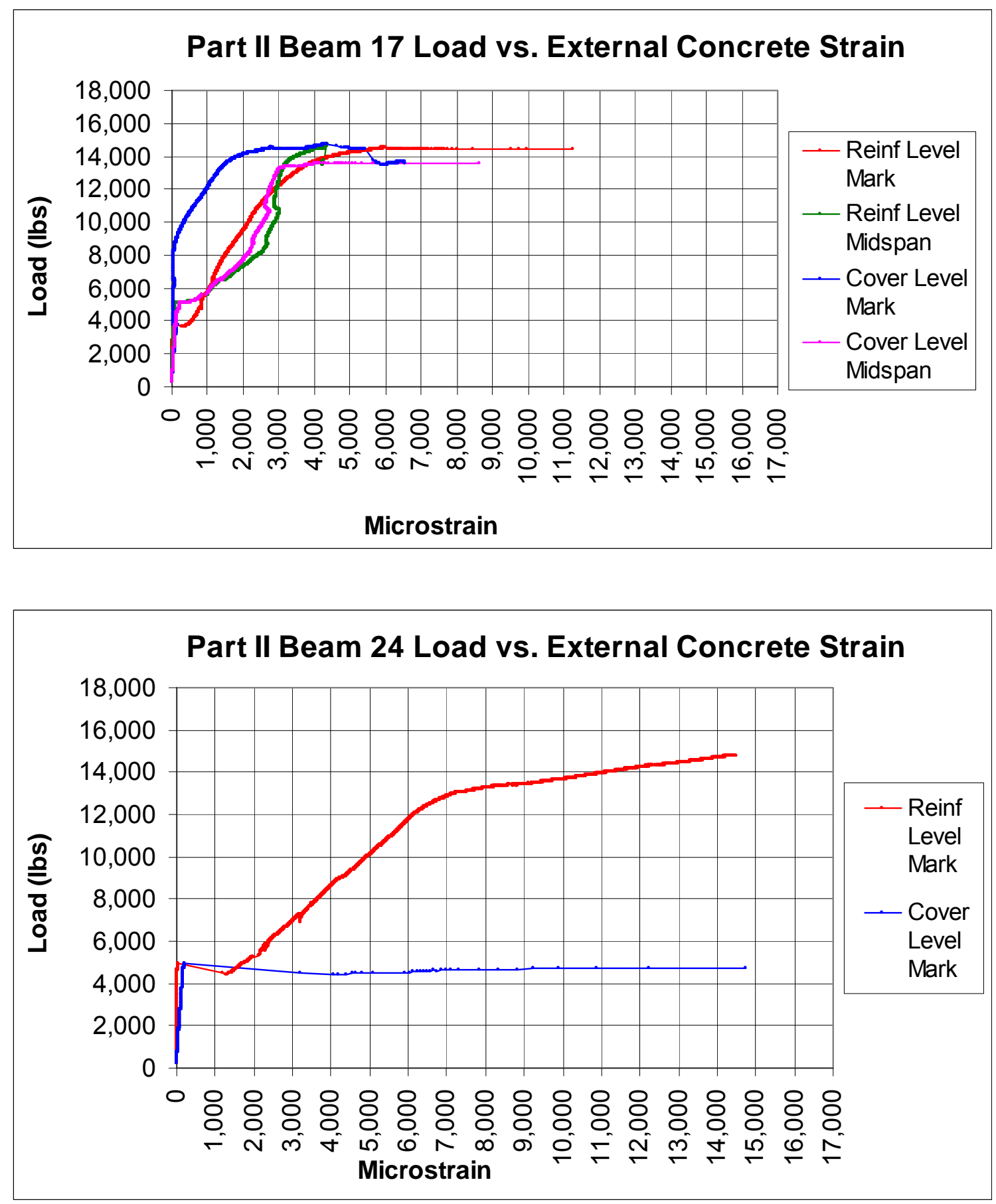


\section{F.1.2.5 Load vs. Embedded Concrete Gages}
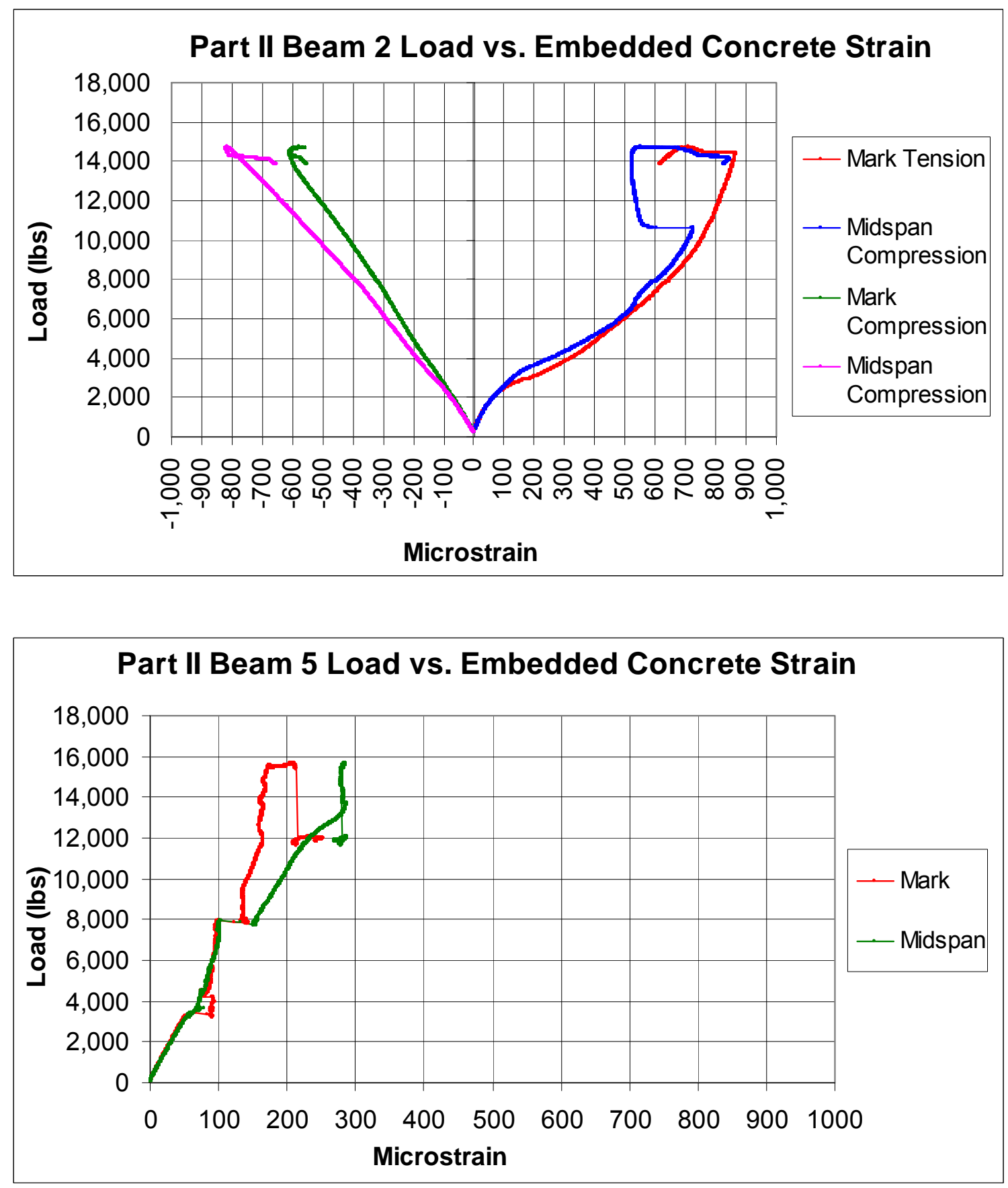

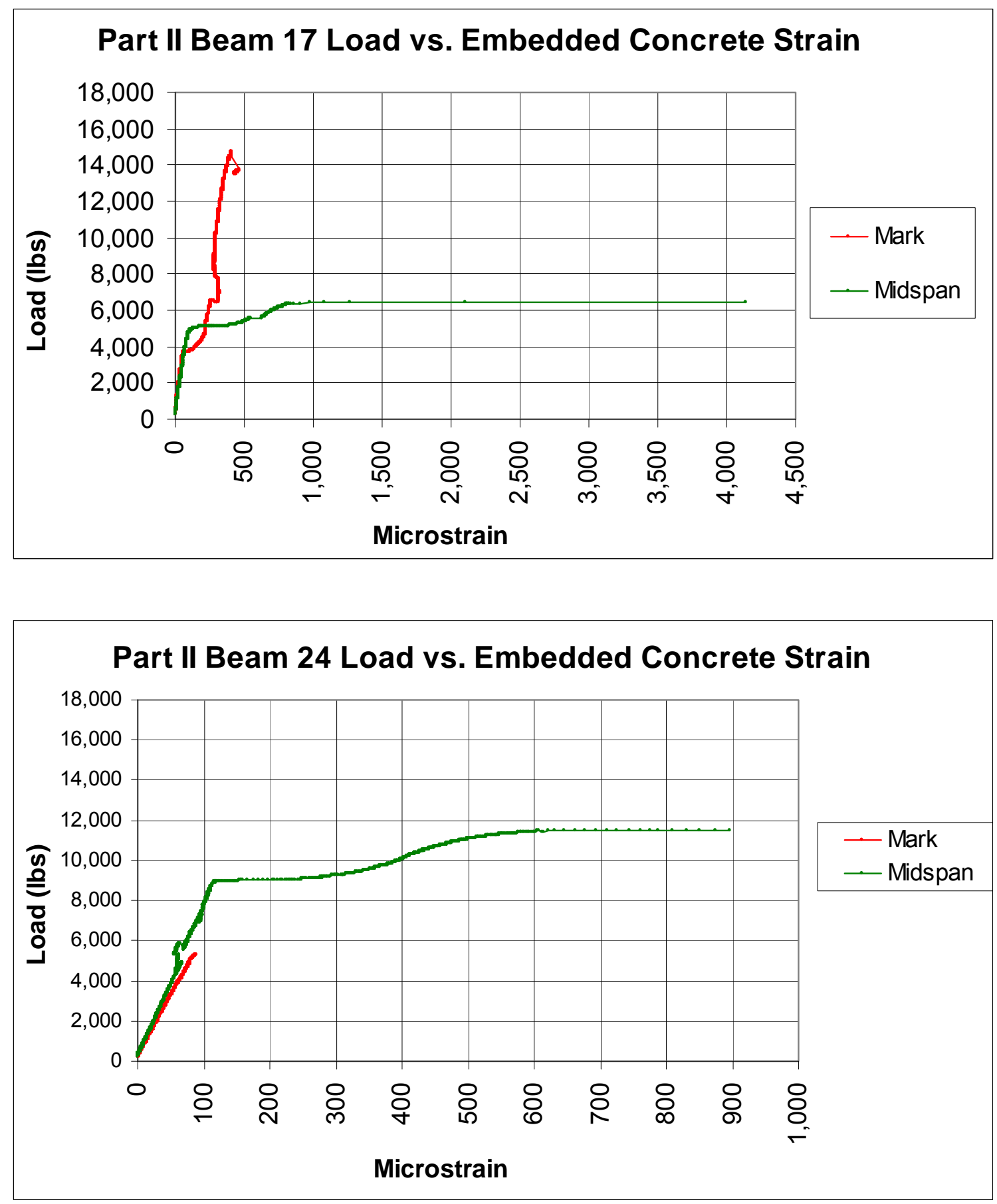


\section{F.2 Cyclic Load Effects}

\section{F.2.1 Deflection}

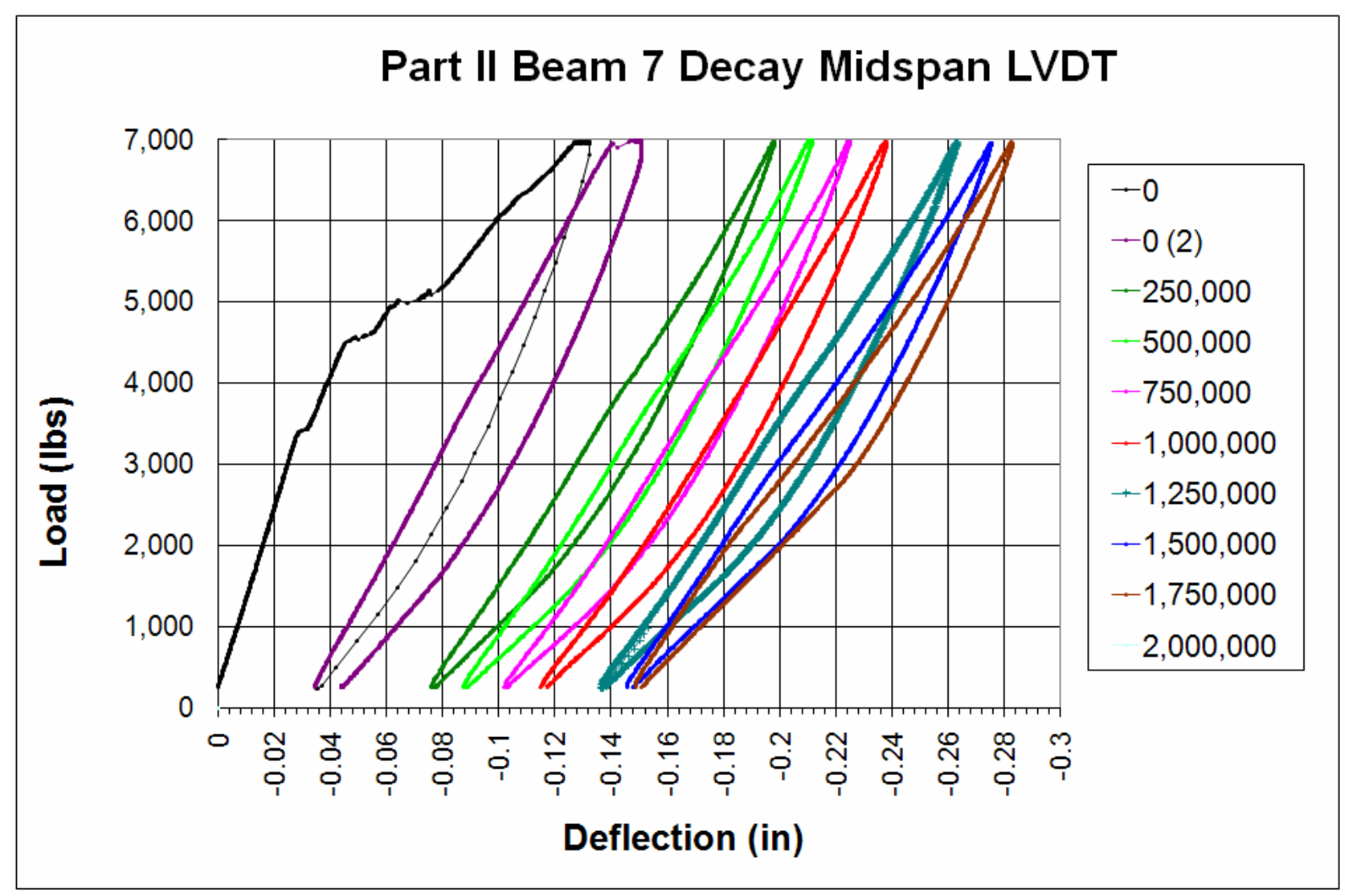



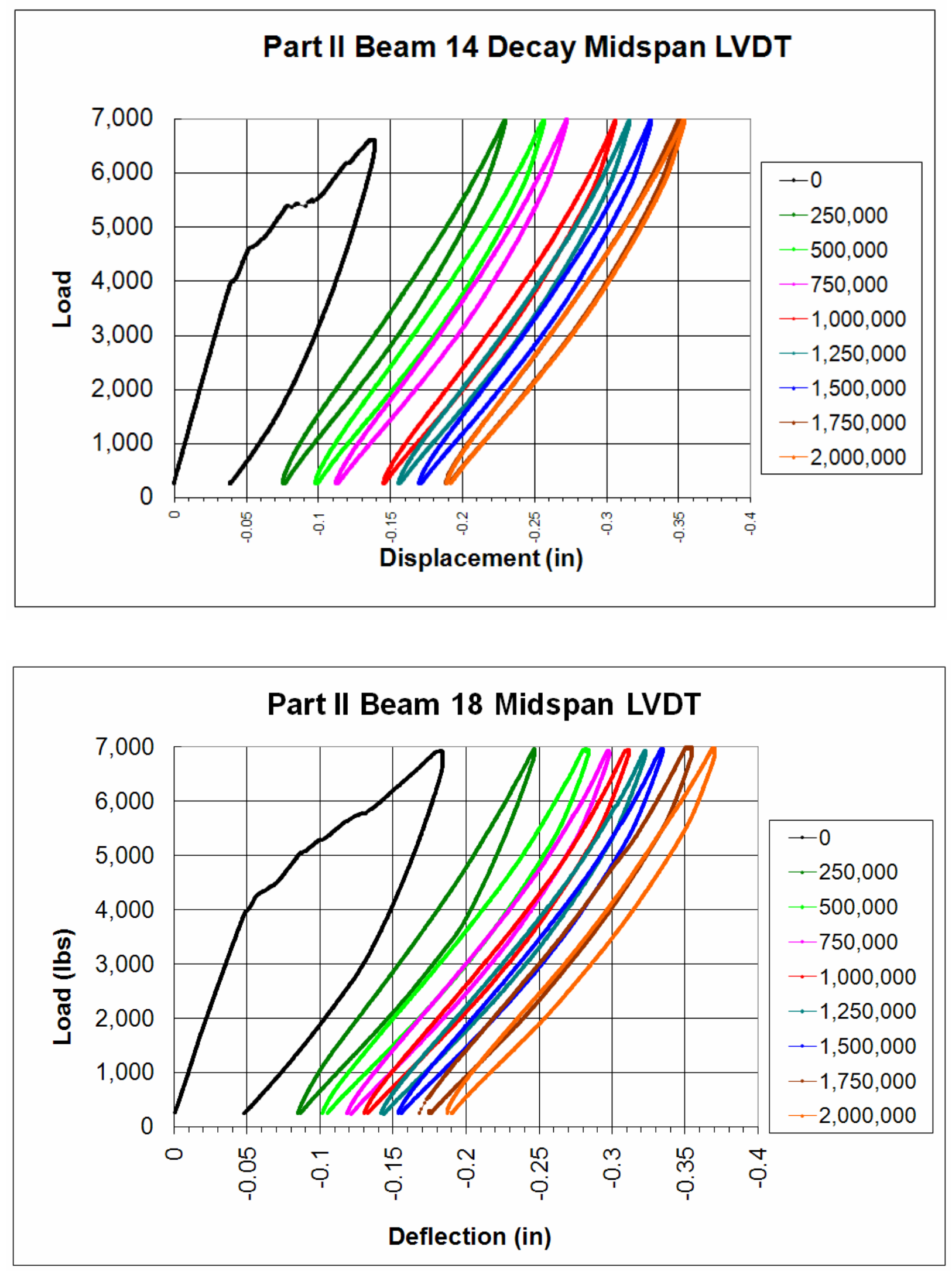

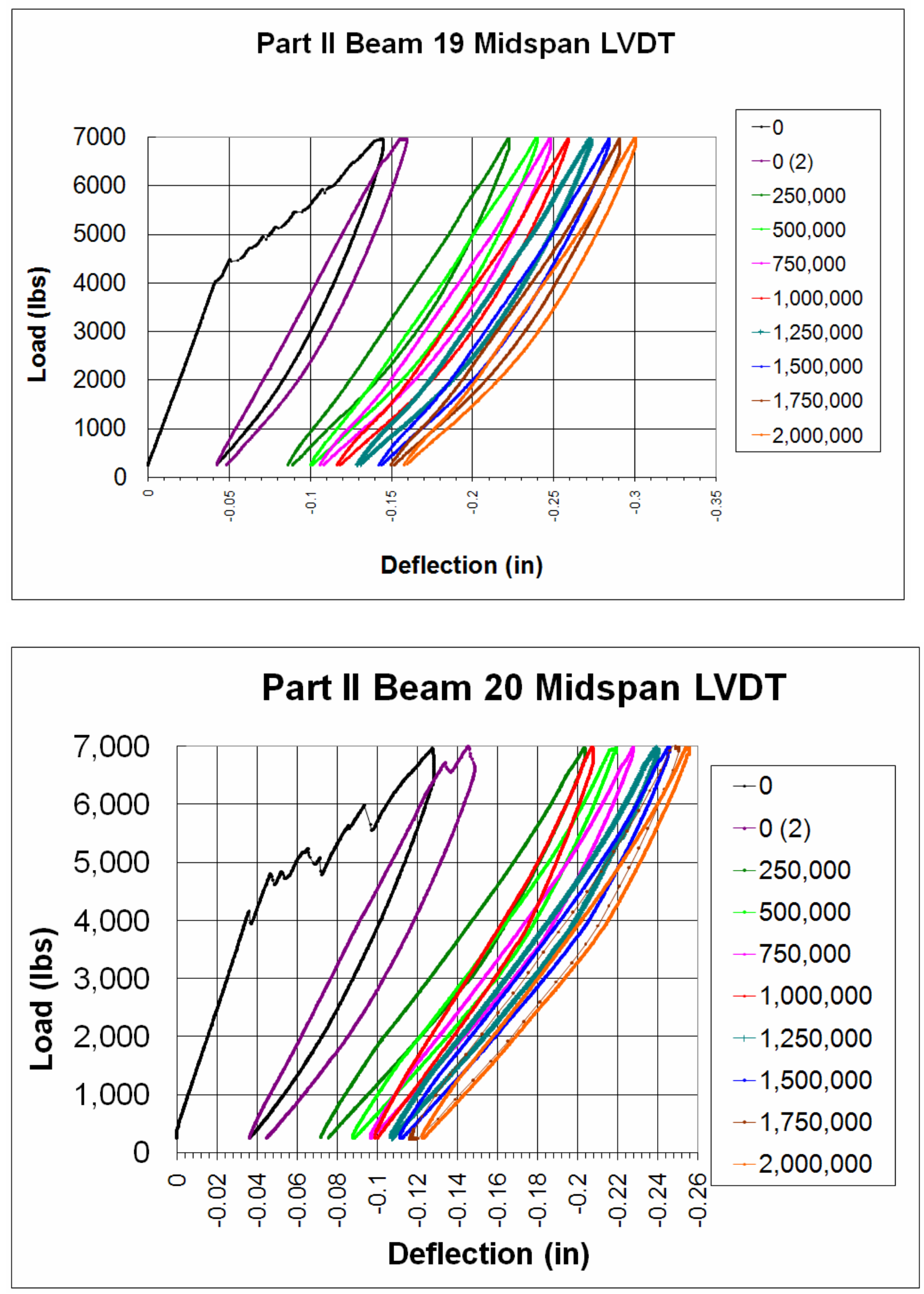


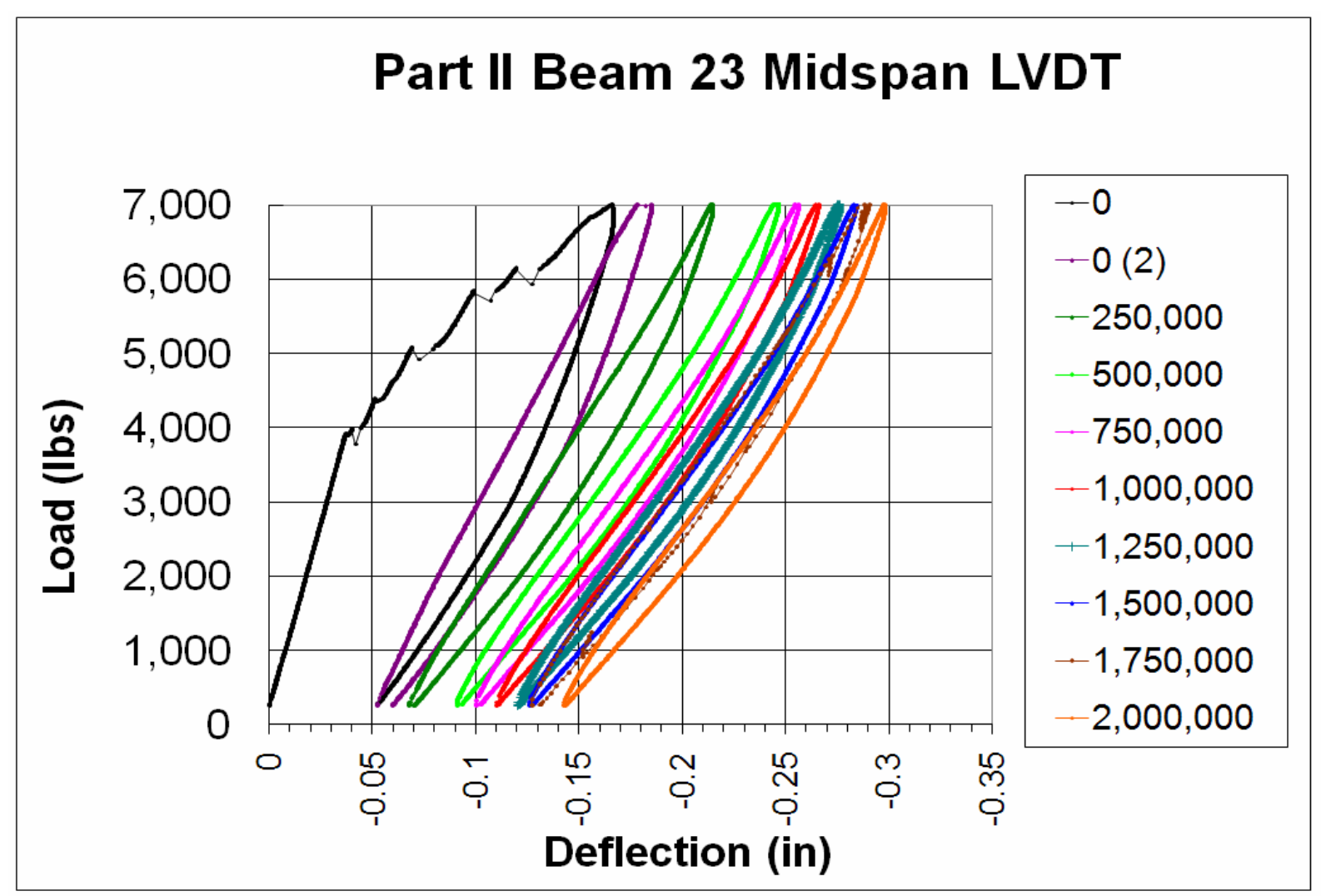




\section{F.2.2 Steel Strain}
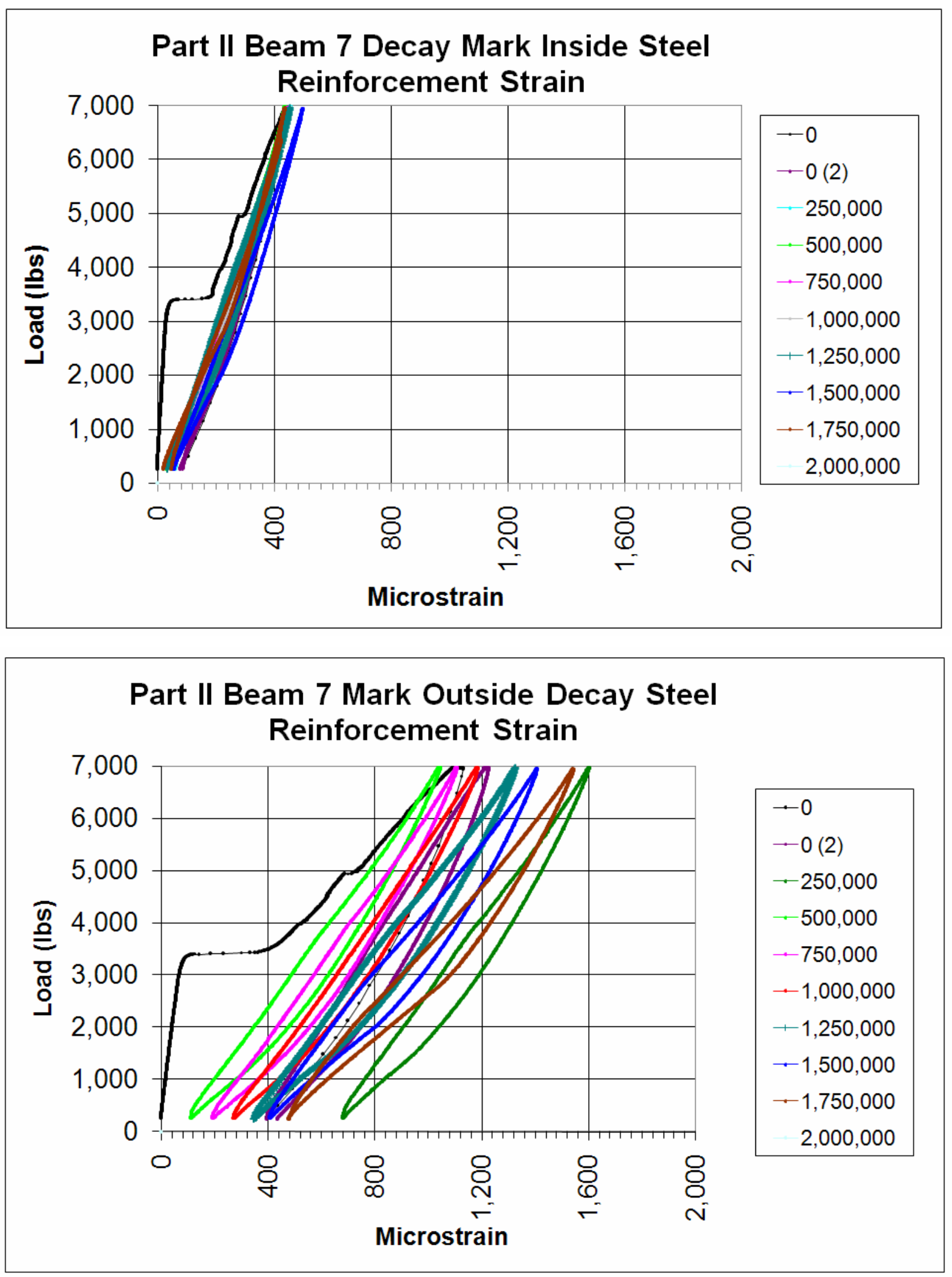

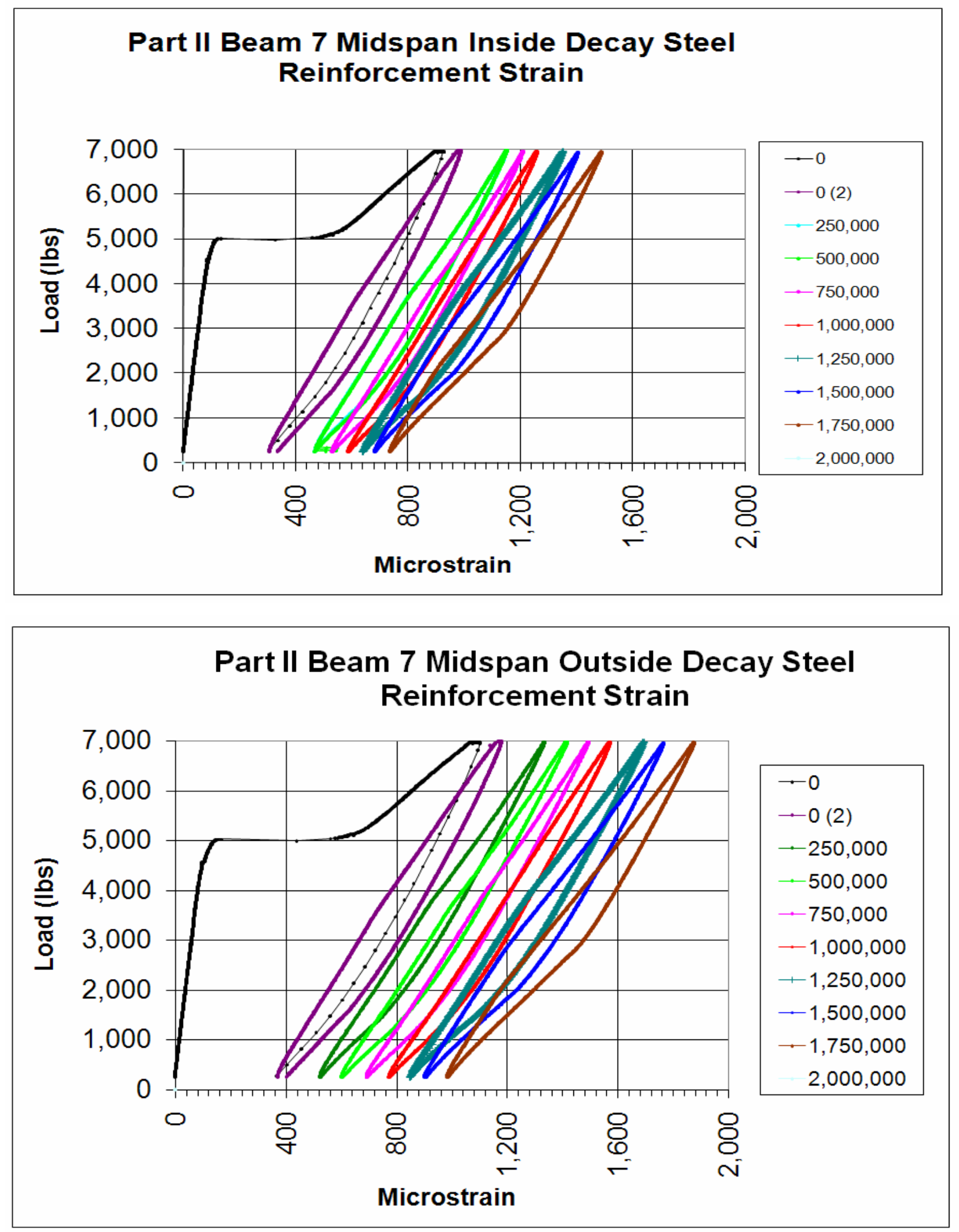

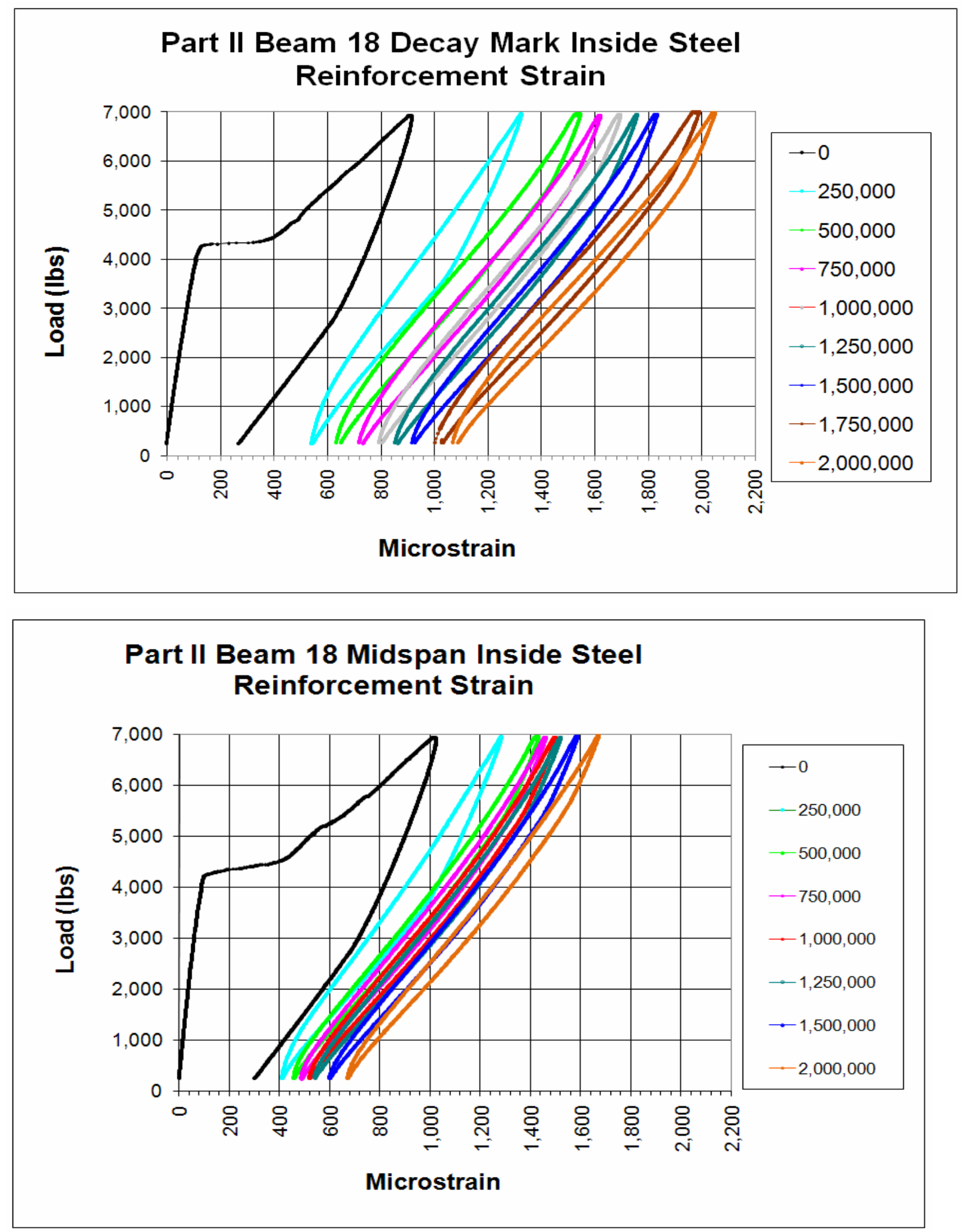

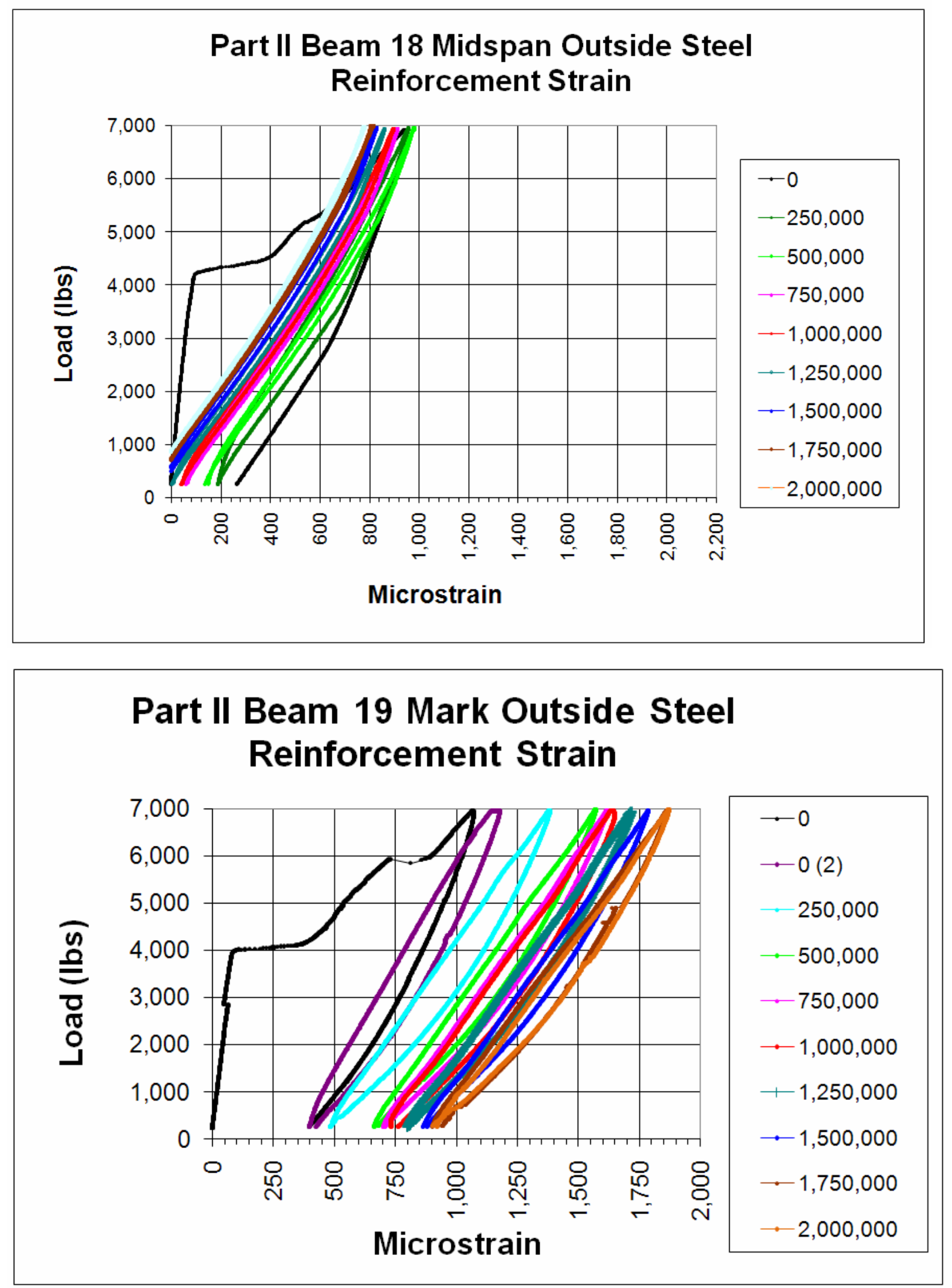

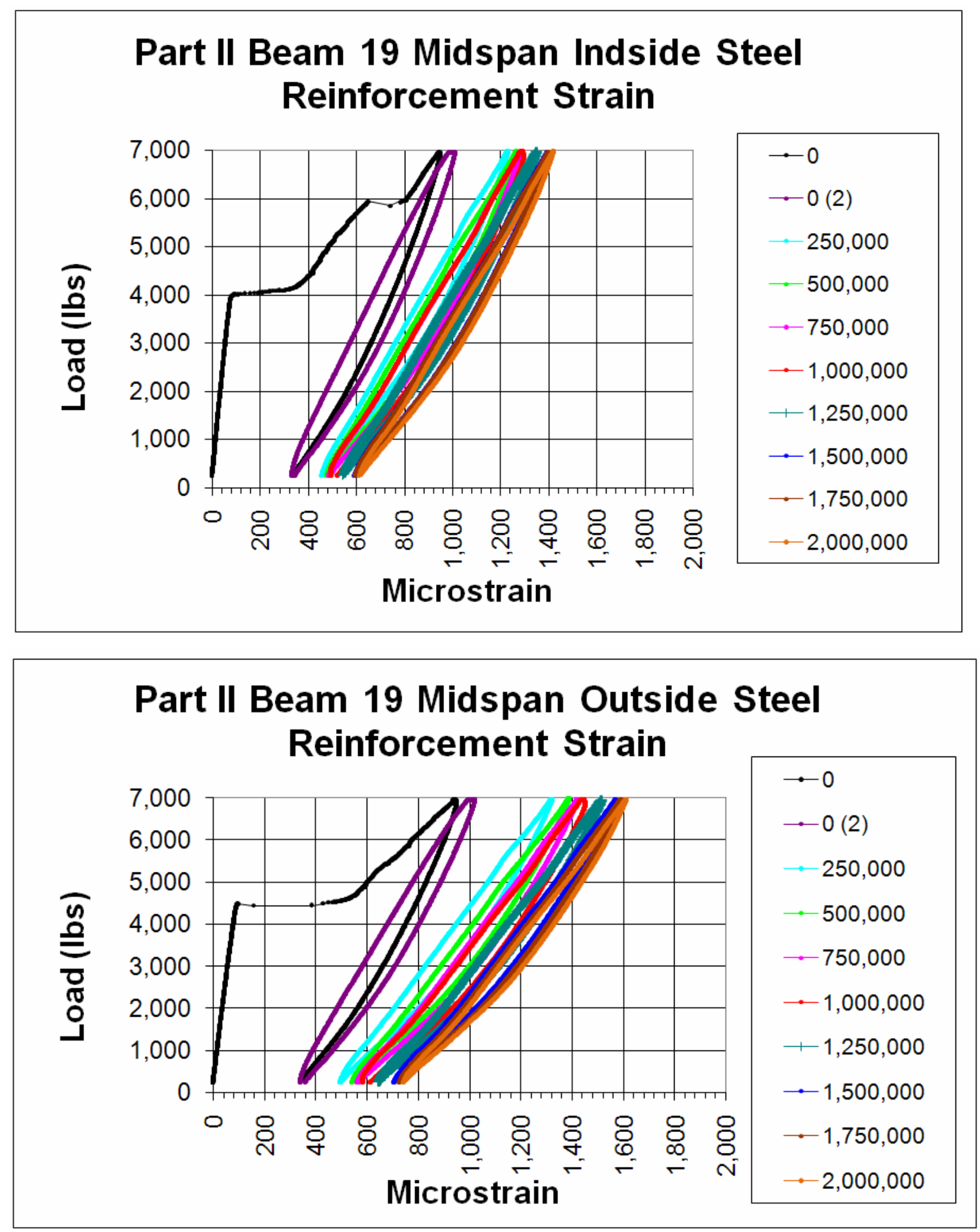


\section{F.2.3 FRP Strain}
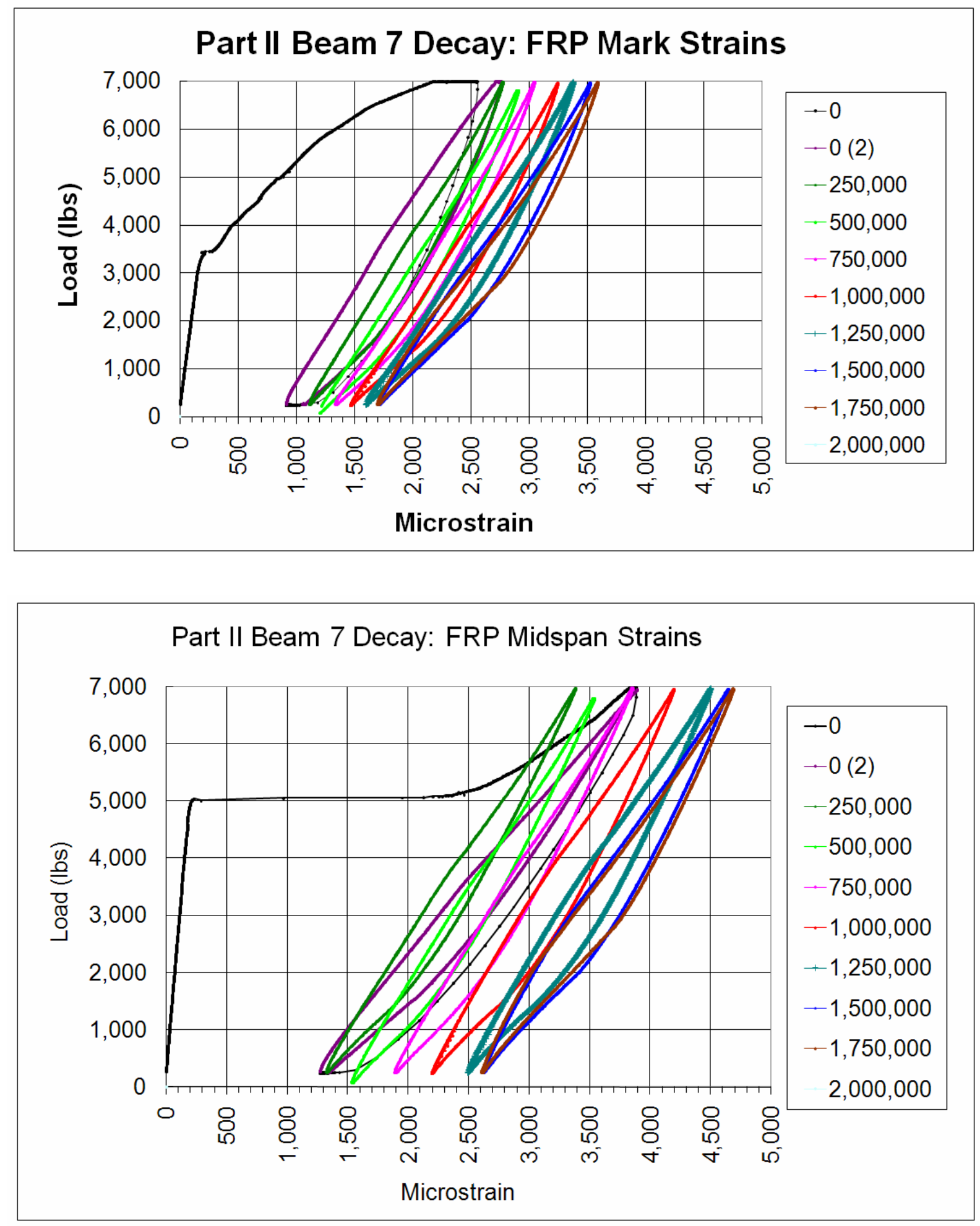

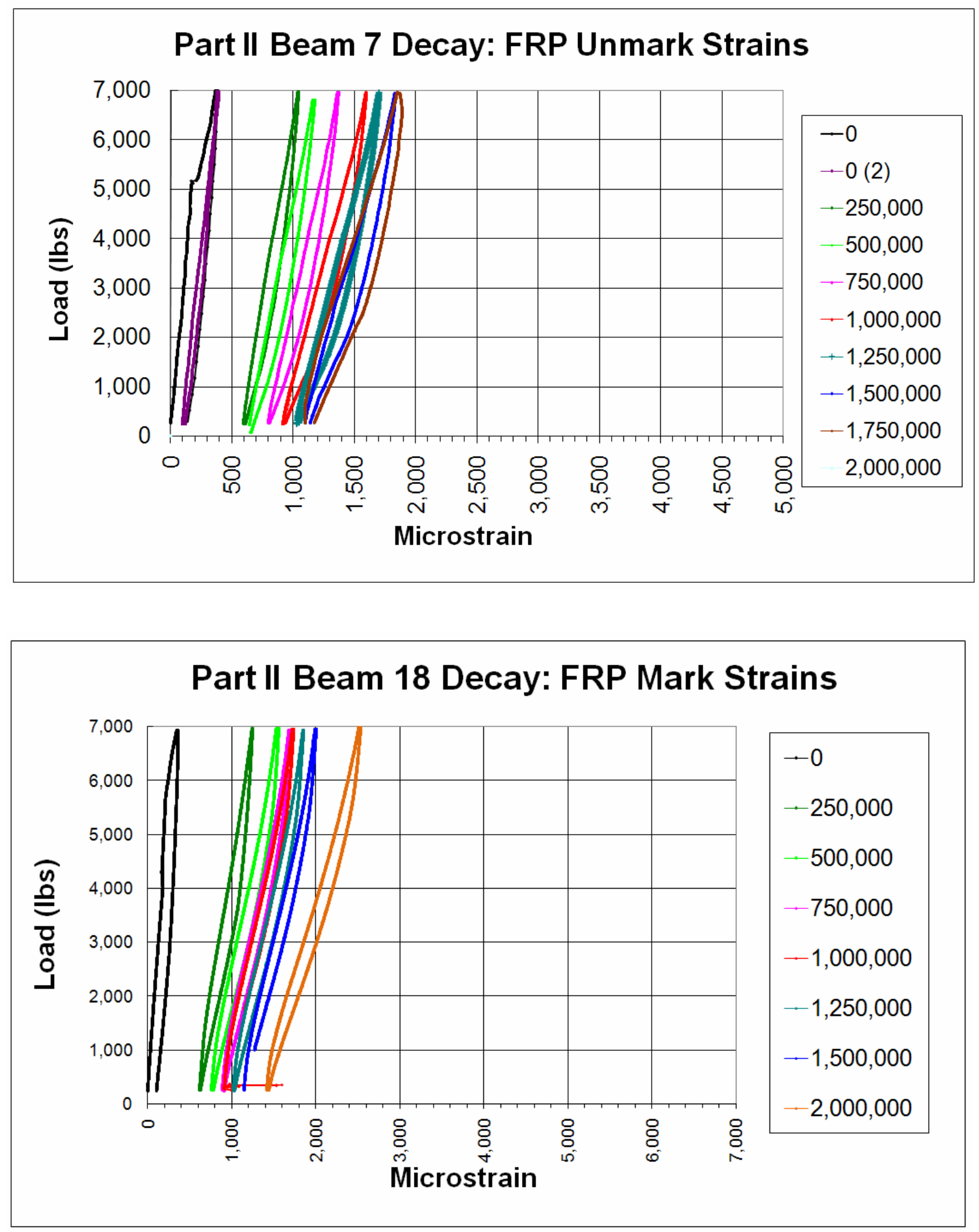


\section{Part II Beam 18 Decay: FRP Midspan Strains}

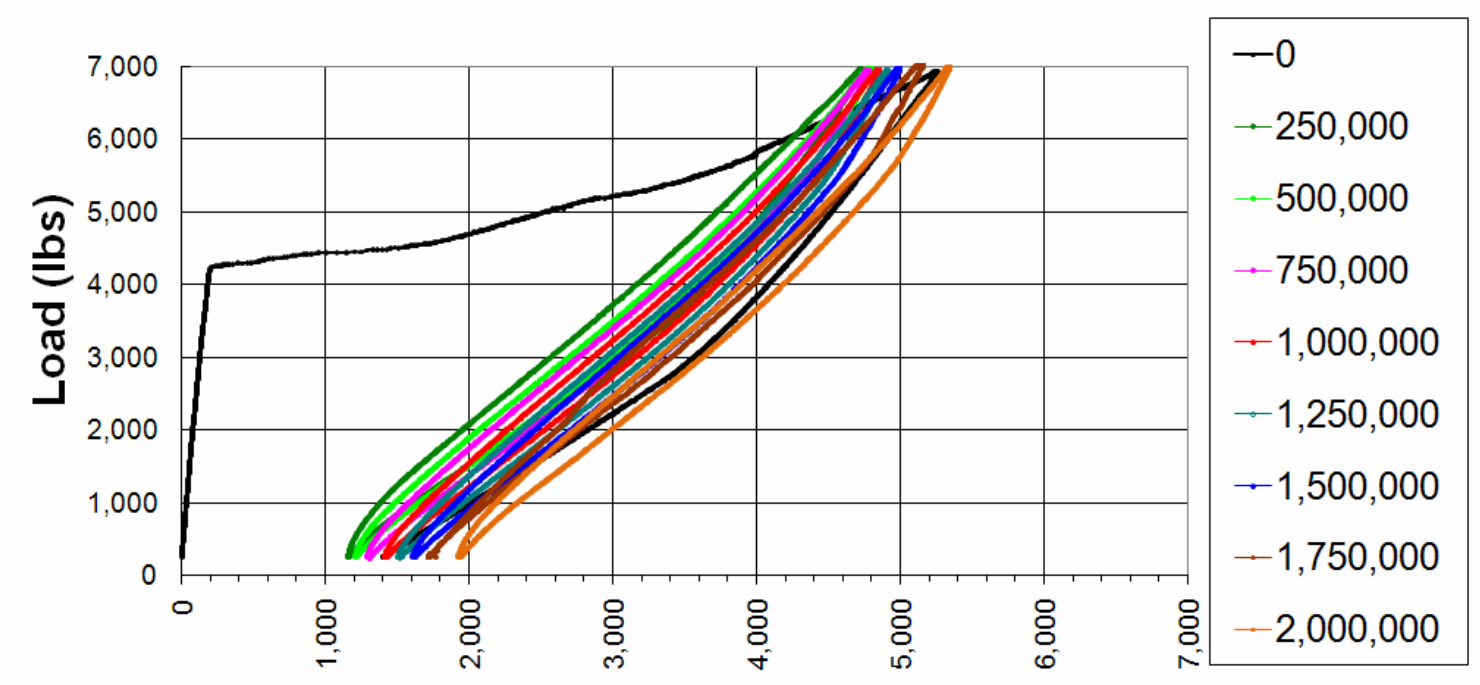

Microstrain

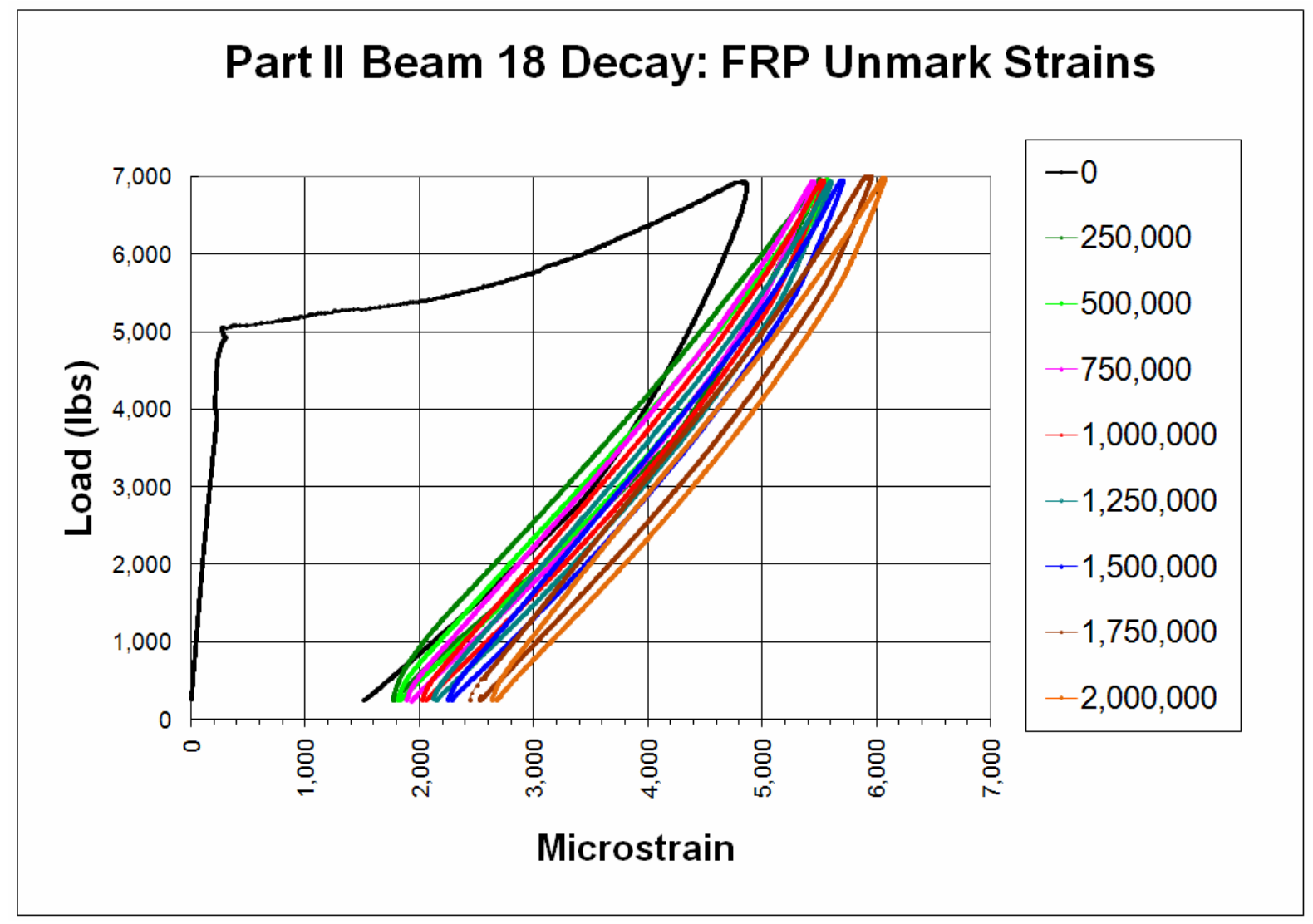



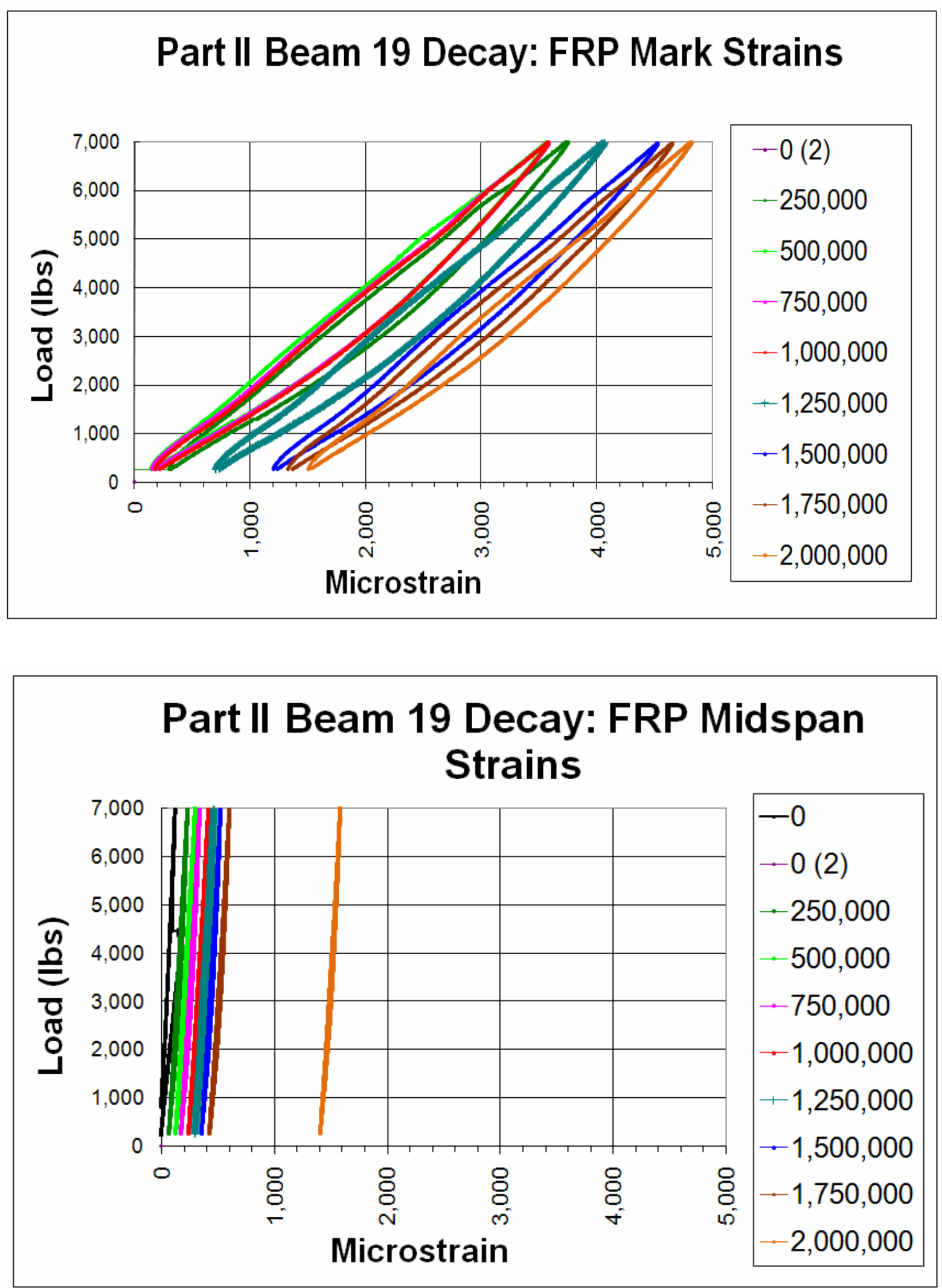


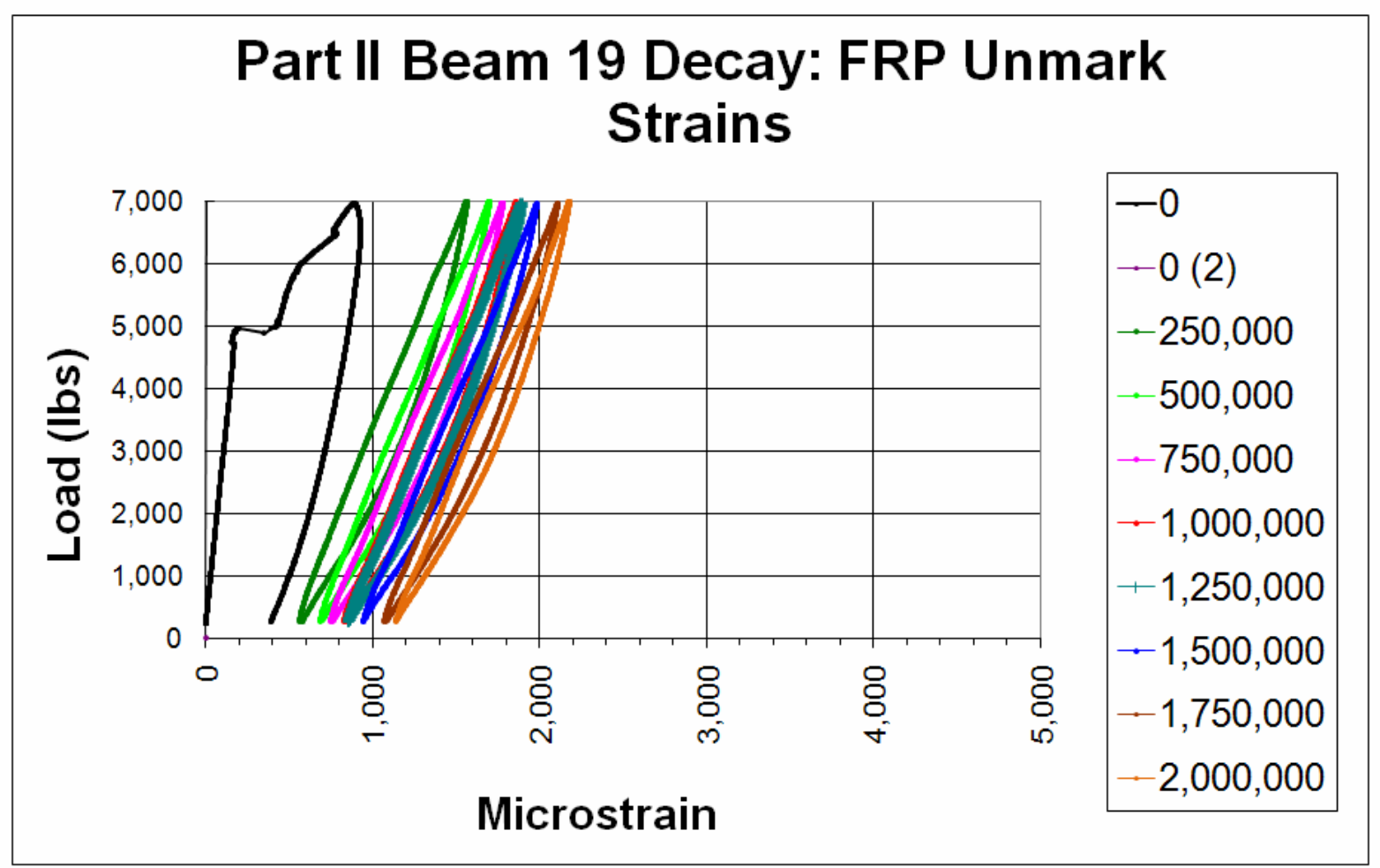




\section{F.2.4 Externally Bonded Concrete Strain}
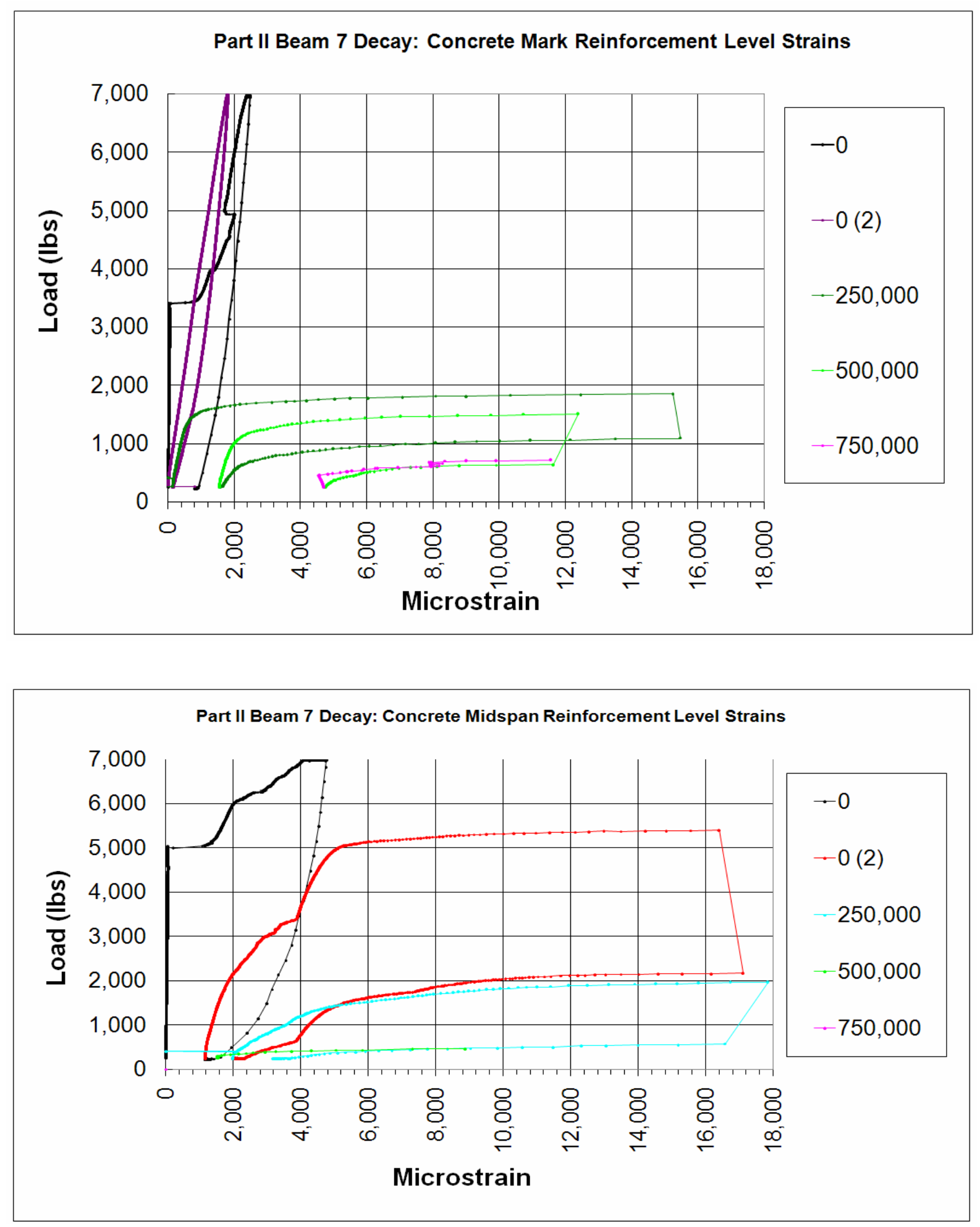

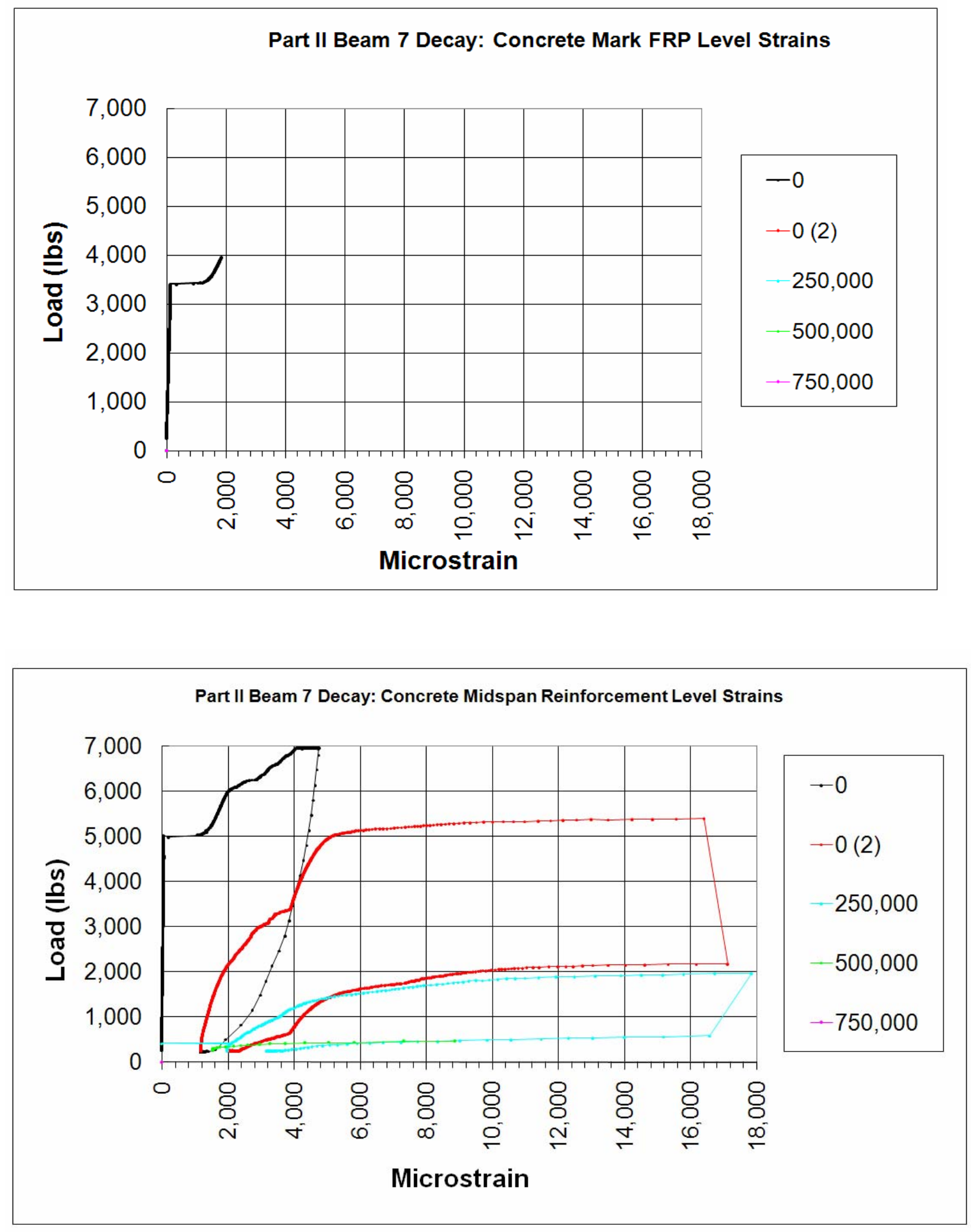


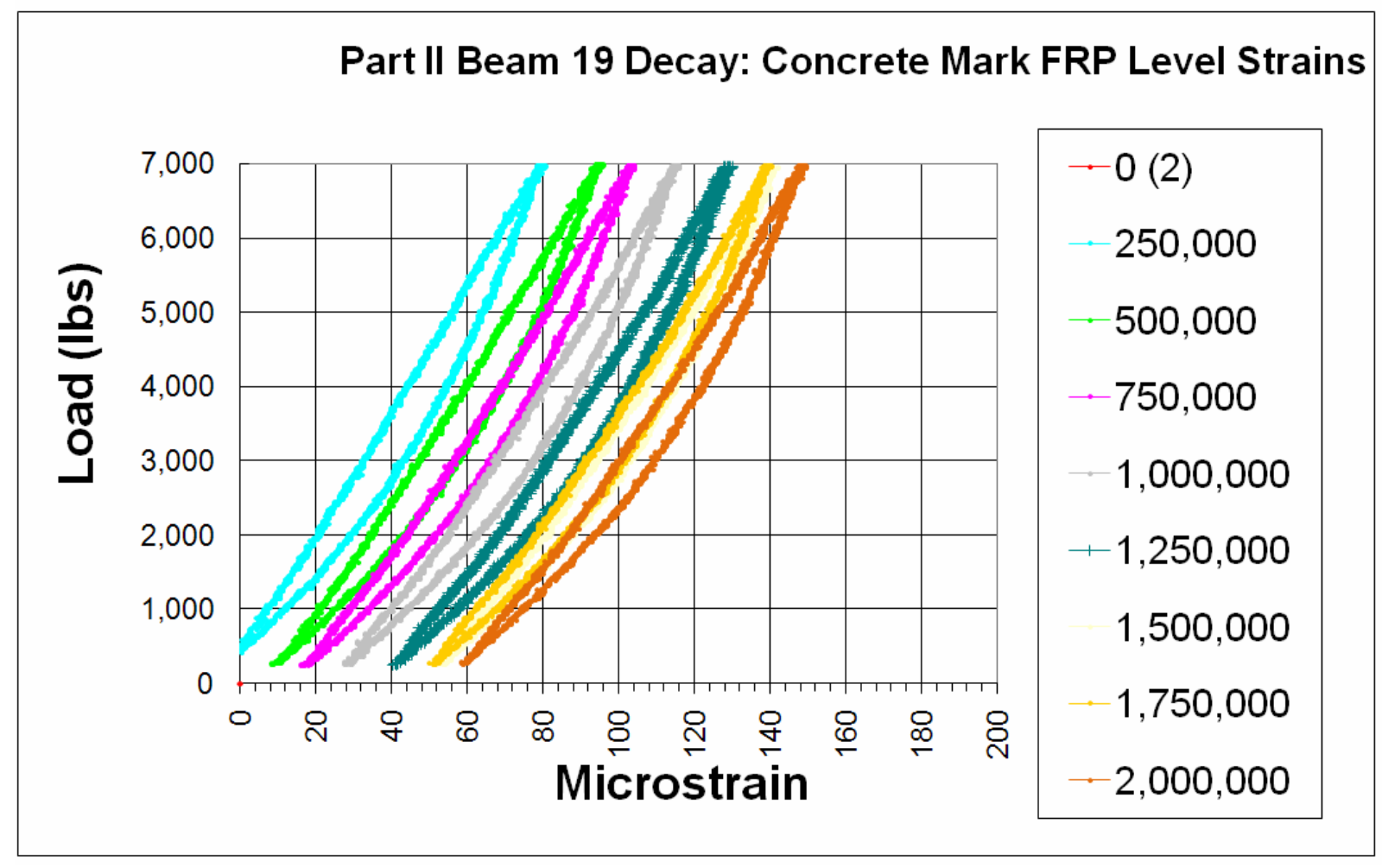




\section{F.2.5 Embedded Concrete Strain}
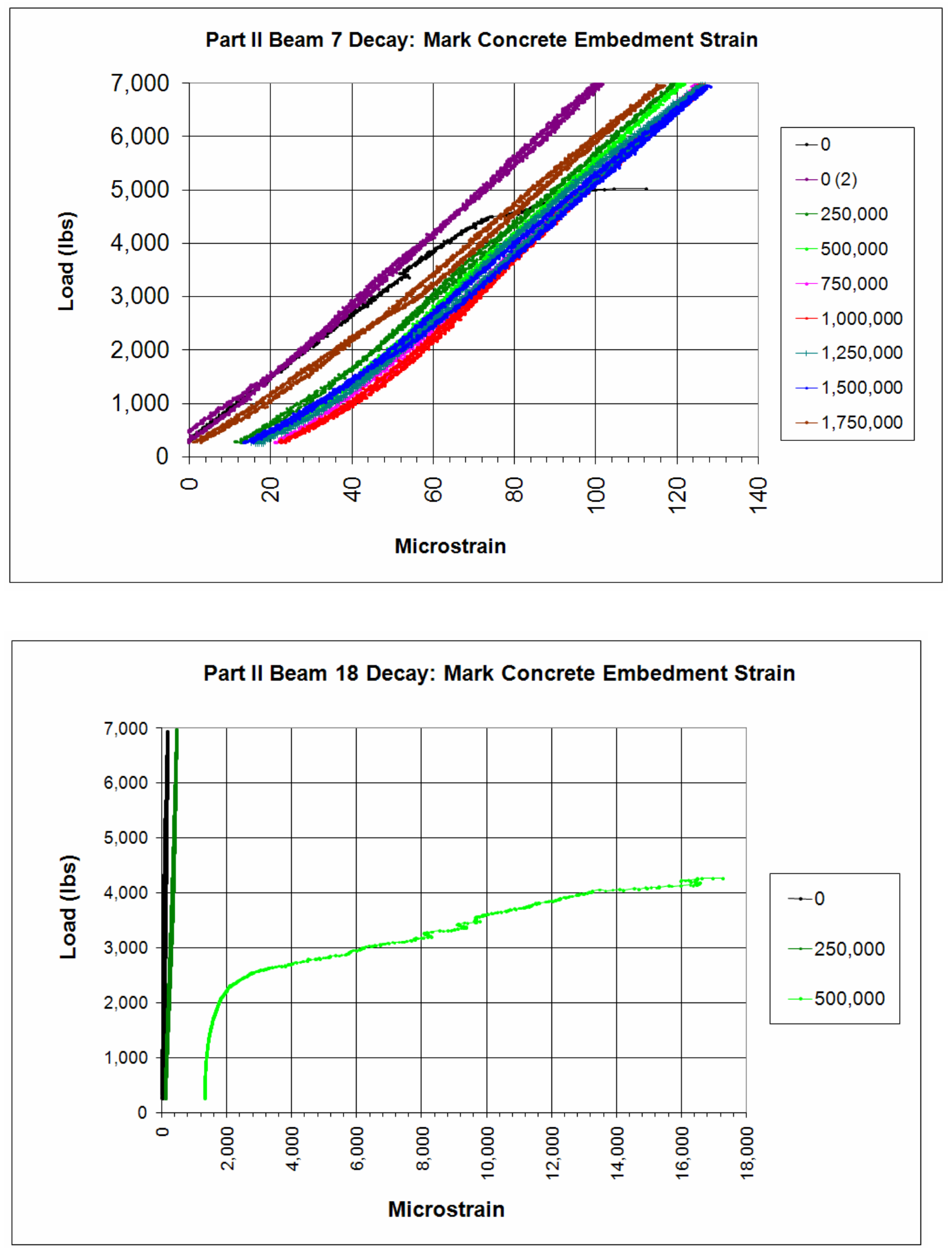


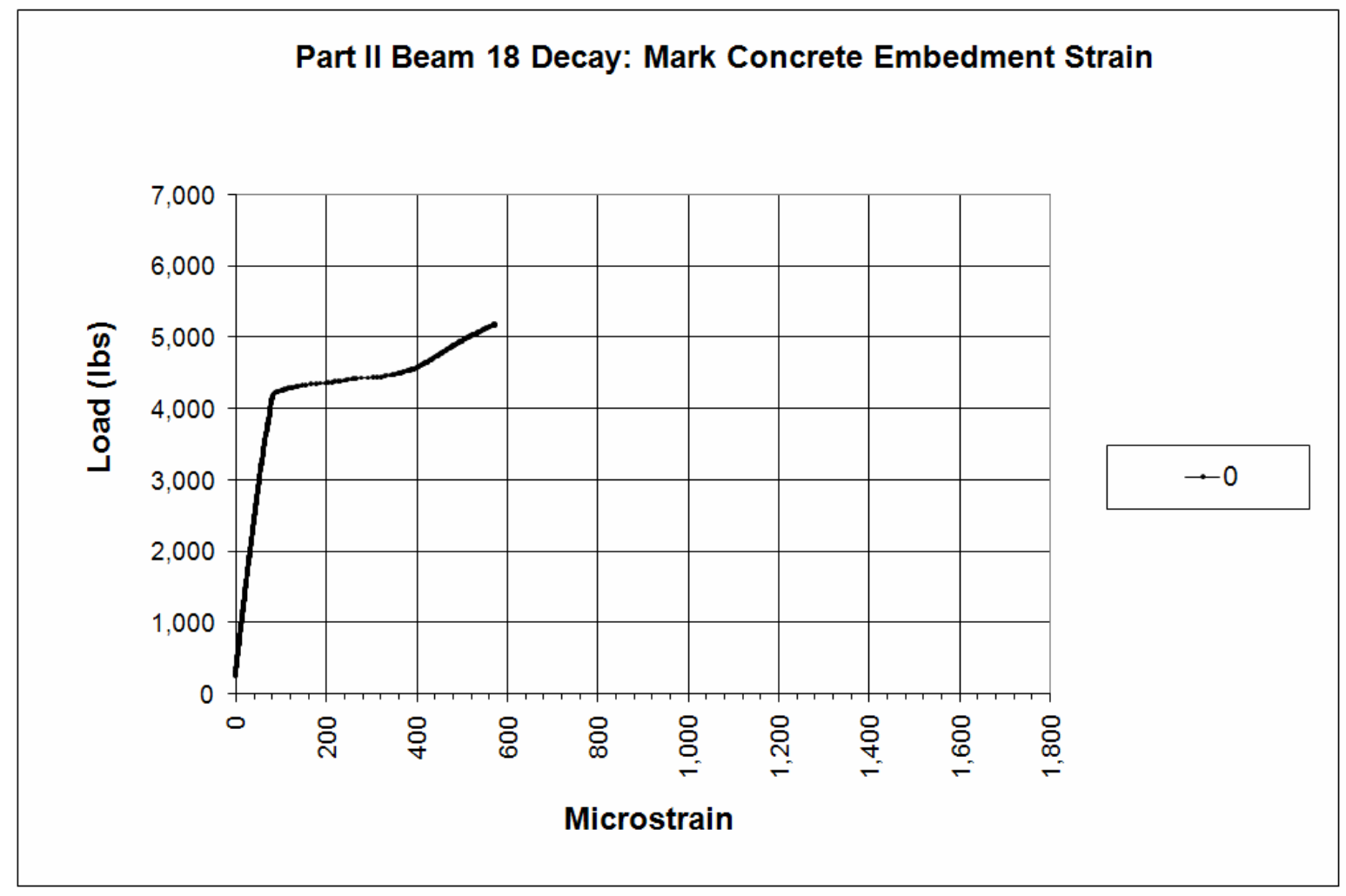




\section{F.2.6 Actual Stiffness}

Table F.1 Actual Stiffness at 250,000-Cycle Intervals

\begin{tabular}{|c|r|r|r|r|r|r|r|r|r|}
\hline & \multicolumn{9}{|c|}{ Number of Cylces (Millions) } \\
\hline Beam & 0 & 0.25 & 0.5 & 0.75 & 1 & 1.25 & 1.5 & 1.75 & 2 \\
\hline II-7 & 111,360 & 54,360 & 54,101 & 54,602 & 55,272 & 52,324 & 50,490 & 48,161 & 46,080 \\
\hline II-14 & 94,519 & 39,135 & 38,460 & 38,490 & 38,021 & 38,007 & 38,086 & 37,372 & 37,372 \\
\hline II-18 & 77,588 & 36,908 & 33,053 & 32,877 & 32,753 & 32,688 & 32,824 & 33,166 & 33,122 \\
\hline II-20 & 104,386 & 46,567 & 45,980 & 45,722 & 45,668 & 45,531 & 44,896 & 46,201 & 45524 \\
\hline II-19 & 91,119 & 49,145 & 48,185 & 47,143 & 47,275 & 46,971 & 47,090 & 47,550 & 47275 \\
\hline II-23 & 99,253 & 52,761 & 43,900 & 39,755 & 38,981 & 39,013 & 39,179 & 38,752 & 38,667 \\
\hline
\end{tabular}




\section{Appendix G: Materials and Technical Data Sheets}

\section{G.1 List of Materials}

Air-Entraining Admixture (Master Builders Technologies MB-VR Standard )

Aluminum Splice Connectors

Banana Plugs (Monster® Two Pair QuickLock ${ }^{\mathrm{TM}}$ )

Burlap Sheets

Carbon Steel Wire (0.014" Diameter, Zinc Galvanized)

Cement (Type I)

Coarse Aggregate (\#8 Limestone)

Epoxy (Tyfo S)

Epoxy All Purpose (Tyfo WS)

Epoxy Cement Bonding Agent / Corrosion Protection (Tyfo CB)

Epoxy Protective Coating (Fox Industries; FX-470)

CFRP Composite (Tyfo SCH-7UP)

Gage 12 Coated Solid Copper Wire

Hexamethane Tetramine (Fischer Scientific)

Hydrochloric Acid (Concentrated; Fischer Scientific)

Injection Epoxy (Sikadur 52 Advanced, Very-Low-Viscosity, Moisture-Tolerant Epoxy Injection Adhesive)

Lumber $(2 \mathrm{x} 4,1 / 2$ " Plywood)

Petroleum Jelly (CIP Lube)

Pin Punch (Dasco Pro 1/16" x 4-1/2" )

Polymer Patch Repair Concrete (SikaTop 111 PLUS Two-Component, Polymer-Modified, Cementitious, Screed Mortar Plus FerroGard 901 Penetrating Corrosion Inhibitor)

Sand

Standard 0.401" Shank Air-Powered Hammer

Steel Rebar (\#3, \#4, and \#5 bars)

Rebar Ground Clamps (Brass; 3/4" and 1/2" Diameter)

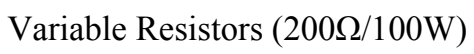

Water 


\section{G.2 Technical Specifications}

\section{G.2.1 Sikadur 52}

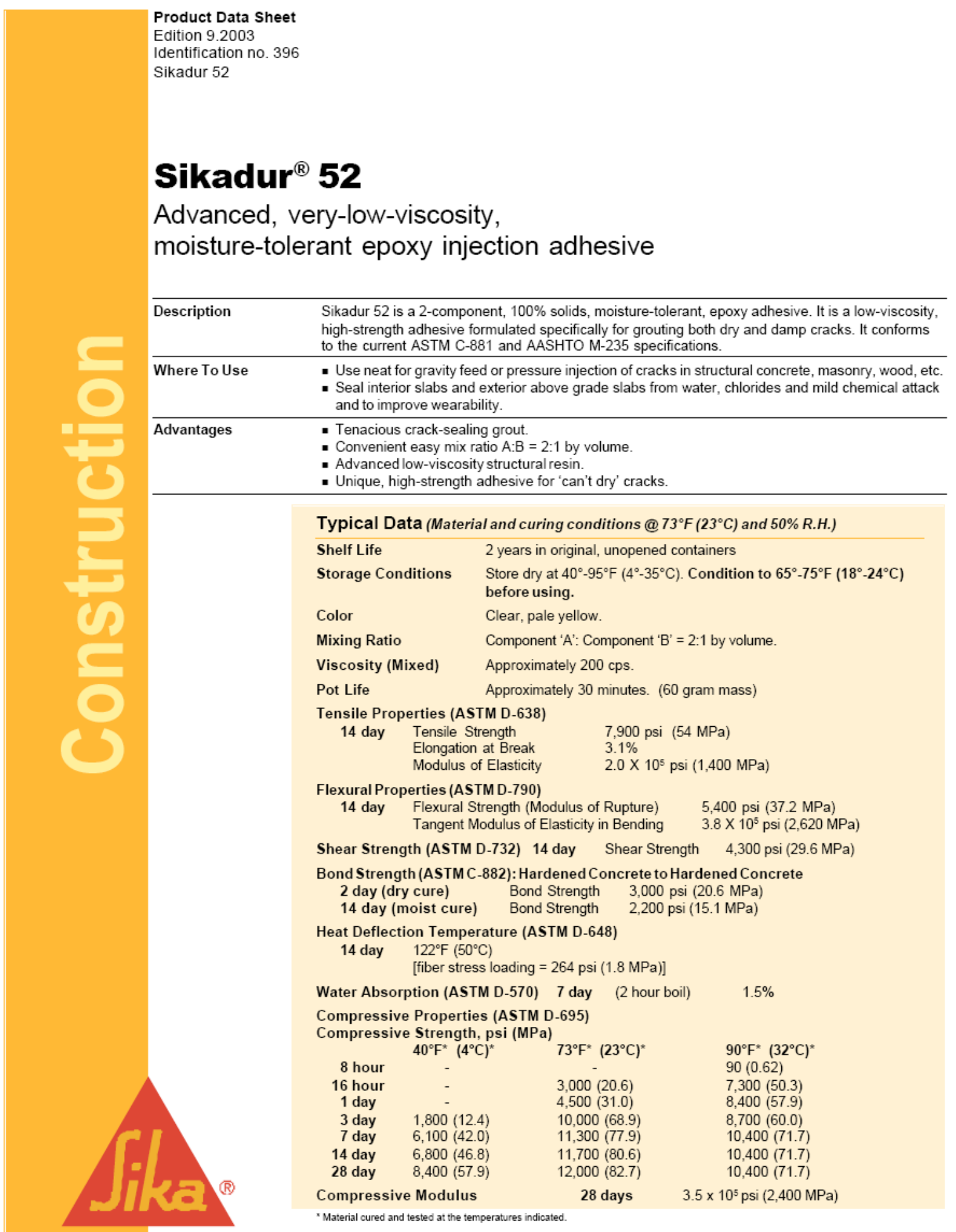




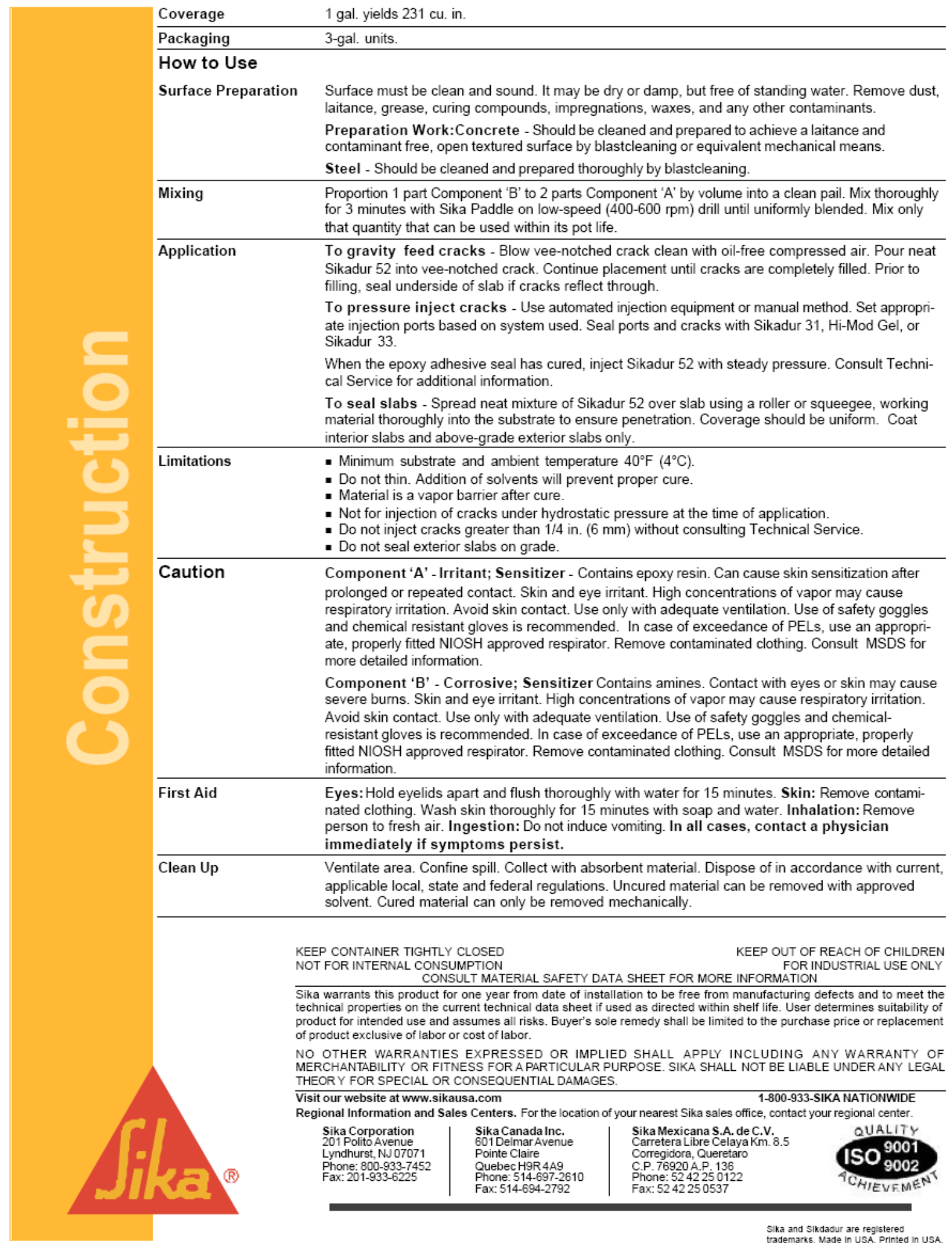




\section{DIVISION 3 - CONCRETE}

Section - 03930 Concrete Rehabilitation

\section{Part 1 - General}

1.01 Summary

A. This specification describes the grouting of cracks by gravity flow with an epoxy resin adhesive.

1.02 Quality Assurance

A. Manufacturing qualifications: The manufacturer of the specified product shall be ISO 9001/9002 certified and have in existence a recognized ongoing quality assurance program independently audited on a regular basis.

B. Contractor qualifications: Contractor shall be qualified in the field of concrete repair and protection with a successful track record of 5 years or more. Contractor shall maintain qualified personnel who have received product training by a manufacturer's representative

C. Install materials in accordance with all safety and weather conditions required by manufacturer or as modified by applicable rules and regulations of local, state and federal authorities having jurisdiction. Consult Material Safety Data Sheets for complete handling recommendations.

1.03 Delivery, Storage, and Handling

A. All materials must be delivered in original, unopened containers with the manufacturer's name, labels, product identification, and batch numbers. Damaged material must be removed from the site immediately.

B. Store all materials off the ground and protect from rain, freezing or excessive heat until ready for use.

C. Condition the specified product as recommended by the manufacturer.

1.04 Job Conditions

A. Environmental Conditions: Do not apply material if it is raining or snowing or if such conditions appear to be imminent. Minimum application temperature $40^{\circ} \mathrm{F}\left(5^{\circ} \mathrm{C}\right)$ and rising.

B. Protection: Precautions should be taken to avoid damage to any surface near the work zone due to mixing and handling of the specified material.

1.05 Submittals

A. Submit two copies of manufacturer's literature, to include: Product Data Sheets, and appropriate Material Safety Data Sheets (MSDS).

1.06 Warranty

A. Provide a written warranty from the manufacturer against defects of materials for a period of five (5) years, beginning with date of substantial completion of the project. 


\section{Part 2 - Products}

\subsection{Manufacturer}

A. Sikadur 52, as manufactured by Sika Corporation, is considered to conform to the requirements of this specification. 2.02 Materials

A. Epoxy resin adhesive binder:

1. Component "A" shall be a modified epoxy resin of the diglycidiether bisphenol A Type containing suitable viscosity control agents. It shall not contain butyl glycidyl ether.

2. Component "B: shall be primarily a reaction product of a selected amine blend with an epoxy resin of the diglycidiether bisphenol A Type containing suitable viscosity control agents, pigments, and accelerators.

3. The ratio of Component " $A$ ": Component " $B$ " shall be $2: 1$ by volume.

\subsection{Performance Criteria}

A. Typical Properties of the mixed epoxy resin adhesive binder:

1. Pot life: $25-30$ minutes

2. Tack-free time to touch (3-5 mil thickness at $73 \mathrm{~F}): 5-7$ hours

4. Color: clear, pale yellow

B. Typical Properties of the mixed neat cured epoxy resin adhesive binder:

1. Compressive Properties (ASTM D-695) at 28 days

a. Compressive Strength: $12,000 \mathrm{psi} \min (82.7 \mathrm{MPa})$

b. Modulus of Elasticity: 350,000 psi (1,379.3 MPa)

2. Tensile Properties: (ASTM D-638) at 14 days

a. Tensile Strength: 7,900 psi min (54 MPa)

b. Elongation at Break: $3.1 \%$

c. Modulus of Elasticity: 200,000 psi (2551.7 MPa)

3. Flexural Properties: (ASTM D-790) at 14 days

a. Flexural Strength (Modulus of Rupture): 5,400 psi min (37.2 MPa)

b. Tangent Modulus of Elasticity in Bending: 380,000 psi (2,620.6 MPa)

4. Shear Strength (ASTM D-732) at 14 days: $4300 \mathrm{psi} \min (29.6 \mathrm{MPa})$

5. Total water absorption (ASTM D-570) at 7 days: $1.5 \%$ (2 hour boil)

6. Bond Strength (ASTM C-882) Hardened Concrete to Hardened Concrete

a. 2 days (dry cure): $\quad 3000 \mathrm{psi} \min (20.6 \mathrm{MPa})$

b. 14 days (moist cure): $2200 \mathrm{psi} \min (15.1 \mathrm{MPa}$ )

7. Deflection Temperature (ASTM D-648) at 14 days: $124 \mathrm{~F}$ min. (fiber stress loading $=264 \mathrm{psi}$ )

Note: Tests above were performed with the material and curing conditions @ $71^{\circ} \mathrm{F}-75^{\circ} \mathrm{F}$ and $45-55 \%$ relative humidity. 


\section{Part 3 - Execution}

\subsection{Surface Preparation}

A. Vee notch the surface of the crack with mechanical router or hand chipping tool to a maximum width of $1 / 4$ ". Remove loose debris. The substrate may be dry or damp prior to product application. Where accessibilty to the underside of the slab is available, seal all visible cracks with an epoxy resin adhesive paste or portland cement-based quicksetting compound to act as a dam to hold the liquid epoxy resin adhesive until cured.

3.02 Mixing and Application

A. Mixing the epoxy resin adhesive binder: Premix each component. Proportion 2 parts by volume of Component "A" and 1 part of Component " $\mathrm{B}$ " by volume into a clean, dry mixing pail. Mix thoroughly for 3 minutes min. with a jiffy paddle on a low-speed (400-600 rpm) drill. Mix only that quantity of material that can be used within its pot life (20-30 minutes at $73 \mathrm{~F}$ ).

B. Placement Procedures: Place the mixed epoxy resin adhesive into the vee-notch crack. Replenish the reservoir with the mixed epoxy resin adhesive until the crack has been completely filled.

B. If penetration of any crack is impossible, consult the Engineer before discontinuing the procedure. If modification of proposed procedure is required to fill the crack, submit modification in writing to the Engineer for acceptance prior to proceeding.

C. Adhere to all limitations and cautions for the epoxy resin adhesive binder in the manufacturers current printed literature.

\subsection{Cleaning}

A. The uncured epoxy resin adhesive can be cleaned from tools with an approved solvent. The cured epoxy resin adhesive can only be removed mechanically.

B. Leave finished work and work area in a neat, clean condition without evidence of spillovers onto adjacent areas. 


\section{SC-005 Sikadur 52 \\ Crack Filler (Horizontal)}

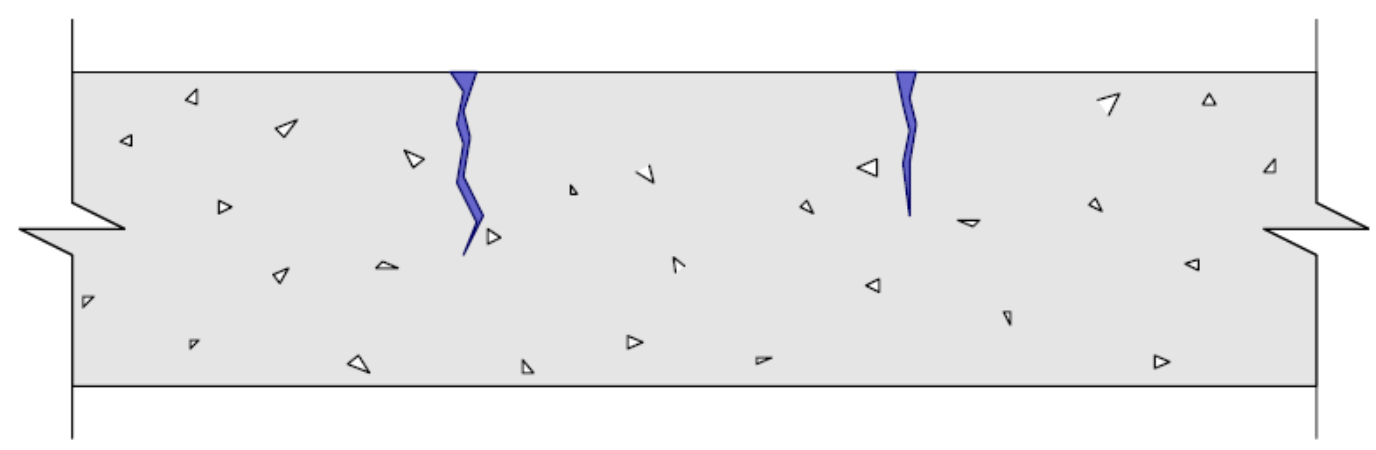

1. Pour neat Sikadur 52 epoxy resin adhesive into vee-notched cracks.

2. Continue placement until cracks are completely filled.

Note: Prior to filling, seal underside of slab if cracks reflect through. 


\section{G.2.2 SikaTop 111 Plus}

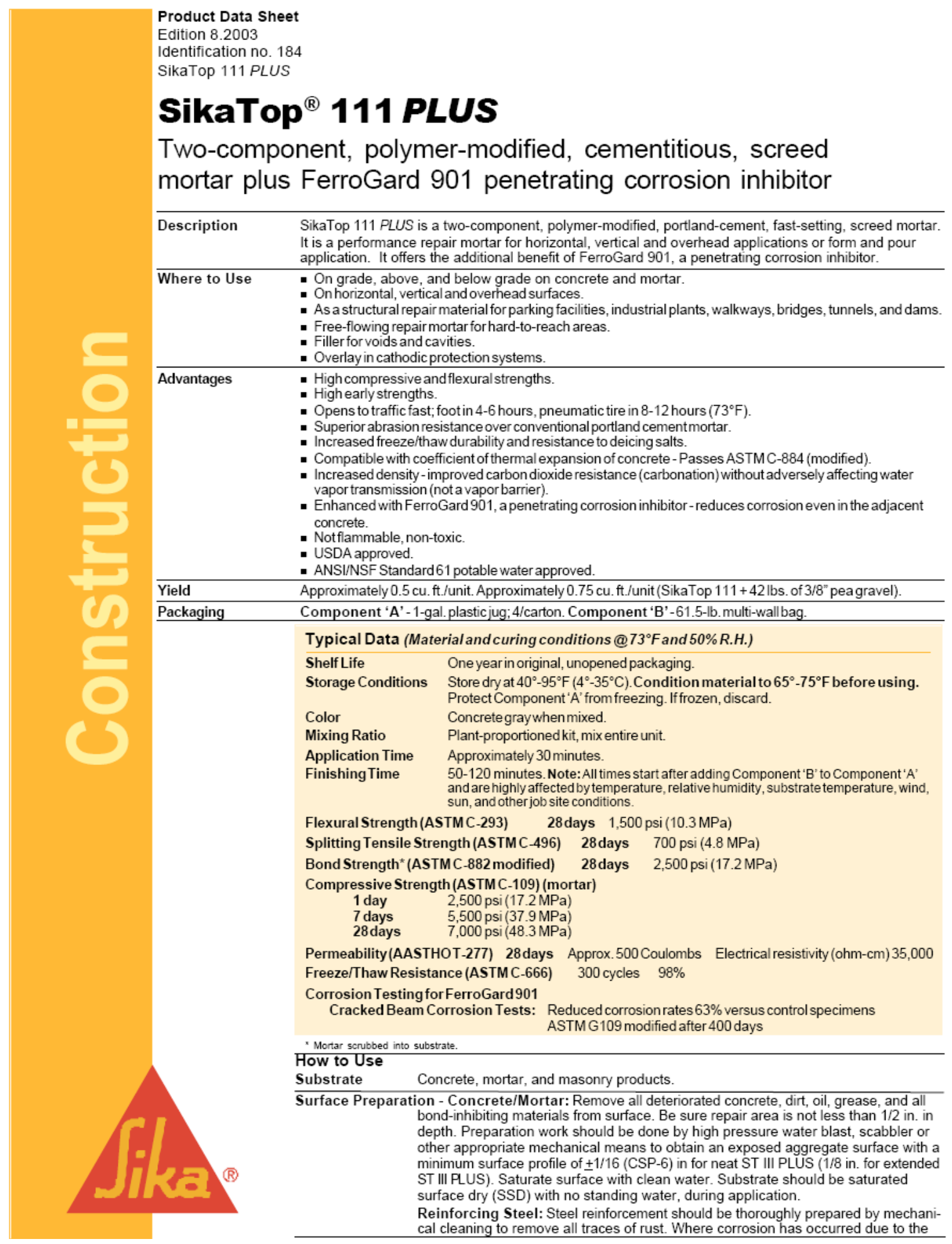




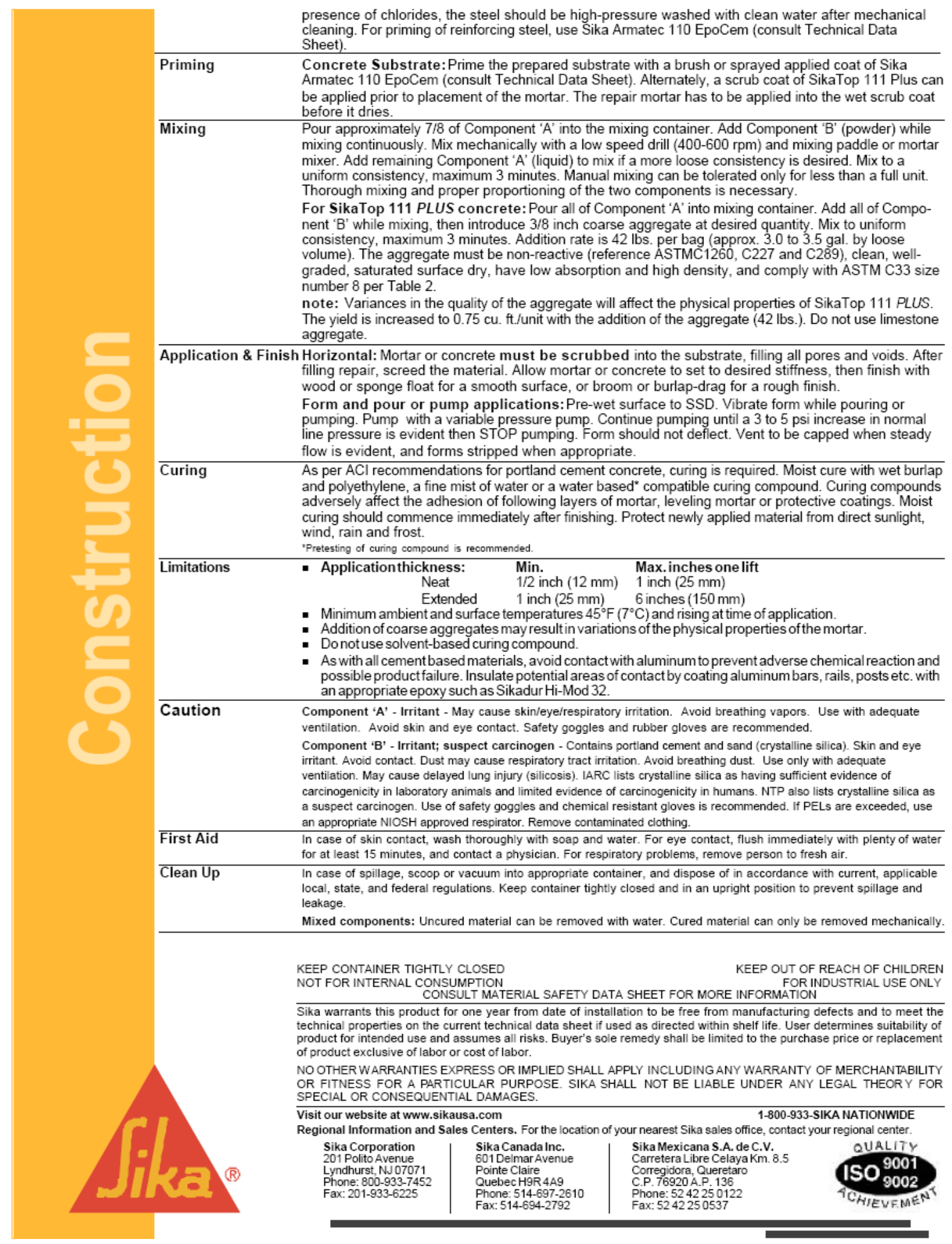




\section{DIVISION 3 - CONCRETE \\ Section - 03550 Concrete Toppings \\ 03720 Concrete Resurfacing \\ 03730 Concrete Rehabilitation}

\section{Part 1 - General}

1.01 Summary

A. This specification describes the patching or overlay of interior and/or exterior horizontal surfaces with a polymermodified, portland cement mortar/concrete.

1.02 Quality Assurance

A. Manufacturing qualifications: The manufacturer of the specified product shall be ISO 9001 certified and have in existence a recognized ongoing quality assurance program independently audited on a regular basis.

B. Contractor qualifications: Contractor shall be qualified in the field of concrete repair and protection with a successfu. track record of 5 years or more. Contractor shall maintain qualified personnel who have received product training by a manufacturer's representative.

C. Install materials in accordance with all safety and weather conditions required by manufacturer or as modified by applicable rules and regulations of local, state and federal authorities having jurisdiction. Consult Material Safety Data Sheets for complete handling recommendations.

1.03 Delivery, Storage, and Handling

A. All materials must be delivered in original, unopened containers with the manufacturer's name, labels, product identification, and batch numbers. Damaged material must be removed from the site immediately.

B. Store all materials off the ground and protect from rain, freezing or excessive heat until ready for use

C. Condition the specified product as recommended by the manufacturer.

1.04 Job Conditions

A. Environmental Conditions: Do not apply material if it is raining or snowing or if such conditions appear to be imminent. Minimum application temperature $45^{\circ} \mathrm{F}\left(7^{\circ} \mathrm{C}\right)$ and rising.

B. Protection: Precautions should be taken to avoid damage to any surface near the work zone due to mixing and handling of the specified material.

1.05 Submittals

A. Submit two copies of manufacturer's literature, to include: Product Data Sheets, and appropriate Material Safety Data Sheets (MSDS).

1.06 Warranty

A. Provide a written warranty from the manufacturer against defects of materials for a period of five (5) years, beginning with date of substantial completion of the project. 


\section{Part 2 - Products}

\subsection{Manufacturer}

A. SikaTop 111 Plus, as manufactured by Sika Corporation, is considered to conform to the requirements of this specification.

\subsection{Materials}

A. Polymer-modified Portland cement mortar:

1. Component $\mathrm{A}$ shall be a liquid polymer emulsion of an acrylic copolymer base and additives

$$
\begin{aligned}
& \text { a. pH: } 4.5-6.5 \\
& \text { b. Film Forming Temperature: } 73^{\circ} \mathrm{F} \text { max } \\
& \text { c. Tear Strength: } 950 \text {-psi min. } \\
& \text { d. Elongation at Break: } 500 \% \text { min. } \\
& \text { e. Particle Size: less than } 0.1 \text { micron }
\end{aligned}
$$

2. Component $A$ shall contain an organic, penetrating corrosion inhibitor which has been independently proven to reduce corrosion in concrete via ASTM G3 (half-cell potential tests). The corrosion inhibitor shall not be calcium nitrite, and shall have a minimum of 5 years of independent field testing to document performance on actual construction projects.

3. Component $B$ shall be a blend of selected portland cements, specially graded aggregates, admixtures for controlling setting time, water reducers for workability, and an organic accelerator.

4. The materials shall be non-combustible, both before and after cure

5. The materials shall be supplied in a factory-proportioned unit

6. The polymer-modified, portland cement mortar must be placeable from 1/2-in. to 1 -in. in depth per lift for horizontal applications.

B. To prepare a polymer-modified portland cement concrete: aggregate shall conform to ASTM C-33. The factoryproportioned unit shall be extended with $42-1 \mathrm{lb}$. max. of a $3 / 8$ in. (No.8 distribution per ASTM C-33, Table II) clean, well-graded, saturated surface dry aggregate, having low absorption and high density. Aggregate must be approved for use by the engineer.

\subsection{Performance Criteria}

A. Typical Properties of the mixed polymer-modified, portland cement mortar:

1. Working Time: Approximately 30 minutes

2. Finishing Time: $50-120$ minutes

3. Color: concrete gray

B. Typical Properties of the cured polymer-modified, portland cement mortar:

1. Compressive Strength (ASTM C-109 Modified)

a. 1 day: $2500 \mathrm{psi} \min .(17.2 \mathrm{MPa})$

b. 7 day: $5500 \mathrm{psi} \min . \quad(37.9 \mathrm{MPa})$

c. 28 day: 7000 psi min. $\quad(48.3 \mathrm{MPa})$

2. Flexural Strength (ASTM C-293) @ 28 days: 1500 psi (10.3 MPa)

3. Splitting Tensile Strength (ASTM C-496) @ 28 days 700 psi (4.8 MPa)

4. Bond Strength (ASTM C-882 Modified) @ 28 days: 2500 psi (17.2 MPa)

5. The portland cement mortar shall not produce a vapor barrier.

6. Density(wet mix): $136 \mathrm{lbs} / \mathrm{cu}$. ft. $(2.18 \mathrm{~kg} / 1)$

7. Permeability (AASHTO T-277 @ 28 days Approximately 500 Coulombs)

Note: Tests above were performed with the material and curing conditions @ $71^{0} \mathrm{~F}-75^{\circ} \mathrm{F}$ and $45-55 \%$ relative humidity. 


\section{Part 3 - Execution}

\subsection{Surface Preparation}

A. Areas to be repaired must be clean, sound, and free of contaminants. All loose and deteriorated concrete shall be removed by mechanical means. Mechanically prepare the concrete substrate to obtain a surface profile of $+/-1 / 16$ " (CSP 5 or greater as per ICRI Guidelines) with a new exposed aggregate surface. Area to be patched shall not be less than $1 / 2$ " in depth.

B. Where reinforcing steel with active corrosion is encountered, sandblast the steel to a white metal finish to remove all contaminants and rust. Where corrosion has occurred due to the presence of chlorides, the steel shall be high pressure washed after mechanical cleaning. Prime steel with 2 coats of Sika Armatec 110 EpoCem as directed by manufacturer. (See Spec Component SC-201-0699)

\subsection{Mixing and Application}

A. Mechanically mix in appropriate sized mortar mixer or with a Sika jiffy paddle and low speed (400-600 $\mathrm{rpm})$ drill. Pour approximately $4 / 5$ gal Component $\mathrm{A}$ into the mixing container. Add Component $\mathrm{B}$ while continuing to mix. Mix to a uniform consistency for a maximum of three minutes. Add remaining Component $A$ to mix if a more loose consistency is desired. Should smaller quantities be needed, be sure the components are measured in the correct ratio and that the Component B is uniformly blended before mixing the components together. Mix only that amount of material that can be placed in 30 minutes. Do not retemper material.

B. Mixing of the polymer-modified portland cement concrete: Pour all (1-gal) of Component A into the mixing container. Add Component B while continuing to mix. Add correct amount of the pre-approved coarse aggregate, and continue mixing to a uniform consistency. Mixing time should be 3 minutes maximum.

C. Placement Procedure: At the time of application, the substrate should be saturated surface dry with no standing water. Mortar and/or concrete must be scrubbed into substrate filling all pores and voids. While the scrub coat is still wet, force material against edge of repair, working toward center. If repair area is too large to fill while scrub coat is still wet use Sika Armatec 110 EpoCem in lieu of scrub coat (See Spec Component SC-200). After filling, consolidate, then screed. Allow mortar or concrete to set to desired stiffness, then finish with trowel, manual or power, for smooth surface. Broom or burlap drag for rough surface. Areas where the depth of the repair is less than 1-inch shall be repaired with polymer-modified portland cement mortar. In areas where the depth of the repair is greater than $1 \mathrm{inch}$, the repair shall be made with polymer-modified portland cement concrete.

D. As per ACI recommendations for portland cement concrete, curing is required. Moist cure with wet burlap and polyethylene, a fine mist of water or a water-based* compatible curing compound. Moist curing should commence immediately after finishing and continue for 48 hours. Protect newly applied material from rain, sun, and wind until compressive strength is $70 \%$ of the 28 -day compressive strength. To prevent from freezing cover with insulating material. Setting time is dependent on temperature and humidity.

*Pretesting of curing compound is recommended.

E. Adhere to all procedures, limitations and cautions for the polymer-modified portland cement mortar in the manufacturers current printed technical data sheet and literature.

\subsection{Cleaning}

A. The uncured polymer-modified portland cement mortar can be cleaned from tools with water. The cured polymer modified portland cement mortar can only be removed mechanically.

B. Leave finished work and work area in a neat, clean condition without evidence of spillovers onto adjacent areas. 


\section{SC-026 SikaTop 111 Plus Hand-applied Repair}

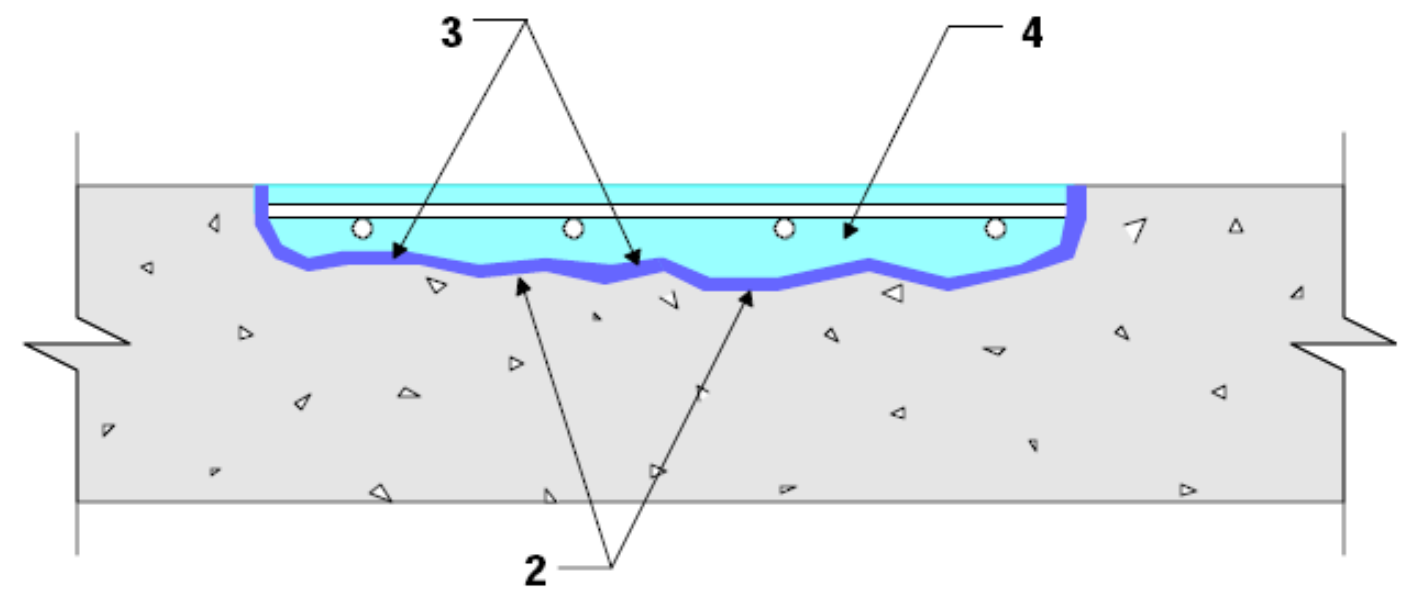

1. Repair area should not be less than $1 / 2$ " in depth.

2. Substrate should be saturated surface dry (SSD) with no standing water.

3. Apply scrub coat to substrate, filling all pores and voids.

4. While scrub coat is still wet apply SikaTop 111 Plus.

Note: If repair area is too large to fill while scrub coat is still wet, use Sika Armatec 110 EpoCem in lieu of the scrub coat. (See Spec Component SC-200)

For applications greater than 1 " in depth, add a $3 / 8$ " coarse aggregate. 


\section{G.2.3 Tyfo SCH-7-UP Composite}

\section{Tyfo® SCH-7UP Composite}

using Tyfo® $S$ Epoxy

\section{DESCRIPTION}

The Tyfo $®$ SCH-7UP Composite is comprised of Tyfo $®$ S Epoxy and Tyfo® SCH-7UP reinforcing

fabric. Tyfo $®$ SCH-7UP is a custom, uni-directional carbon fabric. The Tyfo $® S$ Epoxy is a twocomponent epoxy matrix.

\section{USE}

Tyfo $\circledR$ SCH-7UP Fabric is combined with Tyfo $®$ Epoxy to add strength to bridges, buildings, and other structures.

\section{ADVANTAGES}

- Good high \& low temperature properties

- Long working time

- High elongation

- Ambient cure

- $100 \%$ solvent-free

- Rolls can be cut to desired widths prior to shipping

\begin{tabular}{|c|c|c|c|}
\hline \multicolumn{4}{|c|}{ COMPOSITE GROSS LAMINATE PROPERTIES } \\
\hline Property & $\begin{array}{l}\text { ASTM } \\
\text { Method }\end{array}$ & Typical Test Value & Design Value* \\
\hline $\begin{array}{l}\text { Ultimate tensile strength } \\
\text { in } \\
\text { primary fiber direction, } \\
\text { psi }\end{array}$ & D-3039 & $\begin{array}{c}\text { 154,000 psi (1062 } \\
\text { MPa) } \\
\text { (1.5 kip/in. width) }\end{array}$ & $\begin{array}{c}130,900 \text { psi (903 MPa) } \\
\text { (1.3 kip/in. width) }\end{array}$ \\
\hline Elongation at break & D-3039 & $1.05 \%$ & $1.05 \%$ \\
\hline Tensile Modulus, psi & D-3039 & $\begin{array}{c}14.8 \times 106 \text { psi (102 } \\
\text { GPa) }\end{array}$ & $\begin{array}{c}12.6 \times 106 \text { psi (86.9 } \\
\text { GPa) }\end{array}$ \\
\hline $\begin{array}{l}\text { Ultimate tensile strength } \\
90 \\
\text { degrees to primary fiber, } \\
\text { psi }\end{array}$ & D-3039 & 0 & 0 \\
\hline Laminate Thickness & & 0.007 in. $(0.18 \mathrm{~mm})$ & 0.007 in. $(0.18 \mathrm{~mm})$ \\
\hline
\end{tabular}




\section{G.2.4 Tyfo S Epoxy}

\section{Tyfo® S Epoxy \\ using Tyfo® S Epoxy}

\section{DESCRIPTION}

The Tyfo® S Epoxy is a two-component epoxy matrix material for bonding applications. It is a high elongation material which gives optimum properties as a matrix for the Tyfo® Fibrwrap System. It

provides a long working time for application, with no offensive odor. Tyfo® S Epoxy may also be thickened and used as a prime or finish coat depending upon the project requirements.

\section{USE}

The Tyfo $₫ S$ Epoxy matrix material is combined with the Tyfo $®$ fabrics to provide a wet-lay-up composite system for strengthening structural members.

\section{ADVANTAGES}

- ICC-ES ESR-2103 listed product

- Ease of application

- Can be applied to horizontal, vertical, and overhead surfaces

- Migrates throughout concrete element in vapor phase

- Forms passive film on surface of white steel

- For new and old structures

\begin{tabular}{|c|c|}
\hline \multicolumn{2}{|c|}{ EPOXY COMPONENT PROPERTIES } \\
\hline Property & Typical Test Value* \\
\hline Color & $\begin{array}{l}\text { Component } A \text { is clear to pale yellow } \\
\text { Component } B \text { is clear }\end{array}$ \\
\hline Viscosity & $\begin{array}{l}\text { Component } A \text { at } 77^{\circ} \mathrm{F}\left(25^{\circ} \mathrm{C}\right) \text { is } \\
11,000-13,000 \mathrm{cps} \\
\text { ASTM D-2392-80. } \\
\text { Component } \mathrm{B} \text { at } 77^{\circ} \mathrm{F}\left(25^{\circ} \mathrm{C}\right) \text { is } 11 \\
\text { cps } \\
\text { ASTM D-2393-80. }\end{array}$ \\
\hline Pot Life & $\begin{array}{l}3 \text { to } 6 \text { hours at } \\
68^{\circ} \mathrm{F}\left(20^{\circ} \mathrm{C}\right)\end{array}$ \\
\hline Viscosity of Mixed Product & $600-700 \mathrm{cps}$ \\
\hline $\begin{array}{l}\text { Density at } 68^{\circ} \mathrm{F}\left(20^{\circ} \mathrm{C}\right) \\
\text { (Pound/Gallon) }\end{array}$ & $\begin{array}{l}\text { Component } A=9.7(4.4 \mathrm{~kg} / 3.79 \mathrm{~L}) \\
\text { Component } B=7.9(3.6 \mathrm{~kg} / 3.79 \mathrm{~L}) \\
\text { Mixed product }=9.17(4.2 \mathrm{~kg} / 3.79 \mathrm{~L})\end{array}$ \\
\hline
\end{tabular}

- Specification values can be provided upon request. 


\section{G.2.5 Tyfo WS Epoxy}

\section{Tyfo® WS Epoxy \\ All Purpose Epoxy}

\section{DESCRIPTION}

Tyfo ${ }^{\circ}$ WS (thickened Tyfo ${ }^{2}$ S Epoxy) is a two-component, hi-build, 100\% solids, ICC-ES ESR2103

listed product formulation developed for bonding applications. It can be used as a final protective coating or as a fill-and-level undercoat over which the Tyfo® Fibrwrap ${ }^{\circledR}$ System may be applied. This material may be used either as a surface coating or a primer material.

\section{USE}

This material is suggested for use in application where irregular substrates exist and/or where protection of the Tyfo $®$ System is necessary. This material may also be used for a primer layer under the Tyfo $\circledR$ System and is formulated to "stay-in-place" such as may be required on vertical walls or overhead beams. This material is also suitable for filling voids in concrete up to one half-

inch depth. In some applications, sand may be added to fill larger voids and grout lines as required.

\begin{tabular}{|c|c|}
\hline \multicolumn{2}{|c|}{ EPOXY COMPONENT PROPERTIES } \\
\hline Property & Typical Test Value* \\
\hline Color & $\begin{array}{l}\text { Component } A \text { is clear to pale } \\
\text { yellow } \\
\text { Component } B \text { is clear }\end{array}$ \\
\hline Viscosity & $\begin{array}{l}\text { Component } A \text { at } 77^{\circ} \mathrm{F}\left(25^{\circ} \mathrm{C}\right) \text { is } \\
11,000-13,000 \mathrm{cps} \\
\text { ASTM D-2392-80. } \\
\text { Component } \mathrm{B} \text { at } 77^{\circ} \mathrm{F}\left(25^{\circ} \mathrm{C}\right) \text { is } 11 \\
\text { cps } \\
\text { ASTM D-2393-80. }\end{array}$ \\
\hline Pot Life & $\begin{array}{l}3 \text { to } 6 \text { hours at } \\
68^{\circ} \mathrm{F}\left(20^{\circ} \mathrm{C}\right)\end{array}$ \\
\hline Viscosity of Mixed Product & $600-700 \mathrm{cps}$ \\
\hline $\begin{array}{l}\text { Density at } 68^{\circ} \mathrm{F}\left(20^{\circ} \mathrm{C}\right) \\
\text { (Pound/Gallon) }\end{array}$ & $\begin{array}{l}\text { Component } A=9.7(4.4 \mathrm{~kg} / 3.79 \mathrm{~L}) \\
\text { Component } B=7.9(3.6 \mathrm{~kg} / 3.79 \mathrm{~L}) \\
\text { Mixed product }=9.17(4.2 \mathrm{~kg} / 3.79 \mathrm{~L})\end{array}$ \\
\hline
\end{tabular}

* Specification values can be provided upon request. 


\section{G.2.6 Tyfo CB Epoxy}

\section{Tyfo $\mathbb{R}$ CB \\ Epoxy Cement Bonding Agent/Corrosion Protection}

\section{DESCRIPTION}

The Tyfo $® C B$ is a three-component bonding agent composed of a specialty water-based epoxy and selected cementitious components. Tyfo $®$ CB provides and extended open time, allowing for

placement of concrete toppings and repair mortars up to 24-hours later, depending on ambient temperature. The product also provides significant protection against steel reinforcement corrosion when applied to properly prepared rebar. Tyfo® CB has excellent adhesion to concrete

and steel, and allows flexibility in topping placement, including traffic from ready-mix trucks when

tack-free.

USE

Recommended for use with the Tyfo $®$ Concrete Repair System. Tyfo $®$ CB serves as a bonding agent for floor toppings, concrete repair, and as a bond coat for concrete repair mortars such as Tyfo ${ }^{2}$ P and Tyfo $®$ PF. Tyfo $®$ CB offers corrosion protection for reinforcing steel. It is suitable for

exterior and interior concrete.

\section{ADVANTAGES}

- Extended open time

- Rebar corrosion protection

- Excellent adhesion to concrete and steel

\begin{tabular}{|c|c|c|}
\hline \multicolumn{3}{|c|}{ MATERIAL PROPERTIES } \\
\hline Property & ASTM Method & Typical Test Value* \\
\hline Slant Shear Bond to Concrete & C-882 & \\
\hline $\begin{array}{lr}\text { Open Time }^{* *} 0 \text { hours } \\
12 \text { hours }\end{array}$ & & $\begin{array}{l}\text { 2,800 psi (19.3 MPa) } \\
\text { 2,600 psi (17.9 MPa) }\end{array}$ \\
\hline Direct Tensile Bond to Concrete & (Germann Bond Test) & \\
\hline $\begin{array}{rr}\text { Open Time }^{* *} \quad 0 \text { hours } \\
12 \text { hours }\end{array}$ & & $\begin{array}{l}400 \text { psi (2.8 MPa) } \\
350 \text { psi (2.4 MPa) }\end{array}$ \\
\hline $\begin{array}{l}\text { Bond to Steel } \\
\text { 7-day bond strengths }\end{array}$ & (Patti Adhesion Test) & \\
\hline $\begin{array}{r}\text { Sandblasted Steel } \\
\text { Wire Wheel Prep } \\
\text { Oxidized Steel }\end{array}$ & & $\begin{array}{l}900 \text { psi (6.2 MPa) } \\
650 \text { psi (4.5 MPa) } \\
450 \text { psi (3.1 MPa) }\end{array}$ \\
\hline Weatherometer Testing & G-93 & $\begin{array}{l}2,000 \text { hours } \\
\text { no cracking or } \\
\text { peeling over steel }\end{array}$ \\
\hline
\end{tabular}

${ }^{*}$ Specification values can be provided upon request.

** Open Time: Time from initial application of Tyfo $®$ CB on

14-day old, hardened concrete until application of fresh concrete topping over the Tyfo ${ }^{\circ} \mathrm{CB}$. 


\title{
Appendix H: Testing Equipment and Tools
}

\section{H.1 List of Testing Equipment}

\author{
Bio-Rad 1000/500 Power Supplies \\ Compression Tester \\ Hitachi S 4700 model scanning electron microscope \\ James Instruments Inc. Non-Destructive Testing Systems T-90 Trident Microwave Moisture Meter \\ MTS 290 Hydraulic Service Manifold \\ MTS SilentFlo ${ }^{\circledR}$ Hydraulic Power Unit (Model 505.90, 3000 psi working pressure, 90 GPM flow rate) \\ MTS Single Ended Actuator (Model 243.40, 12.0” Stroke, 110 kip) \\ MTS 810 Material Test System with hydraulic wedge grips for tension testing \\ Proceq Canin Corrosion Analysing Instrument \\ Proceq Schmidt Hammer \\ Pull-Off Tester (Proceq Dyna Pull-Off Tester, DeFelsko PosiTest Digital Coating Pull-Off Adhesion \\ Tester) \\ TestStar System Software (Model 793.00, Version 3.4B) \\ TestStar IIm Digital Controller
}

\section{H.2 List of Tools}

Air Compressor

Angle Grinder (DeWalt 4-1/2"; Small)

Bar Clamp (Bessey; 12"; Clutch Style)

Bar Clamps (Bessey; 12"; Doubleheaded)

Concrete/Masonry Grinding Wheels (DeWalt; 4" x 1/4" x 5/8")

Concrete Vibrator (Chicago Electric Power Tools; $3 / 4$ HP)

Diamond Masonry Blade (DeWalt@; 7"; High Performance) 


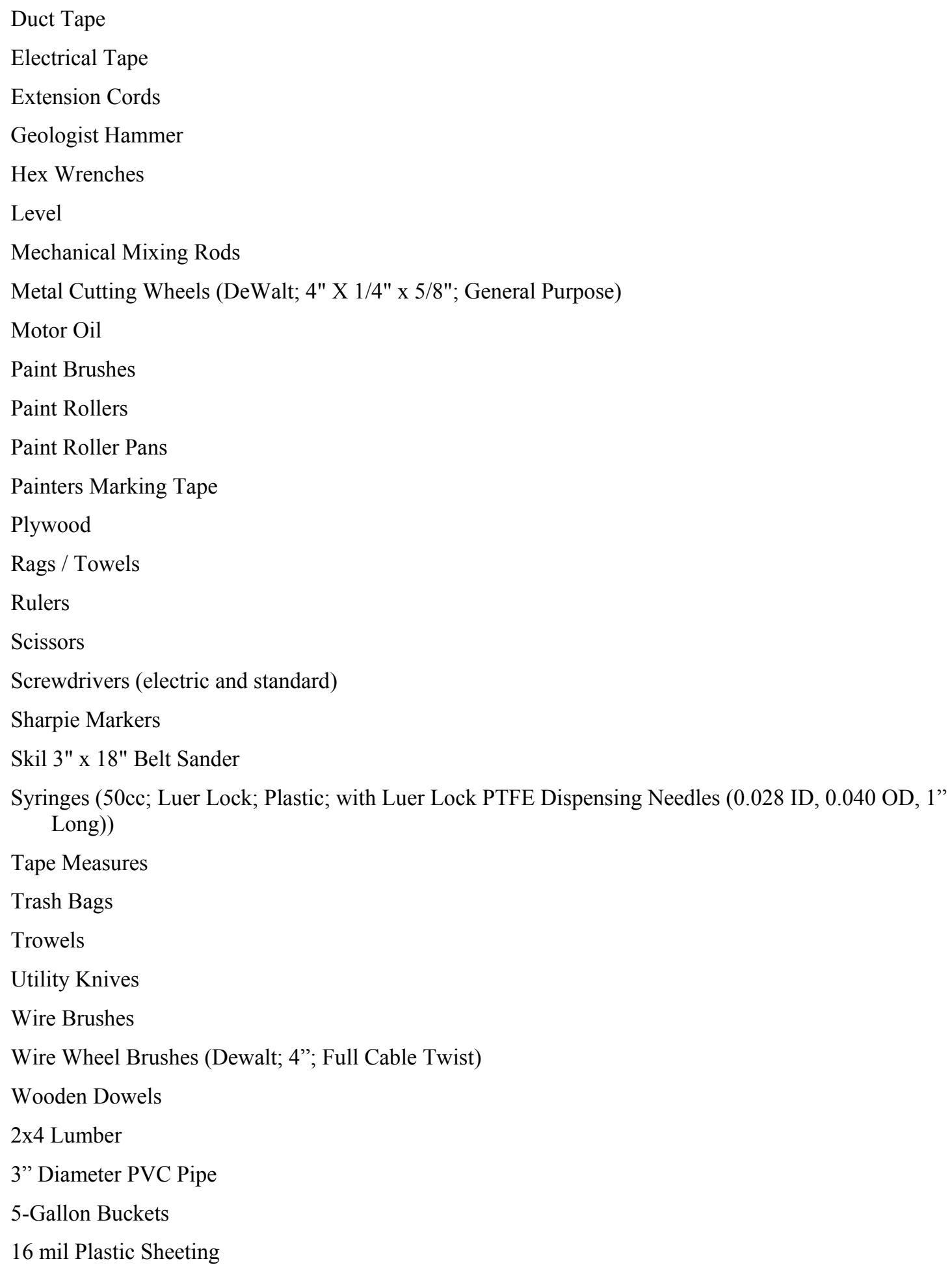




\title{
H.3 List of Safety Equipment
}

\author{
Caution Tape \\ Disposable Coveralls (Tyvek) \\ Latex Gloves \\ Respirators (Air-Purifying; Half Mask) \\ Respirator Masks (N-95) \\ Respirator Masks (N-99) \\ Safety Goggles \\ Silvershield Gloves (Epoxy-Resistant) \\ Vinyl Gloves
}

